

Complinentor of

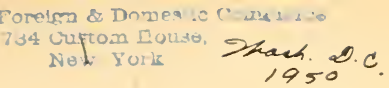

Robert A. Elabs. S. 



DEPARTMENT OF C OMMERCE BUREAU OF FOREIGN AND DOMESTIC COMMERCE

E. E. PRATT, Chief

MISCELLANEOUS SERIES-No. 60

\title{
THE GLASS INDUSTRY
}

\author{
REPORT ON THE COST OF PRODUCTION OF \\ GLASS IN THE UNITED STATES
}

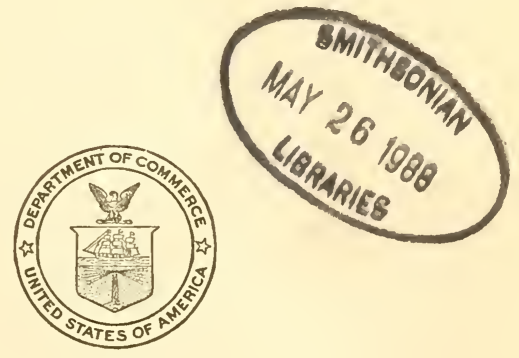

PRICE, 35 CENTS

Sold by the Superintendent of Documents, Government Printing Office Washington, D. C. 



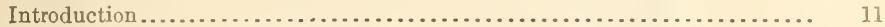

Establishment of the American glass industry................... 11

Early development..................................... 11

Adoption of coal for fuel............................... 11

Introduction and development of tank furnaces................ 11

Influence of the fuel supply............................. 12

Introduction of machinery............................... 13

Making of bottles........................................ 14

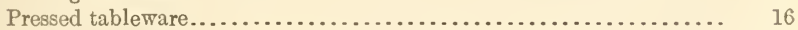

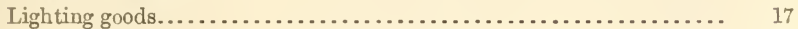

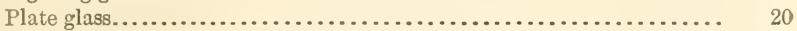

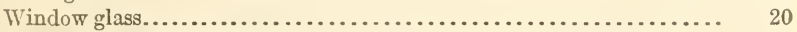

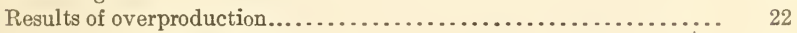

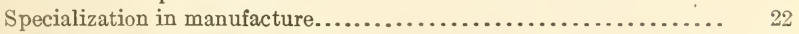

Effects of the European war............................. 23

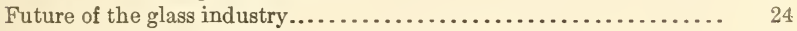

General statistics of the industry ............................ 24

Scope and method of the investigation........................ 31

Group classification of establishments....................... 33

Distribution of industry by States........................ 35

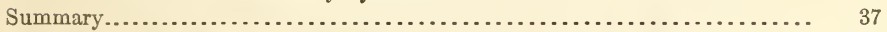

General results of the investigation........................... 37

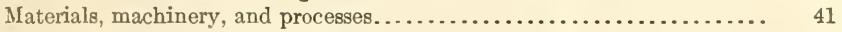

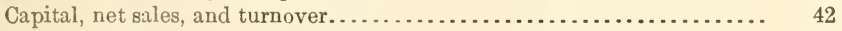

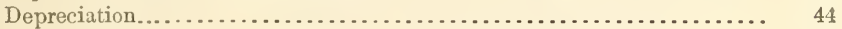

Cost and profit by establishments............................ 45

Cost and profit by specified units............................. 46

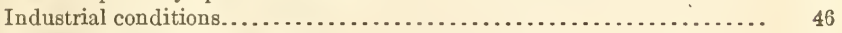

Selling expense and conditions.............................. 48

Wages and labor conditions................................. 49

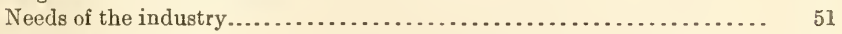

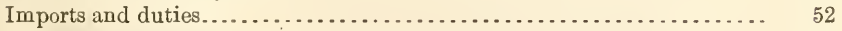

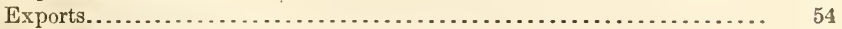

Chapter I.-Materials, machinery, and processes................... 55

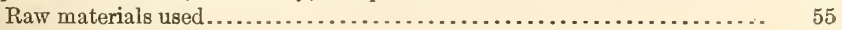

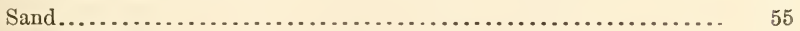

Alkaline bases.......................................... 56

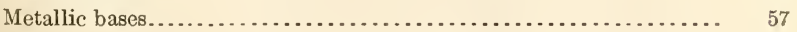

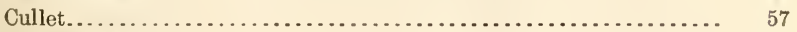

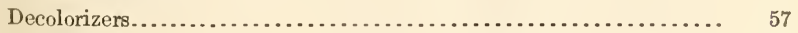

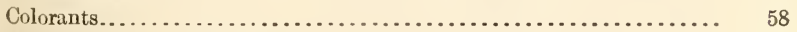

Mixtures for American glass................................ 59

Machinery, tools, and equipment............................ 60

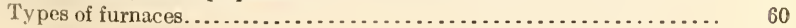

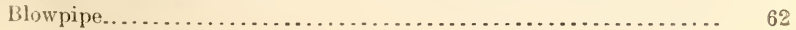


Chapter I.-Materials, machinery, and processes-Continued.

Machinery, tools, and equipment-Continued.

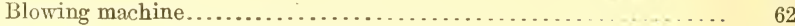

Paste-mold blowing machine............................ 63

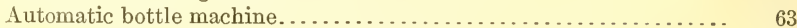

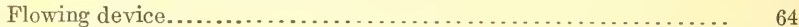

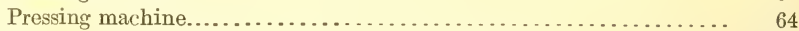

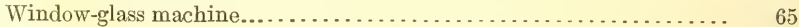

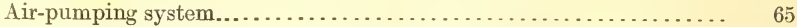

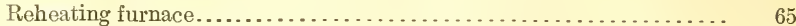

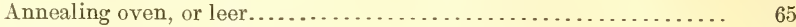

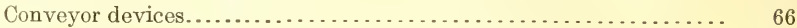

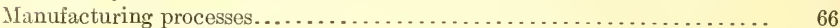

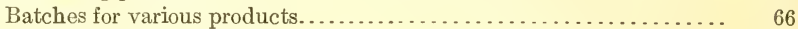

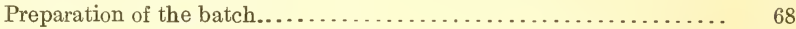

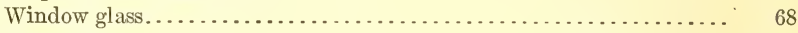

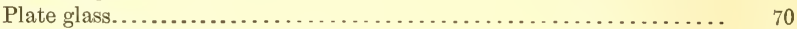

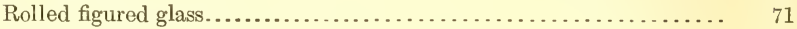

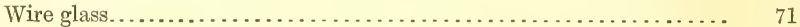

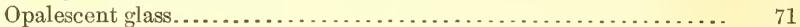

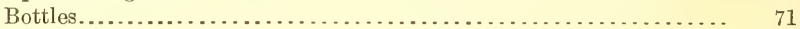

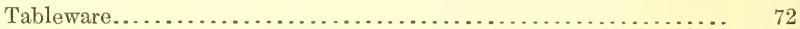

Lighting goods............................................... 74

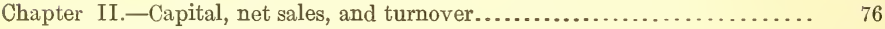

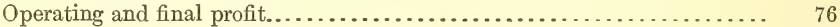

Percentages of profit on capital and net sales................... 78

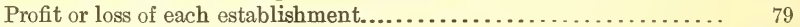

Number of establishments showing profit or loss.............. 83

Variations in profits and losses............................ 84

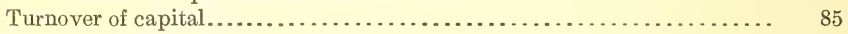

Chapter III.-Depreciation of plant and equipment................... 86

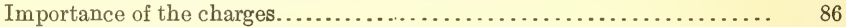

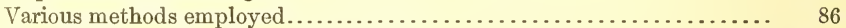

Neglect of charges by glass-making plants........................ 88

Relation to net sales, capital, and investment................... 90

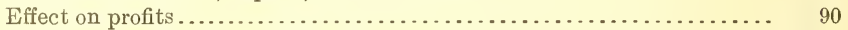

Chapter IV.-Cost and profit by establishments.................... 94

Cost and profit based on net sales............................. 94

Cost and profit based on sales value of goods produced .............. $\quad 99$

Method of determining sales value of goods.................. 99

Average production costs by groups........................ 100

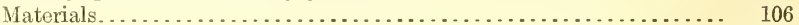

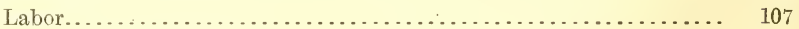

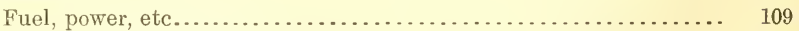

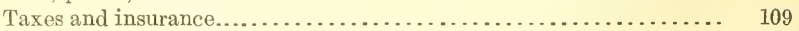

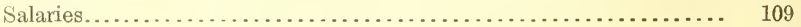

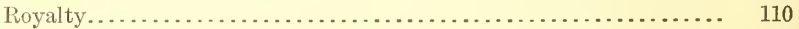

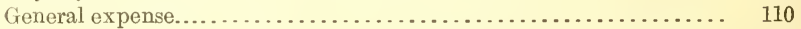

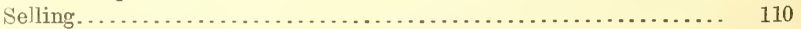

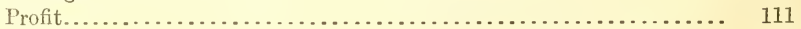

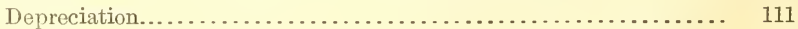

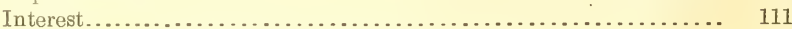

Miscellaneous expense and miscellaneous income............ 112 
Chapter IV:-Cost and profit by establishments-Continued.

Cost and profit in individual establishments............ . . . . . . . . 112

Handmade window glass................................ 112

Machine-made window glass........................... 116

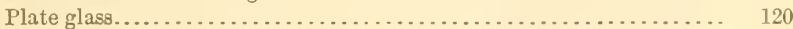

Wire and opalescent glass................................ 122

Handmade bottles.................................... 124

Machine-made bottles.................................. 129

Hand and machine made bottles........................ 132

Jars.............................................. 137

Blown tableware..................................... 141

Blown and pressed tableware......................... 143

Lighting goods.................................... 146

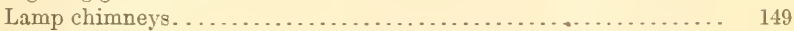

Miscellaneous articles............................... 15]

Cost based on total expenses, excluding depreciation and interest. . . . . . 154

Lowest and highest cost establishments . . . . . . . . . . . . . . . . . . . $15 \vec{i}$

Sales in previous years. . . . . . . . . . . . . . . . . . . . . . . . . . 161

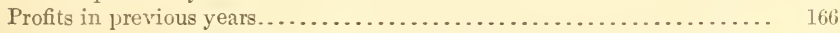

Chapter $V$.-Cost and profit by specified units.................. 171

Tabulation of cost and profit by articles. . . . . . . . . . . . . . . 171

Unit cost for window glass. . . . . . . . . . . . . . . . . . . . . . . . . 176

Handmade product.................................... 177

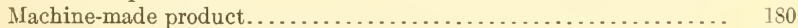

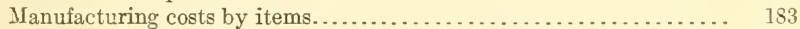

Production at a profit and at a loss. . . . . . . . . . . . . . . . . 186

Chapter VI. - Industrial conditions........................... 187

Fuel as a factor in location and operation. . . . . . . . . . . . . . . . . . 187

Increase in output of building glass . . . . . . . . . . . . . . . . . 188

Window glass. . . . . . . . . . . . . . . . . . . . . . . . . . . . . . . 189

Effect of selling agencies on prices..................... 190

Number and equipment of hand and machine plants. . . . . . . . . 190

Production affected by machinery . . . . . . . . . . . . . . . . . . . . . . 192

Factories operated on part-time basis...................... 192

Effect of machines on glass blowers' earnings . . . . . . . . . . . . . . 193

Price list and discounts.............................. 194

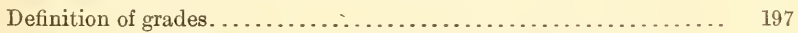

Hand production classified by grade, size, and strength........... 198

Proportion of production by hand and machine................ 199

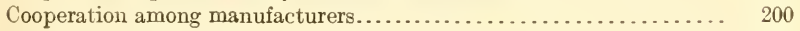

Increased demand for first grade and for small sizes. . . . . . . . . . . 200

Manufacturing to fill orders and for stock................... 201

Conditions outlined by manufacturers..................... 201

The sheet-glass machine............................. 205

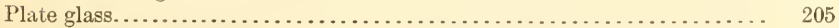

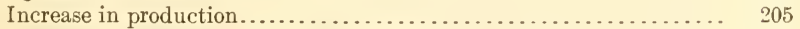

Number and equipment of plants. ...................... 206

Trend of prices and sizes............................... 206

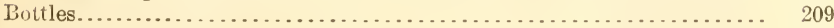

Production affected by machinery . . . . . . . . . . . . . . . . . 210

Number of establishments and their equipment. . . . . . . . . . . . . 211

Number of automatic machines. . . . . . . . . . . . . . . . . . . . . . . . . 212

The problem of standard capacity ......................... 214

Localization in the industry . . . . . . . . . . . . . . . . . . . . 215

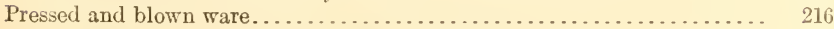

Number, location, and equipment of plants................ 216 
Chapter V.L-Industrial conditions-Continued. Page.

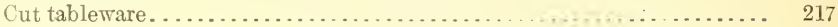

Superiority of American cut glass........................ 218

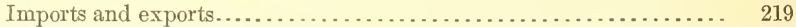

Methods of manufacture............................... 219

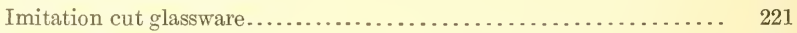

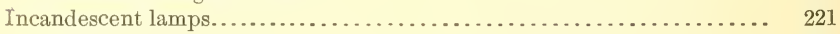

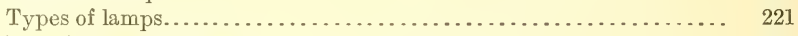

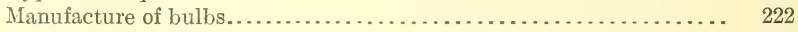

Chemical glassware........................................ 222

Germany former source of supply ........................ 223

Imports free of duty for schools, colleges, etc................. 223

Development of American industry....................... 224

High quality of American product. . . . . . . . . . . . . . . . . . .

Present conditions in the industry ...................... 225

Proposed restriction of free importation.................... 227

Photographic glass. ...................................... 229

Comparatively high cost of production...................... 229

Amount consumed-Tariff rates......................... 230

Chapter VII.-Selling expense and conditions....................... 231

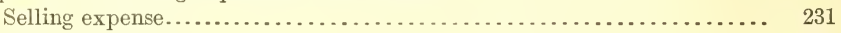

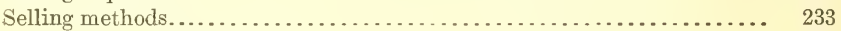

Distribution of goods............................. 233

Views of a bottle manufacturer........................... 234

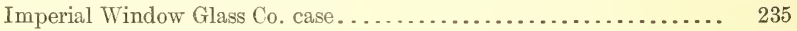

European plate-glass trust ............................. 236

European watch-crystal selling agreement.................. 237

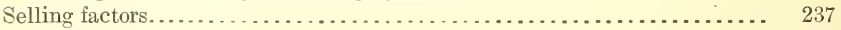

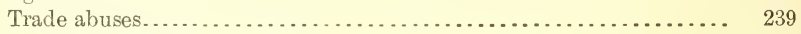

Trade acceptances..................................... 239

Economies possible through cooperation...................... 240

Chapter VIII.-Wages and labor conditions....................... 242

General data relating to the industry .......................... 242

Wages in glass and other industries compared................. 245

Employees by sex and age................................ 250

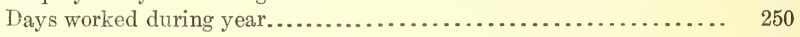

Number of employees in the industry . . . . . . . . . . . . . . . 251

A verage working hours and earnings........................ 253

Classification of occtipations. ............................ 289

Window glass............................................. 290

Advantages of location................................. 290

Wages and wage scales. ................................ 291

Labor-union regulations. ............................... 295

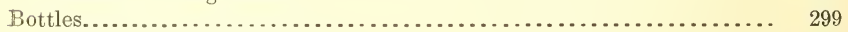

Effect of shop system on labor........................... 299

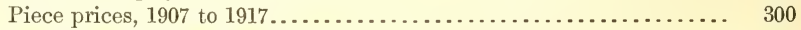

Glass Bottle Blowers' Association......................... 303

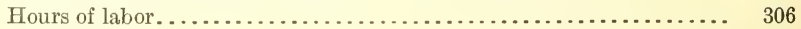

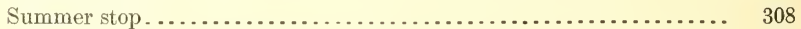

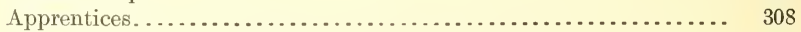

Extension of labor organization control................... 309 
Chapter VIII.- Wages and labor conditions-Continued.

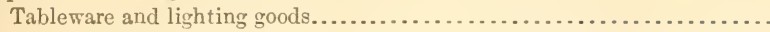

Number employed and unemployed......................... 310

Strikes and lockouts.................................. 311

Piece and time work.................................... 311

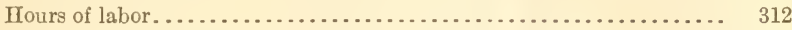

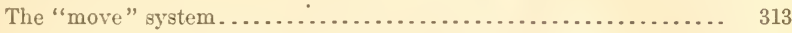

Summer stop and holidays............................. 314

Apprentices and child labor............................... 314

Women employees....................................... 315

Chapter IX.-Needs of the industry........................... 316

Lack of efficiency in manufacture and selling................. 316

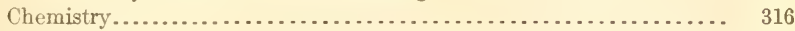

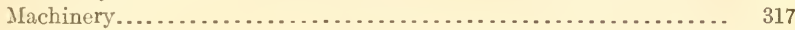

Buildings. ....................................... 317

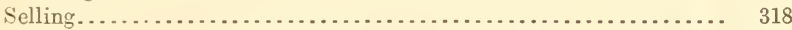

Other desirable improvements. .......................... 318

Methods of computing costs................................. 319

Ruinous price cutting caused by crude cost finding.............. 319

Advantages of modern cost keeping. .................... 320

The per-pound method................................. 321

The shop-hour method................................. 322

Overhead expense in making window glass. ................ 326

Predetermined costs.................................... 327

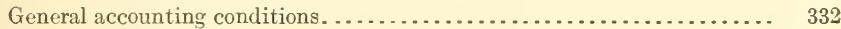

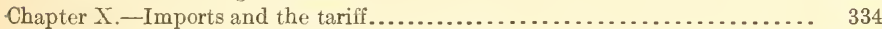

Production, imports, and exports compared..................... 334

Imports compared with rates of duty......................... 335

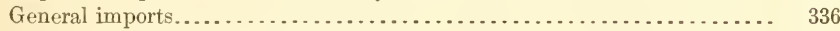

Value of imports by class of products...................... 337

Imports from principal countries........................ 338

Increases in imports.................................... 340

Window glass imported................................. 342

Plate glass imported....................................... 344

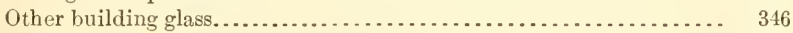

Bottles and jars.......................................... 346

Pressed and blown ware................................... 347

Statistics of imports for consumption......................... 351

Cylinder, crown, and common window glass................ 352

First three brackets of window glass....................... 356

Plate glass, cast, polished, and unsilvered.................. 357

Bottles, vials, demijohns, and carboys, empty................. 360

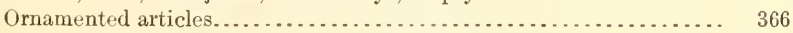

Other cylinder, crown, and common window glass............... 368

Other plate glass...................................... 369

Bottles, vials, demijohns, and carboys, filled................. 369

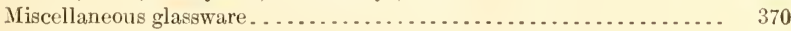

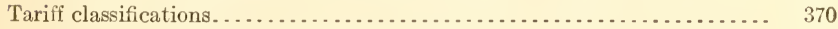

Decisions regarding classification of imports................... 370

Principal branches of the glass industry . . . . . . . . . . . . . . . . . 373

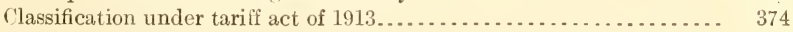

Suggested classification..................................... 375 
Chapter XI_-Products exported

Growth of trade in recent years................................. 378

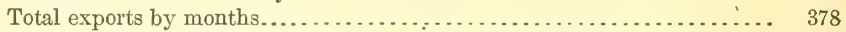

Exports of principal products by months....................... 380

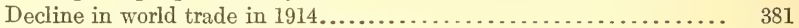

Exports of principal products by continents................... 382

Exports of principal products by countries..................... 383

Effects of European war.................................. 390

Establishments in foreign trade.............................. 391

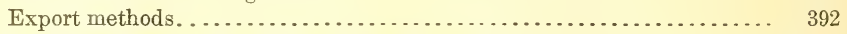

Chapter XII.-Opportunities in the export trade.................... 394

Imports of foreign countries.................................. 395

Suggestions for increasing foreign trade....................... 403

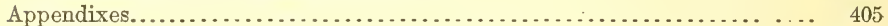

A. List of references on the glass industry..................... 405

B. Schedules used in the investigation......................... 424 


\section{LETTER OF SUBMITTAL.}

\section{Department of Commerce, Bureau of Foreigx and Domestic Comerce, Washington, May 31, 191\%.}

SIR: I beg to submit herewith a report on the conditions in the glass industry and the cost of production in its rarious branches. This report is the ninth of a series of reports issued by the Bureau of Foreign and Domestic Commerce regarding the cost of production in different industries. The investigation was begun in January, 1916, and conducted in accordance with the act of Congress approred August 23, 1912.

The report contains principally cost of production data. In addition, information is given concerning labor and industrial conditions, factory equipment, selling methods, and suggestions regarding better general accounting and more accurate cost-finding methods. The suggestions are based on interviews with manufacturers and on the personal observations of the special agents. A comprehensive bibliography, prepared in the Library of Congress, is appended.

The investigation was planned and directed by Walter B. Palmer, a special agent of the Bureau of Foreign and Domestic Commerce. In the field work and in the preparation of the report he was assisted by Special Agents David M. Barclay, Harry Gell, Marion C. Howard, Frank B. Meador, Thomas Mills, Thomas C. Stewart, Stanley D. Winderman, and Charles F. Yauch.

'To Hon. William C. Redfield,

$$
\begin{aligned}
& \text { E. E. Pratt, } \\
& \text { Chief of Bureau. }
\end{aligned}
$$

Secretary of Commerce. 



\title{
COST OF PRODUCTION IN THE GLASS INDUSTRY.
}

\section{INTRODUCTION.}

\author{
ESTABLISHMENT OF THE AMERICAN GLASS INDUSTRY.
}

\section{E.ARLY DEYEIOPMENT.}

The manufacture of glass in the United States was begun by the first English colonists in 1608 or 1609 , when they established a glass plant near Jamestown. Wood was plentiful and potash was made from wood ashes. The product was probably only bottles, although the claim is made that window glass also was made. The great interest in tobacco soon caused glassmaking to be neglected. In 1621 Italian workmen were induced to come to Virginia to make beads for trade with the Indians, funds having been raised to erect a new glasshouse.

In 1639 a glass plant was erected at Salem, Mass.; glass was made in New York during the Dutch régime and in 1747 in Connecticut. The first factory in New Jersey was established by Wistar at Allowaystown between 1760 and 1765 , and upon the failure of this plant in 1775 the workmen went to Glassboro, N. J., and established a factory which is still in operation. This is the oldest continuously operated factory in the United States. In 1769 Baron Stiegel, of Germany, established a glass plant at Manheim, Pa., for the manufacture of richly colored bowls, and goblets. By 1800 . other factories had been established in Philadelphia, New York City, Connecticut, Brooklyn, Germantown (Quincy), Mass., Salem County, N. J., Temple, N. H., Boston, Albany, and Keen, N. H. The product of these factories was mainly bottles or bottles and window glass.

ADOPTION OF COAL FOR FUEL.

Messrs. Craig \& O'Hara established glass works near Pittsburgh in 1796. This plant was the first to use coal for fuel. Wood had beon the fuel used up to this time. The introduction of coal as fuel was intentional and not due to any lack of wood. As late as 1810 it was only the glass plants around Pittsburgh that used coal for fuel. The plant of Craig \& O'Hara made window glass, but, like most of the plants in the early glassmaking days, one or more pots were used for making bottles, flasks, and other hollow ware. The nearness of coal and the abrundance of excellent sand in adjoining rivers resulted in the phenomenal rise of the Pittsburgh district as the glass center.

\section{INTRODUCTION AND DEVEIOPMENT OF TANK FURNACES.}

The desire to increase production and to meet the very keen competition that had sprung up led soon after 1870 to improvements in furmaces. 
In 1861 Siemens introduced, in Germany, the first regenerative glass furnace. Up to the time of the Siemens furnace direct firing was the universal rule, that is, the heat of artificially dried wood or coal was applied directly to the pots. With wood or coal direct firing only was possible.

In the Siemens furnace the fuel was first converted into gas outside the furnace and then heated, generally with preheated air, on the principle of the Bunsen burner. The gas and the air were heated separately by means of regenerators placed beneath the furnace, which utilized the waste heat from the gases of combustion. By this method a great saving was made in the fuel, the melting time was reduced, the output was increased and the quality of the glass improved. In the seventies other gas-pot furnaces, such as those of Nicholson and Gill, were introduced in the vicinity of Pittsburgh.

It was not Siemens' original furnace-a pot furnace-but the tank, which covers the whole area of the furnace and does away entirely with the use of pots, that reached its greatest development in this country. In 1872 the tank furnace was divided into three compartments by means of two transverse floating bridges; the batch was melted in the first compartment, the glass was refined in the second, and the third held the purified glass. A later improvement did away with these floating bridges by substituting refining vessels that were floated opposite each gathering hole.

The introduction of the tank furnace was made possible only by the use of gas as fuel, and the commercial utilization of natural gas greatly stimulated its extension and development. Direct firing: ceased to exist. Because of its size, a tank can not be properly heated by direct firing. In order to reach the contents effectively, it is necessary that the flames be forced across the top of the tank and this is possible only by the use of gas.

In the last 25 or 30 years a large number of the pot furnaces have been replaced by tank furnaces. The only efficient plants that use pots at present are plate-glass plants, those that manufacture very fine qualities of tableware and other goods, and establishments in which a great diversity of colored glass is made.

The use of the continuous tank enables a plant to work 24 hours a day. Tanks are more economical, regular, and durable, and produce a more uniform molten glass. While the first cost of the tank is large, the tremendous expense for pots, which last but a short time, and the time lost in removing and setting them make tanks just as cheap for a permanent investment. The adoption of tanks increased the production of the blower, due to the possibility of using shorter gathering irons, which skim the glass from the surface of the tank more rapidly than the long irons formerly necessary to gather glass from the pot.

Several furnaces have been patented for melting glass by electricity but none has as yet been perfected so as to make its commercial introduction possible.

INFLUENCE OF THE FUEL SUPPLY.

The cost of fuel is, exclusive of labor, generally the largest single expense that enters into the manufacture of glass. It is not surprising therefore to find manufacturers influenced to a very great extent 
in locating their plants by the source of the fuel supply. Fuel is the prime reason for locating factories at a particular place. The glass industry in its early days was established along the Atlantic coast, that being the first settled section of the country. Wood, which was lried to expel all moisture, was to be had in almost erery section of this territory. With the adoption of coal as fuel in Pittsburgh in 1796, the glass industry mored west of the Alleghenies and centered in the Pittshurgh district. Wood and coal were used for direct firing. Since the introduction of the Siemens furnace, howerer, improvements have been in the direction of substituting gaseous for solid fuel.

The discorery of natural gas and cheap oil in western Pennsylrania caused factories to locate in the gas and oil regions of that State, and the discovery of natural gas, first in Ohio and then in Indiana, caused the glass industry to move farther west. Hundreds of "mushroom" factories sprang up orer night. On the failure of the natural-gas supply some plants moved to new fields, but the "mushroom " plants as well as many old-established factories were compelled to quit business. In recent years the natural gas of West Virginia has been the direct cause for the erection in that State of some of the largest factories in this country. When natural gas failed, oil was substituted and proved to be an excellent fuel.

Gas, either natural or artificial, is an ideal fuel; it is free from ashes and dirt, and gives a uniform heat which is essential in the manufacture of glass. It gires an almost perfect combustion, and the flame is easily applied and controlled. Natural gas is preferred because it is cheaper than artificial gas and gires a greater heat; but it is unreliable, as the supply is usually uncertain. Oil furnishes an intense and easily regulated heat, but is as yet too expensive for universal use.

In the days when natural gas was the chief fuel because of its low cost, plants moved about from year to year following the gas supply. This moving was made possible because of the cheap cost of constructing the frame buildings and the absence of any great amount of machinery. At the present time, howerer, factories are large, the buildings are more or less substantial, and, since the machinery and equipment are costly and not easily moved, the industry is comparatively stable. Plants now, as formerly, prefer to use natural gas, and when this supply is exhausted, generally change to artificial (producer) gas or oil. Electricity may probably prove to be the ideal fuel, but as yet has not been used commercially as a glass fuel.

\section{INTRODUCTION OF MACHINERY.}

The invention, introduction, and development of machinery in the glass industry has resulted from the desire to displace the skilled and highly paid blower and to increase production and cheapen cost.

The making of glass from earliest history down to recent times was a handicraft, and much glass is still blown by the breath of a glass maker. Later molds were invented to assist the blower in shaping the articles. The machine for pressing the simpler articles in molds, without the aid of blowing, has been used since 1827. It has been chiefly in the manufacture of bottles, jars, and window glass that machinery has been invented and developed. 
MAKING OF BOTTLES.

Early nineteenth-century product.-From about 1808 to 1870 an important branch of the glass industry was the manufacture of fancy pocket flasks and bottles. These were blown in engraved metal molds. The early bottles had mouths cut with shears when in a plastic or soft condition, which resulted in a rimless, irregular edge. The base has a circular scar made where the bottle was broken from the punty rod which held it while workmen finished the neck. Later this scar was removed from the finer products by grinding. In the fifties a "snap" was used to hold the bottle, which came from the mold with a smooth hollow base. A rim or beading formed by a "tool" was also added to the mouth. All the early bottles were green in color and it was not until 1861 that flint glass was used for prescription bottles.

Beginning of the shop system.-In order to increase production there was introduced in bottle factories about 1870 what is known as the "shop system." Instead of the single blower, who previous to this time had produced the entire bottle, three men ("the shop") worked together, two of them gathering and blowing while the third made the neck smooth and otherwise finished the bottle. The average output of bottles for each gang of three men working together in this way is 275 to 300 dozen per day; in the case of especially expert men the day's work is often much larger. Formerly, the single blower, working with only the mold-shutting and snapping-up boys' help, was regarded as having produced a very good day's work when he made 40 or 42 dozen per day. "The "shop system" is still in vogue in plants where bottles are made by hand.

Machinery.-Ashleigh, an Englishman, made the first automatic bottle machine, but it was unsuccessful for narrow-neck bottles, because only a small percentage of the ware had a good enough neck to be marketable. In 1882 the process of prepressing a blank, forming the neck in the pressing operation, then transferring the neck to a blow mold and blowing it into the finished form by compressed air was invented by Arbogast, of Pittsburgh.

There are three methods of making wide-mouth bottles under the Arbogast patent. By the first the pressed blank is transferred from the blank mold to the blow mold and blown by means of a disk with a handle to which compressed air, controlled by a stopcock, is fed through a rubber hose. Later, to increase production, the blank and blow molds were mounted on separate revolving tables. By the second method the blank mold is telescoped into the blow mold against the shoulder forming the neck. This system was invented by Windmill, of England, and was used successfully for fruit jars, but legal entanglements and litigation caused manufacturers to discard it. The third method consists in pressing the blank in the blank mold.

About 1896 a machine was perfected which, though commercially successful, was somewhat crude and restricted to the making of widemouth bottles and jars. This machine was not automatic.

Since about 1900 any number of bottle-making machines that required one, two, or three skilled operators have appeared on the

1 Twenty-eighth Annual Report, Bureau of Statisties of Labor and Industries of New Jersey, 1905, p. 201 
market: these machines are usually designated as one, two, or three man machines. In 1900 a two-man machine for making wide-mouth bottles was invented. Shortly after the automatic machine was introduced, there appeared on the market the "Johnny Bull," or United, an English three-man machine for narrow-mouth bottles. In 1908 there appeared a three-man machine for narrow-neck bottles, in 1912 a one-man machine for wide-mouth bottles, and in 1914 a one-man machine for narrow-neck bottles.

Owens automatic machine.-In 1903 the Owens automatic machine, invented by Michael J. Owens, of Toledo, was introduced commercially. The machine revolutionized the entire bottle-maling industry, and since its introduction has greatly increased the standard of efficiency in the bottle-manufacturing plants of the United States and has made possible the gradual reduction in the price of bottles that has been noted during the years since its invention.

The first Owens machine that appeared on the market had six arms; the latest type of machine has 15 arms. Improvements have been made so that to-day practically any kind or shape of bottle from one-tenth of an ounce to 13 gallons in capacity can be made upon some one of the four types of Owens machines.

The operating speed of the 15-arm machine is indicated by the fact that more than 75,000 quart fruit jars are manufactured by a single machine in a 24-hour day. The machine is entirely automatic, gathering its own glass and blowing the bottle, and when an automatic conveyor is used, delivering it to the leer without the touch of a worker's hand. The machine can be run for 24 hours a day and every day in the year.

The machine is very costly, and the special equipment necessary to operate it makes the initial outlay exceedingly large. This fact, together with a serious doubt as to the machine's competitive ability, kept manufacturers from installing it generally. Prior to 1908 the Owens machine was restricted almost exclusively to licensing on a basis of royalty. In that year, however, the Owens people began the manufacture of bottles. In a report by President Libbey, of the Owens Bottle Machine Co., he states that, exclusive of the plants controlled by the Owens Bottle Machine Co., there are 15 factories operating 114 machines and having a normal annual production of over 850,000,000 bottles. ${ }^{1}$ There are installed in the United States at present 6 fifteen-arm, 97 ten-arm, 87 six-arm, and 1 special machine, making a total of 191 machines. There are 13 machines in Canada.

The Owens European patents were sold in 1907, to a European combination controlled by German shareholders, for 12,000,000 marks. The first three Owens machines were sold in Europe in 1908, and there are now 60 or 70 machines in use. It is significant that Japanese capitalists, despite the cheap hand labor to be had in that country, have purchased the Owens Japanese patents and aro now installing the most modern Owons machines.

Flowing device.-From the time of the ancient Egyptian glass blowers up to 1903, when a patent for a flowing device was issued to Homer Brooke, and the Owens machine, which gathered its own glass, was commercially introduced, hand gathering was the first step in the process of glassmaking. Brooko's device consists in permitting the 
molten glass to flow continuously and freely from the furnace, and then severing this flowing stream below its point of exit from the furnace to obtain the desired unformed molten mass, allowing the severed mass to fall in the mold and supporting the upper portion of the stream, which continues flowing from the furnace until another mold comes into position to receive another mass to be severed.

In hand gathering, which was the universal method up to this time, the glass gathered is usually more than the amount necessary for the required ware. The glass is dropped into the mold and the proper amount has to be cut off by shears or by other means. The Brooke patent accomplished the gathering and cutting automatically.

Previous to Homer Brooke's invention many attempts had beel made to do away with hand gathering. Haley devised a machine which manipulated the gathering rod in exactly the same manner as in the hand operation. In 1885 Rylands patented a device (British patent) to start and stop the flow of glass by means of a lever. In 1890 came the Schulze-Berge patent, by which desired quantities of glass were forcibly ejected from the furnace by means of a plunger acting in the furnace or by means of air pressure in the furnace. Eunsen (British patent) started and stopped the flow of glass by means of a revolving cylinder with pockets in its periphery. The difficulty with all these intermittent start-and-stop devices was that the glass adhered to the cut-off device or stopper, or congealed and did not flow. The Brooke patent provided for a continuous flow, thus preventing the glass from congealing.

The advantages claimed from the use of the Brooke patents are greatly increased production, uniform quantities, reduced cost of manufacture, and ability to work throughout the hot months, when it is difficult to get hand gatherers to work.

It appears that other manufacturers have been working on flowing or pouring devices since Brooke received his patent, and some claim to have perfected and to be using such systems. There are 10 or 12 firms making bottles and jars by the flowing method. ${ }^{1}$

\section{PRESSED TABLEWARE.}

The discovery of a process for pressing glass in 1827 is credited to a carpenter of Sandwich, Mass. Deming Jarves in that year made the first pressed tumbler. Up to this time all glassware not cast had been blown. The shaping of glass to the desired form and size by means of a mold and pressing was at first used only for the commoner grades of goods. This discovery revolutionized the industry. It greatly reduced the cost of production, making it possible for immense quantities of the same article to be turned out at a low cost, and permitted the imitation of fine ware. Toward the close of the sixties goblets and wineglasses were made by the pressed method and were almost as fine and delicate as those made by blowing and cutting.

Up to 1864 the finer pressed-glass articles were made of flint glass, composed of the best sand, pearl ash, refined saltpeter, and oxide of lead, while the cheap tumblers and other common ware were made of German flint glass composed of soda ash, lime, nitrate of soda, and sand. About 1864 William Leighton, of Wheeling, discorered a

1 D. A. Hayes, president of the Glass Bottle Blowers' Asscciation, in The Glassworker, July 22, 1916, p. 3. 
method of making a clear brilliant glass which rerolutionized the pressed-glass business. By his process the batch was made of bicarbonate of soda, pure samd. lime, and refimed nitrate of soda, and its cost was about one-third that of the lead-flint batch.

\section{LIGIITIXG GOODS.}

Lamps and tamp chimneys.-There was a great depression in the glass industry from 1850 to 1860 , but this was followed by a great derelopment in the flint-glass business, due to the making of coal oil from coal and the later discorery of petroleum. Though lamp chimneys were manufactured about 1555 , it was not until about 1859 , when refined petroleum for lighting purposes was commercially marketed. that their manufacture assumed large proportions. With the introduction of petroleum the demand for lamps and lamp chimneys grew by leaps and bounds until the introduction of gas and olectricity about 1585 led the manufacturer's to commence the making of modern lighting goods. Lamp chimneys and oil lamps are manufactured in the United States in considerable quantities at the present time and are exported to countries where gas and electricity hare not yet been introduced. Lamp chimneys were at first blown off-inand and some with flat sides were made in molds. In recent years lamp chimmeys have been manufactured in a paste-mold machine.

Bulbs for incandescent lamps. - The first glass bulbs used for incandescent lamps were made from tubing by manipulating the latter over a flame. This practice was followed until such time as the incandescent lamp began to assume commercial importance, when the manufacturers began to cast about for a cheaper and more expeditious method of production.

As far as is known, the first attempts to make bulbs on a blow iron (i. e., a glassworker's blowpipe) direct from the molten glass were made in Corning N. Y., in the late seventies. After laborious experiments with glasses of different composition and with different methods of manipulation, a process was evolved for making a socalled "off-hand" bulb, which was a distinct improvement over the bulb previously used, in that it was more uniform in shape and size, was of a satisfactory and fairly uniform thickness, and possessed other physical properties-correct coefficient of expansion, fusibility, freedom from visual defects, etc.-necessary to successful use. This type of bulb moreover was susceptible of manufacture in existing glass plants by workmen then available. This no doubt was an important consideration, as it was desired to get bulbs promptly in what were then considered large quantities.

It will be understood that while these off-hand bulbs were a great improvement over those made from tubing and temporarily met the requirements of the lamp manufacturer, the art of lamp making was then distinctly a hand art, and uniformity was not needed. As the art of lamp making progressed, attempts were made to expedite the process by substituting machinery for hand operators. In fact, it becamo obvious that machinery must be substituted if incandescent electric lighting wero to assume the importanco hoped for it. 
With the development of machines for holding and manipulating lamps in process, the need of greater accuracy in the manufacture of the bulb became imperative, and the glass manufacturer met the situation by substituting the "wooden-mold" process for that previously employed.

In the off-hand process the glassworker gathered a small ball of glass on the end of his iron by dipning the latter in the molten mass and quickly rotating and withdrawing it. He then rolled the "gather" on a polished iron plate, cooling it and causing it to assume any approximate cylindrical shepe. Then, by a combination of blowing and swinging, he caused the glass to elongate and distend to the proper shape. It is needless to say that this was an operation requiring a high degree of skill and great care. No measuring tools or gauges could be touched to the plastic glass, and the uniformity of the product was strictly dependent on the ability and care of the operator.

The wooden-mold process had long been in use in the glass trade for the production of globes, chimneys, and similar articles. Just why it was not originally adopted for the making of bulbs instead of the off-hand process is not known. The preliminary steps in both processes are identical. In the wooden-mold process, however, the "gather" or blank when only partially distended is introduced into a hardwood water-soaked mold, whereupon the operator blows into the iron and at the same time rolls it between the palms of his hands, thus imparting a rotary motion to the blank, while it assumes the contour of the mold. As soon as the glass becomes sufficiently stiff, but before it has entirely lost its plasticity, the mold is opened and the bulb still attached to the iron is removed. Finally the bulb is removed from the iron by cracking close to the latter with a wet, or at least a cold, file or "knife."

This wooden-mold process was a distinct advance in the art. The product was much more uniform in size and shape, had a high polish due to the rotary motion of the glass while in contact with the mold, and could be made faster and more cheaply than previously. The hand process of bulb making in vogue at the present time is a direct development of this wooden-mold process, and differs from it only in the refinement of tools employed.

As the development of machinery for lamp making progressed, the requirements of the lamp maker became more and more exacting, and the glass manufacturer soon began to cast about for a more reliable material than wood from which to make his molds, for it was found that wooden molds soon warped and burned out of shape, with resultant inaccuracies in the product. This more reliable material was soon forthcoming in the form of cast iron, coated with a so-called "paste" of linseed oil and charcoal or hardwood sawdust.

As nearly as can be ascertained this new or "paste" mold was developed in France and introduced here by certain itinerant French chimney or tumbler blowers. These men traveled from place to place as suited their whims, carrying their molds with them, and accepting employment wherever offered or whenever necessity urged them. They guarded most jealously the secret of their paste and it was some little time before Americans acquired the secret. However, in the late eighties American glassmakers did learn how to properly coat or paste their molds, and from that time until the pres- 
ent day practically all incandescent lamp bulbs made in America have been blown in these irom molds coated with carbonaceous paste.

It is a rather surprising fact that this process was not generally adopted in European countries and in Japan until very recent rears. Iron molds of great accuracy are now used by all bulb manufacturers. and with proper handling these continue accurate through years of constant use.

Briefly the process of "pasting" is as follows: The inner surface of the mold is spread with a thin layer of boiled linseed oil, applied with a brush like paint. Other substinnees, such as wax or rosin, are sometimes dissolved in the oil. The mold is then dipped in powdered charcoal, in fine sawdust (usually of apple wocd), or more recently in cork flour, which is powdered cork sifted or bolted to make it of uniform grain. The mold is then shaken or tapped to remove the surplus powder and immediately placed in a baking oven, where it is subjected to sufficient heat to partially carbonize the oil and coating without warping the mold.

After carbonization has progressed sufficiently, the mold is remored from the oven and allowed to cool. A heary "gather" or blank is prepared on a blow iron and introduced into the mold: the latter is closed and the blank is blown up tight against the coated surface. The extreme heat of the glass blank serves to complete the carbonization of the paste, and upon opening the mold its working surface is found to be coated with an exceedingly thin, smooth, and closely adhering coating of carbon, almost graphitic in character.

The mold is then dipped in water and is ready for use. This dipping in water is a vital part of the process and must be repeated each time before a bulb is blown. Without the water it is impossible to rotate the blank in the mold, and the resultant article has a rough or pitted surface. The high polish of a paste-mold bulb is doubtless due to the rotation of the glass over the "graphitic" surface lubricated by water and water vapor.

As already stated, save for the introduction of the paste mold and the use of semiautomatic derices for opening, closing, and wetting molds (so-called "dummy mold holders") the process of making bulbs by hand is much the same as 20 years ago. Recently, howerer, a variety of machines have been introduced, both semiautomatic and automatic, which give promise of both cheapening and improving the incandescent lamp bulb. Such machines are in use in several manufacturing plants and are turning out a satisfactory product. There is much development work still to be done on these machines, but it seems probablo that within a fow years they will largely supersede the hand process.

These machines have not introcluced any really new fundamental principles in the art of bulb making; the indivicual steps in the process are similar to those in the manual process and the sequence of steps is the same. The machine simply imitates with great precision the movements of the adept artisan and produces a very uniform procluct.

From a small beginning 30 years ago, the business of bulb making has grown to considerable importance. There are now in the United States alone about 4,000 persons, mostly men, employed in the making of glass bulbs and tubing for incandescent lamps. Thronghout the 
world there are probably from 10,000 to 12,000 so employed, though definite statistics are not available. It is estimated on good authority that production of incandescent lamp bulbs in the United States is now going on at the rate of $20,000,000$ per month or nearly $1,000,000$ for each working day.

Decorated lighting glassware. -The principal items of lighting glassware are incandescent bulbs, lamp chimneys, lamp shades, lantern globes, arc-light globes, reflectors, and decorated globes and shades. Decorated globes and shades are made in a variety of shapes and designs, both for ornamental and practical purposes. They are pressed or blown, plain or decorated, machine-cut or hand-cut, needle-etched or acid-etched, and are made from flint, opal, and colored glass. It is claimed that American lighting goods are now superior to those made in Germany and, except in fine colors, are better than the products of Austria and Venice.

\section{PLATE GLASS.}

The making of plate glass in the United States was first attempted in Brooklyn, N. Y., in 1852. In 1869 John B. Ford, after visiting the Lenox works, where plate glass had previously been made, and securing all possible information from the imported workmen, established a plant at New Albany, Ind., which, though successful in manufacturing plate glass, was not profitable financially. This plant was equipped with imported machines for grinding, smoothing, and polishing. In 1872 the newly formed American Plate Glass Co., erected a plant at Crystal City, Mo. This plant, like Ford's, was not financially successful at the outset, though it manufactured a good quality of glass. Mr. Ford operated two other plants subsequent to operating the New Albany plant, but it was not until 1881, when he established a large plate-glass factory at Creighton, $\mathrm{Pa}$., that plate glass was profitably manufactured. This plant is one of the original works of the present Pittsburgh Plate Glass Co.

Previous to 1880 every investment in plate-glass manufacturing in the United States had resulted in financial failure. The wonderful progress and development of the plate-glass industry began in 1880 and has continued until the present day, when American plate glass, it is claimed, is the equal of the European in clearness, finish, and freedom from flaws and defects. Regular plate glass is one-quarter of an inch thick. There are, however, American companies at the present time that are specializing in the manufacture of a very thin or a very thick plate glass.

The first process for making commercially successful wire glass was patented by Frank Shuman in 1892. Since 1890 there has been a wonderful development in the manufacture of cathedral, opalescent, and art sheet glass, and all kinds of figured, ribbed, and colored glass.

\section{WINDOW GLASS.}

Crown glass, a variety of blown glass, was the original form of modern window glass. A bulb of glass was blown, and after the lower part of the bulb had been opened by shears, the bulb was flared out to a sheet by a rapid rotation of the blowpipe. The circular sheet or 
disk was cut into two half circles and squared for glazing. From the crescent shape of the cut halres was derived the term cromn glass. The cylinder process of forming window glass probably originated in Italy and about 1830 was introduced into England from France.

The great development in window-glass manufacture dates from 1SS0. Previous to that time American window glass was of poor quality and was made in the old type of pot fumace, whereas the English and Belgium window-glass manufacturers had adopted the tank furnace. It is estimated that fully 25 per cent of the window glass userl in the Lnited States at that time was imported. ${ }^{1}$ In $18 S 8$ James Chambers, after visiting the European glass factories and securing all possible information, built at Jeannette, Pa., a plant equipped with tanks, and although opinion forcasted its failure, it was successful from the start in the continuous and regular production of clear, faultless glass which was superior to that in which the batch had been melted in pots.

Cylinder machinery.-In 1854 Loup introduced a device (French patent) for the mechanical production of cylinders of glass. A "bait member" drew a cylinder from the molten glass into which it had been lowered, air pressure forming the cylinder. In 1856 Martin Andreas Oppermann, a Belgian glass manufacturer, designed and constructed another machine for the making of window glass in cylinder form. This machine was so arranged that cylinders of considerable length could be made, compressed air being used to blow out the cylinder and mechanical means applied for drawing the cylinder. Oppermann stated in his patent that he anticipated using this machine as a means for drawing such cylinders from a tank or bath of molten glass, as also from a bath of glass contained within a refractory receptacie, whereby segregated portions of glass taken from the pot or tank could be operated upon, so that either cylinders or other forms of glass could be made.

Numerous other attempts were made between 1890 and the time that Lubbers (in 1903) brought out his window-glass cylinder machine. However, the various ideas and designs which had been brought out by several different inventors were but little developed, owing to the skepticism of manufacturers and the antagonism of the dominant labor unions in that branch of the industry.

The Lubbers machine was brought out in 1903 and was taken up by the American Window Glass Co. and installed at Alexandria, Ind. It did not, however, reach a stage of commercial utility until approximately 1905. This machine is used in the plants of the American Window Glass Co. Several other machines for the making of window glass have been installed and are now producing large quantities of commercial glass of high quality, among which is the Healy machine, owned and controlled by the Consolidated Window Glass Co., and the Frink machine, invented and owned by Robert L. Frink. The Pittsburgh Plate Glass Co. has also several factories operating under methods which it owns and controls for the production of window glass, in conjunction with its plate-glass business. Other types of machines used are the Douchamp, the Douchamp-Henshaw, and the Okmulgee. It will be seen therefore that machine making of window glass has to a great extent supplanted the old hand process. 
It is claimed that hand-blown window glass is not so apt to break as machine-made glass because it is better tempered, due to the constant reheating in the blowing process. Machine-made glass is drawn which, it is claimed, makes it more brittle.

Sheet-glass machinery.-In 1882 Clarke attempted the mechanical production of sheet glass. Since then numerous inventors have attempted to solve the same problem. About 1908 Irving W. Colburn, of Franklin, Pa., perfected a machine that draws continuous sheets of glass of any desired width and thickness. The width is regulated by a perfected device that makes it uniform. The thickness of the glass is varied at the will of the worker. It is stated that single-strength glass can be drawn at a linear speed of 56 inches a minute and double-strength at 48 inches a minute. The only worker required is a cutter to cut the sheet into various sizes as it emerges from the leer. The people who successfully produced the Owens machine for bottles are now erecting a large plant for the manufacture of sheet glass by the process which Colburn invented and perfected.

\section{RESULTS OF OVERPRODUCTION.}

Until recently, the establishment of a glass factory required a comparatively small investment; a cheap frame structure built near a sand supply or fuel field was the only building necessary. The cheapness of wood and sand was no doubt responsible for the building of numerous plants. With the discovery of natural gas many towns offered large bonuses and other inducements, such as free sites and free or cheap gas, and people entered the business who had neither the knowledge nor the ability successfully to conduct a glass plant. The overproduction which followed, together with the general business ignorance of many who had recently entered the field as a getrich-quick speculation, resulted in a period of price cutting.

In numerous instances manufacturers attempted by purchase or organization to remedy the evil results of this keen competition and overproduction. In 1885 almost all the large glassware plants in New Jersey formed a manufacturers' association for the purpose of fixing prices, and in 1891 a number of manufacturers formed a stock company, known as the United States Glass Co., which bought up 15 of the largest and most complete press-manufacturing plants in the country, located in Pennsylvania, Ohio, and West Virginia. The Pittsburgh Plate Glass Co., formed in 1895, purchased all the plateglass factories in the United States with the exception of three. Many manufacturers, it is stated, have been deterred from combining for the purpose of fixing prices by fear of the Sherman Act. At the present time many window-glass manufacturers market their product through the same selling agent, and manufacturers in other branches of the glass industry are contemplating some such arrangment.

\section{SPECIALIZATION IN MANUFACTURE.}

There is a tendency in glass manufacturing, as in most other industries, toward specialization, and its cheaper cost of production and improvement of quality. Specialization would, for one thing, greatly lessen the expense for molds, which is very large. Users of the Owens machine usually manufacture only a few products and other 
manufacturers have also begun to concentrate on one product or one line of goods. This specialization, probably due to keen competition and the perfection of various machines, is likely to continue.

Following is a brief description of the specialties manufactured by the leading glass-producing countries of Europe:

England: Beautiful, pure, brilliant, lead flint ware; cut and engraved ware and excellent quality of colored ware.

France: Polished plate glass that is considered the standard; stained glass windows; enameled and etched fancy ware; lenses; ware with elegance of shape, lightness of design, and beauty of glass.

Belgium: Window glass of fine quality at a low price.

Germany: Mirrors: cheap tableware; colored rases.

Austria-Hungary (Bohemia): Beautifully cut, engrared, and decorated glassware of beautiful color and purity of glass; glass gems, beads, pearls, and buttons.

\section{EFFECTS OF THE EUROPEAN WAR.}

The war in Europe has had, indirectly, a beneficial effect on the American glass industry. Manufacturers and inventors in this industry, as in others. have been concerned chiefly with increased production and lower labor cost, and all their energies, consequently, have been spent in perfecting the mechanical end of the business and the inrention and improvement of machinery. The batch and the application of chemical principles, howerer, have been neglected. This most important detail of successful manufacturing, a knowledge of the glass itself, its behavior, the ingredients that go to make up the batch, was lacking. A manufacturer made glass as his father made it before him (empirically) or as his competitor made it. At the time of this inrestigation the agents found comparatirely few plants that employed a chemist of any kind and only one that had a chemical physicist.

With the adrent of the war, glass manufacturers faced the same situation that confronted the user's of dyestuffs. They had learned to depend upon foreign countries for many of the principal ingredients of glass. Shut off from their usual supply, manufacturers began to grope about for themselves and a great impetus was giren to chemical research. Soda ash has been manufactured in this country for many years. Since the war started another chemical has been substituted for pearl ash, heretofore considered indispensable. A substitution was also made for zinc oxide when its price went up, and one manufacturer stated that he had discorered a decolorizer to take the place of manganese. The war has of necessity compelled American manufacturers to shift for themeslves in a field of their business which they had heretofore neglected. The start has been made, and it is hoped that American manufacturers will continue the work so well begun, so that before many years there will be a thorough knowledge of glass chemistry.

Laboratory and chemical glassware was not manufactured to any extent in the United States prior to the European war, being imported principally from Germany. With its importation impossible, colleges, hospitals, laboratories, etc., looked about for American-made goods, and several manufacturers were quick to take advantage of the opportunity of the times and bogan to manufacture the much sought-for chemical and laboratory ware. For the short time they have been 
engaged in manufacturing these products, remarkable progress has been made. It is claimed that a new branch of the glass industry has been established and that it will remain after the war is over.

\section{FUTURE OF THE GLASS INDUSTRY.}

There is at present a tendency toward large factories with their greater production and correspondingly lower overhead cost, greater opportunity for efficiency, and increased purchasing power. The profitable factory of the future will probably be a large one. Manufacturers are gradually installing modern machines, specializing in one product or line of goods has been begun, and the manufacture of chemical glassware has been developed to comparatively large proportions. With the perfection of machines and the elimination of a large amount of hand labor, it is probable that the annual production will greatly exceed the domestic demand. This will necessitate some plants withdrawing from the business or the entrance of the industry in general into the export trade on a large scale.

American glass of almost every kind equals the foreign product; in some lines, such as lead cut glass, all forms of pressed ware, and machine-made fruit jars and bottles, the domestic glass is superior in purity of glass, pattem, design, utility, and is lower in price. The demand for glass products is increasing rapidly and should grow to immense proportions. With the present total absence of foreign competition of any kind and with the high prices now prevailing, glass manufacturers have the opportunity to remedy the evils of the trade, improve their factories, put themselves in sound financial condition, and so put their house in order as to insure future stability and prosperity regardless of the outcome of the war, its effects or influences.

\section{GENERAL STATISTICS OF THE INDUSTRY.}

General statistics of the glass industry shown in Tables 1 to 10 were furnished by the Bureau of the Census

Table 1.-Value of Glass Production, by States.

[Data from the Bureau of the Census.]

\begin{tabular}{|c|c|c|c|c|c|c|}
\hline States. & 1879 & 1889 & 1899 & 1904 & 1909 & 1914 \\
\hline Pennsylvania....... & $\$ 8,720,584$ & $\$ 17,179,137$ & $\$ 22,011,130$ & $\$ 27,671,693$ & $\$ 32,817,936$ & $\$ 39,79 \pi, 822$ \\
\hline 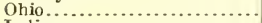 & $1,549,320$ & $5,649,183$ & $4,547,083$ & $9,026,208$ & $14,358,274$ & $19,191,342$ \\
\hline Indiana... & 790,781 & $2,995,409$ & $14,757,883$ & $11,706,929$ & $11,593,094$ & $14,881,372$ \\
\hline West Virginia.............. & 748,500 & 945,224 & $1,871,795$ & $4,59 \$, 563$ & $7,779,483$ & $14,631,171$ \\
\hline 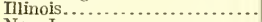 & 901,343 & $2,372,011$ & $2,834,398$ & $5,619,740$ & $5,047,333$ & $7,680,343$ \\
\hline New Jersey. & $2,910,170$ & $5,218,152$ & $5,093,822$ & $6,450,195$ & $6,961,088$ & $7,597,754$ \\
\hline New York. & $2,420,796$ & $2,723,019$ & $2,756,978$ & $4,279,766$ & $4,508,790$ & $5,156,714$ \\
\hline 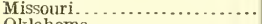 & 919,827 & $1,215,329$ & 765,564 & $1,781,026$ & $1,992,583$ & $3,882,420$ \\
\hline 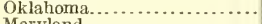 & 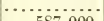 & 1050007 & $\cdots \cdots$ & (c) & (a) & $2,005,736$ \\
\hline$\ldots \ldots \ldots \ldots$ & 557,000 & $1,256,697$ & 557,895 & 589,589 & $1,038,368$ & $1,500,982$ \\
\hline & …… & $\cdots \ldots \ldots$ & $\cdots$ & 958,720 & $2,036,573$ & 728,681 \\
\hline 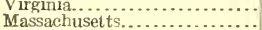 & $\ddot{2} \dot{4} \ddot{3} \ddot{4} \dot{5}$ & $\cdots \cdots$ & (a) & 549,031 & 681,900 & 690,420 \\
\hline 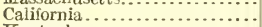 & $\begin{array}{l}204,5 \pm 3 \\
140,000\end{array}$ & $(a)$ & $\begin{array}{l}418,408 \\
(a)\end{array}$ & $\begin{array}{r}1,011,583 \\
915,446\end{array}$ & (a) & (a) \\
\hline Kentucky.. & 588,405 & (a) & & 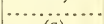 & $(a)$ & \\
\hline Michig & 90,000 & (a) & (a) & (a) & (a) & (a) \\
\hline Connecticut..... & 160,000 & & & $\ldots \ldots$ & $\cdots$ & $\ldots \ldots \ldots$ \\
\hline Now Hampshire..... & $\begin{array}{r}70,000 \\
3,500\end{array}$ & $\cdots$ & $\cdot$ & (n) & $\cdots$ & 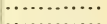 \\
\hline All other States & 3,500 & $1,065,397$ & 924,706 & $1,449,719$ & $3,279,481$ & $5,340,263$ \\
\hline United States. & $21,154,571$ & $41,051,004$ & $56,539,712$ & $79,607,998$ & $92,095,203$ & $123,085,019$ \\
\hline
\end{tabular}


Table 2.-Proportion of Production axd Raxk of States ix Manufacture of Giass.

[Data from the Bureau of the ('ensus.]

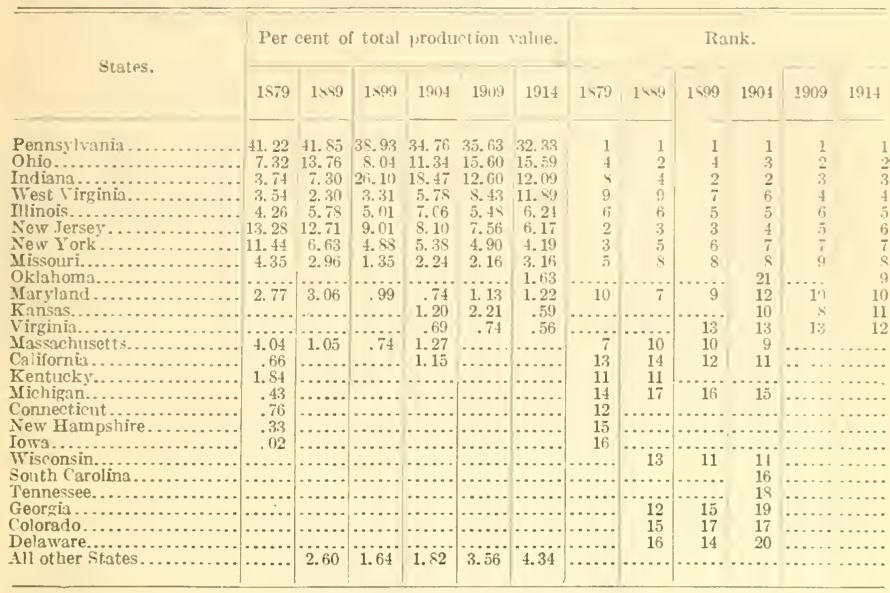

Table 3.-General Statistics of the Glass Industry.

[Data from the Bureau of the Census.]

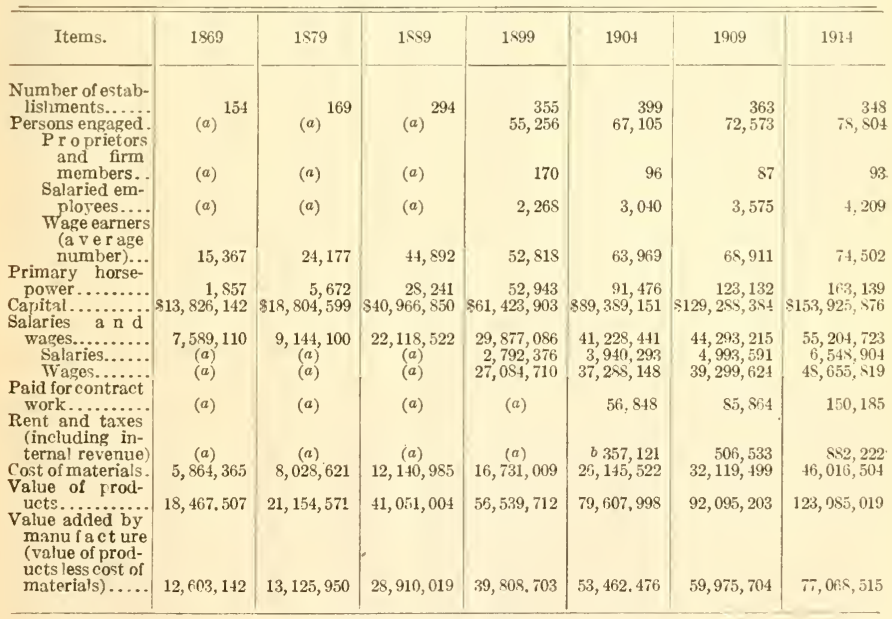


Table 4.-Per Cent of Increase ${ }^{a}$ in Each Census Period after 1869.

[Data from the Bureau of the Census.]

\begin{tabular}{|c|c|c|c|c|c|c|}
\hline Classification. & $1869-1879$ & $1879-1889$ & 1889-1899 & 1899-1909 & 1904-1914 & $1909-1914$ \\
\hline Number of establishments. & 9.7 & 74.0 & 20.7 & 2.3 & -12.8 & -4.1 \\
\hline Persons engaged........... & & ...... & & 31.3 & 17.4 & 8. 6 \\
\hline Proprietors and firm & & & & -48.8 & -3.1 & 6.9 \\
\hline Saluried employee & & & & 57.6 & 38.4 & 17. 7 \\
\hline WVage earners (average number). & (b) & (b) & 17.7 & 30.5 & 16.5 & 8.1 \\
\hline Primary horsepower.................... & 205.4 & 397.9 & 87.5 & 132.6 & 78.3 & 32.5 \\
\hline Capital.................. & 36.0 & 117.9 & 49.0 & 110.5 & 72.2 & 19.1 \\
\hline Salaries and wages...... & 20.5 & 141.9 & 35.1 & 48.3 & $33 . \overline{9}$ & 24.6 \\
\hline Salaries................ & & & & 78.8 & 66.2 & 31.1 \\
\hline Wages........ & & & & 45.1 & 30.5 & 23.8 \\
\hline $\begin{array}{l}\text { Paid for contract work } \\
\text { Rent and taxes (including internal reve- }\end{array}$ & & & & 45.6 & 164.2 & 74.9 \\
\hline 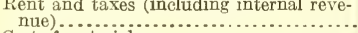 & & & & 90.7 & 147.0 & 74. \\
\hline Cost of materials... & 30.9 & 51.2 & 37.8 & 92.0 & 76.0 & 43.3 \\
\hline 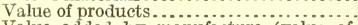 & 14.6 & 94.1 & 37.7 & 62.9 & 54.6 & 33. 6 \\
\hline $\begin{array}{l}\text { Value added by manufacture (value of } \\
\text { products less cost of materials)........... }\end{array}$ & 4.1 & 120.2 & 37.7 & 50.7 & 44.2 & 28.5 \\
\hline
\end{tabular}

a A minus sign (-) denotes decrease.

$b$ Figures not strictly comparable.

Table 5.-Detall of Persons Engaged in the Glass Industry, by States, in 1914.

[Data from the Bureau of the Census.]

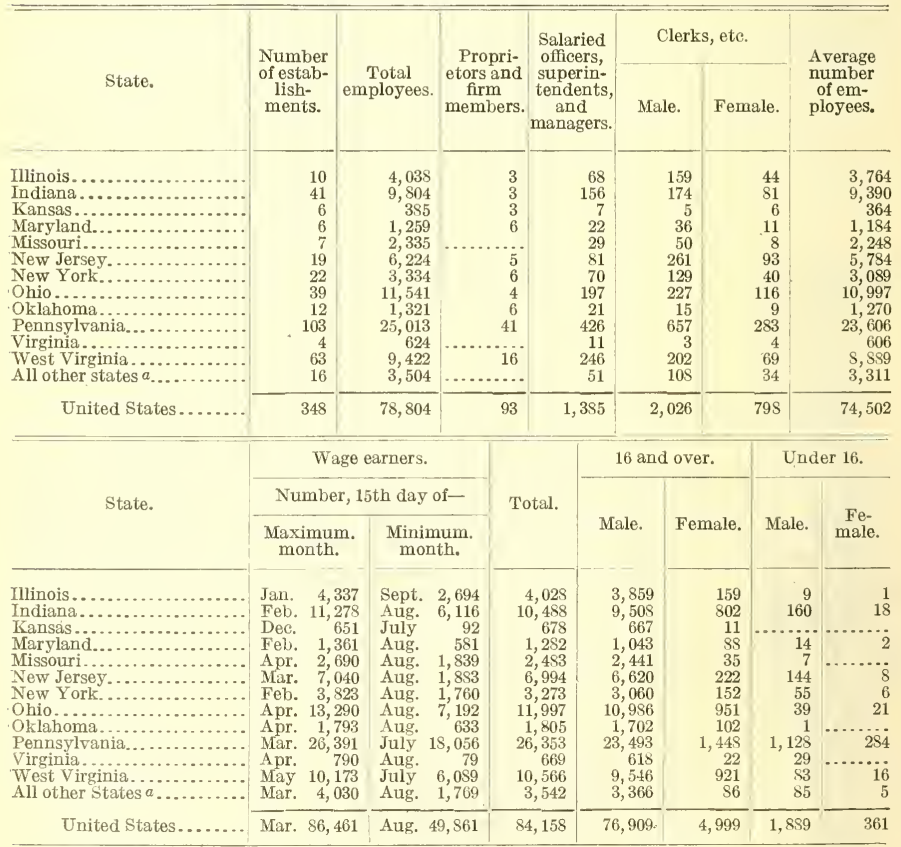

a All other States embrice: California, 3 establishments; Louisiana, 2; Massachusetts, 2; Michigan, 2; Irhode Island, 1; South Carolina, 1; Tennessee, 1; Texas, 2; Washington, 1; Wisconsin, 1. 
Table 6.-Cost of Princtpal Materials, Wages, and Salaries, Other Expenses, and Value of Products in the Glass Industry, by States, in 1914.

[Data from the Bureau of the Census.]

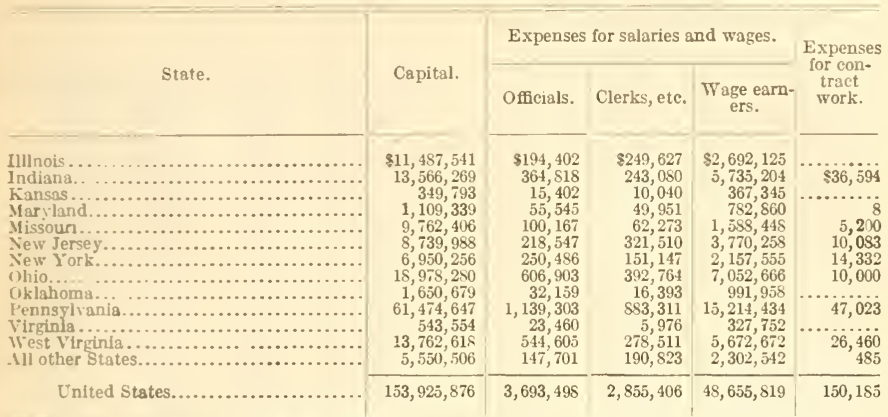

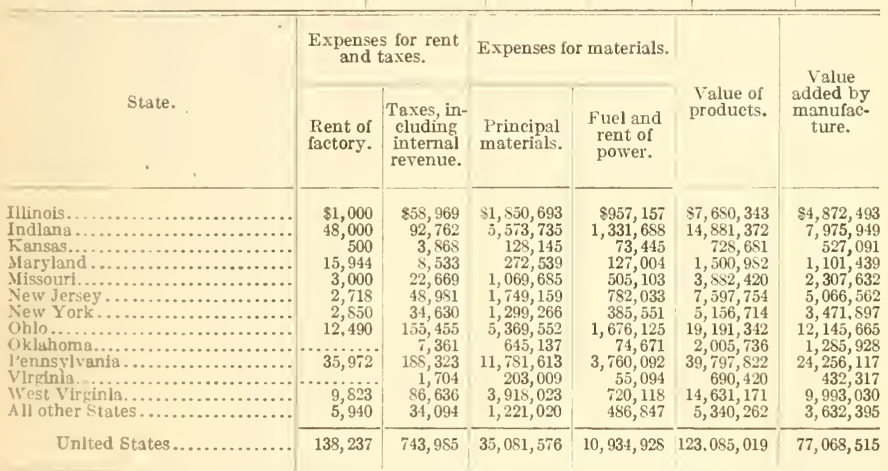

Table 7.-Value of Production in Main Divisions of Glass Manufacture, by States.

[Data from the Bureau of the Census.]

Product and State.
1899

\begin{tabular}{r}
$\$ 17,096,234$ \\
\hline 24,000 \\
$5,711,948$ \\
505,564 \\
274,011 \\
316,790 \\
671,422 \\
$9,213,545$ \\
101,242 \\
247,712
\end{tabular}

1904

1909

1914

Building glass, total value.

Illinois.

Indiana

Ki souri.

New Jersey

New York

Ohio .......

Pennsylvania.

West Virginia...

Ill other States.

1004

$\$ 21,697,861$

281,559
$3,790,618$

381,084

$1,036,433$

201,922

$4,5,310$

$1,625,126$

(a)

$12,169,013$

$1,323,896$

431,900

$\$ 26,308,438$

648,718

$1,616,092$

$1,131,808$

1, 778,364

(a)

173,357

$2,744,513$

( $\pi)$

$14,958,649$

$2,751,133$

505,774
$\$ 36, \$ 24,069$

(a)

$2,356,946$

(a)

$3,122,793$

(a)

$3, \times 05,669$

$1,181,657$

18, 968,873

$4,410,710$

$4,470,710$
$2,977,421$

$a$ Included in " $\Lambda 11$ other States" to avoid individual disclosures. 
Table 7.-Value of Production in Main Divisions of Glass Manufacture, by STATES-Concluded.

\begin{tabular}{|c|c|c|c|c|}
\hline Produet and State. . & 1899 & 1904 & 1909 & 1914 \\
\hline Pressed and blown glass, total value. & $\$ 17,076,125$ & $\$ 21,956,158$ & $\$ 27,398,445$ & $\$ 30,279,290$ \\
\hline 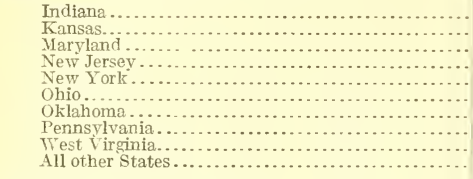 & $\begin{array}{r}2,691,787 \\
100,000 \\
1,173,784 \\
2,738,289 \\
8,453,550 \\
1,379,706 \\
517,709 \\
\end{array}$ & $\begin{array}{r}2,859,087 \\
64,697 \\
46,191 \\
181,559 \\
1,932,524 \\
3,954,660 \\
9,406,183 \\
2,620,665 \\
890,592 \\
\end{array}$ & $\begin{array}{r}2,774,128 \\
202,696 \\
508,492 \\
1,019,836 \\
1,926,852 \\
6,160,707 \\
(a) \\
9,847,228 \\
4,306,528 \\
651,978 \\
\end{array}$ & $\begin{array}{r}2,926,296 \\
\quad(a) \\
\quad(a) \\
\quad(a) \\
2,237,960 \\
6,490,498 \\
220,520 \\
11,241,495 \\
6,263,554 \\
898,967\end{array}$ \\
\hline Bottles and jars, total value... & $21,676,791$ & $33,631,063$ & $36,018,333$ & $51,958,728$ \\
\hline 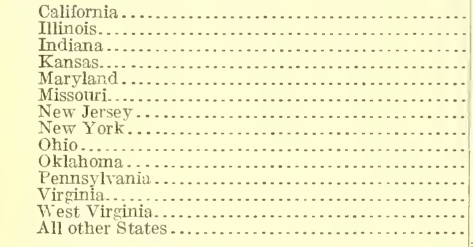 & $\begin{array}{r}(a) \\
2,678,780 \\
6,327,468 \\
346,633 \\
260,000 \\
4,452,219 \\
1,195,276 \\
1,058,955 \\
4,162,990 \\
(a) \\
381,847 \\
812,623 \\
\end{array}$ & $\begin{array}{r}855,446 \\
4,949,156 \\
7,213,456 \\
407,868 \\
536,478 \\
607,383 \\
6,066,714 \\
1,866,245 \\
2,961,727 \\
(a) \\
5,951,144 \\
549,031 \\
602,002 \\
1,064,413 \\
\end{array}$ & $\begin{array}{r}873,434 \\
4,304,795 \\
6,982,378 \\
651,376 \\
528,767 \\
(a) \\
5,884,605 \\
1,884,394 \\
4,717,658 \\
(a) \\
7,778,787 \\
681,900 \\
646,521 \\
1,083,718 \\
\end{array}$ & $\begin{array}{r}(a) \\
6,680,700 \\
9,155,163 \\
7,244,760 \\
1,259,627 \\
7,176,787 \\
2,343,683 \\
7,422,402 \\
603,559 \\
8,930,255 \\
690,420 \\
3,777,445 \\
3,173,927 \\
\end{array}$ \\
\hline All other produets. & 690,562 & $2,322,916$ & $2,369,987$ & $4,022,932$ \\
\hline United States..... & $56,539,712$ & $79,607,998$ & $92,083,203$ & $123,085,019$ \\
\hline
\end{tabular}

$a$ Included in "All other States" to avoid individual diselosures.

Table 8.-Quantity and Value of Production in the Glass Industry, by Articles.

[Data from the Bureau of the Census.]

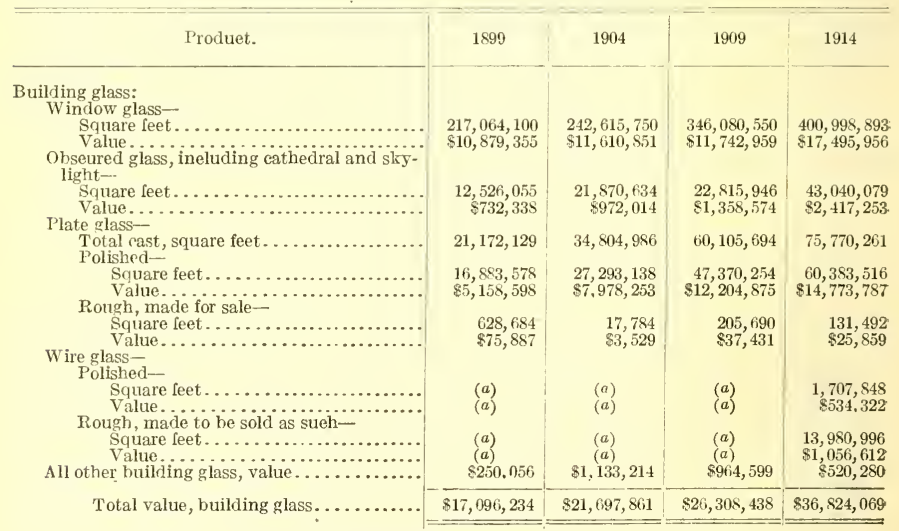

$a$ Not reported separately. 
Tabie S. Qtantity and Value of Prodection 1 is the Glass Indestri, by Articles-Concluded.

\begin{tabular}{|c|c|c|c|c|}
\hline Product. & $1 \diamond 99$ & 1904 & 1909 & 1914 \\
\hline 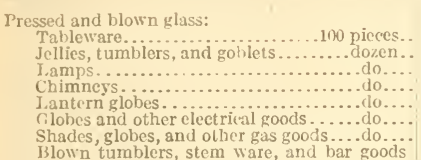 & $\begin{array}{r}(45 ., 741 \\
8,544,050 \\
807,705 \\
6,901,192 \\
1,044,816 \\
(a) \\
2,673,854\end{array}$ & $\begin{array}{r}1,283,974 \\
7,34 i, 214 \\
4 \$ 7,017 \\
7,039,756 \\
1,765,247 \\
1,901,415 \\
875,244\end{array}$ & $\begin{array}{r}1,286,056 \\
11,+157,036 \\
322,482 \\
6,+i 52,917 \\
9.52,620 \\
11,735,795 \\
1,541,449\end{array}$ & $\begin{array}{r}1,554,056 \\
18,030,213 \\
5 \times 0,196 \\
6,989,624 \\
1,3,3,562 \\
10,411,843 \\
2,016,800\end{array}$ \\
\hline 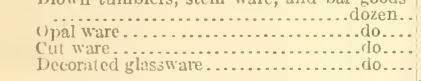 & $\begin{array}{r}6,127,367 \\
3,750,443 \\
134,726 \\
(a)\end{array}$ & $\begin{array}{l}6,2 \& 2,606 \\
1,091,205 \\
83,736 \\
(a)\end{array}$ & $\begin{array}{l}9,152,060 \\
3,095,666 j \\
206,336 \\
(a)\end{array}$ & $\begin{array}{r}11,377,310 \\
4,639,051 \\
297,957 \\
1,158,077\end{array}$ \\
\hline Total value, pressed and blown glass... & $\$ 17,076,125$ & $\$ 21,956,158$ & $\$ 27,398,44 \bar{i}$ & $\$ 30,279,290$ \\
\hline 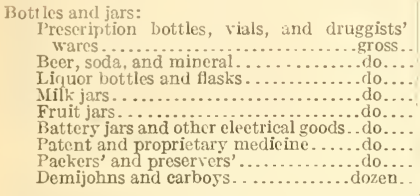 & $\begin{array}{r}2,423,932 \\
1,351,11 S \\
955,374 \\
146,142 \\
789,298 \\
(a) \\
1,296,131 \\
794,588 \\
\$ 3,243 \\
\end{array}$ & $\begin{array}{r}3,202,586 \\
2,351,852 \\
2,157,801 \\
253,651 \\
1,061,829 \\
19,974 \\
1,657,372 \\
1,237,065 \\
64,450\end{array}$ & $\begin{array}{r}3,624,022 \\
2,345,204 \\
1,857,344 \\
440,302 \\
1,124,455 \\
9,981 \\
1,637,795 \\
1,237,175 \\
122,570\end{array}$ & $\begin{array}{r}4,893,410 \\
4,573,610 \\
2,659,022 \\
1,188,891 \\
1,198,952 \\
79,211 \\
1,384,689 \\
3,271,174 \\
160,796\end{array}$ \\
\hline Total value, bottles and jars. . & $\$ 21,676,791$ & $\$ 33,631,063$ & $\$ 36,018,333$ & $\$ 51,958,728$ \\
\hline All other produets, value. & $\$ 690,562$ & $\$ 2,322,916$ & $\$ 2,369,98 i$ & $\$ 4,022,93 \mathcal{L}$ \\
\hline Grand total value ................ & $\$ 56, \overline{539,712}$ & $b \$ 79,607,998$ & c $\$ 92,095,203$ & $\$ 123,085, \overline{019}$ \\
\hline
\end{tabular}

a Not reported separately.

$b$ In addition, glassware to the ralue of $\$ 9,6 f 3$ was made as subsidiar produets by establishments engaged primarily in other lines of manufacture.

c In addition, 42,639 gross of bottles and jars, valued at $\$ 99,490$, were made by establishments engaged primarily in other lines of manufacture.

Table 9.-Proportion of Glass Production, by Value, in the Main Divisions of Manufacture.

[Data from the Bureau of the Census.]

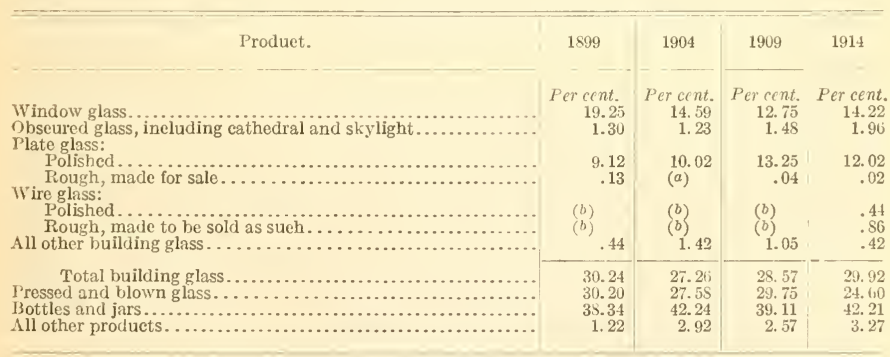

a Less than one one-thousandth of 1 per cent.

$\checkmark$ Not reported separately. 
Table 10.-Increase in Production of Glassware Compared with Increase in Population in the United States, 1904 to 1914.

[Data from the Bureau of the Census.]

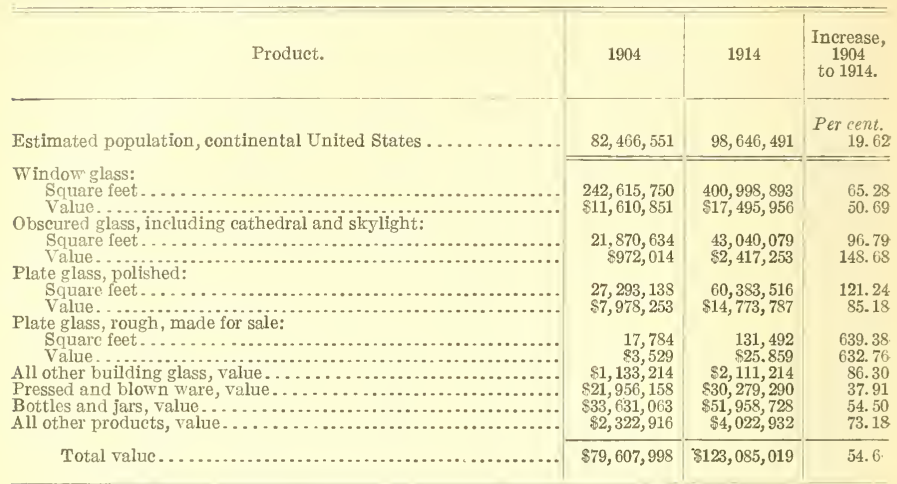

Referring to Table 6 , it will be seen that the total value of glass products in 1914 was $\$ 123,085,019$, and the amount paid wage earners was $\$ 48,655,819$, or 39.53 per cent of the value.

Table 1 shows that during the 35 years from 1879 to 1914, Pennsylvania was the leading State in value of production of glass and glassware. New Jersey changed from second to sixth rank among the glass-producing States, and New York from third to seventh rank.

The production of glass of all kinds remained practically stationary in Indiana during the 15 years from 1899 to 1914 . In 1914 the production in West Virginia was slightly less than it was in Indiana, but during the 15 prior years it had increased nearly sevenfold in West Virginia, a greater rate of increase than in any other State. Cheap gas accounts for the great development of the glass industry in West Virginia and for the establishment of the industry in Oklahoma.

Table 7 shows that during the years from 1899 to 1914 the production of bottles and jars considerably more than doubled in value; the production of building glass more than doubled, while the production of pressed and blown glass did not increase so rapidly. Nearly all of the production of glass in New Jersey consists of bottles and jars. New York, which was seventh among the States in the production of glass in 1914, produced very little building glass, while Inlinois, which was fifth in order of production, produced practically no building glass or pressed and blown glass, nearly all of its products being bottles and jars.

Referring to Table 8, it will be seen that in window glass, obscured glass, polished plate glass, and polished and rough wire glass there were large increases in the production from 1899 to 1914. The table shows that $75,770,261$ square feet of plate glass were cast in 1914, that $60,383,516$ square feet were polished and 131,492 square feet were not polished. The waste, mostly from breakage, appears, therefore, to have been about one-fifth of the quantity cast. 
In pressed and blown glass the largest number of articles produced were jelly glasses, tumblers, and goblets, and the next largest number was of blown tumblers, stem ware, and bar goods. During the yoars 1899 to 1914 the number of glass lamps and of shades, globes, and other gas goods decreased, the number of lamp chimners and lantem globes increased slightly, and the number of globes and other electrical goods increased enormously. The increase in the number of milk jars was large, which may be accounted for by the enactment of law's requiring that corered jars be used for the distribution of milk. The number of prescription hottles, rials, and druggists' wares doubled during the 15 years, while the number of bottles for patent and proprietary medicines increased comparatirely little.

Examining the section of Table $S$ referring to bottles and jars, it will be noticed that from 1599 to 1914 there was a large increase in the number of liquor bottles and flasks produced. Though during that time prohibition was adopted by many States and the saloons in them were closed, liquor was dispensed in bottles and flasks. It is also noticeable that there was a large increase in the number of beer, soda, and mineral bottles and of demijohns and carboys.

There was an increase in the number of fruit jars, but a much greater increase in the number of packers and preservers, which indicates that a less proportion of the preserved fruits and regetables are canned in the homes of the consumers than formerly.

Table 10 shows that the percentage of increase in all kinds of glass and glassware specified by the Census of Manufactures during the 10 years from 1904 to 1914 was rery much larger than the percentag $\theta$ of increase in population.

\section{SCOPE AND METHOD OF INVESTIGATION.}

This inrestigation of the cost of manufacturing glass and glassware was undertaken in compliance with the act of Congress approved August 23, 1912, which created the Bureau of Foreign and Domestic Commerce, and which contained the following section proriding for investigations of the cost of production of articles dutiable in the United States:

Those certain duties of the Department of Labor, or Bureau of Labor, contained in section seven of the act approved June thirteenth, eighteen hundred and eightyeight, that established the same, which especially charged it "to ascertain, at as early a date as possible, and whenever industrial changes shall make it essential, the cost of producing articles at the time dutiable in the United States, in leading countries where such articles are produced, by fully specified units of production, and under a classification showing the different elements of cost, or approximate cost, of such articles of production, including the wages paid in such industries per day, week, month, or year, or by the piece; the hours employed per day; and the profits of manufacturers and producers of such articles; and the comparative cost of living, and the kind of living; what articles are controlled by trusts or other combinations of capital, business operations, or labor, and what effect said trusts, or other combinations of capital, business operations, or labor have on production and prices," are hereby transferred to and shall hereafter be discharged by the Bureau of Foreign and Domestic Commerce, and it shall also be the duty of said Bureau of Foreign and Domestic Commerce to make such special investigation and report on particular subjects when required to do so by the President or either IIouse of Congress.

The investigation was greatly aided by the very hearty cooperation of most of the manufacturers visited. The number of plants that refused to furnish agents of the Burnau with the desired information was 19. 
The information secured during the investigation was obtained directly from the manufacturers and from their books. No data regarding the cost of production were accepted that the agents did not find recorded on the books of the establishment reporting. From the data obtained and entered on establishment schedules were derived the figures that show the various items in the cost of production and also the percentages of profit on net sales, on sales value of goods produced, and on the capital employed in the business. Other schedules, designated "unit schedules," were used to ascertain the cost of manufacturing specified units of glass products. Copies of the forms used by the agents of the Bureau are reproduced in Appendix B (p. 424).

In order to obtain permission to examine the books of manufacturers, assurance was given that the information would be regarded as confidential and would not be used in such a way that the establishment could be identified. The form of the assurance was as follows:

\section{Department of Commerce, Bureau of Foreign and Domestic Commerce, CONFIDENTIAL. \\ Washington.}

[One copy of this agreement to be retained by the manufacturer and one copy to be forwarded to the Chief of the Bureau.]

The information which has been given to Mr. ..........., special agent of the Bureau of Foreign and Domestic Commerce, is furnished with the understanding that neither the name nor the address of the establishment will be written on the schedule; that the information on the schedule will be considered by the Bureau and its special agents as absolutely confidential, and that the information will not be divulged nor published in such a way that the identity of the establishment will be shown.

This information, which appears on establishment schedule No. ......, has been obtained from the books and from the officers of the establishment, and, to the best of our knowledge, is correct.
Special agent's signature:
Date: ......, 191...

Many manufacturers were interviewed by special agents of the Bureau in regard to subjects relating to the glass industry that were not included in either the establishment schedule or unit schedule, and much valuable information regarding general trade conditions was thus obtained.

The statistics regarding wages and hours of labor which appear in this report were secured from only those establishments, which, in the opinion of the agent, maintained accurate labor records. The period taken was the last full-pay period at the time of the agent's visit.

The investigation was begun in January, 1916, and the field work was completed within seven months. Special agents of the Bureau secured reports from 213 establishments, owned by 189 companies or firms, operating 245 plants. Of these 245 plants, for which data were obtained, 69 are located in Pennsylvania and 53 in West Virginia, where the industry is largely centered. Reports were solicited from all plants engaged in the manufacture of glass products except those whose product was specialties or of such character as to make their classification in the various groups impossible. The establishments varied greatly in size, the amount of capital employed, and 
in the amount of business. Of the 213 establishments, 211 reported capital employad in business amounting to $\$ \$ 9,103,387$; two establishments did not report the amount of capitul. 'The total net sales of the 21:3 establishments was \$79,91S,801. According to the Census of Manufactures, 191.t, the value of the total production of all kinds of glass was $\$ 123,0 \$ 5,019$. Of this total the net sales of the 245 plants that reported data for this investigation is 64.93 per cent.

\section{GROUP CLASSIFICATION OF ESTABLISHMENTS.}

The 213 establishments for which data were obtained were classified into 13 groups according to their products and methods of manufacture. These groups are as follows:

Group I.- Thirty-seven establishments making hand-blown window glass.

Group II.-Twelve establishments making window glass by machine.

Group III.-Six establishments making plate glass.

Group IV.-Nine establishments making wire and opalescent glass.

Group V.-Twenty-six establishments making hand-blown bottles.

Group VI.-Eighteen establishments making bottles by machine.

Group VII.--Twenty-seven establishments making bottles by hand and machine.

Group. VIII.-Thirteen establishments making jars. This group includes plants manufacturing milk jars, fruit jars, and packer's and preservers' jars.

Group IX.- Eight establishments making blown tableware.

Group X.-Twenty establishments making blown and pressed tableware.

Group XI.-Eighteen establishments making lighting goods. This group includes plants manufacturing bulbs for incandescent lamps, lamp shades, headlights, railroad lamps, semaphores, etc.

Group. XII. - Six establishments making lamp chimneys.

Group XIII.-Thirteen establishments making miscellaneous glass products. This group includes plants manufacturing marbles, nest eggs, demijohns, chemical ware, milk testers, specialties, novelties, etc. $102511^{\circ}-17-3$ 
The following table shows the number of establishments by groups and also the business period for which data were obtained.

Table 11.-Establishments, by Groups, Showing Business Period for Which Data were Obtained.

\begin{tabular}{|c|c|c|c|c|c|c|c|c|}
\hline \multirow{2}{*}{ Classification. } & \multirow{2}{*}{ Group. } & \multirow{2}{*}{$\begin{array}{l}\text { Estab- } \\
\text { lish- } \\
\text { ment. }\end{array}$} & \multicolumn{6}{|c|}{ Business year ending- } \\
\hline & & & $\begin{array}{l}\text { Oct., } \\
1914 .\end{array}$ & $\begin{array}{l}\text { Dec., } \\
1914 .\end{array}$ & $\begin{array}{l}\text { Feb., } \\
1915 .\end{array}$ & $\begin{array}{l}\text { May, } \\
1915 .\end{array}$ & $\begin{array}{l}\text { June, } \\
1915 \text {. }\end{array}$ & $\begin{array}{l}\text { July, } \\
1915 \text {. }\end{array}$ \\
\hline \multicolumn{9}{|l|}{ Establishments making- } \\
\hline Window glass by machine........ & II & 12 & 1 & & .. & $\cdots$ & 1 & .. \\
\hline Plate glass........................ & III & 6 & & 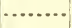 & & & & \\
\hline $\begin{array}{l}\text { Wire and onalescent glass......... } \\
\text { Bottles by hand }\end{array}$ & IV & 9 & & $\dddot{2}$ & & & & 1 \\
\hline 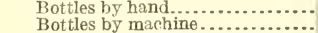 & $\begin{array}{r}\text { V } \\
\text { VI }\end{array}$ & $\begin{array}{l}26 \\
18\end{array}$ & & & $\cdots$ & 1 & $\begin{array}{l}3 \\
4\end{array}$ & 10 \\
\hline Bottles by hand and machine..... & VII & 27 & & $\cdots$ & & .... & 7 & \\
\hline 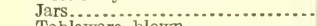 & VIII & 13 & $\cdots$ & -. & $\cdots$ & & & \\
\hline Tableware, blot & IX & 8 & & & & .... & 4 & \\
\hline & $\underset{x}{x}$ & $\begin{array}{l}20 \\
18\end{array}$ & & & $\begin{array}{l}\cdots \\
\cdots\end{array}$ & & $\begin{array}{r}10 \\
3\end{array}$ & \\
\hline $\begin{array}{l}\text { Lighting goods....................... } \\
\text { Lamp chimneys...................... }\end{array}$ & XI & $\begin{array}{r}18 \\
6\end{array}$ & & $\cdots$ & $\cdots$ & $\cdots$ & $\begin{array}{l}3 \\
5\end{array}$ & \\
\hline Miscellaneous articles............... & XIII & 13 & & & $\cdots$ & .......... & 1 & (n......... \\
\hline Total.. & & 213 & 1 & 2 & 1 & 3 & 45 & 27 \\
\hline \multirow{2}{*}{ Classification. } & \multirow{2}{*}{ Group. } & \multicolumn{7}{|c|}{ Business year ending- } \\
\hline & & $\begin{array}{l}\text { Aug., } \\
1915 .\end{array}$ & $\begin{array}{l}\text { Sept., } \\
1915 .\end{array}$ & $\begin{array}{l}\text { Oct., } \\
1915 .\end{array}$ & $\begin{array}{l}\text { Nov., } \\
1915 .\end{array}$ & $\begin{array}{l}\text { Dec., } \\
1915 .\end{array}$ & $\begin{array}{l}\text { Feb., } \\
1916 .\end{array}$ & $\begin{array}{l}\text { June, } \\
1916 .\end{array}$ \\
\hline \multicolumn{9}{|l|}{ Establishments making- } \\
\hline $\begin{array}{l}\text { Window glass by hand............. } \\
\text { Window glass by machine..... }\end{array}$ & & 7 & 9 & & 2 & 4 & & \\
\hline $\begin{array}{l}\text { Window glass by } \\
\text { Plate glass........ }\end{array}$ & III & $\begin{array}{c}5 \\
\cdots\end{array}$ & & 1 . & $\cdots$ & $\begin{array}{l}4 \\
6\end{array}$ & & \\
\hline Wire and opalescent glass. & IV & & & & ... & 7 & $\ddot{i}$ & $\ldots \ldots$ \\
\hline 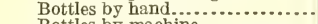 & $\mathrm{V}$ & 3 & & 1 & .... & 6 & ... & ......... \\
\hline $\begin{array}{l}\text { Bottles by machine..................... } \\
\text { Bottles by hand and machine.... }\end{array}$ & $\begin{array}{l}\text { VI } \\
\text { VII }\end{array}$ & $\begin{array}{l}4 \\
8\end{array}$ & & 1 & (n.......... & $\begin{array}{l}3 \\
6\end{array}$ & $\cdots$ & .......... \\
\hline 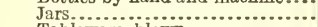 & VIII & 2 & 1 & $\ddot{3}$ & $\ddot{i}$ & 6 & $\cdots$ & ....... \\
\hline $\begin{array}{l}\text { Tableware, blown.... } \\
\text { Tableware, blown an }\end{array}$ & $\underset{\mathrm{X}}{\mathrm{IX}}$ & & & & & $\begin{array}{l}4 \\
9\end{array}$ & & ...... \\
\hline Lighting goods........ & $\hat{X I}$ & & & $\cdots$ & $\cdots$ & 12 & & $\cdots$ \\
\hline Lamp chimneys...... & XII & & $\ldots$ & $\ldots$. & $\cdots$ & 1 & & \\
\hline Miscellaneous articles. & XIII & & & & 1 & 11 & & \\
\hline Total.. & & 29 & 14 & 6 & 4 & 79 & 1 & 1 \\
\hline
\end{tabular}


Table 12 which follows gives the number of establishments from which schedules were secured, the number of plants operated, and the number of firms or companies owning such plants.

Table 12.-Number of Cost Schedules Secured, Number of Companies or Firms Represented, and Number of Plants Operated, by Groups.

\begin{tabular}{|c|c|c|c|c|}
\hline Fstablishments making- & Group. & $\begin{array}{l}\text { Sched- } \\
\text { ules } \\
\text { secured. }\end{array}$ & $\begin{array}{l}\text { Compa- } \\
\text { nies or } \\
\text { firms. }\end{array}$ & $\begin{array}{c}\text { Plants } \\
\text { operated. }\end{array}$ \\
\hline 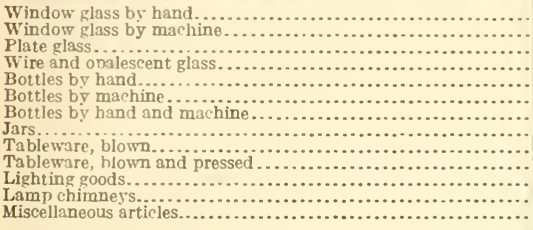 & $\begin{array}{l}\text { I } \\
\text { III } \\
\text { IV } \\
V \\
\text { VI } \\
\text { VII } \\
\text { VIII } \\
\text { IX } \\
\text { XI } \\
\text { XII } \\
\text { XIII }\end{array}$ & $\begin{array}{r}37 \\
12 \\
6 \\
9 \\
26 \\
18 \\
27 \\
13 \\
8 \\
20 \\
18 \\
6 \\
13\end{array}$ & $\begin{array}{r}35 \\
10 \\
6 \\
9 \\
26 \\
11 \\
25 \\
7 \\
8 \\
15 \\
18 \\
6 \\
13\end{array}$ & $\begin{array}{r}38 \\
12 \\
6 \\
12 \\
26 \\
21 \\
30 \\
14 \\
9 \\
26 \\
27 \\
7 \\
17\end{array}$ \\
\hline Total.... & & 213 & 189 & 245 \\
\hline
\end{tabular}

\section{DISTRIBUTION OF INDUSTRY BY STATES.}

Table 13 that follows shows the location of the 245 plants by States and also classifies them according to products produced.

Table 13.-Plants Classified b Products and States.

\begin{tabular}{|c|c|c|c|c|c|c|c|c|c|c|c|c|c|c|}
\hline States. & 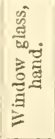 & 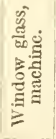 & 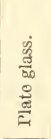 & 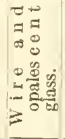 & 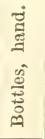 & 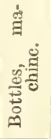 & 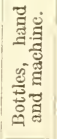 & 总 & 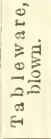 & 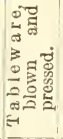 & 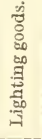 & 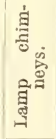 & 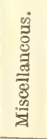 & \\
\hline & & & 1 & $\begin{array}{l}2 \\
2\end{array}$ & $\begin{array}{l}2 \\
3\end{array}$ & 3 & 3 & 1 & & 2 & 3 & & $\begin{array}{l}1 \\
1\end{array}$ & $\begin{array}{l}10 \\
20\end{array}$ \\
\hline & $\begin{array}{l}5 \\
5 \\
1\end{array}$ & & & & & & & & & & & & & \\
\hline & & & & & 1 & .. & $\dddot{2}$ & & 1 & $\cdots$ & i & & $\cdots$ & \\
\hline & & & 1 & & & & . & & & & & & 2 & \\
\hline & & & & ï & & & ii & & & & ... & & $\ldots$ & \\
\hline & & & ... & $\cdots$ & 6 & 2 & 5 & & & $\cdots$ & 1 & & 2 & 1 \\
\hline & 4 & 1 & 1 & $\dddot{i}$ & 2 & 5 & 4 & 1 & & $\dddot{4}$ & 7 & 2 & $\begin{array}{l}6 \\
2\end{array}$ & 3 \\
\hline & $\begin{array}{l}2 \\
9\end{array}$ & 5 & 3 & 4 & & 1 & 9 & 1 & & & & 1 & & ( \\
\hline . & & & 3 & 4 & 9 & & $\begin{array}{l}9 \\
1\end{array}$ & & 1 & 14 & 7 & & 1 & 6 \\
\hline & 1 & 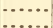 & ... & & * & & & & & & & & ... & \\
\hline & 14 & $\dddot{5}$ & …..... & $\dddot{2}$ & 1 & 4 & 1 & 4 & 7 & $\dddot{6}$ & 3 & $\dddot{4}$ & $\dddot{2}$ & \\
\hline & & & & & & 1 & & & & & & & & \\
\hline Total. & 38 & 12 & 6 & 12 & 26 & 21 & 30 & 14 & 9 & 26 & 27 & 7 & 17 & 245 \\
\hline
\end{tabular}


Table 14 shows the total number and location by States of the glass plants listed in the Glass Factory Directory for 1916, and also the number for which cost of production schedules were obtained and the number omitted from the investigation, with the reason for such omission.

Table 14.-Number of Plants Listed in the Glass Factort Directory, 1916 , Number Furnishing Cost Schedules, and Number Omited, with Reasons FOR OMISSION.

\begin{tabular}{|c|c|c|c|c|c|c|c|c|c|}
\hline States. & $\begin{array}{l}\text { Sched- } \\
\text { nles ob- } \\
\text { tained. }\end{array}$ & $\begin{array}{l}\text { Plants } \\
\text { closed. }\end{array}$ & \multicolumn{4}{|c|}{ Schedules not secured because- } & $\begin{array}{l}\text { Sched- } \\
\text { ules } \\
\text { secured } \\
\text { and can- } \\
\text { celed.c }\end{array}$ & $\begin{array}{l}\text { Plants } \\
\text { omit- } \\
\text { ted.d }\end{array}$ & $\begin{array}{l}\text { Plants } \\
\text { not } \\
\text { visited. }\end{array}$ \\
\hline Total......... & 213 & 19 & 19 & 8 & 22 & 15 & 11 & 18 & \\
\hline
\end{tabular}

a A full vear's schedule could not be secured for the period desired.

b A complete schedule could not be secured because of methods of keeping books of account.

c Schedules were canceled because of abnormal conditions existing in the plant, or period was less than a year, or equipment of plant was being changed.

$d$ These plants were not visited because of the class of product manufactured, change of ownership, plant in an experimental stage, or because the product was manufactured as a side line for consumption by the same company in a different business.

A contemplated investigation by the Bureau of Foreign and Domestic Commerce of the cost of production of glass products in European countries was prevented by the war. 


\section{SUMMARY.}

\section{GENERAL RESULTS OF THE INVESTIGATION.}

There are several distinct branches of the glass inclustry, each different and complete in itself. Of the 331 establishments listed in the Glass Factory Directory of 1916, reports were secured from 213 establishments operating 245 plants. The reports cover establishments manufacturing hand and machine blow'1 window glass, plate glass, wire and opalescent glass, hand and machine blown bottles and jars, blown and pressed tableware, lamp chimneys and other lighting goods, and miscellaneous products. Some plants visited were found to have suspended operations, and some refused to furnish the information requested. I few schedules obtained (not included in the 213 reported) were not used because abnormal conditions existed in the plants. Schedules could not be secured in some establishments because the records in their books of account were incomplete. The investigation was greatly facilitated by the unreserved cooperation of most of the manufacturers risited.

According to the Census of Manufactures, the value of the total production of all kinds of glass and glassware in 1914 was \$123,085,019. Of this total the net sales of the 213 establishments from which data were secured is 64.93 per cent.

As shown by the census, the ralue of the production of all kinds of glass and glassware was $\$ 56,539,712$ in $1899, \$ 79,607,998$ in 1904 , and $\$ 123,085,019$ in 1914 . The increase in production (square feet) from 1899 to 1914 was 84.74 per $^{\circ}$ cent for window glass and 357.65 per cent for polished plate glass. The increase in value of production was 139.7 per cent for bottles and jars and 77.32 per cent for pressed and blown ware. This great increase in production during the 15 years is due, primarily, to the general introduction of machinery in some branches of the industry, which has replaced the highly skilled hand labor previously employed.

The industry is to a great extent localized. Excepting labor, the cost for fuel is generally the chief item of expense. Manufacturers have therefore erected plants where cheap fuel (natural gas, coal, or oil) could be obtained. This localization is shown by the fact that, according to the census of 1914, Pennsylvania, Ohio, Indiana, and West Virginia, in each of which cheap fuel in some form is to be had, ranked highest, and in that order in value of production; and the value of the production in these four States was $\$ 88,501,707$, or 71.90 per cent of the total value of the production in the United States during that year, \$123,085,019.

The introduction of automatic and other machinery has greatly increased production, lowered cost and selling prices, driven many highly skilled workers from the industry, and has been a disturbing factor in the respective branches of the industry where it has been installed. 'The automatic bottle machine, introdriced about 1903, was followed shortly by the flowing device, which did away with the skilled gatherer.

Manufacturers using the automatic machines or flowing device probably produce more than all other brttle manufacturers. Those 
who use other machines, which have been introduced in an effort to offset the lower cost of the automatic-machine product, or who make bottles by hand. unless their factories are very advantageously located, find it difficult to compete with manufacturers using the automatics or flowing device, especially on large orders.

The extended use of window-glass machinery, introduced in 1903, resulted in overproduction. This led about 50 window-glass manufacturers in 1909 to form the Imperial Window Glass Co., which curtailed production and raised prices. The officers and directors of this company were, in 1910, indicted and fined. In recent vears the prices announced by the company that is the largest producer of window glass in this country are followed by the other manufacturers. At present the entire product of about half of the 51 hand factories and of a few machine factories is sold through one agent or broker.

Many branches of the industry operate only a part of the year. Hand window-glass manufacturers work only about seven months; machine manufacturers usually average about eight months a year. Many other branches lose one or more months a year. The reasons are fear of overproduction, the inability of the men to work around the furnaces in the great heat of summer, the necessity for replacing pots, fixing tanks, regulating bad glass, repairs, etc.

Despite the generally improved quality of the ware produced, the tendency, until the war changed normal business conditions, was for prices to decline. This decrease was due to the introduction of machinery, which has considerably lowered costs, and to the very keen competition that is general in the glass industry.

The prices of all sizes of plate glass have been reduced-in the size 5 to 10 square feet, from $\$ 0.60$ per square foot in 1900 to $\$ 0.43$ in 1910 and $\$ 0.29$ in 1915. In March, 1912, the price of the 16 by 24 bracket, single strength, A quality window glass, was $\$ 1.74$ per per box of 50 feet, and in January, 1914, \$1.58; the same bracket and strength B quality, \$1.63 in March, 1912, and \$1.47 in January, 1914. The price of incandescent lamps has decreased from something over \$0.036 per candlepower in 1907 to $\$ 0.006$ in 1916 .

There is much inefficiency in the industry. Until very recently only a few manufacturers had an essential knowledge of the chemistry of glass. In the plants risited not more than one in twenty enuployed a chemist. Most plants, except the few large ones erected in recent years, are poorly constructed and arranged. Accounting, generally, is not up to the standard expected in an important industry, and, with the exception of a few excellent systems found, there are no accurate cost-keeping methods or records. Many manufacturers do not even attempt to compute costs.

At least two new branches of the industry have been recently established. Photographic glass, first made commercially in the United States in 1911, has been developed. Prior to the war only one American factory manufactured chemical glassware, and its production was inconsiderable. A number of progressive manufacturers have begun to make such ware, and the quality of most articles produced in the United States is as good or superior to what was formerly imported. Men in the trade feel that with proper encouragement these new and necessary products will continue to be manufactured in the United States after the war. 
Of the 213 establishments from which data were obtained the business rear of 45 ended in June, 1915, S0 from July to November, 1915, and $79 \mathrm{in}$ December, 1915 . The agents endeavored to obtain data for business periods ending in 1915 , because up to late in that year the prices of raw materials had adranced very little, due to the practice of purchasing materials under long-term contracts. and because at that time selling prices were still comparatively stable.

The capital turnorer in the glass industry is exceptionally small. The average ratio of net sales to capital employed for the 211 establishments reporting capital employed is in the proportion of $S \mathrm{~S}$ to 100 , the ratio varying from 174 to 100 for the highest group to 37 to $100 \mathrm{for}$ the lowest group. This low turnover is due to the unusually large capital investment required by a glass plant for its land, buildings, and equipment. The arerage capital for the 211 establishments is $8+22,291$.

The average operating profit, computed after deducting depreciation and interest on current loans, for the 211 establishments that reported capital is 4.66 per cent on the capital employed. The highest percentage of operating profit, $15.4 \mathrm{~s}$ per cent, is shown by the miscellaneous group which manufactures norelties, specialties, etc., and the lowest percentage, an operating loss of 0.15 per cent, by the blown and pressed tableware group. The arerage operating profit on net sales of the 213 establishments, computed after deducting depreciation and interest, is 5.57 per cent. The average final profit of the 213 establishments, on the basis of the sales value of goods produced, is 6.12 per cent.

Four of the 13 groups had greater average sales in 1915 than in previous years. Eight groups had smaller average sales in 1915 than in either 1914 or 1913 . One group had greater average sales in 1913 and smaller arerage sales in 1914 than in 1915.

Five of the 13 groups showed a higher average percentage of final profit (based on the sales of each year) for the year 1915 than for 1914, 1913, or 1912. Five groups showed lower arerage percentages of final profit for the year 1915 than for 1914, 1913, or 1912 . Three groups showed lower arerage percentages of final profit for the year 1915 than for 1914 or 1913 but greater percentages than for 1912.

Of the 211 establishments that owned land, buildings, and equipment only 102, or less than half, made a charge for depreciation. Of these 102 only 35 had separate depreciation charges for land, buildings, and machinery and equipment. Depreciation for the 109 plants that made no charge for depreciation was computed for tables in this report at the average percentage of those plants in their respective groups that made such a charge. After this computed depreciation was added, 20 plants that had previously shown a final profit showed a final loss.

Labor constitutes the chief single item of expense. The labor cost for the 213 establishments is 40.57 per cent of their net sales; three groups show averages over 50 per cent. The highest percentage is shown by the hand window glass group, 58.53 per cent, and the lowest by the wire and opalescent group, 20.95 per cent.

Practically all the skilled labor is on a piece-rate basis; all other Jabor is on a time-rate basis. Females are employed only to an insignificant extent and in only a few occupations in the industry. 
Owing to the desire to increase production and to the impracticability of extinguishing furnaces every day, the work in many branches of the industry, especially where continuous tanks are used, continues day and night. The skilled workers usually alternate at day and night work, as do some of those less skilled who assist them. Most of the unskilled workers do not alternate but are more frequently either day or night workers only.

In the manufacture of hand window glass and also of blown and pressed ware, which includes tableware, bar goods, lighting goods, laboratory ware, vases, and miscellaneous articles, the labor unions restrict the output of the plants by limiting the maximum production of workers in each turn of a specified number of hours. This system decreases production and increases cost.

Wages in the highly skilled occupations are relatively high. The hours of labor are comparatively short, averaging between 45 and 50 hours a week, and in some cases 45 hours or less. A week's work in some few of the unskilled occupations is 84 hours in 7 days, but the usual average for unskilled occupations is a week of 60 hours in 6 days.

Selling expense is exceptionally low in this industry, being only 4.01 per cent on net sales for all the establishments reporting. Due to the small turnover of capital, manufacturers generally prefer to sell their output to jobbers and large consumers who usually buy in considerable quantities and on comparatively short terms.

Although the Bureau prepared special forms for obtaining the cost of specified units in the various branches, it was generally found impossible to use them. In the groups that made diversified products it was impossible, generally, to obtain comparable costs. Many manufacturers had no cost records whatever, and even among those that kept records there was a lack of uniformity in the consideration of the various items of expense. Unit cost data were obtained from only those plants which, in the opinion of the visiting agent, had reasonably accurate cost recolds.

The average cost of each specified item of expense was computed for a 50 -foot box of single-strength window glass, both machine and hand made. For establishments reporting wage data in detail costs were also computed for 50-foot boxes, A and B grades, by different brackets, the items consisting of the cost for materials, fuel, piece-paid labor, other factory labor, salaries, and all other cost. For all other units, which consist of bottles and jars, blown and pressed tableware and stem ware, lamp chimneys, and lighting goods, only the total cost, net selling price, and profit or loss were obtainable on a comparable basis.

Imports for consumption as compared with the domestic production have largely decreased. The percentage that imports for consumption (fiscal year) was of the domestic production (calendar year), as reported by the Bureau of the Census, was as follows: 15.51 per cent in $1879,18.91$ per cent in $1889,7.58$ per cent in $1899,8.33$ per cent in 1904, 5.75 per cent in 1909, and 6.68 per cent in 1914 .

The imports for consumption during the fiscal year 1913 (the last full year of the Payne-Aldrich Tariff Act) were $\$ 6,436,662$. During the fiscal year 1914 (the Underwood-Simmons Act became effective Oct. 4,1913 ) imports increased to $\$ 8,219,112$. Since the war began imports have very materially decreased. 
The general dutiable imports during the fiscal year ending Jume 30, 1914, were as follows: Cylinder, crown, and common window glass, $\$ 1,356,218$; plate glass, cast, polished, and unsilvered, $\$ 72 \bar{\tau},-$ $\$ \$ 9$ : bottles, jars, etc., used for containers in transportation, $\$ 1,14 \mathrm{~s}$, 460: articles cut or ornamented, $\$ 1,151, \$ 76$; spectacles, lense's, and optical instruments, $\$ 721,560$; all other, $\$ 2,46 \$, 128$. The free general imports were: Plates or disks for optical purposes, s617.70:3: white enamel glass for watch and clock dials, $\$ 12,970$.

Window-glass manufacturers did not complain of the rates of duty on glass larger than the first three brackets. However, all those interviewed claimed that the rates on the lirst three brackets (3St square inches and under) were too low. Manufacturers of plate glass claimed that in their case also the smaller sizes were inadequately protected.

The present tariff classification on imports has not been changed for many rears. No criticism was made as to the classification of any kind of building glass. Schedule classifications of other products, however, were criticised, and suggestions were made that some of them might be improved by making them more specific and descriptive. A proposed revision of these classifications is presented in the report.

Glass exports from the United States increased from $\$ 2,252,799$ during the fiscal year 1905 to $\$ 3,729,623$ during the fiscal year 1914 . From the fiscal years 1905 to 1913 (the last full year under the ParneAldrich Tarifi Act) the ratio of exports to imports increased from 38 to 65 per cent. In 1914 , due to the great business depression in all countries of the world, the ratio of increase fell to 45 per cent.

Prior to the war most of the exports were "all other kinds," which includes heary cut ware of which the exports are considerable and the imports very little. This ware went largely to Europe. This classification also includes lamp chimneys, of which a large quantity is exported. Most of the small amount of window and plate glass and bottles and jars that were exported went principally to Canada and Mexico. During the fiscal year ending June 30, 1916, the total exports of glass and glassware were $\$ 12,321,338$, an increase of 30.27 per cent over 1914. The largest exports during the fiscal year 1916 went to England, Canada, and Australia.

\section{MATERIALS, MACHINERY, AND PROCESSES.}

The raw materials employed in glass making are usually silica, various alkalies, alkali oarths, and metals. Cullet (broken glass) in varying amounts is generally added to the batch. Silica in the form of sand is usually 50 to 75 per cent of the batch. The allialine bases usually employed are soda ash, salt cake, and potassium: the alkaline earths are lime and (occusionally) barium carbonate; the metallic bases are lead and (occasionally) aluminum, arsenic, and zinc. Manganese principally, and to some extent selenium, cobalt, and nickel, is used to neutralize the colors imparted by other clements. A number of other elements used to color glass are enumerated in the report.

There are two types of furnaces employed, the pot furnace and the tank furnace (day or continuous). 'They are heated by natural or artificial gas or fuel oil. Furnaces employ either the regenerative 
or recuperative system of heating; the regenerative system is more commonly used. A temperature of about $2,600^{\circ} \mathrm{F}$. is necessary to melt the batch.

An iron blowpipe from $4 \frac{1}{2}$ to $5 \frac{1}{2}$ feet in length is used for all hand blowing. Molds are used to facilitate blowing and are employed in all blowing (hand and machine) except in ofthand blowing.

There are automatic, semiautomatic, and other machines for blowing bottles, and a flowing device which dispenses with the skilled hand gatherer is installed in a few factories. There are pastemold machines for blowing seamless ware such as tumblers, lamp chimneys, etc. Presses are employed for certain lines of tableware and are either stationary or rotary. Several types of machines are in use for blowing cylinders of window glass.

The leer in general use is a long brick structure heated at diminishing temperatures; the ware is tempered by being passed slowly through the leer. Various devices are employed for carrying ware from the blowing room to the leer and conveying boxes of packed ware.

The eylinders from which window glass is made are blown either by hand or by machine. After it has been blown the cylinder is split lengthwise, flattened, and cut to size.

Plate glass is cast on a smooth, highly polished table. A heary roller passes over it. The glass is then ground and polished.

Bottles are blown by hand or by automatic, semiautomatic, or other machines.

Tableware is blown, made in a paste-mold machine, or pressed.

Lighting goods are blown (offhand, in a mold, or in a paste mold) or pressed. The ware is often decorated by sand-blasting, etching, cutting, painting, or a combination of these methods. Bulbs for incandescent lamps are blown in a paste mold or by a machine.

\section{CAPITAL, NET SALES, AND TURNOVER.}

Of the 213 establishments for which data were obtained, 211 reported capital employed in business amounting to $\$ \$ 9,103,387$, or an average of $\$ 422,291$ per establishment.

In tabulating the data, the establishments were divided into 13 groups, according to the kinds of glass and glassware manufactured, as shown in the following table, which gives, for each group, the number of establishments, the number having operating profits and the number having losses on net sales, the average per cent of such profits or losses on the capital employed in business and on net sales (depreciation and interest on current loans considered in each case), and the ratio of net sales to capital: 
Table 15.-Operating Profits and Losses. Depreciation and Interest ConSIDERED, BY Grotps of EstablishueNts.

\begin{tabular}{|c|c|c|c|c|c|c|c|}
\hline \multirow{2}{*}{ Establishments making- } & \multirow{2}{*}{ Group. } & \multirow{2}{*}{$\begin{array}{l}\text { Fstab- } \\
\text { lish- } \\
\text { ments. }\end{array}$} & \multicolumn{2}{|c|}{$\begin{array}{l}\text { Establlshments } \\
\text { having profits } \\
\text { or losses on net } \\
\text { sales. }\end{array}$} & \multicolumn{2}{|c|}{ Per cent of profit- } & \multirow{2}{*}{$\begin{array}{l}\text { Ratio of } \\
\text { net sales } \\
\text { to capital. }\end{array}$} \\
\hline & & & Profits. & 1.osses. & $\begin{array}{l}\text { On capi- } \\
\text { tal em- } \\
\text { ployed. }\end{array}$ & $\begin{array}{l}\text { On net } \\
\text { sales. }\end{array}$ & \\
\hline Window glass by hand........ & I & 37 & 31 & 6 & 7.22 & 5.33 & 1.35 \\
\hline Window glass by machine....... & II & 12 & 7 & 5 & 2.14 & 1.99 & 1.08 \\
\hline Plate glass................... & III & 6 & 3 & 3 & .08 & .16 & .51 \\
\hline Wire and opalescent glass....... & IV & 9 & 6 & 3 & 1. 8.5 & 4. 99 & .37 \\
\hline 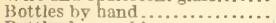 & $\mathrm{V}$ & 26 & 16 & 10 & a 3.26 & 2. 28 & a. 1.40 \\
\hline 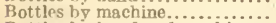 & i & 18 & 16 & 2 & 7.39 & 10. 79 & .69 \\
\hline Bottles by hand and machine.. & $\overrightarrow{V I I}$ & 27 & 14 & 13 & 2.27 & 1.98 & 1. 15 \\
\hline Jars . . . & Vill & 13 & 10 & 3 & 4.97 & 5.04 & .98 \\
\hline 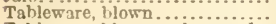 & IX & 8 & 8 & 0 & 10.30 & 9.29 & 1. 11 \\
\hline Tableware, blown and pressed.. & $\mathrm{X}$ & 20 & 12 & 8 & b. 16 & b. 15 & 1.06 \\
\hline 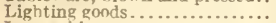 & XI & is & 14 & 4 & $c 9.64$ & 9. 59 & c. 91 \\
\hline 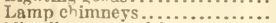 & $\mathrm{XII}$ & 6 & 5 & 1 & 4.91 & 2. 91 & 1. 68 \\
\hline Miscellaneous articles........... & XIII & 13 & 13 & 0 & 15.48 & 8.90 & 1. 74 \\
\hline $\begin{array}{l}\text { All establishments rc- } \\
\text { porting................. }\end{array}$ & & 213 & 155 & $5 \$$ & d. 4.66 & 5.57 & d. 88 \\
\hline
\end{tabular}

a Compoted on the basis of 25 establishments, 1 not reporting capital. $b$ Operating loss.

c Computed on the basis of 17 establishments, 1 not reporting capital. $d$ Computed on the basis of 211 establishments, 2 not reporting capital

With the exception of Group $\mathrm{X}$, all of the groups show an operating profit on both capital and net sales, depreciation and interest on current loans considered, this profit averaging only a fraction of 1 per cent in Group III. The highest average percentages of profit on capital are shown by Groups XIII and IX. The average operating profit for all groups was 4.66 per cent on capital and 5.57 per cent on net sales.

Capital is not turned orer so rapidly in the glass industry as in many other industries. The net sales of the 211 establishments reporting capital amounted to 88 per cent of the capital they employed. The net sales of 8 of the 13 groups were larger, and of 5 groups smaller, than their capital.

A comparison of Groups I and II shows that the percentages of profits of establishments making window glass by hand averaged considerably more than the average percentages of establishments making window glass by machinery. Comparing Groups V and VI, it is seen that the converse is true, the percentages of profits of establishments making bottles by machine avoraging considerably more than the average percentages of establishments making them by hand. The turnover was greater in the cases of both window glass and bottles made by hand than of those made by machinery.

Detailed tables in Chapter II show, by establishments, as well as by groups, the operating profit when depreciation and interest are not considered, and operating and final profits when these items are considered. The final profit was obtained by adding to the operating profit (depreciation and interest considered) items of income and deducting items of outgo not strictly connected with manufacturing.

As shown by Table 16, the number of establishments having final profits on net sales was 155 and the number having final losses was 58, depreciation and interest on current loans considered, but 
reference to the tables in Chapter II shows that when these items are not considered the number having operating profits was 189 and the number having operating losses was 24.

Reference to these tables shows also that, when depreciation and interest on current loans are considered, the greatest percentage of operating profit on capital was 251.71 , earned by an establishment in Group XIII; and the greatest percentage of operating loss on capital was 30.89 , by an establishment in Group $\mathbf{X}$; also that the greatest percentage of operating profit on net sales was 32.3 , earned by an establishment in Group XIII ; and the greatest percentage of operating loss on net sales was 33.19 by an establishment in Group V.

\section{DEPRECIATION.}

Of the 213 establishments reporting data, 109 did not provide for depreciation charges, while 2 manufacturers rented plants. Of the 102 plants charging depreciation, only 35 had separate amounts for buildings, machinery, and other equipment; the others charged lump sums on the total value of the property.

In tabulating the schedules secured from these 109 establishments, depreciation was calculated on the average percentage of depreciation reported by the other establishments in their respective groups. The total depreciation both charged and thus estimated amounted to $\$ 2,970,021$, or 6.38 per cent of the total value of land, buildings, and equipment, $\$ 46,576,584$. The number of establishments having final profits or losses as reported, and the number after the estimated depreciation for the remainder is deducted, is shown in the following table:

Table 16.-Establishunents Having Final Profits or Losses, With and Withour Depreciation.

\begin{tabular}{|c|c|c|c|}
\hline & $\begin{array}{l}\text { Having } \\
\text { final } \\
\text { profit. }\end{array}$ & $\begin{array}{l}\text { Having } \\
\text { final } \\
\text { loss. }\end{array}$ & Total. \\
\hline 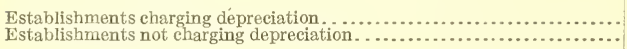 & $\begin{array}{r}87 \\
a 88\end{array}$ & $\begin{array}{l}15 \\
23\end{array}$ & 102 \\
\hline 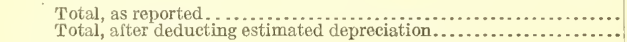 & $\begin{array}{l}a 175 \\
a 155\end{array}$ & $\begin{array}{l}38 \\
58\end{array}$ & $\begin{array}{l}\text { a } 213 \\
\text { a } 213\end{array}$ \\
\hline
\end{tabular}

a Includes 2 rented plants; no depreciation charged.

Excluding all depreciation, the total final profit of the 213 establishments amounted to $\$ 7,844,111$. The extent to which profits aro affected by depreciation is shown by the fact that a deduction of $\$ 2,970,021$, the depreciation charged by 102 establishments and average estimated depreciation for the remaining 109, reduces the final profit to $\$ 4,874,090$. 


\section{COST AND PROFIT BY ESTABLISHMENTS.}

The data secured from the 213 establishments showed that the averace sales value of goods produced per establishment was $\$ 362,596$; average operating profit without depreciation and interest, 838,035 , and with depreciation and interest, $\$ 20,199$; a verage final profit, depreciation and interest considemel, $92,2,200$. When interest is included it is interest on current loans. Lin Table 17, which follows, averares are shown for sales value of goods produced, cost of goods produced, excluding and including depreciation and interest, and the profits, by groups of establishments.

Table 17.-Average Sales Value of Goods Produced, Average Cost of Goods Produced, and Average Operating and Final Profits, by Groups of EstabLISHMEXTS.

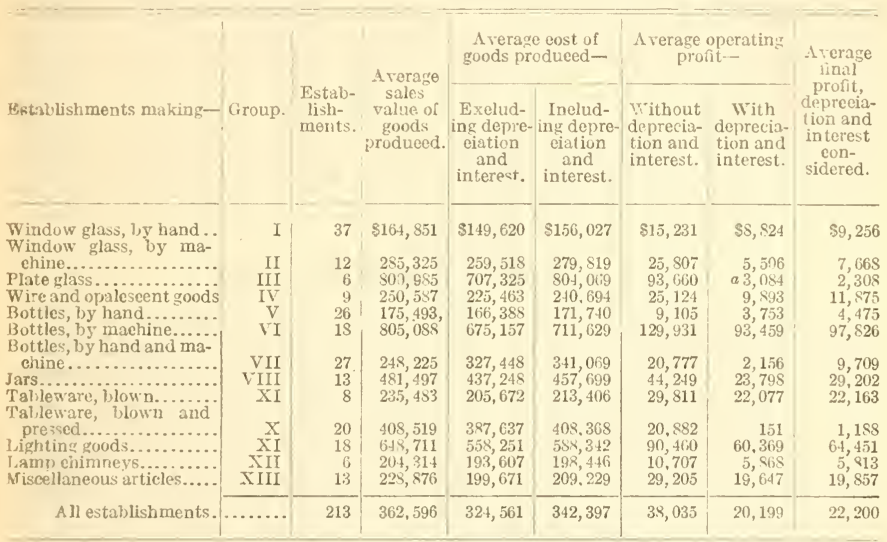

a Operating loss.

The figures in the ahove table, when reduced to percentages based on the sales value of goods produced, show that the total cost of goods produced, excluding depreciation and interest, ranged from 83.86 per cent in bottles made by machine, Group VI, to 94.89 per cent in blown and pressed tableware, Group X; including depreciation and interest, the cost ranged from 88.37 per cent in bottles made by machine, Group VI, to 100.39 per cent in plate glass, Group IV.

The average operating profit for all establishments, computed without depreciation and interest, was 10.49 por cent; computed with depreciation and interest, 5.57 per cent; final profit, depreciation and interest considered, 6.12 per cent. The establishments in Group III, plate glass, showed an average operating loss of 0.39 per cont after depreciation and interest were deducted. The highest average profit, 11.61 per cent, was found in Group VI, bottles made by machine.

In Table 18, which follows, percentages, based on sales value of goods produced, are shown for the total cost of goods produced, excluding and including depreciation and interest, and for the profits, by groups of establishments. 
Table 18.-Percentages of Total Cost of Goods Produced, Operating Profit, and Final Profit; Based on Total Sales Value of Goods Produced, by Groups of Establishments.

\begin{tabular}{|c|c|c|c|c|c|c|c|c|}
\hline \multirow{2}{*}{ Establishments making- } & \multirow{2}{*}{ Group. } & \multirow{2}{*}{$\begin{array}{l}\text { Estab- } \\
\text { lish- } \\
\text { ments. }\end{array}$} & \multirow{2}{*}{$\begin{array}{c}\text { Sa'es } \\
\text { value of } \\
\text { goods } \\
\text { produced. }\end{array}$} & \multicolumn{2}{|c|}{$\begin{array}{l}\text { Per cent cost of } \\
\text { goods produced } \\
\text { was of sales valuc. }\end{array}$} & \multicolumn{2}{|c|}{ Operating profit. } & \multirow{2}{*}{$\begin{array}{l}\text { Final } \\
\text { profit, } \\
\text { deprecia- } \\
\text { tion and } \\
\text { interest } \\
\text { consid- } \\
\text { ered. }\end{array}$} \\
\hline & & & & $\begin{array}{l}\text { Exclud- } \\
\text { ing de- } \\
\text { preciation } \\
\text { and } \\
\text { interest. }\end{array}$ & $\begin{array}{l}\text { Includ- } \\
\text { ing de- } \\
\text { preciation } \\
\text { and } \\
\text { interest. }\end{array}$ & $\begin{array}{l}\text { Without } \\
\text { deprecia- } \\
\text { tion and } \\
\text { interest. }\end{array}$ & $\begin{array}{c}\text { With } \\
\text { deprecia- } \\
\text { tion and } \\
\text { interest. }\end{array}$ & \\
\hline Window glass by hand... & I & 37 & 100.00 & 90.76 & 94.64 & 9.24 & 5.36 & 5.62 \\
\hline Window glass by machine & II & 12 & 100.00 & 90.96 & 98,07 & 9.04 & $\begin{array}{l}0.00 \\
1.93\end{array}$ & $\begin{array}{l}2.02 \\
2.69\end{array}$ \\
\hline Plate glass. ............... & III & 6 & 100.00 & 88.31 & 100.39 & 11.69 & a.39 & .29 \\
\hline Wire and opalescent goods & IV & 9 & 100.00 & $\$ 9.97$ & 96.05 & 10.03 & 3.95 & 4.74 \\
\hline Bottles by hand.......... & V & 26 & 100.00 & 94.81 & 97.86 & 5.19 & 2.14 & 2.55 \\
\hline Bottles by machine...... & VI & 18 & 100.00 & 83.86 & 88.37 & 16.14 & 11.61 & 12.15 \\
\hline $\begin{array}{l}\text { Bottles by hand and ma- } \\
\text { chine.......................... }\end{array}$ & VII & 27 & 100 & 94,03 & & 5 & & \\
\hline Jars............. & VIII & 13 & 100.00 & $\begin{array}{l}94.05 \\
90.81\end{array}$ & $\begin{array}{l}97.94 \\
95.06\end{array}$ & $\begin{array}{l}5.97 \\
9.19\end{array}$ & $\begin{array}{l}2.05 \\
4.94\end{array}$ & $\begin{array}{l}2.79 \\
6.06\end{array}$ \\
\hline Tableware, blown.... & $\mathrm{IX}$ & 8 & 100.00 & 87.34 & 90.63 & 12.66 & 9.37 & 9.41 \\
\hline $\begin{array}{l}\text { Tableware, blown and } \\
\text { pressed.......................... }\end{array}$ & $\mathrm{x}$ & 20 & 100.00 & 94,89 & 99,96 & 5,11 & 04 & 9 \\
\hline Lighting goods............. & XI & $\begin{array}{l}20 \\
18\end{array}$ & 100.00 & 86.06 & $\begin{array}{l}93.90 \\
90.70\end{array}$ & $\begin{array}{r}0.11 \\
13.94\end{array}$ & 9.30 & 9.93 \\
\hline Lamp chimneys............ & XII & 6 & 100.00 & 94.76 & 97.13 & 5.24 & 2.87 & 2.85 \\
\hline Miscellaneous articles..... & XIII & 13 & 100.00 & 87.24 & 91.41 & 12.76 & 8.59 & 8. 68 \\
\hline All establishments. & & 213 & 100.00 & 89.51 & 94.43 & 10.49 & 5.57 & 6.12 \\
\hline
\end{tabular}

a Operating loss.

\section{COST AND PROFIT BY SPECIFIED UNITS.}

The average cost and profit or loss in making a 50-foot box of singlestrength window glass are shown by data furnished by 35 hand factories and 11 machine factories. The costs of window glass of different grades and various sized brackets, single and double strength, are shown by data furnished by 18 hand factories and 3 machine factories.

Data obtained from 29 establishments show the total cost, net selling price, and profit or loss in making 259 different units, including different kinds of bottles, jars, stem ware, tumblers, tableware, and lamp chimneys. Lack of uniformity in the records and cost systems employed by these establishments made it impossible to obtain in detail the cost of materials, labor, and overhead expense.

\section{INDUSTRIAL CONDITIONS.}

The glass industry is located mainly west of the Alleghenies and in districts, such as West Virginia and Oklahoma, where cheap natural gas can be obtained. The glass factories in the East use producer gas or oil for fuel, and the high cost of the fuel is an offset to the market advantage. The manufacture of building glass, that is, of window glass, plate glass, etc., more than doubled in the United States during the period 1899 to 1914 . In 1916 there were 51 hand windowglass plants in the United States, with 1,737 pots and 25 machine plants with 296 machines. The production by hand has decreased, being only about 40 per cent of the entire production in 1915-16. The American Window Glass Co. operated 116 of the 296 machines in the United States in 1916.

The average value per box of window glass produced decreased in the period 1899 to 1909 from $\$ 2.51$ to $\$ 1.70$. This decline is not attributable to the Dingley tariff act, which was in force during this 
period, but to intense competition among domestic manufacturers, which greatly increased after the manufacture of window glass by machinery began on a commercial basis in 1903. Prices again increased after the folmation of a combination of manufacturers to control production and price. Since 1904 the increase in the number of machines has depressed prices. The union has shortened the time corered by its agreements with manufacturers making window glass by hand, in some years to only seven months, while machine windowglass factories arerage about eight months a year. Sheet-glass machines are expected further to rerolutionize the industry when they are successfully operated on a commercial basis.

The production of plate glass in the United States has increased much more rapidly than the production of window glass, although the number of factories manufacturing polished plate glass (15) is small compared with the number of window-glass factories. The trend of prices has been downward. There has been an increased demand for plate glass of the smaller sizes for use in place of window glass.

The production of bottles and jars is not only larger but more widely distributed than the production of other varieties of glass and glassware. The automatic bottle-blowing machine and the flowing process which require no skilled labor to operate them, have caused great changes in the bottle industry since 1903. Their production is probably much in excess of the production by hand and by hand machines. Nearly all the establishments that succeed by the older methods are favorably located with reference to cheapness of fuel or accessibility to markets. Recently the tendency toward the standardization of shapes and sizes has been increased by the greater production of bottles by machinery and has resulted in lower prices. The Glass Bottle Blowers' Association has endeavored to secure more uniformity in State laws regarding the capacity of containers.

The American public generally considers the heavy cut tableware manufactured in the United States superior to similar ware made in Europe. Before the war it was sold in all parts of Europe.

The duty on ornamented glass, including cut glass, has been reduced from 60 to 45 per cent ad valorem under the present tariff act; still the imports have been decreasing and are now very small.

Among the reasons for the cheaper production of heavy cut-glass tableware in the United States than in Europe are: Differences in the methods of cutting glass and in machinery and tools used; the use of blanks with pressed designs, which reduces the amount of cutting; and larger sales of each design in America than in Europe. Manufacturers of high-grade cut glassware have made much complaint about imitation cut glassware, with which many people are deceived.

In 1880 the regular manufacture of incandescent lamps was begun. By 1885 electric lighting became general and the manufacture of lighting good became an important branch of the glass industry. The number of electric lamps for domestic use produced in the United States in 1915 was about 125,000,000. In 1907 the tungsten lamp appeared and nearly revolutionized the industry. 'The Mazda lamp is the most recent development in high-efficiency illuminants. Glass bulbs for incandescent lamps are made in only five plants in the United States. About two-thirds of the total number produced are blown by hand. From 1892 to 1915 electric lighting was one of 
the few well-known commodities to show a marked decrease in cost, and this reduction was due to the higher efficiency of the lamps produced.

The development in the manufacture of chemical glassware in the United States since the war in Europe began is analogous to the development in the manufacture of dyestufis. Formerly few chemists in Amercia acknowledged that any chemical glassware made in the United States was equal to German or Bohemian ware. The war having caused a great reduction in imports, the serious shortage led in 1915 to a greatly increased domestic production. The product was soon recognized as of the highest quality. Beakers and flasks now made in America are better than even Jena ware.

Glassware used for educational or scientific purposes has been admitted free of duty under various tariffs. Manufacturers interviewed regarding the duty on chemical glassware consider it much more important that there should be some duty on apparatus for educational or scientific use than that the rate of duty on the remainder of such imports should be raised above 45 per cent ad valorem the present rate. Some college professors agree that apparatus imported for educational or scientific use should pay a duty.

The manufacture of photographic glass, which is thinner than window glass, is a new industry in the United States. Manufacturers claim that the rate of duty on photographic glass should be higher than on window glass, because of the very much greater labor cost, and the greater loss from breakage. There is at present no tariff distinction between photographic glass and window glass and no separate statistics of imports are kept.

\section{SELLING EXPENSE AND CONDITIONS.}

The glass industry in general, compared with other industries, has a small selling expense. The total selling expense for all the establishments reporting, based on the net sales, was 4.01 per cent. Goods are usually sold in large quantities, generally to the jobber, large consumer, or distributor. About 30 window-glass manufacturers sell their entire output through one sales agent.

In 1909, 50 or more window-glass manufacturers organized the Imperial Window Glass Co. Following the formation of this company, prices greatly advanced. In 1910 the officers and directors of the company were indicted and fined.

The cost for packing material, owing to the fragile nature of the product, is a very largs item of expense. The losses due to bad debts are very small. The seasons have some effect on the industry. Although goods are usually manufactured long in advance, the tendency is for the size of orders to decrease. There are but few job lots. Trade abuses are not very serious, although there are some unjust claims, unwarranted cancellations, etc. No branch of the glass industry has as yet adopted the trade acceptance, although its use has been emphatically urged.

It has been suggested that if manufacturers would cooperate, selling costs could be reduced. Such cooperation would include a uniform cost-finding system, standard contract, standardization of shapes, styles, etc., a credit and information bureau, a central selling or show room, and a cessation of "dumping" in one another's regular selling territory. 
Labor cost is very high in the glass industry. Table 36 of this report shows that the average labor cost based on sales value of product was 41.98 per cent; in one lamp-chimney establishment it was 71.69 , and in one machine bottle plant it was 18.2 per cent. In none of the industries for which a cost of production report has been made by this Bureau, nor in the cotton and wool reports made by the Tariff Board was the proportion of labor to the sales value of product (Bureau reports) or to the cost of manufacture (Tariff Board reports) so large as in glass. Of 334 industries reported by the Census of Manufactures for 1914, glass ranked thirteenth in labor cost based on the value of product. Its proportion was 39.53 per cent. In 33 of these industries, each having a value of product exceeding $\$ 150,000,000$, the average percentage of labor cost, based on the value of product, was 7.92 .

Data from various Government reports show the rates of wages to be very much higher in the skilled occupations of the glass industry than in the higher-paid occupations of other trades and industries.

The total number of employees in 208 factories during the busy season of their last business years was 60,375 , the average being 290.3. Of the total, 2.48 per cent were under 16 years of age. Females constituted 8.15 per cent of the total. More women were employed in the tableware and lighting goods groups than in any of the others; in four groups none were employed.

Fewer days were worked in the last business year than the average for the three preceding years, in all but three groups.

According to the Bureau of the Census, 36,668 out of a total of 68,911 employees in the glass industry worked 54 hours or less per week in 1909, and 51,250 out of a total of 74,502 in 1914. The largest increase in number of employees was in West Virginia.

Pay rolls for 19,092 employees, 18,235 male and 857 female, were furnished by 132 of the glass establishments visited. Of the total male workers 2,772 were employed in plants making window glass, 1,049 in plate-glass plants, 6,716 in bottle plants, 1,895 in plants making jars, 2,566 in tableware plants, 3,063 in plants making lighting goods and lamp chimneys, and 174 in plants making miscellaneous articles of glass. Of the total female workers, 135 were employed in bottle plants, 398 in tableware plants, and 324 in plants making lighting goods and lamp chimneys.

The following table shows the lowest and highest average earnings per hour and the average full-time weekly hours and earnings, for male workers in some of the more skilled occupations.

$$
102511^{\circ}-17-4
$$


Table 19.-Male Workers in Some of the More Skilled Occupations.

\begin{tabular}{|c|c|c|c|c|c|c|}
\hline \multirow{2}{*}{ Groups and occupations. } & \multirow{2}{*}{$\begin{array}{l}\text { Estab- } \\
\text { lish- } \\
\text { ments } \\
\text { report- } \\
\text { ing. }\end{array}$} & \multirow{2}{*}{$\begin{array}{l}\text { Employ- } \\
\text { ees. }\end{array}$} & \multicolumn{2}{|c|}{ Average earnings per hour. } & \multicolumn{2}{|c|}{ Full-time weok. } \\
\hline & & & Lowest. & Highest. & $\begin{array}{l}\text { A verage } \\
\text { hours. }\end{array}$ & $\begin{array}{l}\text { Average } \\
\text { earnings. }\end{array}$ \\
\hline \multicolumn{7}{|l|}{ Window glass: } \\
\hline Machine ope & 7 & 50 & $\$ 0.25-\$ 0.30$ & $\$ 0.65-\$ 0.70$ & 48.1 & $\$ 21.02$ \\
\hline Blowers... & 24 & 691 & $.35-.40$ & 1.50 and over. & 43.6 & 41.99 \\
\hline Gatherers. & 21 & 459 & $.45-.50$ & 1.50 and over. & 43.5 & 35.06 \\
\hline Snappers.. & 22 & 122 & $.20-.25$ & $.65-.70$ & 43.8 & 15.55 \\
\hline Flatteners. & 25 & 172 & $.45-.50$ & 1.50 and over. & 55.8 & 45.79 \\
\hline \multirow{2}{*}{\multicolumn{7}{|c|}{ Plate glass: }} \\
\hline & & & & & & \\
\hline Rough-plate cutter & 3 & 11 & $.25-.30$ & $.35-\quad .40$ & 67.6 & 19.48 \\
\hline Layers.... & 3 & 75 & $.20-.25$ & $.30-.35$ & 68.8 & 16. 72 \\
\hline Grinders. & 2 & 152 & $.15-\quad .20$ & $.35-.40$ & 61.3 & 14. 34 \\
\hline Polisher's & 3 & 87 & $.15-.20$ & $.30-.35$ & 61.9 & 13. 18 \\
\hline Tablemen & 2 & 44 & $.15-.20$ & $.30-.35$ & 71.5 & 16. 02 \\
\hline Finis lers. & 3 & 14 & $.20-.25$ & $.30-.35$ & 63.4 & 19.27 \\
\hline Pot maker & 3 & 9 & $.20-.25$ & $.40-.45$ & 61.3 & 21.21 \\
\hline \multicolumn{7}{|l|}{ Bott'es: } \\
\hline Ma hine operators & 22 & 756 & $.20-.25$ & $1.00-1.25$ & 18. 6 & 29.06 \\
\hline Blowers... & 29 & 1,370 & $.25-.30$ & $1.25-1.50$ & 46.3 & 27.87 \\
\hline Gatherers. & 5 & 66 & $.25-.30$ & $.85-\quad .90$ & 45.2 & 23.50 \\
\hline Finis'ers.. & 6 & 12 & $.25-.30$ & $.65-.70$ & 50.2 & 24.85 \\
\hline St pper grinders. & 2 & 10 & $.60-.65$ & $1.00-1.25$ & 53.0 & 49.13 \\
\hline \multirow{2}{*}{\multicolumn{7}{|c|}{ Jars: }} \\
\hline & & & & & & \\
\hline $\begin{array}{l}\text { Machine of } \\
\text { Gatherers. }\end{array}$ & 4 & 164 & $.15-.20$ & $1.00-1.25$ & 46. 1 & 27.01 \\
\hline $\begin{array}{l}\text { Gratherers } \\
\text { Mold mak }\end{array}$ & $\frac{4}{5}$ & $\begin{array}{l}95 \\
82\end{array}$ & $\begin{array}{r}.25- \\
.30 \\
15-\end{array}$ & $.85-.90$ & 46.3 & 23.01 \\
\hline \multicolumn{7}{|l|}{ Tableware: } \\
\hline Blowers.. & 15 & 307 & $.35-.40$ & $.90-\quad .95$ & 45.2 & 27.57 \\
\hline Gatherers & 22 & 532 & $.20-.25$ & $.70-.75$ & 45.0 & 17.64 \\
\hline Finishers & 17 & 219 & $.25-.30$ & $1.00-1.25$ & 44.9 & 24.02 \\
\hline Pressers. & 18 & 266 & $.35-.40$ & $.85-.90$ & 44.6 & 25.78 \\
\hline Foot casters... & 2 & 7 & $.50-.55$ & $.75-\quad .80$ & 44.6 & 29.93 \\
\hline Cutters.. & 8 & 83 & $.15-.20$ & $.45-.50$ & 50.9 & 19.65 \\
\hline Mold makers..... & 10 & 87 & $.20-.25$ & $.60-.65$ & 52.1 & 22.04 \\
\hline \multirow{2}{*}{\multicolumn{7}{|c|}{$\begin{array}{l}\text { Lighting goods and lamp chim- } \\
\text { neys: }\end{array}$}} \\
\hline & & & & & & \\
\hline Pressers. & $\begin{array}{r}12 \\
7\end{array}$ & $\begin{array}{r}719 \\
39\end{array}$ & $\begin{array}{l}.30- \\
.20-.35\end{array}$ & 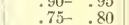 & $\begin{array}{l}49.9 \\
50.6\end{array}$ & $\begin{array}{l}27.25 \\
27.32\end{array}$ \\
\hline Gatherers & 14 & 714 & $.15-.20$ & $.65-.70$ & 50.8 & 19.56 \\
\hline Blockers.............. & 7 & 104 & $.30-.35$ & $.70-.75$ & 45.8 & 23.31 \\
\hline Finishers.. & 3 & 14 & $.30-.35$ & $.60-.65$ & 45.4 & 23.56 \\
\hline De sorat rs.......... & 2 & 25 & $.15-.20$ & $.40-.45$ & 55.0 & 16.94 \\
\hline \multicolumn{7}{|l|}{$\begin{array}{l}\text { Miscellane ou articles: } \\
\text { Blowers }\end{array}$} \\
\hline Blowers... & 1 & 12 & $.25-.30$ & $.40-.45$ & 49.5 & 17.97 \\
\hline Pressers. & 98 & 7 & $.35-.40$ & $1.00-1.25$ & 46.0 & 28.06 \\
\hline Gafiers. & 1 & 12 & $.40-.45$ & $.85-.90$ & 49.5 & 33.91 \\
\hline Gat ierers & 1 & 7 & $.50-.55$ & $.65-.70$ & 54.0 & 32.40 \\
\hline Cutters-of & 1 & 8 & $.40-.45$ & $.65-.70$ & 54.0 & 31.27 \\
\hline Servitors. . & 1 & 11 & $.40-.45$ & $.60-\quad .65$ & 49.5 & 24.95 \\
\hline
\end{tabular}

The average hourly earnings of workers other than those shown in the foregoing table ranged in the various plants as follows: Window glass, male, $15-20$ to $65-70$ cents; plate glass, male, $10-15$ to $35-40$ cents; bottles, male, 10-15 to 65-70 cents, female, under 10 cents to 35-40 cents; jars, male, $10-15$ to $40-45$ cents ; tableware, male, 10-15 to $80-85$ cents, female, under 10 cents to $40-45$ cents; lighting goods and lamp chimneys, male, 10-15 to 60-65 cents, female, under 10 cents to 25-30 cents; miscellaneous product, male, $15-20$ to $25-30$ cents.

The skilled workers in hand window-glass factories earn more than those in the skilled trades of any other branch of glass manufacturing, but their season is very short-about seven months.

In spite of the effect on labor produced by the introduction of machines for window-glass making, the skilled operatives in handmade window glass, through the efforts of a strong labor union, have been able to maintain a high scale of wages. In some years from 
1904 to 1913 they were forced to accept lower piece price rates, but in the seasons of $1914-15,1915-16$, and 1916-17 very substantial increases were given.

There are three labor organizations connected with window-glass manufacturing. The oldest and strongest is the National Window Glass Workers. It had a membership of 4,301 in 1915-16. It meets annually with the manufacturer's' association to adopt a wage scale and to dispose of other matters coming up for settlement.

Labor in bottle manufacturing was greatly benefited by the increased production that resulted from the establishment of the "shop" system in 1870 , and later from the substitution of the tank for the old-style furnace.

Bottle machines were first commercially successful in 1896, but it was not until 1903, when the Owens automatic machine was introduced, that the remarkable production by machines, began to have a serious effect on labor. In factories using these machines skilled labor is not necessary, and in factories that competed with them piece rates for many year's remained the same or were reduced. The first increase in many years was granted for the season 1916-17.

The Glass Bottle Blowers' Association of the United States and Canada is the only labor organization connected with bottle manufacturing. It originated in 1847 and adopted a wage scale in 1861 . It is one of the oldest labor unions, and its record presents one of the best examples of successful collective bargaining between labor and its employers. There has not been a national strike in the glassbottle industry since 1884 .

The American Flint Glass Workers' Union, the only labor organization connected with tableware or lighting goods, takes in the skilled workers of the various departments. Its membership has increased but slightly in several years; in 1916 it was 9,430. The number of members unemployed during the season of 1914-15 was 1,075 and during 1915-16 it was 218. This branch of the business has been seriously affected by strikes; in very few years has it been entirely free from strikes and lockouts.

\section{NEEDS OF THE INDUSTRY.}

There is need in the glass industry for extensive chemical research and experiment; the buildings should be improved and modernized, so as to facilitate production and lower manufacturing cost; machinery and labor-saving devices should be inrestigated and installed; accounting conditions should be improred and accurate cost-keoping methods adopted.

There is perhaps no industry in which a good cost-keeping system is more needed than it is in glass manufacturing. Not only have American glass manufacturers had to meet sharp foreign competion in several lines, but there is probably no industry that lias suffered more from intense competition among domestic mimufacturers. The increased use of and improrements in machinery have made radical changes in the methods of manufacturing glass and glassware during recent years. Hand manufacturers have strugoted dosperately against the competition of those using machines, and of ten the market was demoralized in consequence. Ruinous competition is usually the result of trying to fix prices without a knowledge of the unit eosts of production. 
1 large proportion of the establishments that were visited during this investigation had crude cost-finding methods and poor general accounting systens. It is more difficult to determine the costs of units in manufacturing glass than in some other industries, and some manufacturers express the opinion that it is impossible to devise an accurate method that is adapted to this industry. This, however, is erroneous. No association of glass manufacturers has approved any costfinding system, but the subject has been discussed in association meetings, and in the last few years some of the more enterprising of the manufacturers have employed cost accountants to study their methods of production and to install cost-finding systems. Articles explaining improved methods of cost accounting, prepared by manufacturers that have given special attention to the subject, are embodied in the report.

\section{IMPORTS AND DUTIES.}

During the fiscal year 1913, the last full fiscal year under the PayneAldrich Tariff Act, the imports for consumption of glass and glassware into the United States were valued at $\$ 6,436,662$; during the fiscal year 1914 they increased to $\$ 8,219,112$. Since then they have declined greatly on account of the war in Europe. In the fiscal year 1889 the imports were 18.91 per cent of the production of the calendar year 1889. This was more than twice as large as the proportion in 1899 or 1904 and about three times as large as the proportion in 1909 or 1914.

In 1872 the duties on the principal commodities were reduced 10 per cent. Tariff acts, since that of 1872 , were passed in 1883,1890 , $1894,1897,1909$, and 1913 . The duty on glass and glassware averaged highest in 1894. In 8 of the 38 years it was over 60 per cent. Other statistics are given in tables in the chapter on general imports (p. 334), showing increases and decreases by months and imports by kinds of glassware and by exporting countries.

While the imports of glass and glassware in general increased about one-fourth in the fiscal year 1914, as compared with the fiscal year 1913, imports of plate glass more than doubled and imports of window glass and bottles increased more than one-third.

The general imports of eylinder, crown, and common window glass were $\$ 977,211$ during the fiscal year 1913 and $\$ 1,356,218$ during the fiscal year 1914, or 5.59 and 7.75 per cont, respectively, of the production during the calendar yoar 1914 as reported by the census, $\$ 17,495,956$.

Of the imports of window glass, more than so per cent was of the smaller sizes (of the first three brackets) during the fiscal year 1906 to 1914. From 50 to 60 per cent of the domestic consumption is of single-strength glass of these sizes.

The rates of duties have been lower on the smaller than on the larger sizes for 20 years. No manufacturer interviewed complained of the duties on glass larger than the first three brackets, and some admitted that these duties might be somewhat reduced. All, however, claimed that the rates on the first three brackets were too low.

Imports of window glass before the European war came mostly from Belgium. Few of the imports go to interior points. Before the European war some imports went by ocean freight to Pacific coast points and as far east as Salt Lake City. 
Prices in the Lnited States have at times been lower than the total of the Belgian price with the freight and duty added. The serere competition among Imerican manufacturers was caused largely by the introduction of machinery for making window glass; this led to reductions of wages in the hand factories, some of which were driven out of business.

General imports of plate glass, cast, polished, and unsilrered, amounted to $\$ 321,605$ in the fiscal year 1913 and $\$ 727,859$ in the fiscal year 1914 , or $2.1 \mathrm{~s}$ and 4.93 per cont, respectively, of the production of polished plate glass in the calender year 1914 as reported by the census, $\$ 14,773,7 \$ 7$. The plate glass imported consists mainly of the finer and more expensive grades; its ralue averaged $\$ 0.224$ per square foot in the fiscal yoar 1914.

Most of the imported plate glass is used for mirrors and is of first quality. Most of the imports of plate glass, as of window glass, go to Atlantic, Pacific, and Gulf ports and near-by points.

Imports of other building glass are small. Rough plate glass is probably made cheaper in the United States than anywhere else in the world. Our manufacturers compete successfully in Canada with English manufacturers who enjoy a preferential tariff. Most of the wire class and opalescent and cathedral glass used in the United States is of domestic manufacture; nearly all the antique glass, howerer, was imported before the war from Germany and England.

The pressed and blown glass imported for consumption in the fiscal year 1913 amounted to $\$ 3,006,621$, and in the fiscal year 1914 to $\$ 3,387,858$, or 9.93 and 11.19 per cent, respectively, of the production during the calendar year 1914 as reported by the census, $\$ 30,279,290$. With lower duties on pressed ware, less of it was imported than of blown ware. All manufacturers of blown ware interviewed complained of foreign competition. Yet the group of eight establishments, as a whole, that manufactured blown ware exclusively had an operating profit (charges for depreciation and interest considered) of 9.29 per cent on net sales, while the group of 20 establishments, as a whole, that manufactured both blown and pressed ware had an operating loss of 0.15 per cent on net sales.

Glassware of different colors is not made extensively in the United States. Though the wages of workers are higher in the United States than abroad, the import of cut glass is small; it consists largely of novelties.

The general imports of bottles, jars, etc., during the fiscal year 1914 amounted to $\$ 1,1+8,460$, or 2.21 per cent of the production of bottles and jars during the calendar year 1914 as reported by the census, $\$ 51,958,728$.

Extensive tables are also giren in the chapter on imports to show the quantity, value, duty, etc., for the principal classes of glass entered for consumption. Other tables show for years during which the last three tariff acts were in force the imports of glass and glassware for consumption and the computed ad valorem rate of duty for specified classes.

The duty on "glassware composed wholly or in chief value of glass, blown, either in a mold or otherwise, "is now higher (45 per cent) than the duty on glassware made by pressing (30 per cent). A court decision made in 1916 permits much blown stem ware to be imported at the lower rate. Manufacturers claim that this does not give them the protection Congress intended in the tariff act of 1913. 


\section{EXPORTS.}

The exports of glass and glassware from the United States amounted to $\$ 2,252,799$ during the fiscal year 1905 and to $\$ 3,729,623$ during the fiscal year 1914. The exports increased more rapidly than the imports during this 10-year period, which closed a month before the war in Europe began. The ratio of exports to imports increased from 38 per cent during the fiscal year 1905 to 65 per cent during the fiscal year 1913, the last full year under the Payne-Aldrich Tariff Act. It fell to 45 per cent during the following fiscal year, the UnderwoodSimmons Act having gone into effect October 4, 1913. The decline in exports may be attributed to a business depression in the leading countries of the world, indicated by figures in Table 134, showing the decrease in the foreign trade of these countries in July, 1913, as compared with July, 1914.

Bafore the war most of the small amount of the window glass, plate glass, bottles, and jars exported went to North American countries, principally Canada, Mexico, and Cuba. On the other hand, the exports of "all other" kinds (pressed tableware, lighting goods, optical goods, etc.) went largely to Europe, where their superiority was recognized over European-made goods, and such exports increased annually.

During the two fiscal years ending June 30, 1916, the total exports of glass and glassware increased 230 per cent. The largest increases in value were in exports to Europe, and second to North America. Of the 213 establishments for which data were obtained, 68 reported exports to 39 countries during 1915 , and 41 reported $\$ 1,550,883$ as the total of their exports. The largest exports went to England, followed by Canada and next by Australia. Nearly all the manufacturers reported large increases in foreign shipments in 1916, notwithstanding lack of shipping space and freight rates that were often prohibitive; some sold products even to countries that have preferential tarifiss.

An embargo on imports of window glass, plate glass, and tableware into the United Kingdom went into effect August 21, 1916. American manufacturers, however, expect to do a still larger business with other parts of the world during the war and to do a larger foreign business after the war than they did before it began. The usual method employed has been to sell through American export commission houses. 


\section{CHAPTER 1.}

\section{MATERIALS, MACHINERY, AND PROCESSES.}

\section{RAW MATERIALS USED.}

Commercial glass is a fused mixture of silica, usually in the form of sand, in combination with at least two bases, one of which is an alkali. Glass at a high temperature is fluid and at lower temperatures is semifluid and solid. In its semifluid, plastic state it is ductile and capable of being cast, pressed, rolled, blown, or otherwise manipulated.

The raw materials that enter the batch for the making of glass are usually silica, rarious alkalies, alkali earths, and metals. The proportion of the ingredients raries with the kind of glass desired, the type of furnace, the custom of the plant, and the knowledge or lack of knowledre of the individual under whose supervision the mixing is performed.

Silica in the form of sand comprises the chief ingredient of the batch, usually from 50 to 75 per cent of the mixture. The sources of the alkaline ingredients were originally the ashes of plar.ts and seaweed. At the present time the source is the natural deposits and other compounds of sodium, potassium, and lithium. The alkaline earths usually employed are calcium, barium, strontium, and magnesium. The metallic sources are lead, zinc, and aluminum. Of all these elements, sand, sodium in the form of sodium carbonate (soda ash), sodium sulphate (salt cake), potassium in the form of potash, alcium, and lead form the basic ingredients for nearly all the glass made.

\section{SAND.}

Sand that is usually acknowledged to be superior to the foreign is found in abundant quantities in Pennsylvania, West Virginia, Illi. nois, Missouri, New Jersey, Massachusetts, Ohio, Indiana, New York, Maryland, and many other States. In the States enumerated the sand is found practically pure in the form of rocks and stones, which are quarried and crushed. This sand is used for the finer grades of glassware. For cheaper products, like insulators and some fruit jars, the sand employed is often dredged from rivers.

The sand is thoroughly washed to remove as much alumina, organic matter, and other foreign substances as possible, and is then dried. One glass chemist who has done much experimental work has suggested the use of unwashed sand, thus not only saving the cost of washing and drying but preserving the otherwise washed-out alumina, which he considers one of the most valuable constituents of the sand in making glass. When over 75 per cent of sand is introduced the batch increases in refractoriness to such an extent as to make working very difficult. 
ALKALINE BASES.

Soda ash (sodium carbonate, $\mathrm{Na}_{2} \mathrm{CO}_{3}$ ) is now manufactured from common salt (sodium chloride, $\mathrm{NaCl}$ ) by the Solvay process, which decomposes the sodium chloride by means of ammonium bicarbonate. Soda ash is an active flux and reduces the melting point of the batch to a lower temperature than an equal amount of potash and when mixed with the proper proportion of lime makes an easily worked glass.

Salt cake (sodium sulphate, $\mathrm{Na}_{2} \mathrm{SO}_{4}$ ), d erived bydecomposing sodium chloride by sulphuric acid, is not used so extensively as soda ash. It is used primcipally in window glass and green bottle glass. It is not so desirable as soda ash, because it is necessary to introduce with it carbon in some form, usually coal, to decompose it. Although salt cake is cheaper than soda ash, it requires extra time and excess heat in the furnace and its use tends to produce stony glass.

Potassium is introduced into a glass batch generally in the form of the carbonate, which is known as pearlash or potash. Potash, like soda, acts as a flux in a glass batch. It is not used extensively, as it is always considerably more expensive than sodium salts. It is a desirable flux, however, in optical glass or other glasses where a high brilliancy of color is desired. Lithium is sometimes used for optical glass, but its cost is too high for general use.

Other alkali salts introduced occasionally for their oxygen are the nitrates of soda and potash and soda as borax. These salts are also more easily decomposed than the carbonates. An excess of alkali in glass causes it to undergo what is known as "fading," which results from the chemical action of the atmosphere and moisture upon the free alkali, soda, or potash that has not been satisfied by the silica. Such a chemical process causes a deliquescence of the alkali salt and produces minute crystals that give to the glass an iridescent appearance. Sometimes this iridescence will cover but small areas and at other times it will appear throughout the entire glass, depending upon the care with which the glass has been made or its homogeneity.

\section{ALKALINE EARTH BASES.}

Lime in the form of calcium carbonate $\left(\mathrm{CaCO}_{3}\right)$ or slaked lime $\left(\mathrm{Ca}(\mathrm{OH})_{2}\right)$, when used as the other basic constituent, hardens the glass, giving it stability and permanency, and facilitates melting and refining. An excess of lime prevents chords but increases the tendency to devitrification. Where limestones containing very little iron are hard to obtain the better grades of burnt lime are sometimes used. The limestone rock is preferable, however, as the evolution of the carbon dioxide gas assists in the melting process. In many cases dolomitic limestones containing a considerable portion of magnesium carbonate are being used satisfactorily. The magnesium decreases the tendency to devitrify but makes the glass more refractory.

Barium carbonate, when substituted in small amounts for lime, is said to increase the strength and brilliancy of the glass. Experience seems to show, however, that when more than 3 per cent of barium carbonate is used the glass is increasingly difficult to work. 
METALLIC BASES.

Lead in the form of litharge $(\mathrm{PbO})$ or red lead $\left(\mathrm{Pb}_{3} \mathrm{O}_{4}\right)$ imparts to the glass a brilliant color and increases its weight. Ilthough red lead would seem most desirable because of its greater content of oxygen, litharge is used to a greater extent because of its constancy of composition and very small content of metallic lead. Lead is a very active flux and is used in all glasses which must have a low softening point, and where it is desired to weld a metal to the glass.

Other metallic bases are aluminum, arsenic in the form of white arsenic $\left(\mathrm{As}_{2} \mathrm{O}_{3}\right)$, zinc oxide, and carbon (nonmetallic).

Arscnic is used chiefly to act as an oxidizing agent in remoring carbonaceous material and to assist in freeing the glass from gas bubbles.

Carbon is employed with salt cake to provide a relucing agent to assist in the decomposition of the sulphate, thereby reducing the deleterious and erosire effect on the furnace walls and flues. Carbon is also used in amber glass as a coloring agent. It may be used in the form of coal or charcoal.

Of the principal aforementioned substances the following are obtained in the United States: Salt cake, lime, red lead, litharge, soda ash, arsenic, and manganese. The following are imported: Nitrate of soda from South America, arsenic from England and British Columbia, manganese from Saxony and Russia, and potash from Germany.

\section{CULLET.}

In the making of glass there is usually added to the batch some cullet (broken glass) of the same composition. The amount of cullet added raries from a small quantity up to about one-half the bulk of the batch as a maximum. Cullet is used for two reasons: First, because of the economy in remelting the broken glass about the plant, and, second, in tank furnaces because it provides a foundation in the molten bath whereby the batch or raw materials are maintained more compact and more positirely in that portion of the furnace where the temperature gires the best melting conditions, for as soon as the cullet becomes plastic the batch constituents adhere to it and in that manner are to a degree cemented together until they hare undergone sufficient temperature to carry out the complete melting process. The cullet also assists in removing the gas bubbles. Too much cullet is said to make the glass brittle and difficult to work.

\section{DECOLORIZERS.}

Practically all the raw materials used in glass contain some iron as an impurity. This iron, when present in small amounts, imparts to the glass a pale green color, which increases in intensity as the content of iron increases. When a colorless glass is desired this green color must be removed, which is done by using decolorizers. If the total percentage of iron in the ordinary soda lime glass exceeds 0.05 per cent, a slight green color will be imparted to tlie glass. If the amount of iron exceerls 0.2 per cent the color is too intense to be destroyed. 
Manganese, selenium, cobalt, and nickel are the chief decolorizing agents used. Manganese, selenium, and nickel act as decolorizers because of their chromatic action on the green color of iron by the complementary pink color they produce. Manganese is most commonly used, because it permits easy control of the color. In using selenium and nickel the quantity used must be very carefully controlled. These latter substances are desirable in window or plate glass, as glass decolorized with manganese changes to a pink color when exposed to light a great length of time.

Cobalt in the form of powder blue is used in conjunction with manganese or selenium to destroy any pink color produced by an excess of the decolorizer.

\section{COL.ORANTS.}

There is no definite knowledge as to the cause of color in glass. What is known is that certain chemicals, such as metallic compounds of manganese, nickel, selenium, etc., added to and melted with various batches will produce glass of a certain color. Glass made from sodium, potassium, lime, and lead, with silica and the other necessary ingredients, has no color unless a large amount of iron is present as an impurity. The coloring agents are generally metallic oxides. While a very few elements produce a definite color, as the blue of cobalt, the color produced is generally uncertain. The same oxide may produce different colors with different batches and different oxides of the same element may also produce different colors.

Following is a brief description of the effects produced on glass by the various coloring agents employed. The coloring agents are arranged in the alphabetical order of the elements:

Aluminum.-Certain compounds of aluminum impart a white opacity to glass, such glass being known as opal glass. Aluminum sodium fluoride (cryolite) produces an opal glass, but is objectionable because it injures the pots.

Antimony.-Antimony in large quantities produces white opacity. Antimony sulphide (SbS) exerts an uncertain color effect due to its volatility. In some cases it produces a fine yellow color.

Arsenic.-Arsenic used in excess produces milkiness.

Barium.-The sulphur compounds of barium produce deep green and yellow colors.

Cadmium.-Cadmium sulphide (CdS) produces rich yellow colors.

Carbon.-Carbon, when introduced for coloring purposes, produces a color ranging between straw yellow and a dark amber. Finely divided vegetable charcoal gives a yellow color. Carbon also affects the color of glass by reducing other substances that may be present.

C7romium.-Chromium oxide produces a grass-green color and is used considerably. In the form of potassium bichromate it produces a bright green color. Chromium with iron gives a cold blue color; with copper, a sea green.

Cobalt.-Cobalt produces all shades of blue and is generally used in the form of oxide of cobalt.

Copper.-Copper or copper oxide $\left(\mathrm{CuO}_{2}\right)$ produces a peacock blue which becomes emerald green if the proportion of copper oxide is increased. When full oxidation of the copper is prevented by the 
presener of a reducing agent and the glass is cooled slowly or reheated, the resulting color is an intense crimson-ruby. Cupric silicates produce intense green to greenish-blue colors.

Gold.-Gold produces a brilliant ruby which, though less crimson than the copper-ruby color, is more regular and uniform.

Iron. - Ferrous oxide produces an olive green or pale bluo according to the composition of the batch. Ferric oxide gires a yellow color. Lead. - Lead gives a pale yellow color. Lead increases the coloring effect of other chemicals present in the batch.

Manganese.- Thie compounds of manganese, when other co'oring ingredients are absent. product colors betreen pinkish purple and violet according to the chemical nature of the glass. Nanganese dioxide $\left(\mathrm{MnO}_{2}\right)$ derelops a pink tint which neutralizes the green color due to the presence of iron compounds in the sand. Used in excess manganese gires an amethyst tint. Mangano:e u=ed in excess with the oxide of iron or cobalt produces black. The riolet of manganese, if neutralized by the oxides of copper or iron, results in a gray color.

Nickel.-Nickel with a potash-lead glass gives a violet color; with a soda-lime glass, a brown color.

Phosphorus. - Calcium phosphate $\left(\mathrm{Ca}_{2} \mathrm{PO}_{4}\right)$ produces an opalescent glass. It is, however, rarely used.

Selenium.- Selenites give glass a pale pink or pinkish yellow color, and a ruby red under conditions of reduction.

Sitver. Silver oxide $\left(\mathrm{Ag}_{2} \mathrm{O}\right)$ mixed as a paint and spread on the suriace of glass which is then heated results in a permanent yellow color. Silver is nerer applied to the batch but is used as a surface stain and gives a color from a delicate lemon to a deep orange in proportion to the quantity used.

Sulphur.-Sulphur gases are very apt to produce a rollowish milkiness.

Tellurium.-Tellurium appears to give glass a pale pink tint.

Thallium.- Thallium is introduced to increase the coloring effect of other substances.

Tin.-Tin in conjunction with copper produces a copper ruby. Tin oxide in a finely suspended state produces opalescence and in large quantities white opacity.

Vanadium.-Vanadium produces vivid yellow and greenish tints, but is too rare to be introduced in the batch.

Uranium.-Uranium, though costly, is sometimes introduced in small quantities in the form of a chemical compound and produces a beautiful fluorescent yellow. Uranium oxide will produce a greenish yellow opalescent effect.

MIXTURES FOR AMERICAN GI.ASS.

The following typical mixtures for American glass have been taken from the New International Encyclopredia. These recipes are not intended as standardized batches to be strictly followed by manufacturers. It has been pointed out that the batch will vary with the kind of furnace, the temperature, and numerous other factors, and the following formulas are intended only to indicate, in a very 
broad and general way, the ingredients and the proportions of materials that enter the batches for various kinds of American glass:

Recipes for American Glass.

\begin{tabular}{|c|c|c|c|c|c|c|c|c|c|c|c|}
\hline \multirow{3}{*}{ 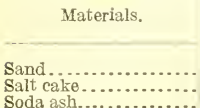 } & \multicolumn{3}{|c|}{ Window glass. } & \multicolumn{3}{|c|}{ Plate glass. } & \multicolumn{3}{|c|}{ Green bottles. } & \multicolumn{2}{|c|}{ Lead flint. } \\
\hline & $\begin{array}{r}100.0 \\
44.0\end{array}$ & $\begin{array}{r}100.0 \\
40.0\end{array}$ & $\begin{array}{r}100.0 \\
42.0\end{array}$ & 100.0 & 100.00 & $\begin{array}{r}100.0 \\
40.0\end{array}$ & 100.0 & 100.0 & 100.0 & 100.0 & 100.00 \\
\hline & & 4. 0 & & 30.0 & 36.00 & & 380 & 35.0 & & & $\cdots$ \\
\hline Limestone................... & 26.0 & 38.0 & 40.0 & 24.0 & 24.00 & 38.0 & 24.0 & 22.0 & 34.0 & & \\
\hline Carbon..... & 4. 0 & 8. 0 & 6.0 & 1.0 & .75 & 4. 0 & ....... & ........ & & & ...... \\
\hline $\begin{array}{l}\text { Arsenic.. } \\
\text { Charcoal }\end{array}$ & 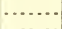 & ......... & (....... & (........ & 1.00 & 2.0 & - & & $\because \cdots$ & .5 & .15 \\
\hline $\begin{array}{l}\text { Charcoa. } \\
\text { Potash. }\end{array}$ & & & & & $\cdots$ & $\cdots$ & & & $\begin{array}{c}5.0 \\
\ldots . .\end{array}$ & 36.0 & 34.00 \\
\hline Red lead. & & & & & & & & & .......... & 40.0 & 48.00 \\
\hline Niter... & & & & & & & & & & 5.0 & 6.00 \\
\hline Borax.... & & & 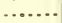 & & & & & & & .3 & .06 \\
\hline Antimony.. & $\cdots \cdots$ & & - & & & & & & & $\ldots . .$. & \\
\hline
\end{tabular}

MACHINERY, TOOLS, AND EQUIPMENT

TYTES OF FURNACES.

The oldest furnace for melting glass was a fire-brick box in which stood the pot with the fire of wood or coal on either side. Two general types of furnaces are now used for melting glass, pot furnaces, and tank furnaces. They are heated by natural or artificial (producer) gas or by fuel oil, and the usual temperature required to melt the batch is about $2,600^{\circ} \mathrm{F}$. A temperature of about $2,000^{\circ} \mathrm{F}$. is maintained at the gathering holes or working-out end of the furnace. These temperatures are not absolute; they vary with the size of the furnace, the use of the pot or tank, the composition of the batch, and numerous other factors.

Pot furnace.-Pot furnaces are either conical, circular, elliptical, rectangular, or square, and usually have huge chimneys, the upper tapering half of which is usually above the roof of the building. The size of the furnace varies with the shape and the number of pots used, and the pots usually number from 6 to 12 . Plate-glass furnaces employ the largest pots, usually about 20 in number, and have an opening opposite each pot to permit its hurried removal for casting.

The walls are about 18 inches thick, with a number of openings at intervals, which are arched over. At the base of the chimney is the central fire, about which, in all but square and oblong furnaces, the melting pots, varying in number and size with the establishment and the ware produced, are arranged in the arched-over openings. In oblong-shaped fumaces the pots are usually placed in two rows, one on either sicle of the fire, and the furnace is provided with a door at each end for removing and replacing broken pots. The heat from the central fire, forced outward by drafts, envelops the pots and heats the batch until it is in the proper state for gathering. In rectangular furmaces the flame travels from one end of the furnace and by a manipulation of the draft is made to completely fill it.

A covered pot is used for melting flint glass. In the manufacture of window and plate glass, bottles, and other glassware, open pots are used. Covered pots are usually used in a circular furnace and open pots in a rectangular fumace. The closed pot is beehive-shaped and has a hooded opening on one side near the top. This opening 
projects to the wall of the furnace: through it the batch is charged and the nolten glass extracted. Open pots are open truncated cones, the smallest diameter being at the bottom, and the batch is charged through openings in the side of the furnace.

Pots are made of fire clay and their manufacture is a long, careful, tedious process, requiring many months for completion. Thoy are costly and their life is comparatively short, closed pots lasting several months, open pots abeut six weeks, and the pots for plate glass only about 25 days. The installation and remoral of pots is a laborious task. Pots have a limited capacity; continuous tanks hare not, some being built to hold up to 500 toins of glass. Then pots are used the work ceases when the pot has been emptied of the melted batch, and it is resumed again only after many hours, during which time a new batch has been melted. When a continuous tank is used the work is nerer interrupted.

Tank furnace. - The tank furnace has genernlly displaced the pot furnace. The adrantages claimed for it are increased production, continuous operation, regularity of work, more efficient utilization of the heat and flame of the furmace, greater durability, and hetter glass production, in that the molten glass in a tank can be maintained at or near a constant level, which makes gathering easier. Tank furnaces are generally oblong in shape, the width being about one-fourth or one-fifth of the length, the depth from 3 to 6 feet; they contain about 6 to 20 ring holes. Tank furnaces hold the glass on the hearth of the furnace; the flame sweeps across the furnace and abore the batch. Tank furmaces are of two types, the day tank and the continuous tank, and are usually constructed of the same material as are pots.

The day tank, intermittent in its action, is practically a large pot, in which the batch is charged, melted, and then extracted, in somewhat the same manner as in working the pot. It may be considered a pot furnace in which the one large open pot is square or rectangular.

The continuous tank permits charging the batch at any time and continual extraction of the molten glass, irrespective of the time the batch is charged. The tank is always full or nearly full. The tank covers the whole area of the furnace and is divided, by means of two transverse floating bridges or partitions, into three compartments. The batch is charged into the first or melting compartment, and the flames, entering at one side or end of the furnace and escaping at the other, melt the batch. The released gases and acid rapors are carried off through the stack, thus preventing injury to the fumace. The molten glass flows into the second compartment, where, by means of a higher temperature, it is freed of its impurities, and it then flows into the last compartment, where a reduced temperature prepares it for gathering. Nany tank furnaces have only two compartments, one for melting and one for gathering the glass.

The more modern tanks disponse with the floating bridges. When the glass is melted it sinks and trarels toward the gathoring holes at the other and. A refining vessel, floated opposite each gathering hole, gathers the molten glass at the lowest depth in the tank, raises it to the surface, where it is completely refined in a compartment prepared for that purpose; then, on sinking, the glass flows only into the working-out ond. The working-out end of the tank usually projects into the shop, is usually semicircular or crescent shaped, 
and contains a varying number of ring holes or openings through which the blowers or gatherers extract the glass. Furnaces employing gaseous fuel use either the regonerative or tha recuperative system of heating. Both systems employ the waste heat of the furnace gases to heat air for combustion. The regenerative system is the one generally used.

The regenerative system employs two chambers, called rezenerators, one on each side of the furnace, which contain loosely stacked fire bricks. When the bricks in one regenerator have become hot from contact with the waste gases of combustion, the direction of the flames is reversed, and the air for combustion passes through the hot regenerator, while the waste gases now pass through the regenerator on the other side of the furnace. Reversing the direction of the flame, usually about every 20 minutes, results in heating the air before it enters the furnace proper while the waste gases are heating the other regenerator preparatory to the air passing through it.

The recuperative system does not employ a reversal of current. The incoming air absorbs the heat, which has penetrated the thin walls as the waste gases pass through the flues.

\section{BLOWPIPE.}

The blowpipe which is used to blow all glassware that is neither blown nor pressed by machine, is an iron pipe or steel tubing from $4 \frac{1}{2}$ to $5 \frac{1}{2}$ feet in length, and from about three-fourths of an inch in the smallest part up to $1 \frac{1}{4}$ inches in diameter. A hole about one-fourth of an inch or more runs lengthwise through the pipe. At one end is a mouthpiece for blowing; the other end, upon which the glass is gathered, is slightly enlarged and somewhat funnel-shaped.

\section{MOLDS.}

Molds are used to facilitate the work of blowing. Molds that are not used in machines rest upon or above the fioor, depending upon the height of the foot bench, or in pits.

The joint open-and-shut mold in common use consists of two hollow cast-iron pieces fastened together by heary hinges. The mold opens and closes horizontally by means of two short handles. The parts of the mold which are cast in separate pieces can be removed and others, for ware of a different size and shape inserted. Each half of the top of the mold is indented so that when the mold is closed the top fits around the blowpipe and, in bottles, forms the long, narrow neck.

\section{BLOWING MACHINE.}

A "gob" of glass, the proper amount cut off by shears as the molten glass is dropped from the gathering iron, is deposited in the first or press mold, and a descending plunger presses the neck of the bottle. The partially formed bottle is then transferred to the second or blow mold, and the bottle is then blown by means of compressed air. The latest machines have a revolving framework containing a series of molds. This machine is used for wide-mouth ware.

One type of machine in use for wide-mouth and semiwide-mouth jars turns out 16 jars a minute. A greater speed is not possible, it 
is claimed, because the glass would not then have time to sottle and would care in. The machine requires a gatherer and a turn-out boy, but if a flowing derice is emploved, only a turn-out boy is necessary. This blowing machine is generally employed only for wide-mouth bottles and jars.

In some bottle-blowing machines, the plunger is raised to the proper point in tho blank mold, after which the necessary amount of glass is dropped in the blank mold, sheared off, and foreed down around the plunger by compressed air to form the neck of the bottle. The partially formed bottle is then inverted, and compressed air blows the bottle in a second mold.

\section{PASTE-MOID BLOWING MACHINE.}

Seamless ware like lamp chimneys or tumblers can not be made in an ordinary mold but requires a mold (paste mold) coated with a carhon or other paste. Since 1898 a machine has been successfully producing this class of ware.

The machine consists of a series of revolving paste molds. The blowpipe with its gather of glass, which has been shaped on the marver and slightly blown, is clamped perpendicularly into a socket exactly above the mold and so arranged that the bulb of glass just fits into the mold. The upper end of the pipe is connected with the valve controlling the compressed air. The revolving mold opens and receives its gather of glass; after it closes the comnected pipe supplies the compressed air for blowing. The constant mechanical rotation of the pipe and its bulh of glass while the compressed air is blowing prevents the formation of seams on the ware. After the machine has revolved halfway, during which time the ware has been completely blown, the mold opens and, after the pipe and attached blown ware has been removed, dips into water. Tnis bath is necessary to keep the paste lining wet.

One such blowing machine, in use for making light tumblers in paste molds, has five molds to the machine, and, with one tumbler to each mold, produces 12 to 14 tumblers a minute. Some machines have two tumblers to the mold. Not only does this machine produce ware much cheaper than when hand blowing is employed, but it is superior in that it blows articles of considerable length with the sides and walls absolutely uniform in thickness.

\section{AUTOMATIC BOTTLE MACHINE.}

The automatic bottle machine consists of a series of arms, radiating from a perpendicular axis, each terminating in a combination mold. The glass is melted in the furnace and flows to a refiner and then to a specially constructed revolving pot or tank, which supplies the hot glass that is constantly used. 'The arms, one after another, dip, and as the blank mold on the end of the arm projects into the molten metal in the revolving tank, it sucks up its capacity of glass. As the arm rises from the tank, the mold forms the neck of the bottle and gives the glass a general shape, cooling it so that it will not rum. Is the first mold withdraws, a second or finishing mold, rises and closes around the still red-hot glass form, and, when this mold is closed, compressed air which is turned on forces the glass to take the shape of the mold. 
The process is continuous and uninterrupted, the forming of the bottle taking place while the molds are in motion. The arm having completed its circuit, the mold opens and the bottle drops out. When an automatic conveyor is used, the bottle drops onto the conveyor.

This machine makes the bottle automatically from the gathering of the glass to the completed bottle that is to be put in the leer. It puts the same amount of glass into every bottle, and makes each exactly the same length, weight, finish, shape, and capacity, which is almost impossible by the hand method, even with the most skilled labor. The machine wastes no glass and can be operated continuously.

FLOWING DEVICE.

There are a numbor of machines which, with the application of a flowing or pouring device that does away with the gatherer, are practically automatic. It will be sufficient to describe one such flowing device to illustrate the general principle and processes involved.

As the revolving molds of a machine pass below a specially built projection of the tank, a stream of glass flows down vertically into it. A cup-shaped cutter from the left of the down-flowing stream, and a blade from the right, are mechanically made to come together like the blades of a pair of scissors. The stream of glass is cut off, but continues to flow into the cup-shaped cutter instead of flowing into the mold. The cup-shaped device is then turned part way over, but still receiving the stream of flowing glass from the tank. As the next mold is brought into position, the cup-shaped device spills its accumulated glass into the mold, and the stream of glass from the tank then flows directly into this new mold. This operation is repeated as each mold comes into position. With the filling of the mold with the exact amount of glass required the work of the flowing device is completed.

Flowing devices, it is claimed, have been successful only with widemouth bottles and jars. One manufacturer, however, claims to have a flowing device which he has successfully used for manufacturing narrow-neck bottles.

PRESSING MACHINE.

Presses for tableware are either stationary or rotary. In the stationary machine the mold is filled with molten glass and, as the side lever is pulled, the overhanging plunger descends into the mold, pressing the plastic glass into the desired shape. The stationary machine is equipped with either one or two molds, which rest upon a stand and are removed by hand. The rotary machine consists of a series of revolving molds, usually four or eight in number. The gatherer fills the passing molds and the glass is then pressed.

The kind of ware that can be made on a pressing machine is limited to that class in which the opening tapers downward, thus permitting the plunger to be easily withdrawn. When a solid or block mold is used the outer surface of the articles, as smooth tumblers, smooth nappies, etc., must be of a downward tapering shape to permit removal after pressing. For ware with outer surfaces of other shapes, a joint mold is used, which is opened when the ware is to be removed 
One of the rotary tumbler presses in use employs 8 molds and produces about 18 tumblers a minute. This press is semiautomatic; with the aid of the flowing device, which one company uses in conjunction with this machine, it is practically automatic.

WINDOW-GLASS MACHINE.

A ring is dropped for a moment into the surface of the molten glass, and the glass adheres to it by molecular attraction. The ring is pulled upward and draws a cylinder of glass as it ascends. The rate of draw is from 1 to 2 feet per minute depending on the thickness, size, and temperature of the glass and on the type of machine. The diameter of the cylinder is regulated by compressed air, introduced in some machines through the bait to which the ring which draws the glass is attached, and in another through an aperture in the center of the pot. The thickness of the glass is regulated by the speed with which the ring is elevated. Cylinders 25 feet or even 35 feet long may be drawn. The machine operator occupies a tower, 12 or 15 feet above the floor, and is called a towerman or a blower. Each towerman operates the electrical mechanism which draws two, and in some cases three, cylinders simultaneously, and controls the air pressure and speed.

\section{AIR-PUMPING SYSTEM.}

Most factories have an air-pumping system, which forces a current of cool air upon molds and machines, preventing them from becoming so heated that the plastic molten glass would adhere to them. Where no such system is employed, the molds are cooled by playing a stream of cold water upon them. The air system also serves to cool the workers.

\section{REHEATING FURNACE.}

In addition to the furnace in which the batch is melted, bottle plants employ a reheating furnace, called a "glory hole," and tableware factories use one usually called a warming-in furnace. These furnaces are used for partially reheating the ware, which facilitates the manipulation necessary to shape it to the desired pattern during the process of manufacture.

\section{ANNEALING OVEN, OR LEER.}

Practically all glassware must be annealed, or gradually cooled, immediately after it has been blown or pressed. Glass can not be annealed by exposure to the air, as this generally causes some of the pores, usually those in the exterior, to close more quickly than others, which results in an internal strain and a brittle glass, easily cracked or broken. One form of annealing is to place the ware in a heated furnace, box, or other receptacle, and gradually diminish the heat until it equals the temperature of the outside air. This method consumes much time and is rarely used at the present time, the kiln having been displaced by the leer.

The leer is a long, narrow, tunnel-like, brick structure, closed on all sides but open at both ends. The heat is kept at about $1,200^{\circ} \mathrm{F}$. at the end called the "mouth," in which the ware is first put. The 
ware is placed in iron pans resting on the bottom of the leer, which are pulled very slowly, by means of a moving-belt arrangement, through the leer's entire length. The heat, high at the mouth, is maintained at a gradually decreasing temperature throughout the length of the leer, and.the ware, traveling very slowly through these various zones, is thoroughly annealed when it reaches the end. The length of time necessary for thorough annealing depends upon the kind of product, and grade of goods manufactured. The pans are brought back from the rear of the leer to the front by means of pulleys swung from an overhead track.

\section{CONVEYOR DEVICES.}

In order that the ware may not chill after it is made, it is necessary that it be transferred to the leer as quickly as possible. Where conveyors are not used, bottles or jars, immediately after being blown, are carried to the leer on handled trays. Other ware is placed on a sliding tray in a warming stove, and the tray when full is carried to the leer.

In some factories mechanical conveyors are used to carry bottles or jars to the leer. An overhead track circles the shop and passes the leer door. Suspended cars are pushed around the shop and the ware is gathered therein as the car passes the various shops. When the sliding tray on which the ware is placed is full, the car is pushed to the leer and the ware transferred.

Some factories have installed automatic conveyors which operate on the principle of the endless belt. The belt carries the bottles singly and runs from the shop to the leer, where the bottles are transferred by hand, or in some cases mechanically.

In a few factories conveyors are in use which carry packed boxes, barrels, etc., from the packing room to the warehouse, where they are stored, and thence to the freight car on the siding. On a decline the package descends by gravity over a series of rollers, but on an incline power is applied, the package being lifted by an endless chain. These conveyors are comparatively cheap to construct and the packed ware is not injured or broken in transit.

\section{MANUFACTURING PROCESSES.}

The manufacturing processes described on the following pages are not given as standardized processes in the glass industry or to inform manufacturers as to the best possible method of production. They are intended to indicate in a very general way how the various products are manufactured and the sequence of operations. All the descriptions omit annealing or tempering the ware, a description of which has been given. A description of packing and storing of the ware after it has come from the leer and been examined has also been omitted, as these operations are not strictly manufacturing processes.

\section{BATCHES FOR VARIOUS PRODUCTS.}

Glass may be divided into the five following classes: (1) Lime-flint glass, (2) lead-flint glass, (3) plate glass, (4) window glass, and (5) optical and special glasses. These are again subdivided according to the ware made from the glass under each of these classifications. 
Lime flint is the glass which is used in manufacturing tableware, norelties, bottles, lamp rhimneys, lighting goods, and globes. In the making of lime-flint glass, the compositions vary greatly, and until a few years ago cach manufacturer or glassmaker had his own particular formula from which he made his glass. The composition often contained as many as 20 ingredients, of which sand was the principal one, and in addition to which there was used burned lime, soda ash, pearlash, magnesium carbonate, barium carbonate, antimony oxide, antimony sulphide, arsenic, feldspar, cryolite, fluorspar, borax, manganese, and cobalt, or "blue" (cobalt silicate). Of late years, howerer, the manufacturer has to a great extent dropped the use of many of the expensive chemicals last enumerated, and in the making of a lime-flint glass confines himself to the use of sand, soda ash, and burned lime, with antimony, arsenic, or nanganese as a decolorizer, or other chemicals like nickel, selenium, or cobalt, or combinations of these metals.

For many years burned lime was supposed to be the only alkali earth which could be successfully used in making flint glass, and lime obtained from certain localities was assumed to be particularly adapted to its manufacture, for the reason that it contained a considerable quantity of magnesia. In recent years, however, particularly in tank-furnace operation, raw lime has come into successful use, from which a glass has been produced equal in brilliancy and stability to that produced from burned lime. In pot furnaces burned lime is still preferable, inasmuch as the increased boiling action produced by the raw lime causes the melting material to boil excessively and does not permit of as great a charge being made at any one time, and therefore increases the attention and labor necessary to obtain a full pot of glass.

Lead flint is used for making cut glass, goblets, the better grade of tableware, etched ware, and novelties. This batch consists principally of sand, red lead (minium), and litharge in combination with soda ash, pearlash, and other alkali salts, and, as in lime-flint glass, with antimony, arsenic, borax, and manganese as decolorizers. More recently nickel, cobalt, and selenium, either separately or in combination with manganese, have been used as the decolorizing agents. Lead has also been used in combination with or partially replaced by lime, magnesia, or barium.

Plate glass is melted in pots, cast, ground, and polished. The batch is usually made up of sand, soda ash, and lime. Sometimes salt cake replaces a portion of the soda ash, and with it some of the abovementioned decolorizers are also used as required.

Window glass is made by the hand-blown or machine method in cylinder form, being subsequently flattened into sheets and cut, but not ground and polished. This batch is composed of sand, salt cake, and lime, with a small amount of powdered coal or charcoal, although in some instances soda ash replaces a portion of the salt cake.

Optical and other special glasses vary in composition, according to the uses for which they are intended and the respective physical properties which are desired. Chemical glassware and special glasses will, of course, have formulas for their batches to meet the physical properties required of the finishied product.

The preparation of the batch for each of the foregoing classes or subclasses is largely dependent upon its composition and upon the 
procedure necessary to melt and refine it to the degree that will insure the product desired.

\section{PREPARATION OF THE BATCH.}

Sand contains iron, lime, alumina, and other impurities, to remove which it is first washed by stirring it in large volumes of water and allowing it to settle. The sand is then burned by playing flames directly upon it, to expel the moisture and remove the organic and extraneous matter, and is then sifted. The sand and other ingredients that make up the batch are then weighed out according to the formula of the plant. The amounts are actually weighed in many establishments, but in some are only an approximation on the part of the mixer. The batch is then mixed. This may be done by hand, by hand and machine, or entirely by machine. Hand mixing is usually employed for small quantities. The various substances are mixed on a clean floor by turning them over with a wooden shovel. The machine for mixing consists of a hollow drum with revolving paddles which beat and mix the batch. The mixing machine has generally displaced the hand-manipulated wooden shovel, because its use results in a better and more uniform mixture.

Cullet (broken glass), which aids fusion, is then added to the batch, which is then carted to the pot or tank on wheelbarrows, or in modern plants is mechanically shot through tubes. When a pot or day tank is used, the batch is generally charged in the morning before work commences or at night when work is over. When a continuous tank, which is always at about the same temperature, is used, the charging goes on continuously so as to keep the glass at a constant level.

During the melting of the batch there is a loss of material, due to evaporation and volatilization, which will generally average, it is claimed, about one-sixth the weight of the batch.

The temperature necessary to melt the batch can not be stated positively. It depends on the use of furnace or pot and the composition of the batch. The average actual temperature generally required is about $2,600^{\circ} \mathrm{F}$. and in some few instances as much as $2,850^{\circ} \mathrm{F}$. (glass temperature).

The molten glass is worked into commercial products by three methods-blowing, pressing, and casting.

WINDOW GLASS.

Window glass is made by the cylinder process, blown by hand or machine, and by the automatic sheet method. In the cylinder method the difference is only in the blowing of the cylinder, either by the blower or by a machine. The subsequent treatment of the cylinder is practically the same.

In making hand-blown window glass the gatherer uses a blowpipean iron tube about 50 inches long, one end enlarged to approximately 3 inches in diameter-which, being previously heated, he dips into the mass of glass contained in the pot or tank furnace. Rotating the pipe permits a film of glass to adhere to the enlarged head. The gatherer removes the head from the furnace and cools the pipe by immersing it in water or allowing water to flow upon it, cooling it and the glass gathered upon the head. By repeated gatherings and coolings in the cooling "buck" or tub, the gatherer obtains a 
sufficient quantity of glass of spherieal form upon the pipe head as will in his judrment make a cylinder of the desired size and thickness, after which he places th's in what is known as the "block," a concave iron receptacle so fashioned as to give the glass a pearshaped form when it is rotated therein.

T'ne blower takes the blowpipe, and by blowing enlarges the glass bulb into the form of a huge cylinder. In doing this he swings his blowpipe through an opening or pit in the floor, and when the glass cools, reheats and softens it in the furnace so that the cylinder can be easily elongated. The material is evenly distributed by the blowing and the glass is made single or double strength, or heavier, by the amount of molten glass that is gathered, the size of the eylinder originally formed in the iron mold, or block, the speed or rapidity with which the blower swings or clongates the crlinder, and the amount of air he puts into it. ( $A$ description of the machines that blow the cylinder of glass mecbanically is giren on page 65.)

When br intermittent blowing and swinging a cylinder of proper length has been formed and the glass has sufficiently cooled, the blower brimgs it into a horizontal position upon a crane support. He then introduces the lower or closed end of the cylinder into an opening in the furnace known as the "blow furnace," or into an opening of the tank known as the "blow ring," permitting the heat of the furnace to come in contact with the small area of this closed end, so manipulating the cylinder as to have the more intense heat in the exact center of the closed end of the cylinder. When the end has become sufficiently heated he blows into the cylinder with considerable force, places his thumb orer the open end of the blowpipe, and then by introducing a considerable portion of the cylinder into the hot gases of the furnace causes the air within the cylinder to expand. The plastic glass is forced out over the intensely heated closed end of the cylinder and bursts an opening therein. A high temperature is again applied to this bursted opening until it becomes quite soft and plastic. The blower then remores the cylinder from the horizontal position, drops it into the pit or "swing hole" and by careful rotation and manipulation enlarges or opens up the hole to the full diameter of the cylinder proper.

The snapper then lifts the eylinder from the swing hole or pit and places it in a horizontal position upon wooden supports known as the "horse" (usually made of wood filled with saw-dust). He touches the neck, or that portion next to the head of the pipe, with a moist iron, which starts a check or erack in the glass, and by gently tapping the blow pipe he severs the cylinder from the blowpipe. He then, with a small iron rod, gathers a few ounces of molten glass and with a pair of pincers draws it out into a thin thread which he wraps around the cylinder, thereby heating a narrow zone to a temperature considerably in excess of the temperature of the main body of the cylinder. By applying a cold or moist iron to this heated zone, he separates from the body of the cylinder that portion which is known as the "cap." When required, a portion of the lower or" hole end of the cylinder is also severed from the main body of the cylinder in like manner, thereby preparing the cylinder for flattening. When the cylinder has been blown by machinely it is usual to employ an electrically heated wire instead of a thread of glass. 
The splitter, or opener, then splits the cylinder longitudinally or lengthwise by means of an iron rod heated at one end to a bright-red heat; he draws the rod back and forth through the cylinder and then touches this heated zone with a moist glove.

The roller boy wheels the cylinder to the flattening oven, and the cracked cylinder is placed on a large, smooth, circular, stone table inside the oven. As the heat softens the glass and it begins to wilt, the flattener by means of a long-handled wooden block quickly flattens out the cylinder until it is a flat sheet. The stone on which the flattened glass rests is turned and the glass is then sent through. the leer where it is tempered.

Due to the fact that window glass made by flattening cylinders can not be flattened perfectly, it usually has a slight bend or bow Such glass also has a possible variation in thickness due to the blowing, though how the blower blows a practically uniform cylinder of glass is one of the wonders of the glass industry. These defects, however, are accepted by the trade.

It is claimed that window glass made from hand-blown cylinders is generally of better quality than that made from machine-blown cylinders, although some manufacturers assert that good glass blown by machine is of better quality than the hand-blown product. (As mentioned on page 205, a factory is being erected for the manufacture of window glass in sheet form, so that flattening will be unnecessary.)

\section{PLATE GLASS.}

As the door of the furnace is opened, the pot, usually containing about 1 ton of molten glass, is removed from the furnace by means of wrought-iron tongs attached to an electrically operated traveling crane, which, after the surface impurities have been skimmed off, carries it to the casting table.

The casting table is made of iron with a smooth, highly polished, trued surface, and is from 12 to $16 \frac{1}{2}$ feet in width and from 20 to $27 \frac{1}{2}$ feet in length. The pot is tipped, and, as the molten glass is poured or cast upon the table in front of it, a heavy roller attached to the table quickly passes over the glass, rolling it into a sheet of uniform thickness. The roller is of cast iron and hollow, about 18 inches in diameter, covers the entire width of the table, and rolls over its entire length. Both the table and the roller are water-cooled by mean: of water circulating through them during the casting operation. The roller travels on adjustable strips or iron tracks on each side of the table, and the thickness of the glass depends on the thickness of these strips. When the glass has been rolled out and the sheet which has sufficiently hardened by cooling is pushed into the leer and by means of mechanical appliances, it is made to successively travel from one position in the leer to another, thus passing through a gradually diminishing temperature.

After the glass has been removed from the leer it has a rough, opaque appearance. This is rough plate glass. The sheet is carefully inspected, the rough edges are cut off, and the glass cut to the desired size.

The glass is then ground. It is secured to a revolving iron table, 25 or more feet in diameter, by means of plaster of Paris, and in some cases is further secured by wooden blocks. As the table revolves water and sharp river sand are applied to the glass and revolving 
iron runners begin to grind. The table revolves slowly at first, but the speed is gradually increased as the grinding continues. The revolution of the table and the constant rotation of the runners insure the whole surface being evenly ground. After the sharp sand, emery is used in a similar manner. Formerly, after grinding one side, it was necessary to turn the glass and grind the other side before polishing. At the present time one side is ground and polished before work on the other side is begun.

The glass, after being ground, is placed on a special polishing table. Rouge and water are applied and felt-covered oscillating blocks or disks polish the glass. After it has been -ground and polished, the glass is about one-half the thickness of the original rough plate, one-fourth being usually lost on each side of the plate during the processes of grinding and polishing.

\section{ROLLED FIGURED GLASS.}

The process of making rolled figured glass is similar to that of making plate glass, except that it is not ground and polished. The pattern which it is desired to produce is engraved on the roller which passes over the glass, these designs being known in the trade as ribbed, pyramid, etc. Sometimes the patterns are cut in the surface of the casting table.

\section{WIRE GLASS.}

Wire glass is manufactured by three different methods: (1) A sheet of glass is rolled and, while the glass is still soft, the wire is pressed in and embedded in the glass, which is then smoothed; (2) the wire mesh is placed over a thin sheet of glass which has been rolled and another sheet is simultaneously poured and rolled over it; (3) a wire netting is mechanically crimped, placed on the casting table and a sheet of glass is then poured upon it and rolled.

\section{OPALESCENT GLASS.}

The colorless glass is ladled out of the pot, and poured upon that part of the machine called the table. One or two workers (according to the size of the sheet) stand at the machine and turn this colorless glass over once or twice with a two-pronged iron shaped like a tuning fork. The colored glass is then ladled out and put on the glass already on the table. The two glasses are mixed together by turning the glasses over several times. A worker then turns the crank (in some plants this is now done by electric power) which moves the table under and against a stationary roller which is part of the machine. The table runs along tracks. As the crank is turned, a boy pushes the glass against the roller, distributing it evenly. The roller flattens out the glass, after which it is lifted, by means of a padle, to a swinging pan suspended from an overhead track and moved to the leer, where it is pushed in to be annealed. After annealing, the sheets are cut up for decorative glass, window work, lamp shades, etc.

\section{BOTTLES.}

The blower or gatherer inserts his blowpipe into the tank or pot and a small lump, or "gob," of the molten glass adheres to the end of it. Sometimes it is necessary to return to the furnace two or more 
times to gather sufficient glass for the size of the bottle desired. By blowing gently, the bulb of glass is slightly enlarged and it is then rolled on a flat plate of iron or stone called a marver, until it assumes a symmetrical pear shape, and on being reheated to the proper temperature the glass is ready to be blown. The work up to this point may be performed by a gatherer who does no blowing, or by the blower himself.

A mold boy opens the iron mold into which the slightly enlarged ball of glass is lowered. When the boy has closed the mold the blower blows into the blowpipe sufficiently to force the glass to take exactly the shape of the mold. In some cases the mold is opened and closed by a treadle operated by the blower's foot. The bottle shows seams where the two halves of the mold join. Circular, seamless bottles are blown in a paste mold by twirling the blowpipe during the blowing process.

Some ware, such as carboys (large bottles of several gallons capacity for mineral waters, chemical liquids, etc.), are blown offhand without the use of a mold, but aided by an arm arrangement upon which the heavy weight of a carboy can be supported without hindering the blower in his work. This, the earliest method of blowing bottles and other ware, is seldom used at the present time.

Continued blowing after the glass has taken the shape of the mold causes the glass above the top of the mold to break. After the mold has been opened and the bottle removed, a snapper-up seizes it with a pair of pincers and places it neck upward in a "snap," a sheetiron can with an iron handle about 3 feet long, which is of the same size and shape as the bottle.

The snapper up rubs the jagged neck of the bottle on a piece of sheet iron and then inserts the bottle, still in the snap, into the "glory hole," or reheating furmace, the neck of the bottle just touching the flame.

When the neck has been heated sufficiently to make it workable, the bottle is taken out of the glory hole. With his left hand the finisher rolls the handle of the snap on the horizontal arm of his bench, and with his right hand he finishes the neck of the bottle by means of a tool, one part of which, inserted in the neck, opens it out and the other part, a pair of hinged jaws, makes the lip as the bottle is turned.

Three men, constituting "a shop," usually work together, two of them gathering the glass and blowing the bottle and the third finishing the neck. The three may interchangeably perform these operations.

The carry-in boy then takes the bottles to the leer for annealing. In some factories the bottles are taken to the leer by a mechanicallyoperated, or automatic, conveyor.

(For a description of the blowing machine and the automatic bottle machine see p. 63. For a deseription of the flowing device, which does away with hand gathering and which is employed in the manufacture of bottles and jars, see p. 64.)

\section{TABLEWARE.}

Though a large quantity of tableware is blown or made in pastemold machines, a great portion of the production is made by a pressing process, in which the article takes its form from a mold under the 
pressure of a plunger, the exterior surface modeled by the mold, the interior surface by the plunger. Sometimes ware is ground and polished in order to enhance its appearance.

Pressed tableware.-In making pressed tumblers, dishes, nappies, jugs, tankards, goblets, rases, ete. (these articles may also be blown), the gatherer gather's his "moil" of glass just as in hand blowing and suspends the lump of glass immediately abore the mold of the stationary press or the revolving mold of the rotary press, which is of the pattern of the desired article. Is the soft glass drops into the mold the presser cuts off the exact amount with shears. The presser then pulls down the lever, which causes the plunger to descend and press the plastic glass to the pattern of the mold. The descent of the plunger is sometimes automatic.

The ware is then fire polished by being put into the glory hole (on an iron pontee). where it is heated sufficiently to melt out the mold marks on the surface of the glass article, after which it is buffed into shape again by a finisher using wooden tools. The finisher either restores the article to its original shape as given by the mold, or he rubs the top out to form a bell shape or rubs it in to form a barrel shape. After this process the article is annealed.

Plain jelly tumblers, commonly designated "unfinishedl," are annealed at once after removal from molds. Such articles are used mostly for packing purposes.

In many of the better grades of pressed ware the rough and uneven bottoms are ground down on a flat revolving stone to remove the marks of the pontee rod. This process follows annealing. (For a description of the pressing machine see p. 64.)

Blanks for cut glass are pressed for the cheaper grades and hand blown for the better grades. Cheap pressed glass is made to imitate good cut glass by molding the facets instead of cutting them and sharpening the angles.

Paste-mold blowing.-Practically all blown tableware is blown in a paste mold, an iron mold coated on the inside with a paste of carbon or other greasy coating, which is kept moist so that the glass when blown will not touch the mold itself. Such contact would result in roughening or crinkling of the glass. The blower gathers his "moil" of glass and proceeds as in ordinary blowing, except that as he blows he constantly rotates his pipe, so that the ridges formed where the two halves in the mold come together and other mold irregularities will not make an impression on the ware. The mold is opened and closed mechanically by the blower's foot. Only ware of a round shape, which can be rotated in the mold, can be made in a paste mold. Paste-mold ware, it is claimed, is much better than iron-mold ware and can be made finer and more delicate.

The blown ware is then taken out of the mold and a helper knocks it off the pipe. It is then carried to the leer for annealing, after which it goes to the finishing department. In the ease of a tumbler, finishing consists in cracking off the top of the tumbler, where it has been broken from the pipe, by means of a special flat blowpipe flame or electrically heated wire, and grinding and glazing the top of the tumbler. Some ware is ground without glazing and other ware is only glazed.

In the making of cheap wine glasses and goblets, the body is blown in a paste mold. After the body of the glass has been knocked off 
it goes to the finisher, who, receiving from a boy a thread of hot glass on a pipe, attaches one end of the thread to the body and cuts off the other end from the pipe with shears. With a tool he works this thread into the stem, to the free end of which is attached another "moil" of glass, which he works, with tools, into the foot or base. (For a description of machine paste-mold blowing see p. 63.)

\section{LIGHTING GOODS.}

Lighting glassware is divided, as to qualities, into translucent, semitranslucent, and opaque glass. Translucent glasses in general use include ordinary crystal glass and plain, decorated, and colored glasses of all colors, shades, and tints. Semitranslucent glass is glass in which the opacity is given by visible particles of opaque matter seemingly suspended in a crystal glass. This class of glass is represented by a series of trade-named glasses, of which the "Alba" glass was the first. Opaque glasses are either opal, plated opal, or opal with a dense colored covering. Lighting glassware is made either by blowing or by pressing.

Blown glass.-In blown goods the articles are either handmade (blown offhand) or are blown in a mold, the mold being either an iron mold or a paste mold. In all blown glassware the blowpipe is used as a gathering rod.

The gatherer gathers the requisite amount of glass on the head of the blowpipe by dipping it into the molten metal through the mouth of the pot. The treatment after the first gathering depends upon the method of blowing that is to be employed. If the article is handmade (blown offhand), it is manipulated entirely by hand, without the use of a mold, by the gatherer, blocker, and finisher. If the article is blown in an iron mold, there is usually no additional glass gathered, but after the gather has been uniformly distributed it is placed just above an iron mold, which is of the design of the glass desired, and the glass is blown usually by the blower and not by compressed air. If the article is to be blown in a paste mold, a small ball of glass is gathered on which a sufficient additional quantity is gathered to make the article desired. Generally only plain articles that can be turned in the mold are blown in a paste mold.

Pressed glass.--Pressed glass is stamped out by a machine operated either by power or by a hand lever.

Decoration.--Lighting glassware is ornamented by sand blasting, etching, cutting, painting, or by a combination of these methods, some of which are very expensive. In the decalcomania process the desired design is printed on paper, and, after it has been put on the glass, the paper is rubbed off, leaving on the glass only the design traced in acid-resisting ink. The part of the glass not included in the design is then covered with paraffin to resist the acid when the ware is given an acid bath. The acid attacks the uncovered design.

Lamp chimneys. - Lamp chimneys are blown offhand without the aid of molds, in a paste mold, or made by machine.

Incandescent lamps. - Glass bulbs for incandescent lamps are blown either in a paste mold or by a machine. The principal parts of an incandescent lamp are the glass bulb, the base, the filament, the inside stem upon which the filament is mounted, and the leading-in wires passing through the stem and connecting the filament with the 
base. Some 50 different and distinct operations, with an equal number of additional handlings for inspection, are necessary in the practical manufacture of lamps.

The first step in the manufacture of an incandescent lamp is the preparation of the bulb. As received from the glass works, the bulb has considerable superfluous glass at the neck, which has to be cut off. The process of making the lamp consists first of melting a hole in the rounded end of the bulb. The exhaust tube is then welded to the bulb at this point, care being taken to maintain a free air passage so that later the air may be pumped out through this tube.

( The tubulated bulb is then placed over the completed mount, both being held in their proper relative positions. Bunsen flames are applied at the neck of the bulb, and both the bulb and mount are rotated slowly until the neck of the bulb is welded to the flare of the stem tube. The seal thus formed at the neck of the bulb must be absolutely air-tight.

1 The exhaust tube is then connected to a vacuum pump and all air exhausted from the lamp. At the same time this is done the lamp is inclosed in an oven heated to a high temperature. After the air is exhausted the tube is remored and the lamp is sealed, this operation forming the tip which everyone has noticed on incandescent lamps. The lamp is then based. One of the leading-in wires is brought down through and soldered to a cap at the end of the base. This cap is insulated from the shell by black glass. The other leading-in wire is soldered to the brass shell, and the lamp is completed.

In a newer type of lamp the bulb, after being exhausted, is filled with an inert gas, such as nitrogen. The presence of this gas retards the evaporation of the filament and permits its operation at a much higher temperature and hence with much greater efficiency. 


\section{CHAPTER II.}

\section{CAPITAL, NET SALES, AND TURNOVER.}

While data regarding the cost of pruduction in the glass industry were obtained from 213 establishments, capital employed in business is shown, in the following tables, for only 211 establishments, as 2 did not report this item.

\section{OPERATING AND FINAL PROFIT.}

Table 20, which follows, shows the amount of capital employed in business by each group of the 211 establishments reporting, the net sales and their ratio to capital, the operating profit when depreciation and interest on current loans are considered and when not considered, and the final profit when these items are considered.

The operating profit was found by adding the cost of goods pro. duced, the selling expense, and the cost of finished goods purchased, and from this sum.deducting any increase in the stock of goods during the year or adding any decrease in the stock of goods; the deduction or addition of the difference in inventories, in each instance, gave the cost to the manufacturer of goods sold, which figure subtracted from the net sales gave the operating profit. The operating profit with depreciation and interest not considered was, of course, larger than with these items taken into account.

Of the 213 establishments, only. 102 charged off depreciation, 109 did not show depreciation on their books, and 2 plants were rented. Before final profit or operating profit with depreciation and interest on current loans charged was arrived at, the average rate of depreciation of establishments that actually charged depreciation in each group was applied to establishments in that group which did not charge depreciation.

What is called the final profit was found by adding to the operating profit (computed with depreciation and interest on current loans considered) the miscellaneous income from real estate, bank balances, or investments outside the manufacturing business and deducting miscellaneous expenses.

Salaries of active officers and the drawing accounts of individual owners or partners were included in the cost of production before profits or losses were figured. Also, before profits or losses were computed, all expenses for selling were included in the cost of production.

Each of the 13 groups shows an operating profit when depreciation and interest on current loans are not taken into consideration; when they are considered, Group X, embracing 20 establishments manufacturing blown and pressed tableware, shows an operating loss. 
CAPITAL, NET SALES, AND TURNOVER.

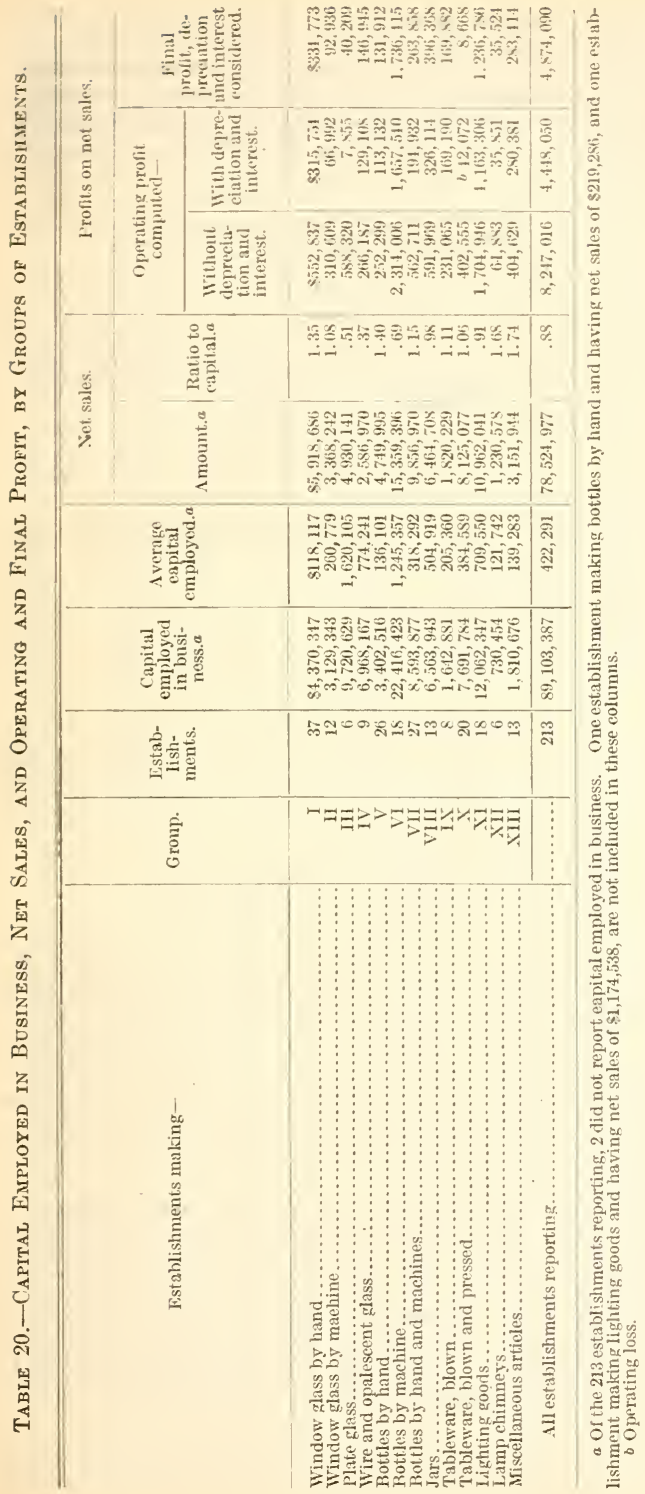




\section{PEBCENTAGES CF PECEIT ON CAPIIAL AND IET SALES.}

The percentuges of operstir z protit with and mithout consideration of deoseration and interest on errent loars and of tin-l protit with denreiation and interes considered. bused both on caviral emplored in ousiness wnd on net sales. are shown in the following table" by grougs of estabisinments.

Insta 2l.-1

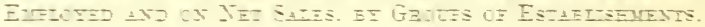

\begin{tabular}{|c|c|c|c|c|c|c|c|c|}
\hline \multirow{3}{*}{ 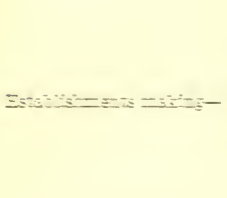 } & \multirow{3}{*}{$=0}$. & \multirow{3}{*}{ 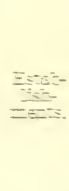 } & \multicolumn{4}{|c|}{ 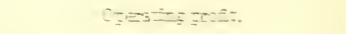 } & \multirow{2}{*}{\multicolumn{2}{|c|}{ 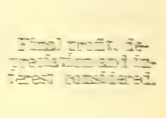 }} \\
\hline & & & \multicolumn{2}{|c|}{ 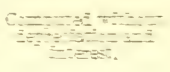 } & \multicolumn{2}{|c|}{ 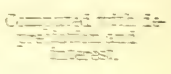 } & & \\
\hline & & & cons- & joles. & $9=$ & $\begin{array}{l}0=-2 e= \\
\text { silis. }\end{array}$ & ons & $\begin{array}{l}0=-20 a \\
\text { ssles }\end{array}$ \\
\hline 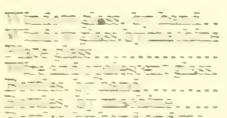 & $\frac{\bar{Z}}{\underline{\underline{H}}}$ & 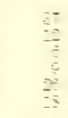 & $\begin{array}{ccc}0 \\
0\end{array}$ & 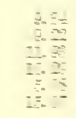 & $=$ & 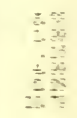 & $=\frac{1}{2}$ & 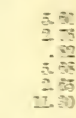 \\
\hline a & 严 & $\bar{z}$ & 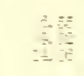 & 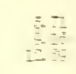 & $\frac{1}{2}$ & $\frac{18}{20}$ & $\frac{1}{x}$ & 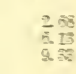 \\
\hline 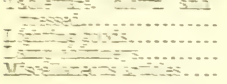 & $\frac{E}{E}$ & $\frac{n}{2}$ & 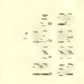 & $\frac{1}{2}$ & 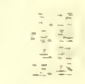 & 然 & 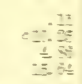 & 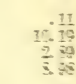 \\
\hline 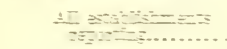 & . & $\approx$ & in & $=3$ & 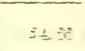 & $E$. & $z=15$ & $2: 2$ \\
\hline
\end{tabular}

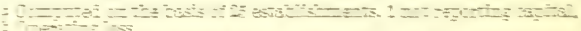

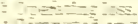

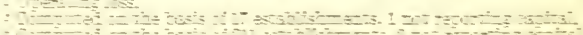

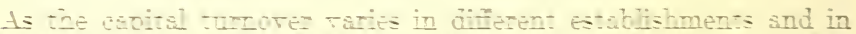

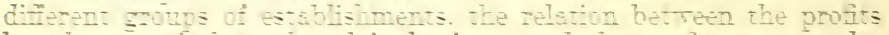
busad on capotil emoloted in husiness and the onotit on net sales

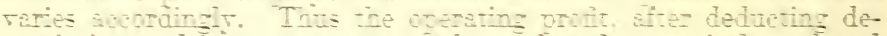

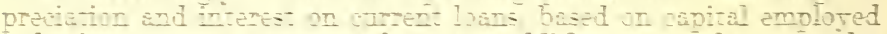

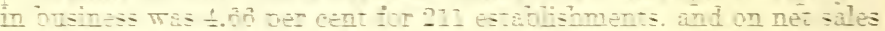
5.5: per ent for 213 essblismmes. The sume ziation existed be

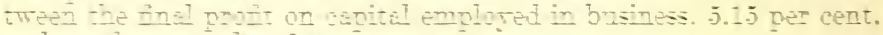
and on the ret sales. 6.1 pér cent.

Group IIII. esteblisments monufucuring miscellonecus products.

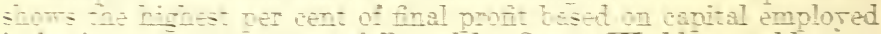
in businss. $2.6 \div$ jer cent followed bT Goup II. bionn tablemare. and Gromp II. Highting goods. With $10.3 \pm$ ner cent and 10.25 per cent. aspectirelr. Group TI bothles made br machine. shows the highes. per cen: of Enal proti: bused on net sales. 11.3 per cent. followid. in tine order mentioned. br Group II. lizhting goods. and Grup II. blown tubleware. With 10.19 per cent and g.35 per cent. respectiteit.

A comparison of Groups I and II shows that the arerage percentages of protits are considerably higher for hondmade window 
glass than for machine-made window glass. On the other hand, a comparison of Groups $V$ and VI show the conrerse to be true, the establishments making bottles by machinery showing considerably higher average percentages of profits than those in which bottles are blown by hand. Howerer, as shown by Table -, the hand plants. in both window glass and bottles, show a greater capital turnorer than the machine establishments in these lines.

\section{PROFIT OR LOSS OF EACH ESTABLISHMENT.}

Table 2.2, which follows, shows for cach indiridual establishment, as well as for each of the 13 groups, operating profit, when deprecintion and interest on current loans are considered and when not considered, on capital employed in business and on net sales; and final profit, when depreciation and interest on current loans are considered, on capital and on net sales.

Table 22.-Percestage of Operatixg axd Final Profit ox Capital Euployed aid ox Net Sales, bi Grotps axd by Establishmexts.

\begin{tabular}{|c|c|c|c|c|c|c|}
\hline \multirow{3}{*}{ Establishments. } & \multicolumn{4}{|c|}{ Operating profit. } & \multirow{2}{*}{\multicolumn{2}{|c|}{$\begin{array}{l}\text { Final profit, } \\
\text { depreciation and } \\
\text { interest considered. }\end{array}$}} \\
\hline & \multicolumn{2}{|c|}{$\begin{array}{l}\text { Computed without } \\
\text { depreciation and } \\
\text { interest. }\end{array}$} & \multicolumn{2}{|c|}{$\begin{array}{l}\text { Computed with } \\
\text { depreciation and } \\
\text { interest. }\end{array}$} & & \\
\hline & $\begin{array}{l}\text { On } \\
\text { capital. }\end{array}$ & $\begin{array}{c}\text { On } \\
\text { net sales. }\end{array}$ & $\begin{array}{l}\text { On } \\
\text { capital. }\end{array}$ & $\begin{array}{c}\text { On } \\
\text { net sales. }\end{array}$ & $\begin{array}{l}\text { On } \\
\text { capital. }\end{array}$ & $\begin{array}{c}\text { On } \\
\text { net sales. }\end{array}$ \\
\hline 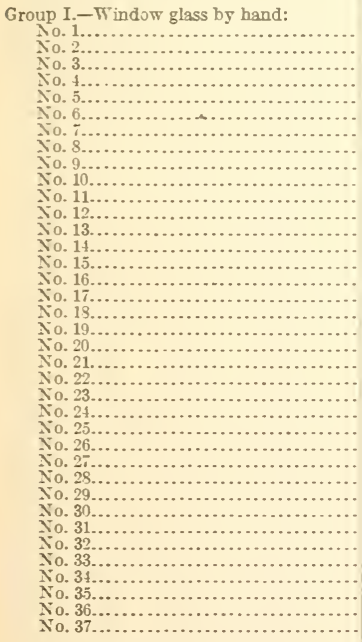 & $\begin{array}{r}24.63 \\
a 4.13 \\
a 5.33 \\
39.19 \\
11.27 \\
6.23 \\
13.44 \\
1.05 \\
14.24 \\
12.48 \\
10.42 \\
15.07 \\
25.56 \\
15.52 \\
34.14 \\
5.74 \\
28.99 \\
30.99 \\
30.24 \\
4.61 \\
10.69 \\
37.72 \\
19.27 \\
13.27 \\
11.50 \\
1.63 \\
7.44 \\
11.39 \\
21.07 \\
6.25 \\
21.10 \\
17.93 \\
10.39 \\
7.96 \\
21.16 \\
14.40 \\
12.39\end{array}$ & $\begin{array}{r}12.00 \\
12.35 \\
a 2.92 \\
13.33 \\
5.71 \\
6.69 \\
12.09 \\
1.64 \\
8.89 \\
10.32 \\
8.06 \\
11.79 \\
5.62 \\
14.25 \\
14.34 \\
7.47 \\
14.73 \\
5.74 \\
4.97 \\
2.91 \\
6.31 \\
12.65 \\
14.55 \\
8.87 \\
7.99 \\
1.30 \\
4.57 \\
7.95 \\
15.36 \\
12.32 \\
14.82 \\
17.85 \\
3.65 \\
9.93 \\
11.99 \\
7.13 \\
10.37 \\
\end{array}$ & $\begin{array}{r}10.50 \\
a 9.74 \\
a 13.15 \\
35.04 \\
7.44 \\
1.22 \\
7.91 \\
a 6.39 \\
9.55 \\
6.27 \\
4.76 \\
9.65 \\
25.56 \\
9.06 \\
29.70 \\
. .76 \\
25.24 \\
26.53 \\
7.64 \\
a .96 \\
2.12 \\
25.60 \\
13.00 \\
4.38 \\
6.13 \\
a .05 \\
7.99 \\
5.97 \\
15.66 \\
2.48 \\
16.55 \\
16.13 \\
a 8.12 \\
4.44 \\
12.94 \\
11.07 \\
9.92 \\
19\end{array}$ & $\begin{array}{r}5.11 \\
a 29.11 \\
a 7.22 \\
11.92 \\
5.75 \\
1.31 \\
7.12 \\
10.01 \\
5.96 \\
5.19 \\
3.68 \\
7.55 \\
5.62 \\
8.32 \\
12.45 \\
.99 \\
13.23 \\
4.92 \\
1.25 \\
a .60 \\
1.25 \\
9.59 \\
9.82 \\
2.93 \\
4.26 \\
.04 \\
a 4.91 \\
4.16 \\
13.60 \\
4.89 \\
11.62 \\
16.05 \\
a 2.85 \\
5.54 \\
7.33 \\
5.48 \\
8.30 \\
\end{array}$ & $\begin{array}{r}9.84 \\
a .74 \\
a 13.02 \\
35.04 \\
7.44 \\
1.22 \\
7.91 \\
a 6.39 \\
9.55 \\
6.01 \\
4.76 \\
9.65 \\
26.49 \\
9.06 \\
29.70 \\
.76 \\
26.28 \\
26.53 \\
7.64 \\
a .96 \\
2.12 \\
25.60 \\
13.08 \\
4.38 \\
7.69 \\
1.42 \\
a 7.21 \\
11.68 \\
19.21 \\
2.48 \\
16.72 \\
16.30 \\
a 8.12 \\
4.44 \\
13.18 \\
11.07 \\
10.14 \\
\end{array}$ & $\begin{array}{r}4.79 \\
a .99 .11 \\
a 7.15 \\
11.92 \\
5.75 \\
1.31 \\
7.12 \\
\text { a } 10.01 \\
5.96 \\
4.97 \\
3.68 \\
7.55 \\
5.83 \\
8.32 \\
12.48 \\
1.99 \\
13.77 \\
4.92 \\
1.25 \\
a .60 \\
1.25 \\
9.59 \\
9.88 \\
2.93 \\
5.33 \\
1.13 \\
a 4.43 \\
8.15 \\
14.00 \\
4.89 \\
11.74 \\
16.22 \\
a .85 \\
5.54 \\
7.46 \\
5.48 \\
8.49 \\
\end{array}$ \\
\hline A rerage... & 12.65 & 9.34 & 7. 22 & 5.33 & 7.59 & 5.60 \\
\hline
\end{tabular}


Table 22.-Percentage of Operating and Final Profit on Capital Employed and on Net Sales, by Groups and by Establishments-Continued.

\begin{tabular}{|c|c|c|c|c|c|c|}
\hline \multirow{3}{*}{ Establishments. } & \multicolumn{4}{|c|}{ Operating profit. } & \multirow{2}{*}{\multicolumn{2}{|c|}{$\begin{array}{l}\text { Final profit, } \\
\text { depreciation and } \\
\text { interest considered. }\end{array}$}} \\
\hline & \multicolumn{2}{|c|}{$\begin{array}{l}\text { Computed without } \\
\text { depreciation and } \\
\text { interest. }\end{array}$} & \multicolumn{2}{|c|}{$\begin{array}{l}\text { Computed with } \\
\text { depreciation and } \\
\text { interest. }\end{array}$} & & \\
\hline & $\begin{array}{c}\text { On } \\
\text { capital. }\end{array}$ & $\begin{array}{c}\text { On } \\
\text { net sales. }\end{array}$ & $\underset{\text { On }}{\text { capital. }}$ & $\begin{array}{c}\text { On } \\
\text { net sales. }\end{array}$ & $\underset{\text { eapital. }}{\text { On }}$ & $\begin{array}{c}\text { On } \\
\text { net sales. }\end{array}$ \\
\hline 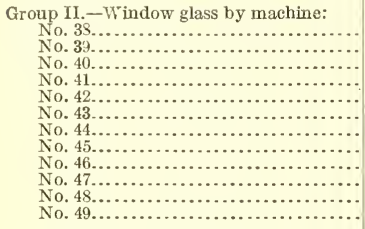 & $\begin{array}{r}a 3.44 \\
a 15.77 \\
a .07 \\
15.49 \\
18.95 \\
7.65 \\
13.27 \\
19.25 \\
14.46 \\
7.33 \\
9.73 \\
16.65\end{array}$ & $\begin{array}{r}a 2.68 \\
a 12.10 \\
a .16 \\
10.55 \\
12.80 \\
6.15 \\
6.47 \\
11.89 \\
12.53 \\
7.10 \\
11.79 \\
14.03\end{array}$ & $\begin{array}{r}a 15.06 \\
a 20.02 \\
a 3.14 \\
6.55 \\
14.58 \\
3.43 \\
7.96 \\
14.76 \\
2.33 \\
a 2.37 \\
a 2.47 \\
8.50\end{array}$ & $\begin{array}{r}a 11.73 \\
a 15.36 \\
a 7.09 \\
4.46 \\
9.85 \\
2.76 \\
3.88 \\
9.12 \\
2.02 \\
a 2.29 \\
a 3.00 \\
7.16\end{array}$ & $\begin{array}{r}a 4.40 \\
a 20.02 \\
a 3.14 \\
6.55 \\
14.58 \\
4.91 \\
10.25 \\
16.53 \\
2.33 \\
a 2.37 \\
a 2.15 \\
9.45\end{array}$ & $\begin{array}{r}a 3.43 \\
a 15.36 \\
a 7.09 \\
4.46 \\
9.85 \\
3.95 \\
5.00 \\
10.21 \\
2.02 \\
a 2.29 \\
a 2.61 \\
7.96\end{array}$ \\
\hline Arerage............................ & 10.39 & 9.22 & 2.14 & 1.99 & 2.97 & 2.76 \\
\hline 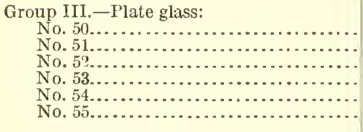 & $\begin{array}{r}6.48 \\
3.32 \\
12.69 \\
2.64 \\
8.32 \\
4.68\end{array}$ & $\begin{array}{r}6.15 \\
4.14 \\
24.97 \\
5.11 \\
12.09 \\
13.89\end{array}$ & $\begin{array}{r}4.62 \\
a .01 \\
6.00 \\
a 2.36 \\
2.76 \\
a 1.34 \\
\end{array}$ & $\begin{array}{r}4.38 \\
a 7.50 \\
11.80 \\
a 4.55 \\
4.00 \\
a 3.98\end{array}$ & $\begin{array}{r}4.62 \\
6.01 \\
6.00 \\
a .90 \\
3.04 \\
a .83\end{array}$ & $\begin{array}{r}4.38 \\
a 7.50 \\
11.80 \\
a 3.67 \\
4.41 \\
a 2.46\end{array}$ \\
\hline Average.......................... & 6.05 & 11.93 & .08 & .16 & 4.14 & .82 \\
\hline 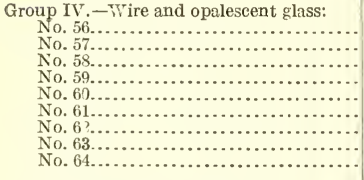 & $\begin{array}{r}2.09 \\
7.75 \\
21.73 \\
20.95 \\
15.73 \\
37.95 \\
a 6.44 \\
17.79 \\
2.87\end{array}$ & $\begin{array}{r}7.88 \\
18.45 \\
28.88 \\
11.08 \\
23.47 \\
18.66 \\
a 12.90 \\
16.71 \\
11.19\end{array}$ & $\begin{array}{r}a 3.88 \\
a 10.18 \\
20.45 \\
15.23 \\
13.83 \\
30.73 \\
a 8.17 \\
14.17 \\
1.12\end{array}$ & $\begin{array}{r}a 14.63 \\
a 24.22 \\
27.18 \\
8.05 \\
20.64 \\
15.11 \\
a 16.37 \\
13.31 \\
4.37\end{array}$ & $\begin{array}{r}a 3.86 \\
a 10.18 \\
20.45 \\
15.23 \\
14.42 \\
30.73 \\
a 7.98 \\
14.17 \\
1.42\end{array}$ & $\begin{array}{r}a 14.56 \\
a 24.22 \\
27.18 \\
8.05 \\
21.52 \\
15.11 \\
a 15.98 \\
13.31 \\
5.52\end{array}$ \\
\hline Average.......................... & 3.82 & 10.29 & 1.85 & 4.99 & 2.11 & 5.68 \\
\hline 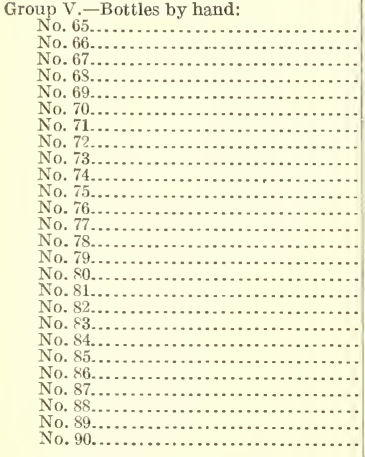 & $\begin{array}{r}2.22 \\
9.72 \\
1.73 \\
19.03 \\
1.78 \\
4.08 \\
a 8.39 \\
8.55 \\
7.71 \\
9.07 \\
7.35 \\
17.55 \\
15.28 \\
34.51 \\
a 1.76 \\
2.88 \\
12.94 \\
25.00 \\
22.47 \\
(b) \\
7.55 \\
a 3.73 \\
6.01 \\
14.29 \\
15.39 \\
4.60\end{array}$ & $\begin{array}{r}7.47 \\
14.08 \\
1.13 \\
a 27.42 \\
1.03 \\
2.19 \\
a 6.35 \\
6.17 \\
5.52 \\
13.99 \\
4.41 \\
8.21 \\
11.89 \\
10.84 \\
a 1.39 \\
1.14 \\
4.60 \\
13.90 \\
6.65 \\
5.97 \\
6.67 \\
a 1.36 \\
5.25 \\
8.24 \\
8.47 \\
4.39\end{array}$ & $\begin{array}{r}a .45 \\
a .13 \\
a 3.24 \\
a 23.03 \\
a .20 \\
a 1.94 \\
a 12.96 \\
3.50 \\
4.32 \\
6.78 \\
.65 \\
16.35 \\
13.65 \\
34.51 \\
a 6.54 \\
a 1.41 \\
6.87 \\
21.83 \\
14.43 \\
(b) \\
1.30 \\
a 13.51 \\
3.74 \\
11.33 \\
9.24 \\
2.77\end{array}$ & $\begin{array}{r}a 1.53 \\
a .18 \\
a 2.11 \\
a 33.19 \\
a .11 \\
a 1.00 \\
a 9.83 \\
2.53 \\
3.09 \\
10.46 \\
.39 \\
7.65 \\
10.62 \\
10.84 \\
a 5.17 \\
a .56 \\
2.44 \\
12.13 \\
4.27 \\
a .95 \\
1.14 \\
a 4.94 \\
3.26 \\
6.53 \\
5.09 \\
2.66\end{array}$ & $\begin{array}{r}a .45 \\
a .13 \\
a 3.24 \\
a 22.79 \\
.61 \\
a 1.94 \\
a 12.70 \\
3.85 \\
8.43 \\
6.78 \\
.65 \\
23.93 \\
14.11 \\
34.51 \\
a 4.18 \\
a 1.41 \\
5.14 \\
21.83 \\
14.43 \\
(b) \\
1.30 \\
a 13.51 \\
3.69 \\
12.81 \\
9.52 \\
3.26\end{array}$ & $\begin{array}{r}a 1.53 \\
a .18 \\
a 2.11 \\
a 32.84 \\
.35 \\
a 1.00 \\
a 9.63 \\
2.78 \\
6.00 \\
10.46 \\
.39 \\
11.19 \\
10.97 \\
10.84 \\
a 3.30 \\
a .56 \\
1.82 \\
12.13 \\
4.27 \\
a .95 \\
1.14 \\
a 4.94 \\
3.23 \\
7.38 \\
5.24 \\
3.13\end{array}$ \\
\hline 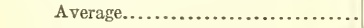 & $c 7.04$ & 5.08 & $c 3.26$ & 2.28 & $c 3.82$ & 2. 65 \\
\hline
\end{tabular}

a Loss. $\quad b$ Capital not reported.

.c Exclusive of 1 establishment not reporting eapital. 
Table 22.-Percentage of Operating and Final Profit ox Captral Employed and on Net Sales, by Groups and br Establishments-Continued.

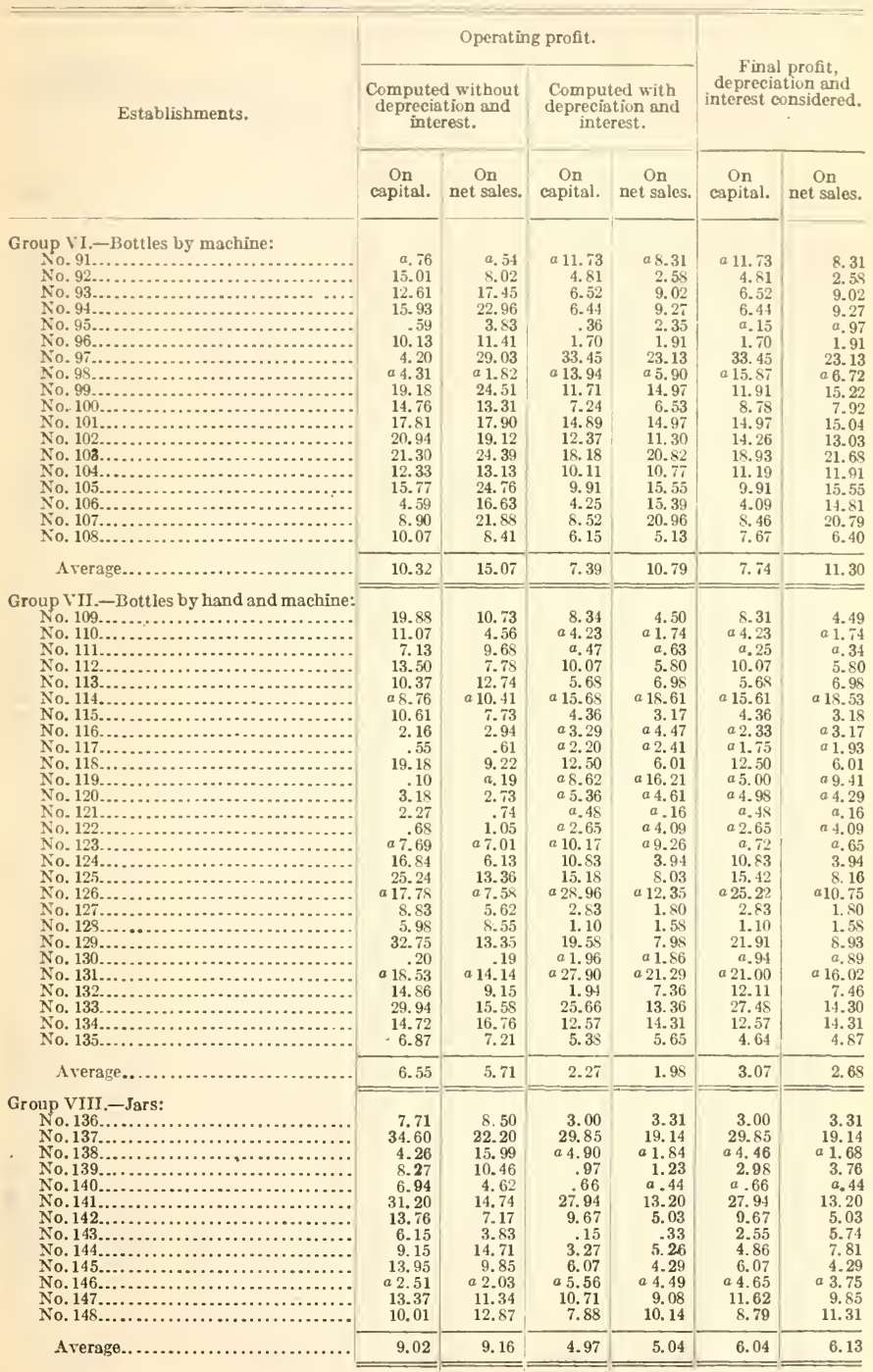

a Loss. 
Table 22.-Percentage of Operating and Final Profit on Capital Employed and on Net Sales, by Groups and by Establishments-Continued.

\begin{tabular}{|c|c|c|c|c|c|c|}
\hline \multirow{3}{*}{ Establishments. } & \multicolumn{4}{|c|}{ Operating profit. } & \multirow{2}{*}{\multicolumn{2}{|c|}{$\begin{array}{l}\text { Final profit, } \\
\text { depreciation and } \\
\text { interest considered. }\end{array}$}} \\
\hline & \multicolumn{2}{|c|}{$\begin{array}{l}\text { Computed without } \\
\text { depreciation and } \\
\text { interest. }\end{array}$} & \multicolumn{2}{|c|}{$\begin{array}{l}\text { Computed with } \\
\text { depreciation and } \\
\text { interest. }\end{array}$} & & \\
\hline & $\underset{\text { capital. }}{\text { On }}$ & $\underset{\text { net sales. }}{\text { On }}$ & $\underset{\text { On }}{\text { enital. }}$ & $\underset{\text { net sales. }}{\text { On }}$ & $\begin{array}{c}\text { On } \\
\text { capital. }\end{array}$ & $\underset{\text { On }}{\text { On sales. }}$ \\
\hline 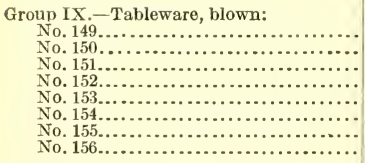 & $\begin{array}{r}3.87 \\
8.02 \\
37.12 \\
11.99 \\
\mathbf{1 1 . 0 0} \\
9.05 \\
9.88 \\
23.88\end{array}$ & $\begin{array}{r}5.28 \\
6.11 \\
16.86 \\
6.24 \\
8.82 \\
10.70 \\
11.49 \\
21.50\end{array}$ & $\begin{array}{r}.86 \\
3.86 \\
30.43 \\
1.05 \\
7.19 \\
5.62 \\
6.55 \\
21.60\end{array}$ & $\begin{array}{r}1.18 \\
2.94 \\
13.82 \\
.54 \\
5.77 \\
6.65 \\
7.61 \\
19.45\end{array}$ & $\begin{array}{r}.86 \\
3.87 \\
30.43 \\
1.05 \\
7.19 \\
5.78 \\
6.58 \\
21.60\end{array}$ & $\begin{array}{r}1.18 \\
2.95 \\
13.82 \\
.54 \\
5.77 \\
6.84 \\
7.65 \\
19.45\end{array}$ \\
\hline 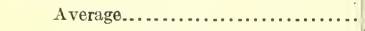 & 14.06 & 12.69 & 10.30 & 9.29 & 10.34 & 9.33 \\
\hline 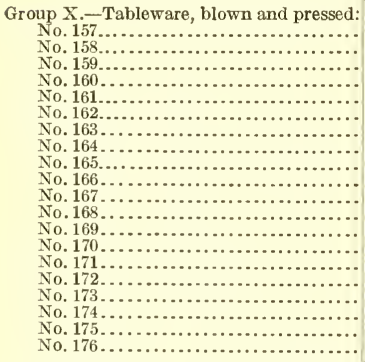 & $\begin{array}{r}11.85 \\
5.67 \\
a 3.28 \\
7.66 \\
a 3.18 \\
5.95 \\
a 22.88 \\
14.45 \\
6.20 \\
9.78 \\
33.76 \\
a 2.07 \\
25.36 \\
13.26 \\
3.80 \\
3.17 \\
11.50 \\
1.04 \\
5.31 \\
5.34\end{array}$ & $\begin{array}{r}10.33 \\
9.71 \\
a 6.76 \\
7.21 \\
5.81 \\
6.17 \\
a 12.99 \\
11.38 \\
3.60 \\
9.44 \\
11.35 \\
2.01 \\
20.81 \\
7.19 \\
4.34 \\
2.61 \\
10.89 \\
1.80 \\
2.58 \\
3.91\end{array}$ & $\begin{array}{r}7.70 \\
a .75 \\
a 9.91 \\
4.44 \\
a 10.95 \\
4.26 \\
a 30.89 \\
10.38 \\
a 2.93 \\
2.53 \\
29.26 \\
a 7.56 \\
14.67 \\
8.75 \\
2.09 \\
a 2.86 \\
7.31 \\
a 5.65 \\
1.83 \\
1.34\end{array}$ & $\begin{array}{r}6.71 \\
a 1.29 \\
a 20.43 \\
4.18 \\
a 20.04 \\
4.41 \\
a 17.54 \\
8.18 \\
a 1.70 \\
2.45 \\
9.83 \\
a 7.34 \\
12.04 \\
4.74 \\
2.39 \\
a 2.36 \\
6.92 \\
a 9.72 \\
.89 \\
.98\end{array}$ & $\begin{array}{r}7.70 \\
a .75 \\
a 9.91 \\
5.38 \\
a 10.95 \\
4.26 \\
a 30.89 \\
10.80 \\
a .06 \\
2.53 \\
29.26 \\
a 7.56 \\
14.77 \\
9.58 \\
2.33 \\
a 2.86 \\
8.23 \\
a 5.63 \\
1.83 \\
1.98\end{array}$ & $\begin{array}{r}6.71 \\
a 1.29 \\
a 20.43 \\
5.06 \\
a 20.04 \\
4.41 \\
a 17.54 \\
8.50 \\
a .03 \\
2.45 \\
9.83 \\
a 7.34 \\
12.13 \\
5.19 \\
2.67 \\
a 2.36 \\
7.30 \\
a 9.68 \\
. .89 \\
1.45\end{array}$ \\
\hline 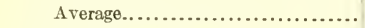 & 5.23 & 4.96 & $a .16$ & $a .15$ & .11 & .11 \\
\hline 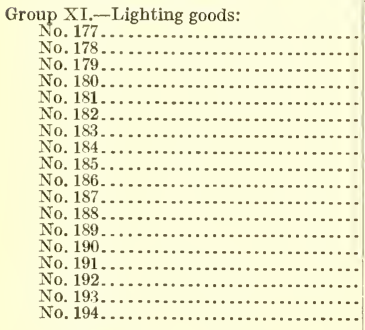 & $\begin{array}{r}.34 \\
17.85 \\
7.38 \\
27.30 \\
3.87 \\
9.97 \\
18.92 \\
29.66 \\
20.24 \\
9.07 \\
8.35 \\
32.94 \\
3.46 \\
1.53 \\
(b) \\
40.37 \\
21.34 \\
15.46\end{array}$ & $\begin{array}{r}.15 \\
9.80 \\
10.89 \\
11.02 \\
4.75 \\
14.45 \\
14.54 \\
18.76 \\
16.79 \\
10.72 \\
2.51 \\
10.70 \\
4.86 \\
6.29 \\
9.75 \\
21.42 \\
24.44 \\
13.67\end{array}$ & $\begin{array}{r}a .61 \\
3.26 \\
1.40 \\
14.11 \\
a 7.39 \\
7.62 \\
15.68 \\
23.88 \\
17.20 \\
5.64 \\
3.71 \\
21.47 \\
1.42 \\
a .08 \\
(b) \\
38.02 \\
18.07 \\
11.14\end{array}$ & $\begin{array}{r}a 4.80 \\
1.79 \\
2.07 \\
5.70 \\
a 9.06 \\
11.05 \\
12.06 \\
15.11 \\
14.27 \\
6.67 \\
1.11 \\
6.97 \\
2.00 \\
a .31 \\
a 2.86 \\
20.18 \\
20.70 \\
9.85\end{array}$ & $\begin{array}{r}a 6.67 \\
3.26 \\
2.04 \\
14.11 \\
a 7.39 \\
7.86 \\
16.21 \\
24.67 \\
17.20 \\
6.42 \\
3.71 \\
23.09 \\
1.42 \\
a .08 \\
(b) \\
40.10 \\
18.47 \\
12.63\end{array}$ & $\begin{array}{r}a 3.02 \\
1.79 \\
3.01 \\
5.70 \\
a 9.06 \\
11.40 \\
12.46 \\
15.61 \\
14.27 \\
7.59 \\
1.11 \\
7.50 \\
2.00 \\
a .35 \\
a 2.86 \\
21.28 \\
21.15 \\
11.17\end{array}$ \\
\hline Average.................................. & c 13.19 & 14.05 & c 9.64 & . 9.59 & $c 10.25$ & 10.19 \\
\hline 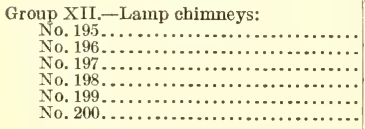 & $\begin{array}{r}29.94 \\
13.11 \\
31.44 \\
20.38 \\
24.43 \\
4.52\end{array}$ & $\begin{array}{r}7.20 \\
10.88 \\
15.54 \\
5.27 \\
11.07 \\
3.22\end{array}$ & $\begin{array}{r}27.51 \\
19.27 \\
27.07 \\
18.82 \\
15.52 \\
1.20\end{array}$ & $\begin{array}{r}6.62 \\
15.99 \\
13.38 \\
4.87 \\
7.03 \\
.85\end{array}$ & $\begin{array}{r}27.51 \\
19.27 \\
27.18 \\
18.82 \\
15.95 \\
1.07\end{array}$ & $\begin{array}{r}6.62 \\
a 15.99 \\
13.43 \\
4.87 \\
7.23 \\
.76\end{array}$ \\
\hline 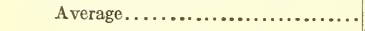 & 8.88 & 5.27 & 4.91 & 2.91 & 4.86 & 2.89 \\
\hline
\end{tabular}

$a$ Loss. $\quad b$ Capital not reported.

c Exclusive of 1 establishment not reporting capital. 
Table 22.-Percentage of Operating and Final Profit on Capital Employed and on Net sales, by Groups and by Establishments-Concluded.

\begin{tabular}{|c|c|c|c|c|c|c|}
\hline \multirow{3}{*}{ Establishments. } & \multicolumn{4}{|c|}{ Operating profit. } & \multirow{2}{*}{\multicolumn{2}{|c|}{$\begin{array}{l}\text { Final profit, } \\
\text { depreciation and } \\
\text { interest considered. }\end{array}$}} \\
\hline & \multicolumn{2}{|c|}{$\begin{array}{l}\text { Computed without } \\
\text { depreciation and } \\
\text { interest. }\end{array}$} & \multicolumn{2}{|c|}{$\begin{array}{l}\text { Computed with } \\
\text { depreciation and } \\
\text { interest. }\end{array}$} & & \\
\hline & $\begin{array}{c}\text { On } \\
\text { capital. }\end{array}$ & $\begin{array}{c}\text { On } \\
\text { net sales. }\end{array}$ & $\begin{array}{c}\text { On } \\
\text { capital. }\end{array}$ & $\begin{array}{c}\text { On } \\
\text { net sales. }\end{array}$ & $\underset{\text { Onpital. }}{\text { On }}$ & $\underset{\text { net sales. }}{\text { On }}$ \\
\hline 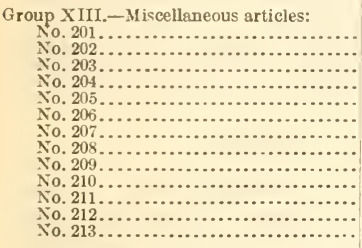 & $\begin{array}{r}22.61 \\
13.74 \\
10.01 \\
22.13 \\
34.45 \\
263.20 \\
38.31 \\
10.23 \\
17.22 \\
20.81 \\
22.61 \\
23.49 \\
26.84\end{array}$ & $\begin{array}{r}40.45 \\
4.21 \\
10.58 \\
17.11 \\
14.44 \\
19.49 \\
8.75 \\
10.92 \\
17.59 \\
18.15 \\
7.23 \\
13.61 \\
11.52\end{array}$ & $\begin{array}{r}18.05 \\
11.42 \\
6.73 \\
19.08 \\
23.38 \\
251.71 \\
25.69 \\
2.86 \\
15.04 \\
18.76 \\
19.14 \\
16.12 \\
13.45\end{array}$ & $\begin{array}{r}32.30 \\
3.50 \\
7.11 \\
14.75 \\
9.80 \\
18.64 \\
5.87 \\
3.05 \\
15.37 \\
16.37 \\
6.12 \\
9.34 \\
5.88\end{array}$ & $\begin{array}{r}18.05 \\
11.42 \\
7.22 \\
19.09 \\
23.38 \\
251.71 \\
25.69 \\
3.24 \\
15.06 \\
18.76 \\
19.64 \\
16.12 \\
13.68\end{array}$ & $\begin{array}{r}32.30 \\
3.50 \\
7.63 \\
14.76 \\
9.80 \\
18.64 \\
5.87 \\
3.46 \\
15.38 \\
16.37 \\
6.28 \\
9.34 \\
5.98\end{array}$ \\
\hline 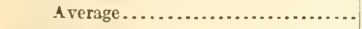 & 22.52 & 12.84 & 15.48 & 8.90 & 15.64 & 8.98 \\
\hline
\end{tabular}

\section{NUMBER OF ESTABLISHMENTS SHOWING PROFIT OR LOSS.}

The following table is a summary of the preceding table and shows for each group of establishments the number having operating profits and the number having operating losses (depreciation and interest on current loans considered and not considered) on capital employed in business and on net sales, and also the number having final profits or losses (depreciation and interest on current loans considered).

Table 23.-Number of Establishments Having Operating and Final Profits OR LOSSES.

\begin{tabular}{|c|c|c|c|c|c|c|c|}
\hline \multirow{2}{*}{ Establishments making - } & \multirow{2}{*}{ Groups. } & \multicolumn{2}{|c|}{$\begin{array}{l}\text { Without deduction } \\
\text { for depreciation } \\
\text { and interest. }\end{array}$} & \multicolumn{4}{|c|}{$\begin{array}{l}\text { After allowance for depreciation and } \\
\text { interest. }\end{array}$} \\
\hline & & $\begin{array}{l}\text { Operat- } \\
\text { ing } \\
\text { profit. }\end{array}$ & $\begin{array}{l}\text { Operat- } \\
\text { ing } \\
\text { loss. }\end{array}$ & $\begin{array}{l}\text { Operat- } \\
\text { ing } \\
\text { profit. }\end{array}$ & $\begin{array}{l}\text { Operat- } \\
\text { ing } \\
\text { loss. }\end{array}$ & $\begin{array}{l}\text { Final } \\
\text { profit. }\end{array}$ & $\begin{array}{l}\text { Final } \\
\text { loss. }\end{array}$ \\
\hline 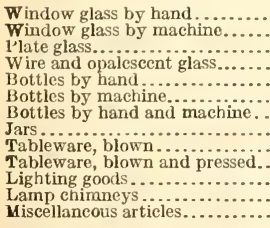 & $\begin{array}{r}\text { I } \\
\text { II } \\
\text { III } \\
\text { IV } \\
\text { VI } \\
\text { VII } \\
\text { VIII } \\
\text { IX } \\
\text { XI } \\
\text { XII } \\
\text { XIII }\end{array}$ & $\begin{array}{r}35 \\
9 \\
6 \\
7 \\
22 \\
16 \\
22 \\
12 \\
8 \\
16 \\
18 \\
5 \\
13\end{array}$ & $\begin{array}{l}2 \\
3 \\
0 \\
2 \\
4 \\
2 \\
5 \\
1 \\
0 \\
4 \\
0 \\
1 \\
0\end{array}$ & $\begin{array}{r}31 \\
7 \\
3 \\
6 \\
16 \\
16 \\
14 \\
10 \\
8 \\
12 \\
14 \\
5 \\
13\end{array}$ & $\begin{array}{r}6 \\
5 \\
3 \\
3 \\
10 \\
2 \\
13 \\
3 \\
0 \\
8 \\
4 \\
1 \\
0\end{array}$ & $\begin{array}{r}31 \\
7 \\
3 \\
6 \\
16 \\
15 \\
14 \\
10 \\
8 \\
12 \\
14 \\
5 \\
13\end{array}$ & $\begin{array}{r}10 \\
3 \\
13 \\
3\end{array}$ \\
\hline Total.................... & 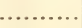 & 159 & 24 & 155 & 58 & 154 & 59 \\
\hline
\end{tabular}

The preceding table shows that of 213 establishments reporting, depreciation and interest not considered, 189 had operating profits 
and 24 operating losses. When depreciation and interest are considered, 155 establishments had operating profits and 58 operating losses and 154 establishments had final profits and 59 final losses. Over 27 per cent of the 213 establishments from which data were secured showed a final loss.

Group IX, blown tableware, and Group XIII, miscellaneaous articles, are the only groups which do not include establishments showing losses.

Of the establishments making bottles by hand, Group V, over 38 per cent had a final loss; of those making bottles by machine, Group VI, over 16 per cent; and of the establishments making bottles by hand and machine, Group VII, over 48 per cent.

A much higher percentage of establishments in Group II, window glass made by machine, show a final loss than is shown by establishments in Group I, window glass made by hand.

\section{VARIATIONS IN PROFITS AND LOSSES.}

Of the establishments in the 13 groups, depreciation and interest on current loans considered, the highest percentage of operating profit on capital employed (251.71 per cent) is shown by an establishment in Group XIII, making miscellaneous articles of glass, and the greatest percentage of operating loss on capital employed (30.89 per cent) is shown by an establishment in Group X, making blown and pressed tableware.

Depreciation and interest on current loans considered, the highest percentage of operating profit on net sales (32.34 per cent) was also made by an establishment in Group XIII, manufacturing miscellaneous articles of glass, and the greatest percentage of operating loss (33.19 per cent) was made by an establishment in Group V, manufacturing bottles by hand.

The following table shows, in percentages, the highest final profit and greatest final loss by any establishment in each group and the average profit for the group based on capital employed and on net sales, depreciation, and interest on current loans considered and miscellaneous income and outgo included:

Table 24.-Highest and Average Percentage of Final Profit and Greatest Percentage of loss on Capital Employed and on Net Sales, by Groups of Establishments.

\begin{tabular}{|c|c|c|c|c|c|c|c|}
\hline \multirow{2}{*}{ Establishments making- } & \multirow{2}{*}{ Group. } & \multicolumn{3}{|c|}{ On capital. } & \multicolumn{3}{|c|}{ On net sales. } \\
\hline & & $\begin{array}{l}\text { Highest } \\
\text { profit. }\end{array}$ & $\begin{array}{c}\text { A verage } \\
\text { profit. }\end{array}$ & $\begin{array}{c}\text { Greatest } \\
\text { loss. }\end{array}$ & $\begin{array}{l}\text { Highest } \\
\text { profit. }\end{array}$ & $\begin{array}{l}\text { A verage } \\
\text { profit. }\end{array}$ & $\begin{array}{l}\text { Greatest } \\
\text { loss. }\end{array}$ \\
\hline 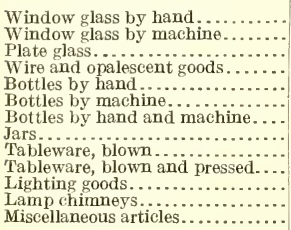 & $\begin{array}{r}1 \\
\text { II } \\
\text { III } \\
\text { IV } \\
\text { V1 } \\
\text { VII } \\
\text { VIII } \\
\text { IX } \\
X 1 \\
\text { X1 } \\
\text { XII } \\
\text { XIII }\end{array}$ & $\begin{array}{r}35.04 \\
16.53 \\
6.00 \\
30.73 \\
34.51 \\
33.45 \\
27.48 \\
29.85 \\
30.43 \\
29.26 \\
40.10 \\
27.51 \\
251.71\end{array}$ & $\begin{array}{r}7.59 \\
2.97 \\
4.14 \\
2.11 \\
3.82 \\
7.74 \\
3.07 \\
6.04 \\
10.34 \\
.11 \\
10.25 \\
4.86 \\
15.64\end{array}$ & $\begin{array}{r}13.02 \\
20.02 \\
6.01 \\
10.18 \\
22.79 \\
15.87 \\
25.22 \\
4.65 \\
a .86 \\
30.89 \\
7.39 \\
19.27 \\
a 3.24\end{array}$ & $\begin{array}{l}16.22 \\
10.21 \\
11.80 \\
27.18 \\
12.13 \\
23.13 \\
14.31 \\
19.14 \\
19.45 \\
12.13 \\
21.28 \\
13.43 \\
32.30\end{array}$ & $\begin{array}{r}5.60 \\
2.76 \\
.82 \\
5.68 \\
2.65 \\
11.30 \\
2.68 \\
6.13 \\
9.33 \\
.11 \\
10.19 \\
2.89 \\
8.98\end{array}$ & $\begin{array}{r}29.11 \\
15.36 \\
7.50 \\
24.22 \\
32.84 \\
8.31 \\
18.53 \\
3.75 \\
a .54 \\
20.43 \\
9.06 \\
15.99 \\
a 3.46\end{array}$ \\
\hline
\end{tabular}




\section{TURNOVER OF CAPITAL.}

Capital in the rarious branches of the glass industry is not turned over rapidly. In the 211 establishments for which capital employed in business was reported, Table 20 shows that the average turnorer, or the ratio of net sales to capital, was as SS to 100 . In other words, the capital was turned over less than once during the course of a year's business. The table indicates that the amount of capital required to finance some glass factories is greater than the amount of net sales.

Comparing Group I with Group II, it is seen that the average turnorer of han I window-glass factories was greater than in the case of machine wintor-glass factories. A comparison of Groups V with VI shows, likewise, that the arerage turnorer of hand bottle factories was greater than in the case of machine bottle factories.

The greatest arerage turnorer by groups in order was in the manufacture of miscellaneous articles; lamp chimneys; bottles by hand; window glass by hand; bottles by hand and machine; tableware, blown; window glass by machine: and tableware, blown and pressed. In all of these groups the arerage sales exceeded the arerage capital emplored. Groups in which the net sales were less than the capital, in the order of the largest turnover to the smallest, was in the manufacture of jars, lighting goods, bottles by machine, plate glass, and wire and opalescent glass.

The 1914 Census of Manufactures of the United States gives the value of the product of 348 establishments in the glass industry as $\$ 123,085,019$ and the capital invested as $\$ 153,925,876$, a ratio of product to capital as 80 to 100 . 


\section{DEPRECIATION OF PLANT AND EQUIPMENT.}

\section{IMPORTANCE OF THE CHARGES.}

The importance of considering depreciation as an element of cost to be charged to operating expense or deducted from income is recognized by practically all accountants. Many establishments believing that they were conducting a profitable business have found themselves facing financial ruin because the importance of providing for a depreciation reserve was not recognized.

The invention of new and more efficient machinery necessitates the scrapping of obsolete equipment. Very frequently glass plants are compelled to move to different locations on account of a shortage of natural gas. These elements of hazard are incidental to industry and must be guarded against by reserves or sinking funds. Unless they are taken into consideration, no cost or accounting system is scientifically accurate or sate.

The amount or percentage and the method to be employed in charging depreciation is a mooted question. Little doubt exists, however, that systematic provision must be made for it in order to arrive at the accurate state of affairs of any manufacturing business.

The value of buildings, machines, and other equipment deteriorate from many causes - from use, abuse, accident, obsolescence, etc. In an article on the subject of depreciation appearing in the new American Handbook for Electrical Engineers, written by Wm. A. Del Mar, some of the factors that affect depreciation are defined as follows:

Deterioration.-Any change in a property due to wear and tear or the ravages of the elements which tends to impair either its usefulness or its life.

Loss of useful association. - Any change in the associations of a property which tends to impair its usefulness or its life.

Obsolescence.-A loss of commercial ability in any property due to the advent of superior substitutes.

Inadequacy.-Loss of commercial utility in a property due to its inability to meet increased business conditions.

While it is possible to estimate quite accurately how much should be charged for wear and tear, it is impossible to do so for the elements of obsolescence and the like. It requires an "insurance" or reserve fund to overcome this industrial hazard.

\section{VARIOUS METHODS EMPLOYED.}

There is no uniform practice as to the percentage of original cost to be charged off for depreciation. The "straight-line depreciation" consists of estimating the expected life of a machine and charging depreciation each year according to the percentage found by dividing the original cost by the number of years estimated. Estimating a certain percentage of depreciation each year, figuring this amount every year after the first on the depreciated or net value of the machine, is also frequently employed. Another method is that of charging the amount of depreciation to a reserve account or sinking fund.

The crude and inaccurate method of lumping all property and machinery and charging a uniform percentage of depreciation is 
absolutely incorrect and can only lead to a false statement of values. Some machinery and equipment must necessarily be treated differently than others. The amount to be charged is largely a matter of experience and sound business judgment. The hazardous element of competition enters into the life of machinery and equipment as it does in all branches of business and industry, and the wise business man will insure himself against this factor.

To arrive at the proper amount of depreciation it is essential to provide for a detailed inventory of the value of buildings, machinery, and equipment. It must also be recognized that no amount of maintenance, repairs, or renewals can prevent depreciation. To argue that such charges cover depreciation is inaccurate. The time will arrive when a machine or even a building, regardless of the repairs and renewals, will have to be scrapped, either because it is worn out or obsolete or because of any of the other causes mentioned above.

Many manufacturers are in the habit of showing charges for depreciation when profits are exceptionally high, neglecting to do so when the business year shows a loss or only a small profit. This is frequently done in order to show the business in a better light, when applying for loans or commercial ratings. This method can not be too strongly condemned. An accumulated charge for depreciation covering several years should not be charged against the cost of manufacturing or against surplus account of a single business year. Depreciation differs in the different departments and therefore should not be charged at a common rate for the whole establishment, but the charge should be made at a proper rate for each department separately.

Most manufacturers visited during this investigation paid little attention to this subject. The books of many did not provide for depreciation accounts. Out of 102 establishments reporting such charges, only 35 charged depreciation separately on buildings and machines and on different types of machines. The others charged off lump sums without regard to the classification of the property. In one instance an establishment charged off almost 50 per cent of the value of the plant and equipment for one business year, an amount which represented the accumulated depreciation for eight years.

Some of the statements made by manufacturers in answer to the inquiry concerning depreciation are as follows:

We usually charge for depreciation, but profits must warrant it.

Five per cent annually if profits warrant; if not, no depreciation is charged for the business year but is doubled in the following year.

Repair account is sufficient to cover depreciation.

Several of the establishments from which data were obtained provided accurate methods of charging depreciation. One of these classified its annual depreciation charges as follows:

Buildings:

Per cent.

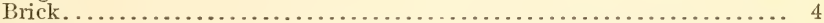

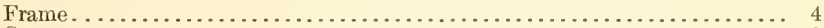

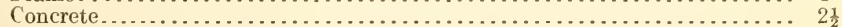

Machines and tools:

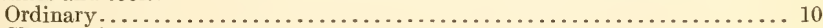

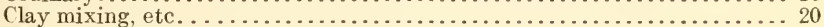

Equipment (blowing rods, etc.) .................................... 10

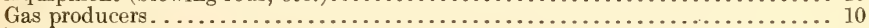

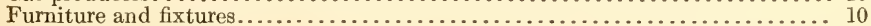

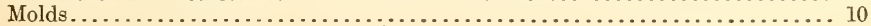


Of the 213 establishments reporting data, 109 did not provide for depreciation charges, but in tabulating the schedules secured from these 109 establishments depreciation was calculated on the average percentage of depreciation reported by establishments in their respective groups. This percentage was based on the total value of the plant, including the land, which in some cases was not reported separately from the buildings and equipment.

\section{NEGLECT OF CHARGES BY GLASS-MAKING PLANTS.}

The following table shows in detail the number of establishments that charged and that did not charge depreciation, and the amounts charged and estimated, by groups:

Table 25.-Value of Plants, Number of Establishments Charging Depreciation and Amount Charged, and Number Not Charging Depreciation, with Estimated Amount, by Groups.

\begin{tabular}{|c|c|c|c|c|c|c|c|c|c|}
\hline \multirow{2}{*}{$\begin{array}{l}\text { Establishments } \\
\text { manufacturing- }\end{array}$} & \multirow[b]{2}{*}{ Group. } & \multicolumn{3}{|c|}{$\begin{array}{l}\text { Number of establish- } \\
\text { ments. }\end{array}$} & \multirow{2}{*}{$\begin{array}{l}\text { Total } \\
\text { value of } \\
\text { land, } \\
\text { buildings, } \\
\text { and equip } \\
\text { ment. }\end{array}$} & \multicolumn{4}{|c|}{ Depreciation. } \\
\hline & & Total. & $\begin{array}{l}\text { Charg- } \\
\text { ing } \\
\text { depre- } \\
\text { ciation. }\end{array}$ & $\begin{array}{l}\text { Not } \\
\text { charg- } \\
\text { ing } \\
\text { depre- } \\
\text { ciation. }\end{array}$ & & Charged. & $\begin{array}{l}\text { Esti- } \\
\text { mated. }\end{array}$ & Total. & $\begin{array}{l}\text { Per } \\
\text { cent of } \\
\text { value. }\end{array}$ \\
\hline $\begin{array}{l}\text { Window glass by } \\
\text { hand... glass by }\end{array}$ & I & $a 37$ & 10 & 26 & $\$ 2,404,400$ & $\$ 42,433$ & $\$ 129,816$ & $\$ 172,249$ & 7.16 \\
\hline Windo & II & 12 & 7 & 5 & 1,81 & 13 & 74,252 & 15 & \\
\hline $\begin{array}{l}\text { Plate glass.......... } \\
\text { Wire and opalescent }\end{array}$ & 1II & 6 & 4 & 2 & 876 & & 116,933 & & 8.25 \\
\hline $\mathrm{BO}$ & IV & $\begin{array}{r}9 \\
a 26\end{array}$ & $\begin{array}{l}5 \\
8\end{array}$ & $\begin{array}{r}4 \\
17\end{array}$ & $\begin{array}{l}2,707,412 \\
2,221,981\end{array}$ & $\begin{array}{l}89,772 \\
32,896\end{array}$ & $\begin{array}{l}13,328 \\
44,905\end{array}$ & $\begin{array}{r}103,100 \\
77,801\end{array}$ & $\begin{array}{l}3.81 \\
3.50\end{array}$ \\
\hline $\begin{array}{l}\text { Bottl } \\
\text { Bottl }\end{array}$ & VI & 18 & 16 & 2 & 10,69 & 535 & 19,003 & 554 & 5.18 \\
\hline $\begin{array}{l}\text { an } \\
\text { Jars }\end{array}$ & VII & 27 & 12 & 15 & $3,506,898$ & 130,959 & 125,259 & 256,218 & \\
\hline Tableware, blown.. & VIII & $\begin{array}{r}13 \\
8\end{array}$ & $\begin{array}{r}12 \\
5\end{array}$ & $\begin{array}{l}1 \\
3\end{array}$ & $\begin{array}{r}2,971,069 \\
786,030\end{array}$ & $\begin{array}{r}176,501 \\
28,538\end{array}$ & $\begin{array}{r}7,357 \\
18,170\end{array}$ & $\begin{array}{r}183,858 \\
46,708\end{array}$ & $\begin{array}{l}6.19 \\
5.94\end{array}$ \\
\hline $\begin{array}{l}\text { Tableware, blown } \\
\text { and pressed....... }\end{array}$ & & 20 & & 14 & $4,314,405$ & 137,251 & 233,117 & 370,368 & 8.58 \\
\hline $\begin{array}{l}\text { Ligl } \\
\text { Lam }\end{array}$ & $\begin{array}{r}\mathrm{XI} \\
\mathrm{XII}\end{array}$ & $\begin{array}{r}18 \\
6\end{array}$ & $\begin{array}{r}11 \\
2\end{array}$ & $\begin{array}{l}7 \\
4\end{array}$ & $\begin{array}{r}7,425,008 \\
431,794\end{array}$ & $\begin{array}{r}336,593 \\
3,600\end{array}$ & $\begin{array}{l}77,138 \\
16,089\end{array}$ & $\begin{array}{r}413,731 \\
19,689\end{array}$ & $\begin{array}{l}5.57 \\
4.56\end{array}$ \\
\hline $\begin{array}{r}\text { Miscellaneous arti- } \\
\text { cles.................. }\end{array}$ & XIII & 13 & 4 & 9 & $1,118,199$ & 64,351 & 43,468 & 107,819 & 9.64 \\
\hline Total. & & b) 213 & 102 & 109 & $46,576,584$ & $2,051,096$ & 918,925 & $2,970,021$ & 6.38 \\
\hline
\end{tabular}

$a$ One plant is rented; no depreciation charged.

$b$ Two plants are rented; no depreciation charged. 
One defect of the accounting systems used in many glass factories was shown by answers to inquiries as to whether there were reserves for bad dedts and for depreciation or whether an amount for depreciation was charged against the capital account. 'The answers to these inquiries are tabulated below:

Table 26.-Establishanents Which Charge Off Depreciation and Which Have Reserves for Depreciation and Bad Debts. by Groups.

\begin{tabular}{|c|c|c|c|c|c|c|c|c|}
\hline \multirow{2}{*}{ Establishments manufacturing- } & \multirow{2}{*}{ Group. } & \multirow{2}{*}{$\begin{array}{l}\text { Estab- } \\
\text { lish- } \\
\text { ments. }\end{array}$} & \multicolumn{2}{|c|}{$\begin{array}{c}\text { Deprecia- } \\
\text { tion } \\
\text { eharged. }\end{array}$} & \multicolumn{2}{|c|}{$\begin{array}{l}\text { Reserve for } \\
\text { deprecia- } \\
\text { tion. }\end{array}$} & \multicolumn{2}{|c|}{$\begin{array}{l}\text { Reserve for } \\
\text { bad debts. }\end{array}$} \\
\hline & & & Yes. & No. & Yes. & No. & Yes. & No. \\
\hline 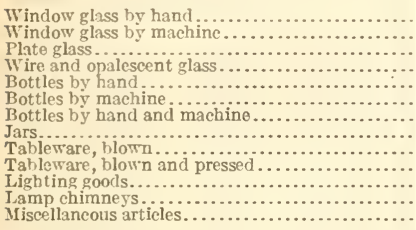 & $\begin{array}{l}\text { I } \\
\text { III } \\
\text { IV } \\
\text { V } \\
\text { VI } \\
\text { VII } \\
\text { VIII } \\
\text { II } \\
\text { XI } \\
\text { XII } \\
\text { XIII }\end{array}$ & $\begin{array}{r}a \\
37 \\
12 \\
6 \\
9 \\
25 \\
19 \\
a 27 \\
13 \\
8 \\
20 \\
18 \\
6 \\
13\end{array}$ & $\begin{array}{r}10 \\
7 \\
4 \\
5 \\
8 \\
16 \\
12 \\
12 \\
5 \\
6 \\
11 \\
2 \\
4\end{array}$ & $\begin{array}{r}a \\
26 \\
5 \\
2 \\
4 \\
18 \\
2 \\
a \\
14 \\
1 \\
3 \\
14 \\
7 \\
4 \\
9\end{array}$ & $\begin{array}{r}5 \\
5 \\
0 \\
2 \\
3 \\
14 \\
8 \\
7 \\
.1 \\
4 \\
3 \\
1 \\
2\end{array}$ & $\begin{array}{r}32 \\
7 \\
6 \\
7 \\
23 \\
4 \\
19 \\
6 \\
7 \\
16 \\
15 \\
5 \\
11\end{array}$ & $\begin{array}{l}1 \\
1 \\
0 \\
0 \\
3 \\
9 \\
5 \\
6 \\
0 \\
2 \\
4 \\
1 \\
1\end{array}$ & $\begin{array}{r}36 \\
11 \\
6 \\
9 \\
23 \\
9 \\
22\end{array}$ \\
\hline Total......... & & $b 213$ & 102 & b 109 & 55 & 158 & 33 & \\
\hline
\end{tabular}

$a$ Includes one rented plant; no depresiation charged.

$b$ Includes two rented plants; no depreciation charged.

The preceding table shows that of 213 establishments, 158 had no reserve account for depreciation; 109 (not including 2 that rented factories) made no charge for depreciation against capital account, and 180 had no reserve for bad debts (though some stated that they had no bad debts). Probably all glass manufacturers realize that there is a shrinkage in the values of their buildings and equipments outside of repairs and additions from year to year, yet over half of those that reported in this investigation did not charge off depreciation in making up their profit and loss statements. Some charged off depreciation only after several years, and then in insufficient amounts; others only in years when they made an unusually large profit. Many establishments do not charge off depreciation every year for the reason that they wish to make favorable showings in regard to capital and profits to bankers and commercial agencies.

If proper charges for depreciation are made, some establishments that show final profits by their annual profit and loss statements are found to have had final losses when depreciation is deducted. This is illustrated by Table 28. As reported, 175 of the 213 establishments earned final profits and 38 had final losses, but when allowances were made for depreciation in the reports of those that did not charge off depreciation on their own books (this allowance being at the average rate of those that did charge off depreciation), the number that earned a final profit was reduced from 175 to 155 , and the number that had a final loss was increased from 38 to 58 . 


\section{RELATION TO NET SALES, CAPITAL, AND INVESTMENT.}

The following table clearly illustrates the relation between the net sales, capital employed in business, and the amount invested in land, buildings, and equipment. It will be noticed that the amount of plant value is over 50 per cent of the total capital invested.

Table 27.-Amount of Net Sales, Capital Employed, Value of Plants, and Amounts of Depreciation Charged by Establishments and Estimated, by Groups.

\begin{tabular}{|c|c|c|c|c|c|c|c|}
\hline \multirow{2}{*}{$\begin{array}{l}\text { Establishments manufac- } \\
\text { turing- }\end{array}$} & \multirow[b]{2}{*}{ Group. } & \multirow{2}{*}{$\begin{array}{l}\text { Estab- } \\
\text { lish- } \\
\text { ments. }\end{array}$} & \multirow{2}{*}{ Net sales. } & \multirow{2}{*}{$\begin{array}{c}\text { Capital } \\
\text { employed } \\
\text { in } \\
\text { business. }\end{array}$} & \multirow{2}{*}{$\begin{array}{c}\text { Invest- } \\
\text { ment, } \\
\text { land, } \\
\text { buildings, } \\
\text { and } \\
\text { equipment. }\end{array}$} & \multicolumn{2}{|c|}{ Depresiation. } \\
\hline & & & & & & $\begin{array}{c}\text { Charged } \\
\text { bv estab- } \\
\text { lishments. }\end{array}$ & $\begin{array}{c}\text { Esti- } \\
\text { mated. }\end{array}$ \\
\hline Window glass, & I & 37 & $\$ 5,918,686$ & $\$ 4,370,347$ & $\$ 2,404,400$ & $\$ 42,433$ & 129, \\
\hline Window glas & II & 12 & $3,368,242$ & $3,129,343$ & $1,815,956$ & 80,313 & 74,252 \\
\hline Plate glass... & III & 6 & $4,930,141$ & $9,720,629$ & $6,176,876$ & $392,4^{2} 0$ & $116,9^{2}$ \\
\hline ent glass... & IV & 9 & $2,586,970$ & $6,968,167$ & $2,707,412$ & 89,772 & 13,32 \\
\hline Bottles, by hand. & V & 26 & $4,969,281$ & a. $3,402,516$ & $2,221,981$ & 32,896 & 44,905 \\
\hline Bottles, by machine........ & VI & 18 & $15,359,396$ & $22,416,423$ & $10,696,556$ & 535,459 & 19,093 \\
\hline 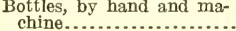 & VII & 27 & $9,856,970$ & $8,593,877$ & $3,506,898$ & 130,959 & 125,259 \\
\hline Jars .............................. & VIII & 13 & $6,464,708$ & $6,563,943$ & $2,971,069$ & 176,501 & 7,357 \\
\hline Tableware, blown ................ & IX & 8 & $1,820,229$ & $1,642,881$ & 786,030 & 28,538 & 18,170 \\
\hline 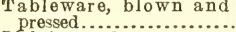 & $\mathrm{X}$ & 20 & 8,12 & $7,691,784$ & $4,314,405$ & 137,251 & 233,117 \\
\hline Lighting goods.. & $\mathrm{XI}$ & 18 & $12,136,579$ & $a_{12}, 062,347$ & $7,425,008$ & 336,593 & 77,138 \\
\hline Lamp chin & XII & 6 & $1,230,578$ & 730,454 & 431,794 & 3, 600 & 16,089 \\
\hline Miscellaneous & $\mathrm{XIII}$ & 13 & $3,151,944$ & $1,810,676$ & $1,118,199$ & 64,351 & 43,468 \\
\hline Total. & & 213 & $79,918,801$ & $b 89,103,387$ & $46,576,584$ & $2,051,096$ & 918,925 \\
\hline
\end{tabular}

a One establishment in this group did not report capital.

$\checkmark$ Two establishments did not report capital.

\section{EFEET ON PROFITS.}

That depreciation materially affects the operating cost and the profit is clearly shown in the following series of tables. Table 28 shows the number of establishments having final profits and losses with and without charged and estimated depreciation. It also shows that after including an estimated amount for depreciation on plants that did not charge any, the number of plants showing final losses increased from 38 to 58 . 
Table 2S.-Number of Establishments Charging and Not Charging Depreciation, and Showing a Final Profit or Loss, by Groups.

\begin{tabular}{|c|c|c|c|c|}
\hline \multirow{2}{*}{ Establishments manufacturing- } & \multicolumn{3}{|c|}{ As reported. } & \multirow{2}{*}{$\begin{array}{l}\text { Total, } \\
\text { with de- } \\
\text { preciation } \\
\text { charged } \\
\text { or } \\
\text { estimated. }\end{array}$} \\
\hline & $\begin{array}{l}\text { Charging } \\
\text { deprecia- } \\
\text { tion. }\end{array}$ & $\begin{array}{l}\text { Not charg- } \\
\text { ing depre- } \\
\text { ciation. }\end{array}$ & Total. & \\
\hline 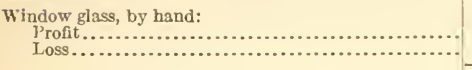 & $\begin{array}{l}9 \\
1 \\
\end{array}$ & $\begin{array}{r}\text { a } 25 \\
2 \\
\end{array}$ & $\begin{array}{r}a 34 \\
3 \\
\end{array}$ & a 31 \\
\hline Total... & 10 & $a 27$ & a 37 & $a 37$ \\
\hline 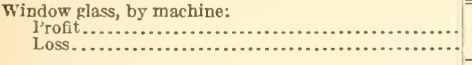 & $\begin{array}{l}5 \\
2 \\
\end{array}$ & $\begin{array}{r}5 \\
\cdots \ldots \ldots \ldots \\
\end{array}$ & $\begin{array}{r}10 \\
2\end{array}$ & 5 \\
\hline Total................. & 7 & 5 & 12 & 12 \\
\hline 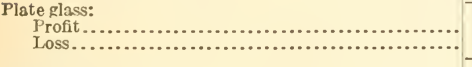 & $\begin{array}{l}3 \\
1 \\
\end{array}$ & $\begin{array}{l}1 \\
1\end{array}$ & $\begin{array}{l}4 \\
2 \\
\end{array}$ & $\begin{array}{l}3 \\
3\end{array}$ \\
\hline 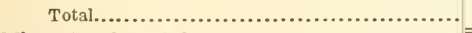 & 4 & 2 & 6 & 6 \\
\hline 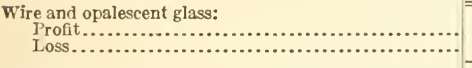 & $\begin{array}{l}4 \\
1 \\
\end{array}$ & $\begin{array}{l}2 \\
2\end{array}$ & $\begin{array}{l}6 \\
3 \\
\end{array}$ & $\begin{array}{l}6 \\
3\end{array}$ \\
\hline Total $\ldots \ldots \ldots \ldots \ldots \ldots \ldots$ & 5 & 4 & 9 & 9 \\
\hline 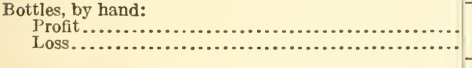 & $\begin{array}{l}6 \\
2\end{array}$ & $\begin{array}{r}a 13 \\
5\end{array}$ & $\begin{array}{r}a 19 \\
7\end{array}$ & $\begin{array}{r}a 16 \\
10\end{array}$ \\
\hline Total...................................... & 8 & a 18 & a 26 & $a 26$ \\
\hline 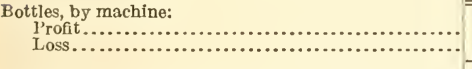 & $\begin{array}{r}15 \\
1 \\
\end{array}$ & an. & $\begin{array}{r}15 \\
3\end{array}$ & $\begin{array}{r}15 \\
3\end{array}$ \\
\hline Total............................ & 16 & 2 & 18 & 18 \\
\hline 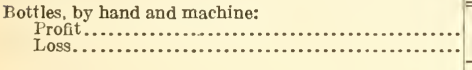 & $\begin{array}{l}9 \\
3\end{array}$ & $\begin{array}{r}12 \\
3\end{array}$ & $\begin{array}{r}21 \\
6\end{array}$ & $\begin{array}{l}14 \\
13\end{array}$ \\
\hline Total ................................... & 12 & 15 & 27 & 27 \\
\hline 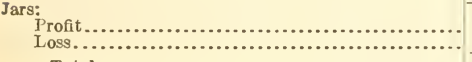 & $\begin{array}{r}10 \\
2 \\
\end{array}$ & 1 & $\begin{array}{r}11 \\
2 \\
\end{array}$ & $\begin{array}{r}10 \\
3 \\
\end{array}$ \\
\hline 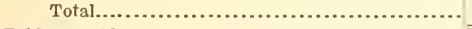 & 12 & 1 & 13 & 13 \\
\hline 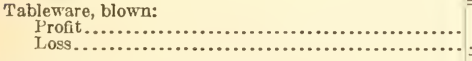 & $\begin{array}{r}5 \\
\ldots \ldots \ldots \\
\end{array}$ & $\begin{array}{c}3 \\
\ldots \ldots \ldots \ldots \\
\end{array}$ & $\begin{array}{c}8 \\
\cdots\end{array}$ & n........... \\
\hline 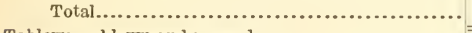 & 5 & 3 & 8 & \\
\hline 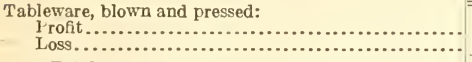 & $\begin{array}{l}5 \\
1 \\
\end{array}$ & $\begin{array}{l}9 \\
5 \\
\end{array}$ & $\begin{array}{r}14 \\
6 \\
\end{array}$ & $\begin{array}{r}13 \\
7 \\
\end{array}$ \\
\hline 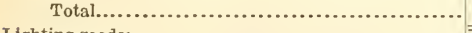 & 6 & 14 & 20 & 20 \\
\hline 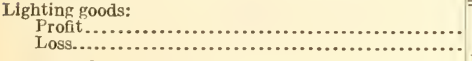 & $\begin{array}{r}10 \\
1\end{array}$ & $\begin{array}{l}5 \\
2 \\
\end{array}$ & $\begin{array}{r}15 \\
3 \\
\end{array}$ & 14 \\
\hline 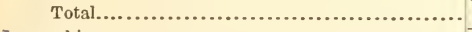 & 11 & 7 & 18 & 18 \\
\hline 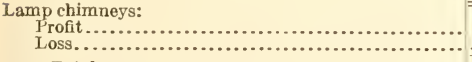 & $\begin{array}{r}2 \\
2 \\
\cdots\end{array}$ & $\begin{array}{l}3 \\
1 \\
\end{array}$ & $\begin{array}{l}5 \\
1 \\
\end{array}$ & \\
\hline 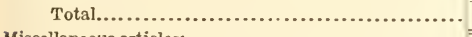 & 2 & 4 & 6 & 6 \\
\hline 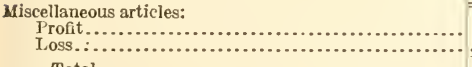 & $\begin{array}{r}4 \\
\ldots \ldots . . . \\
\end{array}$ & $\ldots \ldots \ldots$ & $\begin{array}{r}13 \\
\ldots \ldots \ldots . . . \\
\end{array}$ & $\begin{array}{r}13 \\
\ldots \ldots . . . \\
\end{array}$ \\
\hline 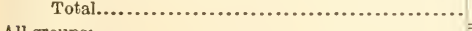 & 4 & 9 & 13 & 13 \\
\hline $\begin{array}{l}\text { All groups: } \\
\text { Profit....... } \\
\text { Loss....... }\end{array}$ & $\begin{array}{l}87 \\
15 \\
\end{array}$ & $\begin{array}{r}b 88 \\
23 \\
\end{array}$ & $\begin{array}{r}b \quad 175 \\
38 \\
\end{array}$ & $\begin{array}{r}b \quad 155 \\
58 \\
\end{array}$ \\
\hline Total........................... & 102 & $b 111$ & $b 213$ & \\
\hline
\end{tabular}


The following table shows the final profits, excluding charges for depreciation reported, including such charges and including reported and estimated charges. These profits are based on the net sales. The table shows to what extent profits are affected by depreciation. In two groups, viz, plate glass and blown and pressed tableware, profits of $\$ 549,572$ in the first case and $\$ 379,036$ in the second are reduced to profits of $\$ 40,209$ and $\$ 8,668$, respectively.

Table 29.-Amount of Net Sales, Final Profits With and Without Depreciation Charged, and Amounts of Depreciation Charged and Estimated, by Groups.

\begin{tabular}{|c|c|c|c|c|c|c|c|c|}
\hline \multirow{3}{*}{$\begin{array}{l}\text { Establishments manu- } \\
\text { facturing- }\end{array}$} & \multirow{3}{*}{$\begin{array}{l}\text { Estab- } \\
\text { lish- } \\
\text { ments. }\end{array}$} & \multirow{3}{*}{ Net sales. } & \multicolumn{3}{|c|}{ Final profit. } & \multicolumn{3}{|c|}{ Depreciation. } \\
\hline & & & \multirow{2}{*}{$\begin{array}{l}\text { Without } \\
\text { any } \\
\text { charges } \\
\text { for de- } \\
\text { precia- } \\
\text { tion. }\end{array}$} & \multicolumn{2}{|c|}{$\begin{array}{l}\text { With charges for } \\
\text { depreciation. }\end{array}$} & \multirow[b]{2}{*}{$\begin{array}{l}\text { Charged } \\
\text { by estab- } \\
\text { lish- } \\
\text { ments. }\end{array}$} & \multirow[b]{2}{*}{$\begin{array}{l}\text { Esti- } \\
\text { mated. }\end{array}$} & \multirow[b]{2}{*}{ Total. } \\
\hline & & & & $\begin{array}{c}\text { As } \\
\text { charged } \\
\text { by estab- } \\
\text { lish- } \\
\text { ments. }\end{array}$ & $\begin{array}{l}\text { As } \\
\text { charged } \\
\text { and } \\
\text { esti- } \\
\text { mated. }\end{array}$ & & & \\
\hline \multirow{2}{*}{$\begin{array}{l}\text { Window glass, by hand. } \\
\text { Window glass, by ma- } \\
\text { chine.......................... } \\
\text { Plate glass. }\end{array}$} & a 37 & $\$ 5,918,686$ & $\$ 504,022$ & $\$ 461,589$ & $\$ 331,773$ & $\$ 42,433$ & $\$ 129,816$ & $\$ 172,249$ \\
\hline & 12 & $3,368,242$ & 247,501 & 167,188 & 92 , & 80,313 & 74,252 & 154,565 \\
\hline \multirow{2}{*}{ 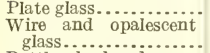 } & & $4,930,141$ & & & & 39 & 11 & 50 \\
\hline & 9 & $2,586,970$ & 250,045 & 160,273 & 146,945 & 89,772 & 13,328 & 103,100 \\
\hline $\begin{array}{l}\text { Bottles, by hand ......... } \\
\text { Bottles, by machine. }\end{array}$ & $\begin{array}{l}a 26 \\
18\end{array}$ & $4,969,281$ & 209,713 & 176,817 & 131 & 32,896 & 44, & 77,801 \\
\hline \multirow{2}{*}{$\begin{array}{l}\text { Bottles, by hand and } \\
\text { machine........................ }\end{array}$} & 18 & $15,359,396$ & $2,290,667$ & $1,755,208$ & 1,73 & 535,459 & 1 s & 55 \\
\hline & 27 & $9,856,970$ & 520,076 & 389,117 & 263,858 & 130,959 & 125,259 & 256,218 \\
\hline $\begin{array}{l}\text { Jars .......................... } \\
\text { Tableware, blown... }\end{array}$ & $\begin{array}{r}13 \\
8\end{array}$ & $6,464,708$ & 580,226 & 403,7 & 39 & 176,501 & $\begin{array}{r}7,357 \\
18\end{array}$ & $\begin{array}{r}183,858 \\
46,708\end{array}$ \\
\hline \multirow{3}{*}{$\begin{array}{c}\text { Tableware, blown...... } \\
\text { Tableware, blown and } \\
\text { pressed.................... } \\
\text { Lighting goods. }\end{array}$} & & 1,8 & 21 & 1 & 1 & 28,038 & 18, & 80 \\
\hline & 20 & $8,125,077$ & 379,036 & 241,785 & 8.668 & 137,251 & 233,117 & 370,368 \\
\hline & 18 & $12,136,579$ & $1,650,517$ & $1,313,924$ & 1,236, & $\begin{array}{r}336,593 \\
3,600\end{array}$ & $\begin{array}{r}77,138 \\
16,089\end{array}$ & $\begin{array}{r}413,731 \\
19,689\end{array}$ \\
\hline $\begin{array}{l}\text { Lamp chimneys........ } \\
\text { Miscellaneous articles... }\end{array}$ & $\begin{array}{r}0 \\
13 \\
\end{array}$ & $3,151,944$ & $\begin{array}{r}55,213 \\
390,933 \\
\end{array}$ & $\begin{array}{r}51,013 \\
326,582 \\
\end{array}$ & 283, & $\begin{array}{r}3,000 \\
64,351\end{array}$ & 43,468 & 107,819 \\
\hline Total. & b 213 & $79,918,801$ & $7,844,111$ & $5,793,015$ & $4,874,090$ & $2,051,096$ & 918,925 & $2,970,021$ \\
\hline
\end{tabular}

$a$ One plant rented; no depreciation charged. $\quad b$ Two plants rented; no depreciation charged.

The amounts shown in the preceding table are given in the form of percentages in the table which follows:

\section{Table 30.-Per Cent of Final Profit, With and Without Depreciation Charged, Based on Net Sales, by Groups.}

\begin{tabular}{|c|c|c|c|c|c|}
\hline \multirow{3}{*}{ Establishments manufacturing- } & \multirow{3}{*}{ Group. } & \multirow{3}{*}{$\begin{array}{l}\text { Estab- } \\
\text { lish- } \\
\text { ments. }\end{array}$} & \multicolumn{3}{|c|}{ Per cent of final profit on net sales. } \\
\hline & & & \multirow{2}{*}{$\begin{array}{l}\text { Without } \\
\text { any charges } \\
\text { for de- } \\
\text { preciation. }\end{array}$} & \multicolumn{2}{|c|}{$\begin{array}{l}\text { With charges for } \\
\text { depreciation. }\end{array}$} \\
\hline & & & & $\begin{array}{l}\text { As charged } \\
\text { by estab- } \\
\text { lishments. }\end{array}$ & $\begin{array}{l}\text { As charged } \\
\text { and esti- } \\
\text { mated. }\end{array}$ \\
\hline Window glass, by hand. & I & a 37 & 8.52 & 7.80 & 5.60 \\
\hline Window glass, by machine. & 11 & 12 & 7.35 & 4.96 & 2.76 \\
\hline Plate glass...................... & 111 & & 11.15 & 3.19 & .82 \\
\hline Wire and opalescent glass.......... & IV & & 9.67 & 6.20 & 5.68 \\
\hline 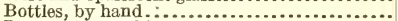 & V & a 26 & 4.22 & 3.56 & 2.65 \\
\hline Bottles, by machine... & VI & 18 & 14.91 & 11.43 & 11.30 \\
\hline Bottles, by hand and machine............... & V11 & 27 & 5.28 & 3.95 & 2.68 \\
\hline 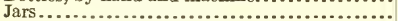 & viIl & 13 & 8.98 & 6.25 & 6.13 \\
\hline Tableware, biown................................ & 1X & 8 & 11.90 & 10.33 & 9.33 \\
\hline Table ware, blown and pressed. & $\mathrm{X}$ & 20 & 4.67 & 2.98 & \\
\hline Lighting goods..................... & $\mathrm{X} 1$ & 18 & 13.60 & 10.83 & 10.19 \\
\hline Lamp chimneys...... & $\mathrm{X} 11$ & 6 & 4.49 & 4.19 & 2.89 \\
\hline Miscellaneous articles. & $\mathrm{X} 111$ & 13 & 12.40 & 10.36 & 8.98 \\
\hline Total.. & & $b 213$ & 9.82 & 7.25 & 6.10 \\
\hline
\end{tabular}


Table 31 , which follows, is similar in form to Table 29, except that operating profits are shown in place of final profits, the latter including miscellaneous income and outgo items. The operating profits shown in this table differ from operating profits in other tables in that interest charges have been included in the operating outgo.

Table 31.-Amount of Net Sales, Operating Profits With and Without Depreciation Charged, and Amounts of Depreciation Cinarged and EstiMATED, BY GROUPS.

\begin{tabular}{|c|c|c|c|c|c|c|c|c|}
\hline \multirow{3}{*}{$\begin{array}{l}\text { Establishments manu- } \\
\text { facturing- }\end{array}$} & \multirow{3}{*}{$\begin{array}{l}\text { Estah- } \\
\text { lish- } \\
\text { ments. }\end{array}$} & \multirow{3}{*}{ Net sales. } & \multicolumn{3}{|c|}{ Operating profit. } & \multicolumn{3}{|c|}{ Depreciation. } \\
\hline & & & \multirow{2}{*}{$\begin{array}{l}\text { Without } \\
\text { any } \\
\text { charges } \\
\text { for de- } \\
\text { precia- } \\
\text { tion. }\end{array}$} & \multicolumn{2}{|c|}{$\begin{array}{l}\text { With charges for } \\
\text { depreciation. }\end{array}$} & \multirow[b]{2}{*}{$\begin{array}{l}\text { Charged } \\
\text { by es- } \\
\text { tablish- } \\
\text { ments. }\end{array}$} & \multirow[b]{2}{*}{$\begin{array}{l}\text { Esti- } \\
\text { mated. }\end{array}$} & \multirow[b]{2}{*}{ Total. } \\
\hline & & & & $\begin{array}{l}\text { As } \\
\text { charged } \\
\text { by es- } \\
\text { tablish- } \\
\text { ments. }\end{array}$ & $\begin{array}{l}\text { As } \\
\text { charged } \\
\text { and } \\
\text { esti- } \\
\text { mated. }\end{array}$ & & & \\
\hline \multirow{4}{*}{ 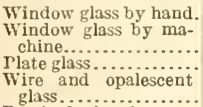 } & a 37 & $\$ 5,918,686$ & $\$ 488,000$ & $\$ 445,567$ & $\$ 315,751$ & $\$ 42,433$ & $\$ 129,816$ & $\$ 172,249$ \\
\hline & 12 & $3,368,242$ & 221,557 & 141,244 & 66,992 & 80,313 & 74,252 & 154,565 \\
\hline & & $4,930,141$ & 517,218 & 124,788 & 7,855 & 392,430 & 116,933 & 509,363 \\
\hline & 9 & $2,586,970$ & 232,208 & 142,436 & 129,108 & 89,772 & 13,328 & 103,10 \\
\hline Bottles by hand......... & a 26 & $4,969,281$ & 190,933 & 158,037 & 113,132 & 32,896 & 44,905 & 77 \\
\hline \multirow{2}{*}{$\begin{array}{l}\text { Bottles by hand and } \\
\text { machine................ }\end{array}$} & 18 & $15,359,396$ & $2,212,062$ & $1,676,603$ & $1,657,510$ & 535,459 & 19,093 & 554,5 \\
\hline & 27 & $9,856,970$ & 451,150 & 320,191 & 194,932 & 130,959 & 125,259 & 256,218 \\
\hline Jars $\ldots \ldots \ldots \ldots \ldots \ldots$ & 13 & $6,464,708$ & 509,972 & 333,471 & 326,114 & 176,501 & 7,357 & 183,8 \\
\hline \multirow{5}{*}{$\begin{array}{l}\text { Tableware, blown and } \\
\text { pressed................. } \\
\text { Lighting goods........... } \\
\text { Lamp chimneys........ } \\
\text { Miscellaneous articles.. }\end{array}$} & 8 & $1,820,229$ & 215,898 & 187,360 & 169,190 & 28,538 & 18,175 & 46,70 \\
\hline & 20 & $8,125,077$ & 358,296 & 221,045 & b 12,072 & 137,251 & 233,117 & 370,3 \\
\hline & 18 & $12,136,579$ & $1,577,037$ & $1,240,444$ & $1,163,306$ & 336,593 & 77,138 & 413,7 \\
\hline & 6 & $1,230,578$ & 55,540 & 51,940 & 35,851 & 3,600 & 16,089 & 19,689 \\
\hline & 13 & $3,151,944$ & 358,200 & 323,849 & 280,381 & 64,351 & 43,468 & 107,819 \\
\hline Total.............. & $c 213$ & $79,918,801$ & $7,418,071$ & $5,366,975$ & $4,448,050$ & $2,051,096$ & 918,925 & $2,970,021$ \\
\hline
\end{tabular}

a One plant rented; no depreciation charged. $b$ Loss.

c Two plants rented; no depreciation charged.

The amounts shown in the preceding table are given in the form of percentages in the table which follows:

Table 32.-Per Cent of Operating Profit, With and Without Depreciation Charge, Based on Net Sales, by Grdeps.

\begin{tabular}{|c|c|c|c|c|c|}
\hline \multirow{3}{*}{ Establishments manufacturing- } & \multirow{3}{*}{ Group. } & \multirow{3}{*}{$\begin{array}{c}\text { Number } \\
\text { of estab- } \\
\text { lish- } \\
\text { ments. }\end{array}$} & \multicolumn{3}{|c|}{$\begin{array}{l}\text { Per cent of operating profit on net } \\
\text { sales. }\end{array}$} \\
\hline & & & \multirow{2}{*}{$\begin{array}{l}\text { Without } \\
\text { any } \\
\text { charges } \\
\text { for depre- } \\
\text { ciation. }\end{array}$} & \multicolumn{2}{|c|}{$\begin{array}{l}\text { With charges for } \\
\text { depreciation. }\end{array}$} \\
\hline & & & & $\begin{array}{l}\text { As charged } \\
\text { by estab- } \\
\text { lishments. }\end{array}$ & $\begin{array}{l}\text { As charged } \\
\text { and esti- } \\
\text { mated. }\end{array}$ \\
\hline 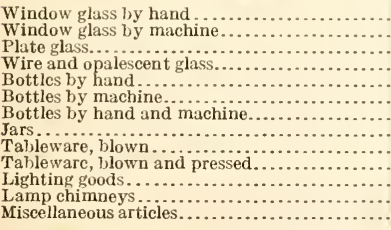 & $\begin{array}{r}11 \\
111 \\
\text { IV } \\
V \\
V 1 \\
\text { VII } \\
\text { VIII } \\
1 X \\
\text { XI } \\
\text { XII } \\
\text { XIII }\end{array}$ & $\begin{array}{r}a \\
37 \\
12 \\
6 \\
9 \\
a 26 \\
18 \\
27 \\
13 \\
8 \\
20 \\
18 \\
6 \\
13\end{array}$ & $\begin{array}{r}8.25 \\
6.58 \\
10.49 \\
8.98 \\
3.84 \\
14.40 \\
4.58 \\
7.89 \\
11.86 \\
4.41 \\
12.99 \\
4.51 \\
12.32\end{array}$ & $\begin{array}{r}7.53 \\
4.19 \\
2.53 \\
5.51 \\
3.18 \\
10.92 \\
3.25 \\
5.16 \\
10.29 \\
2.72 \\
10.22 \\
4.22 \\
10.27\end{array}$ & $\begin{array}{r}5.33 \\
1.99 \\
.16 \\
4.99 \\
2.28 \\
10.79 \\
1.98 \\
5.04 \\
9.29 \\
6.15 \\
9.59 \\
2.91 \\
8.90\end{array}$ \\
\hline Total. . & & $c 213$ & 9.28 & 6.72 & 5.57 \\
\hline
\end{tabular}




\section{CHAPTER IV.}

\section{COST AND PROFIT BY ESTABLISHMENTS.}

The 213 establishments for which data were obtained have been divided into 13 groups. The 64 establishments in Groups I to IV, inclusive, produced goods used in the building trades; the 84 establishments in Groups $\mathrm{V}$ to VIII, inclusive, produced prescription bottles, beer, soda, and whisky bottles, packers, preservers, jars, etc.; the 28 establishments in Group IX and X produced tableware, blown, pressed, and cut; the 24 establishments in Groups XI and XII produced all varieties of lighting goods, including such articles as incandescent bulbs, gas and electric globes, bowls, lantern globes, lamp chimmeys, etc.; the 13 establishments in Group XIII produced a great variety of articles, such as marbles, nest eggs, advertising novelties, specialties, chemical goods, and other articles which could not be assigned to one of the other groups.

It niust not be assumed, because an establishment was assigned to a certain group, that it produced exclusively goods of the kind described in that group. As an illustration of the method used in determining the group to which an establishment manufacturing goods of a different character should be assigned, we may take an establishment producing both tableware and lighting goods, which was not uncommon. In such a case the establishment as a whole was assigned to the group which most fairly represented the product of the establishment.

\section{COST AND PROTIT BASED ON NET SALES.}

In presenting the data secured from the 213 establishments, actual amounts are not shown by individual establishments, because by such figures it might be possible to identify establishments. The items of expense, sales value of goods produced, and the profits or losses are shown by percentages for individual establishments and by amounts, averages, and percentages for groups. In Table 33, which follows, total amounts for the various items are shown for all establishments and for each group.

For the 213 establishments, the net sales amounted to $\$ 79,918,801$; operating profit without charges for depreciation and interest, $\$ 8,247,016$; total labor and royalty on bottle machines, $\$ 32,420,970$; and total materials, $\$ 17,527,264$. These figures, taken in conjunction with census figures for 1914, which gave the value of glass products as $\$ 123,085,019$, show that about 65 per cent of the industry was covered in this investigation.

In Table 34 the amounts in Table 33 have been reduced to percentages. 


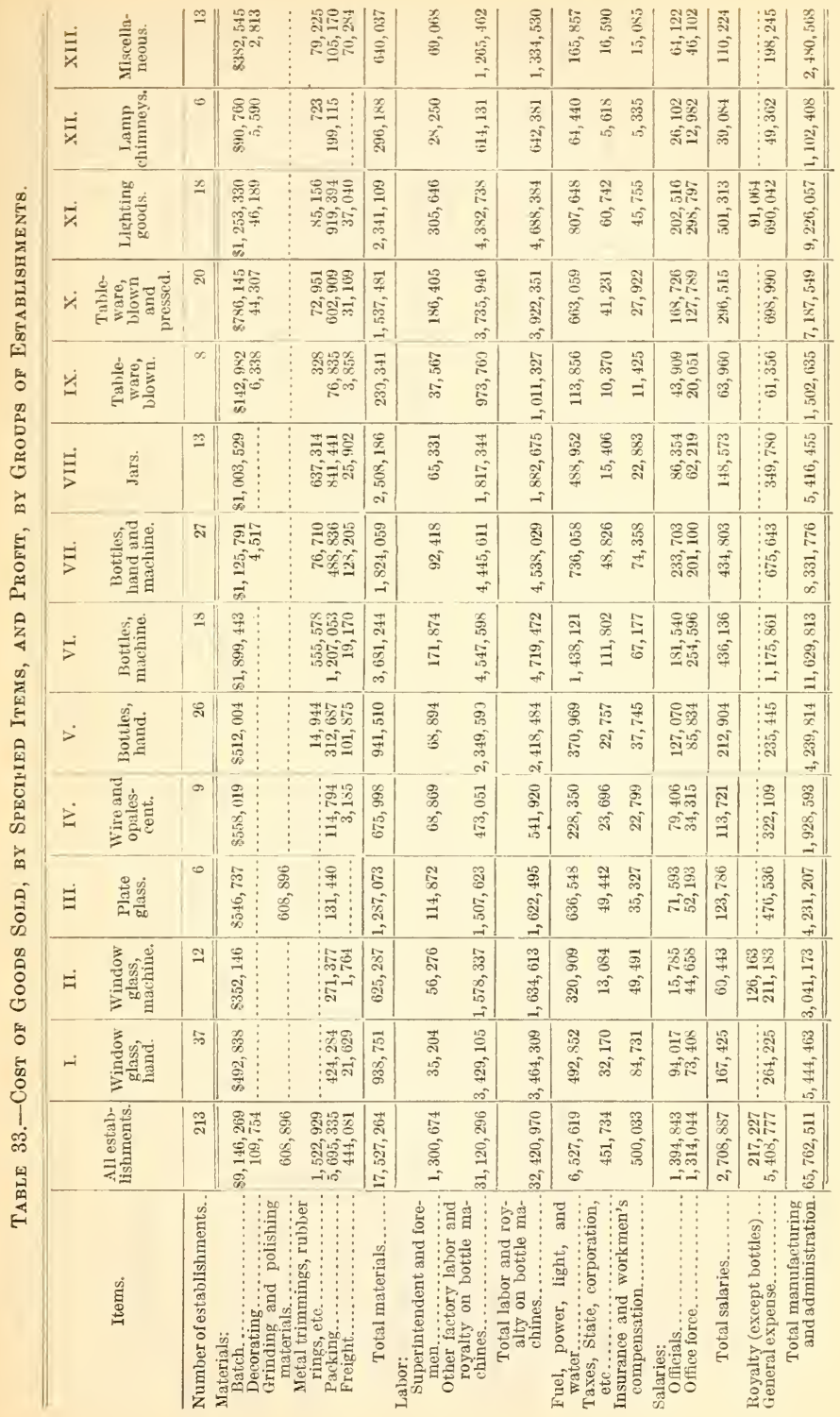




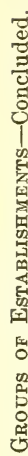

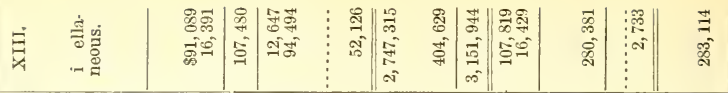

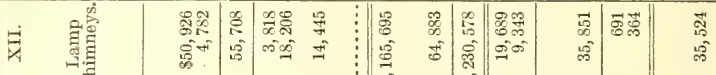

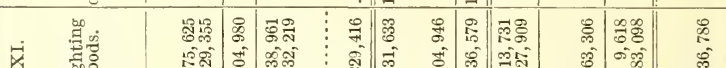

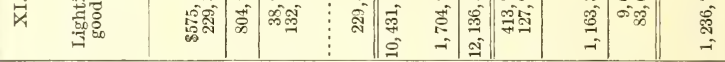

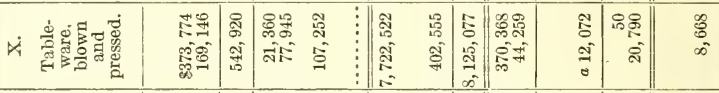

\begin{tabular}{|c|c|c|c|c|c|c|c|c|c|c|c|c|c|}
\hline & 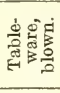 & 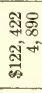 & 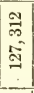 & $\begin{array}{l}298 \\
50 \\
\infty \\
\infty\end{array}$ & & & 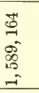 & $\frac{8}{\tilde{\sigma}}$ & 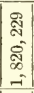 & 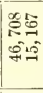 & $\begin{array}{l}\stackrel{8}{-} \\
\stackrel{\circ}{\circ}\end{array}$ & 8 & జి \\
\hline & 总 & 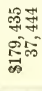 & $\mid \begin{array}{c}8 \\
\infty \\
0 \\
0 \\
\text { สี }\end{array}$ & 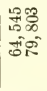 & & & $\begin{array}{l}\text { 范 } \\
\text { 今̂ } \\
0 \\
\text { in } \\
\text { in }\end{array}$ & 总 & 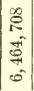 & $\mid \begin{array}{l}\infty \\
\infty \\
\infty \\
\infty \\
\infty \\
\sigma\end{array}$ & \&్లి & 溚 & ్ల్ల \\
\hline
\end{tabular}

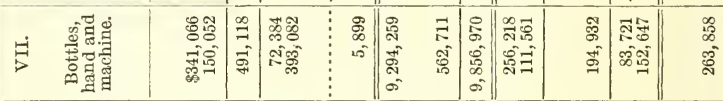

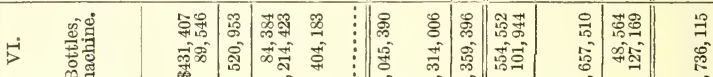

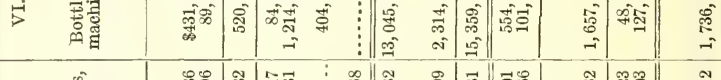

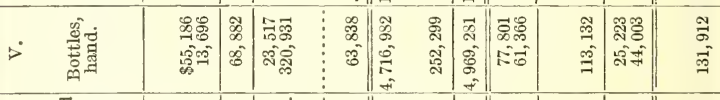

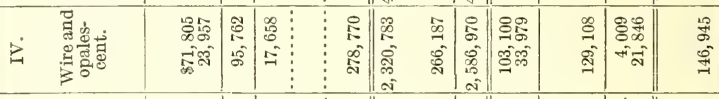

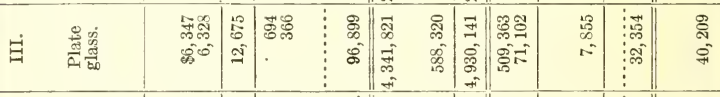

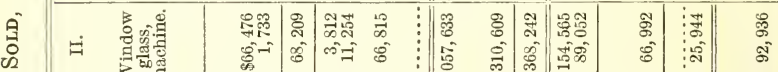

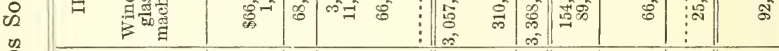

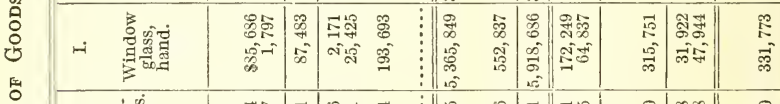

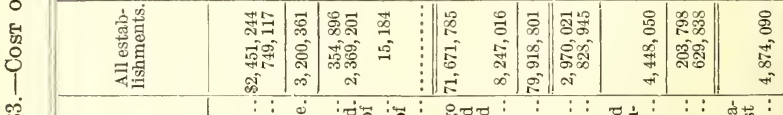

넌

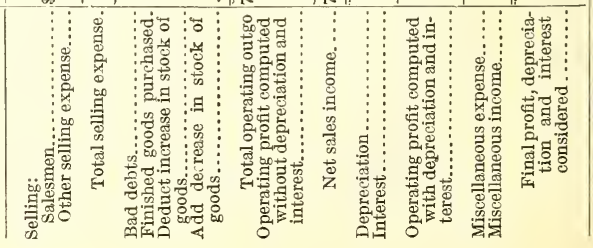




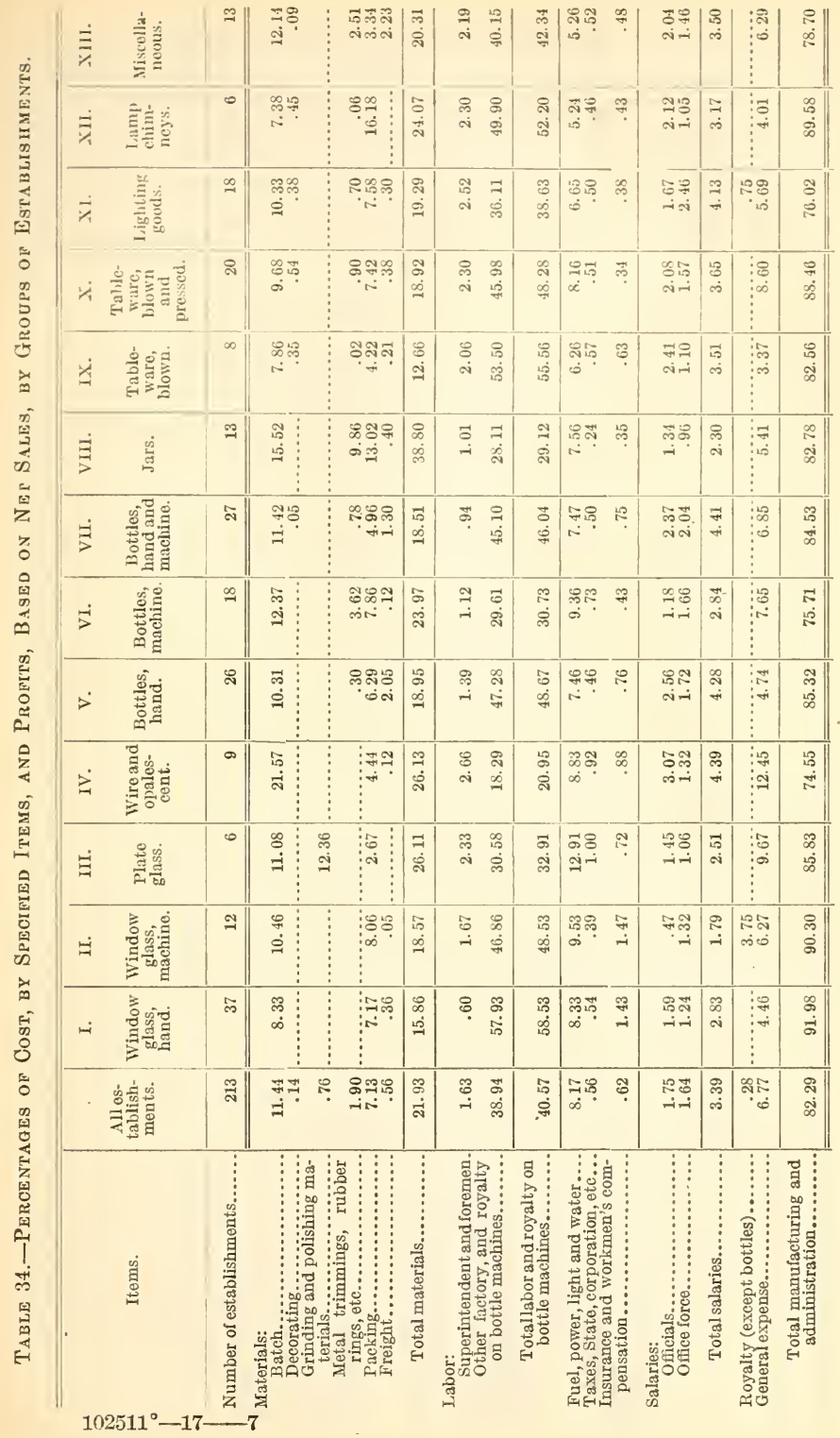




\begin{tabular}{|c|c|c|c|c|c|c|c|c|c|c|}
\hline$\exists$ & 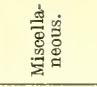 & 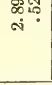 & $\begin{array}{l}F \\
\infty \\
\infty\end{array}$ & 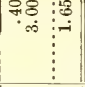 & $\mid \begin{array}{ll}1 & 0 \\
\infty & 0 \\
\infty & 2\end{array}$ & $\begin{array}{l}8 \\
\stackrel{0}{0} \\
\stackrel{0}{-1}\end{array}$ & 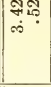 & $\begin{array}{l}8 \\
\infty \\
\infty\end{array}$ & $\stackrel{8}{0}$ & $\begin{array}{l}\mathscr{O} \\
\infty \\
\infty\end{array}$ \\
\hline$\ddot{\vec{x}}$ & 拲尚官 & $\underset{+}{J}$ & 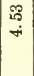 & क्क & \begin{tabular}{ll}
$\Re$ & 0 \\
\hdashline & 2
\end{tabular} & $\begin{array}{l}8 \\
\dot{8}\end{array}$ & si & के & छे़े & $\begin{array}{l}\mathscr{\infty} \\
\text { +i }\end{array}$ \\
\hline$\ddot{x}$ & 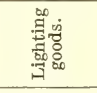 & $\begin{array}{l}\text { Ni⿱ } \\
\text { Ui- }\end{array}$ & $\begin{array}{l}80 \\
0 \\
0\end{array}$ & 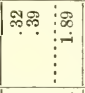 & 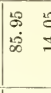 & $\begin{array}{l}8 \\
\stackrel{8}{\$}\end{array}$ & $\begin{array}{l}F=8 \\
\infty-1\end{array}$ & $\stackrel{8}{\circ}$ & $8 \%$ & $\stackrel{9}{9}$ \\
\hline & 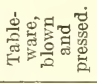 & 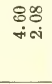 & $\begin{array}{l}\infty \\
0 \\
0\end{array}$ & क्षः & $\begin{array}{ll} & 8 \\
\dot{\delta} & \end{array}$ & $\begin{array}{l}8 \\
\dot{8} \\
\end{array}$ & 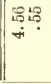 & $\stackrel{20}{9}$ & $a^{4}$ & $\exists$ \\
\hline$\ddot{\sharp}$ & 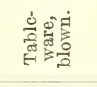 & స్ & $\begin{array}{l}\mathscr{D} \\
0 \\
0\end{array}$ & 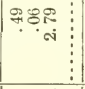 & $\mid \begin{array}{ll}-1 & 8 \\
\infty & 8 \\
\infty & ?\end{array}$ & $\begin{array}{l}8 \\
\dot{8} \\
\dot{0}\end{array}$ & $\| \hat{a}^{\infty} \infty$ & $\begin{array}{l}\stackrel{\text { A }}{ } \\
\text { के }\end{array}$ & 苛 & ळొ \\
\hline$\Xi$ & 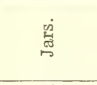 & 总品. & $\begin{array}{l}\infty \\
\infty \\
\infty\end{array}$ & 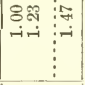 & $\begin{array}{ll}5 & 5 \\
8 & 0\end{array}$ & \begin{tabular}{l}
8 \\
$\dot{8}$ \\
\hdashline
\end{tabular} & 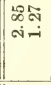 & $\begin{array}{l}\text { मे } \\
\text { is }\end{array}$ & :- & $\stackrel{2}{0}$ \\
\hline$\stackrel{\text { 皇 }}{ }$ & 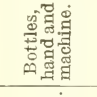 & 아몀 & $\begin{array}{l}\infty \\
\stackrel{5}{+} \\
+ \\
\end{array}$ & $\mid$\begin{tabular}{c:c}
$\Re$ \\
\hdashline
\end{tabular} & $\begin{array}{ll}2 & 7 \\
\text { i } & 4 \\
& 4\end{array}$ & $\begin{array}{l}8 \\
\dot{\Xi}\end{array}$ & 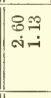 & $\stackrel{\infty}{\stackrel{\infty}{\rightarrow}}$ & $\stackrel{40.18}{\infty 08}$ & $\begin{array}{l}\infty \\
\dot{0}\end{array}$ \\
\hline$\dot{5}$ & 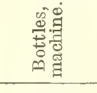 & 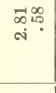 & $\begin{array}{l}\stackrel{p}{m} \\
\infty \\
\infty\end{array}$ & 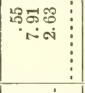 & 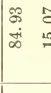 & $\begin{array}{l}8 \\
\dot{8} \\
\stackrel{-1}{1}\end{array}$ & $\mid \begin{array}{ll}-1 \\
0.0 \\
0.0\end{array}$ & $\begin{array}{l}9 \\
\stackrel{9}{9}\end{array}$ & శ్ఞొ & $\stackrel{\circ}{=}$ \\
\hline$>$ & 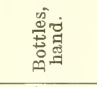 & $\begin{array}{l}z^{\infty} \\
i^{-}\end{array}$ & 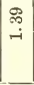 & 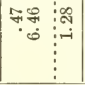 & $\begin{array}{ll}\text { क } & \alpha \\
\dot{\delta} & x\end{array}$ & $\begin{array}{l}8 \\
8 \\
8\end{array}$ & 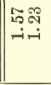 & $\begin{array}{l}\text { a } \\
\text { ง }\end{array}$ & దृं & $\begin{array}{l}\text { : } \\
\text { i }\end{array}$ \\
\hline$z$ & 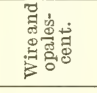 & $\begin{array}{l}\text { N: } \\
\text { ลं. }\end{array}$ & $\begin{array}{l}R \\
\infty \\
\infty\end{array}$ & 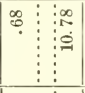 & $\mid \begin{array}{ll}\overrightarrow{1} & 8 \\
\infty & 0 \\
\infty & 9\end{array}$ & $\begin{array}{l}8 \\
8 \\
8\end{array}$ & $\mid \begin{array}{l}8 \vec{\infty} \\
\dot{\infty}-1\end{array}$ & $\stackrel{8}{\stackrel{8}{+}}$ & $\stackrel{2}{\rightarrow \infty}$ & $\begin{array}{l}\infty \\
\text { is }\end{array}$ \\
\hline$\dot{\Xi}$ & 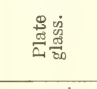 & $\Re$ & คั & 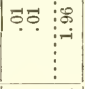 & $\mid \begin{array}{ll}0 & 8 \\
0 & 8 \\
\infty & =\end{array}$ & $\begin{array}{l}8 \\
\dot{8}\end{array}$ & 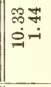 & $\stackrel{0}{?}$ & : & జ. \\
\hline$\ddot{\forall}$ & 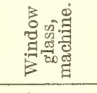 & 5. & $\mid \begin{array}{l}\text { शे } \\
\text { बं }\end{array}$ & =요 & $\mid \begin{array}{ll}\infty & \vdots \\
1 & \vdots \\
\delta & 0\end{array}$ & $\begin{array}{l}8 \\
8 \\
8\end{array}$ & 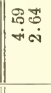 & $\stackrel{\mathscr{S}}{-}$ & 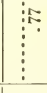 & i̊ \\
\hline$\dot{H}$ & 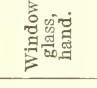 & \&̊ & $\stackrel{\infty}{\stackrel{\infty}{\leftarrow}}$ & 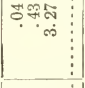 & $\begin{array}{ll}8 & 0 \\
8 & 0\end{array}$ & $\begin{array}{l}8 \\
\dot{8}\end{array}$ & 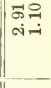 & ڤึ & एँ. & $\stackrel{8}{8}$ \\
\hline & 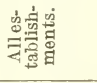 & $\begin{array}{l}\overrightarrow{0} \\
\dot{\infty}\end{array}$ & $\begin{array}{l}\overrightarrow{0} \\
\dot{\pi}\end{array}$ & सैं8ू & {$\left[\begin{array}{ll}\infty & 8 \\
\infty & 0 \\
\infty & 5\end{array}\right.$} & $\begin{array}{l}8 \\
8 \\
0\end{array}$ & $\mid \begin{array}{l}F+5 \\
\infty \\
\infty\end{array}$ & 25 & |ำ & $\begin{array}{l}\circ \\
0\end{array}$ \\
\hline & 离 & 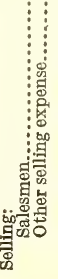 & 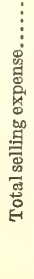 & 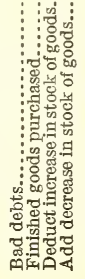 & 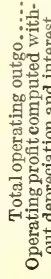 & 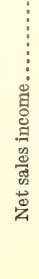 & 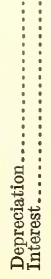 & 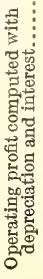 & 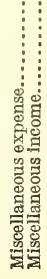 & 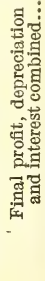 \\
\hline
\end{tabular}




\section{COST AND PROFIT BASED ON SALES VALUE OF GOODS PRODUCED.}

The percentages in the preceding table will not correspond to the percentages shown in Tahle 36 , which also shows percentages of cost and profit for all establishments and by groups. In Table 34 the percentages are based on net sales and in Table 36 they are based on the sales value of goods produced. Thile at first glance the base used in each table appears to be the same, it is different, as explained below. The same general conditions applying to both tables, no discussion is made of the former.

\section{METHOD OF DETERMINING SALES VALUE OF GOODS.}

Up to this point the items of cost have been shown as they appear on the books of the various establishments. Table 33 gives actual returns for all establishments and for establishments in the various groups. Table 34 shows in the form of percentages the relation of each item to the total net sales.

It is necessary now to go a step further and segregate the items of cost pertaining to the goods produced. In order to accomplish this certain adjustments are necessary. The original returns show for example the selling expenses, the loss from bad debts, and the operating profit. All of these items are strictly speaking dependent on the amount of goods sold rather than the amount of goods produced. To get the amount properly chargeable to goods produced, it is necessary to increase proportionately the selling expenses, bad debts, and profits, when the amount of goods produced exceeds the amount sold, and to decrease proportionately these items, when the amount of goods sold exceeds the amount of goods produced.

From the books of the establishments are ascertained the cost of the goods produced within the business year, the cost of the goods purchased, and the increase or decrease in the stock of goods on hand (unsold) at the end of the period as compared with the beginning of the period. Goods produced and goods purchased, increased or decreased by the change in the inventory, gives the cost of the goods sold. If the stock has increased during the business year, more goods have been produced than have been sold and accordingly the difference must be subtracted. If, on the other hand, the inventory shows a decrease in stock, more goods have been sold than were produced within the period under consideration, and accordingly the difference must be added.

Since selling expense and bad debts are incurred on the total amount of goods sold and the profit is obtained on the entire amount of goods sold, it is fair to adjust these figures in the ratio of goods produced to goods sold. The process can be made much clearer by an illustration. The data are hypothetical, but correspond more or less closely to returns from a number of establishments. The figures printed in roman type are obtainable directly from the books of the establishments, while derived figures are printed in italics. The problem is to ascertain from the original returns the amounts chargeable to goods produced during the business year. 


\begin{tabular}{|c|c|c|c|c|c|}
\hline Items. & \multicolumn{2}{|c|}{$\begin{array}{l}\text { Manufacturing and } \\
\text { administrative cost. }\end{array}$} & \multirow{2}{*}{$\begin{array}{c}\begin{array}{c}\text { Selling } \\
\text { expense } \\
\text { and bad } \\
\text { debts. }\end{array} \\
\text { Dollars. } \\
\text { 31,029 } \\
441 \\
-1,470\end{array}$} & \multirow{2}{*}{$\begin{array}{l}\text { Profit. } \\
\begin{array}{r}\text { Dollars. } \\
103,4 \$ 0 \\
1,470 \\
-4,900\end{array}\end{array}$} & \multirow{2}{*}{$\begin{array}{c}\begin{array}{c}\text { Sales } \\
\text { value. }\end{array} \\
\begin{array}{r}\text { Dollars. } \\
1,190,479 \\
16,920 \\
-56,399\end{array}\end{array}$} \\
\hline 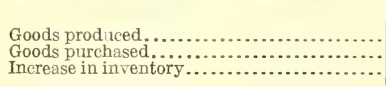 & $\begin{array}{r}\text { Dollars. } \\
1,056,000 \\
15,000 \\
-50,000\end{array}$ & $\begin{array}{r}\text { Per cent. } \\
103.49 \\
1.47 \\
-4.90\end{array}$ & & & \\
\hline 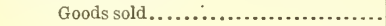 & $1,021,000$ & 100.00 & 30,000 & 100,000 & $1,151,000$ \\
\hline
\end{tabular}

In this particular case the cost of the goods produced exceeded the cost of the goods sold by 3.43 per cent. The selling expenses, bad debts, and profit, as taken from the books, have therefore been increased in the same proportion.

If the stock on hand had decreased $\$ 50,000$ instead of increased by that amount-or, in other words, if $\$ 50,000$ worth of goods more had been sold than were purchased or produced-the total value of goods sold during the business year would have been $\$ 1,121,000$. In that case the cost of the goods produced would represent only 94.2 per cent of the cost of the goods sold, and accordingly the selling expenses, bad debts, and profits would have to be reduced 5.8 per cent.

The adjusted items for the establishments in each group were added to obtain the group averages shown in Table 35.

\section{AVERAGE PRODUCTION COSTS BY GROUPS.}

In Table 35, which follows, data are presented in the form of averages for all establishments and for groups of establishments. Examination of this table shows that the average sales value of goods produced per establishment was over $\$ 500,000$ in only three groups, being $\$ 800,985, \$ 805,088$, and $\$ 648,711$, respectively, in factories making plate glass, Group III, those making bottles by machine, Group VI, and in those making lighting goods, Group XI. Of the remaining groups, two had an average of $\$ 400,000$ to $\$ 500,000$, one between $\$ 300,000$ and $\$ 400,000$, five between $\$ 200,000$ and $\$ 300,000$, and two between $\$ 100,000$ and $\$ 200,000$.

The average operating profit with charges for depreciation and interest was \$20,199 for all establishments. Group III, plate glass, with next to the largest average sales value of goods produced, showed an average loss per establishment of $\$ 3,084$. Group VI, bottles made by machine, with $\$ 93,459$, showed the highest average profit per establishment. Elsewhere in this report are tables showing percentages based on sales value of goods produced and on investment, which are better guides to the amount of profit earned in the various groups or in individual establishments.

In the series of 14 tables, 36 to 49, inclusive, the sales value of goods produced is used as the basis. As has just been explained, this figure is derived by adding to the actual cost of goods produced the selling expenses and bad debts properly chargeable to such goods and also the profit attributable to such goods. This basis has a distinct advantage over that used in previous reports of the cost of production division-the cost of goods produced. According to the new basis, the value rather than the cost of the output is the criterion. 
The sales value is obriously substantially the same, quality for quality, in different establishments, while the cost may differ widely. The new basis, therefore, makes it possible to show not merely the relative outlay for different items of expense but also differences in total cost for the rarious establishments.

Table 36 shows percentages based on the sales ralue of goods produced for the various items of cost, for the operating profit computed without and with depreciation and interest, and for the final profit by establishments grouped according to the character of the goods produced. 


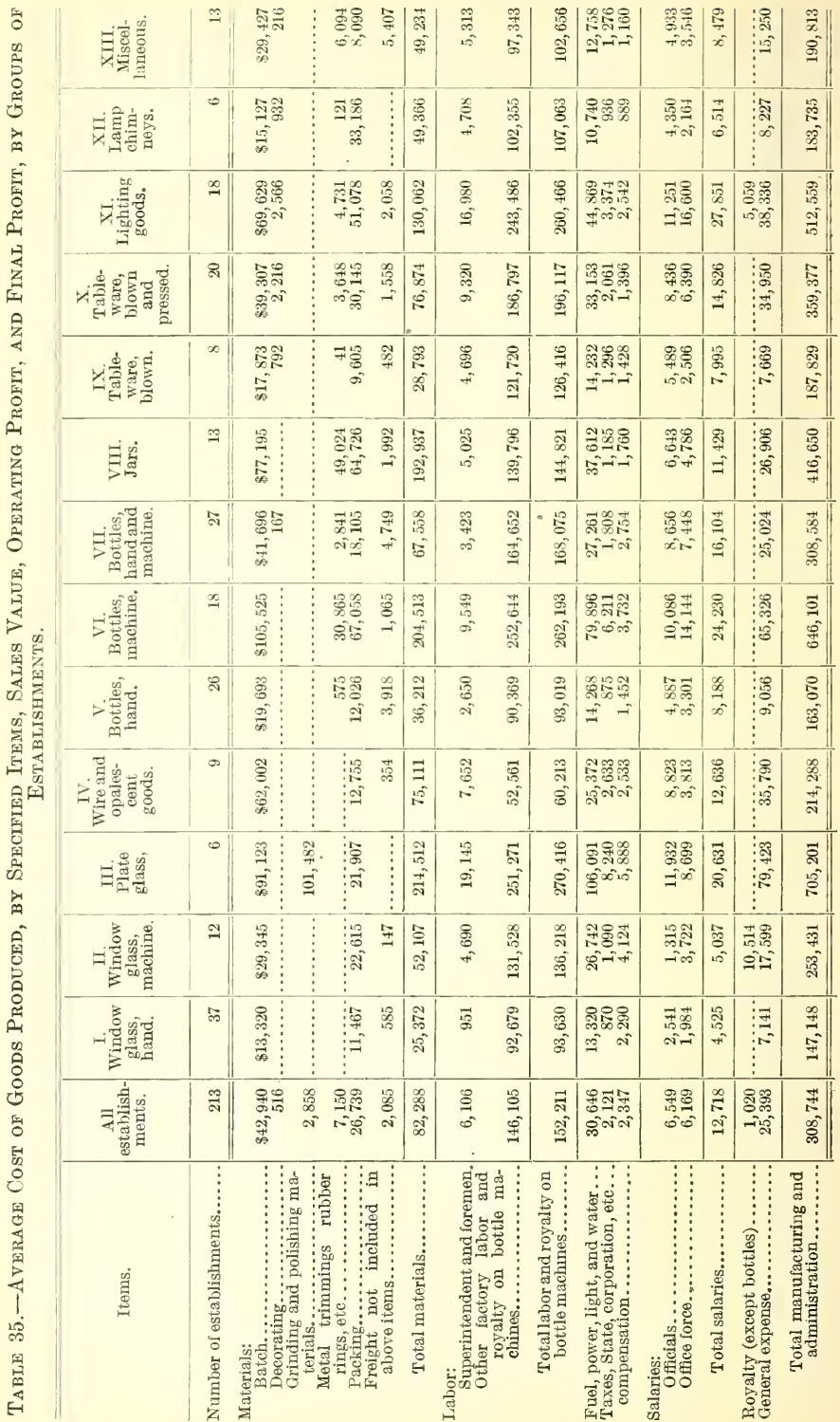




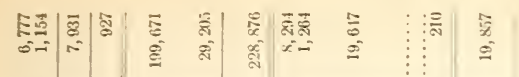

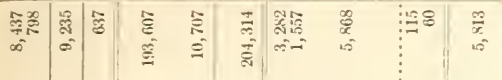

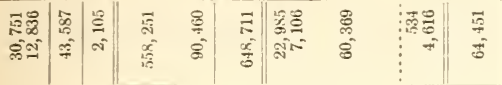

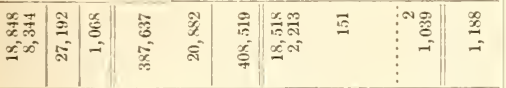

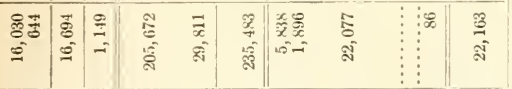

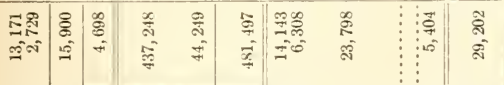

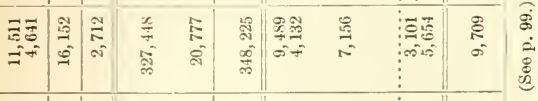

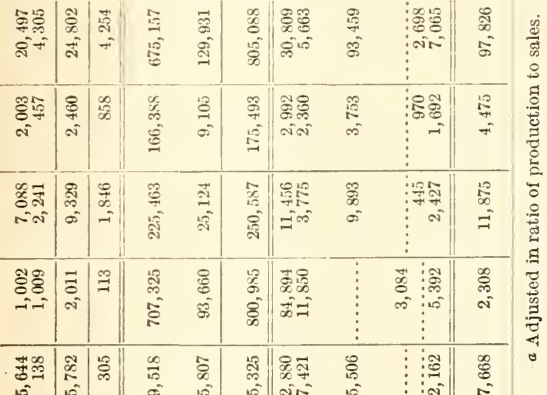

\begin{tabular}{|c|c|c|c|c|c|c|c|c|c|}
\hline $\begin{array}{l}\text { ప్ల్లణ } \\
\text { స్ }\end{array}$ & $\mid$\begin{tabular}{c|}
20 \\
7 \\
-5
\end{tabular} & is & 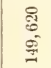 & $\begin{array}{l}\overrightarrow{\text { ते }} \\
\dot{\Delta}\end{array}$ & $\begin{array}{c}\overrightarrow{\tilde{x}} \\
\overrightarrow{\underline{\theta}} \\
\underline{\underline{\theta}}\end{array}$ & 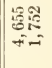 & $\begin{array}{l}\vec{\pi} \\
\infty \\
\infty\end{array}$ & \begin{tabular}{l} 
: \\
$\vdots$ \\
\hdashline
\end{tabular} & $\begin{array}{l}0 \\
\text { i⿱ } \\
\text { के }\end{array}$ \\
\hline $\begin{array}{l}\bar{b} .0 \\
\text { sm }\end{array}$ & $\begin{array}{l}\infty \\
\text { a } \\
\vec{I}\end{array}$ & 总 & $\begin{array}{l}\overrightarrow{0} \\
\vec{D} \\
\vec{ٍ}\end{array}$ & 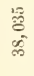 & 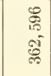 & 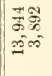 & $\frac{8}{\stackrel{8}{\circ}}$ & 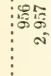 & $\begin{array}{l}\text { छิ } \\
\text { న్ }\end{array}$ \\
\hline 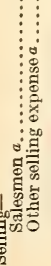 & 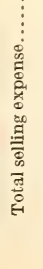 & 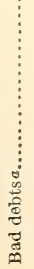 & 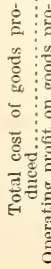 & 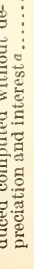 & 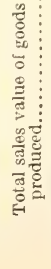 & 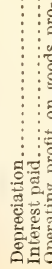 & 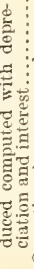 & 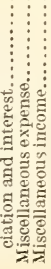 & 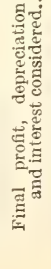 \\
\hline
\end{tabular}




\begin{tabular}{|c|c|c|c|c|c|c|c|c|c|c|c|c|c|c|c|}
\hline 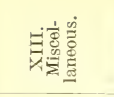 & $\cong$ & $\begin{array}{l}18 . \\
\text { ㄱ. }\end{array}$ & & $\begin{array}{l}80.5 \\
\text { in }\end{array}$ & $\begin{array}{l}\infty \\
i \\
i\end{array}$ & $\left|\begin{array}{l}\vec{b} \\
\vec{a}\end{array}\right|$ & ल્ळ & $\begin{array}{l}\text { ชุ } \\
\text { มุ่ }\end{array}$ & $\begin{array}{l}\infty \\
\neq \\
\neq\end{array}$ & 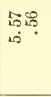 & $\overrightarrow{6} \mid$ & $\begin{array}{l}0.15 \\
\text { sit. }\end{array}$ & 站 & $\begin{array}{l}8 \\
0 \\
0\end{array}$ & $\begin{array}{l}\hat{m} \\
\ddot{\infty}\end{array}$ \\
\hline 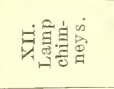 & $\infty$ & 윤? & & 8 중 & $\begin{array}{c}\vdots \\
\vdots \\
\vdots\end{array}$ & $\mid \begin{array}{l}\mathscr{0} \\
\stackrel{\text { जे }}{ }\end{array}$ & ๙ి & $\begin{array}{l}0 \\
0 \\
0\end{array}$ & $\begin{array}{l}\text { 아 } \\
\text { ํ. }\end{array}$ & is? & $\Re$ & 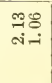 & 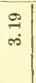 & $\vdots$ & $\begin{array}{l}\mathscr{\wp} \\
\infty \\
\infty\end{array}$ \\
\hline 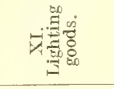 & $\stackrel{\infty}{\sim}$ & 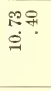 & & ?ִ & థ్లి & $\mid \begin{array}{c}3 \\
\stackrel{3}{\mathrm{~m}} \\
\end{array}$ & $\begin{array}{l}\text { ஜ્ } \\
\text { ๙i }\end{array}$ & 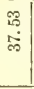 & $\stackrel{2}{\stackrel{0}{0}}$ & 용. & है। & $\begin{array}{l}\text { श: } \\
\text {-ici }\end{array}$ & 胥 & $\stackrel{0}{\circ}$ & $\overrightarrow{0}$. \\
\hline 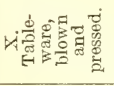 & สิ & 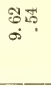 & & 趈 & $\stackrel{\infty}{\infty}$. & $\mid \begin{array}{l}\vec{\infty} \\
\infty \\
-1\end{array}$ & $\begin{array}{l}\text { a } \\
\text { ai }\end{array}$ & 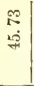 & $\begin{array}{l}\overrightarrow{6} \\
\dot{\phi} \\
\dot{\phi}\end{array}$ & $\begin{array}{l}\text { ज्ञ } \\
\infty^{\circ} .\end{array}$ & $\vec{\oplus}$ & $\begin{array}{l}\text { Sof } \\
\text { if } \\
\text { if }\end{array}$ & \begin{tabular}{|l|}
$\qquad$ \\
$\dot{b}$ \\
$\dot{\infty}$
\end{tabular} & $\begin{array}{l}\vdots \\
\vdots \\
\infty \\
\infty \\
\infty\end{array}$ & $\begin{array}{l}\mathbf{5} \\
\dot{\infty} \\
\dot{\infty}\end{array}$ \\
\hline 逍 & $\infty$ & 䓟 & & 88 & สิ & $\mid \begin{array}{l}\approx \\
\stackrel{2}{ } \\
\simeq\end{array}$ & $\stackrel{8}{\stackrel{8}{-}}$ & $\begin{array}{c}8 \\
\dot{B}\end{array}$ & $\begin{array}{l}\infty \\
8 \\
\varnothing 0 \\
0 \\
0\end{array}$ & $\begin{array}{l}\overrightarrow{0}: 2 . \\
0 \\
0\end{array}$ & $\ddot{6}$ & $\begin{array}{l}\text { ๓⿴囗十 } \\
\text { ஸं- }\end{array}$ & $\mid$\begin{tabular}{l|}
$\infty$ \\
$\infty$ \\
$\infty$ \\
$\infty$
\end{tabular} & : & $\begin{array}{l}0 \\
0 \\
0\end{array}$ \\
\hline 7 & $\cong$ & $\begin{array}{l}\stackrel{8}{0} \\
\dot{0}\end{array}$ & & 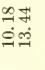 & भै & 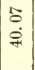 & $\stackrel{\overrightarrow{0}}{-}$ & $\begin{array}{l}\overrightarrow{0} \\
\stackrel{\mathrm{d}}{\mathbf{N}}\end{array}$ & $\begin{array}{l}\infty \\
\stackrel{\infty}{\circ} \\
\dot{\infty}\end{array}$ & 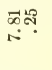 & $\stackrel{\oplus}{\circ}$ & $\underset{-i}{\infty}$ & $\mid \begin{array}{c}\vec{\infty} \\
\dot{\omega} \\
\dot{\omega}\end{array}$ & $\begin{array}{l}\vdots \\
\vdots \\
\vdots \\
\vdots \\
\vdots\end{array}$ & 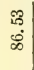 \\
\hline 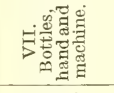 & s & S. & & ભ & $\stackrel{\infty}{-}$ & 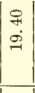 & $\stackrel{\infty}{\circ}$ & $\begin{array}{l}\text { \&্ } \\
\stackrel{H}{4}\end{array}$ & $\begin{array}{l}\hat{A} \\
\infty \\
\alpha\end{array}$ & B. & : & 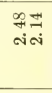 & : & : & $\begin{array}{l}\mathscr{0} \\
\infty \\
\infty\end{array}$ \\
\hline ए蒂 & $\stackrel{2}{\sim}$ & $\begin{array}{l}\exists \\
\stackrel{9}{9}\end{array}$ & & $\begin{array}{l}\infty \infty \\
\infty \infty \\
\infty \infty \infty \\
\infty \infty\end{array}$ & $\cong$ & 要 & $\stackrel{9}{-}$ & $\begin{array}{l}\infty \\
\stackrel{\infty}{-\infty} \\
\dot{\infty}\end{array}$ & 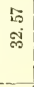 & $\mid \begin{array}{l}\sin ^{2} \\
\sin ^{\circ}\end{array}$ & +ै & ARR & \begin{tabular}{|l|}
$\vec{b}$ \\
$\dot{\infty}$
\end{tabular} & : & $\begin{array}{l}\text { a़े } \\
\dot{\infty}\end{array}$ \\
\hline$>$ की & ลิ & $\begin{array}{l}\mathcal{F} \\
=\end{array}$ & & 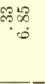 & $\begin{array}{l}\text { ָุ } \\
\text { s }\end{array}$ & : & $\stackrel{\text { है }}{-1}$ & 염 & 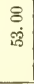 & $\infty_{\infty}^{\infty}$ & $\infty_{\bullet}^{\infty}$ & 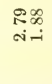 & 苟 & $\begin{array}{c}0 \\
\vdots 0 \\
0\end{array}$ & $\begin{array}{l}\mathscr{\delta} \\
\text { \& } \\
\text { S }\end{array}$ \\
\hline 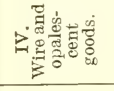 & 0 & $\frac{\pi}{i}$ & & $\begin{array}{c}\phi 9 \\
\vdots \\
\vdots\end{array}$ & \pm & 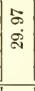 & $\begin{array}{l}\text { ig } \\
\text { is }\end{array}$ & $\begin{array}{l}\mathscr{\infty} \\
\stackrel{5}{1} \\
\text {. }\end{array}$ & $\begin{array}{l}\approx \\
+ \\
+\end{array}$ & $\begin{array}{l}29 \\
99 \\
9-1\end{array}$ & $\begin{array}{l}\overrightarrow{0} \\
-i\end{array}$ & 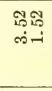 & $\mid \begin{array}{l}\mid \overrightarrow{0} \\
\text { is }\end{array}$ & : & $\begin{array}{l}\overrightarrow{60} \\
20\end{array}$ \\
\hline 园产 & 0 & $\begin{array}{l}\infty \\
\infty \\
=\end{array}$ & 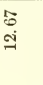 & 初 & $\vdots$ & $\mid$\begin{tabular}{l}
$\infty$ \\
0 \\
\hdashline \\
\hdashline
\end{tabular} & $\begin{array}{l}\mathscr{c} \\
\text { ci }\end{array}$ & $\begin{array}{l}\hat{\infty} \\
\vec{m}\end{array}$ & $\begin{array}{l}\stackrel{0}{0} \\
\infty\end{array}$ & 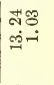 & ? & 아욤 & $\mid \begin{array}{l}\infty \\
i b \\
\text { oi }\end{array}$ & 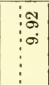 & $\begin{array}{l}\vec{\vdots} \\
\dot{\infty} \\
\infty\end{array}$ \\
\hline 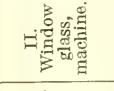 & $\cong$ & $\begin{array}{l}\stackrel{\infty}{a} \\
\stackrel{-}{=}\end{array}$ & & 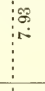 & $\stackrel{18}{9}$ & $\mid \begin{array}{c}8 \\
a \\
\infty \\
-1\end{array}$ & $\stackrel{\overrightarrow{0}}{-1}$ & $\begin{array}{c}\stackrel{9}{1} \\
\stackrel{0}{+1}\end{array}$ & 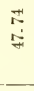 & $\begin{array}{c}\infty \\
\infty \\
\infty \\
\infty\end{array}$ & $\stackrel{2}{-1}$ & $\stackrel{\mathscr{\vartheta}}{\mathscr{\mu}}$ & 点 & $\begin{array}{l}\infty \pi \\
80 \\
\infty \theta 0\end{array}$ & $\begin{array}{l}\infty \\
\infty \\
\infty \\
\infty\end{array}$ \\
\hline - & స్ & $\stackrel{\leftrightarrow}{\infty}$ & & $\begin{array}{l}\mathscr{8} \\
0 \\
0\end{array}$ & ?ִ & $\begin{array}{l}\mathscr{8} \\
\stackrel{2}{2} \\
\stackrel{2}{2}\end{array}$ & 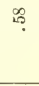 & $\begin{array}{l}\text { สิ } \\
\text { : }\end{array}$ & $\begin{array}{l}\nexists \\
\infty \\
\stackrel{0}{0}\end{array}$ & 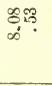 & 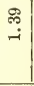 & 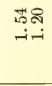 & $\mid \begin{array}{l}\hat{N} \\
\text { â }\end{array}$ & 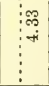 & $\begin{array}{l}\text { \& } \\
\stackrel{\infty}{\infty}\end{array}$ \\
\hline 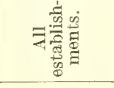 & 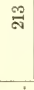 & $\begin{array}{l}\infty \pm 0 \\
\stackrel{\infty}{=}\end{array}$ & $\stackrel{9}{?}$ & $\begin{array}{l}\text { s.m } \\
\text { - }\end{array}$ & 年. & $\begin{array}{l}R \\
\text { ลี } \\
\text { N }\end{array}$ & $\stackrel{8}{-}$ & $\begin{array}{l}\text { \&े } \\
\text { +े }\end{array}$ & $\begin{array}{l}\stackrel{\infty}{\circ} \\
\dot{7}\end{array}$ & 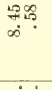 & 8 & $\begin{array}{l}\text { 요 } \\
\text { - }\end{array}$ & $\begin{array}{l}\overrightarrow{5} \\
\ddot{n}\end{array}$ & 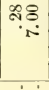 & $\stackrel{20}{20}$ \\
\hline
\end{tabular}
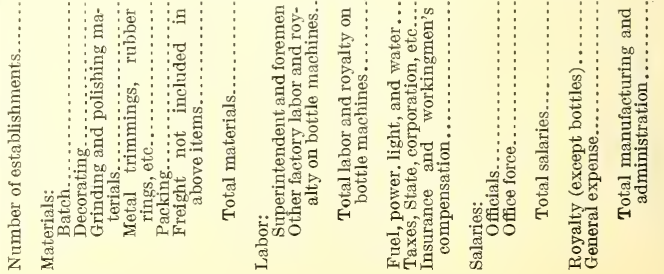


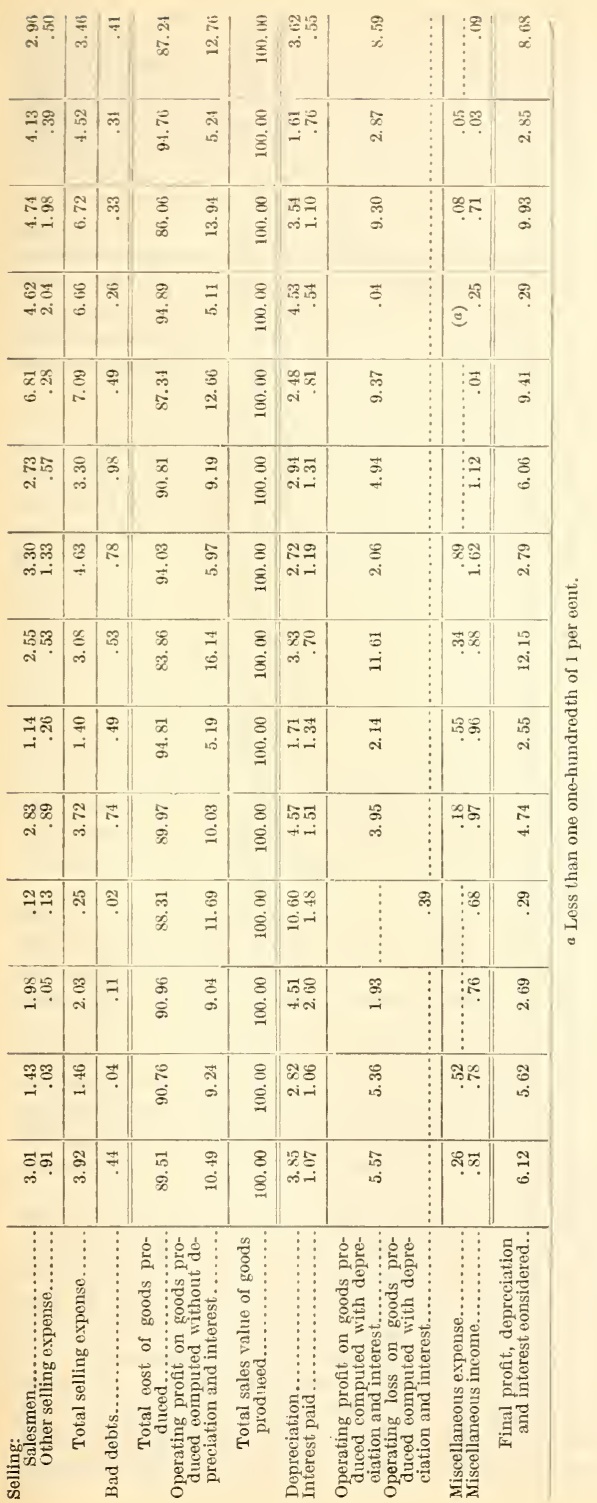




\section{MATERIALS.}

An interesting feature brought out by the above table is the differences in the percentages for total cost of materials in the different groups. In four groups-factories making window glass by hand, Group I; window glass by machine, Group II; blown tableware, Group IX; and blown and pressed tableware, Group Xthe percentages show relatively low costs for materials, which reflects a natural condition, inasmuch as the establishments in these groups produced light-weight goods as compared with the establishments in the other groups, and for every pound of glass used they obtained proportionately a greater number of units than those establishments producing heavier goods. This was especially true of blown tableware group, and would be true in Group XII, lamp chimneys, were it not for the exceptionally high cost of packing materials.

Of the groups showing relatively high percentages of cost for materials, those making jars, Group VIII, with 40.07 per cent, and wire and opalescent goods, Group IV, with 29.97 per cent, showed the highest percentage of cost and were the only groups in which the percentage of cost for materials was greater than the percentage of cost for labor. An examination of the items of materials in Group VIII will show that this high cost was due principally to the large amount of metal trimmings, rubber rings, etc., and packing materials required by establishments producing this class of goods, and in Group IV it was due to the high cost of batch, which in some establishments included wire. Other groups showing relatively high percentages of cost for materials were those making plate glass, Group III, and bottles by machine, Group VI. These groups showed relatively low percentages of cost for labor, and as materials assume greater importance in those establishments producing heavy-weight goods than in those producing light-weight goods, it follows that the percentages for materials must be higher and the percentages for other items must be lower.

Of the different items under materials the percentages for batch were more than one-half the total cost of materials, except for establishments making jars, Group VIII, and lamp chimneys, Group XII. Attention has already been called to the high percentages for packing materials in these two groups and for metal trimmings, rubber rings, etc., in Group VIII. In wire and opalescent goods, Group IV, the percentage for batch was considerably above the average for all groups, being slightly more than twice the average. This high percentage of cost is due largely to the heavy character of the goods produced and partly to the inclusion by some establishments of wire with batch materials.

The next item after batch in importance was packing, with an average of 7.38 per cent of the total sales value of goods produced and a range of 2.73 per cent for plate glass, Group III, to 16.24 per cent for lamp chimneys, Group XII. When the difference in the manner of packing plate glass and lamp chimneys is taken into consideration, this wide variation presents no unusual feature.

The remaining items under materials were relatively of little importance, but the item of freight requires some explanation. In some establishments the books did not show freight separately and it became part of the cost of the materials. In other establishments 
distinction was made only between incoming freight and outgoing freight, and no attempt was made by such establishments to charge the different materials with their proportion of freight. The percentages for freight as reported in this table and the tables which follow therefore represent only that portion of incoming freight which was not distributed to other items under materials.

\section{LABOR.}

In tables showing percentages for the various items of cost, whether based on the total cost of manufacture, net sales, or value of product, perhaps no item receives more attention than that of labor. When it is taken into consideration that only about 2.7 per cent of the industries in the United States, producing slightly over 3 per cent of the total value of products, show a labor cost, based on the value of products, of orer 40 per cent, and that the glass industry is included in the above group, one fully realizes the important part that labor takes in the costs of this industry.

In previous reports on cost of production issued by the Bureau of Foreign and Domestic Commerce, the percentages of costs for labor, based on net sales, were: 23.14 per cent in the knit-underwear industry: 22.07 per cent in the women's muslin-underwear industry; 25.77 per cent in the hosiery industry; 30.69 per cent and 27.05 per cent, respectively, for collars or shirts and collars, and for shirts, in the shirt and collar industries; and 31.23 per cent in the men's factory-made clothing industry. In the pottery industry the labor cost was 58.81 per cent of the total manufacturing cost, including decorating but excluding packing and selling expense, 50.49 per cent of the aggregate cost, and 46.03 per cent of the net value of the product. These percentages would be somewhat higher were packing labor included as part of the manufacturing labor.

It was not thought necessary to show labor by departments, and the only division made is between supervisory labor and other factory labor. Other factory labor includes direct and indirect, productire and nonproductive, skilled and unskilled-in fact, all labor which could not be assigned to supervision. In addition, other factory labor in making bottles by machine, Group VI, bottles by hand and machine, Group VII, and jars, Group VIII, includes royalty on machines. The principal reason for including royalty with labor was to avoid the possibility of disclosing the identity of individual establishments using certain automatic machines. The item "Superintendent and foremen" includes in some instances only part of the salaries of officials who devoted only a part of their time to the factory end of the business, provided an equitable basis for the distribution of salaries of such officers was furnished.

Excluding royalty from the total labor cost the percentages would read: 40.26 per cent for all establishments reporting; 25.04 per cent for bottles by machine, Group VI; 48.04 per cent for bottles by hand and machine, Group VII; and 28.91 per cent for jars, Group VIII. In other words, the percentages for royalty on machines were, respectively, $1.72,7.53,0.23$, and 1.17 of the sales value of the goods produced for all establishments and the groups specified above.

Another method of presenting data relating to royalty on machines without violating any confidences or disclosing the identity of estab- 
lishments is to show the percentage that royalty on machines is of total labor, including royalty. If based on actual figures, the percentages would be for all establishments reporting, 3.66; for Group VI, bottles by machine, 23.12 ; for Group VII, bottles by hand and machine, 0.47; for Group VIII, jars, 3.9.

The difference in the labor costs between handmade and machinemade goods is strikingly brought out by the percentages for window glass, Groups I and II. In Group I, handmade, the labor cost was 56.8 per cent of the selling value of goods produced, and in Group II, machine made, 47.74 per cent. This difference is even more strikingly shown by the percentages for bottles, Groups V to VII, inclusive. The percentages showing labor costs decreased inversely in proportion to the extent that automatic machines were employed in the production of bottles, the percentages being 53, 48.27, and 32.57, respectively, for bottles by hand, bottles by hand and machine, and bottles by machine. Should the percentages for royalty be deducted from the two machine groups, the variation in the labor costs would be more marked. The low labor cost in Group VIII, jars, was also due partly to the use of automatic machines.

Another interesting comparison is that between those branches of the industry employing a comparatively large amount of skilled labor and those branches employing a comparatively small amount of skilled labor. Included in the former mention may be made of factories making window glass by hand, bottles by hand, blown tableware, and lamp chimneys, with percentages for total labor of $56.8,53,53.68$, and 52.4 , respectively; and included in what may be termed the unskilled labor groups are factories making plate glass, wire and opalescent goods, bottles by machine, and jars, with percentages for total labor of $33.76,24.03,32.57$, and 30.08 , respectively; leaving in between the pronounced skilled and unskilled labor groups the factories making window glass by machine, bottles by hand and machine, blown and pressed tableware, lighting goods, and miscellaneous articles, with percentages for total labor of $47.74,48.27,48.01,40.15$, and 44.85, respectively. At first glance it would seem that the lower percentage for labor depended almost entirely upon the use of automatic machines. This, however, was not true, for certain types of machines used can not be classed as automatic, and the lower labor costs in plate glass, Group III, wire and opalescent goods, Group IV, and lighting goods, Group XI, must be ascribed to the unskilled character of the work and not to the use of automatic machines.

The labor cost was found to be highest in window glass made by hand, Group I, 56.8 per cent; lowest in wire and opalescent goods, Group IV, 24.03 per cent; and the average for all establishments reporting was 41.98 per cent of the sales value of goods produced. Eight groups showed a higher labor cost than the average for all establishments, four of them having a labor cost of more than 50 per cent of the sales value of the goods produced, and five groups showed a lower labor cost than the average.

In no group was the percentage for superintendent and foreman above 3.05, and it is interesting to note that this occurred in Group IV, wire and opalescent goods, which had the lowest total labor cost. The average for all establishments was 1.69 per cent; the lowest was 0.58 per cent, in Group I, window glass by hand, which had the highest total labor cost. 
FUEL, ETC.

The item fuel, power, light, and water, next to materials and labor. showed the greatest percentage of cost based on the sales value of goods produced, except in establishments making wire and opalescent goods, Group IV, in which the item general expense was about 2.5 per cent higher.

The variation in percentages for fuel, power, light, and water may be due to several reasons, chief among which may be mentioned: (1) Difference in cost of natural gas; (2) character of glass producedthat is, the plate-glass branch of the industry may require more gas per unit for the fusion of materials than another branch; (3) use of tanks or pots, the fusion of the materials being accomplished in the former by direct contact with the flame of the gas, while in the latter the combustion is outside the pot and the heat must radiate through the pot to accomplish the fusion of materials; and (4) whether producer or natural gas is used.

The arerage for all establishments was 8.45 per cent; the highest, 13.24 per cent, was in Group III, plate glass, and lowest, 5.26 per cent, in Group XII, lamp chimneys. Four groups were above the average for all establishments and nine below.

TAXES AND INSURANCE.

Taxes and insurance were relatively unimportant items. The average expenditure for taxes by all establishments was 0.58 per cent, with a range for the different groups from the lowest, 0.25 , in jars, Group VIII, to the highest, 1.05, in wire and opalescent goods, Group IV. For insurance the average was 0.65 per cent, the percentages in the groups ranging from the lowest, 0.34 , in blown and pressed tableware, Group $\mathbf{X}$, to the highest, 1.45, in window glass made by machine, Group II.

\section{SALARIES.}

It has been previously explained that salaries of officials have in some instances been partly assigned to superintendent and foremen, under labor. A further distribution was made of salaries of officials in establishments where some of the officers devoted their whole time or part of their time to selling, provided such salaries were charged to selling in the books of the establishments, or in case where not so charged an equitable basis for distribution was furnished by the officials themselves. Also, in some establishments no charge was made by officials for services rendered by them, in which case an estimated amount for their services, if furnished by the officials, was charged and then the amount distributed according to the character of the work performed. The percentages for salaries of officials, therefore, do not represent the complete charge, but examination of the percentages for superintendent and foremen and for selling in the individual establishments in the different groups will to a certain extent explain the variation in the percentages for salaries of officials.

The average for total salaries for all establishments reporting was 3.51 per cent, being about equally divided between salaries of officials 
and office force. A similar equal division was not found in the different groups or in individual establishments, as examination of the percentages will clearly demonstrate. In no group was the percentage for total salaries in excess of 5.04 per cent of the sales value of the goods produced, being in one group as low as 1.77 per cent.

\section{ROYALTY。}

In only two groups was royalty, other than on bottles and jars, a part of the charge of the cost of production. In window glass made by machine, Group II, the cost was 3.68 per cent, and in lighting goods, Group XI, 0.78 per cent, the former representing royalties paid on machines and the latter royalties on batch.

\section{GENERAL EXPENSE.}

General expense includes a great variety of charges which could not be assigned to other items in the schedules, among which may be mentioned factory supplies, office expenses other than office salaries, repairs, legal expense, welfare work, etc. Notwithstanding the number of items included with general expense, the percentages for the various groups are not remarkably high. In only wire and opalescent goods, Group IV, was this expense over 10 per cent of the sales value of goods produced. The average for all establishments was 7 per cent, and the lowest, 3.26 per cent, was in blown tableware, Group IX.

\section{SELLING.}

Chapter VII, page 231, is devoted to selling methods employed in the different branches of the glass industry and should be read in connection with the percentages for selling in this and the following tables for a better understanding of the variations in the selling expenses for the different groups.

Establishments making tableware, Groups IX and $\mathrm{X}$, and lighting goods, Group XI, showed comparatively high percentages of cost for selling, and those making window glass, Groups I and II, and bottles by hand, Group V, showed comparatively low percentages of cost for selling. Plate-glass factories, Group III, had the remarkably low selling cost of 0.25 per cent, nearly evenly divided between salesmen and other selling expense.

For all establishments reporting, the average for total selling expense was 3.92 per cent, of which 3.01 per cent, or over three-fourths of the total selling expense, was for salesmen.

Loss from bad debts was remarkably low in this industry. In no group was the loss equal to 1 per cent of the sales value of goods produced, or, in other words, for every $\$ 100$ selling value of goods produced in Group VIII, jars, the amount recovered through sales was only 98 cents less. In establishments making window glass by hand, Group I, and plate glass, Group III, the loss from bad debts was less than 0.05 per cent, or, expressed in dollars and cents, the loss suffered through bad debts was less than 5 cents on every $\$ 100$. For all establishments the average loss from bad debts through converting goods produced into cash was 44 cents on every $\$ 100$ sales value of goods produced. 


\section{PROFIT.}

The margin between the total cost and sales value of goods produced constitutes the profit, the aim and incentive of all business. The wider the margin between these items, the greater the profit, and as competition in the main fixes prices on the one end, it is the desire of the manufacturer to keep the other end, his costs, as low as possible and thus secure for himself a margin between the total cost and selling value. The question naturally arises, What items are properly chargeable to costs? Perhaps on no items more than depreciation and interest is there such a wide difference of opinion as to whether or not they are proper charges to cost; especially is this true of interest. For this reason it was thought adrisable to show total cost of goods produced without charges for depreciation and interest and to show operating profit computed both without and with depreciation and interest.

The tables are so constructed that one can easily determine the total cost including either depreciation or interest, or both, by simply adding the percentages for these items to the total cost. For one who believes that depreciation is a proper charge to costs and that interest is not, and who wishes to know what the operating profit would be if depreciation were charged and interest were not, all that is necessary for him to do is to add the amount shown opposite "Interest paid" to the profit shown immediately below, or in case there was a loss reduce the amount of the loss by the amount of interest paid.

Operating profit on goods produced computed without depreciaciation and interest showed for all establishments an average of 10.49 per cent on the sales value of goods produced, ranging from 5.11 per cent in blown and pressed tableware, Group X, to 16.14 per cent in machine-made bottles, Group VI. Six groups, or one less than half of all the groups, showed profits of more than 10 per cent. Of the remaining groups four showed profits between 5 and 6 per cent and three betweem 9 and 10 per cent.

\section{DEPRECIATION.}

Chapter III, page 86, is devoted to depreciation, and it is believed that a discussion of the subject in this part of the report would be a needless repetition.

The average rate of depreciation based on sales value of goods produced was 3.85 per cent for all establishments. The highest average rate of depreciation was found in plate glass, Group III, 10.6 per cent, and the lowest in lamp chimneys, Group XII, 1.61 per cent. Of the remaining groups, none showed an average rate in excess of 5 per cent.

\section{INTEREST.}

Interest paid excludes interest on investment, bonds, mortgages, and other borrowed capital in all establishments reporting such charges.

Examination of the percentages will show that the average interest. paid in all establishments on the total sales value of goods produced was 1.07 , the highest, 2.6 , in window glass made by machine, Group 
II, and the lowest, 0.54, in tableware, blown and pressed, Group X. In five groups the average was less than 1 per cent; in seven groups considerably below 2 per cent, in only one group was the average over 2 per cent.

\section{MISCELLANEOUS EXPENSE AND MISCELLANEOUS INCOME.}

Miscellaneous expense and miscellaneous income are composed of such items as could not properly be charged or credited to the cost of operating. By taking these items into consideration, the average profit or loss for some groups is slightly modified.

\section{COST AND PROFIT IN INDIVIDUAL ESTABLISHMENTS.}

\section{HANDMADE WINDOW GLASS.}

The following 13 tables show percentages of cost and profit based on the sales value of goods produced, by individual establishments in the different groups. In Table 37, which follows, these percentages are shown for establishments making window glass by hand, Group I.

Data were secured for 37 establishments, the greatest number in any one group. These establishments were located in West Virginia, Pennsylvania, Ohio, Kansas, Indiana, Oklahoma, Louisiana, and Texas, more than 60 per cent of the establishments being located in West Virginia and Pennsylvania.

The total cost of materials varied from 7.11 per cent to 22.72 per cent with an average of 15.39 per cent for all establishments in this group. Batch was the principal item of cost, although in 10 establishments the cost of packing exceeded that of batch.

Owing to the large amount of skilled labor required in the various operations, the establishments in this group showed high percentages for total labor, the average being higher than in any other group. In no establishment was this item less than 50 per cent of the sales value of goods produced, and it was as high as 65.98 per cent in establishment No. 2. It will be seen by an enumeration of the percentages that there were 12 establishments with percentages for total labor ranging between 50 and 55 per cent, 17 between 55 and 60 per cent, 7 between 60 and 65 per cent, and 1 over 65 per cent. 


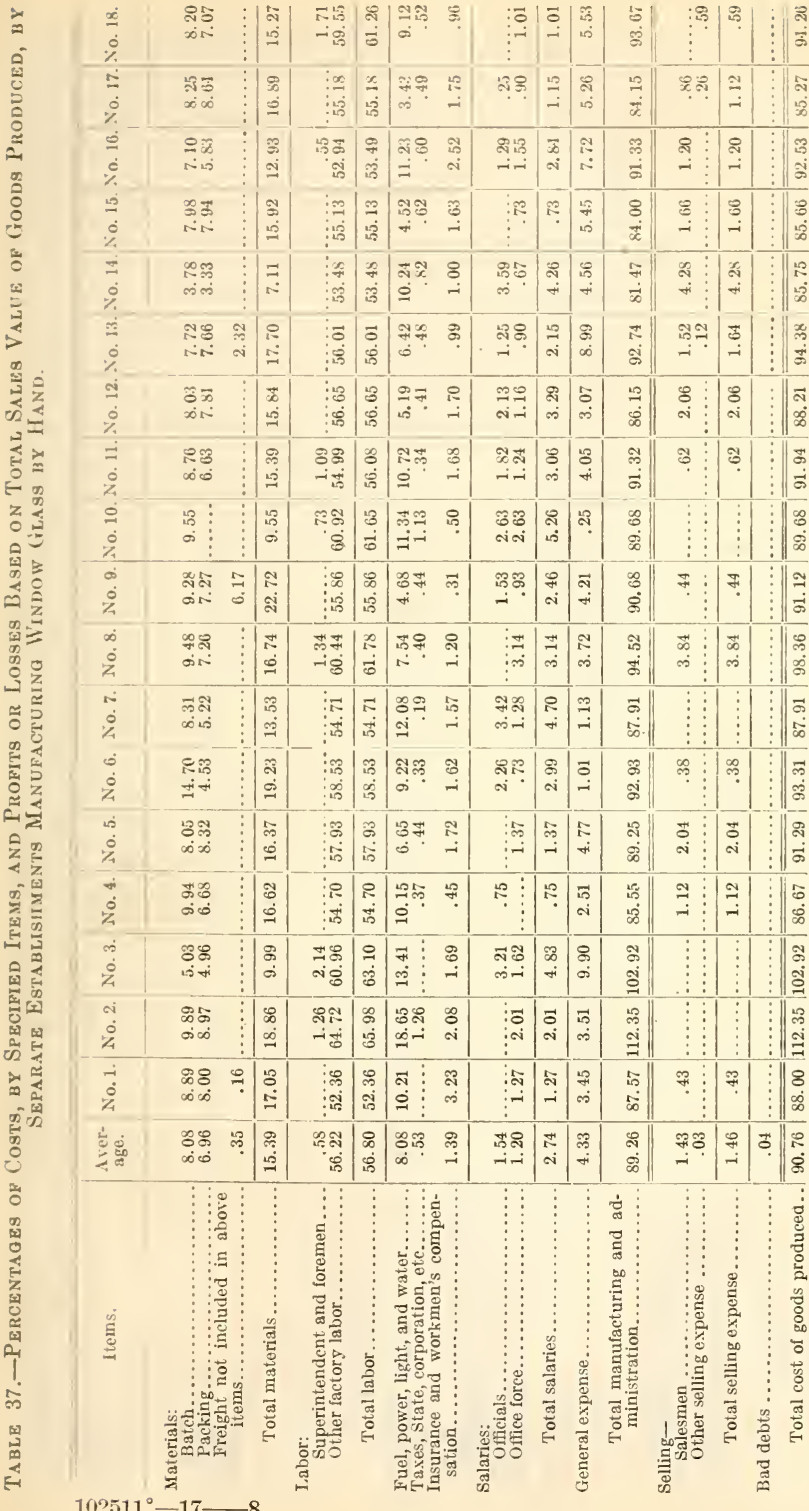




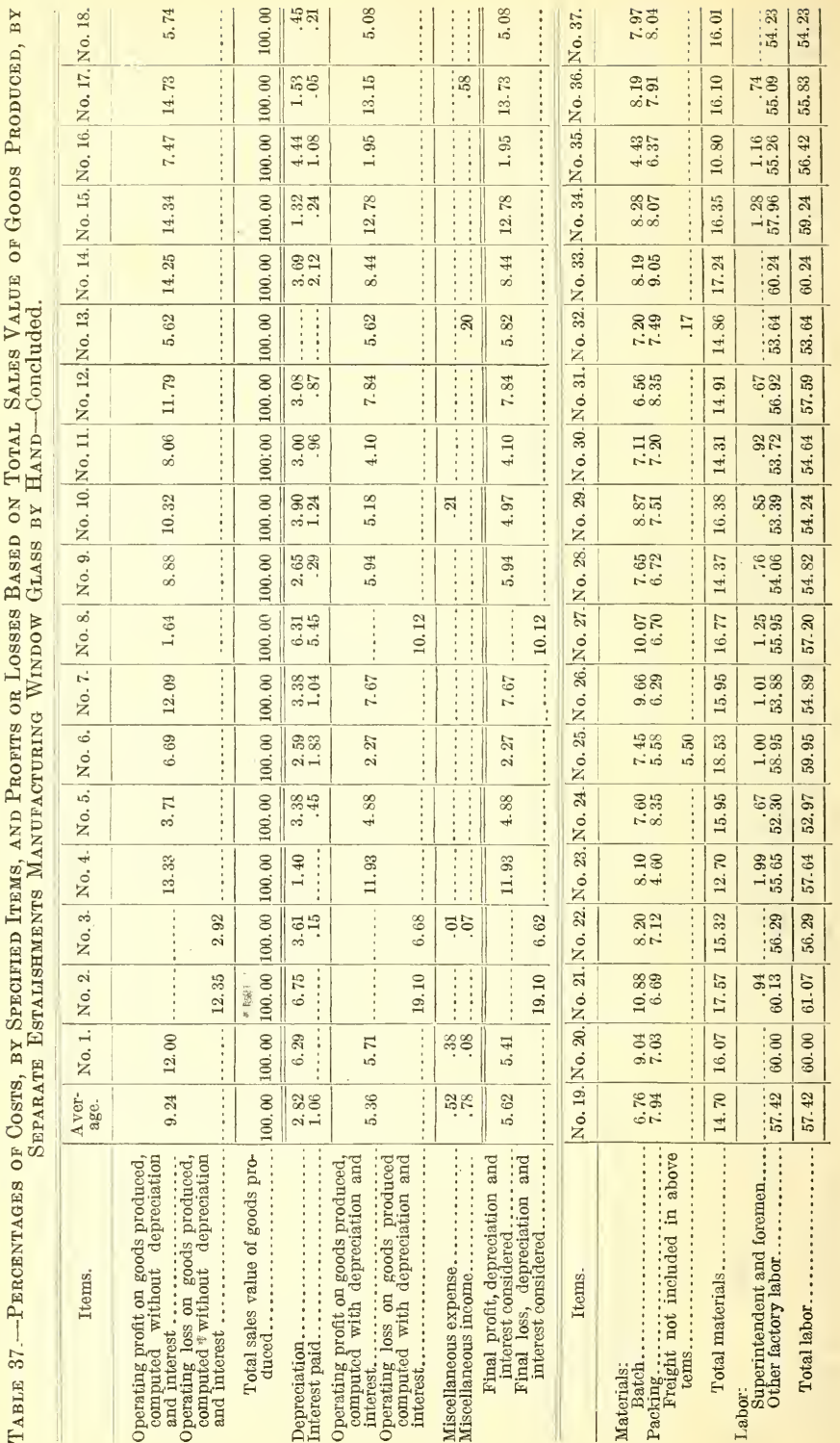




\begin{tabular}{|c|c|c|c|c|c|c|c|c|c|c|c|c|c|c|c|c|}
\hline 89 & $\stackrel{\text { ฐ }}{-}$ & \&. & $\left|\begin{array}{l}8 \\
\text { a }\end{array}\right|$ & 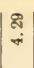 & $\frac{0}{8}$ & 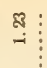 & 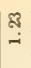 & $\vdots$ & | & $\begin{array}{l}\text { م. } \\
\stackrel{9}{0}\end{array}$ & $\begin{array}{l}8 \\
8 \\
8\end{array}$ & นุฒ & 우 & & $:=$ & $\begin{array}{l}\$ \\
\infty\end{array}$ \\
\hline क्षి: & $\$$ & 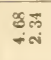 & $\stackrel{8}{\stackrel{2}{0}}$ & $\begin{array}{l}8 \\
\end{array}$ & $\frac{\pi}{6}$ & 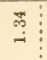 & 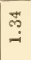 & & $\begin{array}{l}\infty \\
\infty \\
\alpha\end{array}$ & $\stackrel{2}{\stackrel{2}{*}}$ & $\begin{array}{l}8 \\
8 \\
8\end{array}$ & $\mid \begin{array}{c:c}\mathfrak{a} & \vdots \\
-1 & \vdots\end{array}$ & 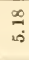 & & & $\underset{\text { is }}{\infty}$ \\
\hline 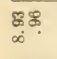 & 8 & ఫ్రా & 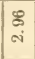 & ऴे & $\frac{\stackrel{5}{5}}{\dot{\infty}}$ & \begin{tabular}{l|l}
$\stackrel{\infty}{*}$ \\
$\stackrel{\infty}{*}$
\end{tabular} & 寓 & & $\begin{array}{l}8 \\
8 \\
\dot{8} \\
\dot{8}\end{array}$ & $\stackrel{\infty}{\stackrel{\circ}{=}}$ & $\begin{array}{l}8 \\
8 \\
8\end{array}$ & $\mid \begin{array}{l}a \\
\infty \\
\infty\end{array}$ & $\circ$ & & 용ㅍ․ & $\stackrel{8}{\stackrel{8}{\sim}}$ \\
\hline श्र० & สี & $\underset{-10}{0}$ & $\mid \begin{array}{l}R \\
i \\
\text { S }\end{array}$ & $\mid \begin{array}{l}\infty \\
\ddot{\infty} \\
\dot{\infty}\end{array}$ & $\begin{array}{l}\hat{\infty} \\
\dot{\infty}\end{array}$ & $\begin{array}{l}\infty \\
\stackrel{\infty}{\infty} \\
- \\
-1\end{array}$ & $\stackrel{\infty}{\infty}$ & øె. & 官 & $\begin{array}{l}ळ \\
\infty \\
\infty\end{array}$ & $\begin{array}{l}8 \\
8 \\
8\end{array}$ & $\mid \begin{array}{l}10 \% \\
120 \\
\infty \\
\infty \\
\infty\end{array}$ & 8 & & & 疋 \\
\hline $\begin{array}{l}\text { किR } \\
\text { के }\end{array}$ & 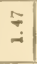 & - & 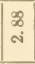 & $\begin{array}{l}2 \\
\infty \\
\end{array}$ & $\begin{array}{l}\$ \\
1 \\
\infty\end{array}$ & ใ? & ㄴํํ. & $\vdots$ & 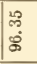 & $\begin{array}{l}\text { \&8 } \\
\text { is }\end{array}$ & $\begin{array}{l}8 \\
8 \\
8\end{array}$ & $\begin{array}{l}0 \% \text { \% } \\
\text { in - }\end{array}$ & & & & \\
\hline $\begin{array}{l}\text { git } \\
\text { is. }\end{array}$ & $\cong$ & द्ञा & $\begin{array}{l}\tilde{\sigma} \\
\tilde{\sigma} \\
\text { oi }\end{array}$ & 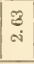 & $\stackrel{+a}{\dot{\infty}}$ & 8 & \&. & $\vdots$ & $\stackrel{2}{\infty}$ & $\begin{array}{l}\stackrel{8}{5} \\
\cong\end{array}$ & $\begin{array}{l}8 \\
\$ \\
\$\end{array}$ & 조. & $\begin{array}{l}\stackrel{8}{0} \\
\dot{0}\end{array}$ & & 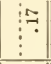 & 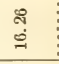 \\
\hline వi? & $\stackrel{\Delta}{-}$ & $\vdots \approx$ & 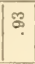 & $\begin{array}{l}8 \\
\text { के } \\
\text { के }\end{array}$ & $\begin{array}{l}\not 2 \\
\dot{8}\end{array}$ & 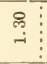 & คి & $\vdots$ & $\begin{array}{l}\infty \\
\infty \\
\infty\end{array}$ & $\begin{array}{l}\infty \\
\dot{J}\end{array}$ & $\begin{array}{l}8 \\
\dot{8}\end{array}$ & | & $\begin{array}{l}\approx \\
\beth\end{array}$ & & $\vdots=$ & $\stackrel{\not}{=}$ \\
\hline $\begin{array}{l}\text { సี่ } \\
\stackrel{9}{\circ}\end{array}$ & $\overrightarrow{-}$ & ๓ొణ & is & $\mid$\begin{tabular}{l|}
0 \\
i \\
i
\end{tabular} & $\begin{array}{l}\text { ळొ } \\
10\end{array}$ & 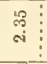 & ๙ึ. & $\vdots$ & $\mid \begin{array}{l}\not{b} \\
\dot{0} \\
\dot{\infty}\end{array}$ & $\begin{array}{l}\text { యे } \\
\text { త్ }\end{array}$ & $\begin{array}{l}8 \\
8 \\
8\end{array}$ & $\begin{array}{l}\text { soㅇ } \\
\text { si- }\end{array}$ & 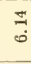 & & & $\stackrel{\Xi}{0}$ \\
\hline ఐ্ল & $\begin{array}{l}\tilde{m} \\
\stackrel{\sim}{i}\end{array}$ & $\vdots$ & ஜ & \begin{tabular}{|l|}
$\mathscr{D}$ \\
if \\
is
\end{tabular} & $\begin{array}{c}\stackrel{\Re}{*} \\
\stackrel{\infty}{\infty}\end{array}$ & స્ & 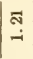 & & \begin{tabular}{|l|}
$\vec{d}$ \\
$\dot{\infty}$
\end{tabular} & $\begin{array}{l}\stackrel{8}{0} \\
\stackrel{2}{0}\end{array}$ & $\begin{array}{l}8 \\
8 \\
8\end{array}$ & \&ুర. & $\stackrel{\mathscr{P}}{\stackrel{9}{-1}}$ & & $\vdots$ & $\begin{array}{l}\infty \\
\stackrel{\infty}{\Omega}\end{array}$ \\
\hline $\begin{array}{l}\infty \\
\stackrel{\infty}{\infty} \vdots \\
\infty \\
\infty\end{array}$ & E & $\begin{array}{l}5-20 \\
\text { i- }\end{array}$ & $\mid \begin{array}{l}8 \\
\dot{\infty} \\
\dot{0}\end{array}$ & $=$ & $\begin{array}{l}\mathbb{5} \\
\dot{\infty}\end{array}$ & \begin{tabular}{l|l}
$\vec{m}$ & $\vdots$ \\
जi
\end{tabular} & है & $\vdots$ & $\begin{array}{l}\ddot{8} \\
\dot{8} \\
\dot{8}\end{array}$ & $\stackrel{2}{\stackrel{2}{\circ}}$ & $\begin{array}{l}8 \\
8 \\
8\end{array}$ & $\begin{array}{l}-\infty \\
\sigma_{\infty}^{\infty} \\
\text {. }\end{array}$ & $\stackrel{2}{+}$ & & 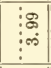 & $\underset{\infty}{\infty}$ \\
\hline \$ू. & $\approx$ & มู- & \begin{tabular}{|l}
$\stackrel{\$}{S}$ \\
जi
\end{tabular} & \begin{tabular}{|l|} 
â \\
Ni
\end{tabular} & $\begin{array}{l}\vec{x} \\
\vec{\sigma}\end{array}$ & \begin{tabular}{l|l} 
if \\
की \\
के
\end{tabular} & कृ & $\%$ & $\mid \begin{array}{l}\dddot{1} \\
10 \\
10\end{array}$ & if & $\begin{array}{l}8 \\
8 \\
8\end{array}$ & 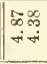 & & & $\vdots$ & \\
\hline 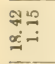 & $\begin{array}{c}8 \\
-i\end{array}$ & $\stackrel{9}{i \infty}$ & is & 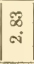 & $\underset{\dot{\delta}}{\vec{\delta}}$ & $\stackrel{\infty}{-}=$ & | & $\vdots$ & $\begin{array}{l}R \\
8 \\
8 \\
\end{array}$ & 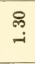 & $\begin{array}{l}8 \\
8 \\
8\end{array}$ & శรశ్ & 8 & & 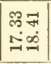 & $\stackrel{I}{-}$ \\
\hline పై & $\stackrel{\text { రి }}{-}$ & $\overbrace{-i}^{0}$ & $\mid \begin{array}{l}\vec{J} \\
\text { बi }\end{array}$ & $\begin{array}{l}\overrightarrow{0} \\
\dot{0} \\
\dot{N}\end{array}$ & $\begin{array}{l}\text { क } \\
\varnothing \\
\end{array}$ & $8 \%$ & $\stackrel{8}{8}$ & 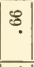 & ه్ & $\stackrel{\circ}{\stackrel{\circ}{\sim}}$ & $\begin{array}{l}8 \\
8 \\
8 \\
\end{array}$ & 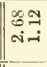 & $\stackrel{\infty}{\stackrel{+}{+}}$ & & :울 & $\begin{array}{l}\stackrel{\infty}{*} \\
\text { is }\end{array}$ \\
\hline $\begin{array}{l}\text { 죽 } \\
\stackrel{9}{\circ}\end{array}$ & $\ddot{\infty}$ & 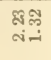 & \begin{tabular}{|l|} 
is \\
के
\end{tabular} & $\mid \begin{array}{l}8 \\
10 \\
10\end{array}$ & $\begin{array}{l}\infty \\
10 \\
\infty \\
\infty\end{array}$ & 足 & 总 & & $\stackrel{\varpi}{\rightleftarrows}$ & $\underset{\infty}{\infty}$ & $\begin{array}{l}8 \\
8 \\
8\end{array}$ & 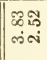 & ชี้ & & & ชิ \\
\hline ্ֻণী & $\exists$ & $=\infty$ & i] & 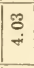 & में & & $\vdots$ & & | & $\begin{array}{l}106 \\
\text { in } \\
+1\end{array}$ & $\begin{array}{l}8 \\
8 \\
8\end{array}$ & : & $\begin{array}{l}\text { สิ } \\
\text { 엉 }\end{array}$ & & $\vdots 8$ & $\begin{array}{l}\mathscr{8} \\
\stackrel{9}{0}\end{array}$ \\
\hline$\underset{0}{0}:$ & $\stackrel{q}{q}$ & in & $\left|\begin{array}{l}\alpha \\
\infty \\
\alpha i\end{array}\right|$ & $\mid \begin{array}{l}\infty \\
\infty \\
\text { is }\end{array}$ & ‡ & $\stackrel{\infty}{\stackrel{1}{二}}$ & $\stackrel{\infty}{=}$ & & $\| \begin{array}{l}\infty \\
\infty \\
\infty \\
\infty\end{array}$ & $\begin{array}{l}\text { 3. } \\
\text { త్ }\end{array}$ & $\begin{array}{l}8 \\
8 \\
8\end{array}$ & iि- & $\begin{array}{l}\text { คํ } \\
\text { के }\end{array}$ & & & $\begin{array}{l}\text { की } \\
\text { के }\end{array}$ \\
\hline FT & $\underset{-}{\mathbb{D}}$ & $\begin{array}{l}8 \% \\
\text { 겨 }\end{array}$ & $\underset{\infty}{\stackrel{P}{9}}$ & $\underset{+\infty}{\stackrel{\infty}{+}}$ & $\begin{array}{l}\text { ণ } \\
\text { ळ }\end{array}$ & :8 & t5 & & $\mid \begin{array}{l}8 \\
8 \\
8 \\
8\end{array}$ & $\begin{array}{l}\vec{m} \\
\dot{0}\end{array}$ & $\begin{array}{l}8 \\
8 \\
\end{array}$ & |ే & $\stackrel{8}{-}$ & & & $\stackrel{8}{\stackrel{8}{\circ}}$ \\
\hline 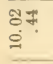 & \begin{tabular}{l}
$\mathcal{d}$ \\
\multirow{i}{*}{}
\end{tabular} & $\underset{-i=}{-\infty}$ & di & i & $\begin{array}{l}8 \\
8 \\
8\end{array}$ & 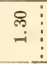 & 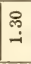 & & $\mid \begin{array}{l}8 \\
0 \\
5\end{array}$ & के & $\begin{array}{l}8 \\
8 \\
8\end{array}$ & 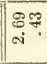 & & & & $\vdots$ \\
\hline $\begin{array}{l}\infty \\
= \\
=\end{array}$ & $\mathscr{g}$ & . & $\begin{array}{l}3 \\
\text { a } \\
\text { i }\end{array}$ & 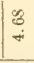 & के & $\begin{array}{l}8 \\
\text { of } \\
\end{array}$ & $\begin{array}{l}\mathscr{8} \\
\dot{\infty}\end{array}$ & & $\mid \begin{array}{l}\xi \\
\dot{c} \\
\dot{8}\end{array}$ & $\stackrel{5}{5}$ & $\begin{array}{l}8 \\
8 \\
8\end{array}$ & $\| \begin{array}{l}=\infty \\
\dot{\infty}^{\infty}\end{array}$ & $\stackrel{\infty}{\stackrel{\infty}{-}}$ & & & $\stackrel{\infty}{\stackrel{\infty}{-}}$ \\
\hline
\end{tabular}

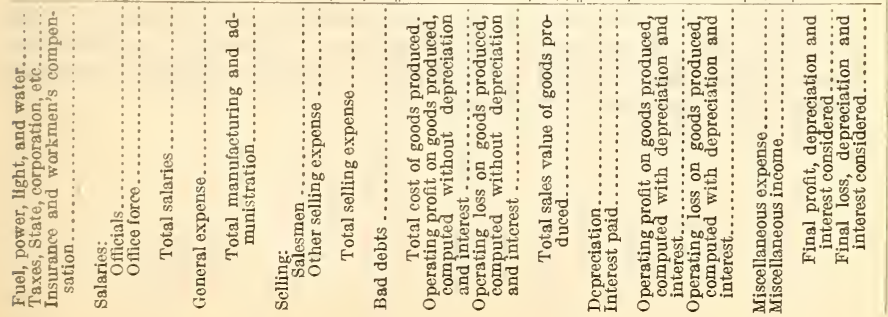


Superintendent and foremen carried a small percentage of the sales value of goods produced, due to several causes, chief among which may be mentioned $(a)$ cooperative establishments in which the owners received no salaries, but wages as workmen; $(b)$ officials of the company acting as superintendents, but charging no part of their salaries to factory supervision; (c) officials acting as superintendents, but receiving no salaries and furnishing no estimates as to the value of their services.

The percentages for fuel, power, light, and water were affected more by the location of the plant than were the percentages for other items. The establishments located in those States where gas is cheap had a decided advantage over those in other States where the natural-gas supply is giving out or where producer gas is used. To localize any individual establishment, even by State, might disclose the identity of that establishment, but it can be generally stated that the establishments located in West Virginia, Oklahoma, and Louisiana had an advantage over those in other States, although some of the establishments in the States named had higher percentages than the lowest in other States.

Of the remaining items of cost, general expense, with an average of 4.33 per cent, was next in importance, followed by total salaries, 2.74 per cent; total selling expense, 1.46 per cent; insurance, 1.39 per cent; taxes, 0.53 per cent; and bad debts, 0.04 per cent. Losses from bad debts were remarkably small for establishments in this group, only three establishments showing such losses.

Of the 37 establishments in this group, only 2 showed operating loss, computed without depreciation and interest, one showing a loss of 12.35 per cent and the other 2.92 per cent. Of the 35 establishments showing profits, 16 had profits of over 10 per cent and 6 less than 5 per cent. The average operating profit for all establishments was 9.24 per cent; the highest was 17.85 per cent, in establishment No. 32 , and the lowest 1.3 per cent, in establishment No. 26.

Allowing charges for depreciation and interest, six establishments showed operating losses ranging from 0.21 per cent to 19.1 per cent, while all establishments showed an average operating profit of 5.36 per cent. A number of the establishments showed expenses and income which could not be correctly charged or credited to the cost of production, and the final profit or loss in some establishments will vary from the operating profit to the extent that these items were found in the accounts of the various establishments.

\section{MACHINE-MADE WINDOW GLASS.}

Table 38, which follows, is like the preceding one in that it deals with the cost of producing window glass, but with the machinemade product instead of the handmade. The percentages are based on sales value of goods produced. 


\begin{tabular}{|c|c|c|c|c|c|c|c|c|c|c|c|c|c|c|c|c|}
\hline $\begin{array}{l}\dot{8} \\
\dot{\alpha}\end{array}$ & $\begin{array}{l}\vec{\infty} \cdot \bar{b} \\
\dot{0}:\end{array}$ & 胥 & تิ8 & $\begin{array}{l}\bar{x} \\
\vdots \\
0 \\
0\end{array}$ & $\underset{\infty}{N}$ & : & $\underline{z}$ & $\begin{array}{l}\vdots \widehat{\mathrm{A}} \\
\vdots \\
\vdots\end{array}$ & $\begin{array}{l}8 \\
\ddot{2}\end{array}$ & $\begin{array}{l}\vec{E} \\
\text { i }\end{array}$ & a & $\stackrel{\infty}{\circ}$ & 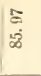 & $\stackrel{\mathscr{E}}{\stackrel{-}{-}}$ & & $\mid \begin{array}{l}\varepsilon \\
\delta \\
\delta\end{array}$ \\
\hline 官 & $\begin{array}{l}8.8 \\
\text { Sin }\end{array}$ & $\mid \begin{array}{l}\infty \\
\vdots \\
\vdots\end{array}$ & $\begin{array}{l}810 \\
\text {-i } \\
\text { - }\end{array}$ & 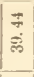 & $\begin{array}{l}=\text { जे } \\
\equiv\end{array}$ & ఏ్ & 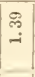 & 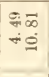 & $\frac{8}{\infty}$ & ले & $\begin{array}{l}\vec{m} \\
\dot{\omega}\end{array}$ & & $\begin{array}{l}\overrightarrow{\text { N }} \\
\dot{8}\end{array}$ & $\begin{array}{l}\infty \\
=\end{array}$ & & $\begin{array}{l}8 \\
8 \\
8\end{array}$ \\
\hline$\stackrel{\check{丶}}{\grave{c}}$ & $\begin{array}{l}\infty \overline{0} \\
\stackrel{5}{0}\end{array}$ & $\frac{9}{9}$ & 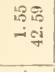 & $\begin{array}{l}= \\
\pm\end{array}$ & $\begin{array}{l}\text { NaR } \\
\stackrel{9}{9}-\end{array}$ & : & 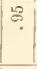 & S9: & 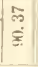 & $\begin{array}{l}\mathscr{1} \\
\text { in }\end{array}$ & $\begin{array}{l}\pi \\
i \\
\text { i }\end{array}$ & & $\begin{array}{l}\& \\
\text { ह่ }\end{array}$ & $\stackrel{9}{\square}$ & & $\begin{array}{l}8 \\
8 \\
\text { g. }\end{array}$ \\
\hline $\begin{array}{l}\dot{5} \\
\dot{0} \\
\dot{z}\end{array}$ & 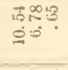 & 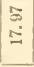 & 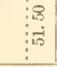 & क. & 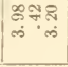 & 350 & : & $\begin{array}{l}\infty=7 \\
\text { के }\end{array}$ & $\begin{array}{l}9 \\
9 \\
8 \\
8\end{array}$ & $\stackrel{\infty}{\stackrel{\infty}{-} \vdots \vdots}$ & $\left|\begin{array}{l}\infty \\
- \\
-\end{array}\right|$ & : & $\underset{\infty}{\stackrel{\infty}{\infty}}$ & $\begin{array}{l}\text { : } \\
\text { İ } \\
\text { İ }\end{array}$ & & $\stackrel{8}{8}$ \\
\hline $\begin{array}{l}2 \\
\dot{0} \\
\%\end{array}$ & $\begin{array}{l}\mathscr{Q}= \\
\dot{\alpha} \dot{\omega}\end{array}$ & $\begin{array}{l}\hat{\text { से }} \\
\text { มี่ }\end{array}$ & $\begin{array}{l}\vdots \\
\vdots \\
\infty \\
\infty \\
\infty\end{array}$ & $\begin{array}{l}0 \\
0 \\
\infty \\
\infty \\
m\end{array}$ & 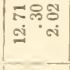 & 鬲 & क् & $\begin{array}{l}80 \\
80 \\
0-1\end{array}$ & $\begin{array}{c}\vec{a} \\
\dot{0} \\
\dot{\infty}\end{array}$ & ज斻 & के & & $=$ & $\begin{array}{l}\infty \\
\stackrel{=}{=}\end{array}$ & & 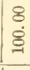 \\
\hline ì & $\begin{array}{l}x 8 \\
\infty \\
0\end{array}$ & $\begin{array}{l}7 \\
\dot{0} \\
0\end{array}$ & $\begin{array}{l}\infty \pi \\
\infty \\
-i 0 \\
-\infty\end{array}$ & 혼 & $\begin{array}{l}8 \overrightarrow{0} \text {. } \\
\text { घं }\end{array}$ & $\begin{array}{l}\stackrel{5}{ } \overrightarrow{0} \\
-i-1\end{array}$ & $\begin{array}{l}\text { a } \\
\text { in }\end{array}$ & $\begin{array}{c}\vdots \\
\vdots \\
\vdots \\
\end{array}$ & 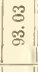 & चం్లి & เุ & & $\begin{array}{l}\tilde{\omega} \\
\tilde{\xi} \\
\tilde{\xi}\end{array}$ & 둥 & & $\begin{array}{l}8 \\
8 \\
\end{array}$ \\
\hline $\begin{array}{l}\stackrel{p}{2} \\
\dot{0}\end{array}$ & 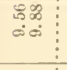 & 亲 & $\begin{array}{l}\vdots \\
\vdots \\
\vdots \\
\vdots\end{array}$ & $\begin{array}{l}\tilde{\infty} \\
\dot{\tilde{\omega}} \\
0\end{array}$ & 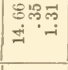 & 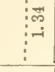 & $\underset{m}{-}$ & 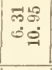 & $\begin{array}{l}\text { N } \\
\dot{\text { है }}\end{array}$ & $\begin{array}{l}\mathscr{3} \\
\text { ì }\end{array}$ & 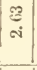 & & $\begin{array}{l}\infty \\
\infty \\
8 \\
\delta\end{array}$ & 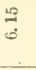 & & $\mid \begin{array}{l}8 \\
8 \\
8\end{array}$ \\
\hline $\begin{array}{l}\text { ज़े } \\
\text { zें }\end{array}$ & $\begin{array}{l}9 ? \\
\text { פñ }\end{array}$ & $\begin{array}{l}\mathscr{Z} \\
\Xi \\
-1\end{array}$ & 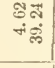 & 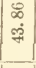 & 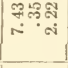 & 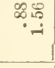 & 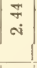 & 茎 & $\frac{2}{3}$ & भૈศ్ & a & ลิ & 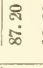 & $\begin{array}{l}\mathscr{\infty} \\
\text { త్ }\end{array}$ & & $\begin{array}{l}8 \\
8 \\
8\end{array}$ \\
\hline $\begin{array}{l}\dot{7} \\
\dot{\delta} \\
z\end{array}$ & $\begin{array}{l}\text { ลี. } \\
\text { =ై }\end{array}$ & ה & 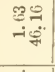 & $\begin{array}{l}8 \\
5 \\
7\end{array}$ & ๓ొఱా: & 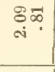 & $\mid \begin{array}{l}8 \\
\text { i } \\
\text { i }\end{array}$ & 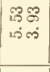 & $\mid \begin{array}{c}0 \\
0 \\
\dot{\infty} \\
\end{array}$ & $\stackrel{8}{-1}$ & \& & 5 & $\frac{2}{2}$ & $\begin{array}{l}\text { : } \\
\stackrel{5}{9}\end{array}$ & & $\begin{array}{l}8 \\
\dot{8} \\
-1\end{array}$ \\
\hline 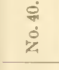 & 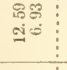 & $\begin{array}{l}\text { 잉 } \\
\stackrel{2}{2} \\
\stackrel{2}{2}\end{array}$ & \begin{tabular}{l}
$\infty$ \\
$\vdots$ \\
$\vdots$ \\
$\vdots$ \\
\hdashline
\end{tabular} & $\frac{\infty}{\infty}$ & $\begin{array}{l}\text { ANES } \\
6:-1\end{array}$ & $\begin{array}{c}55 \\
-55 \\
-i \omega i\end{array}$ & $\begin{array}{l}\pi \\
\text { in }\end{array}$ & 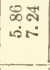 & $\begin{array}{c}\overrightarrow{0} \\
\dot{s}\end{array}$ & $\stackrel{\infty}{\stackrel{0}{-i}}$ & $\stackrel{\substack{\infty \\
0 \\
-i}}{ }$ & ¿े & 要 & & 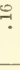 & $\begin{array}{l}8 \\
8 \\
8\end{array}$ \\
\hline 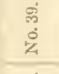 & $\begin{array}{l}-\infty \approx \\
\infty \vdots \\
0\end{array}$ & $\begin{array}{l}\text { गे } \\
\text { வें }\end{array}$ & $\begin{array}{c}\vdots \\
\vdots \\
\vdots \\
\vdots\end{array}$ & $\begin{array}{l}5 \\
\vdots \\
\dot{+}\end{array}$ & 로요 & $\vdots$ & $\stackrel{7}{-}$ & 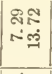 & 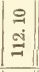 & & $\vdots$ & $\vdots$ & Iㄱ & & 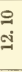 & $\begin{array}{l}8 \\
8 \\
8\end{array}$ \\
\hline $\begin{array}{l}\infty \\
\infty \\
0 \\
0 \\
\%\end{array}$ & 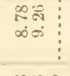 & $\begin{array}{l}\overrightarrow{0} \\
\dot{0} \\
0\end{array}$ & 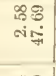 & $\begin{array}{l}\text { A } \\
\text { d. } \\
\text { b. }\end{array}$ & 電 & 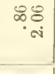 & $\begin{array}{l}\text { S } \\
\text { aे }\end{array}$ & 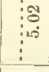 & $\left|\begin{array}{l}5 \\
5 \\
8 \\
0\end{array}\right|$ & $\begin{array}{l}\text { न } \\
\text { ai } \vdots\end{array}$ & $=$ & $\vdots$ & $\begin{array}{l}\infty \\
8 \\
\text { sं } \\
0\end{array}$ & & i & 8 \\
\hline 递 & 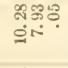 & $\begin{array}{l}\infty \\
\infty \\
\infty \\
-1\end{array}$ & 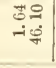 & \begin{tabular}{l}
\multirow{2}{*}{} \\
$\stackrel{+}{*}$
\end{tabular} & कొ & भैल & $\begin{array}{l}5 \\
-i\end{array}$ & क⿺ & $\begin{array}{c}\infty \\
\infty \\
\infty \\
\infty\end{array}$ & \$્ఝ & $\begin{array}{l}\text { ஜ } \\
\text { ii }\end{array}$ & $\exists$ & $\begin{array}{l}\mathscr{8} \\
\& \\
\&\end{array}$ & & & 8 \\
\hline
\end{tabular}

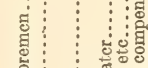

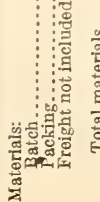

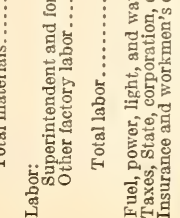
,
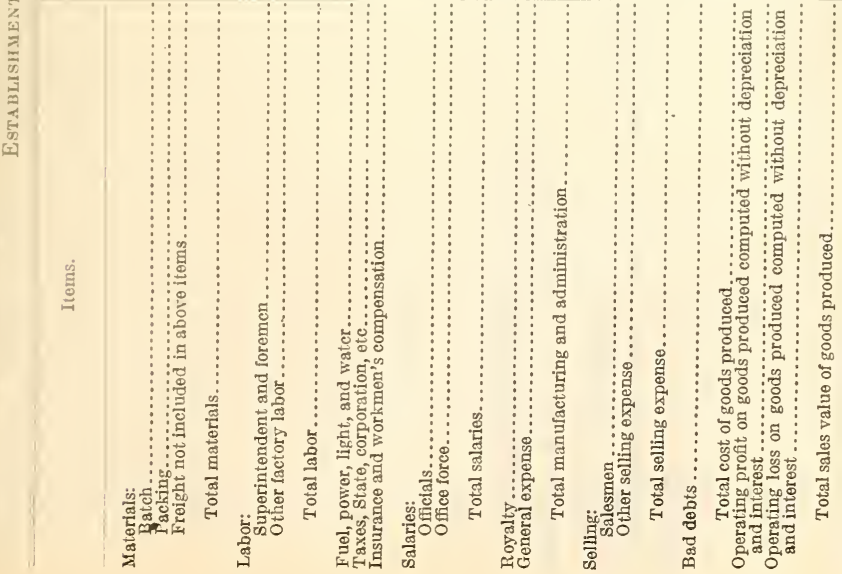


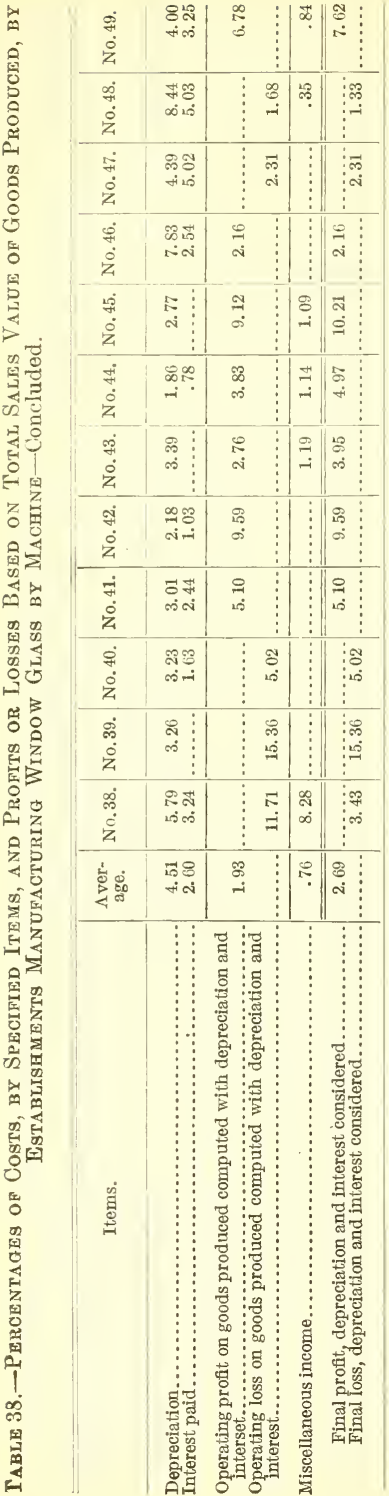


Data were secured for 12 establishments, located in West Virginia, Pennsylrania, Ohio, and Oklahoma. Nearly $\$ 4$ per cent of the establishments were in the first two States named.

Generally speaking, the average percentages for this group were somewhat higher than they were for the group making window glass by hand, with the exception of total labor. Since the percentages for all items of cost and profit or loss must add to 100 per cent, it follows that if for some reason the percentages for one or more items were lower in one group than in another, the other items must necessarily be higher. For example, take Group I, which showed 56.8 per cent for total labor, and Group II, 47.74 per cent; the difference of 9.06 per cent must be taken up by other items in Group II.

Although in this group the arerage for batch was over 2 per cent greater than for packing, four establishments had a higher percentage for packing than for batch. The average cost of all materials was 18.26 per cent, highest in establishment No. 45, 22.76 per cent, and lowest in establishment No. 49, 16.4 per cent.

The total cost for labor in this group fell below 50 per cent in the average for all establishments and in seven of the individual establishments, being as low as 36.86 per cent in establishment No. 43. The highest percentage for labor was 57.84, in establishment No. 49. In certain operations the machine-made window glass requires the same kind of skilled labor as in the handmade product, but the lower labor cost in the machine-made product must be ascribed to the use of automatic machines, which do away with the highly skilled labor in blowing.

The discussion of the item fuel, power, light, and water in the preceding table attempted to bring out the effect that location of establishments had upon the cost of fuel. In that discussion it was pointed out that establishments in certain States in which natural gas was abundant had a decided advantage over those establishments located in other States where natural gas was not so abundant or where producer gas was used. This in general is true. However, because an establishment is located in a natural-gas State, it does not necessarily follow that it can secure cheap gas, for it may be located in a district in which the supply is giving out, or it may be entirely outside a natural-gas district, in which case it would have to pay a higher rate than other establishments more favorably located or be compelled to produce its own gas.

Two establishments, Nos. 35 and 39, with 21.78 and 19.95 per cent, respectively, had exceptionally high costs for fuel, power, etc., as compared with other establishments in this group and with the average for all establishments, their costs being more than twice as much as the average and over five times as much the lowest cost, 3.72 per cent in establishment No. 49. It is interesting to note that these two establishments were operated at a loss, and that if they were more nearly on a par with other establishments in regard to fuel they could greatly reduce their losses or operate at a profit.

Taxes, insurance, and salaries were relatively of little importance, the percentages for all establishments being $0.38,1.45$, and 1.77 per cent, respectively.

Royalty, being a payment for the use of certain automatic machines, was not found in the handmade window-glass group, and in compar- 
ing the labor costs in the two window-glass groups one must not lose sight of the fact that the lower labor cost in the machine group was somewhat offset by the payment of royalty. The average for royalty for the group was 3.68 per cent; three establishments showed no payments for royalty.

General expense showed an average of 6.17 per cent for all establishments, ranging from the highest in establishment No. 39, 13.72 per cent, to the lowest in establishment No. 45, 1.56 per cent.

Selling and bad debts accounted for 2.14 per cent of the 90.96 per cent comprising all costs in manufacturing, administration, and selling. In no establishment was the total selling in excess of 3.31 per cent of the sales value of goods produced, nor bad debts in excess of thirty-eight one-hundredths of 1 per cent. Eight establishments showed no losses from bad debts.

A gieater percentage of the establishments in the machine-made window-glass group were operated at a loss than in the handmade window-glass group. Three establishments showed operating losses when computed without depreciation and interest and two other establishments showed losses after charging depreciation and interest, making in all five establishments, or over 40 per cent of the number reported, operating at a loss. No establishment showed an operating profit as great as 10 per cent after charging depreciation and interest, and in contrast one establishment suffered a loss slightly over 15 per cent of the sales value of the goods produced, or, in other words, there is a difference of 24.9 per cent in the cost of production between establishments No. 39 and No. 42, which showed the greatest loss and the greatest profit.

\section{PLATE GLASS.}

Table 39, which follows, presents cost data in the form of percentages for plate glass, a branch of the industry whose product, like that of the two preceding groups, is used in the building trades. The percentages are based on the sales value of goods produced.

Data were secured for six establishments, one-half being located in Pennsylvania and one each in Ohio, Michigan, and Illinois.

This branch of the glass industry requires an exceptionally large amount of supplies, such as grinding sand, rock and lime, felt, emery, copperas, and muriatic acid for use in the grinding and polishing department, and for this reason a separate line was given to such supplies under materials, although they are not materials in the sense that they are constituent elements of the product. 
Table 39.-Percentages of Costs, by Specified Items, and Profits or Losses, Based on Total Sales Value of Goods Produced, by Establishments Mandfacturing Plate Glass.

\begin{tabular}{|c|c|c|c|c|c|c|c|}
\hline Items. & $\begin{array}{l}\text { Arcr- } \\
\text { age. }\end{array}$ & No. 50. & No. 51. & No. 52. & No. 53. & సo. 54. & No. 55. \\
\hline 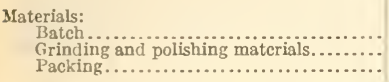 & $\begin{array}{r}11.38 \\
12.67 \\
2.73\end{array}$ & $\begin{array}{r}11.85 \\
10.02 \\
2.17\end{array}$ & $\begin{array}{r}12.54 \\
9.96 \\
2.25\end{array}$ & $\begin{array}{l}5.08 \\
7.12 \\
2.47\end{array}$ & $\begin{array}{r}14.05 \\
16.63 \\
2.61\end{array}$ & $\begin{array}{r}1202 \\
19.89 \\
2.60\end{array}$ & $\begin{array}{r}11.96 \\
10.12 \\
3.49\end{array}$ \\
\hline Total materials........ & 26.78 & 24.04 & 24.78 & 14.67 & 33.29 & 34.51 & 25.57 \\
\hline $\begin{array}{l}\text { Labor: } \\
\quad \text { Superintendent and foremen } \ldots \ldots \ldots \ldots \ldots \ldots \\
\text { Other factory labor } \ldots \ldots \ldots \ldots \ldots \ldots \ldots \ldots\end{array}$ & $\begin{array}{r}2.39 \\
31.37 \\
\end{array}$ & $\begin{array}{r}2.53 \\
32.10 \\
\end{array}$ & $\begin{array}{r}5.49 \\
37.81 \\
\end{array}$ & $\begin{array}{r}2.86 \\
32.32 \\
\end{array}$ & $\begin{array}{r}2.09 \\
25.60 \\
\end{array}$ & $\begin{array}{r}2.20 \\
30.76 \\
\end{array}$ & $\begin{array}{r}1.00 \\
31.71\end{array}$ \\
\hline Total labor........ & 33.76 & 34.63 & 43.30 & 35.18 & 27,69 & 32.96 & 32.71 \\
\hline $\begin{array}{l}\text { Fucl, power, light, and watcr.................. } \\
\text { Taxes, State, corporation, etc................. } \\
\text { Insurance and workmen's compensation...... }\end{array}$ & $\begin{array}{r}13.24 \\
1.03 \\
.73 \\
\end{array}$ & $\begin{array}{r}14.55 \\
1.07 \\
1.82 \\
\end{array}$ & $\begin{array}{r}19.28 \\
.72 \\
1.18 \\
\end{array}$ & $\begin{array}{r}14.72 \\
.59 \\
.36 \\
\end{array}$ & $\begin{array}{r}12.87 \\
.60 \\
.79 \\
\end{array}$ & $\begin{array}{r}10.19 \\
.45 \\
.46 \\
\end{array}$ & $\begin{array}{r}11.68 \\
2.10 \\
.48 \\
\end{array}$ \\
\hline 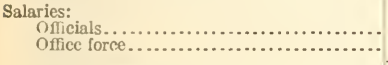 & $\begin{array}{l}1.49 \\
1.09 \\
\end{array}$ & $\begin{array}{l}4.23 \\
1.09 \\
\end{array}$ & $\begin{array}{r}1.88 \\
.87 \\
\end{array}$ & $\begin{array}{r}1.21 \\
.60 \\
\end{array}$ & $\begin{array}{r}1.04 \\
.92 \\
\end{array}$ & $\begin{array}{l}1.16 \\
1.00 \\
\end{array}$ & $\begin{array}{r}.90 \\
1.62 \\
\end{array}$ \\
\hline Total salaries..... & 2.58 & 5.32 & 2.75 & 1.81 & 1.96 & 2.16 & 2.52 \\
\hline General expens & 9.92 & 12.42 & 3.36 & 7.31 & 17.28 & 7.13 & 10.78 \\
\hline Total manufacturing and administration. & 88.04 & 93.85 & 95.37 & 74.64 & 94.48 & 87.86 & 85.84 \\
\hline $\begin{array}{l}\text { elling: } \\
\quad \text { Salesmen } \ldots . \ldots \ldots \ldots \ldots \ldots \ldots \ldots \ldots \ldots \\
\text { Other selling expense } \ldots \ldots \ldots \ldots \ldots \ldots \ldots\end{array}$ & $\begin{array}{r}.12 \\
.13 \\
\end{array}$ & & 49 & 39 & $\begin{array}{r}.35 \\
\cdots \cdot . \\
\end{array}$ & .05 & \\
\hline Total selling exp & .25 & ........... & .49 & .39 & .35 & .05 & .25 \\
\hline Bad debts $\ldots \ldots \ldots \ldots \ldots \ldots \ldots \ldots \ldots \ldots \ldots \ldots$ & .02 & $\cdots$ & ........ & $\ldots \ldots \ldots$ & .06 & $\ldots \ldots \ldots$ & .02 \\
\hline $\begin{array}{l}\text { Total cost of goods produced............. } \\
\text { Operating profit on goods produced, com- } \\
\text { puted without dcpreciation and interest ... } \\
\text { operating loss on goods produced, computcd } \\
\text { without depreciation and interest ........... }\end{array}$ & $\begin{array}{l}88.31 \\
11.69\end{array}$ & $\begin{array}{r}93.85 \\
6.15\end{array}$ & $\begin{array}{r}95.86 \\
4.14\end{array}$ & $\begin{array}{l}75.03 \\
24.97\end{array}$ & $\begin{array}{r}94.89 \\
5.11\end{array}$ & $\begin{array}{l}87.91 \\
12.09\end{array}$ & $\begin{array}{l}86.11 \\
13.89\end{array}$ \\
\hline Total sales value of goods produced..... & 100.00 & 100.00 & 100.00 & 100.00 & 100.00 & 100.00 & 100.00 \\
\hline $\begin{array}{l}\text { Depreciation } \\
\text { Interest paid } \ldots \ldots \ldots \ldots \ldots \ldots \ldots\end{array}$ & $\begin{array}{r}10.60 \\
1.48 \\
\end{array}$ & $\begin{array}{r}1.57 \\
\ldots \ldots \ldots \\
\end{array}$ & $\begin{array}{l}9.44 \\
2.63\end{array}$ & $\begin{array}{r}10.94 \\
3.08\end{array}$ & $\begin{array}{l}7.81 \\
1.67 \\
\end{array}$ & $\begin{array}{ll}7.89 \\
. . .\end{array}$ & $\begin{array}{r}18.36 \\
1.65 \\
\end{array}$ \\
\hline $\begin{array}{l}\text { Operating profit on goods produced, com- } \\
\text { puted with depreciation and interest........ } \\
\text { Operating loss on goods produced, computed } \\
\text { with depreciation and interest............... }\end{array}$ & .39 & 4.58 & 7.93 & 10.95 & 4.37 & 4.20 & 6.12 \\
\hline Miscellaneous income... & .68 & & & .......... & .87 & .40 & 1.70 \\
\hline 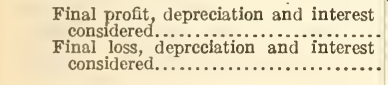 & .29 & 4. 58 & 7.93 & 10.95 & 3.50 & 4. 60 & 4. 42 \\
\hline
\end{tabular}

Grinding and polishing materials were 12.67 per cent of the sales value of goods produced by all establishments, which was greater than the percentage for batch, the principal item under materials in all other groups with the exception of Group XI, lighting goods. In three of the establishments the cost of batch was greater than grinding and polishing materials.

Total materials, with an average of 26.78 per cent for all establishments, ranged from 14.67 per cent in establishment No. 52 to 34.51 per cent in establishment No. 54, or in other words there was a difference of nearly 20 per cent between the lowest and highest cost of materials. 
The cost of labor for all establishments in this group was 33.76 per cent of the sales value of goods produced, of which 2.39 per cent was for supervision and 31.37 per cent for other factory labor. Three groups showed a lower total labor cost and eight a higher cost than the average for the group. The low labor cost in this branch of the glass industry as compared with other branches must be ascribed partly to the comparatively small amount of skilled labor required and partly to the higher percentage of cost for materials. In establishment No. 53 the percentage for total labor was 27.69 per cent, the lowest, and in establishment No. 51, it was 43.3 per cent, the highest.

Fuel, power, light, and water, with 13.24 per cent for all establishments and ranging from 10.19 to 19.28 per cent, was higher in this branch of the glass industry than in any other.

Of the remaining items in the total cost of goods produced, excluding depreciation and interest, general expense was the only one that showed a percentage of any great importance. When it is taken into consideration that this item is so general and is composed of all items that could not be assigned to other headings, it is not surprising that the percentages should be rather high and that they should vary considerably in the different establishments. The average for all establishments was 9.92 per cent, and ranged from 3.36 per cent in establishment No. 51 to 19.28 per cent in establishment No. 53.

Operating profit on goods produced, computed without depreciation and interest, was 11.69 per cent for all establishments and ranged from 4.14 per cent in establishment No. 51 to 24.97 per cent in establishment No. 52. The high percentage of profit in the latter establishment was due to its remarkably low cost of materials.

Allowing depreciation and interest as part of the cost of production, the establishments as a whole were operated at a loss, due princiaplly to the heavy charge for depreciation, which in this group amounted to 10.6 per cent, being more than twice that shown for other groups. Three establishments were operated at a loss and three at a profit.

\section{WIRE AND OPALESCENT GLASS.}

Table 40, which follows, presents cost data in the form of percentages for establishments manufacturing wire and opalescent goods, the last of those groups whose products are used in the building trades. The percentages are based on the sales value of the goods produced. 
Table 4 . - Percentages of Costs, by Specified Iteas and Profits or Losses, Baspi ix Total sales Value of Goods Produced, by Establishments Manupacturing Wire and Opalescent Glass.

\begin{tabular}{|c|c|c|c|c|c|c|c|c|c|c|}
\hline Items. & $\begin{array}{l}\text { Aver- } \\
\text { age. }\end{array}$ & $\begin{array}{l}\text { No. } \\
56 .\end{array}$ & $\begin{array}{l}\text { No. } \\
57 .\end{array}$ & $\begin{array}{l}\text { No. } \\
58 .\end{array}$ & $\begin{array}{l}\text { Yo. } \\
59 .\end{array}$ & $\begin{array}{l}\text { No. } \\
60 .\end{array}$ & Nio. & $\begin{array}{l}\text { No. } \\
\text { i2. }\end{array}$ & $\begin{array}{l}\text { io. } \\
\text { ij3. }\end{array}$ & $\begin{array}{l}\text { No. } \\
\text { bit. }\end{array}$ \\
\hline 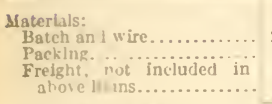 & $\begin{array}{r}24.74 \\
5.09 \\
.14\end{array}$ & $\begin{array}{r}11.96 \\
5.75 \\
\ldots . .\end{array}$ & $\begin{array}{r}13.39 \\
7.19 \\
\\
7\end{array}$ & $\begin{array}{r}13.88 \\
5.97 \\
\\
\end{array}$ & $\begin{array}{r}19.10 \\
5.91 \\
\\
\end{array}$ & $\begin{array}{r}13.82 \\
6.15 \\
3.95 \\
\end{array}$ & $\begin{array}{r}27.57 \\
3.20 \\
\\
\end{array}$ & $\begin{array}{r}33.70 \\
5.55\end{array}$ & $\begin{array}{r}22.53 \\
4.76 \\
\end{array}$ & $\begin{array}{r}25.77 \\
5.17 \\
\end{array}$ \\
\hline Toin1 materials.......... & 29.97 & 17.74 & 20.57 & 19.85 & 25.01 & 23.92 & 30.77 & 39.25 & 27.29 & 30.94 \\
\hline $\begin{array}{l}\text { Labor: } \\
\text { Superint wolent and foremen } \\
\text { Other intory labor........... }\end{array}$ & $\begin{array}{r}3.05 \\
20.95 \\
\end{array}$ & 19.47 & $\begin{array}{r}3.09 \\
34.55 \\
\end{array}$ & 18.86 & $\begin{array}{r}3.28 \\
22.27 \\
\end{array}$ & $\begin{array}{r}2.98 \\
15.21 \\
\end{array}$ & $\begin{array}{r}1.23 \\
18.23 \\
\end{array}$ & $\begin{array}{r}2.69 \\
27.91\end{array}$ & $\begin{array}{r}1.61 \\
23.71 \\
\end{array}$ & $\begin{array}{r}4.35 \\
18.78 \\
\end{array}$ \\
\hline Total lshor...... & 24.03 & 19.47 & 37.64 & $18 . \$ 6$ & 25.55 & 18.19 & 19.46 & 30.60 & 25.32 & 23.13 \\
\hline $\begin{array}{l}\text { Fuel, power, light, and water.. } \\
\text { Taxes. State, corporation, ete.. } \\
\text { Insurauc and workmen's eom- }\end{array}$ & $\begin{array}{r}10.13 \\
1.05\end{array}$ & $\begin{array}{r}14.18 \\
.70\end{array}$ & $\begin{array}{l}8.56 \\
2.16\end{array}$ & $\begin{array}{l}9.96 \\
2.01\end{array}$ & $\begin{array}{r}18.80 \\
.78\end{array}$ & $\begin{array}{r}5.19 \\
.58\end{array}$ & $\begin{array}{r}8.74 \\
.17\end{array}$ & $\begin{array}{r}3.68 \\
.57\end{array}$ & $\begin{array}{r}13.01 \\
.51\end{array}$ & $\begin{array}{r}10.63 \\
1.49\end{array}$ \\
\hline 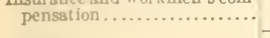 & 1.01 & .53 & 3.96 & .76 & .41 & .27 & 1.48 & 1.15 & .75 & .97 \\
\hline $\begin{array}{l}\text { Salarles: } \\
\text { Offieials...................... } \\
\text { Office force.............. }\end{array}$ & $\begin{array}{l}3.52 \\
1.52\end{array}$ & $\begin{array}{l}5.07 \\
1.69\end{array}$ & $\begin{array}{l}7.93 \\
5.16\end{array}$ & $\begin{array}{l}6.72 \\
1.67\end{array}$ & $\begin{array}{l}5.90 \\
1.16\end{array}$ & $\begin{array}{l}5.96 \\
3.10\end{array}$ & 1.09 & $\begin{array}{l}5.72 \\
1.70\end{array}$ & $\begin{array}{r}1.32 \\
.85 \\
\end{array}$ & $\begin{array}{l}3.65 \\
1.52 \\
\end{array}$ \\
\hline Total salarles.... & 5.04 & 6.76 & 13.09 & 8.39 & 7.06 & 9.06 & 1.09 & 7.42 & 2.20 & 5.17 \\
\hline General expense..... & $\overline{14.25}$ & 15.41 & 21.51 & 6.96 & 5.54 & 11.84 & 16.37 & 25.73 & 13.28 & 12.33 \\
\hline $\begin{array}{l}\text { Total manufaeturing and } \\
\text { administration......... }\end{array}$ & 85.51 & 74.79 & 107.49 & 66.79 & 83.15 & 69.05 & $78.0 \mathrm{~S}$ & 108.40 & 82.36 & 84.66 \\
\hline $\begin{array}{l}\text { Belling: } \\
\text { Salesmen } \ldots \ldots \ldots \ldots \ldots \ldots \ldots \\
\text { Cther selling expense : . . }\end{array}$ & $\begin{array}{r}2.83 \\
.89 \\
\end{array}$ & $\begin{array}{l}16.58 \\
11.64 \\
\end{array}$ & $\begin{array}{r}5.16 \\
\cdots \cdots \\
\end{array}$ & $\begin{array}{r}4.12 \\
.14 \\
\end{array}$ & $\begin{array}{r}4.71 \\
\cdots \cdots \\
\end{array}$ & $\begin{array}{r}1.53 \\
\cdots \cdots \\
\end{array}$ & $\begin{array}{r}.58 \\
\cdots \cdots \\
\end{array}$ & $\begin{array}{r}4.50 \\
\cdots \cdots \\
\end{array}$ & $\begin{array}{r}.93 \\
\ldots . . \\
\end{array}$ & $\begin{array}{l}2.76 \\
1.39 \\
\end{array}$ \\
\hline Total selling expense.... & 3.72 & 28.22 & 5.16 & 4.26 & 4.71 & 1.53 & .58 & 4.50 & .93 & 4.15 \\
\hline Bad debts. & .74 & 4.87 & 5.80 & .07 & 1.06 & 5.95 & 2.68 & & & \\
\hline $\begin{array}{l}\text { Total eost of goods pro- } \\
\text { duced................ } \\
\text { Operating profit on goods pro- } \\
\text { duced, eompinted without } \\
\text { deprelintlon and interest ... } \\
\text { Operatlog loss on goods pro- } \\
\text { duced, computed without } \\
\text { deprecistlon and interest..... }\end{array}$ & 89.97 & 107.88 & $\begin{array}{r}118.45 \\
\cdots \cdots \\
18.45\end{array}$ & $\begin{array}{l}71.12 \\
28.88\end{array}$ & $\begin{array}{l}88.92 \\
11.08\end{array}$ & $\begin{array}{l}76.53 \\
23.47\end{array}$ & $\begin{array}{l}\$ 1.34 \\
18.66\end{array}$ & $\begin{array}{l}112.90 \\
12.90 \\
12.9\end{array}$ & $\begin{array}{c}83.29 \\
16.71 \\
\ldots \ldots \\
\end{array}$ & $\begin{array}{l}\text { S8. } 81 \\
11.19\end{array}$ \\
\hline $\begin{array}{l}\text { Total sales value of goods } \\
\text { produced.............. }\end{array}$ & 100.00 & 100.00 & 100.00 & 100.00 & 100.000 & 100.00 & 100.00 & 100.00 & 100.00 & 100.00 \\
\hline $\begin{array}{l}\text { Deprechatlon } \ldots \ldots \ldots \ldots \ldots \ldots \ldots \\
\text { Interest pald } . . . \cdots \cdots \cdots \cdots\end{array}$ & $\begin{array}{l}4.57 \\
1.51\end{array}$ & $\begin{array}{r}5.70 \\
\cdots \cdots \cdots \\
\end{array}$ & $\begin{array}{l}3.60 \\
2.98\end{array}$ & $\begin{array}{r}1.75 \\
\cdots \cdots \cdots \\
\end{array}$ & $\begin{array}{l}1.98 \\
1.02\end{array}$ & $\begin{array}{r}3.02 \\
\cdots \cdots \\
\end{array}$ & $\begin{array}{r}3.83 \\
.12 \\
\end{array}$ & $\begin{array}{r}3.35 \\
\cdots \cdots \cdots \\
\end{array}$ & $\begin{array}{r}2.79 \\
.43\end{array}$ & $\begin{array}{l}6.14 \\
2.78\end{array}$ \\
\hline $\begin{array}{l}\text { Operating profit on goods pro- } \\
\text { duced, eomputed with de- } \\
\text { preciatlon and interest....... } \\
\text { Operating loss on goods pro- } \\
\text { duced, eomputed with de- } \\
\text { preclation and interest....... }\end{array}$ & 3.95 & 13.58 & 25.03 & 27.13 & 8.08 & 20.45 & 14.71 & 16.25 & 13.49 & 2.27 \\
\hline $\begin{array}{l}\text { Miscellaneous expense......... } \\
\text { Miscellaneous income........ }\end{array}$ & $\begin{array}{l}.18 \\
.97 \\
\end{array}$ & $\begin{array}{r}\cdots \\
.06 \\
\end{array}$ & & & & .94 & $\cdot$ & .37 & . & $\begin{array}{r}.37 \\
1.87 \\
\end{array}$ \\
\hline $\begin{array}{l}\text { Final profit, depreeis- } \\
\text { tlon and interest eon- } \\
\text { sldered................ } \\
\text { Flnal loss, depreeiation } \\
\text { and interest eonsidered. }\end{array}$ & 4. 74 & 13.52 & 25.03 & 27.13 & 8.08 & 21.39 & $\left|\begin{array}{c}14.71 \\
\cdots \cdots\end{array}\right|$ & 15.88 & 13.49 & 3.77 \\
\hline
\end{tabular}

Data were secured for nine establishments located in Pennsylvania, Indiana, Illinois, West Virginia, and Ohio. 'Three were in Pennsylvania, two each in Indiana and Illinois, and one each in West Virginia and Ohio. 
The total cost of materials was higher and the total cost of labor was lower in this group than in any other. It has been pointed out before that all items of cost and profit must add to 100 per cent, and if some items bear, comparatively, a high percentage of cost, then other items must bear a correspondingly low percentage of cost. This, howerer, does not account entirely for the high and low percentages of cost for these items, and other reasons must be assigned.

In the case of materials, this high cost was partly due to the inclusion of materials not common to other branches of the glass industry; especially was this true of those establishments producing goods in which wire was part of the cost of materials. In the case of labor, the low cost was partly due to the relatively small amount of skilled labor required.

The average cost of materials for all establishments was 29.97 per cent of the sales value of goods produced and ranged from 17.74 per cent in establishment No. 56 to 39.25 per cent in establishment No. 62. Batch and wire, on the average, constituted about 80 per cent and packing materials about 20 per cent of the total materials used.

Total labor, with an average of 24.03 per cent, varied from 18.19 per cent in establishment No. 60 to 37.64 per cent in establishment No. 57. Three establishments had a labor cost of less than 20 per cent and two over 30 per cent of the sales value of goods produced.

This group, next to the plate-glass group, showed the highest percentage of cost for fuel, power, light, and water, the average being 10.13 per cent. Four of the establishments showed a higher percentage of cost than the average, one establishment, No. 59, having 18.8 per cent, the highest shown.

Of the remaining items constituting total sales value of goods produced, general expense, with an average of 14.28 per cent for all establishments, was by far the most important. Selling expense showed a wide variation, being as low as 0.58 per cent and as high as 28.22 per cent, the average being 3.72 per cent. The other items, with the exception of salaries, 5.04 per cent, were relatively of little importance and need no comment.

Examination of the percentages for operating profit on goods produced, computed without depreciation and interest, will show that the establishments in this group were either very successful or very unsuccessful. In no establishment was the profit on the sales value of goods produced less than 10 per cent, and in establishment No. 58 the percentage of profit was 28.88 per cent. After charging depreciation and interest, six establishments showed operating profits ranging from 2.27 per cent to 27.13 per cent, and three establishments showed losses, the loss in each establishment being over 10 per cent and as high as 25.03 per cent in establishment No. 57.

\section{HANDMADE BOTTLES.}

Table 41, which follows, is the first of four tables that treat of the bottle and jar branch of the glass industry. 


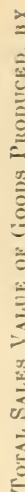

\begin{tabular}{|c|c|c|c|c|c|c|c|c|c|c|c|c|c|c|c|}
\hline $\begin{array}{l}\dot{B} \\
\dot{0}\end{array}$ & 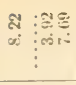 & $\mid \begin{array}{l}\Re \\
\vdots\end{array}$ & $\begin{array}{l}=\bar{x} \\
-\pi \\
-\pi\end{array}$ & | & 行 & $0 \overline{7}$ & \% & o & $\mid \begin{array}{l}x \\
\vdots \\
\vdots\end{array}$ & & 2 & & $=$ & $\stackrel{F}{=}$ & \\
\hline $\begin{array}{l}0 \\
i \\
i\end{array}$ & 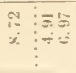 & $\begin{array}{l}\Xi \\
\tilde{\text { ส }}\end{array}$ & 承 & 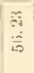 & 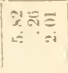 & ڤने & $\frac{\square}{8}$ & $\varrho$ & $\mid \begin{array}{l}\Xi \\
\Xi \\
\vdots\end{array}$ & $\therefore$ & 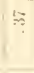 & 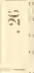 & 公 & $\begin{array}{c}\bar{x} \\
\dot{x}\end{array}$ & \\
\hline \% & $\begin{array}{l}a \\
\vdots \\
\vdots \\
\vdots\end{array}$ & $\begin{array}{l}0 \\
0 \\
0 \\
-1\end{array}$ & \begin{tabular}{l}
$\vdots$ \\
$\vdots$ \\
\hdashline
\end{tabular} & ב: & $\mid \begin{array}{ll}0.5 \\
=\end{array}$ & 令 & $\mid \begin{array}{l}\text { సิ } \\
\text { สิ }\end{array}$ & $\Xi$ & $\begin{array}{l}\approx \\
\approx\end{array}$ & $\overline{\bar{x}}$ & : & & 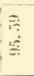 & $\bar{\square}$ & \\
\hline $\begin{array}{l}\pi \\
\vdots \\
j\end{array}$ & $\begin{array}{l}\equiv=\overline{-} \\
\equiv\end{array}$ & 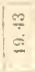 & $\begin{array}{l}\text { dive } \\
\text { if }\end{array}$ & $\begin{array}{l}5 \\
\dot{5}\end{array}$ & $\begin{array}{l} \pm 0 \div \\
\Xi\end{array}$ & 挆 & $\begin{array}{l}\delta \\
\approx \\
\sim\end{array}$ & ĩ & का & 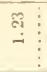 & $\stackrel{\overbrace{}}{\stackrel{2}{-}}$ & 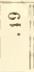 & $\bar{c}$ & $\begin{array}{l}\mathrm{S} \\
\stackrel{g}{2}\end{array}$ & \\
\hline 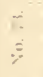 & $\begin{array}{l}= \\
=\vdots \\
\vdots\end{array}$ & $\stackrel{8}{\square}$ & 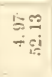 & 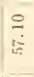 & 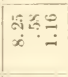 & : & \begin{tabular}{l}
$\Re$ \\
\hdashline \\
$\dot{R}$
\end{tabular} & 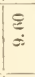 & 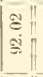 & $=8$ & ¿: & \& & $\stackrel{\square}{\Xi}$ & 웅 & \\
\hline$\stackrel{8}{8}$ & 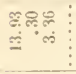 & $\mid \begin{array}{l}8 \\
1 \\
5\end{array}$ & $\begin{array}{l}\vdots \\
\vdots \\
\vdots \\
\vdots\end{array}$ & $\mid \begin{array}{l}5 \\
0 \\
0\end{array}$ & $\mid \begin{array}{l}\dot{x} \\
\dot{0} \\
\dot{0}\end{array}$ & \&i. & 它 & $\frac{1}{2}$ & {$\left[\begin{array}{l}E \\
\dot{a}\end{array} \mid\right.$} & $\stackrel{\mathrm{t}}{\mathrm{t}}$ & 5 & ฐ & $\begin{array}{l}\approx \\
\ddot{\mho}\end{array}$ & $\stackrel{\mathrm{C}}{\mathrm{c}}$ & \\
\hline$\dot{0}$ & 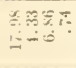 & 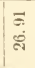 & 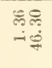 & $\begin{array}{l}E \\
\square \\
\square\end{array}$ & 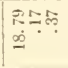 & 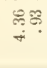 & $\mid \begin{array}{l}\bar{\AA} \\
\text { is }\end{array}$ & $\begin{array}{l}\overrightarrow{5} \\
\dot{\leftrightarrow}\end{array}$ & $\left|\begin{array}{l}m \\
\hdashline \\
\hdashline\end{array}\right|$ & $\stackrel{\cong}{\circ}$ & $\mid \begin{array}{l}\text { N } \\
\dot{\infty}\end{array}$ & & 苛 & & s. \\
\hline $\begin{array}{l}\dot{E} \\
\dot{\Sigma} \\
\ddot{z}\end{array}$ & 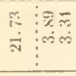 & $\begin{array}{l}\tilde{\delta} \\
\dot{\sigma} \\
\dot{\sigma}\end{array}$ & 요 & $\begin{array}{l}R \\
8 \\
8\end{array}$ & $\stackrel{8}{=}$ & $\begin{array}{l}\text { \&? } \\
\text { s. }\end{array}$ & $\mid \begin{array}{l}\delta \\
\infty\end{array}$ & $\vdots$ & 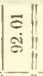 & 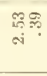 & $\begin{array}{l}\mathcal{Q} \\
\text { i } \\
\text { in }\end{array}$ & $\mid \begin{array}{l}\sigma \\
\text { s. }\end{array}$ & $\frac{8}{6}$ & $\stackrel{\varrho}{\circ}$ & \\
\hline $\begin{array}{l}\ddot{8} \\
\dot{\delta}\end{array}$ & $\begin{array}{l}508 \\
-100\end{array}$ & 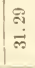 & $\begin{array}{l}x=5 \\
x \neq \\
\text { if }\end{array}$ & 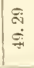 & $\vec{b}_{\infty}^{\infty}$ & 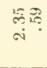 & $\begin{array}{l}\vec{E} \\
\text { si }\end{array}$ & $\begin{array}{l}\mathrm{N} \\
+\end{array}$ & $\left|\begin{array}{l}\vdots \\
\vdots \\
\dot{a}\end{array}\right|$ & 유 & R & $\approx$ & 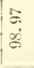 & $\stackrel{\%}{-}$ & \\
\hline $\begin{array}{l}y \\
\dot{y}\end{array}$ & 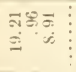 & $\mid \begin{array}{l}\mathscr{E} \\
\dot{\vec{d}}\end{array}$ & 就 & | & 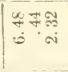 & $\vdots \bar{s}$ & 8 & $\begin{array}{l}\mathscr{E} \\
\dot{\tilde{\pi}}\end{array}$ & 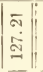 & $\overline{\mathrm{N}}$ & ส & & $\begin{array}{l}\text { : } \\
\text { : }\end{array}$ & $\vdots$ & \\
\hline $\begin{array}{l}\dot{z} \\
\dot{z}\end{array}$ & 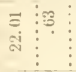 & उ. & ${ }_{0}^{0}$ & $\stackrel{5}{\vdots}$ & $\mid$\begin{tabular}{l}
1 \\
\hdashline
\end{tabular} & $\vec{b}^{x}$ & $\mid \begin{array}{l}\infty \\
\infty \\
\leftarrow\end{array}$ & : & 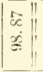 & & 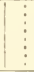 & & $\begin{array}{l}1 \\
\vdots \\
\vdots \\
\vdots\end{array}$ & $\cong$ & \\
\hline ż & 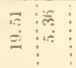 & $\mid \begin{array}{l}\infty \\
\vec{\omega}\end{array}$ & 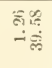 & $\mid \begin{array}{l}\overrightarrow{0} \\
0 \\
0\end{array}$ & 8 & 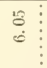 & $\begin{array}{l}3 \\
0 \\
0\end{array}$ & I & 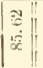 & & 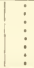 & ำ" & $\frac{8}{\infty}$ & $\begin{array}{l}\stackrel{g}{5} \\
\dot{I}\end{array}$ & \\
\hline 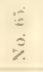 & 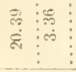 & 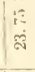 & S: & $\mid \begin{array}{l}\vec{b} \\
\dot{b} \\
\dot{d} \\
\sigma\end{array}$ & 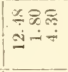 & $\begin{array}{l}E^{2} \\
\dot{\theta} \alpha\end{array}$ & $\begin{array}{l}\mathscr{z} \\
\dot{0}\end{array}$ & $\stackrel{\pi}{\pi}$ & 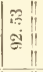 & & $\vdots$ & & ณิ & $\stackrel{5}{5}$ & \\
\hline 至 & 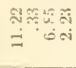 & $\mid \begin{array}{l}\tilde{\sigma} \\
\tilde{\tilde{\sigma}}\end{array}$ & - & : & $\mid \begin{array}{l}m \\
\dot{\infty}\end{array}$ & 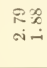 & $\vec{b}$ & $\frac{0}{6}$ & 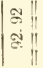 & चิ & $\stackrel{9}{-}$ & 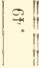 & $\frac{\overline{5}}{5}$ & $\frac{9}{2}$ & \\
\hline
\end{tabular}

ב

曾当

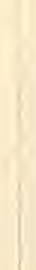

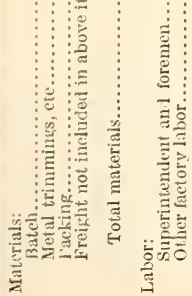

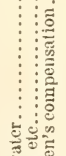

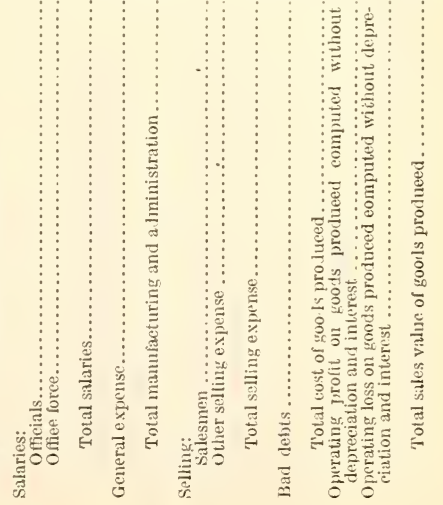


T'HE GLASS INDUSTRY.

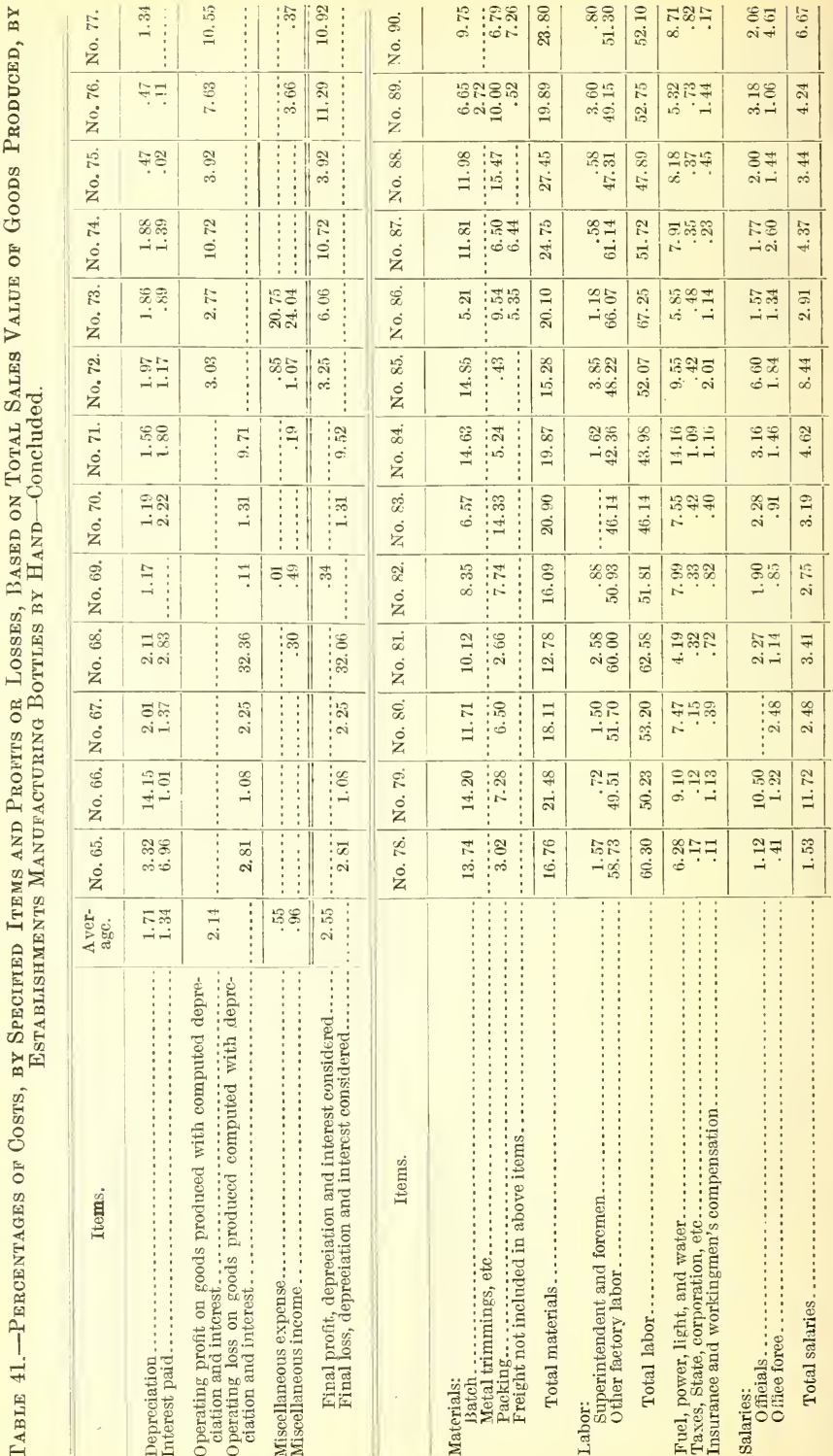




\begin{tabular}{|c|c|c|c|c|c|c|c|c|c|c|c|c|c|}
\hline $\begin{array}{l}\text { है } \\
\text { ¿i }\end{array}$ & $\mid \begin{array}{l}\equiv \\
\vdots\end{array}$ & $\because \overline{0}$ & $\bar{x}$ & $\because$ & $\overrightarrow{5}$ & $\dddot{\div}$ & $:$ & 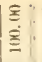 & 至に & $\stackrel{10}{-}$ & & & 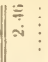 \\
\hline $\bar{\varnothing}$ & $\mid \begin{array}{l}x \\
x \\
x\end{array}$ & $\underline{-}$ & $\begin{array}{l}0 \\
\infty \\
\infty i\end{array}$ & इ" & $\approx$ & 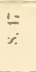 & $\vdots$ & 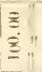 & 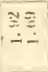 & $\div$ & & $\varepsilon$ & $\mid \begin{array}{l}8 \\
\text { in }\end{array}$ \\
\hline $\begin{array}{l}\text { हो } \\
\text { ले }\end{array}$ & $\mid \begin{array}{l}0 \\
\vdots \\
\vdots\end{array}$ & 리 & $\bar{g}$ & $\vdots$ & $\begin{array}{l}\approx \\
\vdots\end{array}$ & $\begin{array}{l}\bar{x} \\
\dot{x}\end{array}$ & $\vdots$ & $\mid \begin{array}{ll}\bar{z} & 1 \\
\dot{\delta} & \\
\vdots & n\end{array}$ & $\mathrm{E}$ & 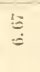 & : & & $\frac{5}{15}$ \\
\hline ळ & $\begin{array}{l}g \\
g\end{array}$ & $\bar{r}$ & $\mid \begin{array}{l}x \\
x\end{array}$ & $\div$ & $\begin{array}{l}19 \\
\vdots\end{array}$ & $\stackrel{2}{4}$ & $\vdots$ & $\left|\begin{array}{c}\Xi \\
\dot{\Xi} \\
\Xi\end{array}\right|$ & 10 & $\begin{array}{l}\mathscr{N} \\
\stackrel{N}{*}\end{array}$ & $\vdots \vdots$ & $\because 2$ & $\ddot{\ddot{\theta}}$ \\
\hline$\underset{\sim}{i}$ & 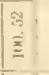 & 인? & $=$ & 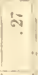 & $\stackrel{\circ}{\Xi}$ & $\vdots$ & $\ddot{\check{n}}$ & $\mid \begin{array}{c}\bar{\Xi} \\
\dot{c} \\
\underline{\Sigma}\end{array}$ & $\begin{array}{l}\text { के } \\
-2\end{array}$ & $\vdots \vdots$ & $\frac{9}{7}$ & & $\begin{array}{l}\vdots \\
\vdots \\
\vdots\end{array}$ \\
\hline نे & $\mid$\begin{tabular}{l|} 
\\
|
\end{tabular} & $\frac{x}{\text { ci }}:$ & $\frac{x}{i}$ & $\bar{a} \mid$ & $\ddot{\leftrightarrow}$ & 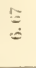 & $\vdots$ & $\left|\begin{array}{l}\varepsilon \\
\vdots \\
\dot{z} \\
=\end{array}\right| \mid$ & $\begin{array}{l}\hat{N} \bar{\sigma} \\
\therefore \dot{\infty}\end{array}$ & $\Longrightarrow$ & $\vdots \vdots$ & & $=\vdots$ \\
\hline 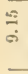 & $\mid \begin{array}{l}\infty \\
\bar{z}\end{array}$ & & $\begin{array}{l}\vdots \\
\vdots \\
\vdots\end{array}$ & $\vdots$ & 13 & $\stackrel{0}{5}$ & $\vdots$ & \begin{tabular}{|l|}
$\vdots$ \\
$\Xi$
\end{tabular} & $\left\{\begin{array}{l}=\Xi \\
\text { si }\end{array}\right.$ & $\vdots \vdots$ & \%. & & $\begin{array}{l}\vdots \\
\vdots \\
\vdots\end{array}$ \\
\hline $\begin{array}{l}x \\
\varrho\end{array}$ & 壬 & $x$ & $x$ & $\cong$ & $\hat{\overbrace{}}$ & : & $\vdots$ & $\mid$ & की: & 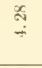 & $\vdots$ & & $\| \begin{array}{c}\vdots \\
\vdots \\
\vdots\end{array}$ \\
\hline $\begin{array}{l}\overline{0} \\
\text { is }\end{array}$ & 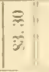 & $\tilde{\xi}$ & 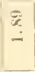 & $E 1$ & 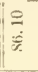 & \begin{tabular}{l}
$\Xi$ \\
$\cong$ \\
\hdashline
\end{tabular} & $\vdots \vdots$ & $\left|\begin{array}{l|}\mid \xi \\
\dot{\delta} \\
\mid\end{array}\right|$ & 90 & $\begin{array}{l}\vec{a} \\
\stackrel{a}{*}\end{array}$ & $\begin{array}{l}\vdots \\
\vdots\end{array}$ & & $\| \begin{array}{l}\overrightarrow{\mathrm{g}} \\
\stackrel{\mathrm{g}}{-} \vdots\end{array}$ \\
\hline$\overline{0}$ & $\left|\begin{array}{l|}\Xi \\
\xi\end{array}\right|$ & 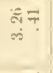 & $\begin{array}{l}0 \\
0\end{array}$ & $\theta$ & $\frac{9}{18}$ & $\stackrel{E}{\div}$ & $\begin{array}{c}\vdots \\
\vdots \\
\vdots\end{array}$ & $\mid \begin{array}{l}8 \\
\delta \\
8 \\
\end{array}$ & 198 & iิ & $\begin{array}{l}\vdots \\
\vdots \\
\vdots\end{array}$ & है. & $\stackrel{5}{2}$ \\
\hline$\stackrel{2}{2}$ & $\left|\begin{array}{c||}m \\
0 \\
0 \\
c\end{array}\right|$ & $\begin{array}{r}\Re \\
-\vdots \\
\vdots\end{array}$ & $\stackrel{\circledast}{-}$ & & $\mid \begin{array}{l}\dot{\sigma} \\
\dot{\delta}\end{array}$ & 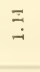 & $\vdots$ & $\left|\begin{array}{l}\S \\
\Xi \\
\Xi\end{array}\right|$ & $\begin{array}{r}5 \\
\vdots \\
\vdots\end{array}$ & $\vdots$ & 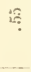 & & $: 18$ \\
\hline$\stackrel{2}{\div}$ & 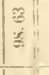 & $\tilde{a}$ & $\frac{\Xi}{\alpha i}$ & 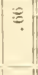 & है & $\vdots$ & $\underset{\sim}{2}$ & $\left|\begin{array}{l}\tilde{E} \\
\tilde{\Xi} \\
\Xi\end{array}\right|$ & $\mid \begin{array}{c}\varrho g \\
-i o i\end{array}$ & $\vdots$ & 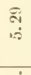 & $\vdots$ & ל气 \\
\hline i & $\left|\begin{array}{l}\pi \\
z\end{array}\right|$ & ‡! & 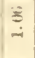 & 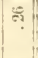 & $\| \frac{0}{8}$ & $\begin{array}{l}\pi \\
\varrho\end{array}$ & $\vdots$ & 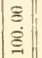 & F & $\begin{array}{l}\vec{x} \\
\dot{0}\end{array}$ & & & $\|$\begin{tabular}{ll}
$\vec{\infty}$ & $\vdots$ \\
0 & $\vdots$ \\
\hdashline & $\vdots$
\end{tabular} \\
\hline
\end{tabular}

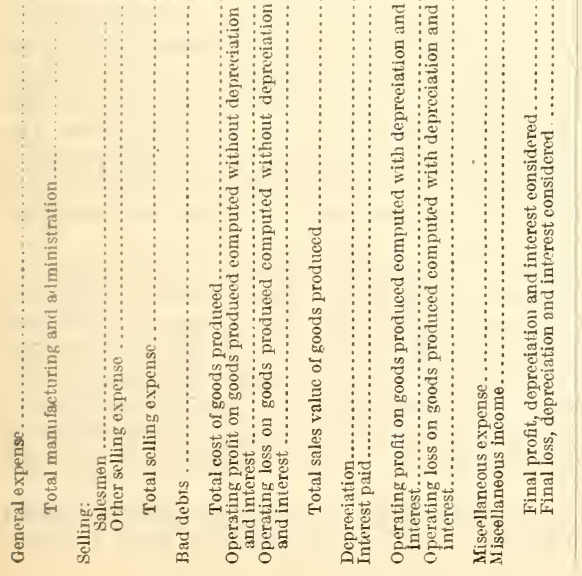


Data were secured for 26 establishments, located in Pennsylvania, New Jersey, Indiana, Illinois, New York, Maryland, Virginia, West Tirginia, and Louisiana. About one-third of the establishments were in Pennsylvania and about one-fourth in New Jersey, no other State having more than three of the establishments reporting.

The total cost of materials for the establishments in this group, like the preceding groups, is composed almost entirely of the cost of two items, batch and packing, although a new factor, that of metal trimmings, etc., enters into the cost of materials in a few of the establishments.

Apparently it is not the custom for the manufacturers of handmade bottles to furnish metal trimmings, etc., for in only six of the establishments were such materials reported. One, however, must take into consideration the different kinds of bottles produced; that is, whether prescription, beer, soda, whisky, or cologne bottles, and whether fancy or plain, some of which may be equipped with patented stoppers, to suit the demands of customers. Even in those establishments reporting such data it does not follow that the whole product of that establishment was equipped with trimmings.

Batch, with an average of 11.22 per cent for all establishments and with a range from 22.01 per cent in establishment No. 67 to 5.21 per cent in establishment No. 86, was with few exceptions, the most important item in the total cost of materials.

Packing, with an average of 6.85 per cent, varied from 15.47 per cent in establishment No. 88 to 0.43 per cent in establishment No. 85. This variation was due principally to the amount of packing required and the kind of bottles produced. An establishment which manufactures, say, soda bottles, may be located in the same city as a bottling concern and a great part of its product disposed of to that concern, in which case the cost of packing would be of little importance, whereas, if the greater part of the product were disposed of to outside concerns, the cost of packing would be increased on account of the extra and better materials required in packing the product for safe shipment.

As indicated by the title given to this group, the product was handmade and required a highly skilled class of labor, especially in blowing. It is only natural, then, that the percentages for total labor for this group are high, being on the average more than 50 per cent of the sales value of goods produced. In 15 establishments the total labor cost was more than 60 per cent, in 13 establishments it was between 50 and 60 per cent, in 7 establishments between 40 and 50 per cent, and only in 1 establishment was the labor cost less than 40 per cent.

Fuel, power, etc., salaries, and general expense, with averages of $8.13,4.67$, and 5.16 per cent, respectively, were items of expense which carried nearly 18 per cent of the sales value of goods produced, and together with materials and labor accounted for over 90 per cent of the cost, so that other items of expense, after taking into consideration operating profit of 5.19 per cent, constituted less than 5 per cent of the sales value. In 5 establishments the percentage of cost for fuel, power, etc., was over 10 per cent, being 18.79 per cent in establishment No. 71 .

Of the 26 establishments in this group, 22 showed operating profit computed, without depreciation and interest, ranging from 1.03 per 
cent to 14.0 s per cent, and 4 showed losses with a range from 1.36 to 27.42 per cent.

After charging depreciation and interest, the operating profit for all establishments was reduced from 5.19 per cent to 2.14 per cent, making a charge of 3.05 per cent for these items. This charge varies greatly in the different establishments, according to the manner in which the owners look upon depreciation; the amount so charged was not determined in many instances until the company found its earnings would warrant a charge for depreciation.

\section{MACHINE-MADE BOTTLES.}

Table 42 presents cost data in the form of percentages for those establichments manufacturing machine-made bottles. The percentagis are based on the sales value of goods produced.

Data were secured for 18 establishments, located in Ohio, West Virginia, Indiana, Hlinois, New Jersey, Pennsylvania, Wisconsin, and Oklahoma. Ahout $\$ 0$ per cent of the establishments were located in the first four States named.

The average cost of materials for all establishments in the machinemade bottle group was somewhat higher than in the handmade bottle group, heing 25.4 per cent in the former and 20.63 per cent in the latter.

Of the different items under materials, two, metal trimmings, etc., and packing, showed a wide variation in the percentages and account principally for the variation in the total cost of materials. The variation in metal trimmings, etc., was due partly to the demands of the trade; that is, some customers prefer to secure such trimmings from concerns other than the manufacturers of bottles, while others depend entirely upon the bottle manufactures for such supplies. The variation in packing materials depended largely upon how the bottles were packed. If in carload lots, the cost of packing materials will be small, but if packed in crates, the cost of such materials will be greatly increased.

$102511^{\circ}-17 \longrightarrow 9$ 


\begin{tabular}{|c|c|c|c|c|c|c|c|c|c|c|c|c|c|c|}
\hline ro & 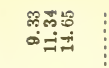 & 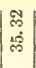 & $\stackrel{\vec{\infty}}{-}$ & \&े & $\mid \begin{array}{l}\underset{\text { జิ }}{\infty} \\
\infty\end{array}$ & J. & 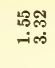 & $\mid \begin{array}{l}\infty \\
+\infty\end{array}$ & $\stackrel{\mathbb{N}}{\mathbb{T}}$ & $\begin{array}{l}\text { J } \\
\dot{\infty}\end{array}$ & สุ\& & 点 & & \\
\hline ำ & 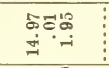 & $\stackrel{\dot{\sim}}{-1}$ & sp & $\begin{array}{l}\infty \\
\stackrel{\infty}{2} \\
\text { న్ల }\end{array}$ & $\mid \begin{array}{ll}0 & 10 \\
0 & 0 \\
\text { s. } & -1\end{array}$ & ग. & 凩 & $\begin{array}{l}28 \\
8 \\
\text { i }\end{array}$ & 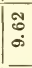 & 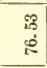 & $\stackrel{\sim}{-}$ & $\stackrel{7}{-}$ & $\stackrel{\infty}{\because}$ & \\
\hline ஜ் & 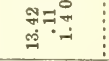 & 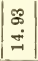 & ले & ले & 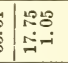 & 요 & 2. & o & 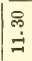 & $\begin{array}{l}\text { ชै } \\
\text { कं }\end{array}$ & 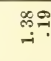 & 祦 & 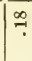 & \\
\hline 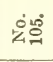 & 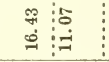 & 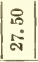 & $\stackrel{\infty}{*}$ & ๙ & 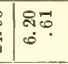 & $\because$ & $\varnothing 8$ & i & $\stackrel{5}{0}$ & $\begin{array}{l}\text { N } \\
\text { ล }\end{array}$ & $\stackrel{-\infty}{-i}$ & $\stackrel{\infty}{-}$ & 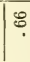 & \\
\hline 穴完 & 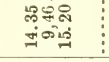 & $\mid \begin{array}{l}\vec{b} \\
\dot{\infty} \\
\end{array}$ & $\stackrel{5}{\circ}$ & ๙ & ปี & 육 & : & $\frac{N}{a}$ & $\mid \begin{array}{l}\text { 운 } \\
\text { i }\end{array}$ & $\begin{array}{l}\infty \\
\infty \\
\infty\end{array}$ & $\begin{array}{l}\text { ळ. } \\
\text { के }\end{array}$ & $\stackrel{\infty}{\circ}$ & F & \\
\hline 。่ & 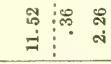 & 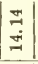 & $\stackrel{\infty}{\infty}$ & 8 & 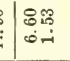 & :̊ำ & $ஜ \%$ & 胥 & $\begin{array}{l}\mathscr{2} \\
\text { as }\end{array}$ & $\begin{array}{l}\infty \\
\stackrel{\infty}{*}\end{array}$ & 8 & 8 & & \\
\hline ஜ் & 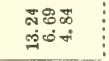 & $\left|\begin{array}{l}n \\
\dot{a}\end{array}\right|$ & "0. & $\stackrel{\check{c}}{m}$ & 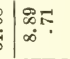 & $\dddot{\wp}$ & ำ & $\underset{\infty}{\infty}$ & ๓ึ & 品 & ঙొ & i & in & \\
\hline 㑒实 & 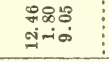 & $\begin{array}{l}\vec{m} \\
\text { ๙ุ }\end{array}$ & 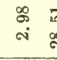 & क्ष & 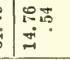 & 7 & $\stackrel{80}{80}$ & $\mid \begin{array}{l}\infty \\
\text { a }\end{array}$ & $\begin{array}{l}\pi \\
\text { m. }\end{array}$ & $\begin{array}{l}\infty \\
\stackrel{8}{1}\end{array}$ & \%क & is & & \\
\hline ○் & 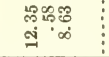 & 点 & I & ल) & $\mid \begin{array}{l}\sigma^{\infty} \\
1 \\
-1\end{array}$ & $\vec{\infty}$. & $\stackrel{\infty}{-\infty}$. & $\mid \begin{array}{l}R \\
\text { i } \\
\text { in }\end{array}$ & $\begin{array}{l}\mathscr{S} \\
\infty\end{array}$ & 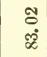 & ๙ึ. & के & ஜ. & \\
\hline 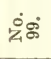 & $\begin{array}{l:l}0 & 0 \\
0 & 0 \\
\infty & 0\end{array}$ & 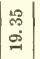 & 疋 & ल & 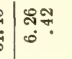 & . & 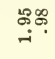 & ஜ & in & $\underset{⿱ 乛}{ \pm}$ & $\begin{array}{l}\text { कृर } \\
\text { ส่. }\end{array}$ & ๙ึ & $\approx$ & \\
\hline 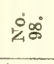 & 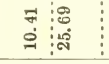 & $\mid \begin{array}{l}0 \\
\dot{0} \\
e\end{array}$ & สี ร & 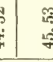 & $\mid \begin{array}{l}\overrightarrow{0} \\
0\end{array}$ & $\begin{array}{l}\infty \\
\stackrel{\infty}{?} ?\end{array}$ & 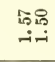 & $\begin{array}{l}0 \\
0 \\
\infty\end{array}$ & I & $\begin{array}{l}8 \\
8 \\
8\end{array}$ & 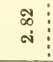 & $\mid \begin{array}{l}\infty \\
\infty \\
\text { ล่ }\end{array}$ & & \\
\hline d & 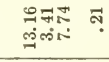 & 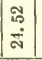 & मे & \& & काँ & ले. & تีన్ & $\begin{array}{l}\Re \\
\stackrel{f}{*} \\
\text { c. }\end{array}$ & 量? & $\begin{array}{l}49 \\
28 \\
18\end{array}$ & $\begin{array}{l}\text { సె. } \\
\text { is. }\end{array}$ & 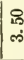 & 疍 & \\
\hline 80 & 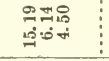 & 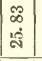 & $\stackrel{\circ}{\check{1}}$ & है & $: \begin{array}{l}\sigma^{\infty} \\
\infty \\
0\end{array}$ & $\stackrel{\oplus}{\dddot{m}}$ & 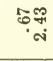 & $\stackrel{0}{\text { is }}$ & $\begin{array}{l}8 \\
\infty \\
\infty\end{array}$ & 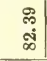 & $\begin{array}{l}\tilde{N}^{\infty} \\
\stackrel{+}{*} .\end{array}$ & $\stackrel{48}{4}$ & เด? & \\
\hline$z$ & 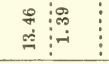 & $\mid \begin{array}{l}\infty \\
\infty \\
+ \\
-1\end{array}$ & 둥 & m & 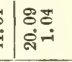 & $F$ & 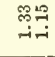 & \begin{tabular}{l}
$\infty$ \\
\multirow{\alpha}{*}{} \\
a
\end{tabular} & 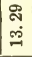 & $\begin{array}{l}N \\
8 \\
8\end{array}$ & 호․ & à & $\stackrel{9}{?}$ & \\
\hline 宅 & 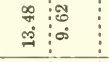 & 年 & $\begin{array}{l}\text { न } \\
\therefore\end{array}$ & ๙ิ & 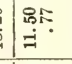 & สี & ชูก & 路 & 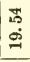 & $\begin{array}{l}8 \\
\dot{5}\end{array}$ & \begin{tabular}{l}
0 \\
\hdashline$\vdots$ \\
-1
\end{tabular} & 19 & ชั & \\
\hline i & 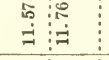 & 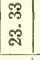 & 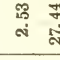 & - & 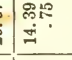 & 5 & జొన్ & 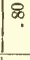 & 占 & $\begin{array}{l}\infty \\
: \\
\dot{\infty} \\
\dot{\infty}\end{array}$ & ำ & & คี & \\
\hline ஜ் & 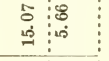 & 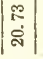 & \& & 5 & 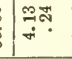 & $\begin{array}{l}\infty \\
: \\
-1\end{array}$ & 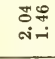 & 品 & $\stackrel{\pi}{\pi}$ & \begin{tabular}{l}
\multirow{0}{0}{} \\
$\infty$ \\
$\infty$ \\
$\infty$
\end{tabular} & $\underset{a}{2}$ & & भ & \\
\hline ஜ & 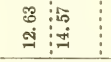 & $\begin{array}{l}\text { Aิ } \\
\text { Aิ } \\
\end{array}$ & 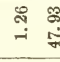 & & 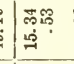 & ชี & สี & $\mid \begin{array}{l}8 \\
0 \\
0\end{array}$ & $\stackrel{0}{\dddot{1} .}$ & 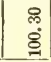 & $\bar{N}$ & స & & \\
\hline 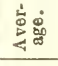 & 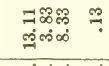 & $\begin{array}{l}\text { 웅 } \\
\text { is }\end{array}$ & $\stackrel{\substack{2 \\
-}}{-\infty}$ & 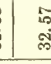 & \begin{tabular}{l|l}
5 & ริ \\
i & के \\
\end{tabular} & ํํ. & มี⿻ & $\overrightarrow{0}$ & 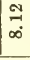 & $\begin{array}{l}\text { 2ิ } \\
\text { ळ. }\end{array}$ & 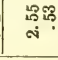 & $\stackrel{\infty}{\infty}$ & ตี & \\
\hline 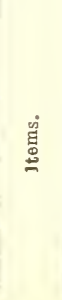 & 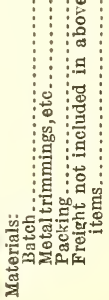 & 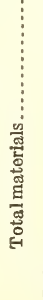 & 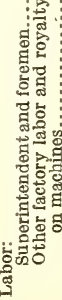 & 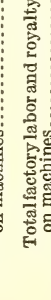 & 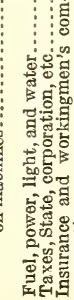 & 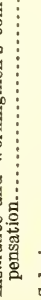 & 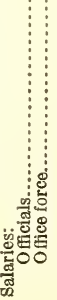 & 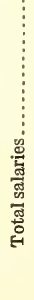 & 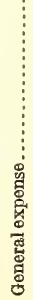 & 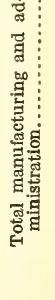 & 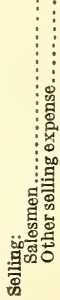 & 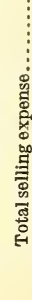 & 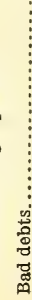 & \\
\hline
\end{tabular}




\begin{tabular}{|c|c|c|c|c|c|c|c|}
\hline & & 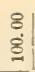 & $\begin{array}{l}\alpha= \\
m=\end{array}$ & ల్ల & & $\begin{array}{c}\vdots \\
\vdots \\
\vdots\end{array}$ & $\begin{array}{l}\text { నึ } \\
10\end{array}$ \\
\hline $\begin{array}{l}\infty \\
\dot{\infty} \\
\dot{\mathrm{d}}\end{array}$ & & $\begin{array}{l}8 \\
8 \\
8\end{array}$ & $i: 8$ & ¿ี & & 85 & $\begin{array}{l}\text { สื. } \\
\text { ฉ่ }\end{array}$ \\
\hline $\begin{array}{l}\mathscr{8} \\
\stackrel{-}{-1}\end{array}$ & & $\begin{array}{l}8 \\
8 \\
8\end{array}$ & ๙ૈ. & $\begin{array}{l}: 8 \\
: 0 \\
2\end{array}$ & & $\infty 2$ & $\stackrel{0}{\stackrel{2}{2}}$ \\
\hline $\begin{array}{l}\stackrel{8}{\tau} \\
\dot{i}\end{array}$ & & $\begin{array}{l}8 \\
\text { है }\end{array}$ & $\|_{\infty} \underset{.}{\infty}$ & $\stackrel{\circ}{\circ}$ & & & $\begin{array}{l}\stackrel{\circ}{0} \\
\stackrel{0}{0}\end{array}$ \\
\hline$\stackrel{m}{2}$ & & $\begin{array}{l}8 \\
\text { हे }\end{array}$ & s: & $\begin{array}{l}50 \\
\stackrel{0}{0}\end{array}$ & & 吾 & $\begin{array}{l}\vec{\infty} \\
=\end{array}$ \\
\hline ๙ూ & & $\begin{array}{l}8 \\
8 \\
8\end{array}$ & $\underset{\sim}{\infty}=$ & ลี & & $\vdots \because$ & $\begin{array}{l}\text { ㅇ. } \\
\text { ส่ }\end{array}$ \\
\hline$\stackrel{\beth}{\Xi}$ & & $\begin{array}{l}8 \\
8 \\
8\end{array}$ & $\begin{array}{l}\text { : } \\
\vdots \circ \\
10\end{array}$ & $\begin{array}{l}\approx \\
\stackrel{0}{0}\end{array}$ & & $\begin{array}{c}\infty \\
- \\
-1\end{array}$ & 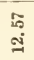 \\
\hline $\begin{array}{l}\mathscr{\&} \\
\cong\end{array}$ & & $\begin{array}{l}8 \\
8 \\
8 \\
\end{array}$ & 露 & $\begin{array}{l}\& \\
\dot{\pi} \\
\end{array}$ & ; & $\vdots \infty$ & $\begin{array}{l}\infty \\
\infty \\
\pm\end{array}$ \\
\hline లే & & $\begin{array}{l}8 \\
8 \\
8\end{array}$ & $\begin{array}{l}30 \\
30 \\
30-1\end{array}$ & స్ & $\vdots$ & $\because$ & $\stackrel{8}{\circ}$ \\
\hline तु & & $\begin{array}{l}8 \\
\delta \\
8\end{array}$ & औ5 & $\stackrel{8}{8}$ & 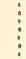 & ఏఃृ & 总 \\
\hline & $\stackrel{\infty}{\sim}$ & $\begin{array}{l}8 \\
\Xi \\
\Xi\end{array}$ & 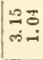 & 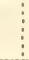 & ప & 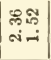 & $\vdots$ \\
\hline $\begin{array}{l}\text { \% } \\
\text { के }\end{array}$ & & $\begin{array}{l}8 \\
8 \\
8\end{array}$ & 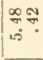 & $\stackrel{\Re}{\overparen{2}}$ & & & 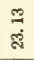 \\
\hline $\begin{array}{l}\text { F } \\
\dot{=}\end{array}$ & & $\begin{array}{l}8 \\
8 \\
8\end{array}$ & $\overbrace{\infty}^{\circ:}$ & รี & & & $\stackrel{\text { \& }}{-}$ \\
\hline $\begin{array}{l}\mathscr{\infty} \\
\tilde{\infty}\end{array}$ & & $\begin{array}{l}8 \\
8 \\
8\end{array}$ & $\stackrel{2}{2}$. & $\begin{array}{l}\text { ช્ઠ } \\
\text { ช่ }\end{array}$ & . & $\mid \begin{array}{ll}\infty \\
m\end{array}$ & \\
\hline $\begin{array}{l}\mathscr{8} \\
\text { สู่ }\end{array}$ & & $\begin{array}{l}8 \\
8 \\
8\end{array}$ & $=0$ & $\begin{array}{l}\text { : } \\
\text { : }\end{array}$ & & & $\begin{array}{l}\stackrel{\Xi}{\circledR} \\
\text { త్ }\end{array}$ \\
\hline 2 & & $\begin{array}{l}8 \\
8 \\
8\end{array}$ & $\begin{array}{l}\infty \\
m^{\circ} \\
\infty^{\circ}\end{array}$ & $\stackrel{\infty}{\stackrel{\infty}{\sim}}$ & : & & $\begin{array}{l}\infty \\
\stackrel{\infty}{\circ}\end{array}$ \\
\hline 후 & & $\begin{array}{l}8 \\
8 \\
8\end{array}$ & $\mid \begin{array}{l}\infty \bar{\infty} \\
\dot{m}-1\end{array}$ & $\stackrel{8}{\circ}$ & & & : \\
\hline : & .5 & $\begin{array}{l}8 \\
8 \\
8\end{array}$ & 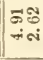 & & $\stackrel{s}{\infty}$ & & \\
\hline-7 & & $\begin{array}{l}8 \\
8 \\
8\end{array}$ & $\|$ & $\stackrel{0}{=}$ & & $m \infty$ & $\stackrel{2}{\stackrel{2}{9}}$ \\
\hline
\end{tabular}

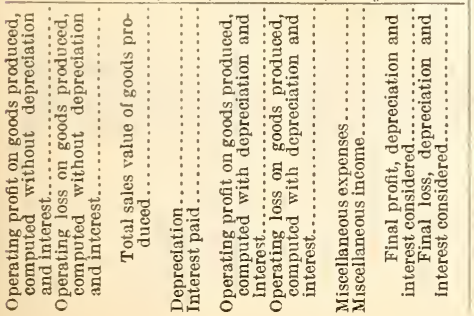


A comparison of the labor costs for the handmade product and the machine-nuade product will show a difference of about 20 per cent in faror of the machine-made product. The average for the former group was 53 per cent and for the latter 32.57 per cent. This, howerer, was not true in individual establishments, for there were some establishments in the machine group which had high percentages for labor cost. An enumeration of the percentages for total labor will show that one establishment had a cost of 56.6 per cent, four between 40 and 50 per cent, nine between 30 and 40 per cent, three between 20 and 30 per cent, and one less than 20 per cent of the sales value of goods produced.

Fuel, power, light, and water, with an average of 9.92 per cent for all establishments and ranging from 2.47 to 20.09 per cent; salaries, with an average of 3.01 per cent and ranging from 0.80 to 6.96 per cent; general expense, with an average of 8.12 per cent and ranging from 0.46 to 19.54 per cent; and selling expense, with an average of 3.08 per cent and ranging from 0.24 to 5.07 per cent were the only other items constituting total cost of goods produced that showed an average cost of over 1 per cent of the sales value of goods produced.

The items, taxes, insurance, and bad debts for all establishments were less than 1 per cent, although in some individual establishments the percentages were above 1 per cent, but in no establishment did they reach 2 per cent of the sales value of goods produced.

Operating profit on goods produced, computed without depreciation and interest, for all establishments was 16.14 per cent, which was reduced to 11.61 per cent after charging depreciation and interest, and after taking into consideration miscellaneous expense and income the final profit was 12.15 per cent.

Two establishments showed losses both before and after charging depreciation and interest, and three a final loss, the inclusion of the third establishment being due to miscellaneous expense in establishment No. 45.

The greatest loss suffered by any establishment after charging depreciation and interest was 8.07 per cent in establishment No. 91, and the greatest profit was 23.13 per cent in establishment No. 97 . Two other establishments had operating profits, after charging depreciation and interest, of over 20 per cent, seven had profits between 10 and 20 per cent, and five less than 10 per cent, only one of the latter in excess of 5 per cent.

On the whole, the establishments manufacturing bottles by machine were more successful than those manufacturing bottles by hand.

HAND AND MACHINE MADE BOTTLES.

Table 43, which follows, presents cost data in the form of percentages for establishments manufacturing bottles by hand and machine. The percentages are based on the sales value of goods produced. 


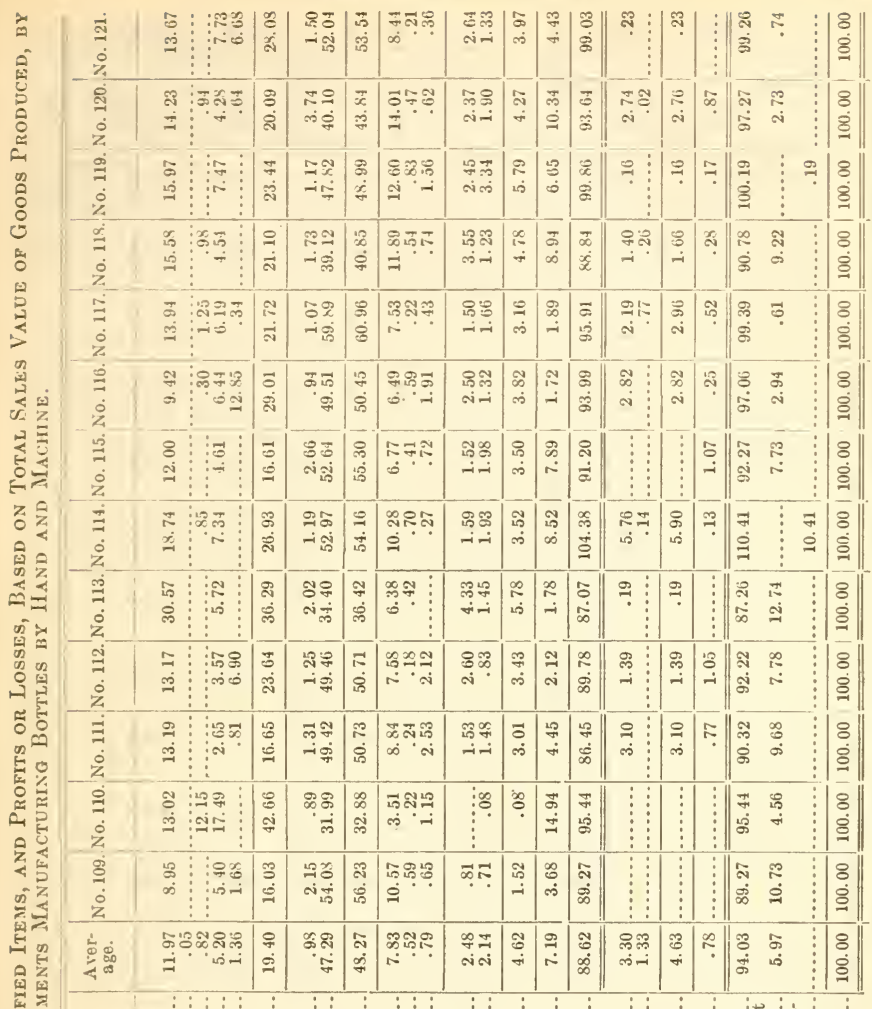




\begin{tabular}{|c|c|c|c|c|c|c|c|c|c|c|}
\hline $\begin{array}{l}\dot{\Xi} \\
\dot{0} \\
\dot{z}\end{array}$ & 冓 & สิ & & :ส্ล & $\begin{array}{l}\stackrel{1}{9} \\
\dot{0} \\
\dot{z}\end{array}$ & $\begin{array}{l:c}\infty & \vdots \\
0 & \vdots \\
0 & \vdots\end{array}$ & $\mid \begin{array}{l}0 \\
-1\end{array}$ & : & $\begin{array}{l}4 \\
4 \\
\dot{4}\end{array}$ & $\mid \begin{array}{ll}\infty \\
0\end{array}$ \\
\hline \begin{tabular}{l} 
क्षे \\
$\dot{0}$ \\
\multicolumn{2}{c}{}
\end{tabular} & 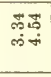 & $\frac{19}{10}$ & ఏః & \begin{tabular}{l}
$\vdots$ \\
$\vdots$ \\
\hdashline \\
\end{tabular} & $\begin{array}{l}\text { 离 } \\
\dot{0} \\
z\end{array}$ & $\begin{array}{l}\stackrel{8}{0} \\
\stackrel{-}{\oplus}\end{array}$ & $\begin{array}{l}8 \\
8 \\
\oplus \\
0\end{array}$ & ผูสำ & 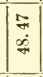 & $\mid$\begin{tabular}{ll|}
$\infty$ & $\vdots$ \\
\hdashline & $\cdots$ \\
\hdashline & $\vdots$
\end{tabular} \\
\hline $\begin{array}{l}\stackrel{\Phi}{\Xi} \\
\dot{0}\end{array}$ & $\begin{array}{l}\infty \\
\infty \\
=\infty \\
=10\end{array}$ & $\stackrel{ \pm}{ \pm}$ & $\vdots_{\substack{\infty \\
\hdashline}}$ & 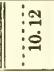 & 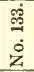 & 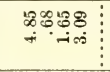 & $\mid \begin{array}{l}\hat{a} \\
\dot{a} \\
0\end{array}$ & 구워 & $\begin{array}{l}\vec{\sigma} \\
\dot{g} \\
\dot{\sigma}\end{array}$ & 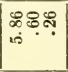 \\
\hline $\begin{array}{l}0 \\
: \\
\dot{0} \\
z\end{array}$ & $\begin{array}{l}\text { 국으 } \\
\text { 섬 }\end{array}$ & $\begin{array}{l}8 \\
0 \\
0\end{array}$ & & $\mid \begin{array}{ll}8 & \vdots \\
0 & \vdots\end{array}$ & $\begin{array}{l}\text { वें } \\
\dot{0} \\
\dot{0}\end{array}$ & 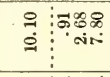 & 氶 & 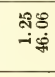 & $\mid$\begin{tabular}{l}
$\overrightarrow{0}$ \\
\multirow{4}{*}{}
\end{tabular} & ஐ⿺辶: \\
\hline$\stackrel{\check{1}}{\ddot{1}}$ & कేరే & a & i़ & in & $\begin{array}{l}\dot{0} \\
\dot{0} \\
\dot{0}\end{array}$ & 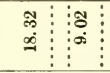 & 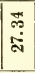 & 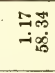 & \begin{tabular}{l|}
$\overrightarrow{6}$ \\
08 \\
8
\end{tabular} & 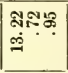 \\
\hline $\begin{array}{l}\dot{0} \\
\dot{0} \\
\dot{0}\end{array}$ & $\begin{array}{l}\sigma_{\text {ô }}^{\infty} \\
\text { fi }\end{array}$ & $\stackrel{\text { జొ }}{\pi}$ & : & 战 & $\begin{array}{l}\dot{9} \\
\dot{0} \\
\dot{0}\end{array}$ & 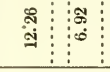 & $\mid \begin{array}{l}\infty \\
9 \\
9\end{array}$ & 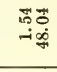 & $\left|\begin{array}{l|}\infty \\
\mathfrak{c} \\
\dot{q} \\
\dot{q}\end{array}\right|$ & 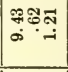 \\
\hline $\begin{array}{l}00 \\
: \\
\dot{0}\end{array}$ & 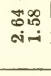 & $\begin{array}{l}\text { का } \\
\text { is }\end{array}$ & & $\mid \begin{array}{ll}\vec{b} & \vdots \\
0 & \vdots \\
\infty & \vdots\end{array}$ & 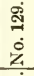 & 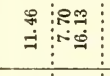 & 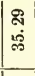 & 距 & $\left|\begin{array}{l}\mathbb{N} \\
0 \\
0 \\
\dot{m}\end{array}\right|$ & 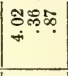 \\
\hline $\begin{array}{l}\dot{I} \\
\dot{8} \\
\dot{z}\end{array}$ & 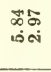 & ๙ิ & : & $\vdots$ & 客. & $\begin{array}{l}\text { क } \\
19\end{array}$ & $\mid \begin{array}{l}8 \\
8 \\
\end{array}$ & 施 & $\mid \begin{array}{l}8 \\
0 \\
\text { ํ. }\end{array}$ & $\mid \begin{array}{ll}\infty & 0 \\
0 & 0 \\
0 & -1 \\
\end{array}$ \\
\hline$\stackrel{\stackrel{9}{二}}{\stackrel{0}{Z}}$ & 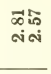 & ஜ্ల & & 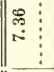 & $\begin{array}{l}\dot{\mathrm{I}} \\
\dot{\mathrm{g}}\end{array}$ & $\begin{array}{l}\mathscr{\infty} \\
\stackrel{\infty}{=}\end{array}$ & 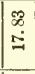 & कึ. & 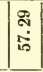 & 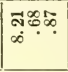 \\
\hline $\begin{array}{l}\text { İ } \\
\dot{0} \\
z\end{array}$ & 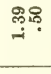 & $\begin{array}{l}\mathscr{8} \\
\text { id }\end{array}$ & & $\mid \begin{array}{ll}\infty & \vdots \\
\infty & \vdots \\
10 & \vdots\end{array}$ & $\begin{array}{l}\text { जे } \\
\dot{0} \\
z\end{array}$ & 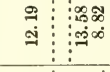 & | & 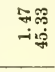 & $\left|\begin{array}{l}\infty \\
\infty \\
\dot{\sigma}\end{array}\right|$ & $\mid \begin{array}{l}\underset{\infty}{\infty} \infty \\
\dot{a} \\
\dot{q}\end{array}$ \\
\hline $\begin{array}{l}\dot{\Xi} \\
\dot{0} \\
\dot{z}\end{array}$ & 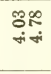 & $\stackrel{\infty}{\infty}$ & ఏ: & $\|$\begin{tabular}{l}
$\approx$ \\
\hdashline
\end{tabular} & $\begin{array}{l}\stackrel{1}{3} \\
\dot{0} \\
\dot{2}\end{array}$ & $\begin{array}{l:l} & 0 \\
\stackrel{\infty}{0} & \vdots \\
= & \vdots\end{array}$ & 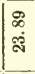 & 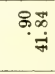 & \begin{tabular}{l}
2 \\
\multirow{2}{*}{}
\end{tabular} & 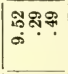 \\
\hline$\stackrel{1}{3}$ & $\begin{array}{l}8 \\
0 \\
0 \\
0 \\
\vdots\end{array}$ & $\vdots \begin{array}{c}0 \\
\vdots \\
\vdots\end{array}$ & & :- & $\begin{array}{l}\stackrel{3}{3} \\
\dot{0} \\
\dot{z}\end{array}$ & $\begin{array}{l}\infty \\
\stackrel{\Xi}{=}\end{array}$ & 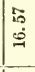 & 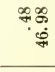 & 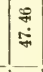 & | వ్రా \\
\hline $\begin{array}{l}8 \\
\stackrel{0}{0} \\
\dot{0} \\
\dot{z}\end{array}$ & 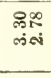 & 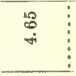 & 58 & 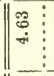 & $\begin{array}{l}\text { ホี } \\
\dot{0} \\
z\end{array}$ & $\begin{array}{l:l}8 \\
\end{array}$ & 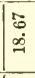 & $\begin{array}{l}\text { 워 } \\
\text { - }\end{array}$ & $\begin{array}{l}\mathscr{m} \\
\dot{\xi}\end{array}$ & S: \\
\hline 它宫 & 족 & $\begin{array}{l}\stackrel{8}{8} \\
\text { i }\end{array}$ & ஜ. & 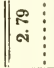 & สิ่ & 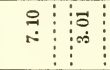 & $\begin{array}{l}7 \\
0 \\
0\end{array}$ & $\begin{array}{l}=15 \\
-i \\
-\dot{0}\end{array}$ & $\stackrel{\infty}{\stackrel{1}{6}}$ & : \\
\hline 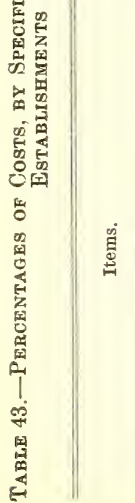 & $\begin{array}{c}\vdots \\
\vdots \\
\vdots \\
\vdots \\
0\end{array}$ & 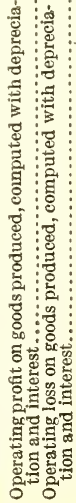 & 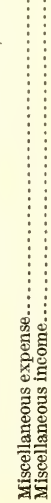 & 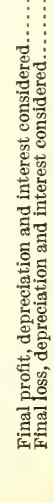 & हี่ & 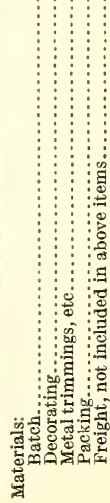 & 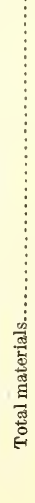 & 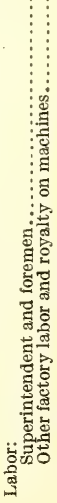 & 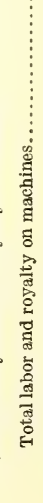 & 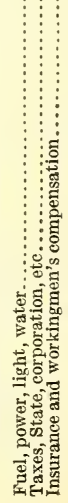 \\
\hline
\end{tabular}




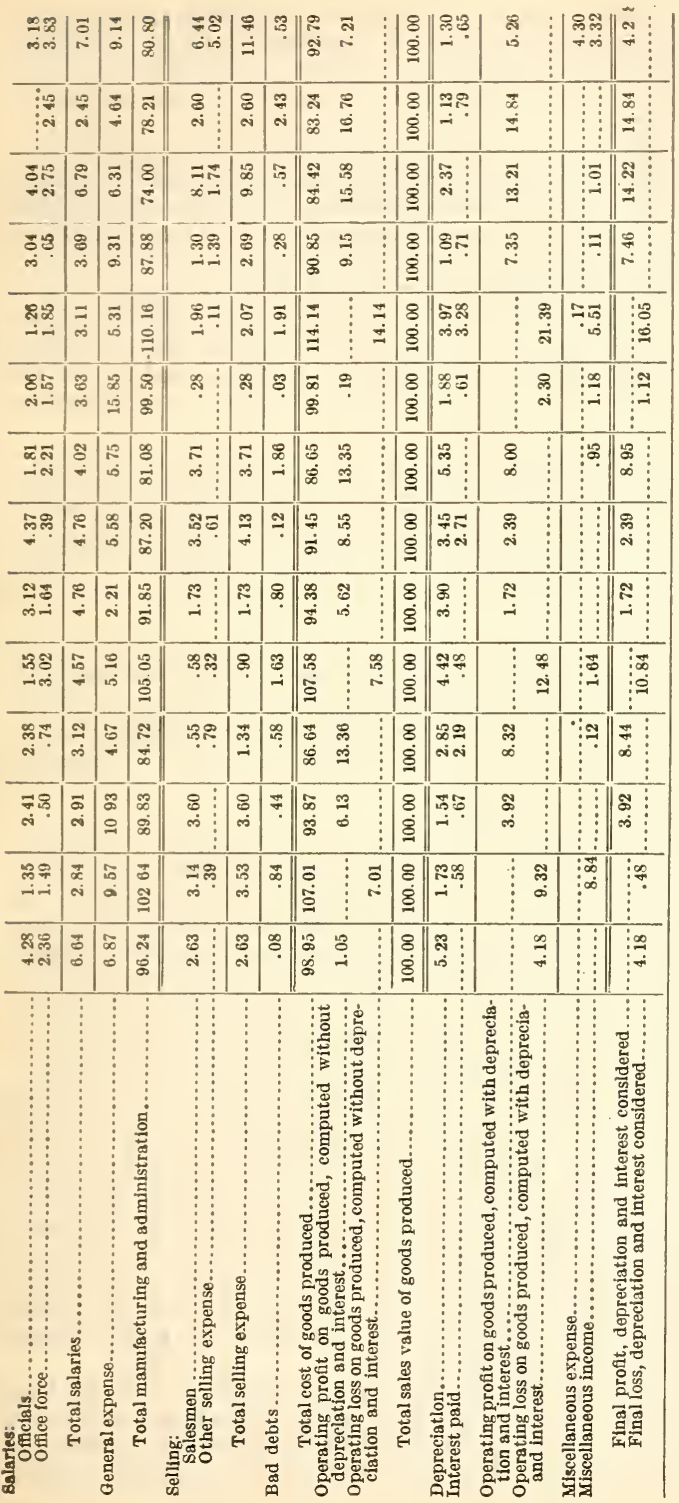


Data were secured for 27 establishments in this group, and next to Group I handmade window glass is the largest group in point of number of establishments included. These establishments were located in 10 States, mainly in Pennsylvania, Ohio, New Jersey, Indiana, and New York.

The wide variation in the percentages for metal trimmings, etc., and in packing found in the establishments of the two preceding groups was also found in the establishments of this group, and the reasons previously given for this variation need not be repeated, as they also account for the variations in this group.

Total cost of materials, with an average of 19.4 per cent, was lower than in either of the other bottle groups. The very high cost of materials in establishment No. 110 was due to the large amount expended for metal trimmings and packing material, and this was one of the establishments in which the cost of materials was greater than the cost of labor.

Labor was higher in this group than in the machine group but less than in the hand group, the arerage for all establishments being 48.27 per cent as against 32.57 per cent in the machine group and 53 per cent in the hand group. Three establishments had a labor cost of over 60 per cent of the sales value of goods produced, 10 had a cost between 50 and 60 per cent, 11 between 40 and 50 per cent, and 3 less than 40 per cent.

Fuel, power, light, and water, with an average of 7.83 per cent for all establishments and a range from 3.51 per cent in establishment No. 110 to 14.01 per cent in establishment No. 120, was an item of considerable magnitude and one over which an establishment has little control. Some plants were favorably located in respect to fuel and had the benefit of cheap gas, while other plants were not so favorably located in this respect.

Salaries, general expense, and selling, with averages of 4.62, 7.19, and 4.63 per cent, respectively, and varying considerably in the different establishments, were items of expenses more or less under the control of the management. A study of the percentages for these items in the different establishments will to some extent indicate those which were operated economically. However, an unfavorable conclusion should not be drawn against those establishments whose percentages appear to be high, as conditions affecting these items can not be given without the possibility of identifying establishments.

Of the 27 establishments in this group, 22 showed an operating profit, computed without depreciation and interest, ranging from 0.19 to 16.76 per cent, and 5 showed losses ranging from 0.19 to 14.14 per cent. After charging depreciation and interest, the number operating at a profit was reduced from 22 to 15 and the number operating at a loss was increased from 5 to 12 . Establishment No. 134 had a profit of 14.84 per cent and establishment No. 131 had a loss of 21.39 per cent. In the matter of profit the establishments in the hand group and the hand and machine group were, on the average, about on an equality, but both groups are at a considerable disadvantage when compared with the machine group.

An examination of the percentages paid for interest discloses that two of the five establishments which showed no charges for interest paid were operated at a loss, and the loss in these two establishments must be ascribed to reasons other than the lack of sufficient working 
capital. Establishments Nos. 111, 119, and 120 showed comparatively high percentages for interest and two were operated at a loss.

JARS.

Table 44, which follows, presents cost data in the form of percentages for establishments manufacturing jars, and is the last of the four tables relating to the bottle groups. The percentages are based on the sales ralue of goods produced.

Data were obtained for 13 establishments, of which 6 were located in Pennsyliania, 3 in West Virginia, and 1 each in New York, Ohio, Illinois, and Oklahoma. 


\begin{tabular}{|c|c|c|c|c|c|c|c|c|c|c|c|c|c|}
\hline 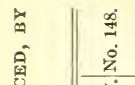 & ปึ่ & $\ddot{8}$ & $\stackrel{\infty}{\infty}$ & 施 & $\underset{\infty}{\infty}$ & 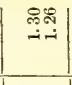 & î & के & $\left|\begin{array}{l}\vec{\infty} \\
\text { ळ் }\end{array}\right|$ & กิ. & $\stackrel{\sim}{\sim}$ & i & $\frac{2}{\infty}$ \\
\hline $\begin{array}{l}\stackrel{i}{-1} \\
\dot{0} \\
\dot{\not r}\end{array}$ & & $\mid \begin{array}{l}8 \\
8 \\
\dot{n} \\
0\end{array}$ & $\underset{-\pi}{+\infty}$ & 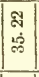 & $\vec{\infty}:$ & $\infty \approx$ & $\mid \begin{array}{c}\infty \\
\stackrel{-}{-}\end{array}$ & \begin{tabular}{|l|}
8 \\
45 \\
45
\end{tabular} & $\begin{array}{l}\text { नี } \\
\dot{\infty}\end{array}$ & & \begin{tabular}{|l|}
$\curvearrowleft$ \\
$\approx$ \\
$\infty$
\end{tabular} & $\stackrel{\cong}{\beth}$ & $\begin{array}{l}8 \\
\infty \\
\infty\end{array}$ \\
\hline $\begin{array}{l}\text { in } \\
\dot{0} \\
\dot{0}\end{array}$ & & $\begin{array}{l}0 \\
\dot{8} \\
\dot{8}\end{array}$ & 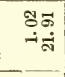 & $\begin{array}{l}\Re \\
\text { มี่ }\end{array}$ & 어요. & 복 & \begin{tabular}{|l}
$\overrightarrow{5}$ \\
- \\
-
\end{tabular} & $\overrightarrow{+}$ & $\mid$\begin{tabular}{|l|} 
\\
5 \\
5 \\
5
\end{tabular} & సొ & 幽 & 离 & 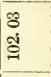 \\
\hline 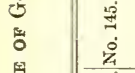 & 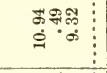 & $\mid$ & Fิ & 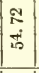 & นึ่ & ๙ิने & $\mid \begin{array}{l} \pm \\
\dot{\infty}\end{array}$ & â & $\left|\begin{array}{l}8 \\
10 \\
10\end{array}\right|$ & $\begin{array}{l}\text { Fै } \\
\text { नी }\end{array}$ & 站 & 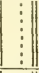 & $\begin{array}{l} \pm \\
8\end{array}$ \\
\hline $\begin{array}{l}\dot{J} \\
\dot{0} \\
\dot{\circ}\end{array}$ & 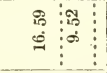 & $\begin{array}{l}7 \\
\text { वें }\end{array}$ & 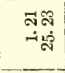 & 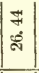 & 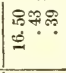 & 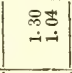 & $\mid \begin{array}{l}\vec{\infty} \\
\dot{\sim}\end{array}$ & $\left|\begin{array}{l}8 \\
\infty \\
\infty\end{array}\right|$ & \begin{tabular}{|l}
8 \\
$\dot{\infty}$
\end{tabular} & $\begin{array}{l}\text { हेढ" } \\
\text { ज. }\end{array}$ & 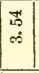 & $\$ 8$ & 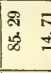 \\
\hline 孚 & $\begin{array}{l:l}\infty & 0 \\
o & \vdots \\
\alpha & \infty\end{array}$ & $\mid \begin{array}{l}8 \\
8 \\
\text { के }\end{array}$ & 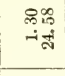 & $\mid \begin{array}{l}\infty \\
\infty \\
\infty \\
\alpha\end{array}$ & 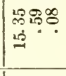 & $\underset{-1}{\infty}$ & $\mid \begin{array}{l}\text { g } \\
- \\
-\end{array}$ & $\left|\begin{array}{l}\infty \\
\infty \\
i\end{array}\right|$ & 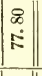 & 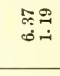 & 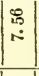 & $\vec{\infty}$. & $\begin{array}{l}7 \\
\square \\
\infty \\
\infty\end{array}$ \\
\hline $\begin{array}{l}\text { Ij } \\
\text { ¿ }\end{array}$ & 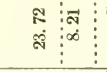 & $\left|\begin{array}{c}\approx \\
\dot{m}\end{array}\right|$ & $\begin{array}{l}\text { R. } \\
\text { is } \\
\text { No }\end{array}$ & $\left|\begin{array}{c}\tilde{a} \\
\dot{z}\end{array}\right|$ & $\mid \begin{array}{l}\hat{\infty}=\square \\
\Leftrightarrow\end{array}$ & 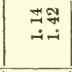 & $\left|\begin{array}{l}: \\
i \\
\text { i }\end{array}\right|$ & $\left|\begin{array}{l}\infty \\
a \\
\infty \\
\infty\end{array}\right|$ & $\left|\begin{array}{c}\vec{\infty} \\
\infty \\
\infty\end{array}\right|$ & $\underset{\text { 小 }}{\infty}$ i & $\left|\begin{array}{l}\hat{\sigma} \\
\dot{\sigma}\end{array}\right|$ & $\stackrel{\text { g. }}{\dot{-1}}$ & $\begin{array}{l}\infty \\
\text { ๙่ }\end{array}$ \\
\hline $\begin{array}{l}\exists \\
\pm \\
\dot{Z}\end{array}$ & 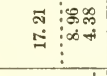 & $\mid$ & 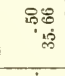 & $\left|\begin{array}{l}0 \\
0 \\
0\end{array}\right|$ & డేలి & $\begin{array}{l}88 \\
8-1 \\
-1\end{array}$ & $\mid \begin{array}{l}\infty \\
\infty \\
\infty \\
\infty\end{array}$ & 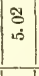 & $\mid \begin{array}{l}\infty \\
\infty \\
\infty\end{array}$ & $\underset{\infty}{\infty}$ & $\infty$ & & $\mid \begin{array}{ll}\infty & 5 \\
\infty & 1 \\
\infty & \pm\end{array}$ \\
\hline 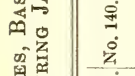 & 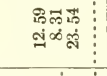 & $\begin{array}{l}\sharp \\
7 \\
j\end{array}$ & : & $\mid \begin{array}{l}7 \\
\text { में } \\
\text { म }\end{array}$ & 赵里施 & 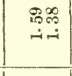 & $\mid \begin{array}{l}\overrightarrow{5} \\
\text { à }\end{array}$ & $\left|\begin{array}{l}\infty \\
0 \\
+ \\
+\end{array}\right|$ & $\left|\begin{array}{l}\infty \\
\delta \\
\delta\end{array}\right|$ & $\begin{array}{l}\infty \\
1 \\
\infty\end{array}$ & $\left|\begin{array}{l}\infty \\
0 \\
0 \\
\infty\end{array}\right|$ & $\infty$ & {$\left[\begin{array}{ll}\infty & 8 \\
\approx & 8 \\
1 & -1\end{array}\right.$} \\
\hline 鹈 & 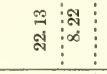 & 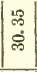 & 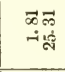 & जิ & מొ & 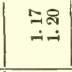 & $\mid$\begin{tabular}{l|}
$\hat{\infty}$ \\
ô \\
in
\end{tabular} & $\left|\begin{array}{c}\mathscr{8} \\
\ddot{\alpha} \\
\dot{\alpha}\end{array}\right|$ & $\mid \begin{array}{c}0 \\
0 \\
\infty^{2}\end{array}$ & $\begin{array}{l}\text { सह } \\
\text { की }\end{array}$ & $\mid$\begin{tabular}{c}
$\infty$ \\
\hdashline \\
+
\end{tabular} & $\infty$ & $\begin{array}{ll}2 & 5 \\
2 & 5 \\
\infty & 9\end{array}$ \\
\hline $\begin{array}{l}\text { مें } \\
\stackrel{0}{\circ} \\
\dot{2}\end{array}$ & 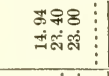 & $\left|\begin{array}{l}\vec{m} \\
\dot{\omega} \\
\dot{\theta}\end{array}\right|$ & : & $\left|\begin{array}{l}\mathfrak{R} \\
\mathfrak{2} \\
\text { มี่ }\end{array}\right|$ & 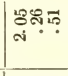 & 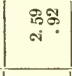 & $\mid$\begin{tabular}{l|}
$\overrightarrow{1}$ \\
$\infty$ \\
$\infty$
\end{tabular} & $\left|\begin{array}{l}\overrightarrow{0} \\
0 \\
0\end{array}\right|$ & $\left|\begin{array}{l}10 \\
8 \\
8\end{array}\right|$ & $\ddot{0}$ & $\mid \begin{array}{c}E \\
\text { - } \\
-1\end{array}$ & : & $\begin{array}{ll}\stackrel{f}{1} & 8 \\
\infty & 0\end{array}$ \\
\hline 嵴 & 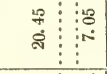 & 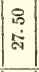 & $\begin{array}{l}2: 8 \\
\stackrel{2}{-1} \\
-4\end{array}$ & $\mid \begin{array}{l}\overrightarrow{3} \\
0 \\
0 \\
\infty\end{array}$ & 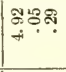 & $\begin{array}{c}8: 9 \\
i=\end{array}$ & $\mid \begin{array}{l}i \\
a \\
a\end{array}$ & $\mid \begin{array}{l}\vec{N} \\
0\end{array}$ & $\mid \begin{array}{l}2 \\
1 \\
1\end{array}$ & હ્ర & ङ & : & 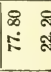 \\
\hline $\begin{array}{l}\dot{9} \\
\stackrel{9}{\circ} \\
\dot{8}\end{array}$ & 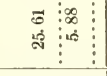 & $\left|\begin{array}{c}P \\
\dot{m}\end{array}\right|$ & 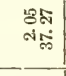 & $\left|\begin{array}{l}\tilde{m} \\
\tilde{m} \\
\tilde{\sigma}\end{array}\right|$ & 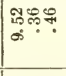 & 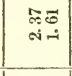 & $\mid \begin{array}{c}\infty \\
\vdots \\
\infty \\
\infty\end{array}$ & $\left|\begin{array}{l}n \\
\infty \\
20\end{array}\right|$ & $\mid$ & 고요 & : & $\left|\begin{array}{l}\infty \\
\infty \\
0\end{array}\right|$ & $\mid \begin{array}{ll}9 & 5 \\
\text { के } & \infty\end{array}$ \\
\hline 安焉 & 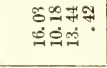 & $\mid \begin{array}{l}5 \\
0 \\
0\end{array}$ & 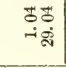 & $\begin{array}{l}\infty \\
0 \\
0 \\
0 \\
0\end{array}$ & దే & $\stackrel{\infty}{\infty}$ & $\begin{array}{l}\hat{a} \\
\text { a }\end{array}$ & $\begin{array}{l}\text { 总 } \\
\text { in } \\
\text { is }\end{array}$ & $\mid \begin{array}{l}\infty \\
i \\
0 \\
0 \\
0\end{array}$ & 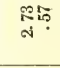 & $\mid$ & $\stackrel{\infty}{\circ}$ & {$\left[\begin{array}{ll}\bar{\infty} & 0 \\
\& & 0\end{array}\right.$} \\
\hline 恋 & 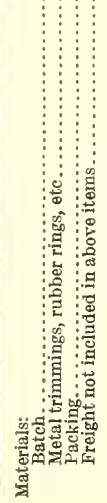 & 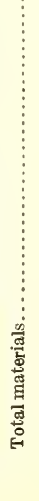 & 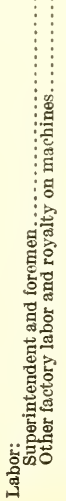 & 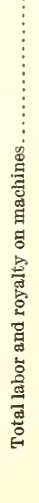 & 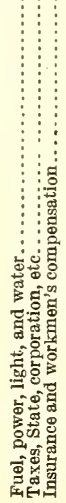 & 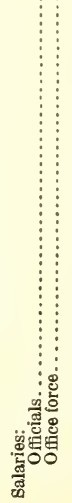 & 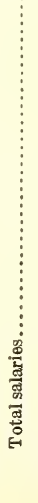 & 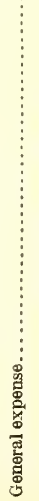 & 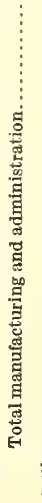 & 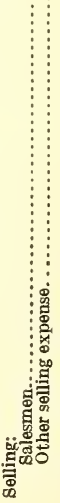 & 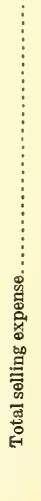 & 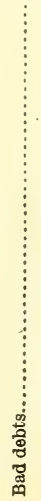 & 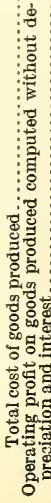 \\
\hline
\end{tabular}




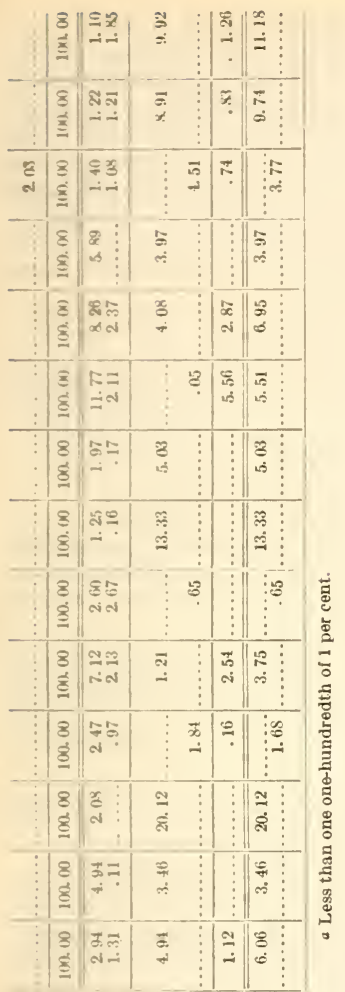

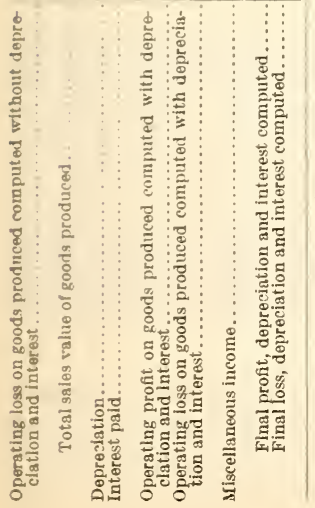


This group and the one making wire and opalescent goods, Group IV, were the only groups which on the average showed a higher percentage of cost for materials than for labor. The average for materials in all establishments in this group was 40.07 per cent, being exceeded by the percentages in establishments Nos. 138, 140, 146, and 148. The high average for materials in this group and the high percentages in the individual establishments were due to the exceptionally large expenditures for metal trimmings, etc., or packing, or both. A perusal of the percentages for these items will indicate the extent to which metal trimmings, etc., were furnished by the establishments and the amount of packing material required.

Royalty paid for the use of automatic machines has been included with labor. This was found necessary to avoid disclosing the identity of establishments and to offset the objections of the owners of the machines, who thought that if such data were shown separately it would disclose confidential information. On page 210 of this report there is a discussion of the relation between labor proper and royalty for the different groups but not for individual establishments.

The total labor cost for all establishments in this group was 30.08 per cent of the sales value of goods produced and in only one establishment was the cost more than 50 per cent. Of the remaining establishments one had a cost of 41.27 per cent, five a cost between 30 and 40 per cent, and six between 20 and 30 per cent.

Six establishments were above and seven below the average cost of 7.81 per cent for fuel, power, light, and water. In establishment No. 144 the cost of this item was more than twice the average for all establishments and more than eight times the cost for establishment No. 38 .

Taxes and insurance combined did not in any establishment amount to as much as 1 per cent, the average for all being 0.61 per cent, of which 0.25 per cent was for taxes and 0.36 per cent for insurance.

The remaining items composing the total cost of goods produced were salaries, with an average of 2.37 per cent and ranging from 1.68 to 3.98 per cent; general expenses, with 5.59 per cent and varying from 1.23 to 8.69 per cent; and bad debts, with 0.98 per cent and ranging in establishments reporting bad debts from 0.38 to 1.70 per cent.

Before charging depreciation and interest, one establishment was operated at a loss of 2.03 per cent, while the others were operated at a profit ranging from 1.60 to 22.20 per cent. After charging depreciation and interest, four establishments were operated at a loss ranging from 0.05 to 4.51 per cent and 9 at a profit ranging from 1.21 to 20.12 per cent.

The average for depreciation was 2.94 per cent and for interest paid 1.31, the former ranging from 1.1 to 11.77 per cent and the latter from 0.16 to 2.67 per cent. Establishment No. 137 was the only one in which no interest charge was found, and it is interesting to note that it showed the highest percentage of profit. 


\section{BLOW: TABLEWARE.}

Table 45 , which follows, presents cost data in the form of percentages for establishments manufacturing blown tableware. 'The percentages are based on the sales value of goods produced.

Table 45.-Percentages nf Costs, BY Specified Items and Profits and Lnsses, Basfid on Total Sales Value of Goods Produced, by Establishuents Manufacturing BlonN Tabletare.

\begin{tabular}{|c|c|c|c|c|c|c|c|c|c|}
\hline Items. & $\begin{array}{l}\text { Arer- } \\
\text { age. }\end{array}$ & No. & $\begin{array}{l}\text { No. } \\
150 .\end{array}$ & $\begin{array}{l}\text { No. } \\
151 .\end{array}$ & $\begin{array}{l}\text { No. } \\
152 .\end{array}$ & $\begin{array}{l}\text { No. } \\
153 .\end{array}$ & $\begin{array}{l}\text { No. } \\
154 .\end{array}$ & $\begin{array}{l}\text { No. } \\
155 .\end{array}$ & $\begin{array}{l}\text { No. } \\
156 .\end{array}$ \\
\hline 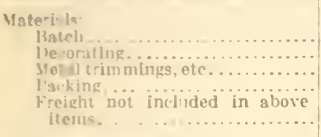 & $\begin{array}{r}7.59 \\
.34 \\
.02 \\
4.05 \\
.20 \\
\end{array}$ & $\begin{array}{r}8.13 \\
.60 \\
9.49\end{array}$ & $\begin{array}{c}6.56 \\
\cdots \ldots \\
4.58\end{array}$ & $\begin{array}{l}7.84 \\
3.85\end{array}$ & $\begin{array}{r}5.24 \\
.10 \\
7.26\end{array}$ & $\begin{array}{l}11.24 \\
\cdots \ldots \\
\cdots \\
2.79\end{array}$ & $\begin{array}{r}8.30 \\
.32 \\
.11 \\
3.26\end{array}$ & $\begin{array}{r}5.35 \\
\cdots \cdots \\
\cdots \\
4.17\end{array}$ & $\begin{array}{r}7.16 \\
1.08 \\
3.16 \\
.89\end{array}$ \\
\hline Total materlals. & 12.23 & 18.22 & 11.14 & 11.69 & 12.60 & 14.03 & 11.99 & 9.52 & 12.29 \\
\hline $\begin{array}{l}\text { Lahor } \\
\text { Siyperintendont and foremen.... } \\
\text { i)ther factory lahor ............. }\end{array}$ & $\begin{array}{r}1.99 \\
51.69 \\
\end{array}$ & 33.51 & $\begin{array}{r}4.62 \\
61.31 \\
\end{array}$ & $\begin{array}{r}1.04 \\
54.98 \\
\end{array}$ & 62.73 & $\begin{array}{r}3.57 \\
50.90 \\
\end{array}$ & $\begin{array}{r}3.23 \\
50.04 \\
\end{array}$ & $\begin{array}{r}.66 \\
55.42 \\
\end{array}$ & $\begin{array}{r}1.84 \\
42.69 \\
\end{array}$ \\
\hline Total labor..... & 53.68 & 53.51 & 65.93 & 56.02 & 62.73 & 54.47 & 53.27 & 56.08 & 43.93 \\
\hline $\begin{array}{l}\text { Fuel, power, light, and water.......... } \\
\text { Taves state, corporation, ete....... } \\
\text { Ins 'rance and irorkingmen's compen- } \\
\text { sation. .............................. }\end{array}$ & $\begin{array}{r}6.04 \\
.55 \\
.61 \\
\end{array}$ & $\begin{array}{r}7.41 \\
.29 \\
1.47\end{array}$ & $\begin{array}{r}4.60 \\
1.06 \\
.44\end{array}$ & $\begin{array}{r}4.29 \\
.89 \\
.72\end{array}$ & $\begin{array}{r}7.34 \\
.28 \\
1.04\end{array}$ & $\begin{array}{r}6.40 \\
.33 \\
.29\end{array}$ & $\begin{array}{r}6.58 \\
.81 \\
.90 \\
\end{array}$ & $\begin{array}{r}5.04 \\
.42 \\
.21 \\
\end{array}$ & $\begin{array}{r}6.43 \\
.51 \\
.56 \\
\end{array}$ \\
\hline $\begin{array}{l}\text { Balaries: } \\
\quad \text { Offictals } \ldots \ldots \ldots \ldots \ldots \ldots \ldots \ldots \\
\quad \text { Onlice force } \ldots \ldots \ldots \ldots \ldots \ldots\end{array}$ & $\begin{array}{l}2.33 \\
1.06 \\
\end{array}$ & $\begin{array}{l}1.10 \\
1.25 \\
\end{array}$ & $\begin{array}{l}3.23 \\
1.91 \\
\end{array}$ & $\begin{array}{l}2.07 \\
1.01 \\
\end{array}$ & $\begin{array}{l}2.55 \\
1.03 \\
\end{array}$ & $\begin{array}{r}4.21 \\
.96 \\
\end{array}$ & $\begin{array}{l}1.36 \\
1.15 \\
\end{array}$ & $\begin{array}{r}.66 \\
1.25 \\
\end{array}$ & $\begin{array}{r}2.88 \\
.71 \\
\end{array}$ \\
\hline Total salaries.... & 3.39 & 2.35 & 5.14 & 3.08 & 3.58 & 5.17 & 2.51 & 1.94 & 3.59 \\
\hline fieneral expense.... .... & 3.26 & 7.44 & 3.16 & .98 & 2.86 & 2.93 & 4.31 & 4.32 & 2.33 \\
\hline $\begin{array}{l}\text { Total manufacturing and ad- } \\
\text { ministration.................. }\end{array}$ & 79.76 & 90.69 & 91.47 & 77.67 & 90.43 & 83.62 & 80.37 & 77.53 & 69.64 \\
\hline 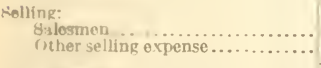 & $\begin{array}{r}6.81 \\
.28 \\
\end{array}$ & $\begin{array}{r}3.73 \\
.30 \\
\end{array}$ & $\begin{array}{r}1.99 \\
.17 \\
\end{array}$ & $\begin{array}{r}5.17 \\
.30 \\
\end{array}$ & $\begin{array}{r}3.33 \\
\cdots \cdots \\
\end{array}$ & $\begin{array}{r}7.12 \\
.16 \\
\end{array}$ & $\begin{array}{r}8.13 \\
.32 \\
\end{array}$ & $\begin{array}{r}9.67 \\
.95 \\
\end{array}$ & $\begin{array}{r}7.59 \\
\ldots \ldots \\
\end{array}$ \\
\hline Total selling expenso. ...... & 7.09 & 4.03 & 2.16 & 5.47 & 3.33 & 7.28 & 8.45 & 10.62 & 7.59 \\
\hline Barl debts.. ............. & .49 & ........ & .26 & $\ldots \ldots$ & $\ldots \ldots$ & .28 & .48 & .36 & 1.27 \\
\hline $\begin{array}{l}\text { Total cost of goods produced.... } \\
\text { Operating profit on goods produced } \\
\text { computer wlthout depreciation and } \\
\text { interest } \ldots . \ldots \ldots \ldots \ldots \ldots \ldots \ldots \ldots\end{array}$ & $\begin{array}{l}87.34 \\
12.66 \\
\end{array}$ & $\begin{array}{r}94.72 \\
5.28 \\
\end{array}$ & $\begin{array}{r}93.89 \\
6.11 \\
\end{array}$ & $\begin{array}{l}83.14 \\
16.86 \\
\end{array}$ & $\begin{array}{r}93.76 \\
6.24 \\
\end{array}$ & $\begin{array}{r}91.18 \\
8.82 \\
\end{array}$ & $\begin{array}{l}89.30 \\
10.70 \\
\end{array}$ & $\begin{array}{l}88.51 \\
11.49 \\
\end{array}$ & $\begin{array}{r}78.50 \\
21.50 \\
\end{array}$ \\
\hline 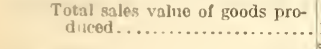 & 100.00 & 100.00 & 100.00 & 100.00 & 100.00 & 100.00 & 100.00 & 100.00 & 100.00 \\
\hline $\begin{array}{l}\text { Dejorerlation. } \\
\text { Interest paid }\end{array}$ & $\begin{array}{r}2.48 \\
.81 \\
\end{array}$ & $\begin{array}{l}.24 \\
2.67 \\
\end{array}$ & $\begin{array}{r}2.73 \\
.78 \\
\end{array}$ & $\begin{array}{l}1.39 \\
1.69 \\
\end{array}$ & $\begin{array}{l}1.72 \\
3.66 \\
\end{array}$ & $\begin{array}{r}2.38 \\
.46 \\
\end{array}$ & $\begin{array}{r}4.18 \\
\ldots \ldots \ldots . \\
\end{array}$ & $\begin{array}{r}2.84 \\
.45 \\
\end{array}$ & $\begin{array}{r}2.02 \\
\cdots \cdots \\
\end{array}$ \\
\hline $\begin{array}{l}\text { Operating profit on goods produced } \\
\text { compited } \\
\text { with } \text { depreciation and }\end{array}$ & 9.37 & 1.37 & 2.60 & 13.78 & .86 & 5.98 & 6.52 & 8.20 & 19.48 \\
\hline Miscellaneous income...... & .04 & & & & & $\cdots$ & .19 & .03 & …... \\
\hline $\begin{array}{l}\text { Final profit, depreriati } \\
\text { interost eonsidered... }\end{array}$ & .41 & 1.37 & 2.60 & 13.78 & .86 & 5.98 & 6.71 & 8.23 & 19.48 \\
\hline
\end{tabular}

Data were secured for eight establishments, of which six were located in West Virginia and one each in Maryland and Pennsylvania. This group showed the smallest percentage of cost for materials, the average being 12.23 per cent, the highest 18.22 per cent, and the 
lowest 9.52 per cent. Batch was more than one-half of the cost of materials, except in two establishments, in which the cost for packing materials was greater than for batch.

The average for total labor for the establishments in this group was 53.68 per cent and, except that for handmade window-glass factories, Group I, was the highest shown. In only one establishment was the percentage of cost under 50 per cent of the sales value of goods produced, and in two establishments the cost was over 60 per cent. 'The establishments in this group employed relatively a large amount of skilled labor, especially in forming and cutting the ware, which in a large measure accounts for the high percentage of labor cost.

The percentage of cost for fuel, power, light, and water for all establishments was 6.04, and in this respect they have a comparatively low cost. As about 75 per cent of the establishments were located in West Virginia, where cheap gas prevails, the low cost for fuel must be ascribed to the advantage of location.

Taxes and insurance together amount to 1.16 per cent of the sales value of goods produced, of which 0.55 per cent was for taxes and 0.61 per cent for insurance. Taxes varied from 0.28 to 1.06 per cent and insurance 0.21 to 1.47 per cent.

Salaries, with an average of 3.39 per cent and ranging from 1.94 to 5.17 per cent, and general expense, with 3.26 per cent and ranging from 0.98 to 7.44 per cent, present no unusual features and require no comment.

Total selling expense, with an average of 7.09 per cent, was highest in this group. Four establishments were above the average and four below. Elsewhere in this report (p. 233) is an article which shows the selling methods employed by the different groups of establishments and in a measure accounts for the differences in percentages for this item.

Each of the establishments in this group was operated at a profit, even after charging depreciation and interest, and of only one other group, miscellaneous goods, can the same be said. This group ranked fourth in the per cent of profit earned, computed without depreciation and interest, and third after depreciation and interest were deducted. The average operating profit on goods produced, computed without depreciation and interest, was 12.66 per cent, and when computed with depreciation and interest was 9.37 per cent.

After charging depreciation and interest, only two establishments showed a profit in excess of 10 per cent, one having 13.78 and the other 19.48 per cent. 
BLOWN AND PRESSED TABLEWARE.

Table 46, which follows, presents cost data in the form of percentages for establishments manufacturing both blown and pressed tableware. The percentages are based on the sales value of goods produced.

Tarle 46.-Percentages of Costs, by Specified Items and Profits or Losses, Based on Total Sales Value of Goods Produced, by Establishants Manupacturing tableware, Blown and Pressed.

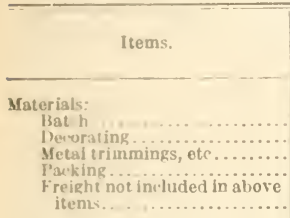

Labor:

Superintendent and foremen. nther fa. tor y labor...........

\section{Total lalior.}

Fuel, power, light, and water. . Taxes, state, corporation, ete.

Insuranie and workmen's compensation.

\section{Saiaries:}

Otiritils.

Othice force.

Total saluries.

General expense.

Total manufarturing and administration........ Selling:

Salesmen

()ther solling exprenso.

Totul selling expense...

Bad debts

Total cost of goods produred............... Operation profit on goods produreil, computed without depre intion and interest..........

Operating loss on goods produced, eomputed without deprociation and interest ..................

Totai sales vaiue of goods produced .......

Depreriation.

Interest paid.

Operating profit on goods produeod, computed with depreelation and interest..

Operating loss on goods producod, computed with depreciation and interest..................

Miscellaneous exponso.

Míscellanoous income. .

Final proft, depreriation and interest eonsidered..........

Final loss, depro iation and interest eonsidered.

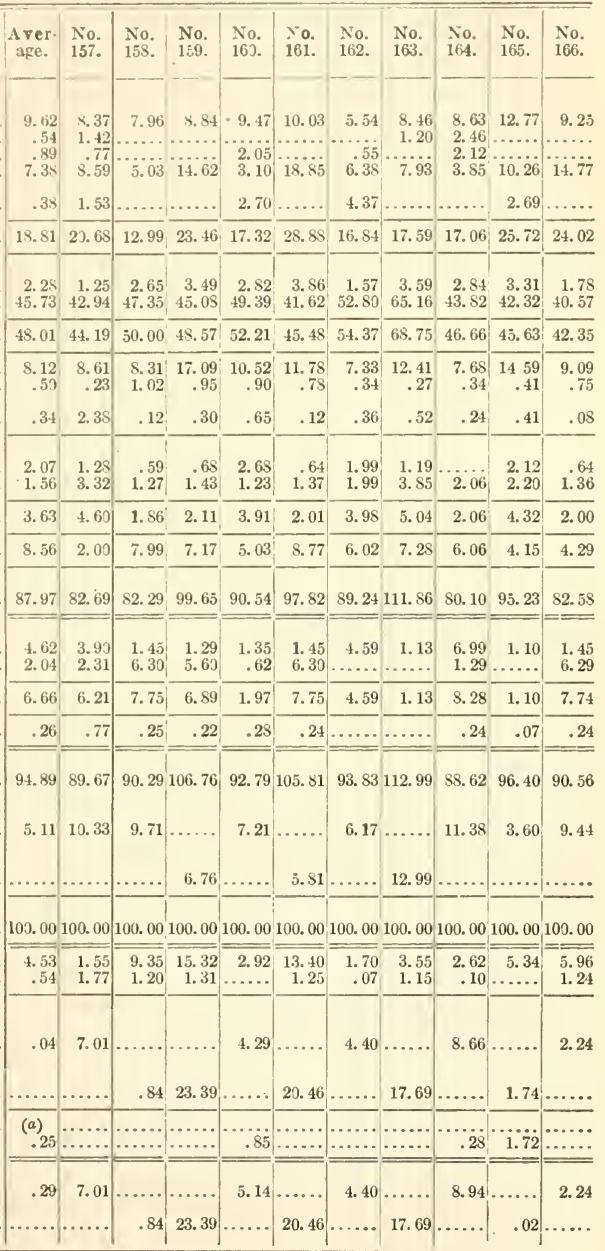

a Less than one ono-hundredth of 1 per eent. 
Table 46.-Percentages of Costs, by Specified Items and Profits or Losses, Based on Total Sales Value of Goods Produced, by Establishuents Manufacturing Tableware, Blown and Pressed-Concluded.

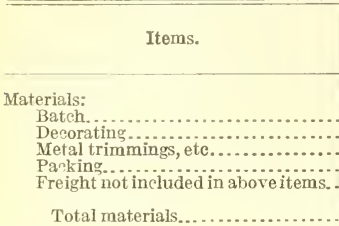

Labor:

Superintendent and foremen......

Other faztory labor.................

Total labor.

Fuel, power, light, and water

Taxes, State, corporation, etc............. Insurance and workmen's eompensation. Salaries:

Officials.

Office force.

Total salaries.

General expense.

Total manufacturing and administration.

\begin{tabular}{|c|c|c|c|c|c|c|c|c|c|}
\hline $\begin{array}{l}\text { No. } \\
167 .\end{array}$ & $\begin{array}{l}\text { No. } \\
168 .\end{array}$ & $\begin{array}{l}\text { No. } \\
169 .\end{array}$ & $\begin{array}{l}\text { No. } \\
170 .\end{array}$ & $\begin{array}{l}\text { No. } \\
171 .\end{array}$ & $\begin{array}{l}\text { No. } \\
172 .\end{array}$ & $\begin{array}{l}\text { No. } \\
173 .\end{array}$ & $\begin{array}{l}\text { No. } \\
174 .\end{array}$ & $\begin{array}{l}\text { No. } \\
175 .\end{array}$ & $\begin{array}{l}\text { No. } \\
176 .\end{array}$ \\
\hline $\begin{array}{r}8.23 \\
-.83 \\
5.14 \\
2.99\end{array}$ & $\begin{array}{l}5.93 \\
1.26 \\
3.81\end{array}$ & 17.25 & $\begin{array}{r}8.35 \\
1.72 \\
3.42 \\
10.47\end{array}$ & $\begin{array}{l}5.91 \\
1.25 \\
3.78 \\
5.62 \\
\ldots . .\end{array}$ & 5.48 & $\begin{array}{r}10.17 \\
.33 \\
.97 \\
5.15 \\
. .2\end{array}$ & $\begin{array}{c}8.25 \\
\cdots \ldots . \\
\dddot{9} .43\end{array}$ & $\begin{array}{l}9.24 \\
1.34 \\
1.52 \\
5.97 \\
\ldots . .\end{array}$ & $\begin{array}{c}9.14 \\
\ldots \ldots \\
\ldots .17\end{array}$ \\
\hline 17.19 & 11.00 & 20.89 & 23.99 & 16.56 & 20.57 & 16.67 & 17.68 & 18.07 & 18.31 \\
\hline
\end{tabular}

\begin{tabular}{|c|c|c|c|c|c|c|c|c|c|}
\hline $\begin{array}{r}2.74 \\
4 \mathrm{~S} .72\end{array}$ & $\begin{array}{r}3.03 \\
61.08\end{array}$ & $\begin{array}{r}1.78 \\
35.67\end{array}$ & $\begin{array}{r}1.89 \\
43.66\end{array}$ & $\begin{array}{r}3.08 \\
45.84\end{array}$ & $\begin{array}{r}1.43 \\
34.08\end{array}$ & $\begin{array}{r}1.25 \\
47.74\end{array}$ & $\begin{array}{r}3.52 \\
48.53\end{array}$ & $\begin{array}{r}.36 \\
44.52\end{array}$ & $\begin{array}{r}2.93 \\
46.59\end{array}$ \\
\hline 51.46 & 64.11 & 49.45 & 45.55 & 48.92 & 35.51 & 48.99 & 52.05 & 44.88 & 49.52 \\
\hline $\begin{array}{r}7.36 \\
.22 \\
.41 \\
\end{array}$ & $\begin{array}{r}9.26 \\
1.09 \\
.17\end{array}$ & $\begin{array}{r}6.79 \\
.05 \\
.25\end{array}$ & $\begin{array}{r}8.23 \\
.38 \\
.19\end{array}$ & $\begin{array}{r}7.29 \\
.55 \\
.66\end{array}$ & $\begin{array}{r}8.31 \\
.69 \\
.18\end{array}$ & $\begin{array}{r}4.68 \\
.41 \\
.62\end{array}$ & $\begin{array}{r}9.31 \\
.77 \\
.12\end{array}$ & $\begin{array}{r}7.31 \\
.36 \\
.24\end{array}$ & $\begin{array}{r}5.95 \\
.31 \\
.25\end{array}$ \\
\hline $\begin{array}{l}3.77 \\
1.48 \\
\end{array}$ & $\begin{array}{r}.65 \\
1.39\end{array}$ & 1.81 & $\begin{array}{r}1.68 \\
.73\end{array}$ & $\begin{array}{l}2.35 \\
2.59\end{array}$ & $\begin{array}{r}3.44 \\
.90\end{array}$ & $\begin{array}{l}2.05 \\
1.58\end{array}$ & $\begin{array}{r}.66 \\
1.42\end{array}$ & $\begin{array}{r}2.40 \\
.83\end{array}$ & $\begin{array}{l}4.58 \\
1.59\end{array}$ \\
\hline 5.25 & 2.04 & 1. 81 & 2.41 & 4.94 & 4.34 & 3.63 & 2.08 & 3.23 & 6.17 \\
\hline 2.26 & 6.35 & 4. 70 & 6.08 & 4.70 & 18. 78 & 7. 69 & 7. 89 & 17.04 & 8. 69 \\
\hline S4. 15 & 94.02 & 74.94 & 86.83 & 83.62 & 88.38 & 82.69 & 89.90 & 91.13 & 89.20 \\
\hline & $\begin{array}{r}1.45 \\
6.29 \\
\end{array}$ & 4. 17 & $\begin{array}{l}3.52 \\
2.18 \\
\end{array}$ & $\begin{array}{r}10.76 \\
1.00 \\
\end{array}$ & $\begin{array}{r}8.05 \\
.61 \\
\end{array}$ & 5.46 & $\begin{array}{l}1.45 \\
6.29\end{array}$ & 6.29 & $\begin{array}{l}4.46 \\
2.26 \\
\end{array}$ \\
\hline 4. 50 & 7.74 & 4. 17 & 5.70 & 11.76 & 8.66 & 5.46 & 7.74 & 6.29 & 6. 72 \\
\hline & .25 & .08 & .23 & $.2 \mathrm{~S}$ & .35 & .96 & .25 & & .17 \\
\hline & & & & & & & & & \\
\hline
\end{tabular}

Total cost of goods produced..... Operating profit on goods produced, computed without depreciation and and interest ........................

Operating loss on goods produced, eomputed without depreciation and interest

Total sales value of goods produced.

Depresiation

Interest paid.

Operating profit on goods produced, computed with depreciation and in-

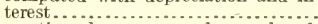

Operating loss on goods produced, computed with depreciation and interest...........................

Miscellaneous expense.

Miscellaneous income.

Final profit, depreciation and interest considered..................

Final loss, depreciation and interest considered.

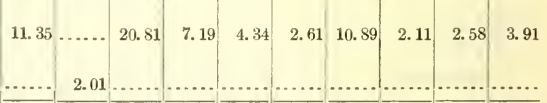

$\overline{100.00} \overline{100.00} \overline{100.00} \overline{100.00} \overline{100.00} \overline{100.00} \overline{100.00} \overline{100.00} \overline{100.00} \overline{100.00}$

\begin{tabular}{|c|c|c|c|c|c|c|c|c|c|}
\hline $\begin{array}{r}1.10 \\
.46\end{array}$ & $\begin{array}{l}\text { 4. } 32 \\
\text { 1. } 26\end{array}$ & $\begin{array}{r}8.59 \\
-\end{array}$ & $\begin{array}{r}2.43 \\
.09\end{array}$ & $\begin{array}{r}1.52 \\
.54\end{array}$ & $\begin{array}{r}4.49 \\
.60\end{array}$ & $\begin{array}{r}3.38 \\
.62\end{array}$ & $\begin{array}{r}11.00 \\
1.29\end{array}$ & $\begin{array}{r}1.71 \\
\hdashline\end{array}$ & $\begin{array}{r}2.21 \\
.11\end{array}$ \\
\hline \multirow[t]{3}{*}{9.79} & & 12.22 & 4.67 & 2. & & 6.89 & & .87 & 1. 59 \\
\hline & 7.59 & & & & $2.4 \mathrm{R}$ & & 10.18 & ... & ... \\
\hline & & . 08 & .46 & .29 & & $\begin{array}{r}.01 \\
.89\end{array}$ & .04 & $\because$ & .37 \\
\hline 9. 79 & & 12.30 & 5.13 & 2.57 & & 7.77 & & .87 & 1.96 \\
\hline & & & & & & & 10.2 & & \\
\hline
\end{tabular}

Data were secured for 20 establishments, of which 11 were located in Pennsylvania, 4 in Ohio, 3 in West Virginia, and 2 in Indiana.

Batch and packing were the two principal items under materials. While percentages are shown for decorating and metal trimmings, etc., these items were not common to all establishments nor were they of great importance, as the percentages for each of the items in the establishments showing such data were less than for either batch 
or packing materials. Howerer, batch in some establishments included decorating materials and metal trimmings, the accounts of these establishments being kept in such a manner as not to permit a segregation of materials. Total materials for the establishments in this group areraged 18.81 per cent of the sales value of goods produced and ranged from 28. Ss per cent in establishment No. 161 to 11 per cent in establishment No. $16 \mathrm{~S}$.

Total labor for all establishments in this group was 48.01 per cent of the sales value of goods produced. In 7 establishments total labor amounted to 50 per cent or over, and in 2 it was over 60 per cent. In 12 of the remaining establishments labor cost was between 40 and 50 per cent, and in 1 it was less than 40 per cent.

Fuel, power, light, and water areraged 8.12 per cent. Of the 20 establishments in this group, 12 had a higher and eight a lower percentage of cost than the average. The highest cost was found in establishment No. 159 , with 17.09 per cent, and the lowest in establishment No. 173, with 4.68 per cent.

Taxes and insurance amounted to 0.84 per cent, of which 0.5 per cent was for taxes and 0.34 per cent for insurance. In only 2 establishments were taxes and in only 1 establishment was insurance over 1 per cent of the sales value of goods produced.

Salaries amounted to 3.63 per cent, of which 2.07 per cent was for officials and 1.56 per cent for office force. In only three establishments did the total expenditures for salaries exceed 5 per cent, and in no establishment was it as high as 7 per cent.

The percentage for total selling expense was comparatively high in this group, being exceeded by only two other groups. The average for the group was 6.66 per cent. The highest percentage was found in establishment No. 171, with 11.76 per cent, and the lowest in establishment No. 165, with 1.1 per cent.

Losses from bad debts were not found in four establishments. Of the establishments which had such losses, the highest was found in establishment No. 173 , with 0.96 per cent, and the lowest in establishment No. 165, with 0.07 per cent.

On the arerage the establishments in this group had the lowest percentage of operating profit when computed without depreciation and interest. The average for the group was 5.11 per cent as against 10.49 per cent for the 213 establishments. Establishment No. 169 , with 20.81 per cent, showed the highest profit, and, excluding the establishments that showed losses, establishment No. 174, with 2.11 per cent, the lowest. Four establishments showed losses ranging from 12.99 per cent in establishment No. 163 to 2.01 per cent in establishment No. 168.

After charging depreciation and interest, eight establishments showed losses, in two of which the loss was over 20 per cent. On the average the establishments in this group, after charging deprociation and interest, were barely operated at a profit, the average for the group being only 0.04 per cent.

Depreciation and interest amounted to 5.07 per cent, of which 4.53 per cent was for depreciation and 0.54 per cent for interest. Depreciation ranged from 15.32 per cent to 1.1 per cent and interest for those establishments reporting such data from 1.77 per cent to 0.07 per cent.

$102511^{\circ}-17-10$ 
.

80

.

苞

క

ฮี

ชิ

党

हี

을 응

స్

क 0

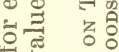

留

कै चु

क्ष

.

융.

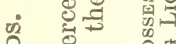

유용

하 융

व

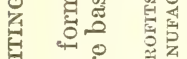

연

号

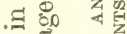

폰

卷

语

ᄋ

जु 空国

ํㅠㄹ

है

ड़ मे

กี

ह

응

웅

?롤

N

त

옹

응

\begin{tabular}{|c|c|c|c|c|c|c|c|c|c|c|c|c|}
\hline 宅㟒 & 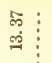 & : & 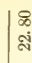 & $\begin{array}{l}8 \% \\
\text { : } \\
\text { ن. }\end{array}$ & 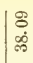 & $\mid \begin{array}{l}8 \\
0\end{array}$ & $\dddot{?}$ & $\overbrace{4}^{\pi}$ & $\mid \begin{array}{l} \pm \\
+\end{array}$ & ब & $\infty$ & 8 \\
\hline${ }^{\circ} \%$ & $\frac{19}{65}$ & 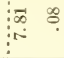 & 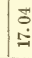 & 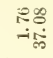 & $\mid \begin{array}{l}\mid \vec{s} \\
\dot{\infty} \\
\dot{c}\end{array}$ & 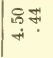 & ฐุ & 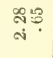 & $\left|\begin{array}{l}\approx \\
\multirow{3}{*}{}\end{array}\right|$ & & \begin{tabular}{|l}
$\underset{\approx}{*}$ \\
$\infty$ \\
$\infty$
\end{tabular} & di \\
\hline هُ & $\begin{array}{l}\text { : } \\
\text { ș } \\
\text { ș }\end{array}$ & $\begin{array}{c}\text { : } \\
\vdots \\
\vdots\end{array}$ & 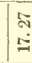 & 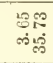 & 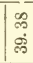 & 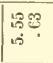 & สุ & $\begin{array}{l}\text { రో } \\
\text { ஸ่ }\end{array}$ & \begin{tabular}{|l|}
0 \\
0 \\
10 \\
1
\end{tabular} & & $\begin{array}{l}\mathscr{8} \\
+ \\
+\end{array}$ & $\begin{array}{l}\text { क् } \\
\text { ஜ̊ }\end{array}$ \\
\hline ฉُ & $\begin{array}{l}\stackrel{9}{\vdots} \\
\stackrel{-}{9}\end{array}$ & $\begin{array}{l}\infty \\
\mathscr{S} \\
\vdots\end{array}$ & $\stackrel{\infty}{\circ}$ & 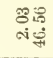 & 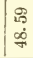 & 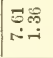 & $\stackrel{9}{7}$ & 요 & $\left|\begin{array}{c}\infty \\
\infty \\
i \\
i\end{array}\right|$ & & $\begin{array}{l}7 \\
\vdots \\
\dot{\Xi}\end{array}$ & $\begin{array}{l}\text { aे } \\
\text { \& }\end{array}$ \\
\hline$\dot{8}$ & $\begin{array}{l}\text { pos } \\
\text { pot } \\
\text { s. }\end{array}$ & & 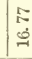 & 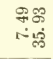 & 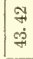 & 곤 & $\Xi$ & 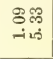 & 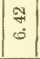 & & $\mid \begin{array}{l}\infty \\
\infty \\
\infty \\
\infty\end{array}$ & $\begin{array}{l}\tilde{\pi} \\
\text { क् }\end{array}$ \\
\hline غे & 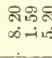 & & สี่ & 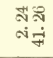 & 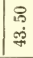 & 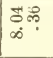 & 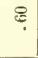 & $\underset{-\infty}{\stackrel{5}{*}}$ & $\left|\begin{array}{c}0 \\
\dot{a} \\
\dot{n}\end{array}\right|$ & & 莕 & 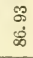 \\
\hline$\dot{8}$ & 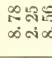 & & . & 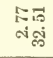 & \begin{tabular}{l}
$\infty$ \\
\multirow{2}{*}{} \\
$\infty$ \\
$\infty$ \\
$\infty$
\end{tabular} & is: & & the & 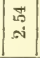 & & $\mid \begin{array}{c}\infty \\
\infty \\
\infty \\
\infty\end{array}$ & $\begin{array}{l}5 \\
\infty \\
\infty\end{array}$ \\
\hline 8 & $\underset{\substack{\infty \\
\infty}}{\infty}$ & 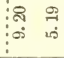 & 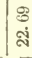 & 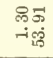 & $\begin{array}{l}\text { नี } \\
\text { : } \\
\text { : } \\
\text { : }\end{array}$ & N:? & 节 & 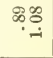 & $\left|\begin{array}{c}5 \\
-1\end{array}\right|$ & & $\begin{array}{l}\mathscr{8} \\
0 \\
0\end{array}$ & $\begin{array}{l}8 \\
8 \\
\dot{8}\end{array}$ \\
\hline 8 & 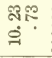 & \begin{tabular}{|cc}
5 \\
5
\end{tabular} & $\begin{array}{r}\stackrel{8}{8} \\
= \\
=\end{array}$ & 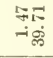 & $\begin{array}{l}\infty \\
= \\
\vec{H}\end{array}$ & 舟 & $\stackrel{3}{3}$ & 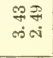 & 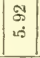 & సี. & 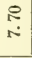 & $\begin{array}{l}\vec{\sigma} \\
\vec{\infty}\end{array}$ \\
\hline i & \begin{tabular}{l} 
N \\
\hdashline
\end{tabular} & 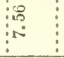 & $\begin{array}{l}\text { \% } \\
\stackrel{9}{9}\end{array}$ & 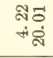 & \begin{tabular}{l}
$\approx$ \\
\multirow{3}{*}{}
\end{tabular} & 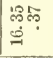 & 点 & 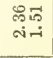 & $\left|\begin{array}{|c|}\infty \\
\infty \\
\infty \\
\infty\end{array}\right|$ & 12 & 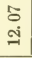 & $\begin{array}{l}\stackrel{8}{\circ} \\
\dot{\infty}\end{array}$ \\
\hline 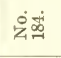 & $\begin{array}{l}\text { सहत } \\
\text { जन }\end{array}$ & $\begin{array}{ll}\text { न } & \text { o } \\
0\end{array}$ & $\begin{array}{l}\text { a } \\
\text { s. }\end{array}$ & 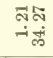 & 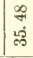 & 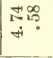 & & 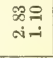 & $\mid \begin{array}{c}\mathscr{m} \\
\infty \\
\infty\end{array}$ & & $\begin{array}{l}\infty \\
\stackrel{\infty}{1} \\
\text { తa }\end{array}$ & $\begin{array}{l}\text { में } \\
\text { ळ. }\end{array}$ \\
\hline$\stackrel{8}{2}$ & 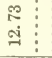 & \begin{tabular}{l}
$\mathscr{8}$ \\
\hdashline \\
\hdashline
\end{tabular} & $\stackrel{8}{\circledR}$ & 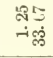 & 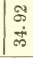 & $\stackrel{\infty}{\stackrel{\infty}{r}}$ & & 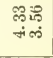 & 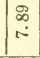 & & 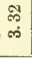 & ণ \\
\hline ஷُ & 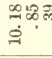 & & 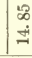 & 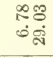 & \begin{tabular}{|l}
$\vec{\infty}$ \\
$\dot{0}$ \\
$\bar{\delta}$
\end{tabular} & 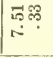 & & $\begin{array}{l}98 \% \\
\text { जico }\end{array}$ & $\stackrel{9}{9}$ & & $\begin{array}{l}5 \\
\infty \\
\infty \\
\infty\end{array}$ & $\stackrel{\pi}{i}$ \\
\hline$\stackrel{8}{3}$ & 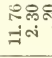 & & ฐี & 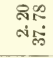 & 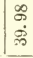 & $\begin{array}{l}\infty \\
\infty \\
\infty \\
\infty\end{array}$ & & 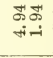 & 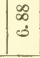 & 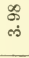 & {$\left[\begin{array}{l}\infty \\
\infty \\
\infty\end{array}\right.$} & $\begin{array}{l}\mathscr{\%} \\
\dot{\omega}\end{array}$ \\
\hline ஜ் & $\begin{array}{l}\infty \\
\text { తa }\end{array}$ & \begin{tabular}{l}
$\infty_{\infty}$ \\
\hdashline \\
\hdashline
\end{tabular} & $\begin{array}{l}8 \\
\text { ๙ุ. }\end{array}$ & 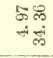 & 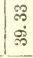 & \begin{tabular}{|l}
$\infty$ \\
$\infty$ \\
is.
\end{tabular} & & 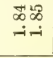 & 夯 & & 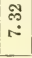 & $\begin{array}{l}\text { 范 } \\
\dot{\infty}\end{array}$ \\
\hline$\stackrel{8}{\circ}$ & 留占 & $\begin{array}{l}\infty \\
\infty \\
\infty\end{array}$ & 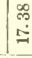 & 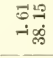 & 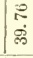 & 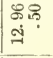 & & 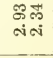 & $\begin{array}{l}\text { a } \\
\text { is }\end{array}$ & & $\frac{28}{47}$ & $\stackrel{0}{\vec{\infty}}$ \\
\hline$\stackrel{8}{\check{r}}$ & $\begin{array}{l}\text { 贵 } \\
\text { us }\end{array}$ & $\begin{array}{cc}0 \\
0 \\
0 \\
0\end{array}$ & 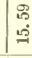 & 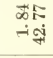 & $\begin{array}{l}0 \\
\dot{5} \\
\dot{H}\end{array}$ & 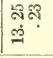 & & 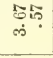 & İ & & $\stackrel{2}{10}$ & $\begin{array}{l}\stackrel{0}{\infty} \\
\infty\end{array}$ \\
\hline & $\begin{array}{l}\overrightarrow{0} \\
\infty \\
\infty\end{array}$ & 0 & 9 & $\begin{array}{r}8 \\
0 \\
\end{array}$ & $\begin{array}{l}8 \\
8 \\
\end{array}$ & 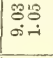 & 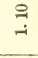 & $\begin{array}{l}\text { कొస } \\
\text { గొ }\end{array}$ & 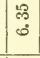 & & $\begin{array}{l}5 \\
0 \\
0\end{array}$ & $\begin{array}{l}\infty \\
\infty \\
\infty\end{array}$ \\
\hline 常 & 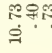 & "ִ & : & 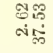 & \begin{tabular}{|l}
$\frac{2}{4}$ \\
$\stackrel{3}{4}$
\end{tabular} & 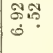 & & 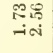 & 蛋 & & $\begin{array}{l}\overrightarrow{5} \\
\text { is }\end{array}$ & 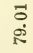 \\
\hline
\end{tabular}




\begin{tabular}{|c|c|c|c|c|c|c|c|c|c|c|}
\hline $\begin{array}{l}\text { గुर } \\
\text { bis }\end{array}$ & $\mid \begin{array}{l}\bar{\alpha} \\
\varrho \\
\Xi\end{array}$ & $\because$ & 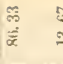 & $\underset{9}{\Phi}$ & $\begin{array}{l}\stackrel{\varepsilon}{E} \\
\stackrel{\dot{\xi}}{0}\end{array}$ & 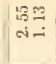 & & $\varepsilon$ & I & $\begin{array}{l}\text { สิ } \\
\text { ב }\end{array}$ \\
\hline$\stackrel{8}{ }$ & $\mid$ & 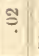 & $\begin{array}{l}\text { i⿱ } \\
\text { is }\end{array}$ & ت્ & $\begin{array}{l}\stackrel{8}{8} \\
\stackrel{\$}{\leftrightarrows}\end{array}$ & $\stackrel{5}{s}$ & & हิ & 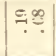 & $\begin{array}{l}\mathscr{\infty} \\
\stackrel{\text { sิ }}{ }\end{array}$ \\
\hline $\begin{array}{l}\text { 규 } \\
\text { vi }\end{array}$ & $\mid \begin{array}{l}\vec{z} \\
\dot{+}\end{array}$ & లి & $\begin{array}{l}\text { î } \\
\text { की } \\
0\end{array}$ & \begin{tabular}{l}
\multirow{+}{*}{} \\
$\dot{A}$
\end{tabular} & $\begin{array}{l}8 \\
\stackrel{8}{0} \\
\text { है }\end{array}$ & సี & & $\begin{array}{l}\cong \\
\text { ฉิ }\end{array}$ & : & $\begin{array}{l}\text { ลิ } \\
\text { สี }\end{array}$ \\
\hline & $\vdots$ & $\vdots \|$ & $\begin{array}{l}\text { :3 } \\
\stackrel{8}{8}\end{array}$ & $\begin{array}{l}2 \\
0\end{array}$ & $\begin{array}{l}\stackrel{8}{0} \\
\stackrel{\Xi}{\Xi}\end{array}$ & 85 & & $\stackrel{7}{+}$ & & \\
\hline $8 \vdots$ & $\begin{array}{l}8 \\
\\
\end{array}$ & की & ๘ & हึ & $\begin{array}{l}\stackrel{8}{0} \\
\stackrel{\Xi}{\Xi}\end{array}$ & $\begin{array}{l}88 \\
\text { m. }\end{array}$ & & $\stackrel{\wp}{-}$ & పี & \\
\hline$\frac{2}{\infty}$ & $\mid \begin{array}{l}\text { సี } \\
\infty\end{array}$ & $\vdots$ & $=$ & $\ddot{\vdots}$ & $\stackrel{\S}{\dot{8}}$ & 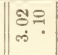 & & $\stackrel{+}{-i}$ & & $\stackrel{5}{-}$ \\
\hline$\stackrel{\infty}{\stackrel{2}{\longrightarrow}}$ & s. & ซै. & ळీ & $\begin{array}{l}R \\
\stackrel{0}{G}\end{array}$ & $\begin{array}{l}8 \\
\dot{8}\end{array}$ & $\infty$ & & $\begin{array}{l}\text { \&े } \\
\dot{\delta}\end{array}$ & 8 & 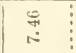 \\
\hline $\begin{array}{c}20 \\
\text { â }\end{array}$ & $\mid \begin{array}{l}2 \\
-7\end{array}$ & 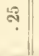 & & i़ & $\begin{array}{l}8 \\
\$\end{array}$ & 루요 & & $\stackrel{\text { N }}{-}$ & & స్ \\
\hline 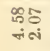 & $\mid \begin{array}{l}3 \\
3 \\
0\end{array}$ & 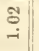 & $\begin{array}{l}\text { a } \\
\dot{p}\end{array}$ & $\stackrel{\Xi}{\Xi}$ & $\begin{array}{l}8 \\
\dot{8}\end{array}$ & 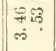 & & : & & \\
\hline & 帘 & & $\begin{array}{ll}\overrightarrow{0} & 8 \\
\infty & =\end{array}$ & 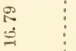 & $\stackrel{8}{8}$ & $\| \begin{array}{l}R \\
\text { i } \\
\text { i }\end{array}$ & & $\begin{array}{l}8 \\
\text { İ }\end{array}$ & & $\stackrel{8}{ \pm}$ \\
\hline $\begin{array}{c}-\infty \\
\infty \\
\infty \\
0\end{array}$ & $\mid \begin{array}{l}\vec{\infty} \\
0 \\
0\end{array}$ & \$? & $\begin{array}{l}\overrightarrow{1} \\
\dot{\infty}\end{array}$ & $\underset{\infty}{\stackrel{0}{\infty}}$ & $\begin{array}{l}8 \\
8 \\
\stackrel{8}{0}\end{array}$ & 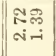 & & 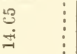 & if & สี \\
\hline $\begin{array}{l}8 \\
\text { g } \\
\text { తa }\end{array}$ & $\begin{array}{l}\mathscr{8} \\
\text { İ } \\
\end{array}$ & J & $\frac{7}{20}$ & $\begin{array}{l}\text { चे } \\
\text { चे }\end{array}$ & $\begin{array}{l}8 \\
\dot{\Xi}\end{array}$ & 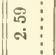 & & $\begin{array}{l}8 \\
\vdots\end{array}$ & & $\begin{array}{l}\text { క్ } \\
\text { త్ }\end{array}$ \\
\hline 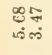 & $\left|\begin{array}{l}2 \\
0 \\
0\end{array}\right|$ & $\begin{array}{l}\text { สี } \\
\text { जे }\end{array}$ & $\begin{array}{l}\text { iी } \\
\text { iक }\end{array}$ & 욤 & $\begin{array}{l}8 \\
\stackrel{8}{0}\end{array}$ & 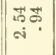 & & Бे & & $\begin{array}{l}\text { స్ } \\
\stackrel{-}{-}\end{array}$ \\
\hline $\begin{array}{l}\text { స్? } \\
\text { ¿. }\end{array}$ & 京 & 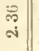 & $\begin{array}{l}28 \\
5\end{array}$ & $\stackrel{9}{+9}$ & $\begin{array}{l}8 \\
\dot{8}\end{array}$ & & & \begin{tabular}{l} 
สี \\
\multirow{2}{*}{}
\end{tabular} & & \\
\hline 군? & $\mid \begin{array}{l}\mathscr{B} \\
\stackrel{5}{-}\end{array}$ & 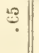 & $\begin{array}{l}\mathscr{8} \\
\infty \\
\infty\end{array}$ & $\begin{array}{l}\text { \& } \\
\\
\end{array}$ & $\begin{array}{l}8 \\
\dot{8}\end{array}$ & $\underset{+}{7} \stackrel{0}{\circ}$ & & is & & is \\
\hline की & $\mid \begin{array}{l}\mid \overline{0} \\
\dot{0}\end{array}$ & $\stackrel{5}{-1}$ & $=$ & $\begin{array}{l}\mathscr{0} \\
\vdots\end{array}$ & $\begin{array}{l}8 \\
\stackrel{\$}{8}\end{array}$ & $\mid$\begin{tabular}{l|l}
$f$ \\
$i$ \\
$i$
\end{tabular} & & $\stackrel{5}{\circ}$ & 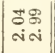 & $\begin{array}{l}\text { ชै } \\
\text { งे }\end{array}$ \\
\hline రై & 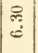 & 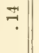 & ๙ิ & $\begin{array}{l}\text { के } \\
\text { के }\end{array}$ & $\begin{array}{l}8 \\
8\end{array}$ & 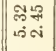 & & $\begin{array}{l}\mathscr{8} \\
\text { si }\end{array}$ & & 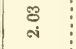 \\
\hline తే: & i & : & $\begin{array}{l}10 \\
8\end{array}$ & $\stackrel{29}{=}$ & $\begin{array}{l}8 \\
8 \\
\varnothing\end{array}$ & 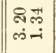 & & $\stackrel{8}{8}$ & $\vdots$ & $\begin{array}{l}\text { : } \\
\text { ì }\end{array}$ \\
\hline 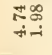 & i & ๗ొ & $\begin{array}{ll}8 & 0 \\
\dot{D} & =\end{array}$ & 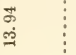 & $\begin{array}{l}8 \\
\grave{8}\end{array}$ & $\left|\begin{array}{c}\overrightarrow{0} 0 \\
\infty \\
\infty\end{array}\right|$ & & ळ్ & \& 8 & $\begin{array}{l}\circledast \\
\infty\end{array}$ \\
\hline 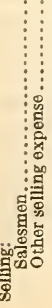 & 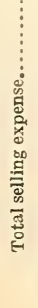 & 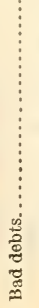 & 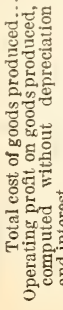 & 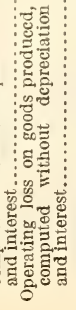 & 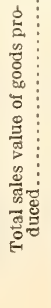 & 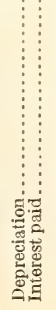 & 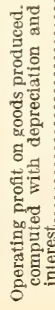 & 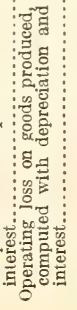 & 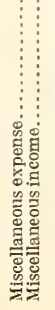 & 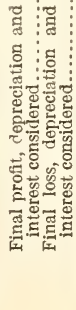 \\
\hline
\end{tabular}


Data were secured for 18 establishments, located in New York, New Jersey, Pennsylvania, Maryland, West Virginia, Ohio, and Indiana. There is no marked centralization of the establishments in any State.

Thile in a few of the establishments decorating and metal trimmings, etc., formed a considerable part of the total cost of materials, it can not be said that it was the general custom for manufacturers of lighting goods to decorate the ware or to furnish the metal trimmings. The average for materials was 20.05 per cent of the sales value of the goods produced. Six of the establishments were above the average and 12 below. The highest establishment, No. 188, had a cost for materials of 31.56 per cent, due largely to decorating and metal trimmings, and the lowest establishment, No. 182, had 14.85 per cent, due to the comparaticely low cost of packing materials.

The labor employed by the establishments in this group may be said to be between the highly skilled labor employed in the handmade and blown ware groups and the unskilled labor in the machine-made ware groups. The average for all establishments in the group was 40.15 per cent. Two establishments, Nos. 177 and 187, with 60.09 and 55.21 per cent, respectively, were exceptions to the comparatively medium labor costs in the group. Of the remaining establishments, five had costs of between 40 and 50 per cent, ten between 30 and 40 per cent, and only one less than 30 per cent.

An examination of the percentages for fuel, power, light, and water will show that the highest cost, in establishment No. 185, was over three times as much as the lowest cost, in establishment No. 184. The percentages of cost for the other establishments were between 5 and 14 per cent, centering around 7 per cent.

The variation in the percentages for taxes and insurance was due partly to the laws of the various States in which the factories were located and partly, in the case of insurance, to the policy of the company. The average for taxes was 0.52 per cent and in only one establishiment was it greater than 1 per cent. The average for insurance was 0.39 per cent, and in three establishments it was over 1 per cent but not greater than 1.65 per cent.

Of the remaining items entering into the total cost of goods produced, selling amounted to 6.72 per cent, general expense 5.91 per cent, salaries 4.29 per cent, royalty 0.78 per cent, and bad debts 0.33 per cont. Owing to a peculiar condition exi-ting in establishment No. 191, no selling expense was reported. Royalty was reported in four establishments and, unlike royalty in other groups, was a payment for the use of a batch formula and not for machines.

The establishments in this group had an average operating profit when computed without depreciation and interest of 13.94 per cent, an operating profit when computed with depreciation and interest of 9.3 per cent, and a final profit of 9.93 per cent. Two establishments, before charging depreciation and interest, showed an operating loss and four establishments showed a loss after charging depreciation and interest. Of the establishments operating at a profit after charging depreciation and interest, two had a profit of over 20 per cent, four between 10 and 20 per cent, four between 5 and 10 per cent, and four less than 5 per cent; and of those operating at a loss one had a loss of 9.22 jer cent and three under 5 per cent. 
Depreciation and interest together amounted to 4.64 per cent, of which 3.54 per cent was for depreciation and 1.1 per cent for interest paid. The two establishments having the greatest percentage of profit had no charges for interest.

\section{L.AIP CHIMXEYS.}

Table 48, which follows, presents cost data in the form of percentages for establishments manufacturing lamp chimneys. The percentages are based on the sales value of goods produced.

Table 48.-Percentages of Costs, by Specififin Items and Profits and Losses, Based on Total Sales Value of Goods Produced, by Establishments ManuFACTURING LAMP CHIMNEYS.

\begin{tabular}{|c|c|c|c|c|c|c|c|}
\hline Iten & $\begin{array}{l}\text { Arer- } \\
\text { age. }\end{array}$ & No. 195. & No. 196. & No. 197 . & No. 198 . & No. 199 & No. 200. \\
\hline 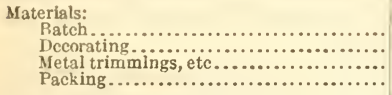 & $\begin{array}{r}7.40 \\
.46 \\
.06 \\
16.24\end{array}$ & $\begin{array}{c}10.00 \\
\cdots \cdots \\
18.11\end{array}$ & $\begin{array}{r}5.75 \\
.18 \\
\hdashline .21\end{array}$ & $\begin{array}{l}5.15 \\
11.95\end{array}$ & $\begin{array}{r}4.12 \\
.12 \\
\hdashline 10.15\end{array}$ & $\begin{array}{r}3.67 \\
.41 \\
\hdashline 15.57\end{array}$ & $\begin{array}{r}9.17 \\
.64 \\
.10 \\
18.64\end{array}$ \\
\hline Total materials................. & 24.16 & 28.11 & 14.14 & 17.10 & 14.39 & 19.65 & 28.55 \\
\hline 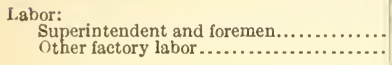 & $\begin{array}{r}2.30 \\
50.10\end{array}$ & 50.61 & $\begin{array}{r}3.00 \\
68.69\end{array}$ & $\begin{array}{r}1.60 \\
50.44\end{array}$ & 67.21 & 56.49 & $\begin{array}{r}3.44 \\
44.17\end{array}$ \\
\hline Total labor..... & 52.40 & 50.61 & 71.69 & 52.04 & 67.21 & 56.49 & 47. 61 \\
\hline 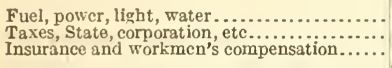 & $\begin{array}{r}5.26 \\
.46 \\
.43 \\
\end{array}$ & $\begin{array}{r}3.60 \\
.11 \\
.55 \\
\end{array}$ & $\begin{array}{r}4.87 \\
.24 \\
.70 \\
\end{array}$ & $\begin{array}{r}2.42 \\
.18 \\
.53 \\
\end{array}$ & $\begin{array}{r}1.92 \\
.33 \\
.37 \\
\end{array}$ & $\begin{array}{r}3.37 \\
.19 \\
.95 \\
\end{array}$ & $\begin{array}{r}6.87 \\
.62 \\
.30 \\
\end{array}$ \\
\hline 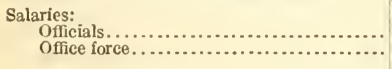 & $\begin{array}{l}2.13 \\
1.06 \\
\end{array}$ & $\cdots \cdot$ & $\begin{array}{l}5.69 \\
2.55\end{array}$ & $\begin{array}{r}2.79 \\
.97 \\
\end{array}$ & $\begin{array}{r}1.05 \\
.41 \\
\end{array}$ & $\begin{array}{r}2.56 \\
.64 \\
\end{array}$ & $\begin{array}{l}2.05 \\
1.26 \\
\end{array}$ \\
\hline 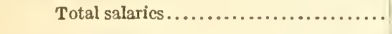 & 3.19 & ...... & 8.24 & 3.76 & 1.46 & 3. 20 & 3.31 \\
\hline Gencral expense..... & 4.03 & .85 & 5 & 5.86 & 1.22 & 1.94 & 4.75 \\
\hline Total manufacturing and administration & 89.93 & 83.83 & 106. 63 & 81.89 & 86.90 & 85.79 & 2.01 \\
\hline ling expense..................... & $\begin{array}{r}4.13 \\
.39\end{array}$ & $\begin{array}{r}8.97 \\
\cdots \cdots \\
\end{array}$ & $\begin{array}{r}2.39 \\
.64\end{array}$ & $\begin{array}{r}2.31 \\
\cdots \cdots\end{array}$ & $\begin{array}{r}7.66 \\
.17\end{array}$ & 1. 69 & $\begin{array}{r}4.09 \\
.58\end{array}$ \\
\hline Total selling expense $\ldots \ldots \ldots \ldots \ldots \ldots$ & 4.52 & 8.97 & 3 & 2.31 & 7.83 & 1.69 & 4.67 \\
\hline Bad debts................. & .31 & , n..... & 1.22 & .26 & .......... & 1.45 & .10 \\
\hline $\begin{array}{l}\text { Total cost of goods produced............. } \\
\text { Operating profit on goods produced, computed } \\
\text { without depreciation and interest............ } \\
\text { Operating loss on goods produced, computed } \\
\text { without depreciation and interest............ }\end{array}$ & $\begin{array}{r}94.76 \\
5.24\end{array}$ & $\begin{array}{r}92.80 \\
7.20\end{array}$ & $\begin{array}{r}110.88 \\
10.88 \\
1 \ldots \ldots\end{array}$ & $\begin{array}{l}84.46 \\
15.54\end{array}$ & $\begin{array}{r}94.73 \\
5.27\end{array}$ & $\begin{array}{l}88.93 \\
11.07\end{array}$ & $\begin{array}{r}96.78 \\
3.22\end{array}$ \\
\hline Total sales value of goods produced..... & 100.00 & 100.00 & 0 & 100.00 & 100.00 & & 100.00 \\
\hline 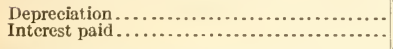 & $\begin{array}{r}1.61 \\
.76^{\circ}\end{array}$ & $\begin{array}{l}.33 \\
.26 \\
\end{array}$ & $\begin{array}{l}2.74 \\
2.37\end{array}$ & $\begin{array}{r}2.05 \\
.18\end{array}$ & .41 & $\begin{array}{l}1.91 \\
2.11\end{array}$ & $\begin{array}{r}1.71 \\
.65 \\
\end{array}$ \\
\hline $\begin{array}{l}\text { Operating profit on goods p } \\
\text { with depreciation and in } \\
\text { Operating loss on goods pr } \\
\text { with depreciation and in }\end{array}$ & 2.87 & 6. 61 & 15.99 & 13. 31 & 4. 86 & 7.05 & .80 \\
\hline 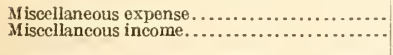 & $\begin{array}{l}.05 \\
.03 \\
\end{array}$ & & & .06 & & .19 & $\begin{array}{l}.09 \\
\ldots .\end{array}$ \\
\hline 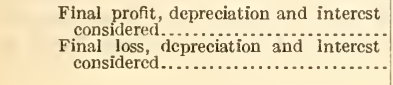 & 2.85 & 6.61 & 15.99 & 13. 37 & 4.86 & 7. 24 & .77 \\
\hline
\end{tabular}


Data were secured for six establishments, of which four were located in West Virginia and one each in Ohio and Oklahoma.

Cost of materials for all establishments in this group averaged 24.16 per cent of the sales value of goods produced. This comparatively high percentage was due largely to the packing cost, which amounted to 16.24 per cent for all establishments and ranged from 8.21 per cent in establishment No. 196 to 18.64 per cent in establishment No. 200.

Lamp chimneys, generally speaking, are packed for both the domestic and export trade with more care than any other of the glass products. The chimneys are generally wrapped in paper, placed in individual tubes or partitioned cardboard, and then placed in wooden cases, so that the comparatively high packing cost is distinctive of this branch of the industry.

This group ranked fourth in labor cost, the average being 52.40 per cent. In establishment No. 196 the labor cost was 71.69 per cent and in establishment No. 198, 67.21 per cent. Of the remaining establishments three had a labor cost over and one under 50 per cent of the sales value of goods produced.

Fuel, power, light, and water was lowest in this group, the average being 5.26 per cent. The highest cost was in establishment No. 200, 6.87 per cent, and the lowest in establishment No. 198, 1.92 per cent. This low cost was due to the location of the factories in districts where natural gas is cheap.

On the average, taxes and insurance showed about the same percentage of cost, being 0.46 per cent for the former and 0.43 per cent for the latter, although an examination of the percentages for the establishments, at first glance, would not indicate this relative position of these two items. Because of the effect of establishment No. 200, the averages do not reflect the actual relative position of taxes and insurance in the other five establishments.

In establishment No. 195 no salaries were reported, nor was any estimate given as to the value of the services rendered by the owners. The average of 3.19 per cent would be somewhat higher if the percentage had been computed for only the fire establishments reporting salaries.

General expense amounted to 4.03 per cent and was lowest in establishment No. 195 , with 0.85 per cent, and highest in establishment No. 196 , with 6.75 per cent.

Selling expense showed no regularity and depended almost entirely upon the course pursued by the different establishments. The average was 4.52 per cent, the highest 8.97 per cent, and the lowest 1.69 per cent. Bad debts were not found in two establishments and in those reporting such losses the range was from 0.1 per cent to 1.45 per cent.

One establishment was operated at a loss of 10.88 per cent when computed without depreciation and interest, the charges for these items increasing the loss to 15.99 per cent. One establishment was barely operated at a profit after charging depreciation and interest, the profit being less than 1 per cent. Of the remaining establishments, after charging depreciation and interest, one had a profit of 13.31 per cent, two between 5 and 10 per cent, and one less than 5 per cent. 
Depreciation and interest paid amounted to 2.37 per cent, of which 1.61 per cent was for depreciation and 0.76 per cent for interest paid. The former varied from 0.33 to 2.74 per cent, and the latter from 0.18 to 2.37 per cent.

MISCELLANEOIS ARTICLES.

Table 49 presents costs data in the form of percentages for establishments manufacturing a variety of articles that could not be assigned to any one of the preceding groups. The percentages are based on the sales value of goods produced. 


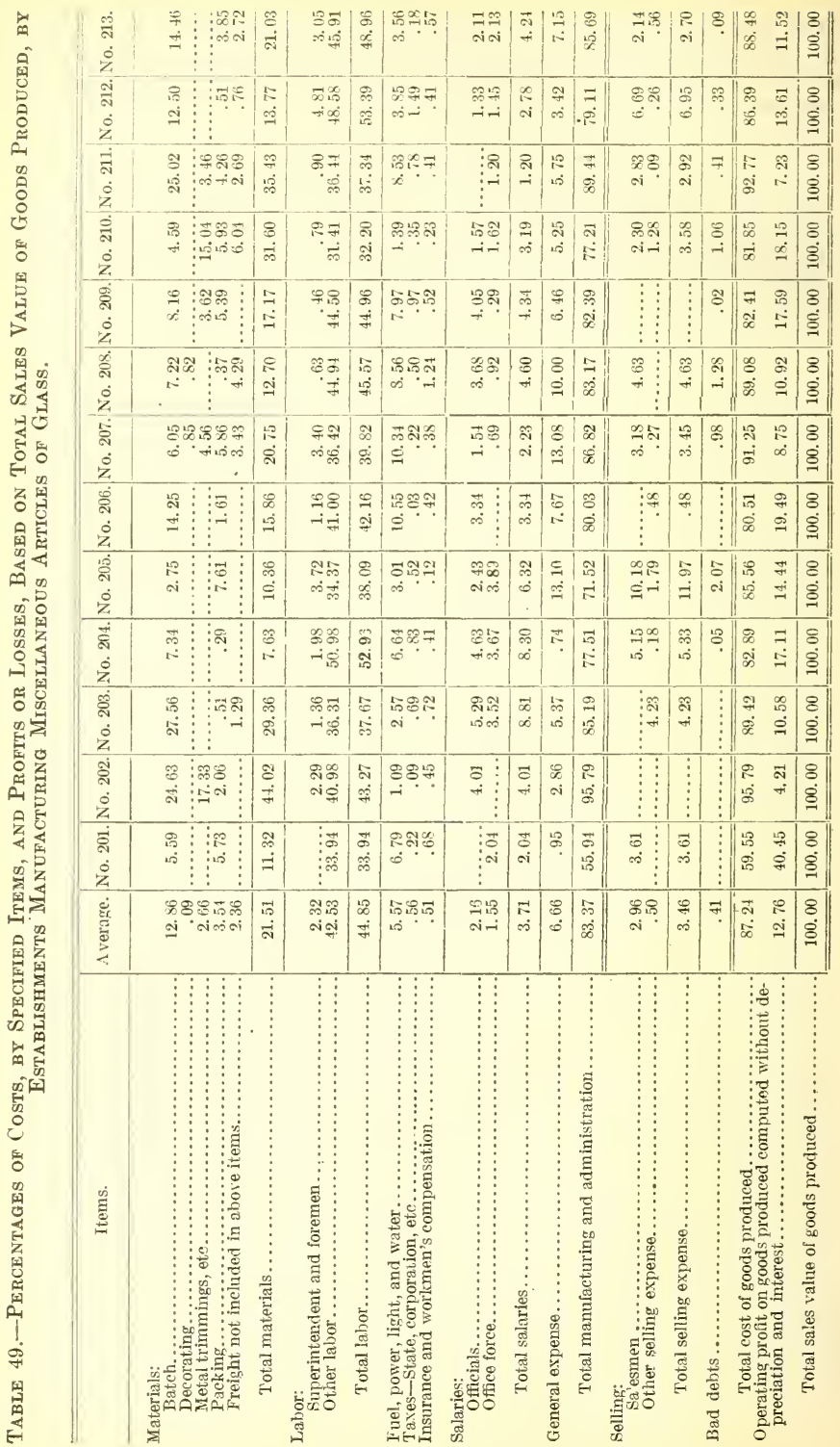




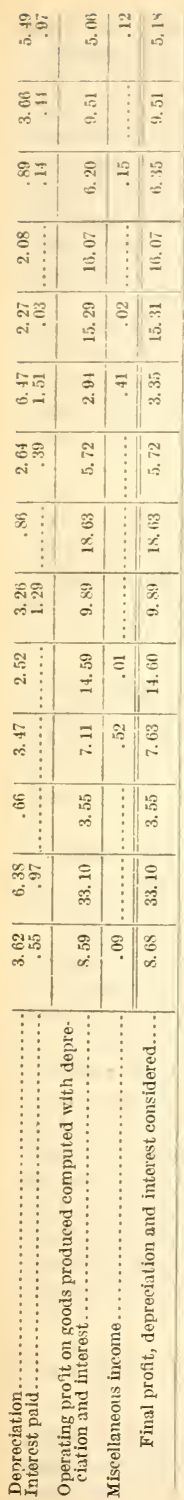


Data were secured for 13 establishments located in Massachusetts, New York, New Jersey, Pennsylvania, West Virginia, Ohio, Indiana, and Illinois. As is indicated by the number of States, there is no centralization of this branch of the glass industry.

The establishments in this group, producing a variety of articles from glass marbles to chemical goods and using different grades and varieties of materials, showed a wide variation in the total cost of materials. The highest percentage of cost was found in establishment No. 202, which was twice the average of 21.51 per cent and almost six times the lowest cost of 7.63 per cent in establishment No. 204.

While undoubtedly some of the establishments, on account of their product, require a greater amount of skilled labor than others, yet the variation in the percentages are not so marked as in materials. In two establishments the percentage for labor was over 50 per cent, in five establishments between 40 and 50 per cent, and in six establishments less than 40 per cent.

Fuel, power, light, and water also shows a wide variation in the percentages, the average being 5.57 per cent, the highest 10.55 per cent, and the lowest 1.09 per cent. Owing to the diverse products of the establishments in this group, the variation in the percentages did not depend entirely upon the location of the factories, but to some extent upon the difference in the amount of fuel consumed for the proper fusion of the materials.

Taxes and insurance amounted to 1.07 per cent, of which 0.56 per cent was for taxes and 0.51 per cent for insurance. The highest percentage for taxes was found in establishment No. 212, with 1.49 per cont, and for insurance in establishment No. 208, with 1.24 por cent. In othor establishments neither of these items amounted to as much as 1 per cent.

Of the other items included in cost of goods produced, salaries ranged from 1.2 to 8.81 per cent, general expense from 0.95 to 13.1 per cent, selling from 0.48 to 11.97 per cent, and bad debts from 0.02 to 2.07 per cent in those establishments reporting such data.

Although the average operating profit, computed without depreciation and interest, was exceeded by the average profit in machinemade bottles, Group VI, and lighting goods, Group XI, yet a greater percentage of the establishments were operated at a profit of over 10 per cent than in either of the other two groups. One of the establishments was operated at the remarkable profit of 40.45 per cent, but it so happens that this establishment has little effect on the average. Four establishments were operated at a profit between 15 and 20 per cent, five between 10 and 15 per cent, and three at less than 10 per cent. After charging depreciation and interest, the average profit was 8.59 per cent, no establishment being oporated at a loss. Depreciation ranged from 0.66 to 6.47 per cent and interest paid from 0.03 to 1.51 per cent in the establishments reporting such data.

COST BASED ON TOTAL EXPENSES, EXCLUDING DEPRECIATION AND INTEREST.

The preceding percentage tables in this section of the report were based on net sales or sales value of goods produced. The percentages for the items of cost based on the total cost of goods produced are 
different from those based on net sales or sales value of goods produced. If based on net sales or sales value of goods produced, profit is a part of the dirisor, and in that case the percentage for each item of cost is smaller than when the computation is based on the total cost of goods produced; when there is a loss, the divisor is correspondingly smaller and tho rosulting quotients or percentages are larger.

Porhaps the most striking way to call attention to the difference between other percentage tables in this section and Tablo 50, which follows, is to state that the percentages in the formor aro based on receipts, or income, and those in Table 50 on expenditures, or outgo, which, howerer, excludes depreciation and interest. In the following table percentages are based on the total cost of goods produced, excluding depreciation and interest. 


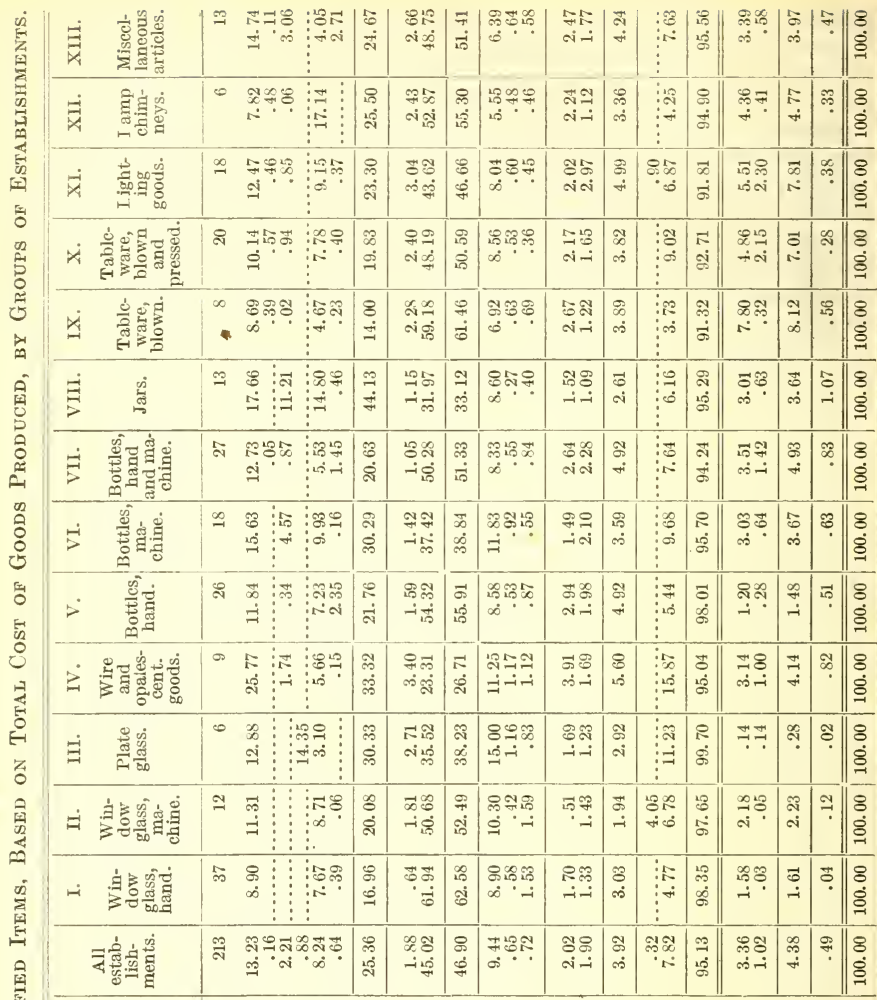


Since the same general conditions apply to all tables showing percentages by groups, it does not seem necessary to discuss the above table, in riew of the fact that these conditions have already been discussed on pages 106 to 112 .

As three different bases have been used in computing percentages for the tables in this section of the report, it may be of interest to compare the percentages for certain items when computed on the different bases. Table 51, which follows, shows percentages for fire items of expense when based on net sales, sales value of goods produced, and total cost of goods produced, excluding depreciation and interest.

Table 51.-Comparative Summary of Percentages for Five Items of Expense Computed on Different Bases.

\begin{tabular}{|c|c|c|c|c|}
\hline & Items. & Net sales. & $\begin{array}{l}\text { Sales ralue } \\
\text { of gonds } \\
\text { produced. }\end{array}$ & $\begin{array}{l}\text { Cost of } \\
\text { goods pro- } \\
\text { duced, ex- } \\
\text { cluding } \\
\text { deprecia- } \\
\text { tion and } \\
\text { interest. }\end{array}$ \\
\hline $\begin{array}{l}\text { Materials... } \\
\text { Total labor. } \\
\text { Fuel......... } \\
\text { Suarias.... } \\
\text { Total selling }\end{array}$ & & $\begin{array}{r}21.93 \\
40.57 \\
8.15 \\
3.39 \\
4.01\end{array}$ & $\begin{array}{r}22.70 \\
41.98 \\
8.43 \\
3.51 \\
3.92\end{array}$ & $\begin{array}{r}25.36 \\
46.90 \\
9.42 \\
3.92 \\
4.38\end{array}$ \\
\hline
\end{tabular}

It will be seen in the above table that the percentages when computed on net sales are lower than when computed on either the sales value or cost of goods produced; that is, total net sales for all establishments were greater in amount than either of the other bases.

\section{LOWEST AND HIGHEST COST ESTABLISHMENTS.}

Because of their location in natural-gas fields, some establishments had a decided advantage in fuel. Others had to produce their own gas from coal or pay a high rate for natural gas brought from distant fields.

To bring the various establishments to a more comparable basis and confine the expenses to manufacturing and administration, the items of fuel, power, etc., selling expense, and bad debts were deducted from the total cost of goods produced. Percentages were then computed on this new base for the different groups and for establishments which showed the lowest and highest percentage of cost in each group. In Table 52, which follows, are given the percentages based on the total cost, excluding fuel, etc., selling expense, bad debts, depreciation, and interest for the various groups and for the lowest and highest cost establishment in each group. 
Table 52.-Average Percentages of Costs by Groups, and Establishments with Lowest and Highest Percentage of Cost in Each Group, by Specified Items, Except for Fuel, Power, Light and Water, Selling, and Bad Debts.

\begin{tabular}{|c|c|c|c|c|c|c|}
\hline \multirow[b]{2}{*}{ Items. } & \multicolumn{3}{|c|}{ Group I.-Window glass, hand. } & \multicolumn{3}{|c|}{ Group II.-Window glass, machine. } \\
\hline & $\begin{array}{l}\text { Average } \\
\text { for group. }\end{array}$ & $\begin{array}{l}\text { Lowest } \\
\text { cost estab- } \\
\text { lishment, } \\
\text { No. } 14 .\end{array}$ & $\begin{array}{l}\text { Highest } \\
\text { cost estab- } \\
\text { lishment, } \\
\text { No. } 2 .\end{array}$ & $\begin{array}{l}\text { A verage } \\
\text { for group. }\end{array}$ & $\begin{array}{l}\text { Lowest } \\
\text { cost estab- } \\
\text { lishment, } \\
\text { No. } 45 .\end{array}$ & $\begin{array}{l}\text { Highest } \\
\text { cost estab. } \\
\text { lishment, } \\
\text { No. } 40 \text {. }\end{array}$ \\
\hline Total materials for product.... & 18.96 & 9.98 & 20.12 & 22.99 & 31.21 & 21.05 \\
\hline $\begin{array}{l}\text { Labor: } \\
\text { Superintendent and fore- } \\
\text { men................. } \\
\text { other factory labor...... }\end{array}$ & $\begin{array}{r}.71 \\
69.25 \\
\end{array}$ & 75.08 & $\begin{array}{r}1.34 \\
69.08 \\
\end{array}$ & $\begin{array}{r}2.07 \\
58.02 \\
\end{array}$ & 53.29 & $\dddot{57.35}$ \\
\hline Total factory labor...... & 69.96 & 75.08 & 70.42 & 60.09 & 53.29 & 57.35 \\
\hline $\begin{array}{l}\text { Taxes, State, corporation, etc.. } \\
\text { Insirance and workmen's } \\
\text { compensation................ }\end{array}$ & $\begin{array}{r}.65 \\
1.71 \\
\end{array}$ & $\begin{array}{l}1.15 \\
1.40 \\
\end{array}$ & $\begin{array}{l}1.35 \\
2.22 \\
\end{array}$ & $\begin{array}{r}.48 \\
1.82 \\
\end{array}$ & $\begin{array}{r}.40 \\
2.77 \\
\end{array}$ & $\begin{array}{r}.76 \\
2.14 \\
\end{array}$ \\
\hline \multirow{2}{*}{ 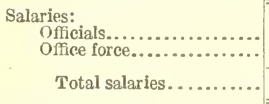 } & $\begin{array}{l}1.90 \\
1.48\end{array}$ & $\begin{array}{r}5.04 \\
.94 \\
\end{array}$ & 2.14 & $\begin{array}{r}.58 \\
1.64\end{array}$ & 1.84 & $\begin{array}{l}1.80 \\
2.77 \\
\end{array}$ \\
\hline & 3.38 & 5.98 & 2.14 & 2.22 & 1.84 & 4.57 \\
\hline \multirow{2}{*}{ 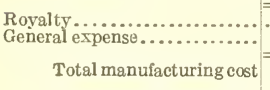 } & 5.34 & 6.41 & 3.75 & $\begin{array}{l}4.64 \\
7.75 \\
\end{array}$ & $\begin{array}{l}8.35 \\
2.14 \\
\end{array}$ & $\begin{array}{l}6.32 \\
7.81 \\
\end{array}$ \\
\hline & 100.00 & 100.00 & 100.00 & 100.00 & 100.00 & 100.00 \\
\hline \multirow[b]{2}{*}{ Items. } & \multicolumn{3}{|c|}{ Group III.-Plate glass. } & \multicolumn{3}{|c|}{$\begin{array}{c}\text { Group } \Gamma \text {. - Wire and opalescent } \\
\text { glass. }\end{array}$} \\
\hline & $\begin{array}{l}\text { Average } \\
\text { for group. }\end{array}$ & $\begin{array}{l}\text { Lowest } \\
\text { cost estab- } \\
\text { lishment, } \\
\text { No. } 52 \text {. }\end{array}$ & $\begin{array}{l}\text { Highest } \\
\text { cost estab- } \\
\text { lishm 'nt, } \\
\text { No. } 03 \text {. }\end{array}$ & $\begin{array}{l}\text { Average } \\
\text { for group. }\end{array}$ & $\begin{array}{l}\text { Lowest } \\
\text { cost estab- } \\
\text { lishment, } \\
\text { No. } 58 .\end{array}$ & $\begin{array}{l}\text { Highest } \\
\text { cost estab- } \\
\text { lishment, } \\
\text { No. } 62 \text {. }\end{array}$ \\
\hline Total materials for product... & 30.81 & 24.49 & 40.80 & 39.70 & 34.92 & 37.48 \\
\hline $\begin{array}{l}\text { Labor: } \\
\text { Superintendent and fore- } \\
\text { men.................... } \\
\text { Other factory labor ....... }\end{array}$ & $\begin{array}{r}3.20 \\
41.94\end{array}$ & $\begin{array}{r}4.77 \\
53.94 \\
\end{array}$ & $\begin{array}{r}2.56 \\
31.37 \\
\end{array}$ & $\begin{array}{r}4.05 \\
27.82 \\
\end{array}$ & 33.18 & $\begin{array}{r}2.57 \\
26.65 \\
\end{array}$ \\
\hline Total factory labor...... & 45.14 & 58.71 & 33.93 & 31.87 & 33.18 & 29.22 \\
\hline \multirow{2}{*}{$\begin{array}{l}\text { Taxes, State, corporation, ctc. } \\
\text { Insurance and workmen's } \\
\text { compensation ................ }\end{array}$} & & .98 & & 1.39 & 3.54 & .54 \\
\hline & .98 & .60 & .96 & 1.34 & 1.34 & 1.09 \\
\hline \multirow{2}{*}{$\begin{array}{l}\text { Salaries: } \\
\text { Officials.................. } \\
\text { Office force.............. } \\
\quad \text { Total salarics........... }\end{array}$} & $\begin{array}{l}1.99 \\
1.45 \\
\end{array}$ & $\begin{array}{l}2.03 \\
1.00 \\
\end{array}$ & $\begin{array}{l}1.27 \\
1.13 \\
\end{array}$ & $\begin{array}{l}4.67 \\
2.02 \\
\end{array}$ & $\begin{array}{r}11.82 \\
2.95 \\
\end{array}$ & $\begin{array}{l}5.47 \\
1.62 \\
\end{array}$ \\
\hline & 3.44 & 3.03 & 2.40 & 6.69 & 14.77 & 7.09 \\
\hline \multirow{2}{*}{$\begin{array}{r}\text { General expense............. } \\
\text { Total manufacturing cost }\end{array}$} & 13. 26 & 12.19 & 21.17 & 18.95 & 12.25 & 24.58 \\
\hline & 100.00 & 100.00 & 100.00 & 100.00 & 100.00 & 100.00 \\
\hline
\end{tabular}


Table 52.-Average Percentages of Costs by Groups. and Establishanents with Lowest a.jd Higeest Percentage of Cost in Each liroup, by Specified Items, Except for Fuel. Power, Lighr and Water, selling, and Bad DebtsContinued.

\begin{tabular}{|c|c|c|c|c|c|c|}
\hline \multirow[b]{2}{*}{ Items. } & \multicolumn{3}{|c|}{ Group V.-Bottles, hand. } & \multicolumn{3}{|c|}{ Group VI.-Bottles, machinc. } \\
\hline & $\begin{array}{l}\text { Average } \\
\text { for group. }\end{array}$ & $\begin{array}{l}\text { Lowest } \\
\text { cost estab- } \\
\text { lishment, } \\
\text { No. } \mathbf{7 4} \text {. }\end{array}$ & $\begin{array}{l}\text { Highest } \\
\text { cost estab- } \\
\text { lishment, } \\
\text { No. } 68 \text {. }\end{array}$ & $\begin{array}{l}\text { A verage } \\
\text { for group. }\end{array}$ & $\begin{array}{l}\text { Lowest } \\
\text { cost estab- } \\
\text { lishment, } \\
\text { No. } 97 \text {. }\end{array}$ & $\begin{array}{l}\text { Highest } \\
\text { cost estal- } \\
\text { lishment, } \\
\text { No. } 98 \text {. }\end{array}$ \\
\hline ials for product.. & 24.33 & 26.46 & 24.09 & $3 \% .12$ & 39.52 & 39.09 \\
\hline $\begin{array}{l}\text { tendent and fore- } \\
\text { ato................... } \\
\text { ietory labor...... }\end{array}$ & $\begin{array}{l}1.78 \\
60.73\end{array}$ & $\begin{array}{r}3.07 \\
60.94\end{array}$ & 55.82 & $\begin{array}{r}1.69 \\
44.62\end{array}$ & $\begin{array}{r}2.40 \\
40.83\end{array}$ & $\begin{array}{r}1.32 \\
48.00\end{array}$ \\
\hline factory labor. & 62.51 & 64.01 & 55.82 & 46.31 & 43.23 & 49.32 \\
\hline $\begin{array}{l}\text { c, corporation, etc. } \\
\text { and workmen's }\end{array}$ & .59 & .70 & .36 & 1.10 & .81 & .37 \\
\hline tion ................ & .98 & $.6 i 5$ & 1.92 & .66 & .51 & .63 \\
\hline & $\begin{array}{l}3.28 \\
2.22\end{array}$ & 4.47 & .75 & $\begin{array}{l}\text { 1. } 75 \\
2.50\end{array}$ & 2.81 & $\begin{array}{l}\text { 1. } 70 \\
\text { 1. } 62\end{array}$ \\
\hline salaries. & 5.50 & $4 .+7$ & .75 & 4.28 & 3.75 & 3.32 \\
\hline se. & 6.09 & 3.71 & 17.06 & 11.53 & 12.18 & 7.27 \\
\hline manufacturing cost & 100.00 & 100.00 & 100.00 & 100.00 & 100.00 & 100.00 \\
\hline
\end{tabular}

Total materials for prorluct....

Labor:

Supcrintendent and fore-

men.

Other factory labor.......

Total factory labor.....

Taxes, State, corporation, etc. Insurance and workmen's compensation................

Salaries:

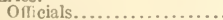

Office force...............

Total salaries.

Gencral expense.

Total manufacturing cost

Group VII.-Bottles, hand and machine.

Firoup VIII.--Jars.

Items.

Total materials for product...

Labor:

Superintendent and foremen .................... other fact ry labor........

Total factory labor.......

Taxes, State, corporation, etc. . Insurance and workmen's compensation..............

Salaries:

Ofricials.................

Office force..................

Total salarics.

verage Lowest

Highest cost estab- cost estabfor group.

lishment, lishment,

No. 133.

No. 131.

A verage

for group.

Lowest

Highest

cost estab- cost cstab-

lishment, lishment,

No. 143. No. 138 .

\begin{tabular}{|c|c|c|c|c|c|}
\hline 24.01 & 15.07 & 28.20 & 50.90 & 41. 79 & 64.77 \\
\hline $\begin{array}{r}1.22 \\
5 \mathrm{~S} .53\end{array}$ & $\begin{array}{r}.61 \\
63.82\end{array}$ & $\begin{array}{r}1.21 \\
60.18\end{array}$ & $\begin{array}{r}1.33 \\
36.88\end{array}$ & $\begin{array}{r}2.09 \\
39.35\end{array}$ & $\begin{array}{r}.69 \\
23.33\end{array}$ \\
\hline 59.75 & 64.43 & 61. 39 & 38.21 & 41.44 & 24.02 \\
\hline .64 & .88 & .74 & .31 & .94 & .28 \\
\hline .98 & .39 & .98 & .47 & .12 & . \\
\hline $\begin{array}{l}\text { 3. } 08 \\
2.65\end{array}$ & $\begin{array}{l}5.93 \\
4.04\end{array}$ & $\begin{array}{l}\text { 1. } 30 \\
1.91\end{array}$ & $\begin{array}{l}1.75 \\
1.26\end{array}$ & $\begin{array}{l}1.89 \\
1.18\end{array}$ & $\begin{array}{r}2.73 \\
.97\end{array}$ \\
\hline 5. 73 & 9.97 & 3.21 & 3.01 & 3.07 & 3.70 \\
\hline 8. 89 & 9.26 & 5.48 & 7.10 & 12. 64 & 6.69 \\
\hline 100.00 & 100.00 & 100.00 & 100.00 & 100.00 & 100. \\
\hline
\end{tabular}

Total manufacturing cost 
Table 52.-Average Percentages of Costs by Groups, and Establishments with Lowest and Highest Percentage of Cost in Each Group, by Specified Items, Except for Fuel, Power, Light and Water, Selling, and Bad DebtsContinued.

\begin{tabular}{|c|c|c|c|c|c|c|}
\hline \multirow[b]{2}{*}{ Items. } & \multicolumn{3}{|c|}{ Group IX.-Tableware, blown. } & \multicolumn{3}{|c|}{$\begin{array}{c}\text { Group X.-Tableware, klown and } \\
\text { pressed. }\end{array}$} \\
\hline & $\begin{array}{l}\text { Average } \\
\text { for group. }\end{array}$ & $\begin{array}{l}\text { Lowest } \\
\text { cost estab- } \\
\text { lishment, } \\
\text { No. } 156 \text {. }\end{array}$ & $\begin{array}{l}\text { Highest } \\
\text { cost estab- } \\
\text { lishment, } \\
\text { No. } 150 .\end{array}$ & $\begin{array}{l}\text { Average } \\
\text { for group. }\end{array}$ & $\begin{array}{l}\text { L.owest } \\
\text { cost estab- } \\
\text { lishment, } \\
\text { No. } 169 \text {. }\end{array}$ & $\begin{array}{l}\text { Highest } \\
\text { cost estab- } \\
\text { lishment, } \\
\text { No. } 163 .\end{array}$ \\
\hline Total materials for product.... & 16.59 & 19.44 & 12.83 & 23.57 & 17.69 & 30. 65 \\
\hline \multirow{2}{*}{$\begin{array}{l}\text { Labor: } \\
\text { Superintendent and fore. } \\
\text { men .................... } \\
\text { Other factory labor....... } \\
\text { Total factory labor....... }\end{array}$} & $\begin{array}{r}2.70 \\
70.12\end{array}$ & $\begin{array}{r}2.97 \\
66.60\end{array}$ & $\begin{array}{r}5.32 \\
70.57\end{array}$ & $\begin{array}{r}2.86 \\
57.26\end{array}$ & $\begin{array}{r}3.61 \\
65.52\end{array}$ & $\begin{array}{r}2.61 \\
56.74\end{array}$ \\
\hline & 72.82 & 69.51 & 75.89 & 60.12 & 69.13 & 59.35 \\
\hline $\begin{array}{l}\text { Taxes, State, corporation, ete.. } \\
\text { Insurance and workmen's } \\
\text { compensation................ }\end{array}$ & $\begin{array}{r}.75 \\
.82 \\
\end{array}$ & $\begin{array}{r}.80 \\
.88 \\
\end{array}$ & $\begin{array}{r}.22 \\
.50 \\
\end{array}$ & $\begin{array}{r}.63 \\
.43 \\
\end{array}$ & $\begin{array}{r}.28 \\
.53 \\
\end{array}$ & $\begin{array}{l}.08 \\
.37 \\
\end{array}$ \\
\hline \multirow{4}{*}{ 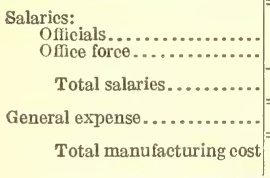 } & $\begin{array}{l}3.16 \\
1.44\end{array}$ & $\begin{array}{l}4.56 \\
1.12 \\
\end{array}$ & $\begin{array}{l}3.72 \\
2.20 \\
\end{array}$ & $\begin{array}{l}2.58 \\
1.96 \\
\end{array}$ & $\begin{array}{l}1.19 \\
3.87\end{array}$ & $\ddot{2.65}$ \\
\hline & 4.60 & 5.68 & 5.92 & 4.54 & 5.06 & 2.65 \\
\hline & 4.42 & 3.69 & 3.64 & 10.71 & 7.31 & 6.30 \\
\hline & 100.00 & 100.00 & 100.00 & 100.00 & 100.00 & 100.00 \\
\hline \multirow[b]{2}{*}{ Items. } & \multicolumn{3}{|c|}{ Group XI.-Lighting goods. } & \multicolumn{3}{|c|}{ Group XII.-Lamp ehimneys. } \\
\hline & $\begin{array}{l}\text { Average } \\
\text { for group. }\end{array}$ & $\begin{array}{l}\text { Lowest } \\
\text { eost estab- } \\
\text { lishment, } \\
\text { No. } 183 \text {. }\end{array}$ & $\begin{array}{l}\text { Highest } \\
\text { eost estab- } \\
\text { lishment, } \\
\text { No. 177. }\end{array}$ & $\begin{array}{l}\text { Average } \\
\text { for grouy. }\end{array}$ & $\begin{array}{l}\text { Lowest } \\
\text { cost estah- } \\
\text { lishment, } \\
\text { No. 197. }\end{array}$ & $\begin{array}{l}\text { Highest } \\
\text { cost estab- } \\
\text { lishment, } \\
\text { No. 196. }\end{array}$ \\
\hline Total materials for product.... & 27.81 & 27.13 & 17.3 .5 & 28.54 & 21.52 & 13.90 \\
\hline \multirow[t]{2}{*}{ 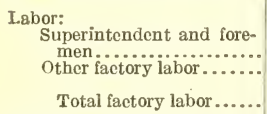 } & $\begin{array}{r}3.63 \\
52.06\end{array}$ & $\begin{array}{r}1.92 \\
51.72 \\
\end{array}$ & 66.53 & $\begin{array}{r}2.72 \\
59.17 \\
\end{array}$ & $\begin{array}{r}2.02 \\
63.47\end{array}$ & $\begin{array}{r}2.95 \\
67.49 \\
\end{array}$ \\
\hline & 55.69 & 53.64 & 66.53 & 61.89 & 65.49 & 70.44 \\
\hline $\begin{array}{l}\text { Taxes, State, coropration, ete.. } \\
\text { Insurance and workmen's } \\
\text { compensation................ }\end{array}$ & $\begin{array}{r}.72 \\
.55 \\
\end{array}$ & $\begin{array}{r}.77 \\
1.24 \\
\end{array}$ & $\begin{array}{l}1.16 \\
1.21 \\
\end{array}$ & $\begin{array}{l}.54 \\
.51 \\
\end{array}$ & $\begin{array}{r}.22 \\
.67 \\
\end{array}$ & $\begin{array}{r}.24 \\
.69 \\
\end{array}$ \\
\hline \multirow[t]{2}{*}{$\begin{array}{l}\text { Salaries: } \\
\text { Officials................... } \\
\text { Office foree.............. }\end{array}$} & $\begin{array}{l}2.40 \\
3.55\end{array}$ & $\begin{array}{l}6.64 \\
5.48 \\
\end{array}$ & $\begin{array}{l}3.41 \\
3.61 \\
\end{array}$ & $\begin{array}{l}2.51 \\
1.25 \\
\end{array}$ & $\begin{array}{l}3.52 \\
1.22\end{array}$ & $\begin{array}{l}5.59 \\
2.50 \\
\end{array}$ \\
\hline & 5.95 & 12.12 & 7.02 & 3.76 & 4.74 & 8.09 \\
\hline \multirow{2}{*}{$\begin{array}{r}\text { Royalty } \\
\text { Total manufacturing cost }\end{array}$} & $\begin{array}{l}1.08 \\
8.20 \\
\end{array}$ & 5.10 & 6.73 & 4.76 & 7.36 & 6.64 \\
\hline & 100.00 & 100.00 & 100.00 & 100.00 & 100.00 & 100.00 \\
\hline
\end{tabular}


Table 52.-Average Percentages of Costs by Groups, and Establishurents with Lowest and Highest Percentage of Cost in Each Group, by Specified Items, Except for Fuel, Power, Light axd Water, Sellixg, and Bad DebtsConcluded.

\begin{tabular}{|c|c|c|c|}
\hline \multirow[b]{2}{*}{ Items. } & \multicolumn{3}{|c|}{$\begin{array}{l}\text { Group XIII.-Miscellaneous } \\
\text { articles. }\end{array}$} \\
\hline & $\begin{array}{l}\text { Arerage } \\
\text { for group. }\end{array}$ & $\begin{array}{l}\text { Lowest } \\
\text { cost estab- } \\
\text { lishment, } \\
\text { No. } 201 \text {. }\end{array}$ & $\begin{array}{l}\text { Highest } \\
\text { eost estab- } \\
\text { lishment, } \\
\text { No. } 202 \text {. }\end{array}$ \\
\hline Total materials for produet ... & 27.65 & 23.04 & 46.48 \\
\hline 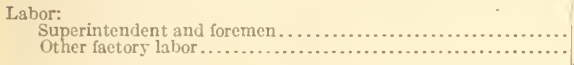 & $\begin{array}{r}2.98 \\
54.67\end{array}$ & 69.06 & $\begin{array}{r}2.42 \\
43.27\end{array}$ \\
\hline Total factory labor.... & 57.65 & 69.06 & 45.69 \\
\hline 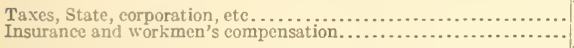 & .72 & .41 & $\begin{array}{l}.09 \\
.48 \\
\end{array}$ \\
\hline $\begin{array}{l}\text { Salaries: } \\
\text { Oflieials .................. } \\
\text { Oflice force............ }\end{array}$ & $\begin{array}{l}2.77 \\
1.99\end{array}$ & 4.14 & 4.24 \\
\hline Total salaries... & 4.76 & 4.14 & 4.24 \\
\hline General expense... & S. 57 & 1.93 & 3.02 \\
\hline Total manufaeturing cost ........... & 100.00 & 100.00 & 100.00 \\
\hline
\end{tabular}

The above table shows wherein the lowest cost establishment was operated at a lower percentage of cost than the highest cost establishments or the average for the group and also wherein it was operated at a higher percentage of cost.

As an illustration, take the group making window glass by hand. Group I. The lowest cost establishment had a lower percentage of cost for materials, taxes, and insurance, but had a higher percentage for labor, salaries, and general expense than the highest cost establishment. The greatest difference in cost was in materials, which in the main accounts for making establishment No. 14 the lowest cost establishment in this group. This difference in the cost of materials may be due to several reasons, among which may be mentioned $(a)$ nearness to source of supply of materials, $(b)$ quality of materials used, (c) greater efficiency in buying, $(d)$ other items of expense relatively high.

\section{SALES IN PREVIOUS YEARS.}

Sales were obtained not only for the year covered by the report but for previous years in as many establishments as possible. The object was to compare the sales in previous years with those of the last business year, 1915. In Table 53, which follows, percentages that sales of previous years were of 1915 sales are shown by establishments and groups.

$$
102511^{\circ}-17-11
$$


Table 53.-Percentages that Sales in Previous Years Were of Sales in 1915, by Establishments and Groups.

GROUP I.-WINDOW GLASS, HAND.

\begin{tabular}{|c|c|c|c|c|c|c|c|c|c|c|}
\hline Establishments, & 1906 & 1907 & 1908 & 1909 & 1910 & 1911 & 1912 & 1913 & 1914 & 1915 \\
\hline 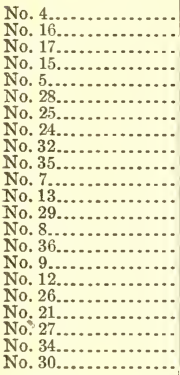 & & \begin{tabular}{c}
77.01 \\
$\cdots \ldots .$. \\
\hdashline$\ldots . .$. \\
\hdashline$\ldots . .$. \\
$\ldots .$.
\end{tabular} & $\begin{array}{r}60.55 \\
82.33 \\
80.84 \\
\ldots \ldots . . \\
\ldots . . .\end{array}$ & $\begin{array}{r}71.56 \\
96.72 \\
87.16 \\
92.17 \\
\ldots \ldots . . \\
\end{array}$ & \begin{tabular}{r}
77.83 \\
159.59 \\
111.49 \\
139.95 \\
72.77 \\
135.74 \\
54.51 \\
78.22 \\
123.63 \\
128.11 \\
\hdashline$\ldots . .$. \\
$\ldots . .$. \\
$\ldots . .$.
\end{tabular} & $\begin{array}{r}57.12 \\
101.92 \\
92.03 \\
94.31 \\
60.90 \\
103.57 \\
39.10 \\
89.20 \\
76.22 \\
58.09 \\
138.32 \\
80.08 \\
94.06 \\
\ldots \ldots . . . \\
\ldots . . .\end{array}$ & $\begin{array}{r}11.61 \\
89.87 \\
72.57 \\
100.85 \\
76.45 \\
92.29 \\
70.49 \\
92.79 \\
91.60 \\
80.39 \\
109.95 \\
85.50 \\
82.52 \\
86.02 \\
65.38 \\
\ldots \ldots . . . \\
\hdashline \ldots . . . \\
\hdashline \ldots . . .\end{array}$ & \begin{tabular}{r}
83.24 \\
126.55 \\
82.30 \\
121.60 \\
74.09 \\
129.46 \\
102.78 \\
9.5 .38 \\
106.69 \\
122.21 \\
127.54 \\
116.99 \\
70.49 \\
127.44 \\
90.71 \\
71.24 \\
145.37 \\
103.13 \\
$\cdots \ldots . . .$. \\
\hdashline$\ldots . .$. \\
\hdashline$\ldots . .$. \\
$\ldots . . .$.
\end{tabular} & $\begin{array}{r}94.63 \\
128.55 \\
110.89 \\
130.88 \\
78.75 \\
118.91 \\
100.08 \\
98.19 \\
113.05 \\
125.73 \\
127.45 \\
114.30 \\
96.86 \\
143.79 \\
80.69 \\
69.14 \\
92.84 \\
91.17 \\
110.80 \\
151.18 \\
102.26 \\
82.13\end{array}$ & $\begin{array}{l}100.00 \\
100.00 \\
100.00 \\
100.00 \\
100.00 \\
100.00 \\
100.00 \\
100.00 \\
100.00 \\
100.00 \\
100.00 \\
100.00 \\
100.00 \\
100.00 \\
100.00 \\
100.00 \\
100.00 \\
100.00 \\
100.00 \\
100.00 \\
100.00 \\
100.00\end{array}$ \\
\hline $\begin{array}{l}\text { Average: } \\
1 \text { establishment... } \\
3 \text { establishments.. } \\
4 \text { establishments.. } \\
10 \text { establishments. } \\
13 \text { establishments. } \\
15 \text { establishments. } \\
18 \text { establishments. } \\
22 \text { establishments. }\end{array}$ & & $\begin{array}{c}77.01 \\
\cdots \cdots\end{array}$ & $\begin{array}{r}60.55 \\
76.30 \\
\ldots . . . . .\end{array}$ & $\begin{array}{c}71.56 \\
86.39 \\
87.80 \\
\cdots \ldots . .\end{array}$ & $\begin{array}{r}77.83 \\
118.65 \\
123.85 \\
108.99 \\
\ldots . . . .\end{array}$ & \begin{tabular}{r}
57.12 \\
86.57 \\
88.46 \\
76.88 \\
81.88 \\
$\ldots \ldots$ \\
\hdashline$\ldots .$. \\
\end{tabular} & $\begin{array}{r}11.61 \\
63.02 \\
72.25 \\
80.73 \\
82.64 \\
80.74 \\
\cdots \cdots \\
\cdots\end{array}$ & $\begin{array}{r}83.24 \\
96.81 \\
102.86 \\
105.93 \\
103.92 \\
103.42 \\
103.81 \\
\cdots \cdots . . .\end{array}$ & $\begin{array}{r}94.63 \\
112.57 \\
117.04 \\
110.86 \\
110.39 \\
108.41 \\
105.04 \\
105.53\end{array}$ & $\begin{array}{l}100.00 \\
100.00 \\
100.00 \\
100.00 \\
100.00 \\
100.00 \\
100.00 \\
100.00\end{array}$ \\
\hline
\end{tabular}

GROUP II.-WINDOW GLASS, MACHINE.

\begin{tabular}{|c|c|c|c|c|c|c|c|c|c|c|}
\hline $\begin{array}{l}\text { No. } 46 \ldots \ldots \\
\text { No. } 45 \ldots \ldots \ldots \\
\text { No. } 38 \ldots \ldots \ldots \\
\text { No. } 40 \ldots \ldots \ldots \\
\text { No. } 42 \ldots \ldots \ldots \\
\text { No. } 49 \ldots \ldots \ldots \ldots \\
\text { No. } 39 \ldots \ldots \ldots \\
\end{array}$ & 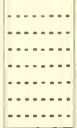 & $\begin{array}{ll}\ldots \ldots & \ldots \\
\ldots \ldots & \ldots \\
\ldots \ldots & \ldots \\
\ldots \ldots & \ldots \ldots \\
\ldots \ldots & \ldots \\
\end{array}$ & $\begin{array}{l}\ldots \ldots \\
\ldots \ldots \ldots \\
\cdots \ldots \ldots \\
\ldots \ldots \ldots \\
\ldots \ldots \ldots \\
\ldots \ldots\end{array}$ & 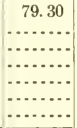 & 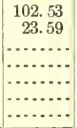 & \begin{tabular}{r}
41.55 \\
27.90 \\
$\ldots \ldots$ \\
\hdashline$\ldots \ldots$ \\
\hdashline$\ldots \ldots$ \\
\hdashline$\ldots \ldots$ \\
$\cdots$
\end{tabular} & $\begin{array}{r}103.99 \\
20.80 \\
122.17 \\
182.99 \\
65.12 \\
\hdashline \\
\hdashline\end{array}$ & $\begin{array}{r}82.23 \\
53.02 \\
118.26 \\
194.78 \\
57.84 \\
\cdots \\
\cdots\end{array}$ & $\begin{array}{r}84.74 \\
76.60 \\
94.21 \\
203.81 \\
42.27 \\
52.95 \\
\cdots\end{array}$ & $\begin{array}{l}100.00 \\
100.00 \\
100.00 \\
100.00 \\
100.00 \\
100.00 \\
\ldots\end{array}$ \\
\hline $\begin{array}{l}\text { Average: } \\
1 \text { establishment... } \\
2 \text { establishments.. } \\
4 \text { establishments.. } \\
5 \text { establishments.. } \\
6 \text { establishments.. }\end{array}$ & 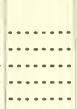 & & & 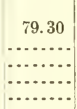 & \begin{tabular}{r}
102.53 \\
48.25 \\
$\ldots \ldots \ldots$ \\
\hdashline$\ldots \ldots$ \\
$\ldots . .$.
\end{tabular} & $\begin{array}{r}41.55 \\
32.16 \\
\ldots \ldots \ldots \\
\ldots \ldots \\
\ldots \ldots\end{array}$ & $\begin{array}{r}103.99 \\
46.79 \\
71.13 \\
70.09 \\
. \ldots . .\end{array}$ & $\begin{array}{c}82.23 \\
62.14 \\
84.11 \\
79.58 \\
. . .\end{array}$ & $\begin{array}{l}84.74 \\
79.14 \\
95.99 \\
86.74 \\
78.94\end{array}$ & $\begin{array}{l}100.00 \\
100.00 \\
100.00 \\
100.00 \\
100.00\end{array}$ \\
\hline
\end{tabular}

GROUP III.-PLATE GLASS.

\begin{tabular}{|c|c|c|c|c|c|c|c|c|c|c|}
\hline $\begin{array}{l}\text { No. } 51 \ldots \ldots \\
\text { No. } 55 \ldots \ldots \\
\text { No. } 50 \ldots \ldots \ldots \\
\text { No. } 52 \ldots \ldots \ldots\end{array}$ & … & . & $\begin{array}{c}56.62 \\
\ldots \ldots \ldots \\
\cdots \ldots \ldots \\
\cdots \ldots \ldots\end{array}$ & \begin{tabular}{|c|}
82.04 \\
$\ldots \ldots$ \\
$\ldots \ldots$ \\
$\ldots$
\end{tabular} & \begin{tabular}{r}
90.79 \\
\hdashline$\ldots$ \\
$\ldots$. \\
\end{tabular} & $\begin{array}{r}82.07 \\
115.41 \\
\hdashline \ldots \\
\hdashline\end{array}$ & $\begin{array}{r}74.05 \\
95.10 \\
131.78 \\
-\ldots \ldots \\
\end{array}$ & $\begin{array}{r}71.56 \\
103.88 \\
124.25 \\
-\ldots . . .\end{array}$ & $\begin{array}{r}88.03 \\
115.81 \\
132.86 \\
91.10\end{array}$ & $\begin{array}{l}100.00 \\
100.00 \\
100.00 \\
100.00\end{array}$ \\
\hline $\begin{array}{l}\text { Average: } \\
1 \text { establishment... } \\
2 \text { establishments.. } \\
3 \text { establishments.. } \\
4 \text { establishments.. }\end{array}$ & 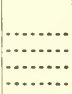 & $\begin{array}{l}\ldots \ldots \\
\ldots \ldots \\
\cdots \ldots\end{array}$ & 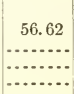 & \begin{tabular}{c}
82.04 \\
\hdashline$\ldots \ldots$ \\
$\ldots \ldots$
\end{tabular} & \begin{tabular}{c}
90.79 \\
\hdashline$\ldots$ \\
$\ldots$
\end{tabular} & \begin{tabular}{r}
82.07 \\
105.41 \\
\hdashline$\ldots .$. \\
\end{tabular} & $\begin{array}{c}74.05 \\
88.79 \\
96.64 \\
. . . . . . .\end{array}$ & $\begin{array}{c}71.56 \\
94.18 \\
99.67 \\
\ldots . . . . .\end{array}$ & $\begin{array}{r}88.03 \\
107.47 \\
112.11 \\
107.26\end{array}$ & $\begin{array}{l}100.00 \\
100.00 \\
100.00 \\
100.00\end{array}$ \\
\hline
\end{tabular}


Table 53.-Percentages that Sales in Previous Years Were of Sales ix 1915, BY Establishyents and Grotps-Continued.

GROUP IV.-WIRE AND OPALESCENT GLASS.

\begin{tabular}{|c|c|c|c|c|c|c|c|c|c|c|}
\hline Establishments. & $19+6 j$ & $190 \bar{i}$ & 1908 & 1909 & 1910 & 1911 & 1912 & 1913 & 1914 & 1915 \\
\hline 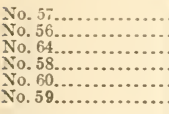 & & & & (2.... & 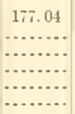 & $\begin{array}{r}243.47 \\
186.15 \\
99.53 \\
\cdots \ldots . . \\
\cdots \ldots . . . \\
\cdots\end{array}$ & $\begin{array}{l}20 \pi .07 \\
177.18 \\
114.68 \\
125.12 \\
105.28 \\
\cdots \cdots\end{array}$ & $\begin{array}{l}220.00 \\
144.86 \\
144.61 \\
123.92 \\
102.79 \\
111.04\end{array}$ & $\begin{array}{r}195.34 \\
129.84 \\
106.42 \\
107.08 \\
87.76 \\
117.38\end{array}$ & $\begin{array}{l}100.00 \\
100.00 \\
100.00 \\
100.00 \\
100.00 \\
100.00\end{array}$ \\
\hline $\begin{array}{l}\text { Average: } \\
1 \text { establishment.. } \\
3 \text { establishments. } \\
5 \text { establishments. } \\
6 \text { establishments. }\end{array}$ & & & & & $\begin{array}{l}177.04 \\
\ldots \ldots \ldots .\end{array}$ & $\begin{array}{c}243.47 \\
107.23 \\
\ldots \ldots . . .\end{array}$ & $\begin{array}{c}207.07 \\
119.79 \\
119.28 \\
\cdots \cdots\end{array}$ & $\begin{array}{l}220.00 \\
147.51 \\
141.14 \\
142.69\end{array}$ & $\begin{array}{l}195.34 \\
110.42 \\
109.10 \\
109.46\end{array}$ & $\begin{array}{l}100.00 \\
100.00 \\
100.00 \\
100.00\end{array}$ \\
\hline
\end{tabular}

GROUP V.-BOTTLES, HAND.

\begin{tabular}{|c|c|c|c|c|c|c|c|c|c|c|}
\hline 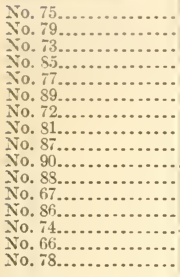 & $\begin{array}{r}81.05 \\
95.83 \\
100.77 \\
83.56\end{array}$ & $\begin{array}{r}96.15 \\
91.04 \\
105.48 \\
83.92 \\
\ldots . . . .\end{array}$ & $\begin{array}{r}112.97 \\
100.49 \\
102.09 \\
87.09 \\
116.90 \\
\ldots . . . . .\end{array}$ & $\begin{array}{r}93.78 \\
96.57 \\
106.61 \\
64.22 \\
97.92 \\
90.32 \\
. . . . . . .\end{array}$ & $\begin{array}{r}83.25 \\
99.90 \\
107.02 \\
90.85 \\
98.40 \\
71.46 \\
\ldots . . . . .\end{array}$ & $\begin{array}{r}105.70 \\
95.00 \\
103.15 \\
100.67 \\
107.43 \\
83.03 \\
123.38 \\
138.36 \\
103.65 \\
133.07\end{array}$ & $\begin{array}{r}82.44 \\
91.62 \\
125.61 \\
102.51 \\
112.55 \\
89.64 \\
111.95 \\
108.45 \\
110.89 \\
138.11 \\
120.55 \\
\ldots \ldots \ldots .\end{array}$ & $\begin{array}{r}132.54 \\
82.43 \\
124.71 \\
97.51 \\
108.67 \\
129.38 \\
125.05 \\
114.53 \\
121.25 \\
137.20 \\
112.19 \\
173.97 \\
165.95 \\
60.92 \\
\cdots \\
\cdots . . . .\end{array}$ & $\begin{array}{r}132.54 \\
110.21 \\
120.26 \\
123.95 \\
118.08 \\
171.87 \\
120.03 \\
96.19 \\
116.16 \\
122.18 \\
120.45 \\
200.31 \\
110.41 \\
96.87 \\
123.56 \\
97.67\end{array}$ & $\begin{array}{l}100.00 \\
100.00 \\
100.00 \\
100.00 \\
100.00 \\
100.00 \\
100.00 \\
100.00 \\
100.00 \\
100.00 \\
100.00 \\
100.00 \\
100.00 \\
100.00 \\
100.00 \\
100.00\end{array}$ \\
\hline $\begin{array}{l}\text { Iverage: } \\
2 \text { establishments. } \\
4 \text { establishments. } \\
5 \text { establishments. } \\
6 \text { establishments. } \\
10 \text { establishments. } \\
11 \text { establishments. } \\
14 \text { establishments. } \\
16 \text { establishments. }\end{array}$ & $\begin{array}{c}90.28 \\
89.58 \\
\ldots . . .\end{array}$ & $\begin{array}{r}92.95 \\
91.72 \\
\cdots \ldots . .\end{array}$ & $\begin{array}{r}105.19 \\
97.60 \\
100.74\end{array}$ & $\begin{array}{l}95.53 \\
85.41 \\
87.44 \\
88.46\end{array}$ & $\begin{array}{l}93.65 \\
94.99 \\
95.55 \\
86.98\end{array}$ & $\begin{array}{r}99.02 \\
100.41 \\
101.55 \\
94.97 \\
109.29 \\
\ldots . . . . .\end{array}$ & $\begin{array}{r}8.5 .17 \\
100.54 \\
102.49 \\
97.92 \\
110.42 \\
111.34\end{array}$ & $\begin{array}{l}101.27 \\
104.07 \\
104.82 \\
113.55 \\
118.74 \\
118.15 \\
121.49 \\
\cdots \cdots \cdots\end{array}$ & $\begin{array}{l}118.61 \\
120.98 \\
120.50 \\
138.76 \\
122.80 \\
122.59 \\
122.32 \\
121.48\end{array}$ & $\begin{array}{l}100.00 \\
100.00 \\
100.00 \\
100.00 \\
100.00 \\
100.00 \\
100.00 \\
100.00\end{array}$ \\
\hline
\end{tabular}

GROUP VI.-BOTTLES, MACHINE.

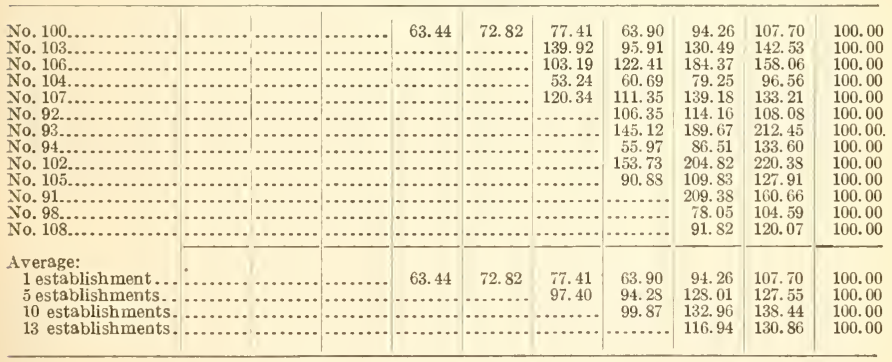


Table 53.-Percentages that Sales in Previous Years Were of Sales in 1915, by Establishments and Groups-Continued.

GROUP VII.-BOTTLES, HAND AND MACHINE.

\begin{tabular}{|c|c|c|c|c|c|c|c|c|c|c|}
\hline Establishments. & 1906 & 1907 & 1908 & 1909 & 1910 & 1911 & 1912 & 1913 & 1914 & 1915 \\
\hline 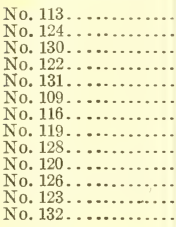 & $\begin{array}{l}5.00 \\
\ldots \ldots\end{array}$ & 201.77 & $\begin{array}{r}318.10 \\
47.45 \\
75.47\end{array}$ & $\begin{array}{r}221.93 \\
39.92 \\
83.64 \\
130.01 \\
80.47\end{array}$ & $\begin{array}{r}256.47 \\
55.42 \\
104.77 \\
137.29 \\
87.09 \\
155.66 \\
133.04 \\
237.23 \\
182.89\end{array}$ & $\begin{array}{r}250.45 \\
66.30 \\
112.52 \\
141.54 \\
83.65 \\
129.50 \\
163.86 \\
151.53 \\
157.96 \\
50.10 \\
121.48 \\
125.08 \\
. . . . .\end{array}$ & $\begin{array}{r}232.47 \\
58.76 \\
123.17 \\
136.83 \\
94.14 \\
136.95 \\
128.23 \\
148.76 \\
143.61 \\
69.06 \\
153.73 \\
140.20 \\
72.86\end{array}$ & $\begin{array}{r}240.52 \\
58.55 \\
110.72 \\
135.49 \\
108.31 \\
162.06 \\
133.27 \\
152.08 \\
183.60 \\
142.43 \\
125.41 \\
138.22 \\
80.98\end{array}$ & $\begin{array}{r}209.50 \\
43.65 \\
107.16 \\
121.45 \\
84.37 \\
153.92 \\
139.76 \\
141.66 \\
97.07 \\
122.87 \\
124.59 \\
128.52 \\
100.07\end{array}$ & $\begin{array}{l}100.00 \\
100.00 \\
100.00 \\
100.00 \\
100.00 \\
100.00 \\
100.00 \\
100.00 \\
100.00 \\
100.00 \\
100.00 \\
100.00 \\
100.00\end{array}$ \\
\hline $\begin{array}{l}1 \text { verage: } \\
1 \text { establishment... } \\
3 \text { establishments. } \\
5 \text { establishments.. } \\
9 \text { establishments. } \\
12 \text { establishments. } \\
13 \text { establishments. }\end{array}$ & 152.00 & 201.77 & $\begin{array}{l}318.10 \\
100.83\end{array}$ & $\begin{array}{r}221.93 \\
90.57 \\
92.96\end{array}$ & $\begin{array}{l}256.47 \\
112.00 \\
108.23 \\
133.78\end{array}$ & $\begin{array}{l}250.45 \\
118.73 \\
111.70 \\
126.26 \\
120.91\end{array}$ & $\begin{array}{l}232.47 \\
120.55 \\
115.14 \\
124.02 \\
124.84 \\
117.88\end{array}$ & $\begin{array}{l}240.52 \\
114.21 \\
115.37 \\
132.20 \\
132.60 \\
125.69\end{array}$ & $\begin{array}{l}209.50 \\
100.29 \\
100.61 \\
107.56 \\
111.86 \\
110.27\end{array}$ & $\begin{array}{l}100.00 \\
100.00 \\
100.00 \\
100.00 \\
100.00 \\
100.00\end{array}$ \\
\hline
\end{tabular}

GROUP VIII.-JARS.

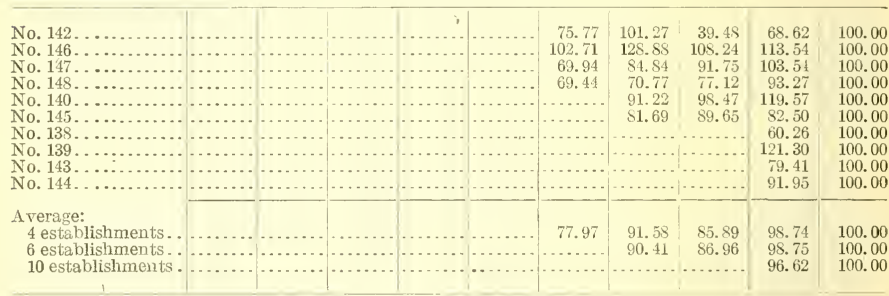

GROUP IX.-TABLETVARE, BLOTN.

\begin{tabular}{|c|c|c|c|c|c|c|c|c|c|c|}
\hline $\begin{array}{l}\text { No. } 150 \ldots \ldots \ldots \\
\text { No. } 154 \ldots \ldots \ldots \\
\text { No. } 149 \ldots \ldots \ldots \\
\text { No. } 156 \ldots \ldots \ldots\end{array}$ & $\begin{array}{c}65.21 \\
\cdots \cdots \cdots \\
\cdots \cdots \\
\cdots \cdots\end{array}$ & $\begin{array}{r}85.51 \\
105.47 \\
\ldots \ldots \\
\cdots\end{array}$ & $\begin{array}{r}92.19 \\
87.63 \\
\ldots \ldots \\
\ldots\end{array}$ & $\begin{array}{r}91.95 \\
99.48 \\
\cdots \\
\cdots\end{array}$ & $\begin{array}{r}73.92 \\
114.56 \\
\cdots \\
\cdots\end{array}$ & $\begin{array}{r}79.69 \\
116.11 \\
43.40 \\
\cdots\end{array}$ & $\begin{array}{r}61.09 \\
119.60 \\
89.40 \\
\cdots\end{array}$ & $\begin{array}{r}99.67 \\
120.65 \\
99.13 \\
104.13\end{array}$ & $\begin{array}{r}89.56 \\
102.65 \\
84.19 \\
91.40\end{array}$ & $\begin{array}{l}100.00 \\
100.00 \\
100.00 \\
100.00\end{array}$ \\
\hline $\begin{array}{l}\text { Average: } \\
1 \text { establishment... } \\
2 \text { establishments.. } \\
3 \text { establishments.. } \\
4 \text { establishments.. }\end{array}$ & $\begin{array}{c}65.21 \\
\cdots \ldots \ldots \\
\cdots \cdots \\
\cdots \cdots\end{array}$ & $\begin{array}{r}85.51 \\
99.64 \\
\ldots \ldots \\
\cdots\end{array}$ & $\begin{array}{r}92.19 \\
88.96 \\
\cdots \\
\hdashline\end{array}$ & $\begin{array}{r}91.95 \\
97.28 \\
\ldots \ldots \\
\cdots\end{array}$ & $\begin{array}{r}73.92 \\
102.70 \\
\cdots \\
\cdots\end{array}$ & $\begin{array}{r}79.69 \\
105.48 \\
96.31 \\
\ldots \ldots\end{array}$ & $\begin{array}{r}61.09 \\
102.52 \\
100.59 \\
\ldots\end{array}$ & $\begin{array}{r}99.67 \\
114.53 \\
112.25 \\
108.57\end{array}$ & $\begin{array}{l}89.56 \\
98.83 \\
96.67 \\
94.28\end{array}$ & $\begin{array}{l}100.00 \\
100.00 \\
100.00 \\
100.00\end{array}$ \\
\hline
\end{tabular}


Table 53.-Percentages that Sales in Previous Years Were of Sales in 1915, bY Establishments and Groups-Concluded.

GROTP X.-TABLEWARE, BLOWX AND PRESSED.

\begin{tabular}{|c|c|c|c|c|c|c|c|c|c|c|}
\hline Establishments. & 1906 & 1907 & 1908 & 1909 & 1910 & 1911 & 1912 & 1913 & 1914 & 1915 \\
\hline 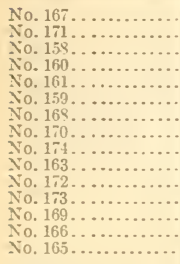 & & & $\begin{array}{r}76.26 \\
92.98 \\
\ldots . . .\end{array}$ & $\begin{array}{r}95.49 \\
106.79 \\
120.86 \\
111.20 \\
120.63 \\
146.33 \\
112.62 \\
110.11 \\
108.13 \\
\ldots \ldots . . .\end{array}$ & $\begin{array}{r}112.62 \\
107.97 \\
154.64 \\
124.39 \\
169.25 \\
161.09 \\
123.64 \\
108.74 \\
129.15 \\
143.17 \\
68.50 \\
64.00\end{array}$ & $\begin{array}{r}100.01 \\
112.77 \\
152.16 \\
126.14 \\
190.57 \\
155.70 \\
128.85 \\
110.93 \\
136.74 \\
100.84 \\
93.92 \\
76.31 \\
\ldots . . . .\end{array}$ & $\begin{array}{r}97.35 \\
107.72 \\
125.49 \\
126.91 \\
165.89 \\
157.22 \\
117.10 \\
123.62 \\
134.36 \\
119.30 \\
105.32 \\
130.94 \\
55.05 \\
71.23 \\
\cdots \cdots\end{array}$ & $\begin{array}{r}93.02 \\
119.82 \\
116.44 \\
118.42 \\
157.19 \\
135.45 \\
111.74 \\
93.71 \\
122.50 \\
93.31 \\
112.25 \\
100.09 \\
74.99 \\
76.50 \\
84.79 \\
\end{array}$ & $\begin{array}{r}73.15 \\
126.05 \\
118.75 \\
125.57 \\
129.51 \\
143.69 \\
142.83 \\
97.86 \\
118.25 \\
84.69 \\
94.36 \\
113.54 \\
74.65 \\
107.92 \\
97.67 \\
\end{array}$ & $\begin{array}{l}100.00 \\
100.00 \\
100.00 \\
100.00 \\
100.00 \\
100.00 \\
100.00 \\
100.00 \\
100.00 \\
100.00 \\
100.00 \\
100.00 \\
100.00 \\
100.00 \\
100.00\end{array}$ \\
\hline $\begin{array}{l}\text { A verage: } \\
2 \text { establishments. } \\
9 \text { establishments. } \\
12 \text { establishments } \\
14 \text { estahlishments. } \\
15 \text { establishments. }\end{array}$ & & & $\begin{array}{r}87.71 \\
\ldots . \ldots . \\
\cdots \ldots .\end{array}$ & $\begin{array}{c}103.23 \\
111.11 \\
\ldots . . . . .\end{array}$ & $\begin{array}{r}109.43 \\
124.73 \\
108.48 \\
\ldots . . .\end{array}$ & $\begin{array}{c}108.75 \\
128.26 \\
114.49 \\
\ldots . \ldots .\end{array}$ & $\begin{array}{c}104.47 \\
124.42 \\
122.85 \\
115.22 \\
\ldots \ldots \ldots .\end{array}$ & $\begin{array}{l}111.38 \\
116.24 \\
112.31 \\
107.74 \\
106.84\end{array}$ & $\begin{array}{l}109.39 \\
114.87 \\
110.43 \\
107.63 \\
107.24\end{array}$ & $\begin{array}{l}100.00 \\
100.00 \\
100.00 \\
100.00 \\
100.00\end{array}$ \\
\hline
\end{tabular}

GROUP XI.-LIGHTING GOODS.

\begin{tabular}{|c|c|c|c|c|c|c|c|c|c|c|}
\hline 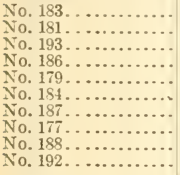 & 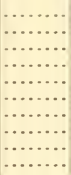 & $\begin{array}{l}\ldots \ldots \ldots \\
\ldots \ldots \ldots \\
\ldots \ldots \ldots \\
\ldots \ldots \ldots \\
\ldots \ldots \ldots \\
\ldots \ldots \ldots \\
\ldots \ldots \ldots \\
\ldots \ldots \ldots \\
\ldots \ldots \ldots \\
\ldots \ldots \ldots \\
\ldots\end{array}$ & 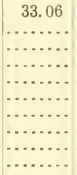 & 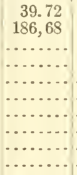 & 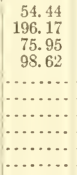 & $\begin{array}{r}58.06 \\
190.69 \\
77.91 \\
99.00 \\
\ldots \ldots \ldots \\
\ldots \ldots \ldots \\
\ldots \ldots \ldots \\
\ldots \ldots\end{array}$ & $\begin{array}{r}72.22 \\
119.51 \\
86.68 \\
100.99 \\
90.63 \\
61.39 \\
95.78 \\
145.50 \\
72.84 \\
\ldots \ldots\end{array}$ & $\begin{array}{r}90.00 \\
150.39 \\
91.16 \\
106.14 \\
108.02 \\
90.47 \\
124.51 \\
122.44 \\
90.51 \\
157.08\end{array}$ & $\begin{array}{r}87.50 \\
116.25 \\
81.34 \\
107.65 \\
109.74 \\
102.54 \\
138.35 \\
123.12 \\
96.88 \\
126.93\end{array}$ & $\begin{array}{l}100.00 \\
100.00 \\
100.00 \\
100.00 \\
100.00 \\
100.00 \\
100.00 \\
100.00 \\
100.00 \\
100.00\end{array}$ \\
\hline $\begin{array}{l}\text { Average: } \\
1 \text { establisment.... } \\
2 \text { establishments.. } \\
4 \text { establishments.. } \\
9 \text { establishments.. } \\
10 \text { establishments. }\end{array}$ & $\begin{array}{l}\ldots \ldots \\
\cdots \ldots \ldots \\
\cdots \ldots \\
\cdots \ldots \\
\ldots \ldots \\
\ldots \ldots\end{array}$ & $\begin{array}{l}\ldots \ldots \ldots \\
\ldots \ldots \ldots \\
\ldots \ldots \ldots \\
\ldots \ldots \ldots \\
\ldots \ldots \ldots\end{array}$ & 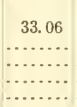 & $\begin{array}{r}39.72 \\
94.51 \\
\ldots \ldots . . \\
\ldots \ldots . . \\
\ldots \ldots\end{array}$ & $\begin{array}{r}54.44 \\
107.28 \\
85.19 \\
\ldots \ldots \ldots \\
\ldots \ldots . .\end{array}$ & $\begin{array}{r}58.06 \\
107.50 \\
86.60 \\
\ldots \ldots . . \\
\ldots \ldots .\end{array}$ & $\begin{array}{r}72.22 \\
89.85 \\
89.34 \\
86.48 \\
\ldots \ldots . .\end{array}$ & $\begin{array}{r}90.00 \\
112.51 \\
97.39 \\
99.15 \\
111.63\end{array}$ & $\begin{array}{r}87.50 \\
98.22 \\
88.35 \\
96.37 \\
102.96\end{array}$ & $\begin{array}{l}100.00 \\
100.00 \\
100.00 \\
100.00 \\
100.00\end{array}$ \\
\hline
\end{tabular}

GROUP XII.-LAMP CHIMNEYS.

\begin{tabular}{|c|c|c|c|c|c|c|c|c|c|c|}
\hline $\begin{array}{l}\text { No. } 197 \ldots \ldots \ldots \ldots \\
\text { No. } 199 \ldots \ldots \ldots \ldots \\
\text { No. } 200 \ldots \ldots \ldots \ldots \\
\text { No. } 195 \ldots \ldots \ldots \ldots\end{array}$ & $\begin{array}{l}\ldots \ldots \ldots \\
\cdots \ldots \ldots \\
\cdots \ldots \ldots \\
\cdots \ldots\end{array}$ & $\begin{array}{l}\cdots \cdots \\
\cdots \\
\cdots \\
\cdots\end{array}$ & $\begin{array}{l}\ldots \ldots \ldots \\
\cdots \ldots \ldots \\
\cdots \ldots \ldots \\
\cdots\end{array}$ & 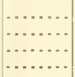 & 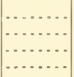 & $\mid \begin{array}{l}\cdots \ldots \\
\cdots \ldots \\
\cdots \cdots \\
\cdots \cdots \\
\cdots\end{array}$ & $\begin{array}{c}49.87 \\
72.24 \\
99.52 \\
\cdots\end{array}$ & $\begin{array}{l}88.16 \\
80.94 \\
98.79 \\
90.66\end{array}$ & $\begin{array}{l}98.83 \\
84.71 \\
84.09 \\
93.57\end{array}$ & $\begin{array}{l}100.00 \\
100.00 \\
100.00 \\
100.00\end{array}$ \\
\hline $\begin{array}{l}\text { Average: } \\
3 \text { establishments. . } \\
4 \text { establishments.. }\end{array}$ & - $\ldots \ldots \ldots$ & $\begin{array}{ll}\ldots \ldots \\
\cdots \ldots \ldots\end{array}$ & $\begin{array}{ll}\cdots \ldots \\
\ldots \ldots \ldots\end{array}$ & $\begin{array}{l}\cdots \\
\cdots \cdots \\
\cdots\end{array}$ & $\begin{array}{l}\cdots \\
\cdots \\
\cdots\end{array} \ldots$ & $\begin{array}{l}\ldots \ldots \\
\ldots \ldots\end{array}$ & $\begin{array}{r}89.04 \\
\ldots . . .\end{array}$ & $\begin{array}{l}94.65 \\
94.51\end{array}$ & $\begin{array}{l}86.02 \\
86.30\end{array}$ & $\begin{array}{l}100.00 \\
100.00\end{array}$ \\
\hline
\end{tabular}

GROUP XIII.-MISCELLANEOUS ARTICLES.

\begin{tabular}{|c|c|c|c|c|c|c|c|c|c|c|}
\hline $\begin{array}{l}\text { No. } 208 \ldots \ldots \ldots \\
\text { No. } 206 \ldots \ldots \ldots \\
\text { No. } 210 \ldots \ldots \ldots \\
\text { No. } 211 \ldots \ldots \ldots \\
\text { No. } 207 \ldots \ldots \ldots \\
\text { No. } 205 \ldots \ldots \ldots \\
\text { No. } 201 \ldots \ldots \ldots \ldots \\
\end{array}$ & 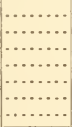 & 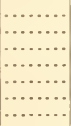 & 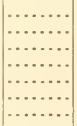 & 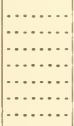 & 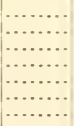 & $\begin{array}{r}97.95 \\
51.67 \\
54.61 \\
118.20 \\
\cdots \cdots \\
\cdots \cdots \\
\cdots\end{array}$ & $\begin{array}{r}100.58 \\
50.56 \\
61.97 \\
117.21 \\
67.79 \\
\ldots\end{array}$ & $\begin{array}{r}97.96 \\
61.45 \\
77.67 \\
132.00 \\
88.66 \\
76.00 \\
\ldots\end{array}$ & $\begin{array}{r}101.18 \\
68.81 \\
82.19 \\
119.04 \\
89.00 \\
79.45 \\
60.30\end{array}$ & $\begin{array}{l}100.00 \\
100.00 \\
100.00 \\
100.00 \\
100.00 \\
100.00 \\
100.00\end{array}$ \\
\hline $\begin{array}{l}\text { A verage: } \\
4 \text { establishments.. } \\
5 \text { establishments.. } \\
6 \text { establishments.. } \\
7 \text { establishments.. }\end{array}$ & $\begin{array}{l}\ldots \ldots \\
\cdots \ldots \\
\cdots \ldots \\
\cdots \ldots \\
\cdots\end{array}$ & $\begin{array}{l}\cdots \\
\cdots \\
\cdots \\
\cdots\end{array} \ldots$ & $\begin{array}{l}\ldots \ldots \ldots \\
\cdots \ldots \ldots \\
\cdots \ldots \ldots \\
\cdots \ldots\end{array}$ & $\begin{array}{l}\ldots \ldots \ldots \\
\cdots \ldots \ldots \\
\cdots \ldots \ldots \\
\cdots \ldots\end{array}$ & $\begin{array}{l}\ldots \ldots \\
\ldots \ldots \ldots \\
\ldots \ldots \ldots\end{array}$ & $\begin{array}{c}83.90 \\
\ldots \ldots \ldots \\
\ldots \ldots . \\
\ldots \ldots\end{array}$ & $\begin{array}{c}86.57 \\
83.93 \\
\ldots . . . \\
\ldots . . . \\
\end{array}$ & $\begin{array}{c}97.63 \\
96.36 \\
95.08 \\
\ldots . . .\end{array}$ & $\begin{array}{l}96.52 \\
95.46 \\
94.46 \\
94.47\end{array}$ & $\begin{array}{l}100.00 \\
100.00 \\
100.00 \\
100.00\end{array}$ \\
\hline
\end{tabular}


An examination of the above table shows that all groups are represented in only the years 1912,1913 , and 1914 . The average sales in Groups II, VIII, XII, and XIII were greater in 1915 than in the years 1912, 1913, and 1914. The average sales in the other groups were less in 1915 than they were in the other years.

\section{PROFITS IN PREVIOUS YEARS.}

Profits in previous years were also obtained from as many establishments as possible. In Table 54 percentages are shown for the profits of previous years based on the sales of that year, by establishments and groups.

Table 54.-Percentages of Final Profit, Based on Sales of Each Year, 1906 to 1915, вy Establishments and Groups.

GROUP I.-WINDOW GLASS, HAND.

\begin{tabular}{|c|c|c|c|c|c|c|c|c|c|c|}
\hline Establishments. & 1906 & 1907 & 1908 & 1909 & 1910 & 1911 & 1912 & 1913 & 1914 & 1915 \\
\hline 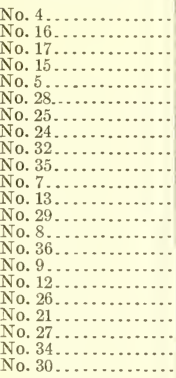 & & $\begin{array}{c}3.05 \\
\ldots \ldots . \\
\ldots \ldots\end{array}$ & 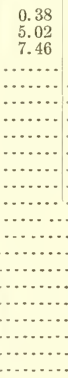 & $\begin{array}{r}0.40 \\
8.30 \\
11.61 \\
7.50 \\
\ldots . . . \\
\ldots . .\end{array}$ & $\begin{array}{r}3.18 \\
a 2.34 \\
28.54 \\
20.70 \\
16.71 \\
22.98 \\
6.70 \\
6.54 \\
23.60 \\
a 1.35 \\
\ldots \ldots . . . \\
\ldots \ldots . . \\
\ldots \ldots . .\end{array}$ & $\begin{array}{r}a 8.11 \\
12.77 \\
6.98 \\
a .67 \\
8.52 \\
a .79 \\
a 18.98 \\
4.90 \\
a 1.99 \\
a 1.96 \\
17.79 \\
a 8.25 \\
8.22 \\
\ldots \ldots . . . \\
\ldots \ldots . . . \\
\ldots . . .\end{array}$ & $\begin{array}{r}a 16.17 \\
5.06 \\
9.92 \\
5.26 \\
6.77 \\
a .12 \\
5.24 \\
8.01 \\
2.42 \\
a .35 \\
a 5.33 \\
2.54 \\
5.35 \\
a 5.55 \\
5.07 \\
\ldots . . . . \\
\ldots . . . \\
\ldots . . . \\
\ldots . . .\end{array}$ & $\begin{array}{r}13.58 \\
13.76 \\
26.66 \\
21.15 \\
16.37 \\
26.30 \\
16.84 \\
9.20 \\
18.46 \\
13.52 \\
12.75 \\
12.95 \\
3.69 \\
a 3.75 \\
17.43 \\
30.92 \\
4.75 \\
12.70 \\
\ldots . . .\end{array}$ & $\begin{array}{r}19.04 \\
12.41 \\
11.23 \\
16.56 \\
16.08 \\
14.58 \\
11.80 \\
6.48 \\
16.04 \\
14.36 \\
10.13 \\
12.38 \\
21.09 \\
a 1.84 \\
8.43 \\
32.75 \\
5.37 \\
2.27 \\
12.67 \\
.55 \\
9.99 \\
10.81\end{array}$ & $\begin{array}{r}12.95 \\
7.47 \\
14.53 \\
12.03 \\
8.08 \\
10.97 \\
7.72 \\
6.36 \\
15.77 \\
7.35 \\
10.59 \\
5.62 \\
13.58 \\
a 3.67 \\
5.13 \\
8.17 \\
10.57 \\
2.16 \\
4.35 \\
a .72 \\
8.57 \\
7.20\end{array}$ \\
\hline $\begin{array}{l}\text { A verage: } \\
1 \text { establishment... } \\
3 \text { establishments.. } \\
4 \text { establishments... } \\
10 \text { establishments. . } \\
13 \text { establishments.. } \\
15 \text { establishments.. } \\
18 \text { establishments.. } \\
22 \text { establishments.. }\end{array}$ & & $\begin{array}{c}3.05 \\
\ldots . . .\end{array}$ & $\begin{array}{r}.38 \\
5.22 \\
\ldots . .\end{array}$ & $\begin{array}{r}.40 \\
7.97 \\
7.86\end{array}$ & $\begin{array}{r}3.18 \\
11.03 \\
13.70 \\
13.31 \\
\cdots . . .\end{array}$ & $\begin{array}{r}a 8.11 \\
6.71 \\
4.26 \\
1.07 \\
2.70 \\
\cdots . . .\end{array}$ & $\begin{array}{r}a 16.17 \\
6.49 \\
6.07 \\
4.05 \\
3.48 \\
3.19 \\
\ldots . . .\end{array}$ & $\begin{array}{l}13.58 \\
18.44 \\
19.22 \\
16.15 \\
14.81 \\
14.02 \\
13.90 \\
\cdots \cdots\end{array}$ & $\begin{array}{l}19.04 \\
13.29 \\
14.19 \\
13.57 \\
14.04 \\
12.57 \\
12.36 \\
11.62\end{array}$ & $\begin{array}{r}12.95 \\
11.87 \\
11.91 \\
10.30 \\
10.36 \\
9.09 \\
8.71 \\
8.13\end{array}$ \\
\hline
\end{tabular}

GROUP II.-WINDOW GLASS, MACHINE.

\begin{tabular}{|c|c|c|c|c|c|c|c|c|c|c|}
\hline $\begin{array}{l}\text { No. } 46 \ldots \ldots \\
\text { No. } 45 \ldots \ldots \\
\text { No. } 38 \ldots \ldots \\
\text { No. } 40 \ldots \ldots \\
\text { No. } 42 \ldots \ldots \\
\text { No. } 49 \ldots \ldots \ldots \\
\end{array}$ & $\begin{array}{l}\ldots \ldots \ldots \\
\ldots \ldots \ldots \\
\cdots \ldots \ldots \\
\cdots \ldots\end{array}$ & 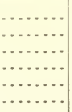 & 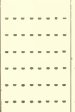 & $\begin{array}{c}4.54 \\
\ldots \ldots \ldots \\
\cdots \cdots \\
\cdots \cdots \\
\cdots \cdots \\
\cdots \cdots\end{array}$ & $\begin{array}{r}6.46 \\
13.55 \\
\cdots \cdots \\
\cdots \cdots \\
\cdots \cdots \\
\cdots \cdots \\
\cdots\end{array}$ & 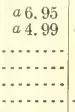 & $\begin{array}{r}a 1.04 \\
a 43.92 \\
18.71 \\
6.90 \\
1.29 \\
\cdots\end{array}$ & $\begin{array}{r}3.38 \\
24.56 \\
8.35 \\
18.29 \\
1.35 \\
\cdots\end{array}$ & $\begin{array}{r}12.75 \\
17.39 \\
a .42 \\
14.88 \\
1.41 \\
a .57\end{array}$ & $\begin{array}{r}1.94 \\
2.69 \\
a 1.46 \\
6.29 \\
9.57 \\
7.84\end{array}$ \\
\hline $\begin{array}{l}\text { A verage: } \\
1 \text { establishment... } \\
2 \text { establishments.. } \\
5 \text { establishments .. } \\
6 \text { establishments .. }\end{array}$ & & & & $\begin{array}{c}4.54 \\
\ldots \ldots \ldots \\
\ldots \ldots \ldots \\
\ldots \ldots\end{array}$ & $\begin{array}{r}6.46 \\
8.84 \\
\ldots \ldots .\end{array}$ & $\begin{array}{c}a 6.95 \\
a 5.78 \\
\ldots \ldots . . .\end{array}$ & $\begin{array}{r}a 1.04 \\
a 14.15 \\
a 1.31\end{array}$ & $\begin{array}{r}3.38 \\
15.81 \\
13.70 \\
\cdots\end{array}$ & $\begin{array}{r}12.75 \\
15.84 \\
12.93 \\
9.45\end{array}$ & $\begin{array}{l}1.94 \\
2.46 \\
2.46 \\
4.41\end{array}$ \\
\hline
\end{tabular}


Table 54.-Percentages of Final Profit, Based on Sales of Each Year, 1906 to 1915, вт Establishments axd Groups-Continued.

GROUP III.-PLATE GLASS.

\begin{tabular}{|c|c|c|c|c|c|c|c|c|c|c|}
\hline Establishments. & 1906 & $190 \%$ & 1908 & 1909 & 1910 & 1911 & 1912 & 1913 & 1914 & 1915 \\
\hline 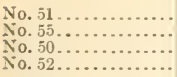 & $\begin{array}{l}\ldots \ldots \ldots \\
\ldots \ldots \ldots \\
\ldots \ldots \ldots\end{array}$ & $\begin{array}{l}\cdots \ldots \ldots \\
\cdots \ldots \ldots \ldots \\
\cdots \ldots \ldots \\
\cdots\end{array}$ & $\begin{array}{l}\text { a } 5.18 \\
\cdots \ldots \ldots \\
\cdots \cdots \\
\cdots \cdots\end{array}$ & $\begin{array}{c}\quad 6.33 \\
\ldots \ldots \ldots . \\
\cdots \ldots \ldots . \\
\cdots \ldots . .\end{array}$ & $\begin{array}{c}21.19 \\
\cdots \ldots \ldots \\
\cdots \cdots \\
\cdots \cdots\end{array}$ & $\begin{array}{r}8.58 \\
8.54 \\
\ldots . \\
\cdots\end{array}$ & $\begin{array}{r}a 4.11 \\
10.36 \\
21.49 \\
\cdots . . .\end{array}$ & $\begin{array}{r}\text { a } 12.41 \\
11.25 \\
19.24 \\
\cdots\end{array}$ & $\begin{array}{r}3.39 \\
a 1.19 \\
15.12 \\
12.17\end{array}$ & $\begin{array}{r}1.57 \\
a 2.46 \\
6.15 \\
11.80\end{array}$ \\
\hline $\begin{array}{l}\text { A verage: } \\
1 \text { establishment... } \\
2 \text { establishments.. } \\
3 \text { establishments.. } \\
4 \text { establishments.. }\end{array}$ & $\begin{array}{l}\cdots \cdots \\
\cdots \\
\cdots \cdots \\
\cdots\end{array}$ & $\begin{array}{l}\cdots \ldots \ldots \\
\cdots \ldots \ldots \\
\cdots \ldots \ldots \\
\cdots \ldots \ldots \\
\cdots\end{array}$ & $\begin{array}{l}a 5.18 \\
\ldots \ldots . \\
\ldots \ldots \\
\ldots \ldots\end{array}$ & $\begin{array}{c}6.33 \\
\ldots \ldots \ldots \\
\cdots \ldots . . \\
\cdots \ldots\end{array}$ & $\begin{array}{c}21.19 \\
\ldots \ldots \ldots \\
\cdots \ldots \\
\ldots \ldots\end{array}$ & $\begin{array}{r}8.58 \\
8.54 \\
\ldots \\
\ldots\end{array}$ & $\begin{array}{r}a 4.11 \\
6.74 \\
10.25 \\
\ldots \ldots .\end{array}$ & $\begin{array}{r}a 12.41 \\
5.91 \\
8.95 \\
\ldots . .\end{array}$ & $\begin{array}{l}3.39 \\
\text { c. } 07 \\
3.22 \\
4.98\end{array}$ & $\begin{array}{r}1.57 \\
\text { a. } 1.25 \\
.10 \\
2.80\end{array}$ \\
\hline
\end{tabular}

GROLP N.-WIRE AND OPALESCENT GLASS.

\begin{tabular}{|c|c|c|c|c|c|c|c|c|c|c|}
\hline 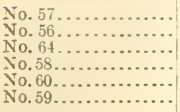 & $\begin{array}{l}\ldots \ldots \\
\cdots \ldots \ldots \\
\cdots \ldots \ldots \\
\cdots \ldots \ldots \\
\cdots \ldots \ldots \\
\cdots\end{array}$ & 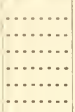 & 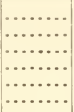 & $\begin{array}{l}\cdots \ldots \ldots \\
\ldots \ldots \ldots \\
\ldots \ldots \ldots \\
\cdots \ldots \ldots \\
\cdots \ldots \ldots \\
\cdots \ldots \ldots\end{array}$ & 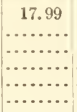 & $\begin{array}{r}25.69 \\
18.04 \\
5.92 \\
\ldots \ldots \\
\cdots \\
\cdots\end{array}$ & $\begin{array}{r}20.09 \\
18.42 \\
6.67 \\
29.33 \\
21.96 \\
\ldots \ldots \ldots\end{array}$ & $\begin{array}{r}8.06 \\
a 9.09 \\
9.98 \\
28.79 \\
31.96 \\
4.17\end{array}$ & $\begin{array}{r}8.05 \\
11.88 \\
14.34 \\
24.23 \\
23.21 \\
5.63\end{array}$ & $\begin{array}{r}a 21.06 \\
a 14.56 \\
5.52 \\
28.88 \\
21.51 \\
10.04\end{array}$ \\
\hline $\begin{array}{l}\text { Average: } \\
1 \text { establishment.... } \\
\text { 3establishments... } \\
\text { 5establishments... } \\
6 \text { establishments... }\end{array}$ & $\begin{array}{l}\ldots \ldots \ldots \\
\cdots \ldots \ldots \\
\cdots \ldots \ldots \\
\ldots \ldots \ldots \\
\ldots \ldots\end{array}$ & $\begin{array}{l}\ldots \ldots \ldots \\
\cdots \ldots \\
\cdots \ldots \ldots \\
\cdots \ldots \ldots \\
\ldots \ldots\end{array}$ & 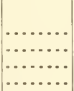 & $\begin{array}{l}\ldots \ldots \ldots \\
\ldots \ldots \ldots \\
\cdots \ldots \ldots \\
\ldots \ldots \ldots\end{array}$ & $\begin{array}{c}17.99 \\
\ldots \ldots \ldots \\
\cdots \ldots . . \\
\ldots \ldots .\end{array}$ & $\begin{array}{r}25.69 \\
8.17 \\
\ldots \ldots . \\
\ldots . . .\end{array}$ & $\begin{array}{r}20.09 \\
7.99 \\
9.61 \\
\ldots . . .\end{array}$ & $\begin{array}{r}8.06 \\
9.40 \\
10.97 \\
10.74\end{array}$ & $\begin{array}{r}8.05 \\
13.14 \\
14.06 \\
13.67\end{array}$ & $\begin{array}{r}21.06 \\
3.99 \\
6.01 \\
6.18\end{array}$ \\
\hline
\end{tabular}

GROUP V.-BOTTLES, HAND.

\begin{tabular}{|c|c|c|c|c|c|c|c|c|c|c|}
\hline No. 75. & 3.71 & 4. 48 & 15.58 & 16.45 & a 6.79 & 13. 27 & $a_{12.93}$ & 11.42 & 6.77 & 3.84 \\
\hline No. $79 \ldots \ldots \ldots$ & .66 & 3.15 & 2.17 & a. 06 & .73 & 1.10 & a. 2.80 & a 4.76 & a. 68 & a 2.07 \\
\hline No. $73 \ldots \ldots \ldots$ & 5.92 & 9.97 & 8.28 & 9.27 & 4. 44 & 5.19 & 3.27 & 3.66 & a. 31 & 6.78 \\
\hline No. $77 \ldots \ldots$ & ........ & ........ & 14.67 & 15.38 & 9.44 & 6.35 & 8.15 & 8.32 & 8.65 & 10.91 \\
\hline No. $89 \ldots \ldots$. & (n) & .......... & ........ & 5.73 & 3.74 & 4.12 & 6.76 & 3.81 & 4.43 & 6.78 \\
\hline No. 72 & & ........... & ......... & ....... & $\ldots . . .$. & 9.54 & 10.72 & 10.31 & 3.24 & 2.62 \\
\hline No.87................... & & ........ & ......... & ......... & $\ldots$ & 6.76 & 5.02 & 6.62 & 1.29 & 3.20 \\
\hline No.90.............. & $\ldots$ & ........ & ....... & ........ & ......... & 4.67 & 1.31 & 1.09 & 2.03 & 3.11 \\
\hline No.88............. & $\cdots$ & $\ldots$. & ........ & ........ & ........ & ......... & 4. 46 & 7.50 & 7.64 & 7.25 \\
\hline No.67................. & .. & $\ldots$ & ........ & ....... & $\ldots \ldots \ldots$ & ........ & $\ldots \ldots$ & 11.50 & 10.91 & a. 18 \\
\hline No.86............. & .. & ... & $\ldots$ & ........ & ........ & ........ & ........ & a. 3.76 & a 1.19 & a 3.41 \\
\hline No.74............ & .. & $\ldots$ & $\ldots$. & ........ & $\ldots$ & $\ldots \ldots$. & $\cdots$ & 15.28 & 11.56 & 12.27 \\
\hline No. $66 . .$. . & ... & $\ldots$ & $\ldots$ & $\ldots$ & $\ldots$ & ......... & $\ldots$ & ....... & a. 3.82 & a. 18 \\
\hline No. $78 . . . . . . . . .$. & ... & $\ldots$ & & $\ldots$. & $\cdots$ & $\ldots$ & $\cdots$ & & 16.34 & 10.83 \\
\hline Avera & & & & & & & & & & \\
\hline 2 establishments.. & 1.69 & 3.67 & 7.59 & 6.04 & 1. 79 & 5.98 & $a 6.36$ & 3.19 & 2.45 & .15 \\
\hline 3 establishments. . & 3.05 & 5.71 & 7.79 & 7.07 & 2.65 & 5. 74 & 2.74 & 3.35 & 1.62 & 2. 12 \\
\hline 4 establishments.. & $\ldots$ & $\ldots$ & 9.60 & 9.06 & 4.30 & 5.89 & 4.17 & 4.55 & 3.30 & 4.24 \\
\hline 5 establishments. . & $\cdots$ & & ........ & 7.64 & 4.09 & 5.19 & 5.25 & 4.19 & 3.91 & 5.37 \\
\hline 8 establishments.. & $\ldots$ & & $\ldots$ & ......... & ........ & 5.29 & 3.48 & 3.29 & 2.82 & 4.08 \\
\hline 9 establishments. . & & & & & & ......... & 3.59 & 3.70 & 3. 31 & 4. 43 \\
\hline 12 establishments.. & & & & & & & ...... & 3.18 & 3. 39 & 3.83 \\
\hline 14 establishments. & & & & & & $\ldots$ & & ....... & 3.70 & 4. 37 \\
\hline
\end{tabular}

a Loss. 
Table 54.-Percentages of Final Profit, Based on Sales of Each Year, 1906 to 1915, By Establishments and Groups-Continued.

GROUP VI.-BOTTLES, MACHINE.

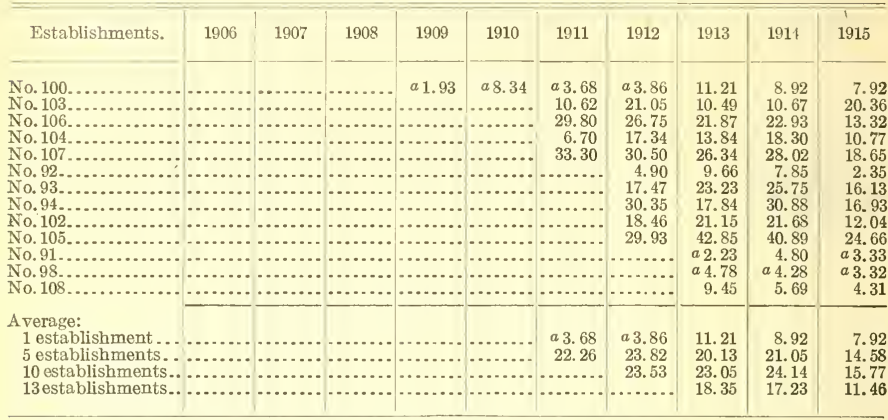

GROUP VII.-BOTTLES, HAND AND MACHINE.

\begin{tabular}{|c|c|c|c|c|c|c|c|c|c|c|}
\hline $\begin{array}{l}\text { Average: } \\
2 \text { establishments. } \\
4 \text { establishments.. } \\
8 \text { establishments. } \\
11 \text { establishments. } \\
13 \text { establishments. }\end{array}$ & $\begin{array}{l}\ldots \ldots \\
\ldots \ldots \\
\ldots \ldots \\
\ldots \ldots\end{array}$ & $\begin{array}{l}\ldots \\
\ldots \ldots \\
\cdots \\
\cdots\end{array}$ & $\begin{array}{c}10.55 \\
\ldots \ldots \\
\ldots \\
\ldots\end{array}$ & \begin{tabular}{r}
7.08 \\
7.88 \\
$\ldots$. \\
\hdashline$\ldots$ \\
\end{tabular} & $\begin{array}{r}9.13 \\
7.13 \\
9.06 \\
. .2 \\
\end{array}$ & $\begin{array}{c}7.41 \\
6.27 \\
6.03 \\
5.12 \\
\ldots . . . \\
\end{array}$ & $\begin{array}{l}9.59 \\
7.33 \\
6.88 \\
5.21 \\
5.71\end{array}$ & $\begin{array}{l}.77 \\
1.57 \\
3.94 \\
3.07 \\
3.65\end{array}$ & $\begin{array}{l}4.77 \\
1.86 \\
2.83 \\
2.30 \\
3.68\end{array}$ & $\begin{array}{r}1.66 \\
a 2.62 \\
a .51 \\
a 1.50 \\
.05\end{array}$ \\
\hline
\end{tabular}

GROUP VIII.-JARS.

\begin{tabular}{|c|c|c|c|c|c|c|c|c|c|c|}
\hline 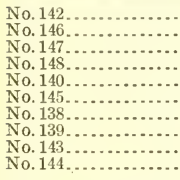 & 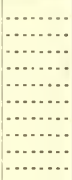 & $\begin{array}{l}\ldots \ldots \ldots \\
\ldots \ldots \ldots \\
\ldots \ldots\end{array}$ & 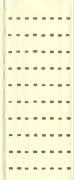 & 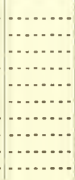 & 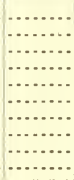 & 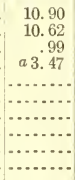 & \begin{tabular}{r}
17.57 \\
2.99 \\
13.76 \\
3.66 \\
6.59 \\
6.42 \\
- \\
\hdashline \\
$-\ldots$. \\
\end{tabular} & $\begin{array}{r}2.96 \\
.99 \\
15.13 \\
10.17 \\
5.25 \\
8.16 \\
- \\
2 . \\
\end{array}$ & $\begin{array}{r}0.06 \\
a 2.65 \\
14.51 \\
10.57 \\
6.34 \\
1.15 \\
1.83 \\
8.59 \\
8.58 \\
8.58\end{array}$ & $\begin{array}{r}5.03 \\
4.49 \\
9.85 \\
11.31 \\
2.05 \\
4.29 \\
a 1.68 \\
3.76 \\
5.74 \\
7.81\end{array}$ \\
\hline $\begin{array}{l}\text { A verage: } \\
4 \text { establishments.. } \\
6 \text { establishments.. } \\
10 \text { establishments. }\end{array}$ & . & . & 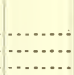 & & & $\begin{array}{r}5.94 \\
. .5 .\end{array}$ & $\begin{array}{r}7.35 \\
7.23 \\
-. . .\end{array}$ & $\begin{array}{c}8.49 \\
8.24 \\
\ldots . . .\end{array}$ & $\begin{array}{l}12.53 \\
11.32 \\
10.65\end{array}$ & $\begin{array}{l}15.83 \\
14.05 \\
11.99\end{array}$ \\
\hline
\end{tabular}

$a$ Loss. 
Table 54.- Percentages op Final Profit, Based ox Sales of Eace Year, 1906 to 1915, Br EstablishmeNts ANd Grours-Continued.

GROUP IX.-T.ABLEW.ARE, BLOWY.

\begin{tabular}{|c|c|c|c|c|c|c|c|c|c|c|}
\hline Establishments. & 1906 & $190 \overline{7}$ & 1908 & 1909 & 1910 & 1911 & 1912 & 1913 & 1914 & 1915 \\
\hline 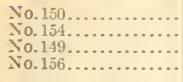 & $\begin{array}{r}0.92 \\
\ldots \ldots \ldots \\
\cdots \cdots \\
\cdots \cdots \\
\end{array}$ & 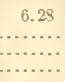 & 3.40 & $\begin{array}{c}6.62 \\
\ldots . . .\end{array}$ & $\begin{array}{r}a .06 \\
10.87 \\
\ldots \ldots . \\
\cdots \ldots .\end{array}$ & $\begin{array}{r}3.91 \\
10.87 \\
8.09 \\
.\end{array}$ & 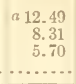 & $\begin{array}{r}a 1.68 \\
10.14 \\
5.22 \\
17.17\end{array}$ & $\begin{array}{r}0.17 \\
12.54 \\
.05 \\
18.67\end{array}$ & $\begin{array}{r}5.26 \\
10.65 \\
1.16 \\
18.92\end{array}$ \\
\hline $\begin{array}{l}\text { A rerage: } \\
1 \text { establishment... } \\
2 \text { establishments.. } \\
3 \text { establishments.. } \\
4 \text { establishments.. }\end{array}$ & .92 & $\begin{array}{r}6.28 \\
\ldots . . .\end{array}$ & 3.40 & $\begin{array}{r}6.62 \\
\cdots \cdots \\
\end{array}$ & $\begin{array}{r}5.06 \\
7.53\end{array}$ & $\begin{array}{r}3.91 \\
9.34 \\
15.37 \\
\ldots .\end{array}$ & $\begin{array}{r}12.49 \\
4.63 \\
4.77 \\
\ldots . \ldots .\end{array}$ & $\begin{array}{r}a 1.6 \mathrm{~S} \\
7.14 \\
6.89 \\
11.37\end{array}$ & $\begin{array}{r}.17 \\
9.27 \\
8.08 \\
12.74\end{array}$ & $\begin{array}{r}5.26 \\
9.07 \\
7.90 \\
12.90\end{array}$ \\
\hline
\end{tabular}

GROUP X.-TABLEWARE, BLOWN AND PRESSED.

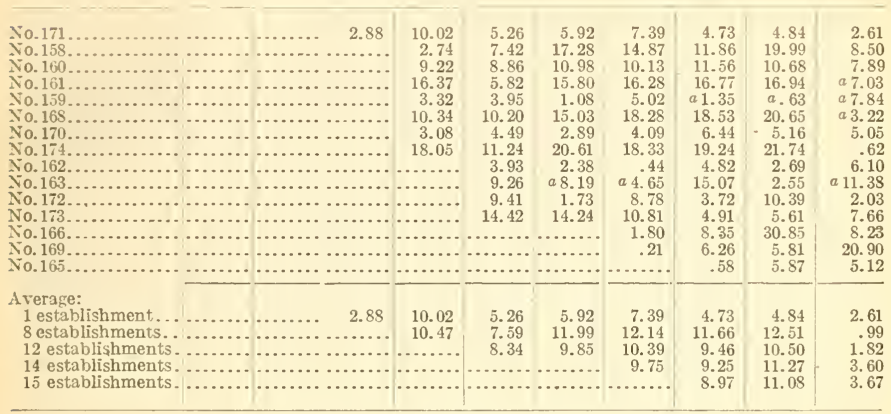

GROUP XI.-LIGHTING GOODS.

\begin{tabular}{|c|c|c|c|c|c|c|c|c|c|c|}
\hline 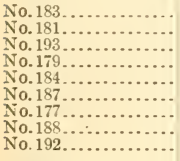 & 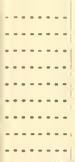 & 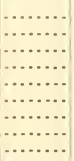 & 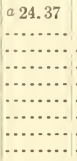 & 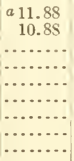 & 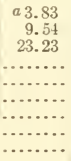 & 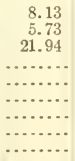 & $\begin{array}{r}6.15 \\
a 7.57 \\
25.31 \\
a .88 \\
19.17 \\
.74 \\
a .48 \\
2.63 \\
\ldots\end{array}$ & $\begin{array}{r}4.63 \\
a 2.92 \\
23.64 \\
a 1.68 \\
13.36 \\
4.55 \\
a 4.77 \\
6.32 \\
19.44\end{array}$ & $\begin{array}{r}9.52 \\
1.94 \\
24.31 \\
a 7.05 \\
13.42 \\
.16 \\
a 2.23 \\
6.84 \\
13.75\end{array}$ & $\begin{array}{r}14.92 \\
a 4.63 \\
20.38 \\
7.29 \\
15.06 \\
1.11 \\
.26 \\
7.50 \\
21.28\end{array}$ \\
\hline $\begin{array}{l}\text { A verage: } \\
1 \text { establishment... } \\
2 \text { establishments.. } \\
3 \text { establishments.. } \\
8 \text { establishments.. } \\
9 \text { establishments.. }\end{array}$ & $\begin{array}{l}\ldots \ldots \ldots \\
\ldots \ldots \ldots \\
\cdots \ldots \ldots \\
\cdots \ldots \ldots \\
\cdots \ldots \ldots \\
\cdots\end{array}$ & & $\begin{array}{l}a 24.37 \\
\ldots \ldots \ldots \\
\ldots \ldots \ldots \\
\cdots \ldots . . \\
\ldots \ldots \ldots\end{array}$ & 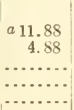 & $\begin{array}{r}a 3.83 \\
5.29 \\
18.04 \\
\ldots . . . \\
\ldots . . .\end{array}$ & $\begin{array}{r}8.13 \\
6.54 \\
17.57 \\
\ldots . . . \\
\ldots . .\end{array}$ & $\begin{array}{r}6.15 \\
a .65 \\
19.34 \\
13.84 \\
\ldots . .\end{array}$ & $\begin{array}{r}4.63 \\
.87 \\
17.68 \\
13.00 \\
15.10\end{array}$ & $\begin{array}{r}9.52 \\
6.18 \\
19.63 \\
12.86 \\
13.12\end{array}$ & $\begin{array}{r}14.92 \\
7.63 \\
17.53 \\
13.67 \\
15.44\end{array}$ \\
\hline
\end{tabular}

GROUP XII.-LAMP CHIMNEYS.

\begin{tabular}{|c|c|c|c|c|c|c|c|c|c|}
\hline $\begin{array}{l}\text { No. } 197 \ldots \ldots \ldots \ldots \\
\text { No. } 199 \ldots \ldots \ldots \ldots \\
\text { No. } 200 \ldots \ldots \ldots \ldots \\
\text { No. } 195 \ldots \ldots \ldots \ldots\end{array}$ & 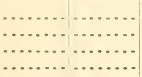 & $\mid \begin{array}{l}\cdots \cdots \\
\cdots \cdots \\
\cdots \cdots \\
\cdots \cdots \\
\cdots\end{array}$ & 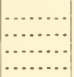 & $\begin{array}{ll}\ldots \ldots \\
\cdots \\
\cdots\end{array} \ldots$ & $\begin{array}{l}\ldots \ldots \ldots \\
\ldots \ldots \ldots \\
\ldots \ldots \ldots \\
\ldots \ldots\end{array}$ & $\begin{array}{r}4.56 \\
.03 \\
a 1.14 \\
. . .\end{array}$ & $\begin{array}{r}10.29 \\
4.00 \\
6.63 \\
8.22\end{array}$ & $\begin{array}{r}14.34 \\
4.83 \\
4.26 \\
8.03\end{array}$ & $\begin{array}{r}14.31 \\
7.05 \\
2.47 \\
6.73\end{array}$ \\
\hline $\begin{array}{l}\text { Average: } \\
3 \text { establishments.. } \\
4 \text { establishments.. }\end{array}$ & $\begin{array}{ll} \\
\ldots \ldots \ldots \\
\ldots \ldots \ldots \ldots\end{array}$ & …........ & $\begin{array}{ll}\cdots \\
\cdots\end{array}$ & $\begin{array}{ll}\ldots \ldots \\
\ldots \ldots\end{array}$ & … & $\begin{array}{r}a .59 \\
\ldots . .\end{array}$ & $\begin{array}{l}6.73 \\
6.75\end{array}$ & $\begin{array}{l}5.78 \\
5.87\end{array}$ & $\begin{array}{l}4.67 \\
4.75\end{array}$ \\
\hline
\end{tabular}


Table 54.-Percentages of Final Profit, Based on Sales of Each Year, 1906 to 1915, By Establishments and Groups-Concluded.

GROUP XIII.-MISCELLANEOUS ARTICLES.

\begin{tabular}{|c|c|c|c|c|c|c|c|c|c|c|}
\hline Establishments. & 1906 & 1907 & 1908 & 1909 & 1910 & 1911 & 1912 & 1913 & 1914 & 1915 \\
\hline $\begin{array}{l}\text { No. } 208 \ldots \ldots \ldots \\
\text { No. } 206 \ldots \ldots \\
\text { No. } 210 \ldots \ldots \\
\text { No. } 211 . \ldots \ldots \\
\text { No. } 207 . \ldots \ldots \\
\text { No. } 205 \ldots \ldots \\
\text { No. } 201 . \ldots \ldots \\
\end{array}$ & & $\begin{array}{l}\cdots \\
\cdots \\
\cdots \\
\cdots \\
\cdots\end{array}$ & & 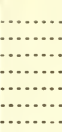 & ( & $\begin{array}{r}13.63 \\
8.14 \\
16.05 \\
6.12 \\
\ldots . . . \\
\end{array}$ & $\begin{array}{r}9.45 \\
1.17 \\
16.87 \\
6.01 \\
5.80\end{array}$ & $\begin{array}{r}2.53 \\
4.11 \\
11.05 \\
4.44 \\
a 1.70 \\
17.17 \\
\ldots . . .\end{array}$ & $\begin{array}{r}2.48 \\
4.77 \\
18.73 \\
7.94 \\
5.38 \\
17.34 \\
29.68\end{array}$ & $\begin{array}{r}9.6 \\
19.49 \\
18.15 \\
6.28 \\
8.17 \\
12.69 \\
32.30\end{array}$ \\
\hline $\begin{array}{l}\text { A verage: } \\
4 \text { establishments. } \\
5 \text { establishments. } \\
6 \text { establishments. } \\
7 \text { establishments. }\end{array}$ & & & & & & $\begin{array}{c}10.34 \\
\ldots \\
\ldots .\end{array}$ & $\begin{array}{c}9.22 \\
8.83 \\
\ldots . . .\end{array}$ & $\begin{array}{l}5.86 \\
4.88 \\
5.50\end{array}$ & $\begin{array}{l}9.71 \\
9.14 \\
9.58 \\
9.61\end{array}$ & $\begin{array}{l}12.68 \\
12.05 \\
12.09 \\
12.15\end{array}$ \\
\hline
\end{tabular}

A study of the above table shows the irregularity of profits, not only in individual establishments but of the average profit in each group as well. This irregularity, in some establishments at least, is due partly to whether or not depreciation was charged. Some establishments do not charge depreciation regularly, but only in those years which show a substantial profit. In some years, then, depreciation may or may not have been considered in computing the rate of profit. No attempt was made to go behind the figures, the percentages being based on the profits and sales as shown on the books of the various companies. Five of the thirteen groups showed a higher and eight a lower average profit in 1915 than in 1914. Groups III, IV, and X reached their highest average profit in 1914, Groups I, II, VI, and XII in 1913, and Group VII in 1912. 


\section{CHAPTER V.}

\section{COST AND PROFIT BY SPECIFIED UNITS.}

The manufacturers who furnished data respecting their total production and net sales were requested to supply also data as to the cost of production of the specific articles of glasiware that formed the major portion of the ware produced. Great difficulty was found in obtaining accurate cost data, not only because of the great variety of articles produced but more particularly because most of the establishments used very crude cost-finding systems, which in many cases were obviously inaccurate.

Data were secured only from plants that had a reasonably accurate cost-finding system, based on actual records of unit production. Whererer possible cost and prices were obtained as they were before they were affected by the war in Europe.

Lack of uniformity in the systems and records of those plants that furnished cost data makes it impossible to present the detailed items of cost of materials, labor, and overhead charges. For this reason only total cost, net selling price, and the profit or loss are shown. In a number of instances where splendid records were kept the agents could not use the data without divulging the identity of the establishments. Such was the case in several plants manufacturing glass bulbs for the incandescent lamp industry.

\section{TABULATION OF COST AND PROFIT BY ARTICLES.}

Data were obtained for 259 separate units from 29 establishments that manufactured bottles, jars, stem ware, tumblers, other tableware, and lamp chimneys. The total cost of producing and selling these articles, the prices at which they were sold, and the profits or losses are shown in the following series of tables.

The number of establishments reporting, the number of units of each class reported, and the number of units manufactured at a profit or loss are shown in Table 55, which follows:

Table 55.-Number of Establishments Reporting and Number of Units Showing Profits and Losses, by Class of Ware.

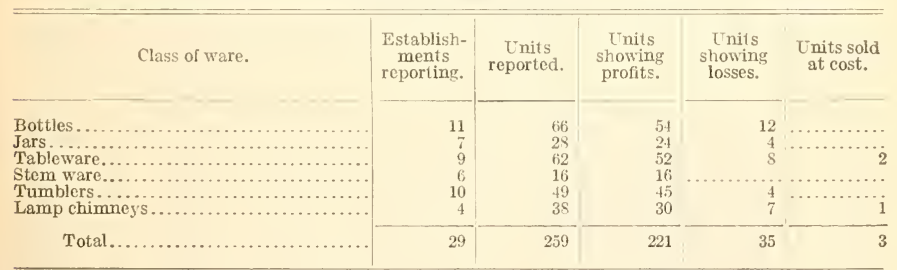

In the above table the figures in the column showing the number of establishments reporting do not add to the total for the reason that in some of the establishments more than one class of ware is made. 
Table 56.-Cost and Profit per Dozen in the Manufacture of Lime-Glass TUMBLERS.

\begin{tabular}{|c|c|c|c|c|c|c|}
\hline $\begin{array}{l}\text { Establish- } \\
\text { ment. }\end{array}$ & Description. & $\begin{array}{l}\text { Blown or } \\
\text { pressed. }\end{array}$ & $\begin{array}{l}\text { Net } \\
\text { selling } \\
\text { price. }\end{array}$ & $\begin{array}{l}\text { Total } \\
\text { cost. }\end{array}$ & Profit. & Loss. \\
\hline $\begin{array}{l}\text { o. } 162 \ldots \\
0.164 \ldots \\
0.176 \ldots \\
0.188 \ldots \\
0.171 \ldots \\
0.165 \ldots \\
0.158 \ldots \\
0.188 \ldots \\
0.171 \ldots \\
0.182 \ldots \\
0.176 \ldots \\
0.182 \ldots \\
\text { o. } 162 \ldots\end{array}$ & 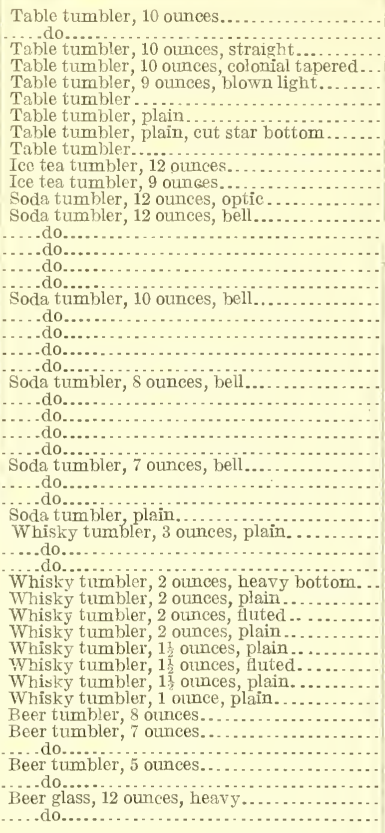 & 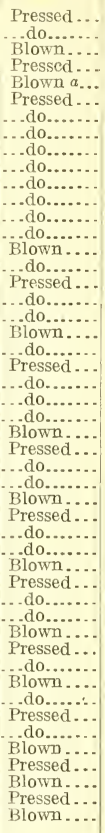 & $\begin{array}{l}80.50 \\
.33 \\
.23 \\
.22 \\
.33 \\
.40 \\
.33 \\
.28 \\
.13 \\
.67 \\
.14 \\
.60 \\
.52 \\
.40 \\
.38 \\
.34 \\
.28 \\
.47 \\
.37 \\
.30 \\
.28 \\
.25 \\
.42 \\
.37 \\
.32 \\
.27 \\
.23 \\
.41 \\
.32 \\
.27 \\
.48 \\
.25 \\
.18 \\
.18 \\
.33 \\
.23 \\
.18 \\
.18 \\
.22 \\
.18 \\
.18 \\
.18 \\
.26 \\
.53 \\
.24 \\
.40 \\
.20 \\
.80 \\
.31\end{array}$ & $\begin{array}{l}\$ 0.40 \\
.30 \\
.20 \\
.23 \\
.31 \\
.27 \\
.29 \\
.32 \\
.12 \\
.60 \\
.12 \\
.51 \\
.36 \\
.38 \\
.31 \\
.23 \\
.18 \\
.33 \\
.34 \\
.22 \\
.25 \\
.16 \\
.28 \\
.59 \\
.31 \\
.21 \\
.15 \\
.26 \\
.28 \\
.20 \\
.37 \\
.17 \\
.11 \\
.16 \\
.30 \\
.17 \\
.09 \\
.15 \\
.14 \\
.08 \\
.15 \\
.14 \\
.24 \\
.45 \\
.22 \\
.34 \\
.15 \\
.72 \\
.27\end{array}$ & $\begin{array}{r}80.10 \\
.03 \\
.03 \\
.02 \\
.02 \\
.04 \\
\ldots .01 \\
.01 \\
.02 \\
.09 \\
.16 \\
.02 \\
.07 \\
.11 \\
.10 \\
.14 \\
.03 \\
.08 \\
.03 \\
.09 \\
.14 \\
.01 \\
.01 \\
.06 \\
.08 \\
.15 \\
.04 \\
.07 \\
.11 \\
.08 \\
.07 \\
.02 \\
.03 \\
.06 \\
.09 \\
.03 \\
.08 \\
.10 \\
.03 \\
.04 \\
.02 \\
.08 \\
.02 \\
.06 \\
.05 \\
.08 \\
.04\end{array}$ & 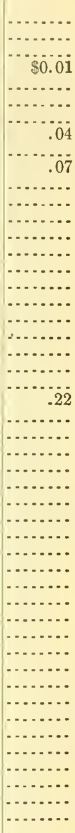 \\
\hline
\end{tabular}

a Made of lead glass.

Table 57.-Cost and Profit per Dozen in the Manufacture of Lime-Glass Stem Ware, Pressed.

\begin{tabular}{|c|c|c|c|c|}
\hline $\begin{array}{l}\text { Establish- } \\
\text { ment. }\end{array}$ & Description. & $\begin{array}{l}\text { Net } \\
\text { selling } \\
\text { price. }\end{array}$ & $\begin{array}{l}\text { Total } \\
\text { cost. }\end{array}$ & Profit. \\
\hline 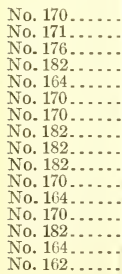 & 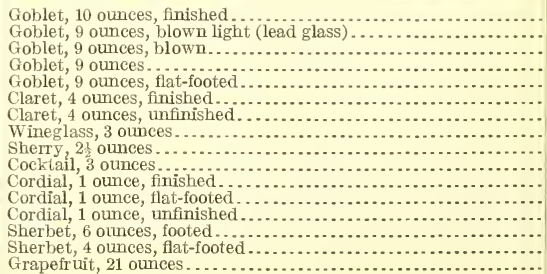 & $\begin{array}{r}\$ 0.30 \\
.86 \\
.70 \\
.69 \\
.40 \\
.26 \\
.18 \\
.43 \\
.35 \\
.53 \\
.19 \\
.16 \\
.13 \\
.59 \\
.37 \\
3.00\end{array}$ & $\begin{array}{r}80.28 \\
.72 \\
.52 \\
.65 \\
.36 \\
.24 \\
.16 \\
.32 \\
.29 \\
.41 \\
.17 \\
.15 \\
.12 \\
.42 \\
.30 \\
2.10\end{array}$ & $\begin{array}{r}\$ 0.02 \\
.14 \\
.18 \\
.04 \\
.04 \\
.02 \\
.02 \\
.11 \\
.06 \\
.12 \\
.02 \\
.01 \\
.01 \\
.17 \\
.07 \\
.90\end{array}$ \\
\hline
\end{tabular}


Table 5S.-Cost and Profit per Dozen in the Manufacture of Lamp Chrmanes, Gas Globes, and Lantern Globes. Blown.

\begin{tabular}{|c|c|c|c|c|c|c|}
\hline $\begin{array}{l}\text { Establish- } \\
\text { ment. }\end{array}$ & Description. & Kind of glass. & $\begin{array}{l}\text { Net } \\
\text { selling } \\
\text { price. }\end{array}$ & $\begin{array}{l}\text { Total } \\
\text { cost. }\end{array}$ & Profit. & Loss. \\
\hline 0.200 & $\begin{array}{l}\text { Lamp chrmney, Rochestcr, No. } 3 \text {, paste } \\
\text { mold. }\end{array}$ & One-half lead.. & $\$ 1.00$ & $\$ 0.94$ & $\$ 0.06$ & \\
\hline 0,200 & $\begin{array}{l}\text { Lamp chimney, student, Rochester, No. } \\
3,10 \text { inches, paste mold. }\end{array}$ & ..... do & .45 & .42 & .03 & \\
\hline 0.1 & aey, Rochester, No. 2, flint, & Lime.... & .54 & .41 & .13 & \\
\hline ? ? & $\begin{array}{l}\text { Lamp chimney, Rochestcr, No. 2, } 10 \\
\text { inches, paste mold. }\end{array}$ & Onc-half lead.. & .50 & .48 & .02 & \\
\hline 0. & $\begin{array}{l}\text { Lamp chimney, Rochester, No. 2, offhand } \\
\text { Lamp chimney, Rochester, No. 2, paste } \\
\text { mold. }\end{array}$ & $\begin{array}{l}\text { Lime... } \\
\text {.... do.. }\end{array}$ & .45 & $\begin{array}{l}.37 \\
.38\end{array}$ & .08 & \\
\hline 0. & chimney, Rochester, No. 1, paste & One-half lead.. & .45 & .37 & .08 & \\
\hline 0. & himney, Rochester, No. 0 , paste & $\begin{array}{l}\text { Lime... } \\
\text {.... do. }\end{array}$ & $\begin{array}{l}.40 \\
.40\end{array}$ & $\begin{array}{l}.33 \\
.27\end{array}$ & $\begin{array}{l}.07 \\
.13\end{array}$ & \\
\hline 0. & imncy, Sun, No. 2, plain....... & One-half & .45 & $\begin{array}{l}.50 \\
.31 \\
32\end{array}$ & .0 & \\
\hline & $\begin{array}{l}\text { Lamp chimney, sun, No. 2, plain, oit- } \\
\text { hand. }\end{array}$ & & & .32 & & \\
\hline 0 & $\begin{array}{l}\text { Lamp chimncy, Sun, No. } 2 \text {, crimp top, } \\
\text { offhand. }\end{array}$ & Onc-half lead & .34 & .41 & & \\
\hline 0 & mney, sun, No. 1, plain top, & Lin & .31 & $\begin{array}{l}.30 \\
.28\end{array}$ & .01 & \\
\hline & $\begin{array}{l}\text { Lamp chimney, Sun, No. 1, crimp top, } \\
\text { offhand. }\end{array}$ & One-half lead. & .30 & .41 & & \\
\hline 0. & & & .26 & $\begin{array}{l}.26 \\
.46\end{array}$ & .13 & \\
\hline & $\begin{array}{l}\text { in tubes. } \\
\text { iey, Phoenix, No. 2, offhand. }\end{array}$ & & .5 & .37 & .1 & \\
\hline & nes, B. \& H., No. 2, paste & & .5 & .4 & .01 & \\
\hline 0. & $\begin{array}{l}\text { himney, B. \& H., No. 2, offhand. } \\
\text { himney, electric, No. 2, flint, in }\end{array}$ & $\begin{array}{l}\text { Lime........ } \\
\text { One-halflead.. }\end{array}$ & .45 & $\begin{array}{l}.37 \\
.41\end{array}$ & .08 & \\
\hline 0 & $\begin{array}{l}\text { Lamp chimney, Belgian, No. } 1,10^{3} \\
\text { inches, paste mold. }\end{array}$ & .. & .50 & .47 & .03 & \\
\hline is & $\begin{array}{l}\text { Gas globes, C. R. I., ball, } 7 \text { inches ........ } \\
\text { Gas globes, C. R. I., ball, } 6 \text { inches ...... } \\
\text { Gas globes, C. R. I., ball, } 5 \text { inches ...... } \\
\text { Gas globes, tungsten, } 8 \text { inches, C. R. I... } \\
\text { Gas globes, tungsten, } 7 \text { inches, C. R. I... } \\
\text { Gas globes, tungsten, } 6 \text { inches, C. R. I... } \\
\text { Gas globes, } 6{ }^{3} \text {-inch air hole, iron mold, } \\
\text { opal. }\end{array}$ & $\begin{array}{l}\text { Lim } \\
\cdots \\
\cdots\end{array}$ & $\begin{array}{r}1.53 \\
1.29 \\
.99 \\
1.24 \\
.94 \\
.84 \\
.65\end{array}$ & $\begin{array}{r}1.04 \\
.81 \\
.81 \\
.85 \\
.71 \\
.63 \\
.45\end{array}$ & $\begin{array}{l}.49 \\
.45 \\
.18 \\
.39 \\
.23 \\
.21 \\
.20\end{array}$ & \\
\hline 0. & $\begin{array}{l}\text { pright, paste mold. } \\
\text { inverted, frosted, }\end{array}$ & One- & .33 & .40 & & \\
\hline & $\begin{array}{l}\text { Gas globes, } 5 . \text { inches, inverted, mission, } \\
\text { paste mold. }\end{array}$ & & .3 & .40 & & \\
\hline & $\begin{array}{l}3 \frac{1}{4} \text { inches, inverted, half- } \\
\text { pple. }\end{array}$ & Lim & .2 & .1 & .07 & \\
\hline & $\begin{array}{l}\text { Lantern globe, Junior, cold blast, No. 2, } \\
\text { iron mold. }\end{array}$ & $\mathrm{d} d$ & .31 & .2 & .03 & \\
\hline & Lantern globe, tubul & & $\begin{array}{l}.28 \\
.28\end{array}$ & .22 & $\begin{array}{l}.06 \\
.04\end{array}$ & \\
\hline
\end{tabular}


Table 59.-Cost and Profit per Dozen in the Manufacture of Lime-Glass Tableware, Pressed.

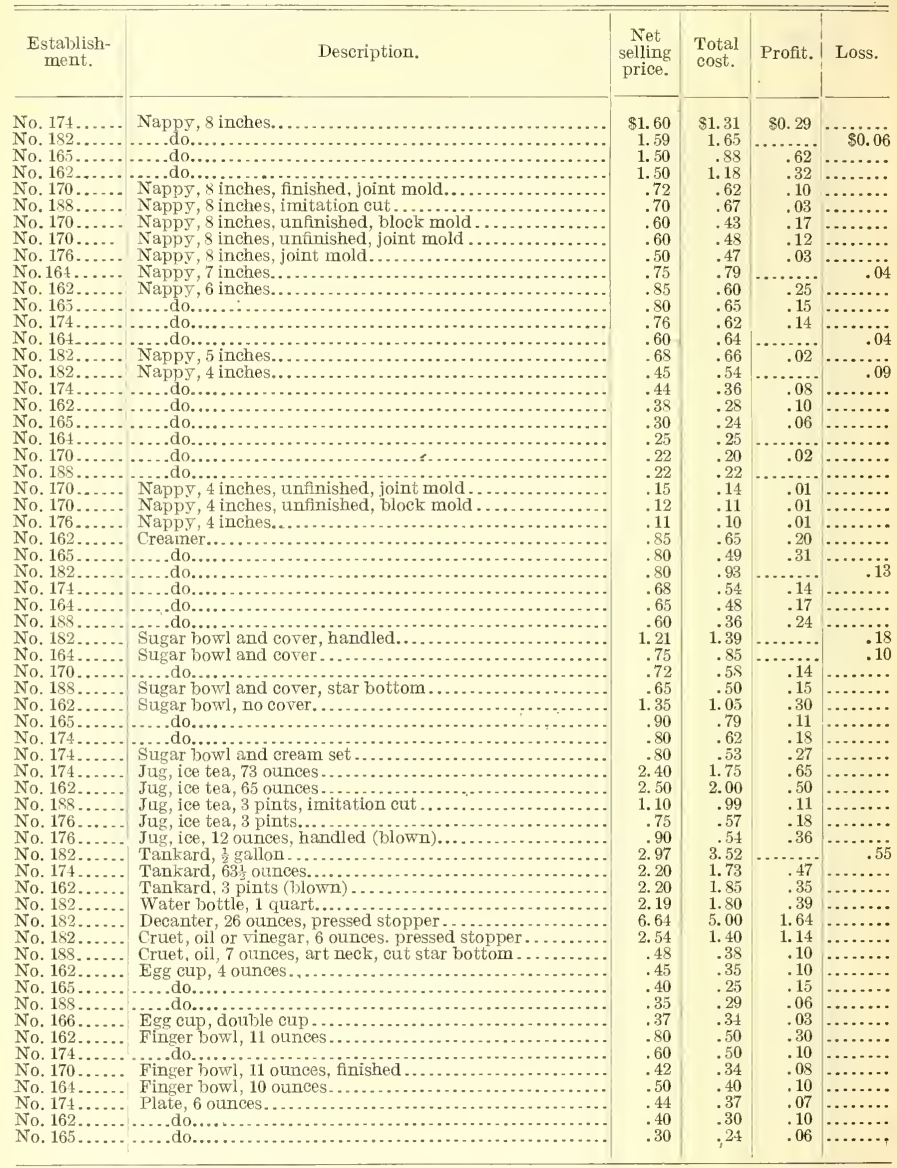


Table 60.-Cost and Profit in the Manufacture of Machine-Made Mile Jars, Fruit Jars, and Packing and Preseriing Tumblers.

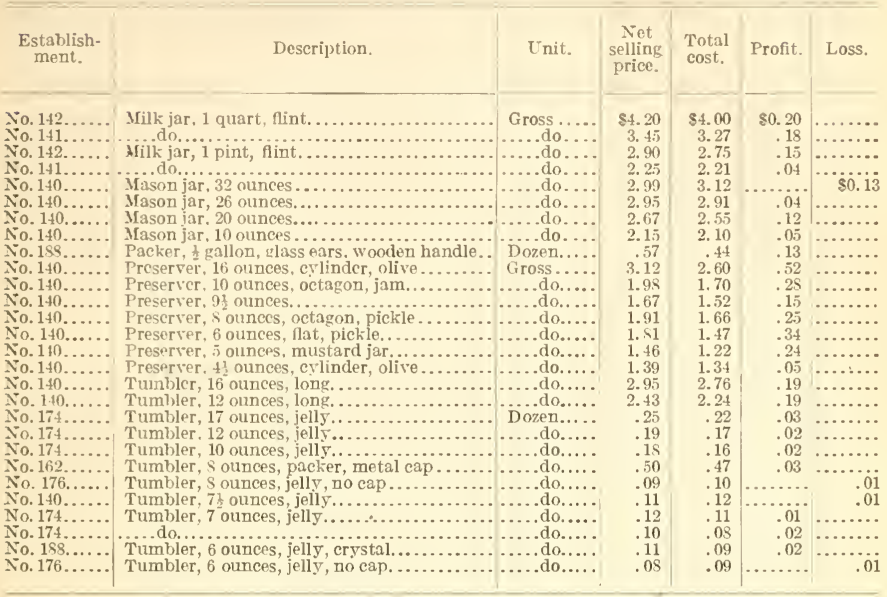

Table 61.-Cost and Profit per Gross in the Manufacture of Bottles.

\begin{tabular}{|c|c|c|c|c|c|c|c|c|}
\hline $\begin{array}{l}\text { Estab- } \\
\text { lish- } \\
\text { ment. }\end{array}$ & Description. & Contents. & $\begin{array}{l}\text { Weight } \\
\text { in } \\
\text { ounces. }\end{array}$ & $\begin{array}{l}\text { Hand or } \\
\text { machine } \\
\text { made. }\end{array}$ & $\begin{array}{l}\text { Net } \\
\text { selling } \\
\text { price. }\end{array}$ & $\begin{array}{l}\text { T'otal } \\
\text { cost. }\end{array}$ & Profit. & Loss. \\
\hline No. 132. & Prescription, oral, narrow & 32 ounces. & 20 & Hand & $\$ 5.50$ & $\$ 4.59$ & $\$ 0.91$ & \\
\hline No. 79 . & Prescription, round, wide & d & 20 & ... do & 5.00 & 5.30 & & 80.30 \\
\hline No. 87 .. & Prescription, oval, narrow & $\cdots$ & 20 & $\ldots$ do & 4. 92 & 4.15 & .77 & \\
\hline No. & P...do & & 19 & & 4.92 & 4. 19 & .73 & \\
\hline No. & $\begin{array}{l}\text { Prescription, oral, narrow } \\
\text { neck, green. }\end{array}$ & ... & 20 & & 4.61 & 4.08 & .53 & \\
\hline No. 132. & $\begin{array}{l}\text { Prescription, oval, narrow } \\
\text { neck, flint. }\end{array}$ & 16 ounces.. & 12 & ...do & 3.65 & 3.16 & .49 & \\
\hline No. $79 .$. & $\begin{array}{l}\text { Prescription, round, wide } \\
\text { mouth, green. }\end{array}$ & … & 12 & $\ldots d$ & 3.25 & 3.35 & & .10 \\
\hline No. $119 \ldots$ & Prescription. oval, narrow & ... & $11 \frac{1}{2}$ & $\ldots$ do & 3.24 & 3.02 & .22 & \\
\hline $\begin{array}{l}\text { No. } 87 \ldots . \\
\text { No. } 90 \ldots\end{array}$ & Preseription, oval, narrow & & $\begin{array}{l}12 \\
12\end{array}$ & & $\begin{array}{l}3.24 \\
3.04\end{array}$ & $\begin{array}{l}3.06 \\
2.85\end{array}$ & $\begin{array}{l}.18 \\
.19\end{array}$ & \\
\hline No. 82 & $\begin{array}{l}\text { neck, green. } \\
\text { Prescription, oval, narrow } \\
\text { neck, flint. }\end{array}$ & & 12 & & 2. 70 & 2.28 & .42 & \\
\hline No. $130 \ldots$ & .....do.......... & 10 ounces. & 11 & Machine & 2.35 & 2.30 & .05 & \\
\hline & $\begin{array}{l}\text {.....do. } \\
\ldots . . . \text { do.. }\end{array}$ & 8 oun & 7 & $\mathrm{H}$ & & 2. & $\begin{array}{r}.61 \\
.22\end{array}$ & . \\
\hline No. 8 & ..... do & & 7 & & 2. & 2.06 & .22 & $\cdots$ \\
\hline No. 9 & $\begin{array}{l}\text { Prescription, oval, narrow } \\
\text { neck, green. }\end{array}$ & Nos & 7 & ser & 2.10 & 1. 91 & .19 & \\
\hline No. 113 . & Prescription, oval, narrow & ... & 7 & do & 2.00 & 1.44 & .56 & \\
\hline No. & Preso do & $\ldots . . .1$ & $\therefore$ & $\because \mathrm{do}$ & 1.8 & 1.63 & .22 & \\
\hline & $\begin{array}{l}\text { Prescription, ammonia, long } \\
\text { neck, flint. }\end{array}$ & & 8 & $\mathrm{Ma}$ & & 1.87 & .13 & \\
\hline No. 132 . & $\begin{array}{l}\text { Preseription, oval, narrow } \\
\text { neck, flint. }\end{array}$ & 4 ounc & 4 & Han & 1.85 & 1.56 & .31 & \\
\hline $\begin{array}{l}\text { No. } 119 . . \\
\text { No. } 87 \ldots\end{array}$ & 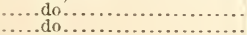 & & $\begin{array}{l}4 \\
4\end{array}$ & $\ldots d$ & $\begin{array}{l}\text { 1. } 72 \\
\text { 1. } 72\end{array}$ & $\begin{array}{l}1.43 \\
1.50\end{array}$ & .29 & \\
\hline & Prescription, oval, narrow & . & 4 & $\ldots$ do & 1. 61 & 1. 42 & .19 & $\cdots$ \\
\hline No.113... & $\begin{array}{l}\text { Prescription. oval, narrow } \\
\text { reck, flint. }\end{array}$ & .....do & 4 & ...do & 1. 53 & 1.30 & .23 & \\
\hline
\end{tabular}


Table 61.-Cost and Profit per Gross in the Manufacture of Bottles.-Con.

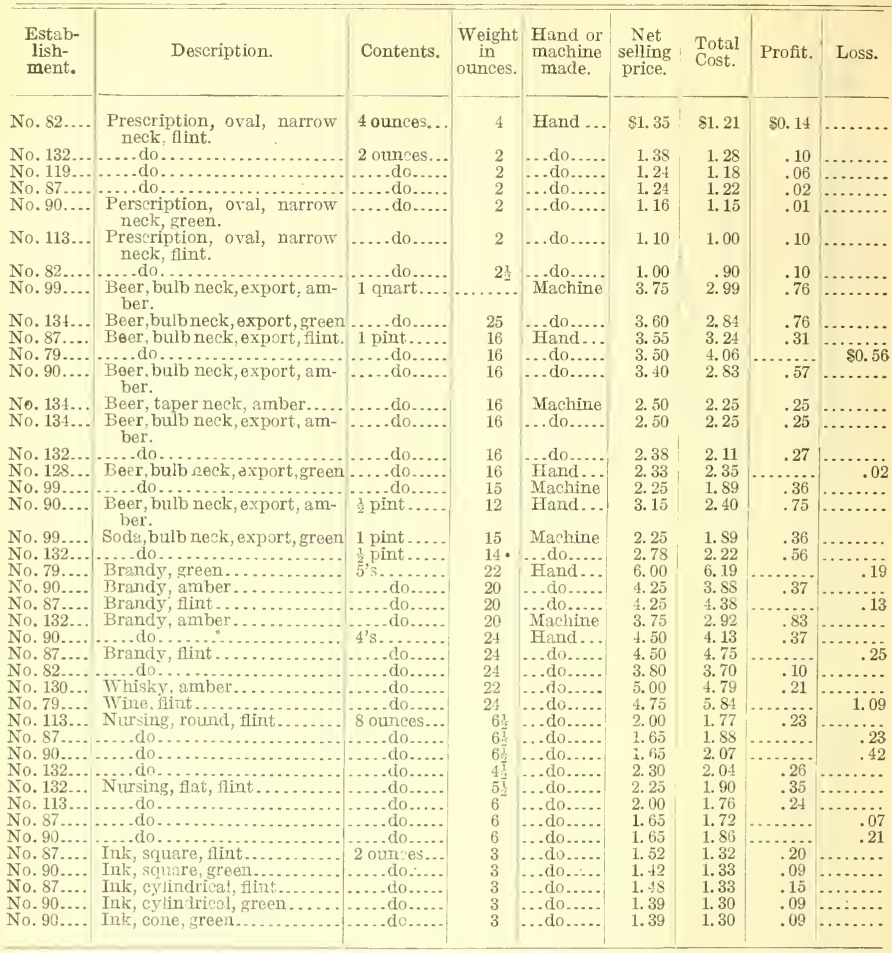

\section{UNIT COST FOR WINDOW GLASS.}

Available data from which unit costs could be derived were obtained from a considerable number of window-glass establishments visited by the agents during this investigation. Such data were reported by 18 establishments manufacturing window glass by hand and 3 manufacturing by machine. These establishments are fairly representative and are located in West Virginia, Pennsylvania, Ohio, Kansas, Indiana, and Texas.

Information was secured as to the total number of 50-foot singlestrength boxes of window glass produced during the business period. All boxes were reduced to a uniform basis of single-strength glass. Double-strengih glass was reduced in the proportion of 8 to 5

The method employed in deriving the cost of various brackets of window glass from the data obtained was briefly as follows: The amount of piece-paid labor was deducted from the total factory labor cost. Piece labor includes the following occupations: In the hand plants, blower, gatherer, flattener, and cutter; in the machine fac- 
tories, blower, flattener, ring man, snapper, capper, cracker open, and cutter. These occupations are paid according to a piece-price scale for the different brackets and grades and are charged directly to the cost of the unit.

The items of cost, except piece-paid labor, are practically the same for all cylinders produced in a factory, as the grades and sizes are not determined until the glass reaches the cutting department. In average cost, therefore, for general expense, administration, fixed charges, and time labor was properly applied to the cost of the unit. This was derived by dividing the total of these charges by the number of boxes produced. This method is employed practically by all window-glass factories and serves as a fairly accurate basis for determining the cost of specific brackets and grades.

\section{HANDMADE PRODUCT.}

The following table is derived from the wage scale agreed upon by the National Window Glass Workers and the National Association of Window Glass Manufacturers. These piece prices were in effect from March 15, 1916, to May 27, 1916.

Table 62.-Rates of Piece-Price Labor for a 50-Foot Box of Handmade Window Glass, by Brackets, A and B Grades, Single and Double Strength.

[Gatherers are paid 80 per cent and flatteners 27 per cent of blower's rates.]

\begin{tabular}{|c|c|c|c|c|c|c|c|c|c|}
\hline \multirow{2}{*}{ Brackets. } & \multicolumn{2}{|c|}{ Blower. } & \multicolumn{2}{|c|}{ Gatherer. } & \multicolumn{2}{|c|}{ Flattener. } & \multirow{2}{*}{$\frac{\text { Cutter. }}{\mathrm{A}_{\mathrm{B} \text {. nd }}}$} & \multicolumn{2}{|c|}{ Total. } \\
\hline & 1 . & B. & A. & B. & A. & B. & & $\Lambda$. & B. \\
\hline SINGLE STRENGTH. & & & & & & & & & \\
\hline $\begin{array}{l}8 \text { by } 10 \text { to } 10 \text { by } 15 \text { inches.... } \\
11 \text { by } 15 \text { to } 14 \text { by } 20 \text { inches... } \\
14 \text { by } 21 \text { to } 16 \text { by } 24 \text { inches... } \\
16 \text { by } 25 \text { to } 20 \text { by } 30 \text { inches... } \\
21 \text { by } 39 \text { to } 24 \text { by } 30 \text { inches... } \\
24 \text { by } 31 \text { to } 24 \text { by } 36 \text { inches... } \\
25 \text { by } 36 \text { to } 30 \text { by } 41 \text { inches... } \\
\Lambda 11 \text { above } 30 \text { by } 41 \text { inches.... }\end{array}$ & $\begin{array}{r}\$ 0.250 \\
.290 \\
.325 \\
.355 \\
.350 \\
.390 \\
.435 \\
.455\end{array}$ & $\begin{array}{r}\$ 0.235 \\
.270 \\
.305 \\
.320 \\
.335 \\
.350 \\
.350 \\
.405\end{array}$ & $\begin{array}{r}\$ 0.200 \\
.232 \\
.260 \\
.284 \\
.304 \\
.312 \\
.318 \\
.364\end{array}$ & $\begin{array}{r}\$ 0.185 \\
.216 \\
.244 \\
.256 \\
.265 \\
.280 \\
.304 \\
.324\end{array}$ & $\begin{array}{r}\$ 0.068 \\
.078 \\
.058 \\
.096 \\
.103 \\
.105 \\
.117 \\
.123\end{array}$ & $\begin{array}{r}\$ 0.063 \\
.073 \\
.082 \\
.086 \\
.090 \\
.095 \\
.103 \\
.109\end{array}$ & $\begin{array}{r}30.127 \\
.127 \\
.127 \\
.127 \\
.127 \\
.127 \\
.127 \\
.127\end{array}$ & $\begin{array}{r}\$ 0.645 \\
.727 \\
.800 \\
.862 \\
.914 \\
.934 \\
1.027 \\
1.069\end{array}$ & $\begin{array}{r}\$ 0.613 \\
.686 \\
.758 \\
.789 \\
.820 \\
.852 \\
.914 \\
.965\end{array}$ \\
\hline DOUBLE STRENGTH. & & & & & & & & & \\
\hline $\begin{array}{l}6 \text { by } 8 \text { to } 16 \text { by } 24 \text { inches.... } \\
16 \text { by } 25 \text { to } 24 \text { by } 36 \text { inches... } \\
24 \text { by } 37 \text { to } 30 \text { by } 40 \text { inches... } \\
39 \text { by } 41 \text { to } 36 \text { by } 51 \text { inches... } \\
36 \text { by } 52 \text { to } 39 \text { by } 60 \text { inches... } \\
40 \text { by } 60 \text { to } 40 \text { by } 78 \text { inches... } \\
\text { All above } 40 \text { by } 78 \text { inches.... }\end{array}$ & $\begin{array}{r}.355 \\
.515 \\
.560 \\
.620 \\
.75 ! \\
1.250 \\
2.3155\end{array}$ & $\begin{array}{r}.320 \\
.460 \\
.500 \\
.560 \\
.665 \\
1.145 \\
2.150\end{array}$ & $\begin{array}{r}.284 \\
.412 \\
.448 \\
.496 \\
.600 \\
1.000 \\
1.844\end{array}$ & $\begin{array}{r}.256 \\
.365 \\
.400 \\
.448 \\
.532 \\
.916 \\
1.720\end{array}$ & $\begin{array}{l}.096 \\
.139 \\
.151 \\
.167 \\
.203 \\
.338 \\
.622\end{array}$ & $\begin{array}{l}.086 \\
.124 \\
.135 \\
.151 \\
.180 \\
.309 \\
.581\end{array}$ & $\begin{array}{l}166 \\
.166 \\
.166 \\
.166 \\
.166 \\
.166 \\
.166\end{array}$ & $\begin{array}{l}.901 \\
\text { 1. } 232 \\
\text { 1. } 325 \\
\text { 1. } 449 \\
\text { 1. } 719 \\
\text { 2. } 754 \\
\text { 4. } 937\end{array}$ & $\begin{array}{r}.828 \\
1.118 \\
1.201 \\
1.325 \\
1.543 \\
2.536 \\
4.617\end{array}$ \\
\hline
\end{tabular}

The following series of tables is presented to show costs of various brackets and grades of single and double strength window glass.

Table 63 shows the cost of production in 1 s establishments of a 50 -foot box of handmade single-strength glass, bracket 6 by 8 to 10 by 15 inches, and illustrates the method employed in computing the total cost of the various brackets as given by separate establishments in Tables 64 and 65 on following pages. 
Table 63.-Cost of Producing a 50-Foot Box of Handmade Single-Strength Window Glass, Bracket 6 By 8 to 10 By 15 Inches, A and B Grades, With Additional Cost for Depreciation and Interest on Current Loans, by Establishments.

\begin{tabular}{|c|c|c|c|c|c|c|c|c|c|c|c|c|}
\hline \multirow{2}{*}{ Establishment. } & \multicolumn{2}{|c|}{ Materials. } & \multirow{2}{*}{ Fuel. } & \multicolumn{2}{|c|}{$\begin{array}{l}\text { Piece-paid } \\
\text { labor. }\end{array}$} & \multirow{2}{*}{$\begin{array}{c}\text { Other } \\
\text { fac- } \\
\text { tory } \\
\text { labor. }\end{array}$} & \multirow{2}{*}{$\begin{array}{l}\text { Sala- } \\
\text { ries. }\end{array}$} & \multirow{2}{*}{$\begin{array}{l}\text { All } \\
\text { other } \\
\text { cost. }\end{array}$} & \multicolumn{2}{|c|}{ Total eost. $a$} & \multirow{2}{*}{$\begin{array}{l}\text { Te- } \\
\text { pre- } \\
\text { cia- } \\
\text { tion. }\end{array}$} & \multirow{2}{*}{$\begin{array}{l}\text { Inter- } \\
\text { est. }\end{array}$} \\
\hline & Batch. & $\begin{array}{c}\text { Pack- } \\
\text { ing. }\end{array}$ & & A. & B. & & & & A. & B. & & \\
\hline $\begin{array}{l}\text { No. } 2 \ldots \ldots \\
\text { No. } 3 \ldots \ldots \\
\text { No. } 5 \ldots \ldots \\
\text { No. } 6 \ldots \ldots \\
\text { No. } 8 \ldots \ldots \\
\text { No. } 11 \ldots \ldots \\
\text { No. } 13 \ldots \ldots \\
\text { No. } 15 \ldots \\
\text { No. } 17 \ldots \ldots \\
\text { No. } 18 \ldots \\
\text { No. } 19 \\
\text { No. } 20 \\
\text { No. } 22 \ldots \\
\text { No. } 24 \\
\text { No. } 29 \\
\text { No. } 31 \ldots \\
\text { No. } 34 \\
\text { No. } 35 \\
\end{array}$ & $\begin{array}{r}\$ 0.174 \\
.097 \\
.129 \\
.285 \\
.238 \\
.170 \\
b .169 \\
.157 \\
.149 \\
.158 \\
.144 \\
.183 \\
.154 \\
.160 \\
.169 \\
.118 \\
.155 \\
.088\end{array}$ & $\begin{array}{r}\$ 0.158 \\
.096 \\
.133 \\
.088 \\
.183 \\
.129 \\
b .168 \\
.156 \\
.156 \\
.136 \\
.168 \\
.143 \\
.134 \\
.175 \\
.143 \\
.150 \\
.151 \\
.126\end{array}$ & $\begin{array}{r}\$ 0.328 \\
.259 \\
.107 \\
.179 \\
.190 \\
.209 \\
.122 \\
.089 \\
.062 \\
.176 \\
.242 \\
.203 \\
.114 \\
.215 \\
.063 \\
.073 \\
.083 \\
.177\end{array}$ & $\begin{array}{l}\$ 0.645 \\
.645 \\
.645 \\
.645 \\
.645 \\
.645 \\
.645 \\
.645 \\
.645 \\
.645 \\
.645 \\
.645 \\
.645 \\
.645 \\
.645 \\
.645 \\
.645 \\
.645\end{array}$ & \begin{tabular}{r|}
$\$ 0.613$ \\
.613 \\
.613 \\
.613 \\
.613 \\
.613 \\
.613 \\
.613 \\
.613 \\
.613 \\
.613 \\
.613 \\
.613 \\
.613 \\
.613 \\
.613 \\
.613 \\
.613
\end{tabular} & $\begin{array}{r}30.428 \\
.333 \\
.279 \\
.346 \\
.490 \\
.315 \\
.259 \\
.296 \\
.276 \\
.358 \\
.394 \\
.402 \\
.287 \\
.309 \\
.326 \\
.300 \\
.317 \\
.332\end{array}$ & $\begin{array}{r}\$ 0.035 \\
.093 \\
.022 \\
.055 \\
.079 \\
.059 \\
.041 \\
.014 \\
.021 \\
.019 \\
.056 \\
.045 \\
.054 \\
.075 \\
.018 \\
.017 \\
.052 \\
.059\end{array}$ & $\begin{array}{r}80.121 \\
.224 \\
.144 \\
.065 \\
.230 \\
.130 \\
.230 \\
.184 \\
.156 \\
.146 \\
.188 \\
.178 \\
.128 \\
.177 \\
.186 \\
.139 \\
.136 \\
.176\end{array}$ & $\begin{array}{r}\$ 1.889 \\
1.747 \\
1.459 \\
1.666 \\
2.055 \\
1.657 \\
1.634 \\
d 1.544 \\
1.465 \\
1.638 \\
1.837 \\
1.799 \\
1.516 \\
1.756 \\
1.550 \\
1.442 \\
1.539 \\
1.603\end{array}$ & $\begin{array}{r}\$ 1.857 \\
1.715 \\
1.427 \\
1.634 \\
2.023 \\
1.625 \\
1.602 \\
d 1.512 \\
1.433 \\
1.606 \\
1.805 \\
1.767 \\
1.484 \\
1.724 \\
1.518 \\
1.410 \\
1.507 \\
1.571\end{array}$ & $\begin{array}{c}\$ 0.119 \\
.070 \\
.054 \\
.050 \\
.159 \\
.058 \\
(c) \\
.026 \\
.028 \\
.008 \\
.066 \\
.054 \\
.033 \\
.080 \\
.036 \\
.032 \\
.067 \\
.073\end{array}$ & $\begin{array}{r}\$ 0.003 \\
.007 \\
.036 \\
.137 \\
.019 \\
.005 \\
.001 \\
.001 \\
.004 \\
.008 \\
.009 \\
.025 \\
.053 \\
(e) \\
.023 \\
.020 \\
.015\end{array}$ \\
\hline
\end{tabular}

a Exclusive of depreciation and interest.

$b$ Including 2.2 cents (total, 4.4 cents) for undistributed freight.

$c$ No depreciation charge; plant is rented.

$a$ Includes 0.003 cent for undistributed freight.

$e$ Less than 0.001 per cent.

Table 64 shows costs for eight different brackets, A and B grades, made in the 18 establishments. It will be observed that the piece-paid labor is identical for all the establishments, but the other costs vary considerably, ranging from $\$ 0.797$ to $\$ 1.41$. These differences are due to a variety of causes, chief among which are more efficient management, advantages of location as to raw materials, freight, and fuel cost, and also to the ability to operate at maximum capacity throughout the blast. 
Table 64.-Cost of Prodecixg a 50-Foot Box of Handmade Single-Strength Window Glass. A AXd 1 Grades, by Brickets, Witholt Additional Cost For Depreciation aNd INTEREST ON C'URRENT LoANs.

\begin{tabular}{|c|c|c|c|c|c|c|c|c|c|}
\hline \multirow{4}{*}{ Establishment. } & \multirow{4}{*}{$\begin{array}{c}\begin{array}{c}\text { All } \\
\text { brack- } \\
\text { ets. }\end{array} \\
\text { Cost, } \\
\text { except } \\
\text { piece- } \\
\text { paid } \\
\text { labor. }\end{array}$} & \multicolumn{2}{|c|}{$\begin{array}{l}8 \text { by } 10 \text { to } 10 \\
\text { by } 15 \text { inches. }\end{array}$} & \multicolumn{2}{|c|}{$\begin{array}{l}11 \text { by } 15 \text { to } 14 \\
\text { by } 20 \text { inches. }\end{array}$} & \multicolumn{2}{|c|}{$\begin{array}{l}14 \text { by } 21 \text { to } 16 \\
\text { by } 24 \text { inches. }\end{array}$} & \multicolumn{2}{|c|}{$\begin{array}{l}16 \text { by } 25 \text { to } 20 \\
\text { by } 30 \text { inches. }\end{array}$} \\
\hline & & A. & B. & A. & B. & A. & B. & A. & B. \\
\hline & & \multicolumn{8}{|c|}{ Total cost, including piece-paid labor, at rate of- } \\
\hline & & $\$ 0.645$ & $\$ 0.613$ & $\$ 0.727$ & $\$ 0.686$ & $\$ 0.80$ & $\$ 0.758$ & $\$ 0.862$ & $\$ 0.789$ \\
\hline 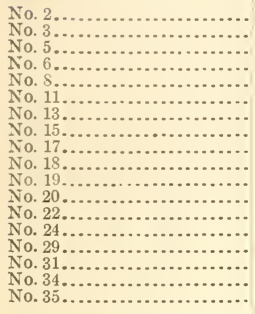 & $\begin{array}{r}\$ 1.244 \\
1.102 \\
.814 \\
1.021 \\
1.410 \\
1.012 \\
.989 \\
.899 \\
.820 \\
.993 \\
1.192 \\
1.154 \\
.871 \\
1.111 \\
.905 \\
.797 \\
.894 \\
.958\end{array}$ & $\begin{array}{r}\$ 1.8 \$ 9 \\
1.747 \\
1.459 \\
1.666 \\
2.055 \\
1.657 \\
1.634 \\
1.544 \\
1.465 \\
1.638 \\
1.837 \\
1.799 \\
1.516 \\
1.756 \\
1.550 \\
1.442 \\
1.539 \\
1.603\end{array}$ & $\begin{array}{r}\$ 1.857 \\
1.715 \\
1.427 \\
1.634 \\
2.023 \\
1.625 \\
1.602 \\
1.512 \\
1.433 \\
1.606 \\
1.805 \\
1.767 \\
1.484 \\
1.724 \\
1.518 \\
1.410 \\
1.507 \\
1.571\end{array}$ & $\begin{array}{l}\$ 1.971 \\
1.829 \\
1.541 \\
1.748 \\
2.137 \\
1.739 \\
1.716 \\
1.626 \\
1.547 \\
1.720 \\
1.919 \\
1.881 \\
1.598 \\
1.838 \\
1.632 \\
1.524 \\
1.621 \\
1.685\end{array}$ & $\begin{array}{r}\$ 1.930 \\
1.788 \\
1.500 \\
1.707 \\
2.096 \\
1.698 \\
1.675 \\
1.585 \\
1.506 \\
1.679 \\
1.878 \\
1.840 \\
1.557 \\
1.797 \\
1.591 \\
1.483 \\
1.580 \\
1.644\end{array}$ & $\begin{array}{r}\$ 2.044 \\
1.902 \\
1.614 \\
1.821 \\
2.210 \\
1.812 \\
1.789 \\
1.699 \\
1.620 \\
1.793 \\
1.992 \\
1.954 \\
1.671 \\
1.911 \\
1.705 \\
1.597 \\
1.694 \\
1.758\end{array}$ & $\begin{array}{r}\$ 2.002 \\
1.860 \\
1.572 \\
1.779 \\
2.168 \\
1.770 \\
1.747 \\
1.657 \\
1.578 \\
1.751 \\
1.950 \\
1.912 \\
1.629 \\
1.869 \\
1.663 \\
1.555 \\
1.652 \\
1.716\end{array}$ & $\begin{array}{l}\$ 2.106 \\
1.964 \\
1.676 \\
1.883 \\
2.272 \\
1.874 \\
1.851 \\
1.761 \\
1.682 \\
1.855 \\
2.054 \\
2.016 \\
1.733 \\
1.973 \\
1.767 \\
1.659 \\
1.756 \\
1.820\end{array}$ & $\begin{array}{l}\$ 2.033 \\
1.891 \\
1.603 \\
1.810 \\
2.199 \\
1.801 \\
1.778 \\
1.688 \\
1.609 \\
1.782 \\
1.981 \\
1.943 \\
1.660 \\
1.900 \\
1.694 \\
1.586 \\
1.683 \\
1.747\end{array}$ \\
\hline \multirow{4}{*}{ Establishment. } & \multirow{2}{*}{$\begin{array}{l}\text { All } \\
\text { brack- } \\
\text { ets. }\end{array}$} & \multicolumn{2}{|c|}{$\begin{array}{l}21 \text { by } 30 \text { to } 24 \\
\text { by } 30 \text { inches. }\end{array}$} & \multicolumn{2}{|c|}{$\begin{array}{l}24 \text { by } 31 \text { to } 24 \\
\text { by } 36 \text { inches. }\end{array}$} & \multicolumn{2}{|c|}{$\begin{array}{l}25 \text { by } 36 \text { to } 30 \\
\text { by } 41 \text { inches. }\end{array}$} & \multicolumn{2}{|c|}{$\begin{array}{l}\text { All above } 30 \\
\text { by } 41 \text { inches. }\end{array}$} \\
\hline & & A. & B. & A. & A. & A. & B. & A. & B. \\
\hline & \multirow{2}{*}{$\begin{array}{l}\text { Cost, } \\
\text { except } \\
\text { piece- } \\
\text { paid } \\
\text { labor. }\end{array}$} & \multicolumn{8}{|c|}{ Total cost, including piece-paid labor, at rate of- } \\
\hline & & $\$ 0.914$ & $\$ 0.820$ & \$0. 934 & 80.852 & $\$ 1.027$ & S0. 914 & $\$ 1.069$ & 80.96 \\
\hline 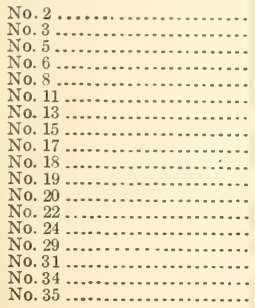 & $\begin{array}{r}\$ 1.214 \\
1.102 \\
.814 \\
1.021 \\
1.410 \\
1.012 \\
.989 \\
.899 \\
.820 \\
.993 \\
1.192 \\
1.154 \\
.871 \\
1.111 \\
.905 \\
.797 \\
.894 \\
.958\end{array}$ & $\begin{array}{r}\$ 2.158 \\
2.016 \\
1.728 \\
1.935 \\
2.324 \\
1.926 \\
1.903 \\
1.813 \\
1.734 \\
1.907 \\
2.106 \\
2.068 \\
1.785 \\
2.025 \\
1.819 \\
1.711 \\
1.808 \\
1.872\end{array}$ & $\begin{array}{r}\$ 2.064 \\
1.922 \\
1.634 \\
1.841 \\
2.230 \\
1.832 \\
1.809 \\
1.719 \\
1.640 \\
1.813 \\
2.012 \\
1.974 \\
1.691 \\
1.931 \\
1.725 \\
1.617 \\
1.714 \\
1.778\end{array}$ & $\begin{array}{r}\$ 2.178 \\
2.036 \\
1.748 \\
1.955 \\
2.344 \\
1.946 \\
1.923 \\
1.933 \\
1.754 \\
1.927 \\
2.126 \\
2.088 \\
1.805 \\
2.045 \\
1.839 \\
1.731 \\
1.828 \\
1.892\end{array}$ & $\begin{array}{r}82.096 \\
1.954 \\
1.666 \\
1.873 \\
2.262 \\
1.864 \\
1.841 \\
1.751 \\
1.672 \\
1.845 \\
2.044 \\
2.006 \\
1.723 \\
1.963 \\
1.757 \\
1.649 \\
1.746 \\
1.810\end{array}$ & $\begin{array}{r}\$ 2.271 \\
2.129 \\
1.841 \\
2.048 \\
2.437 \\
2.039 \\
2.016 \\
1.926 \\
1.847 \\
2.020 \\
2.219 \\
2.181 \\
1.898 \\
2.138 \\
1.932 \\
1.824 \\
1.921 \\
1.985\end{array}$ & $\begin{array}{r}\$ 2.158 \\
2.016 \\
1.728 \\
1.935 \\
2.324 \\
1.926 \\
1.903 \\
1.813 \\
1.734 \\
1.907 \\
2.106 \\
2.068 \\
1.785 \\
2.025 \\
1.819 \\
1.711 \\
1.808 \\
1.872\end{array}$ & $\begin{array}{r}\$ 2.313 \\
2.171 \\
1.883 \\
2.090 \\
2.479 \\
2.081 \\
2.058 \\
1.968 \\
1.889 \\
2.062 \\
2.261 \\
2.223 \\
1.940 \\
2.180 \\
1.974 \\
1.866 \\
1.963 \\
2.027\end{array}$ & $\begin{array}{r}\$ 2.209 \\
2.067 \\
1.779 \\
1.986 \\
2.375 \\
1.977 \\
1.954 \\
1.864 \\
1.785 \\
1.958 \\
2.157 \\
2.119 \\
1.836 \\
2.076 \\
1.870 \\
1.762 \\
1.859 \\
1.923\end{array}$ \\
\hline
\end{tabular}

Table 65 is similar in form to Table 64 and shows costs for seven brackets of double-strength glass. In deriving all other cost except piece-paid labor for a box of double-strength glass, the cost of a single-strength box was increased in the proportion of 5 to 8 or the number of single-strength boxes were reduced to double-strength basis in the ratio of 8 to 5 . 
Table 65.-Cost of Producing a 50-Foot Box of Handmade, Double-Strength Window Glass, A and B Grades, by Brackets, Without Additional Cost for Depreciation and Interest on Current Loans.

\begin{tabular}{|c|c|c|c|c|c|c|c|c|c|}
\hline \multirow{4}{*}{\multicolumn{3}{|c|}{ stablishment }} & \multirow{4}{*}{ 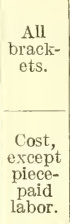 } & \multicolumn{2}{|c|}{$\begin{array}{l}6 \text { by } 8 \text { to } 16 \text { by } \\
24 \text { inches. }\end{array}$} & \multicolumn{2}{|c|}{$\begin{array}{l}16 \text { by } 25 \text { to } 24 \text { by } \\
36 \text { inches. }\end{array}$} & \multicolumn{2}{|c|}{$\begin{array}{c}24 \text { by } 37 \text { to } 30 \text { by } \\
40 \text { inches. }\end{array}$} \\
\hline & & & & A. & B. & A. & B. & A. & B. \\
\hline & & & & \multicolumn{6}{|c|}{ Total cost, including piece-paid labor, at rate of- } \\
\hline & & & & $\$ 0.901$ & $\$ 0.828$ & $\$ 1.232$ & $\$ 1.118$ & $\$ 1.325$ & $\$ 1.201$ \\
\hline \multicolumn{3}{|c|}{ 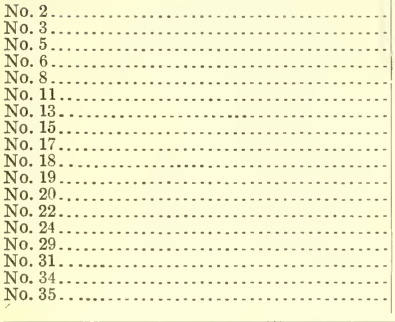 } & $\begin{array}{r}\$ 1.980 \\
1.763 \\
1.302 \\
1.634 \\
2.256 \\
1.619 \\
1.582 \\
1.438 \\
1.312 \\
1.589 \\
1.907 \\
1.846 \\
1.394 \\
1.778 \\
1.448 \\
1.275 \\
1.430 \\
1.533\end{array}$ & $\begin{array}{r}\$ 2.881 \\
2.664 \\
2.203 \\
2.535 \\
3.157 \\
2.520 \\
2.483 \\
2.339 \\
2.213 \\
2.490 \\
2.808 \\
2.747 \\
2.295 \\
2.679 \\
2.349 \\
2.176 \\
2.331 \\
2.434\end{array}$ & $\begin{array}{l}\$ 2.808 \\
2.591 \\
2.130 \\
2.462 \\
3.084 \\
2.447 \\
2.410 \\
2.266 \\
2.140 \\
2.417 \\
2.735 \\
2.674 \\
2.222 \\
2.606 \\
2.276 \\
2.103 \\
2.258 \\
2.361\end{array}$ & $\begin{array}{r}\$ 3.212 \\
2.995 \\
2.534 \\
2.866 \\
3.488 \\
2.851 \\
2.814 \\
2.670 \\
2.544 \\
2.821 \\
3.139 \\
3.078 \\
2.626 \\
3.010 \\
2.680 \\
2.507 \\
2.662 \\
2.765\end{array}$ & $\begin{array}{r}\$ 3.098 \\
2.881 \\
2.420 \\
2.752 \\
3.374 \\
2.737 \\
2.700 \\
2.556 \\
2.430 \\
2.707 \\
3.025 \\
2.964 \\
2.512 \\
2.896 \\
2.566 \\
2.393 \\
2.548 \\
2.651\end{array}$ & \begin{tabular}{r|}
$\$ 3.305$ \\
3.088 \\
2.627 \\
2.959 \\
3.581 \\
2.944 \\
2.907 \\
2.763 \\
2.637 \\
2.914 \\
3.232 \\
3.171 \\
2.719 \\
3.103 \\
2.773 \\
2.600 \\
2.755 \\
2.858
\end{tabular} & $\begin{array}{r}\$ 3.181 \\
2.964 \\
2.503 \\
2.835 \\
3.457 \\
2.820 \\
2.783 \\
2.639 \\
2.513 \\
2.790 \\
3.108 \\
3.047 \\
2.595 \\
2.979 \\
2.619 \\
2.476 \\
2.631 \\
2.734\end{array}$ \\
\hline \multirow{4}{*}{ Establishment. } & \multirow{2}{*}{$\begin{array}{l}\text { All } \\
\text { brack- } \\
\text { ets. }\end{array}$} & \multicolumn{2}{|c|}{$\begin{array}{l}30 \text { bv } 41 \text { to } 36 \text { by } \\
51 \text { inches. }\end{array}$} & \multicolumn{2}{|c|}{$\begin{array}{c}36 \text { by } 52 \text { to } 39 \text { by } \\
60 \text { inches. }\end{array}$} & \multicolumn{2}{|c|}{$\begin{array}{l}40 \text { by } 60 \text { to } 40 \text { by } \\
78 \text { inches. }\end{array}$} & \multicolumn{2}{|c|}{$\begin{array}{c}\text { All above } 40 \text { by } \\
78 \text { inches. }\end{array}$} \\
\hline & & A. & B. & A. & B. & A. & B. & A. & B. \\
\hline & $\begin{array}{l}\text { Cost, } \\
\text { except }\end{array}$ & \multicolumn{8}{|c|}{ Total cost, including piece-paid labor, at rate of- - } \\
\hline & $\begin{array}{l}\text { paid } \\
\text { labor. }\end{array}$ & $\$ 1.449$ & $\$ 1.325$ & $\$ 1.719$ & $\$ 1.543$ & $\$ 2.754$ & $\$ 2.536$ & $\$ 4.937$ & $\$ 4.617$ \\
\hline 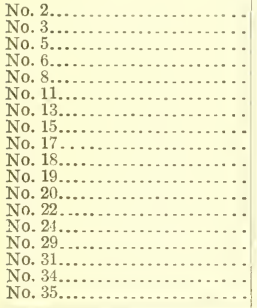 & $\begin{array}{l}\$ 1.980 \\
1.763 \\
1.302 \\
1.634 \\
2.256 \\
1.619 \\
1.582 \\
1.435 \\
1.312 \\
1.589 \\
1.907 \\
1.846 \\
1.394 \\
1.778 \\
1.448 \\
1.275 \\
1.430 \\
1.533\end{array}$ & $\begin{array}{r}\$ 3.429 \\
3.212 \\
2.751 \\
3.0 \$ 3 \\
3.705 \\
3.068 \\
3.031 \\
2.887 \\
2.761 \\
3.035 \\
3.356 \\
3.295 \\
2.813 \\
3.227 \\
2.897 \\
2.724 \\
2.879 \\
2.982\end{array}$ & $\begin{array}{r}83.305 \\
3.088 \\
2.627 \\
2.959 \\
3.581 \\
2.944 \\
2.907 \\
2.763 \\
2.637 \\
2.914 \\
3.232 \\
3.171 \\
2.719 \\
3.103 \\
2.773 \\
2.600 \\
2.755 \\
2.858\end{array}$ & $\begin{array}{r}\$ 3.699 \\
3.482 \\
3.021 \\
3.353 \\
3.975 \\
3.338 \\
3.301 \\
3.157 \\
3.031 \\
3.308 \\
3.626 \\
3.565 \\
3.113 \\
3.497 \\
3.167 \\
2.994 \\
3.149 \\
3.252\end{array}$ & $\begin{array}{r}\$ 3.523 \\
3.306 \\
2.845 \\
3.177 \\
3.799 \\
3.162 \\
3.125 \\
2.981 \\
2.855 \\
3.132 \\
3.450 \\
3.389 \\
2.937 \\
3.221 \\
2.991 \\
2.818 \\
2.973 \\
3.076\end{array}$ & $\begin{array}{r}\$ 4.734 \\
4.517 \\
4.056 \\
4.388 \\
5.010 \\
4.373 \\
4.336 \\
4.192 \\
4.066 \\
4.343 \\
4.661 \\
4.600 \\
4.118 \\
4.532 \\
4.202 \\
4.029 \\
4.184 \\
4.287\end{array}$ & $\begin{array}{r}\$ 4.516 \\
4.299 \\
3.838 \\
4.170 \\
4.792 \\
4.155 \\
4.118 \\
3.974 \\
3.848 \\
4.125 \\
4.443 \\
4.352 \\
3.930 \\
4.314 \\
3.984 \\
3.811 \\
3.966 \\
4.069\end{array}$ & $\begin{array}{r}\$ 6.917 \\
6.700 \\
6.239 \\
6.571 \\
7.193 \\
6.556 \\
6.519 \\
6.375 \\
6.249 \\
6.526 \\
6.814 \\
6.783 \\
6.331 \\
6.715 \\
6.385 \\
6.212 \\
6.367 \\
6.470\end{array}$ & $\begin{array}{r}\$ 6.597 \\
6.380 \\
5.919 \\
6.251 \\
6.873 \\
6.236 \\
6.199 \\
6.055 \\
5.929 \\
6.206 \\
6.524 \\
6.463 \\
6.011 \\
6.395 \\
6.065 \\
5.892 \\
6.047 \\
6.150\end{array}$ \\
\hline
\end{tabular}

\section{MACHINE-MADE PRODUCT.}

The following series of tables showing wage and unit cost data for machine-made glass are similar to the preceding tables for handmade glass. It will be observed that the piece-paid occupations in this group differ from those of the hand group, as do the rates of wages. In the hand group blowing is a highly skilled occupation, but in the machine group it is not classified as such.

The rates of wages as shown in this group are those agreed upon by manufacturers using the Consolidated or Healy machines at the beginning of the blast, October 28, 1915 . 


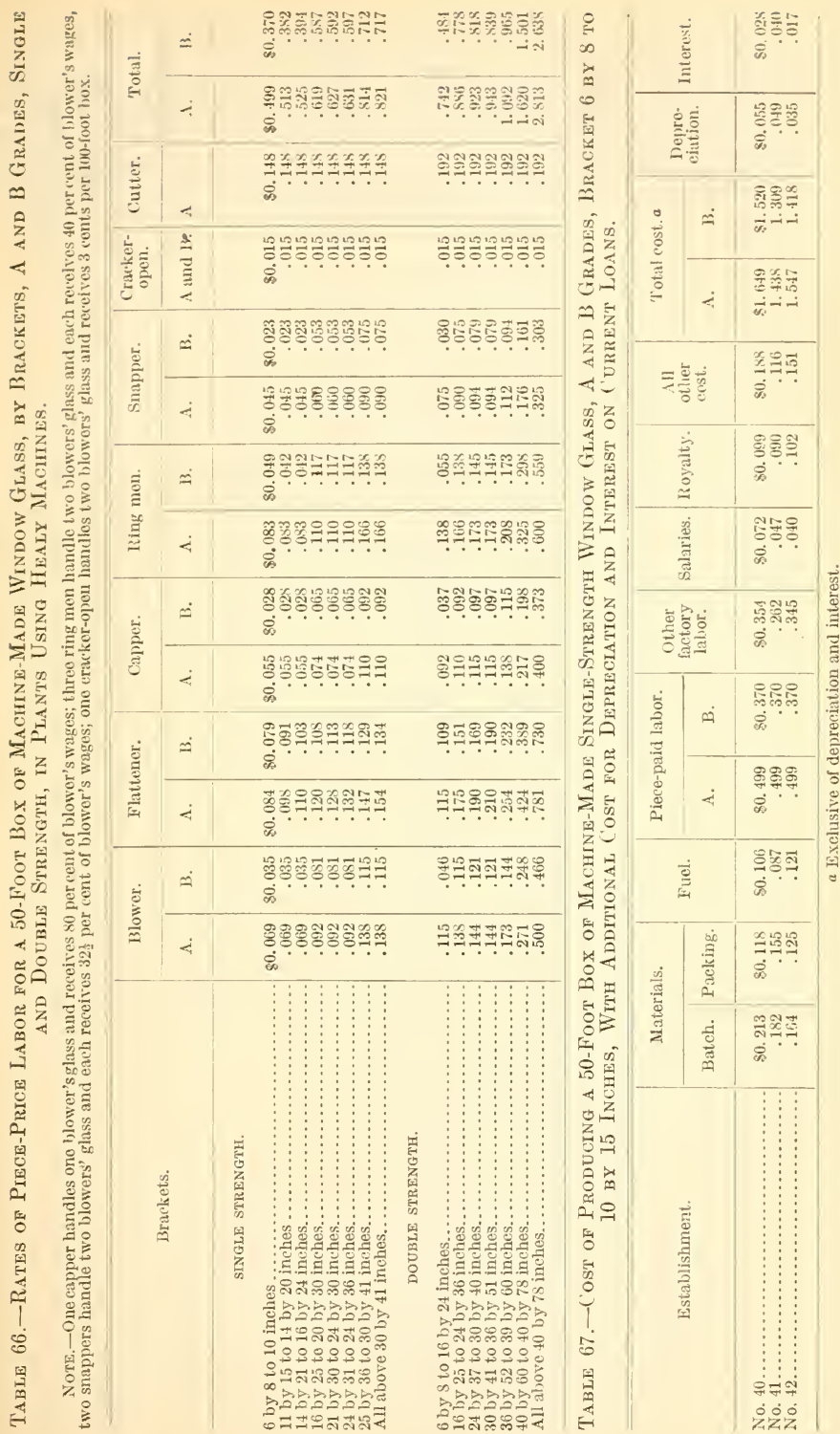


THE GLASS INDUSTRY.

की

会

离

量

3

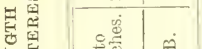

号

舅

कृ

봉

त्रे

运

돈

空

兒早

桨

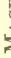

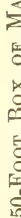



\begin{tabular}{|c|c|c|c|c|}
\hline 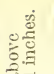 & $\dot{n}$ & \multirow{16}{*}{ 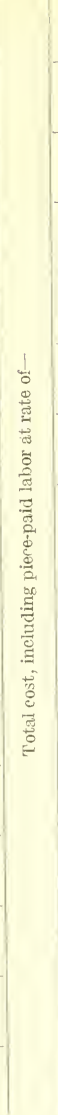 } & $\begin{array}{l}\overrightarrow{1} \\
\dot{\alpha}\end{array}$ & 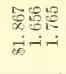 \\
\hline$\equiv$ & $\dot{i}$ & & $\begin{array}{l}\vec{\nabla} \\
\stackrel{8}{\&} \\
\dot{8}\end{array}$ & $\begin{array}{l}58 \% \\
58 \% \\
\dot{m}-\dot{-1}\end{array}$ \\
\hline 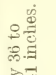 & $\dot{A}$ & & 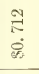 & 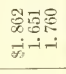 \\
\hline 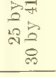 & $\dot{4}$ & & $\begin{array}{l}\vec{\infty} \\
\dot{\infty} \\
\dot{\infty}\end{array}$ & 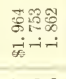 \\
\hline \multirow{2}{*}{ 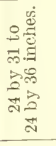 } & $\ddot{n}$ & & $\begin{array}{l}\text { 总 } \\
\stackrel{\circ}{\circ} \\
\text { \& }\end{array}$ & 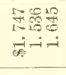 \\
\hline & $\dot{4}$ & & 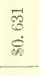 & 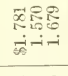 \\
\hline \multirow{2}{*}{ 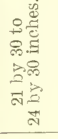 } & $\infty$ & & $\begin{array}{l}\text { 今. } \\
\dot{8} \\
\dot{8}\end{array}$ & 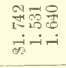 \\
\hline & $\dot{4}$ & & $\begin{array}{l}\text { àं } \\
\dot{\alpha}\end{array}$ & 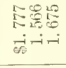 \\
\hline \multirow{2}{*}{ 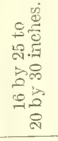 } & $\ddot{n}$ & & $\begin{array}{l}\tilde{D} \\
0 \\
\dot{0} \\
\dot{\infty}\end{array}$ & 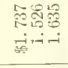 \\
\hline & $\dot{<}$ & & $\begin{array}{l}\stackrel{9}{6} \\
\stackrel{0}{*}\end{array}$ & 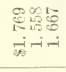 \\
\hline \multirow{2}{*}{ 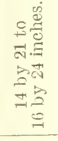 } & $\dot{A}$ & & $\begin{array}{l}\text { 可 } \\
\text { 今. } \\
\stackrel{8}{\circ}\end{array}$ & 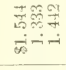 \\
\hline & $\dot{4}$ & & $\begin{array}{l}\text { c. } \\
\text { î } \\
8 \\
8\end{array}$ & 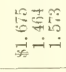 \\
\hline \multirow{2}{*}{ 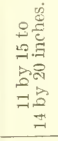 } & $\infty \dot{\theta}$ & & $\begin{array}{l}\tilde{N} \\
\infty \\
\dot{\infty} \\
\dot{q}\end{array}$ & 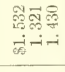 \\
\hline & $\dot{4}$ & & $\begin{array}{l}\text { है } \\
\stackrel{\leftrightarrow}{\circ} \\
\end{array}$ & 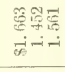 \\
\hline \multirow{2}{*}{ 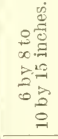 } & $\dot{\sim}$ & & $\begin{array}{l}\stackrel{0}{0} \\
\stackrel{\leftrightarrow}{0}\end{array}$ & 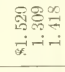 \\
\hline & $i$ & & $\begin{array}{l}\mathscr{8} \\
\stackrel{\leftrightarrow}{\oplus} \\
\dot{\mathscr{\theta}}\end{array}$ & 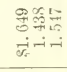 \\
\hline & & & 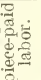 & 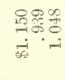 \\
\hline
\end{tabular}

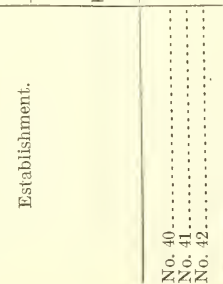

究

解

$\theta$

宅

\begin{tabular}{l}
$\sum_{4}$ \\
4 \\
4 \\
\hline
\end{tabular}

$n^{n-1}$

造貟

3

ค马

蔍骂

당

藏星

舁

我资

奥会

品

คำ

뵛에

产

夏角

छิ용

还

댕 की



대응

ํ.

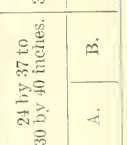

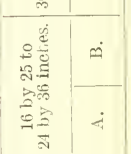

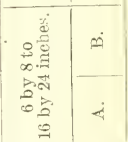

\begin{tabular}{|c|c|}
\hline & $\dot{\theta}$ \\
\hline & $\dot{4}$ \\
\hline & $\infty$ \\
\hline & $<$ \\
\hline
\end{tabular}

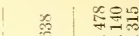

मू में

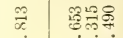

कै मिन्में

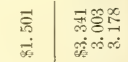

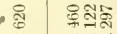

मे कंषे

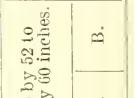

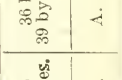

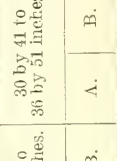

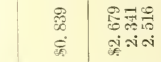

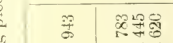

है मूंत

至

है क्षैं

है

- க் भंง

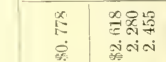

范 率路

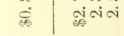

उ तुष्ठ

के ช่-่

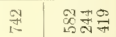

म. अंत्र

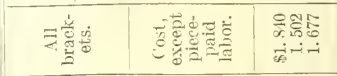




\section{MANLFACTURING COSTS BY ITEMS.}

The following tables show by establishments the arerage cost and profit or loss in manufacturing a 50-foot box of single-strength glass, by hand and by machine. Costs for 35 hand and 11 machine establishments are presented in these tables. The percentages of cost for the rarious items are fully discussed in connection with Tables 37 and 38 . 
THE GLASS INDUSTRY.

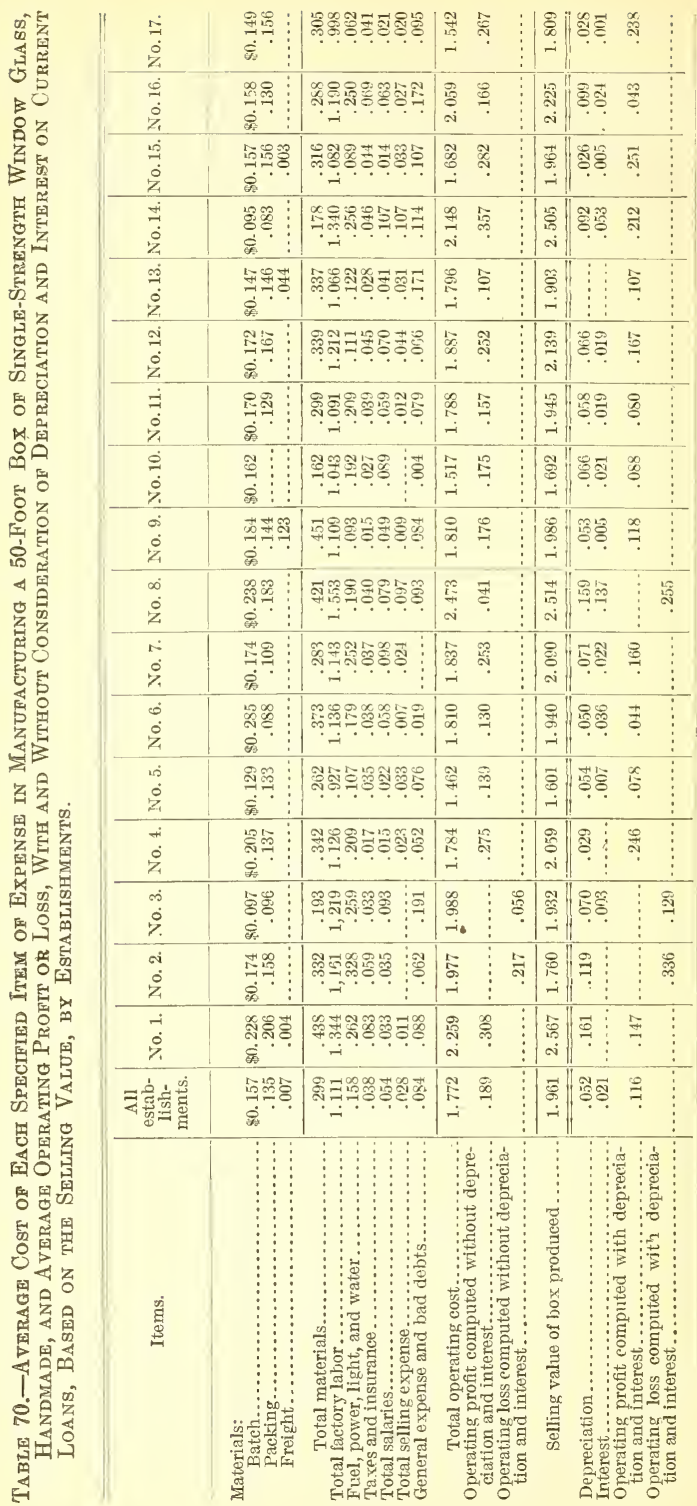




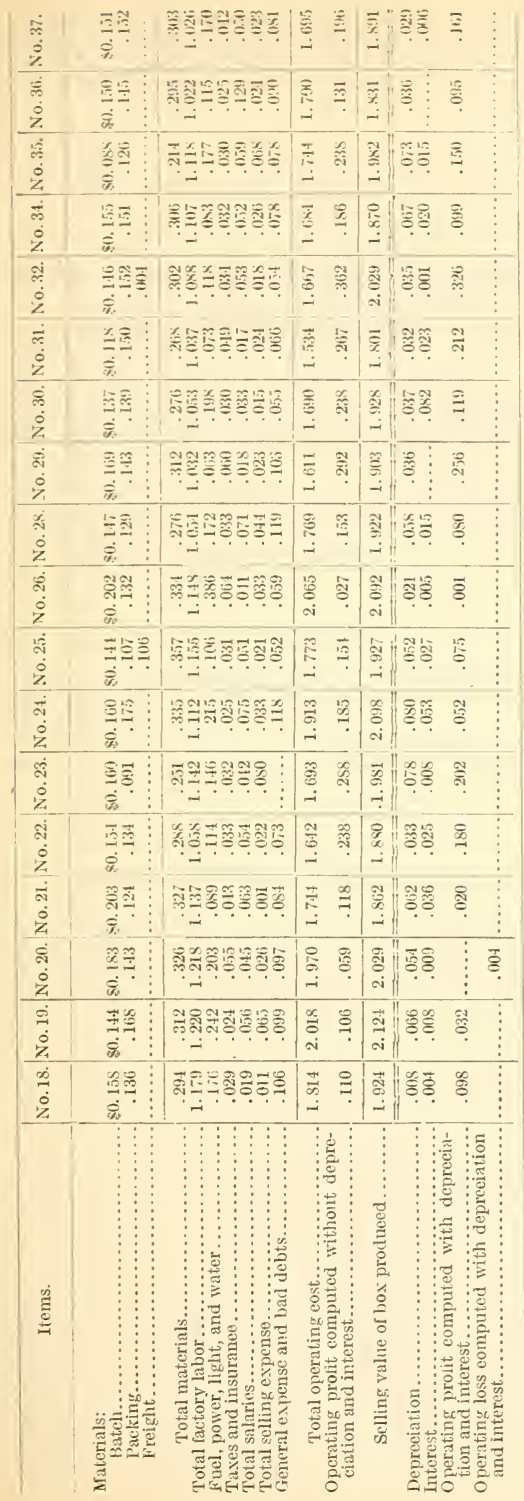


Table 71.-Average Cost of Each Specified Item of Expense in Manufacturing a 50-Foot Box of Single-Strength Window Glass, Machine Made, and Average Operating Profit or Loss, With and Without Consideration of Depreciation and Interest on Current LoAns, Based on the Selling Value, By EsTABLISHMENTS.

\begin{tabular}{|c|c|c|c|c|c|c|c|c|c|c|c|c|}
\hline Items. & $\begin{array}{l}\text { All es- } \\
\text { tablish- } \\
\text { ments. }\end{array}$ & $\begin{array}{l}\text { No. } \\
38 \text {. }\end{array}$ & $\begin{array}{l}\text { No. } \\
39 .\end{array}$ & $\begin{array}{l}\text { No. } \\
40 .\end{array}$ & $\begin{array}{l}\text { No. } \\
41 .\end{array}$ & $\begin{array}{l}\text { No. } \\
42 \text {. }\end{array}$ & $\begin{array}{l}\text { No. } \\
43 .\end{array}$ & $\begin{array}{l}\text { No. } \\
44 \text {. }\end{array}$ & $\begin{array}{l}\text { No. } \\
45 \text {. }\end{array}$ & $\begin{array}{l}\text { No. } \\
46 .\end{array}$ & $\begin{array}{l}\text { No. } \\
48 .\end{array}$ & $\begin{array}{l}\text { No. } \\
49 \text {. }\end{array}$ \\
\hline 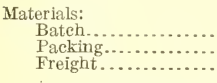 & $\begin{array}{r}\$ 0.148 \\
.111 \\
.001\end{array}$ & $\begin{array}{r}\$ 0.139 \\
.146 \\
\ldots . . \\
\end{array}$ & $\begin{array}{r}\$ 0.133 \\
.138\end{array}$ & $\begin{array}{r}80.213 \\
.118 \\
\ldots \ldots\end{array}$ & $\begin{array}{r}\$ 0.182 \\
.155 \\
\cdots \ldots\end{array}$ & $\begin{array}{r}\$ 0.164 \\
.125 \\
\ldots . .\end{array}$ & $\begin{array}{r}\$ 0.141 \\
.146 \\
\cdots \ldots\end{array}$ & $\begin{array}{r}\$ 0.159 \\
.112 \\
\ldots \ldots\end{array}$ & $\begin{array}{r}\$ 0.218 \\
.146 \\
\ldots \ldots\end{array}$ & $\begin{array}{r}80.186 \\
.120 \\
.012\end{array}$ & $\begin{array}{r}\$ 0.169 \\
.128 \\
\ldots .\end{array}$ & $\begin{array}{r}\$ 0.129 \\
.086 \\
\ldots .\end{array}$ \\
\hline $\begin{array}{l}\text { Total materials..... } \\
\text { Total factory labor ....... } \\
\text { Fuel, power, light, and } \\
\text { water ................. } \\
\text { Taxes and insurance..... } \\
\text { Total salaries.............. } \\
\text { Total selling expense..... } \\
\text { Royalty ................... } \\
\text { General expense and bad } \\
\text { debts....................... }\end{array}$ & $\begin{array}{l}.260 \\
.673 \\
.132 \\
.025 \\
.023 \\
.029 \\
.046 \\
.088\end{array}$ & $\begin{array}{r}.285 \\
.793 \\
\\
.343 \\
.040 \\
.046 \\
.035 \\
.079\end{array}$ & $\begin{array}{r}.271 \\
.636 \\
.270 \\
.035 \\
.019 \\
.100 \\
.186\end{array}$ & $\begin{array}{l}.331 \\
.901 \\
.106 \\
.046 \\
.072 \\
.018 \\
.099 \\
.124\end{array}$ & $\begin{array}{l}.337 \\
.777 \\
.087 \\
.025 \\
.047 \\
.026 \\
.090 \\
.065\end{array}$ & $\begin{array}{l}.289 \\
.712 \\
.121 \\
.042 \\
.040 \\
.028 \\
.102 \\
.081\end{array}$ & $\begin{array}{l}.287 \\
.543 \\
.216 \\
.024 \\
.020 \\
.039 \\
.093 \\
.162\end{array}$ & \begin{tabular}{|l}
.271 \\
.868 \\
.231 \\
.020 \\
.053 \\
.008 \\
.$\cdots$ \\
.092
\end{tabular} & \begin{tabular}{|l|}
.364 \\
.621 \\
.203 \\
.037 \\
.022 \\
.039 \\
.097 \\
.025
\end{tabular} & $\begin{array}{l}.318 \\
.910 \\
.070 \\
.064 \\
.030 \\
.050 \\
.026 \\
.078\end{array}$ & \begin{tabular}{|l|}
.297 \\
.695 \\
\\
.196 \\
.014 \\
.025 \\
.058 \\
.079 \\
.190
\end{tabular} & $\begin{array}{c}.215 \\
.759 \\
.049 \\
.017 \\
.013 \\
.027 \\
\ldots \ldots \\
.048\end{array}$ \\
\hline $\begin{array}{l}\text { Total operating cost } \\
\text { Operating profit com- } \\
\text { puted without deprecia- } \\
\text { tion and interest....... } \\
\text { Operating loss computed } \\
\text { without depreciation } \\
\text { and interest............. }\end{array}$ & $\begin{array}{l}1.276 \\
.155\end{array}$ & 1.619 & 1.517 & 1. 697 & $\begin{array}{l}1.454 \\
.172\end{array}$ & $\begin{array}{r}1.415 \\
.208\end{array}$ & $\begin{array}{l}1.384 \\
.091\end{array}$ & $\begin{array}{r}1.543 \\
.107\end{array}$ & $\begin{array}{l}1.408 \\
.190\end{array}$ & 1.546 & $\begin{array}{l}1.554 \\
.208\end{array}$ & $\begin{array}{r}1.128 \\
.184\end{array}$ \\
\hline $\begin{array}{l}\text { Selling value of one } \\
\text { box produced... }\end{array}$ & 1. 431 & 1.577 & 1.353 & 1.695 & 1. 626 & 1. 623 & 1. 475 & 1. 650 & 1.598 & 1.767 & 7. 1.762 & 2. 1.312 \\
\hline 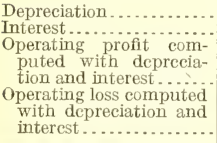 & $\begin{array}{l}.064 \\
.014\end{array}$ & $\begin{array}{l}.091 \\
.051\end{array}$ & .044 & $\begin{array}{l}.055 \\
.028\end{array}$ & $\begin{array}{l}.049 \\
.040\end{array}$ & $\begin{array}{l}.035 \\
.017\end{array}$ & .050 & $\begin{array}{l}.031 \\
.013\end{array}$ & .044 & $\begin{array}{l}.138 \\
.045\end{array}$ & $\begin{array}{l}.149 \\
.088\end{array}$ & $\begin{array}{l}.053 \\
.043\end{array}$ \\
\hline
\end{tabular}

\section{PRODUCTION AT A PROFIT AND AT A LOSS.}

The following table, derived from data shown in Tables 70 and 71 , presents in summary form the number of establishments reporting data and the number of single-strength 50-foot boxes produced at an operating profit or loss, with and without charges for depreciation and interest.

Table 72.-Number of Establishments Producing Single-Strength IVindow Glass, Machine and Hand Made, and Number of Boxes Produced at a Profit or Loss, With and Without Consideration of Depreciation and Interest ON CURRENT LOANS.

Establishments showing-

Number of establishments. Number of 50-foot boxes produced.

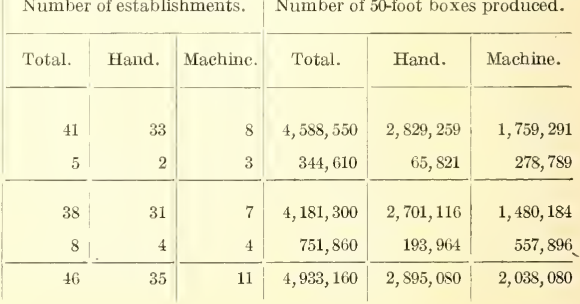

Opcrating profits computed without deprcciation and intercst......... Operating losses computed without depreciation and interest.........

Operating profits computed with depreciation and intercst.........

Operating losses computed with depreciation and interest

All establishments. 


\section{CHAPTER YI.}

\section{INDUSTRIAL CONDITIONS.}

\section{FUEL AS A FACTOR IN LOCATION AND OPERATION.}

The States in which different rarieties of glass and glassware are most largely manufactured are shown below.

Window glass: Pennsylrania, West Virginia, Ohio, Kansas, Oklahoma, and Texas.

Plate glass: Pennsylvania, Ohio, Michigan, and Illinois.

Wire and opalescent glass: Pennsylrania, Test Virginia, Ohio, Indiana, Illinois, and Missouri.

Tableware: Pennsylvania, Maryland, West Virginia, Ohio, and Indiana. Ohio.

Heavr cut glass: Massachusetts, New York, Pennsylvania, and

Fruit and milk jars: New York, Pennsylrania, Indiana, Illinois, and Oklahoma.

Bottles, packers, and preservers: New York, New Jersey, Maryland, Pennsylrania, West Tirginia, Ohio, Indiana, Illinois, and Missouri.

Lighting goods: New York, Pennsylrania, Test Virginia, Ohio, Indiana, and Oklahoma.

Chemical ware: New Jerser, New York, Pennsylvania, and Ohio.

The glass industry is located largely west of the Allegheny Mountains and in districts where cheap natural gas can be obtained. The glass factories in the East have the advantage of being near the large eastern markets, but they use producer gas or oil for fuel, and the high cost of the fuel is an offset to the market advantage.

In Massachusetts, Rhode Island, New. York, New Jersey, and eastern Pennsylvania producer gas made by the glass factories is used. Even in the Pittsburgh district the price of natural gas is how so high that producer gas is used to some extent in glass making. One glass company in that district that makes producer gas estimates that it costs 12 cents per thousand cubic feet and its officers say that in that vicinity where coal is cheap it is more economical to make producer gas than to pay more than 12 cents for natural gas.

One factory in southern Indiana reported that by using 2 by 4 nut coal at $\$ 1.55$ per ton of 2,000 pounds, it made producer gas at a cost of 8 cents per thousand cubic feet.

In Indiana natural gas was cheap years ago, but on account of the failure of the gas supply, several factories have moved to Oklahoma, while some have gone out of business. Oklahoma glass factories paid 3 or 4 cents. per thousand for natural gas in 1916 but have been notified that the price will be 5 cents or higher in 1917. 
In the location of new glass factories cheap fuel has been the controlling factor. A West Virginia manufacturer of window glass who was interviewed during this investigation said:

No doubt freight rates are lower in some localities than here and in many places are higher. These things cut little figure and are entirely overbalanced by the main consideration-fuel. This section has cheaper gas than any other manufacturing center. The price is going up but is still much lower than elsewhere. Pennsylvania used to have cheap gas, but their gas began to "play out" years ago and is now comparatively high. Many factories have moved from Pennsylvania to West Virginia abandoning their plants, in order to get cheaper fuel. There are a number of this sort in this vicinity. This is one of them.

Much of the present gas troubles in this vicinity is due to the fact that the naturalgas companies are pumping their gas right through this section to the Pittsburgh district, where it commands a higher price. It is even pumped to Cleveland (for domestic consumption chiefly), where it is sold for 30 cents to 65 cents and higher, while here the present price is 4 cents. It can readily be seen that the fuel question is very much more important than that of markets.

Contracts for gas were formerly made for as long as five years in Pennsylvania and West Virginia, but the supply of gas having been greatly reduced, contracts are now made for only a year and at advanced prices, and some gas companies now refuse to make contracts at any price.

In West Virginia and Pennsylvania some glass companies own gas wells. Another manufacturer in West Virginia said:

It is generally understood that there is no preventing a very heavy increase soon in the price of gas. Natural-gas companies say that the supply is diminishing at the same time that the demand is increasing. Glass manufacturers feel that if they should persist in holding gas companies to old prices, the gas would be pumped right past their factories to the Pittsburgh district and to f leveland, where it is badly needed, and where manufacturers in different industries would willingly pay more to get gas than is paid in West Virginia.

In normal times before the war in Europe, glass manufacturers made contracts for raw materials usually every year or every two years. Sometimes when prices were low manufacturers agreed to make contracts extending three years. On a rising market, however, manufacturers could not make contracts for longer than a year without offering higher prices than current market quotations. Beginning with 1915, few contracts for longer than a year could be negotiated. The contracts provide that deliveries shall be made as needed. Each factory tries to keep on hand enough raw materials to last ' 60 days.

\section{INCREASE IN OUTPUT OF BUILDING GLASS.}

The manufacture of building glass in the United States more than doubled during the period from 1899 to 1914, as shown by the following table: 
Table 73.-Productiox of Wixdow Glass, Obscured Glass, axd Plate Glass in Cexsus Years.

[Data from the Bureau of the Census.]

\begin{tabular}{|c|c|c|c|c|}
\hline Product. & 1899 & 1904 & 1909 & 1914 \\
\hline 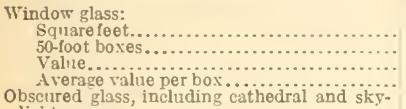 & $\begin{array}{r}217,064,100 \\
4,341,252 \\
\$ 10, \$ 79,355 \\
\$ 2.51\end{array}$ & $\begin{array}{r}242,615,750 \\
4,852,315 \\
\$ 11,610, \$ 51 \\
\$ 2.39\end{array}$ & $\begin{array}{r}346,080,550 \\
6,921,611 \\
\$ 11,742,959 \\
\$ 1.70\end{array}$ & $\begin{array}{r}400,998, \$ 93 \\
\$, 019,978 \\
\$ 17,495,956 \\
\$ 2.18\end{array}$ \\
\hline 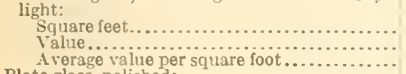 & $\begin{array}{r}12,526,055 \\
\$ 732,338 \\
\$ 0.058\end{array}$ & $\begin{array}{r}21,870,634 \\
\$ 972,014 \\
80.044\end{array}$ & $\begin{array}{r}22, \$ 15,946 \\
\$ 1,358,574 \\
\$ 0,060\end{array}$ & $\begin{array}{r}43,040,079 \\
\$ 2,471,253 \\
\$ 0.056\end{array}$ \\
\hline 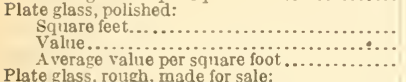 & $\begin{array}{r}16,883,578 \\
\$ 5,158,598 \\
\$ 0.306\end{array}$ & $\begin{array}{r}27,293,138 \\
\$ 7,978,253 \\
\$ 0.292\end{array}$ & $\begin{array}{r}47,370,254 \\
\$ 12,204,875 \\
\$ 0.258\end{array}$ & $\begin{array}{r}60,383,516 \\
\$ 14,773,787 \\
\$ 0.245\end{array}$ \\
\hline 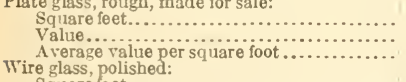 & $\begin{array}{r}628,684 \\
\$ 75,887 \\
\$ 0.121\end{array}$ & $\begin{array}{l}17,784 \\
\$ 3,529 \\
\$ 0.198\end{array}$ & $\begin{array}{r}205,690 \\
\$ 37,431 \\
\$ 0.182\end{array}$ & $\begin{array}{r}131,492 \\
\$ 25,859 \\
\$ 0.197\end{array}$ \\
\hline 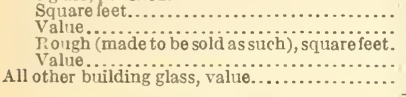 & $\begin{array}{l}\text { (a) } \\
(a) \\
(a) \\
(a) \\
\$ 250,056\end{array}$ & $\begin{array}{l}\text { (a) } \\
(a) \\
(a) \\
(a) \\
\$ 1,133,214\end{array}$ & $\begin{array}{l}\text { (a) } \\
(a) \\
(a) \\
(a) \\
\$ 964,599\end{array}$ & $\begin{array}{r}1,707,848 \\
\$ 534,322 \\
13,980,996 \\
\$ 1,056,612 \\
\$ 520,280 \\
\end{array}$ \\
\hline Total building glass, value. & $\$ 17,096,234$ & $\$ 21,697,861$ & $\$ 26,308,438$ & $\$ 36,824,069$ \\
\hline
\end{tabular}

a Not reported separately.

As shown by the foregoing table, there was an increase in the production of window glass, of obscured glass, including cathedral, and of polished plate glass in each census year from 1899 to 1914 .

\section{WINDOW GLASS.}

During the 10 years from 1899 to 1909 the number of 50-foot boxes of window glass produced increased from $4,341,282$ to $6,921,611$, or 59.44 per cent, and the ralue increased from $\$ 10, \$ 79,355$ to $\$ 11,742,959$, or only 7.94 per cent. The arerage ralue per box decreased from $\$ 2.51$ to $\$ 1.70$.

The decline in the price of window glass was not attributable to the tariff, as the Dingley tariff act was in force from July 24, 1897, to August 6, 1909, and the value of imports of cylinder, crown, and common window glass, unpolished, decreased from $\$ 1,196,461$ during the fiscal year 1899 to $\$ 692,803$ during the fiscal year 1909 .

As shown by the last table, the production of window glass in 1914 amounted to $8,019,978$ boxes of 50 feet each, valued at $\$ 17,495,956$, or an arerage of $\$ 2.18$ per box.

The decline in the arerage ralue per box of window glass from $\$ 2.51$ in 1899 to $\$ 1.70$ in 1909 was due to intense competition between domestic manufacturers, and this competition greatly increased after the manufacture of window glass by machinery began on a commercial basis in 1903 . 


\section{EFFECT OF SELLING AGENCIES ON PRICES.}

The price of window glass increased after the formation in 1909 of the Imperial Window Glass Co. The company was a selling agency or combination of manufacturers that largely influenced the production and price of window glass. This organization, comprised about 50 plants, besides several that were not in operation; only about 6 plants remained independent. The American Window Glass Co. was not in the combination. It manufactured a large proportion of the output, and together with the Imperial Window Glass Co., controlled the prices of window glass. When the combination was formed prices were largely increased; production and profits also greatly increased during the first half of 1910 .

During these months the profits were so great that plants that had been shut down for years began manufacturing, so that by the fall of 1910 there were 14 independent factories in operation and 5 new ones were under construction. The competition of the independents and the overproduction finally broke the market late in the fall of 1910. In a suit brought by the Federal Government against the officers and directors of the Imperial Glass Co., the defendants, in November, 1910, pleaded nolo contendere and were fined. The dissolution of the company followed.

From the late fall of 1910 until the summer of 1912 there were competitive conditions in the window-glass trade. Another selling agency called the Johnson Brokerage Co. was then formed and prices went up. The president of this company, J. R. Johnston, had been secretary of the Imperial Glass Co. In 1916 the Johnston Brokerage Co. sold the product of about 25 hand plants, or about half the number of hand plants in the country, and also sold the product of about 5 machine plants. This company receives orders from jobbers and consumers, distributes them to its patronizing plants, and charges $1 \frac{1}{2}$ per cent commission. Window glass being sold at net in 60 days, the Johnston Brokerage Co. advances money to those factories desiring cash, for which a charge of 1 per cent is made, or a total of $2 \frac{1}{2}$ per cent, including the selling commission.

\section{NUMBER AND EQUIPMENT OF HAND AND MACHINE PLANTS.}

For several years after 1903 all of the window-glass machines used were those of the American Window Glass Co., but by 1908 two other machines, the Healy and the Douchamp, were introduced, and since then machines of different patents have been installed-the Frink, the Pittsburgh, the Okmulgee, and the Douchamp-Henshaw. The following table shows the number of the hand plants and of their pots in 1916, and the number of machine plants and of their machines in the same year. 


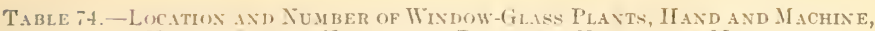
iN the Uxited stites, Jumber of Pots. and Number of Machines.

[Data from Glass Factory Directory, 1916.]

\begin{tabular}{|c|c|c|c|c|}
\hline \multirow{2}{*}{ States. } & \multicolumn{2}{|c|}{ Hand plants. } & \multicolumn{2}{|c|}{ Machine plants. } \\
\hline & Plants. & Pots. & Plants. & Machines. \\
\hline 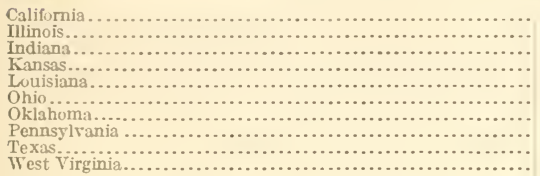 & $\begin{array}{r}1 \\
1 \\
2 \\
5 \\
1 \\
6 \\
2 \\
12 \\
1 \\
20\end{array}$ & $\begin{array}{r}36 \\
30 \\
72 \\
159 \\
36 \\
202 \\
66 \\
486 \\
36 \\
614\end{array}$ & $\begin{array}{r} \\
1 \\
2 \\
1 \\
13 \\
1 \\
7\end{array}$ & $\begin{array}{r}(a) \\
\cdots . . . \\
30 \\
12 \\
172 \\
8 \\
74\end{array}$ \\
\hline Total........ & 51 & 1,737 & 25 & 296 \\
\hline
\end{tabular}

a Machines of 1 plant in Indiana included with machines enumerated in Pennsylvania.

$b$ Includes machines used in 1 plant in Indiana.

The number of plants using each type of machine and the number of each type used in 1916 are shown in the following table:

Table 75.-Location and Number of Machine Plants and of Each Type of Window-Glass Machines Used in the United States.

[Data from Glass Factory Dircetory, 1916.]

NUMBER OF PLANTS USING EACH TYPE OF MACHINE.

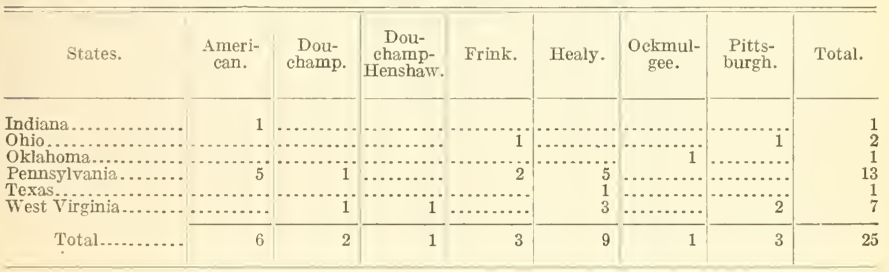

NUMBER OF EACH TYPE OF MACHINES USED.

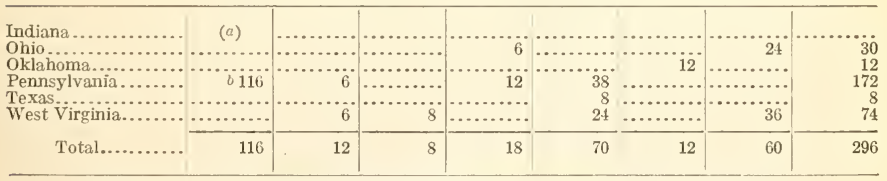

a Machines of 1 plant in Indiana included with machines enumerated in Pennsylvania.

$b$ Includes machines used in 1 plant in Indiana.

As appears by the last two preceding tables, there are 296 windowglass machines in the United States. The machines cost about $\$ 15,000$ each. The following, statement regarding window-glass machines in Europe was made in 1916 by Mr. 1. P. Whittemore, president of the Thatcher \& Whittemore Glass Co., of Dunbar, W. Va., 
which previous to the war had a factory at Roux, Belgium, in which window glass purchased from other factories was flattened and cut:

There were 23 window-glass factories in Belgium with 38 tanks. All were never operating at the same time, so far as I know. There were two window-glass machines in Belginm-the Rowart-Francq, which never got beyond the experimental stage and was never put on commercial basis, and the Fourcault machine, which made very heavy glass for skylight purposes, but, so far as I know, never made and sold ordinary single and double strength window glass commercially. I have since heard that before the war they were making glass commercially, but do not know this except from hearsay.

A number of window-glass machines are operated by Pilkington Bros., St. Helens, England. About eight machines are operated by a factory in Aniche, France, and machines are used also by one factory in Bohemia, one in Russia, and one in Japan. All of these plants operate the American Window Glass Co.'s machines.

\section{PRODUCTION AFFEOTED BY MACHINERY.}

The introduction of machines largely increased the output in the United States. In 1904, when there was only one machine factory in the United States, the production was equal to the consumption, less imports. The general imports of cylinder, crown, and common window glass, unpolished, during the fiscal year 1904 amounted to $\$ 1,356,218$, or 7.75 per cent of the production of window glass during the calendar year 1914, as reported by the census, $\$ 17,495,956$.

The American Window Glass Co., whose first machime factory was started in 1903, during the following years established other factories and installed many machines.

The result was that the window-glass trade was depressed by overproduction. Some hand factories went out of business, some were operated as cooperative plants, and the wages or piece prices paid in all of the hand plants that continued were greatly reduced, in order that these plants might compete with the machine plants, which employed no skilled labor except for flattening and cutting. The National Window Glass Workers, the national organization that includes blowers, gatherers, flatteners, and cutters in hand factories, was a strong union, but for a number of years it could not prevent the reduction in wages or piece prices that was forced upon the hand factories by the competition of the machine plants.

\section{FACTORIES OPERATED ON PART-TIME BASIS.}

The union began to shorten the time over which it made agreements with hand manufacturers, in some years to only seven months. By 1914, when many machines had been installed, the production would have been enormously greater than the domestic consumption if the hand factories had not been operated on short time. The wage agreements of the National Window Glass Workers with the manufacturers of hand-blown window glass during recent years have been for the following periods: September 1, 1909, to May 1, 1910; October 15, 1910, to August 31, 1911; September 9, 1911, to May 31, 1912; October 15, 1912, to May 29, 1913; October 27, 1913, to May 29, 1914; October 31, 1914, to May 29, 1915; November 1, 1915, to May 27, 1916; October 25, 1916, to May 29, 1917.

Even the machine window-glass factories have run on short time in every year. They averaged about eight months a year. 
Figures from the American Window Glass Co. are not arailable, but the production in boxes by the independent machine factories and the number of weeks that they operated during 1914-15 and 1915-16 are shown in the following statement quoted from a paper read by William G. Kischenbower, president of the Window Glass Cutters' and Flatteners' Association of America, before the annual meeting of the National Association of Window Glass Manufacturers, held at Atlantic City, N. J., in July, 1916:

The amount of single and double strength glass produced by the independent machine manufacturers of window glass for the year of October 25, 1914, to October 29, 1915, was: Single, $1,482,410$; double, 323,516 ; total, $1,805,926$ boxes. If the doublestrength glass is reduced to a single-strength basis, the total is $2,000,035$ boxes.

Seventeen tanks were in operation during this period. Average of the 17 tanks: Single, 87,201 ; double, 19,$030 ;$ total, 106,231. If the average production of the 17 tanks is reduced to a single-strength basis, the total is 117,649 boxes. Average number of weeks in operation during this period, 32 .

At this same ratio, reducing double to single, had the independent machine manufacturers operated continuously for one year, production would have been $3,250.052$ boxes of glass. By operating only 32 weeks production was curtailed to the extent of $1,250,017$ boxes, or about $38 \frac{1}{2}$ per cent during that period.

The present wage scale that the independent machine manufacturers of window glass are operating under does not expire until October 29, 1916, but I have prepared a statement of production from the beginning of the scale, October 29, 1915, to July 1 , 1916: Single, 1,288,336; double, 323,453; total, 1,611,789. When the double-strength glass is reduced to single-strength basis, the total is $1,805,860$ boxes.

During this period of eight months there were 19 tanks in operation. Average production of the tanks during this period: Single, 67,807; double, 17,024; total, 84,831 boxes. On a single-strength basis, the average production of the 19 tanks was 95,045 boxes. Average number of weeks in operation during this period was 25 .

At this same ratio, had the 19 tanks operated continuously for the period of 8 months, they w ould have produced 2,528,190 boxes. By operating only 25 weeks, they have created a curtailment of 722,330 boxes, or about $28 \frac{1}{2}$ per cent during that period.

Referring to the general conditions of the $\mathrm{w}$ indow-glass business, all persons engaged in the business must admit that the past two years have been a period of unusual prosperity in this business, $\mathrm{wh}$ hich is greatly due to existing conditions in Eurcpe. The exportation of "indow glass is a new feature for the manufacturers of the United States, which has played a very important part in our present prosperity, and steps should be taken to further this exportation so that the factories of the United States may be kept in continuous operation in the future.

\section{EFFECT OF MACHINES ON GLASS BLOWERS' EARNINGS.}

A résumé of the conditions during recent years is given in the following statement made in October, 1914, by Mr. Joseph M. Neenan, president of the National Window Glass Workers of America, whose members are employed in the hand factories:

For the blast of 1915-16, 5,575,000 fifty-foot boxes were produced by the machine method. This is the first time we have been able to secure anything like accurate information concerning the amount of machine glass produced. The hand production for the same period was 3,725,462 fifty-foot boxes, of which 2,088,82s were of single strength, 1,719,666 of double strength, and 16,968 of triple strength. Our proportion of the entire production was about 40 per cent.

As a result of the introduction of machines into the industry, a vast amount of uncertainty was felt by both the manufacturers and workmen employed in the production of handmade glass. It was feared that, if the machines were a commercial success, it would not be possible to produce liandmade glass on a profitable basis. As a result of this uncertainty, the demoralization which followed affected the entire industry, machine as well as hand. Hand manufacturers feared to carry stocks and placed their product on the market for almost any price they could obtain. The workers accepted a sliding scale arrangement, by which their wages were based upon the price received by the manufacturers, the result of which was that, before the period of uncertainty and demoralization ended, the average of wages of blowers of single-strength 
glass was reduced from about 90 cents per box during the year-1903 to 30 cents per box during the year of 1912-13.

At one time 2,400 pots were operated by the hand method. By the word "pots" I mean that there were that many places for blowers. I feel quite certain that all of the places were not manned; the probabilities are that the greatest number of blowers ever employed at one time was between 1.800 and 1,900 . Last blast we had 1,800 pots in operation, but our membership roll shows that but 1,610 blowers were employed. Our total membership is 4,$241 ; 1,610$ blowers, 1,735 gatherers, 359 flatteners, and 537 cutters.

The working season for window-glass workers has always depended upon market conditions. Previous to the advent of machines, it was customary to place wage scales in effect for 10,8 , and even 7 month periods. Following the introduction of machines, wage scales were placed in effect for 12 -month periods at different times, but this does not mean that factories were operated continuously. At one time or another during the year it becomes necessary to make repairs, and in addition to this, during the period mentioned, a number of companies were forced out of existence, so that I feel quite certain that during the years the 12 -month wage scales were effective glass was not produced in such quantities as it has been during the past four or five years.

The annual statistical report of the National Window Glass Workers, published in The National for August, 1915, shows that during the blast of 1914-15 the union had 3,779 members and that they worked an average of $23 \frac{1}{4}$ weeks. The report published in The National for August, 1916, shows that during the blast of 1915-16 the union had 4,301 members and that they worked an average of 28 weeks. Of the 4,301 members, 60 were spare men and members beyond the age of 55 who were carried on the rolls as permanent members.

\section{PRICE LIST AND DISCOUNTS.}

Window glass is sold on the basis of a price list, which is fixed from time to time and is always subject to very large trade discounts. The price list adopted October 15, 1912, and still in force in 1916 is as follows:

Table 76.-Window-Glass Price List, Oct. 15, 1912.

[All sizes of 100 united inches and under are packed in 50-foot boxes; over 100 united inches in 100-foot boxes.]

\begin{tabular}{r|r|r|r|r|r|r}
\hline United \\
inches.
\end{tabular}


This price list is the same as the preceding price list, dated January 1,1901 , except that in the list of that date prices were given for the 90,94 , and 100 inch brackets of single-strength glass and the prices of the $105,110,115$, and 120 inch brackets were given on the basis of 50 -fnot instead of 100 -foot boxes.

The trade discounts that have been amnounced beginning with March, 1912, are as follows:

March, 1912.--Single strength: Sizes up to and including third bracket, 90 and $22 \frac{1}{2}$ per cent; larger brackets, 90 and 20 per cent. Double strength: 90 and $17 \frac{1}{3}$ per cent.

January, 1914.- Single strength: First three brackets, 90 and 30 per cent; larger brackets, 90 and $7 \frac{1}{2}$ per cent. Double strength: 90 and 20 per cent.

November, 1915. - Single strength: First three brackets, A quality, 90 and 20 per cent; first three brackets, B quality, 90 and 30 per cent; larger brackets, 90 and $7 \frac{1}{2}$ per cent. Double strength: A quality, 90 and 10 per cent; B quality, 90 and 20 per cent.

January, 1916.--Single strength: First three brackets, A quality, 90 and 10 per cent; first three brackets, B quality, 90 and 20 per cent; larger brackets, 89 and 5 per cent. Double strength: A quality, 90 per cent; B quality, 90 and 10 per cent.

Murch, 1916. - Single strength: First three brackets, A quality, 89 per cent; first three brackets, B quality, 90 and 10 per cent; larger brackets, 88 per cent. Double strength: A quality, 89 per cent; B quality, 90 per cent.

The net price computed with these discounts on the basis of the price list of October 15, 1912, were as appear in the following table:

Table 77.-Window Glass Price List: Net Prices per Box, 1912 to 1916.

\begin{tabular}{|c|c|c|c|c|c|c|}
\hline \multirow{2}{*}{$\begin{array}{l}\text { United } \\
\text { inches. }\end{array}$} & \multirow{2}{*}{ Bracket. } & \multirow{2}{*}{ Date of discount. } & \multicolumn{2}{|c|}{$\begin{array}{l}\text { Single } \\
\text { strength. }\end{array}$} & \multicolumn{2}{|c|}{$\begin{array}{l}\text { Double } \\
\text { strength. }\end{array}$} \\
\hline & & & A. & B. & A. & B. \\
\hline 25 & 6 by 8 to 10 by 15 inches... & $\left\{\begin{array}{l}\text { March, } 1912 \ldots . . . \\
\text { January, 1914.... } \\
\text { November, } 1915 . . \\
\text { January, 1916..... } \\
\text { March, 1916...... }\end{array}\right.$ & $\begin{array}{r}\$ 1.60 \\
1.40 \\
1.60 \\
1.80 \\
2.20\end{array}$ & $\begin{array}{r}\$ 1.52 \\
1.33 \\
1.33 \\
1.52 \\
1.71\end{array}$ & $\begin{array}{r}\$ 2.31 \\
2.24 \\
2.52 \\
2.80 \\
3.08\end{array}$ & $\begin{aligned} 82.19 \\
2.12 \\
2.12 \\
2.39 \\
2.65\end{aligned}$ \\
\hline 34 & $\left\{\begin{array}{lll}11 \text { by } 14 \\
12 \text { by } 13\end{array}\right\}$ to 14 by 20 inches.. & $\left\{\begin{array}{l}\text { March, 1912 ...... } \\
\text { January, 1914 .... } \\
\text { November, 1915... } \\
\text { January, 1916..... } \\
\text { March. 1916...... }\end{array}\right.$ & $\begin{array}{l}1.68 \\
1.47 \\
1.68 \\
1.89 \\
2.31\end{array}$ & $\begin{array}{l}\text { 1. } 60 \\
1.40 \\
1.40 \\
1.60 \\
\text { 1. } 80\end{array}$ & $\begin{array}{l}2.56 \\
2.48 \\
2.79 \\
3.10 \\
3.41\end{array}$ & $\begin{array}{l}2.39 \\
2.32 \\
2.32 \\
2.61 \\
2.90\end{array}$ \\
\hline 40 & 10 by 26 to 16 by 24 inches... & $\left\{\begin{array}{l}\text { March, 1912 ...... } \\
\text { January, 1914.... } \\
\text { November, } 1915 \ldots . \\
\text { January, 1916..... } \\
\text { March, 1916...... }\end{array}\right.$ & $\begin{array}{l}1.74 \\
1.58 \\
1.80 \\
2.03 \\
2.48\end{array}$ & $\begin{array}{l}1.63 \\
1.47 \\
1.47 \\
1.68 \\
1.89\end{array}$ & $\begin{array}{l}2.81 \\
2.72 \\
3.06 \\
3.40 \\
3.74\end{array}$ & $\begin{array}{l}2.56 \\
2.48 \\
2.48 \\
2.79 \\
3.10\end{array}$ \\
\hline 50 & $\left\{\begin{array}{l}18 \text { by } 22 \\
20 \text { by } 20\end{array}\right\}$ to 20 by 30 inches.. & $\left\{\begin{array}{l}\text { March, 1912 ..... } \\
\text { January, 1914 } \\
\text { November, } 1915 . . \\
\text { January, } 1916 \ldots \ldots \\
\text { March, } 1916 \ldots \ldots\end{array}\right.$ & $\begin{array}{l}1.84 \\
2.20 \\
2.20 \\
2.48 \\
2.85\end{array}$ & $\begin{array}{l}1.71 \\
2.04 \\
2.04 \\
2.30 \\
2.64\end{array}$ & $\begin{array}{l}3.05 \\
2.96 \\
3.33 \\
3.70 \\
4.07\end{array}$ & $\begin{array}{l}2.85 \\
2.76 \\
2.76 \\
3.11 \\
3.45\end{array}$ \\
\hline 54 & 15 by 36 to 24 by 30 inches... & $\left\{\begin{array}{l}\text { March, } 1912 \ldots \ldots . \\
\text { January, } 1914 \ldots . . . \\
\text { November, } 1915 \ldots . \\
\text { January, 1916 ..... } \\
\text { March, 1916 ....... }\end{array}\right.$ & $\begin{array}{l}1.90 \\
2.27 \\
2.27 \\
2.56 \\
2.94\end{array}$ & $\begin{array}{l}1.74 \\
2.08 \\
2.08 \\
2.35 \\
2.70\end{array}$ & $\begin{array}{l}3.14 \\
3.04 \\
3.42 \\
3.80 \\
4.18\end{array}$ & $\begin{array}{l}2.89 \\
2.80 \\
2.80 \\
3.15 \\
3.50\end{array}$ \\
\hline 60 & 26 by 28 to 24 by 36 inches. . & $\left\{\begin{array}{l}\text { March, 1912 } \\
\text { January, 1914...... } \\
\text { November, } 1915 . . . \\
\text { January, 1916.... } \\
\text { March, 1916 ...... }\end{array}\right.$ & $\begin{array}{l}2.02 \\
2.41 \\
2.41 \\
2.72 \\
3.12\end{array}$ & $\begin{array}{l}1.80 \\
2.15 \\
2.15 \\
2.43 \\
2.79\end{array}$ & $\begin{array}{l}3.22 \\
3.12 \\
3.51 \\
3.90 \\
4.29\end{array}$ & $\begin{array}{l}2.93 \\
2.84 \\
2.84 \\
3.20 \\
3.55\end{array}$ \\
\hline 70 & $\left\{\begin{array}{lll}26 & \text { by } & 34 \\
28 & \text { by } & 32 \\
30 & \text { by } & 30\end{array}\right\}$ to 30 by 40 inches.. & $\left\{\begin{array}{l}\text { March, } 1912 \ldots . . \\
\text { January, } 1914 \ldots . . \\
\text { November, } 1915 \ldots . \\
\text { January, } 1916 \ldots . . \\
\text { March, 1916...... }\end{array}\right.$ & $\begin{array}{l}2.23 \\
2.66 \\
2.66 \\
3.00 \\
3.45\end{array}$ & $\begin{array}{l}1.96 \\
2.34 \\
2.34 \\
2.64 \\
3.03\end{array}$ & $\begin{array}{l}3.47 \\
3.36 \\
3.78 \\
4.20 \\
4.62\end{array}$ & $\begin{array}{l}3.14 \\
3.04 \\
3.04 \\
3.42 \\
3.80\end{array}$ \\
\hline
\end{tabular}


Table 77.- Window Glass Price List: Net Prices per Box, 1912 to 1916 Concluded.

\begin{tabular}{|c|c|c|c|c|c|c|}
\hline \multirow{2}{*}{$\begin{array}{l}\text { United } \\
\text { inches. }\end{array}$} & \multirow{2}{*}{ Bracket. } & \multirow{2}{*}{ Date of discount. } & \multicolumn{2}{|c|}{$\begin{array}{l}\text { Single } \\
\text { strength. }\end{array}$} & \multicolumn{2}{|c|}{$\begin{array}{l}\text { Double } \\
\text { strength. }\end{array}$} \\
\hline & & & A. & B. & A. & B. \\
\hline 80 & $\left\{\begin{array}{l}2 \text { by } 38 \\
34 \text { by } 36\end{array}\right\}$ to 30 by 50 inches.. & $\left\{\begin{array}{l}\text { March, } 1912 \ldots \ldots \\
\text { January, } 1914 . \ldots \\
\text { Novemiber, } 1915 \ldots \\
\text { January, } 1916 . . . \\
\text { March, 1916...... }\end{array}\right.$ & $\begin{array}{r}\$ 2.58 \\
3.08 \\
3.08 \\
3.47 \\
3.99\end{array}$ & $\begin{array}{r}\$ 2.23 \\
2.66 \\
2.66 \\
3.00 \\
3.45\end{array}$ & $\begin{array}{r}\$ 3.80 \\
3.68 \\
4.14 \\
4.60 \\
5.06\end{array}$ & $\begin{array}{r}\$ 3.42 \\
3.32 \\
3.32 \\
3.74 \\
4.15\end{array}$ \\
\hline 84 & 30 by 52 to 30 by 54 inches... & $\left\{\begin{array}{l}\text { March, } 1912 \ldots . . . \\
\text { January, } 1914 . \ldots \\
\text { Tovember, } 1915 \ldots \\
\text { January, 1916.... } \\
\text { March, 1916...... }\end{array}\right.$ & $\begin{array}{l}2.75 \\
3.28 \\
3.28 \\
3.71 \\
4.26\end{array}$ & $\begin{array}{l}2.42 \\
2.89 \\
2.89 \\
3.27 \\
3.75\end{array}$ & $\begin{array}{l}\text { 3. } 88 \\
\text { 3. } 76 \\
\text { 4. } 23 \\
4.70 \\
5.17\end{array}$ & $\begin{array}{l}\text { 3. } 51 \\
\text { 3. } 40 \\
\text { 3. } 40 \\
\text { 3. } 83 \\
\text { 4. } 25\end{array}$ \\
\hline 90 & 30 by 56 to 34 by 56 inches... & $\left\{\begin{array}{l}\text { March, } 1912 . \ldots . . \\
\text { January, } 1914 . \ldots . \\
\text { Tovember, } 1915 . . \\
\text { January, 1916.... } \\
\text { March, 1916..... }\end{array}\right.$ & & $\begin{array}{l}\cdots \\
\cdots \\
\cdots\end{array}$ & $\begin{array}{l}\text { 4. } 13 \\
\text { 4. } 00 \\
\text { 4. } 50 \\
\text { 5. } 00 \\
\text { 5. } 50\end{array}$ & $\begin{array}{l}3.80 \\
3.68 \\
3.68 \\
4.14 \\
4.60\end{array}$ \\
\hline 94 & 34 by 58 to 34 by 60 inches... & $\left\{\begin{array}{l}\text { March, } 1912 \ldots . . . \\
\text { January, } 1914 . \ldots \\
\text { November, } 1915 . . \\
\text { January, } 1916 \ldots . \\
\text { March, } 1916 . . .\end{array}\right.$ & & $\begin{array}{l}\cdots \\
\cdots \\
\cdots\end{array}$ & $\begin{array}{l}\text { 4. } 21 \\
\text { 4. } 08 \\
\text { 4. } 59 \\
5.10 \\
5.61\end{array}$ & $\begin{array}{l}\text { 3. } 88 \\
\text { 3. } 76 \\
\text { 3. } 76 \\
\text { 4. } 23 \\
\text { 4. } 70\end{array}$ \\
\hline 100 & 36 by 60 to 40 by 60 inches... & 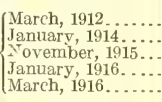 & & & $\begin{array}{l}4.95 \\
4.80 \\
5.40 \\
6.00 \\
6.60\end{array}$ & $\begin{array}{l}\text { 4. } 62 \\
\text { 4. } 48 \\
\text { 4. } 48 \\
5.04 \\
5.60\end{array}$ \\
\hline 105 & 40 by 62 to 40 by 64 inches... & $\left\{\begin{array}{l}\text { March, } 1912 . . . . \\
\text { January, } 1914 \ldots \\
\text { November, 1915... } \\
\text { January, 1916 . . } \\
\text { March, 1916 ..... }\end{array}\right.$ & & $\begin{array}{l}\cdots \\
\cdots \\
\cdots \\
\cdots\end{array}$ & $\begin{array}{l}10.73 \\
10.40 \\
11.70 \\
13.00 \\
14.30\end{array}$ & $\begin{array}{r}9.90 \\
9.60 \\
9.60 \\
10.80 \\
12.00\end{array}$ \\
\hline 110 & 40 by 66 to 40 by 70 inches... & $\left\{\begin{array}{l}\text { March, } 1912 \ldots . . . \\
\text { Yanuary, } 1914 \ldots . \\
\text { November, } 1915 . . \\
\text { January, } 1916 \ldots . \\
\text { March, } 1916 \ldots \ldots\end{array}\right.$ & & & $\begin{array}{l}12.05 \\
11.68 \\
13.14 \\
14.60 \\
16.06\end{array}$ & $\begin{array}{l}11.22 \\
10.88 \\
10.88 \\
12.24 \\
13.60\end{array}$ \\
\hline 115 & 40 by 72 to 40 by 74 inches... & 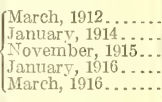 & & $\begin{array}{l}\cdots \\
\cdots \\
\cdots\end{array}$ & $\begin{array}{l}13.37 \\
12.96 \\
14.58 \\
16.20 \\
17.82\end{array}$ & $\begin{array}{l}12.54 \\
12.16 \\
12.16 \\
13.68 \\
15.20\end{array}$ \\
\hline 120 & 40 by 76 to 40 by 80 inches... & $\left\{\begin{array}{l}\text { Mareh, } 1912 . . . . . \\
\text { January, } 1914 . \ldots . \\
\text { Tovember, } 1915 \ldots \\
\text { January, } 1916 \ldots . . \\
\text { March, } 1916 . . . . .\end{array}\right.$ & & $\begin{array}{l}\cdots \\
\cdots \\
\cdots \\
\cdots\end{array}$ & $\begin{array}{l}\text { 15. } 68 \\
\text { 15. } 20 \\
17.10 \\
19.00 \\
20.90\end{array}$ & $\begin{array}{l}\text { 14. } 85 \\
14.40 \\
14.40 \\
16.20 \\
18.00\end{array}$ \\
\hline
\end{tabular}

As appears by this table, the net prices of single and double'strength of the first three brackets were in most instances lower during the period from January, 1914, to November, 1915, or to January, 1916, than they were either before or after. The net prices of the larger brackets in single strength were lowest during the period from March, 1912, to January, 1914, but this was not the case with double-strength glass.

Special discounts apply to window glass of AA quality, which is produced in only limited quantities and by some factories not at all. There is no fixed price list for C quality, which is produced usually. in only first bracket sizes. This grade is sold at net prices per box, the range during $1914 ; 1915$, and 1916 being from $\$ 0.85$ to $\$ 1.20$ per 50-foot box. 
$\mathrm{By}$ an agreement or understanding among the manufacturers, they charge 15 cents each for boxes for glass of the first three brackets and 25 cents for boxes for larger sizes. All of them state that they lose money on the boxes, and when asked why they do not charge more, say that formerly they did not charge anything for boxes, that it was hard to get manufacturers generally to agree to make this charge, and that when the agreement was reached a fow years ago, competition among manufacturers caused some to continue to sell glass without making such a charge. It is, therefore, considered impractical to make a higher charge for boxes at present.

\section{DEFINITION OF GRADES.}

The following definitions of first, second, and third quality glass are quoted from Glass and Glazing, issued in 1916 by the National Glass Distributors' Association:

A.A or first quality. - A A quality should be clear glass, free from any perceptible amount of air bubbles or blisters, burnt specks or burns, cords, and strings. It should have a good gloss and an even surface and be well flattened. By air bubbles it is understood that tiny blisters, or imperfections not perceptible on the cutters' table but detectable when placing the sheet directly toward the light, would not be objectionable. This should be a careful selection in both single and double and should represent the very best that can be produced in window glass by the present methods.

$A$ or second quality. - A quality glass is the normal selection of glass when no special selection is desired or specified and it admits of such defects as small strings or lines, small blisters when not too close to one another or located in the center of the sheet; well flattened, the surface even, and devoid of noticeable scratches, cropper marks, burns, and other prominent defects.

$B$ or third quality. - B glass covers a wider range than either A $A$ quality or A quality. It permits many of the defects inherent to the process of making, such as waves, strings, lines, blisters, scratches, burns, and other similar or equivalent defects. This quality embraces everything below A quality not stony or full of blisters or other large defects objectionable for any common purpose, such as heavy scratches, heavy blisters, cords, and sulphur stains.

\section{The following paragraphs are quoted from the same publication:}

In examining samples of small sizes for inspection of quality, it should be remembered that the large light of glass will show the natural waves and defects, while the small piece may appear nearly perfect. It is not altogether a matter of expert judgment to determine the various grades, and certain rules may be accepted governing window-glass specifications.

Sizes.-Window glass in double strength, or heavier, is made as large as 30 by 90 inches, 38 by 86 inches, and 48 by 80 inches, such extreme sizes containing 25 square feet, but it is inadvisable to use such glass in these measurements on account of the liability of breakage and the distorted vision due to waves, etc. The same may be said of the extreme sizes of single strength, which can be made up to 24 by 60 inches, 30 by 54 inches, and 36 by 50 inches, sizes containing 10 to $12 \frac{1}{2}$ square feet.

Thickness and weight.-Single-strength glass measures approximately 12 lights to the inch, but a small variation either way is permissible. Single-strength weighs approximately 16 ounces to the square foot. Double strength measures approximately nine lights to the inch. The thickness should be fairly uniform and the weight approximately 24 ounces to the square foot.

Factory prekages.-Winclow glass in regular sizes is packed approximately 50 square feet to the box up to the 100 united inch bracket (adding width and length), and 100 square feet to the box in sizes over 100 united inches.

The thickness of glass heavier than double strength is as follows: 26-ounce, one-eighth of an inch; 29-ounco, 135 thousandths of an inch; 34-ounce, 159 thousandths of an inch; 39-ounce, three-sixteenths of an inch. 
The net weight of a box containing approximately 50 square feet of glass is about 55 pounds in single thickness and 80 pounds in double thickness.

\section{HAND PRODUCTION CLASSIFIED BY GRADES, SIZE, AND STRENGTH.}

The proportion of A glass on the basis of total production is usually larger in the hand factories than in the machine factories. The National for August, 1916, published for the National Window Glass Workers of America, shows that in all of the hand windowglass factories in the United States, during the blasts of 1914-15 and 1915-16, the percentage cut into different brackets, $A$ and $B$ grades, single and double strength, on the basis of the total production of $\mathrm{A}$ and $\mathrm{B}$ grades, was as follows:

Table 78.-Percentage of Window Glass Produced by Hand, Blasts of 1914-15 and 1915-16, Cut into Different Brackets, A and B Grades.

[Data from The National, published by the United Window Glass Workers, August, 1915 and 1916.]

\begin{tabular}{|c|c|c|c|c|c|c|}
\hline \multirow{2}{*}{ Bracket. } & \multicolumn{3}{|c|}{$1914-15$} & \multicolumn{3}{|c|}{$1915-16$} \\
\hline & A. & B. & Total. & A. & B. & Total. \\
\hline 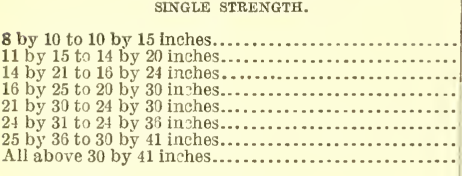 & $\begin{array}{r}\text { Per ct. } \\
3.15 \\
5.16 \\
4.66 \\
7.24 \\
3.04 \\
2.68 \\
1.31 \\
.10 \\
\end{array}$ & $\begin{array}{r}\text { Per ct. } \\
9.84 \\
10.86 \\
11.05 \\
18.72 \\
7.93 \\
7.61 \\
5.70 \\
.95 \\
\end{array}$ & $\begin{array}{r}\text { Per ct. } \\
12.99 \\
16.02 \\
15.71 \\
25.96 \\
10.97 \\
10.29 \\
7.01 \\
1.05 \\
\end{array}$ & $\begin{array}{r}\text { Per ct. } \\
2.55 \\
4.82 \\
4.57 \\
6.35 \\
2.89 \\
2.74 \\
1.18 \\
.11 \\
\end{array}$ & $\begin{array}{r}\text { Per ct. } \\
8.73 \\
11.13 \\
10.09 \\
19.55 \\
9.02 \\
9.13 \\
6.39 \\
.75 \\
\end{array}$ & $\begin{array}{r}\text { Per ct. } \\
11.28 \\
15.95 \\
11.66 \\
25.90 \\
11.91 \\
11.87 \\
7.57 \\
.86 \\
\end{array}$ \\
\hline Total.... & 27.34 & 72.66 & 100.00 & 25.21 & 74.79 & 100.00 \\
\hline 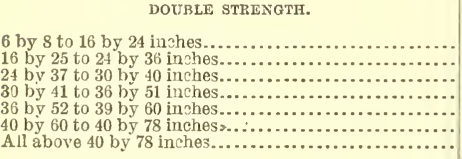 & \begin{tabular}{r|}
5.69 \\
17.37 \\
10.52 \\
7.63 \\
2.11 \\
1.27 \\
.21
\end{tabular} & $\begin{array}{r}8.84 \\
19.85 \\
13.04 \\
9.57 \\
2.44 \\
1.20 \\
.26\end{array}$ & $\begin{array}{r}14.53 \\
37.22 \\
23.56 \\
17.20 \\
4.55 \\
2.47 \\
.47\end{array}$ & $\begin{array}{r}6.47 \\
17.62 \\
10.43 \\
7.77 \\
2.26 \\
1.19 \\
.17\end{array}$ & $\begin{array}{r}7.80 \\
20.50 \\
13.40 \\
8.96 \\
2.29 \\
.98 \\
.16\end{array}$ & $\begin{array}{r}14.27 \\
38.12 \\
23.83 \\
16.73 \\
4.55 \\
2.17 \\
.33\end{array}$ \\
\hline Total....................................... & 44.80 & 55.20 & 100.00 & 45. 91 & 54.09 & 100.00 \\
\hline
\end{tabular}

The proportion of the different grades and the proportion of double and single strength glass varies greatly in the different factories, as shown by the reports of 19 hand factories for the blast of 1914-15, summarized in the following table: 
Table 79.-Proportion of A Quality of the Three Syaller Brackets, Single and Double Strength, Produced by 19 Factories, 1914-15.

[Data from The Glassworker, Aug. 5, 1916.]

\begin{tabular}{|c|c|c|c|c|}
\hline \multirow{2}{*}{ Factory. } & \multicolumn{2}{|c|}{ A grade. } & \multicolumn{2}{|c|}{$\begin{array}{l}\text { Cut in first throe } \\
\text { brackets. }\end{array}$} \\
\hline & $\begin{array}{l}\text { Single } \\
\text { strength. }\end{array}$ & $\begin{array}{l}\text { Double } \\
\text { strength. }\end{array}$ & $\begin{array}{c}\text { Single. } \\
\text { strerigth. }\end{array}$ & $\begin{array}{l}\text { Double } \\
\text { strength. }\end{array}$ \\
\hline 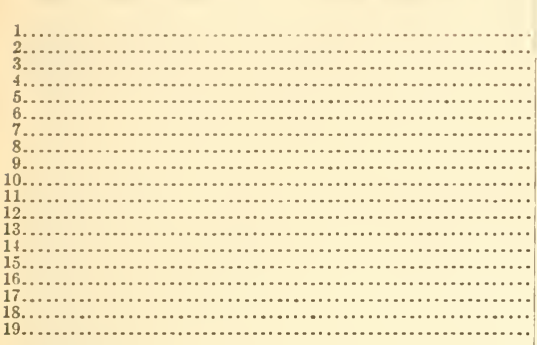 & \begin{tabular}{r|} 
Per cent. \\
47.0 \\
10.0 \\
14.0 \\
18.0 \\
17.0 \\
29.0 \\
22.0 \\
39.0 \\
11.0 \\
23.5 \\
43.0 \\
24.0 \\
25.0 \\
19.0 \\
14.0 \\
24.0 \\
4.0 \\
8.0 \\
9.5
\end{tabular} & $\begin{array}{r}\text { Per cent. } \\
51.0 \\
40.0 \\
29.0 \\
40.0 \\
42.0 \\
47.0 \\
45.0 \\
60.0 \\
12.0 \\
49.0 \\
62.5 \\
50.5 \\
45.0 \\
40.0 \\
42.0 \\
39.0 \\
5.0 \\
26.0 \\
15.0\end{array}$ & $\begin{array}{r}\text { Per cent. } \\
55.3 \\
49.6 \\
48.9 \\
32.9 \\
45.3 \\
35.5 \\
35.9 \\
47.8 \\
50.5 \\
47.3 \\
53.1 \\
51.7 \\
46.0 \\
40.1 \\
47.4 \\
48.6 \\
63.9 \\
27.8 \\
57.3\end{array}$ & $\begin{array}{r}\text { Per cent. } \\
61.8 \\
37.9 \\
37.5 \\
55.8 \\
51.1 \\
42.3 \\
49.0 \\
38.7 \\
44.7 \\
42.6 \\
60.5 \\
47.0 \\
47.3 \\
51.9 \\
51.9 \\
49.9 \\
61.8 \\
51.7 \\
64.5\end{array}$ \\
\hline 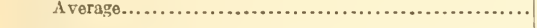 & 21.0 & 39.0 & 47.0 & 50.0 \\
\hline
\end{tabular}

Mr. Neenan's statement, previously quoted, indicates that the production of window glass by hand has decreased, as the number of union blowers was 1,610 during the blast of 1915-16, while formerly it was probably from 1,800 to 1,900 .

\section{PROPORTION OF PRODUCTION BY HAND AND MACHINE.}

The statistics of the Census of Manufactures do not show the proportion of window glass made by hand and by machine, and the statistics of the union do not show the proportion previous to the blast of 1915-16, when, as stated by Mr. Neenan, the production of 50-foot boxes by hand was 3,708,000 and by machine 5,575,000, the hand production being about 40 per cent. The largest producer is the American Window Glass Co., which in 1916 operated 116 of the 296 machines in the United States. The machines of this company have been installed much longer than the machines of any other company and have long since passed the experimental stage.

Mr. W. L. Monro, general manager of this company, in declining to furnish data regarding its business for this report, stated that it could produce window glass cheaper than any other establishment in the United States and would continue to do so until window glass should be made by machines in sheets (instead of cylindrical as at present), the patents for which are controlled by the Owens Bottle Machine Co. The American Window Glass Co., in October, 1916, declared a dividend of $12 \frac{1}{2}$ per cent on its preferred stock, making a total of $54 \frac{1}{2}$ per cont paid on the stock within a year; or $\$ 3, \$ 15,000$ on the issue of $\$ 7,000,000$. 


\section{COOPERATION AMONG MANUFACTURERS.}

The announcement of discounts from the fixed price list is made almost invariably by the American Window Glass Co., and is immediately followed by the Johnston Brokerage Co., which sells the product of about half the hand glass factories and of some other machine manufacturers.

A West Virginia manufacturer, in an interview with a special agent of the Bureau, answered as follows the inquiry as to what cooperation there was among manufacturers of window glass:

About the only steps taken in this direction is that of selling through one man (Johnston). This tends to make stable prices. Curtailment of production is forced on manufacturers by an agreement with the union which fixes the time limits between which dates the plants may operate. Manufacturers have now agreed that this is beneficial to business, for if they were to operate the whole year there would be an overproduction, which would send prices so low that many establishments would be ruined.

Considering the hazard to all concerned, the present lack of intercourse and friendly consideration of the problems involved is worse than a menace to this business. If there was ever a business which demanded the closest cooperation in all matters connected with it, it is this one. There never has been such cooperation. The problem of overproduction is constantly growing worse. It is further complicated by having new factories spring up every time a short period of prosperity comes to the industry. In this immediate locality seven new factories have been built and several old ones enlarged in the past four years. The number already operating is more than sufficient to supply the demand for glass; and they can do this by operating from 26 to 40 weeks - usually about 30 weeks. These new factories are usually the first to go under, but they do damage to the whole industry and make the business still more unstable.

\section{INCREASED DEMAND FOR FIRST GRADE AND FOR SMALL SIZES.}

In the window-glass industry two trade tendencies have been very noticeable during the last few years. One is the demand for A glass. Most of the glass that is sold is of B grade, but there has been a growing demand for A quality. Buyers are now much more strict as to grading than they were formerly, and A glass is at a premium, that is, it has advanced in price more proportionately than have other grades. So strict is the grading now that some factories no longer sell A glass as of that grade. Though some of their product is of A grade, they prefer to sell it all as B grade, to avoid complaints and claims from their customers for allowances. It is generally. conceded that more A glass is made by the hand factories than by the machine factories, but hand manufacturers usually admit that the quality of machine-made glass is constantly being improved.

The other very noticeable tendency in the window-glass industry is that for several years, especially since 1914, there has been an increased demand for the three smaller brackets. Glass of these smaller sizes constitute half or more of the output in ordinary factories, or from 50 to 65 per cent. Most manufacturers claim that they lose money on the first three bracket sizes, because of both domestic and foreign competition. They have not, therefore, witnessed with equanimity the growing popularity of small sizes. The building of so many bungalow houses is given as the principal reason for the increasing demand for small glass.

The fixed price list of window glass, subject to very large discounts, shows marked differences in prices. The list prices for single B glass of the three smallest brackets is $\$ 19, \$ 20$, and $\$ 21$, respectively; for the next three brackets, $\$ 22, \$ 22.50$, and $\$ 23.25$; for the next 
three, $\$ 25.25, \$ 2 \$ .75$, and $\$ 31.25$. This price list was last revised on October 15, 1912. It is the belief of many manufacturers that there is a much greater difference between the net selling prices of the larger and smaller brackets than the costs warrant and that the list price of the three smaller brackets should be advanced. About three-fourths of the imports of window glass before the war in Europe began were of the three smaller sizes, and many manufacturers give this as a reason why such brackets were sold at a loss.

It is remarkable, however, that manufacturers have not increased the prices of the smaller sizes in proportion to the advance in the prices of the larger sizes from 1914 to 1916, especially as during that period there has been practically no foreign competition.

\section{MANUFACTURING TO FILL ORDERS AND FOR STOCK.}

In normal years, window-glass manufacturers make glass both to fill orders and for stock, usually about two-thirds for orders and one-third for stock. The goods made for stock are to fill immediate orders and to take care of the trade between fires. With hand factories the "fire" or manufacturing season extends for seven months, from the first of November to the last of May, and during these months they must make enough for stock to supply customers during the five idle months. Some machine window-glass plants are shut down only three or four weeks, but do not operate with the full force during several months of the year. Some orders for window glass are for immediate delivery, but most of them are for delivery in from one to three months. During the latter part of 1915 and in 1916, when the demand was extraordinarily active, stocks did not accumulate, and the factories were run at capacity to fill orders.

\section{CONDITIONS OUTLINED BY MANUFACTURERS.}

Following are excerpts from speeches made at the annual meeting of the National Association of Window Glass Manufacturers held in 1915 .

Mr. H. R. Hilton, president of the Allegheny Window Glass Co., Port Allegheny, Pa., said:

Increased capacity of hand and machine factories has reduced the operating period to seven and possibly six months each year. The jobber now being able to buy glass at any time to meet all his requirements the year round, no longer finds it necessary to carry more than a small assortment of sizes to meet his current needs. This forces the manufacturer to carry large stocks during the shut-down period, to meet the requirements of the market when glass is called for.

Under present conditions in the hand process window-glass industry, the demand for glass is greater during the shut-down period, June to November, than during the customary operating period, November to June. No manufacturer is so wise that he can foresee what sizes will be in demand the following summer, hence he rarely accumulates a stock that meets the market requirements.

This imposes large financial burdens on the manufacturer in carrying over another year that part of his stock not in demand in addition to losing summer trade by not having the sizes called for.

The wage scales of the past have permitted the setting out of a certain percentage of sheets to enable the manufacturer to fill out short sizes on summer orders, but this percentage is entirely too small for present-day conditions, and besides carries with it a tax of 15 cents per 50 -foot box by compelling the manufacturer to pay full price for cutting when the sheets are set out and full price again when the sheets are cut into marketable sizes. This double price for cutting sheets and the restrictions as to setting them out impose a hardship and expense on the manufacturer that is both unjust and unfair. 
As a partial solution of this problem, I would suggest that each cutter be given the production of four pots or places to cut; that he cut weekly the production of two and a half potsor less according to demand; that the balance be carried directly from the lehr to the sheet storage room to be held for summer cutting without payment for the sheets set out from any of his places, he to have the privilege of cutting this sheet glass during the summer months, as called for, at the scale price.

This would give each cutter from seven and one-half to nine months' work, would give each factory the labor required for this work, and would enable the manufacturer to dispose of his production to the very best advantage by placing him in a position to compete with his machine competitor.

Sheets can be set out to occupy less floor space than the same glass would require packed in 50 -foot boxes and piled 25 boxes high.

\section{Mr. O. C. Teague, secretary of the Utica Glass Co., Utica, Ohio} (also president of the National Window Glass Manufacturers' Association):

The window-glass industry during the past year has operated 50 per cent capacitymeaning that if all available furnaces had operated at maximuin capacity for six months, all demands, both domestic and foreign, would have been fully supplied and some stock to spare.

Most producers have recognized the fundamental law of supply and demand and demonstrated a willingness to exact his share and be satisfied. Unfortunately, however, there are still a few manufacturers who propose to operate full capacity for a full year, furnace conditions permitting. This last-named factor is the dangerous element in our largely overbuilt industry. Unless we can convince these free lances of their mistaken policy our future business life is indeed short. * * *

Evidently the day has passed when the jobber engages in speculative buying of window glass and the result is that manufacturers must carry the bulk of the stock. This necessitates increased resources and good banking connections, or both.

\section{Mr. G. A. Schlosstein, president of the Dunkirk Window Glass Co.,} South Charleston, W. Va.:

Some industries have overproduction in their individual lines of 10 per cent, others as high as 25 per cent, but the sheet-glass business of this country has now reached the alarming figure of 50 per cent overproduction, or, in other words, there are exactly two boxes of glass made where only one is wanted.

While the hand manufacturer during the blast of 1914 and 1915 has operated only six months, many machine-equipped factories have operated from 6 to 11 months, and are still in operation to-day or have just suspended operations. * * *

Since we can no longer form holding companies, or distributing companies, that will absolutely maintain and establish prices, the time is here when everyone, with favoritism to none, should see the importance of intelligently contributing his influence to the maintenance of a profitable market.

During the years 1913 and 1914 there were manufactured by the combined machine plants of the United States $3,969,519$ fifty-foot boxes of window glass, and $3.064,304$ were manufactured by the hand method. The production by machines during the year ending July, 1915, was largely increased, and it begins to look as though the machine interest will in the future dictate the policies, whether we will overproduce, or whether we shall intelligently make as much glass as the country requires and then close the plants. Strange as it may seem to one unfamiliar with the industry, there has been an uncontrollable desire on the part of many manufacturers to keep their plants in operation, tliinking that it was more important to operate than to sell their goods at a profit and to pay dividends to their stockholders.

I can remember as far back as 1887 when the Chambers \& McKee Co. built their first large tank at Jeannette. In a few years others followed, but for a long period of years the pot factories, meaning those who melted their glass in clay pots instead of clay tanks, occupied the same identical position that the hand operators have done in the past few years. Gradually the scene changed as it is changing to-day, and when the dawn of 1906 came, with its business depression, the pot furnace had been driven out, just as the hand operator is being driven out. Those days it was stated that the antiquated pot-furnace factory had to go, that it had no right to exist any longer. When it disappeared, modern tanks took its place, with doubled and tripled capacity.

What made it worse, that much new capital was decoyed into the business and it was more difficult to get along with the new competitors, who knew absolutely nothing about the business. The evolution of cleaning up the pot furnaces and 
bringing tank furnaces into general use caused most of the present overproduction of the industry.

But when we lnok forward to the next five years, what can be done to make the business profitable? Hardly has the cylinder drawing machine been made a commercial s!ıccess, but that we are confronted with a sheet drawing machine which threatens the cylinder process of to-dav.

Even when the sheet drawing machine becomes a success, no more money will be made in the business unless the glass is intelligently distrihuted after it is manufactured. Some of the livest economists have stated that "it was not a question of production in this country, but a question of distribution." Glass must be sold by an experienced salesman; it should be shipped from the factory most favorably located from the point of manufacture to the point of consumption; it should travel the shortest route so as to minimize the freight equalization to the manufacturer. Manufacturers slould produce their proportion of the glass that the country demands and have the glass marketed at a profit which is fair and commensurate with the risk; that the business can not escape. While we bad lean years, and while we have had profitahle vears. have we ever made as much money out of the business as we should have done? Think for a moment that in our great country we are blessed with natural gas for fuel. Think of the fnreign manufacturers, who even during the times of peace were waging a constant battle to produce a superior quality of window glass with the use of manufactured gas, and in addition some wood. The day may come when our gas is gone; then we shall think back to the good old days when it was in abundance. It has given out in Indiana, it has given out in Kansas, and it is rapidly diminishing in Ohio and Pennsylvania. The few years that are left for us to use the precious fuel should be counted and the supply carefully guarded and treasured.

Mr. J. W. Allison, president of the Alliance Window Glass Co., Dubois, Pa.:

Mr. Johnston has a right to sell our glass, and there is no law to interfere with him or with me as salesman, and Mr. Johnston has a right to say at what price he will sell that product-he can do that without conflicting with the law, but we manufacturers can not come here and agree on production or prices, but can only have it understood that each fellow is going to make his proportion and no more. Then, of course, it is up to each man individually and, as one of the gentlemen here has said, the law of supply and demand will take care of the business.

Mr. Frank Bastin, secretary of the Blackford Window Glass Co., Vincennes, Ind.:

If we persist in making more glass than the country can absorb it will be a drug on the market, and it means low prices and impossible conditions for everyone. I think common sense, which is the basis of all laws, should teach us that this should be remedied in some legitimate and legal way. It should not be contrary for us, acting as individuals, to say there is enough glass, when we have statistics before us showing that we have made as much glass as the country required.

Mr. C. E. Hazelton, general manager of the Consolidated Window Glass Co., Bradford, Pa.:

There is no doubt but what the condition of our trade is overbuilt, which makes it a hard proposition to maintain a strictly standard market where we can all make a living, but by cooperation and square dealing I hope we can all continue to live and prosper for years to come. There is one thing that comes to my mind that appeals to me as being worth while, and that is the question of changing our packages to universal 100 -foot packages, such as are used by foreign countries. Just at the present time it is confusing when we manufacturers receive orders for 50 and 100 foot packages, but that can be remedied by establishing the same package that is used in France and Belgium, and I think it would be a good thing for this business.

Mr. C. W. Brown, first vice president of the Pittsburgh Plate Glass Co., Pittsburgh, Pa.:

We all know that the American Window Glass Co. for 10 or 11 years kept on investing more and more money and ran more and more into debt, without making returns to its stockholders. This is a matter of common record. And now in the past two or three years the American Window Glass Co. has perfected its machines and is now able to make the best machine glass in the world. 
During the past year building permits were materially curtailed and the consumption of window glass was greatly limited. There has been a largely excessive production of certain sizes and certain qualities, which have been sold at various prices, until it is impossible to know what the market price really is. I hope to live to see the day when all sales of window glass are reported the same as sales of coffee, sugar, and grain, which will give those in the window-glass business an opportunity to know what the market price really is. * * *

The hand manufacturers have met this condition in a way that $I$ think is very creditable; they have provided for six or seven months' blast. The American Window Glass Co., as you all know, have also recognized the situation, and instead of indulging in a ruinous competition they have been broad enough and sensible enough to materially curtail their production.

Mr. Joseph Neenan, president of the National Association of Window Glass Workers:

Our wages have increased more than 109 per cent from the lowest point to the point where, during the last six weeks of the blast ending May 29, single-strength blowers were averaging 66 cents per box. Contrast this condition with the one that prevailed three years ago last November, and we are forced to the conclusion that both manufacturers and workers have profited through the efiorts that have been made to obtain a living wage rate and bring about a stable condition in the markets. At the time to which I am referring, single-strength blowers were averaging about 30 cents per box; the average selling price of single-strength glass was about \$1.27 per box; a condition which meant that both workers and manufacturers were devoting their interests and giving their time and energy to a business which gave them no returns.

In an address delivered before the convention of the National Association of Window Glass Manufacturers held in 1916, Mr. W. L. Monro, general manager of the American Window Glass Co., the largest producer of window glass in the world, estimated the production in American window-glass factories from September 1, 1915, to September 1, 1916, as 10,600,000 boxes, and said: "Had the manufacturers ever realized the enormous demand for glass, there is no question that they would have demanded more money for their goods and secured it with the greatest ease." He further said:

The past year has been the most notable one in the history of the window-glass business in the United States, not only from a manufacturing but also from a jobbing standpoint. Its claim to note rests on many facts: (1) More glass was manufactured in this country during the past year since September 1, 1915, than in any previous year in the history of the business; (2) more glass has been sold during the same period than ever before in a similar period; (3) window-glass prices steadily increased; (4) the demand absorbed not only all the glass prodiced d iring the past year, but also the greater part of the large accumulations on hand on September 1, 1915; (5) the export business was the largest we have ever done.

If the year has not also been the most profitable year the manufacturers and jobbers have ever known, the fault must not be laid to the business, but to the manner in which those who did not realize their greatest profit have conducted their business. The money was there to be made.

The following, also quoted from Mr. Monro's address, shows that there was comparatively little advance in the price for the first three brackets of B glass, the grade commonly used for window glass as compared with A grade and with larger sizes, during the period from 1914 to 1916, though there were scarcely any imports of window glass during the latter part of this period, and exports were larger than ever:

We hear a great deal of talk about the present prices of window glass being high. I know of but few things that we biy, whether it is what we use or what we eat or what we wear, that have not advanced in price since the beginning of the war far more than window glass. I will only cite two of them-steel from 100 to 130 per cent; soda ash, 100 per cent. The wages for common labor have increased from $16 \frac{1}{2}$ cents per hour to 24 and 25 cents an hour; natural gas from 14 cents to 16 cents in the Pittsburgh district. Building costs have increased 40 per cent. 
The following represents the increase in prices of window glass from May, 1914, to March 10. 1916. Schedule of prices: s. S. first three brackets, 1 quality, 32.5 per cent; S. S. first three brackets, B quality, $\$ .4$ per cent; S. S. above sizes, 40 per cent; an average increase of about 27 per cent. A quality, double strength, has increased 36 per cent. and $\mathrm{B}$ quality, double strength, 24 per cent, or an average increase of 30 per cent. If you will compare the percentages of these increases with the percentaves of increase in other lines, you will see that window-glass manufacturers have failed to secure their proportionate share of the prosperity that has prevailed, and have also failed to secure an increase in the price of window glass proportionate to the increase in the cost of prodlicing it. It is a sad commentary when we realize that $B$ quality glass in the first three brackets is only selling at $\$ .4$ per cent more than in May, 1914, and it is our understanding that some manufacturers are even shading current discounts on that.

THE SHEET-GLASS MACHINE.

All window-glass manufacturers are dreading the time when glass shall be made in flat sheets by the Owens Bottle Machine Co. under the Colburn patents, which it controls. They fear that by the new process window glass can be made much cheaper than by any other process that has been used in the United States; that with the cheaper production there will be an intense competition in the window-glass market, and that the weaker establishments will be forced out of business. The Owens Bottle Machine Co. began in 1916 the erection of an extensive plant at Charleston, W. Va., for the manufacture of window glass in flat sheets instead of cylinders. American manufacturers are apprehensive also about a machine for making flat window glass which was patented in Belgium before the war began. Another machine was made in Saxony before the war began by which window glass is blown and not, as in the ease of American machines, drawn from the pot or furnace. In the United States, however, very little is known about these new European machines.

PLATE GLASS.

\section{INCREASE IN PRODUCTION.}

Table 8 , page 28 , shows that the production of plate glass in the United States has increased much more rapidly than the production of window glass. According to this table, based on data from the Census of Manufactures, 217,064,100 square feet of window glass was manufactured in the United Ste tes in 1899, and 400,998,893 in 1914, an increase of 84.74 per cent; while $16,883,578$ square feet of polished plate glass was manufactured in 1899, and $60,383,516$ in 1914, an increase of 357.65 per cent. According to the same data, the average value of polished plate glass decreased from $\$ 0.306$ per square foot in 1899 to $\$ 0.245$ in 1914 .

The number of square feet of plate glass, cast, polished, finished or unfinished, and unsilvered, imported for consumption during the fiscal year 1899 was 925,212 square feet, or 5.48 per cent of the domestic production. in 1899, and the imports during the fiscal year 1914 were $2,819,611$ square feet, or 4.67 per cent of the domestic production in 1914. While the number of square feet manufactured in the United States increased 357.65 per cent during the 15 years, the number of square feet imported increased 204.75 per cent. 
A brief signed by 10 American manufacturers of plate glass, and submitted to the Committee on Ways and Means in January, 1913, stated: ${ }^{1}$

The production in the United States is about 60,000,000 square feet, about 47 per cent of which is produced by the Pittsburgh Plate Glass Co., and the remainder by 11 separate companies. None of the American product is exported, excepting a negligible quantity to contiguous territory to supply pressing requirements.

The capital invested in the ind ustry in this country is about $\$ 49,000,000$, the smallest concern in the industry having a capital investment of about $\$ 1,000,000$. The average number of men directly employed in the industry in this country is about 11,000 . Those indirectly employed will equal more than twice this number.

\section{NUMBER AND EQUIPMENT OF PLANTS.}

The number of plate-glass factories is small as compared with the number of window-glass factories. A plate-glass factory requires a very large investment for furnaces, annealing ovens, grinding and polishing machines, and other equipment. The number of factories in the United States manufacturing polished plate glass is 15 , including 2 that were closed in 1916 but late in that year were preparing to reopen. Six of these plants, with 52 furnaces and 880 .pots, were operated by the Pittsburgh Plate Glass Co. Of these six plants, four were in Pennsylvania, one in Indiana, and one in Missouri. The number of furnaces and pots of the 15 plants is shown in the following table:

Table 80.-Location and Number of Factories Making Polished Plate Glass and the Number of Their Furnaces and Pots.

[Data furnished by the Pittsburgh Plate Glass Co.]

\begin{tabular}{|c|c|c|}
\hline $\begin{array}{l}\text { Estab- } \\
\text { lish- } \\
\text { ments. }\end{array}$ & Furnaces. & Pots. \\
\hline 1 & 4 & 80 \\
\hline 1 & 10 & 120 \\
\hline 1 & 17 & 304 \\
\hline$b 8$ & 53 & 1,080 \\
\hline$c 13$ & 102 & 1,872 \\
\hline
\end{tabular}

$a$ In addition, 1 plant with 5 furnaces and 100 pots not operated in 1916 was preparing to reopen.

$b$ In addition, 1 plant with 6 furnaces and 144 pots not operated in 1916 was preparing to reopen.

$c$ In addition, 2 plants with 11 furnaces and 244 pots not operated in 1916 were preparing to reopen.

TREND OF PRICES AND SIZES.

The statement of the manufacturers to the Committee on Ways and Means in 1913 says:

The prices to consumers of plate glass in the United States have on the whole been in distinct contrast to the upward tendency in the price of most commodities during the last 10 years, while the manufacturers have been compeller to pay more for the materials entering into its production and have been compelled to increase wages in keeping with the general upward tendency of wages, all of which for a time increased the cost of production. Nevertheless, by the introduction of labor-saving devices and new inventions, the tendency in the cost of production for the last four years has been downward, and the cost to the consumer has also had a downward tendency. 
The manufacturers assert that the cost of manufacturing plate glass is the same per square foot, whether the glass is of a large or small size. Nerertheless, the selling prices are crraded according to sizes, being lowest on the smallest size and hichest on the largest size, as shown by the following table cmbodied in the manufacturers statement:

Table S1.-Retall Prices of Plate Glass per siquare foot, 1875 to 1912.

[From statement of manufacturers in Tariff Hearings, 1913.]

\begin{tabular}{|c|c|c|c|c|c|c|c|c|c|}
\hline Range. & 1875 & $18 s 0$ & 1885 & 1890 & 1895 & 1900 & 1905 & 1908 & 1912 \\
\hline 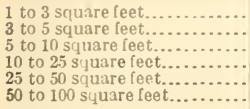 & $\begin{array}{r}\text { s0. } 71 \\
.84 \\
1.12 \\
1.49 \\
1.56 \\
1.69\end{array}$ & $\begin{array}{r}80.51 \\
.61 \\
.80 \\
1.06 \\
1.11 \\
1.21\end{array}$ & $\begin{array}{r}\$ 0.46 \\
.55 \\
.72 \\
.96 \\
1.01 \\
1.09\end{array}$ & $\begin{array}{r}80.40 \\
.48 \\
.64 \\
.85 \\
.89 \\
.97\end{array}$ & $\begin{array}{r}\$ 0.30 \\
.36 \\
.48 \\
.63 \\
.66 \\
.72\end{array}$ & $\begin{array}{r}\$ 0.31 \\
.38 \\
.60 \\
.81 \\
.85 \\
.90\end{array}$ & $\begin{array}{l}80.1875 \\
.225 \\
.36 \\
.416 \\
.436 \\
.462\end{array}$ & $\begin{array}{l}\$ 0.1875 \\
.225 \\
.36 \\
.39 \\
.408 \\
.432\end{array}$ & $\begin{array}{l}\$ 0.22 \\
.241 \\
.342 \\
.365 \\
.38 \\
.392\end{array}$ \\
\hline
\end{tabular}

The following paragraphs are quoted from the manufacturers' statement:

It should be borne in mind that a square foot of plate glass costs the same amount whether manufactured in large or small plates, because it must of necessity be cast first in large plates exclusively. Glass can not economically be melted in small quantities. It is necessary to manufacture in large sizes, in the course of which manufacturing process the unavoidable breaking and cutting down for imperfections produces some smaller sizes under 5 square feet. Normally this production of small sizes, to wit, under 5 square feet, is about 10 per cent.

In answer to the statement made by the representative of the importers four years ago, that the cost of small glass was not the same as the cost of large glass, and to the effect that the small glass was a by-product, we wish to distinctly say that neither one of these statements is in accordance with the facts. Assuming now for the sake of argument that the 10 per cent of glass under 5 square feet above referred to is a by-product, it must be borme in mind that the consumption of the country for glass of this chararter has now grown to be nearly 50 per cent of the entire production, which compels the manufacturer to cut 35 to 40 per cent of additional glass which would normally be large sizes down to the market requirements under 5 square feet, and which can certainly not be considered a by-product from any standpoint.

The query may naturally arise as to why the manufacturer should supply this additional glass if he does it at a loss. The answer is that by increasing his output by this large additional amount of business he is enabled to operate his plants nearly to their capacity, and thus reduce his general production cost. If the American manufacturer were to cease to supply this business, the cost of production would be advanced at least 3 cents per foot.

We do not claim that all glass under 5 square feet is sold at a loss, because for the finer qualities we get what appears to be a fair price; but in order to secure the small pieces of fine quality, it is necessary to cut out of the large plates the patches of fine quality, with the result that this cutting reduces the balance of the plate to odds and ends and strips. The average price secured for all the glass sold under 5 square feet has always netted a loss to the manufacturer.

The increased demand for plate glass of the smaller sizes during recent years is lue to the increased use of plate glass in place of window glass, and to the very much more extensive use of plate glass for shelving, showcases, furniture tops, automobile wind shields, etc. The following is quoted from Glass and Glassware, issued in 1916 by the National Distributors' Association:

Notwithstanding the tremendousinvestment required, the comprehensive machinery and materials used in manufacturing, the cost has been scientifically reduced so that plate glass is no longer considered a luxury and is every day increasing in popularity for general glazing of high-class buildings, store fronts, show cases, for table and desk 
covering, dresser tops, chiffoniers, buffets, taborets, shelves, etc. The use of plate glass adds an elegance and finish whenever it is seen.

The same publication states that polished plate glass is manufactured in thickness ranging from one-eighth of an inch to $1 \frac{1}{2}$ inches and that the standard product runs from one-fourth to five-sixteenths inch thick. It further says:

One-eighth inch to $\frac{3}{16}$-inch glass is used largely for residence windows and by car builders and for boat sash, automobile wind shields, and for other special purposes where perfect surfaces, high polish, and absolutely clear vision is wanted, with minimum weight.

Glass thicker than the standard product is used for counter tops, deal plates, port and deck lights on ships, aquariums, etc.

The increase of the retail price in 1912 over the price in 1908 in the first two sizes shown in Table 81, that is, for sizes of 5 feet and under, reflected the increase in the rate of duty on the smaller brackets under the tariff act which went into effect on August 6, 1909 . Under the tariff acts of 1897 and 1909, the rates of duty per square foot on plate glass, cast, polished, finished or unfinished, and unsilvered, were as follows:

Not exceeling 384 square inches (2.67 square feet): 1897, 8 cents; 1909, 10 cents.

A bove 384 and not exceeding 720 square inches (2.67 to 5 square feet): 1897, 10 cents; 1909,121 cents.

Above 720 and not exceeding 1,440 square inches (5 to 10 square feet): 1897, 22 $\frac{1}{2}$

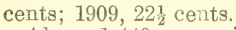

Above 1,440 square inches (10 square feet): 1897, 35 cents; 1909, $22 \frac{1}{2}$ cents.

The following table, showing the retail price of plate glass to consumers during each year 1906 to 1915, inclusive, was furnished by the Pittsburgh Plate Glass Co., which manufactures plate glass and sells it to consumers:

Table 82.-Rutail Prices of Plate Glass Per Square Foot, 1906 to 1915.

[Data from Pittsburgh Plate Glass Co., November, 1916.]

\begin{tabular}{|c|c|c|c|c|c|c|c|c|c|c|}
\hline Range. & 1906 & 1907 & 1908 & 1909 & 1910 & 1911 & 1912 & 1913 & 1914 & 1915 \\
\hline $\begin{array}{l}1 \text { to } 3 \text { square feet.... } \\
3 \text { to } 5 \text { sq'ware feet.... } \\
5 \text { to } 10 \text { square feet... } \\
10 \text { to } 25 \text { square feet.. } \\
25 \text { to } 50 \text { square feet. } \\
50 \text { to } 100 \text { square feet. }\end{array}$ & $\begin{array}{l}80.1875 \\
.225 \\
.36 \\
.41 \\
.42 \\
.45\end{array}$ & $\begin{array}{l}90.1875 \\
.225 \\
.36 \\
.40 \\
.41 \\
.44\end{array}$ & $\begin{array}{l}\$ 0.1875 \\
.225 \\
.36 \\
.39 \\
.408 \\
.432\end{array}$ & $\begin{array}{l}\$ 0.1875 \\
.225 \\
.36 \\
.39 \\
.40 \\
.43\end{array}$ & $\begin{array}{r}\$ 0.26 \\
.29 \\
.43 \\
.46 \\
.47 \\
.50\end{array}$ & $\begin{array}{r}\$ 0.22 \\
.26 \\
.39 \\
.42 \\
.43 \\
.46\end{array}$ & $\begin{array}{l}\$ 0.22 \\
.247 \\
.342 \\
.335 \\
.38 \\
.392\end{array}$ & $\begin{array}{r}\$ 0.22 \\
.26 \\
.36 \\
.38 \\
.40 \\
.41\end{array}$ & $\begin{array}{r}\$ 0.19 \\
.23 \\
.31 \\
.34 \\
.35 \\
.36\end{array}$ & $\begin{array}{r}\$ 0.17 \\
.20 \\
.29 \\
.32 \\
.34 \\
.35\end{array}$ \\
\hline
\end{tabular}

As shown by this table, the retail prices in 1915 were between 4 and 5 cents per square foot lower in each bracket than they were in 1912 .

In furnishing the data for 1906 to 1915, inclusive, supplemental to the data shown in Table 81, Mr. W. L. Clause, chairman of the board of directors of the Pittsburgh Plate Glass Co., wrote November 21, 1916:

The figures shown are intended to represent a fair average for the respective years. In some instances there was quite a wide range of prices prevailing at different portions of the year. In the years 1910 and 1911 the prices were somewhat higher than those prevailing in prior or subsequent years. These higher prices resulted from unusual conditions in the trade. For instance, in 1910 our own company lost by fire its largest works, thus taking out of the market an appreciable percentage of domestic supply. This, together with a strong and firm market, brought about the advanced price con- 
ditions as shown and which extended through a portion of 1911, thus affecting the retail prices during that year.

You will note, also, that no figures are shown for the year 1916, for the reason that we can not supply figures of this character before the end of the year. They will, however, be materially higher, due to the general and extraordinary business conditions prevailing.

The percentage of the so-called small-bracket glass (that is, under 10 square feet) produced and sold has ranged during a period of many years from 20 to 25 per cent of the total production, varying from year to year on account of peculiar conditions experienced in the various factories in the United States. On the other hand, the sales of small-bracket glass range from 60 to 70 per cent of the total production. In the year 1915, which was a fair, average year, our company's sales of small glass amounted to 64.49 per cent under 10 square feet; 1916 bids fair, from present indications, to exceed the percentage shown in 1915. It is obvious from the foregoing figures that of the total production 40 to 45 per cent manufactured as large glass is, of necessity, cut down and sold in the small brackets.

During the fiscal year ending June 30, 1914, the value of the imports of plate glass, cast, polished, finished, or unfinished, and unsilvered, or the same containing a wire netting within itself, was $\$ 265,909$, and during the fiscal year ending June 30, 1915, the amount was $\$ 38,757$.

In spite of the almost entire cessation of such imports on account of the war, the prices of plate glass were lower during the months from February to July, 1915, than ever before in the history of the trade. Afterwards prices increased, and after August 25, 1915, they increased greatly, as shown by the following table:

Table 83.-Prices per Square Foot of Glazing Sizes of Plate Glass.

[All prices are f. o. b. factory, freight equalized from nearest factory to point of destination on all quantities.]

\begin{tabular}{|c|c|c|c|c|c|}
\hline Bracket. & $\begin{array}{c}\text { St. Louis } \\
\text { Plate Glass } \\
\text { Co., Valley } \\
\text { Park, Mo., } \\
\text { Aug. 25, } \\
1915 .\end{array}$ & $\begin{array}{l}\text { Edward } \\
\text { Ford Plate } \\
\text { Glass Co., } \\
\text { Rossford, } \\
\text { Ohio, May } \\
\text { 23, 1916. }\end{array}$ & Bracket. & $\begin{array}{l}\text { St. Lonis } \\
\text { PlateGlass } \\
\text { Co., Valley } \\
\text { Park, Mo., } \\
\text { Aug. 25, } \\
1915 .\end{array}$ & $\begin{array}{l}\text { Edward } \\
\text { Ford Plate } \\
\text { Glass Co., } \\
\text { Rossford, } \\
\text { Ohio, May } \\
\text { 23, 1916. }\end{array}$ \\
\hline
\end{tabular}

Plate glass and wire glass are made both to fill orders and for stock. Orders are usually placed three months in advance of delivery. Opalescent glass is made chiefly for stock because orders usually call for immediate shipment; formerly there were more advance orders.

\section{BOTTLES.}

The production of bottles and jars is not only larger but is more widely distributed than the production of other varieties of glass or glassware. Table 8 , page 28 , shows that, according to the Census of Manufactures, the value of the production of bottles and jars was $\$ 21,676,791$ in $1899, \$ 33,631,063$ in $1904, \$ 36,018,333$ in 1909 , and $\$ 51,958,728$ in 1914 . During the 15 years the increase was 139.7 per cent. In examining these figures it should be remenbered that automatic machines for making bottles and jars were introduced in 
1903. The number of such machines used in 1904 was inconsiderable, and although quite a number of machines were installed during the next five years, the increase of production from 1904 to 1909 was much smaller than from 1899 to 1904 .

The imports of bottles have had but little effect on domestic production. The value of the imports of empty bottles and vials and demijohns and carboys entered for consumption was $\$ 211,729$ during the fiscal year ending June 30,1913 , and $\$ 217,995$ during the following fiscal year, the new tariff having gone into effect on October 4, 1913. The value of filled bottles, vials, jars, demijohns, and carboys imported for consumption during the fiscal year 1914 amounted to $\$ 966,610$.

\section{PRODUCTION AFFECTED BY MACHINERY.}

The disturbing factor in the manufacture of bottles during the years since 1903 has been the automatic bottle-blowing machine. The Owens machine is called automatic, because it requires no skilled labor to operate it. The only attendant is a mechanic, who oils the machine and sees that it runs properly, and whose wages are not equal to those of blowers or hand machine operators. A boy takes off the ware when no automatic conveyor is used. The first automatic had six arms, each arm having a pair of molds, and six bottles were made with one complete revolution of the arms, at the rate of 12 or 14 bottles a minute. Later, machines were equipped with 10 arms, and more recently with 15 arms. The 15 -arm machines can turn out 60 bottles a minute. In making the smaller sizes of bottles, the mold on each arm is cut for three small molds, so that 180 small vials are produced a minute by a 15 -arm machine.

Shortly after the introduction of the Owens automatic machine other bottle machines were introduced, the first one being an English machine. These machines were small and cost considerably less than the Owens machines, but their output was much less, and manufacturers that used them could not compete with manufacturers using automatic machines in filling large orders. The machines other than the Owens are called hand machines; they are called, also, three-man machines, because three skilled men are required to operate each. They have been largely superseded by two-man machines, and more recently one-man machines requiring only one skilled operator for each have been introduced. The one-man machines are called semiautomatic. In some plants three skilled men are employed on two machines. Notwithstanding the improvements in the hand machines so that they can be operated by only one man, the manufacturers using them still find great difficulty in competing with manufacturers that use Owens machines, except on comparatively small orders. The keenness of this competition was assigned as a reason why a large number of establishments have quit business.

The Glass Bottle Blowers' Association is composed of the skilled workers that blow bottles in hand molds, or who operate hand machines, including the semiautomatic. It is organized in only a few of the plants using Owens machines, in which no skilled labor is required, or in plants using the flowing process, in which less skilled labor is required than in plants using the hand machines. 
Demnis 1. Hares, nutional presiclent, in his report to the annual conrention of the association, held in 1915, said:

Shortly after the introduction and installation of the automatic machine, there appeared on the market what is known as the United or English machine for making narrow-mouth ware. A list was adopted by our executive board during the season of 1908 and 1909 covering rounds and ovals, there being no other kinds of ware made on it up to that time.

In many establishments that use the hand machines bottles are also still blown entirely by hand to fill small orders. President Hayes's report to the convention is 1915 said:

In nearly every bottle factory on the American continent there are one or more machines, and those factories not having them will either have to install them or be forced out of business. So it is but natural to assume that manufacturers in order to protect their investment will endeavor to equip their factories with bottle machines. Machines to make narrow-mouth ware are being perfected and simplified to such an extent that it is possible for the man operating them to make first-class wages. To date, however, I know of no machine except the automatic that is capable of producing small ware successfully, especially that of the prescription variety. By "successfully" I mean in commercial quantities.

The number of machines making wide-mouth bottles and jars is given as 193 , employing approximately 700 men; 98 of these machines are operating semiautomatically, employing three men to two machines, at an average wage of $\$ 5.65$ per day. This is an increase of 446 machines over the previous season. There are reported 116 of the United and 0 'Neill machines operating on beer, soda, grape juce, catsup, and ammonia bottles, employing 669 operators at an average daily wage of $\$ 4.75$. There are 86 machines reported employing two men and 63 employing one man, making miscellaneous narrow-mouth ware at an approximate wage of $\$ 6$ per day.

Another invention, in addition to the Owens automatic machine, which had a great effect on the bottle industry was the flowing process. It dispenses with the skilled man that gathers the glass, and is operated with less labor cost than are the machines which require a hand gatherer. The flowing device was patented by Homer Brooke in 1903, and by 1910 it was used in several large establishments. The principal patents on the Owens machine and on the flowing device will not expire until about 1920 .

It is not known what proportion of the bottles produced is manufactured by Owens machines or by the flowing process, but it is probable that the production by both automatic machines and the flowing device largely exceeds the production both by hand machines and entirely by hand. Nearly all of the successful establishments that manufacture with hand machines or entirely by hand are unusually favorably located with reference to cheapness of fuel or accessibility to markets, and nearly all of them manufacture to fill much smaller orders than are accepted by establishments using Owens machines or the flowing process. The manufacturers employing automatic machines of flowing processes, because of the comparatively low price of their product require large orders to insure continuous uninterrupted production.

\section{NUMBER OF ESTABLISHMENTS AND THEIR EQUIPMENT.}

The following table shows, as far as reported, the number of establishments manufacturing bottles and jars in the United States that were operated in 1916, and details about their equipment, not including establishments using Owens machines. 
Table 84.-Location and Number of Plants Making Bottles, Jars, etc., in 1916, and Number of Their Tanks, Rings, and Pots, not Including Plants Using Automatic Machines.

[Data from Glass Factory Directory, 1916.]

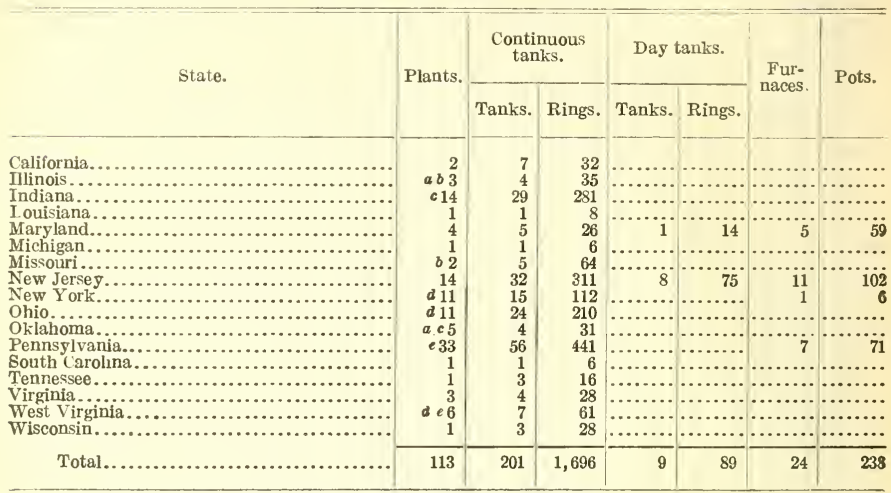

a Tanks and rings of 1 plant in Oklahoma included with Illinois. $b$ Tanks and rings of 1 Illinois plant included with Missouri.

$c$ Tanks and rings of 1 plant in Oklahoma included with Indiana.

$d$ Tanks and rings of 1 plant in New York and 1 in West Virginia, included with Ohio.

$e$ Tanks of 1 plant in West Virginia included with Pennsylvania.

\section{NUMBER OF AUTOMATIC MACHINES.}

The report of President Hayes in 1915 shows that the number of automatic machines in the United States and Canada was then 182, an increase over 1914 of 10 machines, and that of these 169 were operated in the United States and 13 in Canada. His report in 1916 shows that the number was then 193, an increase over 1915 of 11, and that of these 180 were operated in the United States and 13 in Canada.

The number of Owens machines used in the United States in November, 1916, were as follows:

Table 85.-Owens Bottle Machines Installed in the United States.

[Reported by the Owens Bottle Machine Co., November, 1916.]

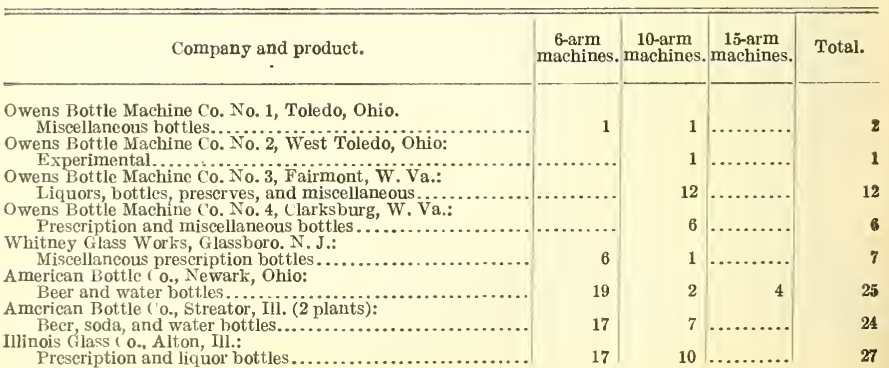


Table 85.-Owens Botrle Machines Installed in the United States.-Con.

Company and product.

6-arm 10-arm 15-arm machines. machines. machines.

Illinois Glass ('o., Gas City, IIl.:

Miscellaneous prescription bottles, fruit jars, paskers, and

preservers.............
Ball 1Bros., Muncie, Ind :

Ifason fruit jars, packers, and preservers..................... $14 \quad 2 \quad 2$

Ball Bros., Wichita Falls, Tex.

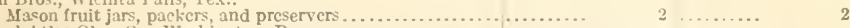

Hazel-At las Glass Co., Washington, $\mathrm{Pa}$.:

Preservers and miscellancous bottles.

Hazel-Atlas Glass Co., (larksburg, W. Ta.:

Proprietary medicine ware and jars. .

Hazcl-Atlas Glass Co., Grafton, W. Va.:

Bottles,.........................

Chas, Boldt Co., Cincinnati, Ohio:

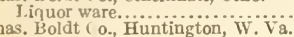

Iiquor ware......................

Thatcher Manufacturing Co., Eimira, N.

Milk jars.............................

Thatcher Mars................................

H. J. Heinz Co., Sharpsburg, $\mathrm{Pa} .:$

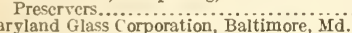

Maryland Glass Corporation, Baltimore, Md.:

Macheth-Evans Glass Co., Bethaven, $\mathrm{Pa} .:$

Experimental.

D. C. Jenkins Glass co., Kokomo, Ind.:

Experimental.

Total.

\author{
.
}

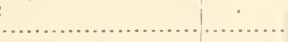

$1 \quad 10 \ldots \ldots \ldots .11$

$1 \quad 2 \quad \ldots \ldots \ldots \ldots . .3$

3

$3 \ldots \ldots \ldots$.

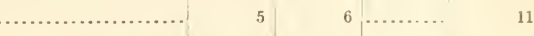

:

....

..............

(2.

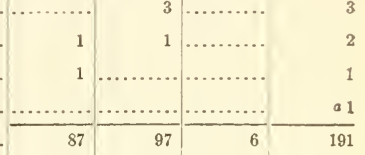

a Special machine.

This table shows that the Owens Bottle Machine Co. itself operates four plants, one each in Clarksburg, W. Va., and Fairmont, IV. Va., and two small plants in Toledo, Ohio. This company also owns the controlling interest in the plant of the Whitney Glass Works at Glassboro, N. J., and in 1916 it took over the three very large plants of the American Bottle Co. at Streator, Ill., and Newark, Ohio. These eight plants now operated by the Owens Bottle Machine Co. use 77 of the 191 automatics that are used in the United States. The other 114 automatics in the United States are operated by 9 establishments with 16 plants. Late in 1916 the Owens Bottle Machine Co. took over the three plants of the Graham Glass Co., located at Evansville, Ind., Loogootee, Ind., and Okmulgee, Okla.

The 13 automatics in Canada are operated by one company with four plants. In 1916 there were 40 Owens machines in use in Europe, and at the close of the same year: automatics were being installed in factories in Japan, the patent rights having been purchased from the Owens Bottle Machine Co. Prior to 1916 the Owens Bottle Machine Co. had issued capital stock to the anount of $\$ 7,000,000$. After taking over the two plants of the American Bottle Co. in 1916 , the stock issue was increased to $\$ 50,000,000$ and the stock was listed on the New York Stock Exchange.

Undoubtedly more manufacturers would use Owens machines than now employ them but for the fact that they can not procure these machines either by buying them or renting them on a royalty basis. The Owens Bottle Machine Co. charges royalty on machines that it supplies to manufacturers, and it has issued licenses for their 
use to only a few establishments, and each establishment that uses its machines is restricted to using them for only the particular line of bottles covered by its license.

Several flowing devices are used, but the one most largely used is covered by the Homer Brooke patents, which are controlled by the Hazel-Atlas Glass Co. President Denis A. Hayes, in his report to the annual convention of the Glass Bottle Blower's' Association held in 1916, said:

Since we first reported on this phase of the bottle-making industry rapid strides have been made in its development, and with the close or the past season there were 10 or 12 firms making bottles and jars by the flowing method. In these days of keen competition, manufacturers are taking advantage of every opportunity to reduce the cost of production, so no one was surprised to learn that the flowing process was in use commercially with varying degrees of success. While fully realizing the importance of this invention to the manufacturer, we should use every honorable means toward securing for our members the right to operate it.

Bottles are made in such infinite number of shapes and sizes that most of them are made only on orders. Some manufacturers never manufacture for stock, while others try to keep on hand a stock of the more standard styles to fill immediate orders and to fill orders received during the summer shutdown. In normal times large buyers generally place contracts for their yearly requirements with options on increases. Single-car orders are generally placed a few weeks ahead of delivery dates, while small orders are often for immediate delivery. During 1916, when prices of raw materials and of the finished product were advancing rapidly, manufacturers discouraged long contracts. Packers and preservers are made almost exclusively to fill orders.

\section{THE PROBLEM OF STANDARD CAPACITY.}

The principal reason that bottles are made in such a great variety of shapes and sizes is that many manufacturers of proprietary preparations have sought to make their products better known by putting the goods up in bottles of unique shapes that would be readily associated with the product. During recent years, however, there has been a tendency toward the standardization of shapes and sizes, and this tendency has been increased by the greater production of bottles by machinery. The expense of making molds is a considerable proportion of the total expense of manufacture when the orders are small, and when automatic machines are used from 6 to 15 sets of molds must be made for bottles of each size and shape. The manufacturer, therefore, can quote lower prices for bottles of standard varieties than for bottles of special designs.

Bottle manufacturers have had trouble in meeting the requirements of different State bureaus of standards and of official sealers in some cities in regard to the capacity of bottles. It is practically impossible to manufacture bottles each of which will have exactly the same capacity, and it is more difficult to make them uniform in this respect by hand than by any kind of machine. Some States and cities allow a smaller variation in capacity than others.

The Bureau of Standards of the United States Department of Commerce, under authority of Federal laws, fixes the standards of weight and measure, but it does not specify what variations in the capacity of containers shall be allowed by the various States or 
cities. Harry Jenkins, executive officer of the Glass Bottle Blowers' Association, said in his report to the annual conrention of the association held in 1915:

I am pleased to say that in dealing with the officials in Washington we are invariably accorded the most patient and courteous treatment. The Bureau of Standards, the department haring charge of all the weights and measures, is doing a wonderful work in this particular line. Four times a year it holds a convention to whicll are invited all the sealers in the United States and the insular possessions, and this invitation includes also anyone who may be interested in this line of work, and all who attend may take part in the discussions and offer whatever suggestions they may deem to be of interest or benefit to the purchasing public. As many as 96 men have attended these conventions, and all seem to be actuated by the same motive-to give to the consumer full value for his money.

The Glass Bottle Blowers' Association has gone on record in favor of a Federal law that will provide for uniform variations in the capacity of containers in all States. A bill with such provisions, H. R. 16876, was introduced in the Sixty-third Congress by Representative William A. Ashbrook, of Ohio. A report of the committee on political protest and injunction, adopted by the convention of the Glass Bottle Blowers' Association held in 1915 contains the following paragraph:

That a glass container capacity law be enacted which will be uniform in all States, with such tolerances that a manufacturer employing hand operators can compete with a manufacturer using machines and thereby allow the workmen an opportunity to earn an honest livelihood.

\section{President Denis A. Hayes, in his report to the 1916 convention, said:}

Most of the States and large cities have laws that allow fair tolerances on containers; then, too, officials are not expecting the impossible in the way of perfect and accurate measure, and our association has done much to make them fully realize the inability of the men of our craft to make an absolutely correct bottle in contents.

\section{LOCALIZATION OF THE INDUSTRY.}

The following article in regard to the development of the bottle industry was contributed by Mr. Herbert B. Garwood, president of the Williamstown Glass Co., Williamstown, N. J.

The glass-bottle manufacturing industry was naturally started on the Atlantic seaboard, because that was the first portion of the country to be settled. In the early days it was confined to the southern part of New Jersey, because sand was found there suitable for glass making, extensive tracts of timber furnished not nnly fuel and boxing material, but the wood ashes when bleached made the potash which was needed for flux. The Delaware River oyster beds furnished the oyster shells from which lime was made, the salt marshes adjoining the coast and river furnished the salt hay used in packing the bottles in the boxes, and the clay beds supplied the materials for the common brick and furnace stone used in building the furnaces. The higher grades of refractory stone were made from German clay which was shipped into Philadelphia and New York, and the proximity of those cities not only made it easy for the skilled glass blower from the Old World to find his way to a new place of employment in his old occupation, but supplied the markets which took care of the output of the little plant.

As the iron business changed to steel and found its way to the Pittsburgh region, on account of cheaper fuel and raw material, so glass followed; and the introduction of soda ash or carbonate of soda in place of potash, and of coal instead of wood, of limestone instead of oyster-shell lime, made Pittsburgh equally well adapted for the industry, except for the higher freight rates to eastern markets, a disadvantage offset by the cheaper price of materials. Next the Indiana gas belt, with its cheap fuel, and the mountain region of northwestern Pennsylvania, with cheap oil and natural gas, attracted many manufacturers, and to-day the newer gas fields in West Virginia with their natural gas at 5 to 6 cents per thousand feet has drawn many manufacturers 
of bottles to that State. During this period the bottle manufacturing industry gained a foothold in many isolated sections and in some instances have held them. To-day the principal centers of the industry are, in their order from east to west, southern New Jersey, Baltimore, Md., Pittsburgh district, northwestern Pennsylvania or mountain district, West Virginia district, middle Ohio district, Indiana gas-field district, and the St. Louis district.

The grade of goods manufactured in each district is about the same, because, except in isolated cases, the glass-bottle business has not as yet been highly specialized, a large percentage of the manufacturers continuing the practice of making all lines of bottles. In milk jars, beer bottles, and some high-grade toilet ware the industry has been specialized to a greater or less extent, and in fruit jars it has been entirely specialized and centralized at Washington, Pa., and Muncie, Ind., and is now being introduced in Texas and Oklahoma.

Manufacturing at this time (January, 1916) appears to be increasing in no particular locality. Within the last few years the greatest increase has been in the West Virginia district, due to the cheap fuel.

The advantages regarding markets are naturally with the southern Jersey district, whose manufacturers are able to make overnight deliveries in New York, which is the largest glass-consuming city in the United States, in Philadelphia, another large purchaser, and 48-hour deliveries in Boston, Baltimore, and Washington, although to the two latter points the Baltimore city factories enjoy the advantage.

The Pittsburgh and mountain district factories naturally enjoy the trade of the cities in the Pennsylvania coal region and the manufacturing towns in central New York, as well as Buffalo and Rochester. The Ohio factories appear to ship to all parts of the country, and in a short time that State will be used only by the manufacturers of beer bottles and some few sundry lines. The Indiana and St. Louis factories seek the cities of the middle West and the South, they enjoying better freight rates to the interior of the South than any other factories. These factories also ship west, but two plants on the Pacific coast and several in Oklahoma in scattered locations are now disputing for that trade.

The New Jersey factories formerly controlled the southern coast line below Norfolk, but a revision of freight rates from West Virginia factories on a combination rail and water route by Norfolk has placed them on an equality with the New Jersey factories and allowed them to compete for the trade of that section.

No section at this time appears to enjoy any ad vantage regarding labor. The skilled workmen are practically all members of the Glass Bottle Blowers' Association, which fixes a wage scale every summer for the ensuing year that is uniform throughout the country, and the supply of skilled labor exceeds the demand, owing to automatic machines displacing many glass blowers, therefore an adequate supply of handworkmen or semiautomatic machine operators can always be secured in any section of the country. In unskilled labor one advantage in one section is balanced by another advantage in another section. Thus in New Jersey boys work for lower wages than in the middle West, but in the spring they leave to work on the farms, and the manufacturer is thereby crippled. In the West the higher wages continue throughout the year, but the boys do not leave in the spring to such an extent as they do in New Jersey. The recent activity in powder works and munition plants have drawn many boys from the glass factories to those industries in the eastern section of the country.

\section{PRESSED AND BLOWN WARE.}

Pressed and blown ware includes tableware, cut glass, bar goods, lighting goods, and miscellaneous ware. Table 8, page 28, shows that according to the Census of Manufactures the value of the production of pressed and blown glass was $\$ 17,076,125$ in 1899 , $\$ 21,956,158$ in $1904, \$ 27,398,445$ in 1909 , and $\$ 30,279,290$ in 1914 . During the 15 years the increase was 77.32 per cent.

NUMBER, LOCATION, AND EQUIPMENT OF PLANTS.

The following table shows, as far as reported, the number of establishments manufacturing pressed and blown glassware in the United States that were operated in 1916, and gives details of their equipment: 
Table 86.-Location and Number of Active Plants Mandfacturing Blown and Pressed Tableware, Lighting Goods, and I,amp Cummers, and Detarl of EquipMENT.

[Data from Glass Factory Directory, 1916.]

State and product.

Indiana:

Tablemare.

Tableware and lighting goods....

Lighting goods.........................

Iarrland:

Tablew:are...

Lighting goods...............

Massach'isetts:

Tableware....................

Tableware and lighting goods..............

New York:

Tableware and lighting goods.

Ohio:

Lighting and lighting goods.............

Tableware.

Tableware and lighting goods..............

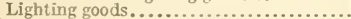

Oklahoma:

Tableware and lighting goods.............

Lighting goods........................

Pennsylvania:

Tableware.

Tableware and lighting goods

Lighting goods.

Lamp chimneys.

IThode Island:

Lighting goods.

West Iirginia:

Tableware.

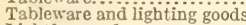

Lighting goods.

Lamp chimneys.

\section{Aggregate:}

Tableware.

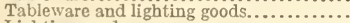

Lighting goods.

Lamp ehimneys.

Total.

\begin{tabular}{|c|c|c|c|}
\hline lants. & $\begin{array}{l}\text { Continuous } \\
\text { tanks. }\end{array}$ & Day tanks. & Fur- \\
\hline times. & anks. Irings & anks. Rings. & naces. \\
\hline
\end{tabular}

\begin{tabular}{|c|c|c|c|c|c|c|}
\hline 3 & 6 & 37 & & & & \\
\hline $\begin{array}{l}b 3 \\
b 3\end{array}$ & $\mathrm{i}$ & $\overline{8}$ & 1 & $\begin{array}{c}4 \\
\dddot{2}\end{array}$ & $\begin{array}{l}2 \\
2\end{array}$ & $\begin{array}{l}24 \\
30\end{array}$ \\
\hline $\begin{array}{l}1 \\
1\end{array}$ & 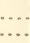 & & $\ldots$ & 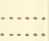 & $\begin{array}{l}1 \\
1\end{array}$ & $\begin{array}{l}14 \\
14\end{array}$ \\
\hline $\begin{array}{l}1 \\
1\end{array}$ & & & 1 & & $\begin{array}{l}3 \\
2 \\
2\end{array}$ & 33 \\
\hline 2 & 2 & 13 & 3 &.. & 13 & 186 \\
\hline 8 & 7 & 66 & 2 & 7 & 9 & 128 \\
\hline $\begin{array}{l}\begin{array}{l}a \\
b 4 \\
b 4\end{array}\end{array}$ & $\begin{array}{l}3 \\
2\end{array}$ & $\begin{array}{l}35 \\
17\end{array}$ & 3 & 7 & $\begin{array}{r}8 \\
11\end{array}$ & $\begin{array}{l}124 \\
153\end{array}$ \\
\hline $\begin{array}{l}1 \\
2\end{array}$ & $\begin{array}{l}3 \\
2\end{array}$ & $\begin{array}{l}18 \\
22\end{array}$ & & $\ldots$ & 1 & 12 \\
\hline 9 & & & 5 & 8 & 22 & 272 \\
\hline $\begin{array}{lll}\begin{array}{lll}a \\
b\end{array} & 14\end{array}$ & $\begin{array}{l}4 \\
2\end{array}$ & 44 & $\frac{2}{17}$ & $\begin{array}{r}2 \\
12\end{array}$ & $\begin{array}{l}21 \\
26\end{array}$ & $\begin{array}{l}451 \\
303\end{array}$ \\
\hline 1 & 1 & $\dddot{5}$ & 1 & & & \\
\hline 1 & & . & & .. & 2 & 16 \\
\hline $\begin{array}{l}9 \\
5\end{array}$ & $\begin{array}{l}8 \\
1\end{array}$ & $\begin{array}{r}65 \\
6\end{array}$ & 7 & 4 & 11 & 146 \\
\hline $\begin{array}{l}2 \\
4\end{array}$ & $\begin{array}{l}3 \\
2\end{array}$ & & $\begin{array}{l}2 \\
2\end{array}$ & $\begin{array}{l}3 \\
1\end{array}$ & $\begin{array}{l}5 \\
2\end{array}$ & 62 \\
\hline & & & & & & \\
\hline $\begin{array}{l}31 \\
29\end{array}$ & $\begin{array}{l}21 \\
13\end{array}$ & $\begin{array}{l}168 \\
116\end{array}$ & 11 & $\begin{array}{l}15 \\
10\end{array}$ & $\begin{array}{l}46 \\
57\end{array}$ & $\begin{array}{l}593 \\
943\end{array}$ \\
\hline 26 & 11 & 47 & 25 & 22 & 54 & 653 \\
\hline & & & & & & \\
\hline 92 & 48 & 348 & 47 & 50 & 159 & 2,200 \\
\hline
\end{tabular}

a Equipment of 1 plant in Indians and 1 plant in Ohio ineluded with Peansylvania.

$b$ Equipment of 2 plants in Indiana and 1 plant in Ohio ineluded with Pennsylvania.

The establishments entered in this table as making tableware made tableware, cut glass, bar goods, and chemical ware; the establishments cntered as making tableware and lighting goods made both products; some of the establishments entered as making lighting goods made lamp chimneys also; the establishments entered as making lamp chimneys made them only.

Tableware is made mostly to fill orders, but when orders are not received the factory makes staple articles for stock. Orders may be for delivery in 30 days, but most of them are for immediate delivery. Lighting goods are made both for orders and stock. Some orders are placed two or three months in advance of shipment, but many are for immediate delivery.

\section{CUT TABLEWARE.}

There are two kinds of cut glass, light or engrared, and heary or deep cut. Articles such as stem ware, vases, bowls, nappies, plates, benbons, colognes, etc., are thin cut or engraved, in designs ranging 
from the common unpolished wheel engraving, which can be purchased in the 5 and 10 cent stores, to elaborate designs, known as "rock crystal." The cutting or engraving on these articles is generally on blown blanks. Heavy or deep-cut glass consists of two grades, one cut on blown blanks, the other cut on pressed or molded blanks, which are made either plain or with a large part of the pattern pressed in them.

Glassware cut on blown blanks usually consist of such items as stem ware, decanters, vases, pitchers, oil cruets, colognes, and other articles in such shapes as to render them impractical for pressing or molding. Pressed or molded blanks can be used only for open pieces, such as bowls, nappies, plates, etc., which can be readily pressed by the use of a plunger, as in the ordinary common pressed glassware.

\section{SUPERIORITY OF AMERICAN CUT GLASS.}

While considerable thin cut or engraved glass was imported before the war in Europe began, very little heavy cut glass was imported. The discriminating American public seems to be satisfied that the heavy cut glass manufactured in the United States is superior to similar ware made in Europe. This opinion has generally prevailed for many years. The popularity of American cut glass was established by a splendid display made by a glass company at the World's Columbian Exposition held at Chicago in 1893. This company made an elaborate exhibit, which showed the actual process of cutting. Since that time the quality of American goods, aided by attractive advertising, has firmly convinced the public that nothing finer is made in the line of heary cut glass than is made in this country.

American cut-glass manufacturers have prided themselves on the quality of their product. It has surpassed that of any other country for crystal brilliancy and sharpness of cutting. Potash and oxido of lead have been used extensively, the potish to flux the other materials, and both potash and lead to give to the glass a prismatic effect with high refractory qualities. The product was so artistically beautiful that the reputation of American cut glass became worldwide. Before the war began in 1914 it was sold in all parts of Europe. Since the war began the quality has necessarily suffered, because it has been impossible to replenish depleted supplies of potash, but this defect will be remedied when potash can again be imported.

Some poople accustomed to traveling abroad are inclined to believe that cut glass from Europe is superior in quality to the best American product. An Amorican munufacturer of cut glass who has a salesroom in New York City informed an agent of the Bureau that two years previously a wealthy woman called at the factory and showed him a glass article which had been broken. She stated that she had purchased the set at one of the fine shops in Vienna and inquired whethor this company had not imported a similar set from which the broken article could be duplicated. The manufacturer examined it closely, and informed her that his salesroom in New York had a similar article in stock and that it would be shipped to her. The cut-glass products of this factory had been exported in considerable quantities to Austria-Hungary, and the broken article that was duplicated had really been made in the American factory. 


\section{IMPORTS AND EXPORTS.}

The duty on ornamented glass, which includes cut glass, was 60 per cent ad valorem under the tariff acts of 1897 and 1909, and is 45 per cent under the present tariff law. Deep-cut glass made in Europe has been almost entirely excluded from the United States under these tariffs. The duty, together with tho fact that the American people have been educated to prefer the American deep-cut glass, may explain why the imports have been decreasing and are now very small. Many more original designs for cut glass are made in America than in Europe, and many of theso designs are taken abroad and imitated.

The sole American agent of one of the most famous tableware factories in the world kept, for several years, a separate account of his imports of heavy cut glass. This agent imported such cut glass to the amount of $\$ 99,273$ in the year ending June 30, 1S93, and these imports declined to $\$ 14,473$ in the year ending June 30, 1901. After the latter date he did not keep a separate account of such imports, but he stated to an agent of this Bureau that they had declined to not over \$2,000 during the 12 months last preceding the beginning of the war in Europe, and that they consisted mostly of special articles.

The fact that before the war began in Europe there were considerable exports of American cut glass to European countries is not easily explained, except on the ground that the American product is recognized in those countries as of superior quality or on the ground of cheaper production in the United States.

Wages of glass cutters are much higher in America than in Europe, and it is remarkable that deep-cut glassware made in artistic designs by highly skilled hand labor should be produced for export at a cost which would make it possible for ware from the United States to compete with the product of factories in European countries. The countries to which American cut glass is exported include countries that produce deep-cut glass and that have high duties on their imports.

\section{METHODS OF MANUFACTURE.}

Cutting designs on glass forms is done by holding the forms against revolving wheels. In the first process, called roughing, the cuts are made with a steel wheel, on which sand and water are poured; in the second process a stone wheel is used for smoothing the cut, and in the third a felt wheel is used for polishing. The wheel used for smoothing is made of a Scotch stone called Craighleith, which is either white or black, but the black stone is preferred because it is softer.

Several reasons are assigned for the cheaper production of cut glass in the United States than in Europe: (1) American glass cutters, being paid piece prices in most cases, work faster than European cutters; (2) in Europe roughing, smoothing, and polishing are of ten done by the same workman, but in the United States the work is divided among three men, and each becomes an expert in one process; (3) in America labor-saving devices and methods are employed that are not used in Europe. 
Where figured or pressed blanks are used, roughing is eliminated entirely, as are also the time and expense of marking the pattern on the glass, which is required when plain blanks are cut. Blanks figured by pressing are made by two large factories in the United States, under a patent which they control. Other factories making cut glass use plain blanks which are pressed by iron molds or are blown offhand.

American manufacturers produce cut glass in designs that can be easily cut on large stones; that is, designs with only few curved lines. Where the designs are intricate and the lines curved, they are cut by small stones, called small-tool work, and the time required is much greater than where large stones are used.

For the process of smoothing, carborundum wheels and carborundrum powder or grains are largely used in America, instead of stone wheels and sand, which are commonly used in Europe.

In America the ware, after being smoothed, is dipped in acid for polishing, instead of being polished by a felt wheel and putty powder, as is customary in Europe. The use of acid in polishing has a great advantage, not alone in the saving of labor, but in adding much more brilliancy to the glass. The explanation of this is that in polishing by hand with the felt wheel and putty powder the sharp cuts are more or less dulled by friction, whereas in using the acid these cuts retain their sharpness, and, as a result, the glass has more refractory power, thus adding greatly to its brilliancy.

Deep-cut glass is much more extensively used in America than in other countries. Each design that is produced in Europe is made up in small quantities, and more exclusive designs are made there than in America. Much larger quantities of each design are made in America, and, although cutting is done by hand, the cutter that cuts the same design many times learns to do it rapidly.

An importer gave to an agent of the Bureau some examples of the difference in the cost of producing deep-cut glass in America and Europe. This foreign factory makes both heavy and light cut glass and exports much of the light cut ware to the United States. The agent said in an interview:

One reason why deep-cut glass is made cheaply in America is that it is produced in large quantities. There is no such demand for heavy cut glass as there is here, becarse thin cut glass is more popular in Europe. Another reason is that, while Amsrican cutters are paid higher wages than cutters in Europe, they work much faster.

About seven years ago I bought from a glass manufacturer in Brooklyn a 9-inch deep-cut glass bowl for $\$ 2.50$, wholesale price, and took it to the factory in Alsace. A wood mold was made for the form and the form was pressed and cut in the same design as the bowl made in Brooklyn. The cost of this reproduction was 15 francs $(\$ 2.90)$ without the cost of the mold.

I import some blanks for deep cutting. I sold the Brooklyn manufacturer an imported blank for a 3-pint jug, which cost here $\$ 1.25$, duty included. He cut it and sold it back to me for $\$ 5$, and I took it to the factory in Alsace. A similar blank there was cut in the same design and the cost was 40 francs (\$7.72).

Five years ago I saw a window full of American deep-cut glass in Strassburg, the capital of Alsace-Lorraine. After that I quit trying to compete in New York with American cut glass. 
IMITATION CUT GLASSWARE.

Among the manufacturers of high-grade eut glass there is much complaint about imitations, with which many people are deceived. Following is an extract from an article by .J. Howard Fry, published in the Glassworker for June 3, 1916:

Iany imitations of real cut glass, on account of the substituting of inferior blanks, are being forced on the market at this time. At the best lime glass, even if properly cut, is inferior, and it is only an imitation of what real cut glass represents. Infortunately, owing to the European war making it impossible for lead-blank manufacturers tn maintain the former high standard of quality, a field is opened for imitations, which otherwise would not exist. The widesprearl popularity of rich cut glass leads to the production of a great deal of cheap ware and imitations of real cut glass.

And unfortunately, again, the idea seems to prevail among some glass manufacturers that cut glass is not a work of art. that it is not a science, and is not worthy of their best effort:. Thay are offering to the unsuspecting public a cheap imitation of cut glass which is not only on a lime blank, but of ten deception is practiced in fooling the public by not cutting all the design. ('ertain parts, such as flowers in the frosted or light skin cut, are placed in the blank, while the leaves or miter and heavy parts imitate cutting, but it is simply pressed glass, sometimes of a very good finish, sufficient to deceive the unsuspecting public, who buy this as good cut glass only to learn later that frand had been practiced.

It is absurd to predict just where this practice will lead to, but it is not difficult to see that if it is continued the higher ideals for which cut glass stands will be lost and the industry as an art will be ruined. The public should be educated to detect the fraud, and until this takes place the market will undoubtedly be flooded with all varieties of cheap imitations.

\section{INCANDESCENT LAMP BULBS.}

A great impetus was given to the development of the manufacture of lighting glassware by the wonderful and successful experiments conducted by Thomas A. Edson, in perfecting his first commercial incandescent lamp, which appeared in 1879. In 1880 the regular manufacture of incandescent lamps was begun in Menlo Park, 1 . J., and during that year 25,000 lamps were made. By 1885 electric lighting became very general, and the manufacture of lighting goods became an important branch of the glass industry. The aggregate production of electric lamps for domestic use totaled about 125,000,000 during the year 1915 and a considerably larger number in 1916.

The incandescent lamp is the one of all electrical appliances most unirersally used, and is available for the lighting of homes, industrial plants, stores, streets, parks, billboards, automobiles, trolley cars, and railway cars.

\section{TYPES OF LAMPS.}

Incandescent lamps are divided into four classes, according to the kind of filament-carbon, Gem, tantalum, and Mazda.

The number of materials which can be used for filaments is very small, for these reasons: First, the filament must be capable of withstanding a very high temperature, and it must also have a high vapor tension point; in other words, it must not evaporate rapidly much below its boiling point; second, it must be a conductor of electricity, and should have a relatively high resistance.

Filaments were made at first from parchmentized thread and thin slips of cardboard and paper, and later from bamboo. For many years the bamboo filament, cut into strips by small knives 
and planes, was exclusively used. The cutting required great care and expense before the filaments were reduced to the required sizes. The bamboo strips were then carbonized.

After bamboo filaments were used squirted filaments were made from carbonized cellulose in one form or another.

Another advance was embodied in lamps still of the carbon type in which the filaments were strengthened by such substances as would justify calling them "metallized." The mere word was a revelation as to the direction in which invention was tending, and very quickly real metallic filaments were available. The metal tantalum was quite rare and useful in many ways, but did not compete successfully with the old carbon lamp.

In 1907 the tungsten lamp appeared, fairly startling the world with its wonderful efficiency, and nearly revolutionizing the incandescent lamp industry. The most recent development in high efficiency illuminants are the Mazda lamps, a trade-mark used by some of the largest manufacturers of incandescent lamps in the United States.

MANUFACTURE OF BULBS.

Glass bulbs for incandescent lamps are made in only five plants in the United States - the General Electric Co., the Libbey Glass Works, the Corning Glass Works, the Rochester Tumbler Works, and the Lippincott Glass Co. It is estimated that of the total number of glass bulbs for incandescent lamps produced in this country, two-thirds to three-fourths are blown by hand and the remainder by machine.

Incandescent lamps are made from bulbs by a number of establishments, of which the General Electric, Westinghouse, and Franklin companies are the largest producers. ${ }^{1}$

While the cost of necessities for living increased from 1892 to 1915 the cost of electric lighting shows a marked decrease, and this reduction was caused by the higher efficiency of the lamps manufactured. The price per candlepower of a 60-watt lamp of the most improved type manufactured by the General Electric Co., decreased from something over 3.6 cents per candlepower in 1907 to 0.6 cent in 1916.

\section{CHEMICAL GLASSWARE.}

The development in the manufacture of chemical glassware in the United States since the war in Europe began is analogous to the development in the manufacture of dyestuffs during the same period.

Chemical glassware includes flasks, beakers, tubing, reagent bottles, desiccators, cylinders, spirit lamps, retorts, jars of various kinds, graduates, percolators, etc., which are usually designated as "hollow glassware" and which are made in a glass factory operating a furnace; and stopcocks, burettes, pipettes, test tubes, potash bulbs, drying tubes, thermometers, hydrometers, and a great variety of additional items, which are made from tubing before the blast lamp and which are usually classified under the heading "lamp-blown and volumetric ware" as their manufacture does not immediately involve the operation of a furnace. 
Before the war began flasks and beakers were made in the United States, but by only one company and in very inconsiderable quantities. This company has been making such articles of excellent quality since 1900 or liefore, but the quality of its product was not widely recognized.

To meet the requirements of chemists in analytical work, glassware must be able to withstand serere tests, of which the most important are the cooling shock test, the test for solubility, and the mechanical shock test. Many chemists have received German training and havo been educated to believe that no chemical glassware could equal that made in Germany and Bohemia and particularly that made in Jena. Comparatively few chemists in America acknowledged that any glassware made in the United States was equal to Jena ware hence the company in this country that has made such ware of rxcellent quality since 1900 found comparatively little sale for it before the war began.

Practically no importations of chemical glassware from Germany hare entered the United States since the summer of 1915. At that time a famine in chemical glassware appeared imminent. Colleges and universities that use large amounts did not know where they could obtain a supply for the scholastic year 1915-16. The annual supply of these institutions amounted in value from several hundred dollars each to over $\$ 10,000$ in some instances.

The numbers of collegiate institutions and schools that reported to the United States Bureau of Education in 1914 were as follows: Colleges and unirersities, 567; public high schools, 11,515; private high schools and academies, 2,199; public normal schools, 235; private normal schools, 46; manual and industrial training schools, 229. Of the 11,515 public high schools, 10,183 reported that they owned scientific apparatus amounting in value to $\$ 16,447, \$ 25$; and of the 2,199 private schools and academies, 1,211 reported that they owned scientific apparatus amounting in value to $\$ 6,992,365$.

\section{IMPORTS FREE OF DUTY FOR SCHOOLS, COLLEGES, ETC.}

Glassware used for educational or scientific purposes has been admitted free of duty under various tariffs, from 1816 to 1846 , from 1857 to 1864 , and since 1870. The section of the tariff act of 1913 which provides for free admission of glass is as follows:

573. Philosophical and scientific apparatus, utensils, instruments, and preparations, including bottles and boxes containing the same. sprcially imported in good faith for the use and by order of any society or institution incorporated or established solely for religions, philosophical, educational, scientifie, or literary purposes, or for the encouragement of the fine arts, or for the use and by ordor of any college, academy, scheol, or seminary of learning in the United States, or any State or public library, and not for sale, and articles solcly for experimental purposes, when iniported by any society or inetitution of the character herein describerl, subject to such regulations as the Secretary of the Treasury shall prescribe.

The importations arlmitted free under this act amounted to $\$ 704,496$ during the fiscal year 1914 and $\$ 370,620$ during the fiscal year 1915 . All of these importations, however, were not of chemical glassware, but of seientific apparatus, which included articles made of metal as well as of glass. 
The imported chemical glassware on which duty was paid is not separately shown by tariff statistics, but a large part of it was used by industrial plants, and the duty on such articles when blown was 60 per cent ad valorem under the tariff law of 1909 and is 45 per cent under the tariff law of 1913 . Very little if any such ware is pressed.

Various estimates are made as to the amount of chemical glassware imported into the United States. One of the largest importers of such ware estimated that the imports before the war amounted to $\$ 500,000$ a year, about half free and half dutiable. The examiner for chemical glass in the appraisers' warehouse, New York City, estimated that such imports amounted to about $\$ 300,000$, of which 50 per cent went to educational institutions free. Most of the imports come from Thuringia in Germany, but some are from Austria. England and France, the warehouse examiner said, made chemical glassware for their own use, but also imported from Germany and Austria.

The quantity of chemical glassware used in the United States has greatly increased from year to year, because of the rapid expansion of educational institutions and because many industrial plants have established or enlarged their chemical laboratories.

\section{DEVELOPMENT OF AMERICAN INDUSTRY.}

The great demand for chemical ware caused a number of enterprising glass manufacturers to begin its manufacture in the summer of 1915. The development in this line was remarkable, and a year later 8 or 10 American companies were producing such ware. Most of the shapes of hollow glassware for laboratory use that were formerly imported are now made in the United States, and the domestic production has fairly caught up with the demand. This can not be said, however, of lamp-blown and volumetric ware, of which there is still a great shortage, and the prices of many articles in this class have increased from 20 to 100 per cent.

In commenting on a copy of this section of this report submitted to Mr. George B. Hollister, general manager of the Corning Glass Works, he wrote December 1, 1916:

In connection with the statement that prices on glassware have increased from 20 to 100 per cent, emphasis should be laid on the fact that the price of the highest-priced American ware is that of the duty-paid Jena before the war. The price of this American ware has not been raised, while Jena has announced two increases in price since the beginning of the war.

Mr. Evan E. Kimble, president of the Kimble-Durand Glass Co., to whom a copy of the article was submitted, wrote October 30, 1916:

Prices increased over the former German prices solely because it is impossible for American manufacturers to make glass apparatus for scientific purposes at a reasonable profit at anywhere near the old prices in a great many lines. The prices have gnne up on account of labor only, and not because of the desire of the American manufacturer to take advantage of the market. Many articles are being made at the present time that compare to the duty-paid prices existing before the war and these prices have been maintained regardless of the demand, which would have allowed glass manufacturers to have increased it. 


\section{IIGII QUALITT OF AMERICAN PRODUCT.}

It is remarkable that the product in this new branch of the glass industry should be so soon recognized by scientific authorities as of the highest quality. A number of professors of chemistry in universities who were interviewed during this investigation declared that the beakers and flasks made now in America are better than what had been imported, better eren than Jena ware. Dr. Owen L. Shinn, professor of applied chemistry in the University of Pennsylvania, said that chemical glassware made for 15 years in a factory in New Jersey had been equal to ware imported before the war began, though this fact had not been generally recognized, and this factory had produced only a limited variety of apparatus. He further said:

The old chemists were German trained and they instilled in the students the thought that anything not German made was inferior. They were hard to convince that American chemical glassware was of good quality; their attitude was that only Jena ware was good. The nonsoluble ware made by several American glass manufacturers is equal to if not better than Jena ware.

It is not now possible to obtain everything in chemical glassware that was formerly imported, but it is the heavier articles that can not be obtained. Beakers, flasks, and the like are now obtainable equal in quantity and quality to any imported ware, but most of the heavier things, such as desiccators, are not vet made here. The reason for this is that the small market for some of these articles has not made it advisable for American manufacturers to make the molds. Nanufacturers have been busy meeting the demands for articles more generally used, and therefore have not yet begun to make these, of which comparatively few are needed.

Not only professors, but even some of the importers who were interviewed, asserted that the best quality of chemical glassware of American make was better than Jena ware. They asserted that such vessels as beakers and flasks, when submitted to various tests, were distinctly superior to Jena ware in resistance to heat shock, stability toward distilled water, and in resistance to mechanical test.

Importers as well as chemists asserted also that microscopes and lenses had long been made of as good quality in America as in Europe.

\section{PRESENT CONDITIONS IN 'THE INDUSTRY.}

An address on "The Manufacture of Chemical Apparatus in the United States" was delivered before the American Chemical Society at its meeting held at Urbana, Ill., April 18-21, 1916, by Mr. Arthur H. Thomas, an importer, exporter, and dealer in laboratory apparatus of both foreign and domestic manufacture. The address was published in full in the Journal of Industrial and Engineering Chemistry for May, 1916. Extracts from it follow:

I propose to remind you briefly of the facts regarding our sources of supply of a few representative classifications of chemical apparatus as they existed before the European war; to compare with these the conditions as they now exist, and then to consider the possibilities of retaining and extending the manufacture of this same merchandise in the United States.

In this tabulation the term "hollow glassware" is used to designate the product of the glass factory with a furnace-the "Hohlglashütte" of Germany-and the term "lamp-blown and volumetric ware" to designate the product of the glass-blowing shop-the "Glassblaserei" of Germany-where the finished product is shaped before the lamp from glass tubing, which tubing is, of course, always made in the glass factory or "hütte." In the United States these two industries are mostly conducted separately, while in Europe they are frequently combined in the same establishment.

$$
102511^{\circ}-17-15
$$




\section{CLASSIFICATION A-HOLLOW GLASSWARE.}

Articles.-Flasks, beakers, and other factory-made ${ }^{1}$ shapes, including blanks for some volumetric ware. Tariff, 45 per cent ad valorem.

Sources before the war.-With the exception of one large factory in the United States which made, in addition to extensive products in other lines, a few llasks and beakers of excellent quality and reasonable price, this ware was purchased exclusively in Europe. The American production was not, in any commercial sense, a factor in the situation.

The present situation.-Five factories in the United States are now regularly making flasks and beakers in large quantities. The glass used by one of these is superior in several important physical characteristics to that used for similar vessels by the European factory whose flasks and beakers have been heretofore considered the best in the world. The four other makers are using a resistance glass much alike in physical characteristics which, while not quite equal to either the American or European product above referred to, is unquestionably superior to the glass generally used throughout Germany and Austria. There are two other American factories making flasks and beakers, about which I have no definite information from actual tests. The ware turned out in one of them is of excellent appearance and that of the other I have not seen. Neither factory is reported as producing large quantities as yet.

With the present conditions of shortage in almost all of the raw material involved, in the labor situation, and in the exhausted condition of stock in unany of the large college and university storerooms, a considerable shortage for some time seems inevitable unless additional capacity is operated. Under norinal conditions the total convenient production of these seven American factories would more than meet our usual consumption.

CLASSIFICATION B-LAMP-BLOWN AND VOLUMETRIC WARE.

Artirles.-All shapes made of tubing before the blast lamp, including the graduation of blarks made in the fartory in addition to those made before the lamp. Tariff, 45 per cent ad valorem.

Sources before the var. - With the exception of a few items not of significance to our discussion, such as hydrometers and thermometers for clinical and industrial use, homeopathic vials and test tubes, milk bottles, and syringes, all staple stock was purchased in Europe. Repair work and the manufacture of a great variety of special items, not in sufficient demand to warrant arrangement for importation in large quantities, was conducted in a few glass-blowing shops operated by some of the larger dealers, in separate small shops in a few of the larger cities, and in the south Jersey district as an important side line in connection with three large glass factories.

The present situation. - Two of the south Jersey factories referred to have practically given up the making of any regular stock in this classification because of the shortage of labor and the great demand for their own specialties. The other south Jersey factory has greatly increased its capacity for the more staple and easily made shapes and is making a commendable but as yet totally inadequate attempt to meet present requirements. This factory, with the few shops just described, constitutes the entire capacity in the United States to make lamp-blown and volumetric chemical apparatus. There are a few additional shops competent to make certain chemical ware but not so engaged because of obligations in more profitable directions.

The combined output of all these establishments in the great variety of items in this classification is far from sufficient to fill the daily orders for immediate shipment. Commitments at the present time for large educational quantities, as usually undertaken at this time of the year, seem not to be justifiable with definite obligation as to either price or time of delivery.

\section{CLASSIFICATION F-OPTICAL MEASURING INSTRUMENTS.}

Articles.-Spectroscopes and spectrometers, polarimeters, and saccharimeters, refractometers, colorimeters, and microscopes. Tariff, 35 per cent ad valorem, except on microscopes, 25 per cent.

Sources before the war.-The instruments in this classification as used in chemical laboratories were all purchased in Europe with the exception of microscopes, the manufacture of which has, as you all know, been extensively and successfully conducted in America for many years.

1 While ordinary bottles are, of course, a factory-made product, my remarks are not intended to apply to them. 
The present situation.-There is no new manufacturing in America to be recorded in this line as a result of the war. The explanation is again the enormous pressure being put upon the several factories equipperl for such work for deliveries of prism binoculars, range finilers, telescopes as used in gunnery, perisnope optirs, etc. Two British fartories have extendel their lines to include certain refractometers and saccharimeters unt heretolore mole in England, but their deliveries are much delayed because of the coatrol of these works by the British Goverament for war requirements. The same situation explains both the inability of certain very exccllent French makers of optical instruments to extend their lines, or even, with one exception, to make any deliveries of their regular goods.

The domestic manufacture of chemical glassware, which previous to the war in Europe was confined to only one American factory, has sixco the summer of 1915 increased very largely, though the product is still insufficient to supply the demand. The increase in the output would have been greater if a larger number of skilled workers could have been obtained. Most of them are Germans, but Americans are being trained for this special work. As the expense of manufacture was exceptionally high during the first year in which this kind of glassware was manufactured in more than very limited quantities, no attempt was made in this investigation to ascertain the cost of any chemical glassware units, but all the domestic manufacturers that make such ware make other kinds of glassware, and reports were secured from these manufacturers covering their last business year.

\section{PROPOSED RESTRICTION OF FREE IMPORTATION.}

Manufacturers who were interviewed during this investigation in regard to the tariff duty on chemical glassware considered it much more important that there should be some duty on the apparatus for educational or scientific use, now admitted free, than that the rate of duty on the remainder of such imports should be raised above 45 per cent ad valorem, the present rate. Some college professors who were interviewed approved the suggestion that the apparatus imported for educational or scientific use should pay a duty, in order firmly to establish the industry in this country, though they did not, however, advocate a duty on imports for such purposes as high as 45 per cent ad valorem.

The American Chemical Society has started a campaign in favor of educational institutions paying duty on chemical glassware and has appointed a committee on the subject, consisting of Prof. Alexander Smith, of Columbia University, Prof. William McPherson, of Ohio State University, and Mr. Arthur H. Thomas, of Philadelphia. Following is a part of the address by Mr. Thomas, extracts from which have already been quoted:

Let us uow consider the possibilities of the future, mentioning first hollow glassware, particularly flasks and beakers. It seems probable that a fair share of our consumption of flasks and beakers will be made in the United States after the conclusion of the war without any increase in duty or any curtailment of the duty-iree privilege. With some restriction of duty-free entry they would, I think, all be made here. This statement is based upon the following facts:

1. The intrinsic excellence of our product. This is certainly the basic economic factor in determining where any merchandise is to be made under normal conditions of competition.

2. The highest priced American flasks and beakers are now sold at exactly the duty-paid prices prevailing before the war for the best European brand. Furthermore, all other American flasks and beakers are now not only sold at less than these 
prices, but at prices no higher, generally speaking, than those hitherto prevailing on Exropean goods of inferior quality.

3. There is a sufficient industrial and other duty-paid demand to justify the continuation of a part, at least, of our present war-time production, even though the large educational business is again placed abroad for duty-free importation. This duty-paid demand is increasingly restricted to flasks and beakers of the highest quality. Those of you engaged in industrial work will agree that in the works laboratory the first consideration is not what the flask or beaker costs but rather that it must not break in use.

4. Flasks and beakers are made in large and well-organized glass factories, of which we have in the United States several quite competent to undertake such work, and the American glass blower accustomed to the manufacture of incandescent lamp bulbs, thermos bottles, ordinary bottles, and the many shapes of household and other ware, can usually make them with a few weeks' practice.

5. And this is important: There is some possibility as to the application of automatic glass-blowing machines (which have reached a truly remarkable development in the United States as applied to the blowing of bottles and incandescent lamp bulbs) to the manufacture of flasks and beakers, if a sufficiently large demand develops. If this should come to pass I think the term "duty-free" would no longer be used in connection with flasks and beakers.

Reasoning in a manner akin to the above seems to justify a similar conclusion, with some qualifications in each instance, for the classifications "Porcelain ware," "Filter paper," and "Optical measuring instruments." "Hardware and sheet-metal ware" and "Analytical and assay balances and weights" have already shown their ability to take care of themselves.

This disposal of these groups leaves for further consideration the very important classification B, "Lamp-blown and volumetric ware." It is the shortage in this group which is now causing the greatest inconvenience, and it is about the making of such goods that we have much to learn if any significant fraction of our annual consumption is to be regularly manufactured in the United States. As compared with flasks and beakers we here face quite a difierent array of facts.

1. Our product thus far is, as a general statement, distinctly inferior in workmanship, appearance, and (too frequently but not always) in accuracy of graduation.

2. These goods must be sold, on the basis of costs prevailing before the war, at much higher prices than the duty-paid prices on equivalent items of foreign make. Since the war this difference in cost has been still further increased, in many instances to the extent of 100 per cent.

3. The duty-pxid demand does not constitute nearly as large a fraction of the total consumption as is the case with flasks and beakers.

4. This ware is mostly made in comparatively small and often poorly organized establishments. This is frequently true, even though the shop is operated by a firm which may be fairly designated as "large and well organized" in other directions. The supply of skilled glass blowers compstent to handle the great variety of such chemical ware is exceedingly limited. I doubt if there are 250 such workmen in the United States at the present time. These mon have mostly come to us from Thuringian factories as skilled and accomplished artisans who were well paid at home. They naturally demand and get still more here. A good all-round worker now gets from $\$ 45$ to $\$ 60$ par week. They do not always lend themselves to the propar subdivisions of labor for economical production. They are quite united in their common interests and naturally not greatly interested in the training and development of apprentices. They frequently are compelled to give up work on general chemical ware because of the high wage they can earn on piecework specialties.

One large concern in south Jersey is here deserving of special mention because of its output in this line, which, while as yet confined largely to the simpler and more staple items, is made almost exclusively by young men and women native in the locality under the direction of a few more experienced workers. I recently visited this plant and was favorably impressed with the very encouraging progress these operatives had made in a comparatively few months.

5. And this again is important: There seems to be little possibility as to the application of automatic machines to this line, with the exception of those already developed and in efficient use for homeopathic vials and syringes.

Mr. J. Howard Fry, vice president of the H. C. Fry Glass Co., having reviewed a copy of this section, wrote November 7, 1916:

To a certain extent, we agree with $\mathrm{Mr}$. Arthur H. Thomas in his statement that tariff duty on all chemical glassware is much more important than an increase of the present tariff; that there should be some duty on glass for educational or scientific use 
now armitted free, rather thau that the rate of duty should be raised above 45 per cent ad valorem. In other Nords, more than likely, the conditions in Europe after the war will be such that, provided the now duty free is abolished, the duty on imports, 45 per cent ad valorem on chemical glassware. will be sufficient protection to allow us to continue manufacturing a good quality of chemical glassware in competition with foreign countries.

It is true that the very high grade chemical ware does find and will continue to find a limited sale in this country, at a price, but the great volume of chemical glassware, such as used by the colleges, industrial plants, and ordinary laboratories, does not need to be the highest grade of chemical glassware, and that business will eventually go to the cheapest market of suitable quality. As the duty-free provision permilted all the universilies to get their beakers and flasks without any duty, it cut out the volums business for the American manufacturer, and there was little or no opport unity then for the American manufacturer to succeed. The demand for the very higligrade stulf is naturally limited, and would possibly only keep one busy, where the popular demand would keep several factories busy. Personally, I can not understand why chemical glassware should be imported free of duty for educational purposes, because those educational institutions should help support the American industry and labor, as undoubtedly the American has to support such institutions. Consequently, by taking that business away from the American manufacturer and giving it to Europe, it is false economy on the part of the educational institutions, and our Government should not encourage it.

In 1914 the council of the British Institute of Chemistry appointed a glass-research committee to conduct investigations with the view of arriving at suitable formulas for laboratory glassware, miners' lamp glasses, combustion tubing, resistant glass for pharmaceutical products, glass for X-ray bulbs, etc. The main part of the report of the committee was published in Nature (London), April 15, 1915, and republished in the Scientific American Supplement, July 24, 1915.

\section{PHOTOGRAPHIC GLASS.}

A new small industry in the United States is the manufacture of photographic glass, which is thinner than window glass. Photographic glass averages 15 panes to the inch, while single-strength window glass averages $11 \frac{1}{2}$ or 12 to the inch and double-strength 8 or 9 to the inch. Photographic glass is packed 100 square feet to the box, window glass 50 feet per box for domestic trade and usually 100 feet for export.

Dry photographic plates, made by coating photographic glass with a sensitive emulsion, have long been made in the United States, particularly in Rochester and St. Louis. Photographic glass, however, was not made commercially in the United States until 1911.

Only the first two qualities of the thin glass, both of which aro better than A quality window glass, are used for photographic plates. The third grade, which is called photographic reject, is used for picture frames, for clock faces, and such purposes.

\section{COMPARATIVELY HIGI COST OF PRODUCTION.}

For several reasons photographic glass is much more expensive to make than is common unpolished window glass. The thin glass is very fragile and the percentage of breakage is much larger than in the case of window glass. In making thin glass there are more burns in flattening. Single and double strength glass does not get hot so quickly on the stone in the oven, and does not have to be taken out so quickly as thin glass, so that it is not so liablo to burn. 
Moreover, when wrinkles on thin glass are rubbed down the sheet often becomes so soft that pimples appear on the surface.

With photographic glass much more cutting and much more careful sorting are necessary than with window glass. The windowglass cutter sorts the glass as he cuts it and piles it on edge according to size and quality. Photographic glass is sorted by the cutter who cuts it into strips. Another cutter cuts panes from the strips. The panes are then examined, sorted, and perhaps three-fourths of them are cut to smaller sizes to remove defects.

The labor cost on photographic glass is much higher than on window glass. The difforence in total cost is indicated by the difference in price. In 1916, when a box of 8 by 10 single-strength A glass sold for about $\$ 2.25$, a box of photographic glass of the same size, 100 square feet to the box, sold for $\$ 11$, or on the basis of $\$ 5.50$ for 50 feet.

\section{AMOUNT CONSUMED-TARIFF RATES.}

The consumption of photographic glass in the United States, first and second quality only, is about 200,000 boxes of 100 feet, which, at 1916 prices, amounted to $\$ 2,200,000$. The imports of photographic glass are considerable, but the amount can not be stated, as there is no tariff distinction betwen such glass and window glass and no separate statistics of imports are kept.

The duty on cylinder, crown, and common window glass, unpolished, which includes photographic glass, is levied on a pound basis and not at an ad valorem rate. Consequently, the amount of duty on a 100-foot box of window glass is the same as the duty on a 100foot box of photographic glass, although the value of the latter is about twice the value of the former, largely because the labor cost of the latter is very much larger.

Most plates for photographic purposes are in small sizes which do not exceed 150 square inches, or panes 10 by 15 inches, and practically all is in the first three brackets, not exceeding 384 square inches. The duty on cylinder glass, whether used for windows or for photographic dry plates, is seven-eighths of a cent a pound on sizes not exceeding 150 square inches, and 1 cent a pound on sizes over 150 and not excoeding 384 square inches.

The manufacturers of photographic glass believe that in the tariff classifications some distinction should be made between photographic glass and window glass, and that the former should have a higher duty. This distinction would be made if there were a classification of glass weighing under 95 pounds per 100 feet, which would include photographic glass, and a classffication of glass weighing 95 pounds or more per 100 feet, which would include window glass of single as well as double strength. The manufacturers claim that the rate of duty on the thin or photographic glass should be higher than that on window glass, and that the rate on dry plates should be correspondingly increased.

There are large dry-plate factories in the United States, and much of the photographic glass that they imported before the war began in Europe was made into dry plates and exported. These concerns, when they exported dry plates, received a drawback of 99 per cent of the duty paid when the glass was imported. With brokerage charges, the drawback amounted to about 94 per cent net. 


\section{('HAP'TER VII.}

\section{SELLING EXPENSE AND CONDITIONS.}

\section{SELLING EXPENSE.}

Table S7, which follows, shows, by groups, the percentage of selling expense and of operating and final profit based on net sales:

Table 87.-Percentage of Selling Expense and of Profit, Based on Net Sales, by Groups.

\begin{tabular}{|c|c|c|c|c|c|c|c|}
\hline \multirow[b]{2}{*}{ Establishments making- } & \multirow[b]{2}{*}{ Group. } & \multicolumn{3}{|c|}{ Selling expense. } & \multicolumn{2}{|c|}{$\begin{array}{l}\text { Operating profit } \\
\text { compute } \downarrow-\end{array}$} & \multirow{2}{*}{$\begin{array}{c}\text { Final } \\
\text { protit, } \\
\text { deprecia- } \\
\text { tion and } \\
\text { interest } \\
\text { consi } 1 \text { - } \\
\text { ered. }\end{array}$} \\
\hline & & $\begin{array}{c}\text { Cost of } \\
\text { salesmen. }\end{array}$ & $\begin{array}{c}\text { Other } \\
\text { expense. }\end{array}$ & Total. & $\begin{array}{l}\text { Without } \\
\text { deprecia- } \\
\text { tion an } 1 \\
\text { interest. }\end{array}$ & $\begin{array}{l}\text { With } \\
\text { deprecia- } \\
\text { tion an } 1 \\
\text { interest. }\end{array}$ & \\
\hline 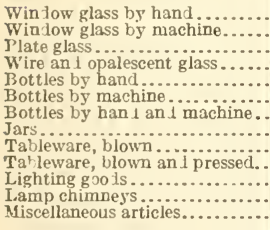 & $\begin{array}{r}\text { I } \\
\text { II } \\
\text { III } \\
\text { IV } \\
\text { V } \\
\text { VI } \\
\text { VII } \\
\text { VIII } \\
\text { IX } \\
\text { X } \\
\text { XI } \\
\text { XII } \\
\text { XIII }\end{array}$ & $\begin{array}{l}1.45 \\
1.97 \\
.13 \\
2.77 \\
1.11 \\
2.81 \\
3.46 \\
2.78 \\
6.72 \\
4.60 \\
4.7 .4 \\
4.14 \\
2.89\end{array}$ & $\begin{array}{r}0.03 \\
.05 \\
.13 \\
.93 \\
.28 \\
.58 \\
1.52 \\
.58 \\
.27 \\
2.08 \\
1.89 \\
.39 \\
.52\end{array}$ & $\begin{array}{l}1.48 \\
2.02 \\
.26 \\
3.70 \\
1.39 \\
3.39 \\
4.98 \\
3.36 \\
6.99 \\
6.68 \\
6.63 \\
4.53 \\
3.41\end{array}$ & $\begin{array}{r}9.34 \\
9.22 \\
11.93 \\
10.29 \\
5.09 \\
15.07 \\
5.71 \\
9.16 \\
12.69 \\
4.96 \\
14.05 \\
5.27 \\
12.84\end{array}$ & $\begin{array}{r}5.33 \\
1.99 \\
.16 \\
4.99 \\
2.28 \\
10.79 \\
1.98 \\
5.04 \\
9.29 \\
a .15 \\
9.59 \\
2.91 \\
8.90\end{array}$ & $\begin{array}{r}5.60 \\
2.76 \\
.82 \\
5.68 \\
2.65 \\
11.30 \\
2.68 \\
6.13 \\
9.33 \\
10.11 \\
10.19 \\
2.89 \\
8.98\end{array}$ \\
\hline Average............. & ....... & 3.07 & .94 & 4.01 & 10.32 & 5.57 & 6.10 \\
\hline
\end{tabular}

a Operating loss.

'The table shows that the cost of salesmen, which includes their salaries, commissions, and traveling and other expenses, is exceptionally low, the average for the 13 groups being but 3.07 per cent of the net sales. The lowest group percentage is that for plate glass, 0.13 per cent; the highest is for blown tableware, 6.72 per cent.

This exceptionally low cost may be explained by the fact that many establishments employ no salesmen whatever, and also because the greater part of the goods, in a majority of the groups, is sold in large quantities to jobbers, large consumers, and distributers. In many establishments the goods are sold by an official of the company or as the result of a successful bid.

Groups IX to XII, inclusive, show the highest percentages for cost of salesmen. All these groups probably have smaller and more diversified sales than do the other groups, where only one product, as window glass, plate glass, bottles, or jars, is sold. 'To sell small quantities of varied goods to numerous accounts requires a comparatively larger selling force. Many lamp chimneys and much pressed tableware are exported, and this also tends to increase the selling cost, not because cost of the salesmen is increased but because of brokers' fees, etc. 
Other selling expense includes the maintenance of selling offices and showrooms in rarious glass centers and miscellaneous selling expense. The table shows the lowest cost, 0.03 per cent, for the hand-made window-glass group and the highest cost, 2.08 per cent, for the blown and pressed tableware group.

Much pressed tableware is exported. This requires showrooms in various centers and other selling expenses not incurred in domestic selling, and to this fact may be attributed the reason for the blown and pressed tableware group showing the highest percentage for "other selling expense," 2.08 per cent.

The average total selling expense for the 13 groups is 4.01 per cent. The plate-glass group shows the lowest cost, 0.26 per cent, and the blown tableware group the highest, 6.99 per cent. The glass industry in general, as compared with other industries, has a small selling expense, and the profit in the industry is not greatly influenced by the selling expense, as is the case in many other industries. This is shown by a comparison of the total selling expense with the profit. As the final profit consists of the operating profit plus miscellaneous income outside the manufacturing business less miscellaneous expense outside the business, it will be best to' compare the total selling expense with the operating profit that is computed with depreciation and interest on current loans.

The highest percentage of operating profit, 10.79 per cent, is shown by the machine-bottle group; the blown and pressed tableware group shows the smallest percentage, a loss of 0.15 per cent. That the selling expense does not greatly influence the profit is illustrated by the following: Blown tableware, with the highest percentage for total selling expense, 6.99 per cent, shows an operating profit of 9.29 per cent; lighting goods, with a total selling expense of 6.63 per cent, shows an operating profit of 9.59 per cent; blown and pressed tableware, with a total selling expense of 6.68 per cent (which is less than the percentage for blown tableware, 6.99 per cent, and only 0.05 per cent more than that for lighting goods, 6.63 per cent), shows an operating loss of 0.15 per cent.

The foregoing table shows that machine-made bottles earned the highest final profit, 11.3 per cent, and blown and pressed tableware the lowest, 0.11 per cent.

Table 88, which follows, shows, by groups, the percentage of packing-material cost, bad debts, and of operating and final profit, based on net sales: 
Table Ss. Percentage of Packing-Material Cost, Bad Debts, and Profit, Based on Net Sales, by Groups.

\begin{tabular}{|c|c|c|c|c|c|c|}
\hline \multirow[b]{2}{*}{ Establishments making- } & \multirow[b]{2}{*}{ Group. } & \multirow{2}{*}{$\begin{array}{l}\text { Packing } \\
\text { materials. }\end{array}$} & \multirow{2}{*}{$\begin{array}{l}\text { Bad } \\
\text { debts. }\end{array}$} & \multicolumn{2}{|c|}{$\begin{array}{l}\text { Uperating profit } \\
\text { computed- }\end{array}$} & \multirow{2}{*}{$\begin{array}{l}\text { Final } \\
\text { profit, } \\
\text { deprecia- } \\
\text { tion, and } \\
\text { interest } \\
\text { con- } \\
\text { sidered. }\end{array}$} \\
\hline & & & & $\begin{array}{l}\text { Without } \\
\text { depre:ia- } \\
\text { tion and } \\
\text { interest. }\end{array}$ & $\begin{array}{l}\text { With } \\
\text { deprecia- } \\
\text { tion and } \\
\text { interest. }\end{array}$ & \\
\hline 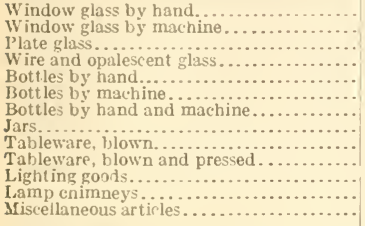 & $\begin{array}{c}\text { II } \\
\text { III } \\
\text { II } \\
\text { Y1 } \\
\text { VII } \\
\text { VIII } \\
\text { IXI } \\
\text { XII } \\
\text { XIII } \\
\text { Xil }\end{array}$ & $\begin{array}{r}7.17 \\
8.06 \\
2 .(17 \\
4.44 \\
6.29 \\
7.86 \\
4.96 \\
13.02 \\
4.22 \\
7.42 \\
7.55 \\
16.18 \\
3.34\end{array}$ & $\begin{array}{r}0.01 \\
.11 \\
.01 \\
.68 \\
.47 \\
.55 \\
.73 \\
1.00 \\
.49 \\
.26 \\
.32 \\
.31 \\
.40\end{array}$ & $\begin{array}{r}9.34 \\
9.22 \\
11.93 \\
10.29 \\
5.05 \\
15.07 \\
5.71 \\
9.11 \\
12.19 \\
1.95 \\
14.05 \\
5.27 \\
12.84\end{array}$ & $\begin{array}{r}5.33 \\
1.99 \\
.16 \\
4.99 \\
2.25 \\
10.79 \\
1.95 \\
5.04 \\
9.29 \\
a .15 \\
9.59 \\
2.91 \\
8.90\end{array}$ & $\begin{array}{r}5.60 \\
2.77 \\
.82 \\
5.68 \\
2.65 \\
11.30 \\
2.48 \\
6.13 \\
9.33 \\
.11 \\
10.19 \\
2.89 \\
8.9 \mathrm{~s}\end{array}$ \\
\hline A rerage... & & 7.13 & .44 & 10.32 & 5.57 & 6.10 \\
\hline
\end{tabular}

aperating loss.

The foregoing table shows that the cost for packing material is, comparatively, a very large expense of the business. This is due to the nature of the product, which, being fragile, requires not only careful packing, but numerous materials to insure a minimum of breakage while in transit. Lamp chimneys show the highest percentage, $16.1 \mathrm{~s}$ per cent, and plate glass the lowest; 2.67 per cent. The high percentage for lamp chimneys is due to the numerous wrappings required, especially when they are for export trade. Excepting the hand and machine bottle, the blown-tableware, and the miscellaneous groups, the remaining 10 groups show much greater cost for packing material than for total selling expense-in the case of plate glass, more than ten times as much.

Bad dobts, as shown by the table, is a very insignificant item of expense. The plate-glass group shows the lowest expense, $0.01 \mathrm{per}$ cent, and jars the highest, 1 per cent.

\section{SELLING METHODS.}

\section{DISTRIBUTION OF GOOUS.}

Most glass manufacturers prefer to sell their ware to jobbers, to consuming manufacturers in other industries who use glass products, and to large wholesale distributers.

$\Lambda$ large amount of merchandise is sold to jobbers who usually have an exclusive territory. In the case of bottles and jars, a large quantity is sold direct to the manufacturers or bottlers of wines, beers, ketchups, grape juice, etc., to large drug concerns, operating a chain of stores, and to small druggists. Only a small amount of glassware is sold to the retailer direct, the nature of the product limiting such sales to cut glass, tableware, some lighting goods, and a few specialties. Only a very limited quantity is sold to mail-order houses, as these houses, owing to their method of distribution, can handle only a fow products, such as cut glass, lamp shades, and tableware. Some 
goods for export trade are sold direct to the consumer, usually through a resident agent or a commission broker.

A number of window-glass manufacturers (about 25 hand and 5 machine) sell their entire product through a sole selling agent or broker. This agent sends out his salesmen and on receiving orders, distributes them among the various plants according to the quantities and grades produced, the nearness of a factory to the point where the glass is to be delivered, etc. At least one other branch of the glass industry is contemplating a somewhat similar selling arrangement. Due to the method of distributing its goods, there are comparatively few salesmen employed in the glass industry. The compensation of salesmen, when they are employed, is in the form of a commission or a salary and traveling expenses. Where the salesman works on a commission basis, it is customary for the manufacturer to allow a drawing account, that is, to allow the salesman to draw a regular amount every week for his current expenses, which is periodically deducted from the actual commission earned.

The sale of a large quantity of goods to jobbers and wholesale distributers is due to necessity rather than to choice. The capital turnover in the glass industry is exceptionally small, which is due to the fact that most of the capital is invested in land, buildings, plant, and equipment. Labor, which has to be paid for at least every two weeks, constitutes the chief item of expense in every branch of the industry except-where the processes of manufacture are entirely mechanical. Practically all the capital being tied up in plant and equipment, it is necessary for an establishment in order to have the cash to meet its heavy pay roll and other current expenses, to sell to jobbers and wholesale distributers, who usually buy on very short terms, and who, if necessary, will pay cash. Another important reason for wishing to sell to them is that they purchase in large quantities, which not only insures a large periodic cash income, but also tends to make production and prices more stable and reduces the overhead expense.

\section{VIEWS OF A BOTTLE MANUFACTURER.}

In 1916 a bottle manufacturer in New Jersey sent a circular letter to other manufacturers in which he referred to the greatly increased cost of raw materials. He said that manufacturers who had bought materials before the advance in prices should realize the difference between the cost when the materials were purchased and the cost after the advance and should not give this difference to the customers and thus demoralize the market price for bottles. He asserted that manufacturers were too much inclined to give away profits to which they were entitled by reason of purchases made on favorable terms. The circular letter was in part as follows:

In the glass-bottle business almost all of us feel that every advantage that we can secure must be immediately transferred to the customer; so to-day is witnessed a spectacle of a group of manufacturers in one of the oldest trades in the world falling over themselves to give their customers not only profits which belong to them by right cf the business but part of their costs.

If John Jones can sell at 85 and 10 per cent, we can go 85-10-5 per cent; he hasn't anything on us; and for the last five years away we went believing every word our salesman told us about the other fellow's prices and going him one better, and costs went into the discard. We could not invent or perfect a labor-saving device without taking the fastest train to our customer so we could give away our saving, and if we 
worked the glass blowers for a 10 per cent reduction in labor some of us were fools enough to think that this mant our entire costs were reduced 10 per cent and we immediately reduced our salling prices 10 par cent.

Here we are in one of the largest business booms this country has seen for years; here we are ficing the highest costs for raw materials we have seen for over 20 years, and we haven't the nerve to put up our prices to cover the advances. True, we have made some raises, but they are a drop in the bucket. The export trade has filled a hole which existed for some years back and the increased domestic business has stopped the last leak. Every bottle manufacturer in the L'nited States can sell his full output for the balance of this blast at any price in reason he asks, and because some few of them won't ask, the rest of $1 \mathrm{~s}$ feel that we must meet their prices. It makes me wonder if we know prosprity when we see it.

We are deaf, dumb, and blind. We have neglected publicity to educate the buyers to higher p:ices; we have neglected politics to keep out foreign-made bottles; we have neglected good fellowship to make our compstitor see and feel that our horns are no longer than his, and instead we have hunched ourselves over a roll-top desk and schemed and planned how to steal some pet order away from our neighbor, and he, in his office, has been playing the same game. We grudge the money to go to a meeting, and if we do get there we have to get away early so that we can get home that night, with the consequence that about the time we "get down to the brass tacks" half of us are on the train. It takes us about five hours to get warmed up and get our nerve steady and be ready to put on the screws, and then we are afraid to do it because some fellow leit, and we are afraid he won't go along and will take some order away from us.

\section{IMPERIAL WINDOW GLASS CO. CASE.}

To eliminate very keen competition and the cutting of prices, 50 or more window-glass concems formed the Imperial Window Glass Co. in April, 1909, and started business in January, 1910. The Imperial company manufactured no glass, but was apparently a selling agoncy for the output of the 50 or more factories. Each plant manufactured its own glass, but was not permitterl to sell any of its product except to the Imperial company and at what had been current prices prior to the organization of this company.

From April, 1909, when the Imperial company was formed, to October, 1910, prices advanced 70 per cent, and it is understood the profits of the company in 10 months of business were considerably over a million clollars. Evidence showed that the Imperial company leased 15 factories at very high rentals for the sole purpose of keeping them closed and removing their production from the market. It is understood that when the company commenced business it had acquired 97 per cent of the pots making hand-blown window glass.

In April, 1910, indictments were procured at Pittsburgh, Pa., against all the officers and directors of the Imperial WVindow Glass Co. A demurrer to the indictment being overruled, the defendants on November 12, 1910, appeared in court (United States District Court, Westem District of Pennsylvania) and pleaded nolo contendere.

The 15 directors and officers of the Imperial company, each of whom was also a president or prominent officer in one of the companies which had agreed to sell its output to the Imperial company, were fined sums aggregating $\$ 10,000$. 


\section{EUROPEAN PLATE-GLASS TRUST. ${ }^{1}$}

Prior to 1904 the European plate-glass industry was in a precarious condition. Very keen competition had lowered the price of plate glass, while at the same time there was an increase in the cost of raw materials. To improve their condition, the manufacturers organized, on August 17, 1904, a trade association known as the International Convention of Plate Glass Manufacturers. The original agreement has been renewed twice and the present agreement expires August 17, 1924.

The association in December, 1912, was composed of 17 companies whose factories were located in France, Belgium, Netherlands, Germany, Austria-Hungary, and Italy-practically all the European plate-glass manufacturers, excepting Pilkington Bros., operating a làrge factory at St. Helens, England, and the Société des Glaces de Courcelles, an independent company of Belgium.

The object of the association is to curb overproduction and by equalizing production and consumption to regulate prices. The association limits the output of each factory by compelling it to close down a certain number of days during each quarterly period. This does not force the factory to shut down entirely. It can continue producing rough plate, but the grinding and polishing machinery must not be employed during the shut-down period. Efforts also have been made to get Pilkington Bros. to curtail their production.

Each member of the convention has selling agents in every market, and, though there is some competition as to the quality of the product, nearness to market, etc., each is required to sell at the prices fixed by the convention. Any deviation from prices or from the selling rules is punished by a heary fine. The convention also regulates selling conditions, such as sizes, breakage allowances, etc. The two large nonmember companies usually observe the prices fixed by the convention.

After the organization of the convention in 1904, the plate-glass industry was prosperous and the manufacturers were financially successful throughout Europe. The selling price fixed by the convention, soon after its organization, remained practically unchanged until December, 1912, when the Union Commerciale Continentale was incorporated at Brussels, with a capital said to be 2,000,000 francs $(\$ 386,000)$, supplied by the members of the convention.

This new corporation is the convention's sole universal selling agent, and it destroyed even the slight competition which prevailed under the convention's rule. This one corporation regulates the production of every factory in the convention, purchases the complete output at a price per square meter, which it determines, and sells the entire product in every country in the world at prices and under conditions that it fixes. The profits of the corporation are distributed in the form of rebates to the various factories.

The new corporation absolutely controls every market in the world except that of the United States, where approximately half the product of the world is consumed. Depending for its profits on its trade

1 The data for this article were secure 1 from briefs submitted to the Committee on Ways and Means in January, 1913, House Document No. 1447, Sixty-second Congress, third session, Schedule B, pars. 101 and 102 .' 
in other countries, where it can sell at its own prices, it can afford, in order to keep its factories in full operation, to sell in the American market at rost or eren lesis.

\section{EUROPEAX WATCH-CRYNTAL SEILING AGREEMENT.}

The following report by Milo A. Jewett. consul at Kehl, Germany, was pullished in Daily Consular and Trade Reports, July 2, 1914:

After some years of price-cutting war between the different European manufacturers of watch crystals. an agreement has been reached for a uniform scale of prices. and peace is declared. In 1905 the Watch-Glass Factories Association. with headquarters at Strassburg, was in control of all the important European manufacturers of watch glasses and was able to fix the producers' selling prices for prantically the whole world. However, through the lapse of some agreements and the establishment of new and independent manufactırers, competition in selling prices grew up until prices were so reduced that there was little or no profit in the industry. Until recently the combine consisted of three factories in Lorraine (one of which also has a factory in France). one in France, and a fifth unimportant factory in Lorraine that, while not an actual member of the combine, sold its watch glasses to or through the combine. The independents consisted of one factory in Lorraine, one in Alsace, two in Switzerland, and one in Bohemia. The annual output of the combine factories was said to be 500,000 gross of watch glasses, and the independents could make about 300,000 gross yearly.

The chief feature of the present agreement concerns the selling prices. It is said that all the manufacturers referred to have agreed to sell at fixed and uniform prices. There is also some understanding in regard to the distribution of territory to be covered by different ccncerns and also in regard to the distribution of business, output, and cales. While all the different factories are now "independent," the Vereinigte Lhrglasfabriken. Vicgesenstrasse, Strassburg. Alsace, will continue to act as selling agents for some of the more important manufacturers and will exercise general control in regard to the matters that form the subject of the present agreement.

As a result of this new arrangement, prices of watch crystals have been advanced from 60 to 90 per cent. While these higher prices will affect wholesale purchasers in America, it is not likely that the consumer will be much affected. Watch crystals were sold extremely low here, and prices will still be relatively low, although about double what they have been. Ordinary watch crystals were selling as low as 4 francs $(\$ 0.772)$ a gross, which is about half a cent a piece.

This is an industry where hand labor must be employed to a considerable extent, and the workmen employed in making the watch crystals and the girls that are employed in putting the labels on each glass and in packing them receive very low wages. It is for this reason that watch crystals can not be made in the United States in competition with European manufacturers.

\section{SELLING FACTORS.}

Effect of seasons.-The seasons have, to some extent, an effect on the glass industry. Bad weather that retards building operations affects window, plate, wire, and opalescent glass and, to a minor degree, lighting goods; a cool summer affects manufacturers of beer, soda, and mineral water bottles, etc.; a poor crop affects manufacturers of ketchup and grape-juice bottles and jars.

Long future deliveries. - The fact that goods are manufactured for long future delivery has little effect on the industry, because most of such goods is manufactured by contract. However, it often leads to overbuying, which results from a poor anticipation of future demand and judgment of the market. When this happens it usually curtails the manufacturer's production and lowers prices during the next blast.

Size of orders. - Though the great bulk of glass products is sold to the jobbers and other large purchasers, and the orders are, therefore, necossarily large, there is a tendency in all branches, and especially 
in bottles, for the orders to become smaller and more frequent. This is in accord with the general tendency in many other industries, and results from the purchaser's desire to rid himself of the responsibility of judging the market and from putting too much cash into large stocks. The automatic bottle-machine manufacturel's insist on large orders, as do many of the manufacturers in the other branches who will not ship less than a carload. The comparatively small orders and the small rush orders go to the hand plants. In general, however, there is a tendency on the part of the jobber or other purchaser of glass products, even in standard goods, to shift whenover possible the burden of carrying the stock onto the manufacturer, and this necessarily results in smaller and more frequent orders.

Discounts.-The following statement gives the discounts usually allowed in the glass industry as reported by manufacturers:

Window glass.............2 per cent 10 days or net 60 days.

Plate glass................. 1 per cent 10 days or net 30 days.

Bottles.................. 1 per cent 10 days or net 30 days.

Tableware................ 1 per cent 30 days ${ }^{1}$ or net 60 days.

Lighting goods. ............ 1 per cent 15 days or net 30 days.

Though these terms are generally uniform throughout the respective branches of the industry, the scale is not strictly adhered to by all manufacturers. It depends to a great extent upon the purchaser and the character, reputation, and business methods of the manufacturer. There are occasions when extra discounts are demanded and secured. A very large purchaser may be allowed an extra cash discount or its equivalent in the form of a freight allowance. It is not unusual for purchasers to deduct the usual discount, although payment is not made until long after the bill is due.

Job lots. - Job lots are made up of imperfect ware, bad sizes, broken stock, standard goods of which too much stock has been produced, special goods left over by cancellations, discarded styles and designs, and odds and ends. There are comparatively few job lots sold in this industry; the ware that can not be sold is utilized to a great extent for cullet. Discounts allowed on what job lots are sold vary, depending upon the ware, its condition, how urgent the manufacturer's need for money is, and numerous other factors.

Advertising.-Though many glass establishments advertise in trade journals, only a very limited number advertise nationally. The great bulk of glass products by their very nature have no particular individuality whose advertising would be warranted or profitable; the principal selling argument is generally the price. Only two or three manufacturers place trade-marks on the ware they manufacture, and these appear on pressed goods. It is impossible to blow a trade-mark on ware made in paste molds or blown offhand.

Trade uncertainties.- There are some trade uncertainties connected with certain branches of the industry. Building-trade strikes which can not be anticipated affect window, plate, wire, and opalescent glass. Prohibition to some extent influences the bottle and bar-goods trades; in addition, bottles are affected by varying laws in regard to size and capacity and by the varying degrees of their enforcement by States and cities. The making of goods lettered with the purchaser's 
name or tracle-mark is to some extent a hazard. Seasonal effects, which have been previously discussed, are trade uncertainties which can not be forecasterl or guarled against.

\section{TRADE ABUSES.}

Is a general rule the manufacturers interviewed complained but little of trade abuses. This absence, to a great extent, of the trade abuses found in many other industries may be explained by the fact that the glass industry sells mainly to the jobber, who usually is a reputable business main. There are, however, abuses in the industry and a description of some of them follows:

Allowances. - On a rleclining market, although the manufacturer is usually protected by a contract, there is some demand for a reduction in price not as an actual reduction in price necessarily but as an allowance, which amounts to the same thing. There is also a tendency on the part of some purchasers to overclaim the amount for shortage and breakage. As is to be expected, there will be some breakage due to the nature of the commodity. When no niaximum breakage allowance is stipulated in the contract or is understood, purchasers occasionally make orerclaims, thus reducing the price of the ware. Some allowance claims for imperfect ware are due to a careless examination of the ware by inspector's in the factory, which may or may not be due to the policy of the plant. It is to be noted, howerer, that allowance claims for imperfect ware are more numerous in bad seasons than in good.

Cancellations.-There are comparatively few cancellations. They usually come when there is a falling off in demand or a sharp break in prices. Occasionally, if the ware has not yet been made or if it is unlettered and of standard size and shape, so that it can be used to fill other orders, manufacturers will accept cancellations. If special molds have been made or the goods lettered, cancellations will not ordinarily be accepted. However, if the house that cancels the order is large and its business profitable, cancellations, eren under the abovementioned conditions, are sometimes accepted.

\section{TRADE ACCEPTANCES.}

As has been pointed out, many glass factories lack ready cash. The arloption of the trade acceptance would help to supply such assets. However, no branch of the glass industry has as yet made use of it. Though it was urged at the 1916 annual meeting of the National Bottle Manufacturers' Association that the adoption of the trade acceptance would eliminate some and minimize other trade abuses now prevalent in the industry, and though such a well-informed glass man as Mr. George W. Yost, who is a banker as well as a glass manufacturer, urged its adoption, the association took no action. Conservatism or a desire to adliere to custom and the usual lack of cooperation among manufacturers are the reasons ascribed for action being postponed.

The acceptance is similar to the sight draft, but is payable on a certain date, depending on whether the terms are $10,15,30$, or more days, instead of being payable on sight. In order to conform to the laws which make it possible for an acceptance to be rediscounted, a brief notation or memorandum of the transaction covered by the 
acceptance should be written on its face. The manufacturer mails the invoice, bill of lading, and acceptance to the purchaser, who accepts by signing his name across the face of the acceptance and returns it to the manufacturer. The manufacturer's bank will then advance the manufacturer money on it or it can be held for collection. The acceptance when properly drawn may be rediscounted hy a Federal reserve bank. When the day for payment arrives the acceptance is forwarded to the bank of the purchaser, which charges it to his account.

It was pointed out at the meeting of the National Bottle Manufacturers' Association that the use of the acceptance would result in the following advantages: It would make capital more elastic, in that a manufacturer could get a cash advance on his shipments, instead of having his money in ledger accounts, and would enable him to better meet his current cash expenditures; it would eliminate the possibility of the purchaser taking unearned cash or trade discounts; it would do away with the arbitrary return of goods and unjust deductions for breakage; it would compel the purchaser to pay his bills when they were due, thus doing away with collection charges; it would tend to make the purchaser buy just what he could pay for, and would wipe out the bad feeling between seller and buyer that results from collection letters, actions at law, etc.; its use would necessitate no change in present accounting methods and would simplify accounting systems.

The following is quoted from a letter received from Mr. George W. Yost.

My remarks before the National Glass Bottle Manufacturers' Association at Atlantic City were on account of a discussion with Mr. D. C. Wills, president of the Federal reserve bank of Cleveland, Ohio, and my experience as a banker, both of which convince me of the advantages which would accrue to all parties in interest if trade acceptances were used instead of the present method of open ledger accounts.

In the discussion with Mr. Wills, I argued that while it was important and proper that the Federal reserve banks should bring the matter to the attention of the public, it would be absolutely necessary to have the assistance of manufacturers, merchants, and vendors of any line or lines where sales are made in large enough quantities to justify the taking of an acceptance.

This end can best be accomplished by agreements by associations of manufacturers and merchants that sales will only be made with the understanding that trade acceptance must be signed unless the buyer expects to and does pay cash for his purchases.

It goes without saying that, except in isolated cases, it will be impossible for a vendor in any particular line to insist upon this method of settlement, unless his competitors in the same line pursue the same course; and on this account I consider it very important that the Federal reserve banks and all other banking institutions take advantage of every opportunity to bring the matter to the attention of associations of manufacturers and merchants, to the end that they may decide to use this method instead of the present plan.

\section{ECONOMIES POSSIBLE THROUGH COOPERATION.}

Though selling expense, as shown by Table 87 , is comparatively small, there are many economies that could be effected. There is among manufacturers no cooperation aside from getting together once a year and, in conjunction with the union, fixing the wage scale for the new blast. Cooperation, though urged time and time again, has never been realized. 
The following is quoted from an interview with one of the bestinformed bottle manufacturers in the United States:

No sp scial antagonism exists as between various manufacturers; on the contrary a more or less friendly spirit prevails. No well-defined or intelligent effort has been made between the manufacturers to correct trade abuses. Discussion between manufacturers relative to certain policies, covering such matters as the form of contract, exchange of credit information, methods of handling breakage claims, the establishment of a uniform discount for cash, and uniform conditions covering the manufacture of new or sp scial mold equipment, would doubtless be beneficial to both buyer and manufacturer.

Various manufacturers who were interriewed offered the following suggestions as desirable, if the cooperation necessary for their fulfillment could be obtained:

1. The establishment of a uniform cost-finding system, which would enable all manufacturers in the respectire branches of the industry to arrive at competitive prices computed on a comparable base.

2. A centrally controlled selling ageney for each branch of the industry that would sell the entire production of all plants in somewhat the same manner as a large quantity of window glass is now distributed through the Johnston Brokerage Co.

3. A uniform, standardized contract for each branch of the industry that would, among other things, provide for a method of packing and would include a specific percentage to be allowed in every case for freight and breakage and abore which no allowance would be granted.

4. The standardization, where possible, of shapes and styles and the requirement that the purchaser pay for new molds the making of which is necessitated by the purchaser's desire to get a product which differs from the standard.

5. The establishment of a central selling or show room (one firm at present maintains offices in about 10 cities) which would reduce materially the selling cost for each individual manufacturer.

6. The establishment of a credit bureau, which would not only give credit information and advice but which would take up and eliminate all abuses that may arise.

7. The abolishment by manufacturers of the practice of dumping their surplus products in territories where they do not ordinarily sell, thus causing manufacturers who sell in that territory to cut prices and in turn to invade the usual market of the manufacturer who has dumped his goods in their territory. The surplus stock, instead of being dumped in this country, should be exported.

There has been but little attempt at cooperation between manufacturers. There is much that could be done. Sizes, shapes, and selling terms could be standardized. There is, in some lines of products, a tendency on the part of the purchaser to insist on his personal lettering, the elimination of which would permit the manufacturer to carry larger stocks without ruming as much risk as this now entails. $A$ more scientific regulation of shipments and deliveries, based on experience and judgment, would result in a saving in freight charges, which is one of the chief items of expense. and would insure more prompt and sativfactory deliverios.

$102511^{\circ}-17-16$ 


\section{CHAPTER VIII.}

\section{WAGES AND LABOR CONDITIONS.}

\section{GENERAL DATA RELATING TO THE INDUSTRY.}

Among the large industries in this country glass manufacturing stands out conspicuously for the large proportion of the labor cost as compared with the total cost or with the selling value of the product. The range and average proportion of labor cost to the total sales value of the product is as follows:

Table 89. - Range and Average Percentage of Labor Cost on the Basis $c^{x}$ the Sales Value of the Product.

\begin{tabular}{|c|c|c|c|c|}
\hline Establishments making- & Group. & $\begin{array}{l}\text { Estab- } \\
\text { lish- } \\
\text { ments. }\end{array}$ & Range. & A rerage. \\
\hline 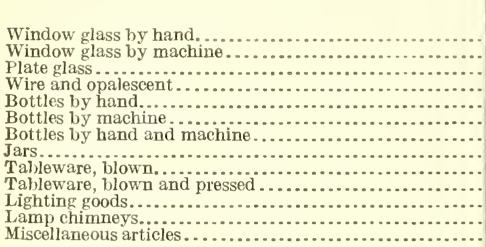 & $\begin{array}{l}\text { I } \\
\text { III } \\
\text { II } \\
\text { V } \\
\text { VI } \\
\text { VII } \\
\text { VIII } \\
\text { IX } \\
\text { XI } \\
\text { XII } \\
\text { XIII }\end{array}$ & $\begin{array}{r}37 \\
12 \\
6 \\
9 \\
26 \\
18 \\
27 \\
13 \\
8 \\
20 \\
18 \\
6 \\
13\end{array}$ & $\begin{array}{c}\text { Per cent. } \\
52.36 \text { to } 65.98 \\
36.86 \text { to } 57.84 \\
27.69 \text { to } 43.30 \\
18.19 \text { to } 37.64 \\
38.64 \text { to } 67.39 \\
18.20 \text { to } 56.60 \\
30.77 \text { to } 63.32 \\
22.32 \text { to } 54.72 \\
43.93 \text { to } 65.93 \\
35.51 \text { to } 68.75 \\
24.23 \text { to } 60.09 \\
47.61 \text { to } 71.69 \\
32.20 \text { to } 53.39\end{array}$ & $\begin{array}{r}\text { Per cent. } \\
56.80 \\
47.74 \\
33.76 \\
24.03 \\
53.00 \\
32.57 \\
48.27 \\
30.08 \\
53.68 \\
48.01 \\
40.15 \\
52.40 \\
44.85\end{array}$ \\
\hline Total.... & & 213 & 18.19 to 71.69 & 41.98 \\
\hline
\end{tabular}

This table shows that in only one group, wire and opalescent glass, is the cost of labor less than 30 per cent of the sales value. In nine of the groups it is over 40 per cent. The percentage is as high as $56.8 \mathrm{in}$ one group, window glass made by hand. In one lamp-chimney establishment it is 71.69 and in one machine bottle plant it is as low as 18.2, but the average for this group is 32.57. The average for all groups is 41.98 .

The percentages for labor as set forth in the following table for various industries, while not exactly comparable with the percentages above because they are on a net sales basis or on a manufacturing cost basis instead of sales value basis, nevertholess are accurate enough for the purposes of rough comparison.

Reports of the Bureau of Foreign and Domestic Commerce relating to the cost of production in five branches of the clothing industry during 1913 or 1914 show the percentages of direct and indirect labor cost, based on net sales, as follows: 
Table 90.-Percentage of Direct and Indirect Labor Cost in Clothing Indos. tries, BASED ON Net SALES.

\begin{tabular}{|c|c|c|}
\hline Industries. & Year. & $\begin{array}{l}\text { Labor } \\
\text { cost. }\end{array}$ \\
\hline $\begin{array}{l}\text { Women's muslin underwear... } \\
\text { Hosiery } \\
\text { Knit underwear. } \\
\text { Shirts and collars } \\
\text { Men's factory-made clothing }\end{array}$ & $\begin{array}{l}1913 \\
1913 \\
1913 \\
1913 \\
1914\end{array}$ & $\begin{array}{r}\text { Per ccnt. } \\
21.54 \\
25.77 \\
23.14 \\
30.69 \\
31.23\end{array}$ \\
\hline
\end{tabular}

The Bureau report on the pottery industry (1912) shows (p. 234) that the percentage of labor cost, based on the total cost of manufacture in a list of reprosentative establishments, ranged from 51.98 (lowest) to 66.40 (highost).

The Tariff Board's report on cotton manufactures (1910) shows (p. 394) the percentage each item of cost is of the total cost of manufacture in the various establishments reporting. From this report is obtained the following information showing the percentage labor cost is of the total cost of manufacture:

Table 91.-Range and Average Percentage of Labor Cost, on the Basis of the Total Cost, in the Manufacture of Cotton Textiles.

\begin{tabular}{|c|c|c|c|c|}
\hline Number of yarn. & Find of cloth. & $\begin{array}{l}\text { Mills re- } \\
\text { porting. }\end{array}$ & $\begin{array}{l}\text { Productive } \\
\text { labor range. }\end{array}$ & $\begin{array}{l}\text { General labor } \\
\text { range. }\end{array}$ \\
\hline $\begin{array}{l}12 \text { and under............ } \\
\text { Over } 12 \text { and not orer } 20 . \\
\text { Over } 20 \text { and not over } 30 . \\
\text { Over } 30 \text { and not over } 40 . \\
\text { Over } 40 \text { and not over } 50 . \\
\text { Over } 50 \ldots . . . . . . . . . .\end{array}$ & 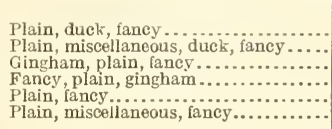 & $\begin{array}{r}8 \\
10 \\
12 \\
18 \\
4 \\
10\end{array}$ & $\begin{array}{l}\text { Per cent. } \\
\text { 11. } 63 \text { to } 27.54 \\
10.56 \text { to } 29.11 \\
12.55 \text { to } 30.41 \\
14.50 \text { to } 36.37 \\
17.18 \text { to } 36.03 \\
17.44 \text { to } 32.37\end{array}$ & $\begin{array}{l}\text { Per cent. } \\
0.28 \text { to } 1.39 \\
.53 \text { to } 1.72 \\
.37 \text { to } 1.53 \\
.32 \text { to } 2.14 \\
.55 \text { to } 1.13 \\
.66 \text { to } 1.81\end{array}$ \\
\hline
\end{tabular}

These reports are comparatively recent and are among the most exhaustive and accurate ever issued by the Government on similar lines. The figures show that in none of these industries, except pottery, does labor constitute nearly so much of the sales value or total cost as in glass.

The Census of Manufactures presents a list of 334 industries and shows for each, for the year 1914, the value of product, amount paid wage earners, and other data. In this list of 334 the average labor cost based on the value of product was 16.82 per cent; glass ranked thirteenth in labor cost with a percentage of 39.53 .

In the following table is presented the list of 13 industries having the highest percentage of labor cost, based on value of product, showing for each the value of product, expenditure for wages, and percentage of labor cost. 
Table 92.--Value of Product, Expense for Wages, and Percentage of Labor Cost in Industries Having Highest Labor Cost.

[Data from Census of Manufactures, 1914.]

\begin{tabular}{|c|c|c|c|}
\hline \multirow[b]{2}{*}{ Industries. } & \multirow[b]{2}{*}{$\begin{array}{l}\text { Value of } \\
\text { product. }\end{array}$} & \multicolumn{2}{|c|}{ Expense for wages. } \\
\hline & & Amount. & $\begin{array}{l}\text { Per cent } \\
\text { of value } \\
\text { of } \\
\text { produet. }\end{array}$ \\
\hline 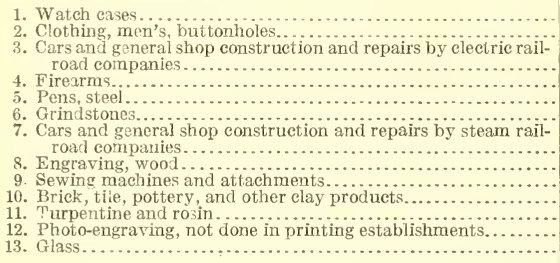 & $\begin{array}{r}\$ 7,831,000 \\
638,000 \\
38,577,000 \\
10,544,000 \\
513,000 \\
684,000 \\
514,041,000 \\
719,000 \\
21,392,000 \\
173,8 \approx 8,000 \\
20,990,000 \\
15,359,000 \\
123,085,000\end{array}$ & $\begin{array}{r}\$ 1,938,000 \\
326,000 \\
18,645,000 \\
5,067,000 \\
243,000 \\
323,000 \\
234,505,000 \\
310,000 \\
8,861,000 \\
71,896,000 \\
8,583,000 \\
6,167,000 \\
48,666,000\end{array}$ & $\begin{array}{l}52.71 \\
51.10 \\
48.33 \\
48.06 \\
47.37 \\
47.23 \\
45.62 \\
43.12 \\
41.42 \\
41.35 \\
40.89 \\
40.15 \\
39.53\end{array}$ \\
\hline
\end{tabular}

From these figures it will be seen that of the 12 industries outranking glass in the percentage paid for labor, only 2 exceed it in the value of product.

Of the 334 industries, all those whose products in 1914 exceeded in value $\$ 150,000,000$ are shown in the following table:

Table 93.-Value of Product and Expense for Wages in Industries Having Largest Production in 1914, and Percentage of Labor Cost.

[Data from Census of Mianufactures, 1914.]

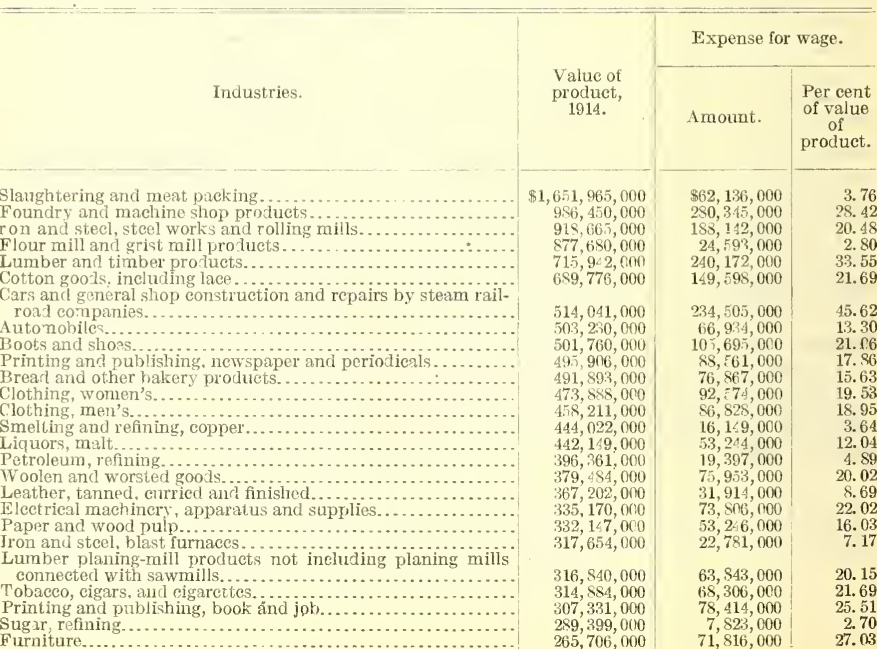


Table 93.- Value of Pronect and Expense for Wages in Indegtries Having Largest Production in 1914, and Percentage of Labor Cost-Concluded.

Hosicry and knit gools...

Silk goots, inelu ling throwsters

Bitt tar....

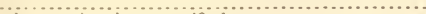

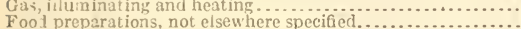

Oil, eotton seer, and eake.

Ligurors, distilled

Cars, steam railroad, not ineluding operations of railroad eom-

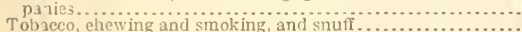

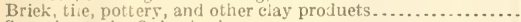

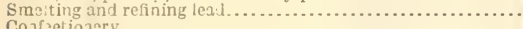

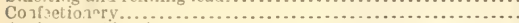

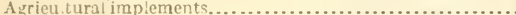

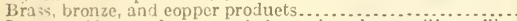

Structural ironwork, not made in steel works or rolling mills. .

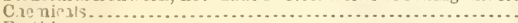

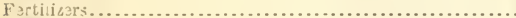

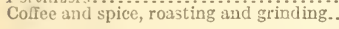

Total.

\begin{tabular}{|c|c|c|}
\hline \multirow[b]{2}{*}{$\begin{array}{l}\text { Value of } \\
\text { Produet, } \\
1914 .\end{array}$} & \multicolumn{2}{|c|}{ Expense for wage. } \\
\hline & I mount. & $\begin{array}{c}\text { Per eent } \\
\text { of vilue } \\
\text { of } \\
\text { produet. }\end{array}$ \\
\hline $\begin{array}{r}\$ 2: \$, 913,000 \\
2.4,011,000 \\
243,379,000 \\
223,611,000 \\
220,238,000 \\
219,333,000 \\
212,127,000 \\
206,779,000\end{array}$ & $\begin{array}{r}\$=9,7: \$, 000 \\
47,104,000 \\
10,119,000 \\
31,279,000 \\
26,802,000 \\
10, \$ 66.000 \\
8,>90,000 \\
3,994,000\end{array}$ & $\begin{array}{r}23.0 \mathrm{~S} \\
18.55 \\
4.16 \\
13.99 \\
12.17 \\
4.95 \\
4.00 \\
1.93 .\end{array}$ \\
\hline $\begin{array}{l}194,776,000 \\
175,281,000 \\
173,88,000 \\
171,579,000 \\
170,84.5,000 \\
164,087,000 \\
162.199,000 \\
1.9,378,000 \\
158,0.74,000 \\
153,196,000 \\
150,749,000\end{array}$ & $\begin{array}{r}41,394,000 \\
9,5: 0,000 \\
71.896,000 \\
6,134,000 \\
21,472,000 \\
34,593,000 \\
25,084,000 \\
33,429,000 \\
22,066,000 \\
10,532,000 \\
7,708,000\end{array}$ & $\begin{array}{r}21.25 \\
5.45 \\
41.35 \\
3 . .8 \\
12.57 \\
21.08 \\
15.26 \\
20.97 \\
13.96 \\
6.87 \\
2.99\end{array}$ \\
\hline $17,-160,149,000$ & $2,812,716,0 \mathrm{C} 0$ & 16.11 \\
\hline
\end{tabular}

In these 45 industries, each with a value of product exceeding $\$ 150,000,000$, the total ralue of product was $\$ 17,460,149,000$; the average value, $\$ 388,003,311$; and the average expense for wages, $\$ 62,504,80 J$, or 16.11 per cant of the ralue of product. In the glass industry the value of product was $\$ 123,0 \$ 5,000$, and the expense for wages $\$ 4 \$, 656,000$, or 39.53 per cent of the ralue of product.

In the 45 industries listed in the table there are 23 in which the expen ie for wages was less than the $\$ 48,656,000$ paid for wages in the glass industry. The total value of product of these 23 was $\$ 5,931,940,000$; the average value, $\$ 260,519,130$; the total expense for wages, $\$ 470,077,000$, and the average expense for wages, $\$ 20,43 \$, 130$. In these 23 industries the expense for wages was 7.92 per cent of the value of product.

\section{WAGES IN GLASS AND OTHER INDUSTRIES COMPARED.}

The following table shows the average wages per hour and average hours of labor per week in the highest-paid occupation in each of the specified industries for the years 1890 and 1903, as reported by United States Commissioner of Labor. 
Table 94.-Average Hourly Wages and Average Hours of labor of Employees in the Highest-Paid Important and Distinctive Occupation in Each of the Specified Industries, 1890 ANd 1903.

[Data from Annual Report of the United States Commissioner of Labor, 1904.]

\begin{tabular}{|c|c|c|c|c|}
\hline Industries. & Year. & Highest-paid occupation. & $\begin{array}{c}\text { Wages } \\
\text { per hour. }\end{array}$ & $\begin{array}{l}\text { Hours } \\
\text { per } \\
\text { week. }\end{array}$ \\
\hline icultural implements. & $\{1890$ & Molders, iron & $\$ 0.2676$ & 59. 66 \\
\hline & $\begin{array}{l}1903 \\
1890\end{array}$ & First hand & $\begin{array}{l}.3149 \\
.2^{297}\end{array}$ & $\begin{array}{l}59.16 \\
66.18\end{array}$ \\
\hline Bakery, br & 1903 & ... do .... & .2808 & 62.02 \\
\hline Blacksmithing and horseshoeing & 1890 & Horsesh & .2944 & 58.81 \\
\hline & $\begin{array}{l}1903 \\
1890\end{array}$ & $\begin{array}{l}\text { Horseshoer } \\
\text { Edge trimr }\end{array}$ & .3276 & 55.61 \\
\hline Boots and sho & 1903 & $\begin{array}{l}\text { Edge trimmers. } \\
\text { Goodvear stitch }\end{array}$ & $\begin{array}{l}.2982 \\
.3849\end{array}$ & $\begin{array}{l}57.41 \\
54.70\end{array}$ \\
\hline Boots and shoes, rubber & 1890 & Bootmakers... & .3053 & 60.00 \\
\hline & $\begin{array}{l}1903 \\
1 \$ 90\end{array}$ & Paper cutters. & $\begin{array}{l}.3580 \\
.2616\end{array}$ & $\begin{array}{l}60 . \mathrm{N0} \\
56.79\end{array}$ \\
\hline Boxe & 1903 & Scorers........ & .2599 & 56.67 \\
\hline Brick & 1890 & Molders, & .2106 & 58.89 \\
\hline Building tra & $\begin{array}{l}1903 \\
1890\end{array}$ & $\begin{array}{l}\text { Kiln burne } \\
\text { Bricklayer }\end{array}$ & $\begin{array}{l}.2^{2} 57 \\
.4316\end{array}$ & $\begin{array}{l}73.64 \\
5^{3} .22\end{array}$ \\
\hline Building trad & 1903 & .....do... & .5472 & 47.83 \\
\hline Butter and cheese. & $\begin{array}{l}1890 \\
1903\end{array}$ & Cheese makers. & $.16^{2} 5$ & 69.75 \\
\hline Cand & 1890 & Cand & $\begin{array}{l}.1750 \\
.2257\end{array}$ & $\begin{array}{l}69.16 \\
59.67\end{array}$ \\
\hline Candy.- & 1903 & ....do.... & $.2^{2377}$ & 59.63 \\
\hline Carpets. & 1890 & Loom fixers... & .2523 & 59.99 \\
\hline Carriages and wago & 1890 & Woodworkers. & $\begin{array}{r}.2650 \\
.2402\end{array}$ & $\begin{array}{l}58.90 \\
57.82\end{array}$ \\
\hline Carriages and wago & 1903 & ..do. & .2503 & 56.26 \\
\hline Cars, steam railroad & $\begin{array}{l}1890 \\
1903\end{array}$ & $\begin{array}{l}\text { Molder } \\
\text { do }\end{array}$ & .2877 & 59.42 \\
\hline & 1890 & Buttonhole makers, & .2109 & $\begin{array}{l}56.19 \\
59.00\end{array}$ \\
\hline Clothing, lactory pr & 1903 & ....do.... & .3056 & 54.00 \\
\hline Clothing, men's, custom work. & $\begin{array}{l}1890 \\
1903\end{array}$ & Cutters......... & .5280 & 58.17 \\
\hline & 1890 & Raisers... & $\begin{array}{r}.0393 \\
.2422\end{array}$ & $\begin{array}{l}56.48 \\
60.00\end{array}$ \\
\hline Coop & 1903 & .... & .3478 & 54.00 \\
\hline Cotton goods. & $\begin{array}{l}1890 \\
1903\end{array}$ & $\begin{array}{l}\text { Spinners, } 1 \\
\ldots . . . \text { do... }\end{array}$ & $\begin{array}{r}1696 \\
2139\end{array}$ & $\begin{array}{l}60.00 \\
58.85\end{array}$ \\
\hline Dyeing, finishing & 1890 & Printers.. & .4461 & 60.00 \\
\hline Dyeing, finlshing & 1903 & ....do... & .4614 & 58.58 \\
\hline Electrical apparatus and supplies. & $\begin{array}{l}1890 \\
1903\end{array}$ & $\begin{array}{l}\text { Pattern } \mathrm{m} \\
. . . \text { do ... }\end{array}$ & $\begin{array}{r}.3000 \\
3710\end{array}$ & $\begin{array}{l}59.00 \\
55.00\end{array}$ \\
\hline & 1890 & Millwright & .2588 & .63 .20 \\
\hline & 1903 & .... & .2774 & 61.31 \\
\hline Foundry and machine sho & $\begin{array}{l}1890 \\
1903\end{array}$ & Pattern makers.... & $\begin{array}{r}.2783 \\
3224\end{array}$ & 59.43 \\
\hline Fruits and vegetables, canning and pre- & 1890 & Canners... & .0 .1750 & 70.00 \\
\hline serving & 1903 & ..... & .1787 & 72.05 \\
\hline Furniture.. & $\begin{array}{l}1890 \\
1903\end{array}$ & $\begin{array}{l}\text { Carvers, hand...... } \\
\text { Upholsterers....... }\end{array}$ & .2402 & $\begin{array}{l}58.74 \\
54.19\end{array}$ \\
\hline & 1890 & Pipe fitters........... & .2504 & 60.00 \\
\hline & 1903 & Chargers ............. & .2529 & 74.85 \\
\hline Glass & $\begin{array}{l}1890 \\
1903\end{array}$ & $\begin{array}{l}\text { Blowers, window glass } . \ldots \ldots \ldots \\
\ldots\end{array}$ & $\begin{array}{r}.8202 \\
1.1728\end{array}$ & $\begin{array}{l}36.63 \\
36.78\end{array}$ \\
\hline Harn & 1890 & 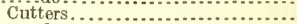 & $\begin{array}{r}1.17 .38 \\
.2598\end{array}$ & $\begin{array}{l}36.78 \\
59.00\end{array}$ \\
\hline & 1903 & 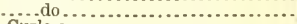 & .3053 & 57.57 \\
\hline Hats, fur. & 1890 & Curlers......................... & .4220 & 55. 19 \\
\hline nd knit gc & $\begin{array}{l}1903 \\
1890\end{array}$ & Knitters... & $\begin{array}{l}.4082 \\
.1753\end{array}$ & $\begin{array}{l}54.79 \\
60.00\end{array}$ \\
\hline nd knit st & 1903 & do... & 2017 & 56.86 \\
\hline Iron and steel, bar iron and stee & $\begin{array}{l}1890 \\
1903\end{array}$ & Rollers........................................... & .6262 & $\begin{array}{l}64.63 \\
62.96\end{array}$ \\
\hline ste & 1890 & (1) & .5469 & 54.86 \\
\hline d steel & 1903 & Blowers............................. & .6089 & 59.95 \\
\hline Iron and steel, blast furnace & $\begin{array}{l}1890 \\
1903\end{array}$ & Keepers. & $\begin{array}{l}.1844 \\
.1940\end{array}$ & $\begin{array}{l}84.00 \\
84.00\end{array}$ \\
\hline Iron and steel, blooming mills.. & 1890 & Rollers............................ & .4555 & 62.12 \\
\hline Tron and steel & $\begin{array}{l}1903 \\
1890\end{array}$ & 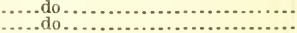 & $\begin{array}{l}.6768 \\
.3775\end{array}$ & $\begin{array}{l}54.17 \\
60.96\end{array}$ \\
\hline & 1903 & (1) & $\begin{array}{r}-5409 \\
-2811\end{array}$ & 61.38 \\
\hline Iron and steel, open-hearth steel. & $\begin{array}{l}1890 \\
1903\end{array}$ & $\begin{array}{l}\text { Melters... } \\
\text {......do... }\end{array}$ & $\begin{array}{l}.3811 \\
.4594\end{array}$ & 73.88 \\
\hline Iron and steel, rails. & 1890 & Rollers... & .6067 & 72.00 \\
\hline Leatl & $\begin{array}{l}1903 \\
1890\end{array}$ & Shavers.. & $\begin{array}{l}.7259 \\
.2607\end{array}$ & $\begin{array}{l}60.00 \\
59.64\end{array}$ \\
\hline Terantie & & (n) & .2190 & 59.56 \\
\hline Liqua & $\begin{array}{l}1890 \\
1903\end{array}$ & (n) & $\begin{array}{l}.6182 \\
.5868\end{array}$ & $\begin{array}{l}66.00 \\
66.00\end{array}$ \\
\hline Liquor, malt. & $\begin{array}{l}1890 \\
1903\end{array}$ & $\begin{array}{l}\text { Kettlemen... } \\
\text {....do....... }\end{array}$ & $\begin{array}{l}.2574 \\
.3197\end{array}$ & $\begin{array}{l}60.24 \\
52.91\end{array}$ \\
\hline
\end{tabular}


Table 94.-Average Hourly Wages and Average Hours of Labor of EyploteEs in the Highest-Paid Important and Distinctive Occupation in Each op the Specified Industries, 1890 and 1903-Concluded.

\begin{tabular}{|c|c|c|c|c|}
\hline Industries. & Year. & Highest-pa id occupation. & $\begin{array}{c}\text { Wages } \\
\text { per hour. }\end{array}$ & $\begin{array}{l}\text { Hours } \\
\text { per } \\
\text { week. }\end{array}$ \\
\hline Lithographing. & $\left\{\begin{array}{l}1890 \\
1903\end{array}\right.$ & $\begin{array}{l}\text { Engrarers.. } \\
\text {.....do..... }\end{array}$ & $\$ 0.3958$ & $\begin{array}{l}48.00 \\
48.00\end{array}$ \\
\hline Lumber.. & 1890 & Sawyers, band. & .4013 & $\begin{array}{l}48.00 \\
61.88\end{array}$ \\
\hline Marble and stone work. & & do. & .4451 & 60.90 \\
\hline Marble and stone work & $\left\{\begin{array}{l}1890 \\
1903\end{array}\right.$ & ....do. & $\begin{array}{l}.4454 \\
.5607\end{array}$ & $\begin{array}{l}51.54 \\
47.85\end{array}$ \\
\hline Musical instruments, organs. & $\left\{\begin{array}{l}1 \times 90 \\
1003\end{array}\right.$ & Voicers... & .4128 & 60.00 \\
\hline Musical instruments piano & 1890 & Tone reg & $\begin{array}{l}.4146 \\
.3259\end{array}$ & 57.60 \\
\hline Hesical instrinents, pano & 1903 & Key mak & .3667 & 54. 00 \\
\hline Oil, cottonseed. & $\{1903$ & $\begin{array}{l}\text { Pressers. } \\
\ldots . . \text { do... }\end{array}$ & $\begin{array}{l}.1284 \\
.1375\end{array}$ & S1. 00 \\
\hline Oil, linseed. & $\left\{\begin{array}{l}1890 \\
1903\end{array}\right.$ & Refiners................. & .2500 & \\
\hline & 18 & Grin & .1794 & $\begin{array}{l}60.00 \\
59.21\end{array}$ \\
\hline & & 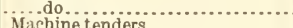 & $\begin{array}{r}-2067 \\
2193\end{array}$ & $\begin{array}{l}7.90 \\
8.54\end{array}$ \\
\hline Paper and wood pulp & $\left\{\begin{array}{l}1890 \\
1903\end{array}\right.$ & & .2634 & 59. 93 \\
\hline Petroleum, refining. & & C & $\begin{array}{r}2563 \\
2818\end{array}$ & 59. 20 \\
\hline Plar & 1. & $\mathrm{Car}$ & .2318 & 58.26 \\
\hline & 19 & . & & 55. 17 \\
\hline Pottery.. & & & .5297 & 45.75 \\
\hline Printing and publishing, book and job & $\left\{\begin{array}{l}18 \\
19\end{array}\right.$ & erators..... & $\begin{array}{r}.3254 \\
.4328\end{array}$ & $\begin{array}{l}59.94 \\
50.92\end{array}$ \\
\hline Print & & (n........... & .5695 & 48.90 \\
\hline & 1 & Rol & $\begin{array}{r}.5277 \\
1770\end{array}$ & $\begin{array}{l}47.75 \\
60.00\end{array}$ \\
\hline Rope a & & $\cdots$ & $\begin{aligned} 1870 \\
.1870\end{aligned}$ & 60.00 \\
\hline Shipbu & $\left\{\begin{array}{l}1 \\
1 \mathrm{~S}\end{array}\right.$ & 1... & $\begin{array}{r}3892 \\
.3797\end{array}$ & $\begin{array}{l}57.60 \\
50.77\end{array}$ \\
\hline ill & & bon.. & .2765 & 58.98 \\
\hline & & ( & & \\
\hline ing and me & $\begin{cases}18 \\
19\end{cases}$ & & & \\
\hline & & & & \\
\hline & & & & \\
\hline Stov & & & & $\begin{array}{l}5.52 \\
52,15\end{array}$ \\
\hline Street and sewers, contract wor & & & & 59.44 \\
\hline municingl wo & 1890 & .... & & $\begin{array}{l}55.85 \\
55.63\end{array}$ \\
\hline & & & & 50.50 \\
\hline Bugar & & Bo & $\begin{array}{l}.2284 \\
.2523\end{array}$ & $\begin{array}{l}65.12 \\
67.93\end{array}$ \\
\hline Tin & & & & 56. \\
\hline - & & & & \\
\hline Tobe & & Clga & .1572 & $\begin{array}{l}57.25 \\
57.24\end{array}$ \\
\hline Tob & & & & \\
\hline & & & & $\begin{array}{l}54.57 \\
59.14\end{array}$ \\
\hline SI & & & & \\
\hline Woolen and worsted g & 1903 & Loon & .2452 & $\begin{array}{l}59.40 \\
58.59\end{array}$ \\
\hline
\end{tabular}

a Female; all others male.

This table shows that of the 66 industries and occupations appearing in the table the highest wages per hour were paid in the glass industry, to window glass blowers, who received, in $1903, \$ 1.1738$ per hour. The next highest wage was paid to rollers in the bar iron and steel industry, $\$ 0.8331$ per hour-a difference of $\$ 0.3407$, or over 40 per cent less than the rate paid window-glass blowers. In only 27 of the 66 occupations were the wages over 35 cents per hour and in only 11 of the occupations were they over 50 cents. 
The following table shows the highest and lowest union wages per hour and the corresponding hours of labor per week in distinctive occupations in specified industries for cities in the north central division of the United States:

Table 94.-Range of Union Wages in Distinctive Occupations in Each Specified Industry and Hours of Labor per Week in North Central Citres, $a$ MAY, 1915.

[Data from Bulletin 194 of Bureau of Labor Statisties, 1916.]

\begin{tabular}{|c|c|c|c|c|}
\hline \multirow[b]{2}{*}{ Industries and occupations. } & \multicolumn{2}{|c|}{ Lowest wages. } & \multicolumn{2}{|c|}{ Highest wages. } \\
\hline & $\begin{array}{c}\text { Wages } \\
\text { per hour. }\end{array}$ & $\begin{array}{c}\text { Hours } \\
\text { per week. }\end{array}$ & $\begin{array}{c}\text { Wages } \\
\text { per hour. }\end{array}$ & $\begin{array}{l}\text { Hours } \\
\text { per week. }\end{array}$ \\
\hline Bakery: Foremen, maehine bakeries. & $\begin{array}{c}\text { Cents. } \\
35.2\end{array}$ & 54 & $\begin{array}{c}\text { Cents. } \\
56.3\end{array}$ & 54 \\
\hline $\begin{array}{l}\text { Brewing and b ttling: } \\
\text { Brewers, first men in eellar, fermenting room, and at kettles. }\end{array}$ & & & & \\
\hline 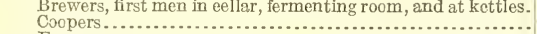 & 39.6 & 48 & $5 ? \cdot 1$ & $\begin{array}{l}48 \\
48\end{array}$ \\
\hline (1) & $\begin{array}{l}37.5 \\
35.3\end{array}$ & $\begin{array}{l}48 \\
56\end{array}$ & $\begin{array}{l}41.7 \\
51.0\end{array}$ & $\begin{array}{l}48 \\
48\end{array}$ \\
\hline Malsters, first..... & 37.5 & 48 & 67.4 & 48 \\
\hline $\begin{array}{l}\text { Build ng trades: } \\
\text { Brieklayers....... }\end{array}$ & & & & \\
\hline $\begin{array}{l}\text { Brieklayers........ } \\
\text { Carpenters....... }\end{array}$ & 65.0 & 44 & 75.0 & 44 \\
\hline Engenters........ & 40.0 & $\begin{array}{l}48 \\
54\end{array}$ & $\begin{array}{l}65.0 \\
75.0\end{array}$ & $\begin{array}{l}44 \\
44\end{array}$ \\
\hline Marhle setters............... & $\begin{array}{l}50.0 \\
68.8\end{array}$ & $\begin{array}{l}34 \\
48\end{array}$ & $\begin{array}{l}15.0 \\
71.9\end{array}$ & $\begin{array}{l}44 \\
44\end{array}$ \\
\hline 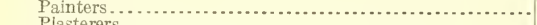 & 33.3 & 54 & 70.0 & 44 \\
\hline 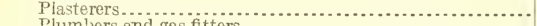 & 60.0 & 44 & 75.0 & 44 \\
\hline 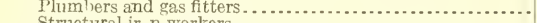 & 50.0 & 44 & 75.0 & 44 \\
\hline 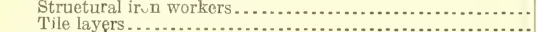 & 62.5 & 44 & 70.0 & 44 \\
\hline $\begin{array}{l}\text { Tile layers ......................... } \\
\text { Granite and stone: }\end{array}$ & 59.4 & 48 & 75.0 & 44 \\
\hline $\begin{array}{l}\text { Granite eutters, outside....... } \\
\text { St ne eutters }\end{array}$ & 51.3 & $44 \frac{1}{2}$ & 62.5 & 44 \\
\hline $\begin{array}{l}\text { St ne eutters.. } \\
\text { Metal trades: }\end{array}$ & 50.0 & 44 & 62.5 & 4 \\
\hline Blaeksmith, outside ................ & 65.0 & 44 & 75. 0 & 44 \\
\hline $\begin{array}{l}\text { Blacksmith, railroad shops............... } \\
\text { Builer makers, outside................ }\end{array}$ & 31.5 & 50 & 46.5 & 54 \\
\hline 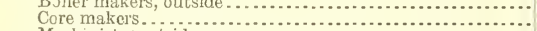 & $\begin{array}{l}45.0 \\
28.5\end{array}$ & $\begin{array}{l}44 \\
55\end{array}$ & $\begin{array}{l}62.5 \\
44.4\end{array}$ & $\begin{array}{l}48 \\
54\end{array}$ \\
\hline Maehinists, outside................. & 40.0 & 54 & 68.8 & 44 \\
\hline 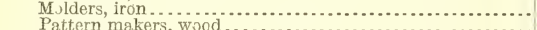 & 33.3 & 54 & 40.0 & 54 \\
\hline $\begin{array}{l}\text { Pattern makers, wood ......... } \\
\text { Printing and publishing, book and job: }\end{array}$ & 35.0 & 55 & 50.0 & 54 \\
\hline Bockbinders, finishers .................. & 36.7 & 49 & 47.9 & 48 \\
\hline 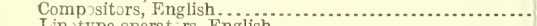 & 41.7 & 48 & 50.0 & 48 \\
\hline 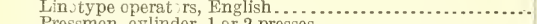 & 50.0 & 48 & 53.8 & 48 \\
\hline 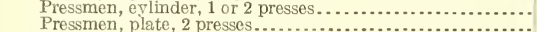 & 33.3 & 48 & 52.1 & 48 \\
\hline $\begin{array}{l}\text { Pressmen, plate, } 2 \text { presses............ } \\
\text { Printing and publishing, newspaper: }\end{array}$ & 25.0 & 48 & 35.4 & 48 \\
\hline Compositor, English, day $\ldots \ldots . . . . .$. & 57.0 & 48 & 62.0 & 45 \\
\hline Compositor, English, night ........... & 56.0 & 48 & 67.0 & 45 \\
\hline Lin type operators, English, day.. & 50.0 & 48 & 55.0 & 48 \\
\hline Lin otype operators, English, night... & 55.0 & 48 & 62.5 & 48 \\
\hline 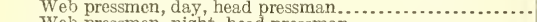 & 37.5 & 48 & 57.5 & 48 \\
\hline Web pressmen, night, head pressman. & 37.5 & 48 & 61.3 & 45 \\
\hline $\begin{array}{l}\text { Stere typer, day } \\
\text { Stereotyper, night }\end{array}$ & 37.5 & 48 & 56.3 & 48 \\
\hline Stereotyper, nigh & 37.5 & 48 & 60.0 & \\
\hline
\end{tabular}

a Ineludes Chieago, Ill, Cineinnati, Ohis, Cleveland, Ohio, Detroit, Mich., Grand Rapids, Mich., Indianap lis, Ind., Kansas City, Mo., Milwaukee, Wis., Minneapolis, Minn., O maha, Nebr., Peoria, Ill., St. Louis, Mo., St. Paul, Minn.

Of the 36 occupations shown in this table the highest union scale of wages for 20 , or 55.6 per cent, was 60 cents or over per hour, and for 6 of these 20 , or $16 \frac{2}{3}$ per cent of the total number, it was 75 cents per hour. The average hours per week in 15 of the 36 occupations was 44 hours and in 15 others 49 hours.

The following table, prepared from Table 100, shows for selected occupations of the glass industry the highest wages per hour, average wages per hour, and average hours per week: 
Table 95.- - Mighest Wages per Hour, Average Wages per Hour, and Averafe Hours per Week iN Selected Occupations in the Glass Industry,

\begin{tabular}{|c|c|c|c|}
\hline Group and oecupation. & Highest wages per hour. & $\begin{array}{l}\text { A verage } \\
\text { wagesper } \\
\text { hour. }\end{array}$ & $\begin{array}{l}\text { Average } \\
\text { hours per } \\
\text { week. }\end{array}$ \\
\hline 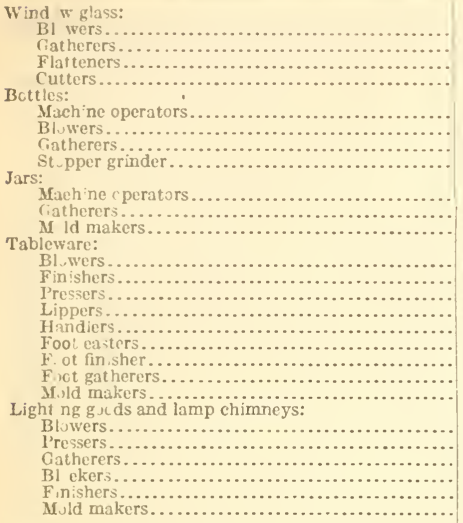 & 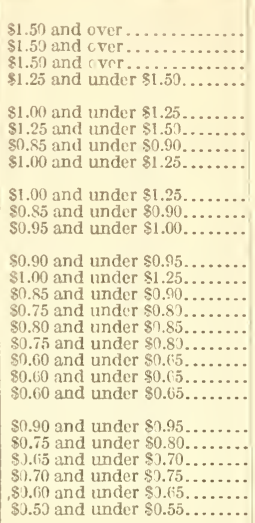 & $\begin{array}{l}\$ 0.9631 \\
.8760 \\
.8206 \\
.6851 \\
.5969 \\
.6020 \\
.5199 \\
.9270 \\
.5859 \\
.4970 \\
.4170 \\
.7000 \\
.5350 \\
.5783 \\
.6989 \\
.7178 \\
.7711 \\
.4949 \\
.5919 \\
.4230 \\
.5461 \\
.5399 \\
.3859 \\
.5390 \\
.5189 \\
.5768\end{array}$ & $\begin{array}{l}43.6 \\
43.5 \\
55.8 \\
59.0 \\
48.6 \\
46.3 \\
45.2 \\
53.0 \\
46.1 \\
46.3 \\
55.4 \\
45.2 \\
44.9 \\
44.6 \\
53.0 \\
46.5 \\
44.6 \\
45.3 \\
44.6 \\
52.1 \\
49.9 \\
50.6 \\
5 J .8 \\
45.8 \\
45.4 \\
32.1\end{array}$ \\
\hline
\end{tabular}

This table shows that in 9 of the occupations, including the 4 occupations in window glass and 3 of the 4 in bottles, the highest wage per hour was $\$ 1$ and over. In none of the occupations was the highest wage less than 50 cents per hour. The highest arerage wage per hour was $\$ 0.9331$ for blowers, window glass, and the lowest was $\$ 0.3850$ for gatherers, lighting goods and lamp chimneys. In 10 of the 26 occupations the average wage was over 60 cents per hour.

The range of average hours per week, omitting mold makers, was from 43.5 to 59 .

This table also shows that in 19 of the 26 occupations appearing in it the wages were higher than 75 cents per hour, the highest union wages paid in any of the trades shown in Table 94 preceding. In three of them the wages were 100 per cent higher and in two others they were $66 \frac{2}{3}$ per cent higher. 
EMPLOYEES BY SEX AND AGE.

The number of employees, male and female, over and under 16 years of age, in 208 factories during the busy season of their last business year, not including the office force, appears in the following table:

Table 96.-Number of Male and Female Employees in Factories (Not Office) Over 16 and Under 16 Years of Age During the Busy Season.

\begin{tabular}{|c|c|c|c|c|c|c|c|c|}
\hline \multirow{2}{*}{ Establishments making- } & \multirow{2}{*}{ Group. } & \multirow{2}{*}{$\begin{array}{l}\text { Estab- } \\
\text { lish- } \\
\text { ments. }\end{array}$} & \multicolumn{2}{|c|}{ Male. } & \multicolumn{2}{|c|}{ Female. } & \multicolumn{2}{|c|}{ Total. } \\
\hline & & & $\begin{array}{c}\text { Over } \\
16 .\end{array}$ & $\begin{array}{c}\text { Under } \\
16 .\end{array}$ & $\begin{array}{l}\text { Over } \\
16 .\end{array}$ & $\begin{array}{c}\text { Under } \\
16 .\end{array}$ & $\begin{array}{c}\text { Num- } \\
\text { ber. }\end{array}$ & $\begin{array}{l}\text { Aver- } \\
\text { age. }\end{array}$ \\
\hline 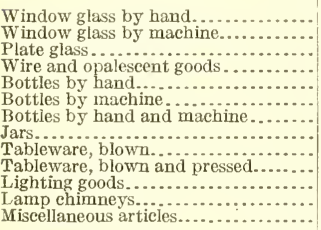 & $\begin{array}{r}\text { I } \\
\text { II } \\
\text { III } \\
\text { IV } \\
\text { V } \\
\text { V1 } \\
\text { VII } \\
\text { VIII } \\
\text { IX } \\
\text { XI } \\
\text { XII } \\
\text { XIII }\end{array}$ & $\begin{array}{r}37 \\
12 \\
6 \\
9 \\
25 \\
18 \\
26 \\
13 \\
8 \\
18 \\
17 \\
6 \\
13\end{array}$ & $\begin{array}{l}5,793 \\
2,398 \\
2,583 \\
1,256 \\
4,450 \\
6,521 \\
8,269 \\
3,069 \\
1,642 \\
6,197 \\
8,582 \\
1,398 \\
1,960\end{array}$ & $\begin{array}{r}85 \\
64 \\
290 \\
54 \\
79 \\
407 \\
221 \\
76 \\
62\end{array}$ & $\begin{array}{r}194 \\
328 \\
295 \\
242 \\
440 \\
981 \\
1,579 \\
152 \\
521\end{array}$ & $\begin{array}{r}4 \\
10 \\
4 \\
53 \\
61 \\
26 \\
\ldots \ldots\end{array}$ & $\begin{array}{r}5,793 \\
2,427 \\
2,583 \\
1,256 \\
4,733 \\
6,913 \\
8,864 \\
3,369 \\
2,214 \\
7,646 \\
10,408 \\
1,626 \\
2,543\end{array}$ & $\begin{array}{l}156.6 \\
202.3 \\
430.5 \\
139.6 \\
189.3 \\
384.1 \\
340.9 \\
259.2 \\
276.8 \\
424.8 \\
612.2 \\
271.0 \\
195.6\end{array}$ \\
\hline Total......... & & 208 & 54,118 & 1,338 & 4,761 & 158 & 60,375 & 290.3 \\
\hline
\end{tabular}

This table shows that of the 60,375 employees reported by the 208 establishments, 54,118, or 89.64 per cent, were males over 16 years of age and 4,761, or 7.89 per cent, were females over 16 years of age. The number of employees, male and female, under 16 years of age was 1,496 , or 2.48 per cent, of the total number. The total number of females was 4,919, or 8.15 per cent of all the employees. (Census statistics for the entire industry are given in Table 5, p. 26.)

The average number of employees per establishment in all the groups was 290.3. Plate glass and tableware had more than the other groups, the number being 430.5 and 424.8, respectively. Wire and opalescent goods and handmade bottles had fewer than any of the others, the figures being 139.6 and 189.3, respectively. Women were employed much more extensively in tableware and lighting goods than in the other groups. In four of the groups, window glass by hand, window glass by machine, plate glass, and wire and opalescent goods, no women were employed.

\section{DAYS WORKED DURING YEAR.}

The following table shows the highest, lowest, and average number of days that the factories in each group were operated during their last business year and the three previous years, so far as reported by the establishments. 
Table 97. -Number of Dars Factories Were Operated During their last Business Year and Average During the Three Previous Years.

\begin{tabular}{|c|c|c|c|c|c|}
\hline \multirow{2}{*}{ Group. } & \multirow{2}{*}{ Establishments making- } & \multirow{2}{*}{$\begin{array}{l}\text { Estab- } \\
\text { lish- } \\
\text { ments } \\
\text { reported. }\end{array}$} & \multicolumn{3}{|c|}{ Number of days operated. } \\
\hline & & & Highest. & Lowest. & A verage. \\
\hline I & $\begin{array}{l}\text { W'indow glass by hand: } \\
\text { Last business year......... } \\
\text { A verage. } 3 \text { previous years.. } \\
\text { Window glass by machine: }\end{array}$ & $\begin{array}{l}36 \\
31\end{array}$ & $\begin{array}{l}224 \\
240\end{array}$ & $\begin{array}{r}83 \\
109\end{array}$ & $\begin{array}{l}172.1 \\
192.3\end{array}$ \\
\hline & $\begin{array}{l}\text { Window glass by machine: } \\
\text { Last business year......... } \\
\text { A verage. } 3 \text { previous years.. }\end{array}$ & $\begin{array}{r}12 \\
9\end{array}$ & $\begin{array}{l}365 \\
365\end{array}$ & $\begin{array}{l}147 \\
140\end{array}$ & $\begin{array}{l}245.8 \\
243.6\end{array}$ \\
\hline III & $\begin{array}{l}\text { Plate glass: } \\
\text { Last business year........... } \\
\text { A verage, } 3 \text { previous rears... }\end{array}$ & $\begin{array}{l}6 \\
5\end{array}$ & $\begin{array}{l}299 \\
299\end{array}$ & $\begin{array}{l}251 \\
2 \div 0\end{array}$ & $\begin{array}{l}273.0 \\
275.5 \\
2 \$ 3.3\end{array}$ \\
\hline IV & $\begin{array}{l}\text { Wire and opalescent goods: } \\
\text { Last business year.......... } \\
\text { Average. } 3 \text { previous years.. } \\
\text { Bottles by hand: }\end{array}$ & $\begin{array}{l}9 \\
7\end{array}$ & $\begin{array}{l}340 \\
340\end{array}$ & $\begin{array}{l}180 \\
255\end{array}$ & $\begin{array}{l}2 \$ 3.3 \\
269.8 \\
302.1\end{array}$ \\
\hline VI & 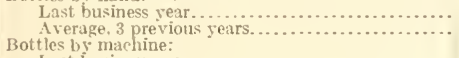 & $\begin{array}{l}23 \\
22\end{array}$ & $\begin{array}{l}343 \\
343\end{array}$ & $\begin{array}{l}150 \\
170\end{array}$ & $\begin{array}{l}259.2 \\
263.0\end{array}$ \\
\hline VII & 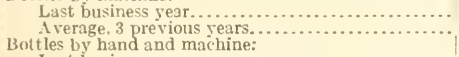 & $\begin{array}{l}14 \\
11\end{array}$ & $\begin{array}{l}345 \\
345\end{array}$ & $\begin{array}{l}150 \\
242\end{array}$ & $\begin{array}{l}271.5 \\
291.5\end{array}$ \\
\hline VIII & 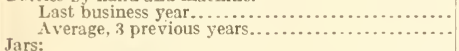 & $\begin{array}{l}24 \\
19\end{array}$ & $\begin{array}{l}346 \\
351\end{array}$ & $\begin{array}{l}122 \\
210\end{array}$ & $\begin{array}{l}261.3 \\
287.4\end{array}$ \\
\hline $\mathrm{IX}$ & 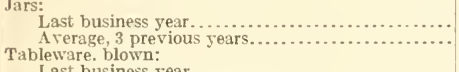 & $\begin{array}{l}13 \\
12\end{array}$ & 345 & $\begin{array}{l}216 \\
250\end{array}$ & $\begin{array}{l}257.0 \\
307.3\end{array}$ \\
\hline $\mathrm{X}$ & 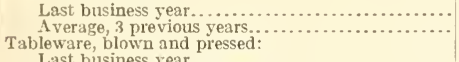 & $\begin{array}{l}5 \\
5\end{array}$ & $\begin{array}{l}330 \\
336\end{array}$ & $\begin{array}{l}215 \\
294\end{array}$ & $\begin{array}{l}293.3 \\
314.0\end{array}$ \\
\hline XI & 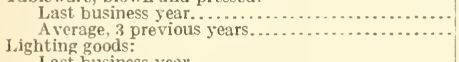 & $\begin{array}{l}12 \\
10\end{array}$ & $\begin{array}{l}351 \\
351\end{array}$ & $\begin{array}{l}216 \\
280\end{array}$ & $\begin{array}{l}299.0 \\
317.0\end{array}$ \\
\hline XII & 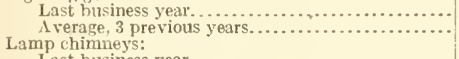 & $\begin{array}{l}17 \\
16\end{array}$ & $\begin{array}{l}350 \\
350\end{array}$ & $\begin{array}{l}248 \\
200\end{array}$ & $\begin{array}{l}289.2 \\
287.3\end{array}$ \\
\hline XIII & 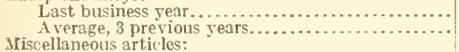 & $\begin{array}{l}6 \\
6\end{array}$ & $\begin{array}{l}315 \\
315\end{array}$ & $\begin{array}{l}278 \\
220\end{array}$ & $\begin{array}{l}296.0 \\
282.9\end{array}$ \\
\hline & 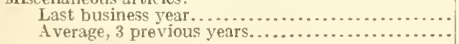 & $\begin{array}{r}11 \\
8\end{array}$ & $\begin{array}{l}350 \\
350\end{array}$ & $\begin{array}{l}250 \\
265\end{array}$ & $\begin{array}{l}304.1 \\
311.9\end{array}$ \\
\hline
\end{tabular}

This table shows that in three of the groups, window glass by machine, lighting goods, and lamp chimnoys, the factories were operated slightly longer during the last business year than was the average for the three years preceding. In all the other groups the number of days operated during the last business year was considerably less than the average for the three years preceding, except in miscellaneous articles, where the diflerence was slight.

Factories making window glass by hand operated a less number of days than any of the other groups, the number for the last year being 172.1 and for the three preceding years 192.3 Factories making window glass by machine were next with 245.8 and 243.6 for the respective periods. In all other groups the number of days in operation was much higher than these figures. 'The group making miscellaneous articles was highest in the number of days operated, the figures for the two periods being 304.1 and 311.9 , respectively.

\section{NUMBER OF WMPLOYEES IN TIE INDUSTRY.}

The data in the following table, from the Bureau of the Census, show the average number of wage earners in glass factories in the United States, the number being given by States and by hours of labor per week for the years 1909 and 1914 . 
Table 98.-Average Number of Wage Earners in Establishments, with Specified Number of Hours of Labor per Week, by States.

[Data from the Bureau of the Census.]

\begin{tabular}{|c|c|c|c|c|c|c|c|c|c|c|}
\hline \multirow[b]{2}{*}{ States. } & \multirow[b]{2}{*}{ Year. } & \multirow[b]{2}{*}{ Total. } & \multicolumn{8}{|c|}{$\begin{array}{c}\text { Average number in establishments where the prevailing hours of } \\
\text { labor per week were- }\end{array}$} \\
\hline & & & $\begin{array}{l}48 \text { and } \\
\text { under. }\end{array}$ & $\begin{array}{c}\text { Be- } \\
\text { tween } \\
48 \text { and } \\
54 .\end{array}$ & 54. & $\begin{array}{c}\text { Be- } \\
\text { tween } \\
54 \text { and } \\
60 .\end{array}$ & 60. & $\begin{array}{c}\text { Be- } \\
\text { tween } \\
60 \text { and } \\
72 .\end{array}$ & 72. & $\begin{array}{l}\text { Orer } \\
72 .\end{array}$ \\
\hline California & $\left\{\begin{array}{l}1914 \\
1909\end{array}\right.$ & $\begin{array}{r}1,084 \\
610\end{array}$ & 203 & $\begin{array}{l}856 \\
100\end{array}$ & $\begin{array}{r}25 \\
5 \leq 0\end{array}$ & & & & & \\
\hline Illinois & $\left\{\begin{array}{l}1911 \\
1009\end{array}\right.$ & 3,764 & 180 & 1,203 & 663 & 1,398 & 320 & & & \\
\hline Indiang & 1914 & $\begin{array}{l}3,507 \\
9,390\end{array}$ & $\begin{array}{r}94 \\
590\end{array}$ & 3,361 & 2,290 & $1,2 i 1$ & $\begin{array}{r}676 \\
1,903\end{array}$ & & $2 \div 0$ & $\begin{array}{l}1,4 C 0 \\
\ldots \ldots\end{array}$ \\
\hline Indiana & 1909 & 9,544 & $1,8 \check{0} 0$ & 2,109 & 1,978 & 1,575 & 1,584 & 448 & $\cdots$ & $\cdots$ \\
\hline Maryland. & $\begin{array}{l}1914 \\
1909\end{array}$ & $\begin{array}{l}1,184 \\
1,052\end{array}$ & $\begin{array}{l}1 \dashv 0 \\
181\end{array}$ & 937 & $\begin{array}{l}107 \\
389\end{array}$ & ...... & ......... & & & - \\
\hline Missouri. & 1914 & 2,218 & 11 & 448 & 35 & & 1,754 & & & \\
\hline & $\begin{array}{l}1909 \\
1914\end{array}$ & $\begin{array}{l}1,755 \\
5,78 t\end{array}$ & 864 & $\begin{array}{r}102 \\
3,602\end{array}$ & 918 & $2 !$ & 151 & $1,0 \approx 6$ & $\begin{array}{l}363 \\
219\end{array}$ & \\
\hline rar & 1909 & 5,651 & 1,007 & 2,451 & 420 & 1,773 & & & & \\
\hline New York & $\begin{array}{l}1914 \\
1909\end{array}$ & $\begin{array}{l}3,089 \\
3,114\end{array}$ & $\begin{array}{l}344 \\
369\end{array}$ & $\begin{array}{l}882 \\
776\end{array}$ & $\begin{array}{l}700 \\
2 \odot 0\end{array}$ & $\begin{array}{r}1,107 \\
328\end{array}$ & $\begin{array}{r}56 \\
1,361\end{array}$ & & & \\
\hline Ohio. & $\begin{array}{l}1914 \\
1902\end{array}$ & 10,997 & $\begin{array}{r}784 \\
\end{array}$ & 4,515 & 2,916 & $\begin{array}{r}198 \\
2.501\end{array}$ & 2,276 & 118 & 190 & ............ \\
\hline Oklahoma & 1914 & $1,270^{-}$ & 856 & 156 & 258 & 2,001 & & $\cdots$ & & \\
\hline Pennsylvania. & $\begin{array}{l}1914 \\
1909\end{array}$ & $\begin{array}{l}23,103 \\
23,710\end{array}$ & $\begin{array}{l}4,494 \\
3,019\end{array}$ & $\begin{array}{l}7,157 \\
4,-03\end{array}$ & $\begin{array}{l}2,734 \\
1,645\end{array}$ & $\begin{array}{l}2,114 \\
6,235\end{array}$ & $\begin{array}{l}2,859 \\
5,468\end{array}$ & $\begin{array}{l}2,432 \\
1,257\end{array}$ & & $\begin{array}{r}1,786 \\
1,650\end{array}$ \\
\hline Virgimia & -1914 & 603 & 163 & 343 & 100 & ......... & ......... & ......... & & ...... \\
\hline W & $\begin{array}{l}1909 \\
1914\end{array}$ & $\begin{array}{r}521 \\
8,889\end{array}$ & 2,315 & 3,931 & $\begin{array}{r}59 \\
532\end{array}$ & 983 & 1,128 & . & & $\cdots$ \\
\hline W & 1909 & 6,190 & 1,866 & 2,252 & 1,424 & 385 & $2 \mathrm{~s} 3$ & 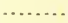 & & \\
\hline All other States & $\begin{array}{l}1914 \\
1909\end{array}$ & $\begin{array}{l}2,591 \\
3,0.5\end{array}$ & $\begin{array}{l}1,261 \\
1,145\end{array}$ & $\begin{array}{l}230 \\
221\end{array}$ & $\begin{array}{l}116 \\
166\end{array}$ & $\begin{array}{l}417 \\
902\end{array}$ & $\begin{array}{l}291 \\
273\end{array}$ & $\ldots \ldots$ & & $\begin{array}{l}2.6 \\
355\end{array}$ \\
\hline Total. & $\left\{\begin{array}{l}1914 \\
1909\end{array}\right.$ & $\begin{array}{l}74,502 \\
68,911\end{array}$ & $\begin{array}{l}12,205 \\
11,358\end{array}$ & $\begin{array}{l}27,651 \\
16, \mathrm{C} 03\end{array}$ & $\begin{array}{r}11,394 \\
8,707\end{array}$ & $\begin{array}{r}7,458 \\
13,323\end{array}$ & $\begin{array}{l}10,743 \\
10,764\end{array}$ & $\begin{array}{l}2,550 \\
3,423\end{array}$ & $\begin{array}{l}439 \\
668\end{array}$ & $\begin{array}{l}2,062 \\
3,465\end{array}$ \\
\hline
\end{tabular}

This table shows that the number of persons employed in tho industry increased from 68,911 in 1909 to 74,502 in 1914. The two States in which the greatest numbers were employed, Pennsylvania and Ohio, practically stood still during this period. Of the two States ranking next in point of numbers, Indiana and West Virginia, the former had a small loss, while the latter had a large gain-about 44 per cent. California and Missouri also had good gains.

Of the 213 establishments for which cost data were obtained, 132 furnished pay rolls of 19,092 wage earners employed in their plants, 18,235 of whom were male and 857 female. The details are shown in the following table: 
Table 99.-Number of Employees, by sex, in 132 Establishiments Reporting WAGE DATA.

\begin{tabular}{|c|c|c|c|c|c|c|c|c|}
\hline Items. & $\begin{array}{l}\text { Window } \\
\text { glass. }\end{array}$ & $\begin{array}{l}\text { Plate } \\
\text { glass. }\end{array}$ & Bottles. & Jars. & $\begin{array}{l}\text { Table- } \\
\text { ware. }\end{array}$ & $\begin{array}{l}\text { Lighting } \\
\text { goodls and } \\
\text { lamp } \\
\text { cł imneys. }\end{array}$ & $\begin{array}{l}\text { Miscel- } \\
\text { laneotis. }\end{array}$ & Total. \\
\hline $\begin{array}{l}\text { Number of establish- } \\
\text { ments reporting- } \\
\text { Male employees } \\
\text { only ........... } \\
\text { Male and remale } \\
\text { employees...... }\end{array}$ & 30 & $\begin{array}{c}3 \\
\ldots\end{array}$ & $\begin{array}{r}39 \\
4\end{array}$ & $i$ & $\begin{array}{r}8 \\
15\end{array}$ & $\begin{array}{c}7 \\
10\end{array}$ & $\begin{array}{l}9 \\
\ldots\end{array}$ & $\begin{array}{r}103 \\
29\end{array}$ \\
\hline Total............ & 30 & 3 & 43 & 7 & 23 & 17 & 9 & 132 \\
\hline $\begin{array}{l}\text { Number of employ- } \\
\text { ees } \\
\text { Male ............... } \\
\text { Female............. }\end{array}$ & $\begin{array}{l}2,772 \\
\cdots \ldots \ldots\end{array}$ & 1,049 & $\begin{array}{r}6,716 \\
135\end{array}$ & 1,895 & $\begin{array}{r}2,566 \\
398\end{array}$ & $\begin{array}{r}3,063 \\
324\end{array}$ & 174 & $\begin{array}{r}18,235 \\
857\end{array}$ \\
\hline Total.......... & 2,772 & 1,049 & 6,851 & 1,895 & 2,964 & 3,387 & 174 & 19,092 \\
\hline
\end{tabular}

\section{AVERAGE WORKING HOURS AND EARNINGS.}

In other sections of this report establishments are grouped according to the predominence of the article manufactured and the method employed in manufacturing. In the treatment of wage data the same divisions could not be made without going into much useless detail; therefore, two, and in one case three, groups were consolidated: "Window glass by hand" and "Window glass by machine," Groups I and II, were consolidated under "Window glass;" "Bottles by hand," "Bottles by machine," and "Bottles by hand and machine," Groups V, VI, and VII, under "Bottles;" "Tableware, blown," and "Tableware, blown and pressed," Groups IX and X, under "Tableware;" "Lighting goods" and "Lamp chimneys," Groups XI and XII, under "Lighting goods and lamp chimneys." No labor data were obtained from plants making wire and opalescent glass.

The above changes reduce the 13 groups shown in other sections of this report to 7 in the section dealing with wages.

The following table, 100, shows the arerage full-time hours and earnings per week, and average classified rates of wages per hour, by occupations, States, and sex. The arerage rates of wages per hour were computed by dividing the actual earnings of each employee by the number of hours rorked, as taken from the pay roll. The averuge classified rate of earnings per hour was ascertained by dividing the argregate earnings per hour of all employees by the total number of employees; the average full-time hour's per week, by dividing the aggregate number of hours that all employees workol by the number of employees; and the average full-time earnings per week, by multiplying the average full-time hours per woek by the average rate of earnings per hour. 


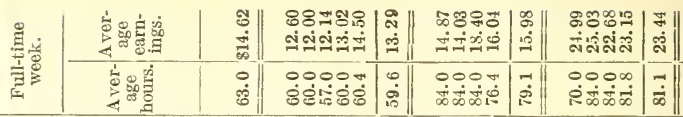

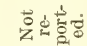

क्रे क्ष

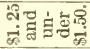

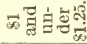

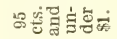

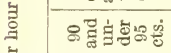

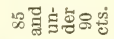

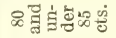

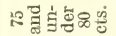

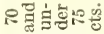

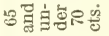

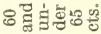

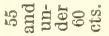

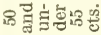

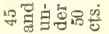

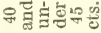

以

คำ

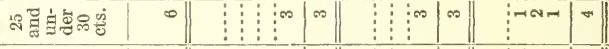

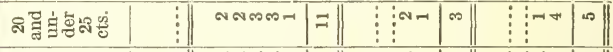

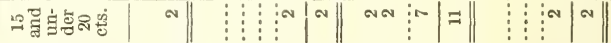

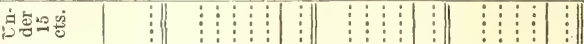

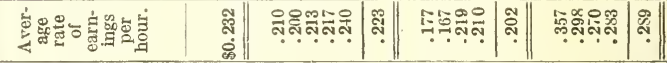

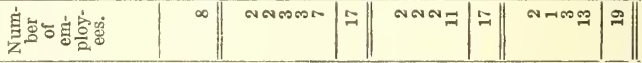

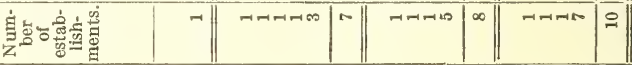

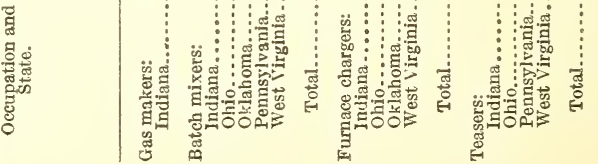




\begin{tabular}{|c|c|c|c|c|c|c|c|c|c|c|c|c|c|c|}
\hline$\stackrel{\pi}{+\infty}$ & $\mid \begin{array}{l}\infty \\
=\end{array}$ & $\stackrel{\text { s. }}{\vdots}$ & 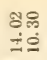 & 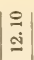 & 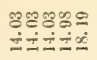 & $\mid \begin{array}{l}\mathbb{5} \\
\vdots \\
-\end{array}$ & $\begin{array}{l}\mathscr{8} \\
\dot{8}: \\
\dot{9}:\end{array}$ & $\begin{array}{l}\stackrel{0}{1} \\
\stackrel{0}{0}\end{array}$ & 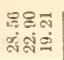 & $\left|\begin{array}{c}\hat{b} \\
\dot{a}\end{array}\right|$ & $\begin{array}{l}8=1 \\
9: 0\end{array}$ & $\left|\begin{array}{l}0 \\
\infty \\
\hdashline\end{array}\right|$ & 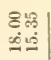 & $\mid$ \\
\hline $\begin{array}{l}00 \\
\text { îं }\end{array}$ & \&ें & $\begin{array}{l}\dot{0} \\
\dot{q}\end{array}$ & $\begin{array}{l}\circ 0 \\
0.0 \\
\text { \&. }\end{array}$ & ช્. & 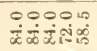 & 5 & $\begin{array}{l}00 \\
\dot{\alpha} \dot{\alpha}\end{array}$ & $\begin{array}{l}0 \\
\alpha \\
\alpha \\
0\end{array}$ & $\begin{array}{l}0013 \\
\dot{+}+\alpha \dot{x}\end{array}$ & $\vec{x}$ & $\begin{array}{l}00 \\
\dot{\infty} \infty \\
\alpha \neq\end{array}$ & $\begin{array}{l}0 \\
\infty \\
\alpha \\
0\end{array}$ & 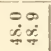 & $\begin{array}{l}0 \\
\dot{0} \\
\stackrel{1}{0}\end{array}$ \\
\hline
\end{tabular}

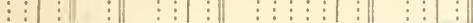

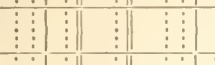

$\vdots$

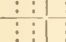

$\vdots$

$\vdots \vdots$

$\vdots \vdots 1$

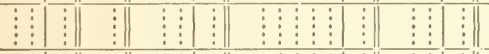

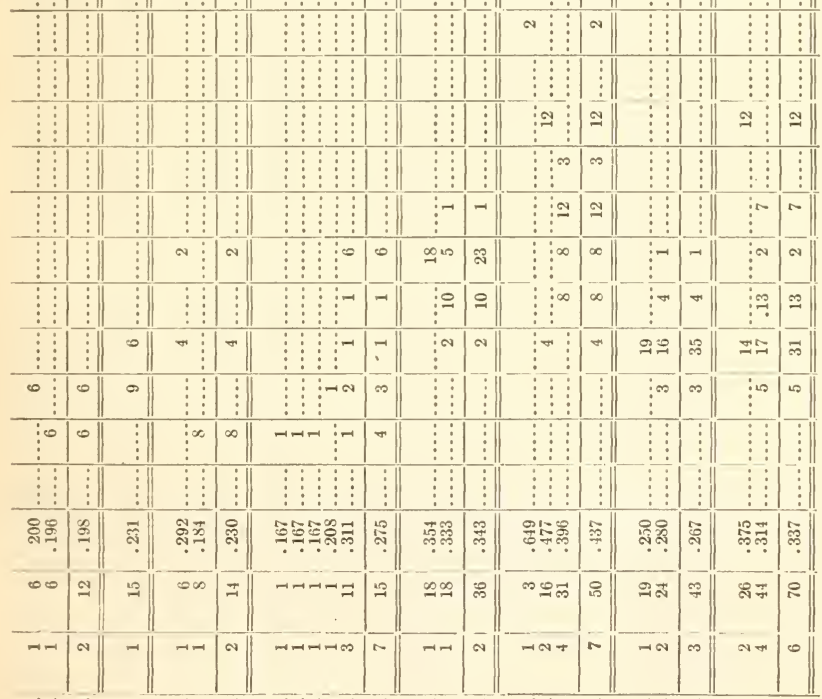

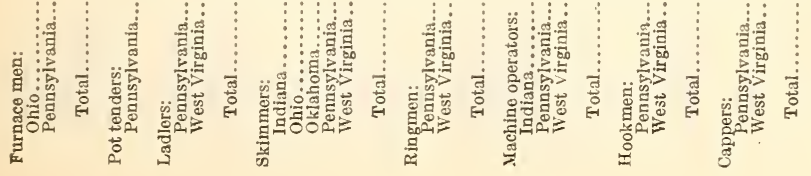




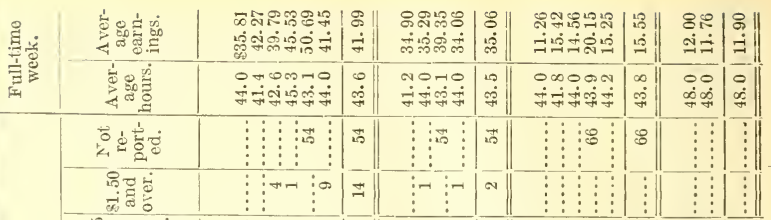

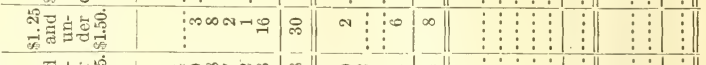

उचี艹

\begin{tabular}{|c|c|}
\hline $5-1$ & 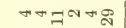 \\
\hline
\end{tabular}

\begin{tabular}{|c|c|c|c|}
\hline 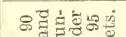 & 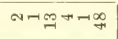 & 8 & 0・न \\
\hline
\end{tabular}

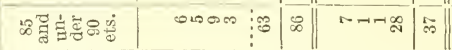

வ

\begin{tabular}{|c|c|c|c|}
\hline 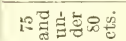 & 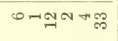 & $\infty$ & Narg \\
\hline
\end{tabular}

\begin{tabular}{|c|c|c|c|}
\hline 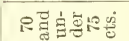 & $0: 20-102$ & జా & n-s \\
\hline
\end{tabular}

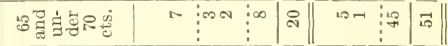

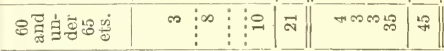

หน

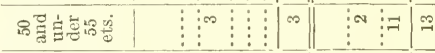

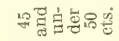

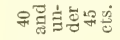

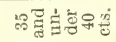

우

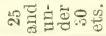

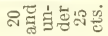

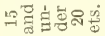

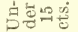

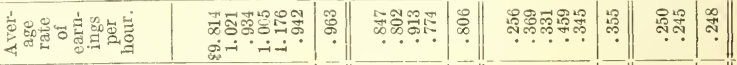

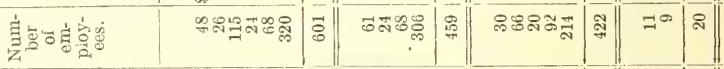

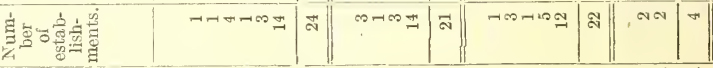


WAGES AND LABOR CONDITIONS.

\begin{tabular}{|c|c|c|c|c|c|c|c|c|c|}
\hline 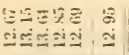 & 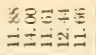 & $\frac{\Xi}{\beth}$ & 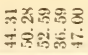 & $\left|\begin{array}{l}3 \\
0 \\
0\end{array}\right|$ & 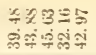 & | & 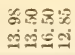 & लि & $\begin{array}{l}\overrightarrow{5} 8 \\
\leqq \dot{0}\end{array}$ \\
\hline $\begin{array}{l}\text { ceopons } \\
\text { inisis }\end{array}$ & 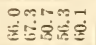 & $\ddot{8}$ & 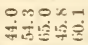 & $\begin{array}{l}\infty \\
18 \\
15\end{array}$ & 무렴 & $\mid \stackrel{0}{8}$ & 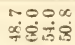 & $\frac{1}{5}$ & $\begin{array}{l}00 \\
\dot{0} 0\end{array}$ \\
\hline
\end{tabular}

$12 \vdots \vdots \vdots \vdots \cdots=1$

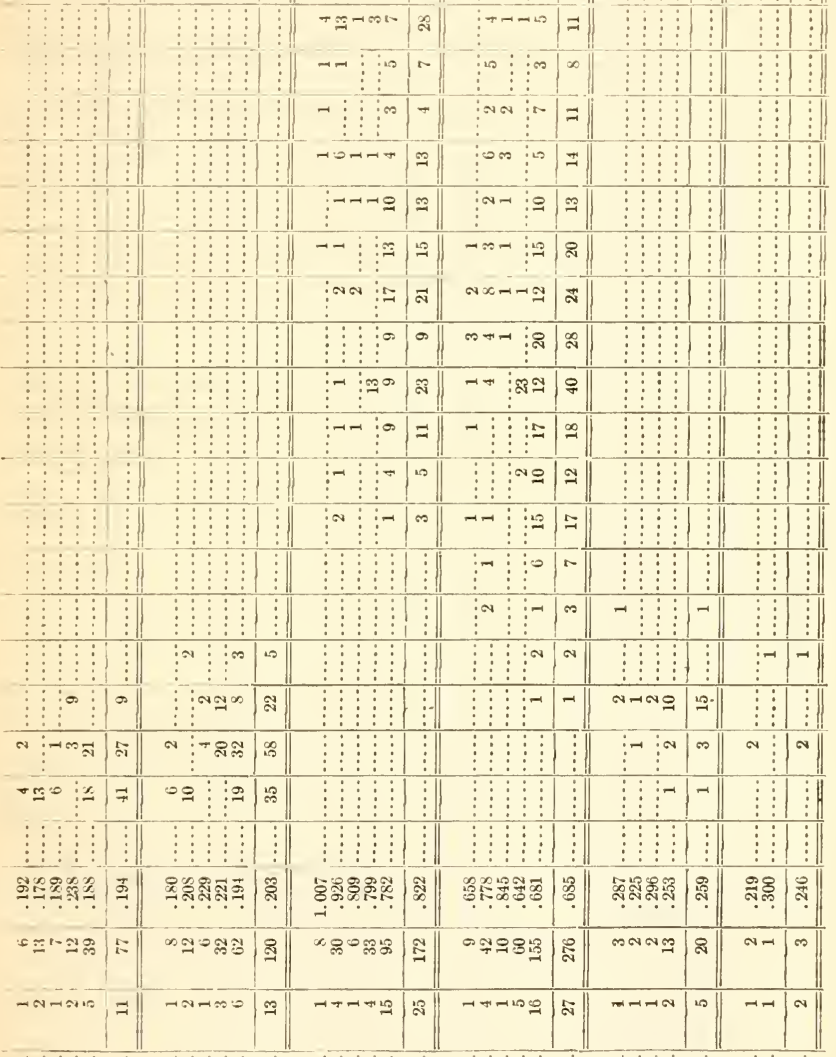

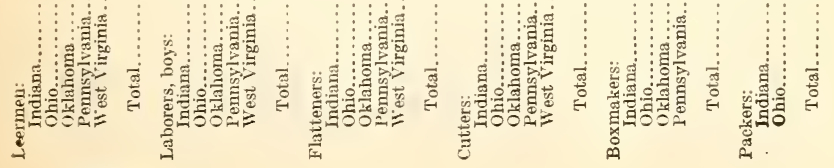
$102511^{\circ}-17-17$ 


\begin{tabular}{|c|c|c|c|c|c|c|c|c|c|c|}
\hline \multirow{2}{*}{ 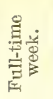 } & & $\begin{array}{l}\text { 요 } 8 \\
\text { - } \\
\text { - }\end{array}$ & 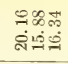 & $\left|\begin{array}{l}\infty \\
\infty \\
\vdots \\
\vdots\end{array}\right|$ & $\begin{array}{ll}2 & 0 \\
i & 0\end{array}$ & 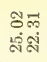 & $\begin{array}{l}\text { N } \\
\text { ลี่ }\end{array}$ & $\begin{array}{l}88 . \\
\text { तี่ }\end{array}$ & 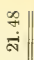 & \\
\hline & 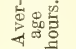 & $\begin{array}{l}\dot{0} \\
\dot{8}\end{array}$ & $\begin{array}{l}000 \\
+\infty \dot{\infty} \dot{0}\end{array}$ & \begin{tabular}{|l|}
0 \\
$\dot{\dot{\infty}}$
\end{tabular} & $\stackrel{\dot{\vec{d}}}{\dot{\alpha}}$ & $\begin{array}{l}0.1 \\
850\end{array}$ & $\ddot{E}$ & $\begin{array}{l}00 \\
8 \dot{8}\end{array}$ & $\stackrel{\circ}{\dot{8}}$ & \\
\hline
\end{tabular}

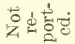

किष

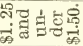

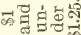

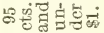

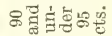

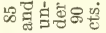

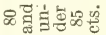

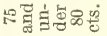

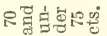

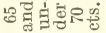

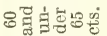

เค

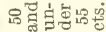

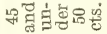

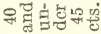

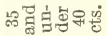

คำ สี่

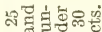

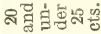

เอำ

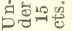

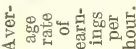

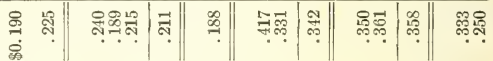

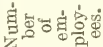

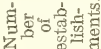
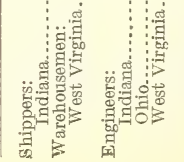

$$
\text { 焉. }
$$

.ึ.

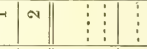

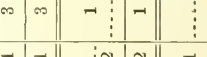

$-1$

\begin{tabular}{l|l|l|l||}
-1 & -1 & $\vdots$ & $\vdots$
\end{tabular}

$-|-| \mid$




\begin{tabular}{|c|c|c|c|c|c|c|c|c|}
\hline 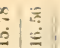 & $\begin{array}{l}x \bar{x} \\
\bar{x}\end{array}$ & $\underline{x}$ & 动 & $\begin{array}{l}\approx \\
\vdots \\
=1\end{array}$ & 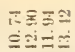 & $\frac{\dddot{x}}{\underline{x}}$ & $\begin{array}{l}\text { ลิ } \\
\text { อี }\end{array}$ & 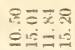 \\
\hline $1 \stackrel{8}{8}$ & $\begin{array}{l}=0 \\
\dot{8}\end{array}$ & $\stackrel{\varphi}{g}$ & $\stackrel{9}{15}$ & $\frac{c}{10}$ & $\begin{array}{l}00 \approx \sim \\
\dot{0} \hat{0}=\end{array}$ & $\stackrel{0}{9}$ & $\stackrel{\theta}{R}$. & $\begin{array}{l}0000 \\
\frac{1}{x}+\frac{1}{x} x\end{array}$ \\
\hline
\end{tabular}

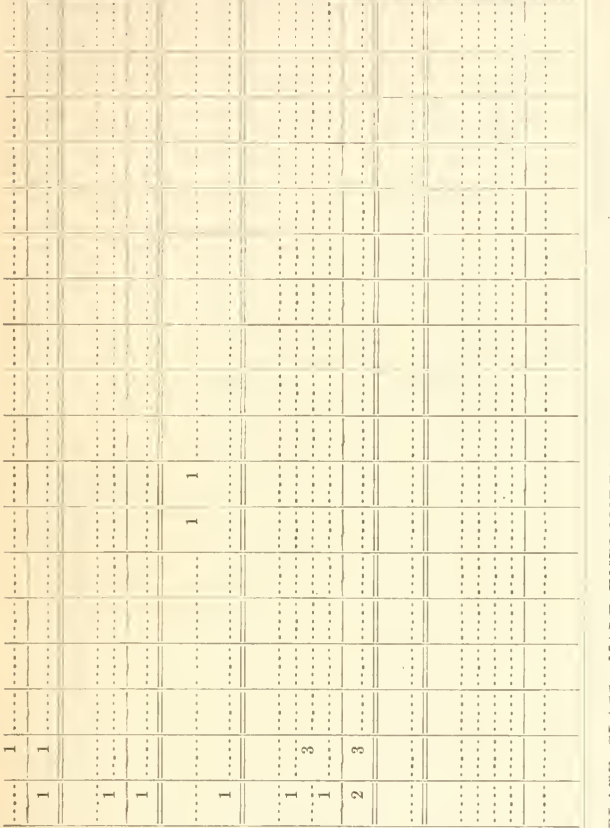

\begin{tabular}{c|c||c|c|}
\hline$\vdots$ & ค & ค & ค \\
\hline$\vdots$ & $\vdots$ & $\vdots$ & -1 \\
\hline & $\vdots$ & $\vdots$ &
\end{tabular}

\begin{tabular}{|c|c|c|c|c|c|c|c|}
\hline$a$ & $a$ & $\curvearrowright$ & : & I & & & \\
\hline & -7 & - & 요육 & 1 & & -7 & -1 \\
\hline-7 & $\vdots \vdots \vdots$ & : & $\rho^{m}$ & 8 & - & $\vdots-\infty$ & $\infty$ \\
\hline & & & $\infty$ & $\infty$ & & $-\infty$ & 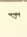 \\
\hline
\end{tabular}

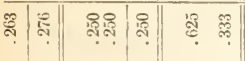

व

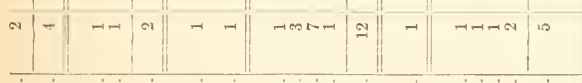

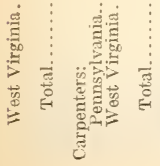

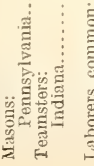

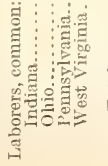

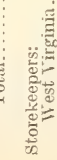

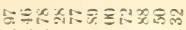

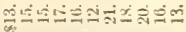

$\infty 13=00-00=00$ ช่ำ

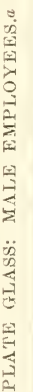

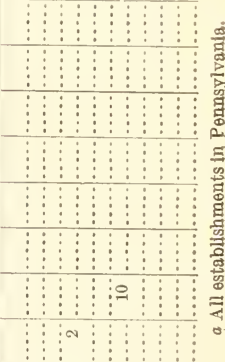

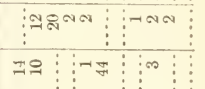

ง $\vdots \vdots \vdots \vdots \vdots \vdots \vdots \vdots \vdots \infty)$

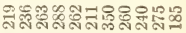
कें

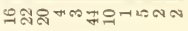

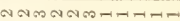

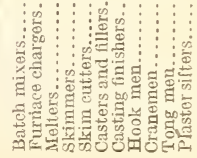




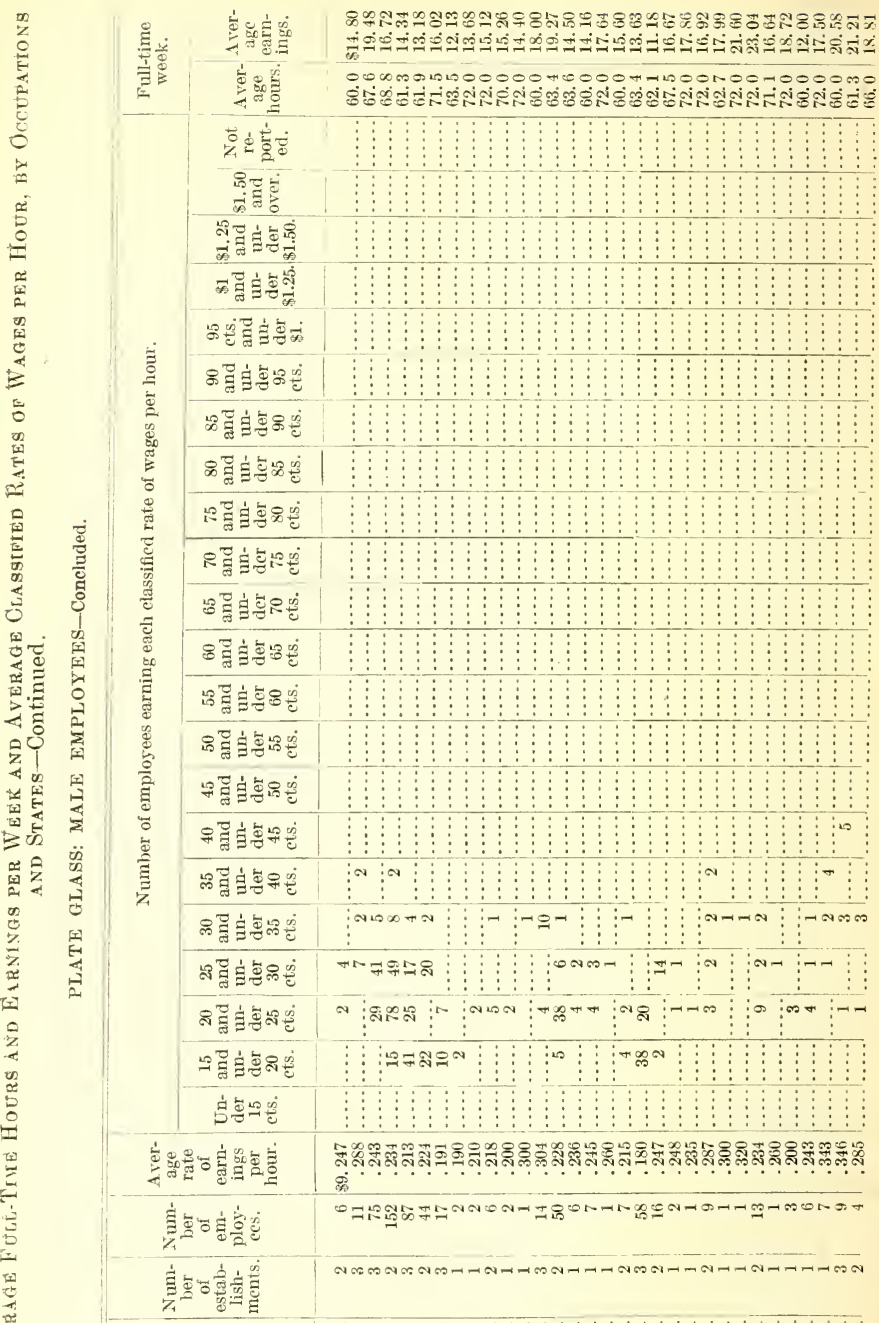


WAGES AND LABOR CONDITIONS.

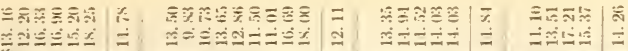

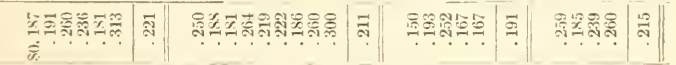




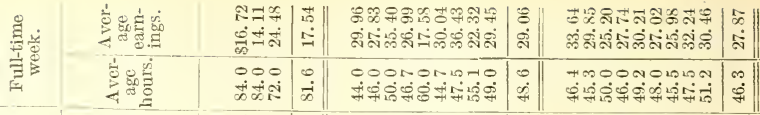

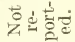

क्षे

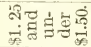

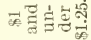

कु

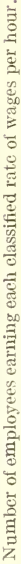

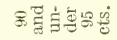

2

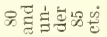

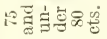

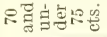

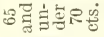

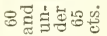

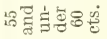

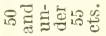

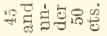

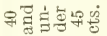

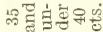

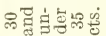

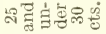

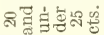

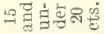

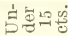

\begin{tabular}{|c|c|c|c|c|c|c|}
\hline 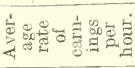 & 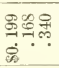 & जิ & 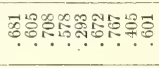 & 总 & 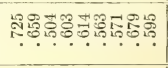 & छิ \\
\hline 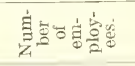 & $4 t a n$ & 9 & 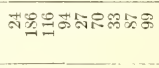 & 苗 & 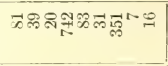 & \\
\hline 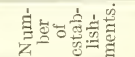 & & $\infty$ & 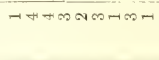 & ลิ & 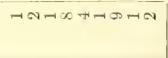 & \\
\hline
\end{tabular}

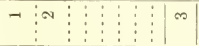

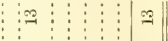

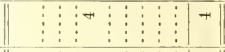

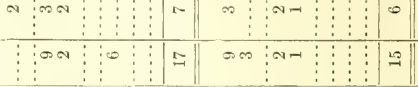

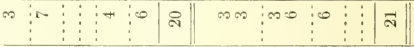

- Hog

ค৪オৈ

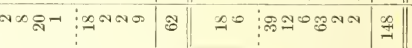
ー

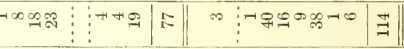

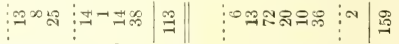

NONG

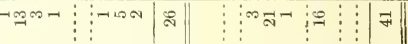

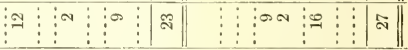

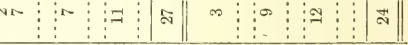

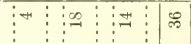




\begin{tabular}{|c|c|c|c|c|c|c|c|c|c|}
\hline 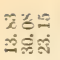 & 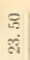 & 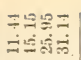 & $\begin{array}{l}\text { : } \\
\dot{\mathrm{i}} \\
\dot{\mathrm{N}}\end{array}$ & 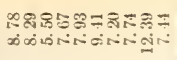 & 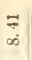 & 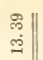 & 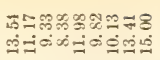 & & $\stackrel{9}{\dddot{D}}$ \\
\hline 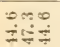 & & 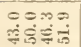 & ¿े. & 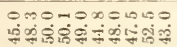 & 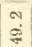 & बิ & 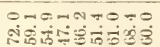 & $\mid$\begin{tabular}{l|}
0 \\
1 \\
1 \\
15
\end{tabular} & ஜூ \\
\hline
\end{tabular}

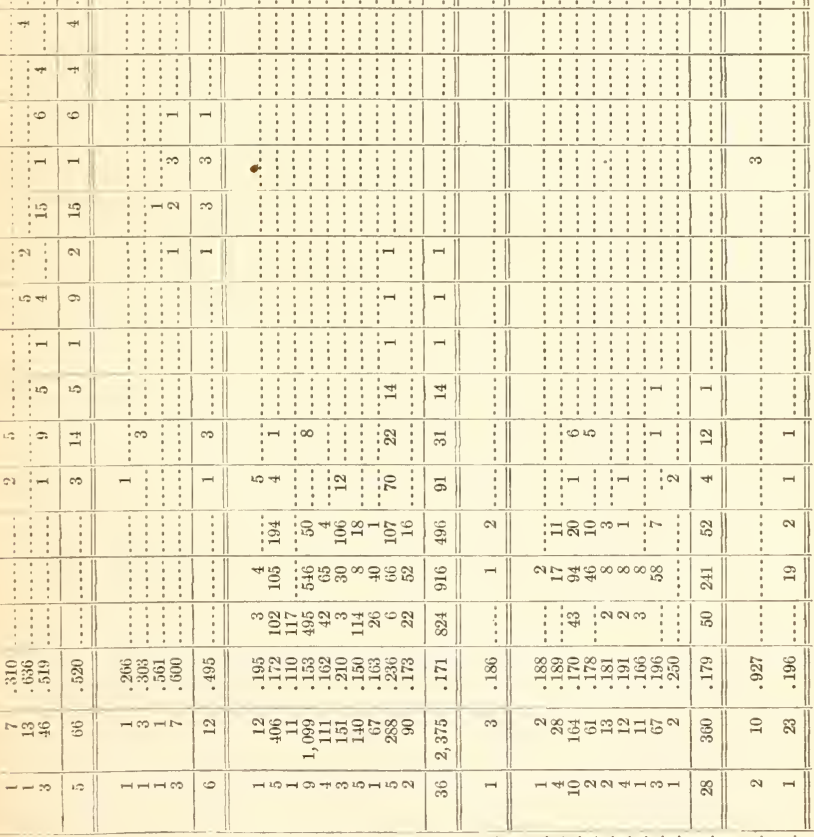

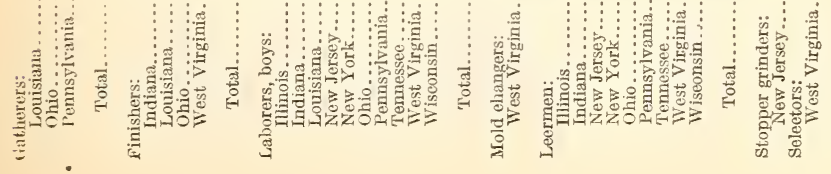




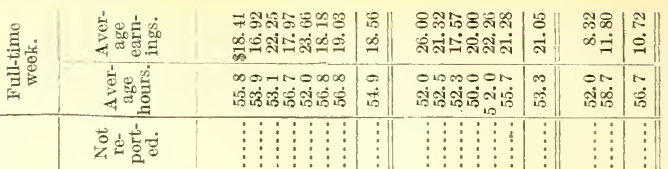

路宁

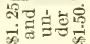

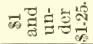

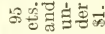

8혏용

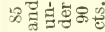

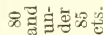

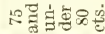

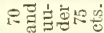

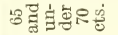

की

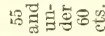

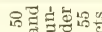

워

o 하

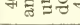

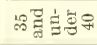

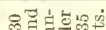

증

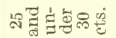

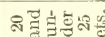

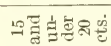

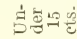

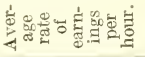

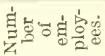

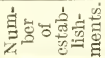
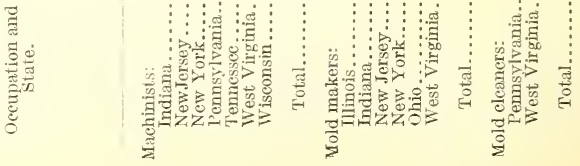
WAGES AND LABOR CONDITIONS.

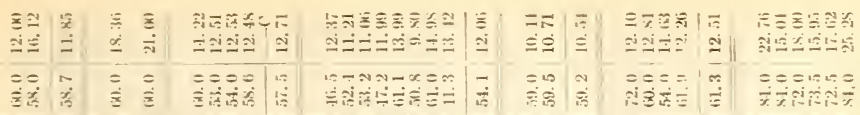

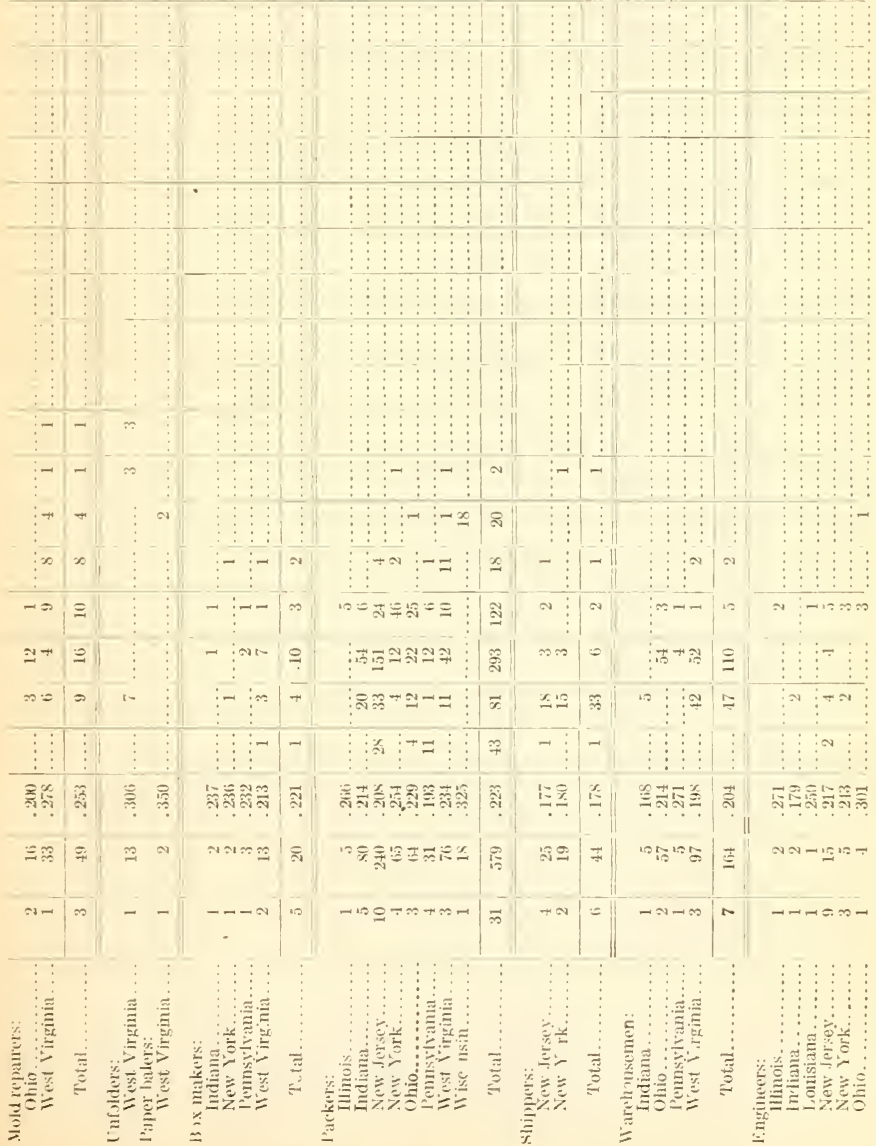




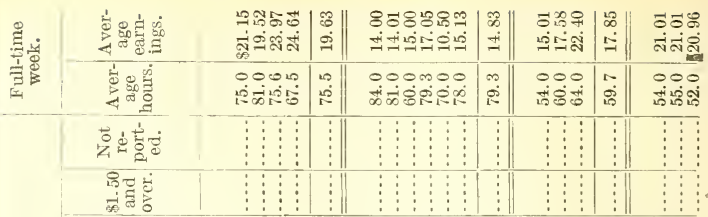

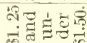

ब.

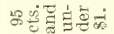

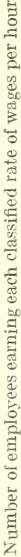

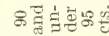

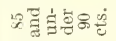

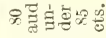

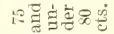

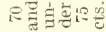

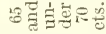

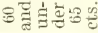

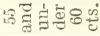

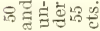

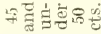

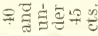

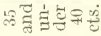

คิ

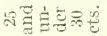

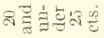

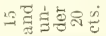

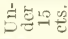

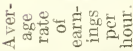

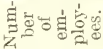

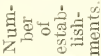

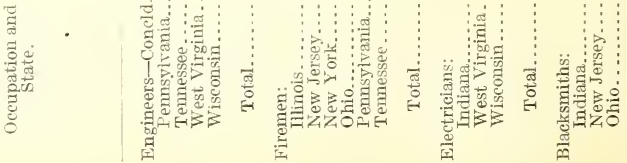




\begin{tabular}{|c|c|c|c|c|c|c|c|c|c|c|c|c|}
\hline 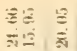 & 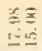 & 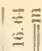 & $\begin{array}{l}\tilde{N} \\
\vdots\end{array}$ & $\begin{array}{l}E= \\
\vdots=0\end{array}$ & $\begin{array}{l}\bar{x} \\
\hat{\Xi}\end{array}$ & 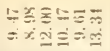 & 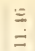 & $\bar{z}$ & $\bar{z}$ & $\begin{array}{l}x=\vdots \\
\leqq \Xi 20\end{array}$ & פُ & $\stackrel{8}{5}$ \\
\hline 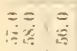 & $\begin{array}{l}00 \\
-150\end{array}$ & 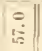 & $\frac{0}{3}$ & $\begin{array}{l}\varepsilon= \\
\dot{8}\end{array}$ & $\stackrel{\varepsilon}{E}$ & $\begin{array}{l}-Z=v== \\
-\pi\end{array}$ & בa & $\therefore$ & 10 & $\begin{array}{l}=001 \\
\text { 1;idis }\end{array}$ & $\begin{array}{l}\text { N } \\
\hat{B}\end{array}$ & \\
\hline
\end{tabular}

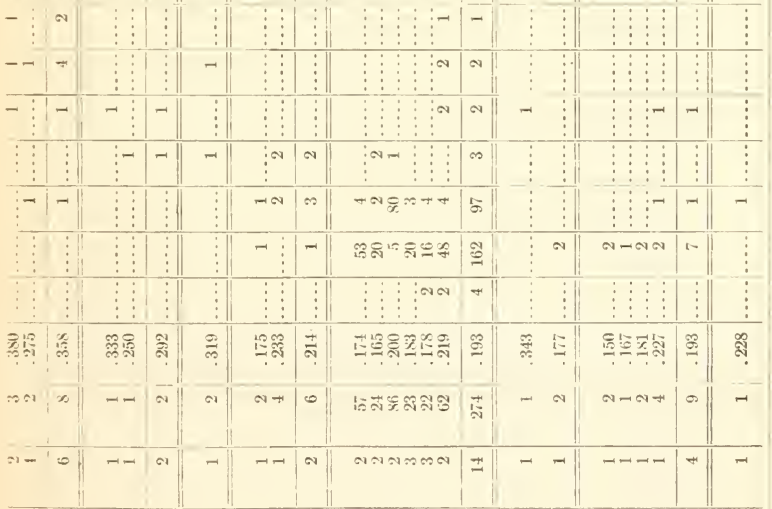

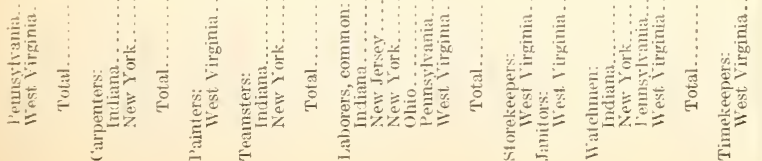




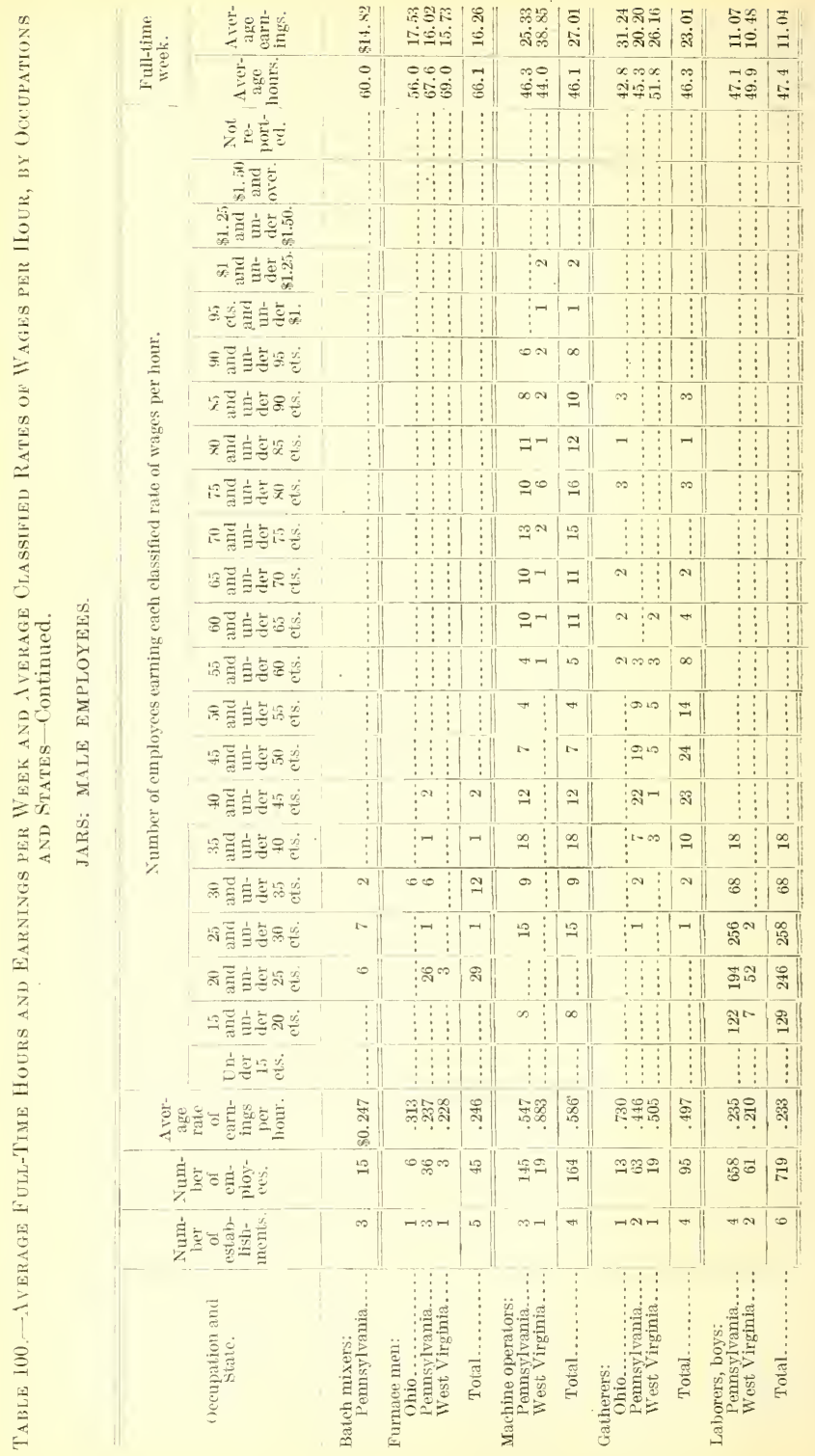




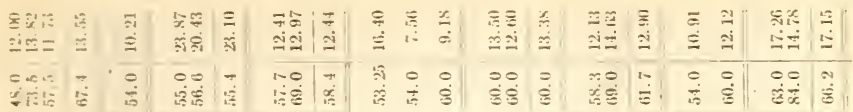

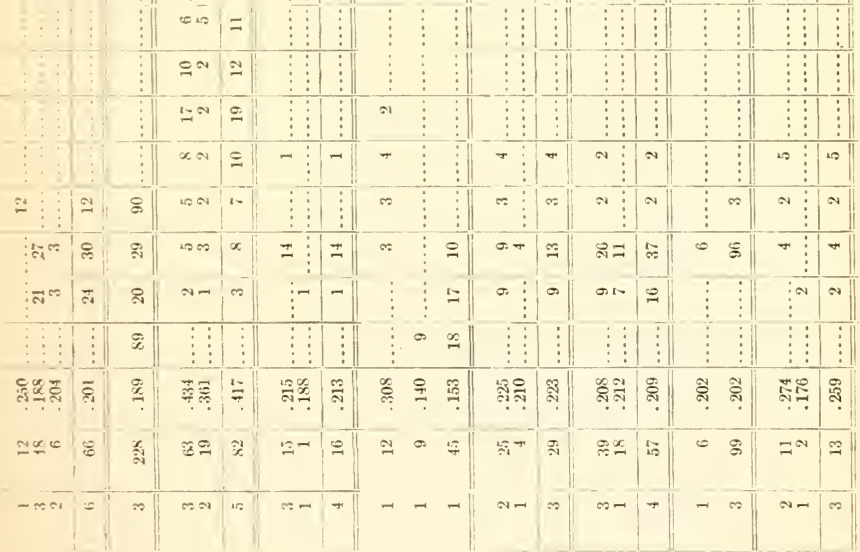

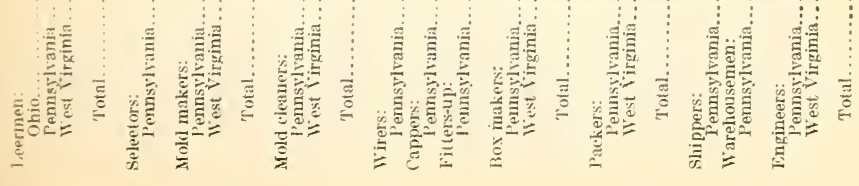




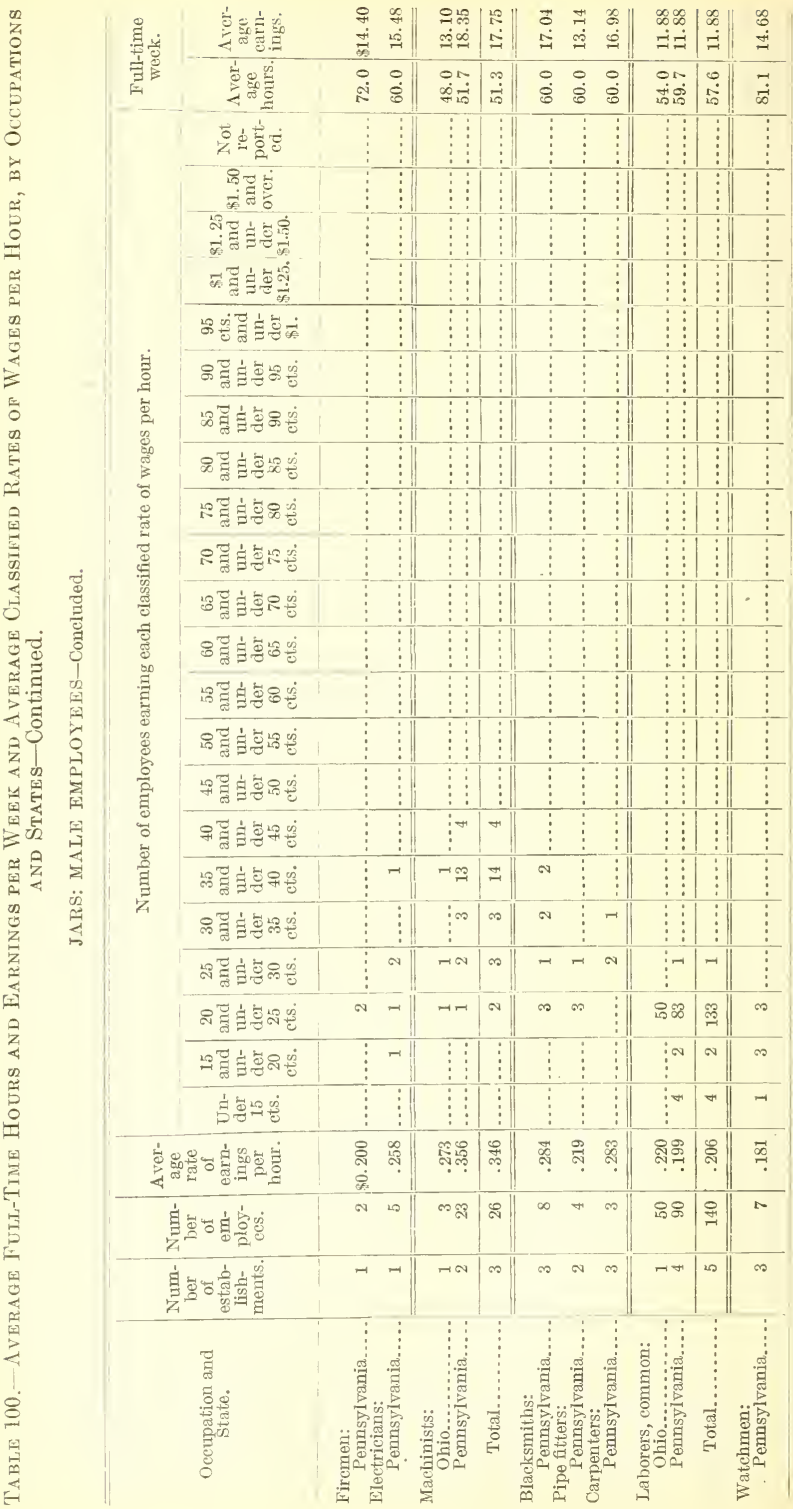




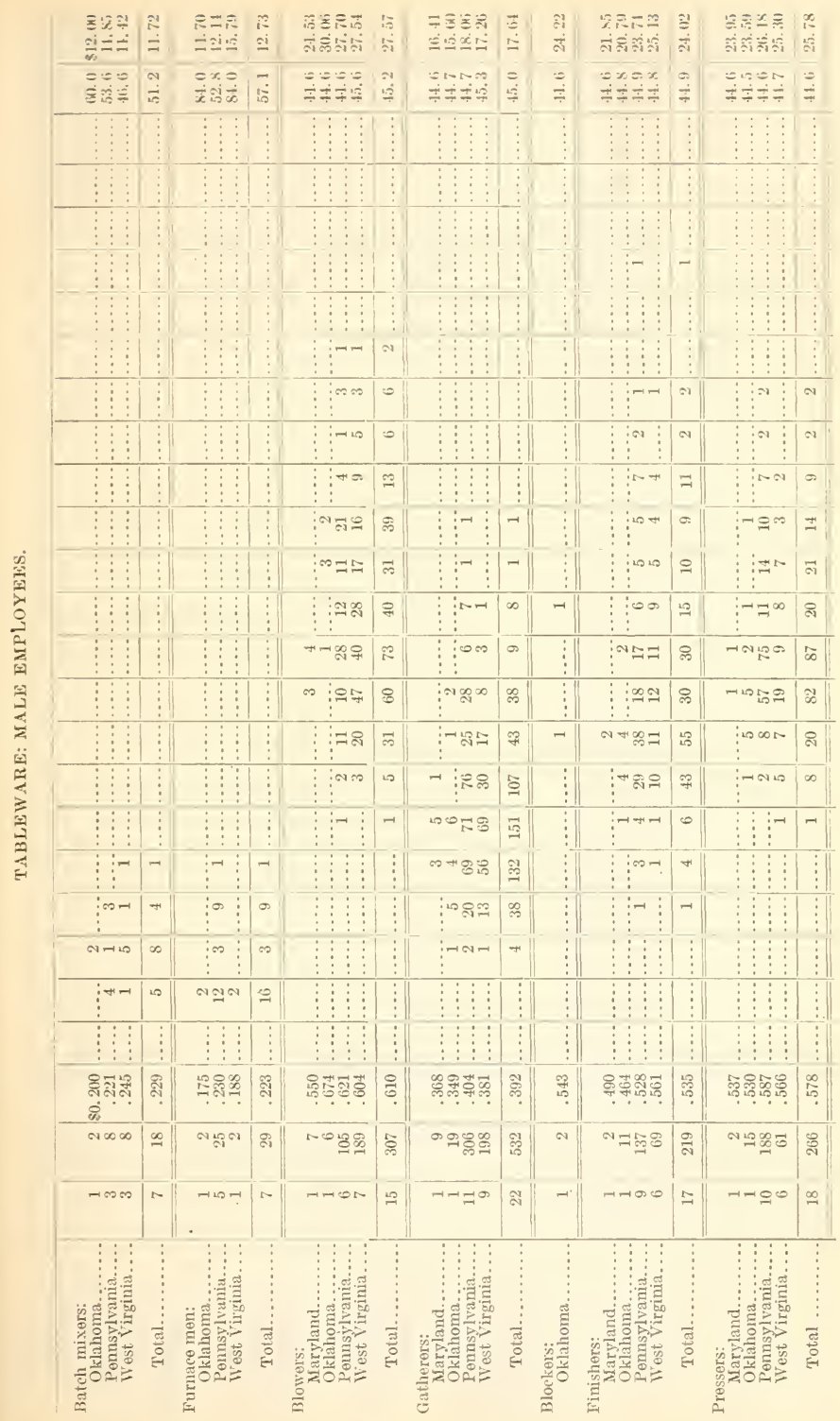


THE GLASS INDUSTRY.

\begin{tabular}{|c|c|c|c|c|c|c|c|c|c|c|}
\hline & & $\stackrel{g}{\stackrel{8}{*}}$ & 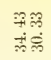 & 党 & 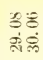 & $\mid \begin{array}{l}\mathscr{3} \\
\widetilde{A}\end{array}$ & 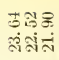 & $\stackrel{7}{\stackrel{3}{3}}$ & $\begin{array}{l}\text { † } \\
\text { ثे }\end{array}$ & $\begin{array}{l}x \& B=3 \\
1 \leqslant 5=6\end{array}$ \\
\hline$\stackrel{0}{\Xi}$ & 爮飐 & $\stackrel{\circ}{\circ}$ & 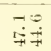 & $\begin{array}{l}10 \\
\text { fo }\end{array}$ & $\begin{array}{l}0: 0 \\
+j\end{array}$ & $\dot{q}$ & 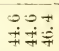 & $\stackrel{9}{9}$ & $\stackrel{\varphi}{\dot{H}}$ & 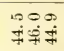 \\
\hline
\end{tabular}

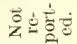
कि

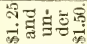
๙

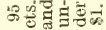

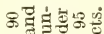

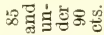

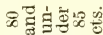

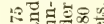
R

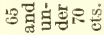

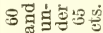

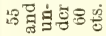

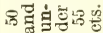

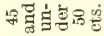

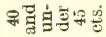

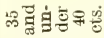
คิ

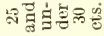
สิ

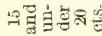

\begin{tabular}{|c|c|c|c|c|c|c|c|c|c|}
\hline & & & & $\vdots$ & & & & உேః & 菬 \\
\hline & : : & $\vdots$ & $\vdots \vdots$ & $\vdots$ & & $\vdots$ & $\vdots$ & "g్ & 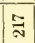 \\
\hline & "ే: & $\stackrel{\infty}{i}$ & 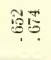 & 5 & ำำํำ & 3 & 욤 & 독 & 곡 \\
\hline & $0 \times 1$ & $\infty$ & -10 & $t$ & $\infty \pi$ & $\infty$ & 0 & : & 落 \\
\hline & $\infty-1$ & + & -1 & $\therefore$ & $-+\infty$ & $\infty$ & - & $\neg N+$ & $=$ \\
\hline
\end{tabular}

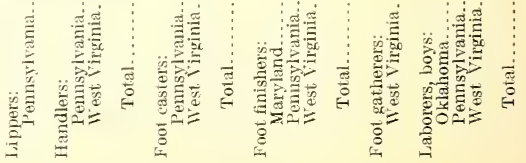




\begin{tabular}{|c|c|c|c|c|c|c|c|c|c|c|c|c|c|c|c|}
\hline 象经起 & & $\begin{array}{l}\bar{\Xi} \equiv \\
\equiv\end{array}$ & $\stackrel{\vec{\sigma}}{=}$ & $\begin{array}{l}\overline{5} \\
x=\end{array}$ & $\frac{2}{2}$ & $\begin{array}{l}\{x= \\
z= \pm \\
=0\end{array}$ & $\mid \begin{array}{l}\stackrel{9}{0} \\
\stackrel{0}{\circ}\end{array}$ & $\stackrel{2}{2}$ & $\begin{array}{l}\text { R } \\
\text { สิ่ }\end{array}$ & $\begin{array}{l}\overrightarrow{\dot{ }} \\
\dot{\square}\end{array}$ & $\cong$ & $\begin{array}{l}\bar{A} \\
=\end{array}$ & 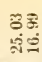 & $\mid \begin{array}{l}\bar{\Xi} \\
\vdots \\
-\end{array}$ & 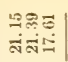 \\
\hline $4 ?$ & d & 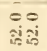 & ) & 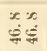 & 7 & 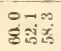 & 4 & $\ddot{\hat{i}}$ & 棺 & 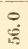 & \% & 萓 & $\begin{array}{l}00 \\
\text { हिं }\end{array}$ & $\left|\begin{array}{l}0 \\
\text { c. } \\
\dot{5}\end{array}\right|$ & \\
\hline
\end{tabular}




\begin{tabular}{|c|c|c|c|c|c|c|c|c|c|c|c|c|}
\hline 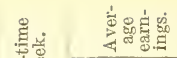 & & 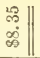 & 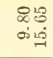 & $\mid \begin{array}{l}\mid \overrightarrow{7} \\
\dot{+}\end{array}$ & 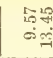 & 胥 & & 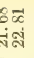 & สิ & $\begin{array}{l}\vec{m} \$ \\
\text { sip }\end{array}$ & & $\begin{array}{l}8 \\
\vdots\end{array}$ \\
\hline $\begin{array}{l}3 \\
4 \\
4\end{array}$ & & & $\begin{array}{l}010 \\
\text { i. }\end{array}$ & 要 & 造话 & $\mid \begin{array}{l}\mid \\
\text { జें }\end{array}$ & & 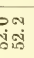 & 욤 & ำ & \& & 옴 \\
\hline 艺它 & & & & & & & & & & & & \\
\hline
\end{tabular}

요웡 का

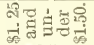

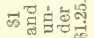

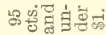

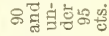

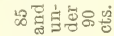

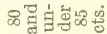

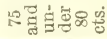

오물

물

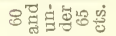

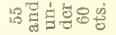

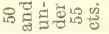

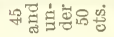

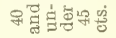

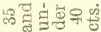

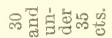

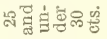

乎 ี艹

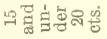

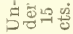

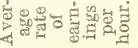

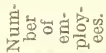

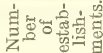

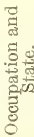
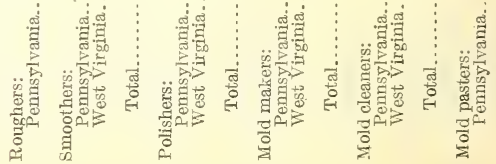


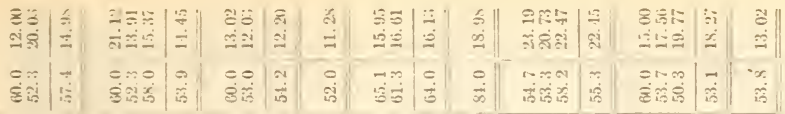

\begin{tabular}{|c|c|c|c|c|c|c|c|c|c|c|c|c|c|c|}
\hline$:^{-}$ & -1 & Nod & + & & & & -1 & -1 & : & $\vdots$ NN & $\sigma$ & $-1-1$ & es & \\
\hline & : & $\omega^{\infty}$ & స్ & ${ }^{-1}$ & - & & : : & $\vdots$ & : & $-\vdots^{-}$ & $\infty$ & - & -1 & \\
\hline & $\vdots$ & $\rightarrow \infty$ & $\therefore$ & $-\infty$ & - & - & $\infty \pi$ & 0 & -1 & - & $\sim$ & $-1-$ & N & \\
\hline ex & $\approx$ & : & $\exists$ & مo & $\infty$ & $\infty$ & $\sim$ & $N$ & $\vdots$ & & $\vdots$ & - & - & - \\
\hline & $\vdots$ & iasus & 10 & as & is & $N$ & $\sim$ & $\infty$ & - & & : & & $\vdots$ & \\
\hline & $\vdots$ & 2 & $\stackrel{\infty}{-1}$ & & & $\vdots$ & $\vdots$ & $\vdots$ & $\vdots$ & & $\vdots$ & $\vdots$ & $\vdots$ & \\
\hline हึి & $\overrightarrow{\overbrace{}^{-1}}$ & 싱ำ & :ै & tचत्त & สิ & ने & ลึ류 & 웍 & มี & 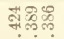 & \& & 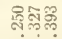 & चे & ते \\
\hline$\because-$ & $\infty$ & Tล & $\stackrel{3}{=}$ & 012 & $\mathscr{2}$ & 0 & $\infty \infty$ & $\Rightarrow$ & $\infty$ & Doth & $\mathscr{2}$ & - & -1 & -1 \\
\hline-1 & $\therefore$ & $-10+1$ & $\approx$ & $-\theta$ & to & -1 & 1 & is & - & -1ா & is & $\rightarrow \infty \infty$ & -1 & -1 \\
\hline
\end{tabular}

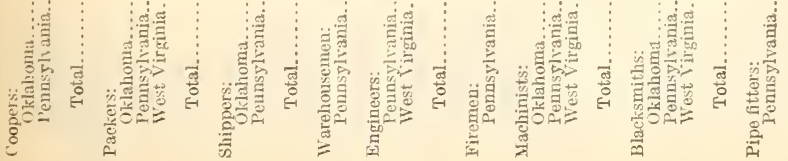




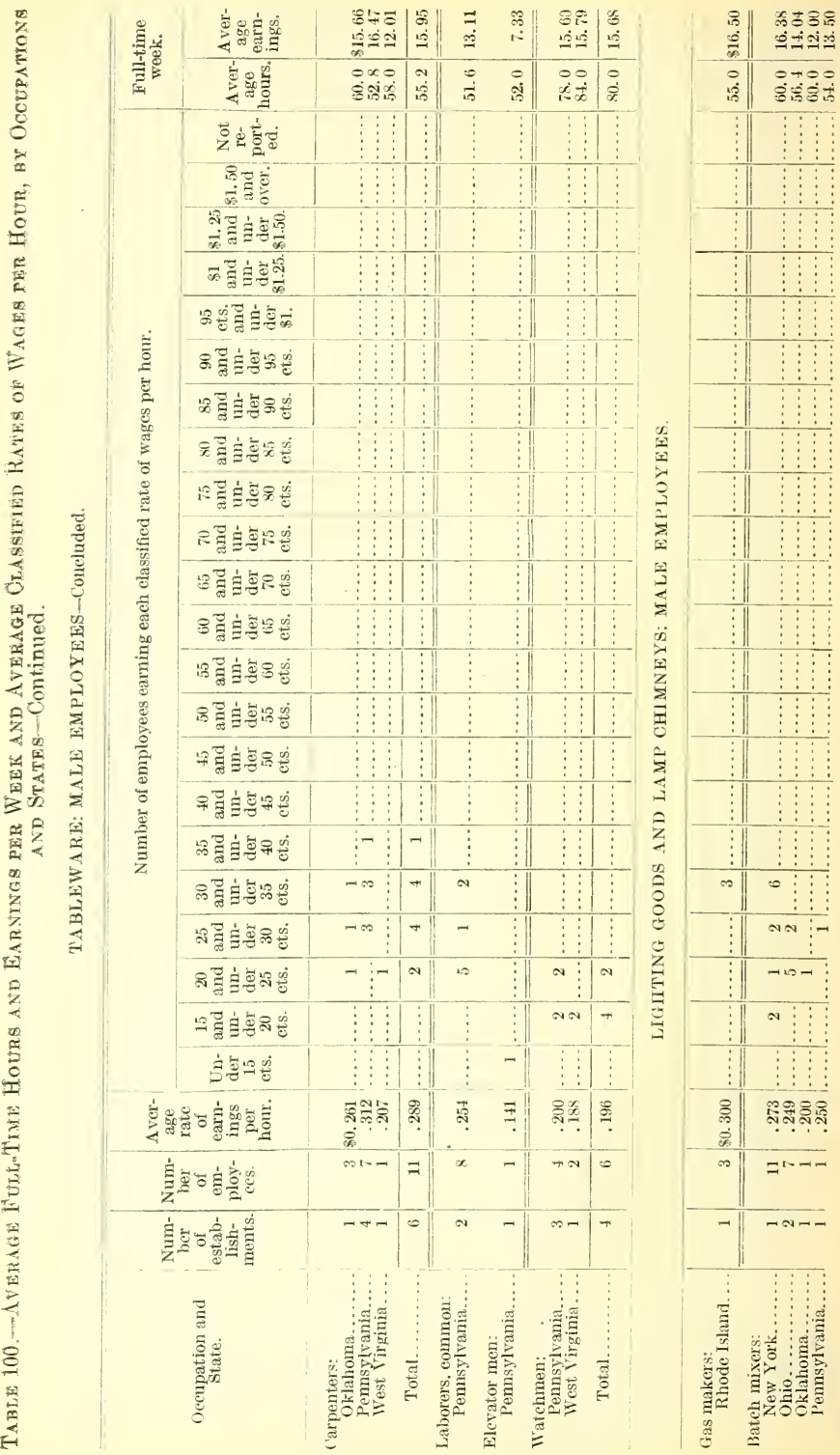




\begin{tabular}{|c|c|c|c|c|c|c|c|c|c|c|}
\hline$\frac{5}{2}$ & \begin{tabular}{l}
-18 \\
\hdashline$i 2$
\end{tabular} & $\stackrel{ \pm}{\beth}$ & 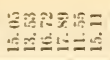 & $\equiv$ & $\begin{array}{l}= \\
\pm\end{array}$ & 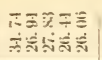 & 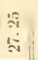 & 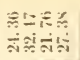 & 荬 & 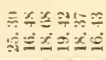 \\
\hline 6 & 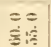 & 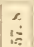 & 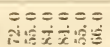 & $m$ & 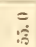 & 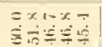 & $=$ & 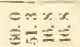 & $=$ & 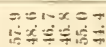 \\
\hline
\end{tabular}

$-\div-12+-$

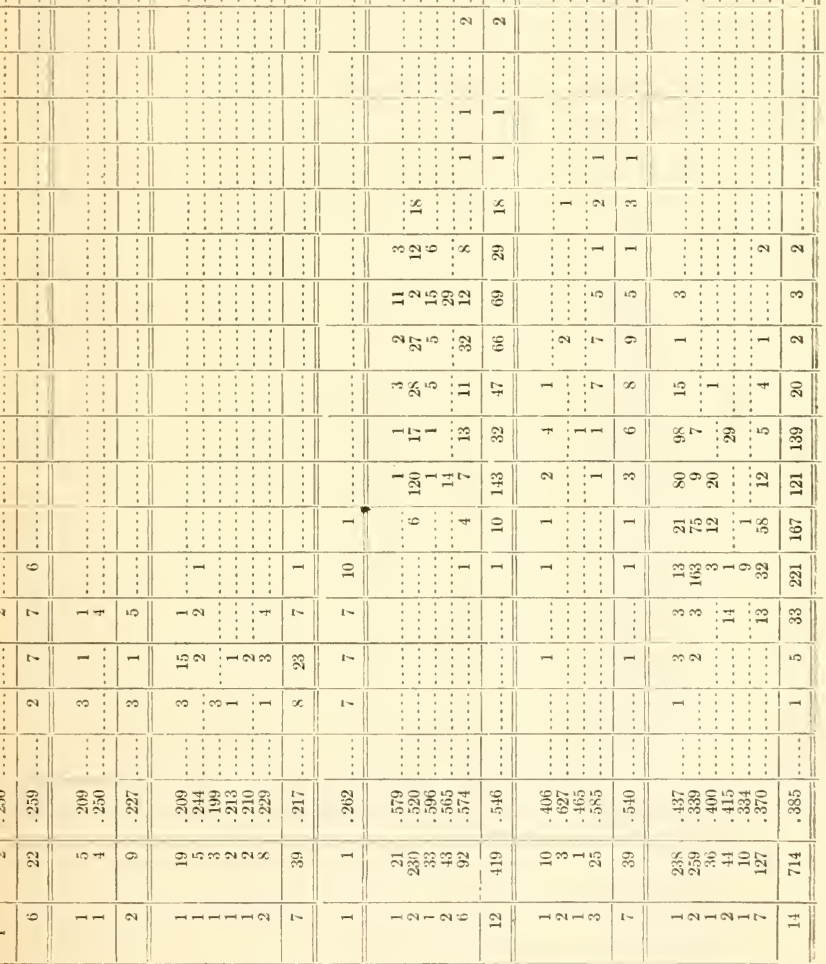

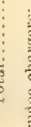
然

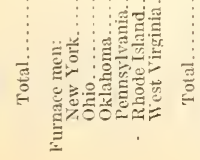

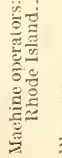

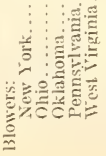

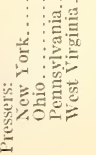
․ำ

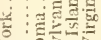
的 हैं 


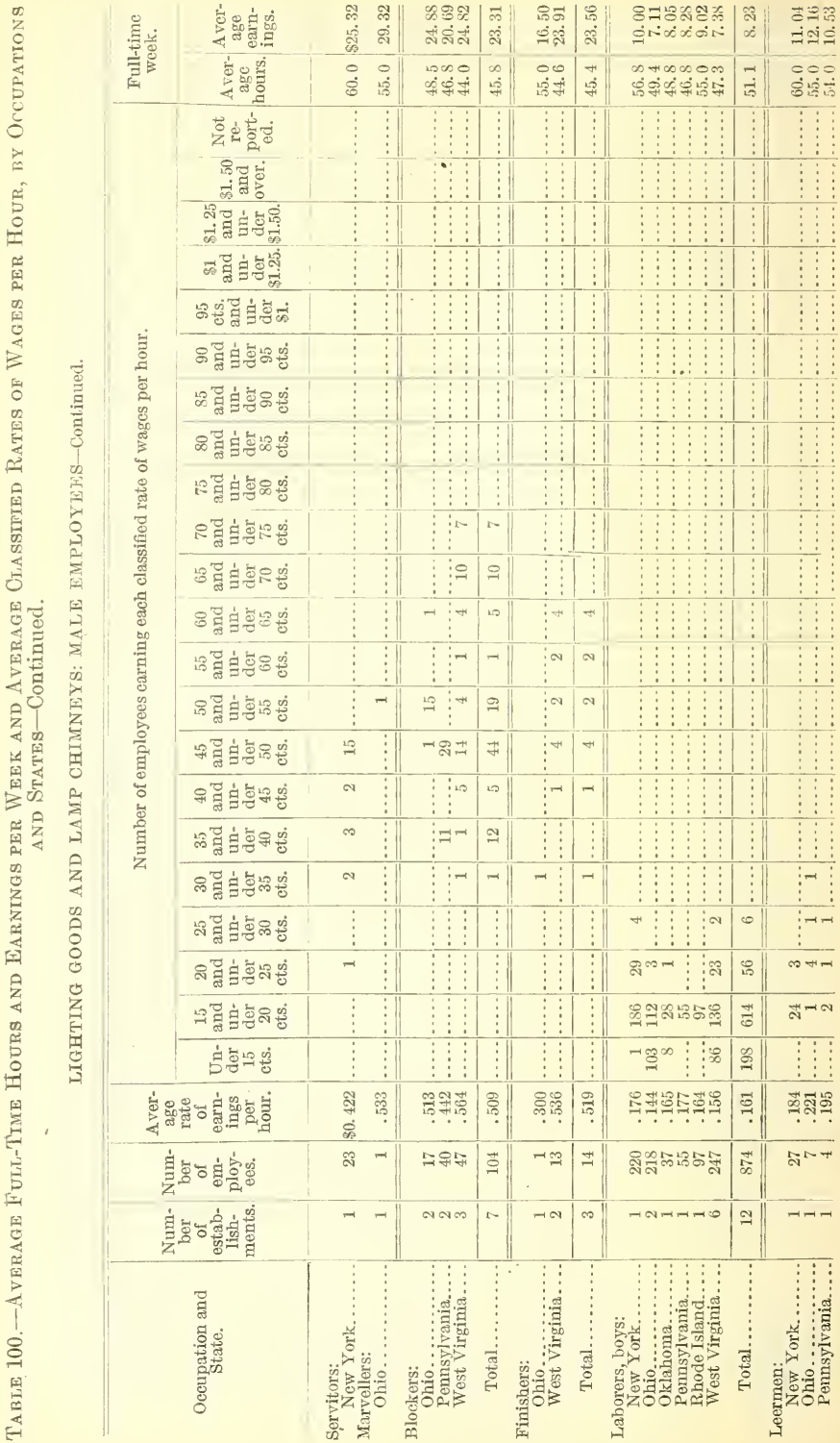




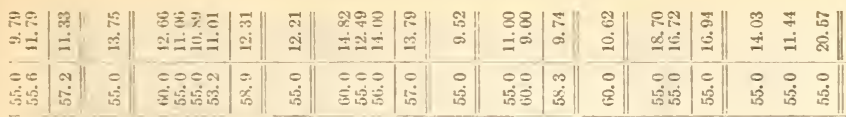

$$
\text { ₹: : : }: \text { : }
$$

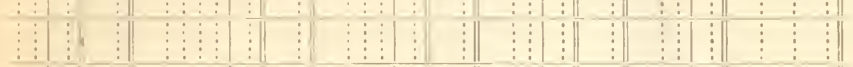

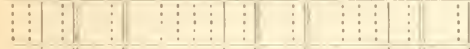

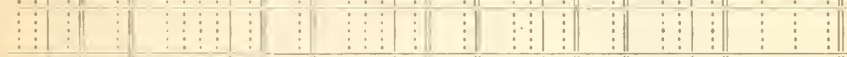

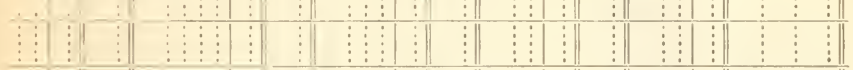

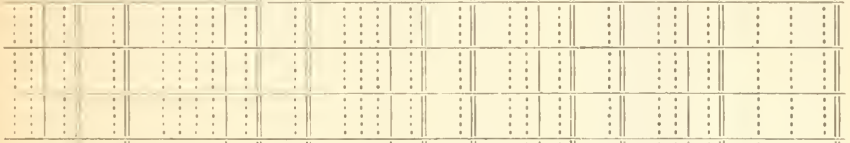

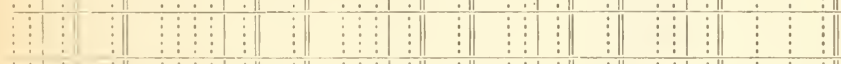

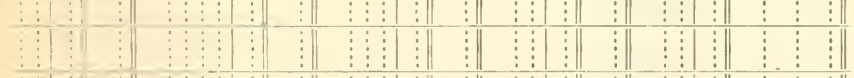

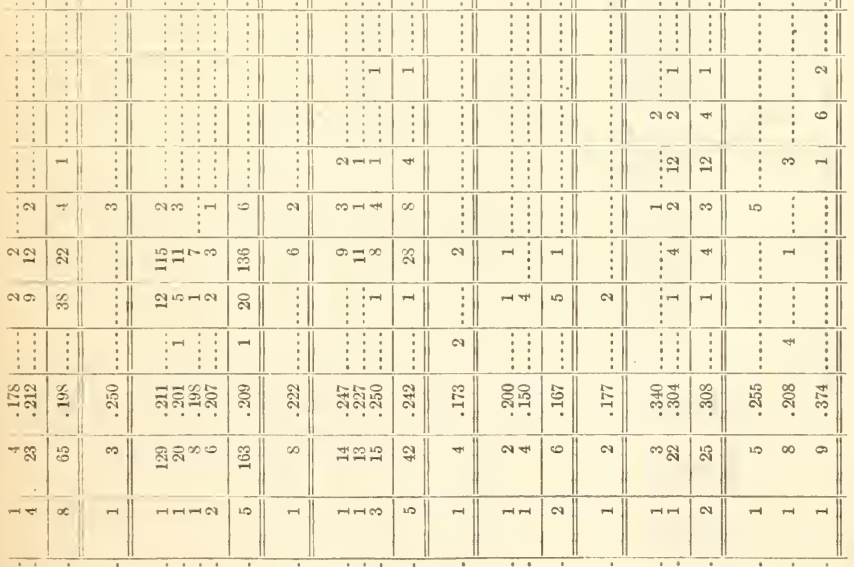

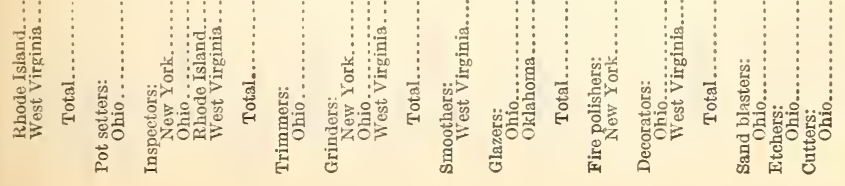




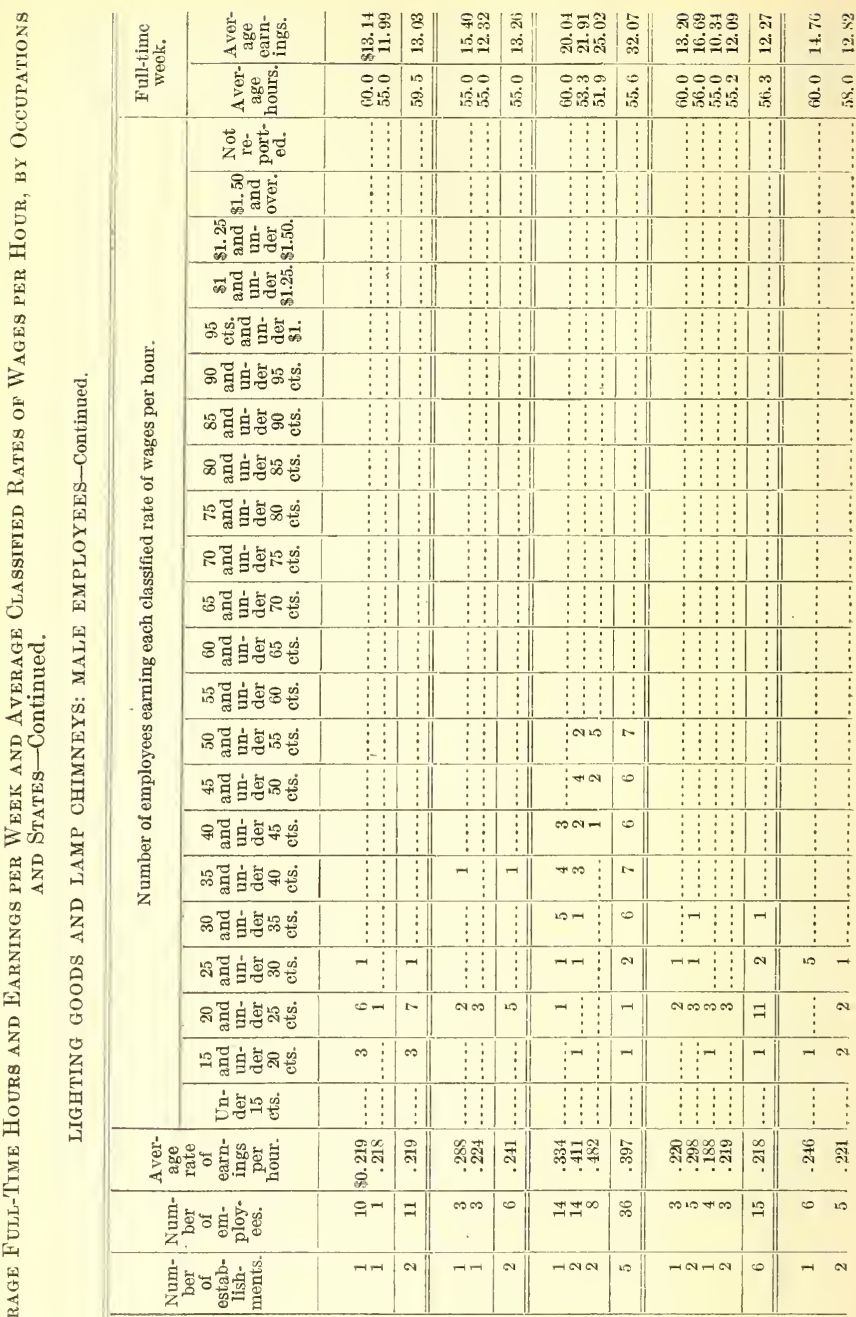

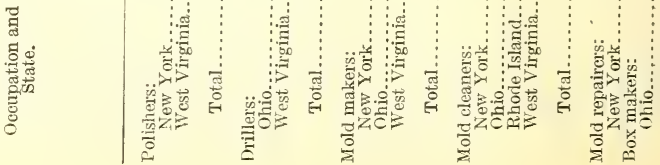




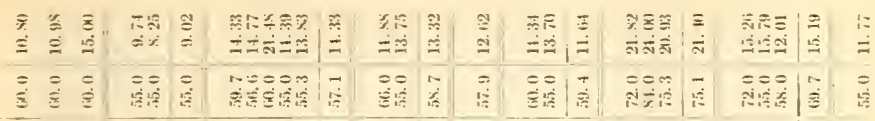




\begin{tabular}{|c|c|c|c|c|c|c|c|c|c|}
\hline & & 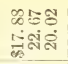 & | & 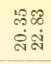 & 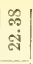 & 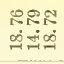 & $\left|\begin{array}{l}\text { की } \\
\text { s. } \\
-1\end{array}\right|$ & 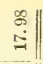 & 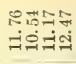 \\
\hline & & : & 熍 & $\begin{array}{l}0.0 \\
\text { isं }\end{array}$ & 10 & 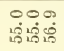 & {$\left[\begin{array}{l|l|}\infty & 0 \\
10 \\
10\end{array}\right]$} & $\begin{array}{l}0 \\
8 \\
B\end{array}$ & 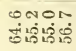 \\
\hline
\end{tabular}

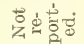

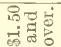

ลิ?

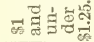

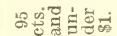

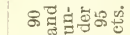

以

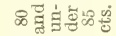

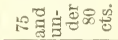

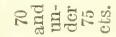

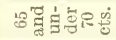

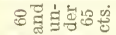

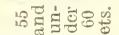

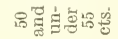

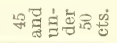

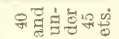

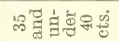

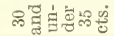

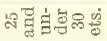

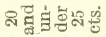

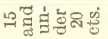

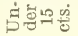

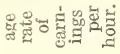

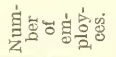

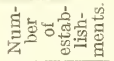

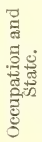

\begin{tabular}{|c|c|c|c|c|c|c|c|c|}
\hline 乩器产 & 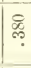 & 일. & ફ్ & 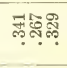 & बै. & बै। & 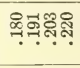 & $\stackrel{\infty}{-}$ \\
\hline tion & $\approx$ & -120 & 0 & m৫ & 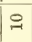 & $\rightarrow$ & Бణ & 역 \\
\hline$=-1+1$ & $\infty$ & $-\infty$ & $\pi$ & $\pi-\sigma$ & 0 & -1 & ユNール & 10 \\
\hline
\end{tabular}

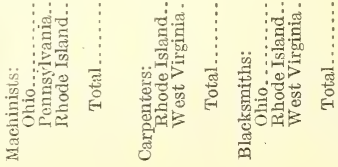

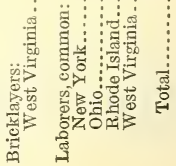




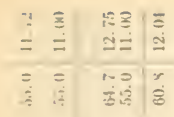

0
0
0
0
0
0
0
0
0
0
0
3
3
3
0
0
0
0
0

๑ 월

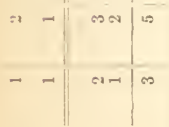

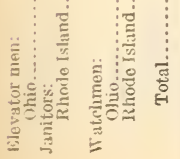

\begin{tabular}{|c|c|c|c|c|c|c|c|c|c|c|}
\hline , & & $\underline{\underline{z}}$ & $\overrightarrow{5}$ & 우 & $t$ & $\cong$ & $\overline{3}$ & 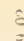 & & है \\
\hline 13 & ลूล & है & $\mathscr{\xi}$ & $\hat{\mathrm{C}}$ & ले & $\therefore$ & 5 & $=$ & & \\
\hline & & $\mid \begin{array}{l}0 \\
\text { S }\end{array}$ & 2 & $\dot{8}$ & $\overline{-1}$ & 5 & ड & 7 & & 28 \\
\hline
\end{tabular}

$\vdots \vdots a_{n}^{\infty}$

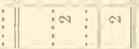

$\vdots^{-1} \vdots-1$

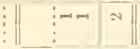

a

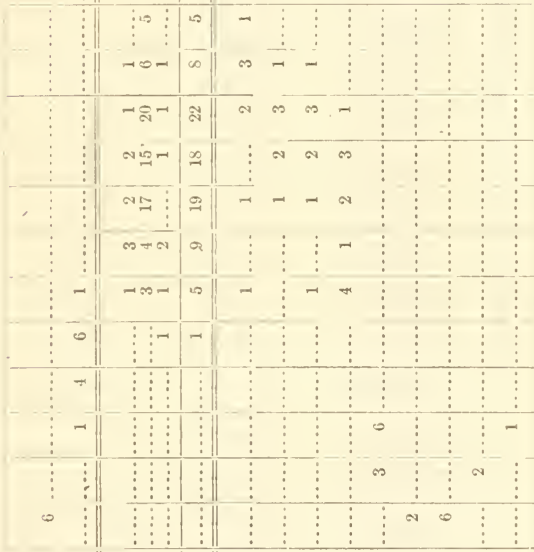

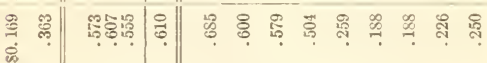

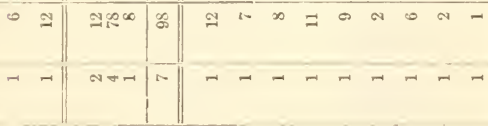

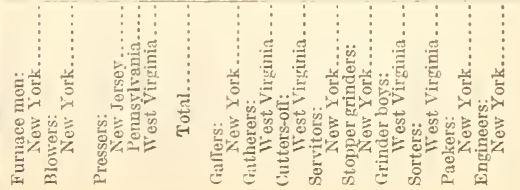


THE GLASS INDUSTRI.

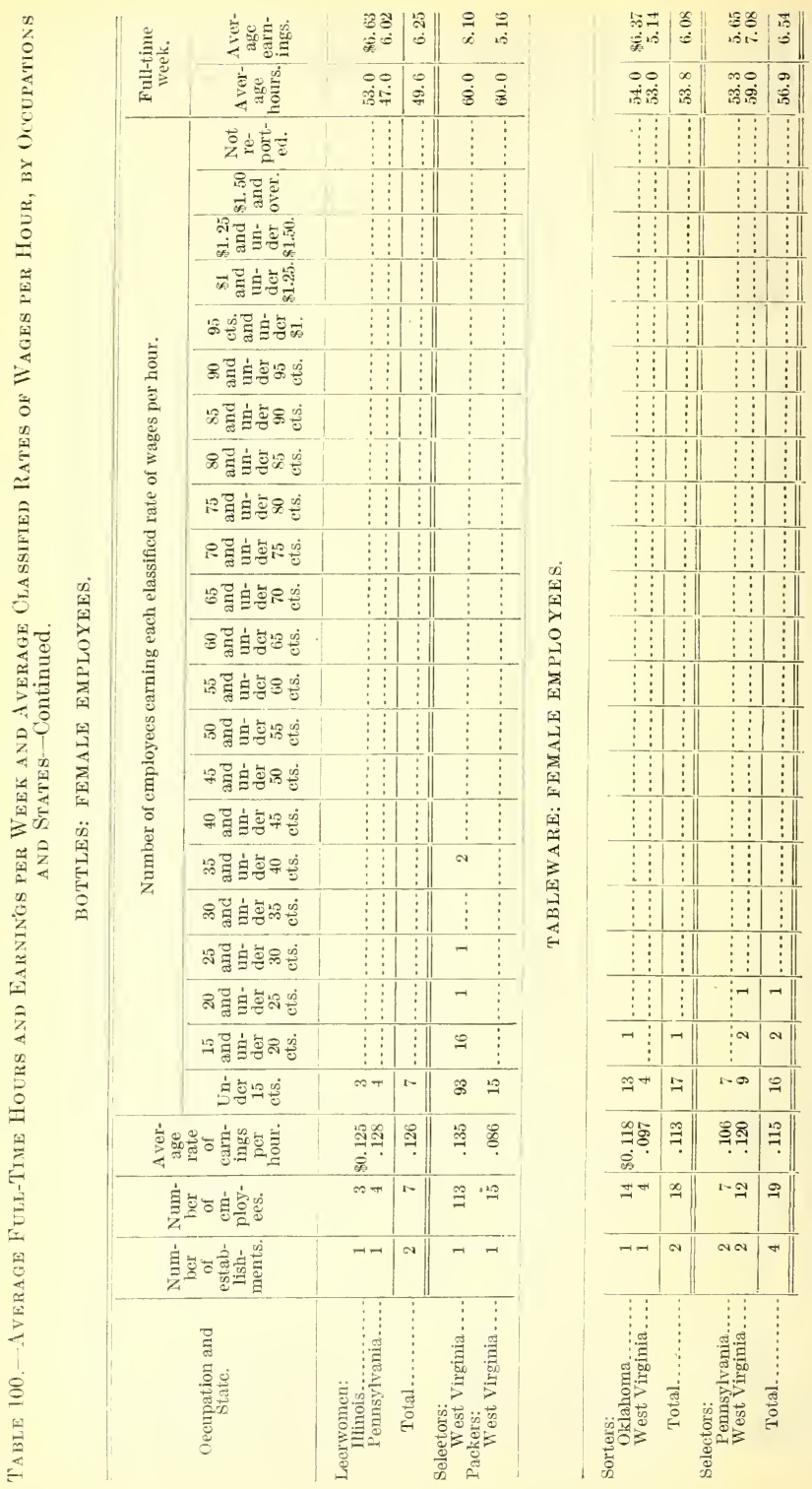




\begin{tabular}{|c|c|c|c|c|c|c|c|c|c|c|c|c|c|c|c|c|}
\hline 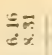 & $\frac{\pi}{x}$ & $\begin{array}{l}\text { SE三 } \\
\therefore=0\end{array}$ & $\begin{array}{l}x \\
i= \\
1\end{array}$ & 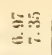 & $\Sigma_{i}$ & 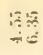 & : & 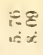 & 空 & $\begin{array}{l}P \\
\dot{x} \\
\dot{x}\end{array}$ & $\stackrel{7}{?}$ & $\begin{array}{l}\mathscr{6} \\
= \\
=\end{array}$ & 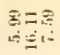 & $\mid \begin{array}{l}\bar{x} \\
0\end{array}$ & 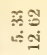 & $\frac{T}{\dot{c}}$ \\
\hline 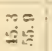 & $\infty$ & 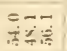 & ง & $\begin{array}{l}x=8 \\
=\hat{=}\end{array}$ & & $\begin{array}{l}00 \\
\text { s. }\end{array}$ & $\left|\begin{array}{l}e \\
\hat{1}\end{array}\right|$ & $\begin{array}{l}x \approx \\
x: 2\end{array}$ & $\overline{1}$ & $\pi$ & 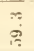 & $\stackrel{\sim}{*}$ & 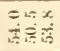 & 蚛 & 的斿 & ิㅗㅇ \\
\hline
\end{tabular}

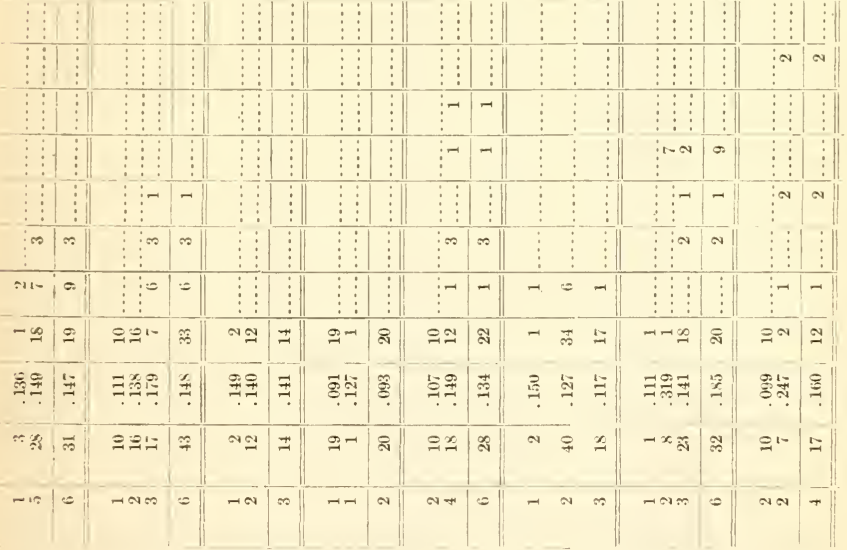

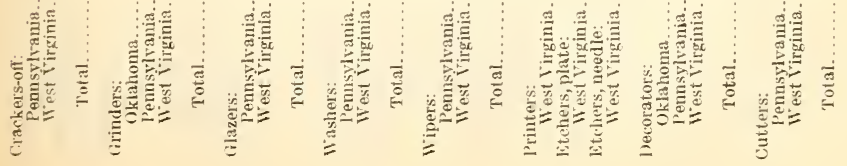


THE GLASS INDUSTRY.

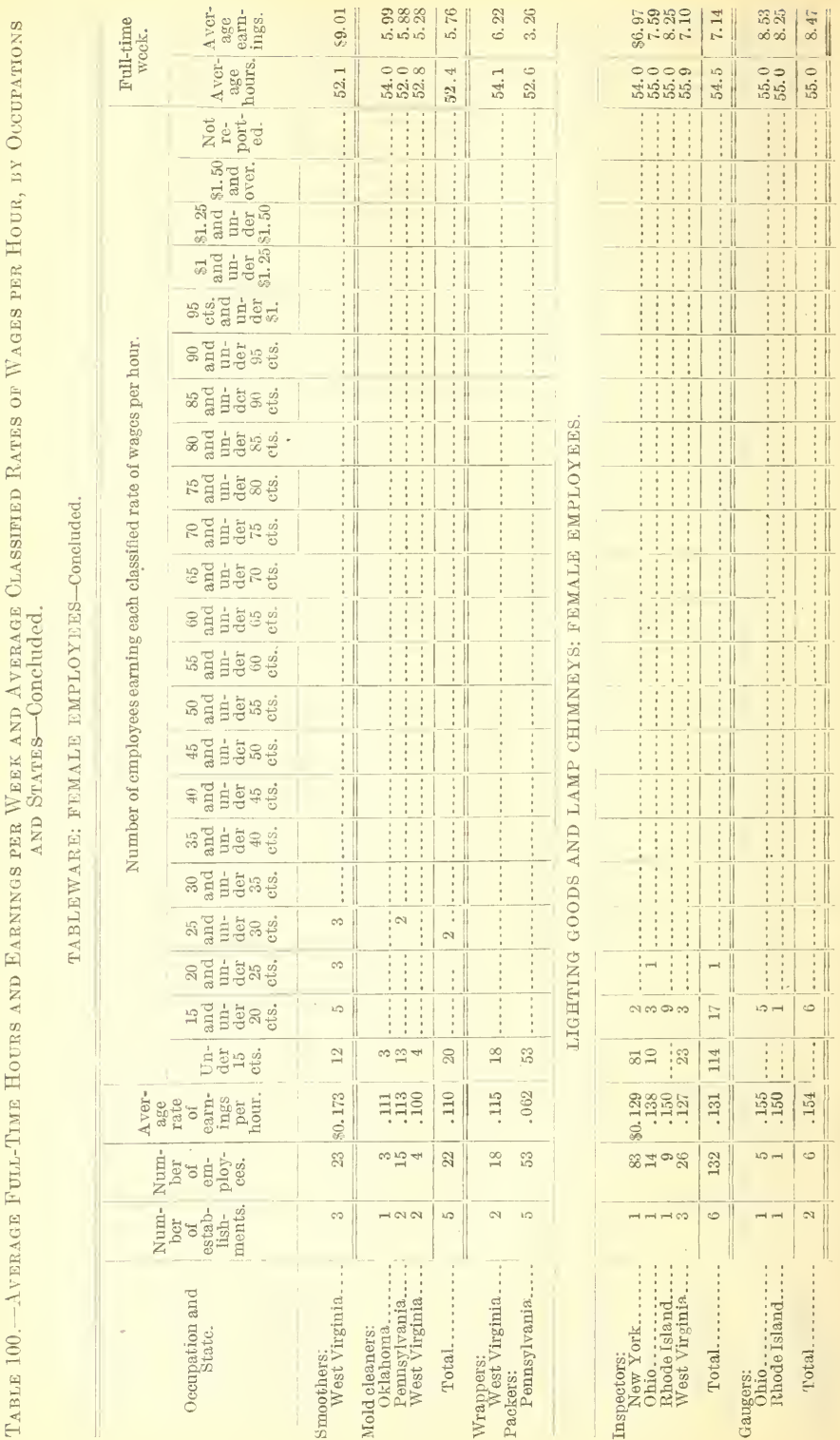


WAGES AND LABOR CONDITIONS.

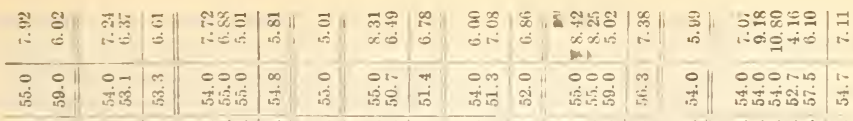

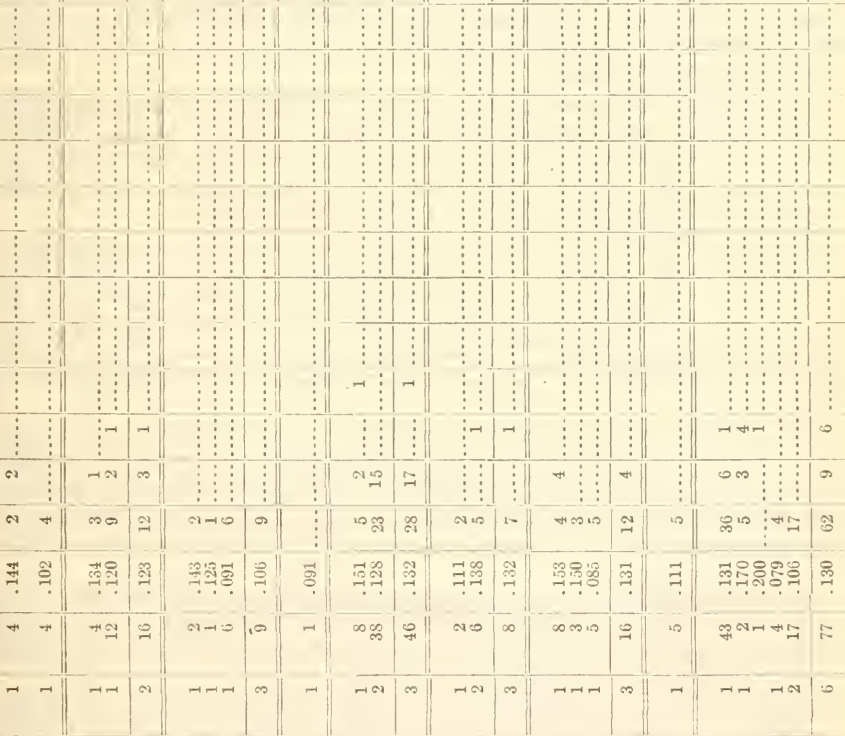

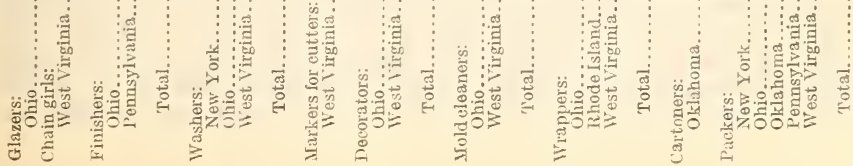


Practically all skilled labor is on the piece-rate basis; all other on the time basis.

The avierage rate of earnings of male employees ranged from under 10 cents per hour, in bottle and tableware plants, to $\$ 1.50$ and over per hour in window-glass plants, and the average rate for female employees from under 10 cents per hour to between 40 and 45 cents per hour.

The foregoing table gives wage data for 2,772 male workers in 30 establishments producing window glass, and shows that none of the workers received an hourly wage of 75 cents and over except blowers, flatteners, gatherers, and cutters, who averaged, respectively, 96.3, $82.2,80.6$, and 68.5 cents per hour. The average full-time weekly hours varied from 43.5 for gatherers to 84 for firemen and watchmen.

Wage data for 1,049 male workers in three establishments making plate glass show that none of the workers received an hourly wage of 40 cents and over except pot makers, five of whom received between 40 and 45 cents. The average for all was 34.6 cents. The average full-time weekly hour's varied from 60 to 72 .

In 43 establishments making bottles wage data for 6,716 male workers show that none of the workers received an hourly wage of 75 cents and over except stopper grinders, machine operators, blowers, and gatherers, who averaged $92.7,59.8,60.2$, and 52 cents, respectively. The average full-time weekly hours varied from 45.2 for gatherers to 81.6 for teasers.

Among the 1,895 male workers in seven establishments making jars none received an hourly wage of 45 cents and over except machine operators, gatherers, and mold makers, who averaged 58.6, 49.7, and 41.7 cents, respectively. The average full-time weekly hours varied from 46.1 for machine operators to 81.1 for watchmen.

Data for 2,566 male workers in 23 establishments making tableware show that none of the workers received an hourly wage of 65 cents and over except handlers, foot casters, blowers, pressers, finishers, and gatherers, who averaged 71.8, 67.1, 61, 57.8, 53.5, and 39.2 cents, respectively. The average full-time weekly hours varied from 44.6 for blockers, pressers, foot casters, and foot gatherers to 84 for firemen.

In 17 establishments making lighting goods and lamp chimneys wage data for 3,063 male workers show that none of the workers received an hourly wage of 70 cents and over except blowers, pressers, and blockers, who averaged 54.6, 54, and 50.9 cents, respectively. The average full-time weekly hours varied from 45.4 for finishers to 75.1 for engineers.

In nine establishments making miscellancous articles of glass wage data for 174 male workers show that the hourly wage ranged from 15 and under 20 cents to $\$ 5$ and under 90 cents. The arerage fulltime weekly hours varied from 48 to 84 .

Wage dat a are included for 857 female workers employed in four establishments making bottles, 15 making tableware, and 10 making lighting goods and lamp chimneys. The hourly wages ranged from under 10 cents in each of the groups to as high as 40 and under 45 cents for cutters in establishments making tableware. The average full-time weckly hours varied from 49.6 for leer women to 60 for selectors and packers, in bottle plants; 50 for washers to 59.3 for 
etchers, plate, in tableware plants; and 51.4 for decorators to 59 for chain girls in lighting goods and lamp chimner plants.

While data regarding the emplovment of female labor were obtained from only establishments making bottles tableware, lighting goods. and lamp chimneys. Table 96, page 250, shows that females were employed also in establishments making window glass by machine and those making jars. Female labor in the glass industry is employed chiefly in finishing and decorating occupations and in packing the ware.

\section{CLASSIFICATION OF OCCEPATIONS.}

Boy labor.- In order to describe fully the occupations of "boy labor," it would be necessary to enter into the details of the various processes of glass making, but as these have already been treated in Chapter I, no attempt will be made in this chapter to relate, except in a general way, the connection of boy labor with the different occupations. It should be understood that labor referred to as boy labor in the glass industry is not always performed by boys, but is the work done by a helper irrespective of age, and in but few of the occupations requires any degree of skill in its performance; in the main, however, boys are employed. Boy labor in the following pages may therefore be considered as unskilled labor, including a small amount of semiskilled labor. Most of the boys are employed in the "shops." From this it will be understood that the work done by boy lahor is by no means uniform, but in many cases the difference is slight and unimportant in so far as it concerns the general character of the work.

Not much boy labor is employed in window-glass factories, and that which is made use of is engaged in carrying cylinders of glass out of the shop and in assisting the flattener. 'These are called roller bovs' and shove boys.

Next to lighting-goods and lamp-chimney manufacture, more boy labor is employed in the manufacture of bottles than in any other branch of the glass industry, and the workers, variously termed mold boys, mold chargers, mold holders, machine boys, stickers-up, cleaning-off boys, takers-off, takers-out, turners-out, tending boys, transfer boys, and carrying-in boys, are engaged principally in attending molds, by opening and closing them as required, cleaning the blowpipes after using, carrying the ware from the blower to the finisher, and from the finisher to the leer and elsewhere in the shop, and in assisting the finisher.

More boy labor was employed in factories making lighting goods and lamp chimneys than in any other branch of the glass industry. In the 12 plants reporting, boy labor was referred to under 18 different names, according to the nature of the operation performed. Although the work done.extended to all parts of the plant, and differed considerably in some cases, the greater number of the workers were engaged in handling ware between blower and finisher and finisher and leer. These workers were variously termed punty boys, ball boys, machine boys, mold holders, turning-out boys, carry-in boys, carry-over boys, passing-along boys, cracking-off boys, stickers-up, $102511^{\circ}-17-19$ 
cleaners-off, finishers, transfer boys, shade boys, warming-in boys, section boys, leer-room boys, and gussers.

Common labor.-Wage earners shown in the tables as "Labor, common," are men doing a variety of work which requires no particular skill, previous knowledge, or training. Under this head are grouped furnace cleaners, leer oilers, pot-wagon men, rope pullers, roughplate men, sand wheelers, blacksmith helpers, floor sweepers, table cleaners, trampers, washers, tar men, carriers-away, clay transformers, coal men, and yard men.

Other consolidations.-For the purpose of avoiding useless detail, occupations of practically the same kind but bearing different names were grouped under general heads in the wage table. The occupations so grouped are given in the following list, the first name in each instance indicating the name of the occupation for the group:

Blowers, tube drawers.

Box makers, crate makers, box shapers.

Decorators, painters.

Drillers, holers.

Engineers, grinder engineers, polish engineers, sand hoist engineers.

Finishers, polisher finishers.

Gas makers, gas producers, producer men.

Gatherers, ball makers, bulb gatherers.

Grinders, chippers.

Hookmen, takers down.

Leermen, leer firemen, leer tenders, takers off leer.

Machine operators, blowers (machine).

Packers, packers and sorters, tubers.

Pot tenders, pot drainers.

Pressers, side-lever pressmen, lid pressers, stopper presser.

Tablemen, first men, second men.

Furnace chargers, shearers, fillers, fillers-in, fillers and toppers.

Teamsters, drivers.

Warehousemen, transfer glass men.

\section{WINDOW GLASS.}

\section{ADVANTAGES OF LOCATION.}

As regards the advantage or disadvantage of one locality over another with respect to labor. manufacturers were of the opinion that in normal times there was none. The union controls the number of skilled men available, which number is sufficient in normal times. This labor must be employed and is always available. It makes little difference where the factory is located; labor will come where it is needed. Of course, surroundings and other conditions have an influence. Labor naturally prefers to live in good surroundings, and factories located where this feature is prominent have an advantage. On the other hand, if such advantages mean a burden in the living cost, labor very frêquently prefers to forego them if it is thereby enabled to live more economically. Thus, a large town, though it may be attractive for many reasons, may not be chosen as a place in which to seek employment, on account of the living cost.

Some manufacturers said they preferred to operate in a neighborhood in which there were other factories, because there was usually a larger supply of floating labor available. Other manufacturers said they preferred to be located at a distance from any other glass plant, because labor has a tendency to change working places in an 
attempt to better its condition; and if one plant has certain adrantages which another plant has not, then the best class of labor will naturally gravitate to the better plant.

\section{WAGES AND WAGE SCILES.}

The skilled workers in hand window-glass factories earn inore during the time ther are employed than the skilled labor in other branches of glass manufacturing. In conparatively few occupations in other industries is the amount earned per dar or week so large, but it should be borne in mind that in hand glass factories the period of work during the year rarely exceeds seren months, and is often less. During this period, howerer, the men in the four skilled occupations-blowing, cutting, flattening, and gathering, particularly in the first three occupations - make exceptionally high wages.

Employees in these four occupations compose the membership of the National Window Glass Workers, an organization which has been verv effective in adrancing the interests of its members, and whose strength has been sufficient to maintain a high scale of wages for the hand operatives, in spite of the effect produced by the introduction and use of machines, which now make 60 per cent of the production. The hand blower and the gatherer are entirely eliminated in the machine window-glass plant, and when wage reductions have been made these two occupations have suffered more than the cutters and flatteners, which occupations are common to both hand and machine plants.

The following, from a bulletin of the Bureau of Labor Statistics, entitled "Union Scale of Wages and Hours of Labor" (1915), bears upon this matter:

The National Window Glass Workers have had wage-scale agreements with their employers since 1879. Agreements exist with practically all the establishments except those blowing window glass by machine processes. Beginning with 1909, competition with the machine made serious inroads upon the scale. In the first column of the table below (Sept. 1, 1908, to Feb. 27, 1909) is shown the rate for blowing single-strength glass by "brackets," as that rate had existed for some years. By "brackets" is meant glass cut to sizes within certain ranges. The blower aims to so blow a cylinder that it will cut the largest possible sizes, since the larger the sizes the higher the rate per 100 feet of glass. The cutter's duty is to cut to the largest sizes the defects in the sheets will permit. In 1908 the old bracket classification existed; that is, the first bracket (single-strength glass), any size from 8 by 10 to 10 by 15 inches, contained the smaller sheets and paid the lowest price, 36 cents per 100 feet. The second brackei, 10 by 16 inches to 16 by 24 inches, paid 46 cents; and so on to the highest designated sizes in the last bracket, 24 by 37 inches to 26 by 40 inches, which paid 86 cents; all larger sizes left unspecified and paid $\$ 1$ per box of 100 feet.

Up to this time, 1908, the commercial qualities A and B had not been written into the workmen's scale. Sheets of double-strength glass not considered salable by the cutter were set aside as "grinders," i. e., to be ground or "frosted" and sold when semiopaque glass could be utilized.

The upheaval in the industry in 1909 , caused principally, though perhaps not entirely, by the uncertainty as to the effect of machine-made glass upon the market, resulted in a complete recast of the scale. All the landmarks of the trade were lost. The commercial qualities of market glass known as $\mathrm{A}$ and $\mathrm{B}$ were passed on the workmen and read into his wage scale. The brackets were abolished for single-strength glass and a flat rate paid per 100 feet of blown glass, regardless of sizes into which it could be cut. The rate for single-strength $\mathrm{A}$ was 42 cents and for B 40 cents. In the double-strength scale two brackets were permitted to remain, but these were made to cover a much wider range of sizes than formerly, as will be noted from the table presented. This scale was made effective February 27, 1909; that is to say, in the middle of a "fire" or working year. 
At the beginning of the next "fire" a new scale, effective September 1, 1909, partially restored the brackets, at least revived the principle of bracket payment. In this scale the two lowest brackets of the 1908 scale were combined to make the small bracket, i. e., 6 by 8 to 16 by 24 ; the old third bracket was made to read 16 by 25 to 24 by 36 , which was an entirely new classification; the old fourth and fifth brackets with "all above" were combined into a new third bracket.

The next scale, effective October 15, 1910, revised the brackets, increased the rates on specified bracket sizes, and restored the "all above" principle. It secured $\$ 1$ per 100 feet for "all above" bracket sizes in the B quality, which was the price of "all above" in the 1908 and prior scales. This was practically as good a scale for the workmen as obtained in 1908. It did not, however, continue during the working year or "fire"; a new midyear agreement, being effective January 24, 1911, went back to the bracket conditions and piece rates established by the scale effective September 1, 1909, and that scale remained unchanged by subsequent agreements up to October 27,1913 . This last-mentioned agreement entirely revised the brackets, elaborated them beyond anything theretolore obtaining in the industry, and increased the piece rates somewhat, but not enough to equal the rates in 1908. The scale of October 27, 1913, was renewed in 1914 and is the present scale.

The period covered by the tables here presenterl represents the most disturbed and turbulent era in the wage-scale history of the industry in the United States, 1908 marking the last year of the old steady rates, 1909 the beginning of the disturbance of rates, and 1913 and since, the apparent settling down to a new basis.

While this analysis has dealt more directly with the first table showing rates for blowing single-strength glass, it has, it is believed, given a sufficiently clear explanation to enable readers to follow the table of rates for double-strength blowing.

Single-strength glass means glass that measures about 13 lights to the inch in thickness and weighs 100 pounds to the box of 100 square feet.

Double-strength measures 8 lights to the inch and weighs about 130 pounds per 100 square feet.

Single and double strengths were the only weights blown in the United States up to a few years ago, when the extended use of lightweight plate glass made it imperative for window-glass establishments to produce a thicker glass to hold the building trade. Quite recently, therefore, triple-strength, or glass weighing 32 ounces to the square foot, is being generally made; and occasionally much heavier than triple is blown, the scale providing for glass weighing 39 ounces, 42 ounces, and even 52 ounces to the square foot. A 29-ounce glass, just between double and triple strength, has also been provided for in the scale. This glass runs seven lights to the inch.

The table, referred to above, has been brought up to date and with additions is as follows: 
Table 101.-Piece Rates for Blowers per Box of 100 SQLare Feet for MakiNg WiNdow Glass BY IIAND, Sept, 1, 1905, to MaY 29, 1917, BY GRADES.

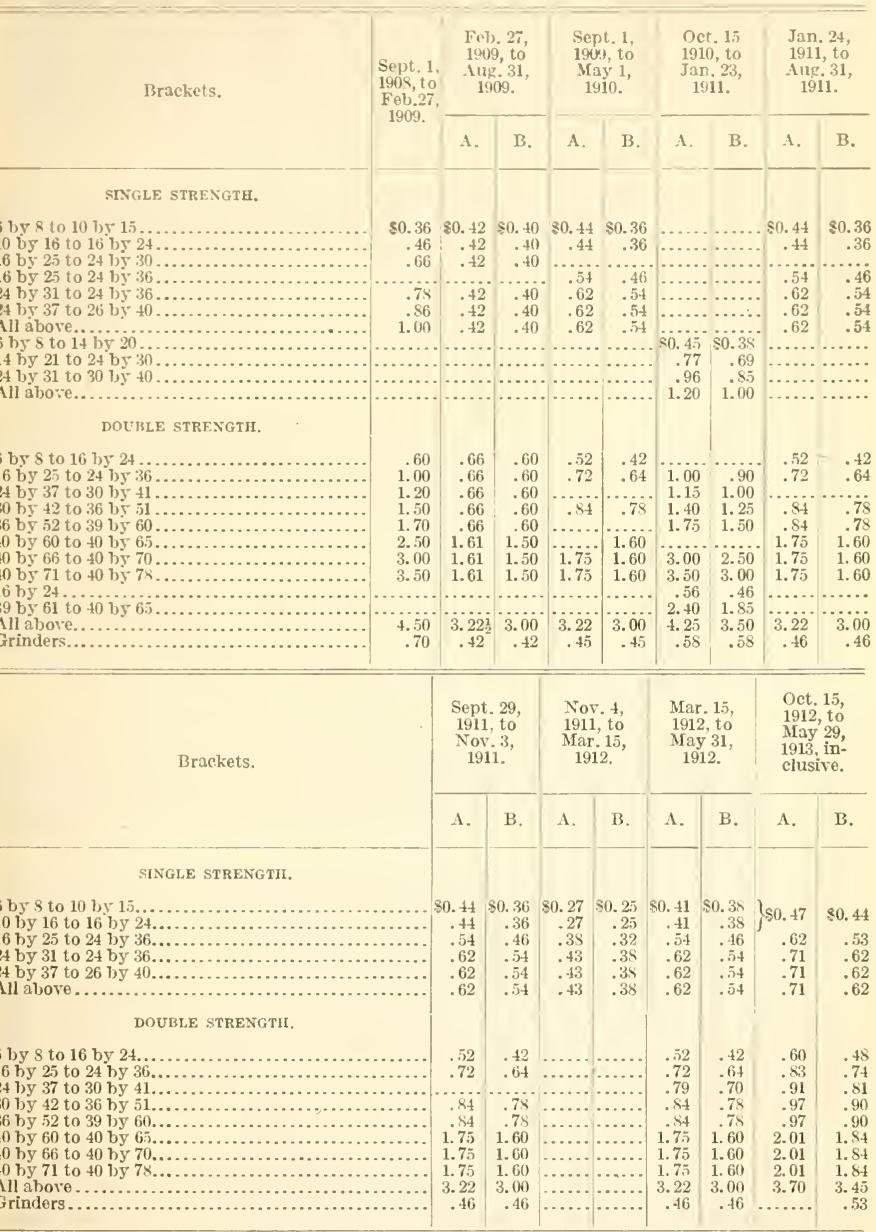


Table 101.- Piece Rates per Box of 100 Square Feet for Making Window Glass by Hand, SePt. 1, 1908, to May 29, 1917, by Grades-Concluded.

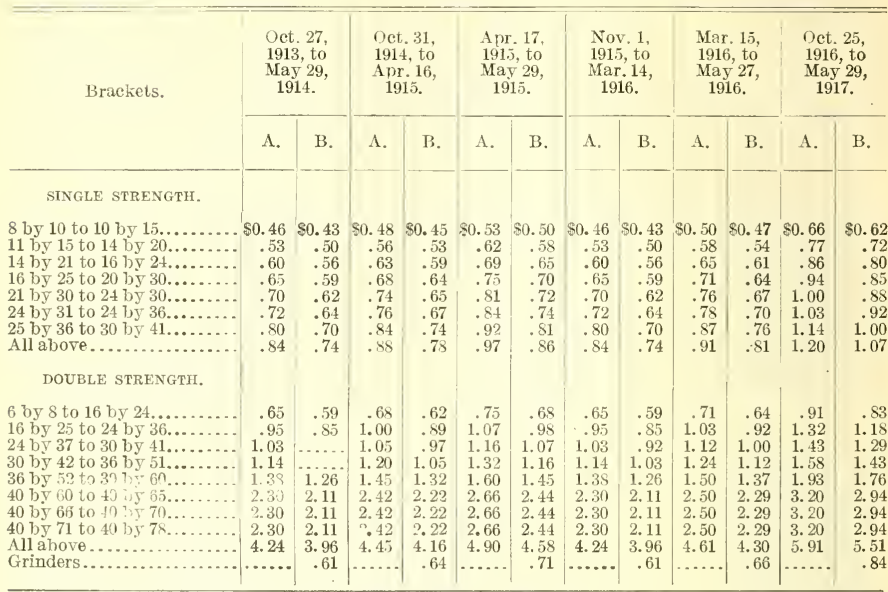

This table shows that important increases have been granted regularly during the past few seasons. At the beginning of the season of 1914-15, there was a 5 per cent increase over the scale of the year before. The agreement relative to this increase is as follows:

On the prices specified (previous year's scale) there shall be paid an advance of 5 per cent. It is also understood and agreed that future advances on this scale shall be computed on the basis of the above brackets after the 5 per cent advance has been added. And be it further agreed that for every point of discount that glass sells above 90-17 single strength and 90-21 double strength, wages shall be advanced $1 \frac{1}{2}$ per cent as above specified.

An additional increase of 10 per cent, computed on the scale at the beginning of the year, with the 5 per cent noted above ircluced, was granted toward the end of the season, and was effective from April 17 to the end of the "fire," May 29.

At the beginning of the season of 1915-16 the scale was the same as that $2 t$ the beginning of the preceding season without the 5 per cent added, or the same as at the beginning of the 1913-14 season. In March, 1916, a voluntary increase of $7 \frac{1}{2}$ per cent was given, which was effective from March 15 to May 27, the end of the fire.

Very large increases were granted for the season of 1916-17. An increase of 20 per cent over the prices prevailing at the end of the season was given to single-strength workmen and $16 \frac{1}{2}$ per cent to double-strength workmen, with an additional 10 per cent advance differential to single-strength blowers exclusively.

The additional 10 per cent to single-strength blowers was urged in the wage conference by the three noncontending trades - gatherers, flatteners, and cutters-voting unanimously. According to the view of the representatives of these three trades the earnings of singlestrength blowers had been out of proportion to those of the other trades, and as a consequence many blowers had returned to gathering or had demanded that they be allowed to blow double-strength glass: 
That the wages earned by skilled workers in hand window-glass factories were very high 25 years ago is clearly shown by the following arerage daily wages in 15 establishments, derived from the Annual Report of the Commissioner of Labor, 1891 (pp. 567 to 586): Blowers, $\$ 6.526$; cutters, $\$ 4.802$; flatteners, $\$ 6.286$; gatherers, $\$ 3.959$ per day. Such wages were exceptional for the period and are, perhaps, much higher than the average of wages paid for skilled labor to-day

At the present time almost all hand window-glass plants work three shifts of eight hours each for five days of the week in the shops. The shifts alternate. On one Saturday, one shift will have no turn, on the next Saturday a 4-hour turn; on the third Saturday an 8-hour turn, the day beginning at midnight. So in three weeks all shifts have worked a 40,44 , and 48 hour week. Hence the average week is 44 hours, and the average Saturday is 4 hours, or one-half of the usual day. A week, therefore, is $5 \frac{1}{2}$ days.

These figures indicate the fact that wages in the skilled occupations of hand window-glass manufacturing have been very high for a long time and are increasing.

It is not to be assumed that wages in the occupations mentioned have increased steadily from year to year. There have been periods when reductions were made, but the tendency over a long period of years has been toward higher wages.

About 1903 the machine for making window glass was introduced, and there followed a number of critical years for both the manufacturer of handmade window glass and the labor employed. Mr. J. M. Neenan, president of the National Window Glass Workers, states:

Before the period of uncertainty and demoralization ended the average of wages was reduced from 90 cents per box in 1903 to 30 cents per box in 1912-13.

According to the manufacturers interviewed during this investigation, the wages paid in the skilled occupations-blowing, gathering, flattening, and cutting - have steadily increased in recent years, though for a period previous to this they had steadily declined, due to overproduction and a general depression in the business. During this period of declining wages labor also suffered from short seasons.

As stated before, the season in this industry is short, rarely exceeding seren months for hand factories. In addition, during this period there are often shutdowns from various causes which further reduces the number of wage-earning days in the year for the glass worker. The machine factories have a season of 10 or 11 months, but do not operate with a full force during the whole season. So, although the daily earnings in the occupations discussed may seem very high, the earnings for the year are not in proportion to the daily earnings.

\section{LABOR-UNION REGULATIONS.}

There are three labor organizations connected with window-glass manufacturing. These are the National Window Glass Workers, the Window Glass Cutters' and Flatteners' Association of America, and the Window Glass Cutters' and Flattener's' Protectire Association of America.

The last two named embrace the cutters and flatteners working in machine plants. The first of these two is identified with what is known as the independent machines and the last with the American 
Window Glass Co. These two organizations are comparatively young, as machines were not used for glass making until about 1903, and take in only two of the four skilled trades. In the machine plant there are no gatherers and the machine operators (unskilled men) take the place of the blower. The "shops" are not organized in machine plants, though the matter has been considered by the National Window Glass Workers, thus far without result. The three organizations are noncontending and work in harmony. The organizations connected with machine plants are by no means so strong as the one connected with the hand factories.

The National Window Glass Workers embraces the occupations of blowing, gathering, cutting, and flattening-the four skilled occupations. It is the only labor organization connected with the hand window-glass industry, and is one of the strongest of labor unions. It meets at least once yearly with the National Association of Window Glass Manufacturers to adopt a wage scale and to dispose of all other matters that come up for settlement. It had a membership of 3,779 during the year 1914-15, and 4,301 during 1915-16; at one time the membership was 6,500 .

Wages based on blowers' earnings.-The wages of the gatherer and flattener are based on the earnings of the blower. The rule relating to this is as follows:

Gatherers shall receive 80 per cent as much as blowers' wages for both single and double sizes.

Flatteners shall receive 27 per cent as much as blowers' wages.

Hours of labor.--The following are the union rules relating to hours of labor in the shops:

Forty hours shall constitute a week's work for blowers and gatherers. The following system may be adopted when locals so decide: In order to do away with the 4-o'clock shift on Saturday morning, the midnight shift shall produce a full day's work, the day shift starting at 8 o'clock and working until 12 noon. The 4-o'clock shift finishes work for the week at midnight Friday night. All work ceases on Saturday at 12 o'clock noon. No member shall gather and blow before 1 o'clock a. m. Monday.

The actual practice is somewhat different. Each shift works two turns of 4 hours each with only an interval of a few minutes between the turns. Practically all factories work three shifts. The first shift begins work at 12 o"clock midnight Sunday and works until 8 a. m. Monday; the second shift begins at $8 \mathrm{a} . \mathrm{m}$. and works until $4 \mathrm{p} . \mathrm{m}$.; the third shift begins at $4 \mathrm{p}$. m. and works until midnight Monday, when the first shift comes on again. Work ceases at noon Saturday, the second shift getting in one turn between 8 and 12 o'clock Saturday. During the week, therefore, the three shifts have worked 12,11, and 10 turns, respectively. In the following week the third shift begins first and on the next week the second shift begins first. So in three weeks each shift has worked a week of 12,11, and 10 turns, making an average of 11 turns of 4 hours or 44 hours per week.

The following is the only rule in effect relating to the hours of labor of flatteners:

All flatteners working 12-hour turns shall stop at least 30 minutes for lunch.

The time at which a flattener must begin and stop work is not prescribed. His hours are somewhat irregular. He has just so much to do-the work of so many blowers-and it can be done at his convenience. Sometimes he can do it by working only a short day and 
at other times he must work long hours to do it. 'Table 9.5 of this report shows the arerage time worked by flatteners to be 55.8 hours per weok.

I cutter works more hours per week than any other employee in a skilled occupation in window glass. His hours are not prescribed, and they are often rerr irregular, depending on the amount of work to be done. He frequently works at night and sometimes on sunday. Table 95 shows the arerage hours of a cutter to be 59 per week.

Limited production of shitled workers. - The hand window-glass factories operate not exceeding seren months a vear, from about Norember 1 to May 30 , and during that time produce what may be required to fill orders during the other fire months. As it is impossible for them to forecast the proportions of each size of glass that will be ordered during the summer, it is customary during the manufacturing season to cut only part of their product in regular sizes and to set aside sheets uncut to be cut as orders may be receired during the fire months when the factory is not in blast. The rules of the union provide that a cutter shall be paid full price for sheets set aside, though they are uncut, also that when they are cut later they shall be paid for at full price. On stock sheets, therefore, double price is paid for cutting. The following is quoted from the union's wage scale for the 1916-17 blast:

\section{Section I.}

ArT. 9. Single strength may be made in the following sizes only; size specified is size work is to cut; 2 inches in length and 2 inches in width is allowed for cutting: 36 by 56 may be made at the rate of ten per hour as special orders; 48 by 56 may be made at the rate of eight per hour as special orders, with the understanding that when orders on either of the above sizes are given glass is to be cut in sizes above the 16 by 24 bracket, provided the quality of the glass is suitable. The following sizes in single strength may be made at the rate of nine per hour: 36 by 64,38 by 60,38 by 62,40 by 56,40 by 58,40 by 60,42 by 54,42 by 56,42 by 58,44 by 52,44 by 54,44 by 56 . The company shall post in blowing room the size each shop single and double shall work on, and preceptors shall see that all workmen work on sizes specified.

Sixty-five rollers shall constitute a day's work. In case of a roller breaking on the crane or on the horse from capping off or cracking open, blowers and gatherers shall be privileged to make up such breakage so that 65 rollers are produced for a day's work.

ART. 10. Number of D. S. rollers allowed per hour.-All sizes up to and including 1,728 square inches, 9 per hour; All sizes up to and including 2,160 square inches, 8 per hour; All sizes up to and including 2,584 square inches, 7 per hour; all sizes above 2,584 square inches, 6 per hour; up to and including 28 by 60,9 per hour; 28 by 72,8 per hour; 30 by 56,9 per hour; 30 by 72,8 per hour; 30 by 86,7 per hour; 32 by 54,9 per hour; 32 by 66,8 per hour; 32 by 80,7 per hour; 32 by 60,8 per hour; 34 by 76,36 by 70 , and 38 by 68,7 per hour; 40 by 54,8 per hour; 40 by 64,7 per hour; 42 by 50,8 per hour; 42 by 60,7 per hour; 44 by 48,8 per hour; 46 by 56 and 48 by 52 , 7 per hour.

ART. 13. The number of lights per box in all strengths shall be uniform.

ART. 14. The following list governs cutters when setting out single-strength sheets: $61 / 2$ lights per 100 feet; in setting out double strength sheets, 50 by 60 , or the equivalent in square inches shall be set out at the rate of 5 lights per box.

Art. 15. Manufacturers may set out stock sheets in amounts not to exceed 2,400 feet per four weeks for any pot, place, or blower. Stock sheets to be set out at a ratio of one box per blowing. This to apply to both single and double.

The single and double strength glass set out shall be booked to the blower at the price the single-strength glass and double-strength glass, respectively, cut and packed during the week it is set out, averages per box.

The cutter is to receive full price for all glass set out in stock sheets. Stock sheets shall not be cut up or shipped during the blast. 


\section{Section III.}

AnT. 14. Any blower or gatherer making more grinders than provided for by law, or any cutter cutting or setting out more stock sheets or grinders than provided by law, shall be fined not less than $\$ 5$ for the first offense and $\$ 10$ for each succeeding offense.

The production of flatteners is limited by the following rules:

\section{SECTION IV.}

ArT. 1. Twelve pots shall be the limit for any one flattening oven.

ART. 2. Where 12 pots are flattened in any oven three flatteners shall be employed on said oven.

ART. 4. No flattener shall flatten for more than four pots, unless in case of actual emergency.

The production of cutters is limited by the following rules:

\section{Section V.}

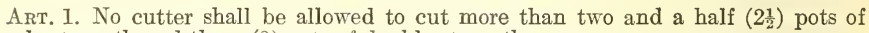
single strength and three (3) pots of double strength.

ART. 3. No cutter shall work while the fire is out filling orders from glass set out in the sheet for weekly wages, when such wages would be exceeded in amount if the glass cut was paid for according to the regular price per box, as fixed in the articles of agreement between this association and the manufacturers.

ART. 4. Cutters setting out single-strength stock sheets shall book six and one-half (63) lights per hundred-foot box to the blower.

Art. 12. Cutters shall not cut or book more than one blower's glass at any one time.

The manufacturers object to these restrictions, but have not been able to get the union to change the rules. They object also to paying guaranties to skilled workers, a practice which is not forced upon them by the union but by the rivalry among themselves. During 1916, when the demand for glass was large, manufacturers found it difficult to engage enough skilled workers, and some offered inducements in the way of guaranties that men they employed would be paid not less than a certain amount per day or per box, regardless of the quantity produced. The effect was that manufacturers that offered guaranties secured skilled workers from those that did not make such offers.

Strikes. - The last general strike in the window-glass manufacturing business occurred in 1907. This came following a period of overproduction, reckless selling, and chronic depression in the business. A higher scale was demanded by the union men, but, after staying out 10 months, they returned to work at the old scale. The general condition of the business made it impossible for the union to force a higher scale at that time. In 1908 a strike was threatened when the union demanded a change from a sliding scale, based on the selling price of glass, to a flat price. The demand was granted.

During the spring of 1916 the snappers in most of the hand windowglass factories demanded higher wages and recognition as a union. In most instances an increase was granted, and in a number of cases before the demands of the men were formulated, but the manufacturers would not recognize them as a union, principally because such action was thought to be contrary to what the other union men of the shop desired.

Holidays.-The following is the agreement with reference to holidays:

There shall be no glass blown, gathered, flattened, or cut, on the following holidays: Thanksgiving, Christmas, and Labor Day. 
Right to enter factory.-Members of the union hare the privilege of entering the factory as explained by the following rule:

No member of the National Window Glass Workers shall be denied the right to enter any factory, flattening house, or cutting room where the national scale is in force. This not to apply to men under the influence of strong drink, sleeping in factories, or using abusive language.

Union dues.-Union dues are collected according to the following provisions:

Manufacturers shall deduct from the earnings of all members of the National Window Glass Workers working for them 2 per cent of the amount earned, for dues to the National Window Glass Workers, and shall, within 10 days after each and every settlement, present a check, for the full amount to the chief preceptor, payable to the Secretary of the National Window Glass Workers, together with the names, amounts earned, and the amount paid by each member during said period, same to be forwarded by the chief preceptor to the national secretary. No debt of any kind that a member contracts shall prevent the deduction of this 2 per cent, and any manufacturer who overpays or fails to deduct and forward said money for dues shall be liable to the National Nindow Glass Workers for the payment of same, whether the member has anything due him or not. This also applies to entire earnings for boss cutters. All bills to be presented weekly with the amount earned. Said bills to have the amount of glass cut in each bracket and the amount of $A$ and $B$.

\section{BOTTLES.}

\section{EFFECT OF SHOP SYSTEM ON LABOR.}

The "shop" system which is still in vogue was established in the glass factories of the United States and Canada in 1870. ${ }^{1}$ A "shop" consists of three men who divide the operations of gathering, blowing, and finishing.

Between 1870 and 1905 the production per blower increased 138 per cent for the medium line of ware, viz, S-ounce bottles. This increase was partly due to the substitution of the tank for the oldstyle furnace, as the average product of the blower increased 25 per cent after its introduction. As a result of this increase, and through the influence of a powerful labor union, wages for skilled labor in bottle manufacturing maintained a very high level through this period as compared with the wages received in the skilled occupations of other industries.

About 1896 a machine was introduced that was commercially successful, and, though it was crude and was restricted to widemouth bottles and jars, it marked the beginning of a revolution in bottle manufacturing which had the most serious effect on labor.

In 1903 the Owens automatic machine was introduced, the first type of which made only narrow-mouth bottles; later this was perfected to make any kind of bottle. The remarkable production obtained from this machine without the use of skilled labor soon demonstrated to all bottle manufacturers that if they were to compete with it, it would be necessary to make a saving in that highest element of cost-labor.

To this end manufacturers exerted their utmost ingenuity, and, as a result, there is now a great variety of machines in use, and practically 80 per cent of the bottles produced is from machines. 
The effect on labor can readily be imagined. With the growth of the use of machines the number of skilled laborers constantly diminished. The condition of the hand manufacturers was such that wage reductions had to be requested. It is to the credit of the employees that such reductions were submitted to, not entirely because they could not be resisted, but because of an honest desire to share mutually with the manufacturers the burden of a situation in which all were placed.

PIECE PRICES, 1907 TO 1917.

The following tables give in detail the piece prices prevailing for the seasons of 1907-8 to 1916-17, inclusive:

Table 102.-Glass Bottles (Hand Blown): Piece Rates per Ğross Paid to Blowers, 1907 To 1917.

\begin{tabular}{|c|c|c|c|c|c|c|c|c|c|c|c|c|}
\hline \multirow[b]{2}{*}{ Kind of bottle. } & \multirow[b]{2}{*}{ Capacity. } & \multirow[b]{2}{*}{ Weight. } & \multicolumn{2}{|c|}{$1907-1912$} & \multicolumn{2}{|c|}{$1912-1914$} & \multicolumn{2}{|c|}{$1914-15$} & \multicolumn{2}{|c|}{$1915-\mathbf{1 6}$} & \multicolumn{2}{|c|}{$1916-17$} \\
\hline & & & 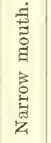 & 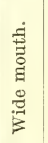 & 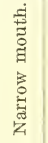 & 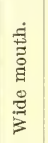 & 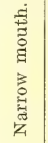 & 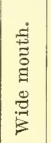 & 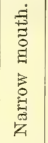 & 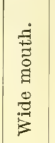 & 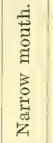 & 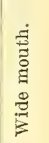 \\
\hline 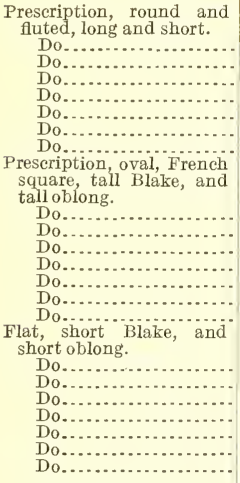 & 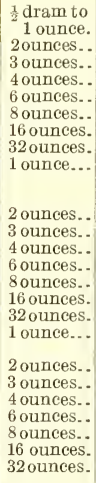 & $\begin{array}{l}1 \frac{1}{4} \text { ounces. } \\
2 \text { ounces. } \\
2 \frac{1}{2} \text { ounces. } \\
3 \frac{1}{2} \text { ounces. } \\
5 \text { ounces.. } \\
6 \frac{1}{2} \text { ounces. } \\
11 \text { ounces. } \\
18 \text { ounces. } \\
1 \frac{1}{4} \text { ounces. } \\
2 \text { ounces.. } \\
3 \text { ounces.. } \\
4 \text { ounces.. } \\
5 \frac{1}{2} \text { ounces. } \\
7 \text { ounces.. } \\
12 \text { ounces. } \\
20 \text { ounces. } \\
1 \frac{1}{2} \text { ounces. } \\
2 \frac{1}{2} \text { ounces. } \\
3 \frac{1}{2} \text { ounces. } \\
42 \text { ounces. } \\
6 \text { ounces.. } \\
8 \text { ounces.- } \\
14 \text { ounces. } \\
22 \text { ounces. }\end{array}$ & $\begin{array}{r}.58 \\
.63 \\
.70 \\
.80 \\
.90 \\
1.19 \\
1.62 \\
.58 \\
.62 \\
.67 \\
.74 \\
.85 \\
.96 \\
1.30 \\
1.78\end{array}$ & $\begin{array}{r}.61 \\
.66 \\
.74 \\
.83 \\
.94 \\
1.24 \\
1.66 \\
.60 \\
.64 \\
.69 \\
.76 \\
.87 \\
.98 \\
1.32 \\
1.80\end{array}$ & $\begin{array}{r}.58 \\
.50 \\
.56 \\
.64 \\
.72 \\
.95 \\
1.30 \\
.58 \\
.62 \\
.54 \\
.59 \\
.68 \\
.77 \\
1.04 \\
1.42\end{array}$ & $\begin{array}{r}.61 \\
.53 \\
.59 \\
.66 \\
.75 \\
.99 \\
1.33 \\
.60 \\
.64 \\
.55 \\
.61 \\
.70 \\
.78 \\
1.06 \\
1.44\end{array}$ & $\begin{array}{r}.46 \\
.50 \\
.56 \\
.64 \\
.72 \\
.95 \\
1.30 \\
.46 \\
.50 \\
.54 \\
.59 \\
.68 \\
.77 \\
1.04 \\
1.42\end{array}$ & $\begin{array}{r}.49 \\
.53 \\
.59 \\
.66 \\
.75 \\
.99 \\
1.33 \\
.48 \\
.51 \\
.55 \\
.61 \\
.70 \\
.78 \\
1.06 \\
1.44\end{array}$ & $\begin{array}{r}.46 \\
.50 \\
.56 \\
.64 \\
.72 \\
.95 \\
1.30 \\
.46 \\
\\
.50 \\
.54 \\
.59 \\
.68 \\
.77 \\
1.04 \\
1.42\end{array}$ & $\begin{array}{r}.49 \\
.53 \\
.59 \\
.66 \\
.75 \\
.99 \\
1.33 \\
.48 \\
.51 \\
.55 \\
.61 \\
.70 \\
.78 \\
1.06 \\
1.44\end{array}$ & $\begin{array}{r}.51 \\
.55 \\
.62 \\
.70 \\
.79 \\
1.05 \\
1.43 \\
.51 \\
.55 \\
.59 \\
.65 \\
.75 \\
.85 \\
1.14 \\
1.56\end{array}$ & $\begin{array}{r}.54 \\
.58 \\
.65 \\
.73 \\
.83 \\
1.09 \\
1.46 \\
.53 \\
\\
.56 \\
.61 \\
.67 \\
.77 \\
.86 \\
1.17 \\
1.58\end{array}$ \\
\hline
\end{tabular}


Table 113.-Glass Bottles and Jars (Machixe): Rates per 100 Pieces Paid to Macirne Operators, 1907 to 1917.

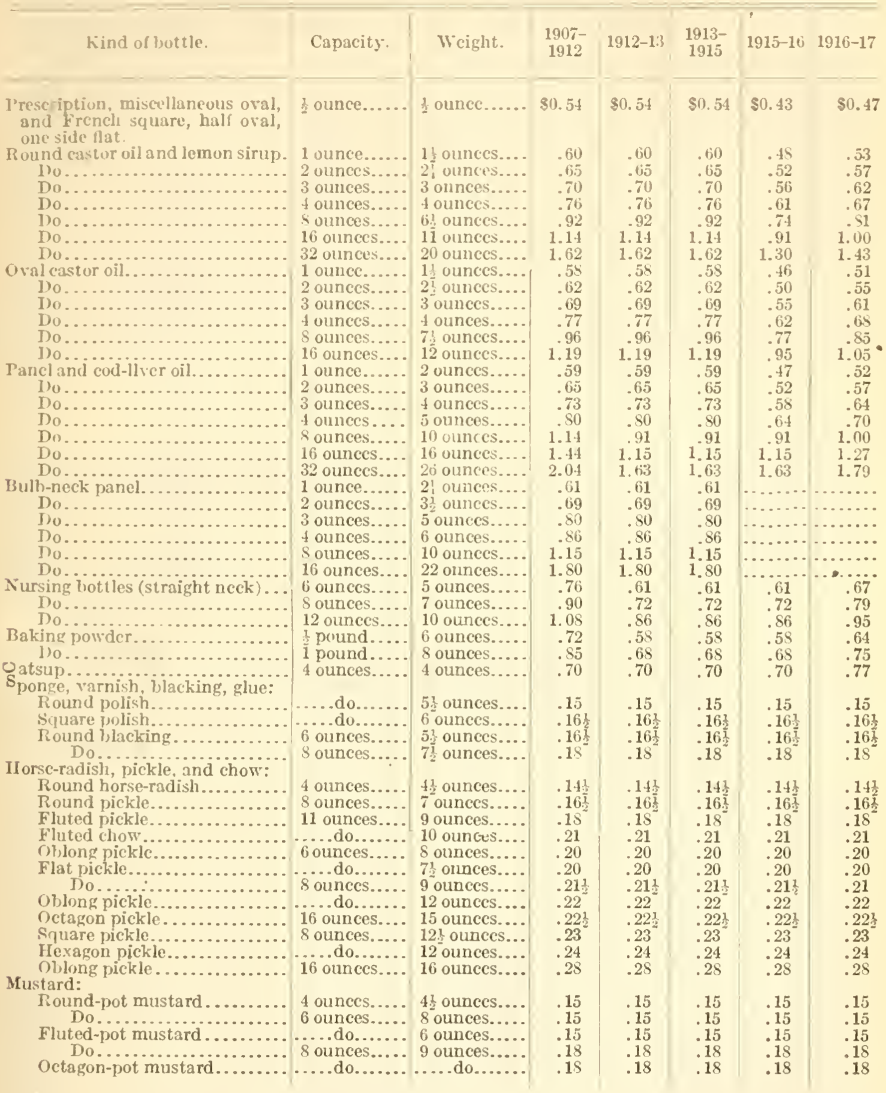


Table 104.-Glass Bottles and Jars (Machine): Rates per 100 Pieces Paid to Machine Operators, 1908 to 1917.

Kind of bottle.

Jars. iruit:

Improved Mason.

Jam jar.

Improved top, Niason.

Milk:

$\frac{1}{4}$ pint

$\frac{1}{2}$ pint.

1 quart.

Cherry and olive:

Round.

Do.

Do....

Jelly and tumblers: $\frac{1}{2}$-pint jelly glasses.

Q aseline, pomade, mucilage, and paste:

Round, wide-mout vaselinc

Do............

Do.............

Jams, preserves:

Round, preserves.... . . .

Round, jam ..........

Round, preserves....

a.t.............................

Round, preserves...........................................

Prescription, bromo, and morphine:

Square, morphine ................

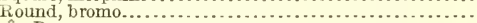

Do

Do.

Table 105.-Glass Bottles (Hand Blown): Piece Rates per Gross Paid to BLOWERS, 1907 to 1917.

\begin{tabular}{|c|c|c|}
\hline Capacity. & Wcight. & $1908-1917$ \\
\hline $\begin{array}{l}\text { pint.. } \\
\text { quart. } \\
\text { gallon. }\end{array}$ & & $\begin{array}{l}\text { So. } 1.5 \\
.15 \\
.18 \\
.241\end{array}$ \\
\hline $\begin{array}{l}\frac{1}{2} \text { ounces.... . } \\
6 \text { ounces...... } \\
6 \text { ounces..... } \\
2 \text { ounces..... }\end{array}$ & $\begin{array}{l}7 \text { ounces....... } \\
11 \text { ounces...... } \\
15 \text { ounces...... } \\
26 \text { ounces...... }\end{array}$ & $\begin{array}{l}.17 \\
.21 \\
.25 \\
.38\end{array}$ \\
\hline $\begin{array}{l}2 \text { ounces...... } \\
6 \text { ounces...... } \\
8 \text { ounces...... } \\
7 \text { ounces...... } \\
\text { ounces...... }\end{array}$ & $\begin{array}{l}11 \text { ounces...... } \\
13 \text { ounces..... } \\
15 \text { ounces...... } \\
22 \text { ounces...... } \\
6 \text { ounces....... }\end{array}$ & $\begin{array}{l}.20 \\
.21 \\
.26 \\
.30 \\
.13\end{array}$ \\
\hline $\begin{array}{l}\text { ounce } . . . . . . \\
\text { ounces....... } \\
\text { ounces....... } \\
\text { ounces....... }\end{array}$ & 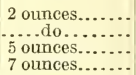 & $\begin{array}{l}.12 \\
.12 \\
.14 \\
.15\end{array}$ \\
\hline $\begin{array}{l}\text { ounces.......... } \\
2 \text { ounces...... } \\
6 \text { ounces...... } \\
\text {...do......... }\end{array}$ & $\begin{array}{l}8 \text { ounces....... } \\
8 \frac{1}{2} \text { ounces..... } \\
10 \text { ounces...... } \\
11_{2}^{1} \text { ounces..... } \\
14 \text { ounces...... }\end{array}$ & $\begin{array}{l}.15 \\
.16 \\
.18 \\
.18 \\
.23 \frac{2}{2}\end{array}$ \\
\hline $\begin{array}{l}\text { ounce......... } \\
\text { ounce........ } \\
\frac{1}{2} \text { ounces...... } \\
\text { ounces....... }\end{array}$ & $\begin{array}{l}2 \text { ounces........ } \\
1 \frac{1}{2} \text { ounces...... } \\
33 \text { ounces...... } \\
6 \text { ounces....... }\end{array}$ & $\begin{array}{l}.12\} \\
.13 \\
.14 \frac{1}{4} \\
.17^{2}\end{array}$ \\
\hline
\end{tabular}

\begin{tabular}{|c|c|c|c|c|c|}
\hline Kind of bottle. & Capacity. & Weight. & $1907-8$ & 1909-1912 & $1913-1917$ \\
\hline 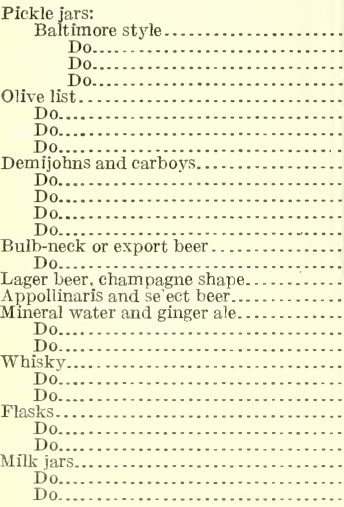 & $\begin{array}{l}1 \text { gallon ........ } \\
2 \text { gallons........ } \\
4 \text { gallons........ } \\
8 \text { gallons........ } \\
16 \text { gallons...... } \\
1 \text { pint ........... } \\
1 \text { quart......... } \\
16 \text { ounces....... } \\
32 \text { ounces....... }\end{array}$ & 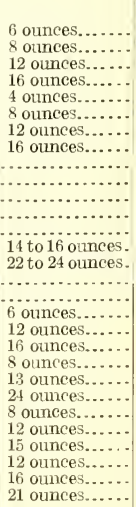 & $\begin{array}{l}\$ 0.86 \\
.98 \\
1.18 \\
1.42 \\
.72 \\
1.02 \\
1.24 \\
1.46 \\
a .26 \\
a .42 \\
a .78 \\
b .081 \\
b .141 \\
1.32 \\
1.59 \\
1.38 \\
2.11 \\
.83 \\
1.181 \\
1.41 \\
.99 \\
1.23 \\
1.71 \\
.77 \\
1.09 \\
1.39 \\
1.24 \\
1.38 \\
1.72\end{array}$ & $\begin{array}{r}\$ 0.86 \\
.98 \\
1.18 \\
1.42 \\
.72 \\
1.02 \\
1.24 \\
1.46 \\
a .26 \\
a .42 \\
a .78 \\
b .081 \\
b .142 \\
1.06 \\
1.27 \\
1.10 \\
1.69 \\
.83 \\
.95 \\
1.13 \\
.79 \\
.98 \\
1.37 \\
.77 \\
1.09 \\
1.39 \\
1.24 \\
1.38 \\
1.72\end{array}$ & $\begin{array}{r}\$ 0.69 \\
.78 \\
.94 \\
1.14 \\
.58 \\
.82 \\
.99 \\
1.17 \\
a .26 \\
a .42 \\
a .78 \\
b .08 \\
b .142 \\
.85 \\
1.02 \\
.88 \\
1.35 \\
.66 \\
.76 \\
.90 \\
.63 \\
.78 \\
1.10 \\
.75 \\
.91 \\
1.01 \\
1.24 \\
1.38 \\
1.72\end{array}$ \\
\hline
\end{tabular}


For the season of $190 \overline{7}-S$ a reduction was made in certain brackets. In 1912 a rery heavy reduction was made, affecting many of the most important brackets of the list. The scale of $1912-13$ prevailed during the following season. For the season of 1914-15 a reduction of 20 per cent from the scale of the year before was made for prescription, miscellaneous oval and French square, round castor-oil and lemon sirup, oral castor-oil, and panel and cod-liver oil bottles. The scale of 1914-15 remained in effect, without change, during the next season. For the season of 1916-17 the first advance in many years was granted. The increase was for 10 per cent, and covers all lines of ware in the hand-blown department that had been reduced in 1912, except beer, soda, flasks, and a few miscellaneous bottles.

According to D. A. Hayes, president, and William Launer, secretary, of the Glass Bottle Blower's' Association, the arerage wage of 11,000 skilled glass blowers in the United States was in 1913 about $\$ 4.60$ per day. ${ }^{1}$

GLASS BOTTLE BLOWERS' ASSOCLATION.

According to President Denis A. Hayes, of the Glass Bottle Blowers, Association of the United States and Canada, this organization, which is the only union in this branch of the industry, had its start in $1847 .^{2}$ Originally it included only labor in the skilled occupations, blowing and finishing, but at the present time may include all workers except mold makers, engineers, and firemen.

A national wage scale was adopted in 1861 . For 35 years, according to Mr. Hayes, the union struggled to get the employers to meet with them for the purpose of agreeing to a wage scale. Finally they consented, and at first annual meetings took place, but later semiannual meetings were held, which is the custom at the present time. The first meeting is held in May, the second in August.

History of the organization.-The glass-bottle blowers were first organized in separate and independent Eastern and Western Leagues of Green Glass Bottle Blowers. In 1886 each became affiliated with the Knights of Labor, as Assembly Nos. 149 and 143, respectively. As early as 1886 there is record of annual conferences between the eastern and western leagues of blowers and of loosely organized associations of eastern and western bottle manufacturers.

As a result of these independent meetings, the two unions often found themselves working at cross purposes. Frequently concessions granted by one of the unions would be used to force concessions from the other. In addition, owing to the fact that journeymen blowers of ten went from one district to the other, it became increasingly difficult to discipline the membership. On account of these things, steps were taken looking to a consolidation of the two unions. This was accomplished in 1890, when they united in one body under the title of the National Trade Assembly. At the same time the sectional conferences of preceding years was succeeded by national conferences between representatives of the unions and of the manufacturers. In July, 1891, the assembly withdrew from the Knights of Labor to become the Green Glass Blowers' Association of the United

1 Hearings before Ways and Means Committee on Underwood-Simmons Tariff Bill, p. 709.

2 Report to 1915 convention, p. 13. 
States and Canada. The present name is the Glass Bottle Blowers' Association of the United States and Canada.

Relations with manufacturers.-During the first few years following the amalgamation of the unions, the conflicting interests of the eastern and western manufacturers operated to make difficult the purpose of the conference. Gradually the manufacturers' association developed into a more compact and more homogenous organization. At the present time it is unlikely that there could be found a better example of successful collective bargaining than that which is carried on between the Glass Bottle Blowers' Association and their employers. On this point Mr. Leo Wolman writes as follows: ${ }^{1}$

The agreement between the Glass Bottle Blowers' Association and the National Glass Vial and Bottle Manufacturers' Association furnished an impressive and an instructive exhibit of the feasibility of carrying on for a long term of years a peaceful and mutually agreeable system of collective bargaining. While friction between the parties to the agreement has at times been great, and while the agreement has often been almost at the breaking point, yet so enlightened has been the policy of the representatives of both the union and the manufacturers' association, in granting concessions and yielding upon disputed points, that the agreement has operated in one form or another for almost a quarter of a century. Nor have external conditions been particularly favorable to the continued life of the agreement. The technical revolution of the industry, beginning in the middle nineties with the installation of the so-called automatic machine, and intensified after 1900 by the invention and the later extensive use of the Owens automatic machine for the manufacture of glass bottles, has presented to the conferences of the manufacturers and their employees problems that every year become more perplexing and difficult of solution. The promulgation of working rules to govern those members of the union who were employed on the semiautomatic machines, the regulation of the wage scale so as to retain a fair wage for the glass blower, and at the same time to permit the employer of hand blowers to compete against the machine, and finally a readjustment of wage scales designed to meet the competition of the automatic, are a few of the problems which have received at the hand of the annual conference, if not a perfect solution, at least a workable settlement.

Conference agreements.-Unlike those national agreements which provide only the machinery for the settlement of disputes and which leave to the local unions the formation of working rules, and in some cases wage rates, the agreement of the Bottle Blowers' Association (the union) with the manufacturers fixes in detail practically all the conditions of employment of the glass-bottle workers. The local unions can legislate only upon such matters as are concerned with the internal government of the union. When, however, some unforseen question arises during the year, an attempt is first made to settle the matter in conference between the factory committee and the employer, and, if they are unable to arrive at an agreement, the question is referred to the president of the union.

All matters of whatever nature which are to come up for settlement with the manufacturers' organization must be presented at the May conference, unless they originate later than that date, in which case they are presented at the final conference in August. Matters upon which adjustment is desired are usually presented in the form of resolutions from local unions or from individual manufacturers.

The members of the executive board, who are elected annually, act as representatives of the union at the conference. The representatives of the union are not bound by specific instructions and have full power to settle questions without referring them back to the organization. While their acts are necessarily subject to the reviow 
of their constituents, ret these acts have accorded so well with the riews of the members of the union that many members of the executive hoard have been reclected over many rears. The president of the union, Denis A. Hayes, who died in 1917 , held the position of president and ex officio imember of the board for 20 years.

The agreement does not provide for any formal system of roting, but it is the custom of the representatives of the union and of the manufacturers to rote as a unit. A mere majority of the members present is not enough. The measure must be agreeable to a majority of the representatives of both the manufacturers and the union.

When the conferences hare resulted in a deadlock, it has been the custom to adjourn and for the establishments to resume operations under the rules and prices of the preceding year. In 1906, following persistent demands for reductions in piece rates, which were refused, the president of the manufacturers' association suggested that "the matter be submitted for arbitration to the judge of the courts." The suggestion was not acted upon, as both employers and employees preferred to thresh out the matters in conference, and if without result to work in a state of truce for one or more rears under the rates of prerious years.

In cases of such deadlocks, it is frequently the case that a situation amounting to a lockout occurs, for, in the interval following the conference and the resumption of work, the agreement is in effect suspended. In 1905 and again in 1909, the conference adjourned without haring come to an agreement and without setting a date for a future conference. In each instance the manufacturers did not open their plants for some time after adjourning. For this period the union president authorized the men to accept employment if it was offered at the scale in effect during the preceding period, and at the same time authorized the branches to assure their employers that they would be giren the advantage of any settlement that might be made later, on and from the date upon which the men began work.

While such a condition amounts, in effect, to a deadlock, both sides have refused to regard it as such; and, even though the conferences have adjourned without coming to an agreement, and the manufacturers, probably on account of the superior strength of the union, have been obliged to employ the men at terms unsatisfactory to themselves, yet they have had such confidence in the system of collective bargaining that the following year has found them again in conference with the union.

Sittlement if disputes. - The annual agreements between the union and the manufacturers are so inclusive and definite in terms, and present in such detail practically all the conditions of employment, that most of the disputes arising during the year can be settled by merely consulting a particular rule of the agreement. For instance, with respect to prices the agreement states that a bottle shall "be rated at the same price and subject to the same rules in regard to weight as those specified in the bracket which they resemble in size, shape, weight, and finish." Under such instructions there can be little room for disagreement.

On the other hand, disputes may arise in which no question as to the interpretation of the rules is involved but where one or the other of the parties has deliberately violated or disregarded the agreement. 
The first step in the adjustment of disputes is to refer the matter to a conference of the employer and a factory committee. When no settlement can be reached, the question is referred either to the president of the union or to one of the executive board whom the president designates as his representative. The president's decisions are final unless reversed at the next joint conference. Although the president of the union has been acting as arbitrator since 1902, his decisions have been but rarely reversed. Most of the matters decided by him have been concerning prices. In those cases where the joint conference has found the prices fixed by him to have been too high the employer is reimbursed for the excess wages paid, and, conversely, when the prices have been fixed too low the employer is required to make up the difference to the workmen.

The great centralization of power in the hands of the national organization and the apparent opinion of the members of the union that such centralization is wise have resulted in the universal support by the "branches" of the mandates of their national officers and of the decisions of the joint conference. Similarly, among the manufacturers, the attempts to violate the agreement by locking out employees, or by running shops under rules contrary to those adopted by the conferences, have been few and far between. In this case, however, compulsion upon the manufacturers has not come from the manufacturers' association. This organization has little control over its members and can, therefore, do little toward forcing them to live up to the decisions of the joint conference.

While the power to compel obedience resides neither in the hands of the union or its president nor in the manufacturers' association, two forces operate potently to keep manufacturers from violating the agreement - the desire of manufacturers to avoid any action that might result in a discontinuance of the annual conferences and the strength of the union, which is able by threatening to withdraw their working force to bring recalcitrant employers into line.

Strikes.-The bottle branch of the glass industry has been very free from strikes. According to the late president of the union, Mr. Denis A. Hayes, ${ }^{1}$ there has not been a national strike in the union since 1884. When it is considered what manifold hardships to both labor and hand manufacturers attended the introduction and use of the automatic machine, it is strange that conflicts did not occur during this period at least. In order to meet the competition of machines working rules and wages had to be radically changed. For a long period following their first use wages remained stationary or were reduced, but even with such a condition no serious. labor trouble resulted.

\section{HOURS OF LABOR.}

Most of the hand bottle factories work on the two-shift system, although about 20 factories now work three shifts. The three-shift system is comparatively new in hand bottle factories. It is only one of a number of changes which manufacturers, with the consent of the union, have been required to make in order to meet the competition of the automatic machines. It assists the manufacturer because of the increased production resulting, and it benefits labor 
because it prorides employment for the men thrown out of work in increasingly large numbers as the use of the automatic machine grows. The three-shift system was made a part of the wage agreement in 1909. Later the manufacturers agreed to a division of work where there was not a sufficient number of men to make up a third shift but more than could be employed in two shifts.

One of the early steps taken by the union with a riew to shortening the hours of labor in bottle factories was to induce manufacturers to abolish the Sunday night shift. Some time after this had been accomplished the 4 o'clock stop agreement was secured from the manufacturer's. Later the Saturday half holiday for five months of the year was granted. The union has fought strenuously to obtain the Saturday half holiday the year around, but has not succeeded in this as yet. Mr. Denis A. Hayes, late president of the union, commenting on the subject of the Saturday half holiday in his annual report for 1916, said:

Most of the skilled trades cease work at noon Saturday during the entire year; some do not work at all on Saturday, and many of the unskilled trade-unionists have succeeded in enforcing the same thing. However, there is this phase of the question that can not be overlooked, and that is that, while we may be successful in enforcing a request for a Saturday half holiday the year around, we must not lose sight of the fact that the automatic is in continuous operation from Monday morning until the following Sunday morning, and in some instances does not stop even on Sunday. Could we, by persuasion, reason, or logic, induce the companies operating the automatic machine to close down their plants at noon on Saturdays, there would be little opposition on the part of the hand manufacturers to do likewise.

The following are the rules relating to hours of labor as agreed upon between the manufacturers and the union workers on the flint prescription (covered pot) and the glass vial and bottle lists:

Eight and one-half hours per day (actual working time) shall constitute a day's work, commencing at 7 o'clock in the morning, 15 minutes tempo at $3 \mathrm{p}$. m., and stop work at 5 p. m., except on Saturday, when there shall be no afternoon tempo, and work shall stop at 4 p. m.; the night shift to work eight and one-half hours also, and there shall be no Saturday night work.

During the months of May, June, July, August, and September work shall cease 12 o'clock noon on Saturday.

There shall be a stop of 15 minutes for each and every open pot to set, and 30 minutes for every monkey covered pot, and 1 hour for large covered pot.

The rules relating to the hours of labor for the workers on the United, O'Neill, and the one and two man narrow-mouth machines (machine and press department) are as follows:

We shall work six days per week on daywork turn and five nights per week on night turn, making an average of five and one-half days per week, except during the months of May, June, July, August, and September.

When working three shifts, work shall begin not earlier than 7 a. m Monday. Actual working time to be seven and one-half hours per day, with one-half hour for dinner. Work to cease not later than $4 \mathrm{p}$. m. Saturday. Sccond and third shifts sliall work seven and one-half hours also.

In the stopper-grinding department the rule is as follows:

Fifty-three hours shall constitute a week's work in the stoppering department. Each day's work to start at 7 a. m.

The following holidays are observed by all departments under the authority of the union: Labor Day and night, Thauksgiving Day and night, December 24, night; Christmas 1)ay and night, Decoration or Memorial Day and night, July 3, night; and Fourth of July, day and night, or the day set apart when any of the above 
holidiys falls upon sunday. In Canada, Victoria Day is observed instead of Decoration Day and Dominion Day instead of Fourth of July.

\section{SUMMER STOP.}

Owing to the inroads made by machines, particularly the automatic and semiautomatic, on the business of the hand bottle manufacturers, the union, after resisting for a long time, finally agreed to a modification of the summer stop in order to increase the production in hand bottle factories, so that the manufacturers might better compete with the automatics. The summer stop was reduced to two weeks in hand and four weeks in machine bottle shops, the length of the summer stop as it now prevails. The argument used by the hand manufacturers to secure a longer season, and one that was effective with the union, was that the automatic and semiautomatic machine plonts were in constant operation the year round, working three shifts in 24 hours, Saturday afternoons, and trequently on Sunday. Working so continuously, they abtained a large product, and therefore a cost so low that the hand manufacturers could not comnete unless they were allowed a longer season. In addition it was pointed out that work was lost to the hand blower and business to the hand manufacturers, which was secured by the machine factories, in consequence of the summer stop.

\section{APPRENTICES.}

The apprentice question has been the cause of much contention between the manufacturers and the union. Manufacturers naturally have desired to have the ratio of apprentices to journeymen as large as possible, in order to have an excess of labor available. The union has resisted strongly any attempt to increase the number of apprentices allowed to each journeymen, because the union has the utmost difficulty in ordinary times to find places for its men. With new journeymen coming on, as their apprenticeship is served, the task becomes even more difficult. At times conditions have been so acute that the manufacturers have agreed to the suspension of the apprentice system during a season. Following a bad season in 1914-15, the union at its annual convention passed a resolution that "no apprentice shall be taken for the blast of 1915-16." A similar resolution was adopted at the convention of the following year. A resolution was also introduced which recommended that the ratio of apprentices to journeymen should be the same in all departments. At the annual wage conference of manufacturers and represontatives of the union held to fix rates and settle other matters for the year 1916-17 the apprentice question was settled on the basis of 1 apprentice to every 15 journeymen.

Prior to September, 1913, apprentices received 50 per cent of a journeyman's wages. At that time the agreement was changed so that apprentices now receive 75 per cent of a journeyman's wages.

The following are the union regulations as they now exist with reference to apprentices:

Firms who from any cause reduce the number of their journeymen must also reduce the number of their apprentices in the proportion to the journeymen employed at the time of reducing their working force, so that they at all times shall be within 
the requirements of this law. Example: If the proportion was 1 apprentice to 3 journeymen before reducing their working force, the reduction would be 1 apprentice to 3 journermen.

When the condition of the trade warrants the issuing of promits 10 apprentices who are unemployed, all such permits are to be uniform, and no permit shall be issued to an apprentice unless it meets with the approval of the branch controlling the factory where the apprentice is to be employed.

Firms liaving put in an apprentice and from any cause said appron ice l aves the trade he can not be duplicated, but should an apprentice die during the first year of his apprenticeship he must be duplicated during that season.

An apprentice shall serve not more than four years, consisting of 40 working months, from the date of being put in to blow. No loss of time to be charged against the upprentice unless the time so lost can be reasonably attributed to said apprentice.

An apprentice who may go to work or continue to work in any factory where association blowers are on a strike shall be fined $\$ 100$ in addition to lis regular initiation fee, unless otherwise ordered by the president and executive board.

No one shall be considered an apprentice unless he be put in a place to blow.

\section{EXTENSION OF LABOR-ORGANIZATION CONTROL.}

Nonunionism does not exist very extensively in the bottle business. The danger which threatened the union from this source as a result of the new conditions following the introduction of the automatic inachine was quickly met by the organization taking steps to encourage the nonunion men to form local unions, which were later merged into State organizations. The plan was proposed by the president of the union in 1904. At that time there were 15 nonunion plants in operation in Indiana and 6 out of blast. In the annual report of the vice president of the union for $1914-15$ it is stated that there were then only three nonunion factories in operation and three out of blast. The late president of the union, Mr. Denis A. Hayes, commenting on the situation in Indiana, which has been termed the "hotbed of nonunionism" by the union officers, in his annual report for the year 1915-16, said:

In spite of the low wages paid to men in nonunion factories, there has been a noticeable falling off in the number of plants operated and the men employed. This, in a large measure, is due to the efforts of our association in dealing with this problem. Realizing that with such a formidable competitor as the automatic we should have to make radical changes in our wages and working rules, and that a number of our men would be displaced, our first thought was to safeguard their interests as best we could and prevent any increase in the number of nonunion men and factories. This was done systematically and thoroughly, and it is gratifying to say that our plans have been successful. *** We are forming them into an auxiliary organization and are making them self-reliant. To-day their affairs are conducted through committees the same as ours, and they hold meetings to discuss matters pertaining to the trade.

\section{TABLEWARE AND LIGHTING GOODS.}

Manufacturers interviewed during this investigation were of the opinion that locality had rery little bearing on the class or quantity of labor available, although it was thought that large towns are attractive to labor in general. It was also thought advantageous for several factories to be located in the same vicinity, as in that case more labor is available, and a manufacturer is less liable to find himself short of help; or, if he becomes short handed, he has less difficulty in filling the places. 
NUMBER OF UNION WORKERS.

The American Flint Glass Workers' Union is composed of workers that make blown and pressed ware, which includes tableware, bar goods, lighting goods, laboratory ware, vases, and miscellaneous articles. It is the only union of workers in tableware and lightinggoods factories. It was established in 1878 and is affiliated with the American Federation of Labor.

Not all establishments are unionized. In establishments where the union is fully organized, it includes the skilled and some of the semiskilled employees. The membership of the union by departments during the last 10 years is shown in the following table:

Table 106.-Membership of the American Flint Glass Workers' Union, by Manufacturing Departments, 1907 to 1916.

[From report of the national secretary-treasurer, 1916.]

\begin{tabular}{|c|c|c|c|c|c|c|c|c|c|c|}
\hline Departments. & 1907 & 1908 & 1909 & 1910 & 1911 & 1912 & 1913 & 1914 & 1915 & 1916 \\
\hline 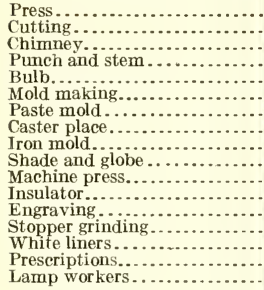 & $\begin{array}{r}1,593 \\
451 \\
1,603 \\
340 \\
506 \\
463 \\
448 \\
331 \\
381 \\
218 \\
290 \\
76 \\
27 \\
8 \\
156\end{array}$ & $\begin{array}{r}1,629 \\
371 \\
1,520 \\
358 \\
666 \\
463 \\
504 \\
383 \\
369 \\
209 \\
278 \\
61 \\
22 \\
8 \\
154 \\
\hdashline . .\end{array}$ & $\begin{array}{r}1,664 \\
1,519 \\
1,504 \\
371 \\
671 \\
488 \\
513 \\
. \quad 380 \\
347 \\
218 \\
227 \\
56 \\
19 \\
9 \\
89 \\
45 \\
\ldots\end{array}$ & $\begin{array}{r}1,911 \\
2,217 \\
1,411 \\
433 \\
636 \\
506 \\
530 \\
311 \\
365 \\
192 \\
247 \\
51 \\
37 \\
10 \\
31 \\
13 \\
\end{array}$ & $\begin{array}{r}1,928 \\
2,258 \\
1,400 \\
540 \\
856 \\
544 \\
478 \\
423 \\
340 \\
165 \\
186 \\
48 \\
54 \\
17 \\
14\end{array}$ & $\begin{array}{r}1,929 \\
1,860 \\
1,150 \\
669 \\
804 \\
584 \\
514 \\
441 \\
354 \\
145 \\
176 \\
41 \\
62 \\
14 \\
\ldots . .\end{array}$ & $\begin{array}{r}2,414 \\
1,989 \\
1,292 \\
951 \\
784 \\
658 \\
514 \\
486 \\
344 \\
134 \\
98 \\
43 \\
32 \\
18 \\
10\end{array}$ & $\begin{array}{r}2,531 \\
1,711 \\
1,126 \\
1,079 \\
730 \\
672 \\
513 \\
526 \\
378 \\
138 \\
115 \\
87 \\
56 \\
19 \\
11\end{array}$ & $\begin{array}{r}2,403 \\
1,620 \\
1,271 \\
1,084 \\
648 \\
720 \\
452 \\
507 \\
345 \\
104 \\
137 \\
51 \\
49 \\
19 \\
10\end{array}$ & $\begin{array}{r}2,269 \\
1,381 \\
1,150 \\
1,073 \\
772 \\
739 \\
445 \\
692 \\
366 \\
101 \\
128 \\
68 \\
59 \\
25 \\
162\end{array}$ \\
\hline Total & 6,891 & 6.994 & 8,120 & 8,901 & 9,251 & 8,743 & 9,767 & 9,692 & 9,420 & 9,430 \\
\hline
\end{tabular}

The table shows that the growth in membership since 1911 has been slight. The maximum membership was reached in 1913 . The largest actual gains from 1907 to 1916 were in the press, cutting, and punch and stem departments; the largest actual losses were in the chimney, shade and globe, and machine press departments. Of the 17 departments, 7 were smaller in 1916 than 1907, namely, chimney, paste mold, iron mold, shade and globe, machine press, insulator, white liners.

\section{NUMBER EMPLOYED AND UNEMPLOYED.}

The American Flint Glass Workers' Union has not been able to limit the number of apprentices so effectually as has the union of window-glass workers. As a result, there is usually an overabundance of skilled men, except during exceptionally good seasons. A considerable proportion of the membership was unemployed for several years prior to 1915 . During the blast of 1914-15, a period when the depression in the industry was at its worst, the number unemployed was 1,075, or 11.41 per cent of the 9,420 members. During the blast of 1915-16 only a few were idle. The number of members in each department during the last two blasts, the number employed at the trade, the number employed outside the trade, and the number unemployed are shown in the following table: 
Talbe 10 7 .- Total Meabership of the Americax Flint glass Workers' Union, Number Employed ix and Outside the Trade, and Number EarPLOYED, BLAST OF 1914-15.

[From report of the national secretary-treasurer, 1916.]

\begin{tabular}{|c|c|c|c|c|c|c|c|c|}
\hline \multirow{2}{*}{ Departments. } & \multicolumn{2}{|c|}{$\begin{array}{c}\text { Total member- } \\
\text { ship. }\end{array}$} & \multicolumn{2}{|c|}{$\begin{array}{l}\text { Employed at } \\
\text { trade. }\end{array}$} & \multicolumn{2}{|c|}{$\begin{array}{l}\text { Employed out- } \\
\text { side trade. }\end{array}$} & \multicolumn{2}{|c|}{ Unemployed. } \\
\hline & $1914-15$ & $1915-16$ & $1914-15$ & $1915-16$ & $1914-15$ & $1915-16$ & 1914-15 & $1915-16$ \\
\hline 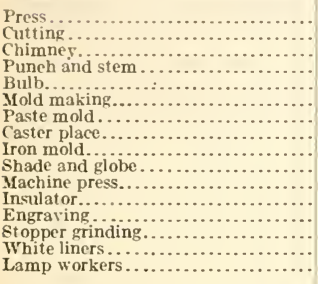 & $\begin{array}{r}2,403 \\
1,620 \\
1,271 \\
1,084 \\
648 \\
720 \\
452 \\
507 \\
345 \\
104 \\
137 \\
51 \\
49 \\
19 \\
10 \\
10 \\
\end{array}$ & $\begin{array}{r}2,269 \\
1,381 \\
1,150 \\
1,073 \\
772 \\
739 \\
445 \\
692 \\
366 \\
101 \\
128 \\
68 \\
59 \\
25 \\
162 \\
\end{array}$ & $\begin{array}{r}1,929 \\
1,069 \\
1,049 \\
964 \\
532 \\
674 \\
394 \\
459 \\
295 \\
80 \\
105 \\
44 \\
43 \\
17\end{array}$ & $\begin{array}{r}1,981 \\
1,062 \\
994 \\
993 \\
653 \\
709 \\
412 \\
669 \\
323 \\
80 \\
119 \\
48 \\
55 \\
23 \\
161 \\
\end{array}$ & $\begin{array}{r}212 \\
115 \\
84 \\
46 \\
109 \\
26 \\
30 \\
16 \\
28 \\
11 \\
3 \\
2 \\
4 \\
1 \\
4 \\
1\end{array}$ & $\begin{array}{r}260 \\
243 \\
110 \\
69 \\
118 \\
21 \\
23 \\
16 \\
37 \\
6 \\
9 \\
8 \\
4 \\
2 \\
\ldots \\
1 \\
\end{array}$ & $\begin{array}{r}262 \\
436 \\
138 \\
74 \\
7 \\
20 \\
28 \\
32 \\
22 \\
13 \\
29 \\
5 \\
2 \\
1 \\
6 \\
\ldots . . .\end{array}$ & 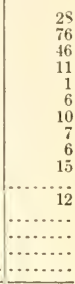 \\
\hline Total... & 9,420 & 9,430 & 7,654 & 8,282 & 691 & 930 & 1,075 & 218 \\
\hline
\end{tabular}

\section{STRIKES AND LOCKOUTS.}

In 1878-79 there was a general strike in this branch of the industry. In 1883-84 there was one that lasted 10 months, and in 1887-88 one that lasted from six months in some plants to two years in others. In 1893 the union employees were locked out by the United States Glass Co., the largest producer in the country, and other lockouts occurred during 1893 and the following two years. There were serious disturbances again in 1903-4. During the last few years there have been numerous strikes and lockouts.

In his report to the annual convention of the American Flint Glass Workers' Union held in 1916, President T. W. Rowe said:

If you estimate our condition by the ability of our opponents, and be guided accordingly, we are far more liable to secure beneficial results and avoid injudicious trouble. We should keep in mind the history of our association and remember our past mistakes.

We must not forget the serious trouble in which we were involved and the causes leading to those conflicts, and we must not become intoxicated with the idea that we have sufficient ability to demand unreasonable things and secure them without resistance. * * * Ve should try to accomplish our desires without repeating the sad and sacrficing experiences of the awful past, and that can only be done by exercising the highest degree of intelligence and equity.

On June 1, 1915, there were strikes in eight plants, and the number on strike was 625 , or 15 per cent of the 9,420 members of the union in that year. During 1915-16 employment was found for all of the strikers.

\section{PIECE AND TIME WORK.}

The strike of 1888 involved the question of pioce and time work. The strikers bitterly resisted the piece-price system, but finally yielded, and it went into effect and has continued until the present time. It is now almost universal for skilled occupations. 
Manufacturers who were interviewed during the investigation said that the employees would now be as unwilling as they themselves to go back to the old system. They said that the piece-work plan is fairest to all concerned; that it is the only system economically sound, for it permits a man to earn according to his ability; and that it is more satisfactory to the men, because the efficient man receives all he can earn. This is a great incentive to them, and makes for better conditions.

It is of the highest importance to the manufacturer to get the maximum production, and this can be obtained only when the men are paid piece rate and not time rate. The piece-rate system is of very great value to the manufacturer, because it is the only scheme of pay which permits him to know what his product costs. By it he knows what the skilled labor, the highest element of cost of an article, will be before he manufactures it. Hence he is able to think intelligently about his selling prices. If the men were paid so much per day, it would be very difficult, if not impossible, to keep accurately. the necessary records of production by which the labor cost in an article could be determined.

\section{HOURS OF LABOR.}

The custom in tableware and lighting-goods factories is to work two shifts daily in the shops, although some small factories sometimes work only one, and the larger ones in times of slack demand also do this. Where there are two shif ts, the day shift works 11 shifts a week, Monday to Saturday noon, inclusive, and the night shift works 10 shifts a week, Monday night to Friday night, inclusive. The day shift alternates with the night shift every week.

While there is no agreement between the manufacturers and the union with respect to the number of shifts, it is quite likely that any attempt to operate three shifts in a union factory would be resisted by the workers, although they desire an 8-hour day. When the question of an 8-hour day was discussed in the annual conference between the manufacturers and the representatives of the union, held in 1914, several manufacturers expressed themselves in favor of granting the 8-hour day, provided they were allowed to have three shifts. The latter proposal was not favored by the union representatives, and the president of the union expressed the views of the union as follows:

The members of the union are not securing steady work at the present time, and if we adopted the 8-hour day basis and the employer insisted on three shifts, we would produce more glass workers, more glassware, and, instead of working steady, we would have a large army of members irregularly employed, with all the dissatisfaction that accompanies a condition of this kind.

Manufacturers claim that shortening the working time to 8 hours a day without three shifts would result in decreased production, and consequently higher costs.

In the 1914 conference the union representatives stated that in other lines of manufacturing an 8-hour day was the rule. The manufacturers replied that in glass factories the glass workers on day shift worked only 11 turns, five and a half days a week, and the glass workers on night shift only 10 turns, or five nights a week, and if the turns were reduced to 4 hours, the day shift would work only 44 hours a week and the night shift only 40 hours, an average of 42 . The 
manufacturers also stated it was unfair to urere an S-hour day when the men often did not do four hours' work in a turn. They cited cases where the men did their turn's work in as short a time as an hour and fifteen minutes, and from that on up to four hours. After much debate and discussion, the conference agreed on the following proposition:

Four and one-quarter hours shall constitute a turn's work in all glass-working departments now working the unlimited system of production, excepting the machine department, this to become effective January 1, 1915. Fifty hours shall consitute a week's work in the eutting department, this to become effecfive October 1,1914 , with the understanding that the 50 hours can be worked on 50 hours pay.

Union glass workers on a limited system, that is where the number of articles produced is limited by union rules, work from four and a quarter to four and a half hours per turn in the different departments.

\section{THE "MOVE" STSTEM.}

The price list that is agreed upon yearly by the union and the manufacturers contains the wages per turn or the piece prices of the skilled workers, and also the number of articles which it is expected that each of the workers in certain departments shall make during a turn. The number is called a "move," and for an article that can be made quickly is larger than that for an article which requires more time in production.

Formerly there was a limited turn system on all ware, under which the worker was not allowed to make during a turn articles in excess of the number prescribed by the move. He was, however, paid the union scale rate per turn, whether or not he reached the move. Urged by the manufacturers, the union has abolished the move in some branches or departments.

At present some union men work on a limited piece-price basis, some on an unlimited piece-price basis, others on a limited turn basis, and others on an unlimited turn basis. Each department legislates as to its own conditions, and, independent of other departments, makes wage agreements with manufacturers.

Under the unlimited turn system, the worker that falls below the move receives the scale rate for a turn, but if he exceeds the move, he is paid for the excess at the move rate. If, for instance, the move were 300 and the wages pep turn $\$ 3$, the worker would be paid 1 cent for each good piece made over 300 , or $\$ 4$ for 400 .

Manufacturers generally object to the move system, and consider that it is economically wrong to both the manufacturer and worker to limit the production of the latter. They say that the rule operates to prevent them from picking the desirable men and eliminating the poor workers. They urge the necessity of unlimited production in order that they may meet foreign competition.

Many members of the union are opposed to the move rule, but they are the rapid workers and are in the minority. The effect of the rule is to increase the cost of production. Without the rule, each factory would seek to get as large a proportion of rapid workers as possible, and in a factory that increased its proportion of such workers the output per individual would be larger and the number of workers employed would be smaller. The rule results in a larger number being employed and in equal pay, though not equal output, for all 
workers. Most of the workers to whom the move applies favor its retention because it operates to provide places for more men, and because, without this restriction, there would be, on a full-time basis, overproduction and the manufacturing season would be shortened.

\section{SUMMER STOP AND HOLIDAYS.}

Wages in the skilled occupations in tableware and lighting goods factories are not so high as in window glass, but the "season" is much longer. Most departments operate throughout the 12 months, with no shut-downs, except for two weeks in the summer and on certain holidays.

New Year's Day, Fourth of July, Labor Day, Memorial Day, and Christmas are observed as holidays by union workers. In addition, most of the departments do not work New Year's eve or Christmas eve and night.

One of the most important considerations relating to wages is that of overproduction. In the manufacture of tableware and lighting goods this condition is not usually so critical as in window-glass or bottle factories, but it exerts an important influence on wages. The union has sought to control this condition by limiting production through the operation of the "move."

Manufacturers have always favored operating their plants as continuously as possible. This results in a maximum product and therefore lower costs. The union has opposed this, on the ground that, if the plants operated continuously, there would be an overproduction which would result in bad business conditions. This would mean irregular employment for labor, with all its attending hardships. At present the summer stop is for a period of from two weeks in most departments to four weeks in a few.

\section{APPRENTICES AND CHILD LABOR.}

The number of apprentices that the union allows in some departments is as follows: Hand press department, 2 apprentices to each 10 pots, 1 to each 15 journeymen on continuous tanks; machine press ware department, 1 apprentice to each 10 journeymen or majority fraction thereof each year; punch tumbler and stem ware department, 1 apprentice "shop" on offhand pulled-out stem ware in each factory; cutting department, 1 apprentice to each 4 journeymen or majority fraction thereof; engraving department, 1 apprentice every two years to each shop employing 2 or more journeymen. A shop employing 9 or more journeymen is entitled to one apprentice every 16 months but never more than three.

Child labor may be said to exist no longer in the glass industry in the United States. Most of the States have laws which forbid the employment of children. Very light work is required in many occupations in which boys were formerly employed but which are now filled by adults. When the laws went into effect manufacturers were compelled to substitute men in the places of boys and pay correspondingly higher wages. Manufacturers complain of the lack of uniformity in the various State laws relating to child labor. Few of the States have exactly the same age limit for employment, and when two adjoining States have different laws, the manufacturer where the age limit is highest is at a disadvantage. One manufac- 
turer who was interviewed said that the worst effect of the laws prohibiting the employment of boys was not the resulting increase in the labor eost but the fact that employers could not train boys in the trade.

\section{WOMEX EMPLOYEES.}

Of the women employed in the glass industry, nearly all are employed in establishments manufacturing tableware and lighting goods. They are not employed in any of the blowing, pressing, or annealing occupations.

In tableware the occupations filled in part or entirely by women are sorting, selecting, cracking off, grinding, glazing, washing, wiping, etching plate, etching needle, decorating, cutting, smoothing, mold cleaning, wrapping, and packing.

In lighting goods the occupations at which women work are inspecting, gauging, glazing, finishing, washing, marking for cutters, decorating, mold cleaning, wrapping, cartoning, packing, and as chain girls.

None of these occupations requires much skill, but in most of them dexterity is essential. None of them is exceptionally taxing to the strength. It is asserted that some of the occupations in which women are employed in the decorating department are harmful to health because of the fumes of acid used in decorating. 


\section{CHAPTER IX.}

\section{NEEDS OF THE INDUSTRY.}

\section{LACK OF ETFICIENCY IN MANUFACTURE AND SELLING.}

\section{CHEMISTRY.}

Glass being the result of chemical reactions, it would seem that a knowledge of chemistry would be absolutely essential to the glass manufacturer in order that he might be enabled to produce the finest grade of desired glass at the smallest possible cost.

The average manufacturer's chemical knowledge of the materials that enter into the manufacture of glass is very vague and indefinite. Exceptionally few men in the United States have carried on any scientific investigations or experiments, and it is to be regretted that there is such a woeful lack of chemical knowledge. It appears as if all the energy of the glass makers in recent years has gone into the perfecting of machinery as the one means of lowering cost. The batch could take care of itself. That the most periect machine is absolutely useless with bad glass or glass of excessive cost does not appear to have been taken into consideration. The manufacturer's lack of chemical knowledge would, however, be harmless if chemists were employed. In the plants visited by the agents during this investigation, not more than one chemist was found to about every 20 plants visited; they were usually employed by only the largest companies. Mr. R. L. Frink, one of the few men in this country who has carried on any research work, has the following to say:

I found that glass making to-day is carried on with no regard to definite proportions or consistent methods of operation; that it is void of any true knowledge, and is essentially an industry based and operated upon and subservient to personal opinions and prejudice, poisoned by legendary ideas and jealousies, and made generally unwholesome by lack of progressiveness or any initiative on the part of those who might, if they would, arise from this quagmire and put themselves on a basis of scientific fact. ${ }^{1} * * *$

One frequently hears the remark that a chemist or scientist is of no use in a glass factory. This, no doubt, in a measure is true, for it is seldom, if ever, that a chemist or scientist will be able to find a manufacturer or owner who would for a moment think of wasting time or money in the consideration or adoption of the suggestions of such individuals, at least not until they are confronted with a situation that legend, sorcery, prejudice, and guesswork can not account for or overcome. ${ }^{2} *$ * *

As a matter of fact, there are a great many so-called first-class glassmakers, and men who are responsible for large productions and the finest quality of ware, whose knowledge of the constitution of glass begins and ends the moment when the material enters the furnace, and as a matter of fact many of them still believe that glass is composed of sand which has been reduced to a molten state by being placed in a mixture with such ingredients as lime, soda, potash, feldspar, fluorspar, cryolite, antimony, zinc oxide, borax, or whatever else their batch formula may call for, and that after it has been subjected to fire all of the ingredients with the exception of sand go up the stack. It is only the more progressive individuals who have studied this matter, who have benefited by research, and who have any true conception of the actual composition of 
Ihe Lla res that they are making. IInwerer, eren they, in many instances, have no true hunwledge a in the properties given to the glass by the naterials they use, and in fart there is but little artual specific knowledge available.

It is true that in Europe, and in recent years also in this country, there has been ronsilerable progress in the nuaking of certain glasses for syecial.purposes, and he owe much to Guignand. Bontemps, Schott. Hovestadt, Harcourt, and others, who having contributed greatly to our knowledge of the composition and making of optical glasses manufactured in closed pots, or under conditions whereby perfect control could be had of the atmospheric, melting. and temperature conditions. But there has been little or nothing done, in a practical wav at least, to give us specific information as to the effects of the chemical constituents of glass when the same is made in tank furnaces, in open pots, or under varying fire conditions, or how they affect our various processes of manufacture. ${ }^{1}$

The lack of research and experimental work has been generally attributed to the expensireness of carrying on such work, which being impossible of satisfactory performance in a laboratory, requires costly furnaces and equipment. Mr. Frink offers the following solution:

What the glass industry needs and must have before it ran become much more than a school of conjecture is a Tedgewood or a Schott, assisted by a society of research, which shall have a backing and be subsidized by the Government or by every manufacturer in the business. ${ }^{2}$

\section{MACHINERT.}

Though much time, money, and energy have been expended in inventing, perfecting, and introducing machinery and mechanical derices that do away with skilled hand labor and lower the cost of production, glass manufacturers, as a rule, have been very lax in inrestigating the merits of such labor-saving machines and devices, with the result that every year finds many of the hand plants driven from the business, while those who remain continue to suffer losses resulting from competition with the machine-made product.

In addition to higher costs, hand plants continue to be confronted by the serious boy problem. Low wages, limited opportunity for adrancement, and especially the high age-limit laws in effect in man; States, have curtailed the supply of young men and women who do the unskilled work around a glasshouse.

The future success of the glass industry and of the individual who desires to remain a glass manufacturer depends to a very great extent upon the adoption and continued use of machinery and laborsaving devices.

\section{BUILDINGS.}

Glasshouses are generally antiquated. Ther are usually flimsy structures put up in the formative period of the industry and have ontlived their usefulness. Tery few plants are constructed on the plan of a modern scientifically laid-out factory. As the business expanded another building, and then another, was added without any idea as to how it would affect the entire plant as a unit. In agent of the Bureau has witnessed, in one of the largest bottle plants, coal and material unloaded from a freight car, loaded on trucks and carted a distance of about three-eighths of a mile to their respective storehouses. Inside many factories the same slipshod, haphazard

1 R. L. Frink: The Relation of Chemistry and Mechanical Manipulation to the Evolution of the Glass Industry. Metallurgieal and Chemieal Engineering, Nov. 1, 1915.

2 Transaetions, American Ceramic Soeiety, 1909, Vol. Xi, p. 316. 
arrangement prevails, decreasing and delaying production and increasing cost.

It is to be noted, however, that many of the larger plants, especially those erected in very recent years, are substantial buildings and are arranged with the idea of facilitating and increasing production.

\section{SELLING.}

It seems that cost does not generally enter into the determination of the selling price of glass, but the price appears to be set at what the other fellow is selling or appears to be selling it for. Buyers have played off salesman against salesman and machine manufacturer against hand manufacturer with such great success that costs, even when vaguely known, have been thrown to the winds. This selling at the other fellow's price, or supposed price, is based on the erroneous assumption that the price-setting manufacturer has a correct cost and that the other manuifacturer is equally efficient. The curbing of mutual distrust and the adoption of a uniform cost system will correct the selling conditions above described.

\section{OTHER DESIRABLE IMPROVEMENTS.}

There is a great need for improvement in the factory buildings so that the present excessive insurance rates may be materially reduced. There is need for manufacturers to get into their factories and really learn the glass business, instead of concentrating on the selling and administrative ends of the business. The chemistry of glass must be thoroughly learned, and research and experimental work entered into and continued.

It is a matter of conjecture as to whether there are at the present time any glassmen who can consistently predict the homogeneity, chemical composition, physical properties, and color, of the finished glass. It is essential that knowledge be obtained of the chemical reactions, the constitution of the glass, its physical properties when in a finished state, the cause and effect existing within the melting mass, the furnace and fire conditions, and the requisite properties of the glass to obtain the maximum efficiency in subsequent processes so as to produce a finished article of maximum quality at minimum cost.

There is in addition very urgent need for much practical and scientific research in order to eliminate poor and variable fuel conditions, bad tank blocks, inferior bricks, improperly made pots and molds, expensive breakage resulting from imperfect annealing, ware with imperfect surfaces produced by the chemical effects of the packing materials, and breakage due to the character of the packing materials, all of which result in the unnecessary loss of thousands of dollars annually.

Advantage should be taken of all labor-saving devices; antiquated machinery should be scrapped and hand methods, where possible, discarded in favor of machinery. Plants should be properly laid out and routing systems installed. Hand operations should be standardized; the workers should not be permitted to shift about for themselves but should be drilled in the proper method of performing their work. Old methods, retained because they resulted in a profit 
in by-gone days, must be discontinued. Aceounting methods must be improred and modern systems installed. The installation of a uniform cost-finding system for the rarious branches, so that manufacturers can, exclusire of their degree of efliciency, intelligently compete on equal terms, is of the most vital importance.

From conversation with numerous manufacturers, it is apparent that most glass manufacturers are distrustful of every other manufacturer. This spirit should be suppressed. Manufacturers should exchange ideas and cooperate in erery possible way. A real spirit of friendliness and good will could not but work to the adrantage of erery manufacturer in the trade.

\section{METHODS OF COMPUTING COSTS.}

The object of conducting business is to secure profits. Nothing that relates to manufacturing is of more importance than "costing." Efficiency rules may be applied in an excellently equipped factory, but, unless the proprietor has an adequate cost-finding system, he is liable to suffer financial loss. If he does not know with a close degree of accuracy what the different articles he manufactures hare cost and at what prices he can afford to sell them, he is not in a position to meet competition intelligently, and he invites business disaster. Eren if a manufacturer is satisfied with the yearly profit which his annual profit and loss statement shows, he should know on which particular products he is making the most profit and on which he is making only a narrow margin of profit or losing money. Intelligent cost accounting would enable him to distinguish between the profits on different products, to discontinue the manufacture of products sold at a loss, to limit the sales of products sold at a small margin of profit, and to give more attention to the manufacture and marketing of products on which the largest profits are realized.

\section{RUINOUS PRICE CUTTING CAUSED BY CRUDE COST FINDING.}

Trying to fix prices without knowledge of costs leads-to ruinous competition. The manufacturer that sells goods at a loss, or at no adequate profit, because he does not keep his books properly and does not know whether he is making a profit, tends to force his competitors into a like situation. Price cutting is nearly always done in ignorance of costs, and comparatirely little of it would be practiced in any industry if adequate cost finding generally prerailed. This investigation has shown that many manufacturers of glass or glassware have either no method of cost finding or crude and inadequate methods. Only very recently have a few glass manufacturers employed cost accountants to study their methods of production and to prepare suitable systems of cost findings. Probably not orer 1 in 20 has employed experts to establish cost-keeping systems.

The accounting methods in vogue in many glass establishments are not modern. All the expenses for the year often appear in a very few accounts, and all sorts of expenses that have no connection are thrown together and included in the same account. It is impossible, without a lengthy analysis of such crude accounts, to secure much of the information with which a manufacturer ought to be familiar. The accounting is frequently such that it would be of 
no aid in the keeping of a cost system if the installation of such a system were contemplated.

As to cost finding, with the exception of a few excellent systems found in some of the larger establishments, it may be stated that an accurate knowledge of cost of production is, generally speaking, unknown in the glass industry. Many establishments, including some of the larger ones, admitted that they made no attempt at arriving at accurate costs. Of the 213 establishments that furnished schedules for this investigation, only 20 reported that they kept a record of recovered cullet which would indicate the cost to be added for defective and imperfect ware.

A cost-finding system would not only show actual cost but would serve as a guide or indicator as to where the cost of labor, material, or overhead could be lowered. The absence of such a system, resulting as it does in not knowing the cost of the ware produced, leads not only to inefficiency and waste but also to the unfair, too keen, ruinous competition of which manufacturers complain so bitterly. The most crying need of the glass industry at the present time is a simple, accurate, inexpensive, uniform cost-finding system to be employed by every manufacturer. Only with the introduction of such a system can the industry be made stable and really competitive.

Generally speaking, only the larger glass manufacturing companies have made any effort to improve their costing methods. Cost accounting is, however, especially important for manufacturers with small or comparatively small capital, in order that they may meet the severe competition of those who manufacture on an extensive scale and whose manufacturing and accounting departments are well organized. It is not infrequently the case that the market for several lines of glassware has been demoralized by price cutting, started by small manufacturers, a contest in which they could less afford to indulge than could their big competitors.

Many glass manufacturers express the opinion that it is impossible to devise an accurate method of finding the costs of units in this industry. This, however, is erroneous. It is more difficult to ascertain correctly the costs in manufacturing glass than in some other industries, but some companies have adopted accurate methods. Some manufacturers, while admitting that accurate cost-finding systems can be devised, raise the objection that the operation of such systems would be very expensive. This also is a mistake, as has been proven in both large and small factories where scientific systems have been installed.

\section{ADVANTAGES OF MODERN COST KEEPING.}

There is perhaps no industry in which a good cost-keeping system is more needed than in glass manufacturing. Not only have American glass manufacturers had to meet sharp foreign competition in several lines, but there is probably no industry that has suffered more from "cutthroat" competition among the domestic manufacturers. Furthermore, the introduction of and improvements in machinery have made radical changes in the methods of manufacturing glass and glassware during recent years. Hand manufacturers have struggled 
desperately against the competition of those using machines, and often the market was demoralized in consequence.

While papers showing the importance of correct cost keeping have been read before meetings of glass manufacturers associations, none of these associations has approved any cost-finding system. If an assuciation would appoint a committee to work out some standard scheme for computing unit costs for each branch of the industry and would recommend an approved scheme, most of the members would probably adopt it and much ruinous competition would be aroided.

An article on the importance of computing costs of units of production in the glass industry from systematically kept records, written by Mr. John T. Fuller, an efficiency engineer, is quoted in part as follows:

Only a few years ago the selling price of most articles in glassware showed a sufficient margin of profit to enable the manufacturer to disregard costs. Under these conditions the management could concentrate his energies on the sales end of the business, and feel fairly well satisfied with his profit and loss statement at the end of the year. Several disturbing elements, however, have crept in during the past few years to change these conditions, and the manufacturer who has not been able to analyze the situation and provide a remedv has had to face a great reduction in profit. A careful analysis has shown that the principal causes for this change are improved machinery and equipment, increased labor costs, keen competition, and increased cost of raw materials.

Such improvements as the automatic presses, flowing devices, automatic leers, etc., have greatly increased the production per dollar invested, and likewise reduced the cost per article. In order to market this increased production, it was thought necessary to reduce the selling price. Competitors found it necessary to meet this condition by a still greater cut in prices. These cuts, for the most part, were based on the competitor's selling price and not on the manufacturer's cost. The result has been a demoralized market.

Working adversely to this condition, labor cost has been continually increasing. Labor unions, increased cost of living, general prosperity, and shortage of labor are responsible for higher wages. This condition in itself, however, should not be objectionable. It is a well-known psvchological principle that a manufacturer can obtain greater efficiency and larger production per man by making it possible for a man to increase his earnings as a result.

Statistics show that the amount of glassware put on the market has been continually increasing. Despite the greater demand, this condition has created a stronger fight for the business and likewise a closer selling price.

As labor enters largely into the cost of raw materials, the increased labor cost has afferted the price of the material. In addition to this, the demand has been greater, therebv resulting in a very noticeable increase in the price of the material.

A careful analvsis of these conditions brings out the fact that the whole situation is based on the cost of the product. Improved equipment reduced the cost and enabled the manufacturer to reduce the selling price and still retain about the same margin of profit. A little later increased cost of labor, and still later increased cost of raw material, was brought to bear, with the result that the margin of profit was greatly reduced.

All managers who are using svstematic methods in figuring their costs and profits are of the opinion that the glass industry as a whole would be greatly benefited if all frms had an accurate knowledge of their costs.

\section{THE PER-POUND METHOD.}

One of the common methods of computing costs on different units of bottles and blown and pressed ware is to divide all expenses for the year, except for skilled labor, by the number of pounds of finished glass produced during the year, to multiply the quotient by the weight of a dozen or gross of each unit manufactured, and to add to this product the amount paid per dozen or gross for skilled $102511^{\circ}-17-21$ 
labor, which is paid on a piece-price basis. This method, called the per pound method, is very inaccurate, because more fuel and labor are required to make a certain weight of small articles than the same weight of larger articles. As a light-weight article when finished may cost more and be of greater value than one which is heavier, a larger overhead should not be apportioned to the heavier one solely on account of its weight. If, for instance, the metal or molten glass is drawn from pots, it is obvious that a longer time will be required to empty a pot from which glass for small ware was drawn than to empty a pot from which glass for large ware was taken. In some cases it would take twice as long and the fuel and labor would be twice as much in one case as in the other. Moreover, the cost for fuel and labor to produce an equal weight of glassware would be twice as much in some cases as in others, whether the glass were drawn from pots or from ring holes in continuous tanks.

\section{THE SHOP-HOUR SYSTEM.}

A more accurate method of computing the cost of units in the manufacture of bottles and of blown and pressed ware is the shophour system, which provides for apportioning expense to each unit according to the time required for producing it in the blowing or pressing room, as compared with the time required for the total production in each of these rooms. Only the indirect labor, fuel, and general expense are thus apportioned. Each unit is charged for all specific costs, such as the shop labor or direct labor, which is usually paid for at piece rates.

Both the per pound system and the shop-hour system are explained in an article by Mr. Robert G. Armstrong, read before the Eastern Glass Vial and Bottle Manufacturers' Association at its annual meeting in 1913. Most of this article is here quoted:

The Cost System in a Botrle Factory.

GENERAL SUGGESTIONS.

In the good old days, when demand was more than equal to the supply, bottle manufacturers easily sold their output at their own prices. Profits were large and everybody was happy-especially the manufacturers. Scientific management and cost-system accounting were unknown because their necessity was not yet felt.

But the good old days are past. Now we have factories enough to produce five bottles where four are needed. A species of ruinous, unintelligent, beat-the-otherfellow's-price competition has set in and sent many a good company to financial ruin.

Those who have survived, realizing that something must be done, have spent their energies on the physical features of their factories, and wonders have been performed in installing furnaces and leers scientifically constructed to produce the most possible and best possible glass at the least possible outlay for fuel. Laborsaving devices of all kinds have been installed. Division of labor has been scientifically applied. In short, many of our factories are highly effective from a manufacturing standpoint. But, unfortunately, many of them are yet without the one thing absolutely essential to continuous success an accurate but usable cost system. What is the.use in scientifically equipping and operating your factory if you do not know what your product costs you? In comparison, the newsboy or peanut vender on the streei is a business expert. They know their costs and sell at a profit or not at all.

The history of too many bottle manufacturing companies has been written in two chapters: Chapter I. Without knowing costs, met or undersold competition. Chapter II. Failure. In many cases the failure could have been avoided by a proper analysis of all the elements of costs, and by applying the remedy found to be necessary. 
There is but little use. however. in intalling a cost system unless von determine to make any and all changes shown to be necessary. You may find it necessary to drop a forminan or some workmen whum you had counted upon because you discover that they are not now efticient. You may discover to your dismay that it is eosting you nore to deliver ware to your "best" customer than he is paying for it. You may" discover llrat rertain clases of ware are ensting you more and others less than you hat estimated. It will regnire some barkbone to correct all these things, but the correction of such faults, discovered through the application of a cost systen, has turned the tide of fortune for hundreds of manufacturers from failure to success.

Some have hesitated to install a cost system, believing that it is not possible to devise a system accurately determining the costs of each different style and size of bottle. That is a mistake. A system producing accurate results can he applied to any line of manufacture. It has been done in the bottle business.

Some have hesitated because they lacked confidence in expert accountants. That too, is a mistake. There are scores of men, any one of whom is an expert in such matters, who will give you a system built to your business that will show the costs and profits of each department of a factory and of each individual gross of bottles made. This service will be conscientiously performed and is invaluable.

Some have hesitated because of the first cost. No one would hesitate to spend $\$ 500$ if assured it would bring in $\$ 1,000$. In the ordinary bottle factory. without a competent cost system, the chances are ten to one that the results would be much more farorable than this, and they would be perpetual.

Some have hesitated on account of the expense of operating the cost system. Let us suppose that in a 24-ring factory it will require all the time of one additional clerk at $\$ 15$ a week $\$ 900$ a year. If the work is thoroughly done and the findings properly taken advantage of the result should cause an average additional profit of at least 1 cent a gross on the output. Such a factory should produce at least 300.000 gross of bottle; in 10 months, showing a resulting net profit of $\$ 2,100$. But these figures are very conservative in comparison with some actual results produced.

\section{ADVANTAGES GAINED BY USE OF COST SYSTEM.}

Briefly stated, some of the advantages of an accurate knowledge of costs, are these:

(1) The exact cost to deliver any 1 gross, or larger quantity of ware, may be absolutely known.

(2) Unprofitable bottles and orders are determined and may be dropped or the prices advanced to the point of a fair profit. The profitable bottles will be determined and sought more diligently.

(3) The exact result of any increase in the cost of labor or material will be automatically shown.

(4) The cost to manufacture any bottle in any quantity may be predetermined with dependable accuracy.

(5) Sales prices may be based on costs, and you will know just how low you can safely go.

(6) Unintelligent competition may be eliminaterl.

(7) Each bottle is made to bear its own burden of high cost resulting from slow production, day work, or heavy loss dne to some peculiarity of the ware. It is clearly unfair to impose part of the expense of making a diffienlt bottle upon others more easily made.

TIE PER POUNI) SYSTEM.

The method best known for computing costs is the "per pound" system. This is a dangerous and illogical system. One illustration will serve to prove this.

Assume that shop No. 1 is working on 2-ounce round prescription bottles at 2-ounce weight. Production 45 gross a day: 810 pounds at $\$ 0.03658, a$ \$ $\$ 29.63$; blowing 45 gross at 58 cents, $\$ 2 \varsigma .10 ; 45$ gross cost. $\$ 55.73 ; 1$ gross cost, $\$ 1.238$.

Assume that shop No. 2 is working on three-fourths-ounce colognes at 2-ounce weight. Production 33 gross a day: 59.4 pounds at $\$ 0.03658, \$ 21.73$ : blowing 33 gross at 65 cents, $\$ 21.45$; 33 gross cost, $\$ 43.18$; 1 gross cost, $\$ 1.308$, or 7 cents more than the 2-ounce round prescription bottles, and that represents exartly the difference in the blowing list.

But we have four boys working in No. 1 shop at an average of $\$ 1.121$ per day, or \$4.50. Divide by 45 gross, and we find the cost per gross for boy labor to be $\$ 0.10$.

$a$ In a letter to the bureau Mr. Armstrong explains that $\$ 0.03658$ was the figure used by a competitor in determining the cost of a gross of bottles of this size, and "was supposed to include all the costs going into the manufacture of bottles except certain specific costs. such as the blowine seale, sales commission, and possibly freight." 
In the case of the colognes, the 33 gross also cost $\$ 4.50$ for boy labor, or $\$ 0.1363$ a gross, a difference of $\$ 0.0363$ in the item of boy labor alone, not taken care of by the per pound method.

There are several other items of expense in the cost of those bottles which are affected in the same manner, thus increasing the inaccuracy. Further, experience has shown that two shops working side by side on the same bottle will vary, considerably in their output. Also that a given shop working on the same bottle will vary for one reason or another -an old mold, a new boy, or other similar cause. All these variations dirertly affect the costs per gross, but the per pound system does not provide for such variation.

Go back to the boy wages, $\$ 4.50$. It matters not what the weight per gross of the bottles they are making may be, whether 2-ounce, 4-ounce, 8-ounce, or more, or whether the production is 50 gross or 35 gross or 20 gross per day-their wages are the same, \$4.50. So that this expense bears no fixed relation to the weight of the bottles or the quantity produced, but it has a fixed relation to the time consumed in making the ware. Therefore the expense, $\$ 4.50$, should be applied to each gross produced during the day in the proportion of 1 gross to the total production. For example, if 10 gross are produced each grnss costs 45 cents for shop boys. If 45 gross were produced each gross costs 10 cents for shop boys.

Take gas: Assume that gas for an 8-ring furnace costs $\$ 32$ a day, $\$ 4$ a day for each ring hole. It will cost practically $\$ 4$ a day for each ring hole no matter what size ware is being produced or how many gross are being turned out. If it is large ware, much gas must be used to thoroughly melt and cook the glass. If small ware, much gas must be used to keep the glass hot. So the size of ware produced makes but little difference in the daily cost for each shop.

Suppose the shop is working two turns on a 2-ounce weight bottle and producing 85 gross a day, or $\$ 0.047$ a gross for gas. Suppose again the shop is on a 2-ounce weight bottle more difficult to make and the production for two turns is 65 gross, then the cost for each gross for gas is $\$ 0.0615$, an actual increase in cost of $\$ 0.0145$ not discovered by the pound system, because the two bottles being of the same weight are charged with the same burden of expense.

The same illustration can be given of bottles of any weight and we are led to the conclusion that the cost of gas bears no direct relation to the weight or the size of the bottles being produced, but that it has a direct bearing on the time consumed and should be applied pro rata on the number of gross produced during any cost period.

We might consume an hour illustrating the inaccuracies resulting from applying all the different sorts of expense items, according to the weight of the bottles, but it is unnecessary, as precisely the same principle applies to all such expense items as batch mixing, furnace tending, gas, shop boys, peanut roasting, leer expense, pacling, shipping, interest, repairs, and depreciation. In short nothing should be figured by the pound except the single item of melted glass, the net cost per pound of which should be ascertained, and each gross of bottles charged according to its weight.

It would appear from the foregoing that some other method of determining costs than the per pound system must be adopted to arrive at correct figures. One such method is the shop-hour system.

THE SHOL-HOUR SYSTEM.

The object of this system is to include every item of expense, manufacturing costs, interest. depreciation, and maintenance, and to apply to each gross of bottles produced the exact proportions of these costs that belong to it. If this is done, we must admit that the resulting figures will be accurate and may safely be used as a basis for establishing selling prices.

The shop-hour system recognizes two principal classes of bottle costs, viz, specific costs and nonspecific costs.

Specific costs.-'The method of handling these is very simple. They consist of the following items: Glass, blowing, mold depreciation, boxes, and packing paper.

At the close of business each month the total production in gross of each kind of bottle made is ascertained. The production of each bottle is charged with the number of gross times the blowing rate.

An account is kept with each mold. Experience will soon determine what portion of the original cost of a mold is depreciated by each 100 gross of bottles produced. Based on this known rate of depreciation, the production of each bottle is charged with the proper amount of mold depreciation.

The box-cost system determines the cost of each box produced. These per box costs are multiplied by the number of boxes required to pack each kind of bottle, and the resulting figures added to the total costs for each bottle produced. 
There is so slight a difference in the amounts of paper required per case to pack the different sizes that we assume all to cost the same per case. On this basis the total costs of each bottle produced are charged with the proper amount for packing paper.

By a method to be explained later, the exact raw materials cost of melted glass per pound is determined. The total cost of each bottle produced is charged with the cost of glass used.

To ascertain the cost per gross of any bottle, add these five items to the total shop-hour cost for that bottle and divide by the number of gross produced.

Shop-hour cos/s. - This is a little more complicated, but easily enough handled. Some period of time must be adopted as the unit. The hour being short and answering all the requirements, is being used.

Shop-hour costs are based on three principles, or theories, as follows: $(a)$ A 1 inanufacturing costs except the specific costs should be calculated on the basis of time; (b) all costs, including manufacturing costs while operating, costs incurred by reason of a shop or shops being idle from time to time, and costs accruing during shut-down periods must be applied to the total number of productive hours; $(c)$ each ring hole or shop must be charged with exactly the same amount of costs in the ratio of its productive hours, without regard to the size or quantity of ware it is producing.

The hour.-At the close of each month the total number of gross of each bottle produced during the period, and the actual hours employed in making each, is ascertained. The total number of hours by the same process is subdivided into hours on handmade, or machine-made, or pressed stoppers, or in making amber, etc.

The process is this: Shop No. 1, handmade ware, works 9 hours (shop hours they are called) on A pril 1. The record of their day's work is made to show this. A similar record is made for every shop for each day of the month, and at the end of the month it is merely a matter of addition to ascertain the aggregate number of shop hours employed on each class of ware by all the shops. Suppose the records indicate 2,500 sh op hours on handmade ware for the month and a total shop-hour cost of $\$ 3,750$; this equals $\$ 1.50$ to be charged to the production of each shop for every hour they have worked during the period. The same process is followed for machine ware, or amber ware, or blue ware, or any other subdivision desired.

This will serve to illustrate the shop-hour cost in practice: Assume the rate to be $\$ 1.50$ per hour. If a shop produces bottles at the rate of 3 gross per hour each gross will have cost 50 cents, which represents the burden for all manufacturing costs except the five items of specific costs mentioned in a previous chapter. If the production is 4 gross per hour the shop-hour cost of each is $37 \frac{1}{2}$ cents; or, if 5 gross per hour, the cost for each is 30 cents, etc.

Cost per pound of melted glass._-By means of forms specially prepared for the work, the wreight and cost of each material that goes into the glass is ascertained and tabulated. These give the total weights of raw materials and their cost. The production record which shows the number of gross of each bottle made also shows the total number of pounds of glass used. The difference between these two total weights represents the shrinkage in melting. The total pounds produced divided into the total cost indicates the actual cost per pound of melted glass for raw materials, and this is the only item of the costs that should be applied at so much per pound.

In addition to manufacturing costs there are merchandising costs, consisting of office expense, sales expense and commissions, cash discounts, and officers' salaries. These added together produce the total of general expense, which is added to the manufacturing cost on a percentage basis.

At the end of a month the records may show that 1,000 gross of 2-ounce round prescription bottles have been produced. The cost to make, sell, deliver, and collect for them is determined by adding together the various sums produced by multiplying 1,000 by the following items: The blowing rate, the mold depreciation, the box cost per gross, packing paper, and glass, and the number of shop hours times the shop-hour rate at $\$ 1.50$. The sum being divided by 1,000 , produces the manufacturing cost of each gross, which we will say is $\$ 1.10$. To this we add the merchandising expenses at, say, 5 per cent, the freight at what it actually is - say $\frac{41}{2}$ cents a gross-and the salesman's commissions, all of which show a cost of $\$ 1.27$ the gross. If 5 per cent protit is satisfactory, the sale price must be $\$ 1.334$ the gross.

Under the method explained by Mr. Armstrong, the cost of the raw materials only is charged to each unit on the pound basis. Specific costs - for blowing, mold depreciation, boxes, and packing paper-are charged according to the actual cost for each unit. All other costs, including fuel, general labor, and general expense of all kinds, are apportioned on the shop-hour basis. Some accountants are in favor 
of including the fuel cost with the cost of raw materials to ascertain the cost per pound of material used.

This system of apportioning costs that are not direct to the different units may be applied to tableware and lighting goods as well as to bottles.

The cost of leering depends on the size of the article, the length of time necessary to anneal it properly, and the temperature required. The labor cost of grinding, ornamenting, inspecting, wrapping, and packing may be charged to each unit according to the time actually spent on it. The selling expense may be apportioned on the total cost of the unit, according to the ratio between the total selling expense and the total cost of the factory product during a certain period.

\section{OVERHEAD EXPENSE 1N MAKING WINDOW GLASS.}

Where both single and double strength window glass is made, the cost of the metal, or molten glass, should be separately figured, as the relative weights are about as 5 to 8 . Window class is made in several grades, called double A, A, B, and C, double A being the best grade, and is cut into panes of different sizes called brackets. The cutters cut the glass sheets to the best advantage, and get as much of the better grades and larger brackets as possible.

In manufacturing window glass the skilled labor consists of gathering, blowing, flattening, and cutting in the case of hand-blown glass, and of flattening and cutting in the case of machine-made glass. The piece prices paid per 100 square feet cut vary under union rules according to thickness, being higher for double strength than for single strength, and also according to grades and brackets, being higher for the better grades and for the larger brackets. This skilled labor can, therefore, be easily charged directly to the cost of 100 square feet of each bracket of each grade, single or double strength.

The expense for metal being computed separately for single and double strength glass and the expense for skilled labor being computed separately for each bracket of each grade, single or double strength, the other expense of manufacture, including the burden or overhead, may be apportioned by dividing this expense by the total number of 100 feet produced, irrespective of thickness, quality, or size of bracket.

Other methods of distributing the burden might be adopted. For instance, the cost of the unskilled labor on a unit might be allocated in the proportion of the cost of the skilled labor, which is paid for at piece prices, according to the various brackets and grades; or the primecost method might be used, by which the burden is distributed on the basis of the total cost of skilled labor and materials of each unit. The effect of either of these methods, the latter to a greater extent than the former, would be to increase the burden on the larger brackets and better grade, and decrease it on the small brackets and lower grade. This is theoretically desirable, and the cost of the small brackets and lower grades, as apportioned by either of these methods, would be less. Consequently there would be less complaint from manufacturers that they had to sell the small brackets and lower grades at a loss; but by either of these methods of apportionment more burden would be distributed to the larger brackets than is done under the present practice. Manufacturers could not sell their larger brackets without reducing their margin of profit if they should apportion overhead by the prime- 
cost method; they would be unable fo compete with manufacturers whe apportion the burden aceording to the prevailing practice. It is, however, on the laracor brackets that manufacturers at present make their la resest pereentage of profit. It would probably be found that it would be very diflicult practically for a manufacturer to use the primerost method unless most of his emmpetitors also should adopt it.

\section{PREDETERMINED COSTS.}

An article by Mr. Herbert B. Garwood shows that whether a factory is operated cfliciently or inefficiently can not be lecided without a study of predetermined costs and comparing them with the actual costs, as show by the factory's records. Such a comparison will show in what departinents of the factory there is preventable waste. He suggests that manufacturers, acting together, should publish the results of a study of their predetermined costs for the bencfit of themselves as well as of their uninfornied competitors. He says that this accurate knowledge of the lowest costs that have been obtained would result in the elimination of preventable waste and in a decrease of price cutting. Such data, if accessible to all manufacturers, would, in his opinion, cause them to fix selling prices with much greater uniformity than has been customary. His article, quoted below, was read before the members of the Glass Bottle Manufacturers' Club at a meeting held in New York City September 12, 1911:

\section{Prenetermined Costs of Manufacturing in the Hand-Blown Glass-Bottle Business.}

\section{THE MODERN THEORY OF COST ACCOUNTING.}

The greater number of those interested in the hand-blown glass-bottle business are agreed that the financial return on the capital invested is inadequate. As to the cause of this inadequacy there is a wide divergence of opinion. The manufacturing department blames the selling department for low prices, the selling department claims that it has to meet the prices of other manufacturers, and that the manufacturing department must be inefficient, otherwise they could produce at the prices of these competitors and show a profit; and the general management blames first one and then the other, as circumstances may be.

The true cause of inadequate returns is probably unintelligent competition plus inefficiency in both manufacturing and selling departments, together with an excess or deficiency of capital, due to lack of system in the general management. Admitting this, is it not a matter of vital importance to manufacturers to know what their costs should be? Not what they have been, not what they are to-day, but what they theoretically should be, plus a certain percentage allowed for inefficiency and waste, the data being obtained from a scientific analysis of the business.

Without this information, how can they tell whether they are operating under efficient or inefficient conditions? Do they know whether they are asking a legitimate profit or a legitimate profit plus a profit upon inefficiency, the latter being manifestly wrong in principle and bound to result in disaster? Last, but not least in importance, can they state for a certainty whether they are making or losing money, and if the amount made or lost is what it should have been under the conditions prevailing during the period of operation?

The old and generally accepted method of cost accounting is to ascertain costs after the work has been completed. The objections to it are that it delays information until the information is of but little value and that it is absolutely incorrect, as it mixes up with costs items that do not have the remotest connection with them.

As an illustration, take this incident: $\mathrm{A}$ shop was making 8-ounce Baltimore ovals. About 2 o'clock in the afternoon the three blowers quit without notice and the three boys were ordered to sweep off the tops of the leers. The time sheets had the total wages of these boys charged to the 8-ounce Baltimore oval order, and it was so recorded in the office. Is such information worth the time expended upon it? 
The modern method of cost accounting is to ascertain costs before work is undertaken. Then, when the job is completed and the actual figures are known, to charge to the job the predetermined cost and to put the excess (that is, the difference between the actual and the predetermined cost) under an account called preventable waste, where the attention of all concerned is immediately called to it.

It will be seen at once that this substitutes for the haphazard reckoning of the old method a scientific basis of determination. The predetermined costs are derived from a careful ascertainment of theoretical costs with allowance for waste and inefficiency. Predetermined costs are therefore never standardized. Any day something may be discovered which will change the theoretical cost or alter the percentage of waste and thus place the predetermined costs on a new level. This predetermination of results based on scientific certainties modified by experience is of more value than retrospective costs based on a servile record of the haphazard.

In the first place, it has its value for superintendents, salesmen, and foremen. It has been customary to hire men for these positions and put them to work with a handful of general instructions and then blame them for whatever went wrong. Perhaps they were told the owners of the business expected it to make a certain amount per year and that the greatest possible production was wanted at the lowest possible cost, and this production was to be sold at the highest price possible. Data as to the results, step by step or unit by unit, was seldom given them; they were hired and turned loose to work out their own salvation. In many cases their employers knew less than they did and could not have given charts had they been asked for.

The modern method gives the men in command a chart to steer by. The greatest possible volume of business a plant is capable of turning out in a given period of time is first determined; a selling force to dispose of this output is then organized; the material and labor necessary to its production is scientifically reckoned; an apportionment of the overhead burden to the different stages of manufacture is made; the required margin of profit is decided upon and standard selling prices established. All of this information is mapped out for the guidance of the men.

As the work progresses actual costs are compared with predetermined costs. Inefficiencies are immediately located and removed. Predetermined costs then fall to new levels and again actual costs are compared, further elimination of waste is made; the cycle continues indefinitely. The men know whether they are doing their work in a satisfactory manner, not only to their employer but to themselves. The salesmen determine their worth not from gross sales, but from net profits forecasted from predetermined costs. Every employer has accurate means of judging the worth of every man in his employ. He is not dependent upon personal feeling or prejudice; he knows what are the actual results accomplished by each man.

In addition to the help the men derive from this knowledge of what their work should be, predetermined costs have a use and are even a necessity in forecasting the results of business policies. Some years ago rather a high scale of prices was put into effect by a combination consisting of the greater number of bottle manufacturers of this country. Almost all plants operated upon a fairly efficient basis commenced to make what would to-day be regarded as an abnormal profit.

Thereupon a number of new plants were started to take advantage of the situation. Had predetermined costs shown that these prices were going to produce excessive profits and the certain attraction of excessive profits to new capital been predicted, a lower scale might possibly have been adopted, and the hand-blown glass industries might have been saved some of the excess production which is to-day responsible for much of the disorganizaion in the business. At the time no such thoughts occurred, prices were fixed on the basis of what the market would stand, and in a few years chaos reigned.

The greatest value of predetermined costs, however, lies in their comparison with actual costs and in the knowledge thus attained of where inefficiencies and preventable waste, accidents, unavoidable expenses have been found and how much they have affected profits.

Suppose under the old method cost records contained an item called "Tending factory No. 1" and during different periods of a year the following charges were made: (1) $\$ 309,(2) \$ 315,(3) \$ 322,(4) \$ 385,(5) \$ 260,(6) \$ 340$. At the end of the fourth period the superintendent would probably have been asked to explain the high cost of $\$ 385$. He would have dissected his time book or cards and in three of four days reported that owing to a shortage of boys he had been compelled to use packers for tending boys and to hire a number of extra boys for the night shift at higher wages. There would have been more or less grumbling and the matter would have passed. At the end of the next period he would possibly have been complimented upon the good showing, and later it might have been discovered that a page of the time book had been mislaid.

Now, assuming this occurred in a plant making nothing but beer bottles and the 
production was exactly 20 gross per shop per shift. the bottles made luring the fourth period would have eost more than those nade during the fifth. Would the salesman have been expected to go out and get a higher price for those made at a hicher cost and would customers have been notified of a reduction in priee during the following period?

This question is of course ridiculous, lut as it is manifestly impossible to get a higher priee for the beer bottles made during the period of high cost the owners of the business nust lose the extra mouey paid out for tending. Knowing they must lose it, why wait for the end of the fiscal year to recognize it? Why not immediately charge it to preventable loss in the books, so that when the end of the year comes not only the losses but their sources mav be deternined?

Take the same situation under the new method. Superintendents, foremen, and accountants are called in and waces tixed for tending. The number of boys to a shop is determined. Allowance is made for extra boys for emergeneies. Wage increases during the year are forecasted, and the burden spread among the various units or shops. Let us assume that the predetermined cost of tending is $\$ 2.90$ per shop per shift and that for a certain period 100 shops are operated. The predetermined eost of tending for this pericd is therefore $\$ 250$. At the end of the period let us imagine that the actual pay roll shows for tending $\$ 325$. Turning to tending aecount in the ledger, which is ruled and headed for three columns instead of one, we post as follows: Standard cost, \$290; preventable waste, \$35; actual eost, \$325. When the end of the year arrives and the books are closed the amount of money lost and the plaee it disappeared are both known, for by the use of this system you are always losing money regardless of what profits you may make. This seeming paradox is explained by the fact that standard eosts are always changing to new levels, so that actual eosts never catch them, preventable waste being always present.

Let us continue to assume nothing but beer bottles are being made and the produetion is still 20 gross per shop per shift. The standard eost does not vary; therefore the standard selling price remains the same. High actual cost lost some money in a eertain period, but instead of tring to saddle it on one order or group of orders, it is spread over the year and reeognized as a penalty for inefficieney instead of a eharge whieh should have been made against a customer.

As Harrington Lmerson expresses it: "A waiter bringing in an expensive dinner to a guest in a hotel stumbles and crashes dinner and dishes to ruin. Shall the guest, besides being put to the annoyanee of waiting another half hour, be charged not only double price for his dinner but also for the broken dishes, or is the expense of the aecident to be charged to inefficiency, a general charge or overhead burden on all dining-room operatious, taken care of in the standardized cost of each dish, without reference to speeific aeeident?"

Standard priees must always be based on standard costs. Suppose in a plant making nothing but beer hottles the aetual cost for one period was $\$ 3.32$ per gross while during the next period it was $\$ 3.41$ per gross. In which period would you determine your selling price? But suppose predetermined eost was $\$ 3.24$, then when the figures came in at $\$ 3.32$ and $\$ 3.41$ you would have data to talk about to the factory management; and bear in mind these figures would eome to you as the aggregate of hundreds of separate operations, so you could immediately put your finger on the item or items responsible for the excess and take steps to prevent its reoecurrence.

If, as many manufacturers believe, present financial returns are inadequate, either eosts are too high, selling prices too low, or both are at fault. Without a scientifie predetermination of costs, how can it be decided where the fault lies? Is it safe either to lower or raise selling priees? One, of eourse, opens the way to bankruptcy, the other to better-informed competitors taking away business. Information as to aetual costs are for the private benefit of each manufacturer. It would be folly to ask or expect them to be divulged in a public meeting or published in any manner. Predetermined eosts are a matter of general interest and information to all and can be discussed and worked over without jeopardizing the position of any manufaeturer taking part.

If this could be generally realized, there would seem to be nothing to prevent manufacturers taking up the study of predetermined costs together and publishing the results, thus educating their uninformed competitors as well as themselves to the necessity of selling prices based on eost secured through elimination of inefficieney, plus a reasonable margin of profit. When this is done, it will be found that a eloser uniformity in selling prices will follow than has ever been secured through any combination heretofore in effect.

Other industries have followed this system of educating their eompetitors and themselves to a true knowledge of eosts to their great benefit. One example is the printing trade. Such a scheme is now being worked out through the Foundrymen's 
Association. Another is in the field of electricity. The number of failures among small electric light plants has been vitally reduced since the inception by the National Electric Light Association of a study of costs. The window glass manufacturers are now engaged in forming an association based on educational lines to study the question of costs. There is no reason to doubt that such a study would be of tremendous advantage when applied to the glass-bottle manufacturing business. Is it not, in fact, almost a matter of vital necessity and should it not be made before any action is taken even for the suggestion of selling prices?

\section{DETERMINATION OF OUTPUT.}

No study of predetermined costs should be undertaken without first making a careful examination of the business and analyzing every step in the operations of the plant. Manufacturing costs are the aggregate of the costs of hundreds of separate operations, and until each one of these is carefully studied and assayed and the results tabulated it is manifestly impossible to attempt to forecast this aggregate. Therefore an analysis of the glass-bottle business is necessary before attempting to take up the question of costs. As each step in the process is shown, the cost of that step can be determined.

This analysis discloses the fact that glass is needed to make bottles; that glass is a mutual solution of a number of chemical substances, usually silicates, their solution being accomplished through the fusion of their mixture by heat applied in a furnace. A furnace is a receptacle not only for making glass but from which it is withdrawn in small units to be fabricated.

The starting point of the business is, then, the furnace. It is next learned that no more glass can be melted in the furnace than is withdrawn by the workmen during the process of manufacture. But the cost of this glass does not bear a direct ratio to the tonnage produced, for heat must be kept on the furnace continuously, regardless of variation in amount of output. There are also certain indirect materials, indirect labor, and general expenses which continue at practically a fixed amount in spite of a wide range in tonnage output.

There is, therefore, in every plant a certain tonnage which should be manufactured in order to secure the greatest possible economy in the cost of glass ma':ing. Knowledge of the amount of tonnage possible is the first step in the study of predetermined costs, for without this the quantity of raw material needed can not be ascertained nor the number of workmen required to manufacture bottles estimated. Therefore we must forecast the output of a given furnace or furnaces before proceeding further.

To ascertain the maximum output of a furnace, the inside dimensions of the melting pot, the area of the ports, and the cubical contents of the generators should be known. The reason for including ports and regenerators is that if these are of insufficient size the furnace with which they are connected will not have the same melting power as a furnace with properly designed ports and generators.

In $1868 \mathrm{Mr}$. C. W. Siemens, in an address before the Chemical Society of England, formulated his principles regarding the design of checkers, and, though many years with their improvements have passed, the furnaces with the greatest melting power in this country to day are those which closely follow the principles then laid down. As a matter of interest the pith of his article is here reproduced:

"The amount of brickwork required to absorb the waste heat of a given furnace is a matter of simple calculation. The products of the complete combustion of 1 pound of coal have a capacity for heat equal to that of nearly 17 pounds of fire brick, and in reversing every hour 17 pounds of regenerator brickwork at each end of the furnace per pound of coal burned in the gas producer would be theoretically sufficient to absorb the waste heat if the whole mass of the generator was uniformly heated at each reversal to the full temperature of the flame and then completely cooled by the gases coming in.

"In practice, however, by far the larger part of regenerator checker work is required to effect the gradual cooling of the prnducts of cornbustion and only a small portion near the top, perhaps a fourth of the whole mass, is heated unitormly to the full temperature of the flame, the heat of the lower portion decreasing gradually downward nearly to the bottom. Three or four times as much brickwork is thus required in the regenerators is is equal in caparity for heat to the products of combustion. The best size and arrangement of the bricks is determined by the consideration of the extent of opening required between them to give a free passage to the air and gas, and by the rule deduced from my experiments on the action of regenerators in 1851 and 1852 a surface of 6 square feet is necessary in the regenerator to take up the heat of the products of combustion of 1 pound of coal in an hour." 
A turnace bult according to this principle is ahle to deliver 40 per cent of its capacity eren ' 2: hours, or 20 per celt in 12 hours, and under the plan of 11 shifts per week, 220 yer cent of its capacity per working week. This does not mean that 40 per cent of capacity is the maximun: output of the furnare. Such a statement would not be

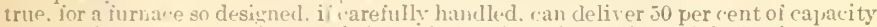
every $2 t$ hours for a s!:stained period, but it does it at the sarrifice of the lasting pow $\mathrm{r}$ of the stone and by ta! ing hig chanres on the quality of glass.

. basis of 40 per cent caparity allows a margin for temporary overloads through in reasing the weight of hottles li,eing made, and is a reserve in case of trouble wiih dirty tires in the gas producer. It is undouhtedly as high a fignre as may safely lie given for a season s operation and is concurred in by two glass-furnace engiveers connected with coutracting concerus and hy several managers. It is only fair to say, hostever, that almost every ons has a different method of reaching this result, but if in the end all arrive at approximately the same ron lusion it may saiely be assumed that reurreut prar.tice is well representert.

The method generally used in determining the calpacity of a furuace is to figure the cubiral contents of the melting pot and count 1.50 jounds of glass to the cubic foot. The mothod of arriving at 150 pounds as the weight of a culvic foot of glass is as folluws:

A cul,i: font of distilled water weighs 62.42 pounds. The specific gravity of a suhstance being the ratio of weight between a given volume of that substance and a like volume of distilled water. it is only necessary to ascertain the specific gravity of glass and multiply it $\mathrm{l} y: 62.42$ pounds. In textbooks the specific gravity of hottle glass is generally given at 2.60 to $\ddot{z} .90$. Actual results with ordinary flint bottle glass show fisures much lower. In average from a plant emploving a chemist who made tests every week gives about 2.415. Multiplying this by 62.42 pounds we have 1503 pounds. For all practical purposes 150 pounds per cubic foot will suffice.

Having secured the capacity of a furnace in tons, and figuring on an output of 20 per cent of caparity per shilt, or 220 per cent per week, it is a simple calculation to determine the yearly output. It is next necessary to make an estimate of the waste betreen ring hole and parking box and to deduct this in order to deternine the anıount of parked pronluct on which the basis of cost is established. In theory this is incorrect. The proper method would be to determine the cost of glass based on the output and onipute the waste (n each job). charge the job with the total amount of glass used, and credit it with the value of the waste returned to furnare. As this would introduce an endless amount of detail and complication the prior-method is here used.

The yriestion of waste between ring hole and packing hox is of great importance and is not receiving the attention it deserves in these days of large continuous tanks. In the old pot-hurnare days it was watched more strictly, as upon the care bestomed on it depended the day 's output. A chapter could easily be filled in duscribing methods used to eliminate it. Filling in at noon all the cullet made in the morring sn as to stretch out the aiternoon's work and throwing spoiler hottles in the back of the pot are tiro illustrations.

With morlerm continuons furmares. records of waste as low as $9 ?$ per cent and as high as 32 per cent are reported. If glass is not used for heating inolds 10 per cent would seem very inefficient: but for the purposes of this explanation 15 per cent will he used. Therefore the parked output per week will he 220 per cent less 15 per cent of 220 . or 187 jer cent of the capacity of the furnace.

To illustrate: $\Lambda$ furnace 20 feet long, 10 feet wide, and 3 feet deep contains 600 cuhic feet: 150 pounds of glass to the cubic foot makes the contents 90,000 pounds, or 45 tons: 187 per cent output of packed glass per week is 84.15 tons, or slightly less than 8 tons per shiit. The number of working shilts in a fire or hlast are next computed and the annual output determined.

At this point the probable production of hottles in sross is forecasted. As each manufar turer is famiiiar with the number of ring holes and the size ware it has heen clistoniary to nıake therefrum, it naturally follows that by figuring the amount of glass packed daily by the difierent shops arjustments cau he made in sizes to keep this aggregate guantity in agret ment with the average daily output. 
To illustrate, let us take 8 tous as the predetermined output per shift:

Pounds.

2 shops, 4-ounce weight, parking 30 gruss of bottles......... 2, 160

2 shofs, 7-ounce weight, packing 25 gross of bottles......... 3,150

1 shop, 12-ounce weight, pacling 20 gross of bottles.......... 2, 160

1 shop, 16-ouice weight, packing 18 gross of bottles.......... 2, $5: 2$

1 shop, 24 -ounce weight, packing 14 gross of bottles......... 3, 024

1 shop, 44-ounce weight, packing 8 gross of bottles.......... 3, 168

Total............................ $\overline{16,254}$

or slightly over 8 tons per shift. These daily quantities multiplied by the number of shifts in a blast give expected output aild are a base for the establishment of a selling organization. By furnishing this organization with a chart of required quantities, the orders received daily may be listed under their proper si\%es so that the selling organization has a thorough knowlerge of the amount of business required at any time during the year. If on account of the state of the market certain sizes run ahead of predetermined quantities or behind them, malufacturiug conditions can be adjusted to suit and revised data furnished the selling organisation, from which they cau work in the future.

The next step is to determine the quantities of raw materials needed to produce a given quantity of molten glass and cost of the same, with due allow ance for the losses taking place during the operation of melting.

\section{GENERAL ACCOUNTING CONDITIONS.}

The general accounting systems of establishments in the glass industry are, as a rule, much better than their cost keeping systems, though this investigation disclosed that in some glass factories very imperfect methods of bookkeeping are employed. The following table indicates the methods of cost finding, the other accounting conditions, and the frequency with which inventories were taken in the glass factories,that were visited by agents of the Bureau. The classification regarding general accounting conditions were made by the agents and were based on their own observations.

Table 108.-Accounting Conditions in Establishments of Various Branches of the Glass Industry.

\begin{tabular}{|c|c|c|c|c|c|c|c|}
\hline Classification. & $\begin{array}{l}\text { All } \\
\text { establish- } \\
\text { ments. }\end{array}$ & $\begin{array}{c}\text { I. } \\
\text { Window } \\
\text { glass, } \\
\text { hand. }\end{array}$ & $\begin{array}{c}\text { II. } \\
\text { Window } \\
\text { glass, } \\
\text { machine. }\end{array}$ & $\begin{array}{l}\text { III. } \\
\text { Plate } \\
\text { glass. }\end{array}$ & $\begin{array}{c}\text { IV. } \\
\text { Wire and } \\
\text { opales- } \\
\text { cent } \\
\text { goods. }\end{array}$ & $\begin{array}{c}\text { V. } \\
\text { Bottles, } \\
\text { hand. }\end{array}$ & $\begin{array}{c}\text { VI. } \\
\text { Bottles, } \\
\text { machine. }\end{array}$ \\
\hline Total establishments..... & 213 & 37 & 12 & 6 & 9 & 26 & 18 \\
\hline 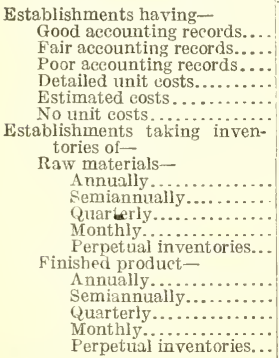 & $\begin{array}{r}90 \\
25 \\
7 \\
22 \\
5 \\
79 \\
70 \\
30 \\
6 \\
19 \\
9\end{array}$ & $\begin{array}{r}25 \\
3 \\
1 \\
4 \\
\ldots . \\
24 \\
4 \\
1 \\
4 \\
2\end{array}$ & $\begin{array}{r}{ }^{8} \\
\ldots \ldots \ldots \\
\cdots \cdots \\
1 \\
1\end{array}$ & 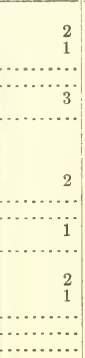 & $\begin{array}{r}5 \\
1 \\
\ldots \\
1 \\
\ldots . \\
5 \\
5 \\
1 \\
1 \\
1 \\
\ldots .\end{array}$ & $\begin{array}{c}8- \\
3 \\
\cdots \\
8 \\
2 \\
\\
6 \\
6 \\
\cdots \\
5 \\
4\end{array}$ & $\begin{array}{r}11 \\
2 \\
1 \\
1 \\
1 \\
8 \\
2 \\
1 \\
4 \\
1\end{array}$ \\
\hline
\end{tabular}


Table 108.-Accounting Conditions in Establisments of Various Branches OF THE GLASS INDUSTRY-Concluded.

\begin{tabular}{|c|c|c|c|c|c|c|c|}
\hline Classification. & $\begin{array}{l}\text { VIl. } \\
\text { Bottles. } \\
\text { hand and } \\
\text { machine. }\end{array}$ & VIII. & $\begin{array}{l}\text { IX. } \\
\text { Table- } \\
\text { ware, } \\
\text { blown. }\end{array}$ & $\begin{array}{c}\text { X. } \\
\text { Table- } \\
\text { ware. } \\
\text { blown } \\
\text { and } \\
\text { pressed. }\end{array}$ & $\begin{array}{c}\text { Xl. } \\
\text { Lighting } \\
\text { goods. }\end{array}$ & $\begin{array}{l}\text { XII. } \\
\text { lamp } \\
\text { chim- } \\
\text { neys. }\end{array}$ & $\begin{array}{l}\text { XilI. } \\
\text { Miiscells- } \\
\text { neous. }\end{array}$ \\
\hline Total establishments...... & 27 & 13 & 8 & 20 & 18 & 6 & 13 \\
\hline 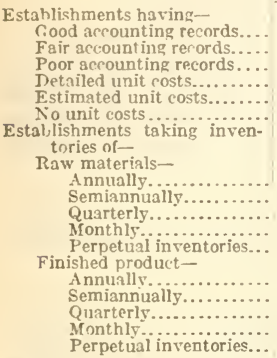 & $\begin{array}{l}9 \\
4 \\
3 \\
5 \\
5 \\
3\end{array}$ & $\begin{array}{l}2 \\
3 \\
3 \\
2 \\
1 \\
1 \\
\\
2 \\
3 \\
3 \\
1 \\
2\end{array}$ & 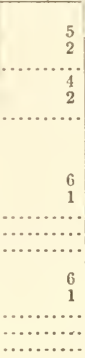 & $\begin{array}{r}5 \\
1 \\
\cdots \cdots \\
\cdots \\
\\
\cdots\end{array}$ & $\begin{array}{l}8 \\
1 \\
1 \\
1 \\
3 \\
3\end{array}$ & $\begin{array}{l}1 \\
1 \\
3 \\
i \\
1 \\
3\end{array}$ & \\
\hline
\end{tabular}

In the above table all establishments maintaining accounts showing a good separation of important items were classified under the head of "Good accounting records"; some of these employed improved modern methods. Those classified under "Fair aceounting records" showed too great a consolidation of important items; those under "Poor accounting records" showed very little segregation in accounts and in some cases also very crude methods.

Of the 213 establishments visited, 149 furnished data regarding their general accounting records, 105 showed good accounting records, 24 fair, and 20 poor accounting records. Many of the manufacturers have inaugurated systems for ascertaining unit costs, some of which are accurate while others are merely estimates.

In the table above all establishments classified under "Detailed unit costs" have either an accurate unit cost system or their unit records are of such detail that but little estimating is done. Under "Estimated unit costs" those establishments are shown whose unit costs are either wholly or in greater part estimated. Of the 213 establishments visited, 21 reported detailed unit costs; 66 estimated, and 32 no unit costs.

Inventories of raw materials were taken annually by 90 establishments, semiannually by 25 , quarterly by 7 , monthly by 22 , and perpetual inventories were kept by 5 establishments. Inventories of finished products were taken annually by 79 establishments, semiannually by 30 , quarterly by 6 , monthly by 19 , and perpetual inventories were kept by 9 establishments.

A large proportion of establishments in the glass industry neither had reserves for depreciation nor charged off anything on account of depreciation. When depreciation is not considered the manufacturer is often under the false impression that his profits are larger than they really are. This subject is discussed in Chapter III, page 86. 


\section{CHAPTER X.}

\section{IMPORTS AND THE TARIFF.}

\section{PRODUCTION, IMPORTS, AND EXPORTS COMPARED.}

Table 109 shows the value of the production of glass and glassware in the United States during each year, beginning with 1879, for which data were collected by the Bureau of the Census. It also shows the general imports, imports for consumption, and domestic exports during each fiscal year from 1879 to 1916, inclusive.

Table 109.-Value of Production in the United States, General Imports and Imports for Consumption, and Domestic Exports of Glass and Glassware, And Excess of Imports over Exports.

\begin{tabular}{|c|c|c|c|c|c|c|c|c|c|}
\hline \multirow[b]{2}{*}{ Years.a } & \multirow[b]{2}{*}{ Production. } & \multicolumn{3}{|c|}{ General imports. } & \multicolumn{3}{|c|}{ Imports for consumption. } & \multirow[b]{2}{*}{$\begin{array}{l}\text { Domestic } \\
\text { exports. }\end{array}$} & \multirow{2}{*}{$\begin{array}{l}\text { Excess of } \\
\text { imports } \\
\text { for con- } \\
\text { sumption } \\
\text { over } \\
\text { exports. }\end{array}$} \\
\hline & & Free. & Dutiable. & Tota!. & Free. & Dutiable. & Total. & & \\
\hline $\begin{array}{l}* \\
\cdots \\
\cdots \\
*\end{array}$ & 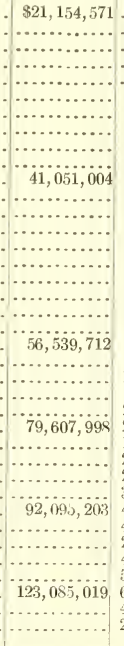 & \begin{tabular}{r}
$\cdots$ \\
\hdashline 4,542 \\
5,146 \\
19,988 \\
16,876 \\
12,538 \\
10,741 \\
58,830 \\
99,623 \\
71,049 \\
61,844 \\
71,881 \\
85,794 \\
92,628 \\
94,242 \\
107,572 \\
123,731 \\
$\mathbf{1} 33,332$ \\
$\mathbf{1} 66,594$ \\
198,922 \\
229,660 \\
225,460 \\
188,644 \\
207,957 \\
232,202 \\
369,866 \\
462,884 \\
407,976 \\
298,362 \\
401,235 \\
520,449 \\
630,673 \\
495,179 \\
265,389
\end{tabular} & 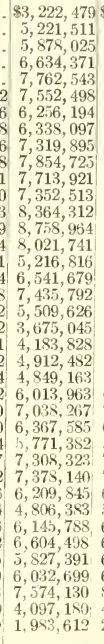 & $\begin{array}{l}83,222,479 \\
5,221,511 \\
5,878,025 \\
6,634,371 \\
7,762,543 \\
7,557,040 \\
6,261,340 \\
6,358,085 \\
7,336,771 \\
7,867,263 \\
7,724,662 \\
7,411,343 \\
8,463,935 \\
8,830,013 \\
8,083,585 \\
5,288,697 \\
6,627,473 \\
7,528,420 \\
5,603,868 \\
3,782,617 \\
4,307,559 \\
5,045,814 \\
5,015,757 \\
6,212,885 \\
7,267,927 \\
6,593,045 \\
5,960,026 \\
7,516,280 \\
7,610,342 \\
6,579,711 \\
5,269,267 \\
6,353,764 \\
6,902,860 \\
6,228,626 \\
6,553.148 \\
8,204,803 \\
4,592,359 \\
2,249001\end{array}$ & $\begin{array}{r}\$ 90 \\
10 \\
3 \\
11 \\
379 \\
7,331 \\
6,696 \\
20,142 \\
16,915 \\
12,572 \\
10,761 \\
61,412 \\
101,227 \\
71,091 \\
62,887 \\
72,012 \\
92,150 \\
103,521 \\
114,199 \\
114,499 \\
123,780 \\
133,477 \\
142,715 \\
203,578 \\
229,660 \\
224,929 \\
188,595 \\
208,128 \\
232,400 \\
369,850 \\
462,240 \\
416,843 \\
298,924 \\
401,588 \\
515,299 \\
6 \pi 3,277 \\
521,870 \\
266,266 \\
\end{array}$ & \begin{tabular}{|l}
$\$ 3,281,453$ \\
$5,133,285$ \\
$5,862,270$ \\
$6,753,537$ \\
$7,597,897$ \\
$7,553,185$ \\
$6,340,721$ \\
$6,341,058$ \\
$7,301,340$ \\
$7,721,453$ \\
$7,750,577$ \\
$7,351,571$ \\
$8,525,880$ \\
$8,881,902$ \\
$7,944,082$ \\
$5,035,673$ \\
$5,939,914$ \\
$6,241,477$ \\
$5,557,133$ \\
$3,711,966$ \\
$4,160,259$ \\
$4,905,388$ \\
$4,865,478$ \\
$6,052,260$ \\
$6,969,959$ \\
$6,404,201$ \\
$5,776,661$ \\
$7,344,6443$ \\
$7,367,742$ \\
$6,175,786$ \\
$4,837,747$ \\
$6,210,134$ \\
$6,639,142$ \\
$5,806,722$ \\
$5,921,363$ \\
$7,565,835$ \\
$4,134,250$ \\
$2,037,042$ \\
\end{tabular} & \begin{tabular}{|}
$83,281,543$ \\
$5,133,295$ \\
$5,862,273$ \\
$6,753,548$ \\
$7,598,276$ \\
$7,560,516$ \\
$6,347,417$ \\
$6,361,200$ \\
$7,318,255$ \\
$7,734,025$ \\
$7,761,338$ \\
$7,412,983$ \\
$8,627,107$ \\
$8,952,993$ \\
$8,006,969$ \\
$5,107,685$ \\
$6,032,064$ \\
$6,344,998$ \\
$5,671,332$ \\
$3,826,465$ \\
$4,284,039$ \\
$5,038,865$ \\
$5,008,193$ \\
$6,255,838$ \\
$7,199,619$ \\
$6,629,130$ \\
$5,965,256$ \\
$7,552,771$ \\
$7,600,142$ \\
$6,545,636$ \\
$5,299,987$ \\
$6,626,977$ \\
$6,938,066$ \\
$6,208,310$ \\
$6,436,662$ \\
$8,219,112$ \\
$4,656,120$ \\
$2,303,3081$ \\
\end{tabular} & \begin{tabular}{r|r}
3 & $\$ 768,644$ \\
5 & 749,866 \\
3 & 756,022 \\
8 & 864,235 \\
6 & 998,857 \\
6 & 839,756 \\
7 & 783,915 \\
0 & 773,878 \\
5 & 883,504 \\
5 & 881,628 \\
8 & 894,200 \\
3 & 882,677 \\
7 & 868,374 \\
3 & 942,302 \\
9 & 973,827 \\
922,072 \\
4 \\
946,381 \\
$1,062,225$ \\
$1,208,187$ \\
$1,211,084$ \\
$1,503,651$ \\
$1,936,119$ \\
$2,126,309$ \\
$1,960,106$ \\
$2,150,699$ \\
$1,978,481$ \\
$2,252,799$ \\
$2,433,904$ \\
$2,604,717$ \\
$2,505,417$ \\
$2,173,193$ \\
$2,805,401$ \\
$3,246,391$ \\
$3,494,153$ \\
$4,193,642$ \\
$3,729,623$ \\
$5,558,717$ \\
$12,321,338$ \\
\end{tabular} & $\begin{array}{r}\$ 2,512,899 \\
4,383,429 \\
5,106,251 \\
5,889,, 313 \\
6,599,419 \\
6,720,760 \\
5,563,502 \\
5,587,322 \\
6,434,751 \\
6,852,397 \\
6,867,138 \\
6,530,306 \\
7,758,733 \\
8,010,691 \\
7,033,142 \\
4,185,613 \\
5,085,683 \\
5,282,773 \\
4,463,145 \\
2,610,381 \\
2,780,388 \\
3,102,746 \\
2,881,884 \\
4,295,732 \\
5,048,920 \\
4,650,649 \\
3,712,457 \\
5,118,867 \\
4,995,425 \\
4,040,219 \\
3,126,794 \\
3,821,576 \\
3,691,675 \\
2,714,157 \\
2,243,020 \\
4,489,489 \\
6,902,597 \\
b 10,018,030\end{array}$ \\
\hline
\end{tabular}

a Proluction is for ealendar years (data from the Bureau of the Census); imports and exports are for fiscal years ending June 30.

$b$ Fxcess of exports over imports. 
The foregoing table show's that the imports were larger during the fiscal year 1914 than during any fiscal year from 1893 to 1913, inclusire. During the fiscal rear 1913, the last full year under the Payne-Aldrich 'Tariff Act, the imports for' consumption amounted to $\$ 6,436,662$; during the following fiscal year, the [nderwood-Simmons Art becoming effective on O-tober 4, 1913, they increased to $\$ \$, 219,112$. Since then there bas been a great decline in imports on aceount of the war in Europe.

\section{IMPORTS COMPARED WITH RATES OF DUTY.}

Table 110 shows for the sume years that appear in Table 109 the percentage that the imports and the excess of imports for consumption over domestic exports, were of the production, and the average rate of duty on imports of all kinds of glass and glassware computed on the ad valorem basis.

TABLE 110.-Percentage of Ijiports for CoNsumption and of Excess of Imports over Exports of Domestic Glass and Glassware, on the Basis of Productio:; asi Courputed Ad Valorem Rate of Duty.

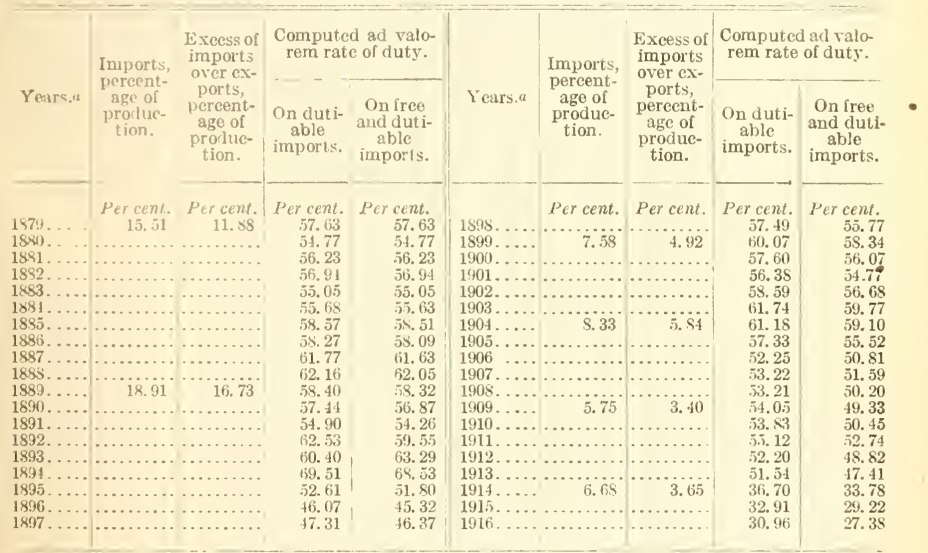

a Produstion is for calentar year (data from the Bureau of the (ensus); imports and exports are for liscal years ending Jume 3 .

The imports during the fiscal year 1889 amounted to 18.91 per cent of the production luring the calendar year 1889 . This was more than twice as large as the proportion in 1899 or 1904 , more than three times as large as the proportion in 1909, and nearly three times as large as the proportion in 1914.

In 1872 Congress enacted a measure that reduced the tariff duties on principal commodities 10 per cent. The dates when the tariff acts since then took effect are as follows: Mills Act, March 3, 1883; McKinley Act, October 6, 1890; Wilson Act, Lugust 28, 1894; Dingley Act, July 24, 1897; Payne-Aldrich Lct, Lugust 6, 1909; Underwood-Simmons Let, Oetober 4, 1913. 
As appears in Table 110, the rates of duty averaged highest on dutiable glass and glassware in the fiscal year 1894 . In 8 of the 38 years it was over 60 per cent. The average during the fiscal year 1913, the last full year of the Payne-Aldrich Act, was lower than it had been since 1896 and 1897, the last two fiscal years under the Wilson Act.

\section{GENERAL IMPORTS.}

Table 111 shows the value of general imports of all kinds of glass and glassware during each month from January, 1908, to December, 1916.

Table 111.-Value of General Imports of Glass and Glassware, by Months, FROM JANUARY, 1909, To June, 1916, InClusive.

AMOUNT OF GENERAL IMPORTS.

\begin{tabular}{|c|c|c|c|c|c|c|c|c|}
\hline Months. & 1909 & 1910 & 1911 & 1912 & 1913 & 1914 & 1915 & 1916 \\
\hline 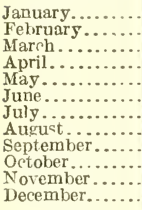 & $\begin{array}{r}\$ 427,150 \\
375,297 \\
472,037 \\
491,541 \\
527,297 \\
550,6.56 \\
480,962 \\
505,525 \\
565,461 \\
522,605 \\
484,645 \\
510,672\end{array}$ & $\begin{array}{r}\$ 520,155 \\
458,257 \\
662,963 \\
609,623 \\
606,185 \\
626,710 \\
635,646 \\
736,538 \\
644,345 \\
606.5 .22 \\
608,991 \\
567,045\end{array}$ & $\begin{array}{r}8502,576 \\
493,4 S 2 \\
583,398 \\
460,450 \\
536,904 \\
505,934 \\
490,919 \\
570,497 \\
568,542 \\
591.826 \\
553,805 \\
571,664\end{array}$ & $\begin{array}{l}8500,297 \\
383,1.58 \\
489,851 \\
504,666 \\
501,549 \\
482,850 \\
546,643 \\
598,337 \\
590,705 \\
630,816 \\
560,264 \\
512,498\end{array}$ & $\begin{array}{r}\$ 517,405 \\
462,947 \\
498,674 \\
578,201 \\
520,081 \\
519,732 \\
598,594 \\
594,160 \\
676,401 \\
715,703 \\
678,704 \\
811,148\end{array}$ & $\begin{array}{r}\$ 682,632 \\
561,420 \\
768,349 \\
685,195 \\
708,435 \\
711,112 \\
751,896 \\
508,157 \\
318,392 \\
308,083 \\
430,733 \\
429,626\end{array}$ & $\begin{array}{r}\$ 469,452 \\
298,824 \\
413,791 \\
226,575 \\
225,717 \\
211.112 \\
171,254 \\
143,920 \\
138,516 \\
248,063 \\
181,017 \\
182,77^{\circ}\end{array}$ & $\begin{array}{r}\$ 180,322 \\
193,772 \\
-179,854 \\
179,439 \\
198,163 \\
258,907 \\
245,256 \\
198.998 \\
269,566 \\
151,257 \\
257,909 \\
205,726\end{array}$ \\
\hline Total... & $5,913,849$ & $7,283,040$ & $6,429,996$ & $6,302,624$ & $i, 172,740$ & $6,864,020$ & $2,905,016$ & $2,518,169$ \\
\hline
\end{tabular}

AMOUNT OF INCREASE (+) OR DECREASE (-).

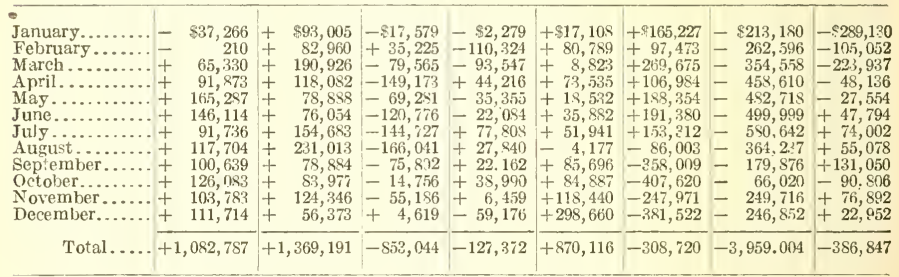

PER CENT OF INCPEASE (+) OR DECREASE (-).

\begin{tabular}{|c|c|c|c|c|c|c|c|c|}
\hline 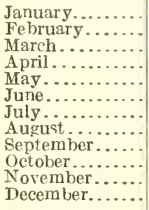 & $\begin{array}{l}-8.02 \\
-\quad .06 \\
+16.06 \\
+22.99 \\
+45.66 \\
+36.12 \\
+23.57 \\
+30.35 \\
+21.65 \\
+31.80 \\
+27.25 \\
+28.00\end{array}$ & $\begin{array}{l}+21.77 \\
+22.11 \\
+40.45 \\
+24.02 \\
+14.96 \\
+13.81 \\
+32.16 \\
+45.70 \\
+13.95 \\
+16.07 \\
+25.66 \\
+11.04\end{array}$ & $\begin{array}{l}-3.38 \\
+7.69 \\
-12.00 \\
-24.47 \\
-11.43 \\
-19.27 \\
-22.77 \\
-22.54 \\
-11.86 \\
-2.43 \\
-9.06 \\
+\quad .81\end{array}$ & $\begin{array}{l}-0.45 \\
+22.36 \\
-16.0^{\circ} \\
+9.60 \\
-6.58 \\
-4.36 \\
+15.85 \\
+4.88 \\
+3.90 \\
+6.59 \\
+1.17 \\
-10.35\end{array}$ & $\begin{array}{l}+3.42 \\
+21.09 \\
+1.80 \\
+14.58 \\
+3.69 \\
+7.42 \\
+9.59 \\
+\quad .70 \\
+14.51 \\
+12.46 \\
+21.14 \\
+58.28\end{array}$ & $\begin{array}{l}+31.93 \\
+21.01 \\
+54.08 \\
+18.50 \\
+36.22 \\
+36.82 \\
+25.61 \\
-14.47 \\
-52.93 \\
-56.95 \\
-36.54 \\
-47.03\end{array}$ & $\begin{array}{l}-31.23 \\
-46.77 \\
-46.14 \\
--66.93 \\
-69.14 \\
-70.31 \\
-77.22 \\
-71.68 \\
-56.50 \\
-21.43 \\
-57.97 \\
-57.46\end{array}$ & $\begin{array}{l}-61.59 \\
-35.16 \\
-56.53 \\
-21.25 \\
-12.21 \\
+22.64 \\
+43.21 \\
+38.27 \\
+94.61 \\
+37.51 \\
+42.48 \\
+12.56\end{array}$ \\
\hline Average... & +22.41 & +23.15 & -11.71 & -1.98 & +13.81 & -4.30 & -57.68 & -13.32 \\
\hline
\end{tabular}


The foregoing table shows that, comparing each month in 1909 and later years with the corresponding month in the preceding year, there were in creases during 1909 after the first two months and during every month in 1910. During 1911 there were decreases except in February and December. During 1912 there were increases in six months and decreases in six months. In 1913 there were increases except in Lugust. The increase's continued from September, 1913, to July, 1914. inclusive. In erery month beginning with August, 1914, the month the war began in Europe, there was a decrease until June. 1916.

\section{VALTF, OF IMPORTS BY CLASS OF PRODLCTS.}

Table 112 shows the value of the general imports of different kinds of glass and glassware during each month for four calendar years, 1912 to 1916.

Table 112. Talle of General Imports of Glass and Glassivare, by Classes A.ND Months, 1912 TO 1916.

\begin{tabular}{|c|c|c|c|c|c|c|c|c|}
\hline Year: and months. & $\begin{array}{l}\text { Cylinder, } \\
\text { crown, } \\
\text { and } \\
\text { common } \\
\text { window } \\
\text { glass, } \\
\text { un- } \\
\text { polished. }\end{array}$ & $\begin{array}{c}\text { Plate } \\
\text { glass, } \\
\text { cast, } \\
\text { polished, } \\
\text { un- } \\
\text { silvered. }\end{array}$ & $\begin{array}{l}\text { Bottles, } \\
\text { etc., used } \\
\text { as con- } \\
\text { tainers. }\end{array}$ & $\begin{array}{c}\text { Bottles, } \\
\text { decanters, } \\
\text { and } \\
\text { other } \\
\text { glassware, } \\
\text { cut or } \\
\text { orna- } \\
\text { mented. }\end{array}$ & $\begin{array}{l}\text { Lenses } \\
\text { and } \\
\text { optical } \\
\text { instru- } \\
\text { ments } \\
\text { (includ- } \\
\text { ing spec- } \\
\text { tacles). }\end{array}$ & $\begin{array}{l}\text { Plates, } \\
\text { or disks, } \\
\text { rough cut } \\
\text { or un- } \\
\text { wrought, } \\
\text { for } \\
\text { optical } \\
\text { purposes. }\end{array}$ & $\begin{array}{c}\text { All } \\
\text { other. }\end{array}$ & Total. \\
\hline 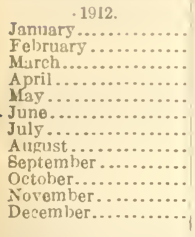 & $\begin{array}{r}\$ 75,420 \\
58,009 \\
98,629 \\
87,625 \\
77,820 \\
80,667 \\
87,618 \\
72,698 \\
78,717 \\
105,054 \\
71,525 \\
73,752\end{array}$ & $\begin{array}{l}\$ 25,067 \\
15,462 \\
20,000 \\
15,696 \\
22,193 \\
21,813 \\
14,355 \\
24,536 \\
22,679 \\
20,966 \\
39,326 \\
27,445\end{array}$ & $\begin{array}{r}862,606 \\
51,905 \\
66,328 \\
81,173 \\
86,381 \\
83,047 \\
67,587 \\
72,741 \\
63,333 \\
75,185 \\
84,899 \\
85,119\end{array}$ & $\begin{array}{r}863,971 \\
56,217 \\
69,905 \\
60,578 \\
71,768 \\
69,265 \\
88,729 \\
103,779 \\
94,060 \\
106,008 \\
91,395 \\
69,117\end{array}$ & $\begin{array}{l}\$ 47,0 \$ 4 \\
32,129 \\
53,854 \\
44,161 \\
59,151 \\
51,281 \\
66,257 \\
62,556 \\
73,093 \\
64,622 \\
49,915 \\
45, \$ 23\end{array}$ & $\begin{array}{r}\$ 36,091 \\
24,186 \\
3 \uparrow, 845 \\
33,522 \\
39,828 \\
33,227 \\
31,487 \\
35,602 \\
35,197 \\
42,802 \\
48,651 \\
42,557\end{array}$ & $\begin{array}{l}\$ 190,058 \\
145,250 \\
143,260 \\
181,857 \\
144,408 \\
144,550 \\
187,580 \\
226,425 \\
223,626 \\
216,179 \\
180,643 \\
168,775\end{array}$ & $\begin{array}{l}8500,297 \\
3 \$ 3,158 \\
489,851 \\
504,642 \\
501,549 \\
4 \$ 3,850 \\
546,643 \\
598,337 \\
590,705 \\
637,816 \\
560,264 \\
512,488\end{array}$ \\
\hline 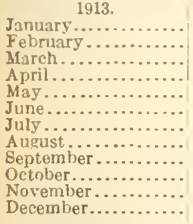 & $\begin{array}{r}64,175 \\
84,798 \\
86,041 \\
110,571 \\
68,631 \\
73,628 \\
92,731 \\
88,249 \\
81,2 \$ 2 \\
96,527 \\
105,883 \\
117,966\end{array}$ & $\begin{array}{l}31,810 \\
19,603 \\
27,735 \\
33,865 \\
33,203 \\
35,052 \\
18,454 \\
27,130 \\
43,765 \\
68,481 \\
80,675 \\
91,28.5\end{array}$ & $\begin{array}{r}60,233 \\
43,063 \\
49,939 \\
89,652 \\
73,726 \\
78,920 \\
86,593 \\
65,624 \\
70,364 \\
87,673 \\
107,803 \\
135,217\end{array}$ & $\begin{array}{r}\$ 1,922 \\
63,466 \\
76,298 \\
82,916 \\
88,440 \\
84,005 \\
112,789 \\
107,735 \\
126,909 \\
139,721 \\
99,915 \\
113,909\end{array}$ & $\begin{array}{l}39,420 \\
51,483 \\
62,992 \\
57,833 \\
62,079 \\
60,062 \\
73,571 \\
90,085 \\
79,302 \\
97,609 \\
42,541 \\
54,834\end{array}$ & $\begin{array}{l}50,254 \\
38,664 \\
52,240 \\
37,977 \\
51,601 \\
31,562 \\
45,132 \\
39,657 \\
47,805 \\
44,850\end{array}$ & $\begin{array}{l}190,591 \\
162,870 \\
143,429 \\
166,387 \\
142,398 \\
153,500 \\
169,314 \\
175,680 \\
226,971 \\
180,842 \\
197,690 \\
239,457\end{array}$ & $\begin{array}{l}517,405 \\
463,947 \\
498,674 \\
578,201 \\
520,081 \\
519,732 \\
598,584 \\
594,160 \\
676,401 \\
715,703 \\
678,704 \\
\$ 11,148\end{array}$ \\
\hline 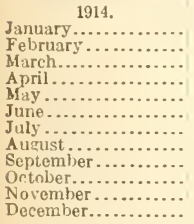 & $\begin{array}{r}112,290 \\
96,164 \\
144,375 \\
115,620 \\
167,054 \\
138,077 \\
187,063 \\
147,560 \\
76,350 \\
52,846 \\
38,709 \\
40,794\end{array}$ & $\begin{array}{r}84,584 \\
57,568 \\
92,996 \\
60,940 \\
49,704 \\
52,397 \\
25,149 \\
27,263 \\
22,127 \\
7,856 \\
4,393 \\
1,472\end{array}$ & $\begin{array}{r}85,654 \\
59,176 \\
82,639 \\
115,547 \\
120,244 \\
\mathbf{1 3 1}, 926 \\
86,314 \\
90,742 \\
68,022 \\
55,913 \\
79,439 \\
88,725\end{array}$ & $\begin{array}{l}76,944 \\
71,450 \\
82,352 \\
76,808 \\
66,240 \\
77,103 \\
83,533 \\
55,029 \\
32,597 \\
33,675 \\
66,873 \\
49,169\end{array}$ & $\begin{array}{l}35,455 \\
35,964 \\
61,640 \\
47,582 \\
50,801 \\
52,176 \\
61,904 \\
34,994 \\
22,432 \\
51,302 \\
21,184 \\
16,653\end{array}$ & $\begin{array}{l}61,536- \\
40,731 \\
65,817 \\
68,161 \\
50,767 \\
50,564 \\
59,217 \\
24,650 \\
26,032 \\
24,380 \\
56,562 \\
47,327\end{array}$ & $\begin{array}{r}226,169 \\
200,364 \\
238,530 \\
200,527 \\
203,625 \\
208,959 \\
242,786 \\
127,919 \\
70,832 \\
85,111 \\
163,573 \\
185,486\end{array}$ & $\begin{array}{l}682,632 \\
561,420 \\
765,319 \\
685,185 \\
708,435 \\
711,112 \\
751,896 \\
508,157 \\
318,392 \\
318,0 \times 3 \\
430,733 \\
429,626\end{array}$ \\
\hline
\end{tabular}


Table 112.-Value of Generai Imports of Glass and Glassware, by Classe 8 AND Months, 1912 то 1916-Concluded.

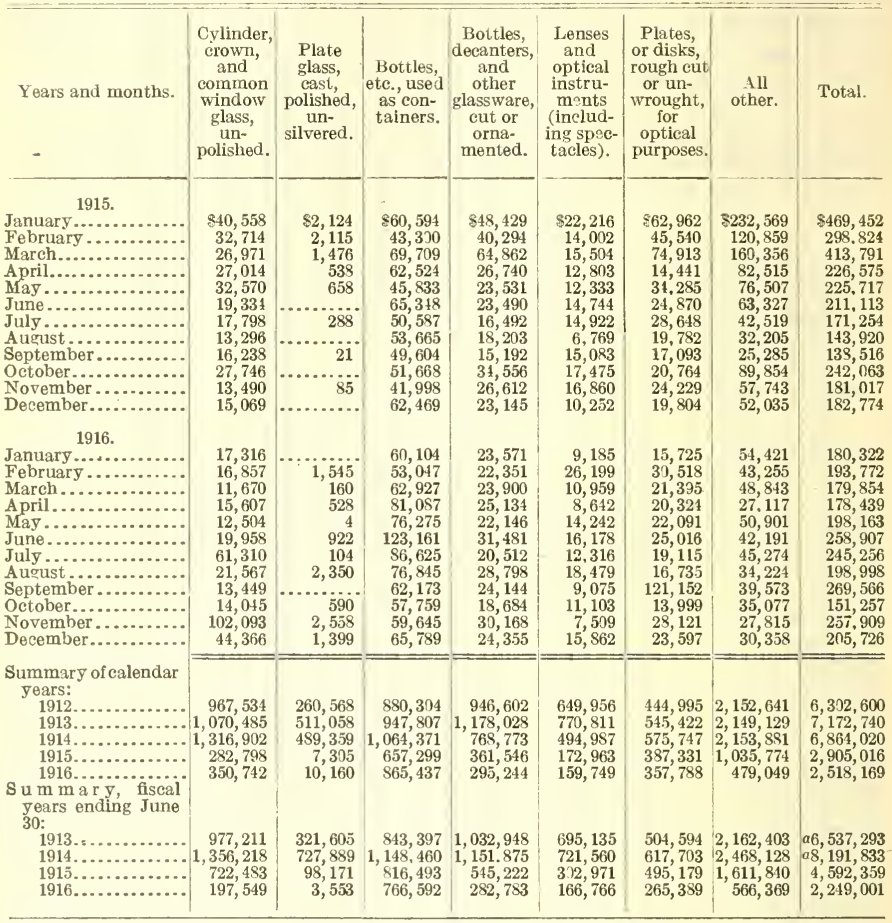

a These fizures are the totals of preliminary monthly returns and for this reason differ slightly from the revised annual totals in Table 113.

\section{IMPORTS FROM PRINCIPAL COUNTRIES.}

Table 113 shows the general imports of the different classes of glass and glassware from the principal countries exporting them during the fiscal years ending June 30, 1911 to 1916 , inclusive. 
Table 113.-Value of General Imports of Guass ani (ilassware into the United States During Fiscal Years Exding June 39, 1911 to 1916, by Classes A.ND Countries.

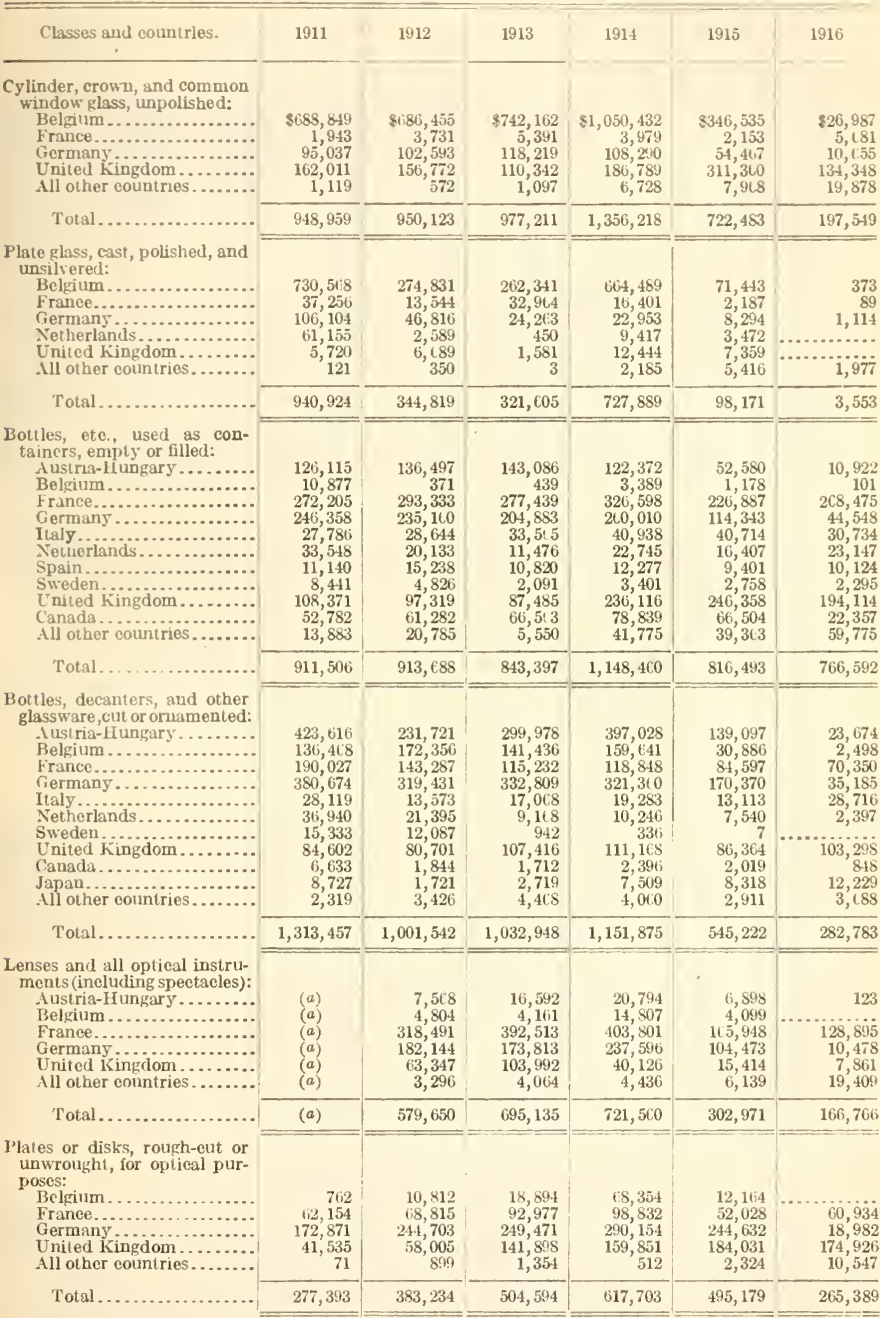

a Ineluded in "All other glass and glassware" in 1911. 
Table 113,- Value of General Imports of Glass and Glassware into the United States During Fiscal Yearg Ending June 30, 1911 to 1916, by Classes And Countries-Concluded.

\begin{tabular}{|c|c|c|c|c|c|c|}
\hline Classes and countries. & 1911 & 1912 & 1913 & 1914 & 1915 & 1916 \\
\hline 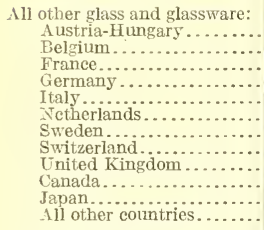 & $\begin{array}{r}\$ 445,320 \\
150,733 \\
530,928 \\
1,133,482 \\
4,443 \\
6,283 \\
7,776 \\
6,705 \\
208,758 \\
5,960 \\
6,540 \\
3,693\end{array}$ & $\begin{array}{r}\$ 654,375 \\
35,150 \\
260,032 \\
903,762 \\
7,086 \\
9,924 \\
12,154 \\
5,905 \\
153, \mathrm{C} 03 \\
5,612 \\
5,284 \\
2, \mathrm{C} 83\end{array}$ & $\begin{array}{r}8690,437 \\
31,679 \\
213,565 \\
1,051,950 \\
6,759 \\
11,139 \\
23,856 \\
4,000 \\
234,136 \\
2,659 \\
5,589 \\
1,889\end{array}$ & $\begin{array}{r}\$ 531,461 \\
130,241 \\
258,267 \\
1,258,529 \\
8,244 \\
20,661 \\
26,007 \\
5,074 \\
227,075 \\
4,640 \\
6, \in 37 \\
4,262\end{array}$ & $\begin{array}{r}\$ 345,525 \\
11,057 \\
130,642 \\
839,213 \\
10,974 \\
21,003 \\
22,982 \\
5,253 \\
195,331 \\
7,142 \\
10,548 \\
12,170\end{array}$ & $\begin{array}{r}\$ 51,191 \\
1,058 \\
96,188 \\
182,412 \\
17,771 \\
5,040 \\
30,360 \\
1,175 \\
146,360 \\
6,157 \\
22,019 \\
6,638\end{array}$ \\
\hline Tota & $2,510,621$ & $2,055,570$ & $2,178,258$ & $2,481,098$ & $1,611,840$ & 566,369 \\
\hline 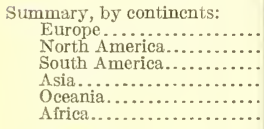 & $\begin{array}{r}6,812,133 \\
69,223 \\
156 \\
21,028 \\
139 \\
181\end{array}$ & $\begin{array}{r}6,140,002 \\
73,399 \\
170 \\
14,456 \\
599 \\
\end{array}$ & $\begin{array}{r}6,465,542 \\
75,440 \\
70 \\
11,950 \\
122 \\
24\end{array}$ & $\begin{array}{r}8,074,171 \\
100,335 \\
76 \\
29,908 \\
92 \\
221\end{array}$ & $\begin{array}{r}4,463,144 \\
93,780 \\
112 \\
34,707 \\
541 \\
75\end{array}$ & $\begin{array}{r}2,142,833 \\
44,014 \\
33 \\
61,514 \\
395 \\
212\end{array}$ \\
\hline Total. . & $6,902,860$ & $6,228,626$ & $6,553,148$ & $8,204,803$ & $4,592,359$ & $2,249,001$ \\
\hline
\end{tabular}

Table 114 shows the quantities of general imports of cylinder, crown, and common window glass, and of plate glass, cast, polished, and unsilvered, during the fiscal years ending June 30, 1911 to 1916.

Table 114.-Quantity of General Imports of Cylinder, Crown, and Common Window Glass, Unpolished, and of Plate Glass, Cast, Polished, and Unsilvered, During Fiscal Years Ending June 30, 1911 to 1916, by Countries.

\begin{tabular}{|c|c|c|c|c|c|c|}
\hline Classes and countries. & 1911 & 1912 & 1913 & 1914 & 1915 & 1916 \\
\hline 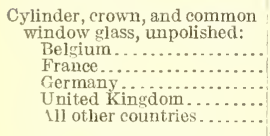 & \begin{tabular}{|r|} 
Pounds. \\
$26,574,343$ \\
18,404 \\
791,563 \\
$3,831,690$ \\
33,928 \\
\end{tabular} & $\begin{array}{r}\text { Pounds. } \\
20,547,158 \\
38,688 \\
777,586 \\
3,437,722 \\
7,532 \\
\end{array}$ & $\begin{array}{r}\text { Pounds. } \\
19,786,225 \\
75,059 \\
882,864 \\
1,968,938 \\
21,797 \\
\end{array}$ & $\begin{array}{r}\text { Pounds. } \\
27,574,477 \\
35,372 \\
977,726 \\
3,586,408 \\
140,776 \\
\end{array}$ & $\begin{array}{r}\text { Pounds. } \\
12,074,320 \\
13,794 \\
341,534 \\
4,378,232 \\
90,586 \\
\end{array}$ & $\begin{array}{r}\text { Pounds. } \\
404,005 \\
18,154 \\
56,768 \\
1,100,915 \\
196,281 \\
\end{array}$ \\
\hline Total.. & $31,249,928$ & $24,808,686$ & $22,734,883$ & $32,314,759$ & $16,898,466$ & $1,776,123$ \\
\hline 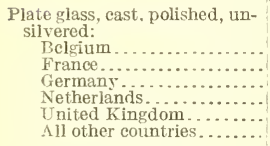 & \begin{tabular}{|r|} 
Square feet. \\
$3,270,356$ \\
144,879 \\
420,523 \\
287,088 \\
32,285 \\
223
\end{tabular} & $\begin{array}{r}\text { Square feet. } \\
1,160,790 \\
28,275 \\
184,140 \\
12,750 \\
36,089 \\
238\end{array}$ & $\begin{array}{r}\text { Square feet. } \\
1,121,907 \\
76,271 \\
75,644 \\
2,000 \\
3,174 \\
6\end{array}$ & $\begin{array}{r}\text { Square feet. } \\
2,943,974 \\
31,010 \\
86,846 \\
44,210 \\
81,566 \\
8,341\end{array}$ & $\begin{array}{r}\text { Square feet. } \\
309,542 \\
4,722 \\
22,823 \\
15,003 \\
27,317 \\
18,202\end{array}$ & 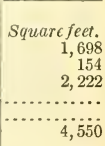 \\
\hline Total. & $4,155,354$ & $1,422,282$ & $1,279,002$ & $3,195,947$ & 397,609 & 8,624 \\
\hline
\end{tabular}

\section{INCREASES IN IMPORTS.}

Table 115, derived from Table 113, shows, for each different class of glass and glassware, the amount and percentage of increase of general imports during the fiscal year ending June 30, 1914, over the fiscal year 1913. The fiscal year 1913 was the last full year under the Payne-Aldrich Tariff Act, and the Underwood-Simmons Act went into effect October 4, 1914, about 10 months before the war in Europe began. 
Table 115.-Amount and Per Cent of Increase in Value of Gexeral imports of lilass and Glasoware in 1914 over IMports in 1913, Fiscal Years ENdiNg JUNE 31).

C'lasses.

Imount of Per cent iucrease. increase.

Cylinder, crow u, und common window glass, unpolislied.

Plate sliss, cast, polished, and unsilvered....

Bottles, vials, demijolins, carbors, and Jars (molded), empty or filled.

Bottles, decanters, and other glissware, eut or ornamented.

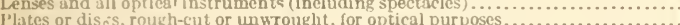

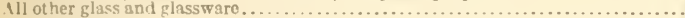

\begin{tabular}{rr}
$\$ 379,007$ & 38.78 \\
$4(4 \mathrm{i}, 2 \mathrm{q}$ & 126.33 \\
305,063 & 36.17 \\
115,927 & 11.51 \\
26,425 & 3.80 \\
113,109 & 22.42 \\
302,840 & 13.90 \\
\hline $1,651,655$ & 25.20
\end{tabular}

As shown in the foregoing table, the imports of plate glass, cast, polished, and unsilvered more than doubled during the fiscal year 1914; the increase in window glass and in bottles, etc., was over one-third, and the total imports of glass and glassware of all kinds increased about one-fourth.

Table 116, derived from Table 113, shows the percentage of the general imports of different kinds of glass and glassware from the principal countries exporting the same to the United States during the fiscal years ending June 30, 1913 and 1914.

Table 116.-Percentages of General Inports of Glass and Glassware Into the [Nited States from Principal Exporting Countries During Fiscal YeARS ENing June 30, 1913 AND 1914.

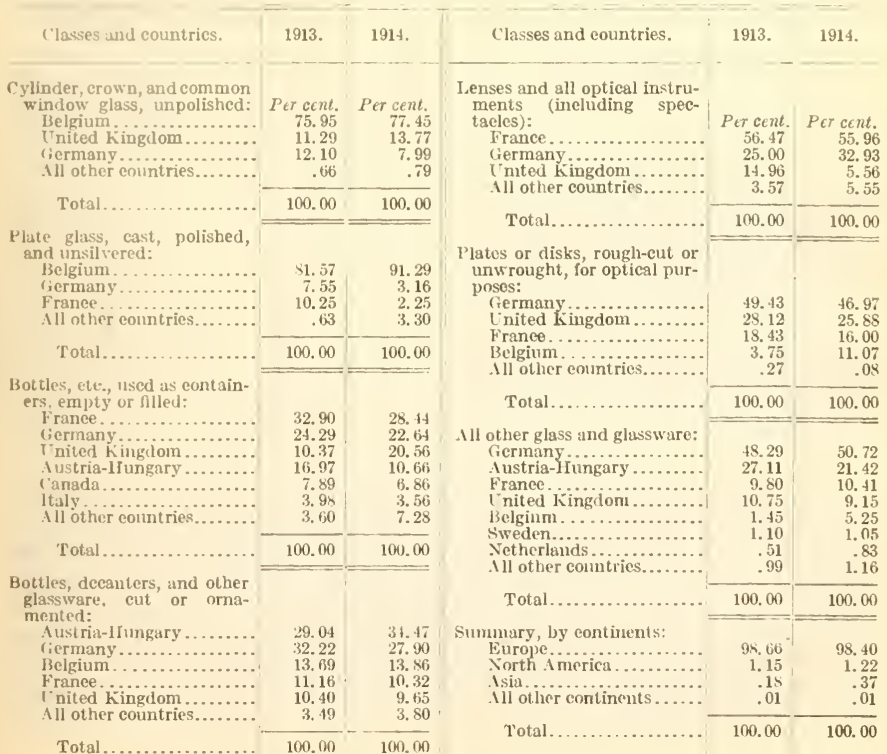




\section{WINDOW GLASS IMPORTED.}

As shown by Table 113, the imports of window glass before the war began were mostly from Belgium. As shown by a previous table, Table 8 , page 28 , the production of window glass in 1914, as reported by the Bureau of the Census, amounted to $\$ 17,495,956$. Computed on this amount, the general imports of cylinder, crown, and common glass in the fiscal year $1913(\$ 977,211)$ were 5.59 per cent, and in the fiscal year $1914(\$ 1,356,218)$ were 7.75 per cent.

As shown by Table 123, page 356, the imports of window glass of the first three brackets were over 80 per cent of the total window glass imported during every fiscal year from 1906 to 1914, inclusive, except 1911. The first three brackets include sizes up to and not exceeding 384 square inches, or 16 by 24 inches.

Under previous tariff acts for 20 years or more, the rates of duty on the smaller sizes of window glass have been lower than on the larger sizes. Table 117 shows the actual rates of duty on different sizes under the Payne-Aldrich Tariff Act and the Underwood-Simmons Act, and the rates computed on an ad valorem basis for the fiscal year 1913 and for the period from October 4, 1913, when the latter act went into effect, until June 30, 1914, the end of the fiscal year:

Table 117.-Rates of Duty on Imports of Cylinder, Crown, and Common Window Glass, Unpolished, Under Tariff Acts of 1909 and 1913, and CoNpUted Ad Valorem Rate Under Each ACt.

\begin{tabular}{|c|c|c|c|c|}
\hline \multirow[b]{2}{*}{ Classification. } & \multicolumn{2}{|c|}{$\begin{array}{l}\text { Rate of duty } \\
\text { per pound. }\end{array}$} & \multicolumn{2}{|c|}{$\begin{array}{l}\text { Computed ad va- } \\
\text { lorem rate. }\end{array}$} \\
\hline & $\begin{array}{l}\text { Act of } \\
1909 .\end{array}$ & $\begin{array}{l}\text { Act of } \\
1913 \text {. }\end{array}$ & $\begin{array}{c}\text { Fiscal } \\
\text { year } \\
\text { ending } \\
\text { June } 30 \text {, } \\
1913 .\end{array}$ & $\begin{array}{c}\text { Oct. 4, } \\
1913, \text { to } \\
\text { June 30, } \\
1914 .\end{array}$ \\
\hline 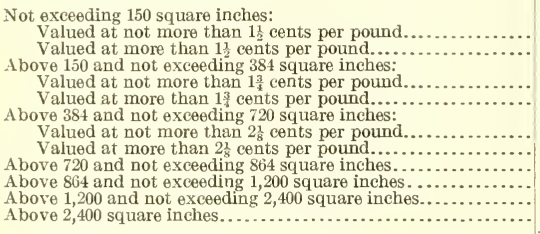 & $\begin{array}{r}\text { Cents. } \\
1 \frac{1}{4} \\
1 \frac{3}{8} \\
1 \frac{3}{4} \\
1_{\frac{7}{8}}^{\frac{7}{8}} \\
2 \frac{1}{21} \\
2_{8}^{3} \\
2^{\frac{3}{4}} \\
3_{4}^{\frac{1}{4}} \\
3_{4}^{\frac{3}{4}}\end{array}$ & $\begin{array}{c}\text { Cents. } \\
\frac{7}{8} \\
\frac{7}{8} \\
1 \\
1 \\
1 \\
1 \frac{1}{8} \\
1 \frac{1}{5} \\
1 \frac{1}{2} \\
1 \frac{1}{2} \\
1 \frac{1}{8} \\
2\end{array}$ & $\begin{array}{r}\text { Per cent. } \\
92.10 \\
34.00 \\
107.51 \\
54.23 \\
107.94 \\
58.66 \\
50.30 \\
52.08 \\
64.27 \\
119.36 \\
\end{array}$ & $\left\{\begin{array}{r}\text { Per cent. } \\
20.77 \\
\quad 31.51\end{array}\right.$ \\
\hline Total........ & & & 41.10 & 26.73 \\
\hline
\end{tabular}

No manufacturer that was interviewed during this investigation complained of the rates of duty on glass larger than the first three brackets, and some admitted that without material injury to the industry in the United States the duties on the larger brackets might be somewhat reduced. Without exception, however, all the manufacturers interviewed claimed that the rates of duty on the first three brackets (384 square inches and under) were too low, and most of them said that foreign competition forced them to sell these brackets below cost. 
The imports of window glass are mostly to places on or near the Atlantic seaboard, the Gulf coast, and the Pacific coast. Comparatively little goes to interior points. Before the war in Europe began window glass was imported to Pacific coast points and shipped as far east as Salt Lake City, because it was cheaper to ship from Europe around Cape Horn than to pay freight rates from Pittsburgh and other plate-glass manufacturing centers. The general imports of cylinder, crown, and common window glass by customs districts during the fiscal year 1914 were as follows:

Table 118.-Quantity and Value of General Imports of Cylinder, Crown, and Common Wrndow Glass During the Fiscal Year Ending Jene 30, 1914, By Customs Districts.

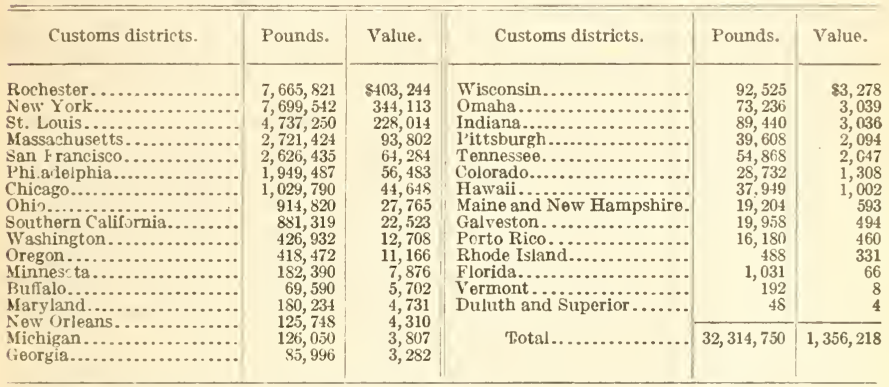

The imports to Rochester and to St. Louis were largely of thin glass used for photographic dry plates, those to Rochester being via New York City and those to St. Louis largely via New Orleans.

While over 80 per cent of the imports of window glass are of the three smaller brackets, only 50 to 60 per cent of the domestic consumption is of single-strength glass of the first three brackets. The following is quoted from a brief by $J$. R. Johnston, president of the Johnston Glass Co., and in 1916 president of the Johnston Brokerage Co., which sells a large part of the product of the hand window-glass factories. This brief was submitted to the Committee on Ways and Means of the House of Representatives in 1913:

In this country about two-thirds of the glass used is single strength, and from 50 to 60 per cent of this single strength is in the first three brackets, which means sizes 16 by 24 and smaller. These sizes especially need an increased tariff, for the reason that in Belgium the percentage of first three bracket sizes consumed is only about 20 per cent. which leaves that country with a surplus of small glass that they are only too anxious to distribute in the United States and other markets.

The following is quoted from the statement of H. R. Hilton, on behalf of the National Window Glass Manufacturers' Association, made to the same committee.

Of the $5,000,000$ boxes of single-strength glass made annually in the United States, consumers call for 50 per cent in the small sizes up to 16 by 24 . The poorest glass is usually cut into the first bracket ( 25 united inches), or all sizes up to 10 by 15 , and represent one-fifth of the total production. These sizes always come in excess of the demand both in Belgium and the United States, and the country is always overstocked with them. In consequence, it is only in rare instances that a manufacturer 
can sell this product at cost price, notwithstanding the fact that on these small sizes of third single the skilled workman receives not more than $\$ 2$ to $\$ 2.25$ per day.

The Pacific coast consumes about 10 per cent of the glass used in the United States, and yet United States factories can not compete with Belgium in Pacific coast market in these small sizes at the present tariff.

Owing to severe competition among domestic manufacturers, the prices in some years have been considerably lower in the United States' than the total of the Belgian price with the freight and duty. F. J. Goertner, sales manager of Semon Bache \& Co., importers, presented figures to the Committee on Ways and Means, in 1913, to show that at times the prices of domestic glass, especially of the larger sizes, were very much less than the cost of Belgian glass delivered at New York, and occasionally was less than the price in Belgium, and occasionally less even than the amount of the duty.

Mr. Goertner pointed out that the wages of skilled workers in the window-glass industry had been reduced while the Dingley and the Payne-Aldrich Tariff Acts were in force, and concluded that "the tariff had absolutely nothing to do with the prosperity of the American window-glass worker." 1 The very severe competition among manufacturers was caused largely by the introduction of machinery for making window glass and the efforts of hand manufacturers to meet lower prices fixed by machine manufacturers. The competition between the hand manufacturers and the machine manufacturers led to reductions of wages in the hand factories. Some hand factories were driven out of business, and without reduction of wages others probably would have been forced to quit.

As explained in the chapter on "Industrial conditions," page 187, prices were stabilized by the formation, in 1909, of the Imperial Glass Co., a selling agency of hand manufacturers, which, when dissolved in 1910, after a Government prosecution for violation of the antitrust act, was succeeded, in 1912, by the Johnston Brokerage Co. This latter company sells a large proportion of the product of the hand factories at prices fixed by the American Window Glass Co., which manufactures by machinery and is the largest producer in the United States.

PLATE GLASS IMPORTED.

As shown by Table 8, page 28, the production of polished plate glass in 1914, as reported by the Bureau of the Census, amounted to $\$ 14,773,787$. Computed on this amount, the general imports of plate glass, cast, polished, and unsilvered, in the fiscal year $1913(\$ 321,605)$ were 2.18 per cent, and in the fiscal year $1914(\$ 727,889)$ were 4.93 per cent.

Table 119 shows the actual rates of duty on different sizes of plate glass under the Payne-Aldrich Tarifi Act and the UnderwoodSimmons Act, and the rates computed on an ad valorem basis for the fiscal year 1913 and for the period from October 4, 1913, when the latter act went into effect, until June 30,1914 , the end of the fiscal year.

1 Hearings before the Committee on Ways and Means, 1913, Schedule B, p. 818. 
Table 119.-Rates of Duty on Imports of Plate Glass, Cast, Polished, Finished or Unfinished, and Uxsllvered, or the Same Containing a Wire Netting Within Itself, Undeir Tariff Acts of 1909 and 1913, ANd Cojputed ad Valorear Rate Under Each Act.

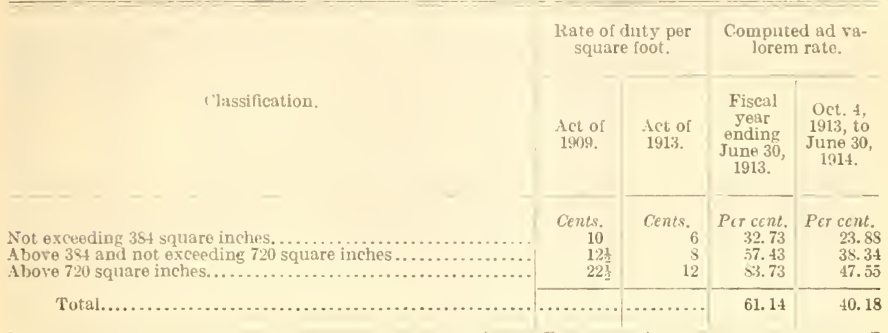

Manufacturers of plate glass claim that it costs them the same, whether in large or small sizes, ${ }^{1}$ yet they sell the smaller sizes for much less than the larger sizes. They claim that the smaller sizes are inadequately protected. Under all tariff acts the rate of duty has been less on the small sizes than on the larger sizes.

The imports of the different sizes of plate glass, cast, polished, finished or unfinished, and unsilrered, are shown in Table 124, page 357. The percentage of imports of each specified size during the fiscal years 1913 and 1914, respectively, was as follows: Not exceeding 384 square inches, 3.7 per cent in 1913, 6.54 per cent in 1914; above 384 and not exceeding 720 square inches, 71.05 per cent in $1913,63.64$ per cent in 1914; above 720 square inches, 25.25 per cent in $1913,29.82$ per cent in 1914 .

The plate glass imported consists mainly of the finer and more expensive grades. In the imports during the fiscal year 1914 the average value per square foot of plate glass, cast, polished, finished or unfinished, and unsilvered, imported for consumption averaged \$0.224. (See Table 124, p. 357.)

Most imported plate glass is used for mirrors, and the greater part of it is of first quality, the second quality being cut to sinall sizes for hand mirrors. For a time a good deal of second-quality plate glass was imported for automobile wind shields, but American manufacturers now make most of the glass used for this purpose in the United States.

As in the case of window glass, the imports of plate glass are mostly to places on or near the Atlantic, Pacific, or Gulf coast. ${ }^{2}$ The general imports of plate glass, cast, polished, finished or unfinished, and unsilvered, by customs districts during the fiscal year 1914 are given in the following table.

1 fearings before the Committee on Ways and Means, House of Representutives, 1913, Schedule B, p. 840. 2 See table of ocean and railroad rates from Belgian factories to principal cities in the lnited States, and railroad rates from plate-glass maniractiring centers in the United States to the same cities, presented to the Committee on VWays and Means, IIouse of Representatives, 1913, lyy Semon, Bache d ('o... New York. Hnarings. Scherlule B. p. 861 . 
Table 120.-Quantity and Value of General Imports of Plate Glass, Cast, Polished, and Unimiered, During the Fiscal Year Ending June 30, 1914, By Customs Districts.

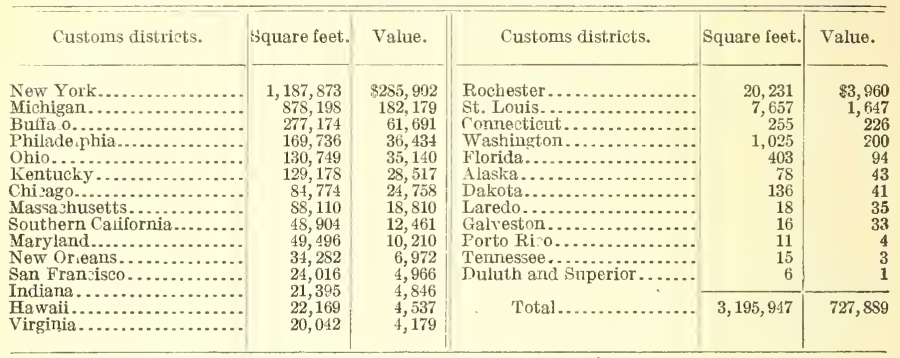

\section{OTHER BUILDING GLASS.}

The imports of plate glass other than that which is cast, polished, and unsilvered is comparatively small. The values of such imports during the fiscal years 1909, 1913, and 1914 appear in Table 128 page 369 .

A statement relative to the imports of rough plate glass, made by F. J. Goertner, sales manager of Semon Bache \& Co., importers, New York, to the Committee on Ways and Means, House of Representatives, in $1913,{ }^{1}$ said:

As a matter of fact, this glass is probably made cheaper in the United States than anywhere else in the world. The manufacturers have been for years exporting considerable quantities to Canada, where they are able to compete successfully not only with European manufacturers in general, but even with the English manufacturers, who enjoy a preferential tariff in Canada.

Most of the wire glass used in the United States is of domestic manufacture. Most of the opalescent and cathedral glass used in the United States is of domestic manufacture, but the finer kinds are imported. Many more colors are used in producing glass of these kinds in Europe than in this country, but the domestic product is sold much cheaper.

Practically all the antique glass used in the United States is imported from Germany and England. Little if any of this glass is made in this country because of the lack of chemical knowledge and of expert workmen.

\section{BOTTLES AND JARS.}

As shown by Table 8 , page 28 , the production of glass bottles and jars in 1914, reported by the Bureau of the Census, amounted to $\$ 51,958,728$. As shown by Table 113 , page 339 , the value of the general imports of bottles, etc., used as containers, during the fiscal year 1914 was $\$ 1,148,460$, or 2.21 per cent of the amount of production reported by the Bureau of the Census. These imports included all bottles ordinarily used as containers for purposes of transportation, except filled bottles that were imported from July 1, 1913, to October 3, 1914. The bottles filled with wines, brandies, mineral waters, and other liquids are sold and used again for containing beverages. 
Bottles containing whiskies, brandies, punches, beer, and mineral waters are imported mainly from the United Kingdom, France, Germany, Austria-Hungary, and Italy.

Some bottles intended to be used as containers for beverages, drugs, and colognes are imported empty and filled in America, so that consumers will think that the contents as well as the bottles hare been imported. Thus, rodka bottles come from Russia, punch bottles from Sweden, and pellet bottles from England.

\section{PRESSED AND BLOWN WARE.}

Table 121 shows the value of pressed and blown glassware imported for consumption during the fiscal years ending June 30, 1913 and 1914, and the percentage of increase during the latter year.

Table 121.-Value of Blown and Pressed Glassware Imported for Consumption, and Ad Valoreal Rates of Duty, Fiscal Years Ending June 30, 1913 AND 1914.

\begin{tabular}{|c|c|c|c|c|c|c|c|c|}
\hline \multirow{2}{*}{ (lassification. } & \multicolumn{2}{|c|}{ Fiscal year 1913.} & \multicolumn{2}{|c|}{$\begin{array}{c}\text { July } 1 \text { to Oet. } 4 \text {, } \\
1913 .\end{array}$} & \multicolumn{2}{|c|}{$\begin{array}{c}\text { Oet. } 4,1913 \text { to } \\
\text { june } 30,1914 \text {, }\end{array}$} & \multirow{2}{*}{$\begin{array}{l}\text { Total } \\
\text { value, } \\
\text { fiscal } \\
\text { year } \\
1914 .\end{array}$} & \multirow{2}{*}{$\begin{array}{c}\text { Increase } \\
\text { in fiscal } \\
\text { year } \\
\text { i } 914 .\end{array}$} \\
\hline & Rate. & Value. & Rate. & Value. & Rate. & Value. & & \\
\hline Blown & Pet ct. & 81 & Pcr ct. & 792 & $P \in r$ ct. & $\$ 925.537$ & \$1.216 & Per cent. \\
\hline $\begin{array}{l}\text { Blown or pressed ware, } \\
\text { dccorated............... }\end{array}$ & & & & & & & $=1,20,000$ & \\
\hline Miscellaneous, including & 00 & 1,02 & 60 & 223,153 & to & 775,909 & 999,692 & a 2.92 \\
\hline $\begin{array}{l}\text { pressed ware not deeo- } \\
\text { rated....................... }\end{array}$ & 45 & 414,764 & 45 & 73,543 & 30 & 353,850 & 427,393 & .30 \\
\hline $\begin{array}{l}\text { Electric lamps: } \\
\text { A re................ }\end{array}$ & 45 & 27,561 & 45 & 7,802 & 20 & 16,883 & 24,685 & a 10.44 \\
\hline $\begin{array}{l}\text { Ineandescent- } \\
\text { ( arbon filament. }\end{array}$ & 45 & $78,0 \div 0$ & 45 & 1.510 & & & 78,409 & \\
\hline Metal filament...... & 45 & 384,247 & 45 & 73,409 & 30 & 479,254 & 552,663 & 30.47 \\
\hline All other. & & & & 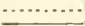 & 30 & 88,687 & 88,687 & \\
\hline Total. & & $3,006,621$ & & 670,839 & & $2,717,019$ & $3,387,858$ & 12.68 \\
\hline
\end{tabular}

a Decrease.

As shown by Table 8 , page 28 , the production of pressed and blown glassware in 1914, as reported by the Bureau of the Census, amounted to $\$ 30,279,290$. Computed on this amount the imports for consumption in the fiscal year $1913(\$ 3,006,621)$ were 9.93 per cent, and in the fiscal year $1914(\$ 3,387,858)$ were 11.19 per cent.

The increase in the imports during the fiscal year 1914 over those for the preceding fiscal year amounted to 12.68 per cent. It is remarkable that, though the duty on arc lamps was decreased from 45 to 20 per cent, the imports decreased 10.44 per cent. There was a decrease also in the imports of blown and pressed ware, decorated, and increases in the other items.

The imports of both blown and pressed ware, plain or decorated, includes not only tableware but lighting goods. The imports of blown ware, plain, includes laboratory ware. Both blown and pressed ware includes specialties and novelties.

Under the Payne-Aldrich Tariff Act the duty on plain pressed ware was 45 per cent and on blown ware 60 per cent; under the Underwood-Simmons Act the duty on the former is 30 per cent and on the latter 45 per cent. It is remarkable that with the lower 
duties on pressed ware much less of it was imported than of blown ware. Of pressed tableware very little is imported and considerable quantities were exported before the war in Europe began. No manufacturer that was interviewed during this investigation complained of the imports of pressed ware, but all who manufactured blown ware complained of foreign competition. Under these conditions it is very remarkable that the eight establishments that manufactured blown ware exclusively and that reported during this investigation had an average operating profit (charges for depreciation and interest considered) of 9.29 per cent, based on net sales, while the group of 20 establishments that manufactured both blown and pressed ware had as a whole an operating loss (charges for depreciation and interest considered) of 0.15 per cent on net sales. It is difficult to account for this difference. It may be explained, however, that while the fine grade of pressed ware made in America is superior to any foreign product, large quantities of domestic pressed ware of very cheap grades are put on the market. Large quantities of this cheap ware are sold to the 10-cent stores, and manufacturers sell to them at cost or even below cost in order to keep their factories operating during seasons when trade from other sources is dull. Department stores compete with the 10-cent stores in this line of goods and they, too, buy in large quantities at or bolow manufacturing cost. So far, therefore, as pressed ware is concerned it appears that the manufacturers in this country suffer from competition among themselves rather than from foreign competition.

Imported pressed ware consists largely of door knobs. Most of the cheap blown tableware and bar goods used in the United States is of domestic manufacture, but there are considerable importations of fine grades of blown ware and decorated blown ware. The foreign competition in this line was perhaps greater before the war than in any other kind of glass or glassware except cylinder glass used for window lights and dry plates. Most imported blown ware is stem ware. Practically no tumblers are imported except from AustriaHungary. Most of the imported tumblers are ornamented, usually by etching, cutting, or coloring; few by sand-blast or enamel. Many plain goblets come from France.

From Austria-Hungary comes cheaply decorated and blown ware, and some that is highly decorated and colored-oil and vinegar cruets, sugars and creams, salts and peppers, and similar articles. Cologne bottles and similar articles come mainly from AustriaHungary and Germany.

Glassware of different colors is not made extensively in the United States, because of the trouble manufacturers have in mixing batches in proportions that will properly assimilate. Very fow American manufacturers employ glass chemists.

It is remarkable that, although there is more hand labor on cut glass than on any other glass product, and although the wages of workers are much higher in the United States than in foreign countries, the imports of eut glass are comparatively small, and before the war considerable quantities were exported. American cut glass is recognized at home and abroad as distinctly superior to the foreign product. This subject is discussed in another section of this report (p. 218). Imports of cut glass consist largely of novelties, with some tableware, usually exclusive designs. 
Ilost gals lighting fixtures come from Austria-Hungary, oil lighting fixtures from Germany, and electric lighting apparatus, are lights, etc., from both countries.

The American mamufacturer has an alrantage in that he can fill orders and deliver goods much more quickly in the Uniterl States than can his foreign competitor. The tendency is toward smaller orders, and the Anerican merchant who imports must buy in large quantities to keep on hand at all times a complete line of goods. Another adrantage that the American manufacturer has is that he can quickly supply ware necessary to replace that which is broken in shipment or in store handling. 'The breakage in blown ware is, owing to its fragile nature, a considerable item. Importers have many broken sets which can not be sold at the full price until duplicates are brought from Europe, and this takes weeks or months.

The following is quoted from a statement made in 1916 to the Bureau by Mr. M. G. Bryce, president of the United States Glass Co., of Pittshurgh, the largest manufacturers of blown and pressed ware in this country:

Prior to the war it was absolutely impossible for a glass manufacturer to compete with a foreign manufacturer on blown ware for table use, and the only goods that could be sold by American manufacturers were those of original design and certain staples which it-paid a dealer to get quickly instead of waiting for importations.

There is very little, if any, pressed glass imported into this country, consequently the glass men are not very much interested in a tariff on that end of the business, and as far as I can learn no manufacturer is anxions for any tariff except one that would make the cost in America and Europe equal; that is to say, the European goods laid down, plus the tariff, should not be any cheaper than what are made in America.

In regard to our foreign business, prior to the war it was simply impossible to do any great volume of business in any foreign country. Anything that was made by the foreigner could be exported by him to the different sections at a very much less cost than an American manufacturer could export it. All of our foreign business consists of goods either of special design or a kind that is not made by foreigners.

The following is quoted from a statement made by Mr. Ernest Nickel, secretary-treasurer of the same company:

The total cost of the material here and abroad would average about the same, some costing more and some less, but the difference in labor costs is so great that protection to take care of the differential should be provided. Undoubtedly our employees, as a whole, live better and have more comforts than their foreign brethren and consequently require larger earnings, but this does not alter the fact that our costs are just so much higher, and, therefore, must be considered. * * *

In the pressed ware we have not, up to the present time, had the serious competition that we have in the blown lines, as the foreign manufacturer has not taken up that line so energetically. However, as to blown ware, the differential in the wages earned is so great that the American manufacturer is unable to overcome the difference, with the result that the foreign manufacturer is able to produce and lay down his goods in New York at a less price than the American manufacturer can produce them, and this is certainly a condition which should not exist. The manufacture of glass of our character is an art and the man must be a skilled workman.

It looks to us that the way to find out what protection should be thrown around any industry is the creation of an impartial tariff commission that will thoroughly investigate every phase of a business, and then if they find au industry which is entitled to protection, so that it may live and flourish in this country and be a benefit to its citizens at large, tariff to the necessary requirement should be provided and should at least equalize the difference in wages. This method would not eliminate foreign competition but would simply serve to place the American mannfacturer on an equal basis in the cost of wages with the European manufacturer. It would still be $1 p$ to the American mannfacturer to strive to make every effort to produce the best quality of ware and not permit himself to fall behind foreign manufacturers in new ideas or improved methods. * * * 
The American manufacturer will undoubtedly appreciate anything that is done which may help to place our blown-ware branch of the business on such basis that at least a reasonable return on the capital invested can be earned.

The following is quoted from a statement made later in 1916 by $\mathrm{Mr}$. Nickel:

Replying to your recent inquiry as to why there is so little competition from abroad in the pressed-ware branch of our business, which carries a duty of only 30 per cent, against the blown ware, which carries a duty of 45 pər cent, would say that this is probably due largely to the fact that in producing pressed ware there is a very heavy investment in molds necessary, whereas in blown ware this is not required; and, inasmuch as labor is so much lower abroad than it is in this country, blown ware could be produced in Europe so much more cheaply that manufacturers there have had no incentive to go as heavily into the production of the cheaper pressed lines.

From your going over our affairs you will probably recall that our investment in molds is one of our largest expense items. There is another reason, possibly, and that is that sometimes a manufacturer makes a heavy investment in molds and gets out a line which he may think is a splendid one, and yet later on it may not find favor with the trade. You can see in this event that a manufacturer could easily make quite an outlay of money and not receive anything like an adequate return. Of course, there is some pressed ware made in Europe, but it has never been developed as in this country. Labor conditions, undoubtedly, have a great bearing on this whole matter.

With reference to the blown ware, for instance, the European manufacturer has been enabled to lay his product down in a port like New York City for a less price than the American maufacturer could produce a similar article. All this shows the necessity for a reasonable protection to such an extent that the differential in wages between Europe and this country is taken care of.

We have enjoyed a splendid business in all lines and, while a great deal of this is due to prosperity which is existing in the country to-day, there is no question that the artificial protection by which we are surrounded, owing to the European war, has enabled the blown-ware manufacturer for the first time in many years to get a fair price for his product.

It would certainly be a fine thing if the Government would go into this matter thoroughly and appoint a competent, nonp rrtisan tariff commission, which would inquire and investigate thoroughly the various industries, and then recommend a protective duty, simply to the extent that the American manufacturer would be placed on an equal basis with the Europ an manufacturer-i. e., however, only to the extent of the differential in wages. Personally I do not think that any industry shonld be protected to any such extent where it eliminates fair competition, whether it be at home or from abroad.

Mr. George M. Stiegler, secretary of Oscar O. Freidlander, a New York importer, in a statement made to an agent of the Bureau in 1916, said:

The lighting goods imported are fine in quality. Lamp shades are produced cheaper abroad. The domestic factories can not meet the competition on 10-inch round-top domes or on green shades white on the inside. Electric shades of foreign make are better but dearer, and the American public buys the cheaper article. Inverted bowls of foreign make are finer, but they are made in America for a much cheaper price. Glass prisms for chandeliers or candelabra are not produced at all in the United States.

Mr. Rudolph Kirschberger, secretary of Kirschberger \& Cole, New York, importer's, in a statement made to an agent of the Bureau in 1916, said:

Imported lamp chimneys, even with the reduction in duty from 60 to 45 per cent, can not compete with the product of the Macbeth-Evans Glass Co. of Pittsburgh, in western territory, on account of freight rates, but imported chimneys are sold in the East, and much is sold to the Standard Oil Co. We import cases of 24 dozen chimneys, to save ocean freights, which would be greater were the package smaller. People out West want batches of 6 to 12 dozen that can be handled easily, so do not buy imported chimneys. 
Mr. William R. Noe, of William Noe Sons, New York, importers, in a statement made to an agent of the Bureau in 1916, said:

Before the Europ an war, American manufacturers complained about the importation of Rochester chimneys, 10-inch cones, and air-hole chimneys for gas. On air-hole chimney No. 198 the Macbeth-Evans Co. began cutting by reducing the price from 69 to 55 ceuts a dozen. Then the importers dropped to 50 cents a dozen. Then about Mav or June, 1914, the Macbeth-Evans Co. took an order at 45 cents.

There are fluctuatious of price in various lines. In December, 1915, all tactories sold lantern globes at 15 cents a dozen, in July, 1916, sold them at 30 cents and up per dozen. The Macbeth-Evans (ilass Co., of Pittsburgh, and Gill \& Co., of Philadelphia, fix the prices. These lantern globes have never been imported.

Silvered-glass reflectors sold in December, 1915, at 80 and 10 off. Now, in July, 1916, the discount is only 60 and 10 . None of these reflectors are imported, so the price is absolutely fixed here. American manufacturers of cheap crystal lamp shades have put the importers out of business in this line.

Another New Tork importer, Mr. H. D. McFadden, said in 1916:

The imports of illuminating glassware are in high-price goods. The common and merlium grades are made as cheaply in the United States as in Europe. The trouble with many American manufacturers is that they want to do business on a big scale and make all kinds of glassware, fine as well as cheap. This causes heary competition but afferts the quality.

\section{STATISTICS OF IMPORTS FOR CONSUMPTION.}

Tables which follow show the imports for consumption of glass and glassware during the fiscal years ending June 30, 1896 to 1916 , inclusive. These tables show the quantity, total value, value per unit of quantity, duty paid, rate of duty, and actual and computed ad valorem duty on the principal classes of glass imports, as follows: Table 122, cylinder, crown, and common window glass, unpolished; Table 124, plate glass, cast, polished, finished or unfinished, and unsilvered; Table 125, bottles and vials, not ornamented, and demijohns and carboys, all empty; Table 126, bottles, decanters, and all articles of glass of erery description, ornamented or decorated in any manner. Following the first of these tables is Table 123, which shows the proportion that imports of glass of the first three brackets was of the total imports of cylinder, crown, and common window glass, unpolished.

These tables are followed by other tables which show the imports of all other glass and glassware for consumption, during the fiscal years ending June 30, 1909 (Dingley tariff), 1913 (Payne-Aldrich tariff), and 1914 (Underwood-Simmons tariff after October 3, 1913). The value of imports and the average computed ad valorem rate of duty in each year are shown for the following classes of glass and glassware: Table 127 , cylinder, crown, and common window glass other than that not specified in Table 122; Table 128, plate glass other than that specified in Table 124; Table 129, bottles, vials, demijohns, carboys, and jars, filled; Table 130, miscellaneous manufactures of glass not shown in the foregoing tables. 
Table 122.-Imports of Cylinder, Crown, and Common Window Glass, Unpolished, Entered for Consumption, Fiscal Years Ending June 30, 1896 to 1915.

Fiscal year and classification.

\section{6-WILSON ACT,}

Not exceeding 10 by 15 inches.

A bove 10 by 15 and not exceeding 16 by 24 inches A bove 16 by 24 and not exceeding 24 by 30 inches A bove 24 bv 30 and not exceeding 24 by 36 inches All above 24 by 36 inches..................

Total.

\section{7-WILSON ACT.}

Not exceeding 10 by 15 inches...

A bove 10 by 15 and not exceeding 16 by 24 inches $A$ bove 16 by 24 and not exceeding 24 by 30 inches A bove 24 by 30 and not exceeding 24 by 36 inches All above 24 by 36 inches...................

Total.

1898-WILson Act to JULY 24, 1897; DINGLeY. ACT AFTERWARD.

Not exceeding 10 by 15 inches.

Above 10 by 15 and not exceeding 16 by 24 inches A bove 16 by 24 and not exceeding 24 by 30 inches ' Above 24 by 30 and not exceeding 24 by 36 inches Above 24 by 36 inches.

A bove 24 by 36 and not exceedinx 30 by 40 inches A bove 30 by 40 and not exceeding 40 by 60 inches Above 40 by 60 inches.

Total.

\section{9-DINGLEY ACT.}

Not exceeding 10 br 15 inches.

A bove 10 by 15 and not exceeding 16 by 24 inches A bove 16 by 21 and not exceeding 24 bv 30 inches A bove 24 by 30 and not exceeding 24 bo 36 inches A bove 24 by 36 and not exceeding 30 by 40 inches A bove 30 by 40 and not exceeding 40 by 60 inches Above 40 by 60 inches.

$$
\text { Total. }
$$

\section{0-DINGLEY ACT.}

Not exceeding 10 by 15 inches.

Above 10 by 15 and not exceeding 16 by 24 inches A bove 16 by 24 and not exceeding 24 by 30 inches A bove 24 by 30 and not exceeding 24 by 36 inches Above 24 by 36 and not exceeding 30 by 40 inches A bove 30 by 40 and not exceeding 40 by 60 inches Above 40 by 60 inches.......................

Total.

\section{1-DiNGLEY ACT.}

Not exceeding 10 by 15 inches...

A bove 10 by 15 and not exceeding 16 by 24 inches A bove 16 by 24 and not evceeding 24 by 30 inches A bove 24 by 30 and not exceeding 24 by 36 inches A bove 24 by 36 and not exceeding 30 by 40 inches A bove 30 by 40 and not exceeding 40 by 60 inches A bove 40 by 60 inches.

Total...

\begin{tabular}{|c|c|c|c|c|c|}
\hline $\begin{array}{c}\text { Duty } \\
\text { per } \\
\text { pound. }\end{array}$ & Pounds. & Value. & Duties. & $\begin{array}{l}\text { Aver- } \\
\text { age } \\
\text { value } \\
\text { per } \\
\text { pound. }\end{array}$ & $\begin{array}{l}\text { Com- } \\
\text { puted } \\
\text { ad val- } \\
\text { orem } \\
\text { rate. }\end{array}$ \\
\hline $\begin{array}{c}\text { Cents. } \\
1 \\
1 \frac{1}{4} \\
1 \frac{3}{4} \\
2 \\
2 \frac{1}{8} \\
\end{array}$ & $\begin{array}{r}12,154,689 \\
15,373,922 \\
12,318,075 \\
3,879,802 \\
9,463,366\end{array}$ & $\begin{array}{r}5332,453 \\
233,441 \\
212,926 \\
72,864 \\
210,205 \\
\end{array}$ & $\begin{array}{r}8131,547 \\
192,174 \\
215,566 \\
77,596 \\
201,097 \\
\end{array}$ & $\begin{array}{r}\$ 0.025 \\
.015 \\
.017 \\
.019 \\
.022 \\
\end{array}$ & $\begin{array}{r}\text { Pet ct. } \\
39.57 \\
82.32 \\
100.77 \\
\mathbf{1 0 6 . 4 9} \\
95.68\end{array}$ \\
\hline & $54,189,834$ & $1,062,889$ & 817,980 & .020 & 76.96 \\
\hline $\begin{array}{l}1 \\
1 \\
1 \frac{1}{3} \\
1_{4}^{3} \\
2 \\
2 \frac{1}{8}\end{array}$ & $\begin{array}{r}14,337,598 \\
15,291,388 \\
12.895,823 \\
4,140,380 \\
9,774,275\end{array}$ & $\begin{array}{r}380,426 \\
237,670 \\
231.752 \\
81,818 \\
227,465\end{array}$ & $\begin{array}{r}143,376 \\
191,142 \\
225,677 \\
82,808 \\
207,703\end{array}$ & $\begin{array}{l}.027 \\
.016 \\
.018 \\
.020 \\
.023 \\
\end{array}$ & $\begin{array}{r}37.69 \\
80.42 \\
97.38 \\
101.17 \\
91.31\end{array}$ \\
\hline & $56,439,464$ & $1,159,161$ & 850,706 & .021 & 73.39 \\
\hline $\begin{array}{l}1 \\
18 \\
1 \frac{1}{8} \\
1 \frac{1}{1} \\
1 \frac{3}{3} \\
23 \\
2 \\
2 \frac{7}{8} \\
24 \\
3 \frac{3}{3} \\
3 \frac{7}{8} \\
4 \frac{3}{8} \\
\end{array}$ & $\begin{array}{r}1,035,996 \\
11,248,185 \\
1,239,593 \\
9,634,752 \\
949,724 \\
7,670,415 \\
301,788 \\
2,300,256 \\
689,859 \\
2,685,627 \\
1,284,246 \\
90,653\end{array}$ & $\begin{array}{r}25,092 \\
364.292 \\
19,020 \\
173,165 \\
1,9,666 \\
154,824 \\
6,588 \\
51,709 \\
17,850 \\
58,548 \\
34,315 \\
2,940\end{array}$ & $\begin{array}{r}10,360 \\
154,663 \\
15.495 \\
180,652 \\
16,620 \\
182,172 \\
6,036 \\
66,132 \\
14,638 \\
90,640 \\
49.765 \\
3,966\end{array}$ & $\begin{array}{l}.024 \\
.032 \\
.015 \\
.017 \\
.019 \\
.020 \\
.021 \\
.022 \\
.025 \\
.021 \\
.026 \\
.032 \\
\end{array}$ & $\begin{array}{r}41.28 \\
42.45 \\
81.45 \\
104.32 \\
89.03 \\
117.66 \\
91.60 \\
127.89 \\
82.01 \\
151.81 \\
145.01 \\
134.90\end{array}$ \\
\hline & $39,130,094$ & 927,009 & 791,139 & .023 & 85.34 \\
\hline $\begin{array}{l}13 \\
18 \\
17 \\
2 \frac{3}{8} \\
28 \\
3 \frac{3}{5} \\
3 \frac{7}{8} \\
4 \frac{3}{8}\end{array}$ & $\begin{array}{r}15,203,738 \\
13,565,227 \\
9,569,483 \\
2,583,378 \\
2,642,829 \\
1,835,799 \\
120,223\end{array}$ & $\begin{array}{r}505,736 \\
273,505 \\
217,600 \\
66,228 \\
69,687 \\
57,419 \\
6,186\end{array}$ & $\begin{array}{r}209,052 \\
254,348 \\
227,275 \\
74,272 \\
89,196 \\
71,137 \\
5,260\end{array}$ & $\begin{array}{l}.033 \\
.020 \\
.023 \\
.026 \\
.026 \\
.031 \\
.051\end{array}$ & $\begin{array}{r}41.34 \\
93.00 \\
104.45 \\
111.98 \\
127.99 \\
123.89 \\
85.03\end{array}$ \\
\hline & $45,520,677$ & 1,19 & 540 & .027 & 77.77 \\
\hline $\begin{array}{l}1 \frac{3}{8} \\
1 \frac{7}{8} \\
2 \frac{3}{8} \\
2 \frac{7}{8} \\
38 \\
3 \frac{3}{8} \\
4 \frac{8}{8} \\
\end{array}$ & $\begin{array}{r}19,173,525 \\
15,611,691 \\
8,963,818 \\
2,446, ; 85 \\
2,722,855 \\
2,019,901 \\
135,797\end{array}$ & $\begin{array}{r}678,532 \\
376,916 \\
246,561 \\
75,445 \\
82,774 \\
65,558 \\
4,852\end{array}$ & $\begin{array}{r}263,636 \\
292,719 \\
212,891 \\
70,334 \\
91,896 \\
78,271 \\
5,941\end{array}$ & $\begin{array}{l}.035 \\
.024 \\
.028 \\
.031 \\
.030 \\
.032 \\
.036\end{array}$ & $\begin{array}{r}38.85 \\
77.66 \\
86.36 \\
93.23 \\
111.12 \\
119.39 \\
122.46\end{array}$ \\
\hline & $51,073,972$ & $1,530,638$ & $1,015,688$ & .030 & 66.36 \\
\hline $\begin{array}{l}1 \frac{3}{8} \\
17 \\
23 \\
28 \\
28 \\
38 \\
37 \\
48 \\
48\end{array}$ & $\begin{array}{r}13,256,312 \\
9,525,835 \\
3,682,572 \\
756,811 \\
646,427 \\
356,810 \\
11,852\end{array}$ & $\begin{array}{r}462,869 \\
264,430 \\
124,668 \\
28,837 \\
24,218 \\
17,190 \\
484\end{array}$ & $\begin{array}{r}182,274 \\
178,610 \\
87,461 \\
21,758 \\
21,817 \\
13,826 \\
519\end{array}$ & $\begin{array}{l}.035 \\
.028 \\
.033 \\
.038 \\
.037 \\
.048 \\
.041\end{array}$ & $\begin{array}{r}39.38 \\
67.55 \\
70.15 \\
75.45 \\
90.09 \\
80.43 \\
107.25\end{array}$ \\
\hline & $28,236,619$ & 922,696 & 506,265 & .032 & 54.87 \\
\hline
\end{tabular}


Table 122.-Imports of Cruinder, Crown, and Comion Window Glass, Unpolished, Entered for Consumption, Fiscal Years Ening June 30, 1896 to 1915-Continued.

Fiscal year and classification.
1902 -DrNGLEY ACT.
Not exceeding 10 by 15 inches.................
A bore 10 by 15 and not e xcee ting 16 by 24 inches
Above 26 by 24 and not exceeding 24 by 30 and not exceeding 24 by 36 inches
Above 24 by 36 and not excee ding 30 by 40 inclies
A bove 30 by 40 and not exceeding 40 by 60 inches
A bove 40 by 60 inches.........................

Total.

\section{3-DINGLEY ACT.}

Not exceeding 10 by 15 inches.

Abore 10 by 15 and not exceeding 16 by 24 inches A bove 16 by 24 and not exceeding 24 by 30 inches A bore 24 by 30 and not exceeding 24 by 36 inches A bove 24 by 36 and not exceeding 30 by 40 inches A bove 30 by 40 and not exceeding 40 by 60 inches A bove 40 by 60 inches.......................

Total.

\section{4-DINGLEY ACT.}

Not exceeding 10 by 15 inches.

A bove 10 by 15 and not exceeding 16 by 24 . A bove 16 by 24 and not exceeding 24 by 30 inches A bove 24 by 30 and not exreeding 24 by 36 inches A bove 24 by 36 and not exceeding 30 by 40 inches A bove 30 by 40 and not exceeding 40 by 60 inches Above 40 by 60 inches.

Total.

\section{5-DINGLEY ACT.}

Not exceeding 10 by 15 inches.

A bove 10 by 15 and not exceeding 16 by 24 inches A bove 16 by 24 and not exceeding 24 by 30 inches A bove 24 by 30 and not exceeding 24 by 36 inches A bove 24 by 36 and not exceeding 30 by 40 inches A bove 30 by 40 and not exceeding 40 by 60 inches A bove 40 by 60 inches.

Total.

\section{6-DINGLEY ACT.}

Not exceeding 10 by 15 inches..

Above 10 by 15 and not exceeding 16 by 24 inches A bove 16 by 24 and not exceeding 24 by 30 inches A bove 24 by 30 and not exceeding 24 by 36 inches A bove 24 by 36 and not exceeding 30 by 40 inclies A bove 30 by 40 and not exceeding 40 by 60 inches A bove 40 by 60 inches.

Total.

\section{7-DiNgLEX ACT.}

Not excecding 10 by 15 inches

Above 10 by 15 and not exceding 16 by 24 inches A bove 16 by 24 and not exceeding 24 by 30 inches Above 24 by 30 and not excceding 24 by 36 inches A bove 24 by 36 and notcxceeding 30 by 40 inches A bove 30 by 40 and not exceeding 40 by 60 inches Above 40 by 60 inches.

Total.

\begin{tabular}{|c|c|c|c|c|c|}
\hline $\begin{array}{c}\text { Duty } \\
\text { per } \\
\text { puund. }\end{array}$ & Pounds. & Value. & Dutics. & $\begin{array}{l}\text { Aver- } \\
\text { age } \\
\text { value } \\
\text { per } \\
\text { pJund. }\end{array}$ & $\begin{array}{l}\text { Crm- } \\
\text { putcd } \\
\text { ad val- } \\
\text { crcm } \\
\text { rate. }\end{array}$ \\
\hline $\begin{array}{r}\text { Cents. } \\
13 \\
1 \frac{7}{8} \\
2 \frac{3}{8} \\
2 \frac{7}{8} \\
3 \frac{1}{38} \\
3 \frac{7}{8} \\
4 \frac{7}{8} \\
\end{array}$ & $\begin{array}{r}23,812,439 \\
16,877,560 \\
6,652,079 \\
1,479,443 \\
1,501,647 \\
661,043 \\
27,246 \\
\end{array}$ & $\begin{array}{r}924,439 \\
487,584 \\
236,535 \\
57,903 \\
59,102 \\
30,393 \\
1,633 \\
\end{array}$ & $\begin{array}{r}\$ 327,425 \\
316,454 \\
157,987 \\
42,534 \\
50,681 \\
25,615 \\
1,192 \\
\end{array}$ & $\begin{array}{r}\$ 0.039 \\
.029 \\
.036 \\
.039 \\
.039 \\
.046 \\
.060 \\
\end{array}$ & $\begin{array}{r}\text { Pet ct. } \\
35.42 \\
64.91 \\
66.80 \\
73.46 \\
85.75 \\
84.28 \\
73.00\end{array}$ \\
\hline .. & $51,011,746$ & $1,797,589$ & 921,848 & .035 & 51.28 \\
\hline $\begin{array}{l}13 \\
17 \\
28 \\
2 \frac{3}{8} \\
3 \frac{7}{3} \\
3 \frac{7}{8} \\
4 \frac{3}{8} \\
\end{array}$ & $\begin{array}{r}23,596,970 \\
22,880,738 \\
8,405,584 \\
2,773,012 \\
2,420,762 \\
1,153,259 \\
55,725\end{array}$ & $\begin{array}{r}719,937 \\
552,361 \\
235,612 \\
79,891 \\
72,427 \\
38,746 \\
3,908\end{array}$ & $\begin{array}{r}324,458 \\
429,014 \\
199,633 \\
79,724 \\
81,701 \\
44,689 \\
2,438 \\
\end{array}$ & $\begin{array}{l}.031 \\
.024 \\
.028 \\
.029 \\
.030 \\
.034 \\
.070 \\
\end{array}$ & $\begin{array}{r}45.08 \\
77.67 \\
84.73 \\
99.79 \\
112.80 \\
115.34 \\
62.36\end{array}$ \\
\hline ... & $61,296,050$ & $1,702,883$ & $1,161,657$ & .028 & 68.22 \\
\hline $\begin{array}{l}1 \frac{3}{8} \\
17 \\
2 \frac{8}{8} \\
27 \\
3 \frac{7}{8} \\
37 \\
4 \frac{37}{8} \\
\end{array}$ & $\begin{array}{r}20,352,746 \\
18,947,772 \\
7,131,937 \\
2,047,593 \\
1,921,493 \\
1,335,829 \\
95,818\end{array}$ & $\begin{array}{r}615,740 \\
411,126 \\
189,024 \\
55,086 \\
51,850 \\
40,086 \\
3,306 \\
\end{array}$ & $\begin{array}{r}280,263 \\
355,271 \\
169,384 \\
58,868 \\
64,850 \\
51,763 \\
4,192\end{array}$ & $\begin{array}{l}.030 \\
.022 \\
.027 \\
.027 \\
.027 \\
.030 \\
.035\end{array}$ & $\begin{array}{r}45.52 \\
85.41 \\
89.61 \\
106.87 \\
125.07 \\
129.13 \\
126.80\end{array}$ \\
\hline$\cdots$ & $51,863,182$ & $1,366,218$ & 984,591 & .026 & 72.07 \\
\hline $\begin{array}{l}1 \frac{3}{8} \\
17 \\
2 \frac{3}{8} \\
2 \frac{8}{8} \\
38 \\
37 \\
48 \\
48 \\
\end{array}$ & $\begin{array}{r}8,359,985 \\
5,914,057 \\
2,162,412 \\
658,425 \\
663,201 \\
174,264 \\
685\end{array}$ & $\begin{array}{r}307,230 \\
163,117 \\
74,056 \\
21,715 \\
19,313 \\
8,228 \\
132\end{array}$ & $\begin{array}{r}114,950 \\
110,858 \\
51,357 \\
18,930 \\
22,383 \\
6,753 \\
30\end{array}$ & $\begin{array}{l}.037 \\
.028 \\
.034 \\
.033 \\
.029 \\
.047 \\
.193\end{array}$ & $\begin{array}{r}37.41 \\
67.98 \\
69.35 \\
87.17 \\
115.90 \\
82.07 \\
22.70\end{array}$ \\
\hline & $17,933,029$ & 593,791 & 325,291 & .033 & $54.78 \theta$ \\
\hline $\begin{array}{l}13 \\
1 \frac{3}{8} \\
28 \\
27 \\
3 \frac{7}{8} \\
37 \\
48 \\
48 \\
\end{array}$ & $\begin{array}{r}20,194,866 \\
8,107,164 \\
3,802,652 \\
914,312 \\
814,545 \\
239,563 \\
298\end{array}$ & $\begin{array}{r}789,642 \\
253,010 \\
136,319 \\
35,555 \\
32,430 \\
12,510 \\
13\end{array}$ & $\begin{array}{r}277,680 \\
152,009 \\
90,313 \\
26,287 \\
37,491 \\
9.283 \\
13\end{array}$ & $\begin{array}{l}.039 \\
.031 \\
.036 \\
.039 \\
.040 \\
.052 \\
.044\end{array}$ & $\begin{array}{r}35.17 \\
60.08 \\
66.25 \\
73.93 \\
84.77 \\
74.20 \\
100.00\end{array}$ \\
\hline$\ldots$ & $34,073,430$ & $1,259,479$ & 593,076 & .037 & 46.30 \\
\hline $\begin{array}{l}13 \\
1 \frac{7}{8} \\
28 \\
27 \\
3 \frac{8}{3} \\
37 \\
4 \frac{7}{8} \\
\end{array}$ & $\begin{array}{r}16,142,735 \\
9,728,174 \\
3,476,572 \\
938,078 \\
682,178 \\
216,735 \\
1,288\end{array}$ & $\begin{array}{r}540,282 \\
251,804 \\
111,100 \\
34,273 \\
26,347 \\
11,695 \\
93\end{array}$ & $\begin{array}{r}221,963 \\
182,403 \\
82,569 \\
26,970 \\
23,024 \\
8,398 \\
56\end{array}$ & $\begin{array}{l}.033 \\
.023 \\
.032 \\
.037 \\
.039 \\
.054 \\
.072 \\
\end{array}$ & $\begin{array}{l}41.08 \\
71.59 \\
74.32 \\
78.69 \\
87.39 \\
71.79 \\
60.60 \\
\end{array}$ \\
\hline .. & $31,185,760$ & 978,597 & 545,383 & .031 & 55.73 \\
\hline
\end{tabular}


Table 122.-Imports of Cylinder, Crown, and Common Window Glass, Unpolished, Entered for Consumption, Fiscal Years Ending June 30, 1896 to 1915-Continued.

Fiscal year and classification.
1908 -DINGLEx Act.
Not exceeding 10 by 15 inches...............
Above 10 by 15 and not exceeding 16 by 24 inches
Above 16 by 24 and not exceeding 24 by 30 inches
A bove 24 by 30 and not exceeding 24 by 36 inches 36 and not exceeding 30 by 40 inches
A bove 30 by 40 and not exceeding 40 by 60 inches
Above 40 by 60 inches.........................

Total.

\section{9-DINGLEX ACT.}

Not exceeding 10 by 15 inches..................

A bove 10 by 15 and not exceeding 16 by 14 inches A bove 16 by 24 and not exceeding 24 by 30 inches A bove 24 by 30 and not exceeding 24 by 36 inches A bove 24 by 36 and not exceeding 30 by 40 inches A bove 30 by 40 and not exceeding 40 by 60 inches

Above 40 by 60 inches. ......................

Total................................... ALDRICH ACT AFTERWARD.

Not exceeding 10 by 15 inches...

Not exceeding 150 square inches:

Valued at not more than $1 \frac{1}{2}$ cents per pound

Valued at more than 12 cents per pound...

A bove 10 by 15 and not exceeding 16 by 24 inches Above 150 and not exceeding 384 square inches:

Valued at not more than $1 \frac{3}{4}$ cents per pound.

Valued at more than $1 \frac{3}{4}$ cents per pound... A bove 16 by 24 and not exceeding 24 by 30 inches A bove 384 and not exceeding 720 square inches:

Valued at not more than $2 x$ cents per pound.

Valued at more than $2 \frac{1}{8}$ cents per pound.... Above 24 by 30 and not exceeding 24 by 36 inches Above 720 and not exceeding 864 square inches. Above 24 by 36 and not exceeding 30 by 40 inches A bove 864 and not exceeding 1,200 square inches A bove 30 by 40 and not exceeding 40 by 60 inches Above 1,200 and not exceeding 2,400 square inches...................................

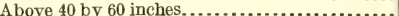

A bove 2,400 square inches.......................

Total.

\begin{tabular}{|c|c|c|c|c|c|}
\hline $\begin{array}{c}\text { Duty } \\
\text { per } \\
\text { pound. }\end{array}$ & Pounds. & Value. & Duties. & $\begin{array}{l}\text { Aver- } \\
\text { age } \\
\text { value } \\
\text { per } \\
\text { pound. }\end{array}$ & $\begin{array}{l}\text { Com- } \\
\text { puted } \\
\text { ad val- } \\
\text { orem } \\
\text { rate. }\end{array}$ \\
\hline $\begin{array}{r}\text { Cents. } \\
1 \frac{3}{8} \\
1 \frac{1}{8} \\
28 \\
27 \\
3 \frac{3}{8} \\
37 \\
3 \frac{7}{8} \\
4 \frac{3}{8}\end{array}$ & $\begin{array}{r}14,390,395 \\
6,609,243 \\
2,391,752 \\
412,663 \\
332,503 \\
135,423 \\
240\end{array}$ & $\begin{array}{r}\$ 252,689 \\
178,168 \\
77,384 \\
14,622 \\
13,238 \\
7,154 \\
18\end{array}$ & $\begin{array}{r}\$ 197,868 \\
123,923 \\
56,804 \\
11,864 \\
11,222 \\
5,248 \\
11\end{array}$ & $\begin{array}{r}\$ 0.032 \\
.027 \\
.032 \\
.031 \\
.040 \\
.053 \\
.075\end{array}$ & $\begin{array}{r}\text { Per ct. } \\
43.70 \\
69.54 \\
73.40 \\
81.13 \\
84.77 \\
73.36 \\
58.33\end{array}$ \\
\hline & $24,272,219$ & 543,273 & 406,940 & .022 & 74.91 \\
\hline $\begin{array}{l}1 \frac{3}{8} \\
17 \\
2 \frac{7}{8} \\
27 \\
3 \frac{7}{8} \\
3 \frac{7}{8} \\
4 \frac{3}{8}\end{array}$ & $\begin{array}{r}14,400,477 \\
5,163,189 \\
2,230,723 \\
436,985 \\
404,105 \\
115,597 \\
3,574\end{array}$ & $\begin{array}{r}447,510 \\
141,411 \\
66,141 \\
14,300 \\
17,179 \\
6,036 \\
226\end{array}$ & $\begin{array}{r}198,007 \\
96,810 \\
52,980 \\
12,563 \\
13,639 \\
4,479 \\
156\end{array}$ & $\begin{array}{l}.031 \\
.027 \\
.030 \\
.033 \\
.043 \\
.052 \\
.063\end{array}$ & $\begin{array}{l}44.25 \\
68.46 \\
80.10 \\
89.25 \\
79.39 \\
74.21 \\
69.19\end{array}$ \\
\hline & $22,754,650$ & 692,803 & 378,634 & .031 & 54.65 \\
\hline$a 1 \frac{3}{8}$ & 87,030 & 1,447 & 1,197 & .017 & 82.70 \\
\hline $\begin{array}{ll}b & 1 \frac{1}{4} \\
b & 1 \frac{3}{8} \\
a & 1 \frac{1}{8}\end{array}$ & $\begin{array}{r}1,826,869 \\
13,372,893 \\
304,727\end{array}$ & $\begin{array}{r}24,814 \\
390,630 \\
6,248\end{array}$ & $\begin{array}{r}22,836 \\
183,877 \\
5,714\end{array}$ & $\begin{array}{l}.014 \\
.029 \\
.021\end{array}$ & $\begin{array}{l}92.03 \\
47.07 \\
91.45\end{array}$ \\
\hline $\begin{array}{ll}b & 13 \\
b & 17 \\
a & 2 \frac{3}{8}\end{array}$ & $\begin{array}{r}1,021,550 \\
5,786,722 \\
62,156\end{array}$ & $\begin{array}{r}16,764 \\
156,795 \\
1,627\end{array}$ & $\begin{array}{r}17,877 \\
108,501 \\
1,476\end{array}$ & $\begin{array}{l}.016 \\
.027 \\
.026\end{array}$ & $\begin{array}{r}106.64 \\
69.20 \\
90.73\end{array}$ \\
\hline $\begin{array}{ll}b & 2 \frac{1}{4} \\
b & 28 \\
a & 27 \\
b & 2 \frac{3}{4} \\
a & 3 \frac{3}{8} \\
b & 3 \frac{1}{4} \\
a & 3 \frac{7}{8}\end{array}$ & $\begin{array}{r}182,289 \\
2,114,764 \\
39,086 \\
336,564 \\
15,114 \\
341,824 \\
14,889\end{array}$ & $\begin{array}{r}3,441 \\
70,131 \\
996 \\
13,011 \\
703 \\
15,434 \\
785\end{array}$ & $\begin{array}{r}4,101 \\
50,226 \\
1,124 \\
9,255 \\
510 \\
11,109 \\
577\end{array}$ & $\begin{array}{l}.019 \\
.033 \\
.025 \\
.039 \\
.047 \\
.045 \\
.053\end{array}$ & $\begin{array}{r}119.19 \\
71.61 \\
112.82 \\
71.13 \\
72.56 \\
71.98 \\
73.50\end{array}$ \\
\hline $\begin{array}{ll}b & 33 \\
a & 4 \frac{3}{3} \\
b & 4 \frac{1}{4}\end{array}$ & $\begin{array}{r}179,600 \\
150 \\
4,200\end{array}$ & $\begin{array}{r}8,586 \\
20 \\
309\end{array}$ & $\begin{array}{r}6,735 \\
7 \\
178\end{array}$ & $\begin{array}{l}.48 \\
.133 \\
.074\end{array}$ & $\begin{array}{l}78.48 \\
32.80 \\
57.77\end{array}$ \\
\hline & $25,690,427$ & 711,741 & 425,300 & .028 & 59.75 \\
\hline $\begin{array}{l}1 \frac{1}{4} \\
1 \frac{3}{8}\end{array}$ & $\begin{array}{r}1,941,648 \\
13,420,505\end{array}$ & $\begin{array}{r}26,523 \\
395,840\end{array}$ & $\begin{array}{r}24,271 \\
184,532\end{array}$ & $\begin{array}{l}.014 \\
.029\end{array}$ & $\begin{array}{l}91.51 \\
46.62\end{array}$ \\
\hline $\begin{array}{l}13 \\
17 \\
18\end{array}$ & $\begin{array}{l}1,716,655 \\
6,848,821\end{array}$ & $\begin{array}{r}27,350 \\
185,999\end{array}$ & $\begin{array}{r}30,041 \\
128,415\end{array}$ & $\begin{array}{l}.016 \\
.027\end{array}$ & $\begin{array}{r}109.84 \\
69.04\end{array}$ \\
\hline $\begin{array}{r}2 \frac{1}{4} \\
23 \\
2 \frac{3}{4} \\
3\end{array}$ & $\begin{array}{r}903,103 \\
3,226,000 \\
759,530 \\
598,738\end{array}$ & $\begin{array}{r}17,426 \\
111,198 \\
24,900 \\
23,229\end{array}$ & $\begin{array}{l}20,320 \\
76,618 \\
20,887 \\
19,459\end{array}$ & $\begin{array}{l}.019 \\
.034 \\
.033 \\
.039\end{array}$ & $\begin{array}{r}116.60 \\
68.90 \\
83.89 \\
83.77\end{array}$ \\
\hline $\begin{array}{l}33 \\
4 \\
4\end{array}$ & $\begin{array}{r}280,690 \\
2,622\end{array}$ & $\begin{array}{r}22,795 \\
121\end{array}$ & $\begin{array}{r}10,526 \\
111\end{array}$ & $\begin{array}{l}.046 \\
.046\end{array}$ & $\begin{array}{l}82.26 \\
92.10\end{array}$ \\
\hline & 99,698 & 825,381 & 515,180 & .028 & 62.42 \\
\hline
\end{tabular}

a July 1, to Aug. 5, 1909, under act of 1897.

b Aug. 6, 1909, to June 30, 1910, under act of 1909. 
Table 122.-Imports of Cyujnder, Crown, and Common Window Glass, Unpolishen, Entered for Consumption, Fiscal Years Ending June 30, 1896 to 1915-Continued.

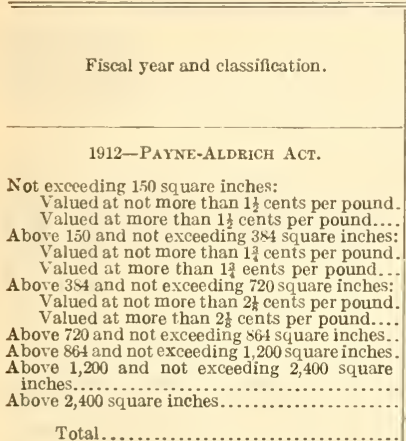

\section{3-PAYNE-ALDRICH ACT.}

Not exceeding 150 square inehes:

Valued at not more than $1 \frac{1}{2}$ cents per pound Valued at more than $1 \frac{1}{2}$ cents per pound... A bove 150 and not exceeding 384 square inches: Valued at not more than $1 \frac{1}{2}$ cents per pound Valued at more than $1 \frac{1}{2}$ cents per pound...

A bove 384 and not exceeding 720 square inches: Valued at not more than $2 \frac{1}{3}$ cents per pound. Valued at more than $2 \frac{1}{8}$ cents per pound... A bove 720 and not exceeding 864 square inches. A bove 864 and not exceeding 1,200 square inches Above 1,200 and not exceeding 2,400 square

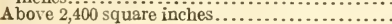

Total...

1914-PAYNE-AldRicil ACT To OCT. 4, 1913; UNDERWOOD-SIMMIONS ACT AFTERWARDS.

Not exceeding 150 square inches:

Valued at not more than $1 \frac{1}{2}$ cents per pound. Valued at more than $1 \frac{1}{2}$ cents per pound... Not exceeding 150 square inches.

A bove 150 and not exceeding 384 square inches: Valued at more than $1 \frac{3}{4}$ cents per pound.... Above 150 and not exceeding 384 square inches... Above 384 and not exceeding $i 20$ square inches:

Valued at more than $2 \frac{1}{8}$ cents per pound....

A bove 384 and not exceeding 720 square inches.

A bove 720 and not exceeding 864 square inches.

A bove 864 and not exceeding 1,200 square inches.

Above 720 and not exceeding 1,200 square inches. Above 1,200 and not exceeding 2,400 square inches.

A bove 2,400 square inehes.

Total.

1915-UNDERWOOD-SMMONS ACT.

Not exceeding 150 square inches.

Above 150 and not cxceding 384 square inches. A bove 384 and not exceeding 720 square inches. A bove 720 and not exceeding 1 , 200 square inches Above 1,200 and not excceding 2,400 square

inches.................................

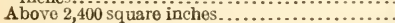

Total

$a$ July 1 to Oct. 3, 1913, under act of 1909.

\begin{tabular}{|c|c|c|c|c|c|}
\hline $\begin{array}{c}\text { Duty } \\
\text { per } \\
\text { pound. }\end{array}$ & Pounds. & Value. & Duties. & $\begin{array}{l}\text { Aver- } \\
\text { age } \\
\text { value } \\
\text { per } \\
\text { pound. }\end{array}$ & $\begin{array}{l}\text { Com- } \\
\text { puted } \\
\text { ad val- } \\
\text { orcm } \\
\text { rate. }\end{array}$ \\
\hline Cents. & & & & & Per ct. \\
\hline $\begin{array}{l}1 \frac{1}{4} \\
11 \frac{1}{8}\end{array}$ & $\begin{array}{r}497,794 \\
15,032,002\end{array}$ & $\begin{array}{r}\$ 6,746 \\
542,179\end{array}$ & $\begin{array}{r}\$ 8,223 \\
206,690\end{array}$ & $\begin{array}{r}\$ 0.014 \\
.036\end{array}$ & $\begin{array}{l}92.24 \\
38.12\end{array}$ \\
\hline $\begin{array}{l}1 \frac{3}{7} \\
1 \frac{7}{8}\end{array}$ & $\begin{array}{r}156, \\
4,664,751 \\
\end{array}$ & $\begin{array}{r}2,851 \\
147,904\end{array}$ & $\begin{array}{r}2,743 \\
87,464\end{array}$ & $\begin{array}{l}.018 \\
.032\end{array}$ & $\begin{array}{l}96.23 \\
59.14\end{array}$ \\
\hline $\begin{array}{l}21 \\
23 \\
2 \\
3 \frac{1}{4} \\
3\end{array}$ & $\begin{array}{r}29,062 \\
2,068,863 \\
375,865 \\
368,924\end{array}$ & $\begin{array}{r}555 \\
75,739 \\
17,959 \\
20,614\end{array}$ & $\begin{array}{r}654 \\
49,136 \\
10,336 \\
11,990\end{array}$ & $\begin{array}{l}.019 \\
.037 \\
.045 \\
.056\end{array}$ & $\begin{array}{r}117.82 \\
64.87 \\
57.55 \\
58.16\end{array}$ \\
\hline $\begin{array}{l}3 \frac{3}{4} \\
4 \frac{1}{4}\end{array}$ & $\begin{array}{r}230,791 \\
1,314 \\
\end{array}$ & $\begin{array}{r}13,214 \\
107 \\
\end{array}$ & $\begin{array}{r}8,655 \\
56\end{array}$ & $\begin{array}{l}.057 \\
.081\end{array}$ & $\begin{array}{l}65.50 \\
52.20\end{array}$ \\
\hline & $23,426,152$ & 827,868 & 383,947 & .035 & 46.38 \\
\hline $\begin{array}{l}1 \frac{1}{4} \\
1 \frac{3}{8}\end{array}$ & $\begin{array}{r}386,838 \\
13,512,880\end{array}$ & $\begin{array}{r}5,250 \\
546,452\end{array}$ & $\begin{array}{r}4,836 \\
185,802\end{array}$ & $\begin{array}{l}.014 \\
.040\end{array}$ & $\begin{array}{l}92.10 \\
34.00\end{array}$ \\
\hline $\begin{array}{l}1 \frac{3}{4} \\
1 \frac{3}{8}\end{array}$ & $\begin{array}{r}19,474 \\
4,211,521\end{array}$ & $\begin{array}{r}317 \\
145,626\end{array}$ & $\begin{array}{r}341 \\
78,966\end{array}$ & $\begin{array}{l}.016 \\
.035\end{array}$ & $\begin{array}{r}107.51 \\
54.23\end{array}$ \\
\hline $\begin{array}{l}2 x \\
2 \frac{1}{3} \\
2 \frac{3}{4} \\
3 \frac{1}{4}\end{array}$ & $\begin{array}{r}3,214 \\
1,608,549 \\
289,684 \\
285,141\end{array}$ & $\begin{array}{r}67 \\
65,131 \\
15,837 \\
17,794\end{array}$ & $\begin{array}{r}72 \\
38,203 \\
7,966 \\
9,267\end{array}$ & $\begin{array}{l}.021 \\
.040 \\
.055 \\
.062\end{array}$ & $\begin{array}{r}107.94 \\
58.66 \\
50.30 \\
52.08\end{array}$ \\
\hline $\begin{array}{l}3 \frac{3}{4} \\
4 \frac{1}{4} \\
\end{array}$ & $\begin{array}{r}141,319 \\
351 \\
\end{array}$ & $\begin{array}{r}8,245 \\
13 \\
\end{array}$ & $\begin{array}{r}5,300 \\
15 \\
\end{array}$ & $\begin{array}{l}.058 \\
.036 \\
\end{array}$ & $\begin{array}{r}64.27 \\
119.36 \\
\end{array}$ \\
\hline & $20,458,971$ & 804,732 & 330,768 & .039 & 41.10 \\
\hline $\begin{array}{cc}a & 1 \frac{1}{1} \\
a & 13 \\
b & \frac{7}{8}\end{array}$ & $\begin{array}{r}60.514 \\
3,2 \times 3,239 \\
13,274,870\end{array}$ & $\begin{array}{r}815 \\
159,170 \\
559,358\end{array}$ & $\begin{array}{r}756 \\
45,145 \\
116,155\end{array}$ & $\begin{array}{l}.013 \\
.048 \\
.042\end{array}$ & $\begin{array}{l}92.81 \\
2 S .45 \\
20.77\end{array}$ \\
\hline $\begin{array}{l}a 17 \\
b 1\end{array}$ & $\begin{array}{r}820,293 \\
7,513,975\end{array}$ & $\begin{array}{r}29,771 \\
238,473\end{array}$ & $\begin{array}{l}15,381 \\
75,140\end{array}$ & $\begin{array}{l}.036 \\
.032\end{array}$ & $\begin{array}{l}51.66 \\
31.51\end{array}$ \\
\hline $\begin{array}{ll}a & 28 \\
b & 1 \frac{1}{8} \\
a & 24 \\
a & 3 \frac{1}{2} \\
b & 12 \\
a & 3 \\
b & 1 \\
b & \frac{1}{5} \\
a & 41 \\
b & 2\end{array}$ & $\begin{array}{r}236,815 \\
3,530,572 \\
37,928 \\
40,932 \\
1,859,718 \\
12,103 \\
506,335 \\
12 \\
20,225 \\
\end{array}$ & $\begin{array}{r}11,122 \\
121,411 \\
2,254 \\
2,775 \\
65,133 \\
936 \\
19,885 \\
5 \\
1,428 \\
\end{array}$ & $\begin{array}{r}5,624 \\
39,719 \\
1,043 \\
1,330 \\
27,896 \\
454 \\
9,493 \\
\ldots \ldots . . \\
405\end{array}$ & $\begin{array}{l}.047 \\
.034 \\
.059 \\
.068 \\
.035 \\
.077 \\
.039 \\
.417 \\
.071\end{array}$ & $\begin{array}{l}50.57 \\
32.71 \\
46.27 \\
47.94 \\
42.83 \\
48.49 \\
47.74 \\
10.20 \\
28.33\end{array}$ \\
\hline & $31,197,531$ & $1,212,536$ & 338,541 & .039 & 27.92 \\
\hline $\begin{array}{l}\frac{7}{8} \\
1 \\
\frac{1}{8} \\
1 \frac{1}{2}\end{array}$ & $\begin{array}{l}5,852,306 \\
4,407,494 \\
3,384,673 \\
2,170,772\end{array}$ & $\begin{array}{r}327,204 \\
164,022 \\
96,536 \\
63,242\end{array}$ & $\begin{array}{l}51,208 \\
44,075 \\
38,078 \\
32,562\end{array}$ & $\begin{array}{l}.056 \\
.037 \\
.029 \\
.029\end{array}$ & $\begin{array}{l}15.65 \\
26.87 \\
39.44 \\
51.49\end{array}$ \\
\hline $2^{1 \frac{7}{8}}$ & $\begin{array}{r}710,911 \\
6,054\end{array}$ & $\begin{array}{r}27,845 \\
377\end{array}$ & $\begin{array}{r}13,330 \\
121\end{array}$ & $\begin{array}{l}.039 \\
.062\end{array}$ & $\begin{array}{l}47.88 \\
32.12\end{array}$ \\
\hline & $16,532,210$ & 679,226 & 179,374 & .040 & 26.41 \\
\hline
\end{tabular}

b Oct. 4, 1913, to June 30, 1914, under act of 1913. 
Table 122.-Imports of Cylinder, Crown, and Common Window Glass, Unpolished, Entered for Consumption, Fiscal Years Ending June 30, 1896 to 1915 - Concluded.

\begin{tabular}{|c|c|c|c|c|c|c|}
\hline Fiscal year and classification. & $\begin{array}{c}\text { Duty } \\
\text { per } \\
\text { pound. }\end{array}$ & Pounds. & Value. & Duties. & $\begin{array}{c}\text { Aver- } \\
\text { age } \\
\text { value } \\
\text { per } \\
\text { pound. }\end{array}$ & $\begin{array}{l}\text { Com- } \\
\text { puted } \\
\text { ad val- } \\
\text { orem } \\
\text { rate. }\end{array}$ \\
\hline 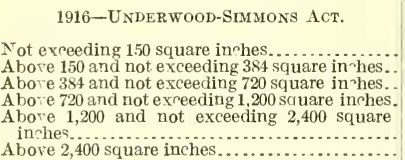 & $\begin{array}{r}\text { Cents. } \\
\frac{7}{8} \\
1 \frac{1}{8} \\
1 \frac{1}{2} \\
1 \frac{7}{8} \\
2\end{array}$ & $\begin{array}{r}861,374 \\
427,067 \\
83,138 \\
22,491 \\
7,002 \\
500\end{array}$ & $\begin{array}{r}\$ 94,922 \\
36,171 \\
6,106 \\
2,080 \\
\\
956 \\
27\end{array}$ & $\begin{array}{r}\$ 7,537 \\
4,271 \\
935 \\
337 \\
\\
131 \\
10\end{array}$ & $\begin{array}{r}\$ 0.110 \\
.085 \\
.073 \\
.092 \\
.137 \\
.054\end{array}$ & $\begin{array}{r}\text { Per } c t . \\
7.94 \\
11.81 \\
15.32 \\
16.22 \\
13.73 \\
37.00\end{array}$ \\
\hline Total. & & $1,401,572$ & 140,262 & 13,221 & .100 & 9.43 \\
\hline
\end{tabular}

Table 123.-Total Imports of Cylinder, Crown, and Common Window Glass, Unpolished, Entered for Consumption, and Proportion Comprised in the First Three Brackets (not Exceeding 16 by 24 Inches, or 384 Square Inches).

\begin{tabular}{|c|c|c|c|c|c|c|c|}
\hline \multirow{2}{*}{$\begin{array}{l}\text { Year ending } \\
\text { June } 30-\end{array}$} & \multirow{2}{*}{$\begin{array}{c}\text { Total } \\
\text { imports. }\end{array}$} & \multicolumn{2}{|c|}{$\begin{array}{c}\text { Imports of the first } \\
\text { three brackets. }\end{array}$} & \multirow{2}{*}{$\begin{array}{l}\text { Year ending } \\
\text { June } 30-\end{array}$} & \multirow{2}{*}{$\begin{array}{l}\text { Total } \\
\text { imports. }\end{array}$} & \multicolumn{2}{|c|}{$\begin{array}{c}\text { Imports of the first } \\
\text { three brackets. }\end{array}$} \\
\hline & & Amount. & $\begin{array}{l}\text { Per cent } \\
\text { of total. }\end{array}$ & & & Amount. & $\begin{array}{l}\text { Per cent } \\
\text { of total. }\end{array}$ \\
\hline 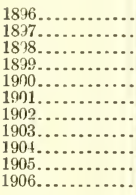 & $\begin{array}{r}\$ 1,062,889 \\
1,159,161 \\
927,009 \\
1,196,461 \\
1,530,638 \\
922,696 \\
1,797,589 \\
1,702,883 \\
1,366,218 \\
593,791 \\
1,259,497\end{array}$ & $\begin{array}{r}\$ 565,894 \\
618,095 \\
581,569 \\
779,241 \\
1,055.448 \\
727,299 \\
1,412,023 \\
1,272,298 \\
1,026,866 \\
470,347 \\
1,042,652\end{array}$ & $\begin{array}{l}53.24 \\
53.32 \\
62.74 \\
65.13 \\
68.95 \\
78.82 \\
78.55 \\
74.71 \\
75.16 \\
79.21 \\
82.78\end{array}$ & 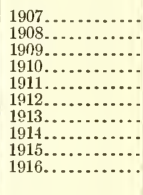 & $\begin{array}{r}8978,597 \\
513,273 \\
692,803 \\
711,741 \\
825,381 \\
827,868 \\
804,732 \\
1,212,536 \\
679,226 \\
140,262\end{array}$ & $\begin{array}{r}\$ 795,086 \\
630,962 \\
588,921 \\
596,698 \\
635,713 \\
699,680 \\
697,645 \\
987,587 \\
491,226 \\
131,093\end{array}$ & $\begin{array}{l}81.25 \\
84.88 \\
85.01 \\
83.84 \\
77.02 \\
84.52 \\
86.69 \\
81.45 \\
72.32 \\
93.46\end{array}$ \\
\hline
\end{tabular}


Table 124.-Imports of Plate Glass, Cast, Polishen, Finished or Unfinished, and Unsilvered. Entered for Consumption, Fiscal Years Ending June 30, 1896 то 1915.

\begin{tabular}{|c|c|c|c|c|c|c|}
\hline Fiscal year and classification. & $\begin{array}{l}\text { Duty } \\
\text { per } \\
\text { square } \\
\text { foot. }\end{array}$ & $\begin{array}{l}\text { Square } \\
\text { fect. }\end{array}$ & Value. & Dutics. & $\begin{array}{l}\text { Aver- } \\
\text { age } \\
\text { value } \\
\text { per } \\
\text { square } \\
\text { fuct. }\end{array}$ & $\begin{array}{l}\text { Ccm- } \\
\text { puted } \\
\text { a } 1 \text { va- } \\
\text { lurcm } \\
\text { rate. }\end{array}$ \\
\hline 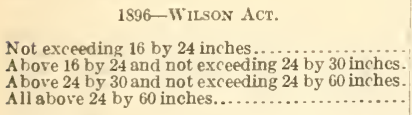 & $\begin{array}{c}\text { Cents. } \\
5 \\
8 \\
221 \\
35 \\
\end{array}$ & $\begin{array}{r}620,901 \\
1,968,658 \\
598,492 \\
105,554 \\
\end{array}$ & $\begin{array}{r}\$ 126,009 \\
443,976 \\
152,349 \\
41,558\end{array}$ & $\begin{array}{r}\$ 31,045 \\
157,493 \\
134,660 \\
36,944\end{array}$ & $\begin{array}{r}\$ 0.20 \\
.22 \\
.25 \\
.39 \\
\end{array}$ & $\begin{array}{r}\text { Pircent. } \\
24.64 \\
3547 \\
85.32 \\
88.89\end{array}$ \\
\hline Total... & $\cdots$ & $3,293,603$ & 763,892 & 360,142 & .23 & 47.14 \\
\hline 1897-WiLsoN ACT. & & & & & & \\
\hline $\begin{array}{l}\text { Not exceeding } 16 \text { by } 24 \text { inches................. } \\
\text { Above } 16 \text { by } 24 \text { and not exceeding } 24 \text { by } 30 \text { inches. } \\
\text { A bove } 24 \text { by } 30 \text { and not exceeding } 24 \text { by } 60 \text { inches. } \\
\text { All above } 24 \text { by } 60 \text { inches..................... }\end{array}$ & $\begin{array}{r}5 \\
8 \\
221 \\
35 \\
\end{array}$ & $\begin{array}{r}129,979 \\
856,121 \\
185,348 \\
21,807 \\
\end{array}$ & $\begin{array}{r}32,636 \\
208,459 \\
58,490 \\
8,452 \\
\end{array}$ & $\begin{array}{r}6,499 \\
68,490 \\
41,703 \\
7,632 \\
\end{array}$ & $\begin{array}{l}.25 \\
.24 \\
.32 \\
.39 \\
\end{array}$ & $\begin{array}{l}19.91 \\
32.86 \\
71.30 \\
90.30\end{array}$ \\
\hline Total.................... & & $1,193,255$ & 308,037 & 124,324 & .26 & 40.36 \\
\hline $\begin{array}{l}\text { 1898-Wilson ACT to JULY 24, 1897; DiNgley } \\
\text { ACT AFTERWARDS. }\end{array}$ & & & & & & \\
\hline Not exceeding 16 by 24 inches.................. & $\left\{\begin{array}{l}5 \\
8\end{array}\right.$ & $\begin{array}{r}22,049 \\
25,403\end{array}$ & $\begin{array}{r}5,180 \\
7,619\end{array}$ & $\begin{array}{r}1,102 \\
2,032\end{array}$ & $\begin{array}{l}.234 \\
.300\end{array}$ & $\begin{array}{l}21.29 \\
26.68\end{array}$ \\
\hline Above 16 by 24 and not exceeding 24 by 30 inches. & $\begin{array}{r}8 \\
10\end{array}$ & & $\begin{array}{l}32,032 \\
89,723\end{array}$ & $\begin{array}{l}11,047 \\
39,270\end{array}$ & .232 & $\begin{array}{l}34.48 \\
43.77\end{array}$ \\
\hline $\begin{array}{l}\text { Above } 24 \text { by } 30 \text { and not exceeding } 24 \text { bJ } 60 \text { inches. } \\
\text { A bove } 24 \text { by } 60 \text { inches........................... }\end{array}$ & $\begin{array}{l}22 \frac{1}{2} \\
35\end{array}$ & $\begin{array}{r}112,959 \\
5,655 \\
\end{array}$ & $\begin{array}{r}30,498 \\
5,769 \\
\end{array}$ & $\begin{array}{r}25,415 \\
1,979 \\
\end{array}$ & $\begin{array}{r}.270 \\
1.020 \\
\end{array}$ & $\begin{array}{l}83.33 \\
34.31 \\
\end{array}$ \\
\hline Total.... & …... & 696,835 & 170,821 & 80,845 & .245 & 47.34 \\
\hline 1899-Dingley ACT. & & & & & & \\
\hline 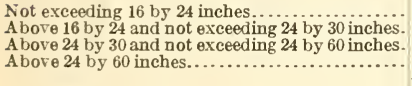 & $\begin{array}{l}8 \\
10 \\
22 \frac{1}{2} \\
35\end{array}$ & $\begin{array}{r}74,704 \\
385,096 \\
404,674 \\
60,738 \\
\end{array}$ & $\begin{array}{r}18,660 \\
88,657 \\
104,751 \\
19,679 \\
\end{array}$ & $\begin{array}{r}5,976 \\
38,510 \\
91,052 \\
21,258 \\
\end{array}$ & $\begin{array}{l}.250 \\
.230 \\
.259 \\
.324\end{array}$ & $\begin{array}{r}32.03 \\
43.44 \\
86.92 \\
108.02\end{array}$ \\
\hline Total $\ldots \ldots \ldots \ldots \ldots \ldots \ldots \ldots$ & $\cdots+$ & 925,212 & 231,747 & 156,796 & .250 & 67.66 \\
\hline 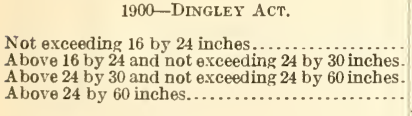 & $\begin{array}{c}8 \\
10 \\
22 \\
35 \\
\end{array}$ & $\begin{array}{l}105,323 \\
42 \times, 214 \\
369,677 \\
145,611 \\
\end{array}$ & $\begin{array}{l}20,227 \\
86,453 \\
99,576 \\
46,043 \\
\end{array}$ & $\begin{array}{r}\times, 426 \\
42, \mathrm{~s} 21 \\
83,177 \\
50,964 \\
\end{array}$ & $\begin{array}{l}.192 \\
.202 \\
.270 \\
.316 \\
\end{array}$ & $\begin{array}{r}41.66 \\
49.53 \\
83.53 \\
110.69 \\
\end{array}$ \\
\hline Total ............................. & .... & $=\underline{\underline{1,048,825}}$ & 252,999 & 185,388 & .240 & 73.48 \\
\hline 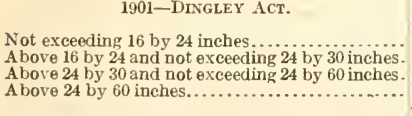 & $\begin{array}{c}8 \\
10 \\
22 ! \\
35\end{array}$ & $\begin{array}{r}332,782 \\
1,475,244 \\
705,309 \\
724,724 \\
\end{array}$ & $\begin{array}{r}69,158 \\
314,858 \\
198,254 \\
210,037 \\
\end{array}$ & $\begin{array}{r}26,622 \\
147,524 \\
158,695 \\
253,654 \\
\end{array}$ & $\begin{array}{l}.207 \\
.213 \\
.250 \\
.290\end{array}$ & $\begin{array}{r}38.50 \\
46.85 \\
80.15 \\
120.76\end{array}$ \\
\hline Total. & ... & $=3,238,059$ & 792,307 & $5 \$ 6,495$ & .245 & 74.02 \\
\hline 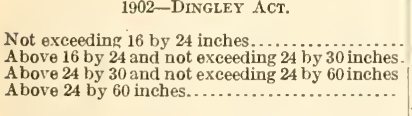 & $\begin{array}{c}8 \\
10 \\
22 ! \\
35\end{array}$ & $\begin{array}{r}381,718 \\
1,545,802 \\
946,916 \\
1,329,455 \\
\end{array}$ & $\begin{array}{r}68,834 \\
310,197 \\
241,254 \\
34,262\end{array}$ & $\begin{array}{r}30,538 \\
154,580 \\
213,056 \\
465,309 \\
\end{array}$ & $\begin{array}{l}.180 \\
.447 \\
.255 \\
.259\end{array}$ & $\begin{array}{r}44.36 \\
49.83 \\
88.32 \\
121.10\end{array}$ \\
\hline Total............... & $\underline{\ldots \ldots}$ & $=\underline{4,203,891}$ & $1,004,547$ & $863,4 \times 3-$ & .239 & 85.94 \\
\hline 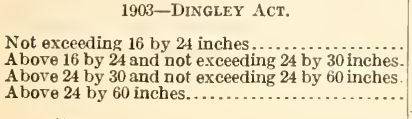 & \begin{tabular}{c|}
8 \\
10 \\
22 \\
35
\end{tabular} & $\begin{array}{r}651,600 \\
3,294,124 \\
1,191,173 \\
1,162,112 \\
\end{array}$ & $\begin{array}{l}111,104 \\
663,425 \\
288,231 \\
291,169 \\
\end{array}$ & $\begin{array}{r}52,128 \\
329,412 \\
268,014 \\
406,739 \\
\end{array}$ & $\begin{array}{l}.171 \\
.202 \\
.242 \\
.251 \\
\end{array}$ & $\begin{array}{r}46.92 \\
49.65 \\
93.00 \\
139.54 \\
\end{array}$ \\
\hline Total & $\cdots \cdots$ & $6,299,009$ & $1,354,229$ & $1,056,293$ & $\stackrel{.215}{=}=$ & 78.00 \\
\hline
\end{tabular}


Table 124.-Imports of Plate Glass, Cast, Polished, Finished or Unfinished, and Unsilvered, Entered for Consumption, Fiscal Years Ending June 30, 1896 To $1915-$ Continued.



1904-DiNGLEY, A CT.

Not exceeding 16 by 24 inches

A bove 16 by 24 and not exceeding 24 by 30 inches. A bove 24 by 30 and not exceeding 24 by 60 inches.

Above 24 by 60 inches........................

Total.

1905-DiNGLEY ACT.

Not exceeding 16 by 24 inches.

A bove 16 by 24 and not exceeding 24 by 30 inches. A bove 24 by 30 and not exceeding 24 by 60 inches. A bove 24 by 60 inches........................

Total.

\section{6-Dinglex ACT.}

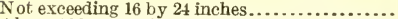
A bove 16 by 24 and not exceeding 24 by 30 inches A bove 24 by 30 and not exceeding 24 by 60 inches. A bove 24 by 60 inches........................

Total.

\section{7-DiNGLEY ACT.}

Not exceeding 16 by 24 inches.

Above 16 by 24 and not exceeding 24 by 30 inches A bove 24 by 30 and not exceeding 24 by 60 inches. A bove 24 by 60 inches.

\begin{tabular}{|c|c|c|c|c|c|}
\hline $\begin{array}{l}\text { Duty } \\
\text { per } \\
\text { square } \\
\text { foot. }\end{array}$ & $\begin{array}{l}\text { Square } \\
\text { feet. }\end{array}$ & Value. & Duties. & $\begin{array}{c}\text { Aver- } \\
\text { age } \\
\text { value } \\
\text { per } \\
\text { square } \\
\text { foot. }\end{array}$ & $\begin{array}{l}\text { Com- } \\
\text { puted } \\
\text { ad va- } \\
\text { lorem } \\
\text { rate. }\end{array}$ \\
\hline $\begin{array}{c}\text { Cents. } \\
8 \\
10 \\
22 \frac{1}{2} \\
35\end{array}$ & $\begin{array}{r}567,892 \\
2,442,960 \\
811,310 \\
595,195\end{array}$ & $\begin{array}{l}\$ 86,911 \\
433,344 \\
184,307 \\
139,015\end{array}$ & $\begin{array}{l}\$ 45,431 \\
244,296 \\
182,545 \\
208,319\end{array}$ & $\begin{array}{r}\$ 0.153 \\
.177 \\
.227 \\
.234\end{array}$ & $\begin{array}{r}\text { Per cent. } \\
52.27 \\
56.37 \\
99.04 \\
149.85\end{array}$ \\
\hline & $4,417,357$ & 843,577 & 680,591 & .191 & 80.68 \\
\hline $\begin{array}{l}8 \\
10 \\
22 \frac{1}{2} \\
35\end{array}$ & $\begin{array}{r}682,597 \\
4,323,669 \\
792,579 \\
265,443\end{array}$ & $\begin{array}{r}110,964 \\
723,807 \\
175,729 \\
66,225\end{array}$ & $\begin{array}{r}54,608 \\
432,367 \\
178,330 \\
92,905\end{array}$ & $\begin{array}{l}.163 \\
.167 \\
.222 \\
.249\end{array}$ & $\begin{array}{r}49.21 \\
59.73 \\
101.48 \\
140.29\end{array}$ \\
\hline & $6,064,288$ & $1,076,725$ & 758,210 & .177 & 70.42 \\
\hline $\begin{array}{l}8 \\
10 \\
22 \frac{1}{2} \\
35 \\
\end{array}$ & $\begin{array}{r}1,050,313 \\
5,178,212 \\
898,294 \\
164,416 \\
\end{array}$ & $\begin{array}{r}184,850 \\
1,059,738 \\
228,756 \\
45,952\end{array}$ & $\begin{array}{r}84,025 \\
517,821 \\
202,116 \\
57,546\end{array}$ & $\begin{array}{l}.176 \\
.205 \\
.255 \\
.279\end{array}$ & $\begin{array}{r}45.46 \\
48.86 \\
88.36 \\
125.23\end{array}$ \\
\hline$\ldots$ & $7,291,235$ & $1,519,296$ & 861,508 & .208 & 56.70 \\
\hline $\begin{array}{l}8 \\
10 \\
22 \frac{1}{2} \\
35\end{array}$ & $\begin{array}{r}1,207,576 \\
4,577,059 \\
741,947 \\
180,913\end{array}$ & $\begin{array}{r}224,238 \\
929,259 \\
204,263 \\
40,687\end{array}$ & $\begin{array}{r}96,606 \\
457,706 \\
166,938 \\
63,320\end{array}$ & $\begin{array}{l}.185 \\
.203 \\
.275 \\
.225\end{array}$ & $\begin{array}{r}43.08 \\
49.25 \\
81.73 \\
155.62\end{array}$ \\
\hline . & $6,707,495$ & $1,398,447$ & 784,570 & .208 & 56.10 \\
\hline $\begin{array}{l}8 \\
10 \\
22 \frac{1}{2} \\
35\end{array}$ & $\begin{array}{r}442,862 \\
2,590,302 \\
643,715 \\
150,345\end{array}$ & $\begin{array}{r}85,818 \\
548,115 \\
172,206 \\
42,762\end{array}$ & $\begin{array}{r}35,429 \\
259,030 \\
144,836 \\
52,621\end{array}$ & $\begin{array}{l}.194 \\
.212 \\
.268 \\
.284\end{array}$ & $\begin{array}{r}91.29 \\
47.25 \\
84.10 \\
123.00\end{array}$ \\
\hline & $3,827,224$ & 848,901 & 491,916 & .222 & 57.95 \\
\hline $\begin{array}{l}8 \\
10 \\
22 \frac{1}{2} \\
35\end{array}$ & $\begin{array}{r}345,560 \\
1,611,845 \\
300,011 \\
22,517\end{array}$ & $\begin{array}{r}57,637 \\
349,260 \\
85,719 \\
7,269\end{array}$ & $\begin{array}{r}27,645 \\
161,185 \\
67,502 \\
7,881\end{array}$ & $\begin{array}{l}.167 \\
.217 \\
.286 \\
.323\end{array}$ & $\begin{array}{r}48.00 \\
46.15 \\
78.75 \\
108.42\end{array}$ \\
\hline 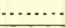 & $2,279,933$ & 499,485 & 264,213 & .219 & 52.85 \\
\hline $\begin{array}{ll} & a \\
b & 8 \\
a & 10 \\
a & 10 \\
b & 121 \\
a & 221 \\
a & 35 \\
b & 221\end{array}$ & $\begin{array}{r}3,974 \\
505,478 \\
49,706 \\
2,057,277 \\
14,813 \\
7,068 \\
511,860\end{array}$ & $\begin{array}{r}858 \\
97,649 \\
10,819 \\
443,421 \\
4,393 \\
1,827 \\
143,072\end{array}$ & $\begin{array}{r}318 \\
50,548 \\
4,970 \\
257,160 \\
3,333 \\
2,474 \\
115,168\end{array}$ & $\begin{array}{l}.216 \\
.193 \\
.218 \\
.216 \\
.297 \\
.258 \\
.279\end{array}$ & $\begin{array}{r}37.05 \\
51.76 \\
45.94 \\
57.99 \\
75.87 \\
135.40 \\
80.50\end{array}$ \\
\hline & & 702,039 & 433,971 & .223 & 61.82 \\
\hline
\end{tabular}

Not exceeding 16 by 24 inches............................ A bove 24 by 30 and not exceeding 24 by 60 inches.

Total.

\section{9-DiNGLEY ACT.}

Not exceeding 16 by 24 inches..

A bove 16 by 24 and not exceeding 24 by 30 inches.

A bove 24 by 30 and not exceeding 24 by 60 inches.

A bove 24 by 60 inches.

Total.

1910-Dingley Act to AUg. 6, 1909; PayneALDRICH ACT AFTERWARDS.

Not exceeding 16 by 24 inches.

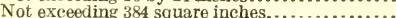

A bove 16 by 24 and not exceeding 24 by 30 inches.

Above 384 and not exceeding 720 square inches.

Above 24 by 30 and not exceeding 24 by 60 inches.

Above 24 by 60 inches........................

Above 720 square inches.........................

Total

$a$ July 1 to Aug. 5, 1909, under act of 1897 . 
Table 124.-Importa of Plate Glass, Cast, Polished, Finishei) or Unfinished, and Unsilvered, Entered for Consumption, Fiscal Years Ending June 30, 1896 ro 1915 - Concluded.

Fiscal year and classification.

$$
\text { 1911-PAY.TE-ALDRICH ACT. }
$$

Not exceeding 384 square inches................ Above 384 and not exceeding 720 square inches.. A bove 720 square inches........................

$$
\text { Total. }
$$

\section{2-PATNE-ALDRICH ACT.}

Not exceeding 384 square inches................ A bove 344 and not exceeding 720 square inches.. A bove 720 square inches.

$$
\text { Total. }
$$

\section{3-PAYNE-ALDRICH ACT.}

Not exceeding 384 square inches................ Above 384 and not exceeding 720 square inches. . A bove 720 square inches......................

Total.

1914-PAYNE-ALdRICH ACt to OCT. 4, 1913; UNDERWOOD-SiMMONS ACT AFTERWARDS.

Plateglass, cast, polished, finished or unfinished, unsilvered, or the same containing a wire netting within itself:

Not exceeding 384 square inches.

Above 384 and not exceeding 720 square inches................................

Above 720 square inches.

Total.

\section{5-UNDERWOOD-SIMMONS ACT.}

Plate glass, cast, polished, finished or unfinished unsilvered, or the same containing a wire netting within itself:

Not exceeding 384 square inches. ............

$\Lambda$ bove 384 and not exceeding 720 square

inches................................

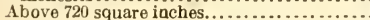

Total.

\section{6-UNDERWOOD-SIMMONS ACT.}

Plate glass, cast, polished, finished or unfinished, unsilvered, or the same containing a wire netting within itself:

Not exceeding 384 square inches. ............

Above 384 and not exceeding 720 square

inches.................................

Above 720 square inches..................

Total.

a July 1 to Oct. 3, 1913, under act of 1909.

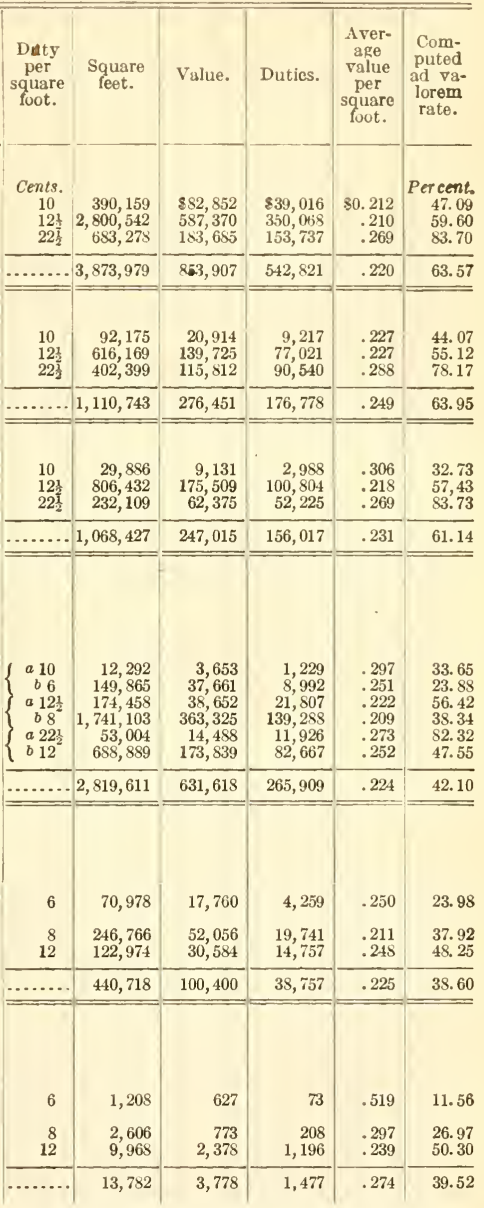

$b$ Oct. 4, 1913, to June 30, 1914, under act of 1913. 
Table 125.-Imports of Bottles and Vials, Not Ornamented, and Demijohns and Carboys, All Empty, Ordinarily Used as Containers in Transportation, Entered for Consumption, Fiscal Year Ending June 30, 1896 to 1915.

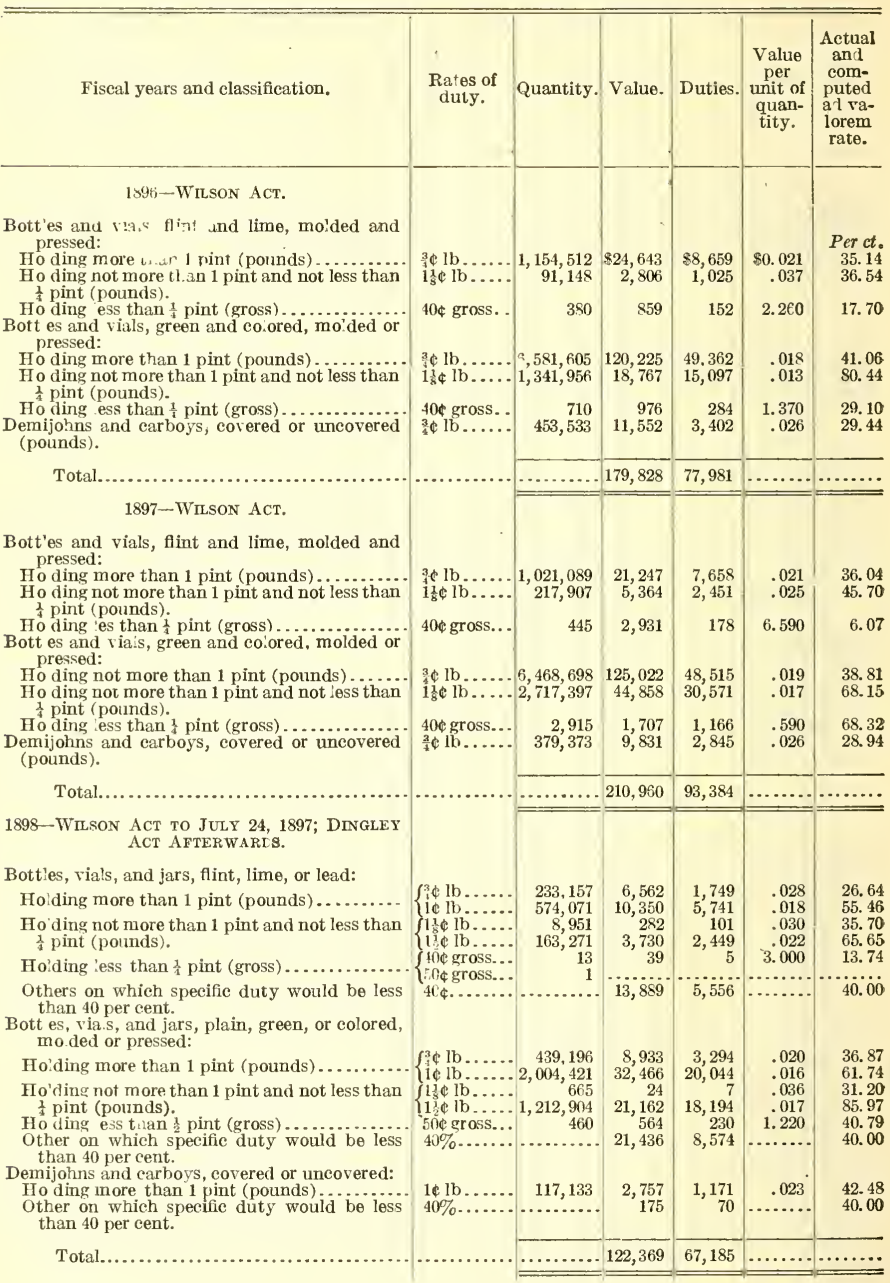


Tarle 125.-Imports of Bottles and Vials, Not Ornamented, ant Demionns and Carboys, All Empty, Ordinarily Used as Containerg in Transportatinn, Entered for Consumption, Fiscal Year Ending June 30, 1896 to 1915Continued.

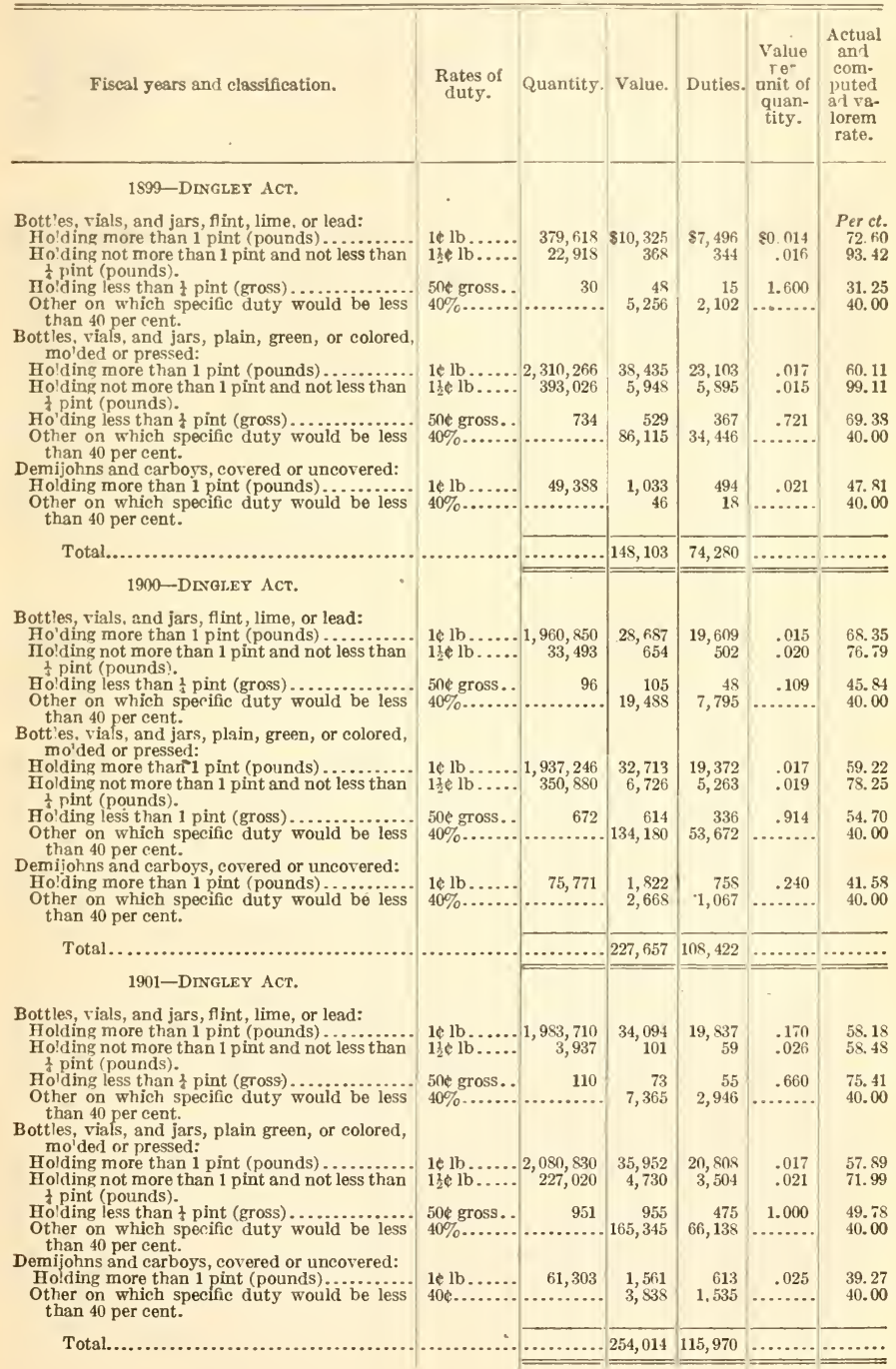


Table 125.-Imports of Bottles and Vials, Not Ornamented, and Demijohns and Carboys, All Empty, Ordinarily Used as Containers in Transportation, Entered for Consumption, Fiscal Year Ending June 30, 1896 to 1915Continued.

Fiscal years and classification.

\section{2-DINGLEY ACT}

Bottles, vials, and jars, fint, lime, or lead:

Holding more than 1 pint (pounds).

Holding not more than 1 pint and not less than 1 pint (pounds)

Holding less than 1 pint (gross) ....

Other on which specific duty would be less than 40 per cent.

B ittles, via's, aud jars, plain, green, or colored, molded or pressed:

Holding more than 1 pint (pounds) ........... Holding not more than 1 pint and not less than 1 pint (pounds).

Holding less than $\frac{1}{4}$ pint (gross) .......................

Other on which specific duty would be less than 40 per cent.

Demijohns and carboys, covered or uncovered:

Holding more than 1 pint (pounds)
Other on which specific duty would be less than 40 per cent.

Total.

1903-DINGLEY ACT.

Bottles, via's, and jars, flint, lime, or lead:

Holding more than 1 pint (pounds) ...........

Holding not more than 1 pint and not less than $\frac{1}{4}$ pint (pounds).

Holding less than $\frac{1}{4}$ pint (gross) ...............

Other on which specific duty would be less than 40 per cent.

Bottles, vials, and jars, plain, green, or colored, mo'ded or pressed:

Holding more than 1 pint (pounds) ..........

Holding not more than 1 pint and not less than $\frac{1}{4}$ pint (pounds).

Holding less than $\frac{1}{3}$ pint (gross) ................

Other on which specific duty would be less than 40 per cent.

Demijohns and carbovs, covered or uncovered:

Ho:ding more than 1 pint (pounds) ...........

Other on which specific duty would be less than 40 per cent.

Total.

\section{4-DiNGLEY ACT.}

Bottles, via's, and jars, flint, lime, or lead:

Holding more than 1 pint (pounds) ........... Holding not more than 1 pint and not less than 1 pint (pounds).

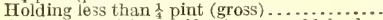

Other on which specific duty would be less than 40 per cent.

Bottles, vias, and jars, plain, green, or coiored, molded or pressed:

Holding more than 1 pint (pounds).

Holding not more than 1 pint and not less than $\frac{x}{3}$ pint (pounds)

Hoding less than ${ }_{4}^{1}$ pint (gross) . . . . . . . . . . Other on which specific duty would be less than 40 per cent.

Demijohns and carbozs, covered or uncovered:

Holding more than 1 pint (pounds) ...........
Other on which sperific duty wo than 40 per cent.

\begin{tabular}{|c|c|c|c|c|c|}
\hline $\begin{array}{l}\text { Rates of } \\
\text { duty. }\end{array}$ & Quantity. & Value. & Duties. & $\begin{array}{l}\text { Value } \\
\text { per } \\
\text { unit of } \\
\text { quan- } \\
\text { tity. }\end{array}$ & $\begin{array}{l}\text { Actual } \\
\text { and } \\
\text { com- } \\
\text { puted } \\
\text { a i va- } \\
\text { lorem } \\
\text { rate. }\end{array}$ \\
\hline $\begin{array}{c}\cdot \\
1 \notin \mathrm{lb} \ldots \ldots \\
1 \frac{1}{2} \phi \mathrm{lb} \ldots \ldots\end{array}$ & $\begin{array}{r}2,274,679 \\
66,802\end{array}$ & $\begin{array}{r}\$ 45,119 \\
1,757\end{array}$ & $\begin{array}{r}\$ 22,747 \\
1,002\end{array}$ & $\begin{array}{r}\$ 0.019 \\
.026\end{array}$ & $\begin{array}{r}\text { Per ct. } \\
50.50 \\
57.00\end{array}$ \\
\hline $\begin{array}{l}50 \mathrm{c} \text { gross. } \\
40 \% \text {....... }\end{array}$ & $\begin{array}{r}382 \\
\ldots .\end{array}$ & $\begin{array}{r}215 \\
29,405\end{array}$ & $\begin{array}{r}191 \\
11,762\end{array}$ & $\begin{array}{r}.563 \\
\ldots . . .\end{array}$ & $\begin{array}{l}88.91 \\
40.00\end{array}$ \\
\hline $\begin{array}{l}1 \mathrm{l} b \ldots . . . . \\
1 \frac{1}{2} c \mathrm{lb} \ldots . .\end{array}$ & $\begin{array}{r}1,366,628 \\
170,859\end{array}$ & $\begin{array}{r}24,855 \\
4,042\end{array}$ & $\begin{array}{r}13,666 \\
2,563\end{array}$ & $\begin{array}{l}.018 \\
.024\end{array}$ & $\begin{array}{l}54.99 \\
63.41\end{array}$ \\
\hline $\begin{array}{l}50 \mathrm{c} \text { gross. } \\
40 \% \text {....... }\end{array}$ & $\begin{array}{r}383 \\
\ldots . .6 \\
.\end{array}$ & $\begin{array}{r}176 \\
126,939\end{array}$ & $\begin{array}{r}192 \\
50,775\end{array}$ & $\begin{array}{r}.460 \\
\ldots . . .\end{array}$ & $\begin{array}{r}108.85 \\
40.00\end{array}$ \\
\hline $\begin{array}{l}1 \mathrm{clb} . \\
40 \% \text {. }\end{array}$ & $\begin{array}{r}38,116 \\
\ldots . \ldots\end{array}$ & $\begin{array}{r}937 \\
7,672\end{array}$ & $\begin{array}{r}381 \\
3,069\end{array}$ & $\begin{array}{r}.025 \\
\ldots . . .6 .\end{array}$ & $\begin{array}{l}40.68 \\
40.00\end{array}$ \\
\hline & & 241,117 & 106,348 & .......... & $\cdots$ \\
\hline $\begin{array}{l}1 \notin \mathrm{lb} \ldots . . \\
1_{2}^{1} \mathrm{el} \text { lb.... }\end{array}$ & $\begin{array}{r}2,197,626 \\
124,230\end{array}$ & $\begin{array}{r}39,642 \\
2,987\end{array}$ & $\begin{array}{r}21,976 \\
1,863\end{array}$ & $\begin{array}{l}.018 \\
.024\end{array}$ & $\begin{array}{l}55.44 \\
62.39\end{array}$ \\
\hline $\begin{array}{l}50 \mathrm{e} \text { gross. } \\
40 \% \text {. . . . }\end{array}$ & $\begin{array}{r}546 \\
\cdots \cdots\end{array}$ & $\begin{array}{r}393 \\
46,795\end{array}$ & $\begin{array}{r}273 \\
18,718\end{array}$ & $\begin{array}{r}.721 \\
\ldots . .\end{array}$ & $\begin{array}{l}69.41 \\
40.00\end{array}$ \\
\hline $\begin{array}{l}1 \mathrm{e} \text { lb...... } \\
1 \frac{1}{2} \mathrm{lb} . \ldots .\end{array}$ & $\begin{array}{r}2,270,721 \\
115,996\end{array}$ & $\begin{array}{r}37,667 \\
2,437\end{array}$ & $\begin{array}{r}22,707 \\
1,740\end{array}$ & $\begin{array}{l}.017 \\
.021\end{array}$ & $\begin{array}{l}60.29 \\
71.40\end{array}$ \\
\hline $\begin{array}{l}50 \mathrm{e} \text { gross. } \\
40 \% \text {....... }\end{array}$ & $\begin{array}{r}372 \\
\ldots . . .6\end{array}$ & $\begin{array}{r}502 \\
126,175\end{array}$ & $\begin{array}{r}186 \\
50,470\end{array}$ & $\begin{array}{r}1.350 \\
\cdots . . . . .\end{array}$ & $\begin{array}{l}37.05 \\
40.00\end{array}$ \\
\hline $\begin{array}{l}1 \mathrm{e} \text { lb } \ldots \\
40 \% \ldots\end{array}$ & $\begin{array}{r}104,647 \\
\ldots \ldots \ldots \ldots\end{array}$ & $\begin{array}{l}2,303 \\
8,643\end{array}$ & $\begin{array}{l}1,046 \\
3,457\end{array}$ & $\begin{array}{r}.022 \\
\ldots . . \cdots\end{array}$ & $\begin{array}{l}45.43 \\
40.00\end{array}$ \\
\hline & & 267,544 & 122,436 & & \\
\hline $\begin{array}{l}1 c \mathrm{lb} \text {. } \\
1 \mathrm{~d} \Leftrightarrow \mathrm{lb}\end{array}$ & $\begin{array}{r}2,876,055 \\
51,009\end{array}$ & $\begin{array}{r}46,690 \\
1,221\end{array}$ & 29, $\frac{761}{765}$ & $\begin{array}{l}.016 \\
.024\end{array}$ & $\begin{array}{l}61.60 \\
62.67\end{array}$ \\
\hline $\begin{array}{l}50 \notin \text { gross.. } \\
40 \% \text {....... }\end{array}$ & 357 & $\begin{array}{r}368 \\
46,953\end{array}$ & $\begin{array}{r}179 \\
18,781\end{array}$ & $\begin{array}{r}1.030 \\
\ldots . . .\end{array}$ & $\begin{array}{l}48.57 \\
40.00\end{array}$ \\
\hline $\begin{array}{l}1 \mathrm{e} l \mathrm{~b} . \\
1 \frac{1 b}{2} \mathrm{lb} .\end{array}$ & $\begin{array}{r}2,870,012 \\
279,413\end{array}$ & $\begin{array}{r}42,870 \\
6,153\end{array}$ & $\begin{array}{r}28,700 \\
4,191\end{array}$ & $\begin{array}{l}.015 \\
.022\end{array}$ & $\begin{array}{l}66.95 \\
68.12\end{array}$ \\
\hline $\begin{array}{l}50 \text { ge gross. . } \\
40 \% \text {. . . . . }\end{array}$ & $\begin{array}{r}1,068 \\
\ldots . . .\end{array}$ & $\begin{array}{r}534 \\
124,516\end{array}$ & $\begin{array}{r}534 \\
49,806\end{array}$ & .500 & $\begin{array}{r}100.00 \\
40.00\end{array}$ \\
\hline $\begin{array}{l}1 \mathrm{e} l \mathrm{~b} . \\
40 \% .\end{array}$ & $\begin{array}{r}91,005 \\
\ldots \ldots . \cdots\end{array}$ & $\begin{array}{l}1,965 \\
6,967\end{array}$ & $\begin{array}{r}910 \\
2,787\end{array}$ & $\begin{array}{c}.022 \\
\ldots \ldots\end{array}$ & $\begin{array}{l}46.31 \\
40.00\end{array}$ \\
\hline & & 278,237 & 135,414 & & \\
\hline
\end{tabular}


Table 125.-Imports of Botrles and Vials, Not Ornamented, and Demijohns and Carboys, All Empty, Ordinarily Úsed as Containers in Transportation, Entered for Consumption, Fiscal Year Ending June 30, 1896 to 1915Continued.

Fiscal years and classification.

\section{5.-DINGLEY ACT.}

Bottles, vials, and jars, flint, lime, or lead:

Holding more than 1 pint (pounds).....

Holding not more than 1 pint and not less than 3 pint (pounds).

Holding less than $\frac{1}{4}$ pint (gToss)

Other, on which specific duty would be less than 40 per cent.

Bottles, vials, and jars, plain, green, or colored, molded or pressed

Holding more than 1 pint (pounds).......... Holding not more than 1 pint and not less than 1 pint (pounds)

Holding less than $\frac{1}{4}$ pint (gross) ................ Other on which specific duty would be less than 40 per cent.

Demijohns and carboys, covered or uncovered:

Holding more than 1 pint (pounds)
Other on which specific duty would be less than 40 per cent.

Total

\section{6-IINGLEY ACT.}

Bottles, vials, and jars, flint, lime, or lead:

Holding more than 1 pint (pounds)

Holding not more than 1 pint and not less than ${ }_{4}^{1}$ pint (pounds).

Holding less than 3 pint (gross) ................

Other on which specific duty would be less than 40 per cent.

Bottles, vials, and jars, plain, green, or colored, molded or pressed:

Holding more than 1 pint (pounds).

Holding not more than 1 pint and not less than $\frac{1}{3}$ pint (pounds).

Holding less than 3 pint (gross)...

Other on which specific duty would be less than 40 per cent.

Demijohns and carboys, covered or uncovered:

Holding more than 1 pint (pounds)

Other on which specific duty would be less than 40 per cent.

Total.

\section{7-J INGLEY ACT.}

Bottles, vials, and jars, flint, lime, or lead:

Holding more than 1 pint (pounds)....

Holding not more than 1 pint and not less than 1 pint (pounds).

Holding less than 1 pint (gross).

Other on which spccific duty would be less than 40 per cent.

Bottles, vials, and jars, plain, green, or colored, molded or pressed:

Holding more than 1 pint (pounds).........

Holding not more than 1 pint and not less than 1 pint (pounds).

Holding less than 1 pint (gross)

Other on which specific duty would be less than 40 per cent.

Temijohns and carboys, covered or uncovered

Holding more than 1 pint (pounds)...........

Other on which specific duty would be less than 40 per cent.

\begin{tabular}{|c|c|c|c|c|c|}
\hline $\begin{array}{l}\text { Rates of } \\
\text { duty. }\end{array}$ & Quantity. & Value. & Dutses. & $\begin{array}{c}\text { Value } \\
\text { per } \\
\text { unit of } \\
\text { quan- } \\
\text { tity. }\end{array}$ & $\begin{array}{l}\text { Actual } \\
\text { and } \\
\text { com- } \\
\text { puted } \\
\text { at va- } \\
\text { lorem } \\
\text { rate. }\end{array}$ \\
\hline $\begin{array}{l}1 \mathrm{e} l \mathrm{~b} \ldots \ldots \\
1 \frac{1}{2} \mathrm{el} . . .\end{array}$ & $\begin{array}{r}2,187,273 \\
35,514\end{array}$ & $\begin{array}{r}\$ 33,913 \\
617\end{array}$ & $\begin{array}{r}\$ 21,873 \\
533\end{array}$ & $\begin{array}{r}\$ 0.016 \\
.017\end{array}$ & $\begin{array}{r}\text { Perct. } \\
64.50 \\
86.34\end{array}$ \\
\hline $\begin{array}{l}50 \text { e gross. } \\
40 \% \text {. }\end{array}$ & $\begin{array}{r}289 \\
\ldots \ldots\end{array}$ & $\begin{array}{r}309 \\
41,087\end{array}$ & $\begin{array}{r}139 \\
16,435\end{array}$ & $\begin{array}{r}1.110 \\
\ldots . \cdots\end{array}$ & $\begin{array}{l}45.11 \\
40.00\end{array}$ \\
\hline $\begin{array}{l}1 \mathrm{c} 1 \mathrm{~b} \ldots \ldots \\
1_{2}^{1} \mathrm{c} l \mathrm{~b} . \ldots\end{array}$ & $\begin{array}{r}3,330,323 \\
493,983\end{array}$ & $\begin{array}{r}47,215 \\
8,997\end{array}$ & $\begin{array}{r}33,303 \\
7,410\end{array}$ & $\begin{array}{l}.014 \\
.018\end{array}$ & $\begin{array}{l}70.54 \\
82.36\end{array}$ \\
\hline $\begin{array}{l}50 \mathrm{e} \text { gross. } \\
40 \% \ldots\end{array}$ & $\begin{array}{r}713 \\
\ldots \ldots . .2\end{array}$ & $\begin{array}{r}580 \\
132,077\end{array}$ & $\begin{array}{r}357 \\
52,831\end{array}$ & $\begin{array}{r}.813 \\
\ldots . .6 \\
\end{array}$ & $\begin{array}{l}61.51 \\
40.00\end{array}$ \\
\hline $\begin{array}{l}1 \mathrm{c} \text { lb } \ldots \ldots \\
40 \%\end{array}$ & $\begin{array}{r}76,006 \\
\ldots \ldots \ldots\end{array}$ & $\begin{array}{l}1,713 \\
6,068\end{array}$ & $\begin{array}{r}780 \\
2,427\end{array}$ & $\begin{array}{r}.022 \\
\ldots . . .\end{array}$ & $\begin{array}{l}45.54 \\
40.00\end{array}$ \\
\hline & .... & 273,296 & 136,088 & ....... & ..... \\
\hline $\begin{array}{l}1 \mathrm{e} l \mathrm{~b} \\
1 \frac{1}{2} \mathrm{e} 1 \mathrm{~b} \ldots\end{array}$ & $\begin{array}{r}1,276,646 \\
38,807\end{array}$ & $\begin{array}{r}19,677 \\
884\end{array}$ & $\begin{array}{r}12,766 \\
582\end{array}$ & $\begin{array}{l}.015 \\
.023\end{array}$ & $\begin{array}{l}64.68 \\
65.85\end{array}$ \\
\hline $\begin{array}{l}50 \mathrm{e} \text { gross } \\
40 \% \ldots \ldots \ldots\end{array}$ & $\begin{array}{r}117 \\
\ldots \ldots\end{array}$ & $\begin{array}{r}116 \\
138,142\end{array}$ & $\begin{array}{r}59 \\
55,257\end{array}$ & $\begin{array}{r}.989 \\
\ldots . . \\
\end{array}$ & $\begin{array}{l}50.63 \\
40.00\end{array}$ \\
\hline $\begin{array}{l}1 \mathrm{c} 1 \mathrm{~b} \ldots . . . \\
1 \frac{1}{2} \mathrm{e} 1 \mathrm{~b} . . .\end{array}$ & $\begin{array}{r}1,898,875 \\
225,608\end{array}$ & $\begin{array}{r}28,850 \\
3,886\end{array}$ & $\begin{array}{r}18,898 \\
3,394\end{array}$ & $\begin{array}{l}.015 \\
.017\end{array}$ & $\begin{array}{l}65.82 \\
87.09\end{array}$ \\
\hline $\begin{array}{l}50 \text { e gross.. } \\
40 \% \ldots \ldots \ldots\end{array}$ & $\begin{array}{r}1,197 \\
\ldots \ldots . . .\end{array}$ & $\begin{array}{r}1,126 \\
120,280\end{array}$ & $\begin{array}{r}599 \\
48,083\end{array}$ & $\begin{array}{r}.941 \\
\ldots . . .\end{array}$ & $\begin{array}{l}53.16 \\
40.00\end{array}$ \\
\hline $\begin{array}{l}1 \mathrm{e} 1 \mathrm{~b} . . . . \\
40 \%\end{array}$ & $\begin{array}{r}53,833 \\
\ldots . . .6 .\end{array}$ & $\begin{array}{l}1,110 \\
7,502\end{array}$ & $\begin{array}{r}538 \\
3,001\end{array}$ & $\begin{array}{r}.021 \\
\ldots . .\end{array}$ & $\begin{array}{l}48.50 \\
40.00\end{array}$ \\
\hline & ...... & 321,573 & 143,258 & .. & $\cdots$ \\
\hline $\begin{array}{l}1 \mathrm{e} l \mathrm{~b} \ldots \ldots \\
1 \frac{1}{2} \mathrm{e} 1 \mathrm{~b} \ldots \ldots\end{array}$ & $\begin{array}{r}364,805 \\
37,557\end{array}$ & $\begin{array}{l}6,091 \\
1,014\end{array}$ & $\begin{array}{r}3,648 \\
563\end{array}$ & $\begin{array}{l}.017 \\
.027\end{array}$ & $\begin{array}{l}59.90 \\
55.56\end{array}$ \\
\hline $\begin{array}{l}50 \mathrm{e} \text { gross.. } \\
40 \% \text {....... }\end{array}$ & $\begin{array}{r}\quad 517 \\
\ldots \ldots \ldots\end{array}$ & $\begin{array}{r}371 \\
142,365\end{array}$ & $\begin{array}{r}259 \\
52,946\end{array}$ & $\begin{array}{r}.718 \\
\ldots . . .\end{array}$ & $\begin{array}{l}69.68 \\
40.00\end{array}$ \\
\hline $\begin{array}{l}1 \mathrm{e} 1 \mathrm{~b} . . . . \\
1_{2}^{1} \mathrm{e} 1 \mathrm{~b} . \ldots\end{array}$ & $\begin{array}{r}3,383,571 \\
672,364\end{array}$ & $\begin{array}{l}55,906 \\
14,940\end{array}$ & $\begin{array}{l}33,836 \\
10,085\end{array}$ & $\begin{array}{l}.017 \\
.022\end{array}$ & $\begin{array}{l}60.52 \\
67.51\end{array}$ \\
\hline $\begin{array}{l}50 \text { e gross.. } \\
40 \% \text {......... }\end{array}$ & $\begin{array}{r}979 \\
\ldots \ldots\end{array}$ & $\begin{array}{r}601 \\
190,042\end{array}$ & $\begin{array}{r}489 \\
76,017\end{array}$ & $\begin{array}{r}.614 \\
\ldots . .\end{array}$ & $\begin{array}{l}81.44 \\
40.00\end{array}$ \\
\hline $\begin{array}{l}1 \mathrm{e} \mathrm{lb} . \ldots \ldots \\
40 \% \ldots \ldots\end{array}$ & $\begin{array}{r}30,590 \\
\ldots . . . \ldots\end{array}$ & $\begin{array}{r}708 \\
8,479\end{array}$ & $\begin{array}{r}306 \\
3,392\end{array}$ & $\begin{array}{r}.023 \\
\ldots . . .\end{array}$ & $\begin{array}{l}43.21 \\
40.00\end{array}$ \\
\hline & & 420,517 & 181,541 & ...... & \\
\hline
\end{tabular}


Table 125.-Imports of Bottles and Vials, Not Ornamented, and Demijohns and Carboys, All Empty, Ordinarily Used as Containers in Transportation, Entered for Consumption, Fiscal Year Ending June 30, 1896 to 1915Continued.

\begin{tabular}{|c|c|c|c|c|c|c|}
\hline Fiscal years and classification. & $\begin{array}{l}\text { Rates of } \\
\text { duty. }\end{array}$ & Quantity. & Value. & Duties. & $\begin{array}{l}\text { Value } \\
\text { per } \\
\text { unit of } \\
\text { quan- } \\
\text { tity. }\end{array}$ & $\begin{array}{l}\text { Actual } \\
\text { and } \\
\text { com- } \\
\text { puted } \\
\text { ad va- } \\
\text { lorem } \\
\text { rate. }\end{array}$ \\
\hline 1908-DINGLEY ACT. & & & & & & \\
\hline $\begin{array}{l}\text { Bottles, vials, and jars, flint, liune, or lead: } \\
\text { Holding more than } 1 \text { pint (pounds) } . . . . \text {. }\end{array}$ & $1 \mathrm{elb}$. & 573,450 & $\$ 11,275$ & $\$ 5,735$ & $\$ 0.020$ & $\begin{array}{l}\text { Per }{ }^{*} c t . \\
50.86\end{array}$ \\
\hline $\begin{array}{l}\text { Holding not more than } 1 \text { pint and not less than } \\
\text { pint (pounds). }\end{array}$ & $1 \frac{1}{2} \mathrm{elb}$ & 102,257 & 2,558 & 1,534 & .025 & 59.96 \\
\hline Holding less than $\frac{1}{4}$ pint (gross) . . . . . . . . . . . & 50 e gross.. & 1,505 & 1,334 & 753 & .886 & 56. 40 \\
\hline $\begin{array}{l}\text { Other on which specific duty would be less } \\
\text { than } 40 \text { per cent. } \\
\text { Bottles, vials, and jars, plain, green, or colored, } \\
\text { molded or pressed: }\end{array}$ & $40 \% \ldots \ldots$ & & 27,486 & 10,994 & & 40.00 \\
\hline Holding more than 1 pint (pounds) ............. & le lb & $3,573,063$ & 59,957 & 35,731 & .017 & 59. 99 \\
\hline $\begin{array}{l}\text { Holding not more than } 1 \text { pint and not less than } \\
\text { pint (pounds). }\end{array}$ & $1 \frac{1}{2} \mathrm{elb}$ & 482,986 & 11,206 & 7,245 & .023 & 64.65 \\
\hline Holding less than $\frac{1}{4}$ pint (gross).. & $50 \mathrm{e}$ gross. & 627 & 474 & 314 & .756 & 66.16 \\
\hline $\begin{array}{l}\text { Other on which specific duty would be less } \\
\text { than } 40 \text { per cent }\end{array}$ & $40 \% \ldots .$. & & 165,892 & 66,357 & ........ & 40.00 \\
\hline $\begin{array}{l}\text { Demijohns and carboys, covered or uncovered: } \\
\text { Holding more than } 1 \text { pint (pounds) } . . . . . . . .\end{array}$ & $1 e \mathrm{lb}$ & 7,511 & 171 & 75 & .023 & 44.05 \\
\hline $\begin{array}{l}\text { Other on which specific duty would be less } \\
\text { than } 40 \text { per cent. }\end{array}$ & $40 \%$ & & 13,147 & 5,259 & ....... & 40.00 \\
\hline Total & $\ldots \ldots . .$. & & 293,500 & 133,997 & ..... & $\therefore$ \\
\hline 1909-DINGLEY ACT. & & & & & & \\
\hline $\begin{array}{l}\text { Bottles, vials, and jars, flint, lime, or lead: } \\
\text { Holding more than } 1 \text { pint (pounds)..... }\end{array}$ & $1 \mathrm{c} \mathrm{lb}$ & 352,598 & 7,513 & 3,526 & .021 & 46.93 \\
\hline $\begin{array}{l}\text { Holding not more than } 1 \text { pint and not less than } \\
1 \text { pint (pounds). }\end{array}$ & $1 \frac{1}{2} \mathrm{ell}$ & 37,711 & 835 & 566 & .022 & 67.75 \\
\hline Holding not less than ${ }^{1}$ pint (gross) $\ldots . . . . . . .$. & 50 e gross. . & 340 & 259 & 170 & .762 & 65.61 \\
\hline $\begin{array}{l}\text { Other on which specific duty would be less } \\
\text { than } 40 \text { per cent. }\end{array}$ & $40 \%$. & & 30,740 & 12,296 & & 40.00 \\
\hline $\begin{array}{l}\text { Bottles, vials, and jars, plain, green, or colored, } \\
\text { molded or pressed: }\end{array}$ & & & & & & \\
\hline Holding more than 1 pint (pounds) & $1 \notin \mathrm{lb}$. & $1,487,409$ & 26,989 & 14,874 & .018 & 55.11 \\
\hline $\begin{array}{l}\text { Holding not more than } 1 \text { pint and not less than } \\
\frac{1}{4} \text { pint (pounds). }\end{array}$ & $1 \frac{1}{2 c}$ & 133,508 & 3,147 & 2,003 & .024 & 63.63 \\
\hline Holding not less than $\frac{1}{1}$ pint (gross) .............. & $50 e \mathrm{~g}$ & 918 & 652 & 459 & .710 & 70.41 \\
\hline $\begin{array}{l}\text { Other on which specific duty would be less } \\
\text { than } 40 \text { per cent. }\end{array}$ & $40 \%$ & & $.132,884$ & 53,154 & & 40.00 \\
\hline $\begin{array}{l}\text { Iemijohns and carboys, covered or uncovered: } \\
\text { Holding more than } 1 \text { pint (pounds).......... }\end{array}$ & $1 \notin 1$ & 5,880 & 144 & 59 & .024 & 40.83 \\
\hline $\begin{array}{l}\text { Other on which specific duty would be less } \\
\text { than } 40 \text { per cent. }\end{array}$ & $40 \%$ & & 3,255 & 1,302 & & 4000 \\
\hline Total. & & & $.206,418$ & 88,409 & & \\
\hline $\begin{array}{l}\text { 1910-DiNGley ACT To AUg. 6, 1909; PAXNe- } \\
\text { AldRICH ACT AFTER WARDS. }\end{array}$ & & & & & & \\
\hline $\begin{array}{l}\text { Bottles, vials, and jars, flint, lime, or lead: } \\
\text { Holding more than } 1 \text { pint (pounds).......... }\end{array}$ & $1 \notin \mathrm{lb}$ & 312,195 & 5,590 & 3,122 & .018 & 55.85 \\
\hline Holding not more than 1 pint and not less than & $1 \frac{1}{2} \phi \mathrm{lb}$. & 12,522 & 352 & 188 & .028 & .53 .37 \\
\hline 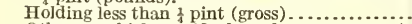 & $50 €$ & 138 & 154 & 69 & 1.120 & 44.92 \\
\hline $\begin{array}{l}\text { Other on which specifie duty does not amount } \\
\text { to } 40 \text { per cent. }\end{array}$ & & & 11,070 & 4,428 & & 40.00 \\
\hline $\begin{array}{l}\text { Bottles, vials, and jars, flint, lime, or lead: } \\
\text { Holding more than } 1 \text { pint (pounds)........... }\end{array}$ & 10 & $1,799,797$ & 31,498 & 17,998 & .018 & 57.14 \\
\hline Holding not more than 1 pint and not less than & $1 \frac{1}{2} \mathrm{e}$ & 191,940 & 4,019 & 2,879 & .021 & 71. 63 \\
\hline Holding less than $\frac{1}{4}$ pint (gross) . ........................ & $50 e \mathrm{~g}$ & 908 & 720 & 454 & .793 & 63.02 \\
\hline $\begin{array}{l}\text { Other on which specific duty does not amount } \\
\text { to } 40 \text { per cent. }\end{array}$ & $40 \%$ & & $.239,517$ & 95,807 & & 40.00 \\
\hline $\begin{array}{l}\text { Demijohns and carboys, covered or uncovered: } \\
\text { Other on which specific duty does not amount } \\
\text { to } 40 \text { per cent. }\end{array}$ & $40 \%$ & & 7,555 & 3,022 & & 40.00 \\
\hline Tota & & & 475 & 127,967 & & \\
\hline
\end{tabular}


Table 125.-Imports of Bottles and Vials, Not Ornamented, and Demijohns and Carboys, All Empty, Ordinarily Úged as Containers in Transportation, Entered for Consumption, Fiscal Year Ending June 30, 1896 to 1915Continued.

Fiscal years and classification.

Bottles, vials, and jars, plain, green, or colored, molded or pressed, and flint, lime, or lead: Holding more than 1 pint (pounds) . ........... 1 pint (pounds).

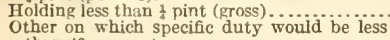
than 40 per cent.

Demijohns and carboys, covered or uncovered. Other on which specific duty would be less than 40 per cent.

Total.

\section{2-PAYNE-ALDRICH ACT.}

Bottles, vials, and jars, plain, green, or colored, molded or pressed, and flint, lime, or lead: Holding more than 1 pint (pounds).......... Holding not more than 1 pint and not less than 1 pint (pounds)

Holding less than $\frac{1}{4}$ pint (gross) ............... Other on which specific duty would be less than 40 per cent.

Demijohns and carboys, covered and uncovered: Other on which specific duty would be less than 40 per cent.

Total.

\section{3-PAYNE-ALDRICH ACT.}

Bottles, rials, and jars, plain. green, or colored, molded or pressed, and flint, lime, or lead:

Holding more than 1 pint (pounds).

Holding not more than 1 pint and not less than $\frac{2}{4}$ pint (pounds).

Holding less than \& pint (gross) ..................

Other on which specific duty would be less than 40 per cent.

Iemijohns and carboys, covered and uncovered: Other on which specific duty would be less than 40 per cent.

Total.

1914-PAYNE-ALDRICH ACT TO OCT. 4, 1913; UNDERWOOD-STMMONS ACT AFTERWARD。

Bottles, vials, and jars, plain, green, or colored, molded or pressed, and flint, lime, or lead, not specially provided for:

Holding more than 1 pint (pounds).

Holding not more than 1 pint and not less than 1 pint (pounds).

Holding less than 1 pint (gross).............. Other on which s pecific duty does not amount to 40 per cent.

All sizes (under act of 1913) (pounds)........

Demijohns and carboys, covered and uncovered: Other on which specific duty would be less than 40 per cent.

Under act of 1913 (pounds).

Total.

a July 1 to Oct. 3, 1913, under act of 1909.

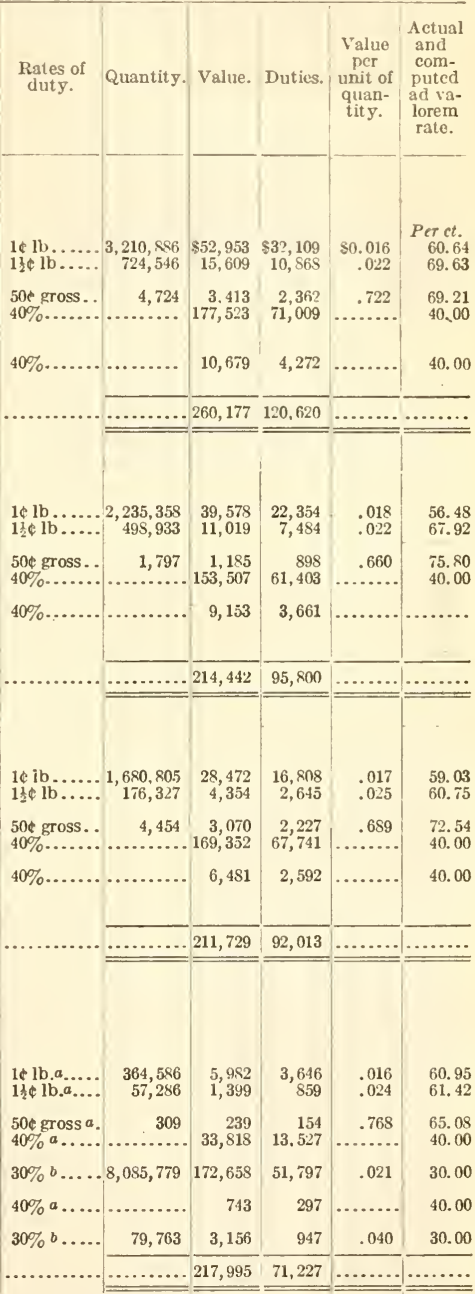

b Oct, 4, 1913, to June 30, 1914, under act of 1913. 
Table 125.-Imports of Bottles and Vials, Not Ornamented, and Demijohns and Carboys, All Empty, Ordinarily Used as Containers in Transportation, Entered for Consumption, Fiscal Year Ending June 30, 1896 to 1915Concluded.

Fiscal years and classification.

\section{5-UNDERWOOD-SIMMONS ACT.}

Bottles, vials, and jars, plain, green, or colored, molded or pressed, and flint, lime, or lead, not specially provided for: Bottles, vials, and jars (pounds).

Demijohns and carboys, covered and uncovered (pounds).

Total.

\section{6-UNDERWOOD-STMMONS ACT.}

Bottles, vials, and jars, plain, green, or colored, molded or pressed, and flint, lime, or lead, not specially provided for: Bottles, vials, and jars (pounds).

Demijohns and carboys, covered and uncovered (pounds).

Total.

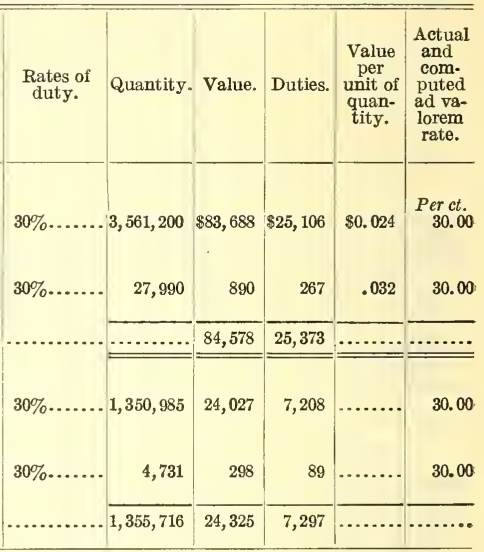

Table 126.--Imports of Bottles, Decanters, and All Articles of Glass of Every Description, Ornamented or Decorated in any Manner, Entered for Consumption, Fiscal Years Ending June 30, 1896 to 1915.

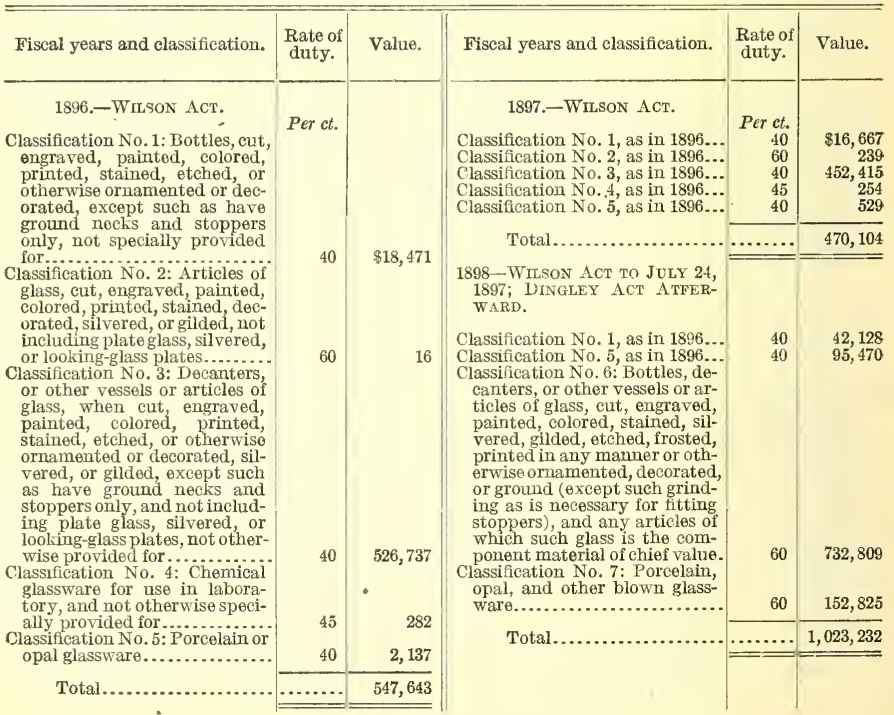


Table 126.-Imports of Bottles, Decanters, and All Articles of Glass op Every Description, Ornamented or Decorated in any Manner, Entered for Consumption, Frscal Years Ending June 30, 1896 to 1915-Concluded.

Fiscal years and classification.

\section{9-Dingley ACT.}

Classification No. 6, as in 1898 .. Classification No. 7, as in $1898 .$.

Total.

1900-Dingley ACT.

Classification ․o. 6, as in 1898... Classification No. 7, as in 1898..

Total.

1901-Dingley ACt.

Classification No. 6, as in 1898... Classification No. 7, as in $1898 .$.

Total.

1902-Dingley ACT.

Classification No. 6, as in 1898 ... Classification No. 7 , as in $1898 .$.

Total.

1903-Dinglex ACT.

Classification No. 6 , as in 1898 ... Classification No. 7, as in 1898 .

Total

\section{4-DingLex ACT.}

Classification No. 6, as in 1898 ... Classification No. 7, as in 1898..

Total.

\section{5-DiNgLey ACT.}

Classification No. 6, as in 1898 .. Classification No. 7, as in 1898..

Total.

\section{6-DingLey ACT.}

Classification No. 6, as in 1898 ... Classification No. 7, as in 1898..

Total.

1907-Dingley ACT.

Classlfication No. 6, as in 1898 . Classification No. 7, as in 1898. ..

Total.

\begin{tabular}{l|l}
60 & $1,627,914$
\end{tabular}

$60 \quad 134,149$

...... $1,762,063$

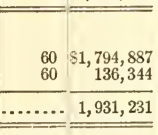

$60 \$ 1,078,213$

$60 \quad 86,410$

...... $\overline{1,164,653}$

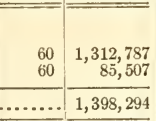

\begin{tabular}{rr}
\hline & \\
60 & $1,318,643$ \\
60 & 142,122 \\
\hline$\ldots \ldots \ldots$. & $1,460,765$ \\
\hline
\end{tabular}

$60 \quad 113,705$

….. $1,521,700$

$60 \quad 1,564,548$

$60 \quad 122,290$

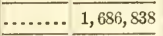

(

$60 \quad 1,742,333$ \begin{tabular}{lr}
60 & $\frac{243,908}{1,986,241}$ \\
\cline { 1 - 2 } & $1,96 .$. \\
\hline
\end{tabular}

1908-DingLeX ACr.

Classification No. 6, as in 1898 . Classification No. 7, as in $1898 . .$.

Total.

$60 \quad 1,463,466$ $60 \quad 313,656$

1909-Dingley ACT.

Classification No. 6, as in 1898 .. Classification No. 7, as in 1898 .

Total

$601,267,705$

108,672 \begin{tabular}{c|c}
60 & 108,672 \\
\hline$\ldots \ldots . .$. & $1,376,377$
\end{tabular}
Classification No. 8, as in 1910 Classification No. 9 , as in $1910 .$. .

Total.

1912-PAYNE-ALDRICH ACT.

Classification No. 8, as in $1910 .$. Classification No. 9, as in $1910 .$.

Total.

1913-PAYNE-ALDRICH ACT. Classification No. 8 , as in $1910 .$. Classification No. 9, as in 1910...

Total.

1914-PAYNE-ALDRTCH ACT TO OCT. 4, 1913; UNDERWOODSIMMONS ACT AFTERWARD.

Classification No. 8, as in $1910 .$. Classification No. 9, as in $1910 .$.

Total.

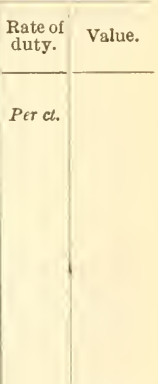

$60 \$ 1,086,209$

$60 \quad 613,957$ ........ $1,700,166$ \begin{tabular}{rrr}
60 & $\begin{array}{r}1,341,976 \\
684,178\end{array}$ \\
\cline { 1 - 2 } & $\frac{2,026,154}{2 . \ldots .}$
\end{tabular}
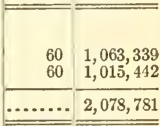

$60 \quad 1,029,730$

$60 \quad 1,072,249$ ...... $2,101,979$ $\underline{\underline{ }}$

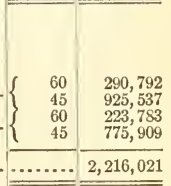

1915-UNDERWOOD-SIMMONS A.T.

Classification No. 8, as in 1910. Classification No. 9, as in $1910 . .$.

Total.

1916-UNDERWOOD-SIMMONS ACT.

Classification No. 8, as in $1910 .$. Classification No. 9 , as in $1910 .$. .

Total.

310,445

$45 \quad 304,468$ 
Table 127.-Value of Imports of Cylinder, Crown, and Common Window Glass, Other than Specified in Table 122, Fiscal Years Endrng June 30, 1909, 1913, and 1914, with Average Computed Ad Valorem Rates of Duty, Under Tariff ACts of 1897, 1909, and 1913.

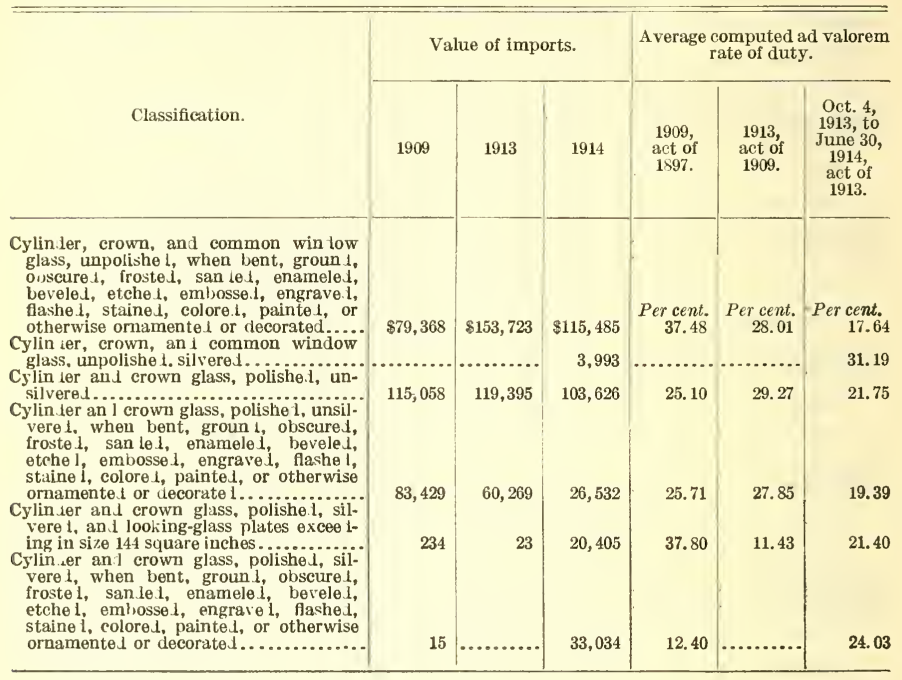


Table 128.-Value of Imports of Plate Glass, Other Than Specified in Table 124, Fiscal Years Ending June 30, 1909, 1913, and 1914, with Average Computed Ad Valorem Rates of Duty, Under Tariff Acts of 1897, 1909, AND 1913.

\begin{tabular}{|c|c|c|c|c|c|c|}
\hline \multirow[b]{2}{*}{ Classification. } & \multicolumn{3}{|c|}{ Value of imports. } & \multicolumn{3}{|c|}{$\begin{array}{l}\text { Average computed ad valorem } \\
\text { rate of duty. }\end{array}$} \\
\hline & 1909 & 1913 & 1914 & $\begin{array}{l}1909 \text {, } \\
\text { act of } \\
1897 \text {. }\end{array}$ & $\begin{array}{l}1913 \text {, } \\
\text { act of } \\
1909 \text {. }\end{array}$ & $\begin{array}{l}\text { Oct. 4, } \\
1913, \text { to } \\
\text { June } 30, \\
1914, \\
\text { act of } \\
1913 \text {. }\end{array}$ \\
\hline $\begin{array}{l}\text { Plate glass, fluted, rolled, ribbed, or rough, } \\
\text { or the same containing a wire netting } \\
\text { within itself (excess of } 1 \text { pound per square } \\
\text { foot dutiable at same rates).............. }\end{array}$ & \multirow[t]{2}{*}{$\$ 13,573$} & \multirow[t]{2}{*}{$\$ 14,812$} & \multirow{2}{*}{$\$ 12,239$} & \multirow[t]{2}{*}{$\begin{array}{r}\text { Per cent. } \\
29.00\end{array}$} & \multirow[t]{2}{*}{$\begin{array}{r}\text { Per cent. } \\
36.08\end{array}$} & \multirow[t]{2}{*}{$\begin{array}{r}\text { Per cent. } \\
25.33\end{array}$} \\
\hline 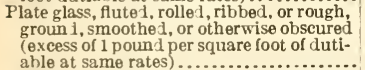 & & & & & & \\
\hline $\begin{array}{l}\text { Plate glass, cast, polished, unsilvered, } \\
\text { when bent, groun } 1 \text {, obscure } 1 \text {, frosted, } \\
\text { san } 1 \text { 1, enameled, beveled, etched, em- } \\
\text { bosse } 1 \text {, engraved. flashed, staine } 1 \text {, col- } \\
\text { ore 1, painte } 1 \text {, or otherwise ornamented }\end{array}$ & 103,758 & 2,247 & 123,992 & 46.45 & 68.69 & 44.95 \\
\hline 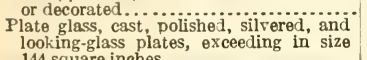 & 7,966 & 47,449 & 52,280 & 20.61 & 33.90 & 25.99 \\
\hline 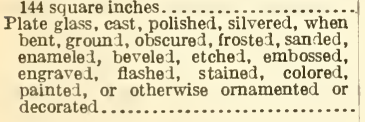 & 533 & 527 & 4,805 & 51.92 & 26.91 & 39.18 \\
\hline
\end{tabular}

Table 129.-Value of Imports of Bottles, Vials, Demuohns, Carboys, and Jars, all Filled, Fiscal Years Ending Jone 30, 1909, 1913, and 1914, with Average Actual and Computed Ad Valorem Rates of Duty, Under Acts OF 1897, 1909, AND 1913.

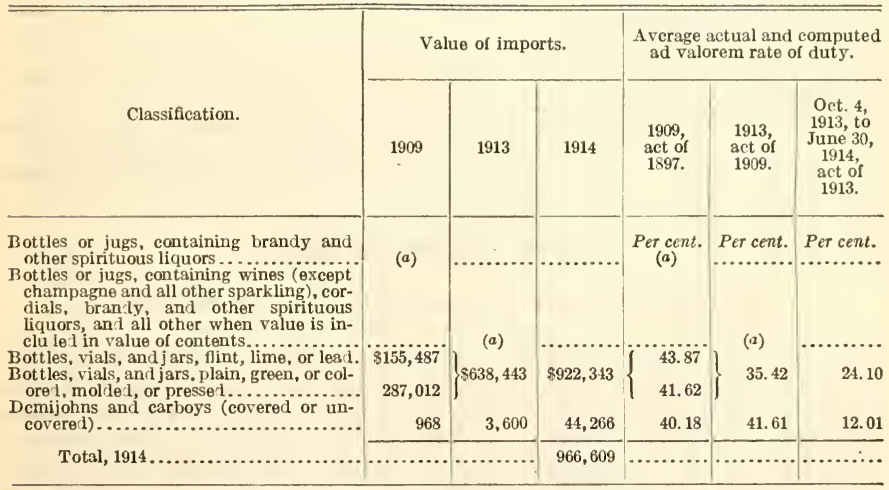

$a$ Value of bottles is returned with value of contents. 
Table 130.-Values of Imports of Miscellaneous Mandfactures of Glass, not Shown in Foregoing Tables, Fiscal Years Ending June 30, 1909, 1913, and 1914, with Average Actual and Computed Rates of Duty Under Tariff ACTS of 1897, 1909, AND 1913.

\begin{tabular}{|c|c|c|c|c|c|c|}
\hline \multirow[b]{2}{*}{ Classification. } & \multicolumn{3}{|c|}{ Value of imports. } & \multicolumn{3}{|c|}{$\begin{array}{l}\text { Average actual and computed } \\
\text { ad valorem rate of duty. }\end{array}$} \\
\hline & 1909 & 1913 & 1914 & $\begin{array}{l}1909 \text {, } \\
\text { act of } \\
1897 \text {. }\end{array}$ & $\begin{array}{l}1913 \text {, } \\
\text { act of } \\
1909 .\end{array}$ & $\begin{array}{l}\text { Oct. } 4 \text {, } \\
1913, \text { to } \\
\text { June } 30, \\
1914, \\
\text { act of } \\
1913 .\end{array}$ \\
\hline $\begin{array}{l}\text { Enamel, white, for clock and watch dials.. } \\
\text { Enamel, fusible, and glass, n. s. p. f....... } \\
\text { Glass tiles or tiling, opal or cylinder...... }\end{array}$ & $\begin{array}{l}\$ 7,052 \\
21,431\end{array}$ & $\begin{array}{r}\$ 15,855 \\
11,997\end{array}$ & $\begin{array}{r}\$ 13,284 \\
13,567 \\
165\end{array}$ & $\begin{array}{l}\text { Per cent. } \\
\text { Free. } \\
25.00\end{array}$ & $\begin{array}{l}\text { Per cent. } \\
\text { Free. } \\
25.00\end{array}$ & $\begin{array}{l}\text { Per cent. } \\
\text { Free. } \\
20.00 \\
30.00\end{array}$ \\
\hline $\begin{array}{l}\text { Plates or disks, rough cut or unwrought, } \\
\text { for use in the manufacture of optical in- } \\
\text { struments, spectacles, end eyeglasses, } \\
\text { and suitable only for such use............... }\end{array}$ & \multirow{2}{*}{$\begin{array}{l}455,188 \\
108,672\end{array}$} & 499,364 & 612,830 & \multirow{2}{*}{$\begin{array}{l}\text { Free. } \\
60.00\end{array}$} & Free. & \\
\hline $\begin{array}{l}\text { Porcelain, opal. and other blown glassware. } \\
\text { All articles of every description, including } \\
\text { bottles and bottle glassware, composed } \\
\text { wholly or in chief value of glass, blown, } \\
\text { either in a mold or otherwise, n. s. p. f. }\end{array}$ & & 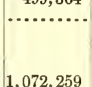 & $\begin{array}{r}012,000 \\
. . . . . . . . .\end{array}$ & & r ree. & r.eb. \\
\hline 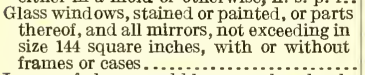 & \multirow[t]{2}{*}{178,289} & \multirow[t]{2}{*}{389,032} & \multirow[t]{2}{*}{290,090} & \multirow[t]{2}{*}{45.00} & \multirow[t]{2}{*}{45.00} & \multirow[t]{2}{*}{30.00} \\
\hline 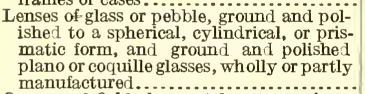 & & & & & & \\
\hline $\begin{array}{l}\text { Opera and field glasses, telescopes, micro- } \\
\text { scopes, photographic and projecting } \\
\text { lenses, and optical instruments, and } \\
\text { frames or mountings for same, n. s. p.f.. }\end{array}$ & \multirow[t]{2}{*}{391,344} & 546,941 & $a 333,388$ & 45.00 & 45.00 & 35.00 \\
\hline 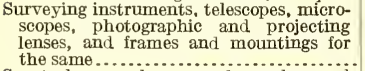 & & & 160,194 & & & 25.00 \\
\hline 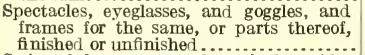 & \multirow[t]{2}{*}{57,341} & \multirow[t]{2}{*}{78,690} & 56,276 & 51.16 & \multirow[t]{2}{*}{51.44} & 35.00 \\
\hline $\begin{array}{l}\text { Strips of glass not more than } 3 \text { inches wide, } \\
\text { ground or polished on one or both sides } \\
\text { to a cylindrical or prismatic form, and } \\
\text { glass slides for magic lanterns............. }\end{array}$ & & & b 26,291 & 45.00 & & 25.00 \\
\hline $\begin{array}{l}\text { All other manufactures of glass or paste, or } \\
\text { of which glass or paste shall be the com- } \\
\text { ponent material of chief value, n. s. p. f.. }\end{array}$ & 517,211 & 414,775 & 353,850 & 45.00 & 45.00 & 30.00 \\
\hline
\end{tabular}

$a$ Not including telescopes, microscopes, photographic, añd projecting lenses, and frames, and mountings for the same.

$b$ Includes strips of glass used in the construction of gauges.

\section{TARIFF CLASSIFICATIONS.}

\section{DECISIONS REGARDING CLASSIFICATIONS OF IMPORTS.}

Under the present tariff law, as well as under preceding laws, the duty on "glassware composed wholly or in chief value of glass blown either in a mold or otherwise" carries a higher rate of duty than glassware made otherwise, that is, by pressing or casting, the present rate being 45 per cent on ware which is in chief value blown and 30 per cent on unornamented pressed ware. A decision made in 1916 by the Court of Customs Appeals permits much blown stem ware to be imported at the cheaper rate. This decision, manufacturers claim, does not give them the protection which Congress intended in enacting the tariff act of 1913 . 
The importers protested the merchandise was not composed in chief ralue of blown glass, and claimed that, under the tariff act of 1913 , the rate of duty should be 30 per cent instead of 45 per cent ad ralorem. The Board of General Appraisers sustained the protest and the Government appealed. The decision of the Court of Customs Appeals (T. D. 36457) follows:

The merchandise seems to be identical with that which was passed upon by this court in the case of Cnited States $v$. Gredelue (5 Ct. Cust. Appls., 298; T. 1). 34476), and the method of manufacturing the glassware there involved appears to be exactly the same as that employed in producing the goods now under consideration. In this case as in that two men are employed to make the bowl, one of whom carries a drop of molten glass to the blower, who blows the same in a mold into the form of a bowl with a boss-shaped top. After the blowing of the bowl a small quantity of the molten glass is bronght by a third workman to a fourth, who shapes it into the stem. Another drop of molted glass is then attached to the stem, which is shaped into the foot. Both stem and foot are made by the same workmen. In the Gredelue case the glassware was composed of blown glass and of molded glass, but whether the merchandise should be classified as blown glass rather than as a manufacture of glass depended wholly on which of the materials was the component of chief value. In order to determine the component of chief value it became necessary to ascertain the value of each of the constituents, and to do that only those expenses incurred in producing the constituents and not those assignable to the article itself could be taken into consideration. Accordingly, we laid down the rule that the value of the blown glass must be taken as of the time it became blown glass and the value of the molded glass as of the time that it became molded glass. The ruling, we think, was not dictum, but was necessary to the decision of the issues raised, inasmuch as the conclusion to be drawn from the testimony adduced as to the relative values of the component materials depended entirely upon the stage of manufacture to which such testimony was addressed.

In support of its appeal the Government contends, first, that in ascertaining the value of the stem no item of cost can be considered after the fused glass has been attached to the bowl, and that the value of the foot must be determined by the cost of the material and the expense incurred in attaching a drop of melted glass to the stem; second, that the witnesses for the importers failed to take into account the cost of removing the boss-shaped top which was blown as a part of the bowl and that therefore the value of the blown glass as fixed by them was less than the true value; and, third, that the testimony submitted by the importers established the value of the stem and the foot in their finished condition in the completed article, and that such value was greater than the true value inasmuch as it included costs incurred subsequent to the time when the stem and the foot became molded glass.

In answer to the first point, we think it is sufficient to say that the glassware is composed of blown glass and molded glase, and that the material in two drops of molten glass and the cost of attaching them to the bowl and the stem respectively does not represent the value of the molded glass, but that of molten glass in place for molding. Component material of chief value is defined by paragraph 481 of the tariff act of 1909 and by paragraph 385 of the act of 1913 as follows:

"The words 'component material of chief value,' wherever used in this section, shall be held to mean that component material which shall exceed in value any other single component material of the article; and the value of each componcnt material shall be determined by the ascertained value of such material in its condition as found in the article." (Italics ours.)

See Seeberger $v$. Hardy ( 150 U. S., 420, 424).

From these provisions it is apparent that Congress did not contemplate the taking of the value of the material put into the article (here molten glass), but the value of the component materials (here blown glass and molded glass).

As to the second point, we are of the opinion that the cost of removing the boss from the top of the bowl was not an expense incurred in blowing the glass or in making the blown glass of the bowl. In other words, the cost of removing the top was an expense incurred after the bowl had become blown glass, and could not be considered as a factor in determining the value of the blown glass in the bowl, which is the only blown glass in the completed article.

The claim made in the third point that the cost of finishing the stem and foot was included in fixing the value thereof we do not think is sustained by the evidence introduced by the importers. The record, as we read it, shows that the importers' witnesses included in the cost of producing the stem and the foot nothing more than 
the value of the molten material used, the expense of putting such material in place, and the labor cost of fashioning, but not of finishing, the stem and foot.

The decision of the Board of General Appraisers is affirmed.

Following is a list of decisions by the Treasury Department and the Board of General Appraisers in cases where controversies arose with regard to the classification of imports of glass and glassware under the tariff act of 1913 :

T. D. 34782. Hand reading glasses held dutiable as optical instruments, paragraph 93,35 per cent, and not as microscopes, paragraph 94,25 per cent, as claimed. September 28, 1914.

T. D. 35056. Stained glass windows, held free if imported to be used in houses of worship, paragraph 655. January 14, 1915.

T. D. 35167. Ornamented and decorated glassware, ornamented so as to give appearance of cut glass, held dutiable under paragraph 84, 45 per cent. February 25, 1915.

T. D. 35168 , G. A. 7690 . Stained glass windows for religious society; religious society need not be incorporated to come under paragraph 655. February 23, 1915.

T. D. 35283. Molded glass articles, cut to represent brilliants, dutiable under paragraph 95, 30 per cent; smaller sizes, paragraph 357, 20 per cent. April 2, 1915.

Abstract 37622. Glass lamp shades, classified under paragraph 358 , as manufactures of silk or cotton, held dutiable as manufactures of glass, paragraph 84,45 per cent. April 14, 1915.

Abstract 38025 . Containers, glass bottles covered with willow, classified under paragraph 173 , held free of duty as coverings of merchandise. July $6,1915$.

Abstract 38138 . Stained glass windows held free under paragraph 655. July 22, 1915.

Abstract 38304. Cylinder glass, silvered and beveled, classified as polished plate glass under paragraphs 88,89 , and 90 , held dutiable under paragraphs 86, 89, and 90 . August 26, 1915.

Abstract 38482 . Stained glass windows claimed free of duty under paragraph 655 , held dutiable under paragraph 95 . September 27, 1915.

Abstract 38569. Sand; manufactures of glass, classified as manufactures of glass, paragraph 95, 30 per cent, and as mineral substance, paragraph 81, 20 per cent, held free, as sand, paragraph 614 . October $15,1915$.

Abstract 38696 . Glass stem ware, classified under paragraph 84,45 per cent; some items found to be composed in chief value of plain glass and held dutiable under paragraph 95,30 per cent. October $29,1915$.

Abstract 39108. Glass sounding tubes, claimed dutiable, paragraph 95, 30 per cent, or paragraph 94,25 per cent, held rightly classified, paragraph 84,45 per cent. January $17,1916$.

Abstract 39403. Glass flower blocks, classified as blown glassware, paragraph 84, 45 per cent, held dutiable as manufactures of glass, paragraph 95, 30 per cent. March $16,1916$.

Abstract 39494. Glass bottles, decorated, ornamented with sprays of leaves and fruit, claimed dutiable as plain bottles, paragraph 83,30 per cent, design being trademark which protestants claimed should not be considered as decoration. Held dutiable as blown glassware, ornamented, paragraph 84, 45 per cent. April 4, 1915.

Abstract 39495. Window glass; glass signs, word "Exit" cut thereon, classified as articles of glass, cut or colored, held dutiable as window glass, flashed, paragraphs 85 and 90. April 4, 1915.

Abstract 39515. Glass rods, colored, milky color, tapered at ends, claimed dutiable as manufactures of glass, paragraph 95,30 per cent, held dutiable as articles of colored glass, paragraph 84. 45 per cent. April 6, 1916.

Abstract 39516. Magnifying glasses; linen provers, classified as optical instruments, paragraph 93, 35 per cent, held dutiable as microscopes, paragraph 94, 25 per cent. April 6, 1916.

Abstract 39687. Glass drinking sets, claimed dutiable either as being in chief value metal, paragraph 167, 20 per cent, or wood, paragraph 176, 15 per cent, held dutiable as blown glassware, paragraph 84,45 per cent. May 5, 1916.

Abstract 39725 . 'Glass vials; blown glass articles, classified, paragraph 84 , as articles in chief value of blown glass; held dutiable as plain glass vials, filled or unfilled, n. s. p. f., paragraph 83, 30 per cent. May 12,1916 .

Abstract 39829. Soap boxes of glass and metal; glass containers, metal covers, classified under paragraph 356 , held dutiable as articles of chief value of metal, paragraph 167, 50 per cent. May $31,1916$.

T. D. 36457. Glass stem ware: (1) In determining the value of each constituent of an article only those expenses incurred in producing the constituent, and not those 
assignable to the article, can be considered. (2) When an article is made of blown glass and molded glass, the one of chief value is the one which had the greatest value at the time it became blown glass or molded glass. (3) When an article is made of blown glass bowl and molded stem and foot, and the removal of the boss-shaped top blown on the bowl is necessary to the completion of the article, the cost of such removal, having been incurred after the bowl had become blown glass, is not a part of the value of the blown glass, but of the article. (4) Plain stemmed glassware, with blown bowl and molded stem and foot, the stem and foot being chief value, is dutiable as a manufacture of glass under paragraph 95, tariff act of 1913, and not as being in chief value of blown glass under paragraph 84. May 23, 1916.

Abstract 40123. Glass articles, classified as artificial flowers, paragraph 347, 60 per cent, held dutiable as glass articles, paragraph 84, 45 per cent. September 15, 1916.

A bstract 40315 . Glass vials, classified as blown glass articles under paragraph 84 , 45 per cent, held dutiable as containers, paragraph 83, 30 per cent. October 23,1916 .

T. D. 36393, G. A. 8005 . Pieces of painted or stained glass intend ed for use in repairing painted or stained glass windows in churches are free of duty under paragraph 655 , and are not dutiable under paragraph 95, as "stained or painted glass windows or parts thereof." It is not necessary for window glass to be imported for presentation to come under the provisions of paragraph 655. December 20, 1916.

\section{PRINCIPAL BRANCHES OF THE GLASS INDUSTRY.}

\section{The following statement, prepared by Mr. Nicholas Kopp, vice} president and general manager of the Pittsburgh Lamp, Brass \& Glass Co., suggests a general division of the glass industry into its principal branches for statistical and tariff purposes:

The classification in the tariff on imports of glass and glassware, which has not undergone a change for many years, should be worded with reference to the different branches into which this industry has developed.

There are from five to seven distinct divisions or branches in the glass industry. In some of these divisions a large investment in factory buildings and machinery is necessary and the labor cost is relatively low; in others the investment in buildings and machinery is small, but the labor cost is high, particularly that of skilled labor, while in still others, the investment in buildings and machinery is small, as is, also, the labor cost. Another branch requires only a room, Bunsen burners, and a very large percentage of labor, and especially skilled labor.

In order to arrive at a proper classification, it seems to me that these branches should be enumerated under separate classes. first, to make it possible to obtain better statistical reports; and, secondly, that the necessary tariff readjustments can be made from time to time without affecting other branches or divisions that have not undergone any special changes.

The industry in the United States at the present state of its development is divided in to the following distinctive branches:

1. Building glass.-Flat glass and bent glass, which again falls into the following branches:

(a) Window glass, flat or bent. Some one who is practical and efficient in this branch could prepare a proper classification according to the differences between plain ordinary glass or bent glass, single or double strength, high or low grade, decorated, stained, or otherwise ornamented. The introduction of window-glass machines has caused great changes in this branch of the industry. Under the old hand process only medium capital is required for the factory and equipment.

(b) Plate glass. One who is experienced in this industry could properly classify the rough glass, polished glass, thick or thin glass, opaque or colored glass. This branch requires larger capital than branch $(a)$ but probably less labor.

(c) Wire glass. Resembles rough plate glass.

(d) Cathedral glass. Can be produced with small amount of capital and small percentage of labor.

2. Blown and pressed glassware-

(a) All plain, colored or clear, ribbed, fluted or figured glassware, provided it consists of one kind of glass only, and provided the ribs, flutes, or figures are produced by molds while the glass is in its original semiplastic state. All glassware, either made offhand or blown, or pressed in mold or drawn out; all glassware such as decanters, pitchers, goblets, wines, liquors, bowls, dishes, plates, disks, bottles, shades, globes, electric bulbs, chimneys, lantern globes, tubes and rods, funnels, flasks, beakers, and articles of every description composed wholly or in chief value of one kind of glass, either pressed or blown, or both. 
(b) All of (a) glass, when plated, consisting of more than one kind of glass, or, when consisting of one kind of glass, but refined by cutting, etching, roughing, engraving, decorating, printing, staining, or improved or refined in any other manner not specially provided for, should be one-third more than class $(a)$. Requires medium size capital; uses more skilled labor.

3. Optical glass.--Rough, in lumps or partly formed, partly ground, fully shaped and ground, or polished, finished lenses, spectacle glasses. Common spectacle glasses, especially colored, belong to class $(a)$, No. 1 .

4. Enamels, colors, fluxes, lusters, for use in decorating glass, china, and porcelain, by firing same, being in either lumps or ground. (Mostly imported, composed of silica, borax, and lead.)

5. Glass beads and buttons, either loose or mounted; colored, silvered, gilted, cut or plain; imitation glass jewels, pressed, cut, silvered, gilted, clear or opaque, colored; Christmas-tree ornaments, colored, plain, decorated, silvered, gilted. This industry is mostly carried on in the homes in Europe or in large rooms in this country, with the aid of Bunsen burners, hence called "lamp work."

6. Chemical apparatus, instruments, also glass eyes and thermometer glass, produced in similar ways as No. 5, viz, by lamp workers, but requiring a larger amount of skilled labor.

\section{CLASSIFICATION UNDER TARIFF ACT OF 1913.}

While the rates of duty have been changed under all tariff acts, there has been very little change in the classification of glass and glassware in recent acts. The classification of all glass products specified in the act of 1913, except of cylinder, crown, and common window glass and of plate glass, is shown below:

\section{SCHEDULE B-EARTHENWARE AND GLASSWARE.}

Par. 83. Plain green or colored, molded or pressed, and flint, lime, or lead glass bottles, vials, jars, and covered and uncovered demijohns, and carboys, filled or unfilled, when suitable for use as and of the character ordinarily employed as containers for the holding or transportation of merchandise, not specially provided for; 30 per cent.

Par. 84. Bottles, decanters, and all articles of every description, composed wholly or in chief value of glass, ornamented or decorated in any manner, or cut, engraved, painted, decorated, ornamented, colored, stained, silvered, gilded, etched, sandblasted, frosted, or printed in any manner, or ground (except such grinding as is necessary for fitting stoppers or for purposes other than ornamentation), not specially provided for; 45 per cent.

Par. 84. All articles of every description, including bottles and bottle glassware, composed wholly or in chief value of glass blown either in a mold or otherwise, not specially provided for; 45 per cent.

Par. 91. Spectacles, ey eglasses, and goggles, and frames for the same, or parts thereof, finished or unfinished; 35 per cent.

Par. 92. Lens ss of giass or pabble, molded or pressed, or ground and polished to a sph rical, cylindrical, or pismatic form, and ground and polished plano or coquille glasses, wholly or partly manulactured; 25 per cent.

Par. 92. Strips of glass, not more than 3 inches wide, ground or polished on one or both sides to a cylindrical or primatic form, including those used in the construction of gauges and glass slides for magic lanterns; 25 per cent.

Par. 93. Opera and field glasses, optical instruments, and frames and mountings for the same; 35 per cent.

Par. 94. Surveying instruments, telescopes, microscopes, photographic and projecting lenses, and frames and mountings for the same; 25 per cent.

Par. 95. Glass windows, stained or painted, or parts thereof; 30 per cent.

Par. 95. Mirrors, not exceeding in size 144 square inches, with or without frames or cases; 30 per cent.

Par. 95. Incandescent electric light bulbs and lamps; 30 per cent.

Par. 95. All manufactures of glass or paste, or of which glass or paste is the component material of chief value, not specially provided for; 30 per cent.

Par. 96. Enamel, not specially provided for, fusible and glass; 20 per cent.

Par. 96. Glass tiles or tiling, opal or cylinder; 30 per cent. 
SCHEDULE C-METALS, AND MANUFACTURES OF.

Par. 161. Watch movements, whether imported in cases or not, watchcases and parts of watches (including watch crystals); 30 per cent.

Par. 167. Articles or wares not specially provided for (including are lamps); 20 per cent.

SCHEDULE H-SPIRITS, WINES, AND OTHER BETERAGES.

Par. 249. Bottles and containers filled with natural or imitations of mineral waters; one-third the rates that would be charged thereon if imported empty or separately.

\section{SCHEDULE N-SUNDRIES.}

Par. 333. Beads and spangles of all kinds, including imitation pearl beads, not threaded or strung, or strung loosely on thread for facility in transportation only; 35 per cent.

Par. 333. ('urtains, and other articles not embroidered or appliquéd, not specially' provided for, composed wholly or in chief value of beads and spangles made of glass or paste, gelatin, metal, or other material: 50 per cent.

Par. 339. Buttons not specially provided for; includes glass buttons; 40 per cent.

Par. 342. All toys, and parts of toys, not composed of china, porcelain, parian, bisque, earthen, or stone ware, and not specially provided for; includes glass (hristmas-tree ornaments: 35 per cent.

Par. 347. Artificial or ornamented feathers, suitable for use as millinery ornaments, artificial and ornamented fruits, grains, leaves, flowers, and stems or parts thereof, of whatever material composed, not specially provided for; 60 per cent.

Par. 356. Imitation precious stones and gems; 60 per cent.

Par. 356. Stampings, galleries, mesh and other materials of metals, whether or not set with glass or paste, finished or partly finished, separate or in strips or sheets, suitable for use in the manufacture of articles worn on apparel or carried on or about or attached to the person, including bracelets, buckles, dress buttons, mesh bags and purses, and millinery and hair ornaments; 50 per cent.

Par. 380. Photographic cameras, and parts thereof, not specially provided for, and photographic dry plates, not specially provided for; 15 per cent.

Par. 384. Waste, not specially provided for; includes cullet; 10 per cent.

FREE LIST.

Par. 493. Enamel, white, for watch and clock dials; free.

Par. 494. Plates or disks, rough-cut or unwrought, for use in the manufacture of optical instruments, spectacles, and eyeglasses, and suitable only for such use; free.

Par. 573. Philosophical and scientific apparatus, utensils, instruments, and preparations, including bottles and boxes containing the same, specially imported in good faith for the use and by order of any society or institution incorporated or established solely for religious, philosophical, educational, scientific, or literary purposes, or for encouragement of the fine arts, or for the use and by order of any college, academy, school, or seminary of learning, or any State or public library, and not for sale, and articles solely for experimental purposes; free.

\section{SUGGESTED CLASSIFICATION.}

None of the manufacturers or importers interviewed during this investigation made any complaint about the tariff classification of any kind of building glass in the tariff act of 1913 . The classifications of other glass products, however, were criticized, and suggestions were made that some of them might be improved by making them more specific. The tariff classifications of many foreign countries are much more detailed than those in the tariff law of the United States. The classifications which follow embody suggestions received from American manufacturers and importers and some items that appear in the tariff laws of foreign countries. These classifications have been approved by the tariff committee of the American Association of Flint and Lime Glass Manufacturers. 
GLASS AND GLASSWARE, NOT ELSEWHERE SPECIFIED.

Bottles, vials, jars, demijohns, and carboys, suitable for use as and of the character ordinarily employed as containers for the holding or transportation of merchandise, not specially provided for:

Bottles, vials, and jars-

Empty.

Filled.

Containing mineral waters.

Demijohns and carboys (covered or uncovered)-

Empty.

Filled.

Containing mineral waters.

Double-wall vacuum bottles or other vessels of chief value of glass-

Mounted, in a container of metal or other material.

Unmounted.

Electric-lighting goods, wholly or in chief value of glass:

Arc lamps.

Incand escent lamps.

Incandescent lamp bulbs, and tubing for making them.

Chimneys for oil lamps.

Chimneys for gas lamps and tubing for making them.

Articles composed wholly or in chief value of glass, including globes, shades, candler sticks, candelabra, chandeliers, and other articles, and parts of, regardless oshape, that can be used in connection with oil, gas, electricity, or any othef artificial method of illumination, whether completed or partially completed, colorless, colored, opal, opaque, or semitranslucent, whether blown, molded, pressed, or made in any other manner, not specially provided for:

Cut or ground, except to efface the marks of the pontee, engraved, painted, stained, fumed, silvered, gilded, etched, sand blasted, frosted, printed, or ornamented or decorated in any manner.

Not cut or ground, except to efface the marks of the pontee, and not engraved, painted, stained, fumed, silvered, gilded, etched, sand blasted, frosted, printed, or ornamented or decorated in any manner.

All articles of every description, including bottles, decanters, and all kinds of tableware, blown in a mold or otherwise, and all kinds of stem ware, either with pulled-out stems and cast feet or with cast stems and cast feet, composed wholly or in chief value of glass, not specially provided for:

Glass of one color, plain, sand blasted, or frosted.

Glass of more than one color, plain, sand blasted, or frosted.

Cut, ground, etched, engraved, silvered, painted or decorated in any manner except by sand blasting or frosting, or with gold, except the grinding of stoppers or stopper necks, and except effacing marks of the pontee.

Decorated with gold.

Articles of every description composed wholly or in chief value of pressed glass, not specially provided for:

Plain, or without ornamentation except from the mold and without cutting or grinding except to efface mold marks.

Cut or ground or otherwise ornamented.

Glass windows, stained or painted, or parts thereof.

Mirrors, not exceeding in size 144 square inches, with or without frames or cases.

Cut to size, adapted for use in the manufacture of dry plates for photographic purposes, when imported by the manufacturers of such dry plates for use exclusively in the manufacture thereof in their own factories.

Dry plates for photographic purposes, covered on one side with a sensitive substance, with or without negative pictures thereon.

Strips of glass, not more than 3 inches wide, ground or polished on one or both sides to a cylindrical or prismatic form, including those used in the construction of gauges and glass slides for magic lanterns.

Photographic cameras, and parts of.

Lenses of glass or pebble, molded or pressed, or ground and polished to a spherical, cylindrical, or prismatic form, and ground and polished plano or coquille glasses, wholly or partly manufactured.

Spectacles, eyeglasses, and goggles, and frames for the same or parts thereof, finished or unfinished.

Surveying instruments, telescopes, microscopes, photographic and projecting lenses, and frames and mountings for the same. 
Buttons, with or without eyelet holes, glass coral, glass balls, and glass drops, whether colored or not:

Not painted, and neither gilded nor silvered.

Pain ted, gilded, or silvered.

Imitation precious stones and gems.

Beads and spangles of all kinds, of white or colored glass, not threaded or strung, or strung loosely on thread for facility in transportation only:

Not painted, and neither gilded nor silvered.

Painted, gilded, or silvered.

Bracelets, earrings, brooches, ornaments for personal wear, and similar articles, not specially provided for.

Imitations of flowers, wreaths, leaves, grains or fruits, for use as millinery ornaments or for other purposes, made of glass, not specially provided for.

Curtains and other articles not embroidered or appliquéd, not specially provided for, compised wholly or in chief value of beads and spangles made of glass or paste, gelatin, metal, or other material.

Stampings, galleries, mesh, and other materials of metals, whether or not set with glass or paste, finished or partly finished, separate or in strips or sheets, suitable for use in manufacture of articles worn on apparel or carried on or about or attached to the person.

Watch crystals.

Enameled watch and clock dials.

Enameled articles not specially provided for.

Enamels and lusters, either lump or ground, for use in decorating glass, china, or porcelain, by firing same.

Toys and parts of toys, including Christmas-tree ornaments, not specially provided for.

Tiling, paving, or roofing, plain, opal, flat, or cylindrical.

Philosophical and scientific apparatus, utensils, instruments, and preparations, including bottles and boxes containing the same, specially imported in good faith for the use and by order of any society or institution incorporated or established solely for religious, philosophical, educational, scientific, or literary purposes, or for encouragement of the fine arts, or for the use and by order of any college, academy, school, or seminary of learning, or any State or public library, and not for sale, and articles solely for experimental purposes.

All other manufactures of glass or paste, or of which glass or paste is the component material of chief value, not specially provided for.

Cullet. 


\section{CHAPTER XI.}

\section{PRODUCTS EXPORTED.}

\section{GROWTH OF TRADE IN RECENT YEARS.}

The value of the imports of glass and glassware compared with the value of the production in the United States, as shown by Table 109, page 334, very materially decreased from 1879 to 1914 . Table 131 shows that the exports have increased more rapidly than the imports during the fiscal years ending June 30, 1905, to 1914, a month before the war in Europe began:

Table 131.-Value of Imports and Exports of Glass and Glassware for Fiscal YeARS ENDING JUNE 30, 1905 to 1916.

\begin{tabular}{|c|c|c|c|c|c|c|}
\hline & 1905 & 1906 & 1907 & 1908 & 1909 & 1910 \\
\hline $\begin{array}{l}\text { Imports for consumption....... } \\
\text { Domestic exports............... }\end{array}$ & $\begin{array}{r}\$ 5,965,256 \\
2,252,799\end{array}$ & $\begin{array}{r}\$ 7,552,771 \\
2,433,904\end{array}$ & $\begin{array}{r}\$ 7,600,142 \\
2,604,717\end{array}$ & $\begin{array}{r}\$ 6,545,636 \\
2,505,417\end{array}$ & $\begin{array}{r}\$ 5,299,987 \\
2,173,193\end{array}$ & $\begin{array}{r}\$ 6,626,997 \\
2,805,401\end{array}$ \\
\hline \multirow[t]{2}{*}{ 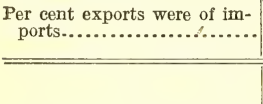 } & 37.76 & 32.23 & 34.27 & 38.28 & 41.00 & 42.33 \\
\hline & 1911 & 1912 & 1913 & 1914 & 1915 & 1916 \\
\hline $\begin{array}{l}\text { Imports for consumption....... } \\
\text { Domestic exports.............. }\end{array}$ & $\begin{array}{r}\$ 6,938,066 \\
3,246,391 \\
\end{array}$ & $\begin{array}{r}\$ 6,208,310 \\
3,494,153 \\
\end{array}$ & $\begin{array}{r}\$ 6,436,662 \\
4,193,642 \\
\end{array}$ & $\begin{array}{r}\$ 8,219,112 \\
3,729,623 \\
\end{array}$ & $\begin{array}{r}\$ 4,656,120 \\
5,558,717 \\
\end{array}$ & $\begin{array}{l}\$ 2,303,309 \\
12,321,338\end{array}$ \\
\hline 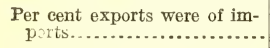 & 46.79 & 56.28 & 65.15 & 45.38 & . 119.39 & 534.94 \\
\hline
\end{tabular}

As appears in this table, the proportion of exports to imports increased from 37.76 per cent in the fiscal year 1905 to 65.15 in the fiscal year 1913, the last full year under the Payne-Aldrich Tariff Act. During the fiscal year 1914 this percentage fell to 45.38 , the Underwood-Simmons Act having been in force from October 4, 1913 . On account of the war in Europe, imports have greatly decreased, and the exports have enormously increased, as shown by the statistics for the fiscal years 1915 and 1916.

\section{TOTAL EXPORTS BY MONTHS.}

Table 132 shows the value of the total exports of glass and glassware, by months, from January, 1909, to December, 1916, together with the increase or decrease of the exports in each month, as compared with the exports in the corresponding month of the preceding year. 
Table 132.-Value of Total Domestic Exports of Glass and Glassware, by Months, From JaNuary, 1909, to JUNe, 1916.

AMOLNT OF DOMESTIC EXPORTS.

\begin{tabular}{|c|c|c|c|c|c|c|c|c|}
\hline Munths. & 1909 & 1910 & 1911 & 1912 & 1913 & 1914 & 1915 & 1916 \\
\hline 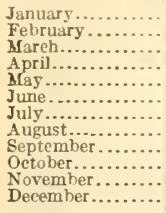 & $\begin{array}{l}\$ 135,732 \\
140,917 \\
177,244 \\
205, \$ 13 \\
207,585 \\
215,626 \\
207,693 \\
215,866 \\
229,920 \\
243,220 \\
294,934 \\
230,103\end{array}$ & $\begin{array}{r}\$ 216,312 \\
195,472 \\
239,220 \\
236,615 \\
249,210 \\
246,836 \\
274,017 \\
243,782 \\
247,549 \\
282,312 \\
286,459 \\
236,391\end{array}$ & $\begin{array}{l}\$ 245,773 \\
247,377 \\
253,027 \\
325,151 \\
303,122 \\
301,431 \\
248,533 \\
257,724 \\
265,663 \\
291,168 \\
295,399 \\
310,775\end{array}$ & $\begin{array}{r}\$ 254,552 \\
286,300 \\
269,637 \\
332,656 \\
344,274 \\
337,472 \\
327,391 \\
351,988 \\
297,132 \\
360,434 \\
379,613 \\
366,046\end{array}$ & $\begin{array}{l}\$ 319,188 \\
335,941 \\
336,028 \\
387,006 \\
380,697 \\
352,178 \\
326,627 \\
323,145 \\
275,343 \\
362,438 \\
345,497 \\
388,703\end{array}$ & $\begin{array}{l}\$ 251,427 \\
242,509 \\
312,500 \\
302,890 \\
319,647 \\
278,897 \\
304,764 \\
181,145 \\
241,447 \\
367,903 \\
269,193 \\
461,389\end{array}$ & $\begin{array}{r}\$ 114,690 \\
565,615 \\
698,672 \\
614,923 \\
689,117 \\
746,859 \\
914,912 \\
725,385 \\
927,945 \\
748,133 \\
998,121 \\
1,022,269\end{array}$ & $\begin{array}{r}\$ 971,125 \\
950,466 \\
1,102,933 \\
1,157,677 \\
1,403,334 \\
1,399,038 \\
1,339,429 \\
1,625,507 \\
1,151,340 \\
1,134,693 \\
1,097,123 \\
1,126,906\end{array}$ \\
\hline Total. & $2,507,953$ & $2,954,175$ & $3,345,143$ & $3,907,495$ & $4,132,791$ & $3,536,711$ & $9,066,641$ & $14,459,571$ \\
\hline
\end{tabular}

AMOUNT OF INCREASE (+) OR DECREASE (-).

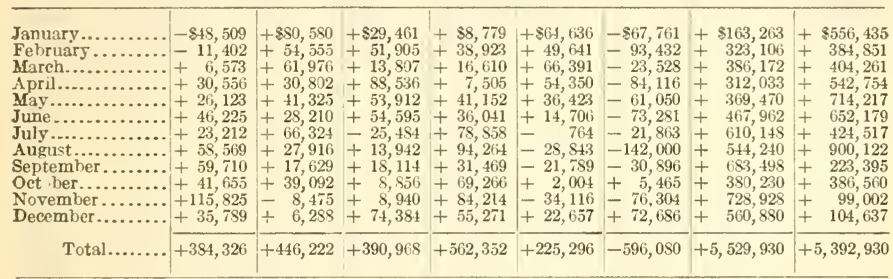

PER CENT OF INCREASE (+) OR DECREASE (-).

\begin{tabular}{|c|c|c|c|c|c|c|c|c|}
\hline 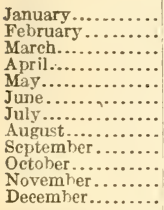 & $\begin{array}{l}-26.33 \\
-7.49 \\
+3.85 \\
+17.43 \\
+14.37 \\
+26.81 \\
+12.58 \\
+37.23 \\
+35.08 \\
+20.67 \\
+64.67 \\
+18.42\end{array}$ & $\begin{array}{l}+59.37 \\
+38.71 \\
+34.97 \\
+14.97 \\
+19.88 \\
+12.90 \\
+31.93 \\
+12.93 \\
+7.67 \\
+16.07 \\
-2.87 \\
+2.73\end{array}$ & $\begin{array}{l}+13.62 \\
+26.55 \\
+5.77 \\
+37.42 \\
+21.63 \\
+22.12 \\
+9.30 \\
+5.72 \\
+7.32 \\
+3.14 \\
+3.12 \\
+31.47\end{array}$ & $\begin{array}{l}+3.57 \\
+15.73 \\
+\quad 6.56 \\
+2.31 \\
+13.58 \\
+11.96 \\
+26.16 \\
+36.58 \\
+11.85 \\
+23.79 \\
+28.51 \\
+17.78\end{array}$ & $\begin{array}{l}+25.39 \\
+17.34 \\
+24.62 \\
+16.34 \\
+10.58 \\
+4.36 \\
-\quad .23 \\
-8.19 \\
-7.33 \\
+\quad .56 \\
+8.99 \\
+6.19\end{array}$ & $\begin{array}{l}-21,23 \\
-27.81 \\
-7.00 \\
-21.74 \\
-16.04 \\
-20.81 \\
-6.69 \\
-43.94 \\
-11.22 \\
+1.51 \\
-22.09 \\
+18.70\end{array}$ & $\begin{array}{l}+64.93 \\
+133.23 \\
+123.58 \\
+103.02 \\
+115.59 \\
+167.79 \\
+200.20 \\
+300.44 \\
+279.61 \\
+103.35 \\
+270.78 \\
+121.56\end{array}$ & $\begin{array}{l}+134.18 \\
+\quad 68.04 \\
+\quad 57.86 \\
+\quad 88.26 \\
+103.64 \\
+\quad 87.32 \\
+\quad 46.40 \\
+124.08 \\
+\quad 30.60 \\
+\quad 51.60 \\
+\quad 9.92 \\
+\quad 10.24\end{array}$ \\
\hline Average..... & +18.10 & +17.79 & +13.23 & +16.81 & +5.77 & -14.42 & +156.36 & +59.48 \\
\hline
\end{tabular}

This table shows a decrease of 0.23 per cent in exports during July, 1913, as compared with July, 1912. From July, 1913, to December, 1914, inclusive, there were increases during only four months-October and December, 1913, and October and December, 1914. During the other 14 months of this 18-month period there were decreases of from 0.23 to 43.94 per cent. 
EXPORTS OF PRINCIPAL PRODUCTS BY MONTHS.

Table 133 shows the exports of different products of glass and glassware by months for five calendar years, 1912 to 1916 :

Table 133.-Exports of Domestic Glass and Glassware, by Principal Articles AND BY MoN'THS, 1912 To 1916.

\begin{tabular}{|c|c|c|c|c|c|}
\hline Years and months. & $\begin{array}{l}\text { Cylinder, } \\
\text { crown, and } \\
\text { common } \\
\text { window } \\
\text { glass. }\end{array}$ & Plate glass. & $\begin{array}{c}\text { Bottles, } \\
\text { vials, demi- } \\
\text { johns, and } \\
\text { jars. }\end{array}$ & All other. & Total. \\
\hline 1912. & & & & & \\
\hline $\begin{array}{l}\text { January.... } \\
\text { February... }\end{array}$ & $\begin{array}{r}\$ 9,718 \\
8,829\end{array}$ & $\begin{array}{r}\$ 2,885 \\
6,725\end{array}$ & $\begin{array}{l}(a) \\
(a)\end{array}$ & $\begin{array}{r}\$ 211,949 \\
270,746\end{array}$ & $\$ 254,552$ \\
\hline $\begin{array}{l}\text { February.. } \\
\text { March..... }\end{array}$ & $\begin{array}{l}8,829 \\
7,459\end{array}$ & $\begin{array}{l}0,725 \\
7,459\end{array}$ & $\begin{array}{l}(a) \\
(a)\end{array}$ & $\begin{array}{l}270,746 \\
254,719\end{array}$ & $\begin{array}{l}286,300 \\
269,637\end{array}$ \\
\hline A pril........ & 15,847 & 6,078 & (a) & 310,731 & 332,656 \\
\hline May..... & 15,141 & 4,513 & (a) & 324,620 & 344,274 \\
\hline June..... & 11,775 & 6,449 & (a) & 319,248 & 337,472 \\
\hline July.... & 17,446 & 8,003 & $\$ 82,017$ & 219,925 & 327,391 \\
\hline August. & 43,475 & 3,064 & 75,684 & 229,765 & 351,988 \\
\hline September & 37,848 & 4,120 & 53,173 & 201,991 & 297,132 \\
\hline October. & 37,933 & 6,119 & 50,360 & 266,022 & 360,434 \\
\hline November. & 33,622 & 12,065 & 59,522 & 274,404 & 379,613 \\
\hline December. & 34,938 & 4,205 & 54,175 & 272,728 & 366,046 \\
\hline Tanuarv & & & & & \\
\hline $\begin{array}{l}\text { January.. } \\
\text { February. }\end{array}$ & $\begin{array}{l}36,028 \\
40,621\end{array}$ & $\begin{array}{l}5,563 \\
3,621\end{array}$ & $\begin{array}{l}64,183 \\
49,915\end{array}$ & $\begin{array}{l}213,414 \\
241,784\end{array}$ & $\begin{array}{l}319,188 \\
335,941\end{array}$ \\
\hline March... & 27,158 & 1,102 & 68,169 & 239,599 & 336,028 \\
\hline April... & 52,525 & 1,868 & 77,260 & 255,353 & 387,006 \\
\hline May... & 42,331 & 749 & 87,833 & 249,784 & 380,697 \\
\hline June... & 30,436 & 8,351 & 86,036 & 227,355 & 352,178 \\
\hline July.... & 36,888 & 5,182 & 57,690 & 226,867 & 326,627 \\
\hline August.. & 38,187 & 2,301 & 71,571 & 211,086 & 323,145 \\
\hline September. & 19,230 & 1,808 & 69,347 & 184,958 & 275,343 \\
\hline October. & 31,830 & 1,942 & 74,987 & 253,679 & 362,438 \\
\hline November. & 17,339 & 1,954 & 54,938 & 271,266 & 345,497 \\
\hline December.. & 16,078 & 723 & 59,265 & 312,637 & 388,703 \\
\hline 1914. & & & & & \\
\hline January. & 15,932 & 2,544 & 46,454 & 186,497 & 251,427 \\
\hline February.. & 18,610 & 3,493 & 60,624 & 159,782 & 242,509 \\
\hline Mareh....... & 19,996 & 5,592 & 43,290 & 243,622 & 312,500 \\
\hline April........ & 40,755 & 4,107 & 51,425 & 206,303 & 302,890 \\
\hline May..... & 34,841 & 3,077 & 60,489 & 221,210 & 319,647 \\
\hline June........ & 21,653 & 2,744 & 61,273 & 193,227 & 278,897 \\
\hline July........ & 14,626 & 3,063 & 76,523 & 210,552 & 304,764 \\
\hline August.... & 11,623 & 5,137 & 49,246 & 115,139 & 181,145 \\
\hline September.. & 31,077 & 10,361 & 47,027 & 155,982 & 244,447 \\
\hline October..... & 41,672 & 34,945 & 66,005 & 225,281 & 367,903 \\
\hline November.... & 23,259 & 22,295 & 40,847 & 182,792 & 269,193 \\
\hline December....... & 131,152 & 96,216 & 48,544 & 185,477 & 461,389 \\
\hline 1915. & & & & & \\
\hline January... & 140,571 & 70,275 & 47,083 & 156,761 & 414,690 \\
\hline February... & 240,641 & 119,392 & 42,317 & 163,265 & 565,615 \\
\hline March..... & 326,868 & 63,499 & 83,687 & 224,618 & 698,672 \\
\hline April.... & 153,200 & 125,954 & 64,176 & 271,593 & 614,923 \\
\hline May..... & 167,961 & 123,732 & 91,384 & 306,010 & 689,117 \\
\hline June............. & 160,463 & 156,858 & 115,588 & 313,950 & 746,859 \\
\hline July.............. & 192,412 & 184,101 & 139,665 & 398,704 & 914,912 \\
\hline August....... & 153,977 & 156,225 & 126,934 & 288,249 & 725,385 \\
\hline September...... & 195,027 & 217,055 & 132,857 & 383,006 & 927,945 \\
\hline October........... & 143,561 & 72,178 & 129,942 & 402,452 & 748,133 \\
\hline November....... & 214,884 & 136,890 & 146,351 & 499,996 & 998,121 \\
\hline December....... & 213,092 & 74,568 & 181,476 & 553,133 & $1,022,269$ \\
\hline 1916. & & & & & \\
\hline $\begin{array}{l}\text { January. } \\
\text { February }\end{array}$ & $\begin{array}{l}229,797 \\
214,600\end{array}$ & $\begin{array}{r}56,776 \\
103,322\end{array}$ & $\begin{array}{l}178,884 \\
167,786\end{array}$ & 505,668 & 971,125 \\
\hline 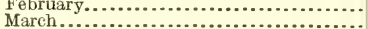 & $\begin{array}{l}214,600 \\
322,736\end{array}$ & $\begin{array}{l}105,322 \\
118,922\end{array}$ & 223,235 & $\begin{array}{l}464,758 \\
438,040\end{array}$ & $\begin{array}{r}950,466 \\
1,102,933\end{array}$ \\
\hline April...... & 386,183 & 134,069 & 207,327 & 430,098 & $1,157,677$ \\
\hline May....... & 438,894 & 134,502 & 280,543 & 549,395 & $1,403,334$ \\
\hline June.... & 418,723 & 179,573 & 253,214 & 547,498 & $1,399,038$ \\
\hline July...... & 335,284 & 186,164 & 222,078 & 595,903 & $1,339,429$ \\
\hline August ...... & 520,607 & 301,491 & 250,623 & 552,786 & $1,625,507$ \\
\hline n.................. & 394,725 & 140,617 & 169,825 & 446,173 & $1,151,340$ \\
\hline October.... & 377,392 & 151,804 & 137,053 & 468,444 & $1,134,693$ \\
\hline November. & 291, 399 & 129,418 & 206,762 & 469,544 & $1,097,123$ \\
\hline December.. & 228,365 & 231,459 & 194,006 & 473,076 & $1,126,906$ \\
\hline
\end{tabular}


Table 133.-Exports of Domestic Glass and Glassware, by Principal Articles AND BY Months, 1912 to 1916 -Concluded.

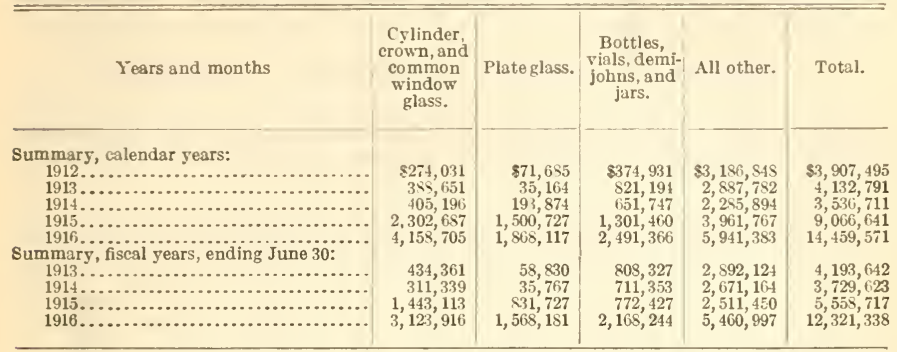

The decline in exports during the fiscal year 1914 may be attributed to a business depression that prevailed in the principal countries of the world during that period. The declines during the months of August, September, and November, 1914, were, of course, largely due to the war in Europe.

\section{DECLINE IN WORLD TRADE IN 1914.}

The business depression that prevailed generally throughout the world during the year before the war commenced about August 1, 1914 , is indicated statistically by Table 134, which shows that from July, 1913, to July, 1914, the imports of merchandise of all kinds into most of these countries decreased or but slightly increased.

Table 134.-Total Imports of Merchandise into Leading Countries of the World During July, 1913 and 1914.

[Data from business activity in the United States and leading foreign countries, Senate Document No. 477,64 th Cong., 1st sess.]

\begin{tabular}{|c|c|c|c|c|c|c|}
\hline Countries. & July, 1913. & July, 1914. & Increase. & Decrease. & $\begin{array}{l}\text { Per cent } \\
\text { of } \\
\text { increase. }\end{array}$ & $\begin{array}{l}\text { Per cent } \\
\text { of } \\
\text { decrease. }\end{array}$ \\
\hline 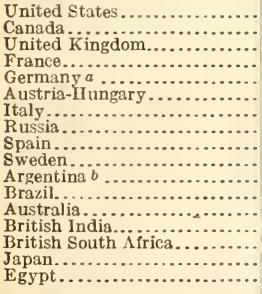 & $\begin{array}{r}\$ 139,061,770 \\
58,926,000 \\
300,670,293 \\
129,327,756 \\
204,991,301 \\
55,509,335 \\
45,599,605 \\
57,578,000 \\
19,364,910 \\
19,481,000 \\
97,005,012 \\
29,744,048 \\
32,132,181 \\
46,964,811 \\
17,216,017 \\
2 \times, 037,000 \\
11,197,546\end{array}$ & $\begin{array}{r}\$ 159,677,291 \\
42,964,000 \\
288,955,659 \\
110,802,651 \\
210,516,236 \\
60,169,200 \\
49,108,633 \\
37,457,000 \\
18,728,712 \\
20,556,000 \\
73,209,228 \\
15,670,130 \\
35,911,007 \\
45,429,932 \\
15,360,231 \\
22,709,250 \\
11,802,653\end{array}$ & 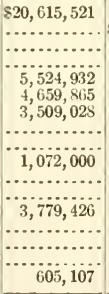 & $\begin{array}{r}\$ 15,962,000 \\
11,714,634 \\
18,525,105 \\
\ldots \ldots . . . \\
\ldots \ldots . . . \\
20,131,000 \\
636,229 \\
\ldots \ldots 795,834 \\
23,795, \\
14,073,913 \\
\ldots 1,334,879 \\
1,855,816 \\
5,327,750 \\
\ldots \ldots \ldots . .\end{array}$ & 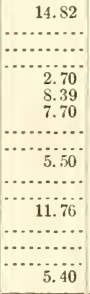 & $\begin{array}{r}34.91 \\
3.29 \\
\ldots . \\
24.52 \\
47.32 \\
\ldots \ldots .27 \\
10.78 \\
19.00 \\
\ldots \ldots\end{array}$ \\
\hline 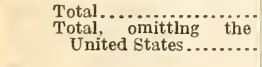 & $\begin{array}{l}1,292,809,698 \\
1,153,747,928\end{array}$ & $\begin{array}{l}1,219,028,413 \\
1,059,351,122\end{array}$ & & $\begin{array}{l}73,781,285 \\
94,396,806\end{array}$ & $\because$ & $\begin{array}{l}5.71 \\
8.18\end{array}$ \\
\hline
\end{tabular}

$a$ Figures are for June. July figures not available.

$b$ Figures are for three months ending June. July figures not a vailable. 
As appears by this table, the total value of the imports of the 17 specified countries decreased 5.71 per cent during the year from July, 1913, to July, 1914. Omitting the United States, the imports decreased 18.8 per cent.

\section{EXPORTS OF PRINCIPAL PRODUCTS BY CONTINENTS.}

The value of the exports of different kinds of glass and glassware during the fiscal years 1912 to 1916, inclusive, are shown by continents in Table 135.

Table 135.-Value of Exports of Domestic Glass and Glassware from the United States During the Fiscal Years Ending June 30, 1912 to 1916.

\begin{tabular}{|c|c|c|c|c|c|}
\hline Classification and dest & 1912 & 1913 & 1914 & 1915 & 1916 \\
\hline 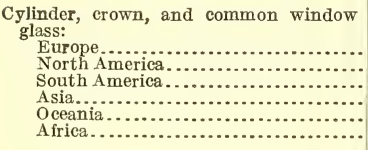 & $\begin{array}{r}\$ 108,704 \\
3,569 \\
192 \\
347 \\
1,297 \\
\end{array}$ & $\begin{array}{r}\$ 99 \\
428,312 \\
3,927 \\
10 \\
1,845 \\
168\end{array}$ & $\begin{array}{r}\$ 511 \\
301,074 \\
2,573 \\
206 \\
6,914 \\
61 \\
\end{array}$ & $\begin{array}{r}\$ 259,011 \\
733,294 \\
158,323 \\
82,090 \\
198,228 \\
12,167\end{array}$ & $\begin{array}{r}\$ 250,364 \\
1,109,081 \\
612,340 \\
688,328 \\
407,126 \\
56,677 \\
\end{array}$ \\
\hline Total. . & 114,109 & 434,361 & 311,339 & $1,443,113$ & $3,123,916$ \\
\hline 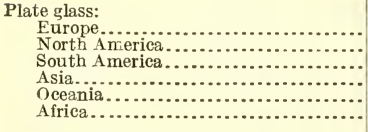 & $\begin{array}{r}12 \\
49,027 \\
829 \\
858 \\
28 \\
\end{array}$ & $\begin{array}{r}190 \\
53,416 \\
1,814 \\
140 \\
3,270 \\
\end{array}$ & $\begin{array}{r}370 \\
32,342 \\
2,033 \\
1,022 \\
\end{array}$ & $\begin{array}{r}305,490 \\
287,304 \\
59,273 \\
9,196 \\
169,889 \\
575 \\
\end{array}$ & $\begin{array}{r}326,388 \\
641,608 \\
201,682 \\
141,957 \\
250,059 \\
6,487 \\
\end{array}$ \\
\hline Tota & 50,754 & 58,830 & 35,767 & 831,727 & $1,568,181$ \\
\hline 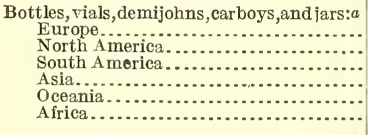 & & $\begin{array}{r}24,238 \\
621,017 \\
106,216 \\
9,116 \\
40,860 \\
6,880 \\
\end{array}$ & $\begin{array}{r}13,160 \\
536,809 \\
109,288 \\
12,488 \\
35,949 \\
3,659\end{array}$ & $\begin{array}{r}89,106 \\
520,485 \\
64,307 \\
11,474 \\
74,394 \\
12,661 \\
\end{array}$ & $\begin{array}{r}748,755 \\
966,174 \\
214,067 \\
40,506 \\
103,885 \\
104,857 \\
\end{array}$ \\
\hline Tot & 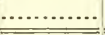 & 808,327 & 711,353 & 772,427 & $2,168,244$ \\
\hline 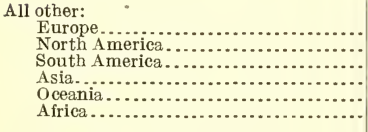 & $\begin{array}{r}501,652 \\
2,127,488 \\
334,704 \\
51,670 \\
278,478 \\
35,298 \\
\end{array}$ & $\begin{array}{r}563,552 \\
1,811,032 \\
228,901 \\
46,293 \\
202,239 \\
40,107 \\
\end{array}$ & $\begin{array}{r}643,551 \\
1,548,076 \\
180,012 \\
45,192 \\
213,941 \\
40,392 \\
\end{array}$ & $\begin{array}{r}678,101 \\
1,256,865 \\
176,820 \\
69,461 \\
299,598 \\
30,605 \\
\end{array}$ & $\begin{array}{r}2,523,644 \\
1,820,553 \\
465,789 \\
136,873 \\
407,919 \\
106,219 \\
\end{array}$ \\
\hline Total.. & $3,329,290$ & $2,892,124$ & $2,671,164$ & $2,511,450$ & $5,460,997$ \\
\hline 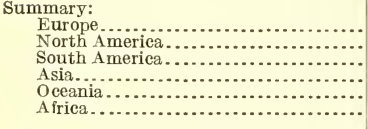 & $\begin{array}{r}501,664 \\
2,285,219 \\
339,102 \\
51,862 \\
279,683 \\
36,623 \\
\end{array}$ & $\begin{array}{r}588,079 \\
2,913,777 \\
340,858 \\
55,559 \\
248,214 \\
47,155 \\
\end{array}$ & $\begin{array}{r}657,592 \\
2,418,301 \\
293,906 \\
57,886 \\
257,826 \\
44,112 \\
\end{array}$ & $\begin{array}{r}1,331,708 \\
2,797,948 \\
458,723 \\
172,221 \\
742,109 \\
56,008 \\
\end{array}$ & $\begin{array}{r}3,849,151 \\
4,527,416 \\
1,493,878 \\
1,007,664 \\
1,168,989 \\
274,240 \\
\end{array}$ \\
\hline Total & $3,494,153$ & $4,193,642$ & $3,729,623$ & $5,558,717$ & $12,321,338$ \\
\hline
\end{tabular}

$a$ Included in "All other glass and glassware" prior to 1913.

During the years 1911 to 1914 , inclusive, the hand factories, which produced between 40 and 50 per cent of the total production of window glass in the United States, operated only from 7 to 9 months each year, and the machine factories did not operate full time. If both kinds of factories had been operated full time, the production 
in the United States would have been far greater than the domestic consumption. Until the war began in August, 1914, American window glass manufacturers did but littlo exporting, and nearly all that they exported went to countries in North America.

In all of the classes of glass and glassware specified in Table 135, the greater part of the exports previous to the war were to North American countries, but the exports of "all other" kinds to Europe were much larger than those to any of the other continents, except North America. For years before the war, American manufactures of pressed tableware, heary cut glassware, and photographic cameras was considerable. The superiority of these goods was recognized even in the European countries where such goods were made, and such exports from the United States increased annually, although the exports of "all other" kinds decreased from 1912 to 1915.

There was a great disparity in the proportions of the various kinds of glass and glassware produced, and the exports of various kinds before the war in Europe began. Of the total value of glass and glassware produced in the United States during 1914, the value of window glass and obscured glass, including cathedral and skylight glass, was 16.18 per cent. But the value of the exports of cylinder, crown, and common window glass during the fiscal year 1914 amounted to only $\$ 311,339$, or 8.35 per cent, of the total glass exports, $\$ 3,729,623$. Practically all of the exports of window glass were of machine manufacture.

\section{EXPORTS OF.PRINCIPAL PRODUCTS BY COUNTRIES.}

The values of the exports of the different kinds of glass and glassware during the fiscal years 1911 to 1916, inclusive, are shown by countries in Table 136.

Table 136.-Exports of Domestic Glass and Glassware from the United States, by Products and Countries, During the Fiscal Years Ending JUNE 30,1911 TO 1916.

CYLINDER, CROWN, AND COMMON WINDOW GLASS: VALUE.a

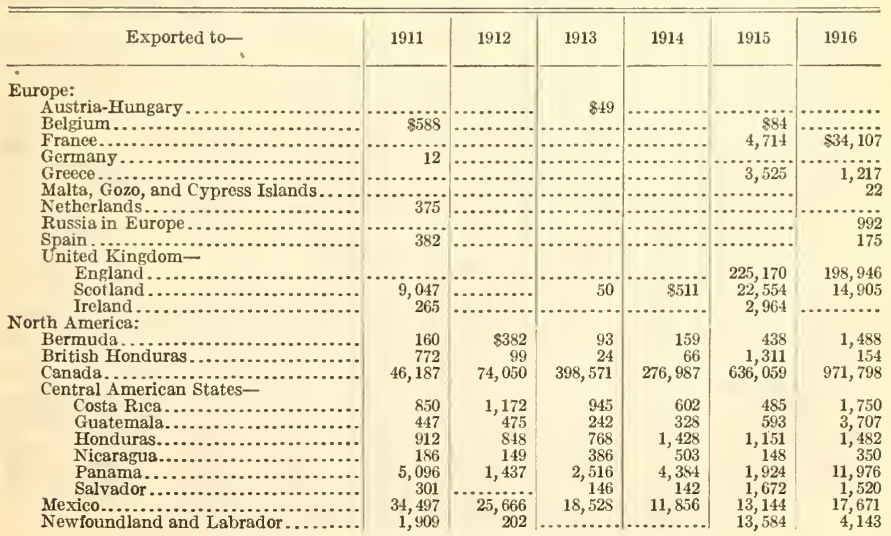


Table 136.-Exports of Domestic Glass and Glassware from the United States, by Products and Countries, During the Fiscal Years Ending JuNE 30,1911 To 1916 -Continued.

CYLINDER, CROWN, AND COMMON WINDOW GLASS: VALUE-Continued.

\begin{tabular}{|c|c|c|c|c|c|c|}
\hline Exported to- & 1911 & 1912 & 1913 & 1914 & 1915 & 1916 \\
\hline \multicolumn{7}{|l|}{$\begin{array}{l}\text { North America-Continued. } \\
\text { West Indies- } \\
\text { British- }\end{array}$} \\
\hline Barbados.... & & $\$ 5$ & & & $\$ 181$ & $\$ 321$ \\
\hline Jamaica... & $\$ 1,510$ & 545 & $\$ 153$ & $\$ 143$ & 529 & 3,106 \\
\hline Trinidad and Tobago............ & 13 & 302 & 76 & 44 & 1,993 & 2,443 \\
\hline Other British................ & & 437 & 426 & 215 & 346 & 842 \\
\hline 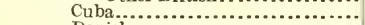 & 5,137 & 2,187 & 4,586 & 3,045 & 59,046 & 84,967 \\
\hline Danish............. & 84 & 16 & 122 & 65 & 133 & 110 \\
\hline Dominican Republic....... & 313 & 159 & 504 & 717 & 401 & 820 \\
\hline 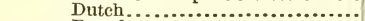 & ..... & 176 & & 12 & & 24 \\
\hline French........... & 104 & 397 & 226 & 378 & ii & 214 \\
\hline South Haiti......... & & & …. & …. & 145 & 195 \\
\hline \multicolumn{6}{|l|}{ South America: } & 247,433 \\
\hline Bolivia..... & & $\begin{array}{l}902 \\
\ldots . . .\end{array}$ & 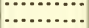 & $\begin{array}{c}390 \\
\cdots . . .\end{array}$ & 2,778 & 8,113 \\
\hline Brazil......... & 15 & ..... & & & 70,536 & 160,023 \\
\hline Chile........... & 727 & ............ & 1,042 & 1,015 & 20,605 & 129,299 \\
\hline Colombia............. & 362 & 815 & 993 & 491 & 2,489 & 8,601 \\
\hline Ecuador........... & 28 & ........... & 32 & ..... & 1,636 & 6,337 \\
\hline Guiana-- & & & & & & \\
\hline British....... & . & . & 17 & 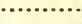 & . & 691 \\
\hline Peru............ & 136 & & $\begin{array}{r}10 \\
479\end{array}$ & & & 19,626 \\
\hline 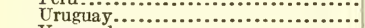 & 131 & & -... & & $\ddot{5}, 904$ & 27,844 \\
\hline 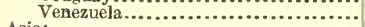 & & 1,792 & 1,354 & 474 & 1,746 & 4,354 \\
\hline \multicolumn{7}{|l|}{ Asia: } \\
\hline 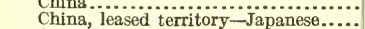 & 119 & $\because$. & & 168 & $\begin{array}{r}13,731 \\
5,097\end{array}$ & $\begin{array}{r}191,768 \\
9,725\end{array}$ \\
\hline 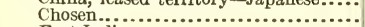 & 10 & 186 & 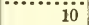 & & & 125 \\
\hline \multirow{2}{*}{\multicolumn{7}{|c|}{$\begin{array}{c}\text { East Indies- } \\
\text { British- }\end{array}$}} \\
\hline & & & & & & \\
\hline British India. & & & & & 11,885 & 81,995 \\
\hline Straits Settlements & & $\cdots$ & .... & .... & 6,464 & 4,362 \\
\hline Other British..... & & & & & 477 & 3,714 \\
\hline Duteh... & 45 & & & & & 7,889 \\
\hline Hongkong..... & 1,002 & 6 & $\cdots$ & & 11,187 & 141,965 \\
\hline Japan. . & 622 & .... & ............ & 15 & 33,249 & 246,056 \\
\hline Russia in Asia.... & ..... & … & ..... & 23 & & 55 \\
\hline \multirow{2}{*}{\multicolumn{7}{|c|}{ Oceania: }} \\
\hline & & & & & & \\
\hline $\begin{array}{l}\text { British- } \\
\text { Australia.... }\end{array}$ & 200 & & 26 & 861 & 180,571 & \\
\hline New Zealand..... & & $\cdots$. & 153 & ..... & 12,791 & 69,029 \\
\hline Other British.. & & & & & 116 & \\
\hline 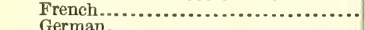 & 795 & 55 & 116 & 51 & .......... & 753 \\
\hline 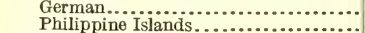 & $\begin{array}{r}131 \\
7.869\end{array}$ & 292 & 550 & 6.002 & 4.750 & 30189 \\
\hline \multirow{2}{*}{\multicolumn{7}{|c|}{$\begin{array}{l}\text { Africa: } \\
\text { British }\end{array}$}} \\
\hline & & & & & & \\
\hline $\begin{array}{l}\text { West... } \\
\text { South... }\end{array}$ & & & 168 & 54 & 10,420 & $\begin{array}{r}3,083 \\
50,112\end{array}$ \\
\hline East.. & & $\dddot{20}$ & & & & 745 \\
\hline Egypt .... & & & & & ...... & 1,205 \\
\hline Liberia & & 1,275 & -.......... & & 22 & \\
\hline Portugese Africa. & & & (n......... & 7 & 1,725 & 1,532 \\
\hline Total. & 121,339 & 114,109 & 434,361 & 311,339 & $1,443,113$ & $3,123,911$ \\
\hline
\end{tabular}

PLATE GLASS: QUANTITY.a

\begin{tabular}{|c|c|c|c|c|c|c|}
\hline $\begin{array}{l}\text { Europe: } \\
\text { Belgium... }\end{array}$ & Sq. Jeet. & $\begin{array}{l}\text { Sq. feet. } \\
\text {............ }\end{array}$ & Sq. Jeet. & $\begin{array}{r}\text { Sq. feet. } \\
580\end{array}$ & $\begin{array}{l}\text { Sq. feet. } \\
\text {-.......... }\end{array}$ & $\begin{array}{l}\text { Sq. feet. } \\
\text { S........ }\end{array}$ \\
\hline Germany... & & & 290 & & & \\
\hline Spain & & & & & 233 & \\
\hline $\begin{array}{l}\text { United Kingdom- } \\
\text { England ............. } \\
\text { Scotland }\end{array}$ & & 40 & 240 & & $\begin{array}{r}1,039,318 \\
114,783\end{array}$ & $\begin{array}{r}1,165,844 \\
62,230\end{array}$ \\
\hline North America & & & & & $11 x, 100$ & \\
\hline Bermuda & 835 & 608 & 1,637 & 884 & 141 & $\begin{array}{r}203 \\
22\end{array}$ \\
\hline 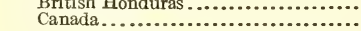 & $\begin{array}{r}933 \\
53,254\end{array}$ & $\begin{array}{r}1,372 \\
49,575\end{array}$ & $\begin{array}{r}1,100 \\
44,277\end{array}$ & $\begin{array}{r}604 \\
40,163\end{array}$ & $\begin{array}{r}198 \\
777,196\end{array}$ & $1,867,216$ \\
\hline
\end{tabular}


Table 136.-Exports of Domestic Glass and Glassware from the [xited States, by Products and Countries, During the Fiscal Years Ending JUNE 30. 1911 TO 1916.-Continued.

PLATE GLASS: QUANTITY-Concluded.

\begin{tabular}{|c|c|c|c|c|c|c|}
\hline Exported to- & 1911 & 1912 & 1913 & 1914 & 1915 & 1916 \\
\hline \multicolumn{7}{|l|}{ North Ameriea-Concluded. } \\
\hline Costa Rica............ & $\begin{array}{l}S g .7 e \ell t .4 \\
6,654\end{array}$ & 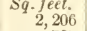 & Sq. feet. & $\begin{array}{l}\text { Sq. feet. } \\
2,398\end{array}$ & $\begin{array}{l}\text { Sq. feet. } \\
936\end{array}$ & $\begin{array}{l}\text { Sq. fed. } \\
2,129\end{array}$ \\
\hline Guatemala. & 102 & 727 & 1,250 & 656 & 1,094 & 120 \\
\hline Hondura & 1,596 & 2,650 & 1,767 & 2,123 & 3,104 & \\
\hline Nicaragu & 6,166 & 2,233 & 907 & 462 & 844 & 1,597 \\
\hline Panama..... & 3,280 & 2,728 & 5,808 & 6,234 & 6,369 & 16,487 \\
\hline 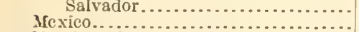 & $\begin{array}{r}835 \\
4085\end{array}$ & 151093 & $\begin{array}{r}30 \\
94,519\end{array}$ & $\begin{array}{r}327 \\
821\end{array}$ & 850 & $\begin{array}{r}1,27 \\
14,34\end{array}$ \\
\hline Vewfoundland and Labrador. & & 151,093 & $\begin{array}{r}94,519 \\
2\end{array}$ & 10,821 & $\begin{array}{r}4,566 \\
150\end{array}$ & $\begin{array}{r}14,34 \\
50\end{array}$ \\
\hline \multirow{2}{*}{\multicolumn{7}{|c|}{$\begin{array}{l}\text { West Indies- } \\
\text { British- }\end{array}$}} \\
\hline & & & & & & \\
\hline Jamaica. & $40^{\circ}$ & 80 & 54 & $\begin{array}{l}34 \\
88\end{array}$ & $\begin{array}{r}640 \\
2,83 \tilde{5}\end{array}$ & \\
\hline Trinidad and Toba & 65. & & 14 & 308 & & \\
\hline Other Brit & & & & & 120 & \\
\hline $\begin{array}{l}\text { Cuba....... } \\
\text { Danish.... }\end{array}$ & 4,644 & 4,013 & 3,421 & 2,490 & 86,980 & 245,62 \\
\hline $\begin{array}{l}\text { Danish.................... } \\
\text { Dominican Republic. }\end{array}$ & & & & & & \\
\hline $\begin{array}{l}\text { Duteh .................. } \\
\text { Haiti. }\end{array}$ & 240 & 138 & 79 & $\begin{array}{r}1,365 \\
20\end{array}$ & 558 & 1,697 \\
\hline $\begin{array}{l}\text { Haiti.... } \\
\text { South America: }\end{array}$ & 250 & 479 & 122 & 114 & & \\
\hline \multicolumn{7}{|l|}{$\begin{array}{l}\text { South America: } \\
\text { Argentina. }\end{array}$} \\
\hline Argentuna... & & & $\begin{array}{r}320 \\
14\end{array}$ & & 145,868 & 317,16 \\
\hline $\begin{array}{l}\text { Brazil........ } \\
\text { Chile...... }\end{array}$ & & & & 125 & $\begin{array}{r}120 \\
5,648\end{array}$ & 40,15 \\
\hline $\begin{array}{l}\text { Chile............ } \\
\text { Colombia... }\end{array}$ & 31 & 18 & 892 & 282 & $\begin{array}{r}5,648 \\
76\end{array}$ & $\begin{array}{r}40,15 \\
158,73\end{array}$ \\
\hline $\begin{array}{l}\text { Colombia.... } \\
\text { Ecuador.... }\end{array}$ & 225 & 1,486 & 718 & 2,010 & 3,383 & $\begin{array}{r}108,738 \\
8,311\end{array}$ \\
\hline $\begin{array}{l}\text { Ecua } \\
\text { Peru }\end{array}$ & 203 & 65 & 80 & & & \\
\hline $\begin{array}{l}\text { Peru } \\
\text { Urug }\end{array}$ & $\begin{array}{r}500 \\
890\end{array}$ & 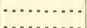 & & & 9,342 & 2,74 \\
\hline $\begin{array}{l}\text { ruguay..... } \\
\text { Venezuela... }\end{array}$ & $\begin{array}{r}1,890 \\
599\end{array}$ & 90 & 706 & 1,116 & 920 & \\
\hline \multicolumn{7}{|l|}{$\begin{array}{l}\text { Venezuela... } \\
\text { Asia: } \\
\text { China....... }\end{array}$} \\
\hline \multirow{2}{*}{\multicolumn{7}{|c|}{$\begin{array}{l}\text { China ........... } \\
\text { Chosen........ }\end{array}$}} \\
\hline \multirow{2}{*}{\multicolumn{6}{|c|}{ Chosen }} & \\
\hline \multirow{2}{*}{\multicolumn{6}{|c|}{ British- }} & \\
\hline \multirow{2}{*}{\multicolumn{6}{|c|}{$\begin{array}{l}\text { British India......... } \\
\text { Straits Settlements.. }\end{array}$}} & \\
\hline \multirow{2}{*}{\multicolumn{7}{|c|}{$\begin{array}{l}\text { Straits Settlements.. } \\
\text { Other British...... }\end{array}$}} \\
\hline \multirow{2}{*}{\multicolumn{2}{|c|}{$\begin{array}{r}\text { Dutch.. } \\
\text { Hongkong.. }\end{array}$}} & & & & & \\
\hline & & & & & 1,680 & $\begin{array}{r}10 \\
40,990\end{array}$ \\
\hline \multicolumn{7}{|c|}{$\begin{array}{l}\text { Japan } \\
\text { Russia in Asia }\end{array}$} \\
\hline \multicolumn{7}{|c|}{ 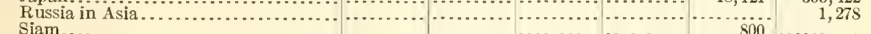 } \\
\hline \multirow{2}{*}{\multicolumn{7}{|c|}{$\begin{array}{l}\text { Siam } \\
\text { Oceania: } \\
\text { British- }\end{array}$}} \\
\hline & & & & & & \\
\hline $\begin{array}{l}\text { Australia } \\
\text { New Zeal }\end{array}$ & & & & 50 & 454,076 & 598,600 \\
\hline $\begin{array}{l}\text { New Zeala } \\
\text { Philippine Isla }\end{array}$ & & & & & 43,772 & 200,17 \\
\hline Philippine Islands.. & 2,025 & 2,558 & 5,519 & 1,613 & 2,785 & 13,925 \\
\hline $\begin{array}{l}\text { British } A \text { frica-Sot } \\
\text { Portuguese........ }\end{array}$ & & 47 & & & 1,601 & 16,021 \\
\hline Portuguese... & & & & & & 600 \\
\hline Total. & 88,596 & 222,206 & 165,129 & 74,867 & $2,730,046$ & $5,149,512$ \\
\hline
\end{tabular}

PLATE GLASS: VALUE,a

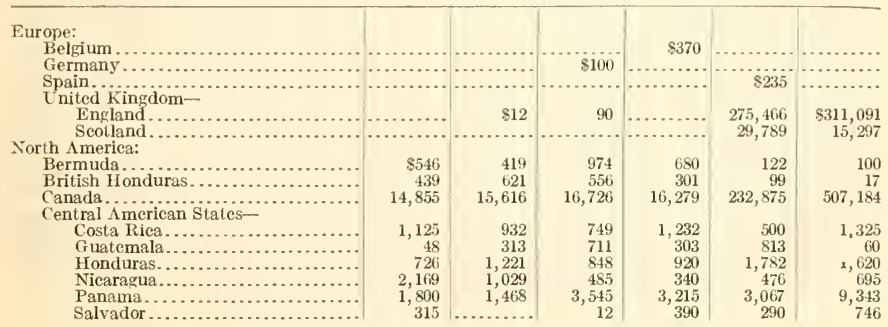

$a$ Figures for 1911 are for six months only, January to June, inclusive. 
Table 136.-Exports of Domestic Glass and Glassware from the United States, by Products and Countries, During the Fiscal Years Ending JUNE 30,1911 To 1916 -Continued.

PLATE GLASS: VALUE-Continued.

\begin{tabular}{|c|c|c|c|c|c|c|}
\hline Exported to- & 1911 & 1912 & 1913 & 1914 & 1915 & 1916 \\
\hline \multicolumn{7}{|l|}{ North America-Concluded. } \\
\hline \multirow{2}{*}{\multicolumn{7}{|c|}{$\begin{array}{l}\text { Newfoundland and Labrad } \\
\text { West Indies- }\end{array}$}} \\
\hline & & & & & & \\
\hline Barbados.. & & & & 25 & 498 & 22 \\
\hline Jamaica.... & 15 & 44 & 40 & 69 & 899 & 59 \\
\hline Trinidad and Tobago......... & 29 & & 10 & 220 & & 20 \\
\hline Cuba............ & 1,887 & $2, \overline{5} 43$ & 2,075 & $\dddot{1}, 551$ & 42,705 & 111,020 \\
\hline Danish............. & & & & & & 23 \\
\hline Dominican Republic............. & 144 & 79 & 47 & 662 & 339 & 907 \\
\hline 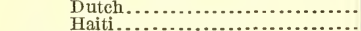 & $\because i 7$ & 135 & & 11 & $\cdots$ & \\
\hline \multicolumn{7}{|l|}{ South America: } \\
\hline Argentina.... & 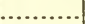 & 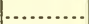 & 271 & & 50,903 & 104,512 \\
\hline Bolivia.... & $\cdots$ & ...... & 11 & & 41 & ......... \\
\hline Brazil...... & 49 & & & 78 & 2,650 & 19,734 \\
\hline Chile......... & 58 & & 565 & 176 & 47 & 69,169 \\
\hline Colombia .... & 168 & 727 & 490 & 1,015 & 1,753 & 5,086 \\
\hline Ecuador..... & 124 & 41 & 37 & & & 554 \\
\hline Peru........ & 305 & (............. & 1 & $\cdots$ & 3,107 & 1,265 \\
\hline Uruguay.... & 853 & & & & & \\
\hline 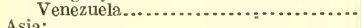 & 386 & & 440 & 764 & 772 & 1,355 \\
\hline \multicolumn{7}{|l|}{ Asia: } \\
\hline \multicolumn{7}{|l|}{ Chosen.......... } \\
\hline \multirow{2}{*}{\multicolumn{7}{|c|}{$\begin{array}{c}\text { East Indies- } \\
\text { British- }\end{array}$}} \\
\hline & & & & & & \\
\hline \multicolumn{7}{|l|}{ British India................... } \\
\hline \multicolumn{7}{|l|}{$\begin{array}{l}\text { Straits Settlements.............. } \\
\text { Other British }\end{array}$} \\
\hline \multicolumn{7}{|l|}{ Dutch.. } \\
\hline \multicolumn{7}{|l|}{ Hongkong. } \\
\hline \multirow{2}{*}{\multicolumn{7}{|c|}{$\begin{array}{l}\text { Japan } \\
\text { Russia in } \mathbf{A s i a} \ldots \ldots \ldots \ldots \ldots \ldots \ldots \ldots \ldots \ldots\end{array}$}} \\
\hline 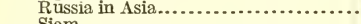 & ........... & & & & $\cdots \cdots$ & 1,119 \\
\hline \multicolumn{7}{|l|}{$\begin{array}{l}\text { Siam......... } \\
\text { Oceania: }\end{array}$} \\
\hline \multicolumn{7}{|l|}{$\begin{array}{l}\text { Oceania: } \\
\text { British- }\end{array}$} \\
\hline Australia & & & & 31 & 154,103 & 186,474 \\
\hline New Zea & & & & & 14,450 & 56,384 \\
\hline Philippine Islands..... & 1,550 & 858 & 3,270 & 991 & 1,336 & 7,201 \\
\hline Africa: & & 28 & & & 575 & 6,187 \\
\hline Portuguese............. & & & & & & 300 \\
\hline Total... & 29,683 & 50,754 & 58,830 & 35,767 & 831,727 & $1,568,181$ \\
\hline
\end{tabular}

BOTTLES, VIALS, DEMIJOHNS, CARBOYS, AND JARS: VALUE.a

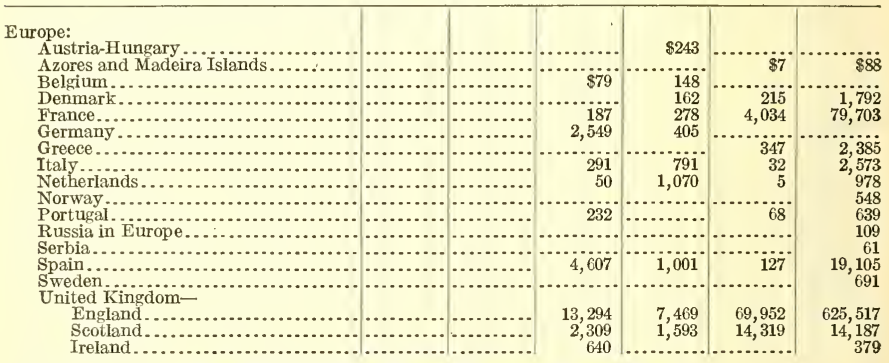

a Included in "All other glass and glassware" prior to 1913. 
Table 136.-Exports of Domestic Glass and Glassware from the Uxited States, by Products and Countries, Durisg the Fiscal Years Ending JU.XE 30, 1911 To 1916 -Continued.

BOTTLES, VIALS, DEMIJOHNS, CARBOYS, AND JARS: VALUE- Concluded.

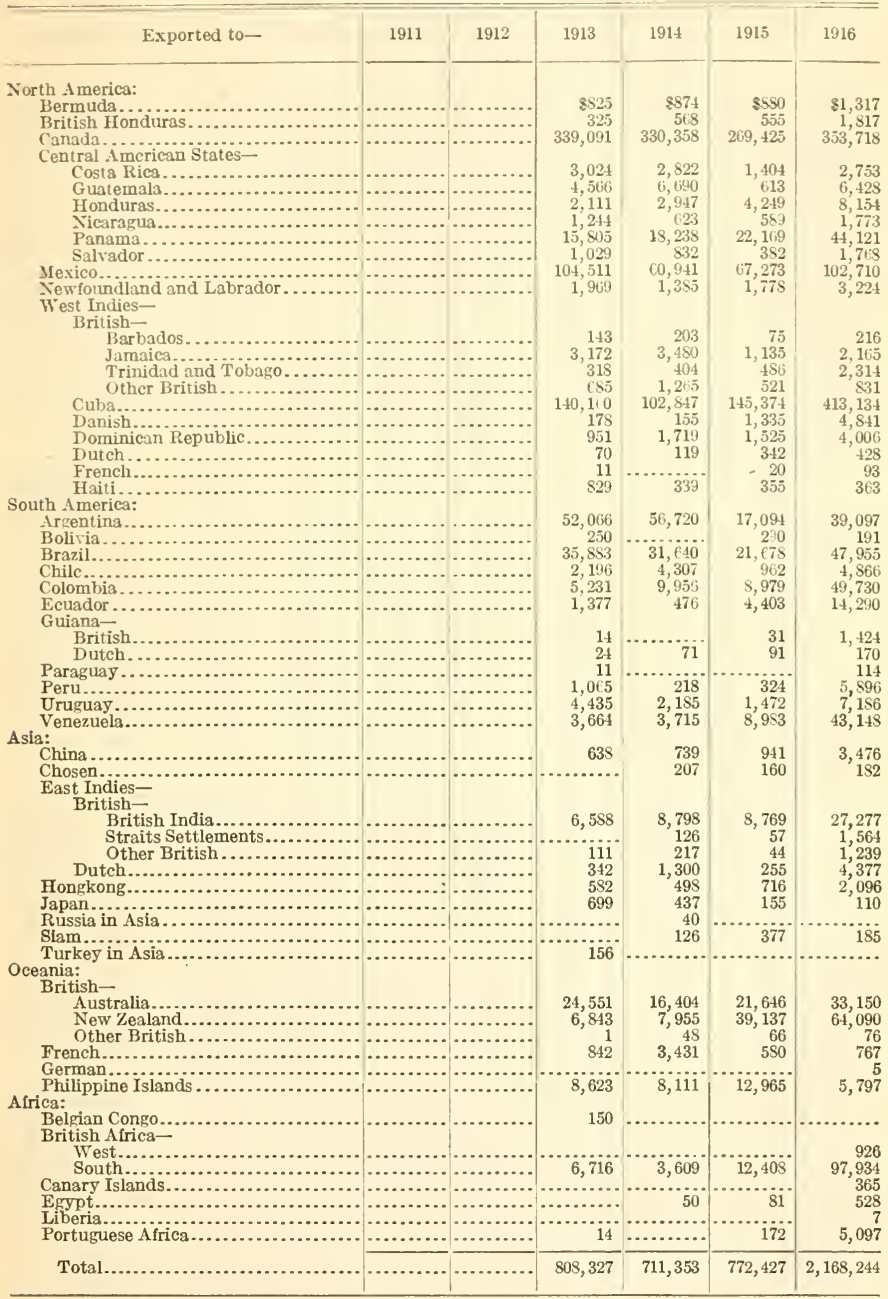


Table 136. - Exports of Domestic Glass and Glassware from the United States, by Products and Countries, During the Fiscal Years Ending JUNE 30, 1911 TO 1916-Continued.

ALL OTHER: VALUE. $a$

\begin{tabular}{|c|c|c|c|c|c|c|}
\hline Exported to- & 1911 & 1912 & 1913 & 1914 & 1915 & 1916 \\
\hline \multicolumn{7}{|l|}{ Europe: } \\
\hline $\begin{array}{l}\text { Austria-Hu } \\
\text { Azores, and }\end{array}$ & $\begin{array}{r}\$ 2,896 \\
26\end{array}$ & $\begin{array}{r}\$ 2,808 \\
23\end{array}$ & $\$ 3,566$ & $\begin{array}{r}\$ 2,165 \\
49\end{array}$ & $\$ 88$ & $\$ 90$ \\
\hline $\begin{array}{l}\text { Azores, an } \\
\text { Belgium. }\end{array}$ & 6,888 & 4,206 & 10,242 & 6,941 & 30 & $\begin{array}{r}\$ 90 \\
\therefore . .\end{array}$ \\
\hline Bulgaria. & $\begin{array}{r}0,000 \\
92\end{array}$ & 85 & 200 & , 27 & 30 & \\
\hline Denmark. & 5,969 & 7,580 & 9,769 & 11,474 & 13,162 & 11,503 \\
\hline Finl & 494 & 929 & 1,348 & 2,428 & & \\
\hline France. . & 13,046 & 12,350 & 27,325 & 24,710 & 25,188 & 48,178 \\
\hline Germany & 118,124 & 149,439 & 134,716 & 111,138 & 12,007 & \\
\hline Gibraltar & ........... & 281 & 209 & 221 & & 389 \\
\hline Gree & 200 & 146 & 750 & 163 & 134 & 389 \\
\hline Italy .... & 6,372 & 4,597 & 4,192 & 5,700 & 5,701 & 6,464 \\
\hline $\begin{array}{l}\text { Malta } \\
\text { Neth }\end{array}$ & $\begin{array}{r}16 \\
48.328\end{array}$ & & & & & 577 \\
\hline $\begin{array}{l}\text { Neth } \\
\text { Norn }\end{array}$ & $\begin{array}{r}48,328 \\
915\end{array}$ & $\begin{array}{r}41,456 \\
683\end{array}$ & $\begin{array}{r}41,985 \\
2,986\end{array}$ & $\begin{array}{r}44,729 \\
2,830\end{array}$ & $\begin{array}{l}7,343 \\
2,189\end{array}$ & 2,271 \\
\hline Portugal. & $\begin{array}{r}\text { Y10 } \\
35\end{array}$ & $\begin{array}{l}000 \\
615\end{array}$ & $\begin{array}{r}2,900 \\
85\end{array}$ & 817 & $\begin{array}{r}2,189 \\
593\end{array}$ & $\begin{array}{l}2,890 \\
1,029\end{array}$ \\
\hline Rou & 51 & 167 & & 590 & 580 & 1,029 \\
\hline Russia in Eur & 3,316 & 4,692 & 5,066 & 4,044 & 6,178 & 21,946 \\
\hline Spain ...... & 2,206 & 3,806 & 1,276 & 1,950 & 2,446 & 10,037 \\
\hline Sweden. & 2,207 & 2,942 & 2,711 & 8,754 & 13,074 & 17,653 \\
\hline Switz & 522 & 192 & 104 & 685 & 20 & \\
\hline Turkey in Eu & 332 & 45 & 278 & 1,537 & 13 & . \\
\hline United & & & & & & \\
\hline Engla & 267,513 & 258,499 & 306,805 & 407,291 & 575,431 & $2,215,804$ \\
\hline & 7,720 & 5,376 & 9,713 & 5,000 & 13,964 & 182,166 \\
\hline Irelat & 2,439 & 735 & 147 & 308 & 540 & 2,258 \\
\hline \multicolumn{7}{|l|}{ North America: } \\
\hline & 6,250 & 7,618 & 6,036 & 6,710 & 4,540 & 7,002 \\
\hline $\begin{array}{l}\text { British Honduras } \\
\text { Canada........... }\end{array}$ & 7,806 & 6,662 & 4,200 & 3,419 & 3,432 & 3,113 \\
\hline 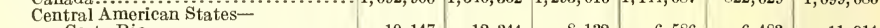 & $1,092,900$ & $1,340,352$ & $1,293,016$ & $1,144,087$ & 822,029 & $1,099,086$ \\
\hline $\begin{array}{l}\text { Central American States- } \\
\text { Costa Rica............. }\end{array}$ & 10,147 & 12,344 & 8,132 & 6,586 & 6,483 & 11,914 \\
\hline Gua & 9,121 & 8,849 & 9,807 & 9,165 & 6,756 & 8,514 \\
\hline Hon & 8,415 & 8,882 & 7,858 & 10,466 & 12,921 & 9,342 \\
\hline Nica & 7,175 & 7,410 & 6,009 & 3,871 & 3,050 & 6,580 \\
\hline Pan & 59,051 & 52,721 & 40,519 & 38,939 & 41,929 & 65,959 \\
\hline Salvado & 7,068 & 4,852 & 3,204 & 2,465 & 3,742 & 10,770 \\
\hline Mexico... & 386,548 & 388,179 & 204,692 & 87,791 & 78,668 & 70,425 \\
\hline Miquelo & 51 & 101 & & & 25 & 184 \\
\hline Newfoundland & 15,147 & 15,518 & 12,507 & 22,614 & 7,969 & 12,733 \\
\hline \multicolumn{7}{|l|}{$\begin{array}{l}\text { West Indies- } \\
\text { British- }\end{array}$} \\
\hline $\begin{array}{l}\text { British- } \\
\text { Barbad }\end{array}$ & 1,755 & 1,842 & 1,881 & 2,018 & 1,647 & - 3,859 \\
\hline Jan & 12,780 & 21,578 & 15,139 & 12,230 & 11,275 & 22,446 \\
\hline Trin & 3,054 & 4,358 & 3,788 & 5,728 & 6,445 & 22,052 \\
\hline Other & 6,115 & 7,479 & 5,674 & 6,967 & 5,720 & 12,036 \\
\hline Cuba.. & 191,743 & 212,733 & 160,820 & 160,201 & 216,391 & 412,514 \\
\hline Danish & 1,279 & 1,195 & 1,903 & 1,875 & 1,809 & 2,052 \\
\hline Dom & 8,949 & 11,260 & 13,202 & 11,754 & 13,400 & 25,173 \\
\hline Dutc & 1,570 & 1,651 & 1,404 & 2,224 & 1,709 & 3,289 \\
\hline Fre & 338 & 881 & 938 & 713 & 956 & 4,999 \\
\hline \multirow{2}{*}{\multicolumn{7}{|c|}{ South America: }} \\
\hline & & & & & & \\
\hline & 125,174 & 99,832 & 71,779 & 33,860 & 29,639 & 126,826 \\
\hline Bolivi & 4,706 & 4,778 & 5,417 & 7,895 & 3,943 & 5,761 \\
\hline Brazil & 73,362 & 93,317 & 57,708 & 38,774 & 44,498 & 84,752 \\
\hline & & 41,661 & 27,020 & 34,726 & 23,042 & 62,054 \\
\hline $\mathrm{Co}$ & 21,900 & 22,219 & 15,978 & 17,426 & 24,634 & 58,902 \\
\hline Ecuador.. & 6,345 & 9,272 & 6,016 & 6,950 & 9,854 & 21,464 \\
\hline Guian & & & & & & \\
\hline & 2,045 & 1,539 & 657 & 960 & 2,813 & 6,367 \\
\hline Dut & 117 & 552 & 240 & 578 & 342 & 1,135 \\
\hline Fre & 14 & 16 & & 6 & 88 & 236 \\
\hline Paraguay ... & 191 & 700 & 35 & 180 & 121 & 111 \\
\hline Реги.. & 17,431 & 22,597 & 16,402 & 18,768 & 16,939 & 28,079 \\
\hline Urugt & 12,596 & 13,545 & 14,994 & 8,763 & 8,645 & 44,375 \\
\hline Venezuela... & 22,285 & 24,676 & 12,655 & 11,126 & 12,262 & 25,727 \\
\hline \multicolumn{7}{|l|}{ Asia: } \\
\hline Ad & & & & & & 151 \\
\hline China. & 17,968 & 19,198 & 10,298 & 20,589 & 28,382 & 47,335 \\
\hline \multicolumn{7}{|l|}{$\begin{array}{c}\text { China, leased territory- } \\
\text { British }\end{array}$} \\
\hline $\begin{array}{l}\text { Brit } \\
\text { Frex }\end{array}$ & 250 & & & 171 & & \\
\hline Ger & & & 114 & 43 & & \\
\hline Japane & 1,863 & 855 & & 267 & & 753 \\
\hline Chosen.... & 574 & 1,772 & 1,279 & 528 & 102 & 381 \\
\hline
\end{tabular}

a In 1911 includes "Cylinder, crown, and common window glass," and "Plate glass" for six months, July to December, 1910. 
Table 136. - Exports of Domestic Gilass aind Glassware from the United States, by Products and Countries, Derisg tile Fiscal Years ENoing JUNE 30,1911 To 1916 - Concluded.

ALL OTHER: V'ALEE-Concluded.

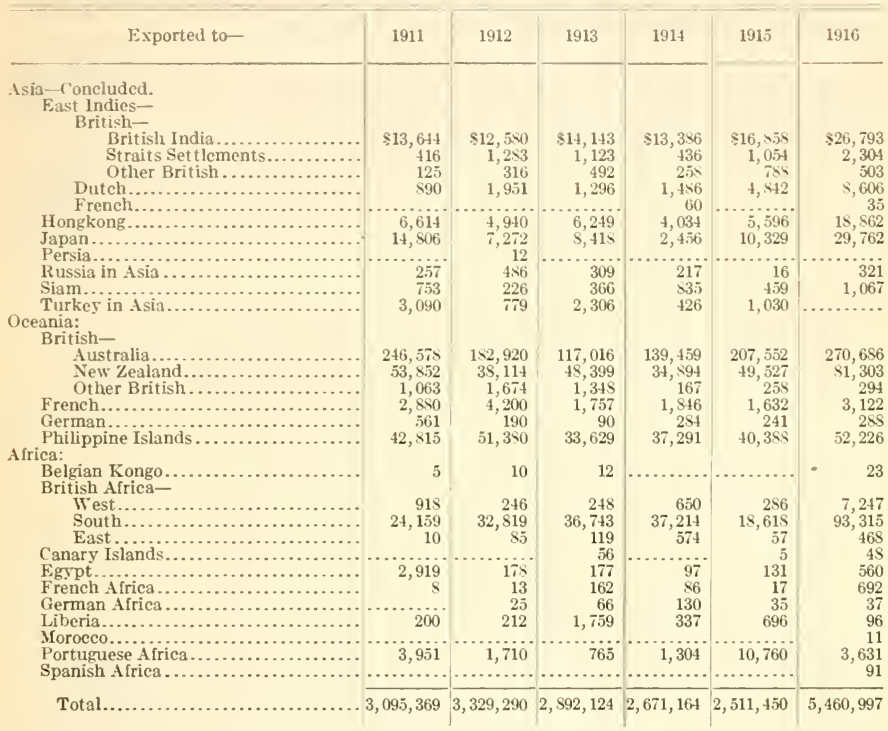

Considering the figures in this table for the fiscal year ending June 30, 1914, a month before the war in Europe began, it will be seen that the largest exports of window glass were, in the order named, to Canada, Mexico, Philippine Islands, Panama, and Cuba; and of plate glass to Canada, Mexico, Panama, and Cuba.

When an examination is made of the figures for the same year showing the exports of bottles, vials, demijohns, carboys, and jars, and of "all other" glassware, it will be seen that considerable quantities were exported to other parts of the world than North American countries. The largest exports of bottles, etc., were, in the order named, to Canada, Cuba, Mexico, Argentina, Brazil, Panama, Australia, Colombia, United Kingdom, British India, Philippine Islands, New Zealand, and Guatemala.

The largest exports of "all other" glassware were, in the order named, to Canada, United Kingdom, Cuba, Australia, Germany, Mexico, Netherlands, Panama, Brazil, Philippine Islands, British South Africa, New Zealand, Chile, Argentina, France, Newfoundland and Labrador, China, Peru, Colombia, British India, Jamaica, Dominican Republic, Denmark, Venezuela, Honduras, Guatemala, Uraguay, Sweden, Iaiti, Bolivia, Ecuador, Belgium, Bermuda, Costa Rica, Trinidad and Tobago, and Italy. 


\section{EFFECTS OF EUROPEAN WAR.}

The enormous increases of exports of glass and glassware since the war began are shown in Table 137 , in which a comparison is made of the exports during the fiscal year ending June 30, 1914, with those during the fiscal year 1916.

Table 137.-Value of Total Exports of Domestic Glass and Glassware During Fiscal Years Ending June 30, 1914 and 1916, with Amount and Percentage of Increase, by Products and Continents.

\begin{tabular}{|c|c|c|c|c|}
\hline \multirow{2}{*}{ Products and continents. } & \multirow{2}{*}{1914} & \multirow{2}{*}{1916} & \multicolumn{2}{|c|}{ Increase, 1914 to 1916.} \\
\hline & & & A mount. & Per cent. \\
\hline 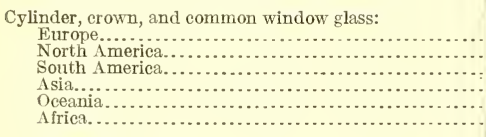 & $\begin{array}{r}\$ 511 \\
301,074 \\
2,573 \\
206 \\
6,914 \\
61\end{array}$ & $\begin{array}{r}\$ 250,364 \\
1,109,081 \\
612,340 \\
688,328 \\
407,126 \\
56,677\end{array}$ & $\begin{array}{r}\$ 249,853 \\
808,007 \\
609,767 \\
688,122 \\
400,212 \\
56,616\end{array}$ & \\
\hline Total. & 311,339 & $3,123,916$ & $2,812,577$ & 903 \\
\hline 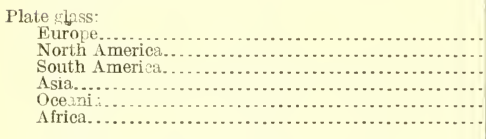 & $\begin{array}{r}370 \\
32,342 \\
2,033 \\
1,022 \\
1, \ldots \ldots \\
\end{array}$ & $\begin{array}{r}326,388 \\
641,608 \\
201,682 \\
141,957 \\
250,059 \\
6,487 \\
\end{array}$ & $\begin{array}{r}326,018 \\
609,266 \\
199,649 \\
141,957 \\
249,037 \\
6,487 \\
\end{array}$ & 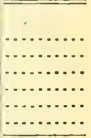 \\
\hline Total.... & 35,767 & $1,568,181$ & $1,532,414$ & 4,284 \\
\hline 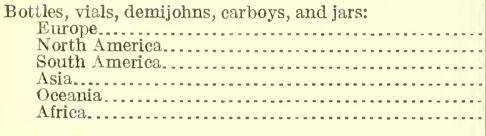 & $\begin{array}{r}13,160 \\
536,809 \\
109,288 \\
12,488 \\
35,949 \\
3,659\end{array}$ & $\begin{array}{r}748,755 \\
956,174 \\
214,067 \\
40,506 \\
103,885 \\
104,857 \\
\end{array}$ & $\begin{array}{r}735,595 \\
419,365 \\
104,779 \\
28,018 \\
67,936 \\
101,198 \\
\end{array}$ & 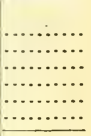 \\
\hline Total & 711,353 & $2,168,244$ & $1,456,891$ & 205 \\
\hline 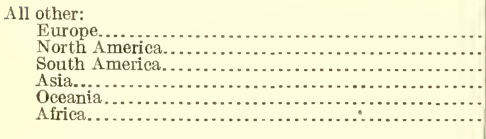 & $\begin{array}{r}643,551 \\
1,548,076 \\
180,012 \\
45,192 \\
213,941 \\
40,392 \\
\end{array}$ & $\begin{array}{r}2,523,644 \\
1,820,553 \\
465,789 \\
136,873 \\
407,919 \\
106,219\end{array}$ & $\begin{array}{r}1,880,093 \\
272,477 \\
285,777 \\
91,681 \\
193,978 \\
65,827 \\
\end{array}$ & $\begin{array}{l}\cdots \ldots \\
\cdots \ldots \\
\cdots \ldots \\
\cdots \cdots \\
\cdots \cdots\end{array}$ \\
\hline Total.... & $2,671,164$ & $5,460,997$ & $2,789,833$ & 104 \\
\hline 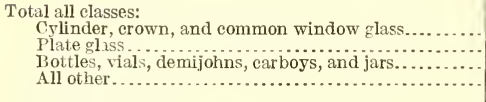 & $\begin{array}{r}311,339 \\
35,767 \\
711,353 \\
2,671,164 \\
\end{array}$ & $\begin{array}{l}3,123,916 \\
1,568,181 \\
2,168,244 \\
5,460,997 \\
\end{array}$ & $\begin{array}{l}2,812,577 \\
1,532,414 \\
1,456,891 \\
2,789,833 \\
\end{array}$ & $\begin{array}{r}903 \\
4,284 \\
205 \\
104 \\
\end{array}$ \\
\hline 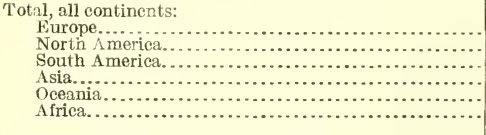 & $\begin{array}{r}657,592 \\
2,418,301 \\
293,906 \\
57,886 \\
257,826 \\
44,112 \\
\end{array}$ & $\begin{array}{r}3,849,151 \\
4,527,416 \\
1,493,878 \\
1,007,664 \\
1,168,989 \\
274,240\end{array}$ & $\begin{array}{r}3,191,559 \\
2,109.115 \\
1,199,972 \\
949,778 \\
911,163 \\
230,128 \\
\end{array}$ & $\begin{array}{r}485 \\
87 \\
408 \\
1,640 \\
350 \\
521\end{array}$ \\
\hline Grand total. & $3,729,623$ & $12,321,338$ & $8,591,715$ & 230 \\
\hline
\end{tabular}

As shown by this table, the total exports of glass and glassware increased 230 per cent during the two-year period. The largest. increases in value were in exports to Europe, North America, and South America, in the order named, but the largest percentage of increase was to Asia, 1,640 per cent. 


\section{ESTABLISHMENTS IN FOREIGN TRADE.}

Of the 213 establishments from which data were obtained, 68 reported some export business during the year 1915. Fifty-seven establishments reported goods shipped to 39 foreign countries, and 11 establishments did not state the destinations of goods exported. In most cases the failure to report destinations was on account of the manufacturer selling to United States jobbers who purchased the product and shipped to foreign countries on their own account. The foreign trade of 27 establishments was confined to single countries and 30 shipped to two or more countries.

Table 138 shows the foreign countries to which shipments were made by the 68 establishments reporting exports, and the number of establishments exporting the various kinds of manufactures of glass to each country.

Table 138.-Foreign Countries to Which Shipments were Made by 68 Establishmejts, and Number of Establishments Making Shipments to Each Country in 1915, By Products.

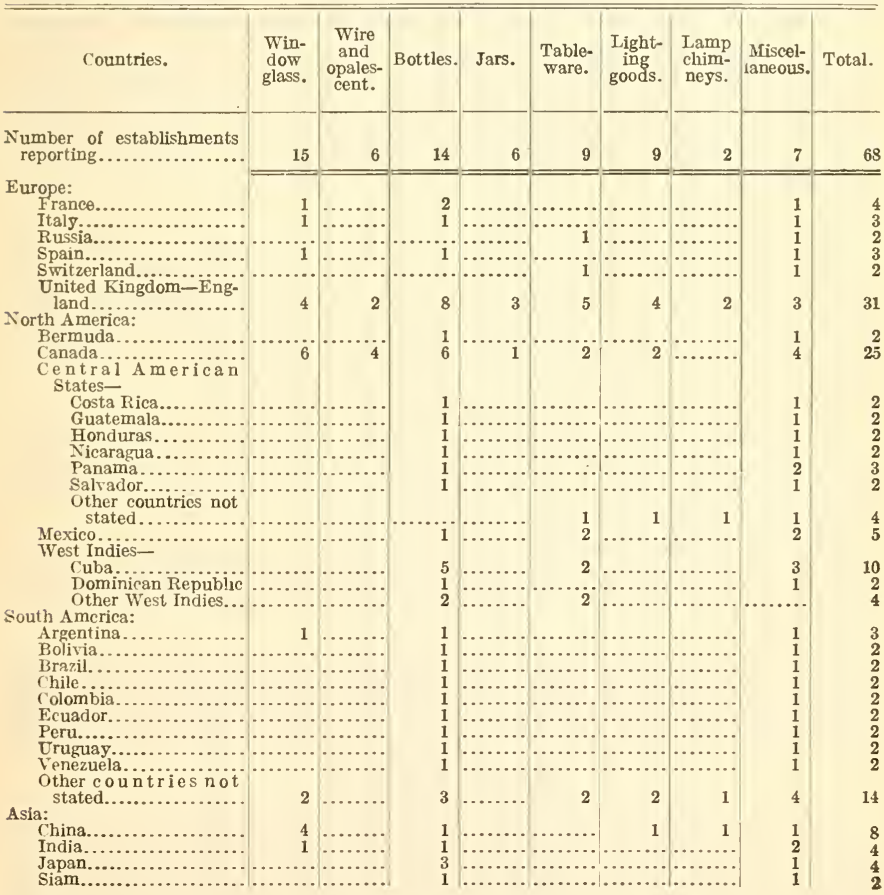


Table 138.-Foreign Countries to Which Shipments were Made by 68 Establishments, and Number of Establishments Making Shipments to Each Country in 1915, By Products-Concluded.

\begin{tabular}{|c|c|c|c|c|c|c|c|c|c|}
\hline Countries. & $\begin{array}{l}\text { Win- } \\
\text { dow } \\
\text { glass. }\end{array}$ & $\begin{array}{c}\text { Wire } \\
\text { and } \\
\text { opales- } \\
\text { cent. }\end{array}$ & Bottles. & Jars. & $\begin{array}{l}\text { Table- } \\
\text { ware. }\end{array}$ & $\begin{array}{l}\text { Light- } \\
\text { ing } \\
\text { goods. }\end{array}$ & $\begin{array}{l}\text { Lamp } \\
\text { chim- } \\
\text { neys. }\end{array}$ & $\begin{array}{l}\text { Miscel- } \\
\text { laneous. }\end{array}$ & Total. \\
\hline $\begin{array}{l}\text { Oceania: } \\
\text { British- } \\
\text { Australia..... } \\
\text { New Zealand. }\end{array}$ & 4 & & $\begin{array}{l}2 \\
2\end{array}$ & & 3 & 2 & 1 & $\begin{array}{l}4 \\
1\end{array}$ & $\begin{array}{r}16 \\
3\end{array}$ \\
\hline $\begin{array}{l}\text { Tasmania....... } \\
\text { Philippine Islands. }\end{array}$ & 2 & $\cdots$ & 1 & & & & & 1 & \\
\hline Africa: & & & 3 & & & & 1 & 1 & \\
\hline $\begin{array}{l}\text { Other count ries not } \\
\text { stated. }\end{array}$ & & & 1 & & & & & & \\
\hline All other countries not stated. & 2 & 2 & & 2 & 2 & $i$ & & 2 & 11 \\
\hline
\end{tabular}

Forty-one establishments reported the amounts of their exports, covering chiefly the calendar year 1915, the total of which was $\$ 1,550,883$. The amounts ranged from $\$ 558$ to $\$ 284,312$ per establishment, the average being $\$ 37,826$. Definite amounts exported to each separate country were not ascertained, but information obtained from the 68 establishments shows that England was the principal country to which shipments were made, Canada coming second and Australia third in order of magnitude. Practically all of the manufacturers that reported exports in 1915 stated in 1916 that their shipments to foreign countries had largely increased during the latter year.

One large establishment that manufactures bottles, packers, and preservers had a selling agency in London before the war began, and its goods were sold on the Continent as well as in England. One large establishment that manufactures pressed and blown tableware, bar goods, and lighting goods, maintains salesrooms in Habana, Cuba; London, England; and Sydney, Australia; and its wares are shipped to almost all countries throughout the world.

A tableware establishment that had done an export business through exporters in 1915 amounting to $\$ 30,000$ had an unfilled order for four carloads to be shipped direct to England, the sale having been made through catalogues.

The export business of one lamp-chimney establishment grew rapidly after the close of the fiscal year 1915, and it became necessary to increase the number of employees 100 per cent in order to take care of it.

In 1915 the exports of an establishment, manufacturing opal, colored, and crystal glass, toy marbles, caster balls, and other specialties was about 10 per cent of the product, and the officials expected them to increase to 40 per cent of the product during 1916

\section{EXPORT METHODS.}

The most popular method employed in selling glass products abroad is through American export commission houses located in New York City. This method is preferred for the reason that it results in a greater number of orders. Many solicit orders through correspondence and catalogues with very good success. A few sell. 
goods through foreign resident agents or traveling agents and others through adrertising. An official of a bottle factory stated that it had attempted to establish a foreign trade through an English agent in London but received no results. An attempt was then made through New York commission houses, with the result that foreign business amountiig to $\$ 125,000$ was secured in six months.

American export agents usually purchase goods outright, and rebill to the foreign customer at an advance of about 2 per cent; they also sell on commission. In some cases the export agents living abroad buy the goods outright and pay for them, in other cases they sell on commission. Unless credit is extended or other arrangments made for payment, the collection of the account is usually taken care of by some New York export house or by means of letters of credit. When goods are sold on credit it is the usual custom to allow a small discount, about 1 per cent, for cash in 30 days from date of shipment.

Mr. Nicholas Kopp, vice president of the Pittsburgh Lamp, Brass \& Glass Co., manuf acturer of lighting goods, stated:

Before the war we exported only to Mexico. In 1909 and 1910 we sold $\$ 5,000$ or $\$ 6.000$ worth of goods to Mexico in each year. In Canada we sold about $\$ 10.000$ worth a year for several years. We had no other exports before the war. Since the war our exports to Canada have increased to $\$ 14,000$. We have started a business with Porto Rico. We may be able to hold our trade with Canada, Mexico, and Cuba.

We sell direct to dealers in Cuba, and have a traveling man there who is apparently making good; he is a Porto Rican. We also sell some to commission houses. We give the same terms in Cuba as in the United States-before January 1, 1916, 2 per cent, 15 days, net 30 days; now 1 per cent, 15 days, net 30 days. In Germany we gave six months. We also have one traveling salesman in Canada. 


\section{CHAPTER XII.}

\section{OPPORTUNITIES IN THE EXPORT TRADE.}

There is some demand for American glass products from most every country in the world and for practically all grades of goods that are manufactured in the United States, from the best and highest priced to the commonest and cheapest; and although some countries have a preferential tariff operating against the United States, this does not prevent manufacturers in this country from selling there to a certain extent. While many small as well as large sales are made, the tendency since the war has been for larger orders. The healthy condition of the markets abroad for American glass products is indicated by the receipt of repeat orders from foreign customers.

Although our foreign trade has of late greatly increased, it no doubt would have been much greater had not ocean freight rates so greatly increased since the outbreak of the war in Europe. Nor did the ocean rates alone operate against exporting, but the great demand for vessel tonnage made it very difficult and frequently impossible to secure shipping space. In this connection, Mr. W. L. Monro, general manager of the American Window Glass Co., one of the best-informed glass manufacturers of the United States, in an address delivered at the National Association of Window Glass Manufacturers at Atlantic City in July, 1916, stated:

I estimated that the total foreign trade of this country for the year from September 1,1915 , to September 1, 1916, would be about $2,000,000$ boxes, but certain conditions arose which reduced very materially the amount of the export trade we otherwise would have done. The principal difficulties were the enormous increase in ocean freight rates, the impossibility of securing vessel space even at those exorbitant rates, and the difficulty of getting glass to the seaboard even after vessel space was available. All these things, each in its turn, contributed to discourage the buying of American glass. But a more important factor sprang up, and that was the resumption of operations by a number of factories in Belgium; and while at first it was not the amount of glass they produced which cut down the export trade, it was the menace which foreign buyers felt that this production would be if they were to lay in large stocks of American glass.

An optimistic view is taken regarding the export trade of manufacturers of handmade window glass in an editorial in The Glassworker of August 12, 1916, which states:

It is impossible that hand-plant window-glass manufacturers will devote more attention to the export trade during the coming season than they did during the last. Statistics show that of the $1,500,000$ boxes of glass shipped abroad last year,including Canadian shipments, only 200,000 were of handmade glass. It has also developed that other prospective sales aggregating easily 500,000 boxes could have been secured by the hand plants but were turned down.

The subject has been brought to the attention of the manufacturers and is now under their consideration. Whether they will take steps to share in this profitable business next year remains to be seen. Of course it is not certain just how big the export business will be, but the impression is strong in many quarters that the coming of peace in Europe will by no means usher in the immediate resumption of European window-glass factories, but that on the contrary a year and perhaps longer must elapse before the skilled labor necessary to operate those plants, even when physical 
repairs are not needed, can be secured. If this view of the situation is borne out by events, the export trade will be well worth paying serious attention to next year. The sale of half a million boxes of glass means a lot of money, and represents a full month's operation.

An embargo prohibiting the importation of window, sheet, and plate glass and glass tableware into the United Kingdom went into effect on August 21, 1916 . It will, however, hardly decrease the exports of glass and glassware from the United States, because the demands from other parts of the world are enormous. Exporting manufacturers do not expect to hold trade to the extent to which it has expanded during the war, but most of them expect to do a larger foreign business after the war than they did before the war began.

\section{IMPORTS OF FOREIGN COUNTRIES.}

The values of glass and glassware imported into foreign countries, colonies, protectorates, and dependencies, shown in Table 139, which follows, were compiled from data published by the various countries and are here given to show approximately the extent of the market for different kinds of glass and glassware open to the American manufacturer. The data given are for the nearest available 12-month period preceding the outbreak of the war in Europe, in 1914, representative of a period when the market was still in a comparatively normal condition.

The statistics of imports of foreign countries are not comparable with exports of the United States to these countries, because different methods of valuation are used in different countries, because the imports in some cases are reported not from the country of origin but from the country where the goods were purchased, and because considerable quantities of imports are reshipped and therefore appear in the statistics of imports of the country to which they are reshipped as well as in those of the country which first imported them. These and similar considerations should be borne in mind when an attempt is made to analyze the commerce of foreign countries, or in making: comparisons between the exports from the United States and imports into foreign countries.

The statistics of imports which follow are as complete as it is possible to make them with the data available, but some of the minor colonies, dependencies, and protectorates are not included.

Ta ble 139.-Value of Imports of Glass and Glassware into Foreign Countries, By Continents.

EUROPE.

AUSTRIA-HUNGARY.a

Electric-light bulbs

IIollow ware:

Fine, etched, smoothed, decorated, emery-ground and cut, common...

Bottles, ordinary ...................

Bottles with ground-in stoppers...... Pressed ware:

Crude, natural color or white........

Colored, painted, etc.................

Mirrors, plate, rough and polished ........

Mirrors, framed............................

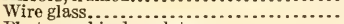

Photographic dry plates...............

\section{EUROPE.}

$\$ 203$

98,802

127,403

39,691

31,565

26,910

340,869

21,800

373,675
Optical goods:

Rough in lumps, sheet or lens shaped,

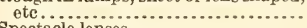

Spectacle lenses......................

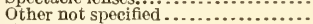

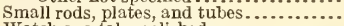

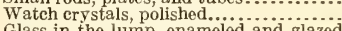

Glass in the lump, enameled and glazed

in lump, glass powder, etc............

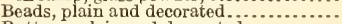

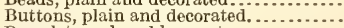

Bracelets and necklaces, etc ............

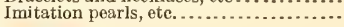

Imitation
$\$ 36,630$ 33,186

24,717

10,576

33,551

191, 109 23,380

15,657

7,456

29,206 
Table 139.-VAlue of Imports of Glass and Glassware into Foreign Countries, By Continents-Continued.

EUROPE-Continued.

A USTRIA-HUNGARY-concluded.

Solid pendants, etc.

Glass and enameled ware, toys, ornaments, etc......................

Total.

AZORES AND MADEIRA ISLANDS, $a$

Bottles.

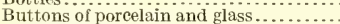

Lamp chimneys.....................

Mirrors

Opera glasses.

Photographic plates

Plate, polished, unpolished, silvered, or unsilvered.

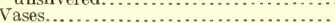

Manufactures not specified.

Total.

\section{BELGIUM. $a$}

Bottles.

Carboys.

Goblets, etc....

Plate glass:

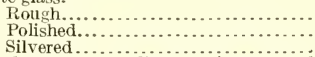

Silvered.............................

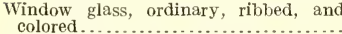

Other glassware not specified .............

Total.

\section{BUIJGARIA. $b$}

Bottles and demijohns.

Charms, buttons, bracelets, ete.

Enamel, and articles of ...............

Lamps and lanterns.

Electric-light globes.................

Mirror glass, framed and unframed.....

Fine glassware.

Vases and other ordinary glassware....

Window and plate, ordinary colored, en-

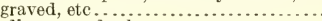

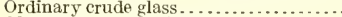

Glassware, not specified.

Total.

DENMARK, $a$

Bottles.

Siphons.

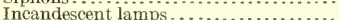

Lamps, shades, and parts of.

Lenses, optical, and photographic ware.

Laboratory and scientific ware.........

Hollow ware and glass $x$ are.

Tableware.

Glass manufactures, metal mounted and other not specified.

Glass, silvered, ground, or not..........

Glass, not silvered or ground.

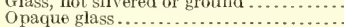

Other glass.

Total.

64,856

4,824

434,160

102,108

111,756

15,812

119,260

140,700

5,092

16,364

48,240

31,892

266,660

$1,391,724$

FINLAND。a

Bottles, ordinary

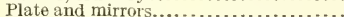

Window glass...

Tiling.

Spectacle rlasses without sett

settings........
273,857

$1,754,008$

6,639

1,732

2,062

1,441

1,602

2,169

1, 007

932

25,924

43,508

68,528

29,450

152

26,960

33,574

53,315

64,618

133,954

2,339

17,379

435,846

FINLAND-concluded.

All other:

Unground, uneolored.

$\$ 73,505$

55,366

18,351

Ground, uncolored.............

Ground, colored, painted, gilded, silvered, etc.........................

Miscellaneous........................... $\quad 190$

Total

303,765

Bottles.

FRANCE, $a$

Lighting goods ........................... $\quad 762,785$
Incandescent electric lamps:

With carbon filaments.......... 18,239

With metallic filaments with fittings. $\quad 421,975$

Not mounted.................. 66, 606

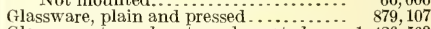

Glassware, turned, cut, or decorated..... $1,426,563$

Mirror and plate.................... 447,706

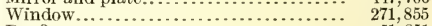

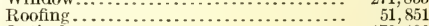

Optical................................ 170,496

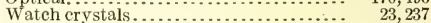

Glass, in lump or tubes, heads, flowers,

imitation stones, cullet, etc......... 924,057

Manufactures, not specified............ 27. 272,371

Total.

$5,994,450$

Hollow ware:

Not pressed, natural color .......... 18,564

Not pressed, white . .

Not specified.................... 424,830

Painted, gilded, plated.............. 103,054

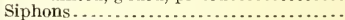

Mirror and plate, not polished, bent, ete.: Not colored nor transparent........ $\quad 275,842$

Colored or opaque ................ 20,944

Other......................... 16,422

Photographic:

Dry plates..................... 208,012

Lenses

Photographs...................... $\quad 5,474$

Optical:

Crude .............................. 39.98

Polished........................ 122,332

Spectacle lenses...................... $\quad 69,020$

Spectacles........................ $\quad 38,794$

Artificial eyes . . . . . . . . . .

Opera glasses.......................... 411,502

Pendants............................... 341,530

Pearls, corals, and paste ware.......... 702,576

Tubes

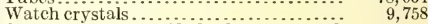

Glassware, not specified, glass wool, col-

ored and uncolored.................

Glass combined with other materials.....

Glass in mass........................

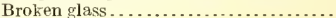

Total. .

$4,077,178$

28,320

69,020

77,826

7,378

GREECE. $a$

Bottles........................ 19,574

Glassware .............................. $\quad 38,085$

Lamp chimneys, ete..................... $\quad 68,569$

Lamps of every kind ................ $\quad 66,795$

Lusters of glass, with and without metal. $\quad 1,185$

Mirrors......................... $\quad 4,103$

Pearls, ete................................ 15, 425

Photographic plates.................. 8, 8,674

Plate glass............................ $\quad{ }_{246}$

Spectacles, eye glasses, and lorgnettes.... $\quad 3,868$

Wateh erystals and lenses. ............ $\quad 1,086$

Window glass ........................ $\quad 55,983$

Broken glass.

85 
Table 139. - Value of I yports of Glass and Glassware into Foreiga Cotwtries BY CoNTINeNTs-Continued.

ELROPE-Continued.

ICELAND,a

Lamps and lamp ware. Window glass.

Total.

11,149 7,963

19,112

ITALY. $a$

Bottles.

Demijohns

Beads.

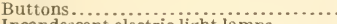

Incandesce

Glassware:

Blown or molded.

Colored and cut, etc..................

White or colored, silvered inside.....

Painted or gilded, etc................

Tolumetric.

Mirrors, plate and framed............

Glass or crystal plates:

Fot polished, common window glass.

vired for roofs

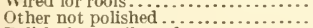

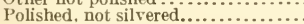

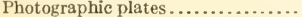

Crude optical. .....................

Broken.

Total.

$4,807,581$

CYPRESS ISLANDS. $a$

Glass and glassware.

36,134

\section{NETHERLANDS, $a$}

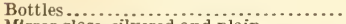

Mirror glass, silvered and plain..........

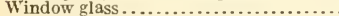

Broken glass.

Manufactures not specified.

Total.

195,232

$\$ 43$

31,337

4,395

$1,754,803$

592,091

562,532

9,921

305,980

2,413

8,054

200,025

12,173

15,233

$1,001,646$

98,700

5,790

3,413

,

22, 766

55,245

101,728

11,649

112,247

303,635

\section{NORWAY,a}

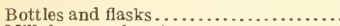

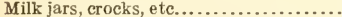

Fishing buoys.....................

Electric incandescent lainps

Mirrors.

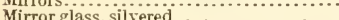

..............

Mirror glass, unsilvered..................

Window glass.

Flooring.

Photographic plates.

Optical glass.

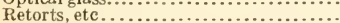

Other glass manufactures.

Total.

57,834

8,308

4, 985

195,721

18,438

47,275

114,516

138,047

16,375

25,406

16,107

2,010

170,234

815,256

PORTUGAL, $a$

Bottles.

Buttons of porcelain or glass. .........

Lamp chimneys......................

Mirrors

Plate:

Polished, unsilvered.

Polished, silvered.

Not polished.

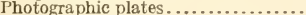

Opera glasses......................

Vases...

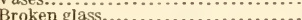

Manufactures not specified...........

Total.

175,009

28,257

14,975

12,554

47,227

52,507

2,114

37,976

$27,56.5$

3,590

908

307,817

710,499
ROUSI.NTA, a

Bottles.

Demijohns

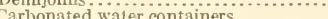

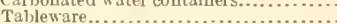

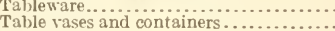

Electric bulbs ........................

Lamp glass...............................

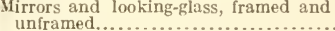

Optical goods

(2)

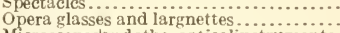

Microscopesandother opticalinstruments.

Watch erystals.

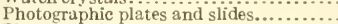

Photographic apparatus . . . . . . . . . . . . .

Roofing glass.

Window and plate......................

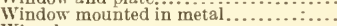

Wire glass.

Cut glassware. .........

Imitation pearls of all kinds ...............

Buttons.

Bracelets

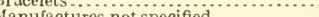

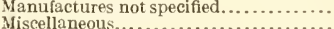

Total.

$\$ 123,724$

2., 160

30,484

3, 337

43,025

66,386

17,114

23,196

2,525

19,879

25,599

1., 655

1, 708

46,690

22,098

4,367

361,258

788
48,040

11,240

51,063

16,710

3,842

34,936

92,960

$1,184,067$

RUSSIA. $b$

Bottles.

Siphons.

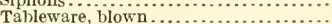

Manufacturers of flint glass

Manufactures:

Uncut, unpolished, unground, pressed

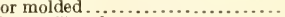

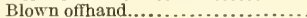

Cut, polished, etc..

Not specified, colored, opaque, etc..

Not specified, etched, unground, etc.

All kinds with ground necks, etc...... Electric-light bulbs:

With carbon filaments. Plate:

With metal filaments.

Not cast, polished ................

Silvered

Wirc glass.

Photographic dry plates.

Broken glass. . .

Spectacles, largnettes, binoculars....

sheet glass, blown or cast, uncut, un-

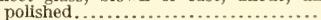

Other sheet.

Sheet glass, embelished with paintings;

lead glass.........................

Total.

56,150

2,859

23,418

47,665

52,675

370,450

204,363

241,948

421,626

83,728

212,056

$2,282,595$

274,686

9,223

90,115

7,578

261, 292

18,245

155,633

387,752

75,060

13,381

$5,292,498$

SERBLA. $C$

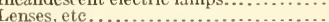

Optical glasses and watch crystals....

Photographie dry plates..............

Plate and window glass................

Wire and opaque glass.

Prisms, pendants, buttons, and pearls,

etc. pendants, buttons, and pearls,

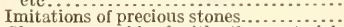

Glassware combined with other materials

Glass and glasswarc, not specified.......

Total.

25,886

$\therefore, 617$

1,018

4, 801

84,276

3,913

11,807

11,120

12,906

141,042

305,386

a Calendar year 1913.

b Calendar year 1913; includes Russia in Europe and Russia in Asia. 


\section{Table 139.-Value of Imports of Glass and Glassware into Foreign Countries,} By Continents-Continued.

EUROPE-Concluded.

SPAIN. $a$

Bottles and demijohns

Flectrie-iight lamps with mountings.....

Optical glass, wateh erystals, and spec-

tacle lenses.......................

Photographic plates...................

Plate and window glass..................

Paving and wire, ete ...................

Ribbed.

Silvered, plated, and nickeled............

Imitation pearls, etc.....................

Manufactures not specified, uncut, un-

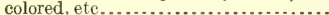

Colored and eut, ete.......................

Total.

SWEDEN_a

Bottles .

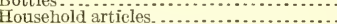
Lamp shades and glasses. . . . . . . . . . . . . .

Photographic dry plates ...................

Window and mirror ....................

Mirrors and paintings.......................

Wire glass

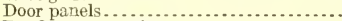

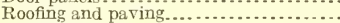

Portholes.

Laboratory articles...................

Tubing.................................

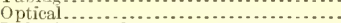

Imitation pearls . . . . . . . . . . . . . . . . .

Buttons of glass or porcelain ...........

All other manufaetures of glassware and enamel ware.

Total. ........................

SWITZERLAND.

Electric-light globes ..................

Insulators and electric battery jars...

Made from brown, black, or green

glass..........................

\section{NORTH AMERICA.}

BRITISH WEST INDIES.

Barbados: $a$

Glass, manufactured

7,713

Jamaica: $a$

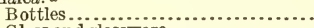

Total.

56,281

64,081

Trinidad and Tobago:

Glass and glassware............. 51,268

Bahamas: $a$

Bottles..

Earthen and glass ware

Total. 186,786

187,238

Leeward Islands: $c$

Earthen and glass ware Grenada: $a$

Glass and glassware

St. Vincent: $a$

Glass and glassware.............. 4,409

St. Lucia: $a$

Glass and glassware.
SWTTZERLAND-concluded.

Hollow ware-Concluded.

Not polishe1, semiwhite glass . . . ... $\$ 32,731$

Not polished, white glass......... 219, 033

Other kinds, polished, unground,

colored, or gilded . . ............. 265, 298

Combined with metal or straw...... $\quad 37,170$

Photographic dry plates.............. 132,383

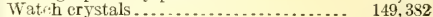

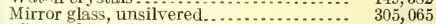

Mirror glass, silvered............... 39,059

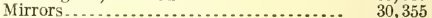

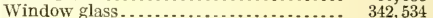

Cathedral glass . . . . . . . . . . . . . . . . . . . $\quad 17,521$

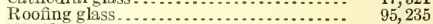

Vitrification, and imitation pearls ...... 21,705

Other manufactures of glass .......... 13,528

Total.

$1,996,785$

TURKEY. $b$

Electrie apparatus and incandescent

bulbs.

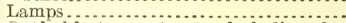

Optical instruments, etc., including pho-

tographic dry plates................

Plate glass and mirrors, framed or not...

Window glass, all kinds ...............

Other glass manufactures...............

Total . $2,436,480$

\section{UNITED KINGDOM. $a$}

Flint, plain, cut, or ornamented, and man-

ufactures of flint glass, except bottles .. 6, 739, 523

Plate glass......................... 2, 641, 799

Window and German sheet, including

shades and eylinders............... 3,416,118

Manufactures unenumerated.............. $\quad 21,306$

Total .................... 16,784,476 $a$ Calendar year 1913.

$b$ Fiscal year ended Mar. 13, 1912; includes Turkcy in Europe and Turkey in Asia.

\section{CANADA. $d$}

Carboys, demijohns, bottles, decanters,

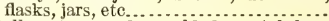
Balls, cut, pressed or molded, crystal glass tableware, blown glass, tableware, and other cut glassware .................. Common window glass................ 1, 497,379 Ornamental figured and enameled, colored glass, and enamel or other ornamental window glass . . . . . . . . . . . . . . . Plain colored, opaque, stained or tinted,

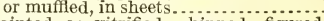
Painted or vitrified, chipped, figured, enameled, and obseured white glass... Plate glass, all kinds and sizes ....... 31, 499 Glass for photographic dry plates......... Glass plates or disks for optical purposes. $\quad 11,520$ Silvered glass, beveled or not, framed or

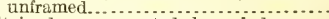
Stained or ornamented glass windows All other articles of glassware......... 470,518 Total. ...................... $\overline{5,103,938}$

¿ Fiscal year ended Mar. 31, 1914. 
Table 139.-Value of Imports of Glass and Glassware into Foreign Countries. BY Continents-Continued.

NORTH AMERICA-Concluded.

\section{COSTA RICA.a}

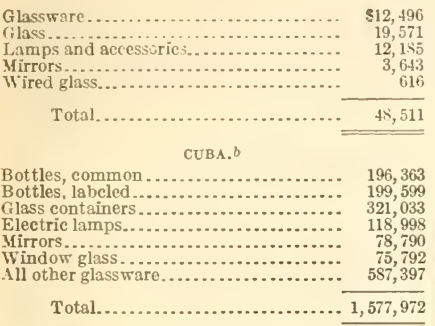

DANTSH WEST INDIES, ST. THOMAS ISLAND,

Glassware

\section{DOMLICAN REPUBLIC. $a$}

Glass and glassware.

55,330

DUTCH WEST INDIES. $a$

Glass and glassware.

FRENCH WEST INDIES. $a$

Guadeloupe and dependencies:

Bottles.

Demijohns . . . . . . . . . . . . . . . . .

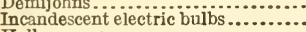

Hollow ware-

Cut, engraved, decorated.

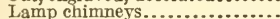

Plain pressed, etc................

Plate glass.

Window glass ........................

Miscellaneous.......................

Total.

2,489

2,893

205

5,030

1,561

5, 748

1,291

583

692

400

20,892

Martinique:

Bottles...........................

Incandescent electric bulbs

Hollow ware-

Cut, engraved, decorated........

Lamp chimneys................

Plain, pressed, etc.................

Plate glass.

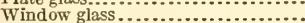

Trinkets, ornaments, beads, etc....

Miscellaneous.......................

Total.

4,520

451

3,492

618

1,689

2,121

714

273

5,952

19,830

GUATEMALA.a

Bottles, flasks, demijohns.

Glassware for houschold use .

Spectacle lenses.........................

Mirrors.

Jardiniers.

GUATEMALA-concluded.

Plate glass.............................

Roofing-glass.

$\$ 4,0 \$ 9$

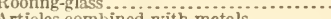

s............

Total.

18,722

\section{HCNDURAS.}

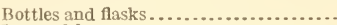

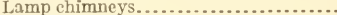

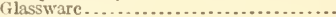

Looking-glasses.........................

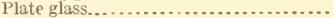

Spectacles.

Total.

\section{MEXICO. $c$}

Bottles.

3 S 3,967

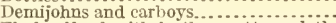

Flasks, lined with leather, rattan, cloth,

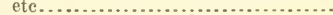

Mirrors and glass for, all kinds..........

Lenses of all kinds with handles and

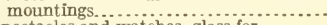

Spectacles and watches, glass for........

Common and plate, polished...........

Cut and engraved .................

Paving glass

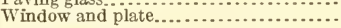

Total.

$\overline{1,301,151}$

2, 735

$150,0 S 1$

15,626

4, 265

301,932

56,567

151,565

9,349

177,953

NEWFOUNDLAND. $d$

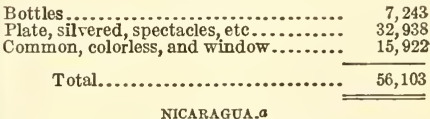

Glass and glassware ............... 39, 323

PANAMA.a

Bottles

6,212

Demijohns

956

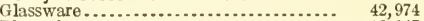

Plate glass................................. 16,147

Glass not specified.....................

Total................... 72,552

ST. PIERRE AND MIQUELON, $a$

Bottles, filled or empty................ 1, 081

Hollow ware, plain, pressed, and lamp

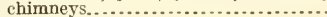

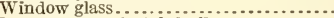

Incandescent eleetric bulbs.............

Miscellaneous........................

Total.

SALVADOR. $e$

Glassware.

d Fiscal ended year Mar. $31,1914$. $b$ Fiscal year cnded June $30,1914$. c Fiscal year ended June $30,1912$.

e Calendar year 1912. 
Table 139.-Talue of Imports of Glass and Glassware into Foreign Countries, By Continents-Continued.

\section{SOUTH AMERICA.}

\section{ARGENTINA.a}

Bottles, ordinary, and flasks. Prescription bottles................ 202,409 Bulbs.............................. 137,165 Incandescent lamps................... 478,101

Insulators ........................... Flooring and skylights..................... Mirrors, finished.

Mirrors, glass for . Lamp ware:

Of glass and porcelain..............

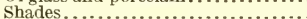

Carriage

Portable.

Not specified

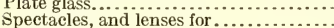

Tubing.

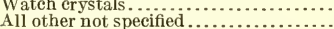

Total $5,229,406$

BOLIVIA.

Mirrors

24,014

Glass

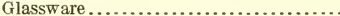

Other glassware

6,626

69,779

9,967

Total.

150,386

BRAZIL. $a$

Bottles

Flasks.

Cups.

Eyeglass lense

Insulators.

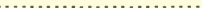

Laboratory apparatus

Lighting goods:

Carriage lamps.

(n)

(2)

Polished glass

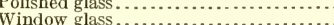

Manufactures not specified

Total. $3,427,853$

BRITISH GUIANA. $a$

Bottles, lamps, lamp chimneys, and ta-

bleware..............

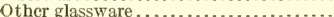

Total.

26,315

CHILE.a

Bottles.

Demijohns.

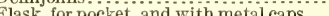

Electric light globes . . . . . . . . . . . . . . . .

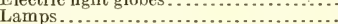

Looking glasses, and mirrors for ..........

Glassware:

Ordinary and metal mounted......

Fine and metal mounted............

Plate glass, beveled or not...............

Colored glass ..........................

Photographie glass.......................

Marine and opera glasses................

Spectacles, lenses, and watch crystals...

Miscellaneous.......................

Total.

$$
\overline{1,759,044}
$$

\section{DUTCI GUIANA, $a$}

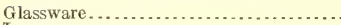

Lamps.

Total.

\section{ECUADOR, $a$}

Ordinary glassware................ \$22,362

Fine glassware ..................... 1,02

Lamps and lanterns................... 11,570

Mirrors

Window, plate, concave, and ribbed glass $\quad \begin{array}{r}5,050 \\ 10,783\end{array}$

Total...................... 50,789

FALKLAND ISLANDS. $a$

Glass and earthenware............ $\quad 4,657$

FRENCH GULANA. $a$

Bottles, filled or empty.

Flowers, ornaments, imitation pearl and porcelain funeral wreaths.

Hollow ware:

Plain, pressed, ete................

Cut, engraved, and decorated...........

Lamp chimneys.....................

Ineandescent electric bulbs ................

Miscellaneous............................

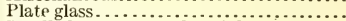

Small glassware, beads, trinkets, etc.....

Spectacles and optical goods..............

Watches and clocks.....................

Window glass, plain.....................

Total.

3,554

566

2,397

2,213

532

1,555

1,062

480

51

10

13

286

12,719

\section{Bottles:}

PERU,a

Ordinary .................... 125,259

Carbonated water containers........ 11, 382

Covered with straw, metal, or leather. $\quad 1,022$

Flasks and demijohns............. $\quad 1,382$

Glassware:

Ordinary ....................... 26, 300

Cut or decorated............... 61,531

With metal mountings ............... 12,207

Field, marine, opera glasses and lorg-

nettes . .............................

Lighting goods:

Lamp shades and bowls.......... 14,727

Kerosene lamps, chimneys, and gas

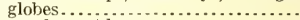

Ineandescent lamps ....................

Carriage and other lanterns...........

Mirrors, and plates for ...................

Photographic and dry plates..............

Spectacles and goggles....................

Window, plate and ribbed glass..........

Miscellaneous.......................

Total.

7,659

39,714

4,333

39,923

4,483

3,115

28,781

3,555

90,460

URUGUAY,

Bottles........................... 72,885

Demijohns...............................

Flasks.

Lamps............................. 17,859

Lamp chimneys ...................... 21, 867

Mirrors ........................... 1,083

Floor glass . . . . . . .

Plate glass............................... 66,420

Ribbed glass ........................... $\quad 9,346$

All other glassware................. 146,948

Total.

382,580

\section{VENEZUELA $a$}

Bottles, ordinary ................. 116,276

Carbonated water bottles............... 3,648

Demijohns.......................... 12,987

Lamps................................... $\quad 26,875$

Lighting goods...................... 12,840

Aleohol lamps. ...................... 4, 206

Glass manufactures.................... $\quad 90,289$

Optical apparatus....................... $\quad 1,112$

Plate............................. 9,986

Total.................... 278,219 
Table 139.- Talde of Imports of Glass and Glassware into Foreign Countres, BY Continents-Continued.

ASIA.

ADEN, $a$

Bangles.

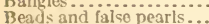

Bottles and phials.....................................

Funnels, globes, and glass parts of lamps.

Tableware, including decanters, tum-

blers, ete.............................

Sheet and plate glass .......................

Other glassware.......................

Total.

$\$ 11,6+5$

1S, 926

5,499

3,577

2,229

1,124

6,721

49,721

BRITISI INDIA. $a$

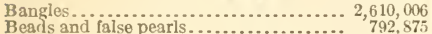

Bottles and phials ................... 711,370

Funnels, globes, and glass parts of lamps.

Tableware, ineluding decanters, tumblers, ete.

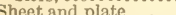

Total.

$6,311,135$

CEYLON.b

Plate glass...............................
Window and German sheet............

Total.

20,766

$3 \mathrm{~S}, 420$

135,504

194,690

CHINA. b

Lamps and lamp war

Glass and glassware.................. 801,727

Window glass....................... 836,204

Total.

$2,924,458$

CHOSEN.C

74,550

Window glass.

\section{DUTCH EAST INDIES, $h$}

Bottles

Lamp ehimneys.........................

Tiling.

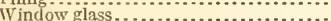

Glassware imported for the Government

All other.

Total.

$1,044,234$

84,277

17,189

65,196

47,896

721,355
Indo China:

Bottles, flled or empty............. \$173,594

Flowers, ornaments, cte............ 10,457

Incandescent electric bulbs............ 46, 445

Hollow ware-

Plain pressed.................. 204,552 Cut, engraved, and decorated.... $\quad 25,363$

Lamp ehimneys.................. 22,530

Plate glass........................ 36,517

Window glass ..................... 59,177

Small glassware, beads, trinkets, etc. $\quad 13,501$

Miseellaneous..................... 22,027

Total.......................

Freneh India:

Plate glass................ 32

Small glassware, beads, trinkets, etc. $\quad 967$

ifiscellaneous.................... 331

Total........................ 1,330

JAPAN. $b$

Sheet glass.......................... 1, 049, 561

Plate glass.

Plate or sheet, silvered .................. 37,564

Plate or sheet, ribbed, embossed, ete..... 39,955

Wire glass .................... 58, 58,423

Photographie plates.................... 187,769

All other manufaetures................. $\quad 54,216$

Total. $1,696,758$

SIAM. $a$

Mirrors, unframed.................. 4, 180

Glazing glass ....................... $\quad 39,742$

Hollow ware...................... 115,533

All other glass manufaetures.............. $\quad 31,310$

Total........................

STRAITS SETTLEMENTS. $d$

Bottles.......................... 236, 202

All other glass and glassware......... 408, 432

Total.

644,634

AFRICA.

ABYSSINIA. $b$

Glass and glassware . . .............. \$3, 651

BELGIAN KONGO,b

Glassware

104,065

BRITISH WEST AFRICA, $b$

Gambia:

filassware...

4,166

Southern Nigeria:

46,236

\section{BRITISI SOUTH AFRICA. $b$}

Bottles and jars .................. $\quad 710,670$ Uther glass and glassware.

Total. $1,356,576$ BRITISH EAST AFRICA.

East ifrica Protectorate: $d$

Glassware and earthenware

64,048

Mauritius: $d$

Glass and glassware

33,288

a Fiseal year ended Mar. 31, 1914.

b Calendar year 1913.

$c$ Calendar year 1914.
BRITISH EAST AFRICA-coneluded.

Seyehelles: $d$

Glassware

$\$ 729$

Uganda Proteetorate:

Earthenware, ehina and glass....... 23, 199

Zanzibar: $d$

Croekery and glassware............ 31, 958

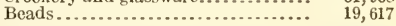

Total.

51,575

FRENCH AFRICA,b

Algeria:

Glasses for table use .............. 237, 583

Window glass .................... 120,818

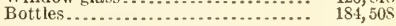

Total.

542,909

Dahomey and dependeneies:

Beads, trinkets, and small glassware. $\quad 19,378$

Bottles......................... $\quad 15,019$

Flowers, ornaments of pearl, ete.....

d Calendar year 1912

e Fiseal year ended Mar. 31, 1913. 
Table 139.-Value of Emports of Glass and Glassware into Foreign Countries, BY Continents-Continued.

AFRICA-Concluded.

FRENCH AFRICA-continued.

Dahomey and dependencies-Concluded. Hollowware, goblets, etc.-

Window glass .
Plain, engrossed, and decorated....

Lamp shades, etc................

Incandescent lamps................

Insulators and tiling...................

Plate glass.........................

Spectacles and optical goods.........

Watch and clock glass...............

Miscellaneous glassware.............

Total.

French Guinea:

Beads, trinkets, and small glassware.

Bottles...........................

Flowers, ormaments of pearl, etc.....

Hollowware, goblets, etc.--

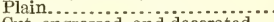

Cut, engrossed, and decorated...

Lamp shades, etc...............

Incandescent lamps ................

Insulators and tiling.................

Plate glass-

Unpolished and polished........ Silvered

Window glass.....................

Miscellaneous glassware...............

Total.

$\$ 2,367$

1,197

483

151

44
2,425
257

37

5
544

2,503

44,218

35,573

310

65

314

502

755

719

303

1,348

23

117

2,741

42,770

French Somali:

Beads, trinkets, and small glassware.

Bottles ...........................

Hollowware, goblets, etc.-

Plain....................................

Cut, engrossed, and decorated...

Incandescent lamps ...................

Plate glass, unpolished and polished.

Watch and clock glass...............

Window glass .....................

Miscellaneous glassware................

Total.

11,341

1,014

15

7,114

3,459

1,341

45

830

3

782

717

26,661

Gabon:

Beads, trinkets, and small glassware.

Bottles ..........................

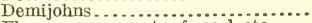

Flowers, ornaments of pearl, etc ....

Hollowware, goblets, etc.-

Plain..................................

Lamp shades, etc...............

Insulators and tiling....................

Plate glass, unpolished and polished.

Window glass . ...................

Miscellaneous glassware.............

Total.

Ivory Coast:

Beads, trinkets, and small glassware.

Bottles ...........................

Flowers, ornaments of pearl, etc.....

Glass in sashes.....................

Hollowware, goblets, etc.--

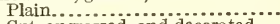

Cut, engrossed, and decorated...

Lamp shades, etc...............

Incandescent lamps.

Plate glass, unpolished and polishe....

Spectacles and optical goods.........

Watch and clock glass.................

Window glass. ........................

Miscellaneous glassware..............

Total.

3,300

173

441

11
279

57

1,063

9,517

30,614

6
564

564
39

232

1,098

298

535

110

1,894

7

10
680

10,312

46,399
Enameled glass.......................
FRENCH AFRICA-concluded.

Madagascar and dependencies:

Beads, trinkets, and small glassware.

Bottles...........................

Flowers, ornaments of peari, etc......

Glass in sashes....................

Hollowware, goblets, etc.--

Plain........................

Cut, engraved, and decorated....

Lamp shades, etc.................

Incandescent lamps. .

Insulators and tiling...................

Plate glass, unpolished and polished.

Watch and clock glass................

Miscellaneous glass ......................

Total

S5, 657

23,937

1,024

11, 788

2,420 .

2,047

1,395

1,249

2,789

10

5,159

3,302

60,804

Middle Kongo and Ubang-Shari-Chad:

Beads, trinkets, and small glassware.

Bottles.

Hollow ware, goblets, etc.-

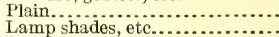

Insulators and tiling...................

Plate glass..........................

Watch and clock glass.................

Window glass . ......................

Miscellaneous glassware...............

Total.

26,161

Reunion:

Glassware .................... 12,980

Senegal:

Beads, trinkets, and small glassware.

Bottles ............................

Demijohns ..............................

Enameled glass....................

Flowers, ornaments of pearl, etc......

Glass in sashes.....................

Hollowware, goblets, etc.-

Plain ..................................

Lamp shades, etc

Incandescent lamps . ..............

Insulators and tiling.

Plate glass, unpolished and polished.

Spectacles and optical goods.........

Stained glass ........................

Watch and clock glass.................

Window glass ........................

Miscellaneous glassware..............

13,099

8,563

1,910

326
202

353

10

868

830

$=$

20,181

1,342

278

10,369

1,758

254

3,037

1,625

1,002

5, 746

539

3,605

104

223

4, 256

5,918

Total.

60,261

Tunis:

181,900

Upper Senegal and Niger:

Beads, trinkets, and small glassware.

Bottles....

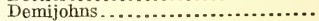

Enameled glass.......................

Hollowware, goblets, etc.

Plain.........................

Lamp shades, etc..............

Incandescent lamps ................

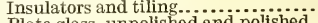

Plate glass, unpolished and polished.

Stained glass.

Window glass.

Miscellaneous glasswar

$$
\text { Total. }
$$

8,834

151

1,892

302

90

1,323

221

14,370

Glass and glassware................ 405,996

MOROCCo.b
Glass and glassware ................ 323,296. 
Table 139.-Value of Eyports of Glass a id Glassware into Foreign Countries, BY Continexts-Concluded.

OCE.INIL.

AUSTRALIA, $a$

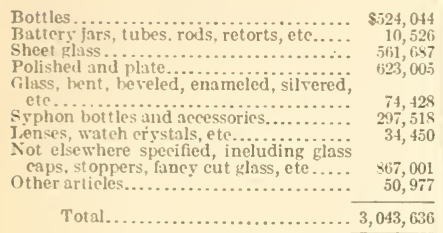

Bottles

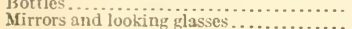

375,543

45,842

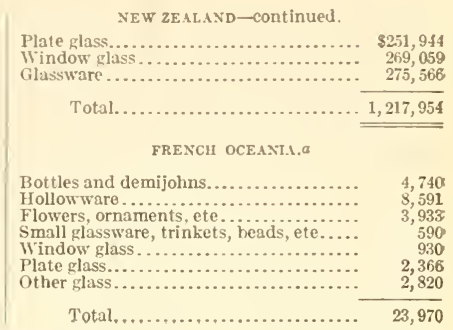

NEW ZEALAND-continued.

Plate glass........................ \$251, 944

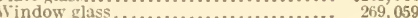

217,954

4,740

, 591

590

930

, 820
Total....

23,970

a Calendar year 1913.

\section{SUGGESTIONS FOR INCREASING FOREIGN TRADE.}

Before the war in Europe began the exports from the United States of plate glass were negligible, of window glass and bottles very small, and of all other glass small compared with the domestic production. Most manufacturers made no serious efforts to build up a foreign trade, and there was a general lack of knowledge among them as regards the requirements of foreign markets and the proper methods to be adopted in building up an export trade. Shipments of all kinds of glass and glassware have enormously increased since the war began, and many more manufacturers are exporting now than ever before. There is much uncertainty as to how much of this foreign trade can be retained after peace is declared, but manufacturers are very hopeful that they can hold a much larger trade abroad than they had before the war.

To hold and extend their foreign trade, manufacturers should inaugurate an active campaign of inquiry and study as regards the requirements of markets in other countries and the proper methods to be adopted to reach these markets. Individually or collectively manufacturers should send representatives into the foreign fields to study the conditions and the tastes of the people, to show samples, and to establish their own agents in the principal countries, who could look after the business when their representatives had returned from the field.

Manufacturers who are unable or unwilling to adopt this policy should avail themselves of the facilities which the Bureau of Foreign and Domestic Commerce provides for assisting them in securing export trade. In the "Trade opportunities" published in the Commerce Reports, issued daily by the Bureau, there are frequently printed inquiries from abroad for the names of American manufacturers and exporters, and if these opportunities are actively followed up connections can be made with foreign importers that may result in good sales.

Manufacturers who seriously undertake the work of selling their products abroad should bear in mind the suggestions which always apply in the development of export trade, namely, to write letters 
and prepare catalogues in a language which the prospective customer understands, to quote prices in a currency with which he is familiar, to furnish c. i. f. (cost, insurance, and freight) quotations as far as possible, to pack goods properly, to fill orders promptly and carefully, to extend a reasonable amount of credit where the standing of the importer justifies.it, and to keep in constant touch with the market through representatives or by correspondence.

Numerous publications have been prepared by the Bureau of Foreign and Domestic Commerce to give manufacturers information as to the character, extent, resources, and trade of foreign countries, and also to enable them to determine in part the most favorable markets for their products. These publications are listed in a catalogue which may be obtained on application to the Bureau or its branch offices.

The original customs tariffs of all foreign countries are on file in the division of foreign tariffs of the Bureau of Foreign and Domestic Commerce, which, in response to specific inquiries, will furnish information concerning the duties on any particular product in any country in which the inquirer may be immediately interested. 


\section{A P PENDIXES.}

\section{APPENDIX A. \\ LIST OF REFERENCES ON THE GLASS INDUSTRY.}

(Compiled under the direction of H. H. B. Meyer, Chief Bibliographer, Library of Congress.)

MANUFACTURE AND HISTORY.

BIBLIOGRAPHY.

1. Edinburgh. Royal Scottish museum. Library. List of books, etc., relating to glass, in the library of the Museum. Edinburgh, Printed by Neill \& company for H. M. Stationery off., 1893. $40 \mathrm{p}$.

2. Great Britain. Patent office. Library. Subject list of works on the silicate industry (ceramics and glass) in the library of the Patent office. London, H. M. Stationery off., Darling \& son, ltd., 1914. 84 p. (Patent office library: Subject lists, new ser., CD-CK.)

3. Meyer, H. H. B., and Laura A. Thompson. List of references on child labor. Washington, Govt. print. off., 1916. 161 p. (U. S. Children's bureau. Industrial series, no. 3.) Glass industry: p. 92-94.

4. New York. Public library. List of works in the New York public library relating to ceramics and glass. [New York, 1908.] 38 p. "Reprinted from the Bulletin, October, 1908.

5. South Kensington museum. A list of books and pamphlets in the National art library of the South Kensington Museum illustrating glass. London, Printed by Eyre and Spottiswoode, 1887. $47 \mathrm{p}$.

6. United States. Geological survey. Investigations relating to clays . . . in 1908. By George C. Matson. Washington, Govt. print. off., 1909. 24 p. Advance chapter from Bulletin no. 380. Survey publications on glass sand and glass-making materials: p. 19.

See also items nos. 18, 21, 49, 82, 93, 94, 100.

\section{BOOKS.}

7. Acton, R. M. A short history of the glass manufacture in Salem County, New Jersey. Pennsylvania magazine of history and biography, Oct. 18s5, v. 9: 343-346.

8. Africa, Walter G. The glass sand industry of the Juniata Valley. (In Pennsylvania. Department of internal affairs. Pt. III, Industrial statistics, 1885. Harrisburg, 1886 . p. 36-43.)

9. [Allegheny plate glass company.] Schedule B, Plate glass. Proposed amendments to paragraphs 98, 100. Sixty-first Congress. [n. p., 1909.] $7 \mathrm{p}$.

10. American flint glass workers' union. Annual reports of national officers of the American flint glass workers' union. [Toledo, Ohio, Kraus \& Schreiber, 1915-1916.] 2 v.

11. American flint glass workers' union. Proceedings of the convention of the American flint glass workers' union. Toledo, Ohio, 1912-1916. $3 \mathrm{v}$.

12. Appert, Léon. La verrerie depuis vingt ans. Paris, E. Bernard et cie., 1894. $148 \mathrm{p}$.

-13. The art of ancient glass making. Corwhill magazine, Nov. 1867, v. 16:580-583.

14. Austria. Arbeitsstatistisches Amt. Die Arbeitszeit in Glashütten. Bericht über die in der Zeit von 14. Juni bis 14. August, 1909, durchgeführte erhebung. Wien, A. IIölder, 1911. $121 \mathrm{p}$.

15. Barff, Frederick S. Glass and silicates. (In Bevan, G. P., ed. British manufacturing industries. London, 1876. v. 7, p. 63-126.) 
16. Bassett, Sara W. The story of glass. Philadelphia, The Penn publishing co., 1916. $230 \mathrm{p}$.

17. Belgium. Office du travail. Monographies industrielles. Groupe IV, Fabrication et travail du verre. Bruxelles, J. L. Le Bègue et cie, 1907. 263 p.

18. Benrath, Hermann E. Die Glasfabrikation. Braunschweig, F. Vieweg und Sohn, 1880. 495 p. (Handbuch der chemischen Technologie, hrsg. von Birnbaum. Neue Folge, 2. Lief.) "Verzeichniss der benutzten umfassenderen Arbeiten": p. 485-487.

19. Biser, Benjamin F. Elements of glass and glass making. A treatise designed for the practical glass maker, comprising facts, figures, recipes, and formulas for the manufacture of glass, plain and colored. Chemically rev. by J. A. Koch. Pittsburgh, Pa., Glass and pottery publishing company [1899]. $124 \mathrm{p}$.

20. Blount, Bertram, and A. G. Bloxam. Chemistry for engineers and manufactures, a practical text-book. 2 ed. London, C. Griffin and company, ltd., 1911, '10. 2 v. (Griffin's scientific text-books.) Glass: v. 2, p. 164-175.

21. Bolas, Thomas. Glass blowing and working for amateurs, experimentalists, and technicians; based upon a course of lectures given under the auspices of the Technical education committee of the Middlesex County council. London, Dawbarn \& Ward, Itd.; New York, Truslove \& Comba [1898]. 212 p. Bibliography: p. 207-209.

22. Bontemps, Georges. Guide du verrier; traité historique et pratique de la fabrication des verres, cristaux vitraux. Paris, Librairie du Dictionnaire des arts et manufactures, $1868.774 \mathrm{p}$.

22a. Boswell, Percy G. H. A memoir on British resources of sands suitable for glass making. London, Longmans, Green \& co., 1916. $92 \mathrm{p}$.

23. Brockbank, C. J. An investigation of the surface devitrification of glasses under thermal after treatment. (In American ceramic society. Transactions, 1913. v. 15. Columbus, 1913. p. 600-605.)

24. Brown, C. W. Plate glass. (In American institute of architects. Proceedings, 1899. Washington, D. C., 1899. p. 92-98.) Brief review of the history of the manufacture of plate glass.

25. Buttram, Frank. The glass sands of Oklahoma. Norman, 1913. 91 p. (Oklahoma. Geological survey. Bulletin no. 10.)

26. Chabrié, Camille. Traite de chimie appliquée. Paris, Masson et cie, 1905-8. 2 v. Verrerie: v. 2, p. 1-89.

27. Cochin, Augustin. La manufacture des glaces de Saint-Gobain de 1665 à 1865. Correspondant, Nov.-Dec., 1865, v. 66; 619-648; 914-956.

28. Cochrane, Charles H. Modern industrial progress. Philadelphia, J. B. Lippincott company, 1904. 647 p. Revolution in methods of glass making: p. 495-501.

29. [Coggeshall, William T.] Five black arts. A popular account of the history, processes of manufacture, and uses of printing, pottery, gaslight, glass, iron. Condensed from the Encyclopedia Britannica. Columbus, Follett, Foster and company, 1861. $392 \mathrm{p}$.

30. Dammer, Otto, ed. Chemische Technologie der Neuzeit. Stuttgart, F. Enke, 1910-11. 3 v. Glas, by R. Dietz: v. 1, p. 803-826.

31. Dorflinger, William F. The development of the cut glass business in the United States. [New York, Press of R. L. Stillson, 1902.] 21 p.

32. Dralle, Robert. Die Glasfabrikation. München, R. Oldenbourg, 1911. 2 v.

33. Duncan, Robert K. The chemistry of commerce. New York, Harper \& brothers, 1907. 263 p. Modern chemistry and glass making: p. 109-127.

34. Dunlop, Madeline A. W. Glass in the Old world. New York, Scribner \& Welford [1882]. $272 \mathrm{p}$.

35. Feuchtwanger, Lewis. A handbook of silex, embraces in three practical treatises: I. On soluble glass, and all its applications in the arts. II. On glass making, in all its details. III. A guide for soap making, the manufacture of all soaps and their manipulations. New York, L. \& J. W. Feuchtwanger, 1871. $347 \mathrm{p}$.

36. Field, Kate. The drama of glass. [Toledo, Ohio.] The Libbey glass co. [189-] $46 \mathrm{p}$.

37. Fournier, Alban. La verrerie de Portieux; origine-histoire. Nancy, Impr. Berger-Levrault et cie., $1886.80 \mathrm{p}$.

38. Fowler, James. On the process of decay in glass, and, incidentally, on the composition and texture of the glass at different periods, and the history of its manufacture. (In Archaeologia; or, miscellaneous tracts relating to antiquity, published by the Society of antiquaries of London, 1880. v. 46. London, 1880 . p. 65-162.) 
39. Frary, Francis C. Laboratory manual of glass bloming. New York, McGrawHill hook company, 1914. $60 \mathrm{p}$.

40. Fremy, Elphage. Histoire de la manufacture royale des glaces de France au YiVII et au XVIII siècle. Paris, Plon-Nourrit et cie., 1909. $444 \mathrm{p}$. "Bibliographie": p. IX-XII.

41. Frink, Robert 1. Causes of breakage in glass manufacture and method of differentiating chemico-heterogeneic strains from cooling strains. (In International congress of applied chemistry, 8th, 1912. ․ 5. ('oncord, N. H., [1912?]. p. $57-71$.

42. The effects of alumina in glass. (In American ceramic society. Transactions, 1909 . v. 11, p. 99-102.)

43. - Questions arising in the making of glass. (In Engineers' society of western Pennsylvania. Proceedings, 1908. v. 23, p. 646-656.)

44. - The requirements of glass for bottling purposes. (In American ceramic society. Transactions, 1913. v. 15 . Columbus, 1913. p. 706-727.)

45. - Some fallacies and facts pertaining to glass making. (In American ceramic society. Transactions, 1909 . v. 11, p. 296-319.)

46. Gandy, $\mathrm{W}$. The romance of glass making. London, $1898.160 \mathrm{p}$.

47. Gelstharp, F. Some chemical reactions of interest to the plate-glass chemist. (In American ceramic society. Transactions, 1913. v. 15. Columbus, 1913. p. $585-590$.)

48. Gessner, Frank M. The American glass industry, its history, development, and present economic importance. (In Pennsylvania. Department of internal affairs. Pt. III. Industrial statistics, 1900, 1901. p. 7-27.)

49. - Glassmakers' handbook, containing recipes for making flint, bottle, window, and architectural glass. Pittsburgh, Pa., G. E. ITilliams, 1891. 185 p. "Bibliography of glass-current literature": p. 150-153.

50. — The mechanical manipulation and conveyance of glass and glassware. A paper read before the annual meeting of the American association of flint and lime glass manufacturers, 1904.

51. Gillinder, James. American glass interests. (In Depew, C. M. One hundred years of American commerce, v. 1, p. 274-284. New York, 1895.)

52. Glass. (In New international encyclopædia, 2d ed. New York, 1915. v. 10, p. $22-34$.)

53. Glass. (In Ure's Dictionary of arts, manufactures and mines. 7th ed. London, 1875. v. 2, p. 644-677.)

54. Glass machinery. (In Spon, Edward. Spon's Dictionary of engineering. London, 1873 . v. 2, p. $1669-1689$.)

55. Granger, Albert. Progrès récents dans l'industrie du verre. [Paris, 1903.] 39 p. (With Le Mois scientifique et industriel. v. 5.)

56. Grossmann, Robert. Die technische Entwicklung der Glasindustrie in ihrer wirtschaftlichen Bedeutung. Leipzig, W. Klinkhardt, 1908. 121 p. (Technisch-volkswirtschaftliche Ilonographien, hrzg. von. L. Singheimer. Bd. 3.)

57. [Hall, Samuel W.] Glass: what it is and how it is made. An account of what the boys and girls saw in the glass houses, during their usual holiday outing. ('hicago, Stromberg, Allen \& co., 1890. $100 \mathrm{p}$.

58. Hasluck, Paul N., ed. Glass working by heat and by abrasion. London, New York, Cassell and company, 1899. 160 p. ("Work" handbooks.)

59. Haudicquier de Blancourt, J. De l'art de la verrerie. Paris, J. Jombert, 1697. $602 \mathrm{p}$.

60. Heaton, Noel. Glass. (In Thorpe, Sir Edward. A dictionary of applied chemistry. Rev and enl. ed. New York, 1912. v. 2, p. 719-739.)

61. Hecht, Otto. Die K. K. Spiegelfabrik zu Neuhaus in Niederösterreich, 17101844: ein Beitrag zur Geschichte des Merkantilismus. Wien, C. Konegen (E. Stulpnagel), $1909.166 \mathrm{p}$.

62. Ilenrivaux, Jules L. C. La verrerie au $\mathrm{XX}^{\mathrm{e}}$ siècle. Paris, E. Bernard et cie., 1903. $464 \mathrm{p}$.

63. Hitchcock, H. K. Heat dissipation with especial reference to the annealing of plate glass. (In Engineers' society of western Pennsylvania. Proceedings, 1906 , v. 22 , p. $357-409$.)

64. Horn, Georg. Die Geschichte der Glasindustrie und ihrer Arbeiter. Stuttgart, J. H. W. Dietz Nachf., 1903. 368 p.

65. Hovestadt, Heinrich. Jena glass and its scientific and industrial applications. Tr. and ed. by J. D. Everett and Alice Everett. London, Macmillan and company, 1902. $419 \mathrm{p}$. 
66. Ihmsen, D. Cylinder or window glass. (In Pennsylvania. Department of internal affairs. Pt. III, Industrial statistics, 1885. Harrisburg, 1886. p. 44-58.)

67. Italy. Ispettorato generale dell' industria e del commercio. Glass and stained glass windows. Rome [Tip. nazionale di G. Bertero e c.] 1913. 61 p. (The artistic crafts of Italy, 3.)

68. Jaques, George M. Glass in its commercial aspect. A paper read before the annual meeting of the American association of flint and lime glass manufacturers, 1904 .

69. Jarves, Deming. Reminiscences of glass making. 2 ed., enl. New York, Hurd and Houghton, $1865.116 \mathrm{p}$.

70. Keppler, Frederick L. Keppler glass constructions; pavements, floors, roofs, walls, partitions, windows, and crystal ceilings: translucent but not transparent. New York City, F. L. Keppler, 1914. 15 p.

71. Key-Aberg, Karl V. V. Arbetsstatistik studie öfver glasindustrien i Sverige af d:r K. Key-Aberg. Stockholm, Samson \& Wallin [1899]. 84 p. (Skrifter utgifna af Lorénska stiftelsen. n:o 17.)

72. Lange, Gustav. Die Glasindustrie in Hirshberger Thale. Leipzig, Duncker \& Humblot, 1889. $145 \mathrm{p}$. (Staats-und socialwissenschaftliche Forschungen, hrsg. von Gustav Schmoller. 9 Bd., 2. Hft.)

73. Linton, Robert. A calculation of the percentage of heat actually utilized in glass melting furnaces. (In Engineers' society of Western Pennsylvania. Proceedings, 1895. v. 11. Pittsburgh, 1895. p. 291-297.)

74. Glass. (In Mineral industry, 1899. v. 8. New York, 1900. p. 234-263.)

75. - A study of glass and the relation of its properties to its chemical composition. (In Engineers' society of Western Pennsylvania. Proceedings, 1895. v. 11. Pittsburgh, 1895. p.119-131. Discussion: p. 131-136.)

76. Lunge, Georg. Technical methods of chemical analysis. English translation from the latest German ed., adapted to English conditions of manufacture, ed. by Charles A. Keane, T. L. Bailey, C. O. Bannister, and others. London, Gurney and Jackson, 1908-14. 6 v. in. 3. Glass, by E. Adam: v. 1, pt. 2, p. $621-657$

77. Manufacture of glass. (In Appleton's cyclopaedia of applied mechanics. Rev. and imp.ed. New York, 1893 . v. 1, p. 932-952.)

78. National board of fire underwriters. Rules and requirements for the manufacture of wired glass and the construction of frames for wired and prison glass used as a fire retardant. Ed. of 1906. [Boston?] 1906. $23 \mathrm{p}$.

79. National glass distributers' association. Glass and glazing. [St. Louis], Press of Kutterer-Jansen, 1916. $46 \mathrm{p}$.

80. Neri, Antonio. Antoni Neri Florentini, De arte vitraria libri septem, \& in eosdem Christoph. Merretti observationes \& notae. Amstelodami, apud A. Frisium, 1668. $455 \mathrm{p}$.

81. - Art de la verrerie, de Neri, Merret et Kunckel. Paris, Durand [etc.], 1752. $629 \mathrm{p}$.

82. Nesbitt, Alexander, and H. J. Powell. History of glass manufacture. (In Encyclopaedia britannica, 11th ed. New York, 1910. v. 12, p. 97-105.) Bibliography: p. 105.

83. New Jersey. Bureau of statistics of labor and industries. Glass [history of manufacture and statistics]. (In its Sixth annual report, 1883. Trenton, 1883. p. 281-315.)

84. - Wages and production in the glass industry from 1875 to 1905 . (In its Twenty-eighth annual report, 1905. Trenton, 1905. p. 199-210.)

85. Court of chancery. The case of George Jonas glass company versus The glass bottle blowers' association of the United States and Canada, et al. Opinion of the Court of chancery of the State of New Jersey. Washington, Govt. print. off., 1912. 10 p. (U. S. 62d Cong., 2d sess. Senate doc. 383.)

86. Court of errors and appeals. Opinion of the Court of errors and appeals of the State of New Jersey in the case of George Jonas glass company, complainant and respondent, versus The glass bottle blowers' association of the United States and Canada et al., defendants and appellants. Washington, Govt. print. off., 1912. 11 p. (U. S. 62d Cong., 2d sess. Senate doc. 374.)

87. Orton, Edward. The progress of the ceramic industry. Madison, Wis., 1903. 279-299 p. (Bulletin of the University of Wisconsin. Engineering series, v. 2 , no. 9.)

88. Peligot, E. Le verre, son histoire, sa fabrication. Paris, 1878.

89. Pellatt, A. Curiosities of glass making. London, 1849. 
90. Pittsburgh plate glass comprany. Statement of assets and liabilities [Pittsburgh. 1911.]

91. [Porter, (ieorge R.] A treatise on the origin, progressive improvenent, and present state of the manufacture of porcelain and glass. Philadelphia, Gihon it Smith, 1s4ti. 252 p.

92. Powell, H. J. lilass. (In Spon's encyclopaedia of industrial arts, manufactures. and rhemi:a! products. London, 18\$2. v. 3, p. 1043-1087.)

93. - - The priviples of glass making, together with treatises on crown and sheet glass, by Henry (hance, and plate glass by II. G. IIarris. London, G. Belt and sons, 1883. $186 \mathrm{p}$. (Technological handbooks, ed. by II. T. Wood.) Bibliography: p. 179-180.

94. - - and II'. Rosenhain. Glass. (In Encyclopaedia britannica, 11th ed. New York, 1910 . v. 12 , p. 86-97.) Bibliography: p. 97.

95. Randau, Paul. I ie farbigen, bunten und zerzierten Gläser. Eine umfassende Anleitung zur Darstellung aller arten Farbiger und verzierter gläser, der vielfarbigen irisierenden und metallisch schimmernden Ifode- und Luxusglïser. Wien und Leipzig, A. Hartleben, 1905. 347 p. (A. Hartleben's chemisch-technische Bibliothek. ('LXXXVI Bd.)

96. Rauter, Gustav. Die Industrie der Silikate, der künstlichen Bausteine und des Mörtels. Leipzig, G. J. Göschen, 1904. 2 v. (Sammlung Göschen, 233-234.) ('ontents: 1. Glas- und keramische Industrie.

97. Reich, Julius. Die Handelspolitischen Interessen der österreichischen Glasindustrie. (In Verein für Socialpolitik. Schriften, 93, p. 199-212. Leip$\mathrm{zig}, 1901$.)

98. Rocheleau, William F. Great American industries. Chicago, A. Flanagan, [1896-1900]. 3 v. (Home and school series for young folks.) "Glass:" v. 3, p. $37-74$.

99. Rogers, Allen, ed. Industrial chemistry; a manual for the student and manufacturer, 2d ed., rev. and enl. New York, D. Van Nostrand company, 1915. 1005 p. Glass, by James Gillinder: p, 290-305.

100. Rosenhain, IValter. Glass manufacture. London, A. Constable \& co., ltd., 1908. 264 p. (The "Westminster" series.) Bibliography: p. 253-255.

101. Sauzay, Alexandre. Marvels of glass making in all ages. London, S. Low, son, and Marston, $1870.272 \mathrm{p}$.

102. Shenstone, William A. The methods of glass blowing and of working silica in the oxy-gas flame, for the use of chemical and physical students. London, New York, Longmans, Green and co., 1907. 98 p.

103. Silverman, Alexander. Glass standards: a necessity. (In American ceramic society. Transactions, 1913. v. 15. Columbus, 1913. p. 684-693.)

104. Stainsby, William. Diseases and disease tendencies of occupation. The glass industry and the hatting industry. Trenton, N. J. [MacCrellish \& Quigley], 1901. $55 \mathrm{p}$.

105. Tariff commission, London. Report of the Tariff commission. v. 6 . The glass industry. London, P. S. King \& son, 1907.

106. Thorp, Frank H. Outlines of industrial chemistry; a textbook for students. New York, The Macmillan company, 1898. 541 p. Glass: p. 165-180.

107. Tscheuschner, E. Handbuch der Glasfabrikation nach allen ihren Haupt und Nebenzweigen. 5. Aufl. Weimar, B. F. Voigt, 1885. xvi, 666 p.

108. Uhlig, Edward C. Chemical analysis for glassmakers. Containing methods of analysis for clays and other silicates which will be found useful for the pottery industry. Pittsburgh, Pa., Kaufmann \& Gauding [1903]. 136 p.

109. United States. Bureau of Labor. Cost of production: The textiles and glass. Washington, Govt. print. off., 1892. 2 v. (Annual report of the commissioner of labor, 7 th, 1891.) (Issued in Congressional series, no. 2958, as House ex. doc. 232, 52d Cong., 1st sess.)

110. _ - Report on condition of woman and child wage earners in the United States. v. III: Glass industry. Prepared under the direction of Chas. P. Neill. Washington, Govt. print. off., 1911. 970 p. (61st Cong.y 2 d sess. Senate doc. 645 [v. 3].)

110a. - Bureau of labor statisties. Summary of the report on condition of woman and child wage earners in the United States. Washington, Govt. print. off., 1916. 445 p. (Bulletin, whole no. 175.) The glass industry: p. 117170 .

111. Union scale of wages and hours of labor May 1, 1914. Washington, Govt. print. off., 1915. $336 \mathrm{p}$. (Its Bulletin, whole no. 171.) Wage scales in various industries: Window glass: p. 319-329; Glass bottles: p. 330-336. 
112. United States. Census office. 10th census, 1880. Report on the manufacture of glass. Washington, Govt. print. off., 1884. $144 \mathrm{p}$. Published also in the general reports of the 10 th census, v.2, p.1029-1152. A preliminary report was "published in Census bulletin no. 118, under date of March 30, 1881."

113. 11th Census, 1890. Report on manufacturing industries in the United States. Pt. 3, Selected industries. Washington, Govt. print. off., 1895. 725 p. Glass, by Joseph D. Weeks: p. 309-340.

114. - 12th census, 1900. Reports. v. 9. Manufactures, Pt. III. Washington, Govt. print. off., 1902. Glass manufacture, by Shirley P. Austin: p. 947-1000.

115. - Census of manufactures, 1905. Glass and clay products. Washington, Govt. print. off., 1907. 107 p. (Bulletin 62.)

116. tries. Washington, Govt. print. off., 1908. 946 p. Glass, by H. B. Peffers: p. $837-874$.

117. ㄴ Thirteenth census of the United States, 1910. Bulletin. Manufactures, 1909. Statistics for the manufacture of glass. [Washington, Govt. print. off., 1913.] $12 \mathrm{p}$.

118. tries. Washington, Govt. print. off., 1913. 975 p. The manufacture of glass: p. $875-884$.

119. Commission to the Paris exposition, 1878. Reports of the United States commissioners to the Paris universal exposition, 1878. Washington, Govt. print. off., 1880. 5 v. (46th Cong., 3d sess. House. Ex. doc. 42, pt. 1-5.) Glass and glassware: by William P. Blake, v. 3, p. 227-387.

120. Congress. House. Committee on ways and means. Tariff hearings before the Committee on ways and means, 1908-1909. Schedule B, Earths, earthenware, and glassware. Washington, Govt. print. off., 1909. 581-1310 p.

121. - Tariff schedules, 1913. Hearings, v. 1. Schedules A and B. Washington, Govt. print. off., 1913. 947 p. Schedule B, Earths, earthenware, and glassware: p. 435-947.

122. Senate. Committee on finance. Tariff schedules. Briefs and statements filed with the Committee on finance. Schedules A and B. Washington, Govt. print. off., 1913.70 p.

123. - Tariff schedules. Briefs and statements. 63d Cong., 1st sess. Washington, Govt. print. off., 1913. 3 v. Schedule B, Earths, earthenware, and glassware: v. 1, p. 201-293.

124. - Geological survey. Nineral resources of the United States. 1914. Pt. II, Non-metals. Washington, Govt. print. off., 1916. 1122 p. Glass sand: p. 272, 278-279.

125. - Immigration commission, 1907-1910. Immigrants in industries. Pt. 12. Glass manufacturing. Washington, Govt. print. off., 1911, 388 p. (Report of the Immigration commission, v. 14.) 61st Cong., 2d sess. Senate doc. $633[\mathrm{v}, 14]$.

126. - Industrial commission. Reports. Washington, Govt. print. off., 1901. v. 7, Capital and labor. Digest: Glass trades: pt. 1, p. 160-171. v. 13, Trusts and industrial combinations. The plate glass combination: p. IviiiIxv; see also Index, p. 991, 998, 1008. v. 17, Labor organization. Labor organizations in the glass and pottery trades: p. 172-184.

127. $\quad$ Tariff commission, 1882. Report. Washington, Govt. print. off., 1882. 2 v. (47th Cong., 2d sess. House. Misc. doc. 6.) Bottles: p. 397, 450, $499,501,1056,1408,1447,2451,2509$. Window and plate glass: p. 226, 561, $563,937,1186,1529,1957,1999,2354$. Optical glass: p. 559, 563, 655, 2454 . Other glass: p. 562, 1408, 1447, 2133.

128. Vopelius, Eduard. Entwickslungsgeschichte der Glasindustrie Bayerns (nach seinem heutigen Umfang) bis 1806 . Stuttgart, J. G. Cotta'sche buchhand. nachf., 1895. 96 p. (Munchener volkswirtschaftliche Studien. 11 Stuck.)

129. Wagner, Johann R. von. Manual of chemical technology ....tr. and ed. by Sir William Crookes from the 13 th German ed. as remodelled by Dr. Ferdinand Fischer. New York, D. Appleton \& co., 1900. 968 p. Glass: see Index.

130. Weyermann, Moritz R. Das Verlagssystem der Lauschaer Glaswareindustrie und seine Reformierung. Naumburg, a. S., Druck von Lippert \& co. (G. Pätzsche buchdruckerei), 1902. $52 \mathrm{p}$.

131. Willets, Gilson, and others. Workers of the nation; an encyclopaedia of the occupations of the American people and a record of business. New York, P. F. Collier and son, 1903. 2 v. Glass and clay industries: v. 1, p. 321-337. 
132. Zschimmer, Eberhard. Die Glasindustrie in Jena, ein Werk von Schott und Abbe. Jena, E. Diederichs, 1909.158 p. Reviewed in Nature, Feb. 3, 1910, v. 82: 391-392.

\section{ARTICLES IN PERIODICALS.}

133. 1894. Hulme, E. WT. English glass making in the sixteenth and seventeenth century. Antiquary, Nov.-Dec. 1894, n. s., v. 30: 210-214, 259-263; Mar.May, 1895, n. s., v. 31: 68-72, 102-106, 134-138.

134. 1898. Hulme, E. IV. The French glass makers in England in 1557. Antiquary, May, 1898, n. s., v. 34: 142-145.

135. 1898. Linton, Robert. Continuous operation in the manufacture of window glass. Engineering magazine, Nov. 1898, v. 16: 243-254. "Especially devoted to the history of the development of the continuous tank furnace as opposed to the older melting pots.'

136. 1900. Tatum, C. A. One hundred years of American glass manufacture. Scientific American supplement, Apr. 21, 1900, v. 49: 20329-20330.

137. 1900. Baker, R. S. Casting a great lens. McClure's magazine, Oct. 1900, v. 15: 544-554.

138. 1900. Application of petroleum to metallurgy and the glass industry. Scientific American supplement, Oct. 20, 1900, v. 50: 20746-20747.

139. 1900. Working silica in the oxy-gas blowpipe flame. Scientific American supplement, June 9, 1900, v. 49: 20441-20442.

140. 1901. Jackson, W., and E. M. Rich. The constitution of glass. Society of chemical industry. Journal, 1901, v. 20: 555-560.

141. 1901. New products in the glass industry. Scientific American, Apr. 20, 1901, v. 84: 242 .

142. 1901. Manufacture of plate glass. Scientific American, May 18, 1901, v. 84: $305,311$.

143. 1901. Manufacture of blown-glass lamp chimneys. Scientific American, July 27,1901, v. $85: 49-54$.

144. 1901. Electrical glass furnace. Scientific American, Oct. 5, 1901, v. 85: 212.

145. 1902. Compressed air in the manufacture of glassware. Scientific American, May 10,1902 , v. $86: 232,329$.

146. 1902. Mechanical manufacture of bottles. Scientific American supplement, June 21, 1902, v. 53: 22128-22129.

147. 1902. Willey, D. A. Process of cutting glass dishes. Scientific American supplement, June 28, 1902, v. 53: 22141-22142.

148. 1902. Electric glass smelting. Scientific American, Sept. 6, 1902, v. 87: 148.

149. 1902. Malleable glass. Scientific American, Sept. 13, 1902, v. 87: 168.

150. 1902. Manufacture of cut glass. Canadian magazine, Oct. 1902, v. 19: 575-576.

151. 1902. Glazebrook, Richard T. Glass for optical purposes. Society of arts. Journal, Oct. 17, 24, 31, Nov. 7, 1902, v. 50: 877-886, 889-896, 901-909, 914-923.

152. 1902. Electricity in glass manufacture. Scientific American supplement, Nov. 1, 1902, v. $54: 22432$.

153. 1903. Kershaw, John B. C. The use of electricity for glass manufacture. Electrical review, 1903, v. 43: 735-738.

154. 1903. Manufacture of quartz glass in Germany. Scientific American, Apr. 11, 1903, v. 88: 274 .

155. 1903. Sharp, T. W. How chipped glass is made. Scientific American, Aug. 1, 1903, v. $89: 87$.

156. 1903. Sievert process of mechanical glass blowing. Scientific American, Oct. 3, 1903 , v. $89: 236$.

157. 1903. Glass making by electricity. Scientific American, Nov. 14, 1903, v. 89 : 348.

158. 1904. Glass industry in France. American review of reviews, Jan. 1904, v. 29: 111.

159. 1904. Production of glass sand in 1902. Scientific American supplement, Mar. 19, 1904, v. 57: 23583-23584.

160. 1904. Manufacture of incised or cut glass. Scientific American, Apr. 30, 1904, v. $90: 341,348-350$.

161. 1904. Stewart, W. R. Great industries of the United States: Glass making. Cosmopolitan magazine, Jan. 1904, v. 37: 139-154.

162. 1904. Blake, J. M. To turn glass in the lathe. Scientific American, June 18, 1904, v. 90: 483.

163. 1904. Pearson, W. H. P. Glass manufacture. World's work (London), June, 1904, v. 4: $49-53$. 
164. 1904. Powell, H. J. Glass blowing in Bohemia. Magazine of art, July, 1904, v. $28: 421-423$.

165. 1906. - Cut glass. Society of arts. Journal, 1906, v. 54: 776-781.

166. 1906. Electric fusion of glass. Scientific American, Feb. 17, 1906, v. 94: 146147.

167. 1906. Day, A. L., and E. S. Shepherd. Quartz glass. Science, Apr. 27, 1906, n. s., v. $23: 670-672$.

168. 1906. Hayes, D. A. Length of trade life in the glass-bottle industry. American academy of political and social science. Annals, May, 1906, v. 27: 496-499.

169. 1906. Blackiston, G. P. The magnitude of the glass industry in the United States. Business man's magazine and bookkeeper, July, 1906, v. 19: 53-63.

170. 1906. Tragic significance of cheap bottles. Current literature, Aug. 1906, v. 41: $218-220$.

171. 1906. Machine for the commercial production of window glass by the sheet process. Scientific American, Dec. 1, 1906, v. 95: 400.

172. 1907. The first glass works in America, Temple, N. H. Granite state magazine, Jan. 1907 , v. 3: 17-21.

173. 1907. Making quartz glass. Scientific American, Apr. 20, 1907, v. 96: 330.

174. 1908. Macbeth, George A. Glass making by machinery. Scientific American supplement, Mar. 7, 1908, v. 65: 151.

175. 1908. The history of glass making. Scientific American supplement, Apr. 25, 1908, v. 65: 271.

176. 1908. Colburn window-glass machine for drawing window glass continuously in any width. Scientific American supplement, May 16, 1908, v. 65: 305, $312-313$.

177. 1908. Middleton, P. H. Sheet glass by machinery. Technical world magazine, Oct. 1908, v. 10: 175-177.

178. 1909. Glass industry of the United States. Scientific American, Apr. 24, 1909, v. 100: 314 .

179. 1910. Bartlett, E. Burglar-proof glass. Technical world magazine, Mar. 1910, v. 13: 27-28.

180. 1910. Bostock, E. H. Glass; its adaptability to building. Architectural record, Apr. 1910, v. 27: 350-358.

181. 1910. Schaller, R. Manufacture of glass. Scientific American supplement, June 11, 1910, v. 69: 373.

182. 1911. Salvage-glass industry. Harper's weekly, Jan. 28, 1911, v. 55: 34.

183. 1911. Gray, H. St. G. The industry of glass-making at Nailsea, Somerset County, England. Connoisseur, June, 1911, v. 30: 85-98.

184. 1911. Saunders, C. H. Cooperative glass making, South Charleston, W. Va. Twentieth century magazine, June, 1911, v. 4: 235-239.

185. 1912. Dorr, R. C. When is a factory not a factory. Hampton's magazine, Feb. 1912, v. 28: 39.

186. 1912. Crookes, William. Devitrification of silica glass by heat and radium rays. Scientific American supplement, June 15, 1912, v. 73: 381.

187. 1912. Unsmashable glass. Literary digest, Sept. 28, 1912, v. 45: 512.

188. 1913. City car window-glass test. Electric railway journal, Jan. 11, 1913, v. 41: 78 .

189. 1913. Luckiesh, M. Investigation of diffusing glassware. Electrical world, Apr. 26, 1913, v. 61: 883-884.

190. 1913. Machine for blowing window glass: Sievert process. Scientific American, July 19, 1913, v. 109: 52-53.

191. 1914. Brady, E. J. Development of daylight glass; with discussion. Illuminating engineering society. Transactions, 1914, v. 9: 937-960.

192. 1914. Uncommon constituents of glass. Engineering and mining journal, Jan. 17, 1914, v. 97: 181-182.

193. 1914. No more flying glass; triplex glass. Literary digest, July 4, 1914, v. 49: 14.

194. 1914. Brady, F. J. Development of daylight glass; summary and discussion. Electrical world, Oct. 3, 1914, v. 64: 655 .

195. 1914. Chalmers, S. D. Glass for optical purposes. Nature, Oct. 1, 1914, v. 94: 117-118.

196. 1914. Sullivan, E. C., and W. C. Taylor. Rapid methods for glass analysis. Journal of industrial and engineering chemistry, Nov. 1914, v. 6: 897-899.

196a. 1915. Bostock, E. H. Sheet glass in lighting. Illuminating engineering society. Transactions, 1915, v. 10, pt. 1a, p. 1086-1096.

197. 1915. Manufacture of optical glass in America. Scientific American, Feb. 20, 1915, v. 112: 175 .

198. 1915. Notes on glass. Nature, Mar. 18, 1915, v. 95: 78-80. 
199. 1915. Supplies of laboratory and optical glass apparatus; reports. Nature. IIar. 25, 1915, ‥ 95: 103-105.

200. 1915. Houghton, A. A. Contributions of the chemist to the glass industry. Journal of industrial and engineering chemistry, Apr. 1915, v. 7: 290-292.

201. 1915. Toxall, J. Gentlemen glass makers come. Living age, Apr. 3, 1915, ‥ 285: $33-37$.

202. 1915. Formulas for glass manufacture. Nature, Apr. 15, 1915, v. 95: 192-193.

203. 1915. Wein. s. Selenium in the production of colored glass. Scientific American, $A$ pr. 17. 1915, $\vee$. 112: 361 .

204. 1915. Smull, Judion G. Causes of the opalescence of glass. Society of chemical industry. Journal. Apr. 30. 1915, v. 34: 402-105.

205. 1915. Spitzer. G.. and L. S. Trachael. Sand blast for marking glassware. Journal of industrial and engineering chemistry, May, 1915, v. 7 : $426-427$.

206. 1915. Supply of optical glass. Tature. May 6, 1915, v. 95: 266-267.

207. 1915. Anderson, 1). (G. Manufacture of laboratory glassware in Great Britain. Journal of industrial and engineering chemistry, June, 1915, v. $7: 543-5+4$. Scientific American supplement, July 24. 1915, v. 80 : 59.

208. 19]5. Evans, WV. A. D. Illuminating of glass factories. Electrical review and westeru electrician, July 10 . 1915, v. 67: 78-81.

209. 1915. Formulas for glass manufacture. Scientific American supplement, July 24 , 1915. v. $80: 59$.

210. 1915. Hulme, E. IV. Chapters in the history of glass making and painting in England. Antiquary, Aug., Nov.. 1915, v. 51: 288-292; 422-426.

211. 1915. Triplex glass. Scientific American supplement, Sept. 18, 19]5, v. 80: 187.

212. 1915. Scott, James. Glass; ingredients and manufacture. Architect, Oct. 29. Nov. 5,1915 , v. $94: 343-344 ; 368-369$.

213. 1915. VcEvoy, if. How glass is graded. Engineering record, Oct. 9, 1915, v. $72: 458$.

214. 1915. Glass making at the Ediswan works. Illuminating engineer, Oct.. 1915, v. 8: $434-435$.

215. 1915. Glass famine in Britain. Literary digest, Oct. 16. 1915, v. 51: 836 .

216. 1915. Gage, S. H. Daylight glass; abstract. Electrical world, Nov. 6, 19]5, v. $66: 1041$.

217. 1915. Frink, R. L. Relation of chemistry and mechanical manipulation to the evolution of the glass industry. Metallurgical and chemical engineering, Nov. 1, 1915, v. 13: 800-802.

217a. 1915. Sullivan, E. C., and W. C. Taylor. New glass; and an application of the low reflectivity of glass for radiant heat. Journal of industrial and engineering rhemistry, Dec., 1915, v. 7: 1064-1065. Scientific American supplement, Aug. 19, 1916, v. 82: 121.

217b. 1916. Mueller, H. O. Glass models of animals. Pan American union. Bulletin, Jan., 1916, v. 42: 95-99.

218. 1916. Lamb, S. Some notes on optical glass. Scientific American supplement, Feb. 5,1916 , v. 81: 86-87.

218a. 1916. Glass research. Engineer (London) Mar. 24. Sept. 22, 1916, v. 121: 249$250 ;$ v. $122: 250,252$.

219. 1916. Cheshire, F. J. Optical glass: an historical note. Nature, Mar. 30, 1916, v. $97: 100-101$.

220. 1916. Eisen, G. Origin of glass blowing. American journal of archaeology, Apr., 1916, v. 20: 134-143.

220a. 1916. Langlands, S. B. Aspects of the design and use of glass ware in relation to natural and artificial illumination. Illuminating engineer, Apr. 1916, v. 9: 118-122. Discussion, p. 123-134.

221. 1916. Glass industry; symposium at meeting of New York section of Society of chemical industry. Metallurgical and chemical engineering, Apr. 1. 1916, v. 14: $357-358$.

221a. 1916. Sullivan, E. C. Development of low expansion glasses. Journal of industrial and engineering chemistry, May, 1916, v. 8: 399-401.

221b. 1916. Gage, H. P. Daylight glass; a color screen for producing daylight artificially. Sibley journal of engineering, May, 1916, v. 30: 247-250.

222. 1916. Blount, B. Production of glass for scientific use. Engineer, July 28, 1916, v. 122: $81-82$.

223. 1916. Low-expansion glass. Engineering magazine, July, 1916, v. 51: 599.

224. 1916. Rosenhain, W. Optical glass; various qualities required, and something of the history and methods of its manufacture. Scientific American supplement, Aug. 19, 1916, v. 82: 118-119. Abstract in Metallurgical and chemical engineering, Mar. 15, 1916, v. 14: 335-336. 
225. 1916. New glass; and an application of the low reflectivity of glass for radiane heat. Scientific American supplement, Aug. 19, 1916, v. 82: 121.

226. 1916. Wolman, $\mathrm{I}_{\text {. }}$ Collective bargaining in the glass-bottle industry. American economic review, Sept., 1916, v. 6: 549-567.

226a. 1916. American-made chemical glass and porcelain, discussion. Journal of industrial and engineering chemistry, Oct., 1916, v. 8: 952-954.

226b. 1916. Boys, C. V. Annealing glass. Nature, Oct. 26, 1916, v. 98: 150-151.

227. 1916. Bryson, F. F. S. Electrochemical action on glass. Scientific American supplement, Oct. 28,1916, v. $82: 277$.

227a. 1916. Sheldon, A. N. Heat transmission through windows. American society of mechanical engineers. Journal, Nov., 1916, v. 38: 890-894. Metal worker, Dec. 29, 1916, v. 86: 791-796.

227b. 1916. French, J. W. Grinding and polishing optical surfaces. Engineer (London), Nov. 17,1916 , v. 122: 443.

227c. 1916. Scientific glassware. Nature, Nov, 16, 1916, v. 98: 210-211.

227d. 1916. Murray, E. A. Gage glass cutter. Railway mechanical engineer, Dee., 1916, v. 90: 660 .

227e. 1916. Manufacture of bottles. Scientific American supplement, Dec. 2, 1916, v. $82: 360$.

227f. 1916. Mueller, H. O. Animals of blown glass. Scientific American supplement, Dec. 9, 1916, v. 82: 372-373.

227g. 1917. Kerr, C. H. Manufacturers' dependence on ceramic research; discussion. Journal of industrial and engineering chemistry, Jan., 1917, v. 9: 96-97.

227h. 1917. Optical glass: a brief historical review. Photo-era, Jan., 1917, v. 38: $20+$.

227i. 1917. Cheshire, R. W. New method of measuring refractive index and dispersion of glass in lenticular and other forms. Scientific American supplement, Jan. 20, 1917, v. 83: 37.

227j. 1917. French, J. W. Glass grinding and polishing. Engineer (London), Feb. 23, 1917, v. 123: 182.

227k. 1917. Linton, R. Window glass machine. Engineers' society of western Pennsylvania. Proceedings, Feb., 1917, v. 33: 1-22. Discussion, p. 23-30.

227m. 1917. Parker, R. G., and A. J. Dalladay, On a precision method of uniting optical glass. Scientific American supplement, Feb. 17, 1917, v. 83: 102-103.

227n. 1917. What industry owes to science. Engineer (London), Mar. 9, 1917, v. 123: 217-218.

227o. 1917. Development of the optical glass industry. Franklin institute. Journal, Mar., 1917, v. 183: 377-378.

227p. 1917. The manufacture of quartz glass: patented by O. C. Trautmann. Metallurgical and chemical engineering, Mar. 15, 1917, v. 16: 343.

227g. 1917. Carrick, A. V. Pressed glassware. House beautiful, Apr., 1917, v. 41: 293-295.

227r. 1917. French, J. W. Glass grinding and polishing: how the surface prepared for optical purposes is formed. Scientific American supplement, May 19, 1917, v. 83: 308-310.

\section{DIRECTORIES.}

228. Complete directory of glass factories in the United States and Canada, 1916. Comp. by H. W. Gauding. [Pittsburgh, Pa., Commoner publishing co., 1916.] $63 \mathrm{p}$.

229. Directory of glass factories in the United States and Canada. 1916. Pittsburgh, National glass budget, $1916.76 \mathrm{p}$.

230. Keller's annual of the pottery and glassware trades. "(rockery dealers' yearboik," 1913. New York. R. H. Keller, 1913.

231. Pottery and glass directory, 1914. New York, Huott publishing co., 1914.

\section{PERIOUICALS.}

232. China, glass, and lamps; a weekly journal for the buyer. Pittsburgh, J. G. Kaufmann, 1890,-date.

233. The Commoner and glass work. Pittsburgh, Commoner publishing co., 18881911. Weekly. Continued as Glassworker.

234. Crockery and glass journal. New York, Whittemore \& Jacques, 1898-date. Weekly. 
235. The Glassworker. Pittsburyh, Conmoner publishing co.

236. The Glass worker, official organ Imal. glass workers' int. ass'n. Chicago, 19041909. Monthly.

237. National glass budget; weekly review of the American glass industry. Pittsburgh, 1896-date.

235. Potcery and glass. [A monthly magazine devoted to the interests of the pottery, glass. lamp, art metal, and allied industries.] New York, Pottery and glass publishing co., 1908-1915. Absorbed the Glass and pottery world in April, 1909.

238a. Sprechsaal. [7eitschrift für die keramischen, glas- und verwandten Industrien.] Coburg, Jüller \& Schmidt, 1904-1916. Weekly.

\section{COLORED AND ART GLASS.}

\section{BIBIJIOGRAPHY.}

239. Boston. Public library. Catalogue of books relating to architecture, construction and decoration in the Public library of the city of Boston. 2d ed. Boston, Published by the trustees, 1914.535 p. Stained-glass: p. 409-412.

240. Drake, Maurice. A history of English glass painting, with some remarks upon the Swiss glass miniatures of the sixteenth and seventeenth centuries. London, T. W. Laurie, ltd., 1912. 226 p. "A bibliography of stained glass": p. 187-191. "A bibliography of Swiss stained glass": p. 193-195.

241. Edinburgh. Royal Scottish museum. Library. List of books, etc., relating to glass. Edinburgh, Printed by Neill \& company for H. M. Stationery off., 1893. 40 p. Pt. II: Stained and painted glass.

242. New York. Public library. List of works in the New York public library relating to ceramics and glass. [New York, 1908.] $38 \mathrm{p}$. Reprinted from the Bulletin, Oct. 1908. Stained and painted glass: p. 33-39.

243. Peabody Institute Library. Glass, painted and stained. (In its Catalogue, 1st ser., v. 2, p. 1614; 2 d ser., v. 3, p. 1752.)

244. South Kensington Museum. A list of books and pamphlets in the National art library of the South Kensington Museum illustrating glass. London, Printed by Eyre \& Spottiswoode, 1887. 47 p. Pt. II: Painted and stained window glass.

See also items no. 253, 254, 259, 273, 276, 280, 303, 306, 308, 310, 316, 320, 329, $331,337,340,348,361$.

\section{BOOKS.}

245. Alte Schweizer Glas-malereien aus dem ehem. cistercienserkloster Rathhausen bei Luzern. Zürich, M. Kreutzmann [1899]. 40 pl. 1 p.

246. André, Auguste. De la verrerie et des vitraux peints dans l'ancienne province de Bretagne. Rennes, Impr. de C. Catel et cie, 1878. 281 p.

247. Arnold, Hugh. Stained glass of the middle ages in England and France, painted by Lawrence B. Saint, described by Hugh Arnold. London, A. and C. Black, ]913. $269 \mathrm{p}$.

248. The art work of Louis C. Tiffany. Garden City, N. Y., Doubleday, Page \& company, 1914. $90 \mathrm{p}$.

249. Atkinson, William, \& co., New York. The artists, painters and glass stainers' coats of arms and crest book of 1871. New York, Russell's American steam printing house, $1871.90 \mathrm{p}$.

250. Azeglio, Vittorio E. T., marchese d'. An exhibition of artistic painted glass from the fourteenth to the nineteenth century. London, Printed by Spottiswoode \& co., $1876.10 \mathrm{p}$.

251. Ballantine, James. A treatise on painted glass, showing its applicability to every style of architecture. London, Chapman \& Hall, $1845.51 \mathrm{p}$.

252. Barber, Edwin A. American glassware, old and new; a sketch of the glass industry of the United States and manual for collectors of historical bottles. Philadelphia, Patterson \& White co., 1900, 112 p.

253. Batissier, Louis. Histoire de l'art monumental dans l'antiquité et au moyen âge, suivie d'un traité de la peinture sur verre. Paris, Furne et compagnie, 1845. 684 p. Bibliographical footnotes.

254. Bégule, Lucien. Les vitraux du moyen âge et de la renaissance dans la région lyonnaise et spécialement dans l'ancien diocèse de Lyon. Lyon, A. Rey \& cie., 1911. 254 p. Bibliographical footnotes.

255. Beltrami, Giovanni. Vetrate artistiche. G. Beltrami, Milano. [Milano? 1902.] 10 phot. 81 . 
256. Bontemps, Georges. Peinture sur verre au XIXe siècle; les secrets de cet art sont-ils retrouvés. Quelques réflecions sur ce sujet adressées aux savants et aux artistes. Paris, Impr. Ducessois, $1845.45 \mathrm{p}$.

:257. Bourassé, Jean J. Verrières du choeur de l'église métropolitaine de Tours, dessinées et publiées par J. Marchand. Paris, V. Didron, 1849. 75 p. 17 col. pl.

258. Bowes, James L. Notes on shippo; a sequel to Japanese enamels. Liverpool, Printed for private circulation, 1895.109 p. "Glass making": p. 65-71.

259. Bruck, Robert. Die elsässische Glasmalerei vom Beginn des XII. bis zum ende des XVII Jahrhunderts. Strassburg i. E., W. Heinrich, 1902.154 p. "Verzeichnis der benutzten Schriften über Glasmalerei und einzelne Glasgemälde": verso of 4 th prelim. leaf.

'260. Burty, Philippe. Chefs-d'oeuvre des arts industriels. Paris, P. Ducrocq [1866]. 598 p. Vitraux: p. 291-317.

261. Camesina, Albert. Die ältesten Glasgemälde des chorherren-stiftes Klosterneuburg und die Bildnisse der Babenberger in der Cistercienser-abtei Heiligenkreuz. Wien, Kaiserl. köngl. Hof und staatsdruckerei, 1857. 34 p. $27 \mathrm{pl}$.

262. Carter, Owen B. A series of the ancient painted glass of Winchester cathedral. Traced from the windows and drawn by Owen B. Carter. London, J. Weale, 1845. 8 p. 27 pl.

263. Charles, Léopold. Atelier de verriers à La Ferté-Bernard à la fin du quinzième siècle et au seizième. Le Mans, Gallienne, 1851. $40 \mathrm{p}$.

264. Clément, Silvain. Vitraux de Bourges; vitraux de XIII ${ }^{\mathrm{e}}$ siècle de la cathédrale de Bourges; illustré de 54 planches autographiées. Bourges, Impr. TardyPigelet, 1900 . $120 \mathrm{p}$.

265. Coussemaker, Edmond. Vitraux peints et incolores des églises de la Flandre maritime. Lille, Impr. de Lefebvre-Ducrocq. $1860.19 \mathrm{p}$.

266. Day, Lewis P. Stained glass. (In Encyclopaedia britannica, 11th ed. New York, 1910. v. 12, p. 105-112.) "Bibliography"; p. 112.

267. - Stained glass. London, For the Board of education by Chapman \& Hall, ltd., 1903. 155 p. (Victoria and Albert museum art handbook.) "Inventory of stained glass exhibited in the museum": p. 146-152.

268. Windows; a book about stained and painted glass. 2d ed. London, B. T. Batsford, $1902.419 \mathrm{p}$.

269. Deane, Anthony C. A short account of Great Malvern priory church, a history of the monastery, and description of the fabric, with a chapter on the ancient glass and tiles. London, G. Bell and sons, ltd., 1914. 100 p. illus. (Bell's cathedral series.)

270. Descamps, André P. V. Les vitraux de la cathédrale de Tournai, dessinés par J.-B. Capronnier et mis sur pierre par J. de Keghel; avec un text historique et descriptif, par MM. Deschamps et Le Maistre-D'Anstaing. Bruexelles, Librairie scientifique et littéraire, 1848.10 p. 14 pl.

271. Des Méloizes, Albert, marquis. Vitraux peints de la cathédrale de Bourges postérieurs au XIII ${ }^{e}$ siècle. Paris, Desclée, de Brouwer \& cie., 1891-97. 82 p. 29 pl.

272. Deville, Achille. Histoire de l'art de la verrerie dans l'antiquité. Paris, Ve A. Morel et cie., 1873. 108 p. 112 pl.

273. Dillon, Edward. Glass. London, Methuen and co. [1907]. 373 p. (The connoisseur's library. General editor: Cyril Davenport.) "Selected bibliography of works on glass": p. xxii-xxviii.

274. Drake, Maurice. A history of English glass painting, with some remarks upon the Swiss glass miniatures of the sixteenth and seventeenth centuries. London, T. W. Laurie, ltd., 1912. 226 p. 33 pl.

275. Duthie, Arthur L. Decorative glass processes. London. A. Constable \& co., ltd., 1908. 267 p. (The "Westminster" series.)

276. Eden, Frederick S. Ancient stained and painted glass. Cambridge, Eng., University press; New York, G. P. Putnam's sons, 1913.160 p. (The Cambridge manuals of science and literature.) "Aids to further study": p. 152154.

277. Elward, Robert. On collecting engravings, pottery, porcelain, glass, and silver. London, E. Arnold, 1904. 90 p. (The wallet series.) Short bibliographies at the end of each subject.

278. Engelbrecht, Karl. Neue Vorlagen für Künst-glaserei. Hamburg, Boysen \& Maasch, 1904.1 p. 18 pl. 
279. Essex, Richard II. Illustrations of the architestural ornaments and enthellishments, and painted glass, on the Temple church, London. London, J. IViale, 18.45 .15 p. 29 pl.

280. Fischer, Josef L. Mandbucli der Glasmalerei für Forscher, Sammler und Kunstfreunde, wie für Künstler. Irchitekten und Glasmaler. Leipzig, K. W. Hiersemann, 1914. $31 \mathrm{~s}$ p. $135 \mathrm{pl}$. (Hiersemann's Handbücher, Bd. 8. "Die wichtigste Literatur über die Glasmalerei": p. 301-311.

281. Fischer. Joseph 1. Jos. Ant. Fischer's Kartons zu den Fenstern der Mariahilfkirche in der Iu zu München und zu den Glasgemailden des südlichen Scitenschiffes in Dome zu Köln. München, Piloty \& Loehle, 1891. 1 p. 19 $\mathrm{pl}$.

282. Florival, 1. de, and E. Midoux. Les vitraux de la cathédrale de Laon. Paris, Librairie archéologique de Didron, 1882-91. 4 pt. 35 pl. "Documents consultés": pt. 4, i-viii at end.

283. Fowler, William. To Heneage Legge esqr. this series of engravings from subjects executed in ancient stained glass in the windows of the Hall at Aston near Birmingham is with permission inscribed. [Winterton, Eng., W. Fowler, 1802-8.] $16 \mathrm{col}$. pl. 141.

284. Frankl, Paul. Die Glasmalerei des fünfzehnten Jahrhunderts in Bayern und Schwaben. Strassburg, J. H. E. Heitz, 1912. 233 p. 17 pl. (Studien zur Deutschen Kunstgeschichte, 152. Hft.)

285. Franks, Sir Augustus TV. A book of ornamental glazing quarries, collected and arranged from ancient examples. London, J. H. Parker, 1849. 31 p. 112 col. pl.

286. Fromberg, Emanuel O. An essay on the art of painting on glass. London, J. Tieale, $1851.116 \mathrm{p}$. (Weale's rudimentary series, no. 41.)

287. Garnier, Edouard. Histoire de la verrerie et de l'émaillerie. Tours, A Mame et fils, $1886.573 \mathrm{p}$.

288. Geiges, Fritz. Der alte Fensterschmuck des Freiburger Münsters. Freiburg i. B., Herder, 1902-1905. 3 pts.

239. Gerspach, Édouard. L'art de la verrerie. [Nouv. éd.] Paris, Quantin [1885]. $320 \mathrm{p}$. (Bibliothèque de l'enseignement des beaux-arts.)

290. Gessert, if. A. Geschichte der Glasmalerei in Deutschland und den Niederlanden, Frankreich, England, der Schweiz, Italien, und Spanien, von ihrem Ursprung bis auf die neueste Zeit. Stuttgart und Tübingen, J. G. Cotta, 1839. $312 \mathrm{p}$.

291. — Rudimentary treatise on the art of painting on glass, or glass staining; comprising directions for preparing the pigments and fluxes, for laying them upon the glass, and for firing or burning in the colours. 3d ed. London, J. Weale, 1857. 92 p. (Weale's rudimentary series no. 40.)

292. Gilbert, Sir John. Fragments towards the history of stained glass and the sister arts of the middle ages. [Chap. 1-3. London, J. Hearne, 1842.] 21 p. No more published.

293. Godwin, Alired. Examples of stained glass windows, for ecclesiastical and domestic purposes. [Philadelphia, Clymer printing company], 1895. $3 \mathrm{p}$. $48 \mathrm{pl}$.

294. Gouda, Netherlands. St. Janskerk. Explanation of the famous painted glass windows in St. John's church at Gouda. Gouda, Printed by J. van Bentum and son [190-?]. $33 \mathrm{p}$.

295. Groom, Edward. The art of transparent painting on glass for the magic lantern; comprising the method of painting and an account of the implements and materials employed in producing subjects for dissolving views, etc. London, Wiusor and Newton, ltd. [n. d.]. 55 p. First published in 1855 .

296. Guelpa, John B. A treatise on painting on glass. Boston, The author, 1860. $33 \mathrm{p}$.

297. Guerber, Victor. Essai sur les vitraux de la cathédrale de Strasbourg. Strasbourg, L. F. LeRoux, 1848. 124 p.

298. Gullick, Thomas J. Oil painting on glass, including mirrors, windows, etc., with remarks upon the principles of painting and decorative art generally. London, Winsor \& Newton, ltd. [n. d.]. 84 p. [One shilling hand books on art, no. 44.]

299. Hancock, E. Campbell. The amateur pottery and glass painter, with directions for gilding, chasing, burnishing, bronzing, and ground laying. [4th ed.] London, Chapman and IIall [1881?]. $213 \mathrm{p}$.

$102511^{\circ}-17-27$ 
300. Hartshorne, Aibert. Old English glasses. An account of glass drinking vessels in England, from early times to the end of the eighteenth century. New York, E. Arnold, 1897. 490 p.

301. Hawkins, John S. An history of the origin and establishment of Gothic architecture and an inquiry into the mode of painting upon and staining glass, as practised in the ecclesiastical structures of the middle ages. London, Sold by J. Taylor, $1813.251 \mathrm{p}$.

302. Historisch-antiquarischer Verein in Winterthur. Meisterwerke schweizerischer Glasmalerei. Erklärender Texte von A. Hafner. Berlin, C. Claesen \& co. [1890]. 14 p. $60 \mathrm{pl}$. Issued in 10 pt., 1888-90.

303. Historischer Verein des Kantons Bern. Die Glasgemälde der Kirche von Sumiswald; der Allgemeinen geschichtsforschenden Gesellschaft der Schweiz gewidmet vom Historischen Verein des Kantons Bern zu ihrer Versammlung in Burgdorf und Sumiswald am 8. und 9. September, 1912. Bern, Buch. G. Grunau, 1912. 10 p. "Quellen und Literatur," p. 10.

304. Holiday, Henry. Stained glass as an art, with a colored reproduction of the drawing for "The Creation," by Sir Edward Burne-Jones, W. B. Richmond, and the author. London, New York, Macmillan and co., ltd., 1896. 173 p.

305. Hucher, Eugène F. F. Vitraux peints de la Cathédrale du Mans; ouvrage renfermant les réductions des plus belles verrières et la description complète de tous les vitraux de cette cathédrale. Paris, Didron, $1865.82 \mathrm{p}$.

306. Hunter, Frederick W. Stiegel glass. Boston and New York, Houghton, Mifflin company, 1914. 272 p. "Stiegel bibliography," p. 263-265.

307. Italy. Ispettorato generale dell'industria e del commercio. Glass and stained glass windows. Rome [Tip. nazionale di G. Bertero e c.], 1913. 61 p. (The artistic crafts of Italy; 3.)

308. Jean, René. Les arts de la terre - céramique-verrerie émaillerie-mosaïquevitrail. Paris, H. Laurens, 1911. 480 p. (Manuels d'histoire de l'art.) "Bibliographie sommaire" at the end of each part.

309. Jessel, Louis. Glasmalerei und Kunst-verglasung. 2 Aufl. Berliu, B. Hessling, 1896. 8 p. $53 \mathrm{pl}$.

310. Klopfleisch, Friedrich. Drei denkmäler mittelalterlicher Malerei aus den obersächsischen Landen, nebst einem Anhang. Jena, O. Deistung, 1860. 132 p. Bibliographical footnotes.

310a. Labarte, Jules. Histoire des arts industriels au moyen âge et à l'époque de la renaissance. Paris, A. Morel, 1864-66. 4 v. Verrerie: v. 4, p. 529-598.

310b. Lacroix, Paul. Les arts au moyen âge et à l'époque de la renaissance. 2. éd., rev. Paris, Firmin Didot frères, fils et cie, 1869. 548 p. Peinture sur verre: p. 257-273.

$310 \mathrm{c}$. - - The arts in the rniddle ages, and at the period of renaissance. $2 \mathrm{~d}$ ed., tr. from the French by James Dafforne. London, Chapman, and Hall, 1870. 520 p. Glass-painting: p. 251-267.

311. La Farge, John. Window, Pt. III, The translucent filling of the lights (stained glass). (In Sturgis, Russell. A dicti nnary of architecture and building, v. 3, p. 1067-1091. New York, 1902.)

312. Langlois, Eustache H. Essai historique et descriptif sur la peinture sur verre, ancienne et moderne, et sur les vitraux les plus remarquables de quelques monumens français et étrangers; suivi de la biographie des plus célèbres peintres-verriers. Rouen, E. Frère, 1832. 300 p.

313. Lehmann, Hans. Zur Geschichte der Glasmalerei in der Schweiz. Antiquariischen Gesellschaft in Zürich, Mitteilungen, v. 26, p. 155-434.

314. Lenoir, Alexandre. Musée des monumens français, ou Description historique et chronologique des statues en marbre et en bronze, bas-reliefs et tombeaux des hommes et des femmes célèbres, pour servir à l'historie de France et à celle de l'art. Paris, Impr. de Guilleminet an IX, 1800-21. 8 v. in 4. Vol. 6 has title: Musée des monumens français, histoire de la peinture sur verre, et description des vitraux anciens et modernes, pour servir à l'histoire de l'art, relativement à la France.

315. Lévy, Edmond. Histoire de la peinture sur verre en Europe et particulièrement en Belgique. Bruxelles, Tircher, 1860. 272, 206 p.

315a. Lewis, J. Sydney. Old glass and how to collect it. London, T. W. Laurie ltd. [1916]. $225 \mathrm{p}$.

316. Lutz, Jules and P. Perdrizet. Die elsässischen typologischen GlasmalereienMülhausen, Weissenburg, Colmar. Mülhausen, Buchdr. E. Meiniger, 1909. 27 p. Bibliographical footnotes.

317. _ L Les verrières de l'ancienne église Saint-Etienne à Mulhouse. Mulhouse, E. Meininger, 1906. $126 \mathrm{p}$. 
318. Lyongrün, Arnold. Vorbilder für Kunstverglasungen in Style der Neuzeit. 1.-2. ser. Berlin, New York. B. Hessling [1900]. 2 v.

319. Magne, Lucien. Décor du verre; gobeleterie. mosaïque, vitrail. Paris, H. Laurens, 1913. 220 p. (His L'art appliqué aux métiers, 3.)

320. - L L'oenvre des peintres verriers français . . verrieres des monuments élevés par les Montmorency; Montmorency-Ecouen-Chantilly. Paris, Firmin-Didot et cie. $15.5 .517 \mathrm{p}$. Bibliograplical footnotes.

321. Les vitranx de Montmorency et d'Ecouen. Paris, Firmin-Didot et cie, 18sis. $69 \mathrm{p}$.

322. Marsaux. L. Vitraux de l'église Saint-Martin de Groslay. Pontoise, Impr. de A. Taris, 18s?. 12 p. "Extrait des Mémoires de la société historique de Pontoise et du Vexin, tome XII."

323. Martin. Arthur, and Charles Cahier. MIonographie de la cathédrale re Bourges. Premier partie. Vitraux de XIII siècle. Paris, Poussielcue-Rusand, 1841-44. $303 \mathrm{p}$.

324. Merson. Olivier. Les vitraux. Paris, Librairies-impr. réunies [1895]. $314 \mathrm{p}$. (Bibliothèque de l'enseignement des beaux-arts.)

325. Merz, Nalther. Hans Ulich Fisch. Ein Beitrag sur Kunstgeschichte des Aarcaus. Aarau, Druck von E. Wirz, vormals J. J. Christen, 1894. 40 p.

326. Mewes, Wilhelm. Moderne Kunstverglasungen, zumeist mit Benutzung von Kathedral und Opalescentglas. 1.-3. ser. Berlin, M. spielmeyer [18991901]. $3 \mathrm{v}$.

327. Nelson, Philip. Ancient painted glass in England, 1170-1500. London, Methuen \& co. [1913]. 280 p. (the antiquary's books, general editor J. C. Cox.)

328. Oidtmann, Heinrich. Die rheinischen Glasmalereien vom 12. bis zum 16. Jahrhundert. Düsseldorf, L. Schwann, 1912. (Preis-schriften der Mevissenstiftung, 3.)

329. O'Kelly de Galway, Alphonse C. A., comte. Notice sur la peinture sur verre en Belgique au dixneuvième siècle. Bruxelles, A. Decq. 1859. 59 p. "Bibliographie belge": following p. 59.

330. Ottin, L. L'art de faire un vitrail. 3. éd. Paris, H. Laurens, [1908?]. 108 p.

331. — Le vitrail; son histoire, ses manifestations à travers les âges et les peuples, Paris. H. Laurens, [1896]. 376 p. "Liste alphabétique des peintres verriers": p. 335-348. "Ouvrages à consulter" : p. 367-370.

332. Paris, Musée des monumens français. Musée des monumens français, ou Description historique et chronologique des statues en marbre et en bronze. Paris, Impr. de Guilleminet an IX, 1800-21. 8 v. in 4. Vol. 6 has title: Musée des monumens français, histoire de la peinture sur verre, et description des vitraux anciens et modernes.

333. Paris. IIuscé national du Louvre. Département des objets d'art du moyen âge, de la renaissance et des temps modernes. Notice de la verrerie et des vitraux, par A. Sauzay. Paris, C. de Mourgues frères, impr., 1882. 148 p.

334. Parry, homas $G$. The ministry of fine art to the happiness of life; essays on various arts. Rev. ed. with index. London, J. Murray, 1887. 387 p. The art and the artists of glass painting, ancient and mediaeval: p. 211-262.

335. Pazaurek, Gustav E. Moderne Gläser. Leipzig, H. Seeman Nachfolger, [1901]. 133 p. (Monographien des Kunst ewerbes, II.)

336. Pegge, Samuel. Some observations on the paintings in the window of Brereton church. [London, 1792?]. 4 p. [With his Mlemoirs of the life of Roger de Wesenham. London, 1761.] From "Archaeologia," v. 10, 1792, p. 50-53.

337. Perdrizet, Paul. L'art symbolique du moyen âge à propos des verrières de l'église st. Etienne à Mulhouse. Leipzig, C. Beck, 1907. 24 p. Bibliographical footnotes.

338. St. IIelen's crown glass company, St. Helen's, Eng. The St. Heleu's crown glass company's trade book of patterns for ornamental window glass; with Designs ior church, hall, staircase, and memorial windows, by Frank Howard. St. Helen's Lancashire, St. Ifelen's crown glass company, 1850.4 p. 50 pl.

339. Schaefer, Karl, and A. Possteuscher. Oruamentale Glasmalereien des Mittelalters und der Renaissance. Berlin, E. Wasmuth, 1888.4 p. 45 pl.

340. Schmidt, Robert. Das Glas. Berlin, G. Reimer, 1912. 402 p. (Handbücher der Königlichen Museen zu Berliu, Bd. 14.) Literatur: p. 392-393.

341. Shaw, Patrick J. An old York church: All IIallows in Torth street. Its mediaeval stained glass and architecture. York, Church shop, 190s. $99 \mathrm{p}$. $35 \mathrm{pl}$.

342. Sherrill, Charles II. Stained glass tours in England. New York, J. Lane company, 1909. 254 p. $16 \mathrm{pl}$. 
343. Sherrill, Charles H. Stained glass tours in France. New York, J. Lane company, 1908. 298 p. 12 pl.

344. A stained glass tour in Italy. New York, The John Lane company, 1913. 174 p. $32 \mathrm{pl}$.

345. Slade, Felix. Catalogue of the collection of glass formed by Felix Slade, with notes on the history of glass making by Alexander Nesbitt. [London, Wertheimer, Lea and co.], printed for private distribution, 1871. $183 \mathrm{p}$. $40 \mathrm{pl}$.

346. Société des amis des arts du département de l'Eure, Evreux. Vitraux du choeur de la Cathédrale d'Évreux. Évreux, La Société des amis des arts, 1893. $131.13 \mathrm{pl}$.

347. Speculum humane salvationis. Speculum humanse salvationis; kritische Ausg. übersetzung von Jean Miélot (1448). Mit der Wiedergabe in I.ichtdruck (140 tafeln) der Schlettstadter Handschrift, ferner sämtlicher alten Mülhauser Glasmalereien, sowie eiviger Scheiben aus Colmar, Weissenburg, etc. Mülhausen, Buchdr. F. Meininger, 1907-9. 2 v. in 4.

348. Stolberg, August. Tobias Stimmer, sein Leben und seine Werke, mit Beiträgen zur Geschichte der deutschen Glasmalerei im XVI Jahrhundert. Strassburg, Universitäts-buchdruckerei von J. H. E. Heitz (Heitz \& Mündel), 1905. 173 p. "Literaturangabe": p. 170-173.

349. Suffling, Ernest R. A treatise on the art of glass painting, prefaced with a review of ancient glass. London, Scott, Greenwood and co., 1902. $144 \mathrm{p}$.

350. Téxier, Jacques R. A. Histoire de la peinture sur verre en Limousin. Paris, V. Didron, 1847. $115 \mathrm{p}$.

351. Theophilus, called also Rugerus. Theophilus presbyter Schedula diversarum artium. I. Band. Rev. text, übersetzing und Appendix von Albert Ilg. Wien, W. Braumüller, 1874. 400 p. (Quellenschriften für Kungtgeschichte und Kunsttechnik. VII.)

352. Thibaud, Emile. Considérations historiques et critiques sur les vitraux anciens et modernes et sur la peinture sur verre. Clermont-Fd, Thibaud-Landriot et cie., $1842.127 \mathrm{p}$.

353. Tiffany studios. Memorials in glass and stone. [Baltimore, Md.] Printed by Muuder Thomsen company, 1913. 43 p.

354. Tourneur, Victol. Histoire et description des vitraux et des statues de l'intérieur de la cathédrale de Reims. Reims, P. Regnier, 1857. 77 p.

355. United States. Military academy, West Point. Association of the graduates. The memorial window United States Military academy, West Point, New York. Designed and executed by William Willet and Annie Lee Willet. [West Point? 1910.] 20 p.

356. Vienna. K. K. Osterreichisches Museum für Kunst und Industrie. Die Glassammlung des K. K. Oesterreich. Museums. Geschichtliche uebersicht und Katalog von Bruno Bucher. Wien, C. Gerold's sohn, 1888. 134 p.

357. Voisin, Charles J. Oeuvres posthumes de Mgr. le vicaire-général Voisin. Tournai, Vve. H. Casterman, 1877. 342 p. (Mémoires de la Société historique et littéraire de Tournai. t. 16.) Vitraux de la chapelle Saint Vincent.

358. Wackernagel, Wilhelm. Die deutsche Glasmalerei. Geschichtlicher Entwurf mit Belegen. Leipzig, S. Hirzel, 1855. $180 \mathrm{p}$.

359. Warnecke, Friedrich. Musterblätter für Künstler und Kunstgewerbtreibende, insbesondere für Glasmaler. [2. Aufl.] Berlin, H. S. Hermann [1883]. 20 p. 100 pl.

N Nachtrag. Berlin, H. S. Hermamn [1887]. 21 pl.

360. Washington, D. C. St. John's church. Subjects of the stained glass windows in St. John's church, Washington. London, Priv. print. at the Chiswick press, 1885.107 p. 21 pl.

361. Westlake, N. H. J. A history of design in painted glass. London, J. Parker and co., 1881-94. $4 \mathrm{v}$. Bibliographical footnotes.

362. Whall, C. W. Stained glass work; a textbook for students and workers in glass. New York, D. Appleton and company, 1905. 380 p. (The artistic crafts series of technical handbooks, ed. by W. R. Lethaby. no. 4.) Glossary: p. 369-372.

363. Whitehead, W. T. Stained glass and leaded glass. London, Dawbarn and Ward; Chicago, The Photo beacon co. [1900]. 23 p. (Úseful arts and handicrafts series, no. 10.)

364. Whittock, Nathaniel. 'The decorative painters' and glaziers' guide; containing the most approved methods of imitating oak, mahogany, [etc.]; also a complete body of information on the art of staining and painting on glass; plans for the erection of apparatus for annealing it; and the method of joining 
figures together 1 y leading, with examples from ancient windows. London, 1. T. Hinton, 18:28. 33:2 $\}$.

365. Willement. Thomas. A concise ar'count of the principal works in stained glass that have been executed. [London.] Printed for private distribution, 1840 . $75 \mathrm{p}$.

36t. [Winston. harles.] An inquiry into the difference of style ohservahle in ancient glass paintings. esper ially in England; with hints on glass painting. Uxford, J. H. Parier. $18+7.2$ v. $75 \mathrm{pl}$.

366a. Foxall, sir James If. Cinlecting old glass: English and Irish. New York, George II. J oran (\%), 1916. $109 \mathrm{p}$.

367. Zettler. Franz X. Stained glass windows, designed and executed by F. X. Zettler. Chicago, Ill., New York, Daprato statuary co., [1911]. 48 p.

\section{ARTICLES IN PERIODICALS.}

368. 18\%. Matthews, Richard. Stained and leaded glass work. Illustrated carpenter and builder, Apr. 16, 1897. Discusses the history of manufacture.

369. 1899. Parkhurst, H. L. Plea for stained glass. Municipal affairs, Dec, 1899, v. 3: $694-701$.

370. 1901. ( oleman, ( . Windows of Gouda. Architectural record, Feb., 1901, v. 10: $225-227$.

371. 1901. Some modern church glass. Art journal, Apr., 1901. p. 120-122.

372. 1901. Day, L. F. Favrille glass. Magazine of art, Oct., 1901, v. 25: 541-544.

373. 1901. The making of stained glass. ('urrent literature, Nov., 1901, v. 31: 547-549.

374. 1901. New window by John La Farge. International studio, Nov., 1901, v. 15, sup. p. 36.

375. 1901. Dodgson, C. Swiss glass paintings and their designers. Connoisseur, Dec., 1901, v. 1: 224-233.

376. 1901. Ames memorial church window by La Farge. Current literature, Dec., 1901, v. 31: 723 .

377. 1901. Thomas, W. H. Window making as an art. Munsey's magazine, Dec., 1901, v. 26: 386-395.

378. 1902. Difficulty and its solution. Architectural record. Jan., 1902, v. 11: 110-112.

379. 1902. Lamb, F. S. Stained glass in its relation to church ornamentation. Catholic world, Feb., 1902, v. 74: 667-677.

381. 1902. Home-made device for decorating glass. Scientific American, Apr. 19, 1902 , v. $86: 273$

382. 1902. Mackay. A. Henry Holiday and his art. Westminster review, Oct., 1902, v. 158: $391-400$.

383. 1902. Ryley, B. Old Venetian glass. Connoisseur, Dec., 1902, v. 4: 267-271.

384. 1902. Heinigke, Otto, Rambling thoughts of "a glass man." (raftsman, Dec., 1902, v. 3: 170-182.

385. 1902. Schroeder, William. The manufacture and application of glass in art and decoration. Overland monthly, Dec., 1902, n. s., v. 40: 525-534.

386. 1903. Dieike, Max. Moderne Glasmosaik. Moderne Kunst, v. 17: 33-35.

387. 1903. New process of stained glass. Scientific American supplement, Jan. 17, 1903 , v. $55: 22610$.

388. 1903. Lamb, Frederick S. The painted window. Craftsman, Mar., 1903, v. 3: 341-349.

389. 1903. ('affin, ( harles H. Decorated windows. Craftsman, Mar., 1903, v. 3: $350-360$.

390. 1903-4. Sparrows, Silvester. The stained glass of the future. Art workers' quarterly, July. Oct., 1903, v. 2: 125-132, 173-180: Jan., 1904, v. 3: 39-16.

391. 1904. Jenkins, F. L. Stained glass windows for Skiho castle. Magazine of art, Jan., 1904, v. 28: 128-136.

392. 1904. Stainer glass and glass mosaics. (current literature, Mar, 1904, v. 36: $331-333$.

393. 1904. Wright, Jielen E. Memorial windows of San Francisco. Overland monthly, Apr., 1904, n. s.. v. 43: 332-335.

394. 1904. Karageorgevitch, B. Emile Galle, a master in glass. Magazine of art, May, 1904. v. 27: $310-314$.

395. 1904. Skinner, A. B. Stained glass window in the Victoria and Albert museum. Magazine of art, May., 1901, v. 27: 315-317.

396. 1904. Wright, Ielen E. The evolution of a window. Overland monthly, May, 1904, n. s., v. 43: $366-369$.

397. 1904. Hadlow, J. Blake. Some pictorial stained glass. Art journal, Aug., 1904, p. $271-275$.

398. 1904. Stained glass. International studio, Sept., 1904, v. 33, sup. p. 359-363. 
399. 1904. Dole, N. H. Stained glass windows of William Willet. International studio, Oct., 1904, v. 23, sup. p. 377-384.

400. 1905. The window opening in decoration. International studio, July, 1905, v. 26, sup. xiv-xix.

401. 1905. Art window glass. Fine arts journal, Jan., 1905, v. 16: 27-31.

402. 1905. Jones, M. C. Memorial window to John Harvard in St. Saviour's church, London. Critic, May, 1905, v. 46: 415-421.

403. 1905. Goodhue, H. E. Stained glass in private homes. Architectural record, Nov., 1905, v. 18: 347-354.

404. 1905. Gascoyne, Alexander, and Arthur J. Dix. Stained glass. Royal institute of British architects. Journal, Dec. 23, 1905, 3d ser., v. 13: 93, 105. Discussion: p. 106, 109 .

405. 1906. Powell, H. J. Picture-windows in New College ante-chapel. Burlington magazine, Feb., 1906, v. 8: 326-332.

406. 1906. Lamb, F. S. Making a modern stained glass window: its history and process. Craitsman, Apr., 1906, v. 10: 18-31.

407. 1906. Thomas, W. H. Glass mosaic-an old art with a new distinction. International studio, May, 1906, v. 28, sup. Ixxiii-lxxviii.

408. 1906. Thomas, W. H. Coloured glass windows - the supremacy of the modern school. International studio, Aug., 1906, v. 29, sup. xliv-1.

409. 1907. Coleman, C. Jesse tree. Architectural record, May, 1907, v. 21: 361-370.

410. 1907. Heaton, N. The production and decay of mediaeval stained glass. Nature, May 2, 1907, v. 76: 19-21.

411. 1907. Heaton, C. Origin of stained glass in Canterbury cathedral. Burlington magazine, June, 1907, v. 11: 172-176.

412. 1907. Pyley, A. B. Bohemian glass. Connoisseur, Aug., 1907, v. 18: 241-246.

413. 1908. Smith, M. C. Saint Michael's window and decorations. International studio, Jan., 1908, v. 33, sup. p. 97-99.

414. 1908. Plymouth church transformed. Outlook, Jan. 18, 1908, v. 88: 114-115.

415. 1908. Forsyth, J. Dudley. Stained glass. British architect, Feb. 7, 1908, v. 69: $105-108$.

416. 1908. Heaton, C. Stained glass and romanesque architecture at Rheims. Burlington magazine, Mar., 1908, v. 12: 366-369.

417. 1908. Fitchfield, P. H. History of stained glass. Christian art, Apr., 1908, v. 3: $3-22$.

418. 1908. Thorley memorial window. International studio, May, 1908, v. 34, sup. p. 120.

419. 1908. Carbonell, F. R. Fairford church windows. Christian art, Oct., 1908, v. $4: 35-46$.

420. 1908. Cowles, G. A. Building a stained-glass window. Craftsman, Oct., 1908, v. 15: $97-103$.

421. 1908. Goodhue, H. E. Painted glass and its problems. Christian art, Nov., 1908, v. 4: $49-60$.

422. 1909. Decorative work of Henry Holiday. International studio, Apr., 1909, v. 37: 106-115.

423. 1909. Parrish, Clara W. American stained glass. Palette and bench, Dec., 1909 , v. 2: $55-57$.

424. 1910. De Kay, C. Welcome in stained glass. Harper's weekly, Jan. 1, 1910, v. $54: 9$.

425. 1910. Phillipps, L. M. Stained glass windows. Contemporary review, Mar., 1910, v. 97: 346-360. Living age, Apr. 16, 1910, v. 265: 138-150.

426. 1910. Windows for Plymouth church, Brooklyn, designed by Frederick S. Lamb. International studio, Apr., 1910, v. 40, sup. p. 44, 45.

427. 1910. Coburn, F. W. Harry E. Goodhue, worker in stained glass. International studio, Aug., 1910, v. 41, sup. p. 37-40.

428. 1910. Vallance, A. Sir Edward Burne-Jones's designs for painted glass. International studio, Dec., 1910, v. 42: 91-103.

429. 1911. Pratt, H. M. Stained glass windows. Chautauquan, Mar., 1911, v. 62 : 83-91.

430. 1911. Painting in glass on a canvas of concrete; mosaic curtain of the Mexican national theatre. Scientific American, Apr. 29, 1911, v. 104: 425.

431. 1911. Vallance, A. Flemish painted glass panels. Burlington magazine, July, 1911, v. 19: 189-192.

432. 1911. Syford, E. Examples of recent work from the studio of Louis C. Tiffany. New England magazine, Sept. 1911, n. s., v. 45: 97-108.

433. 1911. Sears, Taber. Stained glass windows. Art and progress, Nov. 1911, v. $3: 392-397$. 
434. 1912. Heaton, Clement. The art of stained and painted glass. American architect, Jan. 10, Feb. 7, Mar. 6, 27, Apr. 3, May 8, 1912, v. 101: 13-19, 62-66, 6s, 113-11S, 141-145, 153-157, $209-212$; July 3, Aug. 7, Sept. 4, Oct. 9, $1912, v, 102: 1-3,-11-16,81-5.5,125-125$.

435. 1912. Lauber, J. European versus American color windows. Architectural record, liel., 1912, v. 31: 135-151.

436. 1912. Torthwest tradition in stained glass. Western architect, Apr. 1912, ง. $18: 45$.

437. 1912. Stuart, Evelyn M. American ornamental glass. Fine arts journal, June, 1912 , v. $26: 387-398$.

438. 1912. Eberlein, II. D. Use of stained glass for windows in homes. Suburban life. (let. 1912 , v. 15: 183-185, 226 .

439. 1912. Hunter, G. L. New lawvers' club of Jew York city: window by J. G. Guthrie. Architectural record, Nov. 1912, v. 32: 393-404.

440. 1912. Stuart, Evelyn II. The history of artistic glass. lïne arts journal, Nov. 1912 , v. $27: 725-740$.

441. 1912. Viollet-le-Duc, E. E. Vitrail (stained glass). Architectural record, Dec. 1912, v. $32: 4 S 7-195$

442. 1912. Hunter, G. L. Gothic windows in the Lawyers' club of New York city. International studio, Dec. 1912, v. 48, sup. p. 38-39.

443. 1913. Friedley, D. A renaissance window of 1531 , owned by T. F. Ryan. Art in America, Apr. 1913, v. 1: 136-140.

444. 1913. New era in stained glass. Favrile glass. Arts and decoration, June, 1913, v. 3: 288 .

445. 1913. The West window of Proctor Hall, Princeton University. Art and progress, Dec., 1913, v. 5: 50-53.

446. 1914. New glass in old windows. Independent, Jan. 5. 1914, v. 77:9.

447. 1914. Dorr, C. H. Art of mal:ing a stained glass window and the work of (lara II. Burd. Architectural record, Feb. 1914, v. 35: 162-169.

448. 1914. Legge, T. M. The windows of Henry A. Payne. International studio, Apr. 1914, v. 52: 128-131.

449. 1914. Brabazon, T. Old British and continental glass in American mindows. Arts and decoration. May, 1914, v. 4: 263-265.

450. 1914. Thiebault, (. Minnesota history in stained glass. Art and progress, Aug., 1914, v. 5: 351-355.

451. 1914. Burgess, I. J. Modern stained glass. American homes, Nov., 1914, v. 11: $369-370$.

452. 1915. Barber, Edwin A. Mosaic and millefiori glass. Pennsylvania museum. Bulletin, July, 1915, v. 13: 31-40.

453. 1915. Stevenson, W. J. The romance of stained glass. ('hambers's journal, Nov. 20, 1915, 7 th ser., v. 5: 810-812.

454. 1915. Montmorency, J. E. G. de. Idyll in stained glass. ('ontemporary review, Nov., 1915, v. 108: 658-663.

455. 1916. Stained glass. Memorial window by W. and Annie Willet. American magazine of art, Jan., 1916, v. 7: 114-115.

456. 1916. Barber, E. A. Old American glass. Art in America, Apr., 1916, v. 4: $162-172$.

457. 1916. Vallance, A. German painted glass. Burlington magazine, Apr,. 1916, v. $29: 12-15$.

458. 19l6. IIumphrey, G. Blashfield windows. International studio, Sept. 1916, v. 59: sup. p. $59-60$.

459. 1917. Erangelization of the northwest; window placed in the Church of St. Louis, St. Paul. Bellman, Jan. 13, 1917, v. 22: 37-38.

460. 1917. Bayne, P. C. Limitations of stained glass; a comparison of ancient and modern methods. Scientific American supplement, Apr. 28, 1917, v. 83: 262-263. 


\section{APPENDIX B.}

\section{SCHEDULES USED IN THE INVESTIGATION.}

The schedules used by the special agents of the Bureau in collecting the data for this report are reproduced on the following pages.

Establishment No.

UNITED STATES DEPARTMENT OF COMMERCE, BUREAU OF FOREIGN AND DOMESTIC COMMERCE, WASHINGTON.

\section{CONFIDENTIAL}

Each establishment is assured by the Department that its name will not appear on this schedule and its identity will not be disclosed in connection with any figures that it furnishes.

\section{Glass Industry-Establishment Schedule.}

(A) GENERAL INFORMATION.

1. Branch of industry

2. Kinds of goods made.

3. Made by

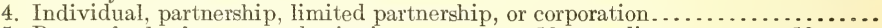

5. Report for business year, beginning ........, 19..; ending ........., 19..

6. Days operated during last business year, ......... ; average during three preceding years...........

(B) LABOR.

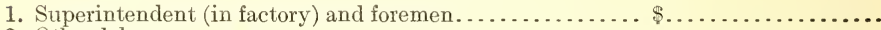

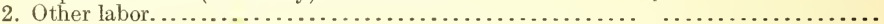

3. Total labor

(c) Fuel, MATERIALS, AND CHEMicAls USED.

1. Fuel, power, light, and water..................

2. Raw materials.

3. Chemicals

4. Decorating materials.

5. Packing materials.

8. Total materials, etc.

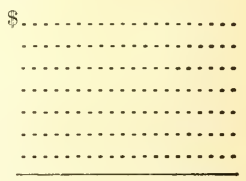

(D) General expense.

1. Salaries of officers, partners, or owner.

(If not charged on books, estimated value of service, $\$$.......)

2. Salaries of general office force and auditor..............

3. Salaries, commissions, traveling, and general expense of

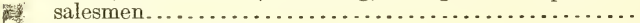

4. Other selling expense.

5. Bad debts charged to reserve or apportioned to this year....

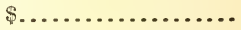


6. All other operating expense (including factory supplies and cost of molds, not of new machinery)..................

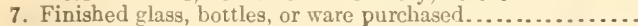

8. Expense on investments outside manufacturing business..

9.

Total.

(E) FIXED CHARgES.

1. Taxes, State, county, city, on property used in manufacturing.

2. Corporation (not income) tax.

3. Insurance fees for this year only.

4. Royalty.

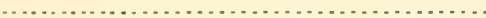

5. Depreciation on property used in manufacturing: Values on depreciated basis, or full value less reserve for depreciation, at beginning of year-

Depreciation above repairs during year, charged or estimated-

Land-Value, \$....... ; depreciation, \$.......

Buildings, tanks, leers, and other real estateValue, $\$ . . . . .$. ; depreciation, $\$ . . . .$. .

Other equipment-Value, \$.......; depreciation, $\$ . . . . .$. .

Total depreciation if charged on books, $\$ . . .$. . (Do not extend depreciation if not charged.)

6. Workmen's compensation or employers' liability

7. Workmen's compensation or employers' hability..........

8.

9 . Interest paid on current loans.

10. Total fixed charges.
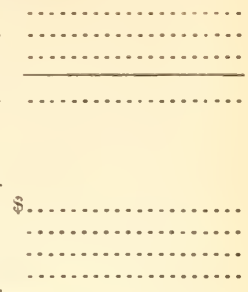
5. Method of inventorying: Estimated, ............ physical, ...........; perpetual, ...................

6. Is there a reserve for bad debts? ..................... for depreciation? ........... ; or is depreciation charged off every year?

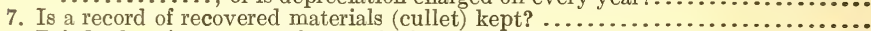

8. Briefly describe system of apportioning overhead and state whether it appears to

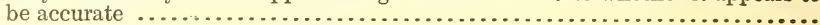

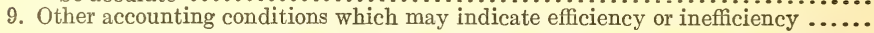

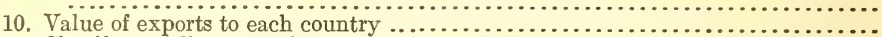

11. Classify, as follows, employees, employees in factory (not office) during the month (busy season) of ..............., 191.... 16 years of age and over-male ....... female ...... ; under 16 years of age-male ......, female ......

Foregoing data furnished ................., 1916, to special agent ... -..........

(H) PROFIT AND LOSS STATEMENT

Outgo.

Labor (B-3).

Fuel, materials, etc

General expenses (D-9 less 7

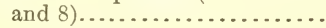

Finished goods purchased (D-7).

Fixed charges (E-10 less 9)....

Inventory, first of year (G-3)...

Operating profit..............

Total................

Operating loss.

Depreciation $(\mathrm{E}-5)$

Interest paid (E-9).............

Sundry expense outside manu-

facturing $(D-8) \ldots \ldots \ldots \ldots \ldots$.

Total..................

Final profit.

Total.

\section{Income.}

Gross sales (F-1).

Less returns and allowances $(\mathrm{F}-1 a) . .$. . $\$ . .$. .

Discounts $(\mathrm{F}-1 b) \ldots \ldots$.......

Outward freight and cartage $(\mathrm{F}-\mathrm{l} c) . .$. .

Total deductions $(\overline{\mathrm{F}-1 d) . .}$

Net sales (F-2)

Inventory, last of year $(\mathrm{G}-3) \ldots$

Operating loss.

Total

Operating profit.

Interest received $(\mathrm{F}-3) \ldots . . .$.

Sundry income outside manufacturing $(\mathrm{F}-4,5,6) \ldots \ldots \ldots$.

Total.................

Final loss.

Total.
$\$ \ldots .$.

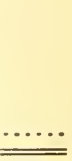

......

$\ldots \ldots$

.....

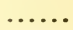

$\underline{ }$

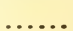

$\ldots .$.

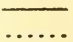

$\ldots$

$\overline{ }$

NoтE.-Unless an explanation is made, the final profit or loss which appears here should be exactly the same as the profit or loss shown by the establishment's profit and loss statement.

\section{(I) PRevious PROFIT AND loss statements.}

If obtainable, file with the schedule copies of profit and loss statements for previous years as far back as possible. If unobtainable, give the following items (provided they can be obtained from the books) as far back as possible:

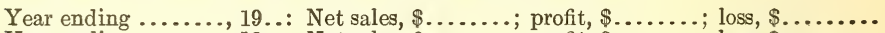
Year ending ........, 19... Net sales, $\$ . . . . .$. ; profit, $\$ . . . \ldots$. ; loss, $\$ . . . . .$. . Year ending ........, 19..: Net sales, $\$ . . . . .$. ; profit, $\$ . . . . .$. ; loss, $\$ . . . . .$. Year ending ........, 19..: Net sales, $\$ . . . .$. ; profit, $\$ . . . .$. ; loss, $\$ . . . . .$. 
Unit Schenule for a j0-Foot Bux of Window Glass.

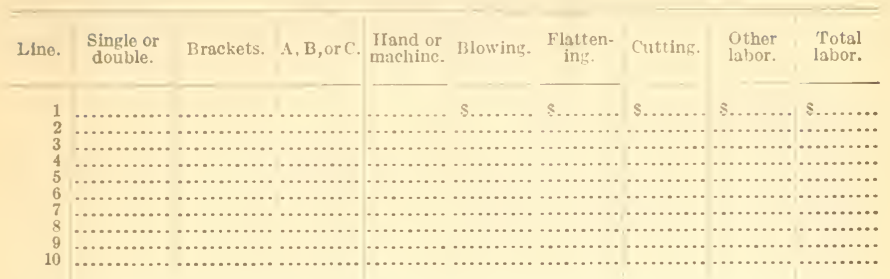

Blowing labor (hand): Gatherers, blowers. Blowing labor (machine): Blowers, ringmen, ladlers, snappers, takers-down, cappers. Other labor and total labor: Not including making or packing boxes.

TOTAL COST PER 50-FOOT BOX.

\begin{tabular}{|c|c|c|c|c|c|c|}
\hline Line. & $\begin{array}{l}\text { Total labor } \\
\text { (furwarded). }\end{array}$ & $\begin{array}{l}\text { Material for } \\
\text { glass. }\end{array}$ & Other cost. & Total cost. & $\begin{array}{l}\text { Usual nct scll- } \\
\text { ing price. }\end{array}$ & Profit. \\
\hline 1 & $\$$.. & $\$ . .$. & $\$ \ldots . . .$. & $\$ \ldots$ & s............ & $s_{1} \ldots \ldots \ldots \ldots$ \\
\hline 2 & $\ldots \ldots \ldots \ldots$ & $\ldots \ldots$ & . $\ldots \ldots \ldots \ldots$ & n......... & $\ldots \ldots \ldots \ldots \ldots$ & $\ldots \ldots \ldots \ldots$ \\
\hline 3 & , $\ldots \ldots, \ldots, \ldots$ & $\cdots, \ldots, \ldots, \ldots$ & n. & $\cdots \ldots \ldots, \ldots$, & $\cdots \ldots \ldots \ldots$ & $\cdots \ldots \ldots \ldots \ldots$ \\
\hline$\frac{4}{5}$ & 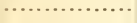 & $\ldots \ldots \ldots$ & … & $\cdots \cdots$ & n. & , n $, \ldots, \ldots$, \\
\hline 5 & , $\ldots, \ldots, \ldots$, & $\ldots \ldots, \ldots$ & n. & $\cdots \cdots$ & - $\ldots, \ldots, \ldots$, & - $\ldots \ldots \ldots \ldots$ \\
\hline 6 & - $\ldots \ldots \ldots, \ldots$ & (n........... & 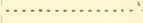 & ............ & 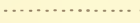 & - $\ldots \ldots \ldots \ldots \ldots$ \\
\hline 7 & $\ldots \ldots \ldots \ldots \ldots$ & . $\ldots \ldots \ldots \ldots \ldots$ & $\ldots \ldots \ldots$ & $\cdots \ldots$ & $\ldots \ldots \ldots \ldots \ldots$ & $\ldots \ldots \ldots \ldots \ldots$ \\
\hline 8 & (n) & 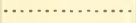 & n. & $\cdots \ldots$ & $\ldots \ldots \ldots$ & - $\ldots \ldots \ldots \ldots$ \\
\hline 9 & $\ldots \ldots \ldots \ldots \ldots$ & $\ldots \ldots \ldots \ldots$ & $\ldots \ldots \ldots$ & $\cdots \ldots$ & $\ldots$ & $\ldots \ldots \ldots$ \\
\hline 10 & (n. & (n.......... & $\ldots \ldots \ldots \ldots$ & $\ldots \ldots, \ldots, \ldots$ & $\ldots \ldots \ldots$ & $\ldots \ldots \ldots \ldots$ \\
\hline
\end{tabular}

Unit Schedule for Bottles.

(Unit 1 gross.)

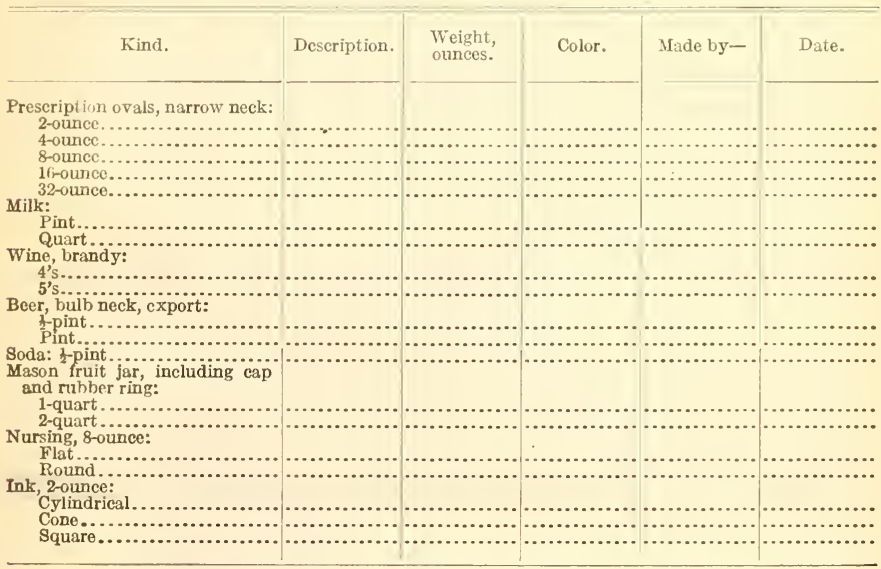

Description: Trade name or other note. Made by hand, 1, 2, or 3 man machine, or number of arm Owens machines. Date on which unit was estimated. 
COST AND SELLING PRICE.

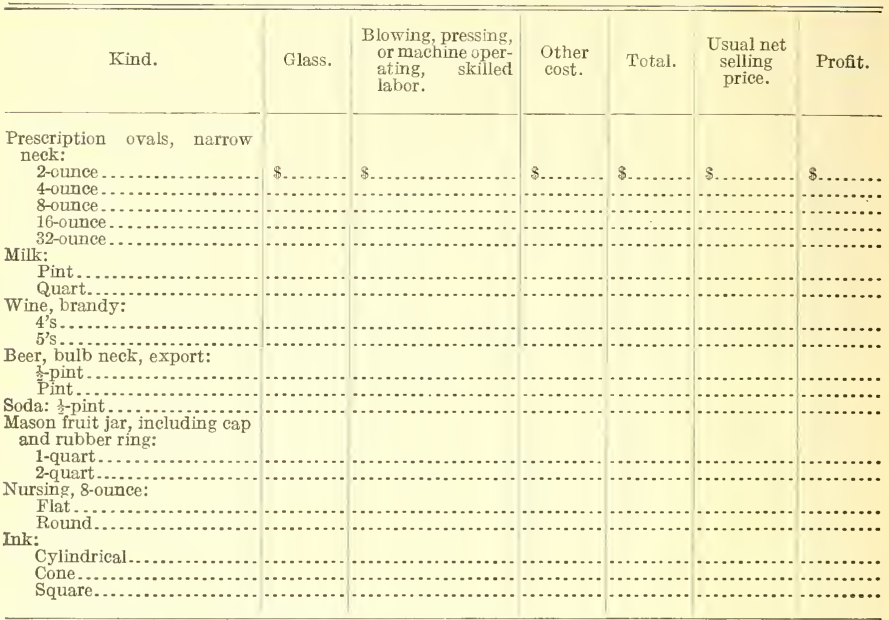

Other cost: All other labor, shop expense, and overhead.

Unit Schedule for Tableware, Bar Goods, Lamp Chimneys, and Gas Globes.

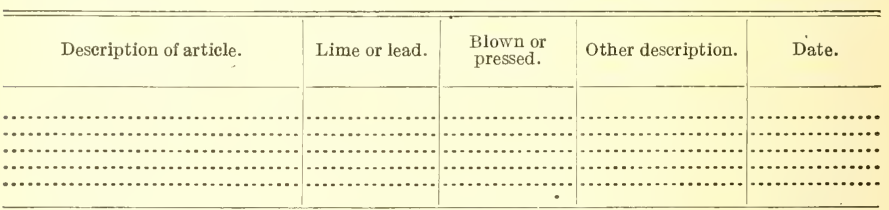

COST AND SELLING PRICE.

\begin{tabular}{|c|c|c|c|c|c|c|}
\hline \multirow[b]{2}{*}{ Description of article. } & \multicolumn{4}{|c|}{ Cost per .................... for } & \multirow{2}{*}{$\begin{array}{l}\text { Usual } \\
\text { selling } \\
\text { price per } \\
\text { dozen. }\end{array}$} & \multirow[b]{2}{*}{ Profit. } \\
\hline & Glass. & $\begin{array}{l}\text { Blowing, pressing, } \\
\text { or operating, } \\
\text { skilled labor. }\end{array}$ & Other cost. & Total. & & \\
\hline (., & 8.......... & $\$ \ldots \ldots . . . \ldots . .$. & $\$ \ldots \ldots . .$. & s......... & $\$ \ldots \ldots \ldots$ & S......... \\
\hline (...6. & ................. & (n. & .................... & ............... & 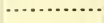 & . \\
\hline (1) & $\cdots$ & (n) & . & 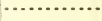 & (n) & . \\
\hline (.). & & (n. & (n) & (n.............. & (n). & (n). \\
\hline 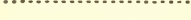 & & (n) & 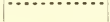 & ........ & (n) & (n) \\
\hline
\end{tabular}

Tumblers, stem and table ware: Cost per 100; selling price per dozen. Lamp chimneys: Cost and selling price per dozen; if record is on a different basis change box head. Prices should not include packing. 
RATES OF WAGES.

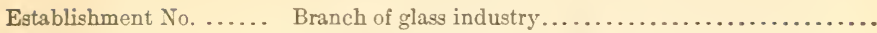
Pay roll for the ...... ending ........, 191..

\begin{tabular}{|c|c|c|c|c|c|c|}
\hline \multirow[b]{2}{*}{ Oecupstion. } & \multirow[b]{2}{*}{$\begin{array}{l}\text { Number of } \\
\text { employees. }\end{array}$} & \multirow[b]{2}{*}{ Sex. } & \multicolumn{2}{|c|}{ Time work. } & \multicolumn{2}{|c|}{$\begin{array}{c}\text { Plecework, if hours are } \\
\text { recorded. }\end{array}$} \\
\hline & & & $\begin{array}{l}\text { Hours } \\
\text { worked } \\
\text { during } \\
\text { period. }\end{array}$ & $\begin{array}{l}\text { Actual } \\
\text { earnings } \\
\text { during } \\
\text { period. }\end{array}$ & $\begin{array}{l}\text { Hours } \\
\text { worked } \\
\text { during } \\
\text { period. }\end{array}$ & $\begin{array}{l}\text { Actual } \\
\text { earnings } \\
\text { during } \\
\text { period. }\end{array}$ \\
\hline (........ & & & $\ldots \ldots$ & s...... & $\ldots$ & \$......... \\
\hline - & $\ldots \ldots$ & ........ & .......... & . $\ldots \ldots \ldots \ldots$ & ............. & ............... \\
\hline . & (n) & (........... & ............ & $\ldots \ldots \ldots \ldots$ & $\ldots \ldots \ldots \ldots$ & ............ \\
\hline (n) & (n) & $\ldots \ldots \ldots$ & . $\ldots \ldots \ldots \ldots$ & $\ldots \ldots \ldots$ & n................ & $\ldots \ldots \ldots \ldots$ \\
\hline с & n. & $\ldots \ldots \ldots$ & n......... & $\ldots \ldots \ldots \ldots \ldots$ & n......... & $\ldots \ldots \ldots \ldots$ \\
\hline
\end{tabular}

OUthine for Interviews with Manufacturers.

Please number replies according to the numbering of inquiries.

A. Manufacturing centers:

1. Principal centers in this line?

2. Grade of goods manufactured at each center?

3. In what localities is manufacturing increasing?

4. Advantages regarding market?

5. Advantages of different localities regarding labor?

B. Labor conditions:

1. Changes in labor conditions in recent years?

2. Date of last strike and effect on cost?

3. Relative increase of wages in this and other localities?

4. Time or piece work preferred by manufacturers? Reason.

5. Time or piece work preferred by employees? Reason.

C. Manufacturing conditions:

1. How long in advance are materials usually purchased?

2. Are goods made for stock or to fill orders?

3. How long in advance are orders placed?

4. Busiest months in manufacturing department? Dullest months?

5. Most popular articles produced? Most profitable articles produced?

D. Selling conditions:

1. Is selling to consumers, retailers, sole agents, jobbers, or commission houses preferred?

2. What cooperation between the manufacturer and retailer is practiced and what is desirable?

3. When do seasons open and when do salesmen start on the road?

4. Months when sales are largest? Smallest?

5 . When is the bulk of deliveries made?

6. Trade as affected by seasonal conditions?

7. Trade as affected by long future delivery?

8. Other trade uncertainties?

9. Is the tendency toward large or small orders?

10. Trade abuses: Extent, chief causes, and effect of each-
a. Returns.
b. Allowances.
c. Cancellations.
d. Special discounts.
e. Dating extensions.
f. Rushing seasons.
g. Selling job lots.
h. Other abuses.

11. Cooperation among manufacturers for protection against trade abuses?

What has been done? What ought to be done?

12. Prices at which left-over goods are sold and to whom?

13. How could selling expense be reduced? 
E. Efficiency of methods:

1. How could manufacturing methods be improved?

2. What economies could be effected?

3. How could accounting methods be improved?

4. Is tendency toward large or small factories?

F. Imports:

5. Are large, medium, or small factories most profitable? Reason.

1. Effect of the tariff act of 1913 ?

2. What kinds and grades are imported? From what countries?

3. Extent of importation of cheap and medium grades?

4. Are imports increasing in greater proportion than the growth of domestic manufacture?

G. Exports:

1. Extent of your foreign trade in this line? To what countries?

2. Is there a foreign demand? From what countries?

3. Have you attempted to establish a foreign trade? By what means? In what countries? With what results?

4. What disadvantages as to tariff have American manufacturers?

5 . Grades of goods salable in foreign countries?

6. Size of foreign orders or sales?

7. Do repeat orders come from foreign countries?

8. Goods sold for export direct or through agents? Which brings better results?

9. Do export agents purchase goods outright or guarantee payment or sell on commission?

10. Discount and time allowance on foreign sales?

11. Credit reporting systems for foreign trade?

12. Collection agencies for foreign trade?

13. To what extent has your foreign trade been profitable? Why not more profitable?

14. Reasons for slow growth of foreign trade?

15. By what means could foreign trade be increased? 






SMITHSONIAN INSTITUTION LIBRARIES 